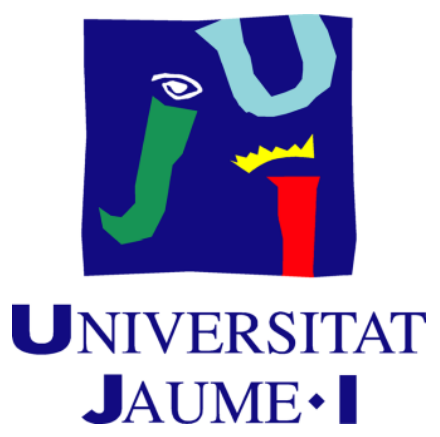

FACULTAD DE CIENCIAS HUMANAS Y SOCIALES

DEPARTAMENTO DE FILOLOGÍA Y CULTURAS EUROPEAS

\title{
LÉXICO DISPONIBLE DE CASTELLÓN. ESTUDIO Y DICCIONARIOS
}

TESIS DOCTORAL

Presentada por Manuela Casanova Ávalos

Director: Dr. D. José Luis Blas Arroyo

Castellón, Julio de 2017 


\section{AGRADECIMIENTOS}

Un proyecto de investigación -y una tesis no es otra cosa- nunca se lleva a cabo sin la cooperación de diferentes personas, que contribuyen de una u otra forma a hacerlo realidad.

Mi agradecimiento, en primer lugar, a todos los alumnos preuniversitarios de la provincia de Castellón, que contestaron las encuestas, base inicial de esta tesis. También a sus profesores, quienes amablemente cedieron su horario de la asignatura de Lengua Española. Sin su colaboración no habría sido posible este trabajo.

Quisiera mostrar también mi agradecimiento al Dr. José Luis Blas Arroyo por su paciencia ante las continuas intermitencias en la elaboración del presente estudio, por su pronta solución a cualquier problema surgido en su redacción, por su orientación y actitud siempre constructivas, y, en definitiva, por su acertada dirección y apoyo hasta el último momento.

Asimismo, deseo manifestar mi gratitud al Dr. José Antonio Bartol, por su generosa ayuda y sus oportunos consejos durante mi estancia de investigación en la Universidad de Salamanca (curso 2004-2005) con la finalidad de recoger bibliografía y aprender el sistema informático que esta institución pone a disposición de los estudiosos de la disponibilidad léxica. Y, cómo no, a todos los demás “disponibles”, que, con sus valiosas investigaciones, han constituido los cimientos de esta tesis.

Al Dr. Santiago Fortuño Llorens, coordinador del programa del doctorado y siempre amigo, por su información en las cuestiones administrativas.

Y, de manera especial, a mi familia por su extremada comprensión ante mis ausencias, ante tantas horas que les hurté.

A todos ellos, gracias. 


\section{ÍNDICE}

1.INTRODUCCIÓN

\section{EL ESTUDIO DE LA DISPONIBILIDAD LÉXICA EN} ESPAÑOL: EL PROYECTO PANHIPÁNICO 19

$\begin{array}{ll}\text { 2.0. Introducción } & 19\end{array}$

2.1. Primeros estudios sobre disponibilidad léxica 21

2.2. El análisis de la disponibilidad léxica en español 24

2.3. Distribución dialectal de los estudios 27

2.4. Perspectivas de estudio 31

2.5. Aplicación de los estudios de la disponibilidad léxica 34

2.6. La disponibilidad léxica y el contacto de lenguas 42

3. CASTELLÓN, PROVINCIA OBJETO DE ESTUDIO 55

3.1. Introducción 55

3.2. Breve sinopsis histórica $\quad 57$

3.3. Distribución geográfica y demográfica de la población 59

3.4. El desarrollo económico de Castellón 63

3.5. La situación sociolingüística de la comunidad: datos sobre el bilingüismo social 65

3.5.1. Distribución de las lenguas en Castellón 65

3.5.2. Breve bosquejo histórico de un proceso de sustitución lingüística 66

3.5.3. Datos sobre el conocimiento y uso de las lenguas en el momento de realización de los test de disponibilidad 69

3.5.4. La presencia de las lenguas en la enseñanza 75

3.5.5. Configuración del castellano hablado en la comunidad 79

4. ASPECTOS METODOLÓGICOS 89

4.1. La muestra $\quad 89$ 
4.2.1. El test de disponibilidad léxica 100

4.2.2. Los centros de interés 102

4.2.3. Aplicación de la prueba 104

4.3. Criterios de edición de los materiales 106

$\begin{array}{ll}\text { 4.3.1. Criterios generales } & 107\end{array}$

4.3.2. Criterios particulares 113

4.4. Procesamiento de los datos 144

5. ANÁLISIS DE LOS RESULTADOS 151

5.1. Datos globales 152

5.1.1.1. Datos globales 152

5.1.1.2. Palabras por centro de interés 153

5.1.1.3. Vocablos por centro de interés 155

5.1.2. Palabras por informante 157

5.1.3. Densidad léxica e índice de cohesión 159

5.1.4. Los datos de Castellón en comparación con otras áreas bilingües 162

5.2. Datos por variables sociales 174

5.2.1. Sexo 174

5.2.2. Ubicación centro 179

$\begin{array}{ll}\text { 5.2.3. Tipo de centro } & 184\end{array}$

$\begin{array}{ll}\text { 5.2.4. Lengua materna } & 190\end{array}$

5.2.5. Nivel educativo de los padres 195

5.3. Anglicismos 201

5.3.1. Introducción 201

5.3.2. El concepto de anglicismo 203

5.3.3. Las principales vías de inserción de los anglicismos 206

5.3.4. Aspectos metodológicos 210

5.3.5. Análisis de los resultados 212

$\begin{array}{ll}\text { 5.3.6. Variables sociales } & 221\end{array}$

5.3.6.1. Sexo 221

5.3.6.2. Ubicación de centro 224 
5.3.6.3. Tipo de centro

5.3.6.4. Lengua materna

5.3.6.5. Nivel educativo de los padres

5.3.7. Conclusiones

5.4. Valencianismos

5.4.1. Algunas cuestiones preliminares sobre la interferencia léxica

5.4.2. Aspectos metodológicos

5.4.3. Análisis de los resultados 248

5.4.4. Tipología de los valencianismos 268

5.4.5. Comparación con otras sintopías 273

5.4.6. Variables sociales 276

5.4.6.1. Sexo 277

5.4.6.2. Tipo de centro 279

5.4.6.3. Ubicación de centro 281

5.4.6.4. Lengua materna 284

5.4.6.5. Nivel educativo de los padres 285

5.4.7. Comparación entre valencianismos y anglicismos en el léxico disponible 288

$\begin{array}{ll}\text { 5.4.8. Conclusiones } & 290\end{array}$

6. CONCLUSIONES 295

7. REFERENCIAS BIBLIOGRÁFICAS 311

8. DICCIONARIOS DEL LÉXICO DISPONIBLE DE CASTELLÓN 351

8.1. Diccionario por orden de disponibilidad 351

8.2. Tablas de los anglicismos 551

8.3. Tablas de los valencianismos 563

$\begin{array}{ll}\text { ANEXOS } & 571\end{array}$

1. Diccionario del léxico disponible por orden alfabético 
2. Diccionario del léxico disponible según las variables sociales

3. Test de disponibilidad 
1

INTRODUCCIÓN 



\section{INTRODUCCIÓN}

El Léxico disponible de España (Bartol y Hernández, 2006: 725-736) es un proyecto que cuenta ya con un amplio recorrido en nuestro país. Este trabajo pretende contribuir a su culminación, para que tal empresa sea una realidad en un futuro cercano.

La idea de delimitar la norma adulta del léxico disponible en español comienza a forjarse cuando Humberto López Morales (1973) estudia el léxico de los escolares de Puerto Rico en la década de los 70 del siglo XX, siguiendo para ello las huellas de los estudios realizados en zonas francófonas por G. Gougenheim y su equipo en los años cincuenta (1956). Es por entonces cuando fragua una nueva especialidad en el seno de la léxico-estadística: la disponibilidad léxica. A día de hoy, López Morales dirige el Proyecto Panhispánico del Léxico Disponible del español en el que están inmersos la mayoría de los estudios tanto españoles como hispanoamericanos.

Con este trabajo completamos la visión general del léxico disponible de la Comunidad Valenciana, y damos un paso más en la delimitación del léxico disponible correspondiente al español de España. En concreto, nuestra aportación al citado proyecto se cifra en determinar este léxico en una muestra representativa de estudiantes preuniversitarios en las zonas bilingües de la provincia de Castellón, así como su análisis detallado en diferentes campos semánticos. A este objetivo principal se suman otros más específicos, que resumimos a continuación:

-Reflejar la situación sociolingüística de la provincia de Castellón mediante el estudio del léxico, tanto globalmente como en relación con una serie factores sociales (sexo, ubicación y tipo de centro educativo, lengua materna y nivel educativo de las familias de los alumnos).

-Analizar las transferencias léxicas entre las dos lenguas en contacto en la Comunidad Valenciana, en concreto, en la dirección catalán $\rightarrow$ castellano.

-Examinar la difusión de los anglicismos -reflejo palmario de la enorme influencia del mundo anglosajón en todas las esferas de la vida cotidiana- en la juventud castellonense.

-Servir como punto de referencia para las programaciones sobre el léxico en la enseñanza-aprendizaje del español como lengua materna o extranjera, una de las finalidades primordiales de los estudios sobre disponibilidad léxica. 
La intuición es un factor importante a la hora de plantear las hipótesis en cualquier trabajo. Esta circunstancia, unida al bagaje aportado por numerosas investigaciones previas, así como al hecho de pertenecer como miembro a la comunidad de habla objeto de estudio, nos permite plantear las siguientes hipótesis, que pondremos a prueba tras el correspondiente estudio empírico:

1. El mayor o menor número de unidades léxicas dependerá de la singularidad temática de los centros de interés propuestos en las encuestas.

2. La mayor o menor cantidad de unidades léxicas se hallará también en relación con el grado de conocimiento, tanto el aprendido en el currículum escolar como el obtenido a través de la experiencia individual de los estudiantes.

Asimismo, en función de los factores extralingüísticos analizados formulamos las siguientes hipótesis adicionales:

3. En relación con el sexo, las chicas obtendrán mejores promedios de repuestas que los chicos.

4. Dado el entorno sociocultural que rodea a la educación pública y privada en nuestro país, esperamos encontrar una mayor disponibilidad léxica entre los alumnos matriculados en centros privados.

5. Se registrarán más unidades léxicas entre los estudiantes que acuden a colegios /institutos situados en zonas urbanas.

6. Los alumnos cuya lengua dominante es el castellano mostrarán mejores promedios de respuestas que aquellos cuya lengua principal es el valenciano, quedando en una posición intermedia los bilingües equilibrados.

7. Se espera una gradación en el léxico disponible de los alumnos asociada al nivel educativo de los padres. De esta manera, el mayor porcentaje de vocablos se dará entre los alumnos que proceden de familias con el nivel de formación más alto, seguidas a continuación, y por este orden, por los niveles medio-alto, medio-bajo y bajo.

8. Respecto a los anglicismos, estos aparecerán en mayor media en el léxico disponible de alumnos que estudian en centros privados y situados en zonas urbanas, con un nivel educativo familiar alto. No esperamos, sin embargo, que el sexo y la lengua materna sean en esta ocasión significativos. Además, su aparición vendrá marcada por el estímulo verbal empleado en las encuestas.

9. En cuanto a los valencianismos, las interferencias léxicas procedentes del valenciano serán mayores entre los alumnos valencianohablantes. Asimismo, la mayor o menor presencia de estos valencianismos dependerá de los propios centros de interés y 
su vinculación temática con aspectos de la vida cotidiana en una sociedad bilingüe como la castellonense.

El presente trabajo se distribuye en ocho capítulos de la forma que resumimos a continuación.

Tras el primero, que recoge la presente introducción, presentamos un panorama general sobre qué se entiende por disponibilidad léxica, ofrecemos un breve estado de la cuestión sobre los principales hitos en su investigación y cómo de los planteamientos iniciales (Gougeheim, 1964) se llega al proyecto encabezado por Humberto López Morales, cuyo objetivo es delimitar el Diccionario disponible del español contemporáneo. Asimismo, en este capítulo repasaremos las investigaciones de léxicoestadística que se inscriben en dicho proyecto, y daremos cuenta de los principales ámbitos de aplicación de los estudios sobre disponibilidad, como la lingüística aplicada, la sociolingüística, la etnolingüística, la dialectología o la lingüística de contacto.

Dada la importancia del marco de referencia en estos estudios, en el capítulo tercero realizamos una síntesis histórica, geográfica y demográfica de Castellón. Estos datos ayudan a comprender la situación sociolingüística de la provincia, que concretamos en distintos apartados, como la distribución de las lenguas en la comunidad, el grado de conocimiento y uso del castellano y el valenciano, y su presencia en los ámbitos sociales y académicos. Por último, reseñaremos también algunos de los rasgos fonéticos, morfosintácticos, léxicos y discursivos que imprimen una configuración especial al español hablado en Castellón, muchos de los cuales tienen su origen en el contacto secular con la lengua catalana.

El cuarto capítulo recoge la descripción de los aspectos metodológicos del presente trabajo, que siguen las pautas establecidas en el macroproyecto del léxico disponible del español, con el objetivo de facilitar las comparaciones entre los diferentes diccionarios léxicos. Especificamos, pues, cómo se ha conseguido la muestra, el porcentaje que representa con respecto a los datos generales de la población de Castellón y su estratificación social, los centros de interés examinados, las pruebas asociativas empleadas para la obtención del corpus y los criterios de edición de los materiales recogidos, tanto generales como particulares, punto este último de gran importancia y complejidad, dadas las dificultades que plantea conjugar la obligada coordinación con el léxico disponible de otras sintopías y el lógico deseo de perder la menor información posible en las encuestas. Para finalizar, en este cuarto capítulo, se 
exponen también los principales detalles del procesamiento de los datos y de las pruebas estadísticas realizadas.

Los resultados del trabajo empírico se exponen en el capítulo quinto, tanto desde el punto de vista cuantitativo como -en menor medida- cualitativo. En primer lugar, se establecen los datos globales (número de palabras, número de vocablos, palabras por informante, así como los índices de densidad y cohesión léxica) y especificados por centros de interés, todo lo cual nos da cuenta de la productividad y la riqueza léxica de los informantes. Tras el correspondiente análisis estadístico, averiguaremos si distintos factores sociológicos relevantes influyen $-\mathrm{y}$ hasta qué punto- sobre el inventario léxico obtenido. Este es el caso del sexo (hombres / mujeres), el lugar en el que se ubican los centros educativos (urbano / rural), la clase de centro educativo (público / privado) donde estudian los encuestados, la lengua materna (castellano, valenciano o ambas) y el nivel educativo de los padres de los informantes (alto, medio-alto, medio-bajo y bajo).

También abordaremos la comparación de nuestros datos con los de otras sintopías, con la finalidad de establecer coincidencias o divergencias entre los diferentes diccionarios léxicos disponibles. Para ello nos centramos en las zonas bilingües, dada la situación sociolingüística de contacto de lenguas que tiene lugar en Castellón.

Tras el análisis del léxico disponible general, abordamos también algunos datos más específicos. Así, se estudia la penetración de anglicismos en los diccionarios disponibles de los castellonenses (apartado 5.3.), tanto desde un punto de visto lingüístico (analizando su distribución por campos semánticos) como en relación con las variables sociales estudiadas. Asimismo, en el apartado 5.4 se analizan los valencianismos, términos que derivan del extenso bilingüismo social e individual que se vive cotidianamente en grandes zonas de la Comunidad Valenciana, y con un especial arraigo en Castellón. Igualmente, en este caso se ofrecen las tablas con todos los valencianismos extraídos del repertorio general y se valoran estos en función de la potencial influencia de diversos factores sociales.

Las conclusiones finales se reúnen en el capítulo seis, en el que se sintetizan los principales resultados que se desprenden de la investigación.

Tras el capítulo que recoge las referencias bibliográficas citadas a lo largo del trabajo (§7), nos encontramos en el octavo con el diccionario del léxico disponible de Castellón. En este aparecen todas las voces actualizadas en las encuestas, agrupadas por centros de interés y ordenadas inicialmente por el índice de disponibilidad. A continuación, se muestran las tablas de los anglicismos y los valencianismos. Por 
último, en un anexo adicional mostramos los diccionarios del léxico disponible ordenado por orden alfabético y por variables sociales. Además, adjuntamos el test de disponibilidad que se ha empleado en las encuestas.

La exhaustividad en cualquier tipo de análisis es una utopía, y más en una temática que tiene tantas perspectivas de estudio abiertas. Somos conscientes de que no se han tratado todos los aspectos y enfoques posibles que permiten estos estudios y quizá algunos de los analizados no han recibido la extensión que merecerían. Sin embargo, creemos que con el presente trabajo se cumplen convenientemente los objetivos que el proyecto panhispánico tiene previstos para cada demarcación geográfica y, en consecuencia, cumplen la finalidad que esbozábamos al principio de estas páginas: contribuir a que el ambicioso proyecto para la edición definitiva del Diccionario del léxico disponible del español llegue a ver la luz algún día (esperemos que no muy lejano). 

2

EL ESTUDIO DE LA DISPONIBILIDAD LÉXICA EN ESPAÑOL:

EL PROYECTO PANHISPÁNICO 


\section{EL ESTUDIO DE LA DISPONIBILIDAD LÉXICA EN ESPAÑOL: EL PROYECTO PANHISPÁNICO}

\subsection{Introducción}

El presente trabajo se enmarca en el macroproyecto panhispánico del léxico disponible del español, que ya iniciara López Morales en su investigación sobre Puerto Rico (1973), y cuyo objetivo principal es la creación del diccionario disponible del español. Muchos han sido los estudios que han ido proliferando desde entonces a ambos lados del Atlántico, como veremos a continuación.

En este capítulo nos limitaremos a comentar diversos aspectos relacionados con la evolución de este proyecto panhispánico, ya que otras informaciones más específicas sobre la léxico-estadística o sobre el propio concepto de disponibilidad pueden encontrarse en numerosos trabajos, como los publicados por Samper, Bellón y Samper Hernández (2003), Carcedo González (1998a), López Morales (1995-1996, 1999b, 2001), Samper Padilla (2006), Samper Padilla y Samper Hernández (2006), Paredes García (2012) y Fernández Smith et al. (2012), entre otros. En todos ellos se pone de relieve el significado de esta parcela de investigación en el conocimiento lingüístico y se ofrece una detallada visión sobre el origen y progreso de los estudios sobre disponibilidad léxica, los grupos de investigación que trabajan en ella y las pautas metodológicas comunes a todos los equipos, incluidos los cálculos estadísticos que se utilizan para la elaboración de los correspondientes diccionarios. En definitiva, en estos trabajos puede verse una perspectiva general de los estudios de disponibilidad y de las características del Proyecto Panhispánico. Otra consulta imprescindible es la página

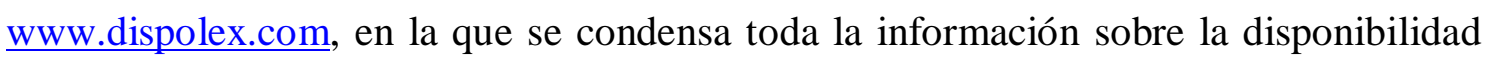
en español, así como el programa que permite generar los diferentes listados de léxico disponible en cada sintopía. En esta página, que coordinan José Antonio Bartol y Natividad Hernández desde la Universidad de Salamanca, se explican, además, las pautas de este tipo de análisis y todo lo publicado hasta la fecha,

Como es lógico, antes de revisar la evolución del mencionado proyecto panhispánico, es obligado precisar algunos conceptos esenciales en el ámbito de la léxico-estadística. Uno de ellos es el de léxico básico, entendiendo por tal el vocabulario de una lengua ordenado de acuerdo con la frecuencia de aparición de las palabras tanto 
en textos orales como escritos. Por ejemplo, en el caso del español se considera como uno de los primeros léxicos básicos el compilado en 1964 por Alphonse Juilland y Eugenio Chang-Rodríguez, publicado con el título de Frequency Dictionary of Spanish Words, y donde se combinan tanto la frecuencia como la dispersión de los vocablos. Sobre la relevancia de este último parámetro, recuerda Bellón (2011: 23) que "una palabra con una frecuencia más alta puede tener un coeficiente de uso menor que el de otra palabra con una frecuencia más baja, si la dispersión de sus numerosas apariciones es desigual. De esta forma se concreta la idea de que la dispersión 'corrige' la frecuencia”. Algún tiempo después de la obra seminal de Juilland y Chang-Rodríguez, aparecerían otros listados dialectalmente más específicos, como el Léxico básico del español de Puerto Rico de Amparo Morales (1986), al que le han seguido más recientemente el Léxico básico de España (LEBAES), y el Léxico básico de las islas Canarias (LEBAICan), a cargo de Benítez, Hernández Cabrera y Samper Padilla (1995).

Ahora bien, junto al léxico básico, surge el léxico disponible, entendiendo por tal: "el caudal léxico utilizable en una situación comunicativa dada", tal como lo define Humberto López Morales (1983: 213). Por tanto, las investigaciones sobre la disponibilidad léxica examinan aquellos vocablos que se actualizan en el momento que la situación comunicativa lo requiere. Se trata, en suma, de palabras temáticas (Michéa, 1953), que aparecen si el asunto lo precisa, o sea, aquellas que están ligadas a un contenido determinado y que se concretan de forma automática en la mente del informante cuando se da el contexto extralingüístico pertinente.

Con la finalidad de recoger ese léxico disponible, en la correspondiente investigación empírica se trabaja con pruebas asociativas, es decir, se pide al informante que durante un periodo de tiempo acotado (en el proyecto panhispánico en el que se inscribe el presente estudio, dos minutos) escriba todas aquellas palabras que vengan a su mente relacionadas con diversos campos de la realidad exterior (ropa, alimentos, transporte, etc.). Estos estímulos lingüísticos se denominan "centros de interés".

Finalmente, ambos léxicos, básico y disponible, contribuyen a conformar el léxico fundamental de una lengua. En palabras de Fernández Smith et alii (2006: 767): "La suma de ambos criterios posibilita una descripción más exacta del repertorio léxico de una comunidad de habla, es decir, de lo que se denomina léxico fundamental de una lengua". Por su parte, López Morales (1986: 63) indica que "no se trata, por tanto, de criterios opuestos sino complementarios. El vocabulario fundamental de una lengua 
estará dado por la combinación o la suma del léxico usual y del léxico disponible”. A lo que añade que solo las palabras altamente disponibles pertenecerán al vocabulario activo de una comunidad lingüística, mientras que las de escaso grado de disponibilidad pertenecerían al léxico activo de algunos hablantes y al léxico pasivo del resto.

\subsection{Primeros estudios sobre disponibilidad léxica}

Los estudios sobre léxico disponible comenzaron en Francia con G. Gougenheim y su equipo (1956), quienes intentaron delimitar el léxico elemental del francés para su posterior enseñanza-aprendizaje a extranjeros, no solo a los inmigrantes que llegaban a este país, sino también a los habitantes de las colonias francesas. Para la delimitación de ese léxico disponible acudieron al criterio de la frecuencia, basándose en la idea de que las palabras más habituales son las primeras que deberían enseñarse. ${ }^{1} \mathrm{Y}$ así surgió L'elaboration du Français élémentaire. Pronto este factor se mostró ineficaz, ya que los listados de términos frecuentes dejaban muchas veces de lado otras palabras comunes, igualmente necesarias para la comunicación usual. Esto obedecía a que la actualización de estos vocablos en el discurso depende del tema o situación de habla. Michéa (1953) llamó a estas palabras "temáticas", frente a las "atemáticas", es decir, aquellas, también frecuentes (a veces más), pero cuyo uso no depende del "tema" o asunto que se está tratando. A este estudioso se debe, justamente, la noción de palabra disponible, que define así:

Un mot disponible est un mot qui, sans être particulièrement fréquent, est cependant toujuour prêt à être employé et se présente immédiatement et naturellement à l'esprit au moment où l'on en a besoin. C'est un mot qui, faisant partie d'associations d'idées usuelles, existe en puissance le sujet parlant, dès que ces associations entrent en jeu (Michéa, 1953: 340).

Con los vocablos disponibles se comienza a tener claro que las palabras frecuentes no son necesariamente las más usuales. Los léxicos disponibles atesoran un tipo de unidades léxicas presentes en la mente de los individuos, que resultan familiares

\footnotetext{
${ }^{1}$ Obras anteriores al estudio galo que se fundamentaron en la frecuencia fueron El Vocabulario usual, común y fundamental de Víctor García Hoz (1953) y el Recuento de vocabulario español de Ismael Rodríguez Bou (1952).
} 
a estos, y que solo surgen si la situación de comunicación lo requiere. De este modo en 1964, Gougenheim, Michéa, Rivenc y Sauvageot elaboran el léxico fundamental del francés. El instrumento de investigación empleado por estos investigadores fueron unas pruebas asociativas que establecían unos estímulos verbales, denominados centros de interés, para obtener las respuestas de los informantes. Los centros de interés encuestados en el trabajo francés son los que todavía se utilizan hoy en día, ${ }^{2}$ a saber (Gougenheim et al. 1964: 152-153):

01. Les parties du corps

02. Les vêtements (peu importe que ce soient des vêtements d'homme ou de femme) home et femme

03. La maison (mais pas les meubles)

04. Les meubles de la maison

05. Le aliments et boissons de repas (à tous les repas de la journée)

06. Les objets placés sur la table et dont on se sert à tous les repas de la journée

07. La cuisine, ses muebles et les utensiles qui s'y trouvent

08. L'ecole, ses meubles et son matériel scolaire

09. Le chauffage et l'éclairage

10. La ville

11. Le village ou le bourg

12. Le moyens de transport

13. Les travaux des champs et du jardinage

14. Les animaux

15. Les jeux et les distractions

16. Les métiers (les different métiers et non pas les noms qui se rapportent à un seul métrier).

Los trabajos sobre léxico disponible fueron continuados por Mackey (1971) en Canadá, con la finalidad de comparar dos comunidades de habla francesa: Canadá (Acadia) y Francia. Por este motivo siguió las pautas metodológicas de los investigadores galos, lo que le llevó a analizar a alumnos de entre 9 y 12 años, mantener

\footnotetext{
${ }^{2}$ En efecto, a día de hoy se siguen utilizando los mismos centros de interés ya empleados por los pioneros en esta disciplina, y cuyo origen resume López Morales (1999b: 32-37). Sin embargo, recientemente diversos autores se han planteado si no habría que cambiar esos centros temáticos para adaptarlos a las nuevas realidades (véanse, al respecto, las reflexiones de Galloso (2002) y Borrego (2004: 67), que retomamos posteriormente en este mismo apartado).
} 
las condiciones de la encuesta (veinte palabras en quince minutos) y utilizar también el criterio de la frecuencia. ${ }^{3}$ La conclusión más importante de este trabajo contrastivo de Mackey fue constatar la existencia de diferencias etnolingüísticas y culturales significativas entre las dos zonas estudiadas. Por su parte, el trabajo de Njock (1978) tenía asimismo en cuenta el francés en su comparación con la lengua basaa en la población infantil de Camerún. Lo más significativo de esta obra es que el análisis se sustentaba en el concepto de rango asociativo o posición en la que se sitúa cada palabra en los listados. Njock observaba que las palabras más disponibles eran aquellas que se evocan con mayor rapidez y, por tanto, acuden a la mente del hablante en primer lugar. ${ }^{4}$ Además, apuntaba que los sujetos bilingües francés -basaa contaban con más palabras y más recursos para describir la realidad que los individuos monolingües. ${ }^{5}$

Por su parte, Dimitrijevic (1969), en su estudio con estudiantes escoceses de enseñanza secundaria, introdujo algunas variantes destacadas con respecto a los estudios anteriores, como la utilización de listas abiertas, frente a las investigaciones francófonas, que empleaban listas cerradas (veinte palabras) y cinco minutos de límite en las respuestas. Más tarde, este mismo autor (Dimitrijevic 1981) comparó los datos de este trabajo con un estudio sobre alumnos monolingües en serbocroata y bilingües en húngaro-serbocroata. Sus datos probaron que la variable lengua materna era un factor significativo, ya que los estudiantes monolingües (así como los de más edad) ${ }^{6}$ obtenían más palabras que los del grupo bilingüe e, incluso, que los alumnos de Edimburgo.

\footnotetext{
${ }^{3}$ Para una utilización de este criterio en el español, véase el diccionario Juilland y Chang-Rodríguez, Frecuency Dictionary of Spanish Words (1964).

${ }^{4}$ Mackey (1971) estudió los 16 centros de interés de Gougenheim et al. más otros seis adicionales: L'eglise et la vie paroissiale; Les sports et l'euipament sportif; Les outils; L'automobile et ses parties; Actions courantes y Les affaires. Sin embargo, Njock analizó únicamente diez centros de interés: 1. Les parties du corps, 2. La nourriture et les boissons, 3. Les vêtements (por hommes et pour femmes), 4. La maison (materiaux de construction et meubles), 5. Le travail au champ, 6. La cuisine (ce qu'on y voit), 7. La salle de casse (ce qui tu vois et/ou utilisies,8. Les moyens de locomotion (ce qui te permet de te déplacer), 9. La musique et la dance (les genres) y 10. Les jeux et devertissementes. Vemos cómo siete de esos centros de interés están tomados directamente del trabajo de Mackey.

${ }^{5}$ En la esfera del bilingüismo, especialmente en su vertiente más aplicada a la educación, disponemos también por aquellos años de un trabajo de Bailey Victery (1971) para el par inglés-español en el estado de Texas.

${ }^{6}$ Dimitrijevic (1981) trabajó con una muestra de 228 alumnos de dos edades: 11 y 14 años.
} 


\subsection{El análisis de la disponibilidad léxica en español}

En el ámbito del español, son ya numerosos los grupos de investigación que han desarrollado estudios sobre disponibilidad léxica. Sus autores, integrados en diferentes universidades españolas y americanas, ${ }^{7}$ han reflexionado desde un punto de vista teórico sobre la disponibilidad léxica, y, en particular, sobre otras cuestiones como:

-qué lugar debe ocupar esta nueva parcela de la investigación lexicológica en la Lingüística,

-qué relación establece con otras áreas de estudio, como la psicolingüística o la sociolingüística, y

-qué métodos deben caracterizar a estas investigaciones (tipo de pruebas asociativas empleadas, criterios de edición de los datos e informatización de los mismos, etc.)

Humberto López Morales comenzó estos estudios en el área del español en 1973 con su obra Disponibilidad léxica en escolares de San Juan, y fue en la década de los noventa ${ }^{8}$ del siglo XX cuando emprendió un ambicioso proyecto cuyo objetivo es la obtención del Léxico Disponible del Español en su totalidad. Hoy en día no se puede hablar de disponibilidad léxica sin mencionar el proyecto panhispánico del léxico disponible del español dirigido por este autor. A raíz de este proyecto, muchos trabajos, entre los que figura el presente, han visto la luz tanto en España como en Hispanoamérica, estudios que, además, comparten unos mismos presupuestos metodológicos, lo que facilita la comparación de sus resultados.

En concreto, en todos ellos:

-se analizan los dieciséis centros de interés que ya se utilizaron en el estudio pionero de Gougenheim (Partes del cuerpo, La ropa, Partes de la casa (sin los muebles), Los muebles de la casa, Alimentos y bebidas, Objetos colocados en la mesa para la comida, La cocina y sus utensilios, La escuela: muebles y materiales, Iluminación, calefacción y medios de airear un recinto, La ciudad, El campo, Medios

\footnotetext{
${ }^{7}$ José Antonio Bartol (2006: 379-391) realiza una exhaustiva enumeración de las universidades y los investigadores que trabajan en este campo.

${ }^{8}$ Cuando publica Léxico disponible de Puerto Rico (1999).
} 
de transporte, Trabajos del campo y del jardín, Los animales, Juegos y distracciones, y Profesiones y oficios), ${ }^{9}$

-los informantes pertenecen a la misma franja de edad, 17-19 años aproximadamente, son estudiantes preuniversitarios (alumnos del antiguo COU o de segundo de bachillerato LOGSE, en la organización actual de la enseñanza en España) que poseen un léxico adulto todavía sin condicionar por las especificidades de los estudios universitarios posteriores,

-la encuesta se realiza por escrito y los estudiantes disponen de dos minutos para responder a cada campo semántico,

-el sexo, el nivel sociocultural, el tipo de centro y su ubicación son las variables extralingüísticas que se tienen presentes en todos los análisis,

-se ha conseguido también una homogeneización en las normas de edición de los datos ${ }^{10}$ y en el empleo de un mismo programa informático para calcular los índices de disponibilidad, ${ }^{11}$

-todos los investigadores utilizan pruebas estadísticas para comprobar la significancia de las variables analizadas.

Como ha señalado Bartol (2006: 726):

Estamos cada vez más cerca de la meta, que no es otra que el establecimiento del Léxico disponible de España, paso previo necesario para el establecimiento del Léxico disponible panhispánico con las aportaciones de los léxicos de los diferentes países hispanoamericanos.

Con todo, existen otros trabajos que estudian la disponibilidad léxica bajo unos presupuestos similares, pero que no se incluyen dentro del proyecto comentado anteriormente: unos, porque analizan informantes de otras edades y niveles educativos, y otros, porque utilizan como muestra estudiantes del español como lengua extranjera.

Pese a estos avances, diversos investigadores se han cuestionado si los presupuestos teóricos y metodológicos en los que se fundamentan los estudios de léxico disponible son acertados o plantean algunos problemas. Nos acercamos, por ejemplo, a

\footnotetext{
${ }^{9}$ Por razones de economía expositiva, a partir de aquí utilizaremos las siguientes denominaciones abreviadas: Cuerpo, Ropa, Casa, Muebles, Alimentos, Mesa, Cocina, Escuela, Iluminación, Ciudad, Campo, Transportes, Jardín, Animales, Juegos, y Profesiones.

${ }^{10}$ Ver José A. Samper (1998): "Criterios de edición del léxico disponible”, Lingüística, 10, pp. 311-333.

${ }^{11}$ Actualmente se dispone de la herramienta Dispolex, administrada desde la Universidad de Salamanca, J.A. Bartol y N. Hernández (2007)
} 
esos interrogantes con Julio Borrego (2004: 59-69) cuando aborda reflexiones sobre temas como la encuesta y los informantes, la comparación de los datos, aspectos cuantitativos como el número de palabras y vocablos, el grado de estandarización de las producciones léxicas, el proceso de lexicalización, el número de los centros de interés y su configuración, etc. De algunos de ellos nos ocuparemos también aquí, en la correspondiente sección metodológica (ver apartado 4).

En relación con la metodología, hay que recordar también que fueron investigadores hispanoamericanos quienes plantearon por primera vez la necesidad de encontrar nuevas fórmulas para medir el grado de disponibilidad de cada vocablo de una manera más precisa. De este modo, tras las propuestas iniciales de Lorán y López Morales (1983), se fijó el índice matemático con la fórmula de López Chávez y Strassburguer $(1987,1991),{ }^{12}$ que mejoraba claramente la anterior y que es la que hoy se emplea mayoritariamente en los estudios sobre disponibilidad. Con esta fórmula en mente, el programa Lexidisp para Windows fue desarrollado por Moreno Fernández y García de las Heras (1995), asesorados por los lingüistas Francisco Moreno Fernández y Pedro Benítez y patrocinado por el Instituto Cervantes, la Universidad de Alcalá de Henares y ALFAL (Asociación de Lingüística y Filología de la América Latina). Este programa informático no solo calculaba el índice de disponibilidad léxica, sino que además ofrecía otras informaciones relevantes, como la frecuencia relativa (número de veces que se actualiza una palabra con respecto al total), la frecuencia acumulada (suma de frecuencias relativas) y el índice de aparición (proporción de encuestados que la usan). Asimismo, servía para cotejar datos de diferentes comunidades de habla.

En la actualidad, la Universidad de Salamanca pone a disposición de los investigadores el programa Dispolex, accesible a través de la página de internet www.dispolex.com, y que permite incluir más factores que el anterior (Bartol y Hernández, 2007). Lo fundamental de esta nueva fórmula matemática es la posibilidad de combinar la frecuencia con la posición que obtiene un vocablo en los listados de cada centro de interés:

Se trata, por tanto, de un valor que predice el comportamiento social, no individual; de ahí que resulte de suma utilidad cuando se pretende determinar la norma de

\footnotetext{
${ }^{12}$ La fórmula parte del análisis de una matriz de vectores en la que participan: la frecuencia absoluta de la unidad léxica, la frecuencia absoluta con que aparece la unidad en cada posición de los listados, el número de individuos que intervienen en la encuesta, el número de posiciones alcanzadas en la encuesta en cada centro de interés seleccionado y las posiciones en que fue actualizada cada palabra.
} 
la comunidad objeto de estudio así como para realizar estudios contrastivos entre variedades sociales o geográficas. Sus aplicaciones en este sentido han sido muy numerosas" (Paredes, 2012:85).

Del mismo modo se puede hallar el índice de disponibilidad individual (López Chávez y Strassburger, 1991), útil para medir "la participación de cada individuo en el resultado global de la muestra. Su hipótesis es que si un sujeto actualiza los términos de mayor índice de disponibilidad léxica probablemente tendrá más disponibilidad que otro" (Paredes, 2012:85). En este mismo sentido, Ávila y Villena (2010: 66-81) proponen utilizar un nuevo índice de medición, al que llaman índice de descentralización léxica, y que permite determinar la capacidad léxica individual al analizar las palabras que un hablante no comparte con los demás en relación con las compartidas colectivamente.

Finalmente, el programa permite obtener también lo que Echeverría (1991) denominó índice de cohesión, con el objeto de determinar si las respuestas de los informantes son coincidentes o no, y así poder precisar la naturaleza de los centros de interés, esto es, si estamos en presencia de campos semánticos mayoritariamente abiertos o difusos, cuando las respuestas son muy diferentes, o, por el contrario, cerrados o compactos, cuando las respuestas resultan coincidentes. ${ }^{13}$

\subsection{Distribución dialectal de los estudios}

Como ya hemos apuntado, el objetivo del proyecto sobre la disponibilidad en español reside en recoger el léxico común de la norma adulta de esta lengua en España e Hispanoamérica. López Morales es el promotor y director de este macroproyecto, que tiene una finalidad última muy clara: la construcción del diccionario disponible del español, para lo cual se han creado diferentes equipos de investigación que se han reunido en varias ocasiones con el propósito de determinar una metodología común, las diferentes fases del proyecto, el estado de las investigaciones en cada comunidad de habla y la aplicabilidad de este tipo de trabajos. El primero de esos encuentros se realizó en Bilbao (1999), con la intención de fijar unos criterios metodológicos comunes que

\footnotetext{
${ }^{13}$ Se trata de un valor muy relevante para los estudios psicolingüísticos, como destaca el propio Echeverría (1991).
} 
tendrían que seguir todos los equipos de investigación integrados en el proyecto panhispánico. Las siguientes reuniones se llevaron a cabo en San Millán de la Cogolla (La Rioja) en 2003 y 2005, mientras que la última tuvo lugar en Salamanca (2011), donde se barajaron diversas propuestas para la edición del diccionario disponible del español. ${ }^{14}$ Ahora bien, esta uniformidad en la metodología de los estudios no ha impedido que los investigadores hayan adoptado ocasionalmente diversas variantes, dependiendo de sus objetivos particulares o de la especificidad de la comunidad de habla analizada.

La gran mayoría de trabajos de España e Hispanoamérica se halla en distintas fases, algunos ya están acabados desde hace años, mientras que otros comienzan su andadura en estos momentos. Sin ánimo de ser exhaustivos, a continuación exponemos los principales trabajos sobre disponibilidad léxica publicados hasta la fecha o programados de cara a un futuro esperemos que no muy lejano. Dada la vinculación mucho más estrecha con los estudios españoles, será de estos de los que nos ocupemos con más detalle en 2.3.2. Antes, sin embargo, dedicaremos un breve espacio para mencionar al menos algunos de los trabajos y equipos de investigación hispanoamericanos.

\subsubsection{Hispanoamérica.}

Como se ha mencionado ya, al otro lado del Atlántico los estudios de disponibilidad comenzaron con los trabajos de López Morales sobre Puerto Rico (1973, 1999b). A este le siguieron los de Cañizal Arévalo (1987) y López Chávez (1993, 1995) en México; Alba (1995) en República Dominicana; Mena Osorio (1986), Echeverría (1991), Echeverría et al. (1987), Valencia y Echeverría (1998, 1999a) en Chile; Murillo Rojas (1993, 1998) o Sánchez y Murillo (2006) en Costa Rica; Meteus Ferro y Álvaro William (2006) en Colombia. Recientemente se han incorporado al proyecto Uruguay (Jones), El Caribe (Rodríguez), Panamá (Vásquez) y La Habana-Cuba (Gregori Torada).

\footnotetext{
${ }^{14}$ Elena Bajo Pérez presentó en ese cuarto encuentro de investigadores en disponibilidad "La planta de los diccionarios de léxico disponible", materia que ya había presentado en 2006 en el curso "Los diccionarios en el nuevo siglo" (Universidad de Salamanca), en una conferencia titulada "¿Diccionarios por imágenes con las listas de Dispolex?". En ella recordaba que los diccionarios de léxico disponible ofrecen muchos datos acerca de las palabras que se recogen, pero en ningún momento se ofrecen definiciones, como los diccionarios que estamos acostumbrados a manejar.
} 


\subsubsection{España.}

En España comienzan estos estudios con diversos artículos de Benítez (1992a y b, 1993, 1994b) sobre Madrid, labor que en esta comunidad lingüística han seguido con posterioridad Guerra Salas y Gómez Sánchez (2004) y, sobre todo, Paredes García (2001a y b, 2005, 2006, 2012), que es el coordinador del léxico disponible de los estudiantes madrileños que actualmente se halla en prensa.

En el País Vasco se inicia esta tarea con la obra de Azurmendi (1983) en su análisis de San Sebastián, pero es Etxeberría (1996, 1997, 1999) con su estudio del área metropolitana de Bilbao la que se inserta ya plenamente en el proyecto panhispánico; al mismo tiempo ha realizado las encuestas de la provincia de Álava. Por su parte, la Comunidad foral de Navarra ha sido estudiada recientemente por Areta (2009) y Saralegui y Tabernero (2008). En la actualidad, de la vecina comunidad de la Rioja se ha ocupado Pérez Jiménez (2016).

Andalucía es una de las regiones donde más se han prodigado los estudios sobre disponibilidad léxica. De ahí que contemos ya con trabajos sobre toda la Comunidad. Así, tras las investigaciones preliminares de García Marcos y Mateo García (1995, 1997), aparece el léxico disponible de Almería (Mateo, 1998), al que le siguen los de Cádiz (González Martínez, 1999, 2002; González y Orellana, 1999, 2000), Córdoba (Bellón, 2011), Huelva (Prado y Galloso, 2005), Sevilla (Trigo, 2007), Granada (Pastor y Sánchez García, 2008), Jaén (Ahumada, 2006) y Málaga (Ávila, 2006).

Prado Aragonés y Galloso (2015) han añadido recientemente a esta lista el léxico disponible de Extremadura, al tiempo que lo han comparado con los resultados obtenidos en Andalucía, con la finalidad de comprobar el grado de convergencia entre las dos zonas dialectales vecinas. Además, junto con Conceiçao (Prado Aragonés, Galloso y Conceiçao, 2010), analizan otras dos zonas de contacto: Extremadura y algunas áreas de Portugal limítrofes, como el Algarbe y el Alentejo.

Otras hablas meridionales analizadas en los últimos años han sido las de Ceuta, (Ayora, 2006) y Melilla (Fernández Smith, Rico, Molina y Jiménez, 2008). Por su parte, la comunidad bilingüe de Gibraltar está siendo estudiada por un equipo de investigación dependiente de la Universidad de Cádiz e integrado por Casas, Díaz, Muñoz, Varó, Paredes Rodríguez-Pinero, Fernández Smith y Escoriza, sobre el multilingüismo y el contacto español-inglés (sobre esta cuestión, véase ya el trabajo de Escoriza, 2007). 
Arnal (2004, 2008a y b, 2009) ha dirigido la investigación de Aragón, mientras que en la región de Castilla-La Mancha, Hernández Muñoz ha sido responsable del análisis del léxico disponible primero de Cuenca (2004) y más tarde de otras provincias de la Comunidad (Hernández Muñoz, 2006). Por su parte, Galloso, autora como hemos visto de diversos estudios sobre hablas meridionales, comenzó el proyecto en CastillaLeón con la provincia de Zamora en su memoria de licenciatura (Galloso, 1998b), estudio que amplió más tarde con las provincias de Ávila y Salamanca en su tesis doctoral (Galloso 2001, 2003a). Bartol, por su parte, concluyó el trabajo sobre Soria (2004), además de ser en la actualidad quien coordina el proyecto del léxico disponible en España. Precisamente, otro trabajo en esta misma comunidad autónoma lo debemos a Fernández Juncal, concretamente el de Burgos (2008), al que se añade el de Segovia, a cargo de Santiago Guervós (2008). Por otro lado, un trabajo sobre toda esta región ha sido publicado recientemente por Cruz Alonso (2016).

Por otro lado, Galicia cuenta también con su léxico disponible gracias a la labor de López Meirama (2008), quien en 2011 publica otra obra con diversos trabajos acerca de galleguismos, interferencias y otros fenómenos derivados del contacto de lenguas, aspecto este del que también nos ocuparemos en estas páginas. Igualmente editados a día de hoy están los léxicos disponibles de otras regiones septentrionales, como Cantabria (Fernández Juncal, 2013), o Asturias (Carcedo, 2001).

En cuanto a las comunidades de habla catalanas contamos con los trabajos de Serrano $(2003,2004,2006,2014)$ en la provincia de Lérida, así como la investigación sobre el habla de Barcelona, llevada a cabo por un equipo formado por Blasco Mateo, Torres Torres, Pérez Edo y Forment Hernández (2003). Por otro lado, estas dos últimas autoras llevan a cabo en la actualidad los trabajos correspondientes al estudio de la disponibilidad léxica en las provincias de Gerona y Tarragona. Asimismo, Pérez Edo estudia las Islas Baleares para su futura tesis doctoral.

En las islas Canarias, las investigaciones comenzaron con los trabajos de García Domínguez et al. (1994) y Samper Padilla, bien en solitario (Samper 1998, 1999), bien en colaboración con Hernández Cabrera (Samper y Hernández 1997, 2006) o bien con M. Samper Hernández $(2006,2007,2009)$ que estudian la isla de Gran Canaria. Por su parte, Torres y García (2009) analizan el léxico disponible de Tenerife. Por otro lado, los equipos de Gran Canaria y Tenerife, dirigidos por Samper y Torres respectivamente, preparan en estos momentos el léxico disponible de la comunidad autónoma. 
También la investigación sobre la Comunidad Valenciana se ha realizado por demarcaciones provinciales. De Valencia se han ocupado Gómez Molina y Gómez Devís (2004) y de Alicante, Martínez Olmos (2008). Al margen de algunos trabajos publicados hace unos años sobre aspectos sociolingüísticos de la disponibilidad léxica en Castellón (Blas Arroyo y Casanova 2001, 2003a, 2003b) el estudio completo sobre esta provincia es, precisamente, el objetivo de la presente investigación. Asimismo, cabe mencionar la aplicación de los principios y métodos de esta disciplina para el estudio de la disponibilidad léxica del valenciano en Valencia, estudio llevado a cabo por Llopis (2009) y Llopis y Gómez Devís (2010).

Como recuerda Samper Padilla (2006: 101), detrás de todos estos estudios se encuentra la labor tenaz de Humberto López Morales, quien ha logrado que:

estudiosos de muy distinta procedencia y formación colaboren en una investigación de gran alcance con unos métodos comunes que, sin duda, han de favorecer las comparaciones y la consecución de unos resultados aplicables a todo el ámbito hispánico.

\subsection{Perspectivas de estudio}

2.4.1. Desde los inicios del proyecto panhispánico, se ha analizado la incidencia de los condicionantes sociales en los índices de disponibilidad. Dentro de los estudios de léxico-estadística, los factores sociales aportan datos muy valiosos sobre la variación léxica. Las variables tenidas en cuenta en la mayoría de los trabajos son: el sexo, tipo de centro escolar, la ubicación de este y el nivel sociocultural. Junto a estas variables, algunas investigaciones contemplan también otros factores potencialmente explicativos, como la lengua materna, la lengua habitual, el modelo de enseñanza, todos ellos, como es lógico, en las comunidades bilingües, donde el español se encuentra con la eventual influencia de otra lengua. Asimismo, otros factores extralingüísticos considerados han sido: la 'situación de los centros públicos urbanos', ${ }^{15}$ valorada en los estudios de Gran Canaria (Samper y Hernández, 1997) y Santander (García Casero, 2013); la ‘distribución geográfica' (zonas del interior vs. costeras) en provincias como Almería

\footnotetext{
${ }^{15}$ En la muestra de Gran Canaria se ha tenido en cuenta la ubicación de los centros dentro de la misma ciudad para comprobar si este factor podría ser discriminatorio entre los alumnos de los barrios periféricos y los de la zona céntrica.
} 
(Mateo García, 1998) y Cádiz (González Martínez, 2002) o la 'regionalidad'16 en Chile (Valencia, 1997). Los estudios dedicados al análisis de la enseñanza del español como lengua extranjera añaden, además, el 'nivel de estudios' o el grado de 'conocimiento de las lenguas'.

2.4.2. En algunos trabajos se plantea investigar la disponibilidad léxica en edades diferentes a las encuestadas en el proyecto panhispánico, edades, por lo general, inferiores a las de los alumnos preuniversitarios. ${ }^{17}$ En relación con el español encontramos que López Morales (1973) y Román (1985) estudiaron a informantes de 6, 8 y 10 años en Puerto Rico. Mesa Canales (1989) en México analizó el nivel preescolar, y Cañizal (1987) trabajó con alumnos que acababan sus estudios primarios. Por su parte, López Chávez et al (1993) han estudiado a infantes desde preescolar hasta $6^{\circ}$ de primaria. Mena Osorio (1986) tres niveles de enseñanza básica $\left(4^{\circ}, 6^{\circ}\right.$ y $\left.8^{\circ}\right)$ en Chile, y Alba (1995a), en la Republica Dominicana, se ocupó de informantes de 13 y 14 años.

Del mismo modo, en España, Samper Hernández (2009) en Las Palmas de Gran Canaria ha analizado a los alumnos de tercero y quinto de Primaria y primero y tercero de la Enseñanza Secundaria Obligatoria; García Megía (2004) ha estudiado a alumnos de nueve y doce años en Almería; Paredes y su equipo (2011) examinan dos niveles de ESO y dos de Bachillerato en Alcalá de Henares; García Casero (2013) investiga a estudiantes de cuarto de la ESO en Santander; y Jiménez Berrio (2015) ha presentado recientemente su estudio sobre alumnos de primaria y secundaria de Navarra.

Asimismo, desde Huelva se han publicado los diccionarios léxicos de $4^{\circ}$ de la ESO (Prado, Galloso y Vázquez, 2006) y $6^{\circ}$ de Primaria (Prado y Galloso, 2008), que junto con el nivel preuniversitario (Prado y Galloso 2005) permiten "valorar la progresión de disponibilidad del alumnado de la provincia onubense en su etapa de formación obligatoria y antes de su entrada en la Universidad" (Prado y Galloso, 2008:11).

\footnotetext{
${ }^{16}$ La regionalidad se refiere al "factor geográfico asociándolo a las Regiones administrativas en que se divide el país (Valencia, 1997: 201). Alba Valencia y Echeverría (1999a y b) concluyeron que los estudiantes de la Región metropolitana obtenían una mayor cantidad de léxico disponible que los que estudiaban en las otras doce regiones que forman Chile.

${ }^{17}$ Ya las primeras investigaciones de Gougenheim (1964) analizaban escolares franceses de 9-12 años. Y lo mismo hacían Mackey en Canadá (1971), Bailey en Texas (1971), Njock (1979) en Camerún o Dimitrijévic (1969) en Escocia.
} 
Todos los datos recogidos en estos estudios suponen valiosos materiales para la lingüística aplicada y la didáctica de la lengua. En palabras de Prado y Galloso, 2008:11):

Cualquier planificación seria de la enseñanza del vocabulario debe partir de la identificación de la disponibilidad léxica de los alumnos a quienes se pretende enseñar, para saber con seguridad cuál es el léxico real que utilizan estos alumnos y cuál es el que tienen que aprender.

Estos trabajos sirven de ayuda para el conocimiento del proceso de adquisición y el incremento del léxico en el proceso de formación, lo que permite una mejor planificación y selección del vocabulario en la esfera curricular (Bartol, 2010). Igualmente pueden ser de gran utilidad en la programación de la enseñanza del español como lengua extranjera. Samper Hernández $(2001,2002)$ afirma al respecto que las pruebas asociativas de la disponibilidad léxica a extranjeros permiten determinar la fase del aprendizaje en la que se encuentran los alumnos, además, de revelar los errores más frecuentes, todo lo cual supone un gran beneficio para la enseñanza del léxico.

2.4.3. Por otro lado, algunos estudios han ampliado la nómina de centros de interés con la intención de recabar el léxico de otras realidades. Convendría llevar a cabo una revisión de los centros clásicos y adaptarlos a la realidad de nuestro tiempo, ya que los más habituales resultan insuficientes para describirla (mundo de la telecomunicaciones, relaciones personales...). Esto es, convendría analizar la naturaleza interna de las áreas léxicas empleadas para descubrir cómo afectan a los resultados obtenidos y aportar la solución pertinente en función de la finalidad pretendida por los investigadores. Ya López Morales (1999b: 33) se preguntaba cuál sería la mejor manera de "encasillar en centros de interés todos los intereses humanos" o cuántos centros de interés serían necesarios para que una investigación fuera exhaustiva. Preguntas de difícil respuesta, puesto que no parece que haya forma de reducir toda la experiencia humana -o una parte significativa de esta- a una relación discreta de áreas temáticas.

Tomé Cornejo (2011) ha reflexionado sobre cuáles son los problemas que presentan los centros de interés clásicos, que, en su opinión, tienen que ver con la manera en que se enuncian, su número, su amplitud semántica, los resultados que proporcionan, etc. Asimismo, una de las deficiencias más recurrentemente comentadas 
acerca de los corpus de léxico disponible es que están integrados mayoritariamente por sustantivos concretos, frente a un grupo muy reducido de adjetivos, verbos y sustantivos abstractos. De ahí que, con el fin de conseguir vocablos de otras categorías gramaticales y realidades, muchos estudiosos hayan ampliado la nómina de los centros de interés en sus trabajos. ${ }^{18}$

De esta manera, junto a los dieciséis en que coinciden todos los estudios publicados hasta la fecha (herederos de los pioneros franceses), algunos investigadores han añadido áreas temáticas como: colores (cf. Gómez Molina y Gómez Devís, 2004; Arnal et al,. 2004; Bellón, 2011; Escoriza et al., 2007; Ayora, 2006; Moreno Fernández, 2007 y nosotros mismos, entre otros), defectos y cualidades físicas y morales (Ayora, 2006; Escoriza et al. 2007, Areta 2009), acciones (Ayora, 2006, Escoriza et al., 2007), religión (Escoriza et al., 2007), inteligencia (Hernández Muñoz, 2004; Areta, 2009), etc. para conseguir adjetivos o la aparición de términos abstractos. En otras investigaciones se ha añadido también el campo semántico relativo al mar (Fernández Juncal, 2013; Mateo García, 1998; Ayora, 2006; Escoriza et al., 2007; García Casero, 2013, entre otros), justificado por la cercanía a este de las respectivas comunidades lingüísticas analizadas. ${ }^{19}$ Por otro lado, en el estudio pionero sobre Houston y Monterrey (Bailey Victory, 1971) se encuestaban campos como la familia, Dios, medicina, música, espacio, guerra, animales, ciudad, diversión. Más recientemente, Moreno Fernández (2007) en Chicago, a los centros habituales ha añadido también los de vida, salud y enfermedades y árboles y plantas.

\subsection{Aplicación de los estudios de la disponibilidad léxica}

Junto a otros muchos autores, López Morales, ha recalcado en diferentes ocasiones las numerosas aplicaciones que tienen los estudios de disponibilidad. Estos abren un amplio abanico de perspectivas de análisis. Y aunque su aprovechamiento más directo se dé quizá en los aspectos pedagógicos y educativos, no es menos cierta su utilidad en disciplinas como la dialectología, la psicolingüística, la etnolingüística y la sociolingüística. Asimismo, otras posibilidades de aplicación se dan igualmente en el

\footnotetext{
${ }^{18}$ Por su parte, González Fernández (2014) y Paredes (2014) han planteado también la idoneidad de los centros de interés clásicos en la enseñanza del español como lengua extranjera.

${ }^{19}$ Para una revisión comparativa de este centro de interés en cinco de estas comunidades -Santander, Ceuta, Málaga, Almería y Galicia-, véase García Casero, 2013.
} 
seno de la lingüística de contacto, la lexicografía o, incluso, la lingüística informática. ${ }^{20}$ De todo ello nos ocupamos de forma más detallada en los siguientes párrafos.

Si comenzamos por la lingüística aplicada, los resultados de los análisis de disponibilidad léxica pueden ser beneficiosos para la planificación de la enseñanza de una lengua, tanto extranjera como materna, ya que son útiles para la elaboración de materiales didácticos, y pueden ser orientativos acerca de cómo introducir el vocabulario en los aprendices. Además resultan sumamente adecuados para la elaboración y actualización de diccionarios. Todo ello entra de lleno en el campo de la planificación lingüística, en el que antes de proyectar, sus responsables deben reflexionar sobre cuántas palabras se han de seleccionar en cada unidad temática, ${ }^{21}$ qué criterio debe seguirse para ello, cómo se presenta ese vocabulario para facilitar la adquisición en el alumno, etc. En este marco, los trabajos sobre disponibilidad léxica ayudan a elegir las palabras que deben enseñarse y en qué contextos -centros de interésdeben ser aprendidas.

Una nueva dimensión en estas investigaciones es su aplicación al mundo concreto de la emigración. A este respecto, los alumnos inmigrantes de diversa procedencia han sido objeto de estudio con una finalidad pedagógica, como se aprecia en los artículos de Fernández-Merino (2011, 2013) en Castilla-León, Gallego (2014) en Alcalá de Henares o el trabajo de Jiménez Berrio (2012, 2013) en Navarra.

También desde una perspectiva educativa, García Casero (2013), en su tesis sobre la disponibilidad léxica en alumnos de cuarto de ESO en la ciudad de Santander, estudia en qué medida los resultados de la disponibilidad sirven para planificar la enseñanza del léxico a esos estudiantes. Tras la recopilación del léxico disponible y su análisis, elabora una minuciosa propuesta didáctica para practicar la enseñanza del vocabulario en el aula e incrementar el caudal léxico del alumno.

Por otro lado, son varios los estudios que se han dedicado al análisis de las aplicaciones pedagógicas de la disponibilidad léxica en la enseñanza del español como lengua extranjera (cf. Benítez Pérez (1994a, 1995), Carcedo (1999a y b, 2000), García Marcos y Mateo García (1996, 2000), Samper Hernández (2002), López González (2010), Sánchez-Saus (2016), entre otros). Carcedo (1999a: 175) señala que, a la hora de planificar la enseñanza de lenguas extranjeras, es necesario integrar los factores culturales:

\footnotetext{
${ }^{20}$ Sobre este tema, véase Paredes (2012:78-100).

${ }^{21}$ Sobre la selección del vocabulario, véase Bartol (2010)
} 
la competencia que permitirá al alumno comunicarse plenamente -utilizar e interpretar correctamente el código que aprende- solo se alcanzará, en efecto, cuando junto al vocabulario, las estructuras morfosintácticas, los sonidos o las propiedades formales que caracterizan al sistema lingüístico, conozca la cultura de la que aquel se convierte en expresión.

Y a ello contribuye, sin duda, "el análisis de la magnitud y el tipo de vocabulario actualizado por alumnos extranjeros mediante pruebas de asociación controlada, y su comparación con normas léxicas disponibles de diferentes sintopías de hablantes nativos" (Carcedo, 1999a: 182).

Este análisis del léxico aporta también información sobre el carácter peculiar de la cultura asociada a una comunidad lingüística determinada, lo que permitirá programar de manera racional la enseñanza del idioma. Vemos, pues, cómo la etnolingüística puede recoger también información relevante de los diccionarios del léxico disponible, dado que ponen de manifiesto la existencia de rasgos culturales idiosincrásicos.

Las investigaciones sobre léxico-estadística también incumben a otras disciplinas científicas, aunque la mayoría de los estudios desarrollados hasta el momento parten de una visión sociolingüística. ${ }^{22}$ Los resultados de estas investigaciones son provechosos para "analizar la variación léxica según distintos condicionantes sociales". ${ }^{23}$ López Morales (1995-96: 252) afirma al respecto que:

la sociolingüística ve en la disponibilidad un instrumento que le permite establecer estratificaciones de comunidades de habla. Somete a análisis de covariación a la disponibilidad con los factores sociales que le interesa manejar y determina la caracterización léxica de los sociolectos que integran la comunidad

Como hemos señalado, la relación entre la disponibilidad léxica y la sociolingüística ha sido, probablemente, la que más se ha desarrollado en las últimas décadas. De hecho, la existencia de unas pautas de trabajo comunes entre ambas disciplinas ha facilitado este tipo de investigaciones. El mismo Goungenheim (et al.) $(1956,1964)$ ya tuvo en cuenta la incidencia de los factores sociales sobre el léxico

\footnotetext{
${ }^{22}$ Véanse al respecto, López Morales (1995-1996), Carcedo (1998a) o Samper, Bellón y Samper Hernández (2003).

${ }^{23}$ Samper (2006: 106).
} 
disponible cuando en sus estudios incorporó dos variables sociales: el sexo y la procedencia geográfica de los alumnos. ${ }^{24}$

Las variables sociales contempladas en la mayoría de los trabajos de léxico disponible hacen referencia al sexo, nivel sociocultural, tipo de centro escolar (público o privado) y zona geográfica (urbana o rural / costera o del interior). En las regiones bilingües también se abordan la lengua materna y la lengua habitual. Y en los estudios de disponibilidad del español como lengua extranjera se analiza también el conocimiento de otras lenguas. Asimismo, varios estudiosos tienen en cuenta la edad cuando examinan longitudinalmente el proceso de adquisición del léxico. No obstante, en las investigaciones inmersas en el macroproyecto del léxico panhispánico, este factor no se analiza puesto que todos los informantes son estudiantes preuniversitarios, con una edad comprendida entre los 17 y 19 años, exactamente la misma franja de edad contemplada en este trabajo.

La mayoría de los trabajos sobre disponibilidad léxica en español comparte este carácter sociolingüístico, puesto que analizan factores sociales diversos, entre los que sobresale el "nivel sociocultural", que en ocasiones se ha puesto en relación con la "teoría de los códigos" de Bernstein (1989) y la potencial existencia de diferencias drásticas de inventario entre los léxicos disponibles de grupos sociales extremos. Aunque muy pocas investigaciones han llegado a esta conclusión, lo cierto es que no son infrecuentes los estudios en los que se advierte una correlación significativa entre el entorno sociocultural de los individuos y el grado de disponibilidad léxica.

El hecho de compartir parámetros en las investigaciones facilita también la comparación cuantitativa y cualitativa de los léxicos disponibles, de modo que se puede establecer el conjunto de palabras generales y comunes a todos los hispanohablantes, tanto de España como de Hispanoamérica. Con ello, podemos acceder al léxico común panhispánico. Y de este modo encontramos trabajos donde los cotejos son la base principal de los estudios correspondientes, como en Bartol (2008) cuando compara dos centros de interés (Ropa y Partes de la casa) en el léxico de Aragón y el de Soria. Por su parte, González Martínez y Orellana (2000) comparan el léxico disponible de Cádiz con el de Zamora; Samper Padilla, Hernández Cabrera y Bellón (2003) han contrastado los léxicos de Gran Canaria y Córdoba; Samper Hernández (2008) los de Aragón y Gran Canaria. Asimismo, encontramos en esta

\footnotetext{
${ }^{24}$ Asimismo Mackey (1971) estableció correlaciones significativas con la edad y Dimitrijevic (1969) estudió la incidencia de la "inteligencia" en el léxico disponible de los informantes.
} 
bibliografía análisis comparativos entre comunidades a uno y otro lado del Atlántico, como los estudios de López Chávez (1992) sobre el léxico disponible de Madrid, Las Palmas de Gran Canaria, República Dominicana y Puerto Rico; el cotejo entre República Dominicana, Puerto Rico, Madrid, México y Concepción (Chile) de Alba (1998). Asimismo, Carcedo (2003, 2004) compara sus resultados de Asturias con los de Cádiz y Puerto Rico y Samper Padilla (1999) hace lo propio con los léxicos de Puerto Rico y Gran Canaria.

La comparación entre los léxicos disponibles de zonas geográficas diferentes es una fuente de datos indispensables para avalar la unidad o, por el contrario, la diversidad léxica del español (Bartol, 2008). En este sentido, una disciplina a la que también pueden serle muy útiles los diccionarios de disponibilidad es la dialectología (Borrego y Fernández Juncal, 2002). En “Aspectos sociolectales del léxico dialectal”, Hernández Muñoz (2009a) recoge los dialectalismos del diccionario disponible castellano-manchego, y valora la difusión y la vitalidad de los vocablos entre los miembros de la muestra. En realidad, este trabajo continúa la senda emprendida por otros autores previamente, que han analizado también los dialectalismos de diferentes zonas geográficas españolas, como Almería (Mateo, 1998), Cádiz (González Martínez, 1999), Gran Canaria (Hernández Cabrera y Samper Padilla 2003, 2006, 2007; Samper Hernández, 2005), Ávila (Llorente, 2005), Castilla-La Mancha (Hernández Muñoz 2006 y 2009a), Aragón (Arnal, 2008a), Navarra (Tabernero, 2008b), Huelva (Prado, 2009). Asimismo, encontramos trabajos de este tipo en comunidades de habla latinoamericanas, como los de Alba $(1998,2000)$ en República Dominicana y Valencia (2005) en Chile.

De toda esta variedad de análisis se pueden derivar ciertas conclusiones:

-La presencia de dialectalismos es normalmente escasa, sobre todo si tenemos en cuenta que el ámbito (escolar) en que se desarrollan las encuestas no propician las respuestas dialectales. Como tampoco lo hacen algunos centros de interés (La ciudad o Medios de transporte) que no facilitan la actualización de regionalismos. «Se trata, en definitiva, de una serie de componentes que no predisponen hacia lo dialectal sino hacia un léxico estandarizado o, incluso -como señalan Borrego y Fernández Juncal (2003:173)- "altamente formalizado"»(Arnal, 2008a:18). Con todo, algunos términos dialectales presentan, ciertamente, un índice disponibilidad alto, aunque son la excepción más que la regla. 
-En todo caso, la aparición de dialectalismos "demuestra que existe un léxico regional 'accesible' para los hablantes jóvenes de la población, que se asegura cierta pervivencia en el marco espaciotemporal.” (Hernández Muñoz, 2009a: 226).

-La distribución de los términos regionales es desigual entre los diferentes centros de interés, ya que hay campos semánticos que favorecen su empleo, como aquellos que mencionan acciones o utensilios cotidianos en la vida de los estudiantes, o los que se hallan mediatizados por las tradiciones de cada espacio geográfico (Arnal, 2008a), frentes a otros que únicamente recogen un vocabulario general, como el que encontramos en La escuela, por ejemplo.

-Por norma general, los alumnos del nivel sociocultural bajo son más propensos al uso de los dialectalismos frente a los del nivel alto (los más reacios), como muestran los estudios de Aragón y Gran Canaria. También nosotros advertimos algo de esto en nuestro estudio sobre los valencianismos en el léxico disponible de Castellón (ver apartado 5.4) Por otro lado, los regionalismos se registran preferentemente en áreas relacionadas con trabajos agrícolas, como ocurre con el centro de interés Trabajos del campo y del jardín

-Como hemos apuntado más arriba, los datos sobre aparición de dialectalismos no son muy pronunciados en las zonas que analizan este tipo de vocabulario. En Castilla-La Mancha alcanzan un 1,27\% (Hernández Muñoz, 2009a:227), un 1,34\% en Cádiz (González Martínez, 1999:192), 2,87\% en Aragón (Arnal, 2008a:29) y suben hasta un 5\% en Gran Canaria (Samper Hernández, 2005: 1070). Ya en comparaciones parciales, Castilla-La Mancha coincide con Aragón en Trabajos del campo y del jardín como el centro más productivo en dialectalismos y Gran Canaria y Cádiz lo hacen en Alimentos. No obstante, hay que tener presente que estos porcentajes pueden variar por el empleo de distintos criterios en la selección de las palabras. Por ejemplo, Hernández Muñoz (2009a: 230) ha utilizado como pauta para la identificación de estas el hecho de que estuvieran marcadas como dialectales en el DRAE o su aparición en compilaciones de dialectalismos en diversas hablas castellano-manchegas. Sin embargo, esta autora marca como dialectalismos peúco, vestidor, desatascador, pese a que el diccionario académico ( $23^{\mathrm{a}}$ ed.) no los marca como tales. Igualmente recoge bajoca, coca, de las que el diccionario señala que provienen del catalán, pero las cataloga como voz de Murcia la primera y de Aragón la segunda. También recoge yesaire como en Aragón y Castellón, vocablo del que hablaremos más adelante (ver apartado 5.4). En todo caso, hay que tener presente que Murcia y Aragón son áreas colindantes con la Comunidad de 
Castilla-La Mancha, y que juntas mantienen abundantes isoglosas comunes con el léxico de otros territorios de la antigua Corona de Aragón, como Valencia.

Por otro lado, a la hora de cotejar los diferentes listados de dialectalismos es importante tener en cuenta que a menudo las respuestas de los alumnos se limitan a un solo individuo y aparecen en posiciones muy atrasadas de los listados, lo que puede desvirtuar los resultados en las comparaciones generales. Por eso, resulta pertinente la pregunta que Hernández Muñoz (2009a) se formula en el artículo al que anteriormente hacíamos referencia: “¿cuál es el número de hablantes que ha de aducir un término para que se considere vigente en una comunidad lingüística o en un grupo social concreto dentro de esa comunidad?" (Hernández Muñoz, 2009a: 241).

Con la ampliación de los estudios de disponibilidad léxica a las zonas bilingües, aparece el análisis de las voces autóctonas procedentes de otras lenguas. Estudios que analizan dialectalismos de este tipo los encontramos en López Meirama (2008) y Álvarez de la Granja (2011), donde se tratan los galleguismos del léxico disponible de Galicia, o el de Tabernero (2008a), quien da cuenta de los regionalismos vascos divididos según su procedencia vasca o romance. También en Ceuta, Ayora (2006: 138) estudia los términos dialectales, los andalucismos, y la presencia de voces autóctonas o localismos derivados de la lengua árabe. Bartol (2011), por su parte, repasa la presencia de vocablos catalanes, gallegos y vascos en comunidades de Galicia (López Meirama, 2008), Valencia (Gómez Molina y Gómez Devís, 2004), Alicante (Martínez Olmos, 2008), Lérida (Serrano Zapata, 2006), Navarra (Areta, 2009) y País Vasco. ${ }^{25}$ También aquí los porcentajes de las transferencias sobre el total de vocablos son bajos: Bartol (2011: 173) señala que en Galicia se da un 2.88\%, en Valencia un 2.3\%, en Alicante un $0.57 \%$, en Vizcaya un $2.35 \%$, en Álava un $0.83 \%$ y, por último, en Navarra apenas un $0.55 \%$. Tan solo en Lérida $^{26}$ el porcentaje se eleva significativamente $(9,21 \%)$ con respecto a las otras áreas.

Por otra parte, los listados de palabras disponibles también sirven para ver el grado de integración de ciertos vocablos en las comunidades de habla correspondientes. Aparte de los dialectalismos, las palabras más estudiadas son los extranjerismos, y en especial, los anglicismos. Ya son muchos los investigadores que los han analizado en sus trabajos. Entre ellos podemos citar a López Chaves (1991), Benítez (1993), Alba (1995c, 1999), López Morales (1999a), Paredes (2001b), Bartol (1998, 2005), Bellón

\footnotetext{
${ }^{25}$ Los datos de las provincias de Vizcaya y Álava han sido proporcionados al autor por M. Etxebarría.

${ }^{26}$ De Lérida únicamente tienen en cuenta los seis centros de interés que M. Serrano analizó en 2006.
} 
(2004, 2005), Carrera de la Red y Bradley (2004), González y Orellana (2006), Castañer (2008), Casanova (2008), Prado (2008), Samper Padilla y Samper Hernández (2009), entre otros. El análisis de estos datos (su empleo, grado de inserción y su incidencia sobre el sistema lingüístico) permiten elaborar propuestas para la enseñanza de la lengua. En relación a los anglicismos, Samper Padilla y Samper Hernández (2009: 876) concluyen que "Los distintos trabajos recogen unos anglicismos muy disponibles que, además tienen presencia destacada en todo el mundo hispánico (al menos en las comunidades estudiadas). Otros, sin embargo, reflejan distintas preferencias geolectales, en especial entre el español de un lado y de otro del Atlántico”. (Ver apartado 5.3).

En el campo de la psicolingüística, los diccionarios disponibles aportan información sobre cómo funciona el lexicón mental y las relaciones que se establecen en su interior, en las llamadas redes semánticas. Ejemplos de estos estudios los encontramos en Baralo (1997), Gómez Molina (2009), Gómez Devís (2010), Gómez Devís y Llopis (2010, 2016), Ferreira y Echeverría (2014), Sánchez-Saus (2011), entre otros. Particular interés suscita la aportación de Hernández Muñoz (2006) en su enfoque psicolingüístico sobre la disponibilidad de los estudiantes castellano-manchegos. En este trabajo, su autora relaciona la disponibilidad y la prototipicidad, y señala que las palabras más disponibles son también las palabras más típicas de cada categoría, es decir, aquellas que representan conceptos más familiares y que, por consiguiente, se aprenden a una edad más temprana (sobre estas cuestiones véase también Hernández Muñoz, 2014). Por su parte, Echeverría (1993) señala que las palabras pueden asociarse según diferentes patrones: coordinación, coocurrencia, superordinación y sinonimia, lazos que se ven en la actualización de los términos en cada centro de interés. Además, Echeverría y su equipo (2008) fueron los creadores de un programa informático, DispoGrafo, basado en las relaciones de secuencia de las palabras disponibles, que configuran las relaciones semánticas subyacentes en el corpus. Gómez Molina (2009) aplica este programa al campo nocional de los Animales para descubrir qué relaciones se establecen entre los vocablos aportados por los estudiantes y concluye que existe un patrón de ordenamiento léxico de dicha categoría semántica en el lexicón mental colectivo:

Dicha estructura queda organizada en diferentes clusters o subcategorías claramente definidas, fruto de la categorización y de los efectos del priming semántico 
(semejanza de significados), perceptual (asociaciones de adyacencia) y fonético (rima o similitud fonológica) (p.1058).

Del mismo modo, las palabras disponibles están interconectadas por relaciones asociativas diferentes: de similitud de significados (conejo-liebre), de semejanza de familias (animales marinos), de adyacencia o contigüidad (perro-gato), de semejanza de significantes (oveja- abeja), etc. Al mismo tiempo, Gómez Molina corrobora su hipótesis inicial, según la cual la organización del léxico en la memoria semántica no coincide con la ordenación de las palabras según el índice de disponibilidad. Asimismo, Henríquez Guarín et al. (2016) aplican el concepto de grafos al campo semántico del Cuerpo humano. Galloso (2001: 96-118), por su parte, indica que en el proceso de evocación de las palabras, algunas de ellas funcionan como núcleos, que van construyendo "cadenas de evocación". Y de forma similar abordan el tema Paredes (2006) y Ávila y Villena (2010) al analizar el comportamiento léxico de sus informantes.

\subsection{La disponibilidad léxica y el contacto de lenguas}

Capítulo aparte merece el tema del contacto linguuístico entre el español y otras lenguas, como el inglés en Gibraltar y Estados Unidos; con las otras lenguas oficiales del territorio español, gallego, vasco y catalán; y, en último lugar, con el árabe en las ciudades de Ceuta y Melilla. ${ }^{27}$ En este apartado, señalaremos los estudios que han hecho referencia a ese contacto; en todos ellos se estudian variables como la lengua materna o habitual (en diferentes ámbitos como la casa, escuela o los amigos), la comunidad de habla o la zona geográfica. El objetivo es analizar qué tipo de hablantes (monolingües, bilingües activos, pasivos o equilibrados) obtienen un léxico disponible mayor y la posible influencia en ello de la adscripción lingüística. Otro aspecto que tratan estas investigaciones es el análisis de las transferencias lingǘsticas entre las lenguas implicadas y su clasificación en distintas tipologías, como préstamos (integrados o en vías de integración), dobletes, calcos semánticos o sintácticos, etc. (ver más adelante,

\footnotetext{
${ }^{27}$ Serrano (2014:103-158) realiza un extenso repaso del estado de la cuestión sobre el bilingüismo y las situaciones de contacto lingüístico dentro del campo de la disponibilidad. Véanse también Appel y Muysken (1996), García Marcos (1999) y Blas Arroyo (2005).
} 
apartado 5.4.) Además, en algunos trabajos se ofrece la comparación de la lengua estudiada con otras que se encuentran en una situación similar de contacto lingüístico.

Las pruebas asociativas empleadas en la disponibilidad léxica permiten determinar no solo los fenómenos de contacto lingüístico, sino también comprobar qué porcentaje de dichos fenómenos léxicos aparece en los diccionarios. Los datos estadísticos ayudan a explicar la presencia y la frecuencia de tales hechos, esto es, si son meras actualizaciones individuales o si, por el contrario, se trata de manifestaciones extendidas socialmente entre los jóvenes.

\subsubsection{Contacto castellano-catalán.}

Después de varios análisis parciales sobre el contacto entre el español y el catalán (Serrano, 2003, 2004, 2006), contamos ya con el estudio completo del léxico disponible en Lérida (Serrano, 2014) cuyo objetivo es la comparación de la dos lenguas que conviven en un mismo territorio, espacio donde se da un bilingüismo social extenso y equilibrado. Lo más novedoso de esta investigación ha sido encuestar la misma muestra en las dos lenguas de la comunidad, español y catalán. Tras el análisis de los datos, Serrano concluye que el catalán supera al español en la totalidad de palabras y vocablos, así como en el promedio de respuestas, un hecho que explica por el predominio de informantes con lengua catalana como materna y escolarización completa en esta lengua. Por otro lado, hay una correlación entre los resultados y la lengua materna de los estudiantes. Así, en el corpus español, son los castellanohablantes quienes presentan mejores promedios, mientras que en el corpus catalán dominan los catalanohablantes. La variable lengua materna establece, pues, diferencias significativas, junto con el sexo y el nivel sociocultural. Al mismo tiempo, Serrano realiza una "revisión epistemológica de las principales consecuencias del contacto lingüístico" y se centra en "los fenómenos originados por el contacto continuado de dos sistemas lingüísticos o por el uso de más de una lengua en un mismo territorio, como sucede con el castellano y el catalán en Lleida" (p.489). Establece, asimismo, una clasificación de los fenómenos de contacto lingüístico en ambas lenguas, siendo el catalán la lengua que más fenómenos recibe y la influencia del castellano sobre el catalán es más notable que en el sentido contrario. No obstante, las transferencias se producen en las dos direcciones. 
Por su parte, Valencia cuenta con el trabajo de Gómez Molina y Gómez Devís (2004). Estos analizan el bilingüismo de la provincia que consideran como no diglósico, con predominio del castellano, y con un porcentaje alto de bilingüismo pasivo en valenciano. Entre las variables sociales estudiadas, el tipo de enseñanza se muestra como la de mayor valor discriminante "tanto en la descripción y explicación del inventario léxico obtenido como en la predicción del comportamiento léxico de los estudiantes" (p. 275), seguida del nivel sociocultural. En cambio, se aprecia una escasa incidencia en las demás variables: sexo, lugar de residencia y lengua habitual. Al mismo tiempo se analizan los catalanismos aparecidos en los listados del léxico disponible en castellano, aunque siempre con índices de disponibilidad bajos. Asimismo, clasifican los fenómenos de contacto lingüísticos en diversas categorías, como: préstamos culturales, dobletes en los que unas veces el mayor índice de disponibilidad recae en el valenciano -que pueden considerarse o bien como préstamos o bien como sustituciones de código- y otras en el vocablo castellano.

Igualmente en Valencia, Llopis (2009) ha estudiado el léxico en valenciano en la misma franja de edad, esto es, los preuniversitarios de las comarcas valencianohablantes de la provincia de Valencia. En este caso se examinan la lengua materna y la habitual (que dividen a los informantes en hablantes monolingües, que son considerados bilingües pasivos, y bilingües activos). A estas, se añaden dos variables nuevas: los programas de enseñanza ${ }^{28}$ y la comunidad de habla, que queda dividida en tres grupos: bilingüismo activo con predominio del castellano, bilingüismo activo con uso equilibrado y bilingüismo activo con predominio del valenciano. En sus conclusiones, Llopis apunta que el tipo de centro, el lugar de residencia de los alumnos y la comunidad de habla a la que pertenecen son las variables más significativas en el léxico disponible de los valencianos. Así, los alumnos de instituciones educativas privadas de zonas bilingües con predominio del valenciano obtienen mejores resultados. A pesar de que los alumnos bilingües muestran mayor productividad, la lengua materna presenta un valor discriminante mucho menor. Asimismo, la lengua habitual tampoco exhibe influencia en la covariación de los datos, y de igual modo se coloca en última posición teniendo en cuenta el grado de convergencia entre las primeras cincuenta palabras. Al mismo tiempo, Llopis analiza las transferencias como resultado del contacto

\footnotetext{
${ }^{28}$ Los programas de educación contemplados son estos: Programa de Incorporación Progresiva (PIP) y el Programa de Educación en Valenciano (PEV). Véase más adelante $§ 3.5 .4$
} 
lingüístico, ${ }^{29}$ y concluye que estos fenómenos interlingüísticos aparecen más en la dirección castellano $\rightarrow$ valenciano. En trabajos posteriores (Llopis, 2008, ${ }^{30}$ 2010) vuelve a estudiarlas, y al analizar la convergencia de las primeras cincuenta palabras desde un punto de vista cuantitativo y cualitativo en la variable comunidad de habla, concluye que la comunidad caracterizada con un bilingüismo activo con un empleo equilibrado entre el castellano y el valenciano presenta un mayor número de fenómenos de contacto lingüístico. Asimismo, en Llopis y López Río (2013) la variable analizada es la lengua habitual, donde indica que los monolingües (bilingües pasivos) destacan por encima de los bilingües en el número de transferencias.

En Alicante, por su parte, Martínez Olmos (2008) analiza las transferencias léxicas detectadas, que aparecen en mayor medida en las comunidades de habla con una competencia comunicativa bilingüe. El perfil sociológico de los informantes que presentan interferencias es el siguiente: informantes del sexo femenino, de centros públicos, pertenecientes a comunidades de bilingüismo activo y alumnos del nivel sociocultural medio-medio.

La otra provincia de la comunidad Valenciana, Castellón, es tratada en la presente investigación. Con anterioridad, Blas Arroyo y Casanova (2003a) ya estudiaron en una submuestra de 246 alumnos y ocho centros de interés (Cuerpo, Ropa, Partes casa, Muebles, Alimentos, Mesa, Transportes y Profesiones) la incidencia de diversas variables extralingüísticas en la disponibilidad léxica de los estudiantes castellonenses, como la influencia de la red educativa (pública o privada) o el entorno sociocultural en el que se desenvuelven los alumnos. ${ }^{31}$ La conclusión a la que llegaron fue que los resultados de la disponibilidad léxica de los informantes no diferían apenas en las dos redes de enseñanza analizados, "ni siquiera cuando los datos de ambos grupos son evaluados en conjunción con el nivel sociocultural de las familias, variable sociológica que, por el contrario, sí tiene una cierta incidencia significativa en la estratificación sociolingüística cuando se considera aisladamente" (2003a: 27). ${ }^{32}$

\footnotetext{
${ }^{29}$ Llopis (2009) clasifica los fenómenos de contacto lingüísticos en: interferencias, préstamos en vías de integración, préstamos integrados, compuestos híbridos y sustituciones de código.

${ }^{30}$ Véase al respecto el apartado 5.4.4.

${ }^{31}$ El nivel en el que se sitúan los alumnos se midió a través del grado de instrucción alcanzado por sus padres.

${ }^{32}$ A través de esta variable solo se pudieron averiguar contrastes claros entre los grupos extremos de la población. Los grupos en los que se dividió la muestra fueron cuatro: Primarios Incompletos (alumnos cuyos padres o bien no habían asistido a la escuela o bien no habían completado el nivel formativo de la enseñanza primaria), Primarios completos (alumnos cuyos padres tenían la formación primaria completada), Secundarios (padres en posesión de estudios secundarios completados) y Superiores (alumnos cuyos padres tenían formación universitaria).
} 
Posteriormente (2003b) se comprobó si la influencia de la lengua materna en algunos valores de la disponibilidad léxica en esta comunidad castellonenses bilingüe era significativa o no. Tras el análisis de la misma submuestra y los mismos centros de interés, se demostró que dicha variable indicaba una incidencia leve, pero significativa estadísticamente, en la mayoría de los índices de disponibilidad léxica estudiados, mientras que en otros, tales diferencias se neutralizaban. Las mayores diferencias se encontraron en los aspectos cuantitativos (número de palabras totales o los promedios correspondientes), en los que los castellanohablantes superaban a sus compañeros valencianohablantes exclusivos. Asimismo, se apreció una mayor congruencia de los léxicos disponibles entre los alumnos con el castellano como lengua materna a través del índice de cohesión. Por otro lado, los valencianohablantes mostraron una variabilidad léxica similar a la de los castellanohablantes.

En un nuevo trabajo (Blas Arroyo y Casanova, 2001), se verificó cómo ciertos factores (sexo, lugar de residencia y nivel educativo familiar) ejercían una influencia significativa sobre la variable lengua materna. Esta influencia actuaba en dos sentidos contrapuestos: o bien aumentando las diferencias o bien neutralizándolas. Por ejemplo, si atendemos al factor lugar de residencia, mientras que en Castellón de la Plana, capital de la provincia, las diferencias entre castellanohablantes y valencianohablantes tendían a atenuarse, éstas se agrandaban entre los que residían en un entorno rural, probablemente como consecuencia del mayor uso del valenciano en la vida social de estas zonas. En cuanto al sexo, se comprobó también que las distancias porcentuales se ensanchaban entre los extremos representados por las chicas castellanohablantes y los chicos valencianohablantes, respectivamente. Por el contrario, en otros subgrupos la incidencia de estos factores actuaba en una dirección inversa, neutralizando las diferencias de partida, como ocurre en el caso de los alumnos pertenecientes a las familias con un nivel sociocultural más alto. Una razón plausible es que "el propio sistema educativo ha podido contribuir a eliminar los puntos de partida diferentes $y$ ha equilibrado los valores de la disponibilidad léxica en la población escolar (Blas Arroyo y Casanova, 2003a: 179).

Por su parte, Arnal (2008a, 2008b, 2009), al analizar los dialectalismos aragoneses en los listados de esta región, ha tenido también en cuenta el área de la "Franja Oriental de Aragón", de habla catalana, y ha incluido entre el léxico regional "las posibles interferencias de esa lengua en el vocabulario disponible del español de los informantes de la zona" (2008a: 20). Asimismo, en estos trabajos está presente la zona 
altoaragonesa, en la que todavía perviven variedades vernáculas, consideradas como la continuación del histórico dialecto aragonés. De esta manera, examina tanto palabras de filiación catalana, ${ }^{33}$ como aragonesismos y otros términos comunes a Aragón y Cataluña.

\subsubsection{Contacto castellano-euskera}

En un primer momento, Azurmendi (1983) describe la situación del bilingüismo vasco-español en San Sebastián con estudiantes de edades de 9-10 y de 13-14 años, y estudia la lengua materna y la lengua más utilizada en diferentes ámbitos (casa o amigos). Más tarde, Etxebarria (1996,1997 y 1999), además de la lengua materna y la lengua de uso fuera de la escuela, analiza el modelo de enseñanza bilingüe y su potencial influencia en el léxico disponible en la ciudad de Bilbao. Llega a la conclusión de que, aunque se dan algunas diferencias a favor de los alumnos que habían seguido el modelo A - con el castellano como lengua vehicular de la enseñanza-, los alumnos euskaldunes que han seguido el modelo $\mathrm{D}$-con el vasco esta vez como lengua principal de la educación-, no presentan un déficit en el conocimiento del español. En palabras de esta autora: "no llega a apreciarse un déficit particularmente intenso en este aspecto, no, al menos, de carácter propiamente asignable al modelo de enseñanza bilingüe" (1996: 325). ${ }^{34}$ Asimismo, Etxebarria ha realizado las encuestas de la provincia de Álava, en las que se aprecia cómo los vasquismos son menos frecuentes en los estudiantes de los centros privados (vid. Bartol, 2011).

Para la Comunidad Foral de Navarra disponemos de los estudios de Saralegui y Tabernero (2008), Tabernero (2008 a y b) y Areta (2009). Como es sabido, en este territorio hay una zona norte bilingüe, con el euskera y castellano como lenguas de uso común, y otra zona totalmente monolingüe en castellano y con distintos modelos de enseñanza vigentes. En estos estudios se seleccionan como variables independientes la lengua materna, la lengua de uso habitual, el modelo lingüístico, la modalidad de bachillerato estudiada, la zona dialectal y la procedencia de los progenitores, como potenciales condicionantes de la presencia de trasferencias desde el euskera en el léxico

\footnotetext{
${ }^{33}$ En este sentido, Arnal (2008b) recoge palabras que aparecen también en el léxico de los estudiantes de Castellón, como empeltar 'injertar', tallar 'cortar', mas 'casa de campo', paella 'sartén', etc.

${ }^{34}$ Los modelos de enseñanza en el País Vasco se configuran de la siguiente manera: modelo A: la enseñanza se imparte en castellano y el euskera se considera como una asignatura más; modelo B: la enseñanza se imparte mitad en castellano y mitad en euskera; modelo D: la enseñanza se imparte básicamente en euskera, y el castellano constituye una asignatura obligatoria.
} 
disponible de Navarra (Saralegui y Tabernero 2008, Tabernero, 2008a). Por otro lado, esta última autora detalla las trasferencias del vasco en el léxico de Navarra y las clasifica en fenómenos de contacto diversos: code-shifting (sustituciones de código o términos del euskera introducidos porque no son recordadas las palabras castellanas y no guardan parecido con las palabras castellanas), interferencias (préstamos puntuales o esporádicos que guardan similitud con las palabras castellanas) y préstamos culturales (voces del euskera que han pasado al castellano, como calimotxo, chistorra). Asimismo, además de estudiar específicamente algunos regionalismos vascos (Tabernero, 2008b), apunta en otro lugar que es elevado el número de palabras castellanas que los estudiantes escriben con grafías del euskera (Tabernero, 2008a).

Por su parte, Areta (2009) proporciona los datos cuantitativos y cualitativos del léxico disponible de Navarra en su tesis y analiza la lengua materna y la de uso habitual, así como el modelo lingüístico seguido por los informantes, variables que constatan la superioridad de los castellanohablantes. Destaca que la lengua materna influye en las respuestas de los informantes, sobre todo, en las áreas relacionadas con la vida cotidiana. De igual modo, estudia los dialectalismos y los términos de diferentes registros lingüísticos que se observan en los listados.

\subsubsection{Contacto castellano-gallego}

En Galicia, López Meirama (2008) tiene en cuenta la lengua habitual ${ }^{35}$ entre otros factores extralingüísticos. Constata la presencia de galleguismos y anota que el centro de interés donde más aparecen es el de los Trabajos del campo y el jardín, área semántica que propicia los dialectalismos en todos los estudios. Concluye que los alumnos que utilizan el castellano habitualmente consiguen promedios más altos en el índice de las respuestas, aunque las diferencias entre los subgrupos no son muy amplias. $\mathrm{Al}$ respecto, indica que "es lógico que los resultados coloquen a este grupo por encima de los otros dos, pues es esperable que un individuo que utiliza solo o habitualmente el castellano sea capaz de activar las palabras de esta lengua con más rapidez" (p. 118). Sobre el léxico dialectal, Álvarez de la Granja (2011: 76) apunta que el estudio a partir de los léxicos disponibles supone un avance frente a otro tipo de investigaciones dialectales, "puesto que se manejan palabras proporcionadas por informantes

\footnotetext{
${ }^{35}$ López Meirama (2008: 116) divide la muestra, según la lengua habitual, en tres grupos, los alumnos que dicen hablar gallego, los que hablan castellano y los que se declaran bilingües equilibrados..
} 
procedentes de toda Galicia, de diferentes niveles socioculturales y con diferentes lenguas iniciales y de uso". Estudia los fenómenos de contacto lingüístico desde un punto de vista funcional y formal. Desde el primero, clasifica los fenómenos de contacto en préstamos integrados (cuando son empleados como mínimo por diez informantes, lo que parece asegurar un cierta integración social del término), interferencia léxicas (vocablos que suponen una forma aproximada a la castellana creados en el momento de la encuesta), lapsus bilingües ${ }^{36}$ (palabras o expresiones gallegas que se insertan inconscientemente en los listados) y cambios de código (se realizan de forma consciente e intencional por un "deseo de introducir el gallego basado en razones pragmáticas de distinto tipo" (p. 29)). Desde el segundo punto de vista, clasifica los fenómenos de contacto lingüístico en formas sin adaptar, formas adaptadas, calcos semánticos y calcos morfoléxicos. Tras el análisis y explicación de todos los grupos concluye que los listados de léxico disponible "pueden ser una evidencia más de la imposibilidad que tienen los [individuos] bilingües de mantener sus lenguas completamente separadas, de la hibridación característica de los idiomas de una comunidad bilingüe..." (p. 79).

Por otro lado, Prado et al. (2009) analizan el contacto entre español y portugués en la zona limítrofe de Extremadura y Andalucía con Portugal (zonas del Algarve y Alentejo). Suministran los datos generales (totales, promedios y porcentajes) de los grupos (españoles y portugueses), pero no realizan un análisis concreto de la lengua materna o habitual.

\subsubsection{Otros contactos en España}

En Asturias conviven el castellano y distintas variedades del asturiano (bable) desde hace siglos. A las variables habituales del proyecto panhispánico, Carcedo (2001), añade la zona geográfica, lo que sirve para estratificar la muestra en cuatro grandes zonas, coincidentes con otras tantas divisiones tradicionales en la dialectología: bable central, bable occidental, bable oriental y zona del gallego asturiano (la ciudad de Oviedo fue considerada como una zona independiente del bable central). Este autor concluye que las similitudes son muy superiores a las divergencias, lo que pone de manifiesto una unidad esencial en el léxico disponible asturiano, con independencia de

\footnotetext{
${ }^{36}$ Alvarez de la Granja adapta la etiqueta de "bilingual slips" utilizada por Matras (2009: 19).
} 
la zona geográfica o la variedad dialectal a la que se adscriben los estudiantes. Asimismo, advierte la presencia de términos autóctonos en los listados generales.

Fuera de la Península encontramos los trabajos sobre Ceuta (Ayora, 2006) y Melilla (Fernández Smith et al., 2008), donde se utilizan el castellano y el árabe, así como el bereber. Ambas investigaciones analizan la lengua materna: junto al castellano, el dariya en Ceuta y el mazigia en Melilla, pero no dedican un capítulo específico en sus trabajos respectivos a los fenómenos de contacto. Hay que subrayar que en Ceuta se da un bilingüismo unidireccional, es decir, solo los hablantes del dariya son bilingües, y se observa un bilingüismo de carácter diglósico favorable al español, que es la única lengua oficial. En los resultados de disponibilidad, los hablantes de árabe presentan un menor número de lexemas en contraste con los hablantes de lengua materna española. Asimismo, Ayora analiza diversos dialectalismos (andalucismos y localismos).

Igualmente, en Melilla conviven hispanohablantes y bilingües con el español y la lengua mazigia (variante del bereber) en distintos grados de conocimiento. En consecuencia, es natural que los primeros muestren una mayor cantidad de léxico en trece centros de interés. En esta ciudad, el español es la lengua de la administración, la cultura y las instituciones, los negocios...

\subsubsection{Contacto español-inglés}

Escoriza (2003, 2007) estudia la vecindad entre el español y el inglés en Gibraltar. Atiende a las variables lengua materna, lengua utilizada en casa y fuera de la escuela. Al analizar los vocablos que penetran en cada una de las lenguas, constata la presencia de numerosos anglicismos en el castellano, que explican las intensas interferencias del inglés en el uso del español. Al mismo tiempo, se interesa por los hispanismos en el inglés de la comunidad estudiada.

Otra zona donde se estudia el contacto entre el español y el inglés la encontramos en Norteamérica. En un trabajo pionero, Bailey Victery (1971) analizó comparativamente a alumnos monolingües en inglés (Houston,Texas) y español (Monterrey, México), así como bilingües en ambas lenguas (Houston). En su estudio tuvo en cuenta la lengua hablada en casa con la finalidad de comprobar diferencias culturales entre nacionalidades. Llegó a la conclusión de que el vocabulario disponible era cuantitativamente muy parecido en inglés y en español; y, en relación con los 
fenómenos de contacto lingüístico, Bailey Victery concluyó también que el grupo bilingüe fue el que manifestó más interferencias entre ambas lenguas.

Más recientemente, Moreno Fernández (2007) ha abordado la cuestión del léxico disponible en informantes de origen mexicano en Chicago, teniendo para ello en cuenta la variable lengua materna. Estudia los anglicismos y las posibles formas resultantes de la mezcla de ambas lenguas. A las variables habituales añade, asimismo, la generación de inmigración y el curso de español (para nativos) en el que se inscriben los informantes. Advierte, al examinar los anglicismos, que estos sobresalen en diversos campos semánticos, como los Juegos y Distracciones, La ropa, y Calefacción, Iluminación y medios de airear un recinto. Asimismo, se observa una tendencia a la aparición de dobletes léxicos en los que, sin embargo, la palabra en español tiene un mayor índice de disponibilidad que el equivalente en inglés.

Por su parte, Sancho Sánchez (2006) aplica el test de disponibilidad a informantes hispanos de diferentes edades en diversos estados norteamericanos, como Nueva York, Nueva Jersey, Carolina del Norte, Georgia, Mississippi, Florida, Texas y California. Le interesa recoger los anglicismos que presentan los hablantes de español y tiene en cuenta el idioma usado fuera de la familia (inglés, español o ambos) así como el tiempo de permanencia en los Estados Unidos. Y concluye que los informantes de los estados americanos emplean considerablemente más anglicismos que los de otros países de habla hispana. Por otro lado, muestran un léxico disponible cuantitativamente mayor los individuos que llevan más tiempo residiendo en EE.UU.

Finalmente, en la ciudad Redwood City, California, Verdeses-Mirabal (2012) analiza el léxico disponible de un grupo de hispanos en esta comunidad bilingüe. Estudia la variable lengua habitual (español o inglés) en relación con la generación de inmigración, el lugar de nacimiento y el nivel de español de los informantes. Entre las conclusiones de este estudio destaca una mayor productividad léxica entre quienes tienen el español como lengua habitual y los de la primera generación de inmigrantes, de las tres que estudia.

\subsubsection{Contacto español-finés}

Por último, podríamos hablar también de otro contacto de lenguas más restringido, el que español y finés mantienen en Finlandia entre inmigrantes de habla hispana en ese país nórdico. Se trata del estudio de Bernal (2004-2005), quien analiza el 
bilingüismo individual dentro del bilingüismo social entre finés y sueco, ambas lenguas oficiales en Finlandia. En su investigación tiene en cuenta los estudios de español, la procedencia de los padres, el tiempo vivido en un país hispanohablante, además del sexo y la edad. Bernal constata que los mejores resultados en español los alcanzan aquellos adolescentes que reciben clases de español de forma regular, y que, además, han vivido en algún país hispanohablante durante algún tiempo. En este trabajo, la edad se muestra también como un factor significativo, ya que la productividad léxica crece de forma paralela al desarrollo cognitivo e intelectual de los informantes. 
3

\section{CASTELLÓN, PROVINCIA OBJETO DE ESTUDIO}





\section{CASTELLÓN, PROVINCIA OBJETO DE ESTUDIO}

\subsection{Introducción}

Con 6.678 kilómetros cuadrados de extensión, Castellón es una provincia situada al este de la península Ibérica y en la parte septentrional de la Comunidad Valenciana. Como se puede apreciar en el mapa 3.1, la provincia limita al norte con Tarragona (Cataluña), al oeste con Teruel (Aragón), al sur con Valencia y al este con el mar Mediterráneo. Geográficamente, se encuentra dividida en dos espacios muy diferentes: el litoral, donde se sitúan los grandes núcleos urbanos, y el interior de la provincia, mucho más extenso y montañoso, y en cuyo seno abundan las poblaciones pequeñas. Al mismo tiempo, ello determina que nos encontremos ante dos zonas claramente diferenciadas, no solo geográfica, sino también, económica y socialmente.

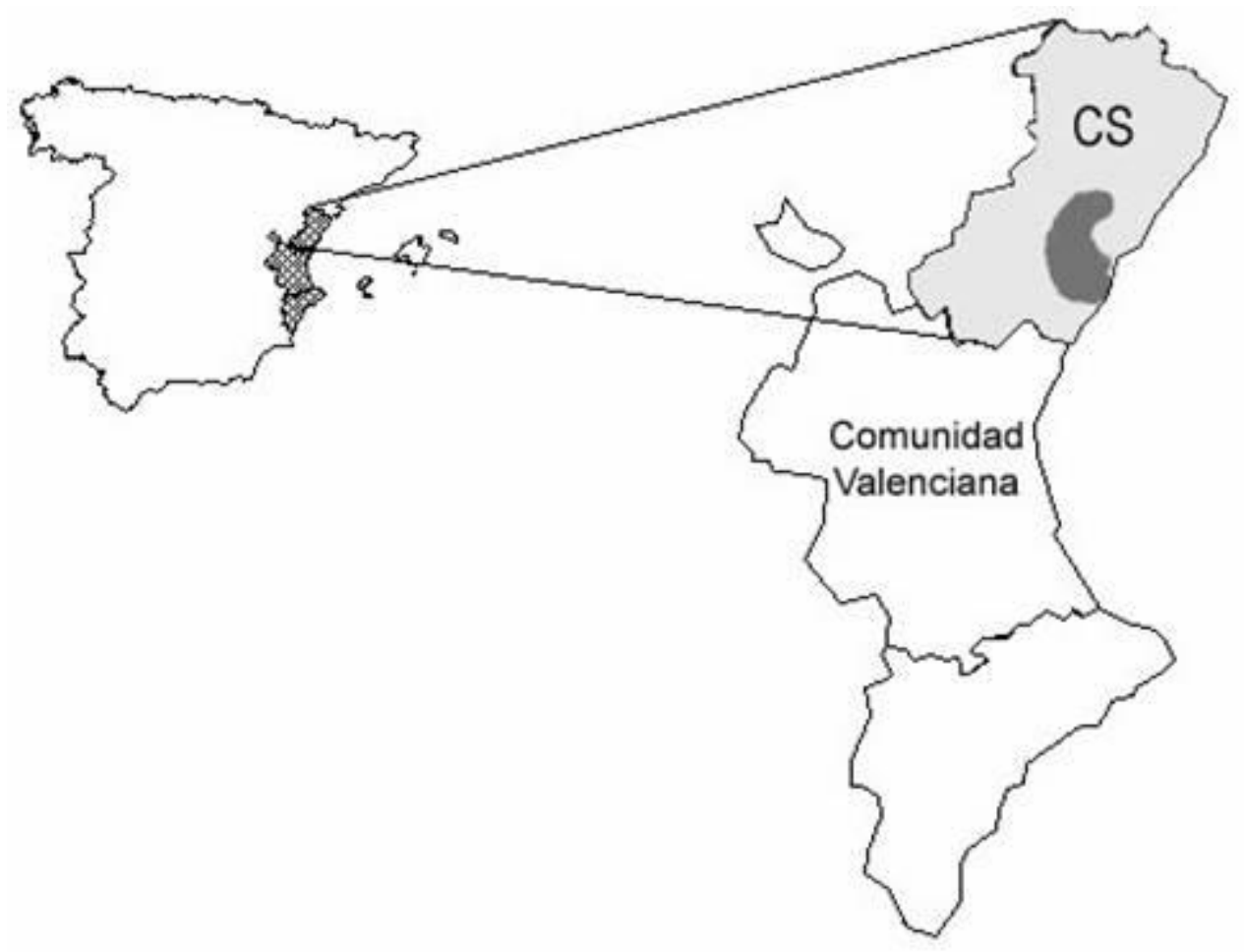

Mapa 3.1. Ubicación de la provincia de Castellón con respecto a España y la Comunidad Valenciana. 
Por otro lado, y para lo que aquí nos interesa, tan importante como esta división es el hecho de que nos encontremos ante una provincia en la que se produce una situación de contacto lingüístico secular, reconocida institucionalmente por el Estatuto de Autonomía de la Comunidad Valenciana, que, desde 1982 avala legalmente la cooficialidad del valenciano (nombre que recibe el catalán hablado en estas tierras) ${ }^{37}$ y el castellano. La mayor parte de la provincia es, ciertamente, bilingüe, ya que en ella alternan de manera fluida el valenciano, a menudo como lengua materna para muchos hablantes (Querol, 2004) y el castellano (Blas Arroyo y otros, 1992), en calidad de lengua segunda, si bien la competencia sobre esta última es, en líneas generales, alta, y en todo caso, se halla alejada de las limitaciones que caracterizan el aprendizaje de segundas lenguas de origen extranjero. Sin embargo, en la franja limítrofe con Aragón, especialmente en el suroeste de la provincia, el castellano es la lengua predominante. Causas históricas en el proceso de la Reconquista, como veremos más adelante, explican este hecho lingüístico.

En definitiva, razones históricas y lingüísticas justifican también una división bipartita de Castellón. Por ello debemos advertir que en esta tesis doctoral únicamente se analizan las encuestas llevadas a cabo en las zonas bilingües de la provincia. Y ello por dos motivos: el primero, porque en el momento de realizar las encuestas de la disponibilidad léxica en alumnos de niveles preuniversitarios estas eran las únicas poblaciones que contaban con estudios de bachillerato; y, en segundo lugar, porque en el presente trabajo de investigación deseamos analizar también la potencial influencia del contacto de lenguas sobre el léxico disponible del castellano.

En los apartados siguientes ofrecemos un breve resumen de los aspectos históricos, sociodemográficos, económicos y lingüísticos más relevantes de la provincia de Castellón.

\footnotetext{
${ }^{37}$ Una característica que distingue a la provincia de Castellón de otras zonas de la Comunidad Valenciana es la ausencia de confrontación social por el reconocimiento de esta filiación entre el valenciano y el catalán. Aunque el nombre que recibe la lengua es casi siempre el primero, existe un amplio consenso acerca de su vinculación genética con la lengua hablada en otros territorios del ámbito linguiístico catalán. No es, pues, casual que Castellón fuera la sede de las famosas Normes de Castelló, que el 21 de diciembre de 1932 adoptaban las normas ortográficas del Institut dEstudis Catalans para la estandarización escrita de la lengua en tierras valencianas.
} 


\title{
3.2. Breve sinopsis histórica
}

Entre el siglo VIII y el XIII, los territorios que hoy conforman Castellón estuvieron en manos de los musulmanes y fue Jaime I, el Conquistador, quien la tomó de manos de los reyes árabes de Valencia. El primer lugar conquistado fue Ares del Maestre (1232), y al año siguiente caían Peñíscola y el castillo de Fadrell (origen de la actual Castellón de la Plana).

En consecuencia, la provincia de Castellón tiene su origen histórico en la reconquista de estos territorios por parte del rey Jaime I, llevada a cabo mayoritariamente por leridanos y aragoneses, que repoblaron estas tierras a partir del siglo XIII y durante toda la baja Edad Media. ${ }^{38}$ Así lo recuerdan algunos historiadores:

\begin{abstract}
El ínclito rey D. Jaime I, aún antes de conquistar el reino de Valencia, había ya repartido, para después de la victoria, las tierras y lugares que pertenecían a los moros, entre los ricoshombres, barones y caballeros que le acompañaban en aquella heroica empresa. Después de la capitulación de Valencia (28 Sep. 1238), continuó el repartimiento; así que la mayor parte de las donaciones llevan la fecha de 1237 a 1249. [...] (Balbás, 1892:57)
\end{abstract}

La Carta Puebla fue otorgada a Burriana el día de Todos los Santos del año 1233. Poco después, el 8 de septiembre de 1251, el rey concedió también la licencia del asentamiento actual a la villa de Castellón de la Plana. A partir de entonces, y de manera progresiva, se fueron sucediendo las autorizaciones, fueros y cartas puebla a otros municipios y villas, como Onda, Tales (1248), etc.

A partir de la Edad Media, Castellón no deja de participar en acontecimientos históricos relevantes. Entre 1520 y 1523 tuvieron lugar las revueltas de las Germanías valencianas, con importantes batallas en Oropesa y Almenara. Siglos más tarde, durante las guerras carlistas (1833-1840), la zona del Maestrazgo, al norte de la provincia, fue un importante foco reaccionario frente al liberalismo, mientras que la capital apoyó a los isabelinos liberales. ${ }^{39}$ Benito Pérez Galdós noveló este suceso en La campaña del

\footnotetext{
${ }^{38}$ Como veremos con detalle más adelante (apartado 3.5), la parte sur del interior de la provincia fue repoblada mayoritariamente por aragoneses, por lo que la lengua usada por estos pobladores es el castellano, mientras que en la costa y el resto de la provincia la repoblación se llevó a cabo por individuos de origen catalán, por lo que el valenciano es la lengua de estas zonas.

39 El siglo XIX representó un avance destacado de estudios sobre la historia castellonense. Historia, geografía y estadística de la provincia de Castellón (1873) de Bernardo Mundina, fue uno de los primeros intentos de estudio sobre Castellón y su provincia desde una perspectiva divulgativa. Algo
} 
Maestrazgo (1899), que incluye dentro de sus Episodios Nacionales (Fortuño, Casanova, Nebot y Pareja 2010: 94). Ya en la guerra civil (1936-1939), estuvo ubicado en Benicàssim el hospital militar, dependiente de las Brigadas Internacionales, en el actual emplazamiento del hotel Voramar que, junto a las villas colindantes, sirvieron de apoyo y cuartel en la zona republicana. Asimismo, en 1938, y como prólogo a la segunda guerra mundial, la aviación alemana destruyó algunos pueblos de la provincia de Castellón (Benasal, Ares, Vilar de Canes, Albocácer...), al servir como campo de pruebas de las bombas de $500 \mathrm{Kgs}$. lanzadas por los recién estrenados aviones Yunkers 87 A (“Stuka”) (Casanova y Fortuño, 2014).

A la guerra civil española, sucedió un periodo en el que el comercio de la naranja, la industria azulejera, la llegada de numerosos emigrantes andaluces y aragoneses, un incipiente turismo (sobre todo de procedencia francesa) y un auge de la construcción favorecieron el tópico conocido como el "Levante feliz".

En el ámbito escolar, en la década de los sesenta aparecen los primeros institutos de la provincia (Villarreal, Almazora, Onda, Nules...), que con el Francisco Ribalta de la capital - también conocido como el Masculino, y ubicado desde 1917 en el emplazamiento actual- venían a completar un incipiente mapa escolar. Por otro lado, en 1969 se fundó el Colegio Universitario de Castellón (CUC), germen de la futura Universidad Jaume I (1991).

En la Transición democrática, tras la promulgación de la Constitución Española de 1978 y el Estatut d’Autonomia (1982), los partidos políticos más votados en la capital y la provincia han sido el Partido Popular (PP), el Partido Socialista Obrero Español (PSOE) y el Partido Comunista, seguidos de otros de orientación nacionalista.

parecido encontramos en la obra de Arcadio Llistar Escrig (1887), que acomete la tarea de redactar una historia de la provincia de Castellón desde la reconquista del rey Jaime I hasta el siglo XIX y, más concretamente sobre las guerras carlistas, de tanta incidencia en la capital y poblaciones de la provincia. De mayor amplitud y profundidad es El libro de la provincia de Castellón (1892) de J.A. Balbás, que resulta insustituible para conocer las efemérides más destacadas de la historia castellonense. En 1985, varios autores universitarios emprenden la redacción de La provincia de Castellón de la Plana. Tierras y gentes, en la que encontramos un amplio recorrido histórico: desde la Prehistoria (Gusí Jener), historia antigua (Olària), medieval (Barceló), Edad Media cristiana (Sánchez Adell), Edad Moderna (Corona) y Contemporánea (Romeu). El resultado es un trabajo de rigor científico, alejado de una visión meramente positivista y descriptiva, costumbrista y legendaria, que predominaba hasta entonces en trabajos aislados. Asimismo, se presentan también otros aspectos de la provincia, como el relieve, estructura y litología (Sanfeliu), geomorfología, clima e hidrología (Quereda), biogeografía (Mulet y otros), demografía (Domingo), fenómenos urbanos (Ortells), el mundo rural (Sancho), la ganadería (Obiol) y las actividades industriales, comerciales y el turismo (Domínguez). 


\subsection{Distribución geográfica y demográfica de la población. ${ }^{40}$}

Durante todo el siglo XX, pero en especial a partir de la década de los años 60, la población de Castellón experimentó un marcado desplazamiento poblacional desde la montaña a los territorios de la costa, lo que fortaleció notablemente a los pueblos de esta, frente a los del interior, que progresivamente vieron reducir sus recursos y restringir su actividad económica a una agricultura de secano y escasa actividad industrial, lo que ocasionó que algunos de ellos quedaran despoblados. Como indica Domingo (1985:123):

La nota constante, el común denominador de las diversas facetas de la población, es la dicotomía existente entre el interior y el litoral de la provincia. En las ciudades y pueblos costeros se acumula la mayor parte de sus habitantes, los focos industriales, los focos comerciales, culturales y sanitarios. [...] Las tierras interiores tienen una comunicación restringida, cuando no francamente difícil, salvando el eje del Palancia. Se habla de gran despoblación, incluso de desertización, densidades bajísimas, estructura envejecida y decrecimiento..

De este modo, en la actualidad la llanura litoral, con 112 kilómetros de costa, donde se encuentra la mayor fuerza agrícola (naranjos) e industrial (cerámica) de la provincia, alberga al $70 \%$ de la población. De hecho, los principales núcleos de población se sitúan en la costa: Castellón de la Plana, capital de la provincia, Almazora, Borriana, y otros muy cercanos Vila-real, Nules, Vall d'Uixó y Onda. A estos hay que añadir algunos municipios turísticos que han conocido un importante auge demográfico, como Oropesa, Benicasim, Peñíscola, Benicarló y Vinaroz, estos últimos próximos ya a la frontera con Cataluña. A lo largo de las últimas décadas, estos centros poblacionales han acogido no solo a numerosas personas procedentes del interior de la provincia, sino también a destacados contingentes migratorios llegados desde otras partes de España, especialmente del sur (Andalucía, Murcia, Castilla la Mancha...), pero también de la vecina Aragón (en particular, la despoblada provincia de Teruel), en busca del trabajo en las fábricas de azulejos y en la explotación naranjera. Por si esto fuera poco, en la

\footnotetext{
${ }^{40}$ Para este apartado resulta fundamental el libro de Carlos Sarthou Carreres, Geografía general del Reino de Valencia. Provincia de Castellón (1913). Pese a los años transcurridos desde su aparición, resulta insustituible para conocer cada uno de los municipios castellonenses. Ya en nuestros días, Las ciudades valencianas. Guía visual de nuestras tierras (1998) recorre con textos de Josep Franco y fotografías de Rafael Gil y Francesc Jarque tanto la capital como las principales ciudades castellonenses en la geografía valenciana.
} 
década de los años noventa, y al calor del boom inmobiliario, se asiste a una nueva etapa inmigratoria que tan solo en los últimos años ha comenzado a remitir (Bernat Martí, 2015: 115 y ss.) Esta nueva oleada de inmigrantes procede de diversos países sudamericanos (Ecuador, Colombia, Bolivia, etc.), Asia (China, de manera especial), África (en particular de la región del Magreb), pero sobre todo de Rumanía. ${ }^{41} \mathrm{La}$ inmigración desde estos países se debe fundamentalmente a razones económicolaborales, a la demanda de mano de obra poco cualificada, que ha generado un gran crecimiento económico, impulsado por la construcción, el servicio doméstico y actividades relacionadas con la agricultura y el turismo en gran medida.

En suma, la población castellonense es un conglomerado de grupos de diferente origen geográfico, lingüístico y cultural, una sociedad, en definitiva, multicultural, multirreligiosa y multilingüística.

Según el INE, la provincia de Castellón registraba una población de 582.327 habitantes en 2015, de los cuales unos 173.841 corresponden a la capital hoy en día. Sin embargo, en 1999, año en el que se realizó la encuesta, se registraban tan solo $139.712,{ }^{42}$ lo que revela el crecimiento exponencial experimentado por la capital de la provincia. Lo mismo ocurre en las poblaciones cercanas a la capital, como Vila-real, que hoy sobrepasa los 52.000 habitantes, así como Burriana y Vall d’Uixó, que superan los 30.000 en la actualidad, mientras que otros muchos pueblos del interior no llegan apenas a los 100 habitantes. ${ }^{43}$ En la tabla siguiente exponemos la evolución del número de habitantes de las poblaciones encuestadas durante los años 1998-1999, que se toman como referencia para los datos de esta investigación. En ella se puede comprobar el mencionado incremento poblacional de estos municipios, aunque a larga distancia del experimentado por Castellón de la Plana. ${ }^{44}$

\footnotetext{
${ }^{41}$ Según los datos del censo de 2015 del Instituto Nacional de Estadística, el 17\% de los habitantes de la provincia son extranjeros. Los rumanos representan un $48,7 \%$ del total de extranjeros; los marroquíes, un $18,8 \%$ y los argelinos un $3 \%$.

${ }^{42}$ Fuente: Anuari Estadístic Municipal i comarcal.

43 En 2015, en pueblos como Espadilla, Sarratella, Villamalur vivían 86, 101 y 70 vecinos, respectivamente. Un año más tarde, esa población exigua se ha visto reducida todavía más $(83,99$ y 68 habitantes, respectivamente).

${ }^{44}$ Fuente: IVE. Generalitat Valenciana, La Comunitat Valenciana en Xifres. 2001. Població provincial i comarques a 1, enero, 1999. INE: Población de los Municipios Españoles. Revisión del Padrón Municipal a 1 de enero de 1999. Madrid, 2001.
} 


\begin{tabular}{|l|c|c|}
\hline Poblaciones & $\mathbf{1 9 9 8}$ & $\mathbf{1 9 9 9}$ \\
\hline Benicarló & 19350 & 19540 \\
\hline Bechí / Betxí & 5314 & 5339 \\
\hline Burriana/Borriana & 26097 & 26323 \\
\hline Castellón/Castelló & 137741 & 139712 \\
\hline Nules & 11490 & 11444 \\
\hline Onda & 18909 & 19110 \\
\hline Vall d'Uixó, La & 28.823 & 28972 \\
\hline Villarreal/Vila-real & 40124 & 40933 \\
\hline Total Provincia & 461712 & 467895 \\
\hline
\end{tabular}

Tabla 3.1. Número de habitantes de las poblaciones encuestadas.

De vuelta a la capital, Ortells (1994: 26) ha recordado que: "Després de Huelva i Logroño i a curta distància, apareix Castelló com la capital que més ha augmentat en els darrers vint anys: un $43 \%$ ", una cifra que contrasta con el 16\% del resto de la provincia. Este crecimiento se produce sobre todo en las últimas décadas del siglo XX, en las que tienen lugar algunas de las principales transformaciones urbanísticas de la ciudad: nuevas plazas y calles, infinidad de planes de reordenación urbanística (los conocidos como Peris, tan asociados a la explosión urbanística y a la corrupción en los últimos tiempos), nuevas sedes institucionales (Museo de Bellas Artes, Recinto de Ferias y Mercados, Palacio de Congresos, campus de la Universidad Jaume I, etc.). Todo ello ha contribuido a un importante desarrollo económico del que nos ocupamos con más detalle en el siguiente apartado.

La provincia de Castellón se encuentra dividida en ocho comarcas, en las que se distribuyen los 135 municipios que la integran. La población de estas aparece en la tabla 3.2. En ella advertimos cómo las comarcas más pobladas son la Plana Alta y la Plana Baixa, que juntas suman 443766 habitantes, más de la mitad del total de la provincia. Por el contrario, la de L'Alt Millars se sitúa como la de menor población, con solo 4055 habitantes. Esta, junto con Els Ports y el L'Alt Maestrat son comarcas de gran raigambre histórica, pero también las que han sufrido un mayor éxodo poblacional. Por su parte, el L'Alt Palància sirve como puente de unión de la Comunidad Valenciana con la vecina Aragón y, junto con la mencionada Alt Millars, es una comarca donde el castellano ocupa una posición dominante por razones históricas (véase más adelante el apartado 3.5.5). En el resto, en cambio, es el valenciano la lengua materna y habitual de la mayoría de sus pobladores. 


\begin{tabular}{|l|c|c|}
\hline Comarca & Población & Capital \\
\hline $\begin{array}{l}\text { Alcalatén/ } \\
\text { L'Alcalatén }\end{array}$ & 16036 & Alcora \\
\hline $\begin{array}{l}\text { Alto Maestrazgo /Alt } \\
\text { Maestrat }\end{array}$ & 7218 & Albocácer \\
\hline $\begin{array}{l}\text { Alto Mijares / L'Alt } \\
\text { Millars }\end{array}$ & 4055 & Cirat \\
\hline $\begin{array}{l}\text { Alto Palancia /L'Alt } \\
\text { Palància }\end{array}$ & 24553 & Segorbe \\
\hline $\begin{array}{l}\text { Bajo Maestrazgo / } \\
\text { Baix Maestrat }\end{array}$ & 82120 & Vinaroz \\
\hline $\begin{array}{l}\text { Plana Alta / Plana } \\
\text { Alta }\end{array}$ & 252157 & Castellón de la \\
\hline $\begin{array}{l}\text { Plana Baja / Plana } \\
\text { Baixa }\end{array}$ & 191609 & Burriana \\
\hline $\begin{array}{l}\text { Los Puertos de } \\
\text { Morella /Els Ports }\end{array}$ & 4669 & Morella \\
\hline
\end{tabular}

Tabla 3.2. Las comarcas y sus capitales en la provincia de Castellón.

En el mapa 3.2 apreciamos la distribución de las ocho comarcas en el espacio geográfico de la provincia de Castellón.

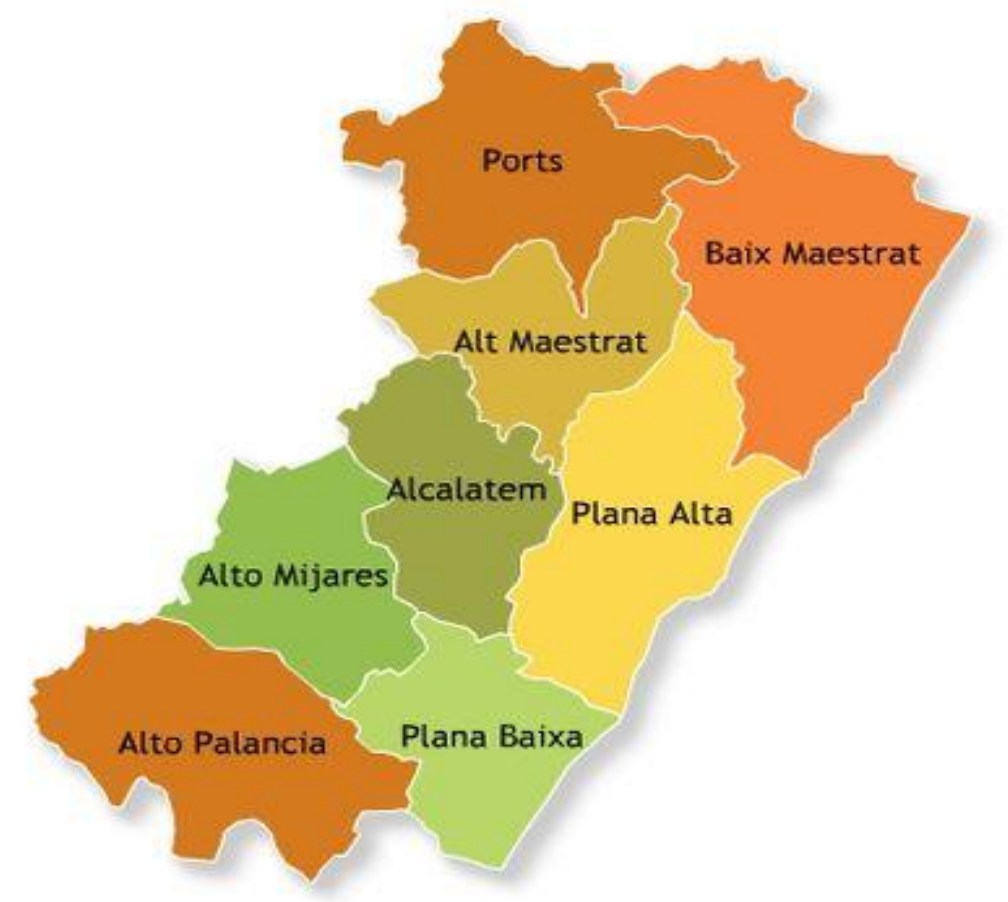

Mapa 3.2. Comarcas de la provincia de Castellón. 
Las poblaciones encuestadas se sitúan dentro de las comarcas más pobladas como ya hemos comentado: Benicarló pertenece al Baix Maestrat; Castellón de la Plana a la Plana Alta; y, por último, Betxí, Burriana, Nules, Onda, Villarreal y La Vall d'Uixó a la Plana Baixa.

\subsection{El desarrollo económico de Castellón}

En sus Observaciones sobre la Historia natural, Geografía, Agricultura, Población y Frutos del Reyno de Valencia, publicada en 1795, el botánico A. J. Cavanilles ponderó ya la actividad comercial y artesanal de la provincia de Castellón, así como su fértil agricultura: "En este estado rinde al labrador quanto le pide, y nunca huelga, sucediéndose de continuo preciosas y abundantes cosechas" (1795: VIII).

El producto interior bruto per capita en la provincia de Castellón es de 22.597 euros, según datos de población del Instituto Nacional de Estadística (1, julio, 2011), y se sitúa como la primera de la Comunidad Valenciana, por encima de Valencia y Alicante. Son la agricultura, la industria y el sector servicios los que impulsan principalmente la economía de la provincia.

La agricultura cuenta con una superficie del $29 \%$ aproximadamente y se distribuye entre zonas de secano (mayor extensión) y de regadío, en estructuras minifundistas y en propiedad. El almendro, el olivo y el algarrobo son los productos base de las tierras del secano, mientras que el cultivo del naranjo lo es en las zonas de regadío, especialmente concentradas en las comarcas de La Plana. La comercialización de la naranja a partir de los años 50 y 60 del pasado siglo dio un gran impulso al comercio exterior, facilitado, además, por su salida a través de los puertos de Burriana y Castellón. Finalmente, en la ganadería hay que destacar el sector porcino, sobre todo en la comarca del Maestrazgo.

En el sector industrial, cabe destacar que en Castellón se concentra buena parte de la industria cerámica y azulejera del país (en poblaciones como Onda, Alcora, Nules, Castellón y Villarreal), y que, junto con la producción naranjera, han dado a conocer esta provincia tanto en España como fuera de ella (Domingo, 1985). Por otro lado, encontramos también algunas comarcas especializadas en la fabricación del mueble en 
el norte de la provincia, en pueblos como Benicarló, Vinaroz y otros municipios del Baix Maestrat. Por último, el sector petroquímico se encuentra representado también en la actividad industrial, esta vez en la capital de la provincia, con la refinería de petróleos en el Grao de Castellón.

Sin embargo, todo lo anterior va dejando paso en los últimos tiempos a una constante tercerización de los sectores productivos, debida al auge del turismo en la economía de la provincia, que ha alcanzado un nivel destacado en las poblaciones costeras castellonenses y, en nuestros días también, del interior. Centros de turismo de playa los encontramos a lo largo de todo el litoral, en la denominada Costa de Azahar (Vinaroz, Benicarló, Peñíscola, Alcocebre, Oropesa, Benicasim...), pero también hoy se encuentran en alza algunos destinos de turismo rural con poblaciones destacadas como Morella, Montanejos, Benasal, Catí o Vilavella, pueblos estos últimos que se han convertido en importantes centros balnearios. ${ }^{45}$

Además, en la sociedad castellonense existe una costumbre arraigada de trasladarse durante la época estival al campo o a la playa (la alquería, el maset, y, más cercano en el tiempo el chalet, el apartamento...). Todo ello ha favorecido un aumento destacable del sector servicios, como ya hemos apuntado. En la actualidad, en la costa alterna el turismo de apartamento, camping y hostelería. Los problemas a los que se enfrenta el turismo castellonense estriban en su marcada estacionalidad, así como en la endeble infraestructura y acondicionamiento de las zonas turísticas. Con la creación del polémico aeropuerto, ${ }^{46}$ situado en las inmediaciones de Villanueva de Alcolea y Benlloch, se abren perspectivas de toda índole, incluido el turismo juvenil de bajo coste. Con todo, se precisa de una preparación tecnológica acorde con los nuevos tiempos, así como abrir el turismo castellonense a otras facetas distintas a las tradicionales del sol y la playa, como ha destacado en los últimos tiempos la clase empresarial.

\footnotetext{
${ }^{45}$ Actualmente, las actividades industriales, comerciales y del turismo han experimentado un importante cambio cualitativo y cuantitativo (Domingo, 1985:189).

${ }^{46}$ El aeropuerto, conocido como Castellón-Costa Azahar, y que no comenzó a operar hasta 2014, se convirtió en imagen repetida del derroche que marcó la crisis económica española entre 2008 y 2015.
} 


\subsection{La situación sociolingüística de la comunidad: datos sobre el bilingüismo social}

En una comunidad bilingüe como la castellonense, la realidad del contacto de lenguas es fundamental para entender la distribución sociolingüística de la lengua que se quiere investigar. De ahí que, en el análisis de la disponibilidad léxica en castellano de los alumnos preuniversitarios de Castellón, sea necesario abordar estas cuestiones por las repercusiones que pueda tener en el grado de competencia léxica de los alumnos en función de su adscripción lingüística (ver apartado 5.4) o las consecuencias lingüísticas que este bilingüismo puede ocasionar en el habla.

Tradicionalmente, el uso del castellano y el valenciano ha diferenciado la estratificación social de la población valenciana, al emplear la población acomodada el castellano, frente a los campesinos, que únicamente hablaban en valenciano. Hasta tiempos muy recientes, hablar en una u otra lengua era una manera de marcar diferencias sociales y económicas entre sus habitantes, pues se consideraba la primera como mucho más prestigiosa que la segunda, siendo esta última ajena a los ámbitos de uso más formales (educación, medios de comunicación, política, administración de justicia, etc.).

\subsubsection{La distribución de las lenguas en la Comunidad Valenciana}

La Comunidad Valenciana está dividida lingüísticamente en dos zonas: una castellanohablante y otra que ha desarrollado un prolongado bilingüismo social a lo largo de los siglos. Razones de índole histórica explican tal situación, que se origina en la época de la Reconquista del rey Jaume I de las tierras valencianas, que comenzó en el 1238, como hemos visto anteriormente. La reconquista del territorio se produjo por gentes de origen geográfico y lingüístico distinto: por castellano-aragoneses en la zona del interior y por catalanes en la franja costera de la Comunidad o País Valenciano. ${ }^{47}$

\footnotetext{
${ }^{47}$ La Comunitat Valenciana, denominación oficial reconocida hoy en día por el Estatuto de Autonomía ha recibido varios nombre a lo largo de la historia: Región valenciana, País Valenciano, Reino de Valencia. Durante el periodo franquista también se la denominó Levante Español, con el fin de camuflar las connotacions históricas originarias (Lo Regne de València). A pesar de que los fueros valencianos fueron disueltos -y, con ellos, la estructura jurídico-administrativa y política del territorio- por Felipe V en 1707, mediante los Decretos de Nueva Planta, el término Reino de Valencia siguió usándose comúnmente durante el s. XVIII y comienzos del XIX. En ocasiones, para matizar la inexistencia del carácter político o jurídico se utilizó como alternativa Antiguo Reino de Valencia. En el siglo XX, este término únicamente se empleó en ámbitos culturales, académicos o literarios asociados a la Renaixença valenciana y el resurgir de un incipiente nacionalismo valenciano.
} 
Ambas zonas muestran, sin embargo, un importante desequilibrio. Así, la zona del interior castellanohablante representa un $40 \%$ de las tierras de la Comunidad, pero su población apenas alcanza el 9\% del total (Ninyoles, 1992). Por el contrario, la mayor parte de la población se concentra en las capitales de provincia y sus alrededores, así como en la zona del litoral, esto es, en las áreas bilingües. De las comarcas que conforman la Comunidad Valenciana, Castellón es la que tiene un porcentaje mayor de población valencianohablante, seguida de Valencia y Alicante.

\subsubsection{Breve bosquejo histórico de un proceso de sustitución lingüística}

Tras el máximo periodo de esplendor del antiguo Reino de Valencia en el siglo XV (conocido desde entonces como el Siglo de Oro), la centuria siguiente fue, sin embargo, un período de decadencia, no solo política, sino también económica y social y la lengua comenzó a ser vista como un dialecto propio de los estamentos más bajos de la sociedad. Como ha destacado Ferrrando (1988:182):

La vinculació de les classes dominants valencianes (aristocracia, alta burgesía) als interessos de la Monarquia hispánica, constituïda arran del matrimoni dels Reis Catòlics, invertirà rápidamente la situació sociolingüística del català, que esdevé llengua $\mathrm{B}$, tot $\mathrm{i}$ mantenir-se de jure com a llengua "oficial" del Regne fins a l'abolició dels Furs (1707). Davant el castellà imperial, considerat ara como la llengua elegant i refinada per antonomasia, els catalanoparlants generen un profund complex d'inferioritat.

Entre los siglos XVI y la primera mitad del XIX tiene lugar un lento, pero inexorable proceso de castellanización en los territorios valencianohablantes del País Valenciano.

L'aristocaracia es beneficia successivament de la desfeta de les Germanies (15191522), de l'expulsió dels moriscos (1609) -que consagra l'actual estructura territorial bilingüe del País-, i de la Guerra de Successió (1701-1716), i converteix el Castellà en llengua de clase i, de fet, en l'única llengua de cultura. L'abolicio del Furs (1707), que posà fi a la sobirania del Regne de València, no fou sinó la consagració legal de la situació sociolingüística anterior, agreujada ara amb l'expulsió del català de la major part dels usos administratius (Ferrando, 1988:182). 
Como consecuencia de este proceso, las clases medias dejaron de utilizar progresivamente el valenciano para emular a la clase alta, que se asoció fuertemente al castellano, sobre todo desde el Decreto de Nueva Planta, promulgado a principios del siglo XVIII tras la Guerra de Sucesión que dio la victoria al centralismo borbónico. Este proceso de sustitución se notó más aún en el XIX por la presión de la burguesía, que adoptó el castellano como un modo de diferenciación del pueblo llano. El uso ya entonces de esta lengua era, pues, una importante marca de ascenso social. Por el contrario, el valenciano quedó relegado a las clases bajas y rurales. Ya en el siglo XX, especialmente durante el periodo franquista, esta sustitución del valenciano por el castellano se intensificó, con la difusión de la enseñanza obligatoria en castellano y la emergencia de nuevos medios de comunicación de masas en esta lengua.

El contacto entre castellano y valenciano ha sido descrito desde puntos de vista teóricos diferentes. Algunos estudiosos han hablado de la existencia de un conflicto lingüístico porque las lenguas han mantenido tradicionalmente una distribución funcional distinta (Ninyoles, 1988; Pitarch, 1988; Ferrando, 1988), interpretada inicialmente como una situación diglósica, con el castellano como lengua A y el valenciano como lengua B, utilizada en el ámbito familiar (Blas Arroyo, 2005). Otros, sin embargo, prefieren ir más allá y hablan de minorización o glotofagia, para referirse, sobre todo, a lo sucedido en las grandes ciudades, como Valencia, Alicante, y en menor medida, la propia Castellón de la Plana. Al respecto, Ferrando (1988:200) señala lo siguiente:

A pesar del predomini de la ideologia bilingüista, que és potenciada des de totes les instàncies del poder, $\mathrm{i}$ de la persistència del sectarisme anticatalanista, hom denuncia cada vegada més la política glotofàgica de l'Estat $i$, malgrat la política institucional de satel.lització lingüística, s'obri pas el reconeixement de la unitat de la llengua, però, contràriament al que s'esdevé a Catalunya, no s'hi han superat les actituds "diglòssiques". Més encara, la sanció estatutària de la ideología bilingüista permet, ara, una política lingüístico-cultural legitimadora de la presència dominant del castellà en la zona catalanòfona i converteix els catalanoparlants en els únics, necessàriament, bilingües.

A esto hay que añadir que algunos sectores de la derecha valenciana niegan que el valenciano esté relacionado genéticamente con el catalán (Pradilla, 1999).

Ninyoles (2000) (apud Blas Arroyo, 2002: 320) considera que se pueden distinguir tres momentos diferentes en ese proceso de sustitución lingüística en la 
Comunidad Valenciana. En una primera etapa (siglos XVI-XIX) encontramos un proceso de bilingüismo horizontal, donde el castellano se extiende solo entre la nobleza y el clero superior, sin afectar al resto de la pirámide social. Durante la segunda mitad del XIX, la sustitución alcanza también a la burguesía, la cual abandona el valenciano para adoptar el castellano, como hemos tenido ocasión de ver. Por último, la consolidación definitiva de este cuadro tuvo lugar durante los procesos intensos de industrialización y urbanización en el franquismo (sobre todo a partir de la década de los años 60 del siglo XX), que dio comienzo al verdadero conflicto lingüístico, con el abandono de muchos valencianos de su lengua tradicional, así como la llegada de cientos de miles de inmigrantes procedentes de otros territorios españoles ajenos al ámbito lingüístico catalán.

Con todo, el papel social del valenciano en esta situación diglósica ha mejorado en las últimas décadas, en particular desde la instauración del Estatuto de Autonomía (1982), cuya reforma en $2006^{48}$ pasa a considerar aquel como lengua propia, y promulga la cooficialidad del castellano y el valenciano en la Comunidad, lo que provoca un importante cambio social en la región y una consideración favorable y positiva hacia la lengua autóctona.

En el artículo primero de ese estatuto encontramos la siguiente declaración respecto a la organización jurídico-administrativa de la Comunidad:

El Pueblo Valenciano, históricamente organizado como Reino de Valencia, se constituye en Comunidad Autónoma, dentro de la unidad de la Nación española, como expresión de su identidad diferenciada como nacionalidad histórica y en el ejercicio del derecho de autogobierno que la Constitución Española reconoce a toda nacionalidad, con la denominación de Comunitat Valenciana.

Y es en el artículo 6 donde se hace referencia a la cooficialidad de las lenguas y a la consideración del valenciano como lengua propia del territorio:

\section{La lengua propia de la Comunidad Valenciana es el valenciano}

2. El idioma valenciano es el oficial en la Comunidad Valenciana, al igual que lo es el castellano, que es el idioma oficial del Estado. Todos tienen derecho a conocerlos y a usarlos y recibir la enseñanza del, y en, idioma valenciano.

\footnotetext{
${ }^{48}$ Ley Orgánica 1/2006, de 10 de abril, de Reforma de Ley Orgánica 5/1982, de 1 de julio, de Estatuto de Autonomía de la Comunidad Valenciana.
} 
3. La Generalitat garantizará el uso normal y oficial de las dos lenguas, y adoptará las medidas necesarias para asegurar su conocimiento.

4. Nadie podrá ser discriminado por razón de su lengua.

5. Se otorgará especial protección y respeto a la recuperación del valenciano.

6. La ley establecerá los criterios de aplicación de la lengua propia en la Administración y la enseñanza.

7. Se delimitarán por ley los territorios en los que predomine el uso de una y otra lengua, así como los que puedan ser exceptuados de la enseñanza y del uso de la lengua propia de la Comunitat Valenciana.

8. L’Acadèmia Valenciana de la Llengua es la institución normativa del idioma valenciano.

3.5.3 Datos sobre conocimiento y uso de las lenguas en el momento de realización de los test de disponibilidad

Diversas encuestas realizadas desde la promulgación del Estatuto de Autonomía ${ }^{49}$ mostraban un incremento general en el uso y conocimiento del valenciano por parte de la población, progreso al que han contribuido las políticas lingüísticas de los sucesivos gobiernos de la Comunidad. Si observamos la tabla 3.3, vemos este crecimiento en varias de las competencias básicas. Con todo, las cifras son todavía bajas en las aptitudes relacionadas con la lectura y la escritura en valenciano. Y más si las comparamos con otras comunidades del ámbito lingüístico catalán, como Cataluña o Baleares, donde la presencia de la lengua autóctona alcanza proporciones mayores en todos los ámbitos (Siguán, 1994, Etxebarria, 1995).

\begin{tabular}{|l|c|c|c|}
\hline Valenciano & $\mathbf{1 9 8 6}$ & $\mathbf{1 9 9 1}$ & $\mathbf{1 9 9 8}$ \\
\hline Entienden & 77.1 & 83.2 & 89.2 \\
\hline Hablan & 49.1 & 51.1 & 55 \\
\hline Saben leer & 24.5 & 38 & 38 \\
\hline Saben escribir & 7 & 15.2 & 19.3 \\
\hline
\end{tabular}

Tabla 3.3. Porcentaje de la evolución del uso del valenciano en la Comunidad Valenciana en las cuatro competencias básicas.

\footnotetext{
${ }^{49}$ Ver Fondo Estadístico Documental de la Conselleria de Eduación. Investigación, Cultura y Deporte (en línea) y las publicaciones del Centro de Investigaciones sociológicas (Siguán, 1994, 1999).
} 
Es interesante también la distribución de estas competencias según el origen de los hablantes. A mediados de los años 90 del pasado siglo, Siguán (1994) proporcionaba la siguiente distribución de las lenguas para los nacidos en la Comunidad Valenciana: en aquel momento tenían el castellano como lengua principal un 54\% de la población valenciana, frente a un $44 \%$ para el valenciano y un exiguo $1 \%$ que consideraba ambas lenguas como primeras.

Sin embargo, si tenemos en cuenta ahora la lengua principal de los no nacidos en la Comunidad (inmigrantes llegados de otras regiones españolas desde los años 60 en adelante), observamos cómo el porcentaje de quienes dicen tener el castellano como lengua principal sube hasta el $95 \%$, mientras que tan solo un $4 \%$ otorga a la lengua propia de la comunidad este papel. En consecuencia, el valenciano no ocupa un lugar preponderante como lengua principal en el conjunto de la sociedad valenciana: no lo hace entre los nacidos en la Comunidad Autónoma, y mucho menos entre quienes han llegado de fuera.

Veamos a continuación de forma más detallada las densidades del dominio del valenciano en las cuatro competencias básicas en el uso de una lengua. De nuevo, los datos del conocimiento y uso social del valenciano que presentamos en la tabla 3.4 corresponden a los años previos a los que se tomaron las muestras para el presente trabajo. Hemos tenido en cuenta las zonas de predominio lingüístico, esto es, las áreas donde predominan los valencianohablantes y las áreas donde destacan los castellanohablantes. 


\begin{tabular}{|c|c|c|c|c|}
\hline & & Total & $\begin{array}{c}\text { Zona } \\
\text { Valencianohablante }\end{array}$ & $\begin{array}{c}\text { Zona } \\
\text { Castellanohablante }\end{array}$ \\
\hline \multirow{4}{*}{ Entiende } & Nada/Poco & 16.8 & 9.5 & 62.3 \\
\hline & & 12.6 & 6.6 & 60.3 \\
\hline & Bastante & 83.2 & 90.5 & 37.7 \\
\hline & bien/Perfectamente & 87.4 & 93.4 & 39.8 \\
\hline \multirow{4}{*}{ Habla } & Nada/Poco & 39.0 & 32.5 & 93.6 \\
\hline & & 37.4 & 30.5 & 91.8 \\
\hline & Bastante & 61.1 & 67.5 & 6.4 \\
\hline & bien/Perfectamente & 62.7 & 69.5 & 8.3 \\
\hline \multirow{4}{*}{ Lee } & Nada/Poco & 56.4 & 52.2 & 87.3 \\
\hline & & 53.5 & 50.0 & 81.5 \\
\hline & Bastante & 43.6 & 47.8 & 12.7 \\
\hline & bien/Perfectamente & 46.5 & 50.0 & 18.50 \\
\hline \multirow{4}{*}{ Escribe } & Nada/Poco & 84.2 & 82.8 & 96.1 \\
\hline & & 79.6 & 77.8 & 94.5 \\
\hline & Bastante & 15.8 & 17.2 & 3.9 \\
\hline & bien/Perfectamente & 20.4 & 22.3 & 5.5 \\
\hline
\end{tabular}

Tabla 3.4. Conocimiento y uso del valenciano en $1992^{50}$ y $1995^{51}$ (Las cifras que aparecen en cursiva corresponden al año 1995)

Observamos una progresión positiva en todas las competencias: mientras va disminuyendo el porcentaje de los individuos que no saben nada o poco, aumenta la parcela de quienes responden con un bastante bien/perfectamente. La competencia que sobresale, como es natural, es la de los individuos que entienden el valenciano $(83.2 \%$ en 1992-87.4\% en 1995) o lo habla, que prácticamente coincide en todos los años evaluados (60\%). No sucede lo mismo en las otras competencias, sobre todo a la hora de escribir la lengua, cuyas proporciones son mucho menores (sin embargo, se nota una aumento de casi un 5\% entre 1992 y 1995).

En cuanto a la distribución por zonas de predominio lingüístico, se observa un mayor incremento en el área valencianohablante, donde las subidas en todas las competencias van desde un $2.9 \%$ en Entiende el valenciano y Sabe hablarlo a un $5 \%$ en Sabe escribir. No pasa lo mismo en la zona castellanohablante, donde el incremento es de apenas uno o dos puntos en las competencias de Entiende, Habla y Escribe en los

\footnotetext{
50 Estadística extraída de una muestra de 6675 entrevistas entre individuos mayores de 15 años y residentes en la Comunidad Valenciana, según el Padrón Municipal de Habitantes de 1986. Trabajo dirigido por Ninyoles.

${ }^{51}$ Datos extraídos de una muestra de 1600 entrevistas de individuos mayores de 15 años y residentes en la Comunidad Valenciana, según el padrón Municipal de Habitantes de 1991. Trabajo dirigido por Ninyoles.
} 
dos periodos analizados. El descenso en Sabe leer en el apartado "Nada o Poco" es de un $5.8 \%$ entre 1992 y 1995, lo que indica que poco a poco el número de los castellanohablantes que aprenden a leer el valenciano se incrementa también lentamente.

A modo de comparación con la actualidad, diremos que este proceso de mejora en el conocimiento y uso del valenciano se ha consolidado en tiempos más recientes, como se desprende de los resultados de las encuestas de 2010 y 2015, realizadas bajo la dirección de Rafael Ninyoles, y cuyos datos podemos ver en la tabla 3.5. Destaca el área de Saber escribir, donde advertimos un crecimiento mayor entre los años 2010-2015 que en los años 90. Si sumamos los porcentajes de los individuos que anotan que no saben escribir nada o un poco (73.6\% en 2010 y $65.2 \%$ en 2015) y lo comparamos con las cifras de 1992-1995 (84.2\% en 1992 y 79\% en 1995) vemos cómo el ascenso de los que han aprendido a escribir es notorio. Y la razón no es otra que la inclusión del valenciano como un pilar fundamental en la educación de los individuos.

Finalmente, si cotejamos las dos zonas de predominio lingüístico, también en esta ocasión es la valencianohablante la que alcanza las cifras más elevadas en el aumento del conocimiento del valenciano en todas las competencias. 


\begin{tabular}{|c|c|c|c|c|}
\hline & & Total & $\begin{array}{c}\text { Zona } \\
\text { valencianohablante }\end{array}$ & $\begin{array}{c}\text { Zona } \\
\text { castellanohablante }\end{array}$ \\
\hline \multirow{5}{*}{ Entiende } & Nada & $\begin{array}{l}6.1 \\
6.2\end{array}$ & $\begin{array}{l}3.9 \\
3.6\end{array}$ & $\begin{array}{l}20.9 \\
23.3\end{array}$ \\
\hline & Un poco & 25.1 & 21.7 & 47.2 \\
\hline & & 24.4 & 18.7 & 39.4 \\
\hline & Bastante bien & $\begin{array}{l}27.1 \\
283\end{array}$ & $\begin{array}{l}28.0 \\
283\end{array}$ & $\begin{array}{l}22.5 \\
283\end{array}$ \\
\hline & Perfectamente & $\begin{array}{l}41.5 \\
44.1\end{array}$ & $\begin{array}{l}46.4 \\
49.3\end{array}$ & $\begin{array}{c}9.5 \\
9\end{array}$ \\
\hline \multirow[t]{4}{*}{ Habla } & Nada & $\begin{array}{l}23.3 \\
21.7\end{array}$ & $\begin{array}{l}17.6 \\
16.7\end{array}$ & $\begin{array}{l}61.1 \\
54.8\end{array}$ \\
\hline & Un poco & $\begin{array}{l}28.2 \\
27.3\end{array}$ & $\begin{array}{l}28.1 \\
26.8\end{array}$ & $\begin{array}{l}28.9 \\
30.5\end{array}$ \\
\hline & Bastante bien & $\begin{array}{l}18.2 \\
17.9\end{array}$ & $\begin{array}{c}20.0 \\
19\end{array}$ & $\begin{array}{c}6.1 \\
10.7\end{array}$ \\
\hline & Perfectamente & $\begin{array}{l}30.3 \\
33.0\end{array}$ & $\begin{array}{l}34.3 \\
37.4\end{array}$ & $\begin{array}{c}3.3 \\
4\end{array}$ \\
\hline \multirow[t]{4}{*}{ Lee } & Nada & $\begin{array}{l}14.1 \\
20.1\end{array}$ & $\begin{array}{l}10.7 \\
16.2\end{array}$ & $\begin{array}{l}36.5 \\
45.9\end{array}$ \\
\hline & Un poco & $\begin{array}{l}40.6 \\
27.0\end{array}$ & $\begin{array}{l}39.3 \\
26.5\end{array}$ & $\begin{array}{l}49.0 \\
30.1\end{array}$ \\
\hline & Bastante bien & $\begin{array}{l}21.7 \\
24.9\end{array}$ & $\begin{array}{l}23.4 \\
25.8\end{array}$ & $\begin{array}{l}10.5 \\
19.1\end{array}$ \\
\hline & Perfectamente & $\begin{array}{l}23.6 \\
28.0\end{array}$ & $\begin{array}{l}26.6 \\
31.4\end{array}$ & $\begin{array}{l}4.1 \\
4.9\end{array}$ \\
\hline \multirow[t]{4}{*}{ Escribe } & Nada & $\begin{array}{l}41.7 \\
40.3\end{array}$ & $\begin{array}{l}36.8 \\
36.2\end{array}$ & $\begin{array}{l}74.1 \\
67.8\end{array}$ \\
\hline & Un poco & $\begin{array}{l}31.9 \\
24.9\end{array}$ & $\begin{array}{l}33.7 \\
25.5\end{array}$ & $\begin{array}{l}20.2 \\
20.8\end{array}$ \\
\hline & Bastante bien & $\begin{array}{l}11.8 \\
14.5\end{array}$ & $\begin{array}{l}13.0 \\
15.5\end{array}$ & $\begin{array}{l}4.1 \\
8.1\end{array}$ \\
\hline & Perfectamente & $\begin{array}{l}14.6 \\
20.2\end{array}$ & $\begin{array}{l}16.5 \\
22.8\end{array}$ & $\begin{array}{l}1.7 \\
3.3\end{array}$ \\
\hline
\end{tabular}

Tabla 3.5. Conocimiento y uso del valenciano por zonas de predominio lingüístico en $2010^{52}$ y $2015^{53}$. (Las cifras en cursiva corresponden al año 2015).

Para terminar este apartado y completar el repaso de la situación sociolingüística de la comunidad lingüística, nos parece interesante dar cuenta de la encuesta sociológica

\footnotetext{
${ }^{52}$ Datos extraídos de una muestra de 6666 entrevistas a individuos de 15 y más años residentes en la Comunidad Valenciana según el padrón Municipal de Habitantes de 2009. Dirección del proyecto: R. Ninyoles

${ }^{53}$ Datos extraídos de una muestra de 6691, un universo de individuos de 15 y más años, residentes en la Comunidad Valenciana, según el Padrón Municipal de Habitantes de 2014. Dirección del proyecto: R. Ninyoles.
} 
que en 1995 llevó a cabo en la ciudad de Castellón el sociólogo valenciano Rafael Ninyoles, sobre el uso del valenciano en diversos dominios sociales, y cuyos resultados son extrapolables a otras poblaciones de la provincia. ${ }^{54}$

Así, en cuanto al grado de utilización social del valenciano, y dado el interés de las funciones sociales de cada lengua en una sociedad bilingüe, a continuación exponemos las cifras en porcentajes que muestran las funciones específicas que cumplen las lenguas en la comunidad de habla castellonense.

\begin{tabular}{|l|c|c|c|c|c|c|c|c|}
\hline $\begin{array}{l}\text { Lengua que } \\
\text { habla en }\end{array}$ & $\mathbf{1}$ & $\mathbf{2}$ & $\mathbf{3}$ & $\mathbf{4}$ & $\mathbf{5}$ & $\mathbf{6}$ & $\mathbf{7}$ & $\mathbf{8}$ \\
\hline Casa & 36.61 & 4.36 & 4.36 & 2.79 & 1.93 & 3.76 & 45.21 & 0 \\
\hline Con los amigos & 15.39 & 13.21 & 10.06 & 10.06 & 6.18 & 5.58 & 39.52 & 0 \\
\hline $\begin{array}{l}\text { Trabajo/con los } \\
\text { compañeros }\end{array}$ & 10.42 & 9.09 & 6.18 & 9.33 & 5.21 & 5.33 & 38.42 & 16 \\
\hline $\begin{array}{l}\text { Trabajo/relaciones } \\
\text { externas }\end{array}$ & 8.85 & 7.64 & 6.06 & 9.70 & 6.79 & 5.70 & 39.27 & 16 \\
\hline $\begin{array}{l}\text { Calle/gente que } \\
\text { no conoce }\end{array}$ & 11.03 & 9.7 & 9.91 & 11.64 & 7.76 & 7.52 & 45.33 & 0.12 \\
\hline $\begin{array}{l}\text { Tiendas } \\
\text { tradicionales }\end{array}$ & 22.91 & 11.15 & 7.64 & 8.85 & 4.12 & 5.45 & 39.88 & 0 \\
\hline $\begin{array}{l}\text { Grandes } \\
\text { superficies }\end{array}$ & 11.76 & 9.09 & 7.52 & 12.61 & 7.15 & 6.30 & 35.58 & 0 \\
\hline
\end{tabular}

Tabla 3.6. Uso del valenciano en las diferentes esferas sociales

Leyenda:

1. Siempre en valenciano

2. Generalmente en valenciano

3. Más en valenciano que en castellano

4. Indistintamente

5. Más en castellano que en valenciano

6. Generalmente en castellano

7. Siempre en castellano

8. $\mathrm{Ns} / \mathrm{Nc}$

Advertimos que los datos son mucho más favorables para la respuesta "Siempre en castellano" que "Siempre en valenciano" en todas las esferas sociales planteadas en la encuesta. Por otro lado, factores sociales como la educación y la edad intervienen de forma directa en la competencia en el empleo del valenciano. Así, cuanto mayor es el nivel educativo, mayor es también el conocimiento de la lengua en las diferentes competencias (leer y escribir, sobre todo). También los jóvenes son los que poseen un conocimiento mayor que los otros grupos, siendo aquellos quienes mejor dominan las

\footnotetext{
${ }^{54}$ La encuesta está basada en una muestra de 825 individuos.
} 
esferas de la escritura y la lectura, unas habilidades que descienden conforme avanza la edad de los hablantes. Una vez más todo ello está relacionado con la presencia del valenciano en el sistema educativo actual, bien como asignatura, bien (sobre todo) como lengua de instrucción (ver apartado 3.5.4).

Con respecto a la actitud de los hablantes hacia la lengua autóctona, varios estudios han señalado que ha aumentado de forma positiva en los últimos años. (Blas Arroyo, 1994a, 1996,1998; González Martínez y Blas Arroyo 2012, Gómez Molina, 1998, 2002). Al comentar estos trabajos, Blas Arroyo (1996: 57) en su investigación sobre estudiantes de un instituto de Valencia indica que podemos seguir hablando de una "situación diglósica de ambas lenguas en el seno de esta comunidad de habla", pero con ciertas matizaciones que rompen el esquema más general de dicho fenómeno sociolingüístico. Como apunta este autor:

Por un lado, si bien es cierto que el castellano supera en evaluaciones positivas al valenciano en status social y personal (se le considera más culto, un habitante de ciudad, rico, conservador, de más elevada clases social [...], no lo es menos que en algunos otros rasgos, también pertenecientes a esta categoría psicosocial, los resultados son similares (influyente) o claramente favorables al último (así se evalúa al valenciano hablante como más inteligente, trabajador y ambicioso). Ello parece significar que, si bien se sigue viendo claramente en el castellano la lengua con un mayor valor instrumental, el valenciano comienza a adjudicársele propiedades también relacionadas con el progreso social y material en la sociedad contemporánea.

\subsubsection{La presencia de las lenguas en la enseñanza}

Un factor fundamental para el incremento del uso del valenciano y el consiguiente cambio en la distribución sociolingüística de la Comunidad ha sido, sin duda, la política lingüística llevada a cabo por los sucesivos gobiernos valencianos a partir de la promulgación en 1983 de la Llei d'Ús i Ensenyament del Valencià. Con ella, y las leyes que la han desarrollado posteriormente, se ha pasado de una enseñanza exclusivamente monolingüe en castellano a otra bilingüe, con diversos modelos alternativos en función de algunos parámetros.

En efecto, en los años de realización de las encuestas, el sistema educativo valenciano ofrecía diferentes modelos de enseñanza (en primaria y secundaria) dependiendo del contexto sociolingüístico, las preferencias educativas de las familias y, 
por supuesto, la disponibilidad de profesorado que pudiera enseñar en las dos lenguas de la Comunidad Valenciana. De este modo, la educación bilingüe ha discurrido en paralelo a las decisiones políticas tomadas al respecto, con el establecimiento de un marco jurídico autonómico que facilitara la recuperación y la progresión en el conocimiento y uso del valenciano.

Blas Arroyo (2002: 322 y ss.) nos ofrece un resumen de estos programas a comienzos del presente siglo, en alguno de los cuales estaban matriculados los alumnos que integran la muestra:

-Programa de inmersión lingüística (PIL), dirigido a los alumnos monolingües de castellano que residen en zonas valencianohablantes y con una actitud positiva hacia la lengua autóctona. Este programa se implantó sobre todo en escuelas de Alicante y Valencia desde el año 1980, aunque solo en el nivel de primaria.

-Programa de Enseñanza en Valenciano (PEV), encaminado a estudiantes valencianohablantes y residentes en áreas de habla valenciana. Aquí el valenciano es la lengua de instrucción y con ello se pretendía perfeccionar y aumentar el prestigio de la lengua materna entre estos alumnos. El español se introducía como asignatura y progresivamente se incluía en la enseñanza. Este programa también era conocido con el nombre de Línea de educación en valenciano.

- Programa de educación bilingüe enriquecido (PEBE), donde tanto el valenciano como el castellano eran lenguas de instrucción, pero en diferentes proporciones, dependiendo del contexto sociocultural de cada escuela y territorio. Este programa se aplicaba a una minoría si lo comparamos con otros. Unas 150 escuelas seguían este programa en el curso escolar 2000-01 (Blas Arroyo, 2002: 326)

Si por cualquier motivo no se podían aplicar los modelos anteriores, era obligatorio adoptar el Programa de Incorporación Progresiva al Valenciano (PIP), especialmente en las poblaciones con una mayoría social castellanohablante. En este, la lengua principal de la enseñanza era el castellano, y gradualmente se incorporaba también el valenciano como idioma de instrucción en algunas asignaturas. Esta incorporación dependía de razones diversas, como las circunstancias particulares de los diferentes municipios, la voluntad de los padres o la disponibilidad de profesores en ambas lenguas, como ya hemos comentado. Al respecto, Blas Arroyo (2002: 327) subrayaba que: "In practice, it is the most commom programme in the Valencianspeaking territories where it meets the mínimum legal requirement”. 
En la ESO (Educación Secundaria Obligatoria), sin embargo, los programas se reducían a dos:

- Programa de Enseñanza en Valenciano (PEV), donde todas las materias se ofrecían en valenciano (excepto Lengua y Literaturas Españolas, claro está).

- Programa de Incorporación Progresiva (PIP), equivalente al mismo en la educación Primaria, y donde la enseñanza tenía como protagonista principal al castellano, con la excepción de algunas asignaturas que se impartían en valenciano.

Blas Arroyo (2002:327) recuerda que, a finales de los años 90, aproximadamente un $60 \%$ de los colegios seguían programas de Incorporación progresiva al valenciano (PIP), un 30\% de centros aplicaba el Programa de enseñanza en valenciano (PEV) y tan solo un 9\% de colegios seguían el Programa de Inmersión Lingüística (PIL). ${ }^{55}$

Los datos estadísticos contenidos en las tablas siguientes muestran el incremento del uso del valenciano en el sistema educativo de la Comunidad a lo largo de la década de los 90:

\begin{tabular}{|l|c|c|c|c|c|c|}
\hline & \multicolumn{3}{|c|}{ Curso 1991-92 } & \multicolumn{3}{c|}{ Curso 1999-2000 } \\
\hline & $\mathbf{1}$ & $\mathbf{2}$ & $\mathbf{3}$ & $\mathbf{1}$ & $\mathbf{2}$ & $\mathbf{3}$ \\
\hline Castellón & 60564 & 6438 & 10.6 & 41566 & 21485 & 51.6 \\
\hline Valencia & 299421 & 17825 & 5.9 & 231715 & 54425 & 23.5 \\
\hline Alicante & 196544 & 8021 & 4.08 & 135261 & 20261 & 14.9 \\
\hline Totales & 556529 & 32284 & 5.8 & 408542 & 96171 & 23.5 \\
\hline
\end{tabular}

Tabla 3.7. Número de estudiantes que siguieron programas bilingües en los niveles de Infantil y Primaria.

\begin{tabular}{|l|c|c|c|c|c|c|}
\hline & \multicolumn{3}{|c|}{ Curso 1991-92 } & \multicolumn{3}{c|}{ Curso 1999-2000 } \\
\hline & $\mathbf{1}$ & $\mathbf{2}$ & $\mathbf{3}$ & $\mathbf{1}$ & $\mathbf{2}$ & $\mathbf{3}$ \\
\hline Castellón & 25967 & 408 & 1.6 & 34634 & 6302 & 18.1 \\
\hline Valencia & 137315 & 1917 & 1.4 & 168930 & 18278 & 11 \\
\hline Alicante & 73957 & 710 & 1 & 113497 & 5740 & 5 \\
\hline Totales & 374554 & 3035 & 1.3 & 317040 & 30320 & 9 \\
\hline
\end{tabular}

Tabla 3.8. Número de estudiantes que cursaron programas bilingües en la Enseñanza Secundaria Obligatoria.

Leyenda:

1. Totalidad del número de estudiantes/ 2. Estudiantes inscritos en los programas PEV y PIL/ 3. Porcentaje de estudiantes inscritos en los programas PEV y PIL.

\footnotetext{
${ }^{55}$ Desde 2012, la situación se ha simplificado con la incorporación del inglés en la denominada educación trilingüe. De este modo, la presencia progresiva de este idioma como lengua de instrucción se produce en el seno de dos únicos programas, cada uno de los cuales tiene al castellano o al valenciano como lenguas vehiculares.
} 
Al analizar las tablas, vemos cómo en diez años ha habido un incremento en el número de estudiantes inscritos en programas de enseñanza en valenciano, tanto en los niveles de Infantil y Primaria como en la Enseñanza Secundaria Obligatoria. Ahora bien, el aumento es mucho mayor en los primeros niveles educativos.

Por otro lado, aunque las tres provincias presentan una evolución positiva en el número de alumnos matriculados en la enseñanza en valenciano, es Castellón la que destaca sobre las demás, cuando de un 10\% en el curso académico 1991-92 pasa a un $51.6 \%$ en el curso 1999-2000 en la enseñanza primaria, a considerable distancia del resto de provincias, en especial, Alicante. Todo ello guarda relación con la mencionada situación sociolingüística de Castellón, la más favorable al empleo de la lengua propia en toda la Comunidad Valenciana.

Si nos fijamos ahora en los datos de la Educación Secundaria (tabla 3.8), la enseñanza en valenciano vuelve a presentar una progresión positiva evidente. También en esta ocasión, su ascenso vuelve a ser superior en Castellón en el transcurso de esa década (de un 1.6\% del curso 1991-92 evoluciona a un 18.1\% en el curso 1999-2000).

Entre las muchas investigaciones que analizan los resultados de la educación bilingüe en la Comunidad valenciana (Pascual et al., 1991; Bueno, 1995; Díez, 1995; etc.) ${ }^{56}$ contamos con un trabajo relacionado, precisamente, con la disponibilidad léxica en la enseñanza secundaria, en concreto con alumnos preuniversitarios (Blas Arroyo y Casanova, 2001, 2003 a y b). Entre los diferentes factores sociológicos considerados en este estudio piloto, observamos el efecto de la lengua materna en la competencia léxica de los alumnos. En aquella ocasión concluimos que la lengua materna de los estudiantes ejercía una leve pero significativa influencia en el repertorio léxico de estos estudiantes: los alumnos hispanohablantes obtenían mejores resultados que sus compañeros valencianohablantes, aunque no necesariamente un léxico más variado. Al mismo tiempo también se observó que los alumnos de familias mixtas (con el español y el valenciano como lenguas maternas) obtenían mejores resultados que los hispanohablantes exclusivos. En todo caso, se trataba de resultados parciales -a partir de una submuestra del presente estudio- y siempre relativos, puesto que este factor debe ponerse en relación con otros no menos importantes, como el sexo o el factor sociocultural.

\footnotetext{
${ }^{56}$ Ver Blas Arroyo, 2002.
} 


\subsubsection{Configuración del castellano hablado en la Comunidad}

El contacto secular del castellano con el catalán otorga al primero una determinada configuración en estas tierras. Con todo, no solo el catalán tiene un papel relevante en este perfil dialectal, sino que a ello hay que sumarle el influjo de otras lenguas, como la imparable influencia del inglés en esferas diversas, como los deportes, la moda o la informática, las telecomunicaciones, el desarrollo científico... (Gómez Capuz, 2000; Gimeno y Gimeno, 2003), algunas de las cuales son objeto de atención en los cuestionarios de disponibilidad léxica (para más detalles sobre este tema, véase más adelante el apartado 5.3). A esto hay que sumar el contacto que el castellano de la Comunidad Valenciana mantiene con otras variedades limítrofes, como las aragonesas y murcianas, todas ellas integradas en un contínuum lingüístico que deja sus huellas sobre todo en el nivel léxico. Así lo recuerda Blas Arroyo (2008a: 25) cuando apunta que a uno y otro lado de la actual línea político-administrativa y lingüística aparecen numerosos “...términos y acepciones comunes tanto en las comunidades de habla valencianas como en las aragonesas, castellanas o murcianas", cuyo origen hay que encontrar nuevamente en la historia. Como muestra de ello, valgan algunas palabras muy características del este peninsular, algunas de las cuales encontraremos en nuestros cuestionarios. Es el caso de verbos como esclafar 'aplastar', socarrar 'quemar', gastar 'utilizar', o sustantivos como horno 'comercio donde se vende pan' y molla 'miga del pan', entre otros muchos.

Sin embargo, este contínuum dialectal no se aprecia solo en el plano léxico, sino que alcanza también a algunos paradigmas del nivel morfológico, como el empleo del sufijo diminutivo -ico (con valores principalmente afectivos en la Comunidad Valenciana, frente a otros usos más funcionales y extendidos en las otras regiones), o la sustitución de cuanto por contra en oraciones comparativas. Asimismo, Montoya (1989) apunta otros rasgos del español hablado en el sur de la Comunidad Valenciana por influencia murciana, como la aspiración o elisión de la /s/ a final de sílaba y palabra, la presencia de algunos cambios de género en ciertos vocablos como la calor, etc.

Centrándonos ya en el habla de Castellón, se han destacado algunos estereotipos lingüísticos, como los usos discursivos de la expresión muy bien (Blas Arroyo, 2008: $25 ; 2011$ a) con significados "diferentes a los que dicha expresión cualitativa presenta en el español general", que suele ser mostrar valoración positiva o acuerdo en una intervención previa. Sin embargo, en el español de Castellón se emplea como elemento 
de confirmación o validación o como respuesta a una pregunta previa; el elemento común a ello es la presencia de pausas o vacilaciones en el contexto ([éramos cinco] muy pequeñitos [...] Muy bien cinco años... / A: ¿[...] fuiste a ese colegio hasta que terminaste los estudios? B: [...] Muy bien, sí.

Varias son las obras que permiten estudiar las consecuencias lingüísticas derivadas del contacto de lenguas en comunidades bilingües como la que nos ocupa, y, por tanto, algunos de los rasgos más representativos del español hablado en Castellón y su provincia. Como materiales de trabajo, merece la pena destacar en primer lugar el Macrocorpus sociolingüístico de Castellón y sus comarcas (MSCS), una colección de 210 entrevistas sociolingüísticas llevadas a cabo por miembros del Laboratorio de Sociolingüística de la Universitat Jaume I y de cuyos materiales se han derivado diversos trabajos de sociolingüística variacionista como los que se reseñan más abajo. ${ }^{57}$ $\mathrm{Al}$ igual que otros corpus existentes hoy en día para el estudio del la lengua oral, ${ }^{58}$ este permite "la descripción y análisis de los principales fenómenos de variación y cambio lingüístico del español en las comunidades de habla castellonense" (Blas Arroyo et al., 2009: 5) en las comarcas de La Plana Baixa y La Plana Alta, donde se ha desarrollado un extenso bilingüismo social, como ya hemos apuntado.

Diversos fenómenos gramaticales y fonéticos característicos del español hablado en Castellón han sido ya descritos a partir de los materiales de este corpus por miembros del grupo de investigación que dirige el profesor Blas Arroyo. Así, Ramírez (2000) y el propio Blas Arroyo (2008) han estudiado la variación en el seno del futuro verbal, donde, entre otras cosas, han comprobado una resistencia considerable de las formas flexivas (cantaré), que en otros dominios del español están en franco retroceso a favor de las variantes perifrásticas (voy a cantar). Blas Arroyo (2008) señala que en ese mantenimiento puede tener un papel importante la convergencia con el catalán, lengua en la que solo existe una forma (flexiva) para la expresión del futuro. Más recientemente, el propio autor ha analizado otro fenómeno de convergencia en la expresión del haber existencia (habían fiestas), similar al que se produce en el catalán central y en el valenciano (Blas Arroyo, en prensa). Además de advertir frecuencias de uso muy similares en ambas lenguas, este autor ha comprobado empíricamente cómo la

\footnotetext{
${ }^{57}$ En 2009 se publicó una edición en CD-ROM con una selección de 75 entrevistas estratificadas por cuotas iguales de sexo, edad y nivel sociocultural (Blas Arroyo et al. 2009).

${ }^{58}$ En esta misma área dialectal cabe destacar el Corpus del español de Valencia, coordinado por Gómez Molina, e integrado dentro del proyecto PRESEEA. En el mismo sentido cabe hablar del Corpus del español coloquial, dirigido por el profesor Briz en la Universidad de Valencia.
} 
distribución de las variantes en las respectivas gramáticas internas es muy similar en los dos idiomas, lo que apoya la tesis de la convergencia, si no en el origen del fenómeno (también visible en variedades americanas y canarias del español), al menos sí en su difusión social en estas modalidades lingüísticas del este peninsular. La misma incidencia del contacto de lenguas ha señalado Blas Arroyo (2007) en el mantenimiento de la /d/ intervocálica en las palabras terminadas en ado al comprobar la existencia de correlaciones muy significativas con diversos factores vinculados con la adscripción lingüística de los hablantes, como la lengua dominante o el grado de bilingüismo. ${ }^{59}$

Una caracterización dialectal del español en la provincia de Castellón la encontramos también en el libro Variedades del castellano en Castellón (Blas Arroyo et al. 1992), donde se describen los hechos lingüísticos más sobresalientes que delimitan la variedad del español castellonense. ${ }^{60}$ Seguidamente, exponemos algunos de los rasgos más singulares de esta variedad, condicionados en buena parte "bien por la influencia directa o por la convergencia con la otra lengua de la comunidad" (Blas Arroyo et al., 2009:18), esto es, por el valenciano.

Así, en el plano fonético podemos ver una serie de hábitos articulatorios derivados del contacto con la fonética valenciana. Entre ellos, el ensordecimiento de la /d/, que en algunas ocasiones acaba convirtiéndose en una consonante muy próxima a la /t/, y que podemos advertir como rasgo general en todos los niveles diastráticos: paret, Madrit, ret en lugar de pared, Madrid, red. (sobre la /d/ intervocálica, véase lo dicho más arriba). ${ }^{61}$

Otro fenómeno fonético singular es la tendencia a desplazamientos acentuales (llevatéla por llévatela) en imperativos en los que se funden dos enclíticos pronominales. Mientras que la norma castellana exige una acentuación superproparoxitona, en Castellón se observa una acentuación grave en estas formaciones, si bien el fenómeno no tiene la difusión sociolectal que alcanzan los anteriores. Más marcado socialmente es aun el seseo valenciano -diferente totalmente al seseo andaluz e hispanoamericano tanto en su articulación como en su origen-, que aparece en el habla de las personas mayores menos instruidas de entornos rurales y cuya

\footnotetext{
59 Al margen del contacto de lenguas, Blas Arroyo y Porcar (1994) han examinado también desde la perspectiva variacionista la distribución de los afijos - ra/-se en las formas del imperfecto y el pluscuamperfecto de subjuntivo, así como la neutralización modal en algunos contornos sintácticos (Blas Arroyo y Porcar, 1997).

${ }^{60}$ En el mismo sentido, véanse también las revisiones más recientes de Blas Arroyo (2004, 2011b), aunque estas afectan a todo el dominio dialectal catalán.

${ }^{61}$ Ver Machuca (2016) sobre la coda silábica en el español de hablantes bilingües español-catalán y Poch (2016) sobre las particularidades fonéticas del español en Cataluña.
} 
lengua dominante -y, en ocasiones, casi exclusiva- es el valenciano, una lengua que no diferencia entre los fonemas /z/ y /s/ en su sistema fonológico. Por último, también en el plano fónico, cabe destacar la articulación de la /1/ intervocálica, alveolar normalmente en el español general, y que en esta área se pronuncia a menudo como una consonante medio-palatal, aunque sin llegar a la velarización característica de las comarcas catalanas.

En cuanto al nivel morfosintáctico, se advierten diferentes fenómenos en los que la influencia del catalán parece también determinante. Este es el caso de la confusión y otros usos vernáculos de algunas preposiciones monosilábicas polifuncionales, como en, $a$, de, con. Así, en estas comarcas podemos escuchar expresiones como paella en conejo, tortilla en patatas, están a casa, la temperatura al exterior es de 9 grados, los hay de mejores, etc. todas ellas calcos de las respectivas estructuras valencianas. Más frecuente aún es la concordancia no normativa en oraciones impersonales con haber (habían muchas chicas), a la que ya nos hemos referido más arriba (sobre este fenómeno, véase también Blas Arroyo, 1993, 2016); o el uso de un que expletivo al comienzo de oraciones interrogativas absolutas -¿Que no conoce usted el parque Ribalta? ${ }^{62}$ Ambos rasgos, pero en especial el primero, se hallan muy difundidos sociolectalmente y, por tanto, afectan tanto a los estratos bajos como a los medios y altos, aunque algunos estudios recientes hayan visto una cierta resistencia entre estos últimos hacia la variante vernácula (Blas Arroyo, 2016).

Más marcados sociolectalmente son los usos de la doble negación, característica igualmente de la sintaxis valenciana, y que encontramos en enunciados en español como este: Tampoco no es eso. En Castellón, es posible escuchar también la amalgama formal entre los adverbios de lugar abajo, debajo y la preposición bajo, muy características de las hablas valencianas, y fenómeno donde la convergencia con el catalán parece también determinante, ya que en esta lengua la confusión (pese a no ser normativa) se produce igualmente (Blas Arroyo, 1999b). Con todo, la difusión social del fenómeno es probablemente menor que en otras comunidades de habla como Valencia y su área metropolitana (Blas Arroyo, 2008a:36).

Otros usos vernáculos del español característicos de esta comunidad, aunque claramente marcados sociolectalmente son: a) el empleo del reflexivo se en frases como

\footnotetext{
${ }^{62}$ Ejemplos extraídos de Blas Arroyo et al. (1992). Otro enunciado donde encontramos este que expletivo, muy similar al hallado en el catalán coloquial es el que aparece en enunciados como el siguiente: Vinieron casi que todos.
} 
se vamos, calco morfosintáctico de la (incorrecta) expresión en valenciano: Se n'anem; b) el empleo del futuro verbal en lugar del presente de subjuntivo en subordinadas temporales (cuando vendrás...), igualmente calco de una estructura valenciana (quan vindràs); c) el uso del artículo en varios contornos sintácticos, como el nombre propio (la Paqui no está), las expresiones del tipo artículo+señor+nombre (la Señora Paqui/ el Señor Rosendo), en lugar de las normativas artículo+señor+apellido, o los sustantivos mamá y papá; ${ }^{63} \mathrm{~d}$ ) el empleo de los diminutivos valencianos -et/a (chiquet/a), etc. ${ }^{64} \mathrm{Ya}$ fuera de la lingüística de contacto cabe reseñar también otros rasgos, tradicionalmente considerados como vulgarismos, como la utilización del presente de subjuntivo por el pasado simple de indicativo (la otra noche cenemos pato), en los que las hablas castellonenses no difieren en lo esencial de lo que podemos encontrar en otras zonas peninsulares.

Ahora bien, es probablemente en el plano léxico donde se aprecian las mayores peculiaridades. ${ }^{65}$ Así, en la región castellonense encontramos valencianismos muy difundidos socialmente, como badado por "agrietado" (del catalán badar), bajoca por “judía verde” (en Castellón específicamente 'judía verde con su vaina’ del valenciano bajoca), desficioso por "intranquilo" (del valenciano desficiós), despagado por “desilusionado" (valen. despagat), engañarse por "equivocarse" (valen. enganyar-se), girarse por "volverse" (valen. girar-se), longaniza por "salchicha" (valen. llonganissa), mallorquina por "sobrasada" (valen. mallorquina), menearse por "moverse" (val. menejar o menejarse), paella por "sartén" (valen. paella), camal por "pernera" (valen. camal), pegar por "dar", en frases como "voy a pegar una vuelta" en lugar de "voy a dar una vuelta", semar, semarse por "marchitar", chafardear del catalán xafardear se emplea por "curiosear" y "chismorrear", parada (o su forma en diminutivo paradeta/paraeta por "puesto en el mercado", tirar (a alguien) 'echar a alguien', etc.

Igualmente características son los vocativos tete y teta, utilizadas profusamente por los castellonenses para dirigirse (e incluso referirse) al "hermano" o la "hermana", y que provienen de la abreviatura de sendos términos valencianos germanet, germaneta. Otros vocablos con ese carácter familiar sería yayo, yaya para referir al "abuelo" o la

\footnotetext{
${ }^{63}$ En la mayoría de estos usos del artículo, los hablantes castellonenses participan de isoglosas más amplias, que se extienden también a otros territorios de la antigua Corona de Aragón.

${ }^{64}$ En relación con los diminutivos, se ha resaltado en ocasiones la particular afectividad del habla castellonense, que se demostraría, por ejemplo, en un uso frecuente de estos sufijos derivativos en todos los sectores de la sociedad. Con todo, hasta donde llega nuestro conocimiento, no existen trabajos contrastivos que hayan dado cuenta empíricamente de este hecho.

${ }^{65}$ También aquí el español de Castellón comparte expresiones con zonas lingüísticas limítrofes como Aragón (Gimeno Betí, 2002).
} 
"abuela", igualmente empleados en otros territorios limítrofes, como el este de la comunidad castellano-manchega (Albacete) y Aragón.

Por otro lado, algunas voces que en Castellón muestran estar muy vigentes en el uso, tienen mucho más restringida su extensión en otras zonas de España, donde en el mejor de los casos se consideran arcaísmos confinados a determinadas áreas rurales. Este es el caso, por ejemplo, de encantado por "atónito", sentir por "oír" o calentura por "fiebre". Incluso a veces, algunas palabras añaden algún significado vernáculo a otros que son comunes en el español general, como sucede con chufa para referirse a "pene" o carlota, con el sentido de "zanahoria". 66

En el ámbito de la fraseología, a locuciones muy idiosincrásicas como la colocación muy bien a la que nos referíamos más arriba, se añaden otras que son utilizadas por un gran número de castellonenses de todas las clases sociales y que representan de nuevo claros exponentes de la influencia ejercida por el valenciano. Por otro lado, su difusión es tanta que no es extraño escucharlas en boca de monolingües catellanohablantes, así como en inmigrantes que cuentan ya con algún tiempo de residencia en las comarcas castellonenses. Así ocurre, por ejemplo, con el uso de expresiones sin traducción como $i$ avant!, que muchos hablantes utilizan como marcador conclusivo con diversos significados: "y ya está", "se acabó", etc.; no cal por "no es necesario" (cal es la tercera persona del singular del verbo caldre catalán); ${ }^{67}$ exclamaciones como el eufemismo collins! (en lugar del más crudo “Collons!” o el castellano “¡Cojones!”). Particular difusión tienen también algunas colocaciones con el verbo hacer(se), en las que la impronta del valenciano es más que evidente. Así ocurre, por ejemplo, en expresiones como vamos a hacernos un café por "vamos a tomarnos un café", con el mismo sentido, pues, que el valenciano Anem a fer-nos un café. Otros usos de este mismo verbo son los de hacer porra para significar "ir por algo y volver sin nada; hacer buena cara (tener buena cara), hacer olor (oler mal), hacer mal (doler), hacer miedo (dar miedo), hacer tarde (llegar tarde) hacer servir (utilizar), etc. ${ }^{68}$

Pese a que en este trabajo tiene preferencia, como es lógico, la huella que el contacto de lenguas ha dejado en el castellano de Castellón, el estudio de las consecuencias lingüísticas de este contacto secular no se limita a la dirección

\footnotetext{
${ }^{66}$ En otras variedades del español existe también la palabra carlota, pero con un significado diferente: 'torta hecha con leche, huevos, azúcar, cola de pescado y vainilla'.

${ }^{67}$ En el DECLC, Corominas recuerda que también es una voz extendida por territorio aragonés.

${ }^{68}$ Es interesante la clasificación de estas manifestaciones del contacto lingüístico entre el catalán y el castellano que realiza Blas Arroyo $(2004,2006$ b) a través de diferentes mecanismos de la interferencia lingüística: subestimación, sobrestimación, reinterpretación, sustitución, importación y pérdida.
} 
catalán $\rightarrow$ español, sino también en la dirección inversa, español $\rightarrow$ catalán, y además en todos los niveles del análisis, desde la fonética a la pragmática. Gimeno Betí (2002: 179) señala al respecto que:

...durant el segles XVI, i sobretot XVII, s'observa una paulatina intromissió de lèxic castellà en tots els àmbits de la vida quotidiana, i això malgrat que el català era encara l'única llengua "ofícial" de l'administració foral en els territoris de parla catalana de l'antiga Corona d'Aragó.

El autor se sitúa en el periodo de "latencia", el inicio de la interferencia lingüística del castellano sobre el valenciano y que en el fondo es un reflejo más de la dependencia política de Castilla que, a partir sobre todo del siglo XVIII, experimentará el antiguo Reino de Valencia. Es el momento en que se inicia la entrada masiva de castellanismos en muchas áreas referenciales (alabrastro, burro, ébano, manantial o salitre, resar, etc.). Por otro lado, como indica el propio Gimeno Betí (2002), el catalán de Castellón ${ }^{69}$ tiene no una, sino dos lenguas de adstrato, pues además del castellano, a quien debe la mayor parte de sus préstamos, ha recibido la impronta histórica del antiguo aragonés, lengua a la que, entre otras cosas, debe el principal rasgo diferenciador del valenciano con respecto al catalán oriental. ${ }^{70} \mathrm{Al}$ respecto, hay que recordar que algunos castellanismos del valenciano no son más que aragonesismos adoptados en tierras valencianas, como apuntan Colón (1989) o el propio Gimeno (1999). ${ }^{71}$

Las interferencias y demás fenómenos derivados del contacto de lenguas descritos en los párrafos anteriores obedecen a razones históricas y lingüísticas: la convivencia durante siglos entre el castellano y el valenciano, así como un origen

\footnotetext{
${ }^{69}$ El nombre más común para referirse a esta variedad, como ya hemos señalado en otras ocasiones, es el de valenciano que se corresponde con el dialecto noroccidental del domino catalán. El rasgo fónico fundamental que lo separa del catalán oriental está basado en el tratamiento de las vocales átonas /a/ y /e/, así como las vocales posteriores $/ 0 / \mathrm{y} / \mathrm{u} /$, neutralizadas en el catalán oriental y diferencias en el occidental. En el domino catalán nos encontramos con dos variedades principales, como resultado de la penetración musulmana y la posterior Reconquista del territorio. Hablamos de los dialectos constitutivos, que tienen como origen el latín de forma directa (tierras situadas al Norte de la línea que va de Mequinensa a l'Hospitalet de l'Infant (Campo de Tarragona); y los dialectos consecutivos, que son el resultado del la introducción del catalán en las tierras que van desde el sur de la línea nombrada anteriormente, es decir desde el Ebro hasta Guardamar, las Baleares, y el Alguer. (J. Veny, 1982).

${ }^{70}$ Hay que recordar que la situación sociolingüística es muy diferente en Cataluña y la Comunidad Valenciana

${ }^{71}$ Es interesante la descripción que Colón (2015) realiza sobre la variedad del léxico catalán castellonense, fruto de sus estudios dialectales sobre Castellón, que formaron parte de su tesis doctoral en los años cincuenta del siglo XX.
} 
genético común, el latín hablado en la península, lo que ha desembocado en sistemas lingüísticos afines y ha permitido la existencia de cruces en todos los niveles del análisis lingüístico. En suma, estos fenómenos en las dos direcciones no son más que el indicador de que la vitalidad de las lenguas en contacto es un hecho constatable tanto en la Comunidad Valenciana en general como en la provincia de Castellón en particular. 
4

ASPECTOS METODOLÓGICOS 



\section{ASPECTOS METODOLÓGICOS}

La metodología empleada en este proyecto de investigación sigue las pautas comunes adoptadas en el proyecto panhispánico de la Disponibilidad léxica del español, dirigido por Humberto López Morales. Esta metodología general permite realizar cotejos entre las diferentes sintopías del español, así como la obtención del Diccionario del léxico disponible del español en su totalidad.

Podemos resumir las etapas en la realización de este estudio de la siguiente forma:

1. Diseño del cuestionario, selección de los centros educativos encuestados y proceso de cumplimentación de las encuestas por parte los estudiantes seleccionados. ${ }^{72}$

2. Homogeneización y edición de los materiales (siguiendo para ello los criterios del mencionado proyecto panhispánico) e informatización de los datos.

3. Análisis de los resultados.

\subsection{La muestra}

La muestra del estudio la componen $354^{73}$ estudiantes de COU (Curso de Orientación Universitaria) y de $2^{\circ}$ de Bachillerato LOGSE (Ley Orgánica General del Sistema Educativo). Los datos fueron recogidos a través de encuestas realizadas a los alumnos de estos niveles preuniversitarios en los cursos académicos 1998-1999 y 19992000.

La edad de estos informantes oscila entre los 17 y los 19 años y su elección obedece al hecho de que representan una norma léxica general, que todavía no ha

\footnotetext{
${ }^{72}$ Se han suprimido aquellas encuestas de individuos que no han residido durante la mayor parte de su vida en la provincia de Castellón y aquellas que estaban incompletas, defectuosas o ilegibles.

${ }^{73}$ No todas las investigaciones han analizado el mismo número de informantes. Así González Martínez (2002) en Cádiz y Mateo García (1998) en Almería encuestan 400 estudiantes, cifra que se aconsejó en la primera reunión de disponibilidad léxica que se celebró en Bilbao en 1999. Sin embargo, otros estudios computan un número de informantes diferente, como han hecho Bartol (2004), que encuesta a 100 alumnos en Soria, Hernández Muñoz (2004) con 117 en Cuenca, Serrano (2014), 240 en Lleida, Prado y Galloso, (2005) 220 en Huelva, etc. Sin embargo, existen otras investigaciones que superan el límite de 400, como sucede en Valencia (Gómez Molina y Gómez Devís, 2004) con 465, Asturias (Carcedo, 2001) con 470, o Aragón (Arnal et alii, 2004) con 417, aunque estas últimas corresponden al análisis de regiones enteras y no de provincias.
} 
sumado a su léxico habitual la terminología específica de una profesión determinada o los tecnicismos propios de los estudios universitarios. ${ }^{74}$

Los centros educativos encuestados pueden verse en la siguiente tabla, donde aparece tanto su carácter público o privado como su ubicación (urbana o rural). Por otro lado, estas variables, junto con el sexo, el nivel sociocultural de las familias y el habla materna o habitual de los informantes, constituyen los factores sociales analizados.

En total, se han encuestado 15 centros de la provincia de Castellón, 5 privados y 10 públicos, lo que representa una buena proporción de los existentes en el momento de realizar las pruebas. ${ }^{75}$ De los primeros, tres están situados en la capital de provincia y los otros en dos poblaciones importantes cercanas a la capital: Borriana y Vila-real. De los centros públicos, cuatro institutos se hallan en Castellón de la Plana y otros seis en otras tantas poblaciones, a saber: Onda, Betxí, Benicarló, Vila-real, Nules y La Vall d’Uixó.

Algunos de estos centros hoy en día han cambiado su nombre. Así sucede con el IES Rebeca Mezquita de Onda y el IES Beltrán Bigorra de Nules, que han pasado a denominarse IES Serrà d'Espadà de Onda e IES Gilabert Centelles, respectivamente. De cada uno de estos núcleos educativos se han elegido al azar 25 encuestas, excepto en aquellos en los que no ha sido posible llegar a esta cantidad, como sucede con el IES Rebeca Mezquita, IB Betxí, IES Beltrán Bigorra y Sos Baynat con 21, 21, 22 y 15 informantes, respectivamente, por razones que comentaremos más adelante.

\footnotetext{
${ }^{74}$ Véanse al respecto los trabajos de Benítez (1992: 73) y López Morales (1999b: 28). En el mismo sentido, resulta interesante el trabajo de Borrego y Fernández Juncal (2003), quienes comparan el léxico de los preuniversitarios de Salamanca con alumnos del último año de carrera, en este caso, de Filología Hispánica en la Universidad de Salamanca. Tras el análisis de los datos, estos autores llegan a la conclusión de que los alumnos preuniversitarios representan bien esa norma y que los universitarios solo superan a lo preuniversitarios en el número de palabras, pero no así en el número de vocablos. Por otro lado, desde un punto de vista cualitativo los lexemas en cada grupo son muy similares y tan solo varían algunas posiciones de aparición.

${ }^{75}$ En el curso 1999-2000, el número de centros educativos que impartían bachillerato en la provincia de Castellón era de 20, de los cuales 6 eran privados (de los que se encuestan 5) y 14 públicos (de estos, se analizan 10).
} 


\begin{tabular}{|l|c|c|c|}
\hline \multicolumn{1}{|c|}{ Centro educativo } & Población & Tipo de centro & Ubicación del centro \\
\hline Colegio Rey D. Jaume & Castelló & Privado $^{76}$ & Urbano \\
\hline Colegio Ntra. Sra. Consolación & Castelló & Privado & Urbano \\
\hline Colegio de los Salesianos & Borriana & Privado & Rural \\
\hline Colegio Mater Dei & Castelló & Privado & Urbano \\
\hline Colegio Santa María & Vila-Real & Privado & Rural \\
\hline IES. Ribalta & Castelló & Público & Urbano \\
\hline IES Tárrega & Vila-Real & Público & Rural \\
\hline IES Beltrán Bigorra & Nules & Público & Rural \\
\hline IES Miquel Peris & Grao de CS & Público & Urbano \\
\hline IES Penyagolosa & Castelló & Público & Urbano \\
\hline IES Honori Garcia & Vall d’Uixó & Público & Rural \\
\hline IES Rebeca Mezquita & Onda & Público & Rural \\
\hline IES Ramón Cid & Benicarló & Público & Rural \\
\hline IES Betxí & Betxí & Público & Rural \\
\hline IES Sos Baynat & Castelló & Público & Urbano \\
\hline
\end{tabular}

Tabla 4.1. Centros educativos seleccionados en la muestra, con indicación del tipo de centro y su ubicación

Tales poblaciones se sitúan casi en su totalidad en la parte más cercana al litoral, en la que se concentra casi el $70 \%$ de los habitantes de la provincia, así como los núcleos urbanos más importantes, por lo que tan solo en ellos se impartía tradicionalmente bachillerato. En el mapa siguiente vemos la ubicación de las poblaciones de los centros educativos encuestados.

\footnotetext{
${ }^{76}$ Según la ley orgánica 2/2006, 3 de mayo de Educación, "la prestación del servicio público de la educación se realizará a través de los centros públicos y privados concertados".
} 


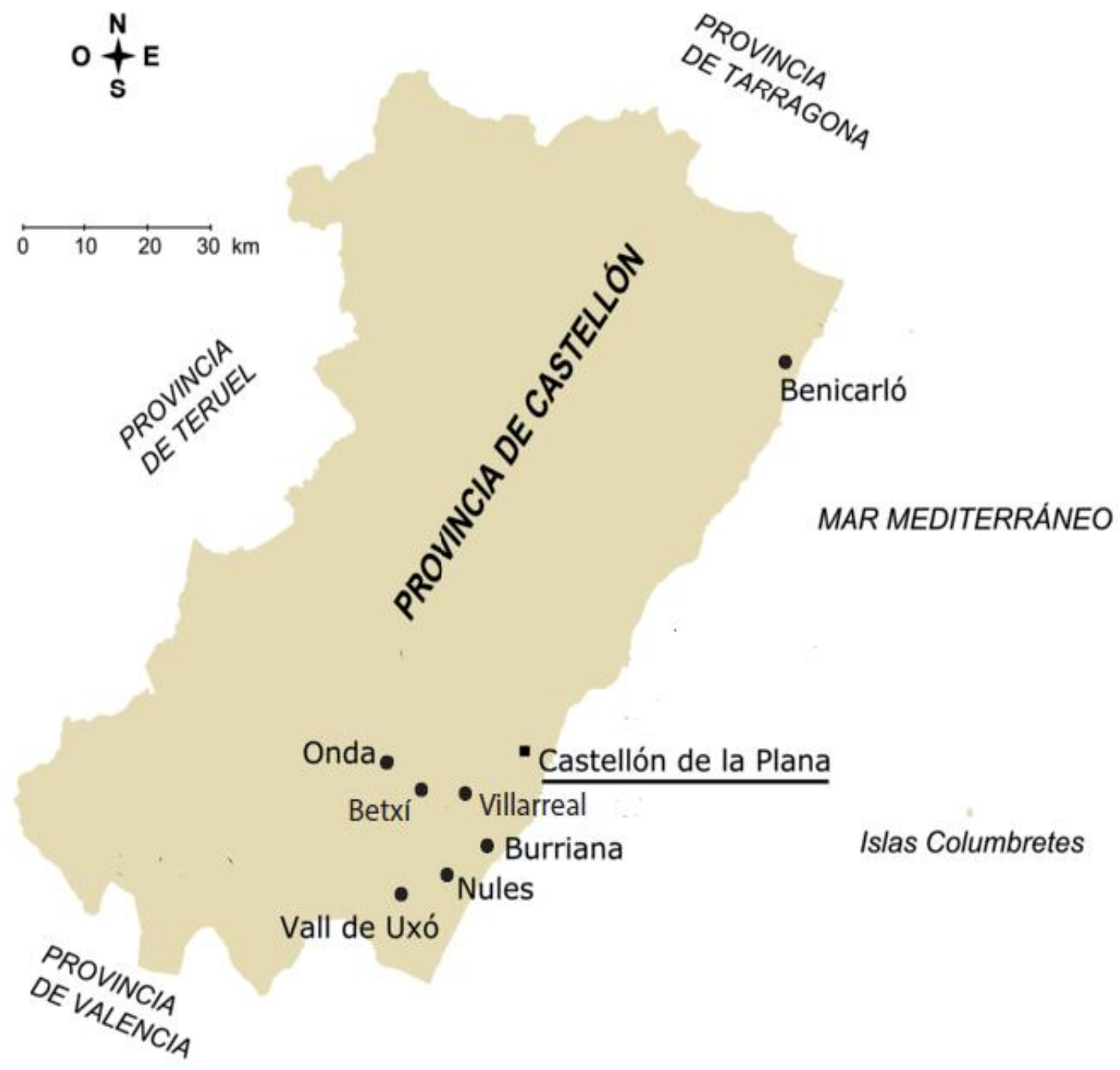

Mapa 4.1. Poblaciones de la provincia de Castellón encuestadas 
Respecto a las variables sociales examinadas en la muestra, se han considerado las habituales en el proyecto panhispánico. Tras el correspondiente análisis estadístico, estas nos permitirán averiguar si distintos factores sociológicos relevantes influyen -y hasta qué punto- sobre el inventario léxico obtenido. Este es el caso del sexo (hombres / mujeres), así como el tipo de comunidad en la que se ubican los centros educativos (urbano / rural) y el clase de centro educativo (público / privado) donde estudian los encuestados.

Se han considerado urbanos los centros ubicados en la capital de la provincia, y rurales los situados en el resto de las poblaciones. Varias razones nos han llevado a caracterizar como urbanos los ubicados tan solo en Castellón de la Plana, aunque sobre todas ellas sobresale el hecho de tratarse de la capital de la provincia, con todo lo que ello supone: centro administrativo, sanitario, de los servicios sociales, etc. Por lo demás, otros estudios del proyecto panhispánico, como los de Prado y Galloso (2005, 2008), Arnal et alii (2004) y Serrano (2014), entre otros, han procedido del mismo modo.

Asimismo, dadas las características particulares de la comunidad lingüística analizada, tendremos también en cuenta la lengua materna de los informantes, distinguiendo a este respecto entre: a) aquellos para los que el valenciano fue su primera lengua y continúa siendo el idioma más habitual, b) los que tienen el castellano como lengua materna y dominante, y c) aquellos bilingües más equilibrados, que han compartido ambas lenguas desde su infancia.

Por último, consideraremos además el nivel educativo de las familias, ${ }^{77}$ extraído a través del nivel de estudios alcanzado por los padres de los alumnos, y distribuido en cuatro grupos:

- estudios primarios incompletos, cuando los padres de los alumnos carecen por completo de formación escolar o, en el mejor de los casos, no terminaron la educación primaria;

- estudios primarios completos, cuando, al menos, se ha concluido la enseñanza primaria;

\footnotetext{
${ }^{77}$ Véanse en el mismo sentido, Benítez (1992), Galloso (2002) y M ${ }^{a}$ L. Arnal et al. (2004: 20). SilvaCorvalán (1989) destaca que, ante la dificultad que entraña delimitar con precisión un factor como la clase social, cabe sustituirlo por un factor mucho más objetivo, como es el nivel de instrucción, una solución a la que han acudido muchas investigaciones sociolingüísticas.
} 
- estudios secundarios, grupo en el que se integran los alumnos cuyos padres están en posesión de instrucción secundaria completa (bachillerato y grados de formación superior);

- y estudios superiores, cuando los padres tiene una formación universitaria.

Los grupos respectivos se han establecido a partir del valor asignado de forma convencional tanto al padre como a la madre de cada alumno, siguiendo los siguientes valores:

\section{Sin estudios: 1}

5 o 6 años de escolaridad (enseñanza primaria): 2

Bachillerato elemental: 3

Bachillerato superior: 4

Título universitario de grado medio: 5

Título universitario superior: 6

Al sumar ambas cifras y dividirlas por dos, se obtiene un resultado que nos disecciona la variable en los cuatro grupos mencionados anteriormente. De esta forma, si el resultado se encuentra entre 1 y 2,5 estamos ante el nivel educativo más bajo; si se halla entre 2,6 y 3,9, obtenemos el nivel medio-bajo; si la cifra está entre 4 y 5 , el nivel medio; y, por último, si está comprendido entre 5,1 y 6 , estaremos ante representantes del nivel alto.

Como es lógico, la edad, ${ }^{78}$ uno de los factores más frecuentes en las investigaciones sociolingüísticas, no se ha tenido en cuenta en esta ocasión, dado que todos los informantes pertenecen a la misma franja generacional, como corresponde a alumnos de los cursos inmediatamente anteriores al comienzo del periodo universitario. $^{79}$

La tabla 4.2 ofrece la distribución de la muestra por cada uno de los factores reseñados:

\footnotetext{
${ }^{78}$ Para el alcance de este factor en los estudios de disponibilidad léxica, véanse López Morales (1999b: 27) y Gómez Molina y Gómez Devís (2004: 38).

${ }^{79}$ Como vimos anteriormente, diversas investigaciones han considerado también otros segmentos de edad. Recuérdense, al respecto, los trabajos pioneros de Gougenhein y su equipo (1956, 1964), así como el estudio de Mackey (1971) en Canadá, que analizaban el léxico disponible de niños entre 9 y 12 años. Entre nosotros, Cañizal (1987) encuestó a alumnos que habían concluido sus estudios de primaria, al tiempo que Butrón (1987) y Prado y Galloso (2008) lo han hecho con estudiantes de $5^{\circ}$ y $6^{\circ}$ de Educación Primaria respectivamente. Asimismo, Samper Hernández (2009) ha trabajado con varios niveles educativos (tercero y quinto de primaria, así como primero y cuarto de secundaria).
} 


\begin{tabular}{|l|c|c|}
\hline \multicolumn{1}{|c|}{ Variables } & $\mathbf{N}^{\mathbf{0}}$ alumnos & Proporción \% \\
\hline Sexo & & 44 \\
\hline Hombre & 155 & 56 \\
\hline Mujer & 199 & 47 \\
\hline Ubicación centro & 165 & 53 \\
\hline Urbano & 189 & \\
\hline Rural & & 65 \\
\hline Tipo Centro & 229 & 35 \\
\hline Público & 125 & \\
\hline Privado & & 45 \\
\hline Lengua materna & 158 & 39 \\
\hline Valenciano & 139 & 16 \\
\hline Castellano & 57 & 41 \\
\hline Ambas & & 28 \\
\hline Nivel educativo familiar & 144 & 23 \\
\hline Nivel Bajo & 98 & 8 \\
\hline Nivel Medio-bajo & 83 & \\
\hline Nivel Medio & 29 & \\
\hline Nivel Alto & & \\
\hline
\end{tabular}

Tabla 4.2. Distribución sociológica de la muestra

Para conocer el grado de representatividad de la muestra seleccionada, a continuación presentamos los datos de la población general, así como, la de los alumnos preuniversitarios en el periodo en que fueron encuestados. Antes de continuar, conviene advertir que en este tipo de estudios resulta muy difícil conseguir una representatividad rigurosa de los distintos grupos sociales, y ello por varias razones. La primera es que las encuestas se realizaron en un día y un grupo elegidos al azar, con lo que, en muchos casos, no todos los alumnos estaban presentes; y, entre aquellos que sí lo estaban, no todos siguieron adecuadamente las pautas previstas, por lo que hay que descartar sus encuestas. Lo mismo sucede con los informantes que han llegado recientemente a las comunidades de habla castellonenses, o con aquellos que no responden a todos los centros de interés. Finalmente, otro factor que ha influido en el grado de representatividad muestral ha sido el número de aulas encuestadas. En centros grandes, en los que había varias clases de un mismo curso, se pudieron encuestar distintas clases de bachillerato, por lo que pudimos llegar al número de 25 encuestas previamente acordado, pero no sucedió lo mismo en institutos pequeños, donde solo se encuestó una clase, como ocurrió en Onda o Betxí.

Durante el curso académico 1999-2000, el número de estudiantes matriculados en bachillerato en la provincia de Castellón ascendió a 3.434 (2.733 alumnos de COU y 
701 de segundo de bachillerato LOGSE), mientras que los estudiantes encuestados para el presente estudio fueron 354, lo que representa un 9,3\% del total (véase gráfico 4.1). Esta cifra supera con creces la ratio de $0,025 \%$ propuesta por Labov (1983) para los estudios de corte variacionista, un índice que, por lo demás, se considera extensible a otras investigaciones sociolingüísticas como la presente.

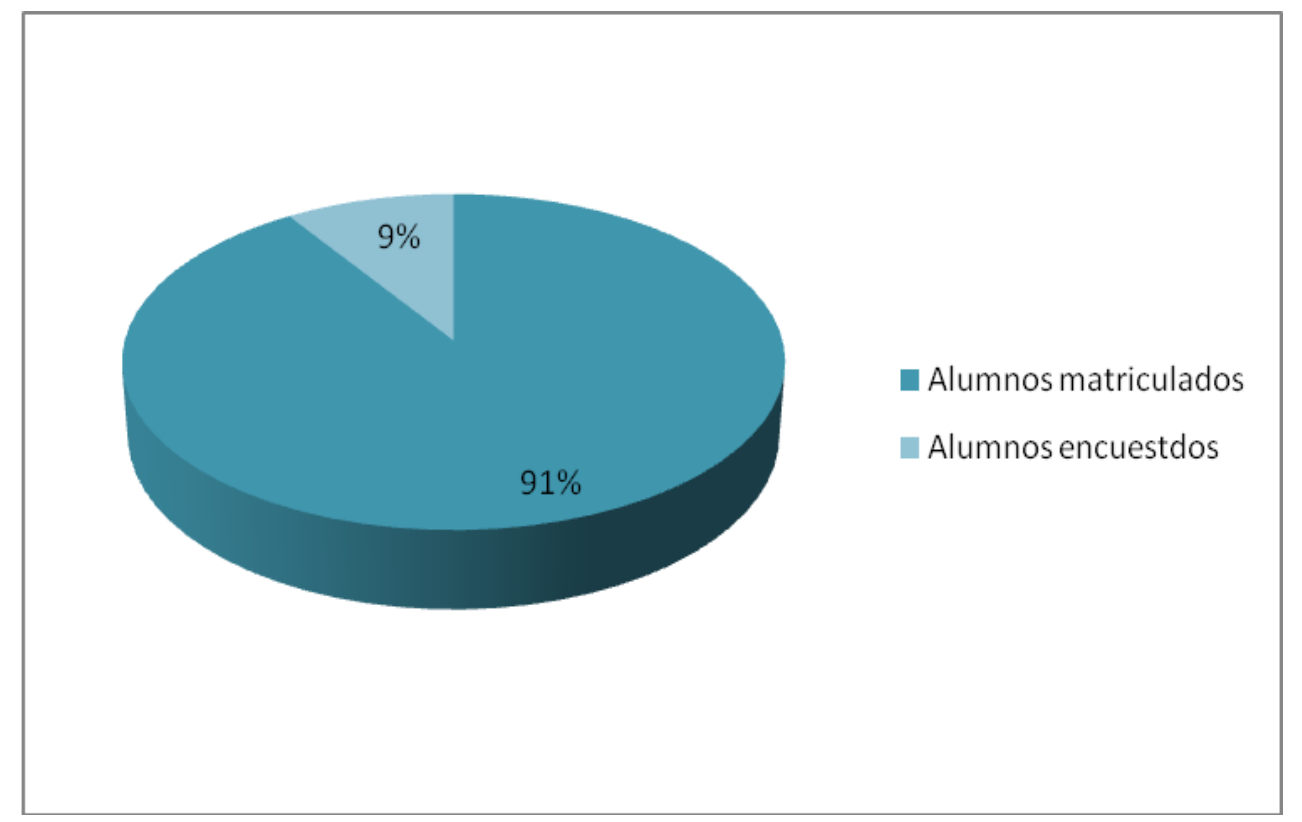

Gráfico 4.1. Porcentaje de alumnos matriculados en bachillerato y alumnos encuestados. 80

${ }^{80}$ Servei de Estudiants de la Universitat Jaume I y Anuari Estadístic Municipal i comarcal, Comunitat Valenciana, 2000-01. IVE. Generalitat Valenciana, València, 2001. 
En la tabla 4.3 aparece esa misma distribución por poblaciones.

\begin{tabular}{|l|c|c|c|}
\hline Población & $\begin{array}{c}\text { Total alumnos } \\
\text { matriculados }\end{array}$ & Muestra & $\begin{array}{c}\text { Porcentaje (sobre } \\
\text { el total) }\end{array}$ \\
\hline Benicarló & 159 & 25 & 15.72 \\
\hline Betxí & 35 & 21 & 60 \\
\hline Borriana & 221 & 25 & 11.31 \\
\hline Castellón & 1429 & 175 & 12.24 \\
\hline Nules & 110 & 22 & 20 \\
\hline Onda & 126 & 21 & 16.66 \\
\hline Vall d'Uixó & 182 & 25 & 13.73 \\
\hline Vila-real & 309 & 50 & 16.18 \\
\hline
\end{tabular}

Tabla 4.3. Distribución del alumnado por poblaciones. ${ }^{8}$

Por lo que a la muestra seleccionada se refiere, encontramos 155 alumnos de sexo masculino y 199 del femenino (gráfico 4.3)

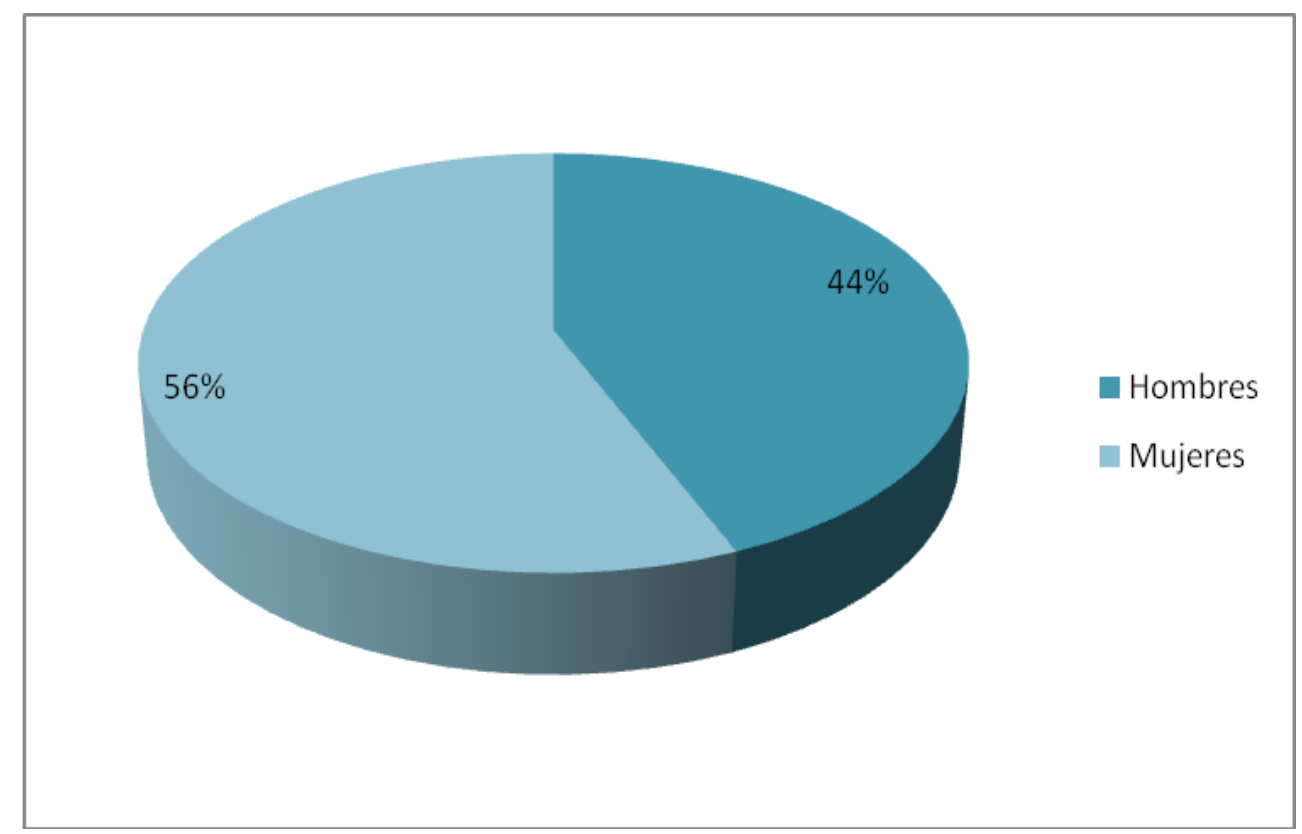

Gráfico 4.3. Representación de la muestra analizada según el sexo de los alumnos.

${ }^{81}$ Fuente: Conselleria de Cultura i Educació. Secretaria General. 
En el gráfico 4.3 observamos cómo, pese a una ligera sobrerrepresentación del sexo femenino en la muestra, esta se aproxima bastante al peso de cada grupo en el sistema educativo castellonense. Por lo demás, en la mayoría de las investigaciones sobre disponibilidad integradas en el citado proyecto panhispánico, se aprecia también este desequilibrio, en parte atribuible a la mayor presencia de las chicas en relación con los chicos -más lastrados por el abandono escolar- en el sistema educativo. Como recuerdan, Prado, Galloso y Conceição (2010: 37): “los chicos tienden más que las chicas a realizar estudios primarios y después incorporarse al mundo laboral a edades más tempranas que las chicas, que continúan sus estudios en niveles superiores como medio de promocionarse socioculturalmente."

Según datos de la Conselleria de Cultura i Educació. Secretaria General, en el curso 99/00 había 20 centros donde se impartía BUP y COU (14 centros públicos y 6 centros privados), más 15 de enseñanza secundaria y bachillerato LOGSE. De todos ellos se encuestaron 15 , lo que supone un $75 \%$ del total de centros educativos de la provincia de Castellón. Por redes educativas, 4499 (84\%) alumnos estudiaban en institutos públicos y 808 (15\%) lo hacían en colegios privados, proporciones que quedan reflejadas en el gráfico 4.4. Sin embargo, en la muestra analizada hay una sobrerrepresentación de los alumnos de colegios privados y concertados, con 125 individuos (35\%), frente a los 229 alumnos (65\%) que estudiaban en centros públicos (gráfico 4.4). 


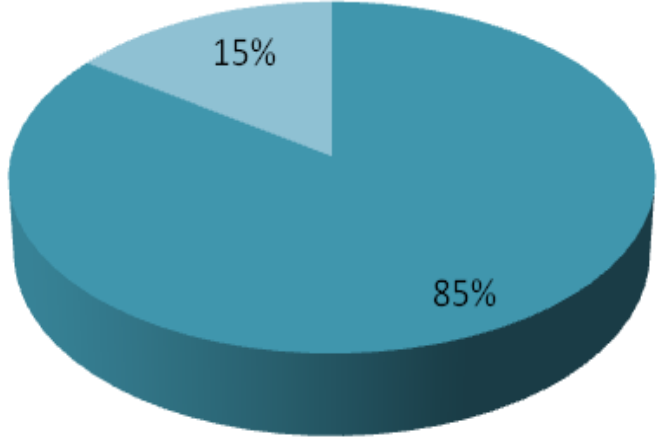

Alumno matriculados en centros públicos

Alumnos matriculados en centros privados

Gráfico 4.4 Proporción de alumnado según la red educativa elegida ${ }^{82}$

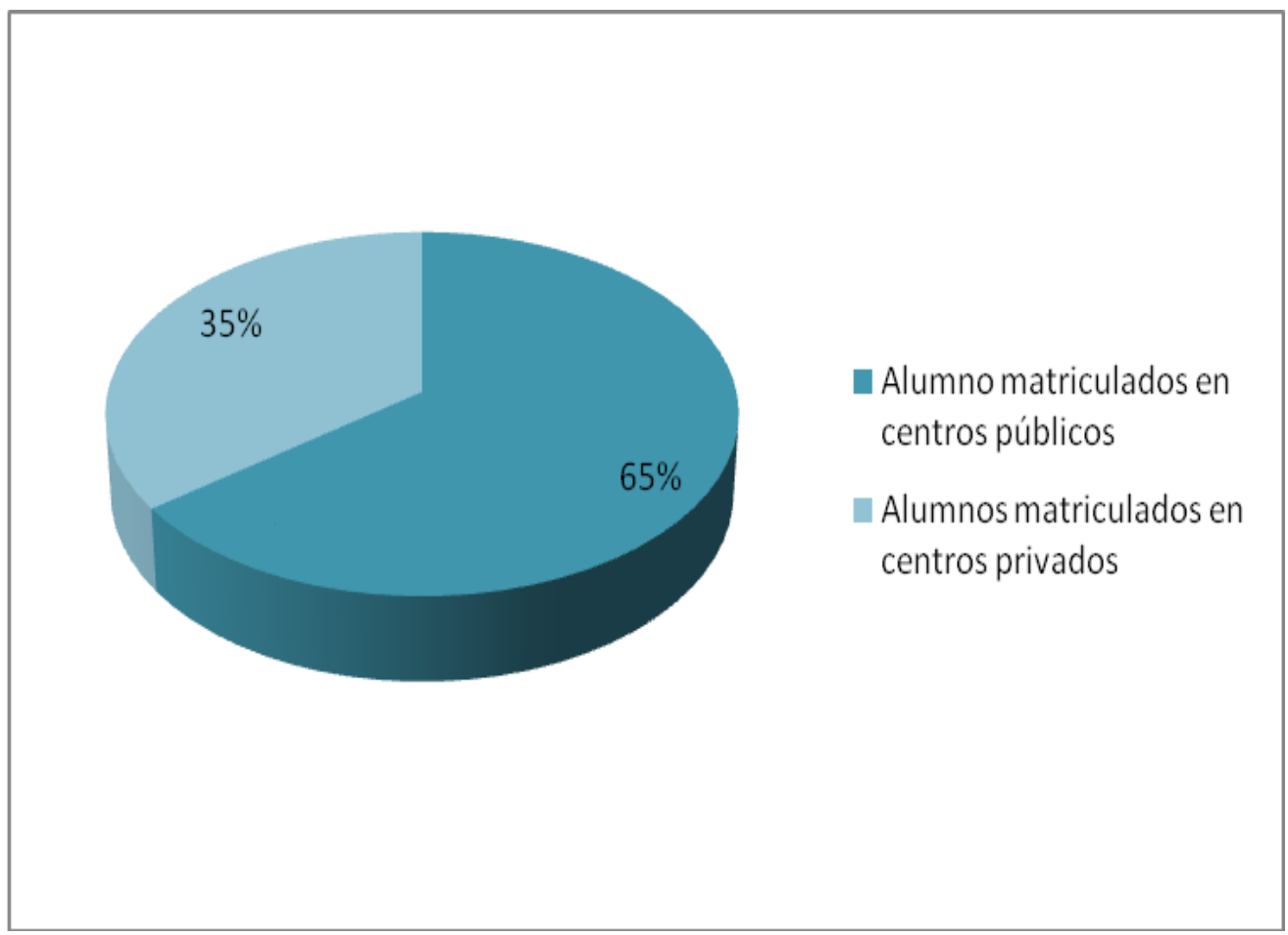

Gráfico 4.5. Proporción de la muestra según la red educativa

${ }^{82}$ Fuente:Conselleria de Cultura, Educació i Ciència. Secretaria General 
Una vez detallados los datos principales de la muestra, en las tablas siguientes mostramos la representación numérica de algunos cruces relevantes.

\begin{tabular}{|l|c|c|c|}
\hline Lengua materna & Centros públicos & Centros privados & Totales \\
\hline Valenciano & 117 & 42 & 159 \\
\hline Castellano & 78 & 60 & 138 \\
\hline Ambas & 34 & 23 & 57 \\
\hline
\end{tabular}

Tabla 4.3. Número de informantes por lengua materna y tipo de red educativa analizados en la muestra.

\begin{tabular}{|l|c|c|c|}
\hline Nivel educativo & Centro públicos & Centros privados & Totales \\
\hline Nivel primario & 117 & 27 & 144 \\
\hline Nivel Elemental & 60 & 38 & 98 \\
\hline Nivel secundario & 37 & 46 & 83 \\
\hline Nivel superior & 15 & 14 & 29 \\
\hline
\end{tabular}

Tabla 4.4. Número de informantes según el nivel educativo de los padres y el tipo de centro educativo.

\begin{tabular}{|l|c|c|c|}
\hline Sexo & Centros públicos & Centros privados & Totales \\
\hline Hombre & 99 & 56 & 155 \\
\hline Mujer & 130 & 69 & 199 \\
\hline
\end{tabular}

Tabla 4.5. Número de informantes según el sexo y tipo de centro educativo

\subsection{Cuestiones metodológicas}

\subsubsection{El test de disponibilidad léxica}

Las investigaciones sobre disponibilidad léxica trabajan con pruebas asociativas, "las únicas que hacen posible, en condiciones experimentales, que se realicen en la actuación lingüística las unidades léxicas con poca estabilidad estadística" tal como indica López Morales (1999: 32). ${ }^{83}$ A los informantes se les proponen determinadas claves temáticas, llamadas en este ámbito de estudio "centros de interés", para que el individuo pueda actualizar los términos potencialmente disponibles de manera inmediata en su lexicón mental.

El test de disponibilidad consiste en un cuestionario formado por una serie de hojas grapadas. En la primera de ellas se recogen diversos datos de los alumnos, que

\footnotetext{
${ }^{83}$ Asimismo, López Morales y García Marcos (1995: 68) añaden que las pruebas asociativas son "capaces de hacer actualizar importantes parcelas del lexicón mental del individuo".
} 
servirá para su estratificación sociológica posterior, y en las siguientes seis páginas se muestran los estímulos lingüísticos a los que deben responder los estudiantes durante un máximo de dos minutos por cada centro de interés. Los alumnos deben escribir tantas palabras como les vengan a la mente una vez nombrados los centros de interés correspondientes. $^{84}$ Debajo del título de cada campo léxico aparecen unas líneas, numeradas del 1 al 31, para facilitar la actualización de los términos a los informantes. Están ordenadas con el fin de hacer posible la visión del rango del vocablo, ya que no poseen la misma disponibilidad ni espontaneidad los vocablos que aparecen en las últimas posiciones que las que se registran en los primeros lugares de las listas. ${ }^{85} \mathrm{~A}$ continuación exponemos, a modo de ejemplo, las respuestas que aparecen en las primeras y últimas posiciones, respectivamente, del centro de interés Partes del cuerpo. En la tabla observamos el grado de disponibilidad de cada unos de los vocablos y el número de informantes que refieren cada unidad léxica. Así, las palabras más disponibles entre los estudiantes castellonenses son ojo, brazo y cabeza, con un índice de disponibilidad de 0,648, 0,634 y 0,615 respectivamente. Sin embargo, los últimos términos aparecen con índices de disponibilidad mucho más bajos, y apenas son mencionados por un único estudiante, cuando la primera palabra del listado (ojo) es citada por 318 informantes.

\begin{tabular}{|c|l|c|c|c|c|}
\hline $\mathrm{N}^{\mathbf{0}}$ & Palabra & Disponibilidad & $\begin{array}{c}\text { Frecuencia } \\
\text { relativa }\end{array}$ & $\%$ Aparición & $\begin{array}{c}\text { Frecuencia } \\
\text { acumulada }\end{array}$ \\
\hline 1 & ojo & 0.64867 & $3.476 \%$ & $89.831 \%$ & $3.476 \%$ \\
\hline 2 & brazo & 0.63469 & $3.105 \%$ & $80.226 \%$ & $6.581 \%$ \\
\hline 3 & cabeza & 0.61583 & $2.842 \%$ & $73.446 \%$ & $9.423 \%$ \\
\hline 4 & pierna & 0.61548 & $3.192 \%$ & $82.486 \%$ & $12.615 \%$ \\
\hline 5 & mano & 0.59788 & $3.083 \%$ & $79.661 \%$ & $15.698 \%$ \\
\hline 6 & dedo & 0.57446 & $3.378 \%$ & $87.288 \%$ & $19.076 \%$ \\
\hline 7 & nariz & 0.57368 & $3.290 \%$ & $85.028 \%$ & $22.366 \%$ \\
\hline 8 & pie & 0.54637 & $3.214 \%$ & $83.051 \%$ & $25.580 \%$ \\
\hline
\end{tabular}

\footnotetext{
${ }^{84}$ Serrano (2014) utiliza una página por centro de interés con la finalidad de que el estudiante no vea previamente el área semántica que tendrá que responder a continuación. Hernández Muñoz (2004, 2006) no mantiene por escrito la nominación del centro de interés, sino que va dictándolo a medida que avanza la encuesta. Otra prueba llevada a cabo por la misma investigadora (Hernández Muñoz, 2006) consiste en contrastar dos formas -escrita y oral- de recoger los datos.

${ }^{85}$ Ver al respecto Etxebarria (1996), Samper y Hernández (1997) o Galloso (2002).
} 


\begin{tabular}{|l|l|l|l|l|c|}
\hline 267 & costado & 0.00053 & $0.011 \%$ & $0.282 \%$ & $99.971 \%$ \\
\hline 268 & lóbulo de la oreja & 0.00053 & $0.011 \%$ & $0.282 \%$ & $99.982 \%$ \\
\hline 269 & glándula & 0.00050 & $0.011 \%$ & $0.282 \%$ & $99.993 \%$ \\
\hline 270 & yunque & 0.00050 & $0.011 \%$ & $0.282 \%$ & $100.004 \%$ \\
\hline 271 & pleura & 0.00040 & $0.011 \%$ & $0.282 \%$ & $100.015 \%$ \\
\hline
\end{tabular}

Una vez seleccionadas las encuestas, se ha llegado al número de 354 informantes. En el proceso de selección se han eliminado todas aquellas que estaban incompletas, defectuosas o con una letra ilegible, o las de aquellos alumnos que llevasen poco tiempo viviendo en la provincia. Siempre se ha procurado una proporción lo más equilibrada posible de estudiantes de sexo masculino y femenino, con las salvedades mencionadas más arriba, así como la clásica división entre alumnos de letras y ciencias, si bien esta no ha sido posible en todos los centros, por lo que se ha descartado del análisis como un potencial factor independiente. En aquellos centros en los que se ha encuestado a dos grupos de estudiantes, se ha logrado ese equilibrio entre estudiantes del género masculino y femenino y la variable letras vs. ciencias, ${ }^{86}$ pero en los institutos pequeños, en los que solo se encuestó a un grupo, no siempre pudo ser así. Por ese motivo en cuatro centros educativos no llegamos a las 25 encuestas por instituto programadas inicialmente. ${ }^{87}$

\subsubsection{Los centros de interés}

En la reunión celebrada en abril de 2003 en San Millán de la Cogolla (La Rioja), en la que participaron los diferentes equipos investigadores de la disponibilidad léxica, se llegó al acuerdo de que los trabajos incluidos en el proyecto panhispánico debían analizar los 16 centros clásicos, necesarios para realizar los análisis contrastivos de las diferentes sintopías del español, si bien a estos podrían añadirse, opcionalmente, otros adicionales. En consecuencia, la mayoría de los estudios de disponibilidad léxica analizan esos dieciséis centros de interés tradicionales, que ya estudiara Gougenheim en

\footnotetext{
${ }^{86}$ Sin embargo, Hernández Muñoz (2002) llega a la conclusión de que la especialidad académica entre ciencias y letras en los estudiantes preuniversitarios no influye en ningún rango cuantitativo ni cualitativo en el léxico disponible. Por el contrario, las diferencias entre unos escolares y otros se deben a factores más complejos.

${ }^{87}$ Otras razones ya fueron argumentadas más arriba.
} 
1964 en su investigación pionera, con pequeñas variaciones en su designación. ${ }^{88}$ En nuestro estudio hemos desarrollado esos mismos centros de interés, además del campo Colores, también presente en los trabajos de Butrón (1987), Benítez (1992), Etxebarría (1996), Samper-Hernández (1997), Mateo García (1998), Arnal et al. (2004) y Gómez Molina y Gómez Devís (2004) entre otros. ${ }^{89}$ López Morales y García Marcos (1995: 70) justifican la inclusión de este nuevo centro de interés aduciendo que los colores "nos introducen en un aspecto básico de la verbalización de la percepción del entorno, de constante referencia desde los trabajos de los antropólogos lingüistas para el examen de las relaciones lengua / pensamiento / realidad".

Por nuestra parte, compartimos esa opinión, ya que la realidad llega a nosotros a través de los colores, y a partir de estos realizamos constantemente asociaciones secundarias. De esta forma, los informantes incluyen términos como apagado, para dar cuenta tanto de un día gris como de la tristeza, o vivo, para indicar la alegría o un día soleado. Al mismo tiempo, los estudiantes preuniversitarios de Castellón matizan los colores básicos con múltiples tonalidades expresadas a través de palabras diferentes.

Las diecisiete áreas temáticas, que sirven de estímulo lingüístico para provocar las respuestas verbales de los estudiantes, quedan formuladas del modo siguiente:

01. Partes del cuerpo

02. La ropa

03. Partes de la casa ( $\sin$ muebles)

04. Los muebles de la casa

05. Alimentos y bebidas

06. Objetos colocados en la mesa para la comida

07. La cocina y sus utensilios

08. La escuela : muebles y materiales

09. Iluminación, calefacción y medios para airear un recinto

10. La ciudad

11. El campo

12. Medios de transporte

\footnotetext{
${ }^{88}$ Las variaciones en la denominación de los centros de interés pueden afectar a las respuestas de los informantes, y, por tanto, a los resultados, lo que ha de tenerse en cuenta en la comparación de los diferentes estudios. En López Morales (1999b:32-38), encontramos un apunte histórico sobre la evolución de los centros de interés desde los estudios franceses.

${ }^{89}$ Como se vio anteriormente, otros investigadores han sumado nuevos centros de interés a esta nómina. Además de los referidos allí, Valencia y Echeverría (1999a) añaden la política, la actividad económica, las artes, ciencia y tecnología, el mundo espiritual, los procesos mentales y los problemas de ambiente. En el caso de Ahumada (2006), en Jaén, el autor ha incluido el campo relacionado con "el olivo y el aceite".
} 
13. Trabajos del campo y del jardín

14. Los animales

15. Juegos y distracciones

16. Profesiones y oficios

17. Los colores.

El enunciado mismo de los centros nos ofrece ya una idea acerca de la cantidad de vocablos que pueden aportar los estudiantes en sus respuestas, al implicar grados de asociación muy distintos. Por ejemplo, el centro de interés 10. La ciudad y el 11. El campo son áreas semánticas muy amplias y abiertas a las agrupaciones y relaciones que provocan, como demuestra el elevado número de palabras recogidas (949 y 1060 respectivamente); en cambio, otros, como el 9. Iluminación, calefacción y medios para airear un recinto o el 6. Objetos colocados en la mesa para comer son más restrictivos en las asociaciones que suscitan, por lo que el número de palabras es notablemente inferior (479 y 317 respectivamente). Por lo demás, estos son datos que se confirman en todos los estudios sobre disponibilidad léxica publicados hasta la fecha.

\subsubsection{Aplicación de la prueba}

La prueba consistió en la realización de una encuesta a los alumnos en sus propios centros educativos y en grupos elegidos al azar. Como indicábamos más arriba, en los institutos o colegios con un número elevado de estudiantes se pudo encuestar a dos grupos escolares (este fue el caso, por ejemplo, del instituto Ribalta de Castellón o el Francesc Tárrega de Vila-real, entre otros), mientras que en los centros pequeños tan solo se pudo acceder a uno. La encuesta se realizó durante la hora asignada a la asignatura de Lengua española, por lo que contamos siempre con la colaboración de los profesores titulares de la asignatura. Los estudiantes debían escribir todas las palabras que les sugiriese el centro de interés enunciado durante un límite de dos minutos. Una vez finalizado ese tiempo, se pasaba a responder el siguiente centro de interés. Pocas fueron las consignas dadas a los estudiantes para no provocar respuestas inducidas. Las instrucciones fueron del tipo siguiente:

-Debían escribir aquellas palabras relacionadas o asociadas con los campos semánticos o temas indicados. 
-No debían preocuparse por la ortografía. Las dudas sobre esta no debía ser motivo para dejar de escribir una palabra. Ni que decir tiene que todos los estudiantes fueron advertidos de que nunca habría consecuencias por este motivo.

-Si finalizaban la columna de líneas preparadas para responder podían continuar escribiendo en la última página del cuestionario que estaba en blanco.

-Se indicó que no era una prueba puntuable, sino simplemente una colaboración desinteresada para una investigación acerca del léxico que suelen emplear los jóvenes.

Sin embargo, otros autores han optado por añadir algunas indicaciones adicionales a las ya reseñadas. Así, por ejemplo, en su estudio sobre el léxico disponible en Valencia, Gómez Molina y Gómez Devís (2004: 49, n. 54) advirtieron a los alumnos seleccionados que, si no se acordaban de la palabra en castellano, podían ponerla en valenciano, además de añadir otras aclaraciones entre un centro de interés y otro. De otro orden son las contribuciones en este sentido de Arnal et al. (2004), quienes, en la explicación sobre los campos semánticos número 13. Trabajos del campo y del jardín y número 16. Profesiones y oficios, pidieron a los alumnos que respondieran con verbos en el primer caso y con sustantivos en el segundo. Por otro lado, $\mathrm{M}^{\mathrm{a}}$ Victoria Galloso (2001) cree que no debe darse ningún tipo de información previa a los estudiantes sobre ningún centro de interés, con la finalidad de no influir en sus respuestas. Es un criterio con el que coincidimos plenamente, y que nos ha guiado en la recogida de los datos para esta investigación.

Otro hecho que necesita ser uniformado obligatoriamente en el cotejo de las distintas sintopías es la forma en que se obtienen los diccionarios del léxico disponible, esto es, el tipo de listas con las que se trabaja, y en particular si estas deben ser abiertas o cerradas. ${ }^{90}$ Los primeros estudios elaboraron listas cerradas, aquellas que solicitan un número exacto de respuestas -mayoritariamente 20-, lo que facilitaba el análisis estadístico, pero, como contrapartida, obstaculizaba la adquisición de otras informaciones potencialmente relevantes. Por el contrario, las listas abiertas permiten recabar mayor número de vocablos, y por tanto, mayor información utilizable en diferentes tipos de análisis. Los investigadores del proyecto panhispánico han convenido en que el uso de las listas abiertas es más fructífero para recoger la máxima información posible, por lo que es el método que hemos aplicado en este trabajo. También el tiempo de respuesta ha sufrido variaciones. En las primeras investigaciones,

\footnotetext{
${ }^{90}$ Aportan información al respecto López Morales (1999b: 38-39), Carcedo (2001: 35-36) y Mateo García (1998: 81-82).
} 
este ascendía a 15 minutos (Gougenheim et alii, 1956 y 1964 o Mackey, 1971), sin embargo, Azurmendi (1983) recortó ya ese plazo a solo 5 minutos. La solución propuesta por Mena Osorio (1986) será la que se mantendrá hasta nuestros días: un límite de dos minutos.

A la vista de estos antecedentes, y fieles a las pautas del proyecto panhispánico sobre el léxico disponible, en nuestra investigación hemos empleado listas abiertas (el alumno puede responder todo aquello que se le ocurra en ese momento), en un tiempo limitado a dos minutos por cada centro de interés.

\subsection{Criterios de edición de los materiales}

Una de la tareas más complicadas en los estudios de disponibilidad léxica es la edición de los materiales recogidos en las encuestas. Como señala Bartol (2004:17): "De ellas depende, además, la fiabilidad de los datos y, consecuentemente, de los estudios posteriores a que den lugar".

El problema aparece cuando no todos los investigadores siguen los mismos criterios de edición en sus respectivos estudios, o no existe una terminología común. Sumamos a ello los objetivos concretos e individuales que persiguen los distintos investigadores, junto con las diferentes denominaciones de los centros de interés, a las que nos referíamos anteriormente. Todo ello repercute en los resultados finales, tanto en el número como en el tipo de respuestas. Nos enfrentamos, pues, a cuestiones metodológicas relevantes de lo que Alba (1995a) y Galloso (2001) han denominado estandarización de los datos. Por su parte, Samper Padilla (1998), Carcedo (2001) y González Martínez (2002) prefieren hablar de edición de los materiales, Mateo (1998) de pautas de unificación; López Morales (1999b) de edición y codificación de los materiales, etc.

Sin embargo, el proyecto panhispánico propone una metodología y unos criterios comunes de edición de materiales, que aglutinan a todas las investigaciones del español. Estas normas generales han sido enumeradas y comentadas por Samper Padilla (1998: 311-333), ${ }^{91}$ quien en este sentido sigue de cerca lo establecido previamente por Muller

\footnotetext{
${ }^{91}$ Ver también Samper, Bellón y Samper Hernández (2003: 95-101), donde se citan los acuerdos de la primera reunión sobre disponibilidad léxica celebrada en Bilbao en 1999, y además, se explican los
} 
(1973: 253-258). No en vano, se trata de un requisito imprescindible si tenemos en cuenta los objetivos fundamentales de los trabajos de disponibilidad léxica: facilitar el cotejo dialectal y la consecución de un diccionario general del léxico disponible del español, o lo que es lo mismo, acceder a la norma léxica disponible común de toda la comunidad hispanohablante. $^{92}$

Como es lógico, aparte de estos criterios comunes, válidos para todos los investigadores, estos pueden abordar otros temas que sean de su interés, y que, generalmente, son de carácter sociolingüístico. Para ello, la mayoría de estudiosos trabaja con dos versiones de los materiales obtenidos en las encuestas: un primer listado con los datos sin pulir, es decir, sin adoptar las normas comunes del Proyecto Panhispánico, y un segundo listado que sigue ya estrictamente los criterios generales del mencionado proyecto (sobre estas cuestiones, véanse Bartol (2004) y Galloso (2003a), entre otros). ${ }^{93}$

De acuerdo con este método hemos procedido también en este trabajo. A continuación exponemos las pautas generales que adoptamos en esta edición de los materiales, en primer lugar, y, a continuación, los criterios específicos o particulares de cada centro de interés en la muestra castellonense analizada en el trabajo.

\subsubsection{Criterios generales}

Los criterios generales adoptados en el tratamiento de los datos de la presente investigación son los siguientes:

1. Eliminación de palabras repetidas en el mismo centro de interés. Aunque no es muy usual este caso, lo hemos encontrado en algunas ocasiones. Cuando ha sido así, se ha optado por eliminar el que aparece en segundo lugar. Por otro lado, cuando han surgido

pormenores del proyecto, su marco teórico, estado de la cuestión, así como la metodología que deben seguir los estudios incluidos en el proyecto panhispánico.

${ }^{92}$ Los encuentros científicos sobre la disponibilidad léxica han ayudado a conseguir unos criterios comunes de edición de los materiales, una metodología general, etc. Todo ello asumido por las distintas investigaciones realizadas. Con todo, todavía quedan cuestiones pendientes. La primera reunión tuvo lugar en Bilbao en 1999, la segunda (2003) y tercera (2005) en San Millán de la Cogolla y la cuarta (2011) en Salamanca, como ya hemos apuntado. .

93 Hernández Muñoz (2004) establece dos criterios: fidelidad al corpus y lematización más conceptualización. Asimismo, Gómez Molina y Gómez Devís (2004) establecen los criterios de esta forma: fidelidad al corpus versus estandarización y lematización versus conceptualización. 
dos palabras en una misma línea, algo, por lo demás, poco habitual también, se ha procedido a colocar una detrás de la otra.

2. Corrección y unificación ortográfica. En este sentido, cabe destacar -y lamentar- el importante número de faltas de ortografía cometidas por los alumnos, y ello pese al nivel avanzado de sus estudios, a las puertas ya de la universidad. La unificación ortográfica se ha realizado siguiendo las normas que aparecen en el DRAE en su vigésima segunda edición (2001) y la página web de la Academia (rae.es). A este respecto, cuando la norma autoriza escribir de dos formas distintas una palabra, se ha elegido una sola opción, la que mayoritariamente utilizan los encuestados. Así, de omóplato/omoplato, whisky/güisqui, kiwi/quivi se ha escogido la primera forma. Esta unificación no afecta a aquellos dobletes que aparecen en las encuestas en los que alternan un extranjerismo y una palabra española. En estos casos se han mantenido las dos (parking/aparcamiento).

En la cuestión de los neologismos y extranjerismos, se ha procedido a uniformar aquellos términos extranjeros que han sido adoptados por el diccionario académico (por ej. cruasán, póquer...), y cuando no están registrados por la Academia, se ha respetado la grafía original (por ej. body, short, bóxer en el campo semántico 2. La ropa).

3. Uso de mayúsculas. Las respuestas de los informantes se han transcrito en minúscula. Solo aparece la mayúscula en las siglas $(A T S, W C$ ), en los nombres propios (mantón de Manila), en las marcas publicitarias (Enmental, Dan up) y en el título de los estudios o carreras universitarias (Filología, Derecho...).

4. Marcas comerciales. Se han consignado todas las enunciadas por los alumnos, estandarizadas en mayúscula y con asterisco al final, independientemente de que estén o no lexicalizadas. Es el caso, por ejemplo, de Intelect*, Monopoly*, Scattergories* en el centro de interés Juegos. En la práctica, es bastante difícil determinar cuándo una marca pertenece ya al vocabulario común de los individuos de una comunidad lingüística, o lo que es lo mismo, cuándo se ha lexicalizado totalmente y pasa a sustituir al nombre genérico. A la vista de estas dificultades, hemos optado por incluirlas en su totalidad, como han hecho también Gómez Devís (2003), Benítez (1992) y Galloso (2001). Por su parte, Mateo (1998:86) advierte que "más allá de que estén formalmente aceptadas o no, lo indudable es que forman parte de las interacciones lingüísticas cotidianas de las 
comunidades de habla examinadas". Pese a ello, autores como Samper (1998: 317) tan solo consignan las palabras que ya están lexicalizadas o en vías de lexicalización, es decir, aquellos vocablos que "en una situación comunicativa determinada, puedan sustituir el nombre del producto aun en el caso de que lo designado no se corresponda con la marca concreta". 94

5. Neutralización de variantes meramente flexivas. Las diferentes estructuras morfológicas de un mismo vocablo quedan reducidas a la forma no marcada: masculino y singular en los sustantivos, así como en los pocos adjetivos que aparecen. Las formas verbales, por su parte, se reducen al infinitivo.

En cuanto al género gramatical, la variación masculino/femenino queda neutralizada en el masculino, como ya hemos indicado, pero hay algunas excepciones. Así ocurre, por ejemplo, en el campo 16. Profesiones y oficios, con aquellos términos en los que los encuestados solo han seleccionado el femenino de una palabra y esta se halla registrada en el DRAE: costurera, niñera, etc. Obviamente, también se mantiene el femenino cuando sirve para establecer una diferenciación de significado: gorro/gorra, pimiento/pimienta...

En los heterónimos se conservan ambas: caballo/yegua, toro/vaca. Del mismo modo, se mantienen los dos vocablos cuando el femenino se halla formado mediante un sufijo específico: gallo/gallina.

En el morfema gramatical de número, la variación singular/plural se ha reducido al singular, aunque, como en el caso anterior, nos encontramos también con algunas particularidades. De esta forma, por ejemplo, usamos el plural en la enunciación de juegos que están lexicalizados: indios y vaqueros, damas, muñecas, chinos... Asimismo lo empleamos también en aquellos vocablos que igualmente están registrados en el DRAE de esta manera: picardías (con la acepción de camisón corto y transparente), bermudas, etc., y en los que forman parte de un complemento sintagmático de sustantivo (cuarto de juegos) o verbos (cortar malas hierbas). ${ }^{95}$

Por último, y como hemos dicho anteriormente, los verbos se reducen a una forma no personal, y en particular al infinitivo. Sin embargo, al igual que en los casos

\footnotetext{
${ }^{94}$ Actúan del mismo modo Carcedo (2001) y Martínez Olmos (2008), entre otros.

${ }^{95}$ Bartol (2004:19), sin embargo, respeta la forma en que aparece la palabra en la encuestas, es decir, mantiene el singular, si la palabra se registra de esa manera, y el plural, si lo hace en plural. Si está en ambos números, el término se lematiza con el morfema de número entre paréntesis: calcetín (es). De esa manera, este autor dice conservar una información útil, sin que afecte negativamente a los datos y criterios generales.
} 
precedentes, también hay salvedades, como sucede con el nombre de juegos (veo veo) o en el campo 12. Medios de transporte, donde aparece ocasionalmente el gerundio: corriendo, andando...

6. Unificación de formas derivadas (diminutivos y aumentativos) en su base léxica, siempre, como en el ejemplo siguiente: florecilla se lematiza como flor. Lógicamente, esto se realizará siempre que no suponga un cambio de significado. Sin embargo, se mantiene la forma derivada cuando hay lexicalización, como en el caso de ensaladilla, cucharilla, futbito, etc. porque encierran un significado distinto de ensalada, cuchara y fútbol, respectivamente. Por lo tanto, constituyen entradas independientes los diminutivos y aumentativos lexicalizados.

7. Unión de formas plenas y acortamientos de determinadas unidades léxicas. En los listados aparecerán de la forma siguiente: bolí(grafo), bici(cleta) para indicar que unos estudiantes han puesto la forma acortada bici y otros ha optado por la forma plena bicicleta.

8. Uso del paréntesis. Este signo de puntuación se registrará para entradas sinónimas, que unas veces aparecen reducidas y, otras, sin embargo con todos sus constituyentes. Un ejemplo lo encontramos en el centro 1. Partes del cuerpo en columna vertebral: en ocasiones hallamos el sintagma completo y otras solo el sustantivo columna. En los listados vendrá como columna (vertebral). Lo mismo sucede con cuarto de baño y baño, que se lematizarán como (cuarto de) baño.

Por tanto, la interpretación del paréntesis será la siguiente: unos informantes actualizan la forma completa y otros la forma reducida. Nos indica, en definitiva, la aparición de dos variantes en la sintopía estudiada.

9. Asociaciones secundarias. Se mantienen todos los vocablos enunciados por el estudiante, aunque aludan indirectamente al campo semántico solicitado, dada la potencial información valiosa que aportan (de carácter sociolingüístico, por ejemplo). ${ }^{96}$ Hay que destacar que este es un hecho relativamente frecuente en las encuestas. Por

\footnotetext{
${ }^{96}$ Esas asociaciones secundarias que provocan algunos centros de interés se mantienen siguiendo los criterios de Galloso (2001), Mateo (1998), Hernández (2004, 2006), Bartol (2004), Ávila (2006), entre otros.
} 
ejemplo, en el centro de interés 2. La ropa encontramos la enumeración de los instrumentos utilizados para confeccionar las prendas de vestir (aguja, dedal, hilo...). Del mismo modo, en el centro de interés 3. Partes de la casa, se mencionan términos como bañera, grifo, etc. e incluso aparecen vocablos que hacen referencia a zonas externas a la casa, como jardín, piscina, pista de tenis... Y hay que reconocer que todas ellas están incluidas en una vivienda, bien sea en el interior o en el exterior, por lo que hemos decidido conservarlas.

10. Valencianismos. En una situación de contacto de lenguas, como la que se vive en la mayor parte de la provincia de Castellón, no es de extrañar que, junto a palabras del castellano, lengua en la que se realiza la encuesta, advirtamos también la aparición de vocablos en valenciano, lengua propia y cooficial de la Comunidad Valenciana. ${ }^{97}$ Los vocablos correspondientes a esta variedad dialectal se registran en minúscula y en negrita para diferenciarlos de los extranjerismos (galicismos, anglicismos o italianismos). Por lo demás, estos términos se rigen también por las mismas normas de edición que los demás vocablos (corrección y unificación ortográfica, neutralización de las variantes flexivas de género y número, etc.). En un capítulo posterior realizamos un análisis específico de estos valencianismos.

11. Extranjerismos. En el proceso de lematización de las respuestas, hemos encontrado también lexemas en otras lenguas. Estas se anotan en los listados con letra cursiva. Uno de los campos semánticos donde se aprecia un porcentaje mayor de extranjerismos es el número 05. Alimentos y bebidas, en el que se consignan galicismos como foie gras, soufflé, mousse, italianismos, como pizza, tortellini, mozzarella y numerosos anglicismos, como bourbon y brandy. ${ }^{98}$ Todos ellos se mantienen bajo la forma original de la lengua fuente, excepto aquellos que ya han sido aceptados por el Diccionario Académico (el caso de cruasán, por ejemplo).

12. Omisión del artículo. Muchos son los alumnos que enuncian los vocablos precedidos por el artículo determinado el/la/los/las y, en algunas ocasiones, por el indeterminado un. En la edición de los materiales se ha procedido a eliminarlos. Por

\footnotetext{
97 Nos referimos al valenciano como la variante dialectal del catalán hablada en la Comunidad Valenciana.

${ }^{98}$ Como es sabido, con este término se designa a cualquier tipo de coñac no elaborado en Francia.
} 
ejemplo, la entrada "los ojos" se lematiza como ojo. Asimismo, quedan excluidos los artículos en los sintagmas formados por un verbo, más el artículo y un sustantivo, como ocurre en "volar la cometa", que aparece en los listados como volar cometa o "tocar la flauta", que se lematiza como tocar flauta. No obstante, se mantendrá el artículo en aquellas ocurrencias que lo precisen, bien sea para recoger un sentido específico, bien porque así son nombradas habitualmente. Así sucede, por ejemplo, en conejo al ajillo, conejo a la brasa, arroz a la cubana o arroz al horno en el centro de interés 05. Alimentos y bebidas. Lo mismo ocurre con el nombre de algunos juegos que siempre llevan el artículo: alto el fuego, corro de la patata, el del medio, etc.

13. Construcciones sintagmáticas. Se mantienen todas las que hemos encontrado en los listados de Castellón. Algunas de ellas se lematizan mediante el paréntesis, como hemos visto en el punto número 8, y otras aparecen en su totalidad, como juego de la botella, morderse las uñas, cuadro de la Virgen, botar a la comba, etc.

14. Empleo de las preposiciones. Mayoritariamente han quedado reducidas a la preposición "de" en conjuntos sintagmáticos como "cuchillo de carne", "cuchillo para la carne", que han sido lematizados como chuchillo de carne. Pero en algunas ocasiones hemos conservado otras preposiciones para mantener el sentido del sintagma. Sirvan de ejemplo: estar con amigos, tiro con arco, salir por ahí, patinaje sobre hielo, correr en bicicleta entre otros.

La existencia de numerosas excepciones a estas normas, como veremos con más detalle a continuación, deriva del deseo de mantener dos objetivos no siempre fáciles de compaginar: por un lado, la necesidad de uniformar al máximo las palabras, con la finalidad de poder comparar más tarde los léxicos disponibles de diferentes zonas dialectales, al tiempo que, por otro, se pretende preservar la mayor cantidad posible de información. Como sostiene Bartol (2004: 18), el principio uniformador es imprescindible en "estudios que se enmarcan en un proyecto mayor, cuyo objetivo final es la publicación de un único diccionario de léxico disponible". Por lo tanto, es fundamental la aplicación de criterios lexicográficos de lematización comunes a todas las investigaciones. Y, sin embargo, para este mismo autor, dicha uniformización deja en el camino demasiada información potencialmente valiosa. De la misma opinión es Galloso (2003a: 33-37), quien cree que las respuestas de los estudiantes deberían quedar 
tal como se presentaron. Por ejemplo, en su trabajo sobre Ávila, Zamora y Salamanca, esta investigadora destaca a menudo este hecho, como en la cita siguiente:

No dejaremos de advertir nuevamente la cantidad de información que se pierde eliminando estas formas: de todos es sabido que una de las características atribuidas al habla femenina es el mayor uso de diminutivos. Por lo que su pérdida elimina elementos que posibilitan afirmar si estamos ante un hombre o una mujer. Por otro lado, en ocasiones nos hemos encontrado con sufijos despectivos, -ucho/a (carreterucha), cuya supresión también borra datos importantes desde un punto de vista psicológico. (p. 42-43)

Galloso manifiesta abiertamente que si se "limpia" demasiado y se lematizan excesivamente los datos "corremos el riesgo de perder, de forma irrecuperable, demasiada información $\mathrm{y}$, por tanto, desvirtuar también los resultados” (p. 33). Asimismo, considera que si se actúa de esa manera se está yendo "en contra de la definición de léxico disponible: todo el caudal léxico utilizable en una situación comunicativa dada, sin excepción" (p. 34).

Tratamos el tema de la misma manera que Benítez (1992) y Mateo (1998), quienes creen que hay información que desaparece irremediablemente cuando se actúa bajo los criterios estrictos expuestos por Samper (1998), ${ }^{99}$ por lo demás necesarios para facilitar la pretendida comparación entre los diferentes léxicos disponibles.

\subsubsection{Criterios particulares}

Pese a la validez y utilidad de los criterios de edición reseñados, por desgracia estos no agotan por sí solos las dificultades con que se enfrentan los estudios sobre disponibilidad léxica. Así las cosas, en lo que sigue comentaremos otros problemas que hemos encontrado en el procesamiento de algunos centros de interés y la solución que se ha adoptado en cada caso.

\footnotetext{
${ }^{99}$ Con todo, es indiscutible que el trabajo de Samper Padilla (1998), en el que proponía las normas de edición de su estudio en Gran Canaria, supuso un gran avance para el establecimiento de unos criterios comunes que sirvieran como punto de partida y modelo para investigaciones posteriores sobre la disponibilidad léxica.
} 


\section{Partes del cuerpo}

Como ya indicó Samper (1998: 318), se trata uno de los centros de interés más homogéneos del estudio, ya que no provoca respuestas asociadas secundariamente y, por ello, no ofrece grandes dificultades en su tratamiento. Encontramos léxico habitual (cara, ojo, boca...) y científico (esternocleidomastoideo, cóccix, apéndice xifoides, hipotálamo, etc.), aunque tampoco faltan muestras de léxico coloquial (culo, teta, moflete, huevo...)

Se sigue la pauta general de unificar en singular muchas de las palabras que aparecen casi siempre en plural en las encuestas: ojos, labios, cejas, quedan, pues, como ojo, labio, ceja, respectivamente.

Como vimos, el paréntesis en columna (vertebral) indica que unos alumnos han utilizado el sintagma completo y otros, en cambio, tan solo el sustantivo columna. Pese a ello, se conservan aquellas combinaciones en las que el sentido de la lexía simple no es tan obvio (Carcedo, 2001: 40), como sucede con alvéolo dental y alvéolo, ya que este último puede ser también pulmonar; o glándula, que puede referirse tanto a la glándula sudorípara como a la glándula salival.

Hemos incorporado términos como embarazo o regazo, que aunque no son partes del cuerpo estrictamente, sí están relacionados directamente con esta área semántica, puesto que el primero se refiere al estado de la mujer encinta y el segundo porque hace mención a la protección de algo, normalmente un pequeño, con el propio cuerpo.

Al mismo tiempo hemos optado por reducir brazo/pierna derecho/izquierdo a brazo y pierna, respectivamente, como se ha hecho en los estudios de Aragón (Arnal 2004: 24), pero se mantiene extremidad superior y extremidad inferior porque los referentes son distintos, ${ }^{100} \mathrm{y}$ reducimos las diferentes variantes sintagmáticas a una sola, como en dedo del pie, dedo de pie, dedos de los pies, etc. en una única solución: dedo del pie, tal como hacen la mayoría de investigadores (Samper, 1998: 318; Carcedo, 2001: 40).

Se han registrado las formas de diminutivo que se hallan lexicalizadas en la lengua, como, por ejemplo, barbilla, espinilla, pantorrilla, paletilla, rabadilla... Se incluye también aquí un valencianismo habitual en el registro coloquial: figa,

\footnotetext{
${ }^{100}$ Así lo consideran también Gómez Molina y Gómez Devís (2004: 56) en su estudio de Valencia.
} 
eufemismo utilizado en esta comunidad para hacer referencia a la "vulva". En los listados aparece lematizada en minúscula y en negrita, como el resto de valencianismos.

02. La ropa

Tampoco este centro ha resultado demasiado problemático. Los alumnos han proporcionado todo tipo de asociaciones con respecto a este tema. Así, encontramos términos referentes a prendas de vestir concretas (pantalón, falda, abrigo...), tipos de calzado (zapato, bota, botín, chancla...), complementos en el vestido (gemelo, cinturón, bolso, peluca, diadema, collar, turbante, bastón, paraguas...), ropa del hogar (manta, cubrecama...), tipos de tejidos (poliéster, nailon, seda, hilo, piel, algodón...), elementos necesarios para la confección de la ropa (aguja, máquina de coser, hilo ...). Al mismo tiempo se consignan las diferentes partes del vestido: cuello, solapa, ojal, capucha... y encontramos algún coloquialismo que otro, como chupa de cuero.

Las marcas comerciales se han aceptado todas, siguiendo el criterio esbozado más arriba, pero no han sido muy abundantes en su conjunto; de hecho solo hemos constatado Wonderbra*, Pikys*,Lycra*. Sí son abundantes, en cambio, los neologismos y extranjerismos: ${ }^{101}$ body, short, panty, slip, bóxer, blazer, jeans, leggings..., unos más adaptados al español que otros. Cuando esos lexemas ya están registrados en el diccionario académico del español, los hemos anotado tal como aparecen en este. Es el caso, por ejemplo, de términos como biquini (también aparece así en los estudios de Valencia, Cádiz y Asturias), niqui o pulóver.

En cuanto a las variaciones morfológicas, hemos singularizado los lexemas, aunque en las encuestas casi siempre aparezcan en plural, términos como zapato, peúco, braga. Sin embargo, hemos dejado en plural bermudas, picardías, porque así se registran en el DRAE. Asimismo, dejamos en plural gafas, puesto que es la única opción aportada por los informantes, y el diccionario académico señala que tiene en plural el mismo significado que en singular. Por lo demás, tienden a ser plurales las prendas formadas por dos partes iguales o simétricas como es el caso de tirantes, o las ya mencionadas bermudas y gafas.

\footnotetext{
101 Observamos anglicismos y galicismos mayoritariamente. Algo explicable por la influencia de las culturas correspondientes en el mundo internacional de la moda.
} 
En lo relativo al género, se ha mantenido el femenino cuando el significado referencial es distinto que el masculino: gorro/ gorra, playero ('vestido')/ playera ('clase de zapatilla')

Del mismo modo, se mantienen separadas camisa, camiseta, camisola y camisón, por tener referentes distintos. Por la misma razón mantenemos los dobletes siguientes, uno de cuyos miembros está formado por un sufijo diminutivo: botal botín, chaqueta/chaquetilla, corbata/corbatín, bata/batín, falda/faldilla, manta/mantilla, tocaltoquilla... Todos ellos han sido recogidos en el DRAE. También lo están chancla y chancleta, y ambos se registran en los listados, si bien en este caso hay que reconocer que en la mayor parte de los estudios de disponibilidad léxica se interpretan como sinónimos. $^{102}$

En cuanto a la palabra braga, nos encontramos con una homonimia difícil de resolver, pues muchas veces no estamos en condiciones de saber si el informante se refiere a la prenda íntima femenina o a la de abrigo, similar a una bufanda. Con todo, algunos informantes sí han especificado el referente, en cuyo caso se han registrado en los listados como las lexías complejas correspondientes: braga de cuello, braga militar.

En cuanto a los grupos sintagmáticos, son mayoritarios los referidos a camisa, camiseta, pantalón, chaqueta, bota, falda, jersey, mono, traje, vestido y zapato/zapatilla. Todos se han mantenido, lo que da lugar a especificaciones que hacen referencia al tamaño (pantalón largo, pantalón corto), uso (body deportivo, body interior, bota de agua) o tejido del que está hecha la prenda (pantalón de pana, gorro de lana).

El paréntesis se ha utilizado en (pantalón) tejano, (pantalón) vaquero, (vestido) playero y (zapatilla) deportiva. Este último es un caso especial. El alumnado siempre ha puesto deportivas para referirse a las zapatillas, pero al singularizarlo nos hemos visto obligados a introducir el paréntesis para no confundirlo con ropa deportiva. Así, deportivas y zapatillas deportivas se han lematizado como (zapatilla) deportiva. Los diferentes empleos de zapatilla de estar por casa, zapatilla de ir por casa, zapatilla de casa, se han lexicalizado como zapatilla de casa.

\footnotetext{
${ }^{102}$ Gómez Molina y Gómez Devís (2004) solo recogen chancla. Galloso (2003 a) chancleta, mientras que Bartol (2004) y Fernández Juncal (2008) lematizan los dos términos. Esta última autora dice que chancleta es un sustantivo lexicalizado. Por su parte, Serrano (2014), al analizar las dos lenguas en contacto en la provincia de Lleida, recoge este vocablo tanto en castellano (chancleta) como en catalán (xancleta).
} 
Finalmente, en este centro de interés se han recogido también tres palabras valencianas, si bien su empleo no es muy frecuente: samarreta 'camiseta', brusa 'blusa' y espardenya 'alpargata o también esparteña, especie de alpargata hecha de cuerda de esparto'.

03. Partes de la casa ( $\sin$ los muebles)

Al igual que otros investigadores en el estudio de la disponibilidad léxica, incluimos también en este apartado aquellas palabras que se relacionan con el área semántica propuesta de un modo más tangencial. De esta manera, junto con términos concretos que aluden a las partes de una casa (cuarto, cocina, comedor...), aparecen otros vocablos referentes a materiales de construcción (cemento, yeso, baldosa, escayola...), componentes arquitectónicos (columna, arco, pilar...), elementos de saneamiento (bañera, grifo, lavabo, caldera...), y todo aquello que se encuentra en el exterior de la vivienda propiamente dicha (jardín, caseta del perro, piscina, paellero....). ${ }^{103}$

En las respuestas a este centro de interés se diferencian con claridad dos tipos de viviendas, individuales o unifamiliares, por un lado, con toda clase de elementos externos (pista de tenis, piscina...) y, por otro, los pisos, situados en bloques de apartamentos, y en los que se comparten diversos espacios (galería o patio de luces...).

Aparecen en este campo léxico muchas construcciones sintagmáticas que tienen como base los sustantivos habitación, sala y cuarto, con nada menos que veinte, veintidós y veinticinco especificaciones respectivamente. Sirvan, a modo de ejemplo: habitación de invitados, habitación de dormir, habitación de estudio; sala de estar, sala de estudio, sala de juegos; cuarto de niños, cuarto de matrimonio, cuarto de planchar, etc. Todas se mantienen, puesto que representan puntualizaciones de acuerdo con lo expuesto en los criterios generales (Samper, 1998: 319). Utilizamos el paréntesis para unificar baño y cuarto de baño en (cuarto de) baño. Y lo mismo en cuarto trastero y trastero en (cuarto) trastero; y cuarto de aseo y aseo en (cuarto de) aseo.

Mantenemos los diminutivos lexicalizados altillo, baldosín, bovedilla, descansillo, pasillo..., que designan realidades específicas y diferentes a las

\footnotetext{
${ }^{103}$ En la Comunidad Valenciana es común entender por paellero una construcción pequeña, normalmente abierta por uno de los lados, y en la que se halla una especie de banco y unas parrillas encima, que sirven para cocinar las paellas con fuego de leña o para asar carne. Ver apartado 5.4.
} 
correspondientes bases léxicas. Y, por el mismo motivo, conservamos salita y el valencianismo saleta junto a sala. Solo aparecen las siglas $T V$ y $W C$, este último al lado de váter. Del mismo modo, se registran algunos extranjerismos: hall, recogido por el DRAE en cursiva, office -que, si bien no aparece en el diccionario académico, sí lo hace en el Diccionario del Español Actual-, parking, etc. Y marcas como Portland* y Jacuzzi*.

También aquí registramos algunos valencianismos, como: desllunat 'patio', rebost 'despensa', pica 'pila', y el ya mencionado diminutivo de sala saleta 'salita' (estancia un poco más pequeña que el salón, donde se reúne la familia y "se hace la vida", como indican los propios alumnos).

Algunos lexemas pueden entenderse en más de un sentido, como biblioteca y lavabo, por ejemplo. La primera puede ser entendida como 'estancia donde están situados los libros de la casa', o como 'estantería'. La segunda, como 'cuarto de aseo o baño' o como 'pila con grifos y otros accesorios que se utiliza para lavarse'. Tienen, por tanto, cabida como partes de la casa, y por ello figuran en los listados de este centro de interés.

04. Muebles de la casa

Siguiendo el criterio general de aceptar la mayor parte del vocabulario del que dan cuenta los informantes, hemos incluido en este apartado no solo el léxico que hace referencia estricta al mobiliario de la casa, sino también el vocabulario relativo a electrodomésticos grandes (lavadora, nevera, lavavajillas, horno, microondas...), electrodomésticos pequeños (sandwichera, termo, plancha, molinillo, báscula, tostadora, freidora...), objetos de decoración (figura, florero, marco de fotos, maceta, cuadro...), sanitarios (bañera, bidé, ducha, lavabo, inodoro...), instrumentos audiovisuales y de comunicación (cadena de música, radiocasete, vídeo, teléfono, minicadena...) y elementos eléctricos (foco, flexo, bombilla...).

Al igual que otros investigadores, también aceptamos términos como comedor, recibidor, trastero, porque, a través de una metonimia, pueden indicar el mobiliario de esas estancias (Arnal et al. 2004: 28, Samper, 1998: 320, Carcedo, 2001: 43). Y por similares motivos, se han admitido puerta y ventana, como hacen Samper (1998:319320) o Carcedo (2001:43), entre otros. 
Se han unido las variantes referentes a ausencia/presencia de diptongación (fregaplatos, friegaplatos) en la forma aceptada por la Academia: friegaplatos. Asimismo se ha lematizado la forma ropero y armario ropero en (armario) ropero, puesto que indican la misma realidad en la comunidad analizada. ${ }^{104}$ No actuamos del mismo modo, sin embargo, con camilla y mesa camilla como hacen Carcedo (2001: 43) y Bartol (2004), entre otros, puesto que camilla puede referirse a una "cama estrecha y portátil, que se lleva sobre varas a mano o sobre ruedas, para transportar enfermos, heridos o cadáveres" (segunda acepción en el DRAE) o simplemente a una cama estrecha donde se efectúan masajes.

Mantenemos como formas separadas los diminutivos lamparilla, altillo, balancín, carretilla ya que indican realidades distintas de aquellas formas de las que derivan.

Son abundantes los grupos sintagmáticos formados con el vocablo mueble (mиeble cama, mueble de baño, mueble de entrada, mueble de jardín...), mesa (mesa de comedor, mesa de centro, mesa de trabajo...) y armario (armario de cocina, armario de comedor, armario de ropa...), Todos se conservan en los listados tal como hemos indicado en los criterios generales.

Se mantienen separadas las formas mesa, mesita y mesilla. Como señala Samper (1998: 320), mesilla indica una realidad distinta de mesa. Y al no poder deshacerse los casos de homonimia con mesita, lo lógico es mantener las tres formas con sus respectivas especificaciones.

Por último, hay que destacar que aparecen las siglas $W C, T V, H I-F I$, así como diversos extranjerismos, algunos ya adaptados al español, como secreter y buró. Dejamos sinfonier, en lugar de chifonier, tal como propone el diccionario académico, porque es mayoritario su uso en Castellón, al igual que ocurre en los léxicos disponibles de Valencia, Cádiz, Asturias, Aragón y Lleida. Asimismo, nos encontramos con otro galicismo en este centro de interés, el de chaise-longue, que igualmente hemos conservado. Por último, mencionemos que en este campo solo hemos contabilizado un valencianismo, el de pica, con el sentido de fregadero.

\footnotetext{
${ }^{104}$ Igual sucede en el estudio de los jóvenes preuniversitarios de Valencia (Gómez Molina y Gómez Devís 2004: 56).
} 
05. Alimentos y bebidas

En este centro de interés constatamos la presencia de un número considerable de palabras, y ello pese a que no hemos encontrado asociaciones secundarias recurrentes, como en otros casos. Aquí hallamos nombres de alimentos básicos (pan, arroz, leche, lenteja...), pero también de platos cocinados (paella, gazpacho, hervido, sopa de ajo, tortilla, potaje...), así como las denominaciones de una gran cantidad de bebidas alcohólicas (whisky, ginebra, cerveza, vodka...). Por otro lado, es en este centro donde encontramos un mayor número de marcas comerciales, que, como se dijo, hemos conservado en todos los casos, al igual que han hecho otros autores, como Gómez Molina y Gomez Devís (2004) y Galloso (1998), en contraposición al criterio de Samper Padilla (1998), Carcedo (1998a) o Serrano (2014), que solo mantienen las que consideran lexicalizadas o en vías de lexicalización. Para ello, estos autores tienen en cuenta el número de informantes que han nombrado tal o cual producto, y rechazan aquellas que presentan un índice de aparición inferior al de los nombres genéricos correspondientes. Así, Carcedo (2001: 44) rechaza $J \& B$ o Ballantin `s, con 54 y 7 apariciones respectivamente, frente al genérico whisky con 211 menciones. Y del mismo modo, actúa Samper (1998: 321-322). Serrano (2014: 281-282), por su parte, mantiene la marca cuando esta aparece "tanto en los listados en castellano como en los del catalán, que fuera más frecuente que su correspondiente nombre genérico y que un número de cinco informantes la mencionan en cada una de las dos lenguas".

El hecho de lematizar en singular, siguiendo las normas comunes de edición de los materiales del proyecto panhispánico, da lugar a expresiones que nos resultan un tanto extrañas al estar habituados a enunciarlas -y escucharlas- en plural. Nos referimos a macarrón, espagueti, lenteja, garbanzo, fruto seco, etc. No obstante, mantenemos algunos plurales como calamares, caracoles (en singular nombran al animal y en plural indican la comida), callos, dulces (con el sentido de pasteles), papas, palomitas, porque designan referentes distintos según se trate del singular o del plural y su eliminación repercutiría en la identificación de la realidad concreta. Asimismo, se mantiene el plural en los complementos nominales de ciertos alimentos (sopa de cardos, sopa de fideos, puré de verduras...), siguiendo los criterios generales comentados más arriba.

Respecto a las formas derivadas, se conservan ciertos diminutivos que se hallan lexicalizados con un significado diferente al del sustantivo base: calabaza/calabacín 
empanada/empanadilla,

ensaladalensaladilla,

manteca/mantequilla,

manzana/manzanilla, pepino/pepinillo, rosquilla/rosquilleta, salmón/salmonete.

Con referencia al género, distinguimos entre pimiento y pimienta por referirse a productos distintos. Y del mismo modo, conservamos como entradas independientes en los listados las especificaciones que modifican a núcleos del tipo zumo (zumo de naranja, zumo de piña...), sopa, queso, agua, arroz, bebida, licor...como explicamos en el punto 13 de los criterios generales.

Los extranjerismos son abundantes en este centro de interés, como demuestra la presencia de italianismos como espagueti, lasaña, pepperoni, tortellini; anglicismos como whisky, brandy, bourbon, gin, beicon, entre otros; galicismos como entrecot, cruasán, mouse, foie gras, etc. Muchos de ellos han sido adaptados ya al español, y así se recogen en los listados. Sin embargo, dado el elevado índice de disponibilidad de whisky, lo mantenemos con esta forma, que, por otro lado, también recoge el DRAE.

Como en el resto de las áreas léxicas, el paréntesis se utiliza siguiendo los criterios generales ya reseñados (véase punto 8) para unir diferentes variantes de una misma palabra sin posibilidad de otra especificación que no sea la actualizada: (carne de) caballo, (carne de) cordero, (vino) tinto...

Por último, como en los otros centros de interés analizados, apreciamos la aparición de diversos valencianismos, en una proporción superior a la media, al lado de sus correspondientes palabras castellanas: abadejo/bacalao, butifarra/botifarra, carlota/zanahoria, clòtxina/mejillón, coca/torta, lluç/pescadilla, bajoca/judía. Por el contrario, en otros casos tan solo aparece el valencianismo, por lo general para aludir a comidas y alimentos originarios de la región valenciana. Este es el caso de fideuà 'comida a base de fideos característica de la Comunidad Valenciana', arròs caldós 'arroz caldoso', bajocó 'variedad de la judía verde', empedrat' comida hecha fundamentalmente de arroz y alubias, particular de algunos pueblos de la comunidad de habla castellonense', fogassa 'hogaza'.

06. Objetos colocados en la mesa para la comida

Aunque se han eliminado los vocablos de alimentos concretos (queso, jamón serrano, carne picada...), ya incluidos en el centro anterior, hemos conservado los nombres genéricos (comida, bebida, carne) y aquellos alimentos básicos que acompañan normalmente a todas las comidas (pan, aceite, vinagre, azúcar, sal, salsa, 
ketchup, mayonesa...). También recogemos las bebidas que habitualmente asociamos a los alimentos (agua, vino, cerveza, Coca-cola $*$ ), ${ }^{105}$ como consecuencia de procesos metonímicos muy comunes en la lengua. Asimismo, términos como mando a distancia y mando de tele(visión) se mantienen en los listados, objetos, en muchos casos, habituales en las mesas a la hora de la comida, aunque reconocemos que son elementos lejanos de lo que se necesita para comer. La alternancia de preposiciones en muchos grupos sintagmáticos se ha unificado con la preposición de, puesto que se trata del nexo con un mayor índice de disponibilidad. Así, cuchillo de la carne, cuchillo para la carne, queda en los listados como cuchillo de carne. Del mismo modo actuamos con el lexema tenedor, que en nuestro diccionario aparece como tenedor de carne, ya que ha sido la forma más frecuente de aparición en nuestros listados.

Los grupos sintagmáticos formados sobre los núcleos cuchara (cuchara de café, cuchara de madera, cuchara de helado...), tenedor (tenedor de carne, tenedor de pescado, tenedor de postre,..), vaso (vaso de agua, vaso de vino...), cuchillo (cuchillo jamonero, cuchillo de pan...), copa (copa de cava, copa de coñac...), botella (botella de agua, botella de cerveza...) y plato (plato de carne, plato liso, plato hondo...) se mantienen todos, puesto que designan diferentes tipos y usos de los correspondientes objetos.

Por lo que al género se refiere, mantenemos separado el de dobletes tales como cesta/cesto, jarra/jarro, canastilla/canastillo, porque designan objetos de distinto tamaño y, al mismo tiempo, tienen entradas distintas en el DRAE. Por la misma razón conservamos en el diccionario disponible de Castellón taza/tazón, jarro/jarrón, tapa/tapón y varios diminutivos lexicalizados como mantequilla, esterilla, canastillo, palillo. Se aceptan también paella y paellera, puesto que hacen referencia a elementos diferentes; el primero alude a la comida típica de Valencia a base de arroz, ${ }^{106}$ el segundo es el recipiente donde se cocina ese arroz. También en el DRAE encontramos dos entradas diferentes. No se unifican, tal como proponen Samper Padilla (1998: 323) y Carcedo (2001) los siguientes lexemas: cuchara, cucharilla, cucharita; plato, platillo, porque se refieren a objetos diferenciados significativamente por el tamaño y el uso.

Las palabras compuestas de verbo + sustantivo aparecen en plural, al igual que en el DRAE: abrebotellas, abrelatas, cascanueces, sacacorchos, portarrollos, posavasos. Y de igual modo hemos actuado con neologismos creados por los propios

\footnotetext{
${ }^{105}$ Sin embargo, no son incluidas por Samper Padilla (1998: 323).

${ }^{106}$ Paella puede significar también 'sartén', muy común en Castellón entre valencianohablantes.
} 
informantes y que, obviamente, no figuran en los diccionarios, como posacubiertos $o$ sujetamanteless. ${ }^{107}$ Asimismo, hemos dejado en plural los sustantivos tenazas y tijeras. Respecto a esta última palabra, seguimos el criterio de Manuel Seco (1986) quien, en su Diccionario de dudas y dificultades de la lengua española señala lo siguiente: "Como nombre de instrumento, el uso más extendido y prestigioso es en plural." Y así lo reflejan también nuestros informantes, que siempre han utilizado el plural en sus respuestas. Como extranjerismos, registramos Ketchup, bol, y como marca comercial, casi ya lexicalizada, aparece Tetra brik*.

Finalmente, la huella del bilingüismo social se encuentra también en este centro de interés por medio de valencianismos como cassoleta 'diminutivo de cazuela', pitxer 'jarro', setrill d'oli 'aceitera', así como una lexía mixta formada por las dos lenguas y de uso habitual en la comunidad castellonense: mortero con alioli 'mortero con ajoaceite'.

07. La cocina y sus utensilios

En este centro de interés se repiten muchos de los términos aparecidos en el anterior, debido a la proximidad semántica entre ambos, como cuchara, cuchillo, vaso, plato, etc. Los nombres de alimentos concretos han sido eliminados puesto que ya han sido recogidos en el campo léxico 05.Alimentos y bebidas, aunque se han mantenido los genéricos (comida, alimento) y aquellos que, por metonimia, pueden referirse también al recipiente que los contiene (aceite, sal, vinagre, especias). Aparece también paella. Como hemos apuntado en el centro de interés anterior, este término no solo se refiere a la comida, sino que puede significar, al mismo tiempo, sartén. En este centro encontramos un gran número de electrodomésticos, tanto de gran tamaño (lavadora, lavavajillas, nevera, frigorífico, horno) como más pequeños (licuadora, freidora, batidora, cafetera, picadora, tostadora, exprimidor...), todos ellos habituales en las viviendas de los informantes castellonenses.

Asimismo se conservan nombres referentes a productos de limpieza (amoniaco, detergente, desinfectante, jabón, lejía, limpiacristales, polvos de lavar) y utensilios para limpiar (mocho, cubo, especificado como de fregar y de basura, respectivamente). E igualmente recogemos aquellos vocablos que se refieren a partes de la cocina y sus

107 Solo en una ocasión hemos mantenido el singular en el vocablo cubremantel porque así lo ha registrado un informante. 
principales ornamentos (chimenea, ventana, mármol, estantería, armario, cuadro, lámpara...)

Aunque en este caso no son tan numerosas como en otros centros de interés, aparecen también especificaciones a núcleos sustantivos, como en los ejemplos siguientes: cuchara de madera, cuchillo de carne, cuchillo jamonero, bombona de Butano, bombona de gas, botella de Butano, cajón de cubiertos, cajón de servilletas, cazuela de barro, reloj de cocina, trapo de cocina, garrafa de agua... Como ya advertimos en los criterios generales, se dan expresiones sintagmáticas difícilmente reducibles en construcciones parentéticas, por lo que optamos por incluirlas todas mediante el uso de la preposición $d e$, por ser la preposición de mayor frecuencia en nuestros listados. De este modo, evitamos la pérdida de una información que consideramos valiosa.

En relación con las variaciones morfológicas, se conservan aquellos diminutivos que están lexicalizados: cocina-cocinilla, cuchara-cucharilla, esterilla, horno-hornillo, molinillo, parrilla. Igualmente mantenemos los aumentativos de cuchara-cucharón, jarro-jarrón, fuego-fogón, taza-tazón. Todos se mantienen porque la lexicalización correspondiente implica un cambio semántico.

El vocablo pajita no aparece en el diccionario de la Academia, en el que sí lo hace, por el contrario, pajilla, con el significado de 'tubo fino para sorber sobretodo refrescos' en su segunda acepción. Con esta, sin embargo, en Castellón el nombre que se utiliza casi categóricamente es pajita, no pajilla.

Como vimos en otro momento, las formas fregaplatos-friegaplatos, se han unificado en la forma diptongada, siguiendo así el criterio de la vigésima segunda edición del diccionario académico. Lo mismo hacemos con fregasuelos-friegasuelos, aunque en este caso ninguno de los dos nombres aparece en el DRAE.

Aunque se ha continuado el criterio general de singularización de los vocablos, mantenemos el plural en las formas compuestas de verbo y sustantivo (abrelatas, cascanueces, escurreplatos, lavavajillas, limpiacristales, mondadientes, pasapurés, secamanos...). De igual manera aparecen algunos neologismos producidos por los informantes (afilacuchillos, cortafiambres, cortapasteles, escurrecubiertos, escurrelechugas, guardaespecias, levantaclaras, montaclaras, subeclaras, pelazanahorias, pelapatatas), ninguna de ellas recogida en el DRAE.

El género femenino se conserva en palabras como paella y paellera, con el sentido esta última de sartén. Por su parte, el masculino paellero hace referencia bien a 
una especie de trébedes que funciona con gas - preferentemente, aunque no de forma exclusiva, para cocinar paellas-, bien al propio lugar de la vivienda -generalmente fuera de ella- habilitado para cocinar este plato de la gastronomía valenciana.

Los paréntesis que aparecen en este centro de interés siguen el criterio general ya mencionado. De esta manera, encontramos (horno) microondas, batería (de cocina), campana (extractora), extractor (de humo), robot (de cocina), tele(visión), etc.

Al igual que en otros campos léxicos, recogemos todas las marcas comerciales mencionadas por los alumnos en sus listados. Así, Ariel*, Butano*, Carmela*, Fairy*, Minipimer*, Mistol*, papel Albal*,Mepansa*, Tupperware*, Turmix*, Scotch Brite*, Spontex*. Algunas de ellas están prácticamente lexicalizadas, como Butano, ya incluido en el DRAE como entrada independiente. Lo mismo ocurre con Minipimer y Turmix, que hallamos en los libros de cocina como un sustantivo común para hacer referencia a la batidora, aunque en Castellón sigue siendo más alto el índice de disponibilidad del genérico batidora (0.17437), con 106 ocurrencias, frente a Minipimer (0. 02950) con apenas 19 apariciones, y Turmix (0.2567) con 16 muestras en los listados. Del mismo modo, Tupperware se usa como un término común para referirse a cualquier recipiente de plástico o fiambrera.

Entre los extranjerismo que encontramos en las encuestas de los estudiantes de la provincia de Castellón podemos citar bol, robot (de cocina), grill o vídeo, todos ellos admitidos por el diccionario de la Academia. No está la palabra sandwichera, aunque sí aparece en el DRAE sándwich.

Por último, también en este centro hallamos trasferencias léxicas del valenciano: pica 'pila', torradora 'tostador', fumeral 'chimenea', banquet 'banco', graella 'parrilla', misto 'cerilla', drap 'trapo', foguer ‘fogón'. Por otro lado, las palabras perola 'caldera' y perol 'caldero' muestran un sincretismo formal en las dos lenguas de la comunidad.

08. La escuela: muebles y materiales

Al igual que Galloso (2003), en nuestras encuestas no dimos ninguna consigna explícita a los informantes para la realización de la prueba, salvo las metodológicamente más generales, ya comentadas (véase 4.2.3). De este modo, los estudiantes podían contestar todo aquello que les viniera a la mente relacionado con el tema. Ello justifica que hayamos recogido en este centro de interés asociaciones secundarias relacionadas 
directamente con la realidad educativa, como, por ejemplo, los nombres que hacen referencia a roles (director, alumno, profesor, maestro, subdirector, conserje, bedel, secretario). Pese a ello, hemos decidido conservarlas, siguiendo así el criterio general de mantener el máximo número posible de respuestas seguido por otros investigadores del proyecto panhispánico (cf. Gómez Molina y Gómez Devís, 2004; Carcedo, 2001; Serrano, 2003; Martínez Olmos, 2008). ${ }^{108}$

De acuerdo con este criterio, incluimos términos que hacen referencia a dependencias de los centros educativos, tanto interiores como exteriores (aula, biblioteca, laboratorio, despacho, dirección, secretaría, gimnasio, capilla, portería, canasta, hall, árbol...), a la indumentaria de los alumnos (babero, uniforme, chaqueta...), a la actividad escolar concreta (notas de clase, prueba, examen, expediente, chuleta...). En definitiva, damos cabida a todo aquello que esté asociado de un modo u otro con la escuela, entendida esta en su sentido más amplio. Y así nos encontramos con los nombres de las asignaturas (Química, Lengua) -consignadas en mayúscula-, las comidas realizadas en los centros (almuerzo, bocadillo, agua, café,..), el mobiliario del aula (mesa, silla, pupitre, estantería...), el material deportivo (aro, potro, balón, raqueta, plinto...) y el escolar (compás, goma, carpeta, mochila, bloc, calculadora...), etc.

En cuanto a la variación morfológica, mantenemos el plural en apuntes, tal como lo recoge el DRAE 'extracto de las explicaciones de un profesor que toman los alumnos para sí...'. También lo conservamos en colores, gafas, pesas y tijeras, así como en vocablos compuestos como sacapuntas, y otros habituales en el lenguaje estudiantil que no aparecen en los diccionarios: portaángulos, quitagrapas, etc. Distinguimos entre lápiz y lapicero, que la Academia define como equivalente de lápiz o como 'instrumento en que se pone el lápiz para servirse de él' (acepción esta última muy poco común en estos tiempos), pero también puede hacer referencia al recipiente que se utiliza para depositar los lápices.

La variación de género la recogemos en los términos bolso-bolsa, por ser relevante desde el punto de vista semántico. Igualmente, anotamos los diminutivos que se han lexicalizado, como colorín, maletín, libreta, colchoneta, barandilla, anilla, cuadernillo, cuartilla, falsilla, gradilla, gravilla, pasillo... Es llamativa la presencia del sustantivo coloquial fosforito, ${ }^{109}$ que hace referencia a unos rotuladores de punta gruesa

\footnotetext{
${ }^{108}$ En contraposición a este criterio, véase, sin embargo, Samper Padilla (1998: 324).

109 Término modificado por los colores verde y azul, cada uno de ellos empleado por un informante.
} 
que se utilizan para destacar algo, y que algunas empresas denominan rotulador fluorescente.

El paréntesis se ha utilizado siguiendo la norma general, como en bolí(grafo), tele(visión), (pluma) estilográfica, mate(máticas), tablón (de anuncios), etc.

Como en otros casos, nos encontramos con sustantivos modificados que forman grupos sintagmáticos a partir de términos como ácido (cítrico, clorhídrico, sulfúrico...), libro (de arte, de lectura, de texto, de pintar...), máquina (de bebidas, de café, de diapositivas, de escribir...), mesa (de alumno, de bar, de dibujo, de laboratorio...), papel (cuadriculado, de cebolla, de charol, de seda, de váter...), sala (de actos, de audiovisuales, de estudios, de teatro...), tubo (de ensayo, de luz, fluorescente...). Todos incluidos porque representan variantes semánticas diferenciadas.

Los extranjerismos son poco relevantes en este centro de interés. Solamente anotamos el galicismo dossier como tal; los otros, como casete, clip, cúter, fax... están ya registrados con esa forma en el DRAE y adaptados totalmente a la ortografía académica. Algo más numerosas son las marcas comerciales que aparecen en los listados, y que se consideran lexicalizadas en la mayoría de los estudios de disponibilidad aparecidos hasta la fecha: Kleenex*, Tipp-ex* (ya incluido incluso en el diccionario CLAVE, bajo la forma típex), Pilot*, Rotring*, DIN A4*, Paralex*, Plastidecor*.

Finalmente, los valencianismos tienen poca presencia en este campo semántico. Solo aparecen taula 'mesa', cadira 'silla', punxó 'punzón' y salfumant 'ácido clorhídrico', en cada caso en boca de un solo informante.

09. Calefacción, iluminación y medios para airear un recinto

Es este un centro que recibe denominaciones diferentes en las investigaciones de disponibilidad léxica. Así, los estudios de las provincias de Soria (Bartol, 2004), Cuenca (Hernández Muñoz, 2004), Asturias (Carcedo, 2001), Ávila, Salamanca y Zamora (Galloso, 2003a) lo designan como Calefacción e iluminación, tal como ya hicieran Gougenheim et al. $(1956,1964)$ en sus primeros trabajos. El léxico disponible de Valencia (Gómez Molina y Gómez Devís, 2004), por su parte, añade todo lo relativo al concepto de ‘ventilación' (Iluminación, calefacción y ventilación). Por último, son los trabajos de Canarias (Samper, 1998), Aragón (Arnal et al., 2004), Almería (Mateo, 1998), Cádiz (González Martínez, 2002) y Lérida (Serrano, 2014) los que enuncian este 
centro del mismo modo que nosotros, esto es, como Iluminación, calefacción y medios para airear un recinto. La razón principal es que el centro de interés hace referencia a las condiciones climáticas de las zonas estudiadas, y, por tanto, se presta a la recogida de léxico diferente, con asociaciones también potencialmente diferentes.

Sin embargo, frente al criterio de Samper (1998: 325) en Las Palmas de Gran Canaria, nosotros no dimos ninguna consigna antes de que los alumnos comenzasen a responder. De esta forma, nos encontramos en los listados de Castellón con una gran dispersión en las respuestas, que atienden tanto a los medios naturales (luna, estrella, sol, sombra, huracán, viento...) como a los artificiales (generador, aire acondicionado, ventilador...). También recogemos lexías que se refieren a prendas de vestir (abrigo, anorak, bufanda, cazadora, mantón de Manila...), incluida la ropa del hogar (manta, colcha, cubrecamas, alfombra...). Se mantienen, asimismo, todas aquellas referencias a partes de la casa: ventana, puerta, patio de luces, terraza, tragaluz, balcón, etc.

En relación con las categorías gramaticales, se trata de uno de los centros de interés donde más variedad encontramos. Y así, aparecen verbos (abrir, cerrar, soplar, abanicar, encender...), un gran número de adjetivos (caliente, acondicionado, central, climatizado, exterior, fresco, eléctrica, solar, corporal, eólica, nuclear...), además de los omnipresentes sustantivos (bombilla, lámpara, radiador, linterna, calefactor...). Los adjetivos fluorescente y halógeno aparecen modificando a diferentes sustantivos, como tubo, luz, barra, bombilla. De ahí la dificultad de utilizar paréntesis en este centro de interés. De hecho, solo lo incluimos en (lámpara de) araña. Los compuestos sintagmáticos se recogen con los siguientes núcleos: aire (7 empleos), bombilla (9), calefacción (17), estufa (13), foco (10), lámpara (13), luz (18), tubo (12).

Se mantiene la diferencia de género cuando alude a realidades diferentes (farolfarola). De igual modo, se conservan los diminutivos siguientes: farolillo, lamparilla, hornillo, cerilla, rejilla, ventanilla. También se recoge en los listados definitivos cada una de las derivaciones de algunos lexemas como faro, farol, farola, farolillo; ventana, ventanal, ventanilla, ventanuco, registrados como entradas independientes en el DRAE.

Como extranjerismos adaptados encontramos gasoil, láser y recogidos en cursiva en el propio diccionario flash, spray. Algunas marcas comerciales que aparecen también lo hacen adaptadas: camping gas o butano. Hay que señalar también una mención a la marca Ambipur* como ambientador. 
Los valencianismos de este centro de interés, para cuyo análisis detallado remitimos al lector a un apartado posterior (véase 5.4) son cuatro: llar hogar, chimenea', foguera 'hoguera', palmito 'abanico' y plafó 'plafón'.

Por último, la dificultad de lematizar en una sola entrada los diferentes tiempos verbales que aparecen modificados con sintagmas distintos nos ha llevado a mantener todas las formas disponibles. Así, abrir ventana, ventana abierta, abriendo ventana. Asimismo, con levantar encontramos ventana levantada, levantar persiana. Lo mismo sucede con el verbo cerrar: cerrar ventana, cerrando ventana, y con soplar: soplar, soplando, soplido, a soplos, a soplidos.

10. La ciudad

Como era de esperar, este centro de interés aporta gran cantidad de vocabulario al léxico disponible, sobre todo debido a las asociaciones que muchas veces comporta el propio concepto de 'ciudad'. Así, para muchos individuos -especialmente en las zonas rurales- la urbe se asocia a vocablos negativos como contaminación, basura, ruido, humo, asesinato, robo, agobio, hacinamiento, droga, asco, delincuencia, desorden, embotellamiento, gamberrismo, pelea, rapto, suciedad, violencia... o incluso a los ambientes marginales o delictivos relacionados con miseria, navaja, pobreza, putrefacción, etc.

Lo anterior hace que, si en otros centros de interés apenas hemos encontrado sustantivos abstractos, en esta ocasión proliferen a través de vocablos como aglomeración, alegría, ansiedad, cansancio, desilusión, estrés, libertad, independencia, peligro, rebeldía, soledad... aparte de otros ya mencionados en el párrafo anterior.

Desde un punto de vista categorial, anotamos asimismo la presencia de adjetivos en este centro de interés: azul, residencial, industrial, público, doméstico, marginal...

Los compuestos sintagmáticos más numerosos se forman esta vez alrededor de los núcleos tienda (19), centro (15), casa (9), señal (8), campo, estación y zona con 6 empleos cada uno y, por último, sala (5).

Se mantiene la distinción de género en bolsa-bolso, puerta-puerto, y los diminutivos lexicalizados callejuela, mercadillo, cuartelillo (así se conoce popularmente el cuartel de la Guardia Civil), barandilla y bordillo, puesto que se asocian a significados diferentes. 
El proceso de singularización ha sido frecuente, ya que muchos lexemas aparecen en plural en las encuestas, quizá como un reflejo inconsciente por parte de los encuestados de la abundancia de referentes nombrados en las ciudades de hoy. De esa forma encontramos personas, ancianos, asesinos, bebés, estudiantes, hombres, mendigos, niños... todos ellos referidos a personas, y que se lematizan en singular. De la misma manera, llama la atención que muchos vocablos referidos a vehículos (taxi, coche, camión, motocicleta), comercios (tienda de ropa, mercería, panadería), locales de ocio (cine, teatro, restaurante), etc. aparezcan en plural, pese a lo cual han sido lematizados íntegramente en singular. No obstante, se mantiene el morfema de pluralidad en aquellos vocablos que lo necesitan para designar realidades específicas; así, grandes almacenes, como equivalente de grandes superficies comerciales, correos, famosos (como sustantivo que alude a personajes famosos y no como adjetivo), obras (con la acepción de edificios en construcción), recreativos (entendido como salas de juegos recreativos), urgencias (el diccionario académico indica que en plural debe entenderse como la 'sección de los hospitales en que se atiende a los enfermos y heridos graves que necesitan cuidados médicos inmediatos'), etc.

A esta nómina hay que añadir la de aquellos modificadores de núcleos que siempre aparecen en plural, como sala de exposiciones, taller de coches, cobrador de impuestos..., así como las palabras compuestas del tipo rascacielos, antidisturbios y ultramarinos, el último de los cuales se usa como sustantivo con el significado de tienda de ultramarinos 'comestibles de ultramar'.

Siguiendo los criterios básicos de lematización, escribimos con mayúscula los nombres de edificios oficiales (Conselleria, Hacienda...), organismos (Cruz Roja), ciudades (Alicante, Ámsterdam...), monumentos (Fadrí, Cibeles...), centros comerciales (Amica*, Alcampo*, PRYCA*, Corte Inglés*, Mc Donalds*, Telepizza*) ${ }^{110}$ marcados con asterisco porque al mismo tiempo también son marcas comerciales. Otras marcas que se mantienen son Vespa* y Vespino*, este último prácticamente lexicalizado. Asimismo, hallamos las siguientes siglas: ONCE, FP, N340, P.G.O.U.

El paréntesis sigue la norma habitual en (auto)bús, bici(cleta), cabina (telefónica), zoo(lógico). Y en cuanto a los extranjerismos, consignamos graffiti, sex shop, boutique, parking, bungalow, frankfurt, pub, camping, jockey, etc.

\footnotetext{
${ }^{110}$ No incluyen estos términos referidos a nombres propios, lugares de las ciudades y comercios con marcas Carcedo (2001), Arnal et al. (2004), López Meirama (2008), Martínez Olmos (2008), Serrano (2014).
} 
También tienen cabida en este campo diversas voces coloquiales o jergales como madero, chulo, pintada, yanqui, camello. Y valencianismos, como Conselleria 'Consejería', carrer 'calle', claveguera 'alcantarilla, cloaca', Fadrí 'torre de la catedral de Castellón', y tauleta 'kiosco'. Comentario aparte requiere el concepto Todo a cien, comercio en el que todo se vendía a 100 pesetas en la fecha en que se realizaron las encuestas. Es curioso que hoy, transcurridos ya algunos años desde la entrada en vigor del euro, esos comercios siguen denominándose de la misma manera (aunque, lamentablemente, ya no a aquellos precios tan modestos).

\section{El campo}

Junto con el anterior, se trata de uno de los centros de interés que más cantidad de léxico ha proporcionado, gracias de nuevo a las asociaciones secundarias que provoca el propio concepto. Así, algunos estudiantes lo han asimilado preferentemente a la noción de 'pueblo pequeño de pocos habitantes y rústico', mientras que otros lo han relacionado básicamente con la naturaleza. De este modo, encontramos nuevamente palabras que se hallan en otros centros de interés y que allí designaban, por ejemplo (el caso del campo 5. Comidas y bebidas) los nombres de comidas y alimentos que se cultivan en las huertas (calabaza, albaricoque, alcachofa...). Asimismo, se incluyen aquí animales que vuelven a mencionarse en el siguiente centro de interés (12. Medios de transporte), como burro, caballo, yegua, mula.

Por lo demás, esta asociación con el concepto más amplio de 'naturaleza' hace que los estudiantes se refieran a animales que se suelen encontrar en el 'campo' (abeja, ardilla, avispa, conejo, cordero...), si bien, otras veces, parecen despistarse a la hora de nombrar referentes como león, canguro, búfalo, koala, etc., que, evidentemente, no son habituales en su entorno. Pese a ello, hemos decidido mantenerlos en los listados porque, al fin y al cabo, son también animales del 'campo' -bien que de otras latitudes-, entendiendo este como lo define el DRAE, esto es, como un 'terreno extenso fuera de poblado', con independencia de dónde se encuentre.

Con el mismo criterio de conservar toda la información posible dentro de unos límites coherentes, se dejan también las acciones propias de la agricultura que aparecen en el centro número 13. Trabajos del campo y del jardín: sembrar, arar, abonar.

Al igual que en el campo anterior, encontramos también aquí una notable variedad categorial en el léxico. Por ejemplo, abundan los sustantivos abstractos que 
informan de las percepciones subjetivas que provoca en los informantes el valor "campo", casi siempre de carácter positivo, frente a los abstractos de carácter negativo que, como vimos, aparecían en la ciudad: belleza, paz, serenidad, tranquilidad, relajación, alegría, quietud, aire puro, sosiego... Con todo, y aunque en menor medida, aparecen también algunos sustantivos modalizados negativamente: suciedad, aburrimiento, monotonía...

Junto a los sustantivos, hallamos también algunos verbos: cultivar, fumigar, labrar, arar, podar, etc., relativos todos ellos a tareas agrícolas. Al lado de estos se encuentran otros que designan realidades más placenteras, como caminar y acampar. Asimismo se utilizan adjetivos sustantivados, como cítrico, tranquilo, trienal, bienal.

Por otro lado, es curiosa la cantidad de nombres de viviendas que aparecen en este centro de interés. Y no solamente las características de esta zona geográfica barraca, alquería, masía, maset, caseta- sino también otras de difusión más general. El caso de: albergue, refugio, mansión, chabola, pazo, choza, granja, ermita, villa, cabaña, chalet, torre, caserío, cortijo, entre otros. Como es lógico, entre los primeros cabe destacar la presencia de valencianismos, tales como maset 'casa de campo pequeña', que es un diminutivo de mas 'casa de campo', caseta, que en la región castellonense no equivale necesariamente a una 'casa pequeña que solo tiene el piso bajo', como nos dice el DRAE, sino que designa en general a una 'casa de campo', ya sea grande o pequeña; y barraca 'barraca o cabaña', incluida como catalanismo en el diccionario académico. Asimismo abundan los árboles característicos de la región mediterránea, no solo de la huerta (naranjo, limonero, almendro, olivo, higuera), sino también silvestres (pino, algarrobo, encina).

Como en los demás campos semánticos, se lematizan los vocablos mayoritariamente en masculino y singular. No obstante, se mantienen en plural alicates, guantes, tenazas, tijeras, vacaciones y el compuesto guardabosques. Y por lo que se refiere al género, se conserva el femenino en aquellas palabras que tienen un significado diferente al masculino; así en: huerto/huerta, charco/charca, fruto/fruta, cubo/cuba, seta/seto, caña/caño, paleta/paleto, etc. De la misma forma, se conservan aquellas variaciones morfológicas con significación diferente al vocablo del que proceden, en senda / sendero, lagarto / lagartija, águila / aguilucho, ciervo / cervatillo, furgón / furgoneta... Observamos activo el sufijo aumentativo -ón: avispa/avispón, azada/azadón, pulga/pulgón, calle/callejón, caja/cajón. Se mantienen los diminutivos carretilla, manzanilla, calabacín, rastrillo, puesto que poseen significados diferentes 
del sustantivo del que derivan. Incluso llegamos a obtener tres o cuatro derivados en algunas ocasiones: carro, carreta, carretón, carretilla; casa, caseta, caserón, caserío; gallo, gallina, gallinero. Los informantes interpretan la diferencia entre el árbol y su fruto mediante el género masculino y femenino respectivamente: naranjo/naranja, algarrobo/algarroba, almendro/almendra, castaño/castaña, cerezo/cereza, ciruelo/ciruela, olivo/oliva, manzano/manzana. Del mismo modo, conservamos el nombre de árbol y el conjunto de ellos a través de la derivación correspondiente: pino/pinar, árbol/arboleda, zarza/zarzal. Por último, nos hacemos eco del muy productivo sufijo -ero/a en dobletes como limón/limonero, melocotón/melocotonero, tomate/tomatera, prado/pradera, términos todos ellos, como es lógico, con diferente entrada en el diccionario académico.

Se utiliza la mayúscula en las siglas ICONA, en sustantivos propios (desierto de Las Palmas) ${ }^{111}$ y en el nombre de ciertas variedades de naranjas: Satsuma, Navelate, Oronul. Se hace uso del paréntesis en (árbol) frutal y en bici(cleta), siguiendo así el criterio general.

En relación con los valencianismos anotamos entre otros: marialluïsa 'hierbaluisa', maset 'casa de campo', espardenya 'alpargata', lligona 'ligona, especie de azada', matxina 'máquina para pulverizar o sulfatar', corbella 'hoz', teuladí 'gorrión', argelaga 'aliaga', garrofera 'algarrobo', carxofa 'alcachofa', fava 'haba', cullidor 'recogedor', perera'peral', etc. Hay que señalar que este centro, junto con el número 13.Trabajos del campo y del jardín y el 15. Juegos y distracciones, es el más productivo en lo que al léxico valenciano se refiere. Todas estas entradas serán comentadas más específicamente en el apartado correspondiente (véase 5.4).

Para finalizar, el hecho de que este centro de interés lleve tan asociado, como hemos visto, todo lo relacionado con el mundo de lo rural podría explicar la ausencia en él de extranjerismos. No obstante, encontramos camping, picnic, bar, relax, pub, etc.

12. Medios de transporte

Aparte de los nombres genéricos de las diferentes clases de transporte (coche, barco, avión, vehículo, turismo, automóvil) se señalan también los medios generales por

${ }^{111}$ El Desierto de Las Palmas es un paraje natural situado en las montañas que rodean a Castellón, y en el que existe un monasterio carmelita fundado a finales del siglo XVII. Recibe el nombre de desierto por tratarse de un lugar apenas poblado, y de Las Palmas, por la gran cantidad de plantas de este tipo que allí crecen. 
los que circulan dichos vehículos (mar, aire, tierra). Asimismo, observamos diferentes vocablos relacionados con ellos (cinturón de seguridad, volante, remo, ala, casco, freno, vela, asiento, rueda, maletero), y las vías específicas por las que transitan (autovía, autopista, calle, vía). Y, por supuesto, se registran también los distintos tipos de coche (ranchera, taxi, limusina, monovolumen), avión (reactor, jet, helicóptero, hidroavión, ultraligero), así como una notable variedad de embarcaciones, hasta un total de veintisiete diferentes, consecuencia, quizá, del influjo marinero en el que se desenvuelve la provincia castellonense. Así, encontramos carabela, catamarán, galera, goleta, chalupa, galeón, petrolero, fueraborda, góndola, canoa, yate, balsa, transatlántico, portaaviones, etc. Especial interés tiene el vocablo golondrina, que el DRAE, en su tercera acepción, define como 'en Barcelona y otros puertos, barca pequeña de motor para viajeros'. Esta embarcación se encuentra también en otros muchos puertos del Levante español, en los que sirve para realizar breves excursiones por la costa con los turistas como principales usuarios, como sucede en Peñíscola.

A diferencia de otras investigaciones sobre disponibilidad léxica (Samper Padilla, 1998: 327-328, Gómez Molina y Gómez Devís, 2004, Carcedo, 2001, entre otras) no hemos eliminado aquí las marcas de coches lematizados en mayúscula y asterisco: Mercedes*, Mitsubishi*, Renault*, Audi* y motos (Harley Davidson*), compañías de transportes (Iberia*), tipos de coches (Smart*). Asimismo, se mantienen los medios de transporte poco convencionales, como cohete, máquina del tiempo, nave espacial, tanque, ala delta, etc.

Aparecen en mayúscula las siglas AVE y RENFE y los nombres de los diferentes trenes: Talgo, Arco, Intercity, Euromed.

Unificamos, como en otros diccionarios léxicos disponibles, las variantes debidas a la presencia o ausencia de preposición, recogiendo la de más alto índice de disponibilidad: a caballo/caballo $\rightarrow$ caballo, camello/ en camello $\rightarrow$ camello, burro/en burro $\rightarrow$ burro, pero se mantiene la preposición en a pie, a dedo, a gatas, a pata coja ...

Se registran en los listados castellonenses verbos de movimiento. Las formas que aparecen con mayor frecuencia son los infinitivos y los gerundios, como ejemplifican los casos de nadar, nadando, andar, andando, correr, corriendo, siendo los segundos los que presentan un índice de disponibilidad mayor. Igualmente, se anotan adjetivos que hacen referencia a toda clase de vehículos: ranchera, todoterreno, descapotable, dirigible, ultraligero, bombardero, utilitario... usados comúnmente como sustantivos. 
Se consignan diferenciados los derivados furgoneta, barcaza, camioneta, avioneta, patinete, carreta, motocicleta, puesto que se refieren a realidades distintas de furgón, barco, camión, avión, patín, carro, moto, respectivamente Asimismo se mantienen por igual motivo los derivados colchoneta y carretilla. Se registran también moto y motocicleta, cuya diferencia reside en la mayor o menor cilindrada de los motores. La mayoría de los alumnos ha nombrado los dos términos en sus listados. ${ }^{112}$

La moción de género mantiene separados barco/barca, motor/ motora, y se conserva el plural en los compuestos montacargas, rompehielos, quitanieves y en las locuciones adverbiales a gatas y a saltos. El paréntesis se utiliza siguiendo la norma común en bici(cleta), (auto)bús, (coche) deportivo, tren de (cercanías), (barco) velero.

Los extranjerismos son abundantes y han sido registrados en cursiva: mountainbike, jeep, jet, kart, hovercraft, quad, ferry, skate, roulotte, jumbo, Boeing...

Señalemos, por último, que se trata del único centro de interés donde no localizamos valencianismos, quizá, en parte, porque muchos vocablos coinciden formalmente en ambas lenguas (carro, carreta, moto, tren, etc.).

13. Trabajos del campo y del jardín

El rasgo más importante de este centro de interés es la aparición de verbos en infinitivo, que pueden ir solos (arar, sembrar, injertar, podar, recolectar, cavar, segar, fumigar, cultivar...) o acompañados de complementos que especifican su significado (alimentar animales, arrancar hierbajos, abonar el huerto, coger naranjas, cortar árboles...). Se anotan, además, sustantivos referentes a las diferentes actividades agrícolas y ganaderas relacionadas con este campo léxico (siega, poda, siembra, recolección, cosecha, apicultura, agricultura, cultivo...), las herramientas y útiles (pico, pala, azada, rastrillo, arado, hoz, manguera...), los animales empleados en estas labores (caballo, buey), las tareas habituales en las granjas (cuidar gallinas, patos, cerdos, conejos...), así como los oficios vinculados a estas (agricultor, ganadero, segador, agrónomo, apicultor, regador, granjero, campesino, capataz, recolector, biólogo...).

Debido a la gran variedad de sintagmas nominales que complementan a un mismo verbo, ha sido imposible utilizar el paréntesis. Con todo, hemos unificado en una

\footnotetext{
${ }^{112}$ Samper Padilla(1998), Carcedo (2001) y Galloso (2001) también mantienen separas ambas entradas. Sin embargo, Arnal et al. (2004) las reducen a una sola.
} 
sola entrada algunos casos: arrancar las hierbas, arrancar hierbas, arrancar la hierba $\rightarrow$ arrancar hierbas. Normalmente se han aunado en un complemento en plural sin artículo (coger aceitunas, abonar plantas, cortar ramas, cuidar caballos, echar fertilizantes, hacer caballones, matar malas hierbas...).

Se ha mantenido el morfema del femenino cuando hay un cambio significativo entre ambos géneros: podador/podadora, fumigador/fumigadora, apisonadora (no aparece el masculino), entendiendo los femeninos como las máquinas que realizan el trabajo de podar, fumigar y apisonar, respectivamente. También el femenino se respeta por distinciones referenciales en huerto/huerta, jardinero/jardinera, entendida esta última como 'mueble o instalación fija para poner plantas de adorno directamente en la tierra o en macetas' según la definición del DRAE, y en lechero/lechera ('vasija en la que se transporta o se sirve la leche').

Se registran en mayúscula, como ya hemos visto en el centro número 11. El campo, las variedades de naranjas: Navel, China, Clementina, Navelate.

Únicamente observamos dos anglicismos en este centro de interés. Se trata de cowboy y kiwis registrados por un solo informante respectivamente. No es un centro propicio para los extranjerismos ${ }^{113}$ y menos para las siglas, que tampoco aparecen en los listados. Sin embargo, es uno de los campos léxicos en los que encontramos más valencianismos, hasta un total de 28 lexemas. Sirvan a modo de ejemplo los de empeltar 'injertar' , arruixar 'regar', espigolar 'espigar', collir 'coger', ensulfatar 'sulfatar', ramader 'ganadero', masover 'el que está a cargo de un mas', etc. En este sentido, las cifras del léxico marcado dialectalmente en Castellón superan levemente a las equivalentes halladas por Goméz Molina y Gómez Devis (2004) en Valencia que solo recogen 22 , pero se quedan claramente a la zaga de la comunidad aragonesa estudiada por Arnal et al. (2004), quienes documentan nada menos que cuarenta y cuatro dialectalismos en este campo. ${ }^{114}$

En relación con el contacto de lenguas, hay que destacar también la aparición en los listados de dos calcos sintagmáticos que representan sendas traducciones literales de

\footnotetext{
${ }^{113}$ Por lo general, en aquellos centros en los que se registran más extranjerismos, se localizan menos dialectalismos, y viceversa. Los campos más propicios al léxico foráneo son aquellos que siguen las modas de las culturas más cosmopolitas (véase ropa, comida o transporte). Sin embargo los centros de interés relacionados con la agricultura o el ocio son ricos en denominaciones asociadas a instrumentos, animales o actividades características de la cultura propia de la zona estudiada. De ahí las transferencias lingüísticas en las regiones donde los hablantes conviven con dos lenguas, como sucede en Castellón.

${ }^{114}$ Otros estudios de interés dialectal son los de Borrego y Fernández Juncal (2002), Arnal et al. (2004, 2008 a y b), Casanova (2010), Serrano (2006), entre otros.
} 
las correspondientes expresiones valencianas: hacer almendras, hacer sazón. Estas son calco de fer ametlles y fer saó, respectivamente, y sirven para aludir a la recolección de las almendras en el primer caso, y al hecho de que la tierra tiene el grado suficiente de humedad para la siembra, en el otro.

\section{Los animales}

Como en la mayoría de investigaciones sobre disponibilidad léxica, son pocas las asociaciones secundarias que se producen en este campo semántico. Se trata, pues, de un centro de interés caracterizado por la concreción léxica. En la lematización de los vocablos se han seguido los criterios de edición generales. No obstante, cabe hacer algunas matizaciones.

Aparte de los nombres referentes a animales concretos, se han mantenido aquellos vocablos genéricos que clasifican estos en tipos, especies, órdenes o subespecies: anfibio, arácnido, crustáceo, felino, herbívoro, mamífero, molusco, marsupial, ovíparo, vivíparo, pájaro, pez. Asimismo, incluimos los vocablos hombre (anotado por 22 informantes), mujer (4 informantes) y ser humano (5 informantes). También registramos palabras que hacen referencia al cuidado de los animales, y que aluden al animal de compañía por excelencia, el perro, como, por ejemplo, collar, correa, pienso, vacuna de la rabia, cuidar, limpiar, llevar a pasear, dar comida, bebedor. Igualmente, aparece el nombre de animales mitológicos o ya desparecidos, y pertenecientes, por tanto, al mundo de la fantasía, como dinosaurio, mamut, mastodonte, unicornio. No eliminamos tampoco las etapas de la vida de los animales: cachorro, larva, ninfa. Y conservamos algunos adjetivos, como doméstico, manso, salvaje.

Con referencia a la neutralización de las variantes flexivas, seguimos el criterio general: los vocablos se lematizan en masculino y singular. Una excepción la representan aquellos sustantivos heterónimos que tienen lexemas distintos para el macho y la hembra, en cuyo caso se mantienen los dos: caballo/yegua, toro/vaca; y aquellos lexemas en los que se utiliza un sufijo específico para el femenino, caso de gallo/gallina.

Como es lógico, se mantiene, asimismo, la diferencia flexiva cuando da lugar a significados distintos, es decir, se trata de animales diferentes: caballo/caballa, caracol/caracola. Se conservan también aquellos vocablos cuyo sufijo especifica un 
animal diferente: lagarto/lagartija, langosta/langostino, pulga/pulgón, rata/ratón salmón/salmonete. Al mismo tiempo se recogen los diminutivos lexicalizados: frailecillo, pescadilla, mariquita, colorín, chochín, mosquito... Y registramos también las unidades léxicas que se refieren a la cría de un animal determinado: cochinillo, aguilucho, osezno, lobezno, cabrito, ballenato, pichón, lechón, chivo, choto... Unificamos caballo/caballito de mar en caballito de mar, ${ }^{115}$ estrella/estrellita de mar en estrella de mar, conejo/conejillo de Indias en conejillo de Indias. En otro sentido, sobresale la presencia de la palabra turcazo, muy habitual entre los cazadores de aves. Pese a que no la encontramos en el diccionario académico, sí la hemos hallado en el diccionario del aragonés-español de Rafael Andolz (1984) con el significado de 'paloma torcaz'. ${ }^{116}$ El lexema caparra, aunque sea considerado como un dialectalismo aragonés (Arnal et al., 2004: 44), también está recogido en nuestros listados, con un significado similar al de garrapata y con mayor índice de disponibilidad que este último. El morfema de pluralidad solo aparece en los compuestos ciempiés, saltamontes y quebrantahuesos. El paréntesis lo utilizamos, siguiendo los criterios generales, en gato (siamés) porque únicamente en este caso o bien aparece el sintagma completo o bien el adjetivo siamés solamente. En todos los demás, siempre se da o bien el sintagma completo o bien una parte de él. Así ocurre con las diferentes razas de perros o gatos: persa, caniche, chihuahua, dálmata, dóberman, mastín, pequinés, todos con entrada en el DRAE. No sucede lo mismo con husky siberiano y pastor alemán, aunque sí aparecen en el CLAVE.

Pocos extranjerismos encontramos en este campo semántico. Los términos hámster y poni están adaptados ya en nuestra lengua y el DRAE los recoge de esa forma. Por el contrario, sí constatamos algunos valencianismos, tales como: colom 'paloma', cadernera 'jilguero', egua 'yegua', granota 'rana', griva 'zorzal', oroneta 'golondrina', rabosa 'zorra', titot 'pavo', llissa 'liza, mújol', llobarro 'lobarro, róbalo', cullerot 'renacuajo', estornell 'estornino', escorpa 'escorpena, peje diablo, rescaza' $o$ vilero 'gorrión'.

\footnotetext{
${ }^{115}$ El diccionario de la Academia define en una de sus acepciones caballito de mar como 'caballo marino' o 'hipocampo'.

${ }^{116}$ Tanto en el DRAE como en el Diccionario del Uso del Español de María Moliner aparece la forma torcazo.
} 
El centro de interés número 15 es uno de los más problemáticos por la cantidad de entradas y la variedad de formas que ofrece. Como Hernández Muñoz (2004), Galloso (2001, 2003a) y Bartol (2004), en el estudio de Castellón hemos decidido mantener la mayor parte de los sintagmas complejos hallados en las encuestas, en contraposición al criterio de Mackey (1971: 46-51), Carcedo (2001: 50), Gómez Devís (2004: 65-66), Arnal et al. (2004: 44-45) y Samper Padilla (1998: 330-331), quienes han reducido al sustantivo la mayoría de las locuciones formadas por verbo + complemento nominal. Hemos procedido así para evitar una pérdida tan destacada de información como la que revelan las encuestas, pero también por el hecho de que, en no pocas ocasiones, se aprecian diferencias de significado relevantes entre las correspondientes lexías. Por ejemplo, con el sustantivo música hemos recogido hasta cinco variantes: música, oír música, componer música, escuchar música y tocar música. Y parece evidente que con la reducción al mero sustantivo música no se puede percibir la variedad de actividades que giran en torno a esta, pues no es lo mismo 'escuchar música' que 'tocar un instrumento'. De este modo, el número de entradas aumenta notablemente y ello habrá que tenerlo en cuenta en las futuras comparaciones entre las diferentes sintopías.

En realidad, es difícil la reducción a un solo término en estos casos. Si acaso, la tarea se simplifica cuando contamos con solo dos variantes, como ocurre, por ejemplo, en el estudio de Bartol (2004: 33) sobre el léxico disponible de Soria con los términos contar cuentos y cuentos. Sin embargo, en los listados de Castellón encontramos también, junto a estas opciones, las de leer cuentos y escribir cuentos. De esta manera, con un único término (cuentos) no se puede recoger toda la información semántica relevante: contar, leer (que, además, puede ser en voz alta, para otra persona o para uno mismo), escribir. Con la palabra fútbol vemos hasta ocho variantes: fútbol, jugar a fútbol, ir a un partido de fútbol, ir al fútbol, fútbol americano, fútbol sala, ver fútbol, $P C$ fútbol. Es imposible con una única entrada, fútbol, aunar todos los sentidos que los informantes ofrecen en sus respuestas. Uno de los estudiantes, por ejemplo, anota en dos entradas diferentes ver fútbol y fútbol, luego no los considera iguales significativamente.

Desde el punto de vista formal, este es el centro de interés en el que más plurales encontramos, no solo los de las palabras compuestas (tragaperras, trabalenguas, 
comecocos), sino también los de todos aquellos nombres de juegos que se han lexicalizado en plural (dados, dardos, damas, chinos...), puesto que el singular tiene otro sentido. Y también se registran en plural aquellos juegos que son resultado de la elipsis de "jugar (a)": cocinitas, muñecas, médicos, polis y cacos, canicas...

El diminutivo se anota en aquellos juegos que siempre se nombran de esa manera: gallinita ciega, cinquillo, caballitos, futbito... Mantenemos, no obstante, diferenciado el doblete máquinas y maquinitas/ maquinetas (este último con el sufijo característico del valenciano) por entender que se trata de referentes distintos (véase en el mismo sentido, Hernández Muñoz 2004: 46). El primero se refiere a las grandes máquinas que se encuentran en las salas de juego o en los recreativos, y con el segundo se designa a los pequeños juguetes electrónicos.

Categorialmente, en este campo encontramos numerosas formas verbales en infinitivo para nombrar las acciones correspondientes: bailar, pasear, leer, luchar, etc. aunque observamos también otras lexicalizadas, como veo veo, adivina adivinanza, burro va, corre corre que te pillo...

El paréntesis se utiliza siguiendo el criterio general, reseñado ya en diferentes ocasiones en estas páginas. Así, en los listados aparecerán (juego de la) oca, (máquina) tragaperras, bici(cleta), tele(visión), zoo(lógico); por su parte, la mayúscula se emplea para aludir a marcas publicitarias y a una serie de juegos de ámbito nacional: Bonoloto, Primitiva, Loto 6/49. Y por lo que a las siglas y acrónimos se refiere, encontramos también algunos en este campo: $O N C E, T V, C D, P C$.

Por lo demás, estamos ante el centro de interés en el que más marcas publicitarias se registran (junto con el 05. Alimentos y bebidas), debido, sobre todo, al hecho de que muchos juegos se reconocen a partir de la marca comercial con que fueron creados. La mayoría de las marcas comerciales se refieren a juegos de mesa muy populares, algunos prácticamente lexicalizados (Trivial*, Monopoly*) y otros a punto de serlo (Hotel $^{*}$, con 18 menciones, Hundir la flota* y Pictionary* con 13 apariciones, Scattergories* con 38 empleos; asimismo, 24 informantes nombran Tabú*. Incluso algunos programas de televisión se han comercializado después como juegos de mesa, lo que tiene también su reflejo en las encuestas. Este es el caso, por ejemplo, de $E l$ Tiempo es oro*, Pasa palabra*, Un dos tres*, Cifras y letras*.

Igualmente destacado es el número de extranjerismos, en su inmensa mayoría procedentes del inglés, y que hacen referencia a deportes o actividades al aire libre: surfing, windsurf, cross, fitness, jockey, handball, karting, mountain bike, paddle... A 
estos hay que añadir otras denominaciones muy corrientes, como rock and roll, walkie talkie, zapping, así como nombres de juegos que se suman a la nómina reseñada más arriba: backgamon, black jack, etc.

En cuanto a los valencianismos, también en este campo se dan abundantemente los nombres de juegos en valenciano, unos, por ser característicos de esta región, y designados categóricamente en esa lengua (sambori, ${ }^{117}$ butifarra ${ }^{118} \ldots$... y otros, porque alternan con las denominaciones en castellano en las encuestas: truc/truque, pedra paper tisora/piedra papel tijera, cinquet/cinquillo, baldufa/trompa o peonza...Para más detalles sobre estos dobletes español/valenciano, véase más adelante 5.4.

\section{Profesiones y oficios}

Es esta un área semántica en la que la concreción es evidente y no provoca apenas asociaciones ajenas al estímulo verbal. No obstante, además de los nombres relativos a oficios y profesiones propiamente dichos, hemos incluido en este apartado una serie de vocablos que también podrían reconocerse como tales, bien es verdad que en una interpretación poco ajustada a los cánones de lo políticamente correcto. Este es el caso, por ejemplo, de términos como camello, famoso, chapero, ladrón, chulo, terrorista, usurero..., ya que todos ellos designan actividades -delictivas en muchos casos- que requieren de una cierta profesionalización. Del mismo modo aceptamos todo tipo de cargos que aparecen en las encuestas: presidente, ministro, diputado, director... Igualmente incluimos, como se hace en los estudios sobre Cuenca (Hernández Muñoz, 2004), Valencia (Gómez Molina y Gómez Devís, 2004) o Lleida (Serrano, 2014), los nombres de las carreras universitarias y estudios necesarios para el desempeño de un trabajo; estas aparecen en los listados en mayúscula: Empresariales, Económicas, Derecho, Teleco(comunicaciones)...

Siguiendo el criterio general panhispánico, todos los nombres se marcan en masculino y singular, pero, como hemos visto a lo largo de las páginas anteriores, las excepciones no escasean precisamente. Enumeramos a continuación, de forma esquemática, las que más conciernen a este centro de interés:

\footnotetext{
117 Comúnmente se conoce con el nombre de rayuela, juego que precisa de habilidad en el lanzamiento de la tella 'piedra plana', equilibrio en el desplazamiento y tacto en el golpeo con el pie. Se nombra de diversas formas según la región española o, incluso, el país.

${ }^{118}$ La butifarra es un juego de naipes de bazas. Se juega con 48 cartas y 4 personas por parejas. Es parecido al tute.
} 
1. Cuando la diferenciación genérica contiene rasgos semánticos distintos: modisto/modista, asistente/asistenta. Incluimos también monja y monje, puesto que en el DRAE posee también entradas diferentes.

2. Cuando en las encuestas solamente se registran en femenino, dejamos este: ama de casa, ama de llaves, prostituta, costurera, azafata, lavandera, chacha, niñera, comadrona. De hecho, en alguna de ellas, el DRAE solo registra la correspondiente entrada femenina.

3. Cuando el femenino se forma con sufijos distintos: actor/actriz.

En cuanto al número, se registran en plural botones, relaciones públicas, o el sintagma sus labores, porque así están ya lexicalizados en la comunidad lingüística. Además, las palabras compuestas: cazarrecompensas, guardabosques, guardacostas, guardaespaldas, y los modificadores de núcleos en sintagmas como agente de seguros, buscador de tesoros, conductor de camiones, funcionario de prisiones... Asimismo, el morfema de plural se encuentra en los nombres de ciertas carreras universitarias: Empresariales, Económicas...

Volvemos a encontrarnos aquí con creaciones sintagmáticas diferentes que dependen de un mismo núcleo: agente (comercial, de bolsa, de seguridad...), conductor (de autobús, de avión, taxi...), director (comercial, de banco, de empresa, de escuela...), jugador (de ajedrez, baloncesto, béisbol, golf...), profesor (de autoescuela, de universidad, infantil...), y el término de ingeniero, con nada menos que diecisiete especificaciones (aeronáutico, agrícola, de caminos, físico...). En cuanto a las siglas, recogemos de forma aislada $A T S, A D E M$, y otras que acompañan a profesor o agente, como $E G B, C I A, F B I, K G B, T V$. Por su parte, el paréntesis sigue el criterio general en otorrino(laringólogo) y teleco(comunicaciones).

Como en otros centros de interés, se anotan los extranjerismos y se marcan como en las lenguas de origen. Así ocurre con galicismos como esthéticien, maître; anglicismos como baby-sitter, disc-jockey, broker, showman; o italianismos como paparazzi. Otros extranjerismos, sin embargo, se señalan siguiendo la norma académica, que los ha adaptado ya a las reglas ortográficas del español: barman, chef, linier, mánager, entre otros.

Otras formaciones creadas por los informantes a partir del verbo (pulimentador, troquelador, reponedor) no aparecen, sin embargo, en el DRAE, aunque algunas sí lo hacen en el CLAVE: segurata (equivalente a vigilante), pizzero ('persona que hace 
pizzas, o las reparte'), gogó, ${ }^{119}$ gigoló. Una derivación interesante desde el punto de vista etimológico es yesaire (esp. 'yesero'), donde el contacto de lenguas juega con la raíz castellana yeso, por un lado, y el sufijo catalán -aire ${ }^{120}$ por otro. El estudio de Arnal et al. (2004) sobre Aragón lo trata como un dialectalismo, con un uso, por tanto, limitado, pero en Castellón es tan corriente la palabra que los trabajadores del ramo se denominan a sí mismos con este nombre: yesaires.

En último lugar, encontramos valencianismos en los términos pescater 'pescadero', llaurador 'labrador', ramader 'ganadero', los cuales serán comentados detalladamente en un apartado posterior (véase 5.4).

\section{Los colores}

Se trata de un campo escasamente problemático por su gran concreción semántica, tanto para la lematización como para la recogida de los vocablos. Hemos utilizado el paréntesis siguiendo el criterio general en (azul) marino, (azul) cielo, (azul) celeste, (azul) pitufo, (color) carne, (color) hueso, (gris) marengo, para indicar que unos informantes han empleado el sintagma completo y otros únicamente una parte del mismo, la que colocamos fuera del paréntesis.

Además de los nombres de los diferentes colores, se han recogido diversos adjetivos independientes que pueden referirse a cualquiera de los colores. Así, apagado, artificial, brillante, cálido, chillón, claro, metálico, llamativo, eléctrico, irisado, oscuro... Asimismo los alumnos se han referido a todo tipo de objetos y seres al pensar en esos colores. Y así, por ejemplo, para referirse al color del cabello encontramos: castaño, rubio, caoba, pelirrojo... o para aludir a los metales mencionan: oro, plata, cobre, bronce, óxido.

Por lo demás, se recogen todas las variantes con sufijo derivativo en las que se añaden más matices y gamas cromáticas: blanquecino, amarillento, anaranjado, cobrizo, metalizado, rosado, violáceo, verdoso... Encontramos un aumentativo lexicalizado: azulón, y en una sola ocasión aparece el morfema de plural: burdeos.

\footnotetext{
${ }^{119}$ En el DRAE tan solo se registra la locución adverbial a gogó 'sin limite'.

120 Como señala la Gramática del Institut d'Estudis Catalans en su versión electrónica, www.iect.net/instituio/seccions/filologica/gramatica (consultada el 18 de mayo de 2013), la terminación aire actúa como sufijo adjetivador (rondinaire 'gruñón'), pero también nominalizador (drapaire 'trapero'), como en este caso.
} 
Son abundantes las modificaciones que observamos en los colores básicos: verde, por ejemplo, llega a tener hasta cuarenta matizaciones, unas más habituales y a las que estamos acostumbrados (verde azulado, verde mar, verde militar, verde pastel...), pero otras no tanto (verde guerra, verde sapo...) Una cantidad inferior de especificaciones, aunque también numerosas en términos absolutos, las hallamos en azul (28), rojo (26), amarillo (13), rosa (12), gris (8). ${ }^{121}$

Hemos optado por mantener en entradas diferentes fosforescente, fosforito (con mayor índice de disponibilidad) y fosfi, como complementos a colores básicos (amarillo fosforito, amarillo fosforescente, amarillo fosfi, verde fosforito o verde fosforescente, rosa fosforito, azul fosforito, naranja fosforito...). También aparecen de forma independiente los vocablos fosforito y fosforescente. Asimismo recogemos el término fluorescente aplicado a los colores verde y amarillo utilizados por tres informantes cada uno, y a rosa, azul y violeta con un empleo en cada caso.

Por último, solo en dos ocasiones encontramos el nombre de colores escrito en valenciano: carabassa 'calabaza', y enrogit 'enrojecido', aunque este término no se encuentra en el DCVB.

\subsection{Procesamiento de los datos}

Una vez que todos los datos han sido lematizados, según los criterios mencionados en el apartado anterior, se han introducido y procesado a través del programa Dispolex (www.dispolex.com), creado por el equipo de disponibilidad léxica de la Universidad de Salamanca, que coordinan José Antonio Bartol y Natividad Hernández. ${ }^{122}$ En esta página encontramos un banco de datos donde se introducen todos los vocablos y datos de las variables utilizadas para su posterior cálculo estadístico. El programa informático tiene su origen en Lexidisp (versión 1.02), creado por J. E. Moreno Fernández y A. J. García de las Heras con el asesoramiento lingüístico de F.

121 Como ejemplos podríamos destacar: azul cielo, azul eléctrico, azul verdoso, azul fuerte, azul metálico...; rojo chillón, rojo Ferrari, rojo pasión, rojo oscuro, rojo láser...; amarillo limón, amarillo oro, amarillo fosforito, amarillo verdoso, amarillo plátano...; rosa pálido, rosa fosforito, rosa pastel, rosa pasión, rosa claro, rosa chicle...; gris perla, gris claro, gris azulado, gris metálico, gris marengo... ${ }^{122}$ Bartol y Hernández (2007) explican pormenorizadamente el funcionamiento de Dispolex. 
Moreno García y P. Benítez, para el Instituto Cervantes, la ALFAL y la Universidad de Alcalá de Henares, como ya hemos apuntado. ${ }^{123}$

La fórmula matemática para calcular la disponibilidad léxica seguida en dicho programa informático es la propuesta por López Chávez y Strassburguer (1987, 1991:92-94), a su vez el resultado de la modificación de fórmulas anteriores. ${ }^{124}$ Lo más importante en ella es que se ponderan dos factores relevantes: la frecuencia de uso de cada vocablo y el orden de mención en los listados. Esa fórmula genera el llamado índice o grado de disponibilidad, puesto que "los índices son medios para ordenar unidades léxicas mediante fórmulas matemáticas" (Butrón, 1987: 33). Y así en los listados aparecerán las palabras más disponibles que serán, al mismo tiempo, las mencionadas más veces en los primeros lugares.

Para volcar las respuestas de los informantes se confeccionan unos archivos en formato de texto (.txt), precedidos de una cadena de dígitos que contiene la información sociológica de los informantes, el número que ocupa cada uno de ellos en las listas y el centro de interés en cuestión. ${ }^{125}$ Por lo que a la información sociológica se refiere, los informantes son identificados con cinco números en el orden siguiente:

- $\quad$ Sexo: $1 \rightarrow$ masculino; $2 \rightarrow$ femenino

- $\quad$ Tipo de centro: $1 \rightarrow$ público; $2 \rightarrow$ privado

- $\quad$ Ubicación del centro: $1 \rightarrow$ urbano; $2 \rightarrow$ rural

- $\quad$ Lengua materna: $1 \rightarrow$ valenciano; $2 \rightarrow$ castellano; $3 \rightarrow$ ambas

- Nivel educativo: $1 \rightarrow$ estudios primarios; $2 \rightarrow$ estudios elementales;

$3 \rightarrow$ estudios secundarios; $4 \rightarrow$ estudios superiores.

Los tres dígitos siguientes representan el número del informante y las dos últimas cifras dan cuenta del número correspondiente a cada centro de interés. Cada uno de los apartados (información sociológica, identificación numérica del informante y centro de interés) debe ir convenientemente separado del resto por un espacio. A continuación aparecen los vocablos entre comas. Sirva a modo de ejemplo el siguiente listado, correspondiente al centro de interés 5. Alimentos y bebidas:

\footnotetext{
${ }^{123}$ Más información en F. Moreno Fernández, J. E. Moreno Fernández y García de las Heras (1995).

${ }^{124}$ Véase información detallada de las sucesivas fórmulas y su reproducción en López Morales (1999b: 13-19) y Carcedo (2001: 52-53). Asimismo, Gloria Butrón (1987: 33-55) analiza las diferentes fórmulas matemáticas para averiguar el índice de disponibilidad. Para detalles adicionales, véase Butrón (1991).

${ }^{125}$ Véase Moreno Fernández et al. (1995).
} 
1112300105 vodka, whisky, Coca cola*, cerveza, Fanta*, absenta, pacharán, pan, jamón, queso, bacon, espagueti, agua, poleo, calimocho, vino blanco, vino tinto, cerveza, sangría, chupito, sopa, pescado, arroz, canelón, moscatel, ginebra, carne, pollo, tomate, salchichón, anís

Se trata de las respuestas proporcionadas por el primero de los informantes de la encuesta: un alumno de sexo masculino, que estudia en un centro público y urbano, cuya lengua materna es el valenciano y con un nivel educativo familiar correspondiente a estudios secundarios.

El programa estadístico, aparte de indicar el ya mencionado índice de disponibilidad, ofrece además la frecuencia relativa, es decir, el número de veces que aparece una palabra con respecto al total, el índice de aparición, esto es, el porcentaje de informantes que mencionan la palabra en cuestión y la frecuencia acumulada, esto es, la suma de las frecuencias relativas. De igual modo, proporciona la totalidad de palabras y vocablos por centros de interés, así como el índice de cohesión (Echeverría, 1991) es decir, si en un área léxica determinada las respuestas de los informantes son coincidentes o no. Se calcula dividiendo el promedio de respuestas de cada individuo entre el número de vocablos ${ }^{126}$ obtenidos en el centro de interés en cuestión. Cuando el grado de coincidencias es mayor, el valor del índice de cohesión se aproximará al 1 y el campo léxico se considera más cerrado o compacto, mientras que si las respuestas son más variadas, el valor se aproximará a 0 y el centro será de carácter más abierto o difuso. Por otro lado, la versatilidad del programa informático permite ver el léxico disponible organizado no solo por el índice de disponibilidad de los vocablos, sino también por orden alfabético o por la frecuencia de aparición. Y además de proporcionar valioso material complementario en forma de tablas y gráficos sobre los factores sociológicos analizados, entre las virtudes del programa está también la de facilitar enormemente las comparaciones entre los distintos estudios del proyecto panhispánico. De todo ello daremos cuenta en los capítulos siguientes, a partir de los resultados que aparecerán plasmados en los correspondientes diccionarios.

Finalmente, cabe señalar que, para la validación de las diferencias entre los diferentes grupos dentro de cada factor social (sexo, tipo de centro, etc.) hemos acudido a dos pruebas de estadística inferencial. Por un lado, la denominada prueba T-student para muestras emparejadas nos permite confirmar si, a la luz de la muestra disponible,

\footnotetext{
${ }^{126}$ Recordamos que vocablo se entiende como cada respuesta diferente, sea una palabra o un sintagma.
} 
tales diferencias invalidan la hipótesis nula o, por el contrario, no se puede descartar el azar en su configuración. Asimismo, en los casos en que contamos con más de dos grupos sociales (lengua materna o nivel sociocultural) hemos acudido también a una prueba ANOVA de un factor con el fin de determinar si las diferencias globales obtenidas en el conjunto de la variable son o no significativas (en estos casos, los cotejos entre los diferentes subgrupos se realizan con la mencionada prueba T). En ambos casos, consideramos que la hipótesis nula queda invalidada cuando alcanzamos un valor p. inferior a 0.05 , cifra habitual en las investigaciones sobre ciencias humanas y sociales. Para todo ello, nos servimos del programa estadístico SPSS v.23, el cual nos proporciona otras medidas, como porcentajes, medias, etc. 

5

ANÁLISIS DE LOS RESULTADOS 



\section{ANÁLISIS DE LOS RESULTADOS}

En el presente apartado abordamos el análisis cuantitativo de los resultados obtenidos en la muestra de los preuniversitarios castellonenses. Como es preceptivo en este tipo de investigaciones, proporcionamos, en primer lugar, los índices generales de las encuestas, que dan cuenta de la productividad y riqueza léxica global de los informantes ${ }^{127}$ y, en segundo lugar, cómo las variables lingüísticas (centros de interés) y sociales afectan a la obtención de lexías. Además comprobaremos si esos datos son, efectivamente, significativos a la luz de la muestra disponible mediante el empleo de las pruebas estadísticas reseñadas en el apartado anterior.

Al mismo tiempo, cotejaremos nuestros datos con los de otras sintopías. En este sentido, tiene especial interés para nuestro objeto de estudio el contraste entre los índices de disponibilidad de Castellón y los de otras zonas bilingües. En concreto, compararemos nuestros resultados con los obtenidos en los estudios de poblaciones donde existe un bilingüismo social oficialmente reconocido, como Valencia (Gómez Molina y Gómez Devís, 2004), Alicante (Martínez Olmos, 2008), Lérida (Serrano, 2014), Galicia (López Meirama, 2008) y Bilbao (Etxebarria, 1996). ${ }^{128}$ En todo caso, hay que advertir que la comparación entre diferentes zonas geográficas es siempre difícil y ha de tomarse de forma relativa porque puede verse afectada, en primer lugar, por la extensión de las muestras y, en segundo lugar, por el proceso de edición de los materiales que, a pesar de seguir las pautas generales del proyecto panhispánico de la disponibilidad léxica, responde también a criterios particulares de los investigadores.

\footnotetext{
${ }^{127}$ La productividad léxica se refiere al número de palabras que emite un individuo en cada centro de interés, mientras que la riqueza léxica alude al número de vocablos recogidos en cada área semántica. Este último índice no puede utilizarse para analizar aspectos individuales, puesto que ofrece datos del "comportamiento global de un grupo de informantes ante una misma área léxica" y fácilmente puede ser alterado por un informante atípico (Serrano, 2014:317). Véase al respecto, la distinción que realiza Hernández Muñoz (2004: 52-54) entre riqueza léxica y disponibilidad léxica.

${ }^{128}$ Para las razones de esta decisión, véase más adelante el apartado 5.1.4. En consecuencia, dejamos de lado regiones como Asturias, comunidad en cuyo Estatuto de Autonomía no se recoge el asturiano como lengua oficial, y la Comunidad Foral de Navarra, donde el vasco sí es lengua oficial, pero solo en aquellos territorios que se especifican (zona norte). El estudio que se ha llevado a cabo en esta región también tiene en cuenta los diferentes modelos de enseñanza que se ofrecen, de tal manera que se pueda conocer mejor la relación del euskera y el castellano como lenguas de uso (Saralegui y Tabernero, 2008). Por su parte, Areta Lara (2007) ha analizado los modelos lingǘsticos de enseñanza bilingüe, en concreto los modelos A y D. Serrano compara también sus datos con los de otras comunidades en la que puede hablarse de bilingüismo social, aunque no reconocido oficialmente (Melilla, Ceuta, Asturias y Navarra, aunque en este último caso, sí lo es en la zona norte). Otra zona de contacto de lenguas -español y portugués- ha sido estudiada recientemente por Prado, Galloso y Célio Conceição (2010).
} 
En el apartado 5.1 analizaremos el volumen de las palabras totales y por centros de interés; a continuación las cifras relativas a los vocablos o palabras diferentes, seguidas de las que conciernen a los promedios de palabras por informantes y a los índices de cohesión por áreas temáticas. Asimismo, analizaremos los datos de Castellón en comparación con los de las comunidades bilingües ya mencionadas. En último lugar, examinaremos las cifras por variables sociales, aquellas que se refieren al sexo, ubicación y tipo de centro, lengua materna de los estudiantes y nivel educativo de sus familias, y cuyos resultados se expondrán en la sección 5.2. Posteriormente, se estudiarán los anglicismos presentes en los listados castellonenses (5.3) así como los valencianismos (5.4).

\subsection{Datos globales}

\subsubsection{Palabras y vocablos}

\subsubsection{Datos globales}

Los datos que interesa conocer en primer lugar hacen referencia al número total de unidades léxicas registradas, que en la muestra castellonense alcanza la cifra de 121792 términos, que se reducen a 9215 vocablos, entendiendo estos como cada una de las palabras diferentes que aparecen en los diccionarios de léxico disponible. ${ }^{129}$ La tabla siguiente muestra, además, los promedios de palabras y palabras diferentes por informante. Como se puede comprobar, cada estudiante castellonense produce 344.04 palabras por término medio, y 26.03 vocablos de promedio.

\begin{tabular}{|l|c|c|c|c|}
\hline & Total palabras & Total vocablos & $\begin{array}{c}\text { Promedio de } \\
\text { palabras por } \\
\text { informante }\end{array}$ & $\begin{array}{c}\text { Promedio de } \\
\text { vocablos por } \\
\text { informante }\end{array}$ \\
\hline Castellón & 121792 & 9215 & 344.04 & 26.03 \\
\hline
\end{tabular}

Tabla 5.1.1. Números globales de la muestra y por informante

\footnotetext{
${ }^{129}$ Müller (1973: 230) diferenciaba ya entre los conceptos de palabra y vocablo. Según esta distinción, que adoptamos aquí, debe entenderse por palabra cada una de las respuestas dadas por los informantes y por vocablo cada una de las palabras diferentes, estén formadas por una unidad léxica o por lexías complejas (combinaciones de lexemas que sirven para designar determinados referentes; así, por ejemplo jersey de cuello alto). Martínez Olmos (2008) utiliza otra terminología, y habla de tipos léxicos diferentes (vocablos, types) y total de ocurrencias (palabras, tokens), términos utilizados también por Gómez Molina y Gómez Devís (2004).
} 


\subsubsection{Palabras por centro de interés}

En la tabla 5.1.2, presentamos la distribución de estas magnitudes en cada uno de los centros de interés analizados en la presente investigación. Así, la primera columna en la tabla indica el número de palabras producidas en cada área temática, mientras que la segunda refleja el porcentaje de representación alcanzado. Por su parte, la tercera columna da cuenta del rango que revela la posición de cada centro de interés con respecto a los demás en función del número de palabras emitidas. Así el rango 1 corresponde al área temática en que más palabras se han formulado, la de Los animales en nuestro caso, con 10051, seguida por Alimentos y bebidas (9411 palabras y rango 2) y Partes del cuerpo (9148 unidades léxicas y rango 3), y así sucesivamente.

\begin{tabular}{|l|c|c|c|}
\hline Centros de interés & $\begin{array}{c}\mathbf{N}^{\mathbf{0}} \text { total de } \\
\text { palabras }\end{array}$ & $\begin{array}{c}\text { Porcentaje de } \\
\text { representación }\end{array}$ & Rango \\
\hline 01. Partes del cuerpo & 9148 & 7.51 & 3 \\
\hline 02. La ropa & 8095 & 6.64 & 7 \\
\hline 03. Partes de la casa (sin muebles) & 5904 & 4.84 & 13 \\
\hline 04. Los muebles de la casa & 5142 & 4.22 & 15 \\
\hline 05. Alimentos y bebidas & 9411 & 7.72 & 2 \\
\hline 06. Objetos colocados en la mesa & 5277 & 4.33 & 14 \\
\hline 07. La cocina y sus utensilios & 6615 & 5.43 & 12 \\
\hline 08. La escuela: muebles y materiales & 8393 & 6.89 & 5 \\
\hline 09. Iluminación, calefacción... & 4677 & 3.84 & 16 \\
\hline 10. La ciudad & 8749 & 7.18 & 4 \\
\hline 11. El campo & 7472 & 6.13 & 8 \\
\hline 12. Medios de transporte & 6826 & 5.60 & 11 \\
\hline 13. Trabajos del campo y del jardín & 4003 & 3.28 & 17 \\
\hline 14. Los animales & 10051 & 8.25 & 1 \\
\hline 15. Juegos y distracciones & 6890 & 5.65 & 10 \\
\hline 16.Profesiones y oficios & 8107 & 6.65 & 6 \\
\hline 17. Los colores & 7032 & 5.77 & 9 \\
\hline TOTAL DE PALABRAS & 121792 & & \\
\hline
\end{tabular}

Tabla 5.1.2. Número de palabras y rango por centros de interés

Como se puede comprobar, hay una notable dispersión en la productividad léxica entre los informantes castellonenses, con diferencias que llegan a superar las 6000 palabras entre el centro de interés con el rango 1, Los animales (10051 palabras), y 
el que aparece en último lugar, el de los Trabajos del campo y del jardín (4003 lexemas).

En efecto, hay centros de interés muy ricos en cuanto a la producción léxica se refiere, como los enunciados al comienzo de este apartado, y áreas semánticas que, por el contrario, presentan una significativa menor productividad. Es el caso de los mencionados Trabajos del campo y del jardín, que ocupa el rango 17, seguido de cerca por Iluminación, calefacción y medios de airear un recinto con 4677 (rango16), Los muebles de la casa con 5142 (rango 15), Objetos colocados en la mesa para la comida con 5277 (rango 14) y Partes de la casa (sin muebles) con 5904 (rango13). En una zona intermedia se situarían los demás centros de interés, que oscilan entre las 6000 y las 8000 palabras.

Advertimos que la producción de unidades léxicas depende más de la composición interna de cada área nocional que de otros factores, o dicho de otra manera, la mayor o menor productividad léxica obedece fundamentalmente al ámbito de la realidad por la que se pregunta. En el gráfico siguiente apreciamos mejor qué estímulos verbales alcanzan mayor cantidad de palabras, aquellos que superan la media de 5000-6000 términos aproximadamente, y cuáles se sitúan por debajo.

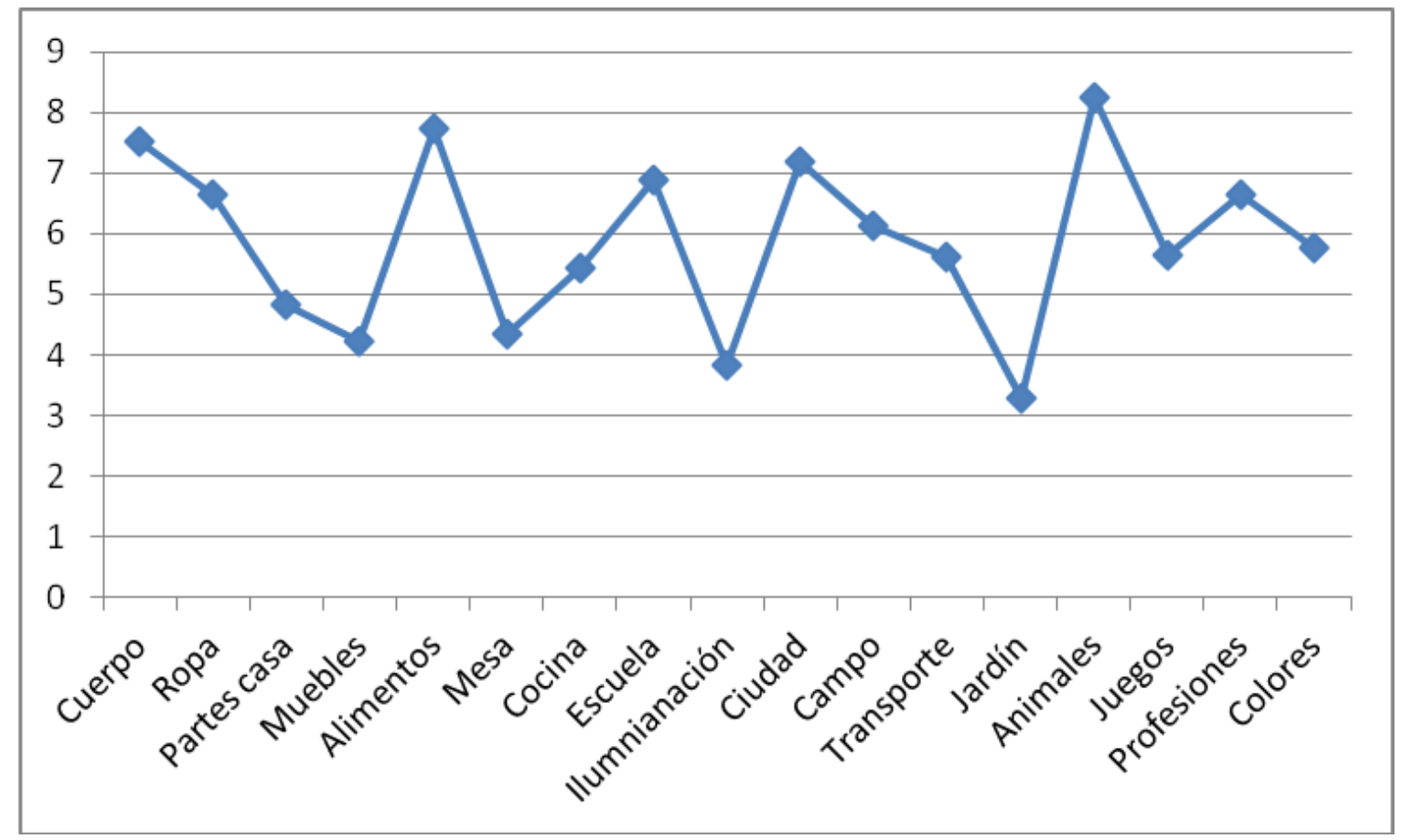

Gráfico 5.1.1. Palabras por centros de interés y su porcentaje 


\subsubsection{Vocablos por centros de interés}

Ahora bien, el perfil de algunos datos cambia sustancialmente si observamos ahora el número total de vocablos por centros de interés (tabla 5.1.3). Así, en esta ocasión el rango número uno pasa al área semántica de El campo, con 1060 vocablos (antes descendía hasta el puesto octavo), y a continuación en orden descendente encontramos La ciudad (949) (anteriormente, el cuarto), Juegos y distracciones (908) (previamente, el décimo), Oficios y Profesiones (732) (anteriormente, el sexto) y Trabajos del campo y el jardín (704) (el último, en el cómputo anterior por palabras). Con todo, hay que observar que en algunos de estos centros léxicos numerosos vocablos han sido expresados por un solo informante, lo que puede distorsionar los resultados.

Asimismo, es revelador que la última posición de la lista la ocupe esta vez el área léxica de las Partes del cuerpo (271 vocablos), que anteriormente presentaba uno de los rangos más elevados (tercero) en productividad léxica. A esta le siguen, en orden ascendente, Los muebles de la casa (rango 16), Partes de la casa (rango 15) y La ropa (rango14) con 303, 307 y 312 vocablos respectivamente. Por otro lado, encontramos una zona intermedia entre los Objetos colocados en la mesa para la comida con 317 (rango 13) y La escuela: muebles y materiales con 623 vocablos (rango 6), en donde se sitúa el resto de centros de interés.

\begin{tabular}{|l|c|c|c|}
\hline Centros de interés & $\begin{array}{c}\mathbf{N}^{\mathbf{o}} \text { total de } \\
\text { vocablos }\end{array}$ & $\begin{array}{c}\text { Porcentaje de } \\
\text { representación }\end{array}$ & Rango \\
\hline 01. Cuerpo & 271 & 2.94 & 17 \\
\hline 02. Ropa & 312 & 3.38 & 14 \\
\hline 03. Partes de la casa & 307 & 3.33 & 15 \\
\hline 04. Muebles & 303 & 3.28 & 16 \\
\hline 05. Alimentos & 607 & 6.58 & 7 \\
\hline 06. Mesa & 317 & 3.44 & 13 \\
\hline 07. Cocina & 502 & 5.44 & 8 \\
\hline 08. Escuela & 623 & 6.76 & 6 \\
\hline 09. Iluminación & 479 & 5.19 & 9 \\
\hline 10. La ciudad & 949 & 10.29 & 2 \\
\hline 11. El campo & 1060 & 11.50 & 1 \\
\hline 12. Transporte & 344 & 3.73 & 12 \\
\hline 13. Jardín & 704 & 7.63 & 5 \\
\hline 14. Animales & 447 & 4.85 & 10 \\
\hline 15. Juegos & 908 & 9.85 & 3 \\
\hline 16. Profesiones & 732 & 7.94 & 4 \\
\hline 17. Colores & 350 & 3.79 & 11 \\
\hline TOTAL DE VOCABLOS & 9215 & & \\
\hline
\end{tabular}

Tabla 5.1.3. Número de vocablos por centros de interés 
Con el objeto de visualizar mejor los resultados, presentamos a continuación el gráfico 5.1.2, en el que se aprecia la representación relativa de cada estímulo verbal en el conjunto de la muestra léxica. Un simple examen nos permite observar qué centros de interés poseen mayor riqueza léxica y cuáles son menos productivos.

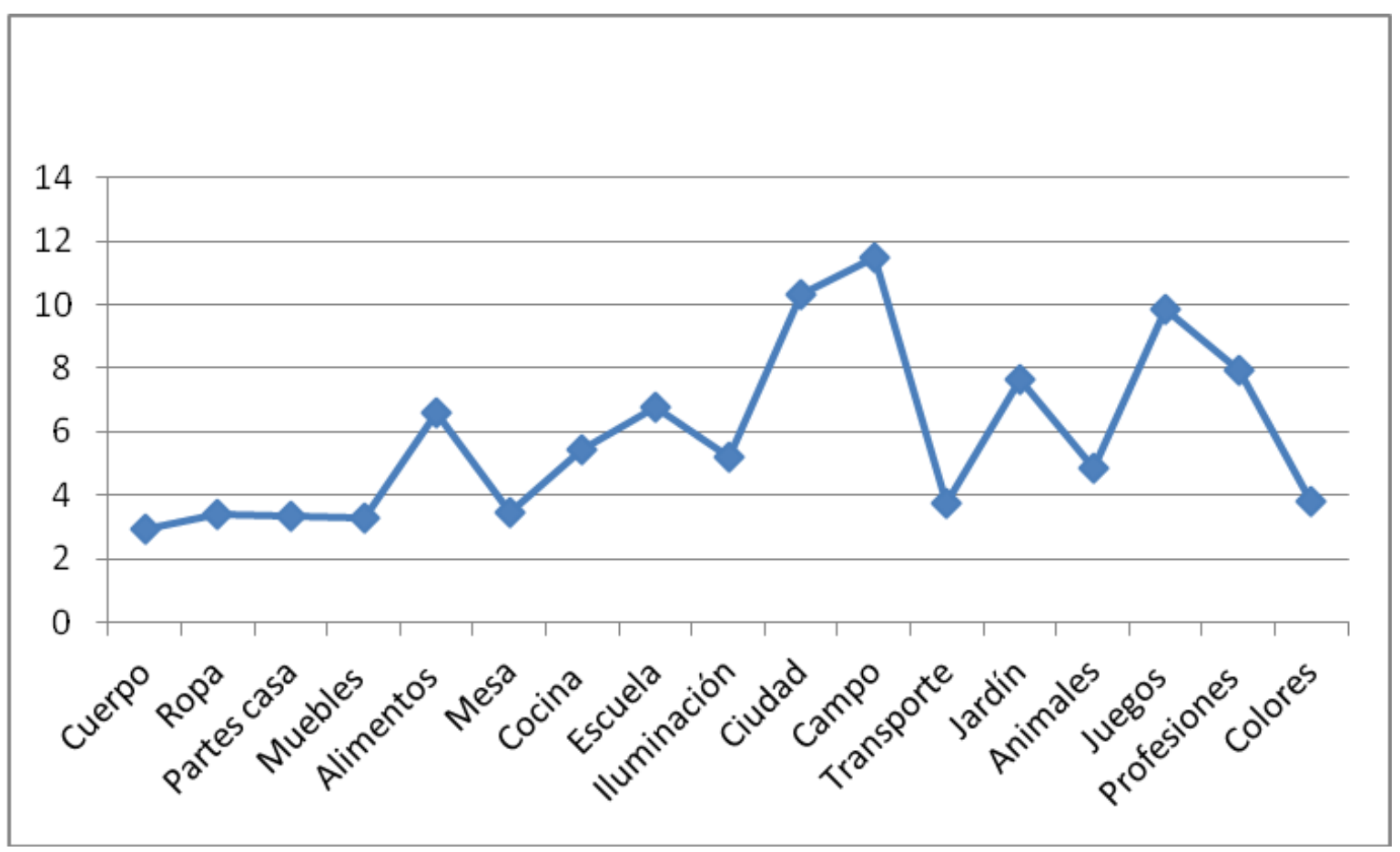

Gráfico 5.1.2. Porcentaje de representación de cada centro de interés

En definitiva, en esta sección hemos comprobado las diferencias entre la producción de palabras y la de vocablos. Así, el centro de interés con el mayor número de palabras, el de los Animales, pasa al décimo lugar en cuanto al volumen de vocablos se refiere. Por el contrario, la relación de trabajos del Campo diferentes es la más variada en la muestra castellonense, pero ocupa una posición intermedia en el listado de productividad léxica. Por lo demás, no coincide ningún centro de interés en las posiciones de ambas tablas, aunque un par de estos ocupen posiciones cercanas. Es el caso de los Muebles, que del décimo quinto lugar pasa a la décimo sexta posición, o las Partes de la casa, que del décimo tercero pasa al décimo quinto.

La siguiente figura nos permite ilustrar de forma gráfica esa diferencia entre las dos magnitudes de la disponibilidad analizadas, la productividad y la riqueza léxica entre los estudiantes castellonenses. 


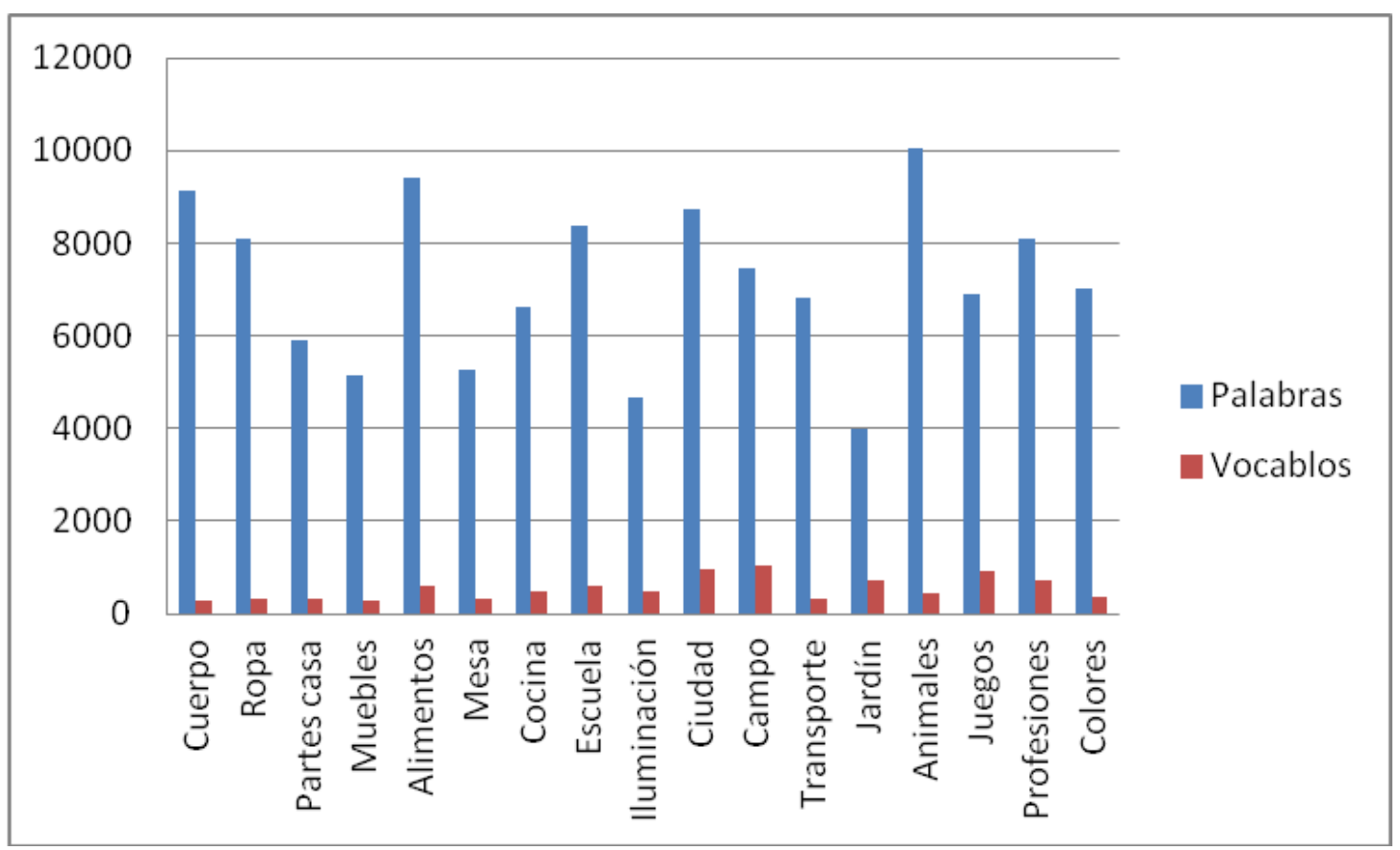

Gráfico 5.1.3. Palabras y vocablos por centros de interés

\subsubsection{Palabras por informante}

Uno de los datos más eficaces en los análisis estadísticos es el promedio de respuestas por informante (Bartol 2001: 223), puesto que es una cifra que no se ve afectada por la presencia de sujetos atípicos o por el tamaño de la muestra. Se calcula dividiendo el total de palabras de cada uno de los centros de interés por el número de informantes. Es muy útil para medir la productividad léxica de un campo semántico y, al mismo tiempo, es un parámetro que nos permite el cotejo con otras comunidades de habla. En la tabla 5.1.4 aparecen los valores correspondientes a la muestra castellonense: 


\begin{tabular}{|l|c|c|c|}
\hline Centros de interés & $\begin{array}{c}\mathbf{N}^{\mathbf{0}} \text { total de } \\
\text { palabras }\end{array}$ & $\begin{array}{c}\text { Palabras por } \\
\text { informante }\end{array}$ & Rango \\
\hline 01. Partes del cuerpo & 9148 & 25.84 & 3 \\
\hline 02. La ropa & 8095 & 22.87 & 7 \\
\hline 03. Partes de la casa & 5904 & 16.68 & 13 \\
\hline 04. Los muebles & 5142 & 14.53 & 15 \\
\hline 05. Alimentos & 9411 & 26.58 & 2 \\
\hline 06. Mesa & 5277 & 14.91 & 14 \\
\hline 07. La cocina & 6615 & 18.69 & 12 \\
\hline 08. La escuela & 8393 & 23.71 & 5 \\
\hline 09. Iluminación & 4677 & 13.21 & 16 \\
\hline 10. La ciudad & 8749 & 24.71 & 4 \\
\hline 11. El campo & 7472 & 21.11 & 8 \\
\hline 12. Transporte & 6826 & 19.28 & 11 \\
\hline 13. Jardín & 4003 & 11.31 & 17 \\
\hline 14. Animales & 10051 & 28.39 & 1 \\
\hline 15. Juegos & 6890 & 19.46 & 10 \\
\hline 16. Profesiones & 8107 & 22.90 & 6 \\
\hline 17. Colores & 7032 & 19.86 & 9 \\
\hline PROMEDIO GLOBAL & & 20.237 & \\
\hline
\end{tabular}

Tabla 5.1.4. Número de palabras por informante en los centros de interés analizados

El promedio de los estudiantes castellonenses es de unas 20 palabras por informante. Se acercan a la treintena en el campo Animales (28.39), seguido en orden descendente por Alimentos (26.58), Partes del Cuerpo (25.84), Ciudad (24.71) y Escuela (23.71). En el extremo opuesto se encuentran algunas áreas léxicas con un número de palabras significativamente menor, como Jardín (11.31), Iluminación (13.21), Muebles (14.53), Mesa (14.91) o Partes casa (16.68). En algunos casos, estas cifras tan bajas quizá haya que ponerlas en relación con el hecho de tratarse de realidades un tanto alejadas de los intereses de los alumnos, como sucede con las Tareas del campo y del jardín, al tiempo que en otros, como sucede con los Muebles, una vez que los estudiantes han enunciado el mobiliario más común que tienen en sus casas, parecen desentenderse de otras posibilidades adicionales. ${ }^{130}$ Como contrapartida, no podemos olvidar la influencia del sistema educativo en la adquisición y, por tanto, extensión, de unidades léxicas en ciertas áreas semánticas estrechamente vinculadas al currículo escolar, como ocurre con las Partes del cuerpo o los Animales.

Todo ello queda bien visualizado en el gráfico siguiente:

\footnotetext{
${ }^{130}$ Se ha podido comprobar que en muchos cuestionarios estos campos solo contenían entre seis y diez respuestas, y, en algunos casos, incluso menos.
} 


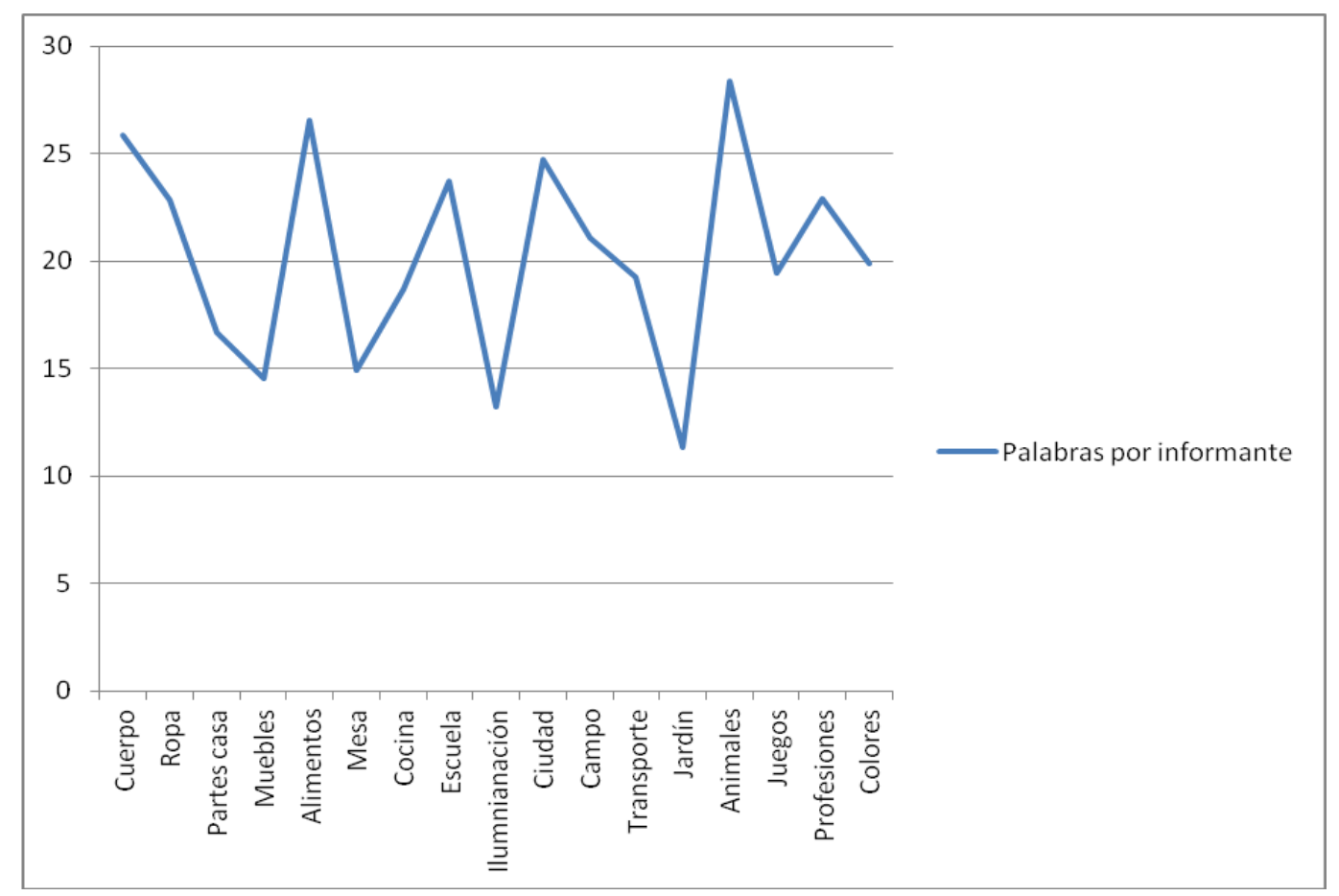

Gráfico 5.1.4. Palabras por informantes y centro de interés

\subsubsection{Densidad léxica e índice de cohesión}

En los trabajos sobre disponibilidad suelen manejarse los factores de la densidad y la cohesión para medir el grado de coincidencia en las respuestas de los estudiantes en un determinado centro de interés. El primero de ellos se obtiene dividiendo el total de palabras de un centro de interés entre el número de vocablos, pero este valor ofrece un obstáculo, como nos recuerda Hernández Muñoz (2004: 57): “ya que carece de límites referenciales que faciliten la comparación y la valoración estadística de los datos", puesto que se ve muy influenciado por el número de informantes.

Así pues, la mayoría de las investigaciones de disponibilidad trabajan preferentemente con el segundo de los índices, ${ }^{131}$ ya que no se encuentra tan mediatizado por el número de informantes. ${ }^{132} \mathrm{El}$ índice de cohesión se halla dividiendo el promedio de respuestas por individuo en cada centro de interés entre el número de

\footnotetext{
${ }^{131}$ Este índice ha sido desarrollado por Echeverría et alii (1987).

132 Tanto la densidad como el índice de cohesión están condicionados no solo por el número (lógicamente, el número de vocablos tiende a ascender si aumenta la muestra) y calidad de los informantes (se incluyen aquí los considerados como 'atípicos', poco representativos de la comunidad de habla), sino también por las decisiones tomadas por los investigadores a la hora de editar las repuestas de los estudiantes (Bartol Hernández, 2001: 222-223).
} 
vocablos de ese mismo centro. Con ello se obtiene un resultado que oscila entre el 0 y el 1. Este dato nos indica el carácter de los centros, es decir, qué áreas léxicas son cerradas o compactas cuando la cifra se acerca más al 1, o sea, cuando todos los informantes han ofrecido las mismas respuestas; o qué centros son abiertos o dispersos, si la cifra se aleja del 1 y se aproxima al 0, lo que refleja un menor índice de cohesión, esto es, que las respuestas son más variadas y no coincidentes porque presentan mayor número de asociaciones secundarias entre sí.

\begin{tabular}{|l|c|c|c|c|}
\hline \multicolumn{1}{|c|}{ Centros de interés } & $\begin{array}{c}\text { Índice de } \\
\text { cohesión }\end{array}$ & $\begin{array}{c}\text { Rango } \\
\text { cohesión }\end{array}$ & Densidad & $\begin{array}{c}\text { Rango } \\
\text { densidad }\end{array}$ \\
\hline 01. Partes del cuerpo & 0.0953 & 1 & 33.75 & 1 \\
\hline 02. La ropa & 0.0733 & 2 & 25.94 & 2 \\
\hline 03. Partes de la casa & 0.0543 & 6 & 19.23 & 6 \\
\hline 04. Muebles & 0.0479 & 7 & 16.97 & 7 \\
\hline 05. Alimentos & 0.0437 & 9 & 15.50 & 9 \\
\hline 06. Mesa & 0.0470 & 8 & 16.64 & 8 \\
\hline 07. La cocina & 0.0372 & 11 & 13.17 & 11 \\
\hline 08.La escuela & 0.0380 & 10 & 13.47 & 10 \\
\hline 09. Iluminación & 0.0275 & 13 & 9.76 & 13 \\
\hline 10. La ciudad & 0.0260 & 14 & 9.21 & 14 \\
\hline 11. El campo & 0.0199 & 16 & 7.04 & 16 \\
\hline 12. Transporte & 0.0560 & 5 & 19.84 & 5 \\
\hline 13. Jardín & 0.0160 & 17 & 5.88 & 17 \\
\hline 14. Los animales & 0.0635 & 3 & 22.48 & 3 \\
\hline 15. Juegos & 0.0214 & 15 & 7.58 & 15 \\
\hline 16.Profesiones & 0.0312 & 12 & 11.07 & 12 \\
\hline 17. Los colores & 0.0567 & 4 & 20.09 & 4 \\
\hline TOTAL & 0.0021 & & 13.21 & \\
\hline
\end{tabular}

Tabla 5.1.5. Índice de cohesión y densidad por centros de interés y rangos

En la tabla 5.1.5 se aprecia la total coincidencia entre los rangos que ocupan los centros de interés según los dos parámetros cuantitativos considerados en la comunidad de habla castellonense, ya que, en el fondo, se trata de indicadores muy parecidos, que informan sobre el grado de coincidencia o dispersión en el seno de los centros de interés. Con todo, en nuestro estudio, y al igual que ocurre en la mayoría de investigaciones sobre disponibilidad léxica, nos fijaremos preferentemente en el índice de cohesión, ya que, como recuerda Hernández Muñoz (2006: 311), posee "un poder explicativo" mayor, al ofrecer "muchos de los fenómenos adyacentes a la pura enumeración de términos" 
Las áreas semánticas que ofrecen un nivel de cohesión más elevado, es decir, aquellas que presentan un mayor número de respuestas coincidentes, son, por este orden: Partes del cuerpo (0.0953), Ropa (0.0733), Animales (0.0635), que se encuentran entre los rangos 1 al 3 respectivamente. En una zona intermedia, cercana al 0.05, se hallan los campos léxicos Colores (0.0567), Transporte (0.0560), Partes de la casa (0.0543). Finalmente, en los últimos lugares, aparecen algunas áreas semánticas que presentan un carácter más abierto y difuso. Es el caso de Jardín (0.0160), Campo (0.0199), o Juegos (0.0214). Percibimos mejor ese carácter abierto o cerrado de las áreas semánticas en el gráfico 5.1.5

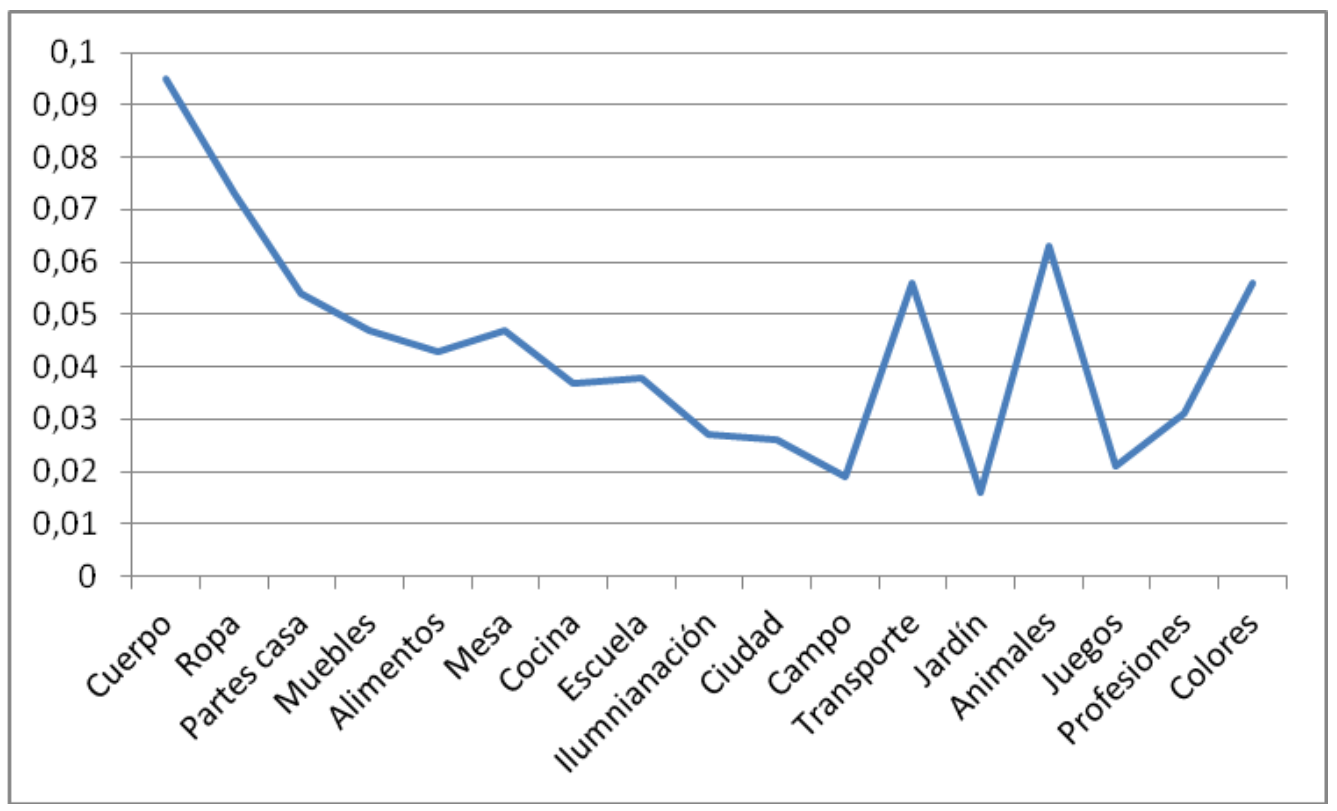

Gráfico 5.1.5. Índice de cohesión por centros de interés.

Como se puede comprobar, existe una relación proporcionalmente inversa entre el número de palabras diferentes y el índice de cohesión. Como hemos visto, cuánto más alto es el número de vocablos menor es el índice de cohesión; ${ }^{133}$ así, el centro $E l$ campo, con 1060 palabras diferentes, obtiene un índice de cohesión de apenas 0.0199. Por el contrario, aquellas áreas temáticas con menor número de palabras diferentes alcanzan un índice de cohesión mayor, como ocurre con Cuerpo, que dispone de tan solo 271 vocablos, pero cosecha el índice de cohesión más alto (0.0953) entre los estudiantes castellonenses.

\footnotetext{
${ }^{133}$ Véase al respecto Hernández Muñoz (2004:62).
} 


\subsubsection{Los datos de Castellón en comparación con otras áreas bilingües}

Un punto en común en todos los trabajos de disponibilidad léxica es tratar de observar el comportamiento léxico de los estudiantes preuniversitarios de las distintas zonas geográficas de habla hispana. A través de los cotejos correspondientes se perciben las tendencias de los alumnos en la producción del léxico y su riqueza en los diferentes centros de interés.

Con todo, en las comparaciones conviene ser cautelosos, ya que algunas diferencias estadísticas pueden provenir no solo de la amplitud de las muestras, sino también de algunos cambios en la metodología de las investigaciones, como las diferentes denominaciones con que se presentan los centros de interés o la posterior lematización de las respuestas. De ahí que, a la hora de realizar los contrastes oportunos, se haya impuesto la comparación de los promedios por informante, y aun así, las conclusiones siempre serán aproximativas.

Castellón, al igual que Valencia (Gómez Molina y Gómez Devís, 2004) y Alicante (Martínez Olmos, 2008), corresponde a una zona bilingüe en la que el castellano convive con el valenciano desde hace siglos. Por ello, nos interesa especialmente cotejar el comportamiento léxico de los informantes en estas provincias $^{134} \mathrm{y}$, de paso, comparar sus índices con los obtenidos en otros estudios sobre regiones bilingües, como los de Lérida (Serrano, 2014), Galicia (López Meirama, 2008) y el País Vasco, en concreto Bilbao (Etxebarria, 1996). ${ }^{135}$

En primer lugar, hacemos referencia al diferente número de encuestados, lo que afecta directamente al volumen de palabras totales y al número de vocablos de las investigaciones.

\footnotetext{
${ }^{134}$ Véase un primer acercamiento a los datos de las provincias de la Comunidad Valenciana en Casanova (2006).

${ }^{135}$ Para otras comparaciones entre diferentes áreas españolas e hispánicas en general, véase Samper et alii (2003: 57-60), quienes tienen en cuenta Puerto Rico, República Dominicana, Madrid, Gran Canaria, Almería, Cádiz, Córdoba, Bilbao, Ávila, Salamanca, Zamora y Asturias. En el contexto estrictamente español, Samper Padilla y Samper Hernández (2006:31), Hernández Muñoz (2006:314) y Arnal et alii (2004: 51) comparan los datos de Huelva, Málaga, Jaén, Ceuta, Soria, Aragón, Castilla-La Mancha, Lérida y Valencia. Por su parte, Serrano (2014:368), a las ya mencionadas, incorpora Melilla, Navarra, Alicante, Galicia, Castellón y Lérida. Finalmente, Fernández Juncal (2013:51-55) añade los resultados de Castilla-La Mancha, Granada, Segovia, Burgos y Cantabria.
} 


\begin{tabular}{|c|c|c|c|c|c|c|}
\hline Centros de interés & $\mathbf{C S}$ & Val. & Alic. & Lérida & Galic. $^{136}$ & Bilbao \\
\hline Número informantes & 354 & 465 & 460 & 240 & $800^{137}$ & 245 \\
\hline Número de palabras & 121792 & 160015 & 141336 & 73038 & 308081 & 72891 \\
\hline Número de vocablos & 9215 & 7643 & 9462 & 6824 & 20507 & 7432 \\
\hline Palabras por informante & 344 & 344 & 307 & 304 & 385 & 297 \\
\hline Vocablos por informante & 26.03 & 16.43 & 20.56 & 28.43 & 25.63 & 30.33 \\
\hline Promedio de pal. por C.I. & 7164 & 9412 & 8833 & 4296 & 17115 & 4287 \\
\hline Promedio de voc. por C.I. & 542 & 449 & 591 & 401 & 1139 & 437 \\
\hline
\end{tabular}

Tabla 5.1.6. Cifras globales de las diferentes sintopías comparadas

Si nos fijamos en el número de palabras por informante que aparece en la tabla anterior, comprobamos que las cifras son bastante aproximadas: prácticamente todas las comunidades superan las 300 palabras, y a poca distancia se queda Bilbao (297). Más disparidad hay, sin embargo, en lo que al número de vocablos por informante se refiere, con Bilbao superando la treintena (30.33), seguido a corta distancia por Lérida (28.43) y Castellón (26.03). En este parámetro, la excepción más llamativa se da en Valencia, con apenas un 16.43 de promedio.

Por otro lado, podemos comprobar cómo, en el seno de la Comunidad Valenciana, Castellón y Alicante se acercan entre sí, tanto en el número de vocablos como en el promedio de palabras y vocablos por centros de interés, alejándose así de Valencia (con todo, Castellón y Valencia coinciden en el promedio de palabras por informante). Por su parte, los estudiantes de Lérida y Bilbao muestran cierta convergencia en número de palabras y vocablos por informante, así como en los promedios por centros de interés.

Aunque no sean comparables las cifras totales de palabras y vocablos por las diferencias muestrales ya señaladas, sí podemos apreciar algunas tendencias de agrupación de los centros de interés en las diferentes sintopías. Por ejemplo, en la tabla 5.1.7, en la que se desglosa el número de vocablos por centros de interés en cada comunidad, advertimos que los primeros campos son ocupados por las mismas esferas léxicas: Campo, Ciudad, Profesiones y Juegos. Y, del mismo modo, aunque esta vez en el otro extremo, los centros menos productivos son en todas partes los siguientes: Partes de la casa, Muebles y Mesa. La posición de los demás campos semánticos fluctúa de una investigación a otra, aunque sin grandes alteraciones.

\footnotetext{
${ }^{136}$ El estudio de Galicia encuesta 18 centros de interés, los 16 básicos del proyecto panhispánico más los de Colores y El Mar, dato a tener en cuenta en las cifras globales, ya que, como es lógico, cuanto más centros de interés hay, mayor es el número de palabras

${ }^{137}$ Hay que recordar que el estudio de Galicia abarca las 4 provincias, de ahí que las cifras de encuestados sean tan abultadas.
} 


\begin{tabular}{|l|c|c|c|c|c|c|}
\hline $\begin{array}{l}\text { Centros de } \\
\text { interés }\end{array}$ & Castellón & Valencia & Alicante & Lérida & Galicia & $\begin{array}{c}\text { País } \\
\text { Vasco }\end{array}$ \\
\hline Cuerpo & 271 & 339 & 328 & 386 & 1083 & 307 \\
\hline Ropa & 312 & 330 & 323 & 291 & 901 & 250 \\
\hline Partes casa & 307 & 263 & 350 & 238 & 751 & 275 \\
\hline Muebles & 303 & 308 & 442 & 263 & 713 & 362 \\
\hline Alimentos & 607 & 561 & 626 & 476 & 1248 & 550 \\
\hline Mesa & 317 & 256 & 397 & 238 & 519 & 252 \\
\hline Cocina & 502 & 372 & 519 & 347 & 781 & 426 \\
\hline Escuela & 623 & 473 & 552 & 420 & 1063 & 480 \\
\hline Iluminación & 479 & 256 & 540 & 297 & 1092 & 351 \\
\hline Ciudad & 949 & 755 & 1011 & 678 & 1591 & 652 \\
\hline Campo & 1060 & 967 & 1196 & 727 & 1738 & 773 \\
\hline Transporte & 344 & 280 & 316 & 276 & 1102 & 291 \\
\hline Jardín & 704 & 491 & 755 & 434 & 1505 & 458 \\
\hline Animales & 447 & 467 & 419 & 347 & 1138 & 425 \\
\hline Juegos & 908 & 546 & 864 & 576 & 1513 & 654 \\
\hline Profesiones & 732 & 715 & 824 & 571 & 1432 & 645 \\
\hline Colores & 350 & 264 & & 239 & 885 & 281 \\
\hline TOTALES & 9215 & 7643 & 9462 & 6824 & 20507 & 7432 \\
\hline
\end{tabular}

Tabla 5.1.7. Número de vocablos de las distintas zonas comparadas por centros de interés

Las similitudes reseñadas pueden verse de forma gráfica en la siguiente figura, donde al margen de las diferencias muestrales (especialmente evidentes en el caso gallego), se comprueba la congruencia léxica entre las diferentes sintopías.

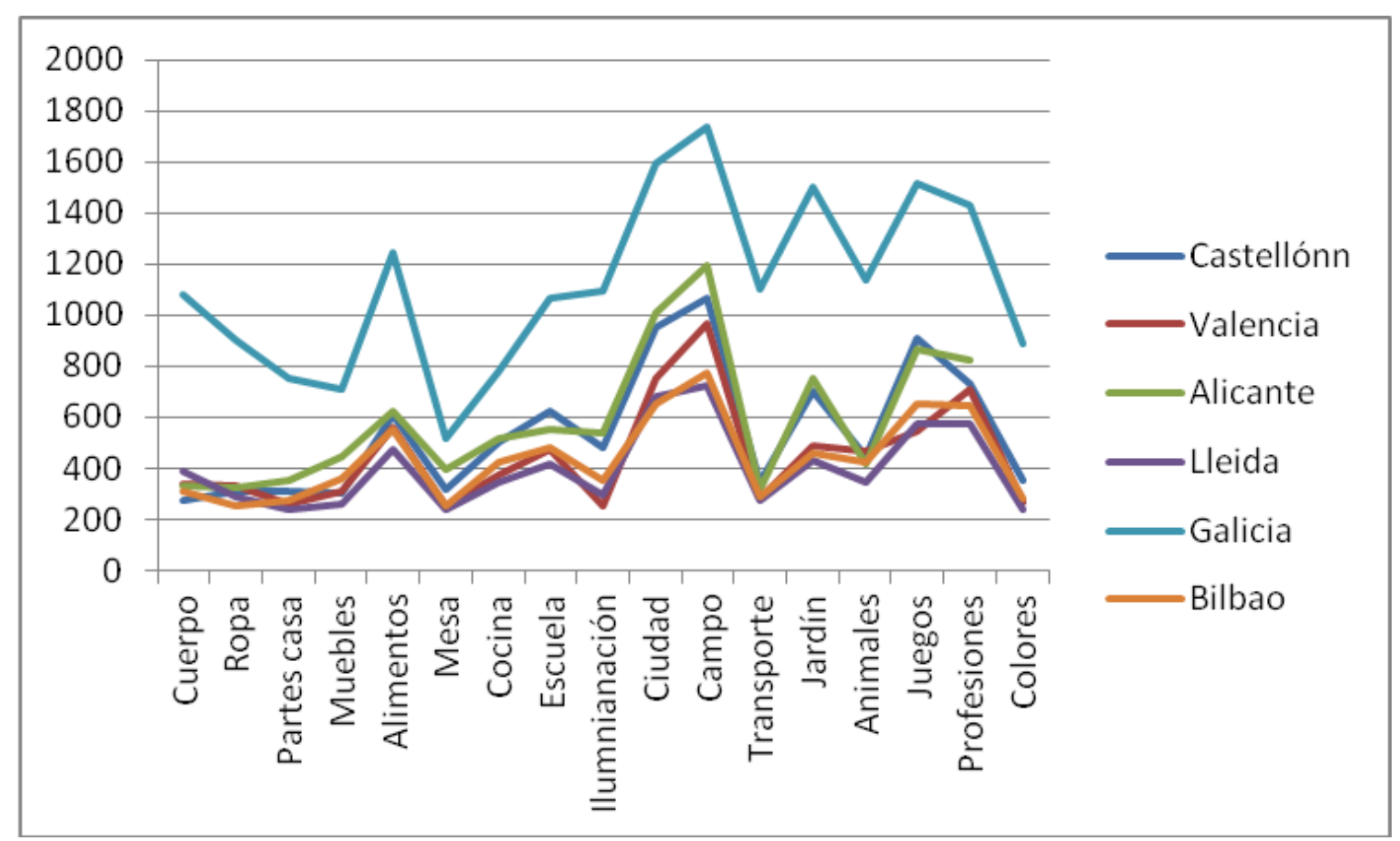

Gráfico 5.1.6. Vocablos en las distintas áreas geográficas comparadas 
Sin embargo, el índice más significativo a la hora de comparar los correspondientes léxicos disponibles de las diferentes comunidades bilingües es, sin duda, el promedio de palabras por informante ya que, como hemos visto anteriormente, no se ve afectado por variaciones debidas al número de individuos en cada muestra o por la presencia de estudiantes atípicos.

\begin{tabular}{|l|c|c|c|c|c|c|}
\hline $\begin{array}{l}\text { Centros de } \\
\text { interés }\end{array}$ & Castellón & Valencia & Alicante & Lérida & Galicia & Bilbao \\
\hline Cuerpo & 25.84 & 27.01 & 24.53 & 25.54 & 29.29 & 25.4 \\
\hline Ropa & 22.87 & 23.63 & 20.66 & 21.62 & 24.69 & 22.7 \\
\hline Partes casa & 16.68 & 15.67 & 15.73 & 14.17 & 18.14 & 15.0 \\
\hline Muebles & 14.53 & 14.83 & 15.78 & 12.40 & 16.46 & 15.8 \\
\hline Alimento & 26.58 & 27.85 & 24.57 & 24.21 & 28.50 & 28.06 \\
\hline Mesa & 14.91 & 16.16 & 15.69 & 13.20 & 17.32 & 16.1 \\
\hline Cocina & 18.69 & 20.54 & 17.11 & 15.38 & 18.84 & 19.1 \\
\hline Escuela & 23.71 & 22.54 & 21.96 & 21.17 & 24.72 & 24.0 \\
\hline Iluminac. & 13.21 & 12.48 & 12.91 & 11.08 & 14.71 & 12.9 \\
\hline Ciudad & 24.71 & 23.77 & 21.44 & 21.35 & 23.57 & 23.3 \\
\hline Campo & 21.11 & 20.82 & 20.18 & 18.20 & 21.20 & 20.8 \\
\hline Transporte & 19.28 & 18.56 & 17.69 & 16.85 & 19.60 & 18.9 \\
\hline Jardín & 11.31 & 11.73 & 11.59 & 8.85 & 12.87 & 11.3 \\
\hline Animales & 28.39 & 28.75 & 26.08 & 26.02 & 29.77 & 28.3 \\
\hline Juegos & 19.46 & 19.10 & 18.94 & 16.31 & 17.98 & 19.8 \\
\hline Profesiones & 22.90 & 21.94 & 22.32 & 19.62 & 22.53 & 22.6 \\
\hline Colores & 19.86 & 18.73 & & 18.35 & 21.87 & 20.0 \\
\hline TOTAL & 20.23 & 20.24 & 19.19 & 17.90 & 21.26 & 20.31 \\
\hline
\end{tabular}

Tabla 5.1.8. Promedio de palabras por informante en las diferentes sintopías estudiadas por centros de interés

Al observar la tabla, descubrimos que las medias totales no se alejan mucho entre sí, con cifras cercanas a 20, con la excepción de Lérida, que, con un promedio global de 17.90 de unidades léxicas, obtiene los índices más bajos. En todo caso, y como se puede apreciar en el siguiente gráfico, aunque varíen los porcentajes de una investigación a otra, los vértices de las líneas convergen en las zonas analizadas, lo que significa que todos los estudios presentan una tendencia similar en la producción de unidades lingüísticas. 


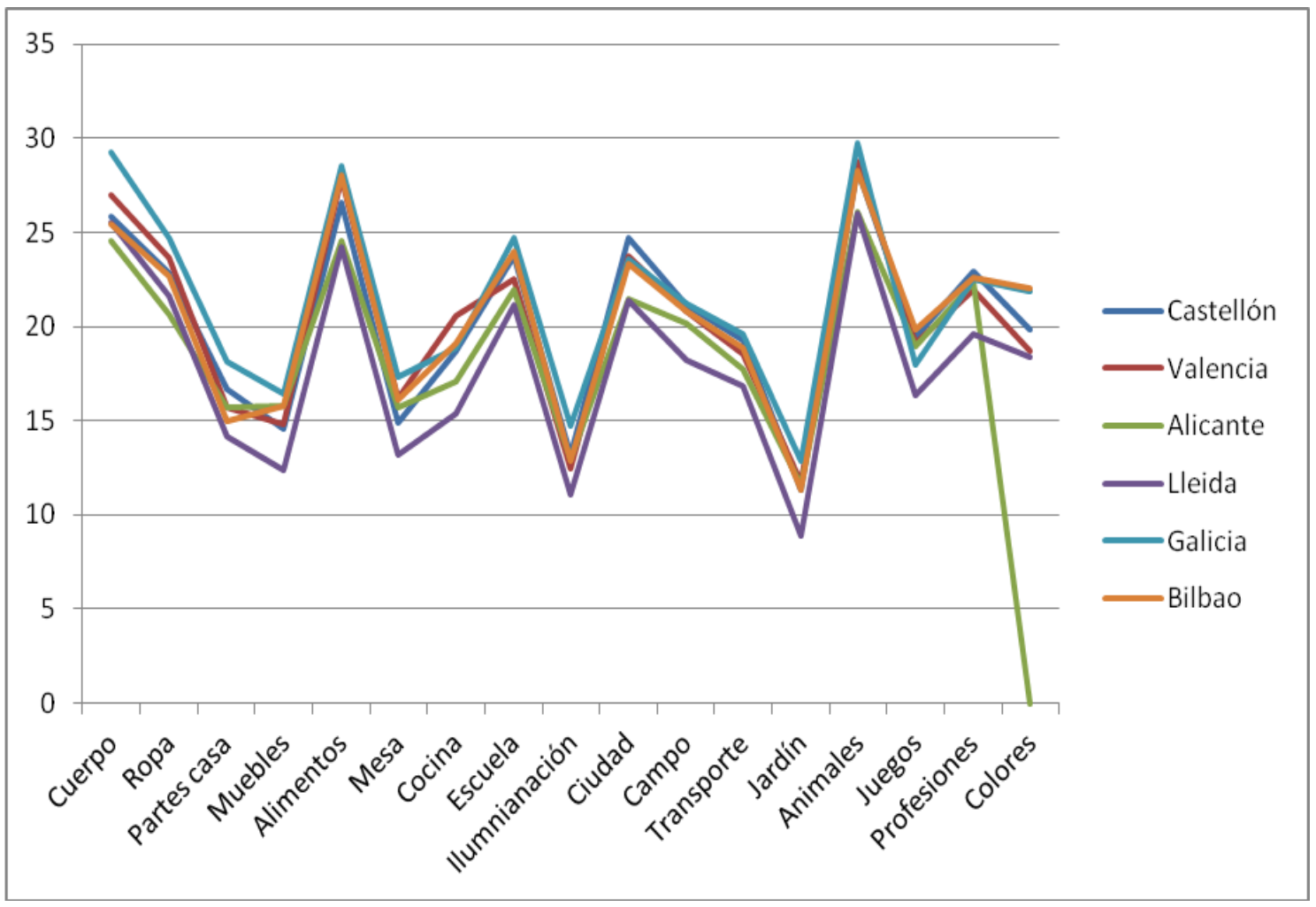

Gráfico 5.1.7. Palabras por informante en las zonas geográficas comparadas por centros de interés

De manera más pormenorizada, y en cuanto a las coincidencias se refiere, cabe destacar que en todas las investigaciones aparece con el rango uno el campo semántico de los Animales, con medias que oscilan entre los 26.07 de Lérida y los 29.77 de Galicia. Las posiciones dos y tres son ocupadas por los centros de interés Alimentos y Cuerpo, aunque varían las posiciones relativas en las diferentes investigaciones. Así, en Alimentos el rango dos corresponde a Castellón, Valencia, Alicante y Bilbao, pero aparece con el rango tres en Lérida y Galicia. Lo mismo sucede con el centro Cuerpo, que obtiene una coincidencia total en las tres provincias de la Comunidad Valenciana y Bilbao en el tercer lugar de la lista, pero la segunda posición en Lérida y Galicia. Igualmente, las últimas posiciones recaen en todas las comunidades en los campos nocionales Jardín, Iluminación y Muebles. En definitiva, se observan ciertos patrones de comportamiento léxico comunes en todas comunidades bilingües comparadas.

De la información anterior se desprende que podemos establecer diversas agrupaciones entre los diferentes estímulos verbales. Así, reconocemos un primer conjunto formado por las áreas asociativas Cuerpo, Alimento y Animales, con promedios que van de las 24 a las 29 palabras. Un segundo grupo está integrado por 
centros de interés que superan la media de respuestas, y que está compuesto por los centros Escuela, Profesiones, Ropa, Campo, Colores. Un tercer grupo lo componen aquellos campos semánticos que no suelen alcanzar esa media de respuestas por informante, como Muebles, Mesa, Cocina, Transporte. Y, por último, un cuarto conjunto que nunca sobrepasa esa media es el formado por dos campos: Iluminación o Jardín. En la siguiente tabla hemos marcado en negrita la coincidencia de los centros de interés que comparten las diferentes sintopías y en cursiva aquellas áreas léxicas que solo aparecen en cinco de las zonas cotejadas. Se manifiesta, pues, una tendencia de agrupación de los centros de interés en las distintas investigaciones.

\begin{tabular}{|c|c|c|c|c|c|c|}
\hline & Castellón & Valencia & Alicante & Lérida & Galicia & Bilbao \\
\hline $\begin{array}{l}29- \\
24\end{array}$ & $\begin{array}{l}\text { Cuerpo } \\
\text { Alimentos } \\
\text { Animales } \\
\text { Ciudad }\end{array}$ & $\begin{array}{l}\text { Cuerpo } \\
\text { Alimentos } \\
\text { Animales }\end{array}$ & $\begin{array}{l}\text { Cuerpo } \\
\text { Alimentos } \\
\text { Animales }\end{array}$ & $\begin{array}{l}\text { Cuerpo } \\
\text { Alimentos } \\
\text { Animales }\end{array}$ & $\begin{array}{l}\text { Cuerpo } \\
\text { Alimentos } \\
\text { Animales } \\
\text { Escuela } \\
\text { Ropa }\end{array}$ & $\begin{array}{l}\text { Cuerpo } \\
\text { Alimentos } \\
\text { Animales } \\
\text { Escuela }\end{array}$ \\
\hline $\begin{array}{l}23- \\
19\end{array}$ & $\begin{array}{l}\text { Escuela } \\
\text { Profesión } \\
\text { Ropa } \\
\text { Campo } \\
\text { Colores } \\
\text { Juegos }\end{array}$ & $\begin{array}{l}\text { Ciudad } \\
\text { Ropa } \\
\text { Escuela } \\
\text { Profesión } \\
\text { Campo } \\
\text { Juegos } \\
\text { Cocina }\end{array}$ & $\begin{array}{l}\text { Escuela } \\
\text { Profesión } \\
\text { Campo } \\
\text { Ropa } \\
\text { Ciudad }\end{array}$ & $\begin{array}{l}\text { Ropa } \\
\text { Escuela } \\
\text { Ciudad } \\
\text { Profesión }\end{array}$ & $\begin{array}{l}\text { Profesión } \\
\text { Transporte } \\
\text { Campo } \\
\text { Ciudad } \\
\text { Colores }\end{array}$ & $\begin{array}{l}\text { Ropa } \\
\text { Cocina } \\
\text { Campo } \\
\text { Juegos } \\
\text { Profesión } \\
\text { Colores } \\
\text { Ciudad }\end{array}$ \\
\hline $\begin{array}{l}18- \\
14\end{array}$ & $\begin{array}{l}\text { Muebles } \\
\text { Mesa } \\
\text { Cocina } \\
\text { Transporte } \\
\text { Partes casa }\end{array}$ & $\begin{array}{l}\text { Transporte } \\
\text { Partes casa } \\
\text { Muebles } \\
\text { Mesa } \\
\text { Colores }\end{array}$ & $\begin{array}{l}\text { Juegos } \\
\text { Transporte } \\
\text { Cocina } \\
\text { Partes casa } \\
\text { Muebles } \\
\text { Mesa }\end{array}$ & $\begin{array}{l}\text { Juegos } \\
\text { Colores } \\
\text { Campo } \\
\text { Cocina } \\
\text { Partes casa } \\
\text { Transporte }\end{array}$ & $\begin{array}{l}\text { Partes } \\
\text { casa } \\
\text { Muebles } \\
\text { Mesa } \\
\text { Cocina } \\
\text { Iluminac. } \\
\text { Juegos }\end{array}$ & $\begin{array}{l}\text { Partes casa } \\
\text { Muebles } \\
\text { Mesa } \\
\text { Transporte }\end{array}$ \\
\hline $\begin{array}{l}13- \\
11\end{array}$ & $\begin{array}{l}\text { Iluminación } \\
\text { Jardín }\end{array}$ & $\begin{array}{l}\text { Iluminación } \\
\text { Jardín }\end{array}$ & $\begin{array}{l}\text { Iluminación } \\
\text { Jardín }\end{array}$ & $\begin{array}{l}\text { Muebles } \\
\text { Mesa } \\
\text { Iluminación } \\
\text { Jardín }\end{array}$ & Jardín & $\begin{array}{l}\text { Iluminación } \\
\text { Jardín }\end{array}$ \\
\hline
\end{tabular}

Tabla 5.9. Agrupación de los centros de interés según su productividad

Si comparamos estos datos con los aportados por Fernández Juncal (2013: 5051), observamos que las agrupaciones no varían demasiado. ${ }^{138}$ El primer grupo estaría formado por Partes del Cuerpo, Alimento y Animales, al igual que sucede en nuestros resultados. El segundo por Profesiones, Escuela, Ciudad, Ropa y Campo. El tercer

\footnotetext{
${ }^{138}$ A su vez esta investigadora recoge los datos de Samper Padilla et alii de (2003a: 58-59; 2006: 31).
} 
grupo abarcaría los centros de interés de Juegos, Cocina, Transporte, Mesa, Parte de la casa y Muebles. Y, por último, el cuarto estaría conformado por Iluminación y Jardín. Por otro lado, el centro de interés Juegos fluctúa entre el grupo dos y tres y Ciudad se sitúa en el grupo dos, excepto en Castellón que aparece en el primero.

En consecuencia, las áreas semánticas más productivas en los estudios analizados son las mismas, Animales, Alimentos y Partes del Cuerpo, y las que presentan índices más bajos de producción son también dos: Iluminación y Jardín. Entre ellas hay una zona intermedia, en la que se distribuyen los demás campos léxicos, con ligeras variaciones en las cifras de palabras por informante y, por tanto, con una pequeña oscilación en el rango de las áreas nocionales.

De vuelta a los índices cuantitativos que arroja el promedio de respuestas por informantes, recordemos que la provincia de Castellón (20.23) se sitúa ligeramente por encima del promedio global de las regiones bilingües analizadas en el presente estudio (19.85), y donde se incluyen situaciones de contacto donde el castellano convive con tres lenguas diferentes: catalán (tanto en su variedad ilerdense como valenciana), gallego y vasco. Así pues, con la excepción de los estudiantes de Lérida, que puntúan claramente por debajo (ver gráfico 5.1.8), los demás no ofrecen diferencias significativas.

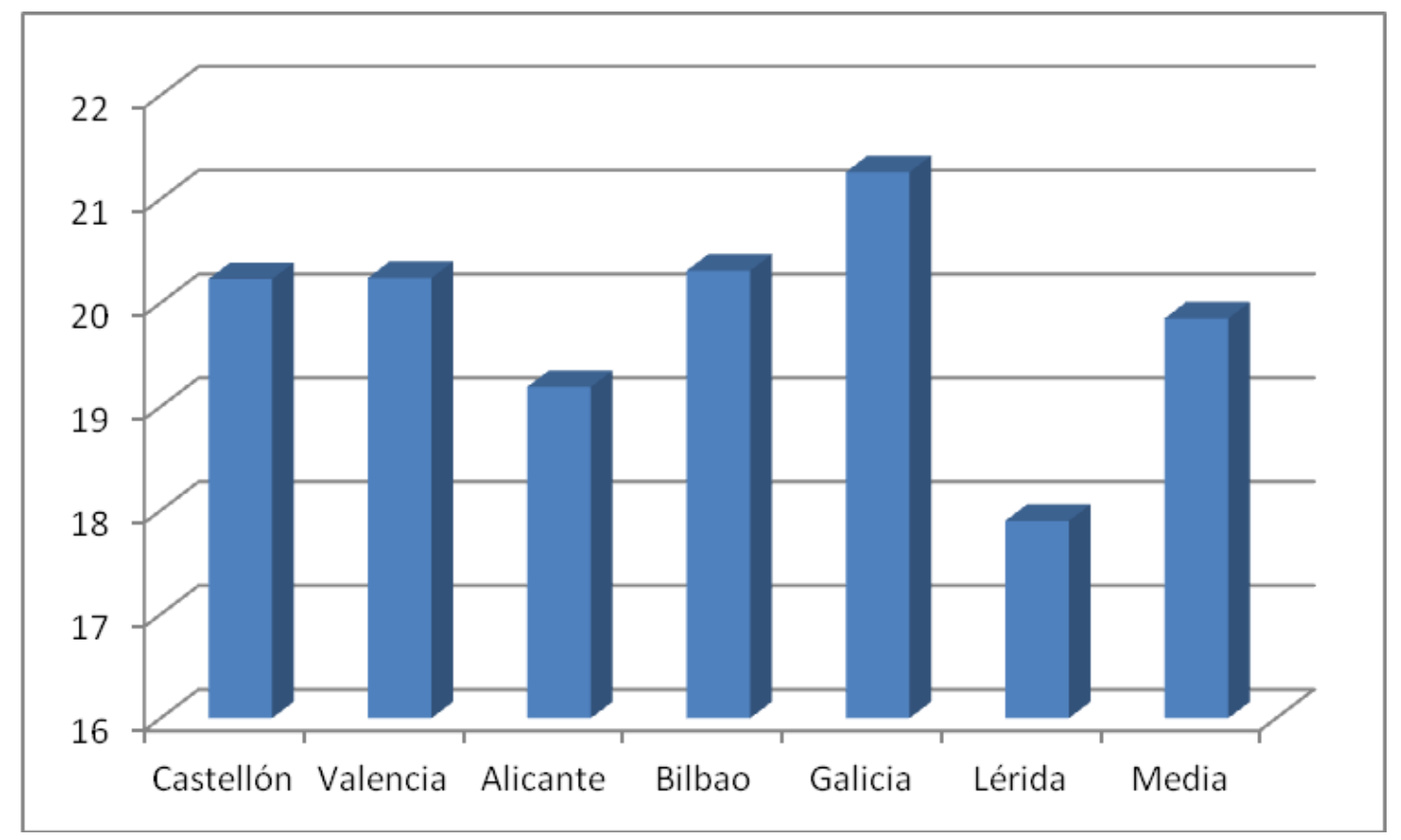

Gráfico 5.1.8. Promedio de palabras en las zonas comparadas con la media 
Por lo demás, estos resultados no difieren tampoco de los ofrecidos en áreas monolingües, como se muestra en la tabla 5.1.10.

\begin{tabular}{|l|c|c|}
\hline Sintopía & $\begin{array}{c}\text { Promedio de } \\
\text { respuestas }\end{array}$ & Rango \\
\hline Castellón & 20.23 & 6 \\
\hline Alicante & 19.19 & 11 \\
\hline Valencia & 20.24 & 5 \\
\hline Lérida & 17.90 & 15 \\
\hline Galicia & 21.26 & 2 \\
\hline Bilbao & 20.31 & 4 \\
\hline Cantabria & 18.50 & 14 \\
\hline Asturias & 19.04 & 12 \\
\hline Cádiz & 18.60 & 13 \\
\hline Huelva & 20.07 & 8 \\
\hline Segovia & 19.85 & 9 \\
\hline Burgos & 19.67 & 10 \\
\hline Soria & 21.31 & 1 \\
\hline Cuenca & 20.12 & 7 \\
\hline Aragón & 21.20 & 3 \\
\hline
\end{tabular}

Tabla 5.1.10. Promedio de palabras por informante en diferentes sintopías ${ }^{139}$

Si examinamos la tabla, comprobamos que las cifras oscilan entre el promedio de Lérida, la provincia con menor número de palabras por informante y centro de interés (17.9), y el de Soria, que arroja las cifras más elevadas (21.31). Entre esos datos extremos se encuentran todas las demás provincias o comunidades autónomas. En la tercera columna del cuadro anterior, marcamos el orden de las comunidades analizadas según el promedio de palabras por informante, lo que visualmente se aprecia mejor en el gráfico siguiente.

\footnotetext{
139 Los promedios de Asturias (Carcedo, 2001), Cádiz (González Martínez, 2002), Huelva (Prado Aragonés y Galloso Camacho, 2005), Segovia (De Santiago Guervós, 2008), Burgos (Fernández Juncal, 2008), Soria (Bartol, 2008), Cuenca (Hernández Muñoz, 2004) se han calculado a partir de los datos ofrecidos en cada investigación.
} 


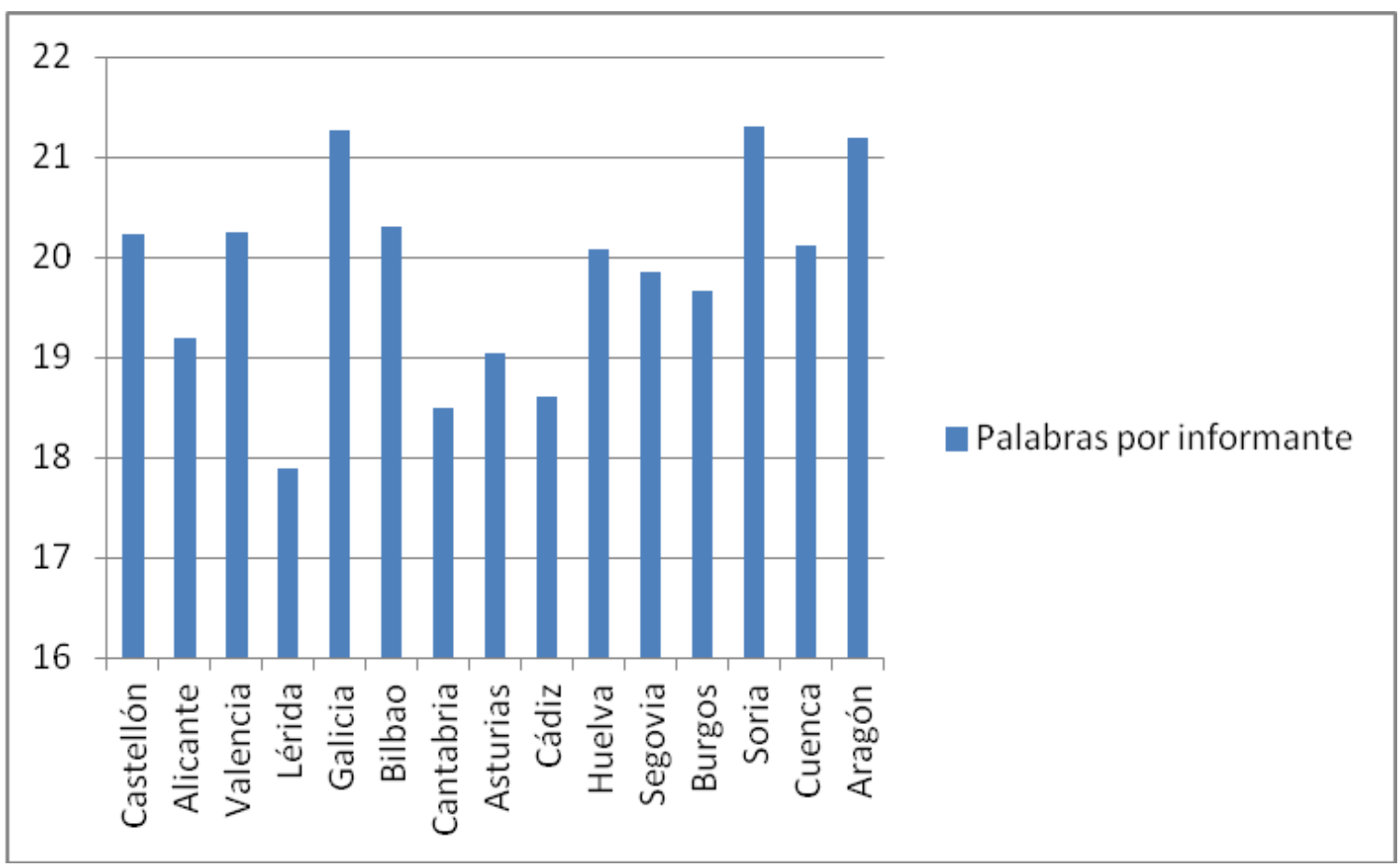

Gráfico 5.1.9. Promedio de palabras por informante de las diferentes sintopías comparadas

A la luz de este gráfico, no parece que, salvo excepciones, las diferencias (en todo caso, menores) tengan mucho que ver con el carácter bilingüe o monolingüe de las respectivas áreas estudiadas. Ciertamente, es una provincia bilingüe como Lérida la que ofrece un promedio menor de lexemas, si bien las características específicas del bilingüismo oficial e institucional de la Comunidad autónoma a la que pertenece la hacen única. ${ }^{140} \mathrm{Al}$ mismo tiempo, son dos zonas monolingües las que cuentan con mayor promedio, Soria y Aragón, pero muy cerca se encuentra una región bilingüe como Galicia. De igual manera, los índices de Castellón (20.23) y Valencia (20.24), prácticamente idénticos entre sí, coinciden con los de Cuenca (20.12), otra área monolingüe.

En suma, con la excepción reseñada, el carácter bilingüe o monolingüe de una comunidad no parece determinante en los resultados obtenidos por la productividad léxica de sus estudiantes universitarios. Por encima de este se sitúan otros factores sociales de los que daremos cuenta más adelante. Al analizar el léxico disponible de

\footnotetext{
${ }^{140}$ Como ha recordado Serrano (2014: 374) "el nuestro es el único territorio donde, con independencia de su lengua materna, no hay ningún informante que se escolarice en lengua castellana sino que todos siguen un programa educativo que utiliza el catalán como única lengua vehicular". Al mismo tiempo, conviene recordar que en este estudio, los alumnos alcanzaron puntuaciones significativamente más elevadas en los índices de disponibilidad en catalán.
} 
Bilbao, y las potenciales diferencias en función del modelo educativo bilingüe elegido por los escolares, Maitena Etxebarria (1996a: 319), comenta unos resultados que en esencia son similares a los obtenidos aquí:

No parece, pues, existir una diferencia notable entre los alumnos que han cursado un modelo y otro, por lo que se refiere, al menos, al promedio general de respuestas. Hay que señalar además que si comparamos las medias obtenidas aquí con las obtenidas en otras áreas del estado español, pero monolingües, como es el caso de Las Palmas, ${ }^{141}$ donde se obtuvo un promedio general de 20.65, o del área metropolitana de Madrid ${ }^{142}$ que arrojó un promedio de 20.63, no parece que pueda deducirse, a partir de diferencias tan pequeñas, que el cursar un modelo de enseñanza bilingüe de tipo $\mathrm{D}$, en el que toda la enseñanza se da en euskera y la lengua española se estudia como asignatura, afecte de un modo efectivo al conocimiento, competencia, y uso del español, en el área del País Vasco examinada, al menos por lo que se refiere al vocabulario básico.

Si damos cuenta ahora de la media de palabras por informantes entre las diferentes zonas comparadas, en el gráfico 5.1.10 podremos ver cómo el caudal de léxico disponible de los estudiantes castellonense (20.23) se sitúa en una posición intermedia y levemente por encima de la media (19.83).

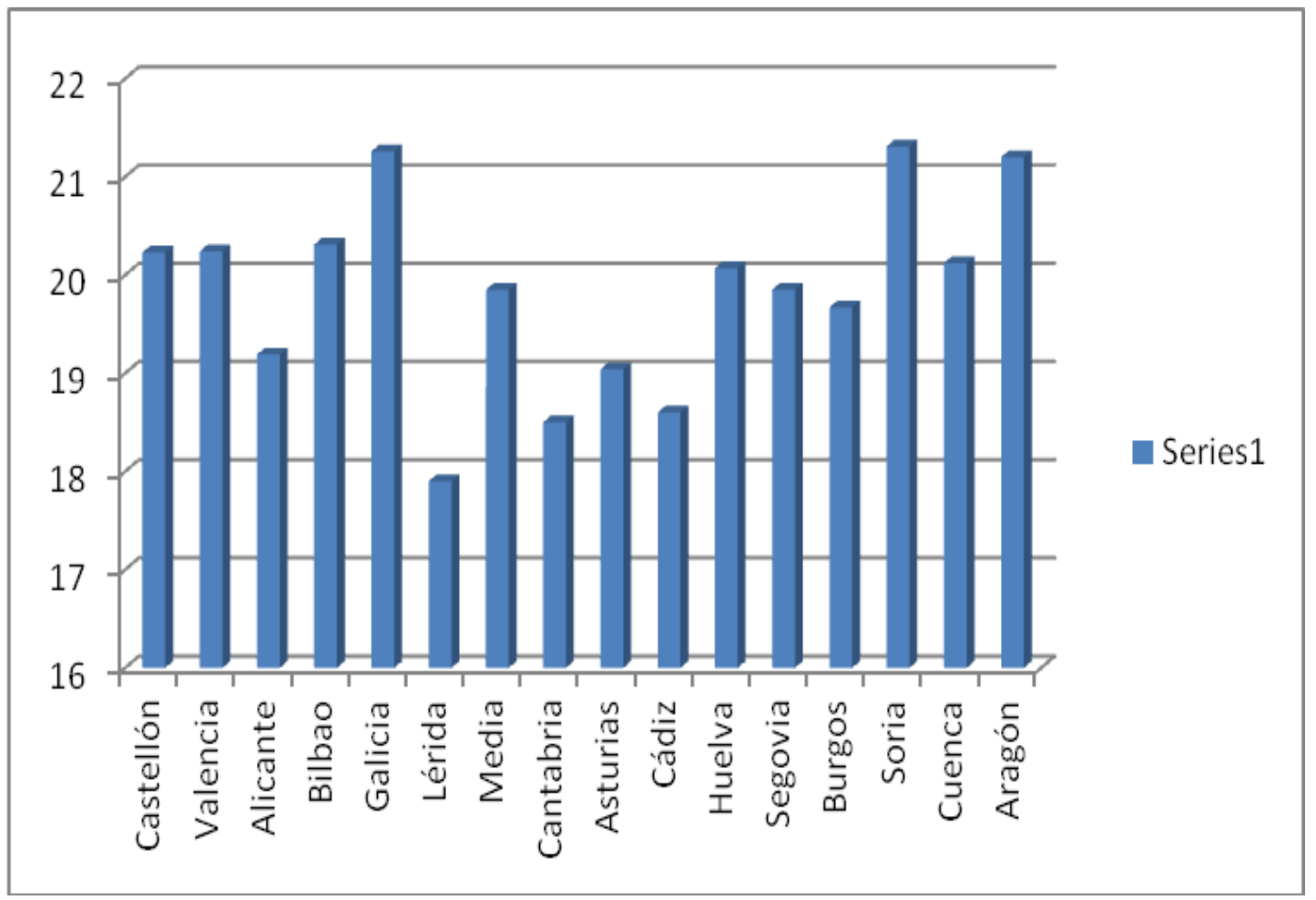

Gráfico 5.1.10. Promedio general de diferentes zonas estudiadas con la media

\footnotetext{
${ }^{141}$ Samper, J.A. y Hernández, C.E. (1997).

${ }^{142}$ P. Benitez (1992).
} 
Siguiendo en el apartado de los análisis comparativos, nos referiremos ahora al índice de cohesión puesto que, como vimos, es preferible al de la densidad para medir el carácter de los centros de interés. Estos pueden ser compactos, si hay coincidencia en las respuestas de los estudiantes, o difusos, si, por el contrario, hay dispersión en estas. En la tabla siguiente comparamos este índice en las diferentes áreas bilingües analizadas.

\begin{tabular}{|l|c|c|c|c|c|c|}
\hline $\begin{array}{l}\text { Centros de } \\
\text { interés }\end{array}$ & Castellón & Valencia & Alicante & Lérida & Galicia & Bilbao \\
\hline Cuerpo & 0.095 & 0.077 & 0.047 & 0.066 & 0.027 & 0.082 \\
\hline Ropa & 0.073 & 0.069 & 0.064 & 0.074 & 0.027 & 0.090 \\
\hline Partes casa & 0.054 & 0.057 & 0.044 & 0.060 & 0.024 & 0.054 \\
\hline Muebles & 0.047 & 0.046 & 0.035 & 0.047 & 0.023 & 0.043 \\
\hline Alimentos & 0.043 & 0.048 & 0.039 & 0.051 & 0.023 & 0.052 \\
\hline Mesa & 0.047 & 0.060 & 0.039 & 0.055 & 0.033 & 0.064 \\
\hline Cocina & 0.037 & 0.053 & 0.033 & 0.044 & 0.023 & 0.045 \\
\hline Escuela & 0.038 & 0.046 & 0.039 & 0.050 & 0.023 & 0.050 \\
\hline Iluminación & 0.027 & 0.048 & 0.023 & 0.037 & 0.013 & 0.036 \\
\hline Ciudad & 0.026 & 0.031 & 0.021 & 0.031 & 0.015 & 0.065 \\
\hline Campo & 0.019 & 0.021 & 0.016 & 0.025 & 0.012 & 0.027 \\
\hline Transporte & 0.056 & 0.065 & 0.056 & 0.061 & 0.018 & 0.065 \\
\hline Jardín & 0.016 & 0.023 & 0.015 & 0.020 & 0.008 & 0.024 \\
\hline Animales & 0.063 & 0.060 & 0.062 & 0.075 & 0.026 & 0.066 \\
\hline Juegos & 0.021 & 0.034 & 0.021 & 0.028 & 0.012 & 0.030 \\
\hline Profesiones & 0.031 & 0.030 & 0.027 & 0.033 & 0.016 & 0.035 \\
\hline Colores & 0.056 & 0.070 & - & 0.077 & 0.028 & 0.071 \\
\hline TOTALES & 0.0021 & 0.0026 & 0.0020 & 0.0026 & 0.0010 & 0.0027 \\
\hline
\end{tabular}

Tabla 5.1.11. Índice de cohesión en las diferentes sintopías tratadas.

Con la excepción de unas cifras singularmente bajas en el estudio de Galicia (0.0010), a la que pueden no ser ajenas unas características muestrales específicas, ${ }^{143}$ en este índice advertimos también coincidencias entre las diferentes sintopías, con cifras globales muy similares, como se aprecia en la tabla 5.1.11. Asimismo, esta coincidencia se aprecia en las escasas variaciones que experimenta el rango de los índices de cohesión en las respectivas áreas léxicas. Por ejemplo, los centros más difusos o abiertos, situados en todos los casos en los últimos lugares de la lista son Jardín, Juegos, Campo y Ciudad. El primero ocupa el rango $16^{\circ}$ en Valencia, Alicante y

\footnotetext{
${ }^{143}$ No debemos olvidar que el grado de cohesión de los centros de interés también depende del tamaño de la muestra, que, como se recordará, es de 800 individuos en la investigación de López Meirama (2008).
} 
Galicia, y desciende hasta la última posición (rango $17^{\circ}$ ) en Castellón, Lérida y Bilbao. Por su parte el centro Juegos se encuentra entre el puesto $13^{\circ}$ en Valencia, el $14^{\circ}$ en Alicante, el $15^{\circ}$ de Castellón, Lérida y Bilbao y el $17^{\circ}$ en Galicia. Por último, el Campo oscila entre el puesto $15^{\circ}$ de Alicante y Galicia, el $16^{\circ}$ de Castellón, Lérida y Bilbao y el $17^{\circ}$ de Valencia.

Los centros más compactos o cerrados muestran también notables coincidencias en cuanto al rango del índice de cohesión se refiere. Así ocurre, por ejemplo, con los centros de Cuerpo, Ropa, Animales y Colores, que fluctúan en todas las sintopías entre la primera y la cuarta posición, como consecuencia de la mayor delimitación cognitiva y cultural en que se encuentran estos campos. ${ }^{144}$

Ello demuestra que, pese a la existencia de potenciales diferencias cuantitativas en la productividad léxica de los informantes entre las diferentes áreas españolas analizadas (por lo demás, poco relevantes, como hemos tenido ocasión de comprobar), existe una notable proximidad en la cohesión interna de los centros de interés respectivos.

Las pequeñas divergencias percibidas pueden deberse a procedimientos de lematización o a variaciones en el nombre dado a los centros de interés, factores todos ellos que pueden influir en las respuestas de los estudiantes. A pesar de esto, no hay que perder de vista que el objetivo fundamental de las comparaciones no es otro que establecer la naturaleza de las áreas semánticas. Las cifras absolutas no interesan tanto, pues vienen mediatizas por el tamaño de la muestras. Es preferible observar, pues, las tendencias que afectan a los centros ${ }^{145} \mathrm{y}$, en relación con estas, vemos que no difieren en términos generales, con independencia del tipo de comunidad de que se trate en cada caso. A este respecto, al analizar la disponibilidad léxica en Lérida, Serrano (2014: 357) destaca que, con independencia de la obtención de mayor productividad léxica en una lengua (el catalán) que en otra (el castellano): la "caracterización que se obtiene de los

\footnotetext{
${ }^{144}$ Martínez Olmos (2008:164), en su análisis de los estudiantes alicantinos, apunta que aquellas áreas semánticas que presentan un índice de cohesión alto coinciden con las incluidas en el currículo de léxico escolar.

${ }^{145}$ Fernández Juncal (2013:55-56) presenta una tabla con el carácter de los centros, difuso y compacto, en varias zonas de estudio (Burgos, Soria, Valencia, Castilla-La Mancha, Melilla y su propio análisis de Cantabria), y concluye también que hay una coincidencia entre los grupos extremos: Cuerpo y Ropa entre los más densos y Campo, Jardín y Juegos entre los más difusos. Luego, hay una zona en la que fluctúan alrededor de la media las demás áreas léxicas, tal como hemos podido comprobar en las zonas bilingües de la península.
} 
centros, según este parámetro [el índice de cohesión], parece ser constante por encima de la lengua en la que se completa la encuesta."

Y no solo el índice de cohesión es similar en las diferentes áreas españolas estudiadas, sino que, con las excepciones reseñadas, también lo son los demás índices. Lo que indica, pues, "una distribución semejante de la cuantía léxica actualizada en los diferentes centros de interés" (Hernández Muñoz, 2006: 318), y una estructura del léxico relativamente común, que subyace a las eventuales diferencias dialectales.

\subsection{Datos por variables sociales}

Uno de los objetivos planteados en las diversas investigaciones de disponibilidad léxica es la posibilidad de valorar la incidencia de diversos factores sociales en la producción y riqueza léxica de los alumnos preuniversitarios. En consecuencia, en este apartado analizaremos la repercusión que las variables independientes seleccionadas en la muestra (sexo, tipo de enseñanza, ubicación del centro educativo, lengua materna de los informantes y nivel educativo de los padres) tienen en los resultados obtenidos. Para ello, seguiremos en todos los casos un mismo orden expositivo. En primer lugar, expondremos las cifras correspondientes al número de palabras y vocablos totales de cada una de las variables analizadas, y a continuación las expresadas en los promedios de palabras por sujeto y centro de interés por ser más eficaces para establecer análisis comparativos. Por último, concluiremos el análisis con la revisión del grado de afinidad o dispersión de las respuestas, medido a través del índice de cohesión que muestra cada uno de los colectivos y áreas léxicas estudiadas.

\subsubsection{Sexo}

Tal como se ha hecho en anteriores investigaciones sobre disponibilidad léxica, también en el análisis de Castellón examinamos la variable sexo con la finalidad de ver si este factor social es discriminador en el comportamiento lingüístico de los informantes. 
En primer término, conviene recordar que la muestra seleccionada en este estudio está constituida por 199 mujeres y 155 hombres, lo que supone un cierto desequilibrio muestral a favor de las primeras. Esto explica, al menos en parte, un mayor número de respuestas totales del sexo femenino (69878) que del masculino (51914) (véase tabla 5.2.1). Sin embargo, esta diferencia de 17964 palabras debe tomarse con precaución debido, precisamente, al desequilibrio muestral reseñado. De hecho, si tenemos en cuenta la totalidad de vocablos, la diferencia entre ambos sexos baja a tan solo 94 unidades léxicas (hombres: 6548; mujeres: 6642). ${ }^{146}$

\begin{tabular}{|l|c|c|c|c|}
\hline Centros de interés & \multicolumn{2}{|c|}{ Hombres } & \multicolumn{2}{c|}{ Mujeres } \\
\hline & PT & PD & PT & PD \\
\hline 01. Partes del cuerpo & 4008 & 230 & 5140 & 211 \\
\hline 02. La ropa & 3337 & 221 & 4758 & 252 \\
\hline 03. Partes de la casa & 2591 & 228 & 3313 & 228 \\
\hline 04. Muebles & 2081 & 198 & 3061 & 254 \\
\hline 05. Alimentos & 3945 & 483 & 5466 & 463 \\
\hline 06. Mesa & 2261 & 225 & 3016 & 245 \\
\hline 07. La cocina y sus utensilios & 2695 & 346 & 3920 & 387 \\
\hline 08. La escuela: muebles y materiales & 3440 & 424 & 4953 & 456 \\
\hline 09. Iluminación & 2081 & 326 & 2596 & 328 \\
\hline 10. La ciudad & 3839 & 646 & 4910 & 655 \\
\hline 11. El campo & 3212 & 771 & 4260 & 741 \\
\hline 12. Medios de transporte & 3024 & 276 & 3802 & 248 \\
\hline 13. Trabajos del campo y del jardín & 1822 & 476 & 2181 & 423 \\
\hline 14. Los animales & 4287 & 387 & 5764 & 319 \\
\hline 15. Juegos y distracciones & 3004 & 621 & 3886 & 627 \\
\hline 16. Profesiones y oficios & 3409 & 541 & 4698 & 539 \\
\hline 17. Los colores & 2878 & 249 & 4154 & 266 \\
\hline TOTALES & 51914 & 6548 & 69878 & 6642 \\
\hline
\end{tabular}

Tabla 5.2.1. Palabras totales (PT) y palabras diferentes $(P D)$ según la variable sexo

Veamos ahora qué sucede si interpretamos los promedios de respuestas en función de cada uno de los centros de interés, datos, como decíamos anteriormente, más fiables para establecer resultados y comparaciones entre las dos submuestras. Estos se muestran en la tabla 5.2.2, donde se aprecia cómo la diferencia global entre los

\footnotetext{
${ }^{146}$ Ello demuestra algo que destacábamos ya anteriormente, y es que no siempre los mayores índices de productividad léxica van acompañados de mayor variedad y riqueza léxicas. El hecho de que las chicas castellonenses superen levemente a los chicos en el número de respuestas, no significa que el léxico de las primeras sea más variado que el de estos últimos. En la práctica, sucede a menudo lo contrario, y son precisamente los jóvenes masculinos quienes obtienen promedios de vocablos diferentes más altos que sus compañeras.
} 
representantes de ambos sexos es de casi un punto (0.95) a favor de las mujeres. Se trata de diferencias globalmente significativas de acuerdo con la prueba $\mathrm{t}$ para la comparación entre muestras independientes (t: -3,55; p. 0,001; gdl: 16).

\begin{tabular}{|l|c|c|c|c|}
\hline Centros de interés & \multicolumn{2}{|c|}{ Hombres } & \multicolumn{2}{c|}{ Mujeres } \\
\hline & P I & I C & P I & IC \\
\hline 01. Partes del cuerpo & 25.86 & 0.11 & 25.83 & 0.12 \\
\hline 02. La ropa & 21.53 & 0.10 & 23.91 & 0.09 \\
\hline 03. Partes de la casa (sin muebles) & 16.72 & 0.07 & 16.65 & 0.07 \\
\hline 04. Los muebles de la casa & 13.43 & 0.07 & 15.38 & 0.06 \\
\hline 05. Alimentos y bebidas & 25.45 & 0.05 & 27.47 & 0.06 \\
\hline 06. Mesa & 14.59 & 0.06 & 15.16 & 0.06 \\
\hline 07. La cocina y sus utensilios & 17.39 & 0.05 & 19.70 & 0.05 \\
\hline 08. La escuela: muebles y materiales & 22.19 & 0.05 & 24.89 & 0.05 \\
\hline 09. Iluminación & 13.43 & 0.04 & 13.05 & 0.04 \\
\hline 10. La ciudad & 24.77 & 0.04 & 24.67 & 0.04 \\
\hline 11. El campo & 20.72 & 0.03 & 21.41 & 0.03 \\
\hline 12. Medios de transporte & 19.51 & 0.07 & 19.11 & 0.08 \\
\hline 13. Trabajos del campo y del jardín & 11.75 & 0.02 & 10.96 & 0.03 \\
\hline 14. Los animales & 27.66 & 0.07 & 28.96 & 0.09 \\
\hline 15. Juegos y distracciones & 19.38 & 0.03 & 19.53 & 0.03 \\
\hline 16. Profesiones y oficios & 21.99 & 0.04 & 23.61 & 0.04 \\
\hline 17. Los colores & 18.57 & 0.07 & 20.87 & 0.08 \\
\hline PROMEDIO GLOBAL & 19.70 & 0.12 & 20.65 & 0.10 \\
\hline
\end{tabular}

Tabla 5.2.2. Promedio de palabras e índice de cohesión por informantes según la variable sexo.

Si observamos ahora cada uno de los estímulos verbales, el hombre consigue mejores resultados en seis áreas temáticas, a saber, Cuerpo, Casa, Iluminación, Ciudad, Transporte y Jardín, aunque con unas diferencias muy pequeñas con respecto a las mujeres; por ejemplo, en las Partes del Cuerpo la distancia es de tan solo 0.03 y en la Casa es de apenas 0.07. ${ }^{147}$ Únicamente es mayor la desigualdad en Jardín, pero tampoco alcanza la unidad (0.79). ${ }^{148}$ Por el contrario, en todas las demás áreas temáticas (once estímulos verbales), la mujer aventaja al hombre, y, además, lo hace con índices mayores que en el sentido contrario. Por orden, este es el caso de los centros de interés siguientes: Ropa (2.38), Alimentos (2.02), Cocina (2,31), Muebles (2.70), Colores (2.32) y con una unidad de diferencia en Muebles (1.85) o Profesiones (1.01). Es revelador que, frente a los centros de interés donde los hombres superan a las mujeres, en estos

\footnotetext{
${ }^{147}$ De hecho, en ambos casos las diferencias no son significatives (p. 0.856 y 0.698, respectivamente).

${ }^{148}$ En este caso, sin embargo, la diferencia sí es significativa a la luz de la muestra disponible (p. 0.039).
} 
casos las diferencias sean en todos los casos significativas de acuerdo con la prueba $\mathrm{t}$ (véase tabla 5.2.3). Estas cifras muestran la relación que parece establecerse en la sociedad castellonense entre el sexo y ciertas temáticas, mediatizadas probablemente por los roles que la sociedad confiere todavía a las mujeres.

\begin{tabular}{|l|c|}
\hline Centros de interés & Sexo \\
\hline Cuerpo & .856 \\
\hline Ropa & .000 \\
\hline Casa & .698 \\
\hline Muebles & .000 \\
\hline Alimentos & .001 \\
\hline Mesa & .048 \\
\hline Cocina & .000 \\
\hline Escuela & .000 \\
\hline Iluminación & .772 \\
\hline Ciudad & .415 \\
\hline Campo & .445 \\
\hline Transporte & .076 \\
\hline Jardín & .039 \\
\hline Animales & .102 \\
\hline Juegos & .727 \\
\hline Profresión & .022 \\
\hline Colores & .000 \\
\hline 5.2.3. Grado se significacion
\end{tabular}

5.2.3. Grado de significación de las diferencias en el promedio de respuestas en función del sexo (prueba t para la comparación de dos muestras emparejadas)

En consecuencia, podemos concluir que las estudiantes castellonenses se colocan levemente por encima de sus compañeros en cuanto a disponibilidad léxica se refiere, unas diferencias que pueden apreciarse de manera más gráfica en la siguiente figura (gráfico 5.2.1). Por lo demás, estos datos coinciden con los observados en algunas investigaciones anteriores, como las de Samper y Hernández (1997) en Las Palmas de Gran Canaria, Bartol (2004) en Soria o Gómez Molina y Gómez Devís (2004) en Valencia. Sin embargo, no han faltado estudios cuyos resultados han sido justamente los contrarios, como los realizados en Madrid (Benítez, 1995), Ávila, Zamora y Salamanca (Galloso, 2003a), Córdoba (Bellón, 2003) o Cuenca (Hernández Muñoz, 2004). 


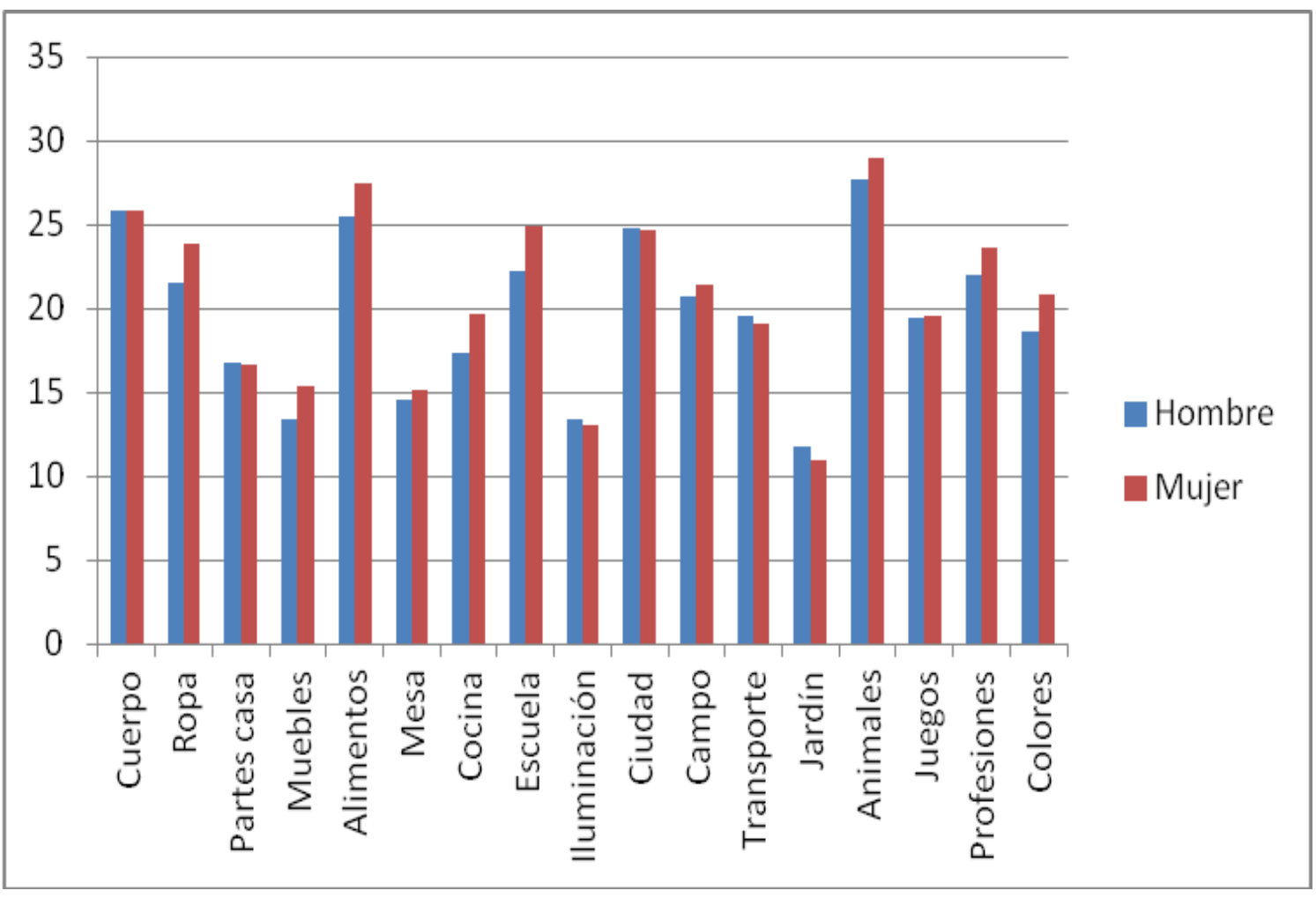

Gráfico 5.2.1. Porcentaje de palabras por informante según el sexo

A pesar de esas diferencias en algunos promedios, ambos grupos coinciden en las posiciones de aparición de los centros de interés en sus respectivos listados. Así, en los primeros rangos aparecen en los dos casos las áreas temáticas de Animales (1), Cuerpo (2), Alimentos (3), Escuela (4) y Ciudad (5), mientras que en las últimas posiciones coinciden también los campos semánticos Jardín (17), Iluminación (16), Mesa (15) y Muebles (14).

Si atendemos ahora al índice de cohesión, comprobamos en qué medida convergen las respuestas de los informantes femeninos y masculinos en cada uno de los centros de interés. Como se puede apreciar en la tabla 5.2.2, los campos léxicos más cohesionados en las mujeres son, por este orden: Cuerpo, Ropa, Animales, Transporte y Colores. Por el contrario, las chicas muestran un léxico más disperso en centros de interés como los de Juegos, Jardín, Campo, Profesiones y Ciudad, donde los estímulos verbales se abren a más asociaciones significativas de carácter secundario. Por otro lado, entre los chicos, los centros más cohesionados son los correspondientes al Cuerpo y la Ropa (coincidiendo en ello con las chicas), pero también las Partes de la casa, los Muebles y los Medios de transporte. En el extremo opuesto, y como campos léxicos 
más dispersos, figuran los mismos que entre las mujeres: Jardín, Juegos, Campo, Profesiones y Ciudad.

Por otro lado, la coincidencia básica de los rangos en las posiciones más bajas de la tabla (de la 13 a la 17) manifiesta el carácter más abierto de esos estímulos verbales en los dos grupos, justo al revés que en los centros más cohesionados léxicamente (Cuerpo, Ropa y Transporte), en los que, sin embargo, hombres y mujeres muestran también un alto nivel de coincidencia. Con todo, se aprecia un mayor grado de concreción, o sea, una mayor afinidad en las respuestas de las chicas en seis categorías semánticas (Cuerpo, Alimentos, Transporte, Jardín, Animales y Colores). Por su parte, los jóvenes de sexo masculino solo muestran mayor homogeneidad en dos centros (Ropa y Muebles). Pese a ello, la prueba t no encuentra esta vez como significativas las diferencias globales entre un grupo y otro (t: -0,76; p. 0,22; gdl: 16).

En definitiva, vemos cómo las estudiantes castellonenses exhiben un léxico disponible algo mayor, pero no necesariamente más cohesionado que sus compañeros.

\subsubsection{Ubicación del centro}

Al igual que en otros trabajos de disponibilidad léxica, otra de las variables extralingüísticas analizadas en esta investigación ha sido la ubicación del centro educativo de los informantes, es decir, si se sitúan en zona urbana o rural. Aunque en la bibliografía sociológica se aplican diferentes criterios demográficos para establecer la división entre zona urbana y zona rural, ${ }^{149}$ en este trabajo hemos considerado como urbanos únicamente los centros ubicados en la capital de la provincia (Castellón de la Plana), y como rurales los emplazados en el resto de poblaciones, como ya explicamos en el apartado 4.1 .

En las investigaciones previas sobre esta variable social, encontramos dos posibilidades. Por un lado, están quienes analizan la zona donde se ubican los centros educativos y, por otro, quienes se detienen preferentemente en el lugar de residencia de los informantes. ${ }^{150}$ Hay que subrayar que en nuestro caso, la coincidencia entre ambas

\footnotetext{
${ }^{149}$ El proyecto del léxico disponible de España tiene en cuenta la convención establecida por el INE para establecer la distinción entre zona rural y zona urbana (Carcedo 2001, Bartol y Hernández Muñoz, 2006).

${ }^{150}$ En Cuenca, Natividad Hernádez (2004) analiza la variable 'comarcas geográficas' y, más tarde, en su tesis doctoral (Hernández Muñoz, 2006), el lugar de residencia de los padres, factor este último que es
} 
variantes es casi absoluta, ya que la inmensa mayoría de los estudiantes vive en las localidades donde realizan sus estudios. Así, pues, no distinguiremos entre ubicación del centro y residencia familiar.

En la tabla siguiente indicamos las cifras globales correspondientes al número de palabras y vocablos que apuntan los alumnos que estudian en centros urbanos y rurales por áreas temáticas.

\begin{tabular}{|l|c|c|c|c|}
\hline Centros de interés & \multicolumn{2}{|c|}{ Urbano } & \multicolumn{2}{c|}{ Rural } \\
\hline & PT & PD & PT & PD \\
\hline 01. Partes del cuerpo & 4345 & 212 & 4803 & 235 \\
\hline 02. La ropa & 3948 & 212 & 4147 & 256 \\
\hline 03. Partes de la casa & 2850 & 208 & 3054 & 243 \\
\hline 04. Muebles & 2517 & 213 & 2625 & 241 \\
\hline 05. Alimentos & 4421 & 428 & 4990 & 507 \\
\hline 06. Mesa & 2498 & 204 & 2779 & 262 \\
\hline 07. La cocina & 3135 & 347 & 3480 & 391 \\
\hline 08. La escuela & 3940 & 400 & 4453 & 472 \\
\hline 09. Iluminación & 2186 & 279 & 2491 & 360 \\
\hline 10. La ciudad & 4171 & 610 & 4578 & 694 \\
\hline 11. El campo & 3437 & 731 & 4035 & 786 \\
\hline 12. Transporte & 3224 & 227 & 3602 & 292 \\
\hline 13. Jardín & 1891 & 412 & 2112 & 476 \\
\hline 14. Los animales & 4638 & 315 & 5413 & 385 \\
\hline 15. Juegos & 3455 & 595 & 3435 & 655 \\
\hline 16.Profesiones & 3900 & 523 & 4207 & 574 \\
\hline 17. Los colores & 3262 & 243 & 3770 & 270 \\
\hline TOTALES & 57818 & 6159 & 63974 & 7099 \\
\hline
\end{tabular}

Tabla 5.2.4. Número de Palabras totales (PT) y palabras diferentes (PD) según la variable ubicación del centro (zona urbana o zona rural).

Si observamos la tabla anterior, advertimos que el número de palabras globales y de vocablos diferentes es mayor en las zonas rurales que en las urbanas, un resultado poco frecuente en los estudios de disponibilidad realizados hasta la fecha. ${ }^{151}$ Los estudiantes del hábitat rural aventajan a los de los centros urbanos en 6156 palabras y 940 vocablos. Las diferencias mayores se dan en los campos léxicos Alimentos (79 vocablos), Escuela (72), Iluminación (81), Ciudad (84) o Animales (70). Por otro lado, en ninguna ocasión superan los informantes urbanos a los rurales, aunque el rango de los centros de interés es el mismo en las primeras posiciones teniendo en cuenta la

considerado, igualmente, en Valencia por Gómez Devís (2003). Por su parte, Enguita (2008) realiza un análisis conjunto de ambos factores, ubicación del centro y lugar de residencia de los padres.

${ }^{151}$ Asimismo los alumnos de los centros rurales superan a sus compañeros de los centros ubicados en zonas urbanas en el estudio de Alicante, (Martínez Olmos, 2008). 
ubicación geográfica. Así encontramos los centros Campo, Ciudad, Juegos y distracciones y Profesiones en ese mismo orden, y, por tanto, con mayor números de palabras y de vocablos.

Con todo, estas cifras podrían obedecer a la existencia de un ligero desequilibrio muestral favorable a las zonas rurales en el presente estudio, donde, como se recordará, estudiaban 189 alumnos (un 53\% del total), frente a los que lo hacían en centros de Castellón de la Plana (165 estudiantes, el 47\% restante). De esta manera, y como venimos haciendo con el resto de variables no estructurales, realizamos una comparación más ajustada y fiable acudiendo a los promedios de respuestas por informante, cuyos datos numéricos aparecen en la tabla 5.2.5.

\begin{tabular}{|l|c|c|c|c|c|c|}
\hline \multicolumn{1}{|c|}{ Centro de interés } & \multicolumn{3}{c|}{ Urbano } & \multicolumn{3}{c|}{ Rural } \\
\hline & P.I. & R & I.C. & P.I. & R & I.C. \\
\hline 01. Partes del cuerpo & 26.33 & 3 & 0.12 & 25.41 & 3 & 0.11 \\
\hline 02. La ropa & 23.93 & 5 & 0.11 & 21.94 & 7 & 0.09 \\
\hline 03. Partes de la casa & 17.27 & 13 & 0.08 & 16.16 & 13 & 0.07 \\
\hline 04. Los muebles & 15.25 & 14 & 0.07 & 13.89 & 14 & 0.06 \\
\hline 05. Alimentos & 26.79 & 2 & 0.06 & 26.40 & 2 & 0.05 \\
\hline 06. Mesa & 15.14 & 15 & 0.07 & 14.70 & 15 & 0.06 \\
\hline 07. La cocina & 19.00 & 12 & 0.05 & 18.41 & 11 & 0.05 \\
\hline 08. La escuela & 23.88 & 6 & 0.06 & 23.56 & 5 & 0.05 \\
\hline 09. Iluminación & 13.25 & 16 & 0.05 & 13.18 & 16 & 0.04 \\
\hline 10. La ciudad & 25.28 & 4 & 0.04 & 24.22 & 4 & 0.03 \\
\hline 11. El campo & 20.83 & 9 & 0.03 & 21.35 & 8 & 0.03 \\
\hline 12. Transporte & 19.54 & 11 & 0.09 & 19.06 & 10 & 0.07 \\
\hline 13. Jardín & 11.46 & 17 & 0.03 & 11.17 & 17 & 0.02 \\
\hline 14. Los animales & 28.11 & 1 & 0.09 & 28.64 & 1 & 0.07 \\
\hline 15.Juegos & 20.94 & 8 & 0.04 & 18.17 & 12 & 0.03 \\
\hline 16. Profesiones & 23.64 & 7 & 0.05 & 22.26 & 6 & 0.04 \\
\hline 17. Los colores & 19.77 & 10 & 0.08 & 19.95 & 9 & 0.07 \\
\hline PROMEDIO GLOBAL & 20.61 & & 0.065 & 19.91 & 0.055 \\
\hline
\end{tabular}

Tabla 5.2.5. Promedio de respuestas por informante e índice de cohesión por centro de interés según la variable ubicación del centro educativo.

Leyenda:

P.I. Palabra por informante

I.C. Índice de cohesión

R. Rango

La comparación entre esta tabla y la anterior nos permite apreciar algunos cambios relevantes, porque en esta ocasión son los estudiantes de los centros urbanos los que, globalmente, aventajan a sus compañeros de los centros rurales, con diferencias que son significativas según el estadístico t (t: 3,36; p. >001; dgl: 16). Por centros de 
interés, esta ventaja se aprecia además en catorce de los diecisiete campos asociativos de que consta el estudio, quedando por encima solo en tres (significativamente los de Campo y Animales, áreas temáticas ligadas a la vida rural, así como el de los Colores) los alumnos que estudian en centros rurales, (gráfico 5.2.2). Con todo, y como puede observarse en la tabla 5.2.6, ninguna de estas diferencias es significativa a la luz de la muestra disponible, a diferencia de lo que ocurre con los centros de interés donde los alumnos de centros urbanos puntúan por encima.

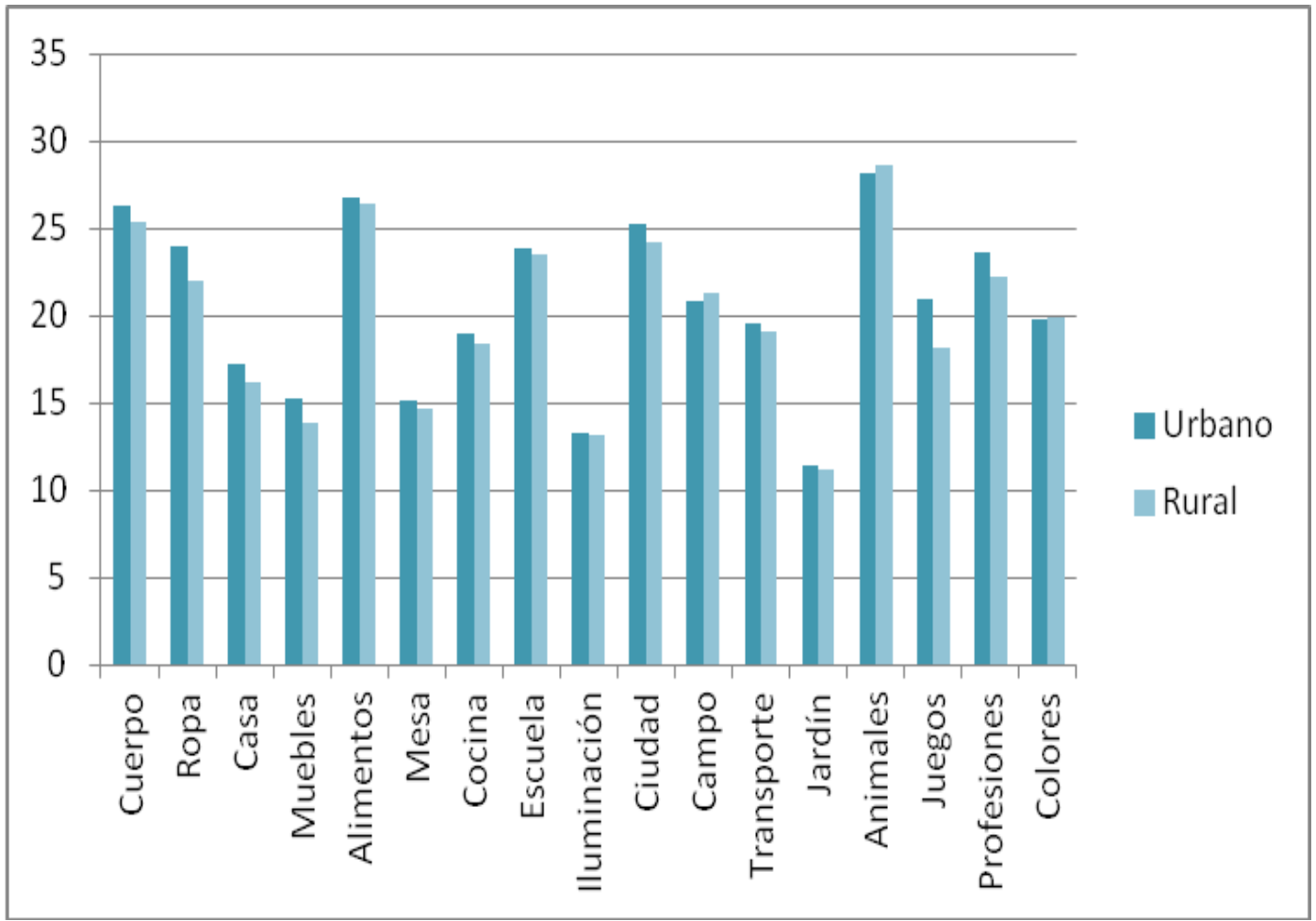

Gráfico 5.2.2. Palabras por informantes por centro de interés según la variable Ubicación de centro educativo. 


\begin{tabular}{|l|c|}
\hline Centros de interés & Ubicación del centro \\
\hline Cuerpo & .050 \\
\hline Ropa & .000 \\
\hline Casa & .001 \\
\hline Muebles & .001 \\
\hline Alimentos & .045 \\
\hline Mesa & .013 \\
\hline Cocina & .009 \\
\hline Escuela & .425 \\
\hline Iluminación & .628 \\
\hline Ciudad & .022 \\
\hline Campo & .989 \\
\hline Transporte & .071 \\
\hline Jardín & .276 \\
\hline Animales & .292 \\
\hline Juegos & .000 \\
\hline Profesión & .072 \\
\hline Colores & .951 \\
\hline
\end{tabular}

Tabla 5.2.6: Grado de significación de las diferencias en el promedio de respuestas por centros de interés en función de la ubicación del centro (prueba t para la comparación de dos muestras emparejadas)

Si analizamos ahora el orden de los rangos obtenidos por cada centro de interés, volvemos a encontrar coincidencia en los primeros de la lista. Así, tanto los estudiantes urbanos como los alumnos que estudian en centros rurales coinciden en los primeros puestos conseguidos por los siguientes centros, que, por orden descendente, son: Animales, Alimentos, Cuerpo y Ciudad. Igualmente, ambos grupos coinciden en la última posición en la esfera semántica de los Trabajos del campo y del jardín, resultado que cuando menos resulta curioso, ya que, al menos inicialmente, podría sospecharse una mejor posición para los centros de ubicación rural. Por último, los demás estímulos verbales ocupan posiciones intermedias, no siempre coincidentes, que, en todo caso, indican una productividad léxica media en ambas submuestras.

Por otro lado, al analizar el índice de cohesión (Ver tabla 5.2.5.), observamos también cómo los alumnos de centros rurales van siempre por debajo respecto a los estudiantes urbanos en cuanto al grado de congruencia de los respectivos léxicos disponibles. Estas diferencias son significativas, tanto globalmente (valor t: 7,86; p. $>001$ ), como en el contraste entre los diferentes centros de interés. En efecto, tal como se puede observar en la tabla 5.2.5, los estudiantes de Castellón de la Plana aventajan a 
sus compañeros de los pueblos en 15 de los 17 centros asociativos, al tiempo que tan solo en dos (La cocina y El campo) se produce un empate.

Con esto se constata una mayor convergencia asociativa en los alumnos que estudian en centros urbanos, cuyo vocabulario disponible aparece, en consonancia, más cohesionado que en el rural. Con todo, ambas submuestras coinciden en los estímulos verbales que ofrecen mayores y menores índices de cohesión. De este modo, los campos semánticos más difusos son en ambos casos El campo, Jardín, La ciudad y Juegos y distracciones. En cambio, las áreas más compactas en los dos grupos son: Cuerpo, Ropa, Transporte y Animales.

\subsubsection{Tipo de centro}

La mayoría de los estudios de disponibilidad realizados hasta ahora han puesto de relieve una superioridad léxica de los informantes que cursan sus estudios en centros privados. Así se comprueba en Almería (Mateo, 1998), Asturias (Carcedo, 2001), Cádiz (González Martínez, 2002), Ávila, Zamora y Salamanca (Galloso, 2003a), Valencia (Gómez Molina y Gómez Devís, 2004), Huelva (Prado y Galloso, 2005), Castilla-La Mancha (Hernández Muñoz, 2006), Galicia (López Meirama, 2008), Burgos (Fernández Juncal, 2008), Lérida (Serrano, 2014), Alicante ( Martínez Olmos, 2008), entre otros. Sin embargo, no siempre las diferencias entre los alumnos de colegios privados y públicos han sido tan evidentes. En Soria, por ejemplo (Bartol, 2004), este factor extralingüístico no posee la importancia que parece tener en otros lugares, lo que invita a investigar con más detalle y, sobre todo, a relacionar esta variable independiente con otras que pueden estar íntimamente relacionadas, como, por ejemplo, el nivel sociocultural de las familias donde esos estudiantes se desenvuelven. Factor este último que sí marca algunas diferencias -especialmente entre los grupos extremos-, y de ahí que no convenga olvidar que, en muchas ciudades de nuestro país, los alumnos con un poder adquisitivo más elevado suelen acudir a instituciones privadas, quedando relegados los centros públicos para los hijos de las clases menos acomodadas y, en los últimos tiempos también, al alumnado inmigrante. 
Tradicionalmente, no ha sido, sin embargo, el caso de la provincia de Castellón, lo que quizá sirva para explicar la aparente anomalía que arrojan los datos castellonenses, y que analizamos en el presente apartado.

Como se recordará, de la totalidad de informantes de la muestra, 229 (65\%) alumnos estudiaban en centros públicos y 125 (35\%) lo hacían en colegios privados $(35 \%)$. Como es lógico, esa desproporción se traduce en una mayor producción léxica por parte de los primeros, con un total de 39298 palabras y 2199 vocablos más que los estudiantes de centros privados. Las áreas temáticas que presentan mayor número de términos en ambos grupos son, por este orden, los de: El campo, La ciudad, Juegos, y Profesiones. A partir de la cuarta posición, sin embargo, los rangos de los demás campos asociativos ya no coinciden.

\begin{tabular}{|l|c|c|c|c|}
\hline \multicolumn{1}{|c|}{ Centros de interés } & \multicolumn{2}{c|}{ Público } & \multicolumn{2}{c|}{ Privado } \\
\hline & PT & PD & PT & PD \\
\hline 01. Partes del cuerpo & 5891 & 252 & 3257 & 190 \\
\hline 02. La ropa & 5265 & 271 & 2830 & 196 \\
\hline 03. Partes de la casa (sin muebles) & 3799 & 249 & 2105 & 195 \\
\hline 04. Los muebles de la casa & 3413 & 255 & 1729 & 189 \\
\hline 05. Alimentos y bebidas & 6173 & 521 & 3238 & 407 \\
\hline 06. Mesa & 3454 & 254 & 1823 & 201 \\
\hline 07. La cocina y sus utensilios & 4429 & 417 & 2186 & 318 \\
\hline 08. La escuela: muebles y materiales & 5440 & 493 & 2953 & 366 \\
\hline 09. Iluminación & 3081 & 371 & 1596 & 267 \\
\hline 10. La ciudad & 5690 & 752 & 3059 & 536 \\
\hline 11. El campo & 4878 & 857 & 2594 & 642 \\
\hline 12. Medios de transporte & 4650 & 315 & 2176 & 170 \\
\hline 13. Trabajos del campo y del jardín & 2660 & 536 & 1343 & 338 \\
\hline 14. Los animales & 6613 & 396 & 3438 & 298 \\
\hline 15. Juegos y distracciones & 4503 & 722 & 2387 & 522 \\
\hline 16.Profesiones y oficios & 5302 & 642 & 2805 & 426 \\
\hline 17. Los colores & 4854 & 326 & 2178 & 166 \\
\hline \multicolumn{1}{|c|}{ TOTALES } & 80995 & 7629 & 41697 & 5430 \\
\hline
\end{tabular}

Tabla 5.2.7. Palabras totales (PT) y palabras diferentes (PD) según el tipo de enseñanza

Con todo, y al igual que hemos visto con otras variables independientes, es en el promedio de respuestas por informante donde apreciamos mejor las divergencias de productividad léxica entre los dos grupos, como se puede comprobar en la tabla 5.2.8 y de forma más gráfica en el gráfico 5.2.3. 


\begin{tabular}{|l|c|c|c|c|}
\hline \multicolumn{1}{|c|}{ Centros de interés } & \multicolumn{2}{c|}{ Público } & \multicolumn{2}{c|}{ Privado } \\
\hline & PI & IC & PI & IC \\
\hline 01. Partes del cuerpo & 25.72 & 0.10 & 26.06 & 0.14 \\
\hline 02. La ropa & 22.99 & 0.08 & 22.64 & 0.12 \\
\hline 03. Partes de la casa (sin muebles) & 16.59 & 0.07 & 16.84 & 0.09 \\
\hline 04. Los muebles de la casa & 14.90 & 0.06 & 13.83 & 0.07 \\
\hline 05. Alimentos y bebidas & 26.96 & 0.05 & 25.90 & 0.06 \\
\hline 06. Mesa & 15.08 & 0.06 & 14.58 & 0.07 \\
\hline 07. La cocina y sus utensilios & 19.34 & 0.05 & 17.49 & 0.05 \\
\hline 08. La escuela: muebles y materiales & 23.76 & 0.05 & 23.62 & 0.06 \\
\hline 09. Iluminación & 13.45 & 0.04 & 12.77 & 0.05 \\
\hline 10. La ciudad & 24.85 & 0.03 & 24.47 & 0.05 \\
\hline 11. El campo & 21.30 & 0.02 & 20.75 & 0.03 \\
\hline 12. Medios de transporte & 20.31 & 0.06 & 17.41 & 0.10 \\
\hline 13. Trabajos del campo y del jardín & 11.62 & 0.02 & 10.74 & 0.03 \\
\hline 14. Los animales & 28.88 & 0.07 & 27.50 & 0.09 \\
\hline 15. Juegos y distracciones & 19.66 & 0.03 & 19.10 & 0.04 \\
\hline 16. Profesiones y oficios & 23.15 & 0.04 & 22.44 & 0.05 \\
\hline 17. Los colores & 21.20 & 0.07 & 17.42 & 0.10 \\
\hline PROMEDIO GLOBAL & 20.80 & 0.052 & 19.62 & 0.070 \\
\hline
\end{tabular}

Tabla 5.2.8. Promedio de palabras por informante e índice de cohesión por centros de interés y según la variable tipo de centro.

Leyenda:

PI: Palabra por informante

IC: Índice de cohesión 


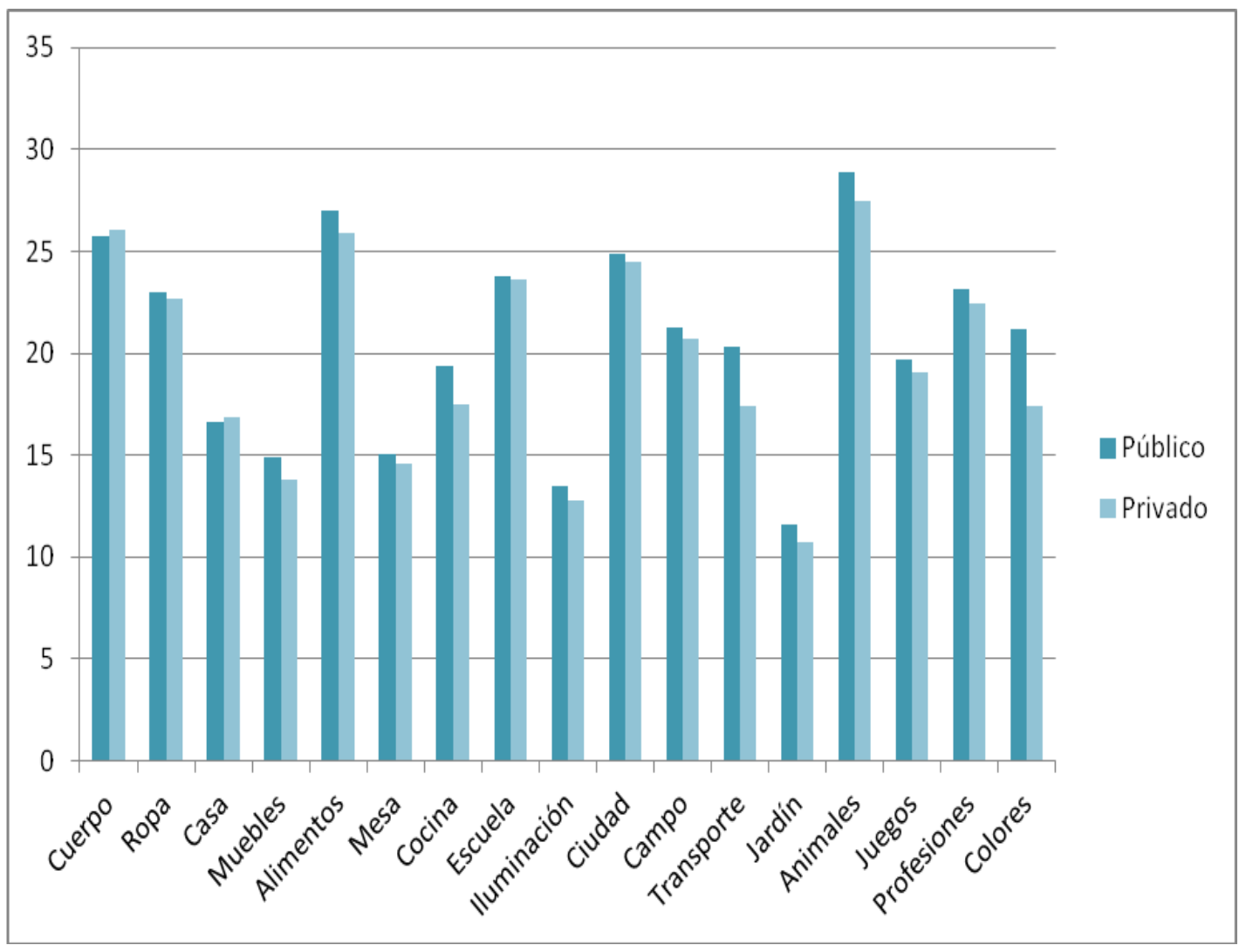

Gráfico 5.2.3. Porcentaje de palabras por informantes por centros de interés según la variable tipo de centro.

Los alumnos de centros públicos obtienen un promedio de 20.80 de respuestas, frente a las 19.62 que alcanzan aquellos que estudian en instituciones privadas. Estas diferencias globales, aunque menores, son significativas de acuerdo con la prueba t para la comparación de medias (t: 3.71; p.:0.001; gdl:16). Solo en dos estímulos verbales superan los estudiantes de colegios privados a los correspondientes de centros públicos en el número de unidades léxicas: Partes del cuerpo y Partes de la casa, pero con distancias mínimas (0.34 y 0.25 puntos respectivamente) y no significativas estadísticamente (p. 0.510). En los demás campos semánticos, los alumnos de los institutos públicos aventajan a sus compañeros de centros privados. En algunas ocasiones con notables diferencias, como en Medios de transporte (p. 0.02) y Colores (p. 0.000), donde se actualizan tres palabras más (2.86 y 3.78 respectivamente) a favor de informantes de colegios públicos. Asimismo, observamos un punto de distancia en áreas nocionales como Muebles (1.07), Alimentos (1.06), Cocina (1.85) y Animales (1.38). Sin embargo, tan solo en dos de estos casos - Cocina (p. 0.017) y Animales (p. 0.050)- las diferencias resultan significativas (véase tabla 5.2.9). 


\begin{tabular}{|l|c|}
\hline Centros de interés & Tipo de centro \\
\hline Cuerpo & .510 \\
\hline Ropa & .406 \\
\hline Casa & .386 \\
\hline Muebles & .199 \\
\hline Alimentos & .309 \\
\hline Mesa & .990 \\
\hline Cocina & .017 \\
\hline Escuela & .337 \\
\hline Iluminación & .243 \\
\hline Ciudad & .978 \\
\hline Campo & .504 \\
\hline Transporte & .002 \\
\hline Jardín & .300 \\
\hline Animales & .050 \\
\hline Juegos & .394 \\
\hline Profesión & .788 \\
\hline Colores & .000 \\
\hline
\end{tabular}

5.2.9. Grado de significación de las diferencias en el promedio de respuestas en función del tipo de centro (prueba t para la comparación de dos muestras emparejadas)

Esta leve ventaja de los estudiantes de los institutos públicos en Castellón frente a lo que demuestran otros estudios de disponibilidad, sugiere que la distribución sociocultural del alumnado en los centros de nuestra provincia es distinta. De hecho, tradicionalmente en Castellón, la distribución del alumnado entre colegios públicos y privados $^{152}$ está mucho menos ligada al poder adquisitivo de las familias, y sí a otras consideraciones religiosas, sociales, culturales, etc. De ahí que, en los centros concertados, regidos por unas normas por lo demás muy similares a las que hallamos en los colegios públicos, podamos encontrar alumnos de muy diversa procedencia social: desde los hijos de las clases acomodadas a aquellos que proceden de clases mediasbajas, una distribución social que es relativamente fácil advertir también en los centros públicos de la provincia, especialmente en algunos con un prestigio labrado a lo largo de muchos años (Ribalta, Sos Baynat, Penyagolosa, Benicarló...). En los últimos tiempos, las diferencias sociales entre el estudiantado de ambos tipos de centros se han

152 Otra cosa son algunos colegios privados, como los colegios bilingües, más elitistas, pero no contemplados en la presente investigación, ya que en el momento de pasar las encuestas no existían todavía en Castellón. 
ensanchado, sobre todo por la presencia casi exclusiva de inmigrantes en institutos públicos, pero no era así en el momento en que se realizaron las encuestas.

Por lo que a los rangos se refiere, estos presentan pautas cercanas, especialmente destacadas en las primeras posiciones de la tabla. Así, ambos grupos sociales coinciden en la primera y cuarta posiciones en los centros de Animales y La ciudad. En los puestos segundo y tercero hay, sin embargo, una inversión. De este modo, la segunda posición entre los estudiantes de entidades privadas es para el área asociativa Alimentos, mientras que este ocupa el tercer rango para los alumnos de enseñanza pública; y viceversa: el centro que aparece en tercer lugar para los colegios privados, Partes del cuerpo, lo encontramos en la segunda posición en los institutos. La coincidencia la volvemos a ver en los últimos rangos, posiciones número 15, 16 y 17 con Muebles de la casa, Iluminación y Trabajos del campo y del jardín, centros de interés con el menor número de unidades léxicas, aunque siempre los alumnos de instituciones públicas superan, como hemos visto, a los correspondientes en las privadas.

Ahora bien, si en los índices de disponibilidad léxica los alumnos de centros públicos superan levemente a los estudiantes de centros privados, tanto en términos generales como, de forma más clara, en algunos centros de interés específicos, las cosas son distintas por lo que al índice de cohesión se refiere. Esta vez es el alumnado de centros privados quien muestra un lexicón más congruente $(0,07)$ que el de los colegios públicos $(0,05)$, diferencias que son de nuevo globalmente significativas de acuerdo con la prueba $\mathrm{t}$ para la comparación de medias independientes (t: -5,81; p. 0.000; gdl: 16). Estas diferencias son más destacadas en algunos centros de interés, como Partes del cuerpo, La ropa y Medios de transporte, donde los privados superan a los públicos en cuatro décimas, seguidos por Los colores, con tres décimas. Los demás campos léxicos lo hacen también, pero con diferencias ya menores (en torno a una décima).

Sea como sea, también en esta esfera encontramos algunos puntos de afinidad. Así, los rangos nos informan de que para ambos grupos las áreas nocionales más compactas o cerradas son El cuerpo, La ropa, La casa, Animales y Los colores. Y, en sentido contrario, las más abiertas a asociaciones secundarias o difusas son los estímulos verbales de El campo, La ciudad, Jardín o Juegos. Por lo tanto, a pesar de las divergencias, ambos grupos sociales actúan de la misma forma y tienen el mismo carácter (abierto o cerrado) en las diecisiete áreas léxicas. 


\subsubsection{Lengua materna ${ }^{153}$}

En este trabajo consideramos como lengua materna aquella que se adquiere de forma natural y se aprende en el entorno familiar (López Morales, 1986; Battaner 1994). En las comunidades analizadas, se trata, además, de la lengua de uso más habitual en la comunicación cotidiana. En consecuencia, la lengua materna es el idioma que las personas aprenden en su infancia y que se convierte en el instrumento natural del pensamiento y la comunicación. Por lo general, es la lengua de sus padres y de la realidad familiar más cercana, la que le sirve, en definitiva, para conocer el mundo, con la que piensa y se comunica con mayor fluidez y espontaneidad. Con todo, en muchas regiones del mundo -y la castellonense no es una excepción- hay hablantes en los que se dan cita más de una lengua materna, como ocurre, por ejemplo, con los hijos de matrimonios mixtos.

La influencia de este hecho, íntimamente asociado al bilingüismo social, se ha recogido también en diferentes estudios realizados en regiones de España en las que coexisten dos lenguas de uso habitual y oficial, como ocurre en el País Vasco ${ }^{154}$, Cataluña ${ }^{155}$, Galicia ${ }^{156}$, Asturias ${ }^{157}$, Navarra ${ }^{158}$ y la Comunidad Valenciana ${ }^{159}$, comunidad esta última a la que pertenece también la provincia objeto de estudio en esta investigación. Asimismo, el factor se ha analizado en otras áreas donde el español

\footnotetext{
${ }^{153}$ Véase un antecedente de este análisis, a partir de algunos resultados parciales de este cuestionario en Blas Arroyo y Casanova Ávalos (2003b).

${ }^{154}$ Maitena Etxebarria (1996), en su estudio sobre el País Vasco, también analiza este factor asociado al bilingüismo, aunque partiendo esta vez del modelo de enseñanza y no estrictamente de la lengua materna del estudiante.

${ }^{155}$ De Cataluña, el único trabajo sobre léxico disponible terminado a día de hoy es el de Lérida (Serrano, 2014). Está en marcha la investigación sobre Barcelona.

${ }^{156}$ Recordamos que en el trabajo sobre Galicia, López Meirama (2008) analiza la lengua habitual y establece tres grupos, alumnos que hablan castellano, aquellos que hablan gallego y un tercer grupo con aquellos bilingües que hablan ambas lenguas, sin un claro predomino de una sobre la otra.

${ }^{157}$ Carcedo (2001) divide el territorio asturiano en cinco grupos lingüísticos: bable central capital, bable central no capital, bable oriental, bable occidental y zona del gallego-asturiano. El Estatuto de Autonomía de Asturias, no recoge la lengua asturiana como lengua oficial, aunque hay una ley que sí regula su uso.

${ }^{158}$ En la Comunidad Foral de Navarra tanto el castellano como el euskera son lenguas propias y oficiales. El castellano lo es en toda Navarra, mientras que el euskera solo en los territorios que la Ley Foral especifica (zona centro y norte).

${ }^{159}$ En Valencia, Gómez Molina y Gómez Devís (2004) analizan la lengua habitual de los informantes y únicamente concretan la muestra en dos grupos, los monolingües en castellano y los bilingües "aquellos sujetos que tienen como lengua de uso familiar, con los amigos y en el centro escolar mayoritariamente el valenciano o ambas" (p. 109). Por otra parte, Martínez Olmos (2008) en Alicante ha establecido las siguientes comunidades de habla: la Marina, el Comtat y el Alcoià, caracterizadas por un bilingüismo activo, aunque con predominio del valenciano; el Alacantí y el Vinalopó, con bilingüismo activo y predominio del castellano; y la zona del Bajo Segura y la zona del Alto Vinalopó, que pertenecen a comarcas de bilingüismo pasivo con claro dominio del castellano.
} 
convive con el árabe, como en las ciudades autónomas de Ceuta y Melilla ${ }^{160}$, si bien en ninguna de ellas el bilingüismo recibe el estatus de cooficial.

En el corpus castellonense hemos considerado tres grupos, con una distribución muestral desequilibrada:

1. Hablantes cuya lengua materna y dominante es el castellano. Este grupo se halla conformado por 139 estudiantes, lo que supone un $39 \%$ del total de alumnos (Castellano en la tabla).

2. Aquellos cuya lengua materna -y también dominante, por más habitual- es el valenciano. Se trata de la opción más numerosa, con 158 alumnos, lo que equivale a un $45 \%$ de la muestra (recogidos bajo la etiqueta de Valenciano).

3. Por último, se encuentran los estudiantes que han aprendido al mismo tiempo ambos idiomas desde temprana edad. Se trata de un subgrupo formado esta vez por 57 informantes, lo que representa el $16 \%$ de la muestra restante (Ambas en la tabla).

Como otras veces, iniciamos este análisis con las cifras globales de disponibilidad, que el lector puede ver en la tabla 5.2.10. En ella se muestran las palabras totales y los vocablos que los informantes han plasmado en las encuestas por cada área temática en función de su adscripción lingüística.

${ }^{160}$ Ceuta ha sido estudiada por Ayora (2006) y Melilla por Fernández Smith, Rico Martín, Jiménez Jiménez y Molina García (2008) 


\begin{tabular}{|l|c|c|c|c|c|c|}
\hline \multicolumn{1}{|c|}{ Centros de interés } & \multicolumn{2}{|c|}{ Valenciano } & \multicolumn{2}{c|}{ Castellano } & \multicolumn{2}{c|}{ Ambas } \\
\hline & PT & PD & PT & PD & PT & PD \\
\hline 01. Partes del cuerpo & 3963 & 218 & 3686 & 206 & 1499 & 169 \\
\hline 02. La ropa & 3433 & 228 & 3303 & 226 & 1359 & 168 \\
\hline 03. Partes de la casa & 2519 & 219 & 2337 & 200 & 1048 & 153 \\
\hline 04. Los muebles de la casa & 2239 & 222 & 2033 & 198 & 870 & 149 \\
\hline 05. Alimentos y bebidas & 4074 & 442 & 3734 & 429 & 1603 & 328 \\
\hline 06. Mesa & 2232 & 226 & 2093 & 210 & 952 & 148 \\
\hline 07. La cocina & 2813 & 328 & 2641 & 335 & 1161 & 244 \\
\hline 08. La escuela & 3718 & 419 & 3242 & 391 & 1433 & 264 \\
\hline 09. Iluminación & 2013 & 312 & 1828 & 273 & 836 & 201 \\
\hline 10. La ciudad & 3803 & 608 & 3465 & 581 & 1481 & 370 \\
\hline 11. El campo & 3249 & 721 & 2898 & 666 & 1325 & 459 \\
\hline 12. Transporte & 2950 & 272 & 2717 & 221 & 1159 & 152 \\
\hline 13. Jardín & 1781 & 429 & 1528 & 360 & 694 & 239 \\
\hline 14. Los animales & 4398 & 362 & 3955 & 298 & 1698 & 256 \\
\hline 15. Juegos y distracciones & 2994 & 606 & 2692 & 565 & 1204 & 358 \\
\hline 16.Profesiones y oficios & 3569 & 521 & 3135 & 502 & 1403 & 345 \\
\hline 17. Los colores & 3245 & 272 & 2592 & 202 & 1195 & 170 \\
\hline TOTALES & 50993 & 6405 & 47879 & 5863 & 20923 & 4173 \\
\hline
\end{tabular}

Tabla 5.2.10. Palabras totales $(P T)$ y palabras diferentes $(P D)$ según la variable lengua materna

Con todo, dadas las notables diferencias muestrales señaladas más arriba, se impone desde el principio una comparación entre los grupos a través de los correspondientes promedios de respuesta por informante, índices matemáticos más fiables para efectuar la comparación de los distintos grupos y obtener con ello resultados más sólidos.

En la tabla 5.2.11 observamos cómo los alumnos que indican que son bilingües totales, aquellos en los que el dominio tanto del castellano como del valenciano se da al mismo nivel, superan a todos sus compañeros, sean estos castellanohablantes o valencianohablantes, en todos los campos semánticos menos en el primero, Partes de сиеrpo, donde aparecen en primer lugar quienes tienen el castellano como lengua materna. Al mismo tiempo, los castellanohablantes obtienen mejores resultados que los valencianohablantes en todas las áreas nocionales a excepción de Trabajos del campo y del Jardin. ${ }^{161}$

\footnotetext{
${ }^{161}$ En un estudio preliminar de Serrano (2003: 91) sobre alumnos de Lérida, sin embargo, eran los estudiantes de habla catalana quienes superaban a sus compañeros castellanohablantes en todos los centros de interés. Sin embargo, en los resultados de su tesis (2014), al analizar una muestra mucho más amplia, los resultados de los cuatro grupos en los que se dividía la muestra (hablantes en castellano, en catalán, ambas lenguas como maternas y aranés), eran los informantes con el castellano y el catalán aprendidos desde la infancia los que superaban a los demás grupos.
} 
Las diferencias globales entre los grupos son significativas de acuerdo con la prueba $t$, con probabilidades que oscilan entre $\mathrm{p}>.0,01$ (castellanohablantes valencianohablantes) y p. >001 (resto de combinaciones).

\begin{tabular}{|l|c|c|c|c|c|c|}
\hline \multicolumn{1}{|c|}{ Centros de interés } & \multicolumn{2}{|c|}{ Valenciano } & \multicolumn{2}{c|}{ Castellano } & \multicolumn{2}{c|}{ Ambas } \\
\hline & PI & IC & PT & IC & PT & IC \\
\hline 01. Partes del cuerpo & 25.08 & 0.12 & 26.52 & 0.13 & 26.30 & 0.16 \\
\hline 02. La ropa & 21.73 & 0.10 & 23.76 & 0.11 & 23.84 & 0.14 \\
\hline 03. Partes de la casa & 15.94 & 0.07 & 16.81 & 0.08 & 18.39 & 0.12 \\
\hline 04. Muebles casa & 14.17 & 0.06 & 14.63 & 0.07 & 15.26 & 0.10 \\
\hline 05. Alimentos & 25.78 & 0.06 & 26.86 & 0.06 & 28.12 & 0.09 \\
\hline 06. Mesa & 14.13 & 0.06 & 15.06 & 0.07 & 16.70 & 0.11 \\
\hline 07. Cocina & 17.80 & 0.05 & 19.00 & 0.06 & 20.37 & 0.08 \\
\hline 08. Escuela & 23.53 & 0.06 & 23.32 & 0.06 & 25.14 & 0.10 \\
\hline 09. Iluminación & 12.74 & 0.04 & 13.15 & 0.05 & 14.67 & 0.07 \\
\hline 10. La ciudad & 24.07 & 0.04 & 24.93 & 0.04 & 25.98 & 0.07 \\
\hline 11. El campo & 20.56 & 0.03 & 20.85 & 0.03 & 23.25 & 0.05 \\
\hline 12. Transporte & 18.67 & 0.07 & 19.55 & 0.09 & 20.33 & 0.13 \\
\hline 13. Jardín & 11.27 & 0.03 & 10.99 & 0.03 & 12.18 & 0.05 \\
\hline 14. Animales & 27.84 & 0.08 & 28.45 & 0.10 & 29.79 & 0.12 \\
\hline 15. Juegos & 18.95 & 0.03 & 19.37 & 0.03 & 21.12 & 0.06 \\
\hline 16. Profesiones & 22.59 & 0.04 & 22.55 & 0.04 & 24.61 & 0.07 \\
\hline 17. Colores & 20.54 & 0.08 & 18.65 & 0.09 & 20.96 & 0.12 \\
\hline PROMEDIO GLOBAL & 19.72 & 0.06 & 20.26 & 0.067 & 21.58 & 0.096 \\
\hline
\end{tabular}

Tabla 5.2.11. Palabras por informante e índice de cohesión por centros de interés según la variable lengua materna

Leyenda:

PI: Palabra por informante

IC: Î́ndice de cohesión

En suma, los bilingües equilibrados aparecen en esta investigación como los informantes con una mayor disponibilidad léxica, seguidos por los castellanohablantes. Por último, y como cabía esperar, aquellos informantes que no tienen el castellano como lengua materna, sino segunda, muestran una disponibilidad menor.

A pesar de esas diferencias, los rangos ocupados por los centros de interés son similares, en los tres grupos lectales. Así ocurre en las cuatro primeras posiciones: Animales, Alimentos, Partes del cuerpo y La ciudad. Igualmente, vuelven a coincidir en los dos últimos centros asociativos, que corresponden a Trabajos del campo y del Jardín y a Iluminación. Además, el resto de áreas temáticas oscila en apenas una o dos posiciones. Todo ello queda mejor reflejado en el gráfico 5.2.4: 


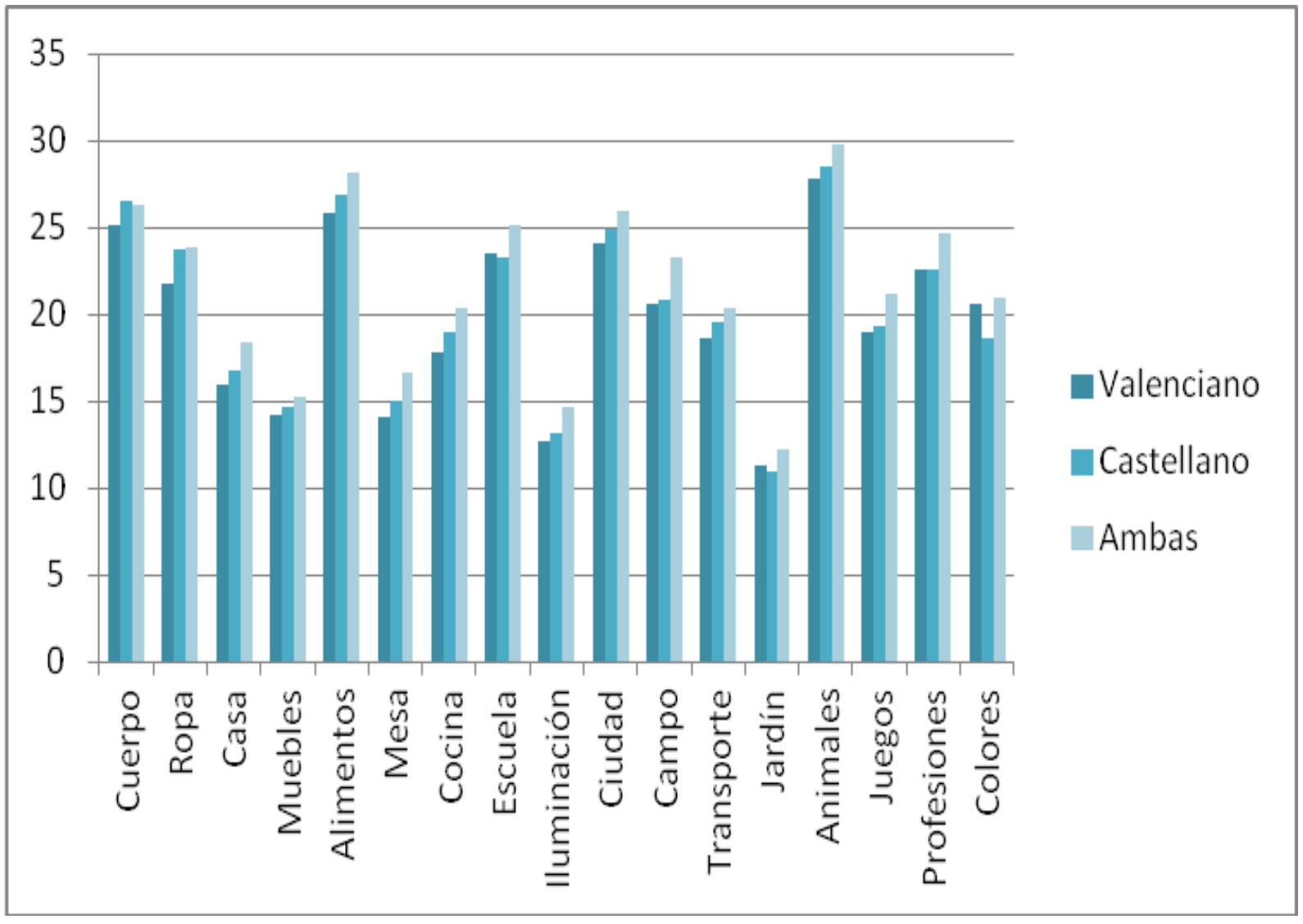

Gráfico 5.2.4. Promedio de palabras por informantes por centros de interés según la lengua materna

Complementariamente, los bilingües equilibrados no solo muestran una mayor disponibilidad léxica, sino también mayores índices de cohesión, o lo que es lo mismo, un vocabulario más congruente. A estos les siguen los alumnos de lengua materna castellana, mientras que una vez más cierran la lista los valencianohablantes. Por otro lado, estas diferencias son de nuevo significativas en todas las comparaciones posibles (con valores p.>001), lo que avala su relevancia. Pese a ello, también en este apartado observamos algunos puntos de coincidencia entre los tres grupos, como sucede con las áreas relativas al Cuerpo, Ropa, Animales y Color (por ese orden), que en todos los grupos aparecen como las más compactas, es decir, las más difíciles de ser ampliadas con asociaciones circunstanciales. Asimismo, vuelven a coincidir en los centros de interés más difusos, aquellos que se ven más frecuentemente ampliados por unidades léxicas secundarias: Campo, Jardín y Juegos.

En definitiva, tras el análisis empírico se comprueba que la variable independiente "lengua materna" aparece como una de las más significativas de todo el 
estudio. Aunque las diferencias entre los grupos no sean grandes, hemos comprobado cómo existe una gradación idéntica tanto en los índices de disponibilidad como en los de cohesión léxica. Con todo, la primera posición no es la ocupada, como podría esperarse en un principio, por los hablantes que declaran el castellano como lengua materna, sino por aquellos que desde su infancia han utilizado indistintamente esta lengua y el catalán, esto es, lo bilingües equilibrados fruto de matrimonios mixtos y contextos similares. En todo caso, este desenlace no es tan inesperado, ya que está en consonancia con los resultados positivos detectados tantas veces en el desarrollo verbal de los bilingües coordinados (Bathia y Ritchie, 2008; González 2008; Grosjean 2008). Como contrapartida, aunque esta vez sí como cabía esperar, la última posición es ocupada por quienes muestran un claro desequilibrio lingüístico a favor del catalán.

\subsubsection{Nivel educativo de los padres}

Tras décadas de investigaciones sociolingüísticas, se ha comprobado que la productividad léxica de los hablantes está íntimamente relacionada con su nivel sociocultural. Por esta razón, se trata de una variable independiente estudiada desde los primeros trabajos de López Morales (1973), y cuyo análisis ha continuado desde entonces en prácticamente todas las investigaciones sobre disponibilidad léxica, lo que ha permitido comprobar que la adquisición del léxico disponible evoluciona, por lo general, de acuerdo con el nivel sociocultural de las familias.

Para estratificar la muestra castellonense hemos tenido en cuenta el nivel académico de los padres, ${ }^{162}$ lo que nos ha permitido delimitar cuatro grupos de alumnos: a) nivel alto, formado por 29 alumnos (8\%); b) nivel medio-alto, con 83 informantes (23\%); c) nivel medio-bajo, compuesto por 98 estudiantes (28\%); y d) nivel bajo, donde se incluye el mayor número de representantes, $144(41 \%) .{ }^{163}$

\footnotetext{
162 Otras investigaciones han tenido también en cuenta la profesión de los padres, como es el caso de Gómez Molina y Gómez Devís, 2004; Hernández Muñoz, 2006; Fernández Juncal, 2013 entre otros. A estos parámetros hay que añadir un tercero, el de los ingresos familiares, que asimismo se ha analizado en otros estudios, como los de López Morales (1973) o Carcedo (2001). Por su parte, Serrano (2014) ha trabajado tanto con la profesión e ingresos de los padres como con el nivel cultural de la familia.

${ }^{163}$ Hay trabajos que solo han tenido en cuenta tres estratos socioculturales: alto, medio y bajo. Al respecto de esta disparidad en el número de grupos, véase el trabajo de Hernández Muñoz (2006), en el que esta autora realiza diversos ensayos para estratificar la muestra de Castilla-La Mancha y comprobar qué división consigue los resultados estadísticos más significativos.
} 
En la tabla 5.2.12 podemos ver el número de palabras y vocablos diferentes de cada uno de estos grupos, en el que, como no podía ser de otra manera, dado el desequilibrio muestral reseñado, el estrato bajo aparece en cabeza.

\begin{tabular}{|c|c|c|c|c|c|c|c|c|}
\hline \multirow[t]{2}{*}{ Centros de interés } & \multicolumn{2}{|c|}{ Nivel alto } & \multicolumn{2}{|c|}{$\begin{array}{l}\text { Nivel medio } \\
\text { alto }\end{array}$} & \multicolumn{2}{|c|}{$\begin{array}{l}\text { Nivel medio } \\
\text { bajo }\end{array}$} & \multicolumn{2}{|c|}{ Nivel bajo } \\
\hline & PT & PD & PT & PD & PT & PD & PT & PD \\
\hline 01. Cuerpo & 803 & 138 & 2176 & 174 & 2514 & 188 & 3655 & 213 \\
\hline 02. Ropa & 726 & 139 & 1942 & 184 & 2220 & 200 & 3207 & 216 \\
\hline 03. Casa & 536 & 122 & 1386 & 142 & 1634 & 189 & 2348 & 206 \\
\hline 04. Muebles & 446 & 111 & 1206 & 178 & 1430 & 176 & 2060 & 219 \\
\hline 05. Alimentos & 813 & 239 & 2228 & 354 & 2595 & 391 & 3775 & 439 \\
\hline 06. Mesa & 429 & 105 & 1248 & 177 & 1488 & 188 & 2112 & 216 \\
\hline 07. Cocina & 599 & 176 & 1558 & 268 & 1775 & 286 & 2683 & 340 \\
\hline 08. Escuela & 718 & 196 & 1997 & 301 & 2283 & 339 & 3395 & 398 \\
\hline 09. Iluminación & 419 & 119 & 1112 & 201 & 1320 & 249 & 1826 & 283 \\
\hline 10. Ciudad & 755 & 247 & 2109 & 442 & 2429 & 482 & 3456 & 576 \\
\hline 11. Campo & 678 & 295 & 1748 & 513 & 2070 & 592 & 2976 & 651 \\
\hline 12. Transporte & 569 & 133 & 1563 & 180 & 1872 & 202 & 2822 & 251 \\
\hline 13. Jardín & 355 & 121 & 923 & 275 & 1084 & 359 & 1634 & 384 \\
\hline 14. Animales & 872 & 207 & 2314 & 257 & 2777 & 293 & 4088 & 331 \\
\hline 15. Juegos & 646 & 261 & 1681 & 461 & 1926 & 447 & 2637 & 548 \\
\hline 16. Profesiones & 725 & 265 & 1901 & 380 & 2247 & 429 & 3234 & 497 \\
\hline 17. Colores & 655 & 124 & 1561 & 155 & 1952 & 215 & 2864 & 262 \\
\hline TOTALES & 10424 & 2720 & 28653 & 4542 & 33616 & 5222 & 48772 & 6030 \\
\hline
\end{tabular}

Tabla 5.2.12. Palabras totales $(P T)$ y palabras diferentes $(P D)$ según la variable nivel educativo de los padres

Sin embargo, es de nuevo en los promedios de palabras por informantes donde se aprecia mejor el comportamiento léxico de los estudiantes castellonenses. Si reparamos ahora en la tabla 5.2.13, se distingue con mayor precisión la actuación de los estudiantes en cada uno de los centros de interés. Y aquí vemos cómo los índices totales están ya bastante más compensados: al nivel educativo medio-alto corresponden los índices de disponibilidad léxica más elevados, con una media de 20.55 de vocablos por informante, seguidos de cerca por el nivel alto con 20.39 y a continuación por el nivel medio-bajo con 20.38. En este sentido, los resultados de los estudiantes castellonenses son similares a los de otras investigaciones, en las que se ha comprobado una diferencia favorable a los sociolectos altos, como en López Morales (1979), Echeverría (1991), Mateo (1988), Carcedo (2001), González Martínez (2002), Bellón (2003), Bartol (2004), Gómez Molina y Gómez Devís (2004), Hernández Muñoz (2006), Martínez 
Olmos (2008), Fernández Juncal (2013) o Serrano (2014). ${ }^{164}$ Sin embargo, las diferencias que mantienen entre sí estos tres grupos no son estadísticamente significativas, ni en términos globales, ni por centros de interés (ver tabla 5.2.13) por lo que no podemos descartar que obedezcan al azar. ${ }^{165}$

Por último, cierran la lista los alumnos del nivel bajo, con una media global de 19.86. Aunque las diferencias de estos últimos con los anteriores no son muy elevadas, resultan esta vez estadísticamente significativas cuando realizamos las comparaciones a través de la correspondiente prueba t (p. >001 en todos los casos), lo que confirma que se trata de los alumnos con un léxico disponible levemente más limitado que el resto de la pirámide social. Por lo demás, este desequilibrio se aprecia también en los promedios obtenidos en nueve de los centros de interés, donde los estudiantes del nivel más bajo puntúan en último lugar (para una visión más ilustrativa de estas posiciones, véase el gráfico 5.2.5).

\begin{tabular}{|l|c|c|c|c|c|c|c|c|}
\hline \multicolumn{1}{|c|}{ Centros de interés } & \multicolumn{2}{|c|}{ Nivel alto } & \multicolumn{2}{c|}{$\begin{array}{c}\text { N. medio } \\
\text { alto }\end{array}$} & \multicolumn{2}{c|}{ N. medio bajo } & \multicolumn{2}{c|}{ Nivel bajo } \\
\hline & PI & IC & PI & IC & PI & IC & PI & IC \\
\hline 01. Partes cuerpo & 25.90 & 0.19 & 26.54 & 0.15 & 25.92 & 0.14 & 25.38 & 0.12 \\
\hline 02. La ropa & 23.42 & 0.17 & 23.68 & 0.13 & 22.89 & 0.11 & 22.27 & 0.10 \\
\hline 03. Partes casa & 17.29 & 0.14 & 16.90 & 0.12 & 16.85 & 0.09 & 16.31 & 0.08 \\
\hline 04.Muebles & 14.39 & 0.13 & 14.71 & 0.08 & 14.74 & 0.08 & 14.31 & 0.07 \\
\hline 05. Alimentos & 26.23 & 0.11 & 27.17 & 0.08 & 26.75 & 0.07 & 26.22 & 0.06 \\
\hline 06. Mesa & 13.84 & 0.13 & 15.22 & 0.09 & 15.34 & 0.08 & 14.67 & 0.07 \\
\hline 07. La cocina & 19.32 & 0.11 & 19.00 & 0.07 & 18.30 & 0.06 & 18.63 & 0.05 \\
\hline 08. La escuela & 23.16 & 0.12 & 24.35 & 0.08 & 23.54 & 0.07 & 23.58 & 0.06 \\
\hline 09. Iluminación & 13.52 & 0.11 & 13.56 & 0.07 & 13.61 & 0.05 & 12.68 & 0.04 \\
\hline 10. La ciudad & 24.35 & 0.10 & 25.72 & 0.06 & 25.04 & 0.05 & 24.00 & 0.04 \\
\hline 11. El campo & 21.87 & 0.07 & 21.32 & 0.04 & 21.34 & 0.04 & 20.67 & 0.03 \\
\hline 12. Transporte & 18.35 & 0.14 & 19.06 & 0.11 & 19.30 & 0.10 & 19.60 & 0.08 \\
\hline 13. Jardín & 11.45 & 0.09 & 11.34 & 0.04 & 11.18 & 0.03 & 11.35 & 0.03 \\
\hline 14. Animales & 28.13 & 0.14 & 28.22 & 0.11 & 28.63 & 0.10 & 28.39 & 0.09 \\
\hline 15. Juegos & 20.84 & 0.08 & 20.50 & 0.04 & 19.86 & 0.04 & 18.31 & 0.03 \\
\hline 16.Profesiones & 23.39 & 0.09 & 23.18 & 0.06 & 23.16 & 0.05 & 22.46 & 0.05 \\
\hline 17. Colores & 21.13 & 0.17 & 19.04 & 0.12 & 20.12 & 0.09 & 19.89 & 0.08 \\
\hline PROMEDIOS & 20.39 & 0.11 & 20.55 & 0.08 & 20.38 & 0.07 & 19.86 & 0.06 \\
\hline
\end{tabular}

Tabla 5.2.13. Palabras por informantes (PI) e índice de cohesión (IC) por centros de interés según la variable nivel educativo de los padres

\footnotetext{
${ }^{164}$ Con todo, lo que nosotros hemos subdividido en alto y medio-alto los análisis precedentes los han calificado simplemente como alto.

${ }^{165}$ La única excepción tiene lugar en el campo Juegos.
} 


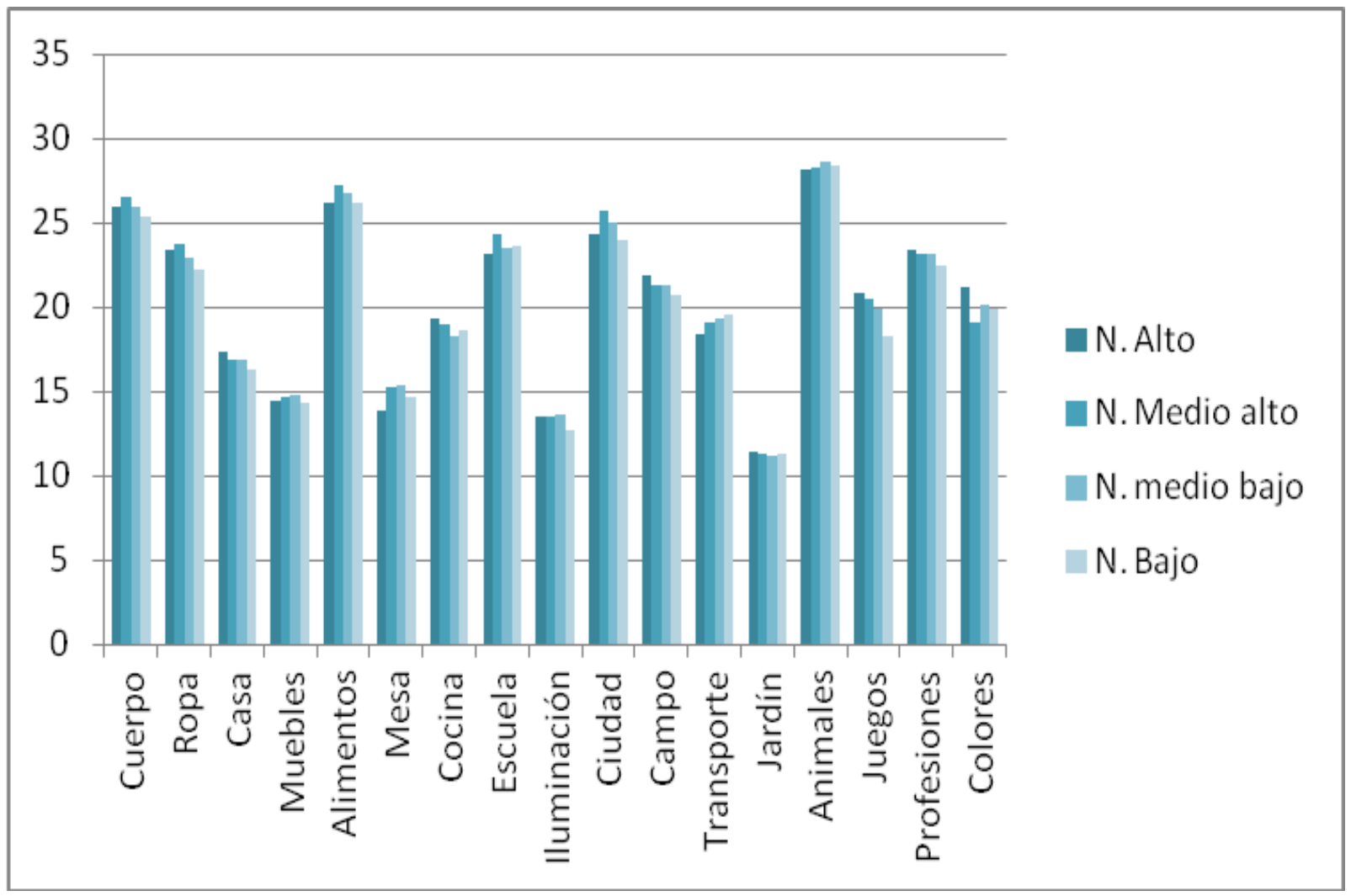

Gráfico 5.2.5. Palabras por informantes por centros de interés según la variable nivel educativo de los padres.

Por centros de interés, el nivel más alto destaca en seis áreas temáticas: Partes de la casa, La cocina, Campo, Jardín, Juegos y Colores. Por su parte, los estudiantes del nivel medio-alto aventajan a los otros compañeros en cinco estímulos verbales, a saber: Partes del cuerpo, Ropa, Alimentos, Escuela, Ciudad y Profesiones. A su vez, los informantes del nivel medio-bajo sobrepasan a los demás en cuatro áreas léxicas: Muebles, Mesa, Iluminación y Animales. Por último, el estrato bajo adelanta a los otros en tan solo un área asociativa (Transporte). Con todo, las diferencias entre unos grupos y otros son también aquí limitadas.

En cuanto a la distribución de los centros de interés por rangos en cada uno de los sociolectos, hay que destacar una notable congruencia de los resultados. Así, los cuatros niveles educativos coinciden en las cuatro primeras posiciones, que, por orden, son: Animales, Alimentos, Partes del cuerpo y La ciudad. Coinciden además en las posiciones octava (El campo), decimotercera (La cocina), así como en las dos últimas: Iluminación y Jardín, respectivamente. Los demás campos semánticos varían muy poco entre los distintos estratos educativos. 
Finalmente, el índice de cohesión, incluido también en la tabla 5.2.13, nos indica qué sociolectos muestran un vocabulario más compacto o, por el contrario, más difuso. Si nos fijamos en las cifras globales observamos una gradación perfecta esta vez, e íntimamente asociada a la pirámide social. Así, el nivel alto presenta la mayor convergencia asociativa (0.12), seguido por el nivel medio-alto (0.08), este por el medio-bajo (0.7) y, en último lugar, el estrato bajo (0.06). Además, las comparaciones entre los grupos son esta vez estadísticamente significativas en todos los casos (valores p. >001), lo que confirma que tal como descendemos en el nivel sociocultural familiar de los estudiantes castellonenses, la cohesión del léxico disponible se debilita; y al revés, conforme mayor es ese nivel, mayor es la congruencia y homogeneidad del vocabulario compartido. Además, el estrato alto sobresale en todos los campos semánticos, y en algunos casos con una amplia diferencia con respecto, sobre todo, al nivel bajo. Este hecho se puede comprobar bien en el gráfico siguiente (5.2.6), al tiempo que verificamos qué estímulos verbales aparecen como más estables y cuáles se muestran, por el contrario, más difusos o abiertos en los distintos estratos en que hemos dividido la muestra.

Como se puede apreciar, los centros de interés más impermeables a la entrada de nuevos términos son, en los cuatro niveles, las Partes del cuerpo y La ropa, aunque siempre con las cifras más elevadas en el estrato alto. En el extremo opuesto, las áreas nocionales más abiertas a la incorporación de otras unidades léxicas, algunas de ellas bastante alejadas del estímulo verbal específico, son nuevamente los Juegos y el Campo, con un perfil similar en los cuatro grupos analizados. 


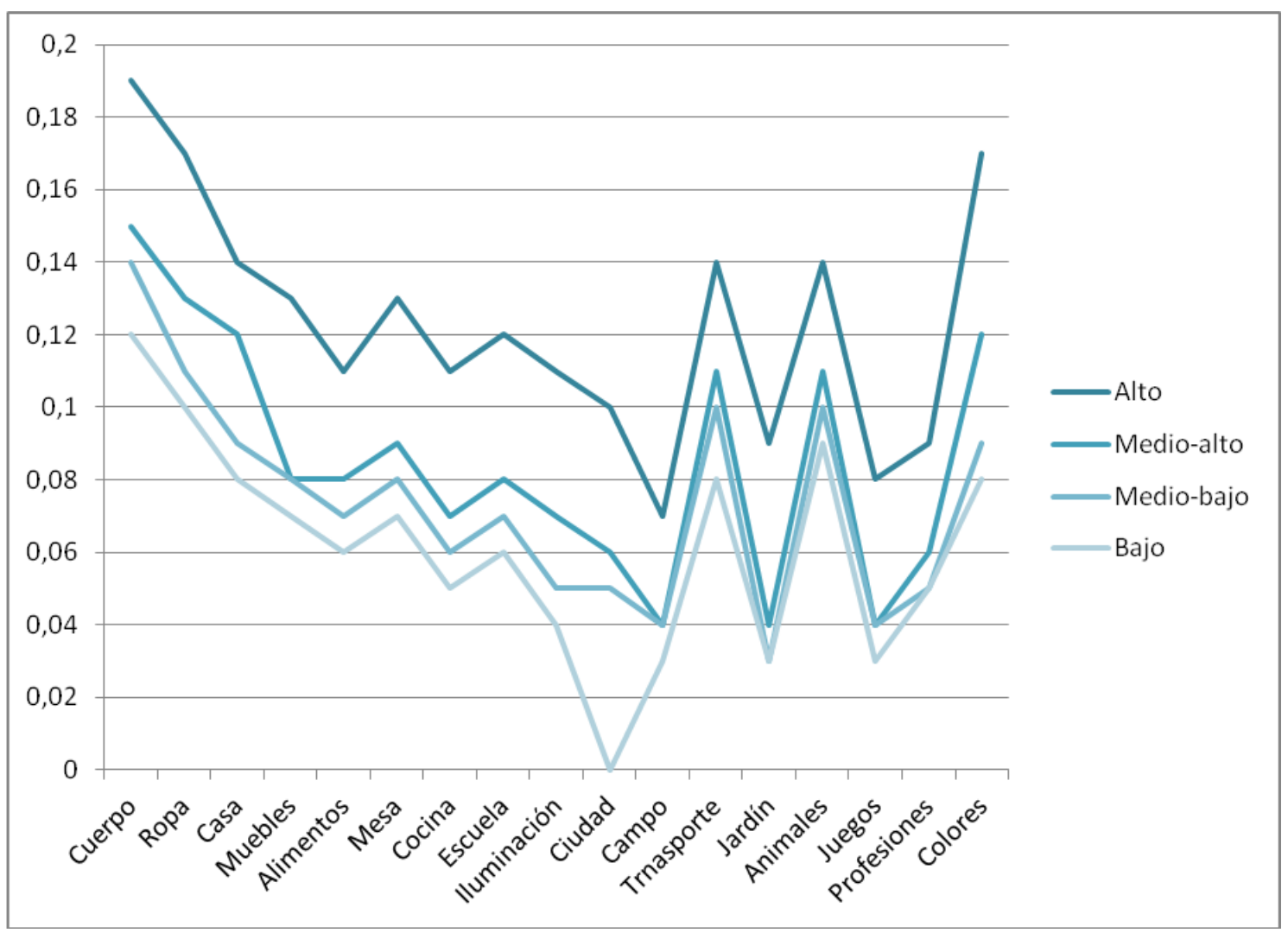

Gráfico 5.2.6. Índice de cohesión por centros de interés según la variable nivel educativo

En suma, también entre los estudiantes castellonenses, y al igual que en investigaciones precedentes, la variable sociocultural se muestra como un factor condicionante en la distribución sociolingüística del léxico disponible. Existe, pues, una relación clara entre la productividad y cohesión de este vocabulario, por un lado, y el nivel educativo de las familias de los informantes, por otro. Con todo, las principales diferencias en el primer caso se concentran en el contraste entre los sectores más humildes de la sociedad y el resto. Sin embargo, existe una asociación directa entre la estratificación social y la cohesión de ese léxico disponible, que aumenta conforme ascendemos en la pirámide social. 


\subsection{Anglicismos}

\subsubsection{Introducción}

El léxico del español está repleto de préstamos de otras lenguas. Dependiendo de la época, la lengua española ha cambiado respecto al origen mayoritario de estos. En el siglo XVII, por ejemplo, prevalecieron los italianismos o los galicismos en el XVIII (Lapesa, 1981: 454-459), pero en la actualidad la influencia del inglés es constante en todos los campos del saber. Al considerar el tema del anglicismo en ese marco amplio, dentro del crecimiento de los procesos de transculturización que vivimos, podemos concluir con Emilio Lorenzo (1995: 166) que:

la difusión internacional que alcanzan los usos lingüísticos ingleses no es más que un complemento, o corolario, de la penetración pacífica, pero incesante, de usos, costumbres y actitudes de origen británico o norteamericano.

En las décadas de los cuarenta a los setenta del siglo XX se observó una postura académica contraria a la incorporación indiscriminada de extranjerismos. Solo eran aceptadas las palabras que no tenían equivalente en español y con cierta prevención. Hoy en día, sin embargo, se manifiesta una actitud más positiva, en el sentido de que los anglicismos enriquecen nuestra lengua. Con todo, la utilización de palabras o expresiones extranjeras ha motivado siempre debates encendidos entre partidarios $y$ detractores de esas incorporaciones léxicas.

Sea como sea, la lengua va al compás de los tiempos, asume una inagotable riada de voces extranjeras nuevas, muchas veces tanto como los objetos y las nuevas realidades que representan. Son divulgadas en el habla cotidiana, algunas se pierden, otras se popularizan y llegan a muchos hablantes de una comunidad lingüística, quienes, en definitiva, son los que acaban adoptando (o no) los extranjerismos. Conocida su afición por los neologismos, Miguel de Unamuno ya apuntaba al respecto que: "Meter palabras nuevas, haya o no otras que las reemplacen, es meter nuevos matices de ideas". 166

\footnotetext{
${ }^{166}$ Miguel de Unamuno, 1945: 322, "Sobre la lengua española".
} 
Sin duda, son los medios de comunicación de masas y el interés creciente por la lengua inglesa en todos los órdenes ${ }^{167}$ los factores que más favorecen la penetración de los anglicismos en el español. Contribuyen también a ello la globalización y la consideración del idioma inglés como la lengua internacional por excelencia. El inglés está presente en nuestras vidas. Se oye, se habla y se lee por todas partes, prueba de ello son el turismo, los negocios, la prensa, la televisión... La última moda en publicidad, por ejemplo, es el empleo del inglés en anuncios breves sin traducir, sin doblaje alguno ni subtítulos, tanto en la televisión como en la prensa escrita. Tanto este ámbito como el de las nuevas tecnologías proporcionan gran cantidad de vocablos anglicados, muchos de los cuales se pronuncian y escriben tal como vienen, siendo los jóvenes uno de los principales vectores para su penetración en el español actual. Desde un punto de vista normativo, algunos de estos vocablos se consideran todavía barbarismos, ${ }^{168}$ y de ahí su exclusión en el Diccionario de la Real Academia Española. Con todo, hay que reconocer los esfuerzos recientes de la Academia por incorporar muchos de estos vocablos extranjeros, determinando también, en buena medida, su uso (el caso de clip, interviú, test, chip, etc.).

Las investigaciones sobre esta materia suelen dividir los anglicismos en varios grupos. Así, se habla de anglicismos superfluos e injustificados; o de aquellos que, aun cumpliendo una función referencial destacada, pueden (y deben) adoptarse a nuestra lengua; pero también "los compuestos y derivados, que se formen con arreglo a los procesos que reconoce el castellano, aunque la formación tenga por causa determinante la influencia del inglés" (Alfaro, 1970: 19).

Para el futuro de nuestra lengua, parece evidente que los anglicismos innecesarios no son precisamente beneficiosos. Ahora bien, no es menos cierta la conveniencia de adoptar -y adaptar- aquellos que resulten de utilidad o no tengan equivalente en español. Muchos de los neologismos corrientes han surgido de la exigencia de nombrar cosas desconocidas o inexistentes hasta ese momento y de la necesidad "de traducir términos nuevos venidos del inglés e impuestos por los descubrimientos, los inventos, la técnica, la industria, las costumbres, las transformaciones en los movimientos ideológicos o estéticos" (Alfaro, 1970: 20).

\footnotetext{
${ }^{167}$ El inglés es el idioma más estudiado y practicado en todos los niveles de la enseñanza básica, media y superior.

${ }^{168}$ Entiéndase barbarismo como aquel "extranjerismo no incorporado totalmente al idioma" (DRAE, 23a ed.).
} 
El propósito de este capítulo es, justamente, dar cuenta de los anglicismos que los estudiantes preuniversitarios castellonenses han producido junto al vocabulario patrimonial español. Con ello, pretendemos comprobar cuáles de estos extranjerismos han penetrado en mayor medida en la lengua de nuestros jóvenes a través de los índices cuantitativos que nos proporciona la léxico-estadística. En este marco, el análisis cuantitativo que realizamos nos permitirá determinar en qué campos léxicos prevalecen esos términos provenientes del inglés. Al mismo tiempo, cotejamos el porcentaje de anglicismos obtenidos en Castellón con otros estudios similares, en concreto con el léxico disponible de Zamora (Bartol, 1998), Cádiz (González y Orellana, 2006) en España y fuera de nuestro país trabajamos también con el léxico de Puerto Rico (López Morales, 1999) y la República Dominicana (Alba, 1996).

Sin embargo, antes de este análisis dedicamos alguna atención al propio concepto de anglicismo (5.3.2), así como a las principales vías de penetración en la lengua actual (5.3.3).

\subsubsection{El concepto de anglicismo}

No es fácil determinar con exactitud los límites del concepto de anglicismo, más allá de que se trata de términos que tienen su origen en la lengua inglesa (Medina, 2004). Así lo entiende el diccionario académico (vigésima segunda edición) cuando, en una de sus acepciones, define este como "vocablo o giro de la lengua inglesa empleado en otra" o "empleo de vocablos o giros ingleses en distintos idiomas". En el mismo sentido, Fernando Lázaro Carreter (1977) simplificaba aún más el concepto en su Diccionario de términos lingüísticos, dejándolo simplemente en: "Palabra de procedencia inglesa".

En la lingüística española encontramos también diversas incursiones en este terreno. Así, en su estudio sobre los anglicismos en el habla culta de San Juan (Puerto Rico), Isabel Huyke (1978: 158), define el anglicismo como:

1. "Palabra cuya forma -ya sea adaptada fonéticamente al español o en su forma original- proviene del inglés" y

2. "Significado que se le atribuye a una voz debidamente aceptada en el idioma español que proviene de una voz inglesa" (1978: 149). 
Partiendo de esta misma definición, y ahondando en ella, encontramos esta de Antonia Sánchez (1993: 24), quien añade lo siguiente: "Un anglicismo es todo elemento lingüístico o grupo de tales elementos que tenga un uso demostrable entre hablantes de castellano peninsular contemporáneo, y que tenga como étimo primario un modelo inglés". 169

En el análisis de los anglicismos en el léxico disponible portorriqueño, H. López Morales (1999a: 151) recoge una acepción amplia del término de la que aquí nos haremos también eco. De este modo, el lingüista cubano considera como anglicismo toda palabra derivada directamente del inglés o que ha penetrado en el español a través de él, actuando aquí el inglés como idioma puente. Con todo, en el seno de estos, López Morales distingue entre préstamos, extranjerismos y calcos. Habla de préstamos cuando los términos se hallan adaptados ortográfica o morfosintácticamente y presentan un índice de disponibilidad considerable, lo "que impide pensar en uso ocasional y minoritario"; de calcos cuando encontramos creaciones paralelas al modelo inglés; y de extranjerismos cuando las palabras no están adaptadas y encuentran un uso circunstancial. A los préstamos crudos Lorenzo (1996: 77-78) ${ }^{170}$ los denomina extranjerismos; reservando el término calco ${ }^{171}$ para los préstamos parciales. Se habla, asimismo, de préstamo semántico cuando el significado de una palabra extranjera es asumido por otra nativa, la cual experimenta un cambio semántico, como resultado del cual dicho término añade una acepción nueva, desconocida hasta entonces.

Con la finalidad de que su trabajo pueda ser comparado con otros similares, Orlando Alba (1996) utiliza un concepto amplio de anglicismo, en la línea de lo planteado por H. López Morales: "Se han considerado anglicismos no solo los términos de origen inglés (los aceptados por la Academia, como bisté, club, suéter, y los no aceptados como clóset, jeans, jeep), sino también palabras cuyo étimo mediato procede de otras lenguas, pero que han entrado al español a través del inglés, como cafetería, mocasín, televisión.” (1999: 854, nota 3)

Cuando estudian los anglicismos en Cádiz, Adolfo González y Pepa Orellana (2006) parten de esta misma opinión, aunque en su estudio solo establecen la distinción

\footnotetext{
${ }^{169}$ Pratt (1980: 15) distingue entre étimo primario (lengua de la que provenga la palabra registrada en el castellano) y étimo último (lengua fijada arbitrariamente como la originaria, en nuestro caso el latín, griego, árabe).

170 "A estos se les supone un uso ocasional y reducido a ciertos tecnolectos, argots o estilo lingüístico, e ininteligible para el hablante medio". Véase también Seco (1977: 197).

${ }^{171}$ Se entiende por calco la transferencia de la sustancia o significado extraño a una palabra de la lengua, en este caso el español.
} 
entre préstamo y extranjerismo. Por su parte, José Antonio Bartol (2005), en su trabajo sobre las palabras ajenas al español en Soria, habla de los anglicismos como simples extranjerismos, es decir, palabras provenientes de otra lengua, en este caso, el inglés.

En su investigación acerca de cómo aparecen los anglicismos en el diccionario de la Academia, Elena Domínguez (2002) clasifica estos por su frecuencia en diferentes áreas temáticas, algunas de las cuales coinciden con los centros de interés de nuestro estudio de disponibilidad: deportes, moda, gastronomía, trasportes. Domínguez recuerda que el diccionario no especifica qué procedimiento se ha seguido en la traducción de cada préstamo ${ }^{172}$ y no utiliza el mismo criterio para todos los anglicismos: unos aparecen en cursiva (normalmente las nuevas incorporaciones) y otros en redondilla (habitualmente los ya admitidos y asimilados en nuestra lengua), pero no siempre es así, como indica la propia autora.

Por lo que al Diccionario panhispánico de dudas se refiere, esta obra de referencia en materia normativa habla de extranjerismos necesarios (incluidos, lógicamente, los anglicismos), como aquellos que no tienen equivalente o no es fácil encontrar uno en la lengua de acogida, al tiempo que su empleo está muy arraigado. Además, desde el punto de vista lingüístico distingue dos tipos:

1. Aquellos en los que se mantiene la grafía y la pronunciación de la lengua origen. Ej.: ballet, jazz, etc. Se resaltan con comillas o con algún otro elemento para distinguir que poseen una ortografía y pronunciación distintas de la española.

2. Los que se adaptan a la pronunciación y la ortografía de la lengua origen. Pueden presentarse de dos formas: aquella que conserva la grafía originaria, pero con una pronunciación española, y la que mantiene la pronunciación extranjera, pero adaptada al sistema gráfico del español.

En su obra La inmigración léxica, donde Gómez Capuz (2005) pasa revista a la compleja cuestión terminológica sobre los préstamos, incluye un concepto que es también de especial atención para nuestro estudio, los pseudoanglicismos. En la práctica son falsos préstamos, pues: "se trata de un término en apariencia originario de una determinada lengua extranjera [en este caso el inglés], aunque en realidad no existe como tal en dicha lengua" (Gómez Capuz, 2005: 63-67). En realidad, ha sido una creación de la lengua receptora siguiendo el modelo de una palabra de la lengua

${ }^{172}$ Elena Domínguez apunta que préstamo es toda palabra "tomada de otra lengua sin traducir" (2002:31). 
originaria, el inglés (son formaciones analógicas, como los casos de sofing, puenting, sillón-ball, etc.).

Por nuestra parte, con la misma actitud de hacer posible las comparaciones entre los diferentes léxicos disponibles, adoptamos en este análisis la concepción de anglicismo seguida por López Morales, Alba, González y Orellana, entre otros. En definitiva, consideraremos anglicismo todo aquel vocablo que tenga su origen en la lengua inglesa, bien directamente, bien a través de ella.

\subsubsection{Las principales vías de inserción de los anglicismos}

Los anglicismos poseen diversas vías de penetración en las lenguas, que se filtran como un río impetuoso y siempre efectivo. Las razones por las que el inglés es la lengua más difundida entre las occidentales estriban fundamentalmente en la extraordinaria influencia de los países anglosajones en las últimas décadas -con un protagonismo especial de Estados Unidos- en las esferas más influyentes y prestigiosas: las agencias de noticias, el cine y la televisión, la prensa escrita, la industria, el comercio, la ciencia y la tecnología, el deporte, los viajes, las relaciones internacionales y sociales entre los diferentes países. En definitiva, el actual predominio económico, científico y político del mundo anglosajón obliga al uso constante del inglés como la lengua de intercambio y de comunicación.

Hay que añadir, además, que el inglés es utilizado como idioma vernáculo por cientos de millones de personas en los países de habla inglesa, así como en numerosas excolonias del antiguo Imperio Británico. A esto hay que sumar el hecho de que los países más poblados del mundo (China, India, Japón y la mayor parte de territorios de Oriente) utilizan también el inglés como la principal lengua auxiliar. Todo ello implica la inevitable influencia que esta lengua ejerce en los hablantes de todas las latitudes: en los despachos de prensa, ${ }^{173}$ las cartas comerciales, la jerga industrial, los documentos

\footnotetext{
${ }^{173}$ Las grandes agencias de noticias del mundo, como Associated Press, United Press International, Reuters, etc. pertenecen a empresas de Estados Unidos o Gran Bretaña.
} 
internacionales, etc. Asimismo, la lengua inglesa es la más empleada en Internet, ${ }^{174}$ así como en las publicaciones de todo el mundo. ${ }^{175}$

Pese a la importancia de todo lo anterior, la razón última de los préstamos radica en que las lenguas son entes vivos, que nacen, se relacionan, cambian constantemente (y hasta, en ocasiones, desgraciadamente mueren). Donde mejor se aprecia este devenir es, precisamente, en el léxico, tema de la presente investigación. Las palabras evolucionan, algunas de ellas entran en desuso, al tiempo que otras se recuperan, renovadas desde el punto de vista semántico: "de suerte que el vocablo que una edad tiene por vulgar, en otra pasa a ser culto y lo que un día se tilda de pedante, en otro se acepta como común y corriente", como apuntaba Alfaro (1970: 24). En consecuencia, si el cambio es consustancial a la lengua, la adopción de extranjerismos es un desenlace natural.

Los cambios son incesantes en nuestras vidas y las innovaciones resultan continuas gracias a los avances de la ciencia y de la técnica, que en los últimos tiempos han sido vertiginosos. Para nombrar estas nuevas realidades, la lengua dispone de varios medios:

bien mediante la creación de un nuevo término (neologismo formal), bien mediante la adopción o adaptación de una forma extranjera (préstamo) o bien mediante la aplicación significativa de dicho concepto a una forma ya existente (neologismo semántico) (Guerrero Ramos 1995: 7)

$\mathrm{Al}$ igual que otros lingüistas, esta autora se pregunta si el neologismo responde a una necesidad en el momento de su creación y si es imprescindible realmente para la comunicación. La respuesta a dichas cuestiones no es monolítica, sino que depende de varios factores, como nos recuerda Guerrero Ramos (1995: 15):

la frecuencia de uso del término, su disponibilidad, su comprensión, su irradiación, el juicio positivo o negativo por parte del usuario, su difusión [...] nos hablará claramente de su utilidad, su riqueza de expresión, su necesidad y su éxito

De ahí que los estudios de disponibilidad léxica sean de especial utilidad para observar el grado de implantación de los préstamos, ya que detectan aquellos términos

\footnotetext{
${ }^{174}$ Internetworldestast.com establece estos porcentajes de uso de las lenguas en la red: inglés (27\%), chino (22.6\%), español (7,8\%), japonés $(5.3 \%)$.

${ }^{175}$ El British Council indica que las lenguas más empleadas en publicaciones son, por este orden: inglés, chino, alemán, francés y español.
} 
que vienen de manera más inmediata a la mente de los hablantes cuando se le pregunta por un tema concreto.

Guerrero Ramos, en el citado trabajo, distingue entre neología denominativa y neología estilística, o lo que es lo mismo, entre préstamo por necesidad y préstamo de lujo. Los primeros sirven para nombrar aquellos objetos o conceptos que proceden de un país extranjero, mientras que los segundos se originan básicamente por imitación de una cultura que se considera prestigiosa. Normalmente, estos últimos provienen de países que dominan el panorama internacional, no solo económicamente, sino también política, social y culturalmente. Y lo que explica, en opinión de esta autora, la “colonización lingüística de España por el inglés americano" (Guerrero Ramos, 1995: 36).

Como se ha mencionado más arriba, muchos de estos préstamos se plasman de forma directa en la lengua escrita, es decir, con nula asimilación gráfica en la lengua de destino, aunque con variaciones en la pronunciación. Es lo que sucede, por ejemplo, con muchos anglicismos relativos al deporte, y que aparecen con grafías extrañas al español, como ejemplifican algunas palabras extraídas de nuestras encuestas: squash, waterpolo, paddle, etc.

Como es sabido, la Real Academia Española tiende a adaptar la ortografía de las palabras extranjeras a las normas españolas (aunque no siempre con éxito). Sirvan como muestra algunas de las nuevas incorporaciones al diccionario académico, y que aparecen también mencionadas (a la española) por nuestros informantes: chándal, cabaré, penalti, test... No obstante, a veces hallamos en el DRAE dos entradas, el anglicismo con su ortografía original, junto a su adaptación al español: whisky y güisqui, bikini y biquini, nailon y nilón, etc. ${ }^{176}$ Ambas versiones aparecen también en nuestro Diccionario del léxico disponible de Castellón.

Por otro lado, la inclinación del español a adaptar los términos extranjeros se percibe también en la derivación de palabras a partir del anglicismo. Por ejemplo, de gol, proceden desde hace décadas otras como golear, goleador, goleada; de cabaré, cabaretero, etc.

Las nuevas generaciones se muestran más propicias a la incorporación y difusión de extranjerismos, en general, que las generaciones mayores. Por otro lado, la adopción de estos no depende solo del nivel sociocultural, ya que posee también un carácter

\footnotetext{
${ }^{176}$ Véanse los capítulos 5 y 6 de El léxico en el español actual: uso y norma de Leonardo Gómez Torrego (1995: 357-380).
} 
fuertemente idiosincrásico. Hoy en día, las características sociales, culturales, políticas y económicas del mundo hacen imparable la penetración de estos neologismos provenientes del mundo anglosajón, como ya apuntábamos más arriba. De este modo, las fronteras entre países, grupos sociales e individuos se difuminan cada vez más no sólo en términos culturales, sino también lingüísticos. La globalización implica a todos los campos del saber.

Como cabía esperar, los centros de interés que más destacan por el empleo de anglicismos corresponden a aquellas áreas de la realidad más afines al mundo juvenil. Así, en el campo Ropa, el término jersey aparece en una posición tan alta como el puesto número siete de todas las recogidas en ese centro de interés. A este se añaden, ya en posiciones más bajas, otros como top, short, jeans, leggings, blazer, cárdigan, etc. Los anglicismos siguen su incursión imparable en este campo semántico, impulsados por la presión de las grandes pasarelas de moda y la publicidad.

Otro ámbito de la realidad donde la entrada de anglicismos ha sido importante es el del deporte, como revela el centro Juegos y distracciones. El número uno lo ocupa, como no podía ser de otra manera en nuestro país, el fútbol, completamente asimilado en la lengua española (footballl ha derivado en fútbol). Otros términos deportivos poseen también una amplia difusión social, aunque las soluciones gráficas con las que aparecen son diversas, y no siempre se ajustan (más bien al contrario) a la ortografía del español; es el caso de béisbol, básquet, hockey, squash, footing, rafting, béisbol, rugby, etc. Lo mismo sucede en la alusión a medios de transporte: yate, sidecar, tándem, surf, ferry, jet, mountain bike, kart, hovercraft, jeep, quad, kayak, scooter... Todos ellos forman parte ya del léxico colectivo, no solo entre los jóvenes, sino en todos los estratos de la sociedad.

En los últimos tiempos, la entrada de anglicismos ha sido particularmente abrumadora en el mundo de la informática, como han demostrado algunos estudios recientes. De ahí que en el trabajo de Ávila y Villena (2010), estos autores hayan añadido como centro de interés número 18 el relativo a Internet y ordenadores, en el que contabilizan nada menos que un total de 438 vocablos, ${ }^{177}$ de los que un $28 \%$ corresponde a anglicismos. Sin embargo, los únicos términos relativos a este campo hallados en nuestro análisis son: Internet, las siglas $P C$ en el sintagma $P C$ fútbol, y chatear en el campo semántico Juegos y distracciones. Sin duda alguna, el número de

\footnotetext{
${ }^{177}$ Recordamos que debe entenderse por vocablo toda palabra individual o la unión de varias de ellas con un solo significado.
} 
anglicismos hubiera sido mucho mayor si también se hubiera propuesto dicho centro de interés en nuestras encuestas. ${ }^{178}$

\subsubsection{Aspectos metodológicos}

En cuanto a la metodología, partimos de la misma empleada para el léxico disponible general ya especificada en el capítulo cuarto de la presente investigación. Como ya se ha dicho en varias ocasiones, trabajamos con un léxico vivo y espontáneo, tal como considera Alba (1996: 854), lo que implica la aparición de anglicismos en las encuestas de nuestros estudiantes en determinados centros de interés que iremos especificando a lo largo del capítulo.

En primer lugar, hemos tenido dificultades a la hora de seleccionar el corpus objeto de análisis, esto es, delimitar qué palabras debíamos considerar como anglicismos para incorporarlas en nuestros listados. Problema que, debemos reconocer, no hemos llegado a resolver de forma totalmente satisfactoria. Por ejemplo, ¿qué hacer con los vocablos que determinan marcas comerciales registradas de productos? Los investigadores reconocen incluir solo los nombres ya lexicalizados o en proceso de serlo, es decir, cuando esos términos, en una situación de comunicación dada, pueden sustituir al nombre general del producto, como sucede con Monopoly, Wonderbra, etc. Pero la cuestión es ¿cuándo se considera que una unidad lingüística está lexicalizada?

Un problema añadido es el criterio de selección o admisión de las palabras en cada centro de interés, es decir, qué pautas siguen los investigadores en dicha selección. En algunos trabajos se incluyen todos los anglicismos, sean préstamos ya integrados o extranjerismos actuales, de reciente incorporación. Sin embargo, en otras investigaciones solo se tienen en cuenta las actuales o se pone una fecha como límite, como hace Bartol (2005), quien restringe el análisis a aquellos extranjerismos que entraron en el español con posterioridad a 1900.

Ciertamente, estas posturas distintas dificultan las comparaciones entre los diferentes estudios. Con todo, para atenuar en la medida de lo posible este problema, la mayoría de los estudios que se inscriben en el proyecto panhispánico procuran tener en

\footnotetext{
${ }^{178}$ Wicherek (2008), en su estudio contrastivo de los anglicismos del español y el polaco, también señala que en las dos lenguas los vocablos anglicados aparecen con más frecuencia en los campos que tienen que ver con los deportes, la economía, la informática y la moda.
} 
cuenta similares criterios, que en este caso parten de la aproximación de López Morales comentada más arriba. Aun así, no hay una coincidencia unánime en todos los casos; por ejemplo, la palabra boeing, que no recogen Alfaro (1970), Pratt (1980), Lorenzo (1996), Alba (1996), Gómez (2000) y Bellón (2005) y, en cambio, sí lo hacen López Morales (1999a) en Puerto Rico y Bartol en Soria (2005) y sin embargo, no en Zamora.

Como hemos dicho anteriormente, en nuestro trabajo, adoptamos el concepto más amplio de anglicismo de entre los expuestos en el apartado 5.3.2 del presente capítulo. En consecuencia, se entenderá por tal, toda palabra procedente directa o indirectamente de la lengua inglesa. Asimismo, se abordarán tanto los préstamos como los calcos de forma conjunta.

A la hora de editar estos términos, en nuestro estudio hemos tenido en consideración los siguientes criterios: los anglicismos admitidos por la Academia se han marcado en redondilla, y los no admitidos totalmente, pero integrados socialmente en nuestra lengua, aparecen en cursiva, tal y como se muestran en el diccionario académico. Las marcas registradas y comerciales aparecen en los listados con mayúscula y asterisco, porque así se lematizan en el Diccionario del léxico disponible de Castellón. Pero solo se han incluido las que son muy comunes, aquellas que tienen un alto índice de disponibilidad y que muchos investigadores consideran ya lexicalizadas (Kleenex*, Trivial*, Monopoly*, etc,), como es el caso de Gómez Capuz (2000), Pratt (1980), Lorenzo (1996); del mismo modo, se incluyen aquellas que aparecen en los estudios de anglicismos en los léxicos disponibles consultados de Cádiz, Zamora, Puerto Rico y República Dominicana, con el objetivo de facilitar las comparaciones. Toda la información sobre la cuantificación de estos materiales sigue las pautas y datos ya comentados, en el citado capítulo cuarto.

Los anglicismos, como vocablos disponibles que son, en algunas ocasiones en posiciones más altas incluso que los términos en castellano, ofrecen la información que proporciona el programa informático empleado: aparte del índice de disponibilidad de una palabra, se indica la frecuencia relativa, es decir, el número de veces que aparece cada vocablo con respecto al total, la aparición o el porcentaje de informantes que han escrito ese término y la frecuencia acumulada, esto es, la magnitud referida a la suma de las frecuencias relativas. Los listados de anglicismos se presentan en el apartado 8.2 en forma de tablas, donde se indican los datos anteriores.

Cuando un vocablo aparece especificado con algún tipo de complemento del nombre, no se ha anotado como entrada distinta y, por tanto, no se ha contabilizado 
como un anglicismo diferente, puesto que la palabra objeto de estudio es la misma. Por ejemplo, bloc aunque aparece modificada en bloc de anillas, bloc de notas, bloc de dibujo, solo se ha marcado una vez en los listados de anglicismos. Siempre que aparecen especificaciones o modificaciones quedan aclaradas en notas a pie de página en las que se indican sus empleos.

Señalemos, por último, que un mayor número de lexemas en un centro de interés no implica necesariamente un mayor número de anglicismos. Así, los centros de interés Ciudad y Campo son áreas semánticas abiertas a las agrupaciones y relaciones secundarias como demuestra la cantidad de palabras recogidas (949 y 1060 respectivamente), pero ello no repercute en la cantidad de anglicismos, puesto que en el primer campo semántico encontramos 44 y en el segundo apenas 15 . Unos datos que, por lo demás, se ven confirmados en la mayoría de los estudios sobre disponibilidad léxica publicados hasta la fecha.

\subsubsection{Análisis de los resultados}

Como se recordará, la cantidad total de palabras recogidas en Castellón asciende a 121.792, de las cuales 9215 son vocablos o palabras diferentes. Y de estas, 380 son anglicismos, lo que representa un porcentaje del $4.12 \%$ sobre el total.

Distribuidos por centros de interés, los resultados son los siguientes: 


\begin{tabular}{|l|c|c|c|}
\hline Centro de interés & $\begin{array}{c}\mathbf{N}^{\mathbf{0}} \mathbf{d e} \\
\text { Vocablos }\end{array}$ & $\begin{array}{c}\mathbf{N}^{\mathbf{0}} \mathbf{d e} \\
\text { Anglicismos }\end{array}$ & Porcentaje \\
\hline 1. Partes del cuerpo & 271 & 0 & $0 \%$ \\
\hline 2. La ropa & 312 & 27 & $8.65 \%$ \\
\hline 3. Partes casa & 307 & 15 & $4.88 \%$ \\
\hline 4. Muebles & 303 & 13 & $4.29 \%$ \\
\hline 5. Alimentos & 607 & 21 & $3.45 \%$ \\
\hline 6. Mesa & 317 & 4 & $1.26 \%$ \\
\hline 7. La cocina & 502 & 12 & $2.39 \%$ \\
\hline 8. La escuela & 623 & 29 & $4.65 \%$ \\
\hline 9. Iluminación & 479 & 16 & $3.34 \%$ \\
\hline 10. La ciudad & 949 & 44 & $4.63 \%$ \\
\hline 11. El campo & 1060 & 15 & $1.41 \%$ \\
\hline 12. Transporte & 344 & 47 & $13.66 \%$ \\
\hline 13. Jardín & 704 & 2 & $0.28 \%$ \\
\hline 14. Los animales & 447 & 10 & $2.23 \%$ \\
\hline 15. Juegos & 908 & 88 & $9.69 \%$ \\
\hline 16. Profesiones & 732 & 31 & $4.23 \%$ \\
\hline 17. Los colores & 350 & 6 & $1.71 \%$ \\
\hline
\end{tabular}

Tabla 5.3.1 Número de Anglicismos diferenciados por centros de interés

Examinando los datos que aparecen en la tabla 5.3.1, llegamos a algunas conclusiones preliminares. Y así, vemos, efectivamente, cómo ciertos centros de interés se encuentran más afectados por los anglicismos, lo que revela que su penetración es mayor en la lengua de nuestros jóvenes.

Esto ocurre, principalmente, con los campos Juegos, Transporte, Ciudad y Profesiones con 88, 47, 44 y 31 anglicismos respectivamente. A estos les siguen otras áreas léxicas, con una densidad intermedia, como sucede con Escuela, Ropa, Alimentos, (29, 27 y 21). Por último, encontramos campos asociativos donde la influencia de los anglicismos es muy limitada, como ocurre con Partes de la casa (15), Iluminación (16), Muebles (13), Animales (10), Colores (6) y Mesa (4). Por último, no hallamos ningún anglicismo en el campo Partes del cuerpo, tal como se constata en otros trabajos consultados.

Los resultados parecen lógicos puesto que los centros que presentan mayor cantidad de anglicismos corresponden a las áreas léxicas más abiertas a la incorporación 
de léxico nuevo, en campos semánticos dominados por el prestigio social y económico del mundo anglosajón. No sucede lo mismo en los centros de interés con escasa o nula penetración de anglicismos, considerados campos cerrados desde un punto de vista lexicológico. Y es que, como apunta O. Alba (1996: 856): "Es posible inventar o crear nuevos juegos y modernos medios de transporte o prendas de vestir, pero no se puede hacer lo mismo con las partes del cuerpo ni con los animales".

Si prestamos ahora atención al siguiente parámetro, la densidad de los anglicismos dentro de cada uno de los centros de interés (columna de porcentajes en la tabla 5.3.1), observamos algún cambio con respecto al criterio anterior, que solo tenía en cuenta el número de vocablos. En esta ocasión, el primer grupo es el formado por los campos Transporte (13.68), Juegos (9.69), los cuales figuraban también en primer lugar en la lista anterior, pero no así Ciudad (4.63), que baja ahora a la segunda posición y Ropa (8.65) que del segundo grupo pasa ahora al primero. Le siguen otros centros con una densidad media: Casa (4.88), Escuela (4.65), Muebles (4.29), Profesiones (4.23). y Alimentos (3.45). En tercer lugar, con escaso porcentaje de anglicismos, figuran los campos Iluminación (3.34), Cocina (2.39) y Animales (2.23). Por último, con una incidencia casi nula en sus respectivos campos, nos encontramos con los anglicismos de Colores (1.71), Campo (1.41), Mesa (1.26), y Jardín (0,28).

Toda esta información se puede resumir en los gráficos siguientes, donde se puede apreciar visualmente cómo hay campos léxicos que son más reacios a la incorporación de nuevas unidades léxicas procedentes de la lengua inglesa, mientras que otros acogen términos anglosajones con mayor facilidad. 


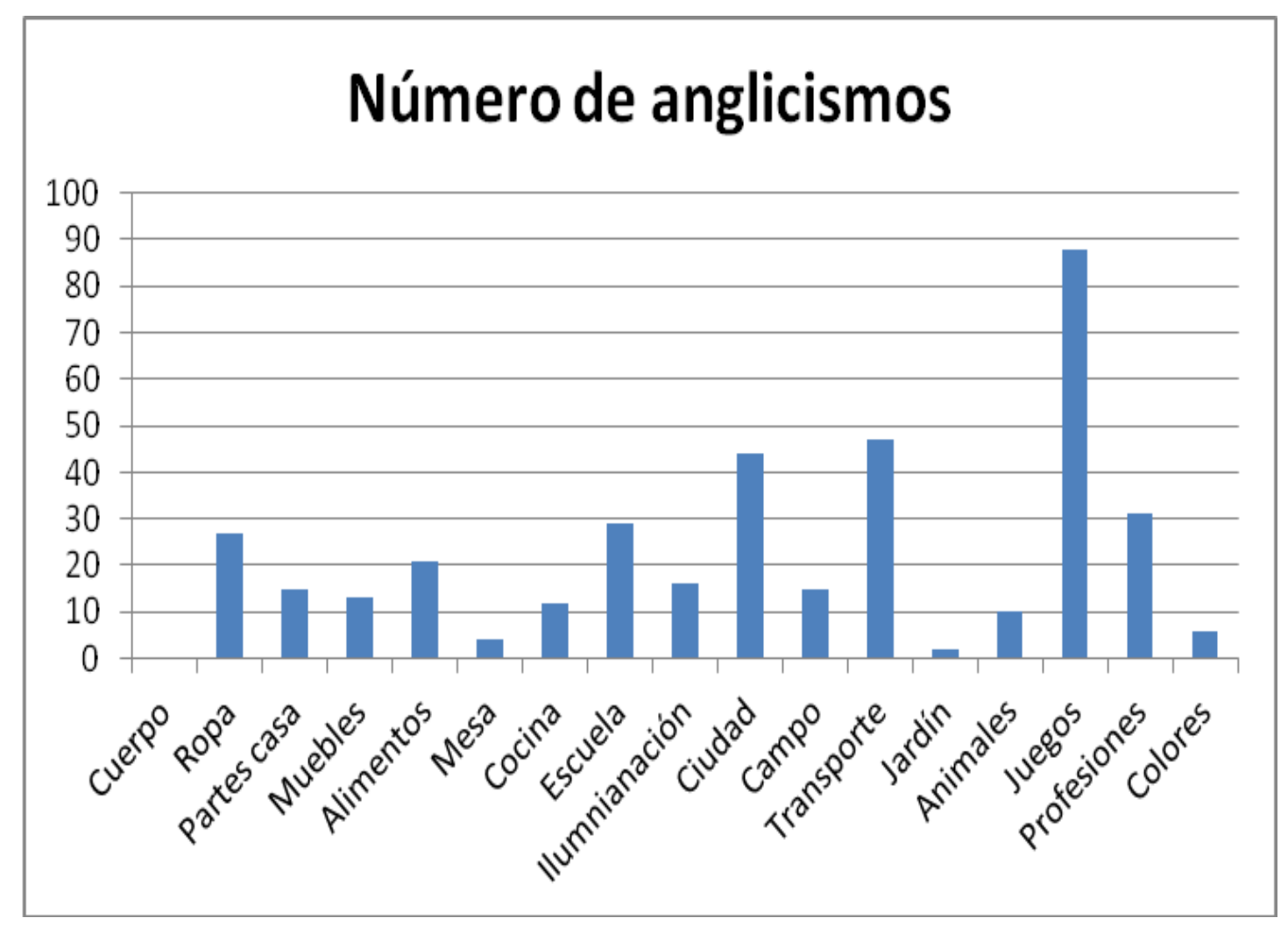

Gráfico 5.3.1. Número de anglicismos por centros de interés

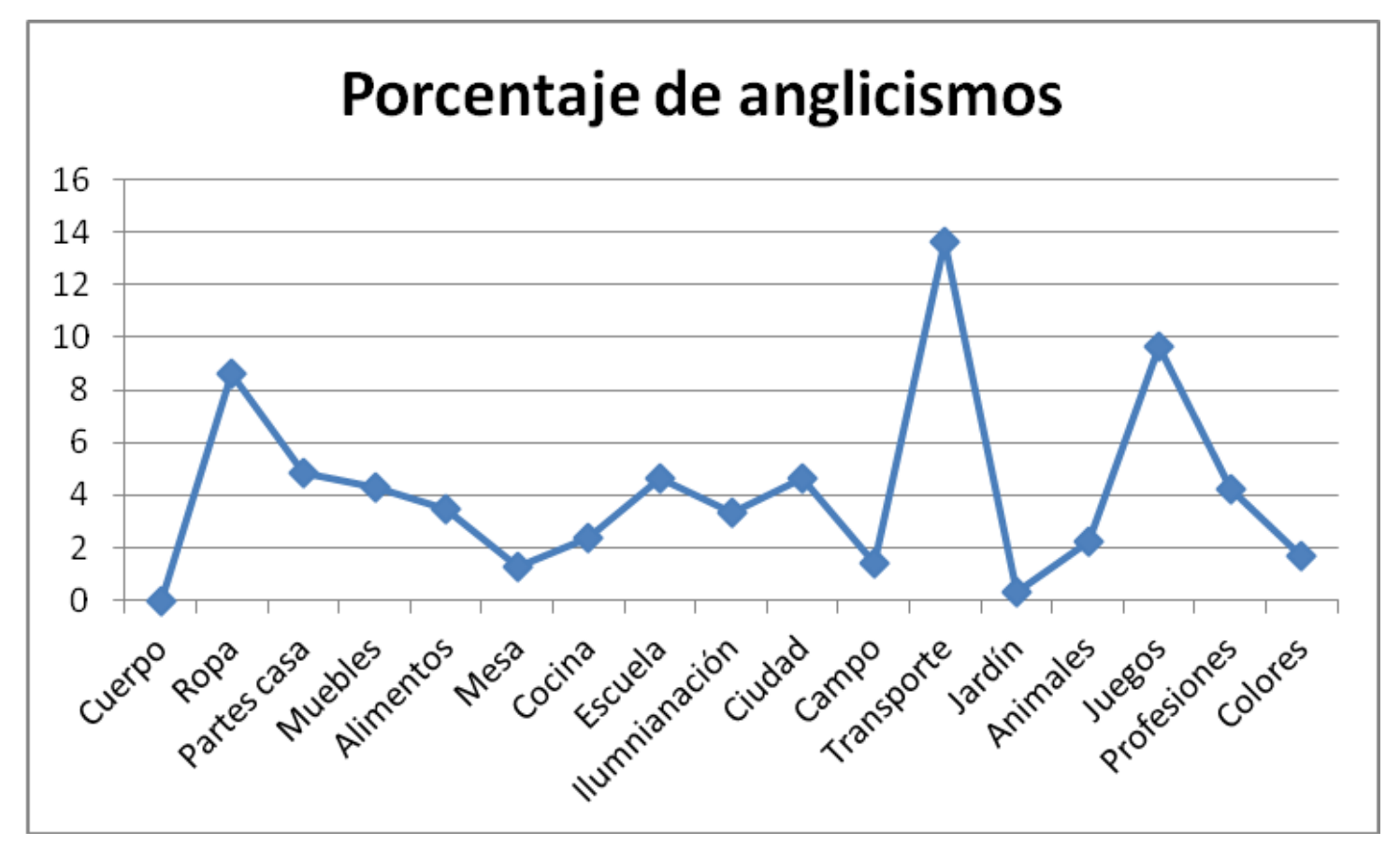

Gráfico 5.3.2. Porcentaje de anglicismos por centros de interés 
A continuación comparamos nuestros datos con los de otras sintopías estudiadas previamente, primero en términos absolutos (tabla 5.3.2) y a continuación por centros de interés (5.3.3).

\begin{tabular}{|l|c|c|c|c|c|}
\hline & Castellón & Zamora & Cádiz & $\begin{array}{c}\text { Puerto } \\
\text { Rico }\end{array}$ & Rep.Dominicana \\
\hline $\mathrm{N}^{\mathbf{o}}$ vocablos & 9215 & 4978 & 6655 & 7311 & 6393 \\
\hline Anglicismos & 380 & 96 & 203 & 444 & 388 \\
\hline Porcentaje & $4.12 \%$ & $1.92 \%$ & $3.05 \%$ & $6.07 \%$ & $6.06 \%$ \\
\hline
\end{tabular}

Tabla 5.3.2. Anglicismos totales en las sintopías estudiadas

\begin{tabular}{|l|c|c|c|c|c|c|c|c|c|c|}
\hline $\begin{array}{c}\text { Centro de } \\
\text { interés }\end{array}$ & \multicolumn{2}{|c|}{ Castellón } & \multicolumn{2}{c|}{ Zamora } & \multicolumn{2}{c|}{ Cádiz } & \multicolumn{2}{c|}{ Puerto Rico } & \multicolumn{2}{c|}{$\begin{array}{c}\text { República } \\
\text { Dominicana }\end{array}$} \\
\hline & Ang. & \% & Ang. & \% & Ang. & \% & Ang. & \% & Ang. & \% \\
\hline Cuerpo & 0 & $0 \%$ & 0 & $0 \%$ & 0 & $0 \%$ & 0 & $0 \%$ & 0 & $0 \%$ \\
\hline Ropa & 27 & 8.65 & 8 & 4.18 & 23 & 9.05 & 37 & 17.37 & 40 & 16.06 \\
\hline Casa & 15 & 4.88 & 4 & 2.29 & 4 & 2.12 & 14 & 8.23 & 13 & 4.43 \\
\hline Muebles & 13 & 4.29 & 1 & 0.46 & 2 & 1.29 & 26 & 10.61 & 34 & 10.75 \\
\hline Alimentos & 21 & 3.45 & 4 & 1.13 & 16 & 3.21 & 43 & 8.95 & 20 & 5 \\
\hline Mesa & 4 & 1.26 & 0 & $0 \%$ & 3 & 1.33 & 5 & 2.67 & 4 & 1.70 \\
\hline Cocina & 12 & 2.39 & 3 & 0.93 & 8 & 2.11 & 22 & 7.16 & 16 & 4.04 \\
\hline Escuela & 29 & 4.65 & 2 & 0.65 & 16 & 3.49 & 23 & 9.54 & 19 & 6.18 \\
\hline Iluminación & 16 & 3.34 & 4 & 1.52 & 1 & 0.62 & 34 & 11.68 & 26 & 7.34 \\
\hline Ciudad & 44 & 4.63 & 11 & 2.22 & 26 & 3.48 & 50 & 7.20 & 36 & 4.97 \\
\hline Campo & 15 & 1.41 & 3 & 0.55 & 7 & 0.74 & 1 & 0 & 9 & 1.22 \\
\hline Transporte & 47 & 13.66 & 11 & 5.3 & 26 & 11.87 & 38 & 23.31 & 32 & 18.93 \\
\hline Campo & 2 & 0.28 & 0 & $0 \%$ & 0 & $\%$ & 2 & 0.43 & 0 & $\%$ \\
\hline Animales & 10 & 2.23 & 3 & 0.95 & 8 & 1.56 & 6 & 2.23 & 3 & 0.90 \\
\hline Juegos & 88 & 9.69 & 40 & 8.35 & 53 & 7.54 & 115 & 20.98 & 116 & 17.23 \\
\hline Oficios & 31 & 4.23 & 2 & 0.44 & 10 & 1.82 & 28 & 5.20 & 20 & 3.10 \\
\hline Colores & 6 & 1.71 & n.d. & n.d. & n.d. & n.d. & n.d. & n.d. & n.d. & n.d. \\
\hline
\end{tabular}

Tabla 5.3.3. Comparación de las frecuencias absolutas y relativas de los anglicismos por centro de interés en las zonas del español estudiadas

Al observar detenidamente las cifras contenidas en la primera tabla, advertimos que hay bastante diferencia entre unos trabajos y otros. Los números de anglicismos, de 388 y 444 de la República Dominicana y Puerto Rico, respectivamente, difieren sensiblemente de las cifras de Cádiz (203), pero aún más de las de Zamora (96 anglicismos). Castellón se situaría en una zona intermedia entre esos dos grupos, con 
380 anglicismos. Con todo, estas diferencias cuantitativas pueden obedecer al número de informantes encuestados en cada zona geográfica, cuyas cifras resumimos en la siguiente tabla:

\begin{tabular}{|l|c|}
\hline \multicolumn{1}{|c|}{ Sintopía estudiada } & Número de informantes \\
\hline Zamora & 100 \\
\hline Castellón & 354 \\
\hline Cádiz & 400 \\
\hline República Dominicana & 347 \\
\hline Puerto Rico & 179 \\
\hline
\end{tabular}

Tabla 5.3.4. Número de informantes en las sintopías estudiadas

El número de informantes similar de Castellón y República Dominicana podría explicar la cantidad también cercana de los anglicismos encontrados: 380 y 388, respectivamente. Por otro lado, el significativo mayor número de estos hallado en Puerto Rico se explicaría por la especial vinculación de la isla con Estados Unidos, como estado libre asociado de la potencia norteamericana que es desde hace décadas.

Esta influencia se confirma si nos fijamos en la densidad, una medida más ajustada para establecer posibles comparaciones. Y es que, efectivamente, observamos cómo los porcentajes globales de los dos países americanos se hallan más próximos entre sí -Puerto Rico (6.07\%) y República Dominicana (6.06\%)- y a considerable distancia de las comunidades de habla españolas. Con todo, en el seno de estas últimas se aprecian diferencias entre los datos computados por Cádiz (3.02\%) y en Castellón (4.12\%), con densidades más próximas, y Zamora (1.92\%), cuyos índices son los más bajos del conjunto.

En nuestra opinión, sin embargo, puede haber una razón más importante para explicar estas divergencias: el proceso de estandarización y procesamiento de los datos extraídos de las encuestas. Aunque todos los estudios inmersos en el Proyecto Panhispánico del Léxico disponible del español comparten una misma metodología general, siempre se aprecian diferencias derivadas, por ejemplo, de los objetivos primarios que se pretenden alcanzar en los análisis o incluso de la propia enunciación de los centros de interés, como hemos repetido en diversas ocasiones.

\footnotetext{
${ }^{179}$ Puerto Rico es un estado libre asociado a EEUU. Es un territorio no incorporado a EEUU con estatus de autogobierno, pero con dos lenguas oficiales: el español y el inglés. Este contacto lingüístico favorece, sin duda, los préstamos de una lengua sobre la otra, siendo el español el idioma vernáculo hablado por la mayoría de la población.
} 
Otra dificultad surge de la propia consideración de la noción de anglicismo, a la que ya nos hemos referido. Y aunque en el estudio sobre Castellón hemos seguido un concepto amplio de anglicismo, en ocasiones nos hemos enfrentado a decisiones difíciles en algunos vocablos. Para intentar solucionarlas hemos consultado los diccionarios y manuales de anglicismos a nuestro alcance: Alfaro (1970), Lorenzo (1996), Rodríguez y Lillo (1997), Pratt (1980), Gómez Capuz (2000), Bellón (2004, 2005), el DRAE (23 ${ }^{\mathrm{a}}$ ed.), entre otros.

La consulta de estas obras nos ha ayudado a decidir qué vocablos incluir en nuestro listado y cuáles rechazar, una decisión en la que ha tenido un papel protagonista el diccionario académico. Así, el término parka no lo incluyen ni Alfaro (1970), ni Gómez Capuz (2000), Pratt (1980), López Morales (1999a), Alba (1996) y González y Orellana (2006); en cambio sí lo anotan Lorenzo (1996), Bartol (1998) y Bellón (2004). En la vigésima segunda edición del diccionario académico no se registra, ni en el Diccionario panhispánico de dudas tampoco. Sin embargo, en la vigésima tercera edición del primero sí se acepta ya, con la siguiente definición: "Prenda de abrigo de material impermeable por fuera y acolchada por dentro". Otra palabra en la que la duda es patente es esqui: el DRAE observa que proviene del francés ski, no está contenida en Pratt (1980), en cambio sí la incluye Lorenzo (1996), aunque con una advertencia "No se ha podido evitar en esta obra, como en las de Alfaro y Pratt, la intromisión de «anglicismos» dudosos o claramente falsos, riesgo del que no se libra quien se aventura en terrenos de estudio un tanto inexplorados".

Dadas estas circunstancias, debemos indicar que, seguramente, no hemos alcanzado un resultado completamente satisfactorio. Es posible que, para algunos, ciertas palabras que hemos seleccionado aquí no deberían figurar en los listados, al tiempo que otras que no están recogidas por nosotros deberían estarlo. Sea como sea, se trata de opciones abiertas al debate y a la reflexión como apuntábamos anteriormente.

Siguiendo con los cotejos, esta vez por centros de interés, observamos cómo en Puerto Rico y la República Dominicana sobresalen las áreas nocionales Juegos y distracciones, Medios de transporte, La ropa y La ciudad, con el mayor número de vocablos de procedencia anglosajona. Encontramos diferencias en el campo de Los muebles, en donde la República Dominicana marca ocho anglicismos más que Puerto Rico. En cambio, este supera a la República Dominicana en 23 vocablos en el centro Alimentos y bebidas. 
Sin embargo, si ahora nos fijamos en los porcentajes, podemos observar cómo estos se acercan enormemente. Así, en el mencionado centro Muebles de la casa, con ocho anglicismos de diferencia a favor de la República Dominicana, el porcentaje se sitúa, en ambos estudios, en el 10\%, lo cual es una nueva prueba de que, a menudo, la densidad es un parámetro más fiable a la hora de realizar cotejos entre varios léxicos disponibles.

Si comparamos Castellón y Cádiz, que poseen los léxicos de España más similares en este cotejo, podemos establecer análogos grupos con los centros de interés enunciados más arriba. Ahora bien, al mismo tiempo cabe resaltar algunas diferencias importantes en tres de ellos: la Escuela, con 29 anglicismos de Castellón, frente a 16 de Cádiz (4.65\% y $3.49 \%$ respectivamente); el centro Ciudad, con 44 anglicismos en la primera provincia, a considerable distancia de los 26 vocablos de Cádiz (4.63\% y $3.48 \%$ respectivamente); con todo, se advierten mayores diferencias todavía en el área semántica de los Juegos y distracciones: 88 en Castellón y 53 en Cádiz (9.69\% y $7.54 \%$, respectivamente).

Desde un punto de vista cualitativo, en el centro Escuela, ambas provincias comparten vocablos como carpeta, bar, póster, escáner, láser, fax, kleenex, váter, CD. En Cádiz, aparecen las palabras filmina, type, rotring y stick, que no se recogen en Castellón, provincia en la que, sin embargo, aparecen otros vocablos como bloc, clip, panel, hall, disquete, cúter, cómic, subcarpeta, básquet, fútbol, tenis y bafle, no hallados en Cádiz. Por su parte, el centro de interés Juegos y distracciones muestra en Cádiz palabras como turismo, party, cowboys, bridge, crocket, fun, hobby, kick boxing, soccer, stripstease que no encontramos en Castellón, mientras que en esta última figuran otros vocablos no listados en la muestra gaditana: rol, pimpón, rugby, pub, vídeo, internet, frontenis, polo, zapping, top model, trial ,bate, test, CD, picnic, walkie talkie, trekking, kung-fu, gymkhana, surfing, minigolf, karting, chatear, Hula hop*, handball, rock and roll, cross, full contact. Por otro lado, en algunos de estos anglicismos la forma escrita es diferente en ambas comunidades lingüísticas: así, en Cádiz tenemos skate board y snow board, mientras que en Castellón solo aparece la primera parte del sintagma: skate y snow.

A pesar de estas diferencias, los resultados entre ambos estudios son en conjunto bastante similares, pudiendo establecerse en las dos comunidades cuatro grandes grupos en la clasificación de los anglicismos: 
1. Centros de interés con mayor número de vocablos procedentes del inglés: Juegos y distracciones, La ciudad, La ropa, Medios de transporte, Profesiones y oficios.

2. Campos semánticos con una densidad media: Partes de la casa, Alimentos y bebidas, La escuela.

3. Áreas léxicas con cifras bajas de anglicismos: Los animales, Iluminación, La cocina; Los muebles de la casa.

4. Centros de interés con escasa o nula incidencia de anglicismos: El campo, Objetos colocados en la mesa y Jardín,

Como señalábamos más arriba, llama la atención la provincia de Zamora por la escasa penetración de anglicismos en el léxico juvenil, no ya solo frente a las comunidades americanas cercanas a EE.UU., como Puerto Rico y la República Dominicana, sino también frente a las otras provincias españolas. En su estudio sobre la disponibilidad léxica zamorana, J. A. Bartol (1998: 123) no aventura ninguna hipótesis al respecto. Quizá contribuya a estas diferencias tan marcadas el hecho de que Zamora es una provincia del interior de España, una zona tradicionalmente rural, mientras que Cádiz y Castellón son provincias costeras y con gran afluencia turística y, por tanto, con un contacto más intenso y habitual con el inglés como lengua de uso internacional. Con todo, hoy en día los medios de comunicación (prensa periódica, radio, televisión, Internet), principales responsables de la difusión de extranjerismos, llegan a todas partes y de hecho, el mismo Bartol (2005) en su estudio sobre los extranjerismos en el léxico disponible de Soria ha comprobado que el número de anglicismos en esta provincia castellana es mayor que en Zamora ${ }^{180}$ y la situación geográfica, demográfica y social es muy similar en ambas provincias castellanas.

Así las cosas, creemos que las razones últimas de estas diferencias entre unas provincias y otras habría que buscarlas, como se ha apuntado anteriormente, en los diferentes criterios de edición de los materiales y en el concepto de anglicismo con el que se aborda la cuestión.

${ }^{180}$ En Soria también el número de informantes es de 100. 


\subsubsection{Variables sociales.}

Como hemos hecho a propósito de los resultados generales del léxico disponible en Castellón (ver apartado 5.2), analizamos a continuación el efecto de las variables sociales entre los anglicismos. Este estudio sociolingüístico permite comprobar si estos factores (sexo, tipo y ubicación de centro, lengua materna y nivel educativo familiar) ejercen alguna influencia significativa en la penetración de las palabras inglesas en los listados castellonenses.

\subsubsection{Sexo}

En el cuadro siguiente se hallan los datos relativos a los anglicismos que aportan los informantes de Castellón en función del factor sexo, con el número total de palabras anglicadas aportadas y la densidad que representan en cada caso.

\begin{tabular}{|l|c|c|c|c|c|c|}
\hline Centro de interés & \multicolumn{3}{|c|}{ Hombre } & \multicolumn{3}{c|}{ Mujer } \\
\hline & Voc. & Ang. & $\%$ & Voc & Ang. & $\%$ \\
\hline 1. Partes del cuerpo & 230 & 0 & 0 & 211 & 0 & 0 \\
\hline 2. La ropa & 221 & 24 & 10.85 & 252 & 29 & 11.50 \\
\hline 3. Partes casa & 228 & 11 & 4.82 & 228 & 11 & 4.82 \\
\hline 4. Muebles & 198 & 10 & 5.05 & 254 & 17 & 6.69 \\
\hline 5. Alimentos & 483 & 21 & 4.34 & 463 & 15 & 3.23 \\
\hline 6. Mesa & 225 & 4 & 1.77 & 245 & 3 & 1.22 \\
\hline 7. La cocina & 346 & 7 & 2.02 & 387 & 8 & 2.06 \\
\hline 8. La escuela & 424 & 25 & 5.89 & 456 & 16 & 3.50 \\
\hline 9. Iluminación & 326 & 15 & 4.60 & 328 & 11 & 3.35 \\
\hline 10. La ciudad & 646 & 43 & 6.65 & 655 & 33 & 5.03 \\
\hline 11. El campo & 771 & 7 & 0.90 & 741 & 11 & 1.48 \\
\hline 12. Transporte & 276 & 42 & 15.21 & 248 & 46 & 18.54 \\
\hline 13. Jardín & 476 & 1 & 0.21 & 423 & 1 & 0.23 \\
\hline 14. Los animales & 387 & 9 & 2.32 & 319 & 8 & 2.50 \\
\hline 15. Juegos & 621 & 88 & 14.17 & 627 & 67 & 10.68 \\
\hline 16. Profesiones & 541 & 17 & 3.14 & 539 & 18 & 3.33 \\
\hline 17. Los colores & 249 & 4 & 1.60 & 266 & 7 & 2.63 \\
\hline TOTAL & 6548 & 328 & 5 & 6642 & 301 & 4.53 \\
\hline
\end{tabular}

Tabla 5.3.5. Frecuencias absolutas y relativas de los anglicismos según la variable sexo

A simple vista, el factor generolectal no parece presentar diferencias relevantes en lo que concierne al empleo global de anglicismos. La diferencia es mínima en los 
resultados totales, con una media del 5\% para los hombres y un $4.53 \%$ para las mujeres, una distancia porcentual que no es significativa a la luz de la prueba $t$ para medias de dos muestras emparejadas $(t=0,42 ; \mathrm{p}: 0,67)$. En este sentido, nuestros datos coinciden con los del estudio de la República Dominicana, donde O. Alba (1996) advierte también diferencias mínimas: los hombres (6.75\%) superan a la mujeres $(6.62 \%)$ con una diferencia aún menor que en la provincia de Castellón (apenas 0,13\%).

Únicamente en el campo léxico Juegos y distracciones observamos una diferencia máxima de 3.49 puntos a favor de los estudiantes, que también aventajan, aunque más levemente a sus compañeras en Escuela, Ciudad, Alimentos e Iluminación. Por su parte, las féminas superan a los hombres con una distancia de 3.33 puntos porcentuales en Transportes y con menor distancia en Ropa, Muebles, y Profesiones. No son apreciables las diferencias en las demás áreas semánticas.

Si centramos la atención en el campo léxico La ropa desde un punto de vista cualitativo, advertimos que la diferencia es también poco relevante. ${ }^{181}$ Para ello solo analizaremos el empleo de las 100 primeras unidades léxicas. ${ }^{182}$. Las palabras únicamente registradas en las listas femeninas son pareo y bóxer. ${ }^{183}$ Ambos lexemas también aparecen en los listados masculinos, aunque en posiciones posteriores. Así pareo la encontramos en la posición 153 y bóxer en el rango número 163. Subrayamos, al mismo tiempo, cómo la palabra jersey se halla en la misma posición séptima de ambos grupos, con un rango, pues, muy elevado en el cómputo general de los vocablos disponibles; y algo parecido sucede con suéter (décima séptima en las mujeres y vigésima cuarta en los hombres) y sudadera (décima novena en el sexo masculino y vigésima primera en el sexo femenino)

Jersey tiene, asimismo, una posición avanzada en las listas de anglicismos de Bellón (2005) en su estudio sobre las palabras anglicadas de Córdoba, con una cuarta posición o un segundo lugar en la provincia de Soria (Bartol, 2005). Sin embargo, no aparece en el estudio de Alba (1996), ${ }^{184}$ donde solo se registra la palabra suéter en una

\footnotetext{
${ }^{181}$ Bellón (2005) realiza una comparativa de este centro de interés, La ropa, en los léxicos disponibles de Puerto Rico, República Dominicana, Zamora y Córdoba.

${ }^{182}$ Alba (1996) considera que las 100 primeras palabras son las verdaderamente disponibles, con vitalidad y funcionalidad evidentes. Señala al respecto que "no cabe duda de que esas primeras palabras son las más importantes para cualquier estudio que intente describir vocabulario vigente, léxico realmente disponible" (1996: 858, nota 11).

${ }^{183}$ La presencia de una palabra en una sola variable se marcará en las tablas mediante la letra cursiva.

${ }^{184}$ Hay que destacar que en los léxicos disponibles de la República Dominica (Orlando Alba, 1999) y Puerto Rico (López Morales, 1999a) aparecen lexemas ingleses que no se registran en ninguna de las provincias españolas, como: polocher, yompa, babydoll, coat, overol, brassiere, baggies...
} 
décima cuarta posición (lexema, por otra parte, también anotado en los listados de las provincias de España).

\begin{tabular}{|c|l|c|l|}
\hline \multicolumn{2}{|c|}{ HOMBRES } & \multicolumn{2}{|l|}{ MUJERES } \\
\hline Rango & Vocablo & Rango & Vocablo \\
\hline 7 & Jersey & 7 & Jersey \\
\hline 18 & Bermudas, & 17 & Suéter \\
\hline 19 & Sudadera & 21 & Sudadera \\
\hline 24 & Suéter & 24 & Pijama \\
\hline 29 & Polo & 26 & Biquini \\
\hline 34 & Anorak & 28 & Top \\
\hline 37 & Pijama & 30 & Short \\
\hline 39 & Biquini & 34 & Minifalda \\
\hline 45 & Minifalda & 36 & Bermudas \\
\hline 51 & Panty & 39 & Body \\
\hline 57 & Top & 42 & Anorak \\
\hline 59 & Short & 45 & Polo \\
\hline 60 & Esmoquin & 50 & Panty \\
\hline 62 & Body & 62 & Slip \\
\hline 63 & Slip & 81 & Pareo \\
\hline 93 & Parka & 89 & Parka \\
\hline & & 98 & Bóxer \\
\hline & & 99 & Esmoquin \\
\hline
\end{tabular}

Tabla 5.3.6. Anglicismos y su posición entre los primeros cien vocablos disponibles según la variable sexo en el centro de interés La ropa

El resumen de las diferencias entre el sexo masculino y femenino queda plasmado en el gráfico siguiente. 


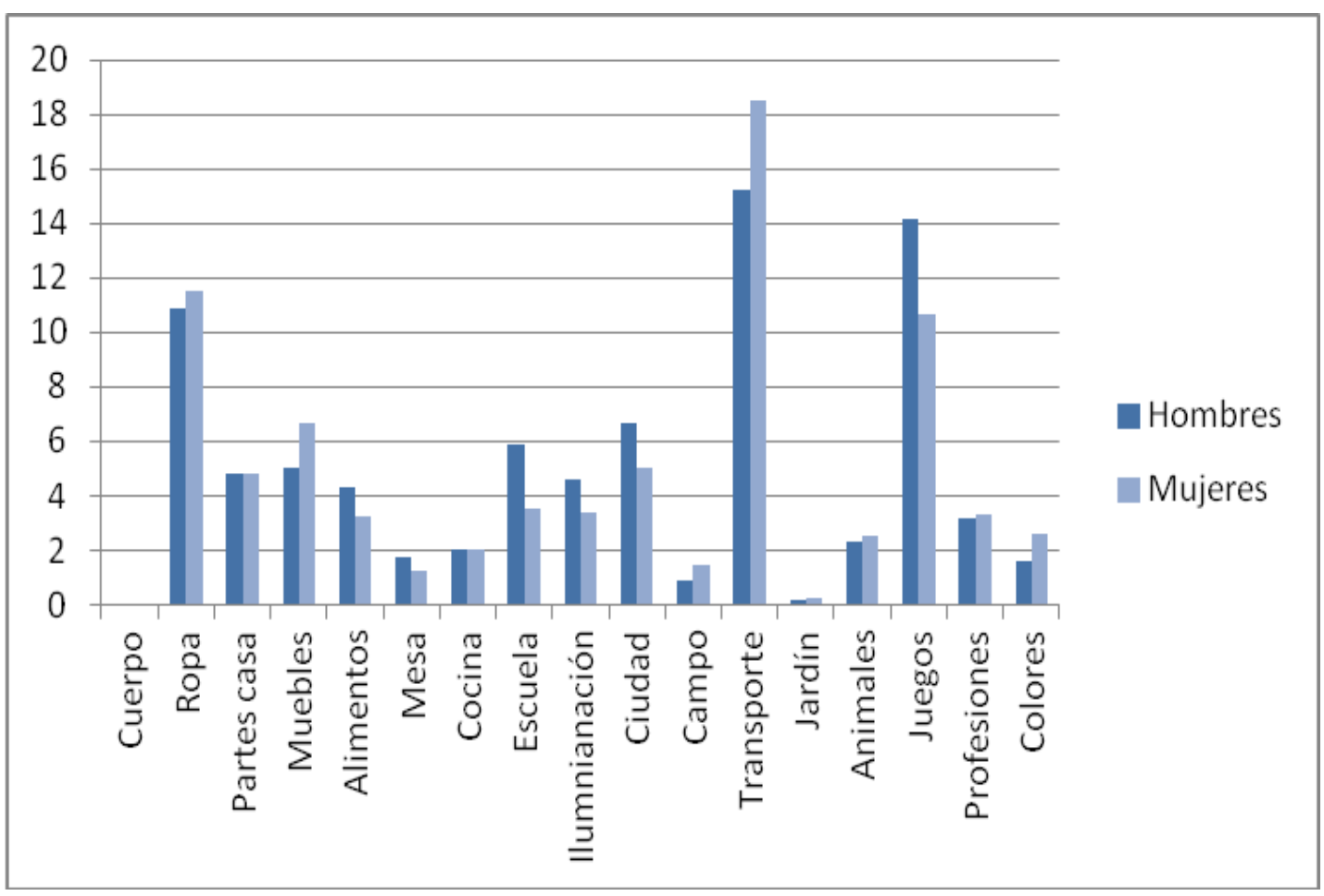

Gráfico 5.3.3. Porcentaje de anglicismos según la variable sexo.

\subsubsection{Ubicación centro}

En la tabla y el gráfico siguientes se encuentran los datos de los anglicismos según la variable Ubicación del centro educativo donde han cursado sus estudios los informantes castellonenses. 


\begin{tabular}{|l|c|c|c|c|c|c|}
\hline Centro de interés & \multicolumn{3}{|c|}{ URBANO } & \multicolumn{3}{c|}{ RURAL } \\
\hline & Voc. & Ang. & $\%$ & Voc & Ang. & $\%$ \\
\hline 1. Partes del cuerpo & 212 & 0 & 0 & 235 & 0 & 0 \\
\hline 2. La ropa & 212 & 26 & 12.26 & 256 & 28 & 10.93 \\
\hline 3. Partes casa & 208 & 9 & 4.32 & 243 & 14 & 5.80 \\
\hline 4. Muebles & 213 & 11 & 5.16 & 241 & 17 & 7.05 \\
\hline 5. Alimentos & 428 & 17 & 3.97 & 507 & 18 & 3.55 \\
\hline 6. Mesa & 204 & 3 & 1.47 & 262 & 3 & 1.14 \\
\hline 7. La cocina & 347 & 11 & 3.17 & 391 & 8 & 2.04 \\
\hline 8. La escuela & 400 & 25 & 6.25 & 472 & 34 & 7.20 \\
\hline 9. Iluminación & 279 & 10 & 3.58 & 360 & 18 & 5 \\
\hline 10. La ciudad & 610 & 36 & 5.90 & 694 & 43 & 6.19 \\
\hline 11. El campo & 731 & 12 & 1.64 & 786 & 12 & 1.52 \\
\hline 12. Transporte & 227 & 40 & 17.62 & 292 & 44 & 15.06 \\
\hline 13. Jardín & 412 & 2 & 0.48 & 476 & 0 & 0 \\
\hline 14. Los animales & 315 & 8 & 2.53 & 385 & 9 & 2.33 \\
\hline 15. Juegos & 595 & 78 & 13.10 & 655 & 77 & 11.75 \\
\hline 16. Profesiones & 523 & 18 & 3.44 & 574 & 18 & 3.13 \\
\hline 17. Los colores & 243 & 7 & 2.88 & 270 & 6 & 2.22 \\
\hline TOTAL & 6159 & 313 & 5.08 & 7099 & 349 & 4.91 \\
\hline
\end{tabular}

Tabla 5.3.7. Frecuencias absolutas y relativas de los anglicismos según la variable Ubicación del centro educativo

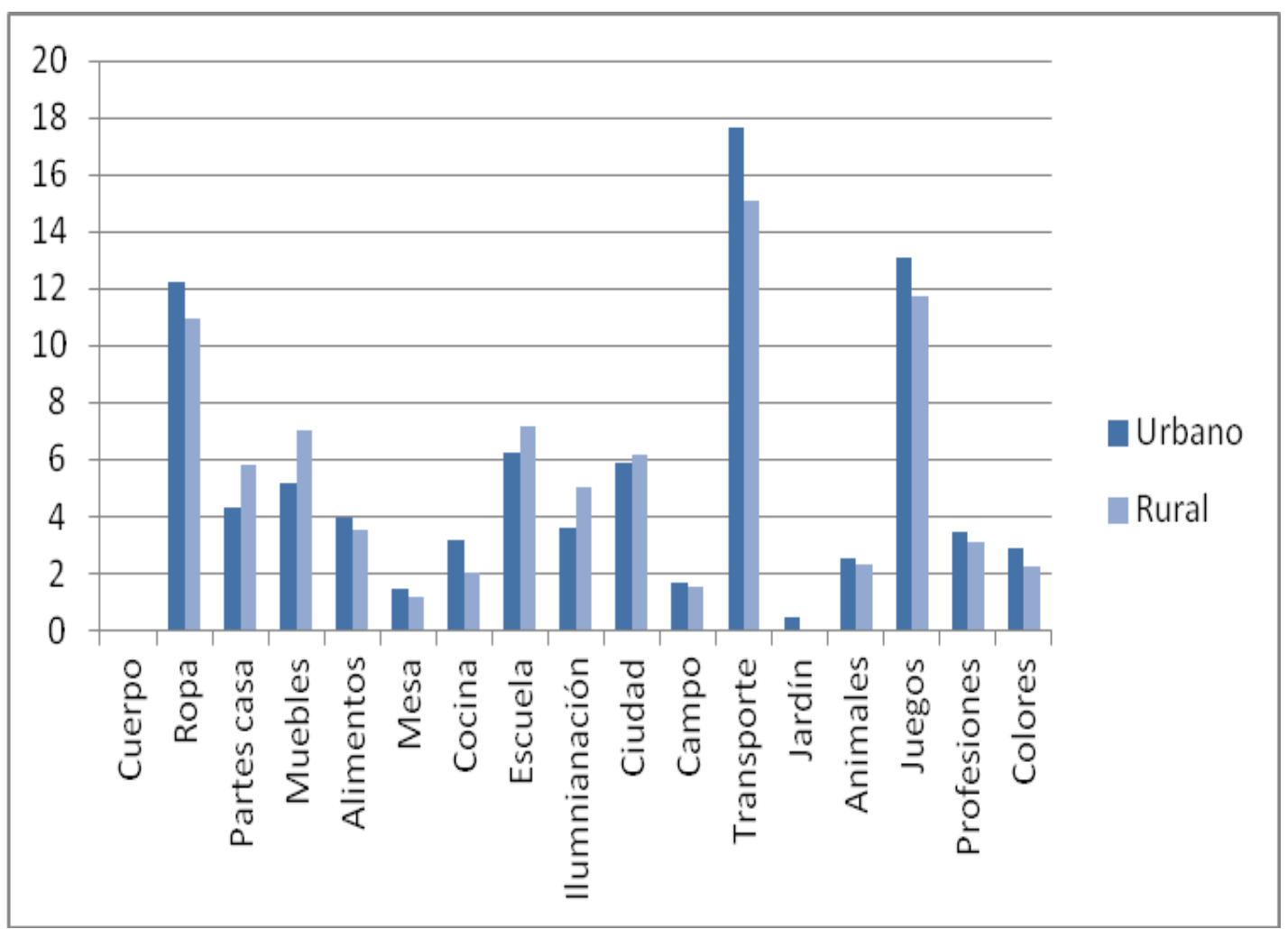

Gráfico 5.3.3. Porcentaje de anglicismos según la variable Ubicación del centro educativo. 
Tampoco en este caso la diferencia entre informantes de centros urbanos y rurales es significativa $(t: 0,60 ;$ p. 0,55$)$. De hecho, la distancia global entre los diferentes grupos (apenas $0,17 \%$ ) es todavía menor que en el caso del sexo de los estudiantes.

Con todo, un análisis más minucioso permite observar que el número de anglicismos entre los alumnos de colegios urbanos es mayor en estos centros de interés: Ropa, Cocina, Transporte y Juegos, con cifras que superan el punto porcentual. Por su parte, los alumnos de institutos rurales superan en similar medida a los anteriores en los campos léxicos relativos a la Casa, Muebles e Iluminación. En las demás áreas léxicas la diferencia entre unos y otros es siempre inferior a un punto.

Un análisis específico del centro de interés Ropa nos permite establecer ahora comparaciones con otros trabajos que han analizado este mismo factor sociológico en sus investigaciones, como es el caso de Bellón (2005) en Córdoba o Bartol (2005) en Soria. De ese estudio contrastivo se deriva que tampoco en esta ocasión las diferencias son importantes entre unas comunidades lingüísticas y otras. Únicamente la palabra pareo de los listados de centros ubicados en zona rural no aparece en los listados de las instituciones urbanas. Las mismas unidades léxicas aparecen en los demás estudios. Asimismo, llama la atención que un lexema que ha sido tradicionalmente muy habitual entre la juventud, como es Jeans, no aparezca entre las 100 primeras palabras de los estudiantes castellonenses. Lo hace en la posición 136 en el inventario de los estudiantes rurales y en el rango 102 en los urbanos. En cambio, en los estudiantes cordobeses de zona rural lo encontramos en el lugar número 86, pero entre los alumnos de centros urbanos, donde dicho lexema cae hasta el puesto número 106. Por otro lado, entre los estudiantes sorianos, dicho vocablo se encuentra en el rango 133 de los estudiantes de centros urbanos, y no aparece entre los que acuden a institutos rurales. 


\begin{tabular}{|c|c|c|c|}
\hline \multicolumn{2}{|r|}{ URBANO } & \multicolumn{2}{|r|}{ RURAL } \\
\hline Rango & Vocablo & Rango & Vocablo \\
\hline 10 & Jersey & 4 & Jersey \\
\hline 16 & Suéter & 18 & Sudadera \\
\hline 21 & Sudadera & 20 & Suéter \\
\hline 24 & Bermudas & 27 & Bermudas \\
\hline 31 & Biquini & 29 & Pijama \\
\hline 34 & Pijama & 34 & Biquini \\
\hline 34 & Polo & 37 & Short \\
\hline 36 & Anorak & 40 & Polo \\
\hline 38 & Top & 41 & Top \\
\hline 41 & Minifalda & 43 & Minifalda \\
\hline 42 & Body & 45 & Anorak \\
\hline 47 & Short & 53 & Body \\
\hline 49 & Panty & 61 & Slip \\
\hline 64 & Slip & 80 & Pareo \\
\hline 68 & Esmoquin & 88 & Esmoquin \\
\hline 95 & Parka & 90 & Parka \\
\hline
\end{tabular}

Tabla 5.3.8. Anglicismos y rango entre las primeras cien palabras según el factor Ubicación del centro educativo.

\subsubsection{Tipo de centro}

Tal como hemos comprobado en las anteriores variables sociales, tampoco en esta ocasión hallamos diferencias reveladoras en el total de anglicismos entre centros de titularidad pública o privada. Así, se observa una diferencia global de un $0.58 \%$ a favor de los alumnos matriculados en centros privados, diferencias que tampoco ahora resultan significativas a la luz del test $t(t:-1,04 ;$ p. 0,31$)$.

Los campos semánticos cuyas diferencias no superan el punto son los más numerosos: Mesa, Cocina, Escuela, Campo, jardín, Colores, Animales, Iluminación y Profesiones. Los alumnos de centros públicos superan a sus compañeros de centros privados en Ropa y Muebles con más de un punto de separación y con $2.44 \%$ en Partes de la casa. Por otro lado, estos últimos aventajan a los inscritos en institutos públicos en Alimentos, Ciudad, Juegos, y con una diferencia mayor, de 5.72\%, en el área semántica de Transportes. Al final, aunque con escasas diferencias, los estudiantes de establecimientos privados superan a sus compañeros en el empleo de anglicismos en diez de los diecisiete centros de interés. 
Resumimos las cifras generales y los porcentajes de los anglicismos de acuerdo con la variable tipo de centro (titularidad pública o privada) de los alumnos de la provincia de Castellón en la tabla 5.3.9 y el gráfico 5.3.4.

\begin{tabular}{|l|c|c|c|c|c|c|}
\hline \multicolumn{1}{|c|}{ Centro de interés } & \multicolumn{3}{|c|}{ Público } & \multicolumn{3}{c|}{ Privado } \\
\hline & Voc. & Ang. & \% & Voc & Ang. & \% \\
\hline 1. Partes del cuerpo & 252 & 0 & 0 & 190 & 0 & 0 \\
\hline 2. La ropa & 271 & 32 & 11.80 & 196 & 21 & 10.71 \\
\hline 3. Partes casa & 249 & 15 & 6.02 & 195 & 7 & 3.58 \\
\hline 4. Muebles & 255 & 18 & 7.05 & 189 & 10 & 5.29 \\
\hline 5. Alimentos & 521 & 19 & 3.64 & 407 & 20 & 4.91 \\
\hline 6. Mesa & 254 & 3 & 1.18 & 201 & 2 & 0.99 \\
\hline 7. La cocina & 417 & 10 & 2.39 & 318 & 9 & 2.83 \\
\hline 8. La escuela & 493 & 36 & 7.30 & 366 & 27 & 7.37 \\
\hline 9. Iluminación & 371 & 16 & 4.31 & 267 & 14 & 5.24 \\
\hline 10. La ciudad & 752 & 39 & 5.18 & 536 & 38 & 7.08 \\
\hline 11. El campo & 857 & 13 & 1.51 & 642 & 10 & 1.55 \\
\hline 12. Transporte & 315 & 45 & 14.28 & 170 & 34 & 20 \\
\hline 13. Jardín & 536 & 1 & 0.18 & 338 & 1 & 0.29 \\
\hline 14. Los animales & 396 & 9 & 2.27 & 298 & 9 & 3.02 \\
\hline 15. Juegos & 722 & 80 & 11.08 & 522 & 75 & 14.36 \\
\hline 16. Profesiones & 642 & 28 & 4.36 & 426 & 15 & 3.52 \\
\hline 17. Los colores & 326 & 8 & 2.45 & 166 & 4 & 2.40 \\
\hline TOTAL & 7629 & 372 & 4.87 & 5430 & 296 & 5.45 \\
\hline
\end{tabular}

Tabla 5.3.9. Frecuencias absolutas y relativas de los anglicismos según la variable tipo de centro educativo 


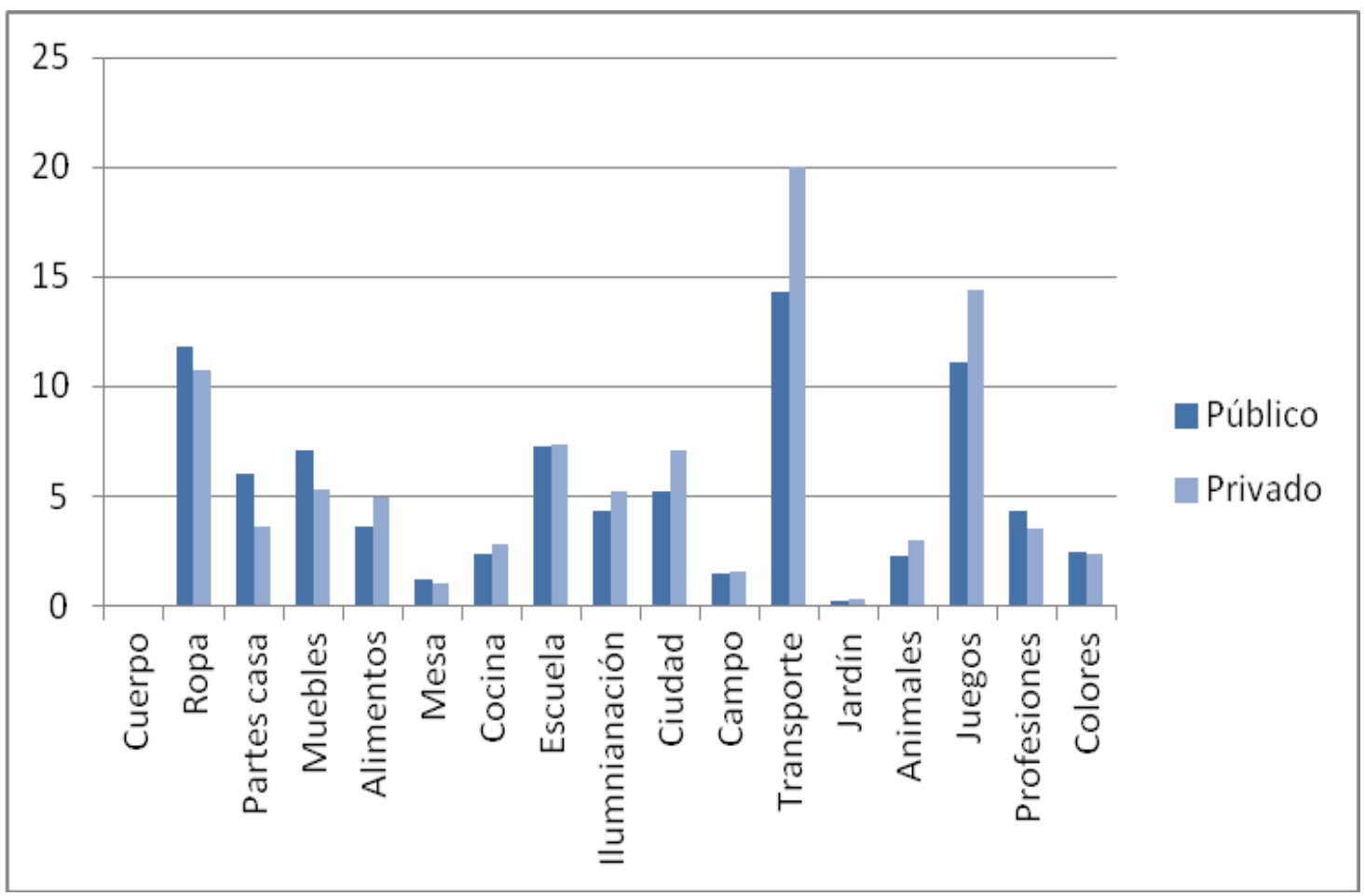

Gráfico 5.3.4. Porcentaje de anglicismos según la variable tipo de centro educativo

Si continuamos comparando el campo específico de la Ropa, advertimos que cuatro vocablos solo se encuentran en los listados de alumnos que estudian en centros privados (sudadera, parka, mocasín y bóxer) entre las 100 primeras palabras. Las demás son las mismas, aunque cambia la posición en la que aparecen. Vuelve a destacar el resultado tan avanzado de la palabra jersey en los dos inventarios, que también alcanza el cuarto rango en las listas de los anglicismos de los estudiantes cordobeses (Bellón, 2005), a gran distancia del segundo (la palabra pijama con rango 29 en los alumnos de centros públicos y rango 33 de los centros privados). 


\begin{tabular}{|c|l|c|l|}
\hline \multicolumn{2}{|c|}{ CENTROS PÚBLICOS } & \multicolumn{2}{c|}{ CENTROS PRIVADOS } \\
\hline Rango & Vocablos & Rango & Vocablos \\
\hline 5 & Jersey & 9 & Jersey \\
\hline 20 & Suéter & 15 & Suéter \\
\hline 26 & Bermudas & 21 & Sudadera \\
\hline 28 & Pijama & 27 & Bermudas \\
\hline 32 & Biquini & 31 & Body \\
\hline 37 & Polo & 33 & Biquini \\
\hline 39 & Anorak & 34 & Pijama \\
\hline 40 & Short & 36 & Polo \\
\hline 41 & Top & 38 & Minifalda \\
\hline 43 & Minifalda & 39 & Top \\
\hline 54 & Panty & 41 & Anorak \\
\hline 55 & Body & 43 & Panty \\
\hline 68 & Slip & 45 & short \\
\hline 75 & Esmoquin & 59 & Slip \\
\hline 76 & Pareo & 75 & Esmoquin \\
\hline & & 77 & parka \\
\hline & & 94 & Mocasín \\
\hline & & 98 & bóxer \\
\hline
\end{tabular}

5.3.10. Anglicismos y su rango entre las cien primeras palabras según tipo de centro.

En el estudio que realiza Bellón (2005) sobre el centro de La ropa, encontramos idénticos vocablos. Al igual que en Castellón, Mocasín también aparece solo en el léxico disponible de los alumnos que estudian en centros privados (en la posición 96). Por su parte, top y parka surgen también en los listados de instituciones privadas, pero lo hacen en posiciones mucho más avanzadas (rango 194 y 147 respectivamente). Sin embargo, en los alumnos de centros públicos dichas palabras se registran en los rangos 50 (top) y 17 (parka), es decir, en posiciones más próximas a las de los informantes castellonenses. Por otro lado, en Zamora (Bartol, 1998) hay también una palabra (esmoquin) que es exclusiva de un grupo (de nuevo el de los colegios privados).

Si en Castellón, en el presente trabajo, y Zamora (1998) se aprecia una ligera ventaja de los alumnos de centros privados en el uso de anglicismos (en todo caso, mayor en la comunidad castellano-leonesa que en la castellonense), no sucede lo mismo en el estudio cordobés, donde son los alumnos de instituciones públicas quienes superan a sus compañeros de enseñanza privada. Con todo, la ventaja de los primeros sobre los segundos se reduce a apenas ocho anglicismos. ${ }^{185}$

\footnotetext{
${ }^{185}$ Hay que señalar que Bellón (2005) apunta resultados generales, no restringe su análisis a las 100 primeras palabras.
} 


\subsubsection{Lengua materna}

Los datos sobre anglicismos que arrojan las encuestas de disponibilidad de los preuniversitarios de Castellón según la variable lengua materna se resumen en la tabla y gráfico siguientes.

\begin{tabular}{|l|c|c|c|c|c|c|c|c|c|}
\hline Centros de interés & \multicolumn{3}{|c|}{ Valenciano } & \multicolumn{3}{c|}{ Castellano } & \multicolumn{3}{c|}{ Ambas } \\
\hline & Voc. & Ang. & \% & Voc. & Ang. & \% & Voc. & Ang. & $\%$ \\
\hline 1. Partes del cuerpo & 218 & 0 & 0 & 206 & 0 & 0 & 169 & 0 & 0 \\
\hline 2. La ropa & 228 & 27 & 11.84 & 226 & 27 & 11.94 & 168 & 20 & 11.90 \\
\hline 3. Partes casa & 219 & 11 & 5.02 & 200 & 12 & 6 & 153 & 9 & 5.88 \\
\hline 4. Muebles & 222 & 14 & 6.30 & 198 & 12 & 6.06 & 149 & 10 & 6.71 \\
\hline 5. Alimentos & 442 & 17 & 3.84 & 429 & 20 & 4.66 & 328 & 15 & 4.57 \\
\hline 6. Mesa & 226 & 3 & 1.32 & 210 & 3 & 1.42 & 148 & 3 & 2.02 \\
\hline 7. La cocina & 328 & 7 & 2.13 & 335 & 8 & 2.38 & 244 & 7 & 2.86 \\
\hline 8. La escuela & 419 & 33 & 7.87 & 391 & 26 & 6.64 & 264 & 18 & 6.81 \\
\hline 9. Iluminación & 312 & 16 & 5.12 & 273 & 12 & 4.39 & 201 & 12 & 5.97 \\
\hline 10. La ciudad & 608 & 37 & 6.08 & 581 & 34 & 5.85 & 370 & 25 & 6.75 \\
\hline 11. El campo & 721 & 14 & 1.94 & 666 & 8 & 1.20 & 459 & 4 & 0.87 \\
\hline 12. Transporte & 272 & 44 & 16.17 & 221 & 37 & 16.74 & 152 & 27 & 17.76 \\
\hline 13. Jardín & 429 & 0 & 0 & 360 & 1 & 0.27 & 239 & 1 & 0.41 \\
\hline 14. Los animales & 362 & 9 & 2.48 & 298 & 8 & 2.68 & 256 & 8 & 3.12 \\
\hline 15. Juegos & 606 & 78 & 12.87 & 565 & 71 & 12.56 & 358 & 52 & 14.52 \\
\hline 16. Profesiones & 521 & 20 & 3.83 & 502 & 19 & 3.78 & 345 & 14 & 4.05 \\
\hline 17. Los colores & 272 & 8 & 2.94 & 202 & 3 & 1.48 & 170 & 4 & 2.35 \\
\hline TOTAL & 6405 & 338 & 5.27 & 5863 & 301 & 5.13 & 4173 & 229 & 5.48 \\
\hline
\end{tabular}

Tabla 5.3.11. Frecuencias absolutas y relativas de los anglicismos según la variable lengua materna 


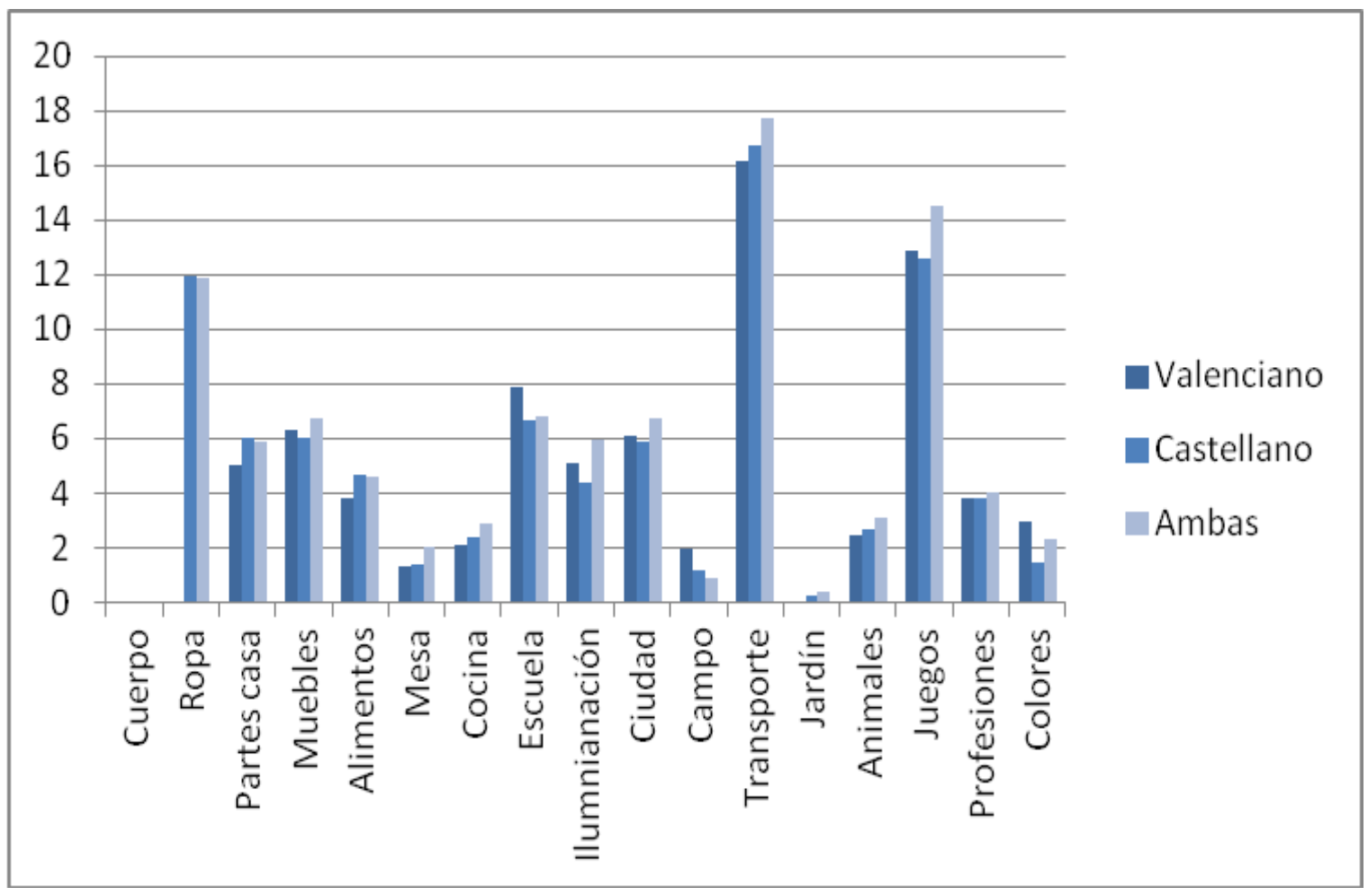

Gráfico 5.3.5. Porcentaje de anglicismos según la variable lengua materna

En la tercera columna de la tabla 5.3.11 (Ambas) aparecen los estudiantes que consideran tanto el castellano como el valenciano como su lengua materna, con un porcentaje de 5.48\%; seguidos de los informantes cuya lengua materna es el valenciano (5.27\%) y, en tercer lugar de los hablantes exclusivos de castellano (5.13\%). Las diferencias globales no resultan significativas estadísticamente tras el análisis de varianza de un factor realizado $(F: 3,19 ;$ p. 0.94). Tampoco lo son las comparaciones entre los grupos castellanohablante y valencianohablante $(t: 0,62 ;$ p. 0,53$)$, pero sí las que se aprecian en el contraste entre cada uno de estos dos grupos y el de los bilingües equilibrados, es decir, aquellos que cuentan con ambas lenguas como maternas. El número global de anglicismos entre estos últimos es significativamente mayor que entre los alumnos que solo cuentan con una lengua materna (castellano-ambas: $t:-3,32 ; \mathrm{p}$. 0,004; valenciano-ambas: $t:-2,15 ;$ p. 0,04$)$.

De hecho, un análisis por centros de interés revela que estos bilingües equilibrados superan a sus otros compañeros en diez centros de interés. Son los siguientes: Muebles, Mesa, Cocina, Iluminación, Ciudad, Transporte, Jardín, Animales, Juegos y Profesiones. Por su parte, los alumnos con el valenciano como lengua materna tan solo superan levemente a los demás en Escuela, Campo y Colores, mientras que los 
informantes con el castellano como primer idioma lo hacen en otros tres Ropa, Casa y Alimentos. Las áreas léxicas Ropa, Transporte y Juegos destacan por ofrecer las cifras más altas de anglicismos en los tres grupos estudiados.

Analizando de nuevo cualitativamente el centro de interés La ropa, observamos una vez más las mismas palabras entre los cien primeros vocablos de los grupos considerados. Con todo, hay alguna excepción. Es el caso de parka, que se encuentra solo entre los hablantes del castellano como lengua materna, y pareo, si bien en este caso aparece también en el léxico disponible de los alumnos valencianohablantes. Por otro lado, las palabras jersey, suéter y sudadera ocupan las posiciones más elevadas de los listados en los tres casos.

\begin{tabular}{|c|l|c|l|c|l|}
\hline \multicolumn{2}{|c|}{ VALENCIANO } & \multicolumn{2}{c|}{ CASTELLANO } & \multicolumn{2}{c|}{ AMBAS } \\
\hline Rango & Vocablos & Rango & Vocablos & Rango & Vocablos \\
\hline 9 & Jersey & 9 & Jersey & 4 & Jersey \\
\hline 19 & Sudadera & 16 & suéter & 17 & Suéter \\
\hline 21 & Suéter & 20 & Sudadera & 24 & Sudadera \\
\hline 26 & Bermudas & 27 & Pijama & 25 & Bermudas \\
\hline 32 & Pijama & 28 & Bermudas & 27 & Pijama \\
\hline 33 & Biquini & 30 & Biquini & 28 & Top \\
\hline 39 & Polo & 31 & Anorak & 32 & Minifalda \\
\hline 40 & Short & 34 & Top & 36 & Polo \\
\hline 41 & Minifalda & 37 & Polo & 38 & Body \\
\hline 45 & Anorak & 40 & Short & 39 & Biquini \\
\hline 47 & Top & 41 & Minifalda & 43 & Short \\
\hline 48 & Body & 43 & Panty & 48 & Anorak \\
\hline 56 & Panty & 47 & Body & 61 & Panty \\
\hline 81 & Slip & 56 & Slip & 66 & Slip \\
\hline 96 & Esmoquin & 65 & Esmoquin & 91 & Esmoquin \\
\hline 97 & Pareo & 73 & parka & 94 & Mocasín \\
\hline & & 82 & Pareo & & \\
\hline
\end{tabular}

Tabla 5.3.12. Vocablos y rango entre las cien primeras palabras según el factor Lengua materna 


\subsubsection{Nivel educativo de los padres}

Los datos recogidos en la tabla 5.3.13 nos ofrecen las cifras relativas a los anglicismos según la variable nivel educativo de los padres.

\begin{tabular}{|l|c|c|c|c|c|c|c|c|c|c|c|c|}
\hline CI & \multicolumn{3}{|c|}{ Nivel Alto } & \multicolumn{3}{c|}{ Nivel Medio alto } & \multicolumn{3}{c|}{ Nivel medio bajo } & \multicolumn{3}{c|}{ Nivel bajo } \\
\hline & Voc. & Ang. & \% & Voc. & Ang. & \% & Voc. & Ang. & \% & Voc. & Ang. & \% \\
\hline 1 & 138 & 0 & 0 & 174 & 0 & 0 & 188 & 0 & 0 & 213 & 0 & 0 \\
\hline 2 & 139 & 22 & 15.82 & 184 & 21 & 11.41 & 200 & 24 & 12 & 216 & 25 & 11.57 \\
\hline 3 & 122 & 9 & 7.37 & 142 & 6 & 4.22 & 189 & 11 & 5.82 & 206 & 12 & 5.82 \\
\hline 4 & 111 & 7 & 6.30 & 178 & 12 & 6.74 & 176 & 11 & 6.25 & 219 & 12 & 5.47 \\
\hline 5 & 239 & 12 & 5.02 & 354 & 14 & 3.95 & 391 & 18 & 4.60 & 439 & 18 & 4.10 \\
\hline 6 & 105 & 2 & 1.90 & 177 & 2 & 1.12 & 188 & 2 & 1.06 & 216 & 3 & 1.38 \\
\hline 7 & 176 & 8 & 4.54 & 268 & 9 & 3.35 & 286 & 9 & 3.14 & 340 & 9 & 2.64 \\
\hline 8 & 196 & 12 & 6.12 & 301 & 25 & 8.30 & 339 & 24 & 7.07 & 398 & 27 & 6.78 \\
\hline 9 & 119 & 6 & 5.04 & 201 & 8 & 3.98 & 249 & 13 & 5.22 & 283 & 14 & 4.94 \\
\hline 10 & 247 & 15 & 6.07 & 442 & 34 & 7.69 & 482 & 28 & 5.80 & 576 & 35 & 6.07 \\
\hline 11 & 295 & 1 & 0.33 & 513 & 10 & 1.94 & 592 & 12 & 2.02 & 651 & 8 & 1.22 \\
\hline 12 & 133 & 25 & 18.79 & 180 & 34 & 18.88 & 202 & 38 & 18.81 & 251 & 39 & 15.53 \\
\hline 13 & 121 & 0 & 0 & 275 & 0 & 0 & 359 & 1 & 0.27 & 384 & 1 & 0.26 \\
\hline 14 & 207 & 5 & 2.41 & 257 & 7 & 2.72 & 293 & 9 & 3.07 & 331 & 8 & 2.41 \\
\hline 15 & 261 & 36 & 13.79 & 461 & 29 & 6.29 & 447 & 66 & 14.76 & 548 & 59 & 10.76 \\
\hline 16 & 265 & 9 & 3.39 & 380 & 15 & 3.94 & 429 & 19 & 4.42 & 497 & 19 & 3.82 \\
\hline 17 & 124 & 1 & 0.80 & 155 & 4 & 2.58 & 215 & 6 & 2.79 & 262 & 7 & 2.67 \\
\hline Total & 2720 & 170 & 6.25 & 4542 & 230 & 5.06 & 5222 & 291 & 5.57 & 6030 & 296 & 4.90 \\
\hline
\end{tabular}

Tabla 5.3.13. Frecuencias absolutas y relativas de los anglicismos según la variable nivel educativo

El análisis general de las diferencias cuantitativas relacionadas con este factor sociológico se revela una vez más como no significativo ( $F: 2,74$; p. 0,95). Otra cosa es, sin embargo, la comparación entre algunos grupos entre sí, especialmente entre los dos más extremos, donde las distancias porcentuales obtenidas son, ahora sí, más reveladoras. Así, la prueba $t$ de student para la comparación de medias de dos muestras emparejadas permite comprobar cómo los índices alcanzados por alumnos del grupo más alto $(6,25 \%)$ son significativamente más altos que los del grupo más bajo $(4,9 \%)(t$ : $2,83$; p. 0,048$)$. No ocurre lo mismo, por el contrario, en el resto de comparaciones.

Los centros de interés en los que destaca sobre todo el grupo social más alto son: la Ropa (15.82\%), Partes de la casa (7.3\%), Cocina (4.54\%). En todos ellos, los 
miembros de este grupo se sitúan a considerable distancia de los demás. Por su parte, los integrantes del nivel medio-alto aparecen por encima en los campos léxicos de Muebles (6.74\%), Escuela (8.30\%), Ciudad (7.69\%) y Transportes (18,88\%), aunque esta vez con diferencias menores con los demás grupos, y no significativas estadísticamente, como vimos. Y lo mismo sucede entre los informantes del nivel medio-bajo, que sobrepasan levemente a sus compañeros en Iluminación (5.22\%), Animales (3.07\%), Profesiones (4.42\%), Colores (2.79\%) y Juegos y distracciones (14.76\%). El resto de centros de interés, esto es, Jardín, Mesa y Campo, apenas poseen anglicismos, por lo que resulta imposible ofrecer comparaciones fiables.

El resumen de la actuación de los alumnos castellonenses en relación con el factor nivel educativo familiar al que pertenecen figura en el gráfico siguiente.

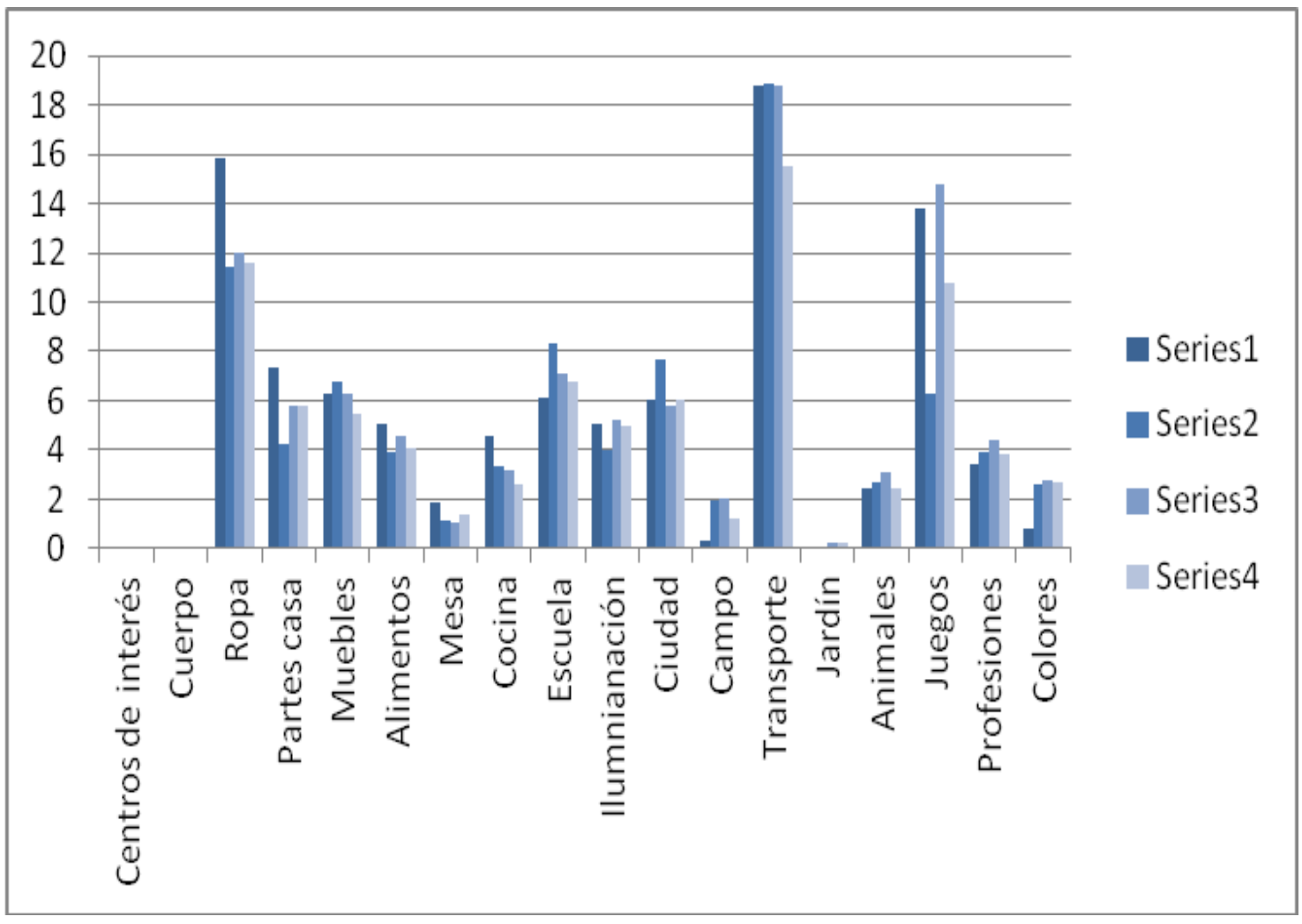

Gráfico 5.3.6. Porcentaje de anglicismos según la variable nivel educativo de los padres.

Leyenda:

Serie 1. Nivel Alto

Serie 2. Nivel Medio-alto

Serie 3. Nivel Medio-bajo

Serie 4. Nivel Bajo 
Como en anteriores ocasiones, analizamos el centro de interés La ropa desde un punto de vista cualitativo. La tabla 5.3.14 nos muestra los lexemas que aparecen en cada uno de los grupos sociales en los que hemos dividido la muestra, y donde nos ocupamos solo de las cien primeras palabras, por ser las más disponibles en un contexto comunicativo concreto.

\begin{tabular}{|l|l|l|l|l|l|l|l|l|}
\hline \multicolumn{2}{|l|}{ NIVEL ALTO } & \multicolumn{2}{l|}{ N. MEDIO ALTO } & \multicolumn{2}{l|}{ N. MEDIO BAJO } & \multicolumn{2}{l|}{ NIVEL BAJO } \\
\hline R. & Vocablos & R. & Vocablos & R. & Vocablos & R. & Vocablos \\
\hline 6 & Jersey & 11 & Jersey & 6 & Jersey & 5 & Jersey \\
\hline 19 & Sudadera & 16 & Suéter & 17 & Sudadera & 18 & Suéter \\
\hline 20 & Bermudas & 21 & Sudadera & 18 & Suéter & 22 & Sudadera \\
\hline 28 & Pijama & 23 & Bermudas & 32 & Polo & 25 & Bermudas \\
\hline 32 & Biquini & 26 & Pijama & 34 & Short & 26 & Pijama \\
\hline 34 & Suéter & 33 & Anorak & 35 & Biquini & 31 & Polo \\
\hline 39 & Top & 37 & Polo & 36 & Anorak & 32 & Biquini \\
\hline 40 & Minifalda & 38 & Top & 37 & Bermudas & 35 & Top \\
\hline 41 & Panty & 41 & Minifalda & 38 & Minifalda & 40 & Short \\
\hline 42 & Slip & 43 & Short & 39 & Body & 42 & Minifalda \\
\hline 43 & Body & 44 & Body & 40 & Pijama & 45 & Anorak \\
\hline 44 & Anorak & 53 & Panty & 44 & Top & 50 & Panty \\
\hline 49 & Short & 65 & Slip & 62 & Panty & 52 & Body \\
\hline 62 & Parka & 78 & Esmoquin & 66 & Slip & 66 & Esmoquin \\
\hline 74 & Polo & 95 & bóxer & 87 & Esmoquin & 70 & Pareo \\
\hline 79 & mocasín & & & 91 & Parka & 72 & Slip \\
\hline 87 & Esmoquin & & & 99 & bóxer & 89 & jeans \\
\hline 89 & Jeans & & & & & & \\
\hline
\end{tabular}

5.3.14. Anglicismos y su rango entre las primeras cien palabras según el factor Nivel educativo de los padres.

Reparamos en que los vocablos biquini, y parka no figuran en el vocabulario disponible de los alumnos del nivel Medio-alto; asimismo el vocablo parka tampoco figura en el listado del nivel Bajo. Por su parte, el lexema mocasín se registra solo en el nivel Alto y la palabra jeans, que presenta la posición número 89 en los niveles alto y bajo, no está presente en los dos grupos intermedios. Con todo, hay que destacar que las unidades ausentes en alguno de los grupos sociales se encuentran en posiciones alejadas en las demás series. 
El término jeans tiene un rango similar (88) y se registra también en el estrato alto del alumnado cordobés que ha analizado Bellón (2005). ${ }^{186}$ El resto de lexemas aparece también en los inventarios de esta investigación, ocupando el primer lugar la palabra jersey en los tres estratos socioculturales. Sin embargo, mientras que Bellón (2005: 27) concluye que el nivel alto "se revela como el menos inclinado al uso de anglicismos" en el contexto cordobés, en nuestro estudio se aprecia justo lo contrario.

\subsubsection{Conclusiones}

Tras realizar un estudio cuantitativo de los anglicismos del léxico disponible de Castellón y la comparación de los datos con otras zonas dialectales (Cádiz, Zamora, Puerto Rico y República Dominicana, principalmente) se llega a las siguientes conclusiones:

1. El número de anglicismos registrado en el trabajo de Castellón es de 380, lo que representa un $4.12 \%$ del total del léxico disponible de la provincia. Es un porcentaje bajo que, consecuentemente, no supone ningún peligro para la lengua española, tal como suelen augurar los más puristas. Lo mismo podríamos decir de los otros léxicos estudiados, aunque la densidad de anglicismos es mayor en países hispanoamericanos como la República Dominicana y Puerto Rico (6.06\% y 6.07\% respectivamente).

2. La mayor o menor presencia de anglicismos está motivada o condicionada por los campos semánticos que se han propuesto en la encuesta, con relevantes diferencias entre ellos. Podríamos decir que hay áreas semánticas que por su estatus de léxico abierto a las innovaciones favorecen más la penetración de anglicismos, mientras que otras áreas dificultan esa entrada, por su carácter más cerrado.

Si tenemos en cuenta el porcentaje de anglicismos, podemos establecer cuatro grupos:

a) Centros con alta incorporación de anglicismos: Juegos y distracciones, Medios de transporte, La ropa.

\footnotetext{
${ }^{186}$ Bellón (2005) divide a los estudiantes de la provincia de Córdoba en tres niveles socioculturales: alto, medio y bajo.
} 
b) Centros de densidad media: La ciudad, La escuela: muebles y materiales, Alimentos y bebidas, Profesiones, Muebles de la casa y Partes de la casa.

c) Centros con baja ocurrencia de lexemas anglicados: Alimentos y bebidas, La cocina y sus utensilios, Iluminación, calefacción y medios para airear un recinto y Los animales.

d) Centros de escasa o nula incidencia: Objetos colocados en la mesa para la comida, Trabajos del campo y del jardín, El campo, Colores y Partes del cuerpo.

3. El centro de interés 1. Partes del cuerpo no registra ningún anglicismo en los trabajos de disponibilidad léxica consultados. Tampoco ofrece anglicismos el campo 13. Trabajos del campo y del jardín en los estudios de la República Dominicana, Cádiz y Zamora. Puerto Rico y Castellón registran dos cada uno, pero, en este último léxico en posiciones de las listas tan avanzadas (posiciones 545 cowboy y 565 sembrar kiwis) que no son representativas.

4. Los países caribeños superan a los españoles en campos semánticos como Juegos y distracciones, Medios de transporte y La ropa, que forman el primer grupo de centros fuertemente influenciados por la cultura anglosajona. Pero también en estas zonas geográficas los vocablos ingleses se dividen en los mismos grupos anteriormente enunciados, y con los mismos centros de interés. Llama la atención, por ejemplo, el centro Muebles de la casa, que aparece en República Dominicana y Puerto Rico con densidades del $10.75 \%$ y $10.61 \%$, frente al bajo porcentaje de anglicismos en las provincias españolas. La razón que aducimos es la cercanía geográfica de Estados Unidos y la especial influencia que de ello se deriva.

5. También contribuye a las diferencias el hecho de que no todas las investigaciones de léxico disponible hayan seguido los mismos criterios de edición y lematización en los vocablos; o el hecho de que tampoco en todas se adopte el mismo concepto de anglicismo, lo cual dificulta la comparación entre las diferentes sintopías analizadas y, lógicamente, obliga a tomar los datos presentados con cierta cautela.

6. En nuestro listado de anglicismos (ver apartado 8.2) observamos palabras inglesas adaptadas al español: bisté, bote, club, cóctel, fútbol, güisqui, pijama, raíl, 
tenis, tranvía, yate. Y vocablos muy usados, pero no incorporados gráficamente al español, al menos por el momento: hall, short, barman, bridge, camping, snack.

7. Podemos concluir que, salvadas algunas diferencias cuantitativas, los centros de interés con mayor penetración de anglicismos coinciden en todos los trabajos estudiados $^{187}$ : Ropa (jersey, suéter, bermudas, top, anorak, body, slip...), Transportes (tranvía, yate, tráiler, ferry, jet, tanque, kart...) y Juegos (fútbol, tenis, voleibol, póquer, básquet, golf, béisbol...), en línea con lo indicado por O. Alba (1996: 860):

Finalmente, la gran diferencia de permeabilidad frente al anglicismo que presentan unos centros de interés con respecto a otros parece constituir un rasgo universal del léxico hispánico, determinado, entre otras razones, por la naturaleza semántica del campo. La comparación con investigaciones similares llevadas a cabo en otras zonas del mundo hispanohablante confirma el hecho de que no solamente los campos más susceptibles, sino también los más reacios a la influencia del inglés son, en todas partes, los mismos.

8. Castellón se aproxima más a otra población española como Cádiz en los porcentajes de densidad de anglicismos que a los países americanos, más influenciados estos por la mayor cercanía a la cultura anglosajona, y, a su vez, se aleja de una comunidad del interior de la Península, de raigambre tradicionalmente rural, como Zamora, con escasa incidencia del léxico procedente de la lengua inglesa, quizá por las razones esgrimidas anteriormente. Aún así, Zamora también coincide en el establecimiento de los mismos cuatro grupos de incidencia de anglicismos marcados más arriba.

9. En lo concerniente a la incidencia de los factores sociales sobre el empleo de anglicismos, no se observan diferencias significativas relacionadas con las variables sexo, ubicación y tipo de centro educativo. En estos casos, los grupos que puntúan por encima, aunque con diferencias menores con respecto a sus contrarios, son los alumnos de sexo masculino, centros urbanos y entidades educativas privadas.

En cuanto a la variable lengua materna no resultan tampoco significativas las diferencias globales entre los grupos de valencianohablantes y castellanohablantes. En

\footnotetext{
${ }^{187}$ Carrera y Bradley (2004: 541), en su artículo sobre los extranjerismos en Cantabria, afirman también que los centros con mayor incidencia de vocablos ingleses son La ropa, Alimentos y bebidas, Medios de transporte y Juegos y distracciones.
} 
cambio, sí se aprecian diferencias de este tenor entre ambos grupos y los bilingües equilibrados, aquellos que emplean ambas lenguas desde la infancia. En el léxico disponible de estos últimos hay una presencia de anglicismos significativamente mayor que en el resto.

Finalmente, la variable nivel educativo familiar ofrece también algunas diferencias significativas, si bien estas se hallan restringidas a los grupos extremos, alto y bajo, respectivamente. Sin embargo, no ocurre lo mismo cuando la comparación se establece entre los demás grupos en que se ha dividido la muestra.

En consecuencia, podremos decir que los alumnos con mayor inclinación a la presencia de anglicismos en su léxico disponible son aquellos que combinan los siguientes perfiles: estudiantes masculinos, bilingües equilibrados, que estudian en centros urbanos y privados, y que pertenecen a un nivel educativo familiar alto.

10. Por último, un análisis específico del centro La ropa, y más concretamente de sus primeras cien palabras, señala la marcada integración de dichos términos en el habla de los jóvenes castellonenses, un resultado en el que coincide con otras sintopías estudiadas previamente.

La influencia del inglés sobre el español de hoy en día es patente. Este tema reclama, pues, una labor compleja, que recoja no solo el léxico importado sino también las posibles consecuencias en otros niveles del análisis, como la morfosintaxis o la pronunciación, y que, desde un punto de vista sociolingüístico, ayude a explicar el complicado proceso de aparición y penetración de estos términos. Los estudios de disponibilidad léxica pueden ayudar a concretar cuáles de esos términos son más disponibles y en qué campos semánticos tienen mayor profusión.

El dominio del inglés como lengua internacional de las comunicaciones, las ciencias y la tecnología es inevitable por las razones ya mencionadas. En este contexto parece irremediable, por tanto, la incorporación de palabras inglesas en otras lenguas como el español. Muchos lingüistas opinan hoy que aquellos vocablos que no tienen correspondencia en la lengua española deben ser voces bienvenidas en el español. Lo censurable sería la importación de vocablos innecesarios, que suplantan a palabras ya existentes en nuestro idioma, y que, pese a ello, se hallan muy extendidos. 
Particularmente grave es el caso de aquellas palabras patrimoniales que convertimos en anglicismos cuando las empleamos con un significado particular derivado de la lengua inglesa (editar por corregir, escenario por posibilidad, salvar por guardar, etc.).

¿Son realmente los anglicismos una amenaza para el español?, ¿empobrecen o, por el contrario, enriquecen nuestra lengua? En nuestra opinión, esta disyuntiva es errónea y no debe tomarse en esos términos, ya que la lengua se transforma, cambia constantemente al hilo de los propios cambios que experimenta la sociedad, en especial con los avances científicos y tecnológicos. $\mathrm{Y}$ si estos han evolucionado exponencialmente en los últimos tiempos, es lógico que ello tenga un reflejo en la lengua.

A este respecto merece la pena rescatar aquí la metáfora empleada por Gómez Capuz (2005: 7) cuando recuerda que los extranjerismos, anglicismos mayoritariamente hoy en día, son los nuevos "inmigrantes" léxicos, que arriban a las costas de nuestro idioma. Unas veces acabarán expulsados, pero otras muchas modificarán sus rasgos gráficos, morfológicos, semánticos y se acomodarán a la lengua de llegada y se comportarán como una palabra española más. Recogiendo sus palabras, el español ha sido una lengua que ha recibido:

....aportes léxicos de otras muchas lenguas, vecinas, lejanas o dominadoras. España ha sido una encrucijada de pueblos y culturas, y por ello es natural que la lengua común de los españoles haya recibido la influencia de muchas otras lenguas: lenguas prerromanas, árabe, visigótico, francés, provenzal, catalán, vasco, gallego, portugués, italiano, lenguas amerindias, inglés, alemán [...] Y no por estar sometida a tan variados e intensos influjos en sus mil años de historia, la lengua castellana ha perdido su fisonomía ni ha visto amenazada su integridad...

¿Es preocupante el porcentaje de anglicismos que hemos hallado en el léxico disponible de los jóvenes castellonenses y en los otros estudios analizados? Ciertamente, no. La proporción no supone un problema grave para la unidad del español. La mayoría de vocablos procedentes del inglés aparecen en posiciones muy atrasadas en los listados; incluso algunos de ellos únicamente son mencionados por uno o dos informantes. No obstante, esta incursión de palabras procedentes de la lengua inglesa en una encuesta que se debe responder en castellano y que muestra un vocabulario espontáneo y vivo, evidencia cómo la influencia de la cultura anglosajona se va incorporando progresivamente a nuestra lengua. 


\subsection{Valencianismos}

5.4.1. Algunas cuestiones preliminares sobre la interferencia léxica

En este apartado analizamos los fenómenos de contacto lingüístico entre dos lenguas que comparten territorio y un mismo origen: castellano y catalán. Como vimos en el capítulo tres, Castellón es una de las tres provincias de la Comunidad Valenciana, donde se produce la cooficialidad de ambas lenguas, así como una clara situación de bilingüismo social. La variedad del catalán empleada en la mayor parte de la Comunidad recibe el nombre de valenciano, y de este modo nos vamos a referir a ella durante toda esta parte.

Desde un punto de vista teórico, en esta sección partimos del concepto de interferencia, una "etiqueta interdisciplinaria", en palabras de Payrató (1985: 190), y en la que confluyen diversas disciplinas, de manera que "un estudi complet de la interferència lingüística ha d'incloure aspectes psicològics, pedagògics, culturals, sociològics i d'altres d'estrictament lingüístics". Con todo, el enfoque global más adecuado para estudiar este fenómeno es el sociolingüístico, por lo que no es casualidad que una de las principales obras de referencia en este ámbito de estudio continúe siendo el trabajo seminal de Weinreich (1953).

En nuestro estudio hablaremos de interferencia en todos aquellos casos en los que se puede ver la influencia estructural de una lengua en otra. ${ }^{188}$ Desde la sociolingüística, Weinreich (1953) define este fenómeno como "aquellos casos de desviación de las normas de cualquiera de las dos lenguas en contacto que ocurren en el habla de los bilingües como resultado del contacto lingüístico". A este autor se debe también el análisis de los factores socioculturales que confluyen en el bilingüismo social (como el prestigio de las lenguas en contacto, las actitudes de los hablantes hacia estas, la intensidad y duración del contacto, etc.), y que intervienen en la producción y difusión de las interferencias.

Para algunos investigadores, el término posee una connotación negativa, puesto que se pone en relación con un atentado a la norma de una lengua, de ahí que, al menos desde Haugen (1970: 6), muchos prefieran el concepto más neutro de transferencia. En

\footnotetext{
188 Al respecto, véase el análisis histórico que realizan Blas Arroyo (1993: 17-43, 2005:539-677) y Payrató (1985).
} 
el proyecto panhispánico para el estudio del léxico disponible, así lo hacen por ejemplo Serrano (2014) y Llopis (2009) en sus respectivos trabajos sobre Lérida y Valencia.

Otra cuestión relacionada con el fenómeno de la interferencia es determinar si este ha de estudiarse en el habla de bilingües individuales o en contextos más amplios de bilingüismo social, que, lógicamente, incluyen también a los potenciales monolingües. A este respecto, sigue siendo válida la distinción establecida por Weinnreich (1953), quien, desde una óptica estructuralista, hablaba de interferencia en el habla para aludir a aquellos "rasgos lingüísticos derivados del conocimiento por parte del bilingüe de una segunda lengua"; por el contrario, la interferencia en la lengua afectaría a aquellos fenómenos que "no son el fruto ocasional de la condición bilingüe de parte de la población, sino algo habitual en toda una comunidad lingüística" y que supone una consolidación social de los cambios provocados por el contacto. Con todo, por la misma época que Weinnreich, autores como Haugen (1954) concluían que cuando las desviaciones son ya adaptadas por toda una comunidad de habla, ya no pueden considerarse interferencias.

Mackey (1976) recoge esta misma distinción, si bien la reformula a través de los conceptos de interferencia e integración, a partir del grado de penetración de los fenómenos de contacto en las lenguas. Así, la integración supone una asimilación a las normas de la lengua que recibe cualquier hecho lingüístico, así como un mayor empleo en el habla de los bilingües, pero también de los monolingües, que casi siempre son inconscientes del origen de dichas variantes vernáculas. La integración social se observa a través de la frecuencia y difusión de estas variantes en el habla de la comunidad. En nuestro estudio, recogemos también esta idea cuando clasificamos los fenómenos de contacto lingüístico en préstamos consolidados y préstamos no integrados.

Al tratar la relación entre la interferencia y la evolución de las lenguas, Blas Arroyo (1993: 26) señala que "la integración social es una fase del cambio lingüístico". Asimismo, al abordar la cuestión específica del léxico, se hace eco de las ideas de Poplack y Sankoff (1984), quienes, en su estudio sobre el bilingüismo entre los hablantes portorriqueños de Nueva York, recuerdan que la integración de los vocablos se realiza, de forma gradual, a través de los siguientes pasos: incremento en la frecuencia de uso, desplazamiento de sinónimos nativos, integración gramatical y, por último, aceptación por parte de los hablantes. También Payrató (1985) considera la progresión como el factor determinante para la clasificación de los fenómenos de interferencia. A este respecto, distingue entre diferentes grados dentro de la 
interferencia: desde la que denomina interferencia estricta, que afecta a aquellos elementos foráneos que aparecen exclusivamente en boca de algunos bilingües, y que no están adaptados ni lingüística ni socialmente, además de no ser aceptados en ningún caso por la norma, hasta los préstamos consolidados, en el otro extremo. Entre ambos se sitúan diversos grados intermedios, en los que, pese a un rechazo todavía por parte de la normativa lingüística, la difusión de los fenómenos interferenciales alcanza ya a amplios sectores de la población, incluidos muchos hablantes monolingües con un escaso o nulo dominio de la lengua fuente.

Otro problema que ha ocupado a los investigadores es el carácter de los elementos "interferidos", y que permite la distinción entre el concepto de interferencia propiamente dicho y otros casos de "convergencia", donde la influencia foránea resulta más compleja. Y es que, como recuerda Blas Arroyo (1993: 29), a menudo no es posible afirmar con total rotundidad que un fenómeno determinado obedece directamente a la influencia de otra lengua, o más bien puede explicarse como una evolución interna. Esto es particularmente así en pares de lenguas genéticamente muy próximas, como ocurre con el castellano y el catalán de nuestro estudio. Como subraya Payrató (1985:182):

Dues llengües emparentades genéticament i estrtucturalment semblants (amb totis les matisacions que calgui) solen tenir tendències d'evolució molt o bastant similars; les convergències (espontànies) de desenvolupament entre aquests idiomes, doncs, són un fet lògic i corrent de l'evolució lingüística.

Por otro lado, entre las razones que explican las interferencias (Blas Arroyo, 2005: 610 y ss.) no solo tenemos que tratar las estrictamente estructurales o cognitivas (la economía lingüística, la competencia de los hablantes bilingües en cada lengua, la frecuencia relativa y el rendimiento funcional de los elementos lingüísticos en el discurso, ${ }^{189}$ etc.), sino que hay que tomar en consideración las extralingüísticas. Es por ello por lo que en esta investigación abordaremos también la potencial influencia de algunos factores sociales en la difusión de los valencianismos dentro del léxico disponible español de los jóvenes castellonenses (ver apartado 5.4.6).

En este trabajo, tal difusión se detecta a través de los resultados que arroja el test de disponibilidad. Este aporta información relevante para:

\footnotetext{
${ }^{189}$ Gómez Molina (1986) establece una relación directa entre el rendimiento funcional de un fenómeno linguístico en el habla y la extensión de la interferencia en su estudio sobre el contacto entre el catalán y el castellano en la población de Sagunto.
} 
... la detección de fenómenos derivados del contacto de dos lenguas y, específicamente, sobre interferencias léxicas [...] Además, los índices matemáticos que nos ofrecen los diccionarios de disponibilidad léxica nos permiten dilucidar qué interferencias son estables y habituales, y por tanto se han incorporado a la lengua de la comunidad desplazando -en algunos casos incluso- al término equivalente de la lengua vernácula, así como en qué casos estamos ante simples interferencias ocasionales que los hablantes bilingües incluyen como resultado de su conocimiento personal de la otra lengua (M. Serrano, 2006: 814).

Con todo, esta metodología para la concreción de influencias mutuas entre dos lenguas no está exenta de problemas, como la producción de palabras de forma artificial, la limitación en el tiempo de respuesta de los alumnos y la restricción que supone la nominación de los centros de interés que se utilizan para provocar las respuestas de los estudiantes. ${ }^{190}$ Ahora bien, aunque la situación descrita no suponga un uso real de la lengua, el léxico que produce el alumno se aproxima bastante a su lexicón mental (Serrano, 2014: 491-494). ${ }^{191} \mathrm{Y}$ el hecho de que algunos vocablos tengan mayor porcentaje de aparición en una lengua que en otra evidencia una difusión social importante de los préstamos. Es esto, precisamente, lo que intentaremos comprobar en este capítulo. Asimismo, analizaremos qué factores sociales intervienen en el empleo de los valencianismos.

Entre los estudios sobre disponibilidad léxica en zonas de contacto lingüístico en España, encontramos varios que tienen en cuenta directamente la adscripción lingüística de los informantes, como los de Lérida (cf. Serrano, 2003, 2014), Valencia (Gómez Molina y Gómez Devís, 2004) y Alicante (Gimeno y Martínez Olmos 2009, Martínez Olmos 2008), todos ellos relacionados con el contacto entre el castellano y el catalán. Asimismo, otros pares analizados aparecen en los trabajos de Etxebarria (1996) en Bilbao, la investigación de Azurmendi (1983) sobre San Sebastián y los estudios de Saralegui y Tabernero, (2008) y Areta (2009) acerca de la Comunidad Foral de Navarra, todos sobre el contacto castellano-euskera. Por otro lado, la influencia del árabe en la ciudad de Ceuta ha sido investigada por Ayora (2000), y lo mismo ha hecho Escoriza (2003, 2007) en el campo de Gibraltar, esta vez con el inglés como protagonista. En el

\footnotetext{
${ }^{190}$ A esto hay que añadir que "las interferencias difieren cualitativa y cuantitativamente de bilingüe a bilingüe" (Gómez Molina, 1986: 82); asimismo en el habla de los informantes con las dos lenguas en igualdad de condiciones, la configuración y las trasferencias variarán dependiendo del momento, la situación comunicativa y de la forma de comunicación, bien sea oral o escrita.

${ }^{191} \mathrm{Al}$ respecto, véase también Hernández Muñoz (2006).
} 
análisis de nuestros resultados tendremos en cuenta las aportaciones de algunos de estos trabajos con fines contrastivos (véase 5.4.5).

\subsubsection{Aspectos metodológicos}

En esta sección, hemos tenido que resolver algunos problemas a la hora de homogeneizar los materiales obtenidos en las encuestas, bien por la presencia de elementos pertenecientes a las dos lenguas en algunas locuciones (cavar soques 'cavar troncos'), bien por la similitud formal entre palabras de dos lenguas tan próximas genéticamente, ${ }^{192}$ lo cual dificulta delimitar con total seguridad qué lengua de las dos está utilizando en cada caso el informante. Con todo, en este trabajo hemos optado por considerar españoles aquellos vocablos que son iguales en ambas lenguas, al menos en la lengua escrita. Por otro lado, para comprobar la adscripción léxica de los valencianismos hemos acudido a la consulta de los siguientes diccionarios: Diccionario de la Real Academia (DRAE, edición 23ª), Diccionario del uso del español (DUE, 1991), Diccionario del español actual (DEA, 1999), Diccionario de uso del español actual (CLAVE, 2006), Diccionario panhispánico de dudas, (2005), Diccionario crítico etimológico castellano e hispánico (2000, $3^{\text {a }}$ reimpr.), Diccionario de dudas y dificultades de la lengua española (2004, 10ª ed.), Diccionari català, valencià, balear (DCVB, 2002), Diccionari de la Llengua catalana (DLLC, DIEC, 2007)), Diccionari general de la Llengua Catalana (DGLLC, 1983, 18 ed.).

Por otro lado, en los criterios de edición de los materiales hemos seguido prácticamente los mismos que para los vocablos en castellano:

1. Reducción al género masculino (coloma pasa a colom 'paloma') y al número singular de los vocablos. Pero hay excepciones: se mantiene en plural soques 'troncos' como complemento de un núcleo verbal al formar un compuesto sintagmático: cavar soques. Igual sucede en hacer els cavallons 'caballones', recoger soques. También mantenemos el plural en la enunciación de los juegos: tres pamets, platerets tets tets.

2. Corrección ortográfica. Se siguen las normas del valenciano. Por ejemplo: el informante escribe abaejo y queda lematizado en la versión estándar: abadejo 'bacalao'.

\footnotetext{
${ }^{192}$ Weinreich (1953) ya apuntó que uno de los factores que favorecen la influencia mutua de dos sistemas lingüísticos es el parentesco entre ellos, pero en ocasiones resulta difícil "decidir acerca de si un determinado fenómeno es debido a la influencia de otro sistema lingüísticos o a cambios internos en la propia lengua" (Blas Arroyo, 1993:30).
} 
3. Unificación ortográfica. Las diferentes variantes aparecidas se lematizan con la forma normativa. Ej. : cardanera, cadarnera se unifican en cadernera 'jilguero'.

4. Compuestos sintagmáticos híbridos. Aparece en algunos casos la combinación del castellano con el valenciano. Se mantienen las formas tal como las han expresado los informantes, marcando en negrita el complemento nominal en valenciano. Ejemplos: hacer els cavallons, recoger collites 'cosechas', cortar soques, pollo a l'ast. ${ }^{193}$

5. Se mantienen algunos diminutivos, unos lexicalizados como samarreta 'camiseta', saleta 'salita o sala de estar', palmito 'abanico', caseta 'casa de campo', maset 'masía', cinquet 'cinquillo'; en cambio, otros no lo están: banquet 'banco', soquetes 'tronco'.

6. Utilización de mayúsculas en los nombres propios: Conselleria, Fadrí.

7. A veces encontramos también palabras híbridas derivadas. Ej.: yesaire. ${ }^{194}$

8. Como apuntábamos arriba, en muchas situaciones, es difícil saber en qué lengua está escribiendo el informante. ${ }^{195}$ En algunas ocasiones, la diferencia estriba en el acento: ${ }^{196}$ grúa, diligencia en castellano / grua, diligència en valenciano. No sabemos si el alumno ha incurrido en falta de ortografía en valenciano como las ha cometido en las palabras castellanas. Del mismo modo, ciertos vocablos coinciden totalmente: carro, carreta, moto, tren, taxi, etc., vocablos que corresponden al centro Medios de transportes, en el que no hemos registrado ningún valencianismo. Pero también esta circunstancia aparece en otros campos semánticos: olla, toca, bancal, judo, etc. Ante la duda, están registradas como pertenecientes al castellano.

\footnotetext{
${ }^{193}$ Ast: barra de hierro o madera en la que espetan longitudinalmente un animal, en este caso el pollo, para asarlo imprimiéndole un movimiento de rotación.

${ }^{194}$ Arnal (2008a) considera este vocablo como dialectalismo del aragonés, al igual que Hernández Muñoz (2006) entre los alumnos castellano-manchegos. Sin embargo, el sufijo -aire es también productivo en valenciano, formando otras palabras como boletaire 'recolector de hongos o setas con el fin de vender', xarraire 'hablador', colomaire 'el que cría o vende palomas' o colombaire 'el que vuela palomas' o 'aficionado a la columbicultura', denominación muy común en esta zona. Creemos que el vocablo yesaire podría considerarse término integrado en el español de toda la zona, incluso en la Comunidad murciana. Ver el artículo de Josep Martines, "El sufix - aire al País Valencià" (1997: 229-262).

${ }^{195}$ Hernández García (1998) apunta que es en el nivel gráfico donde la posible influencia de la forma escrita del catalán se da en informantes que se consideran a sí mismos competentes en ambas lenguas.

${ }^{196}$ Hernández García (1998:74), recogiendo la opinión de Atienza et al. (1996), habla de dos bloques de interferencias en el ámbito ortográfico: "la acentuación, donde se observan interferencias debidas a la norma escrita y a la pronunciación, y las grafías propiamente dichas, donde se distinguen interferencias provocadas por confusión de grafías, así como interferencias ocasionadas por la confusión en la segmentación de algunas unidades".
} 


\subsubsection{Análisis de los resultados}

Como se recordará, los datos globales de la investigación nos llevan a un total de 121.792 palabras recogidas en las encuestas, de las cuales 9.215 son vocablos. De estos, los valencianismos constatados alcanzan los 144 términos. Veamos a continuación esas y otras cifras generales en la tabla 5.4.1.

\begin{tabular}{|l|c|}
\hline & Castellón \\
\hline $\mathrm{N}^{\circ}$. total palabras & 121.792 \\
\hline $\mathrm{N}^{\circ}$ total vocablos & 9.215 \\
\hline $\mathrm{N}^{\circ}$ total valencianismos & 144 \\
\hline$\%$ de palabras & $0,55 \%$ \\
\hline$\%$ de vocablos & $1,56 \%$ \\
\hline $\mathrm{N}^{\circ}$ informantes & 354 \\
\hline Promedio general de palabras & 344 \\
\hline Promedio general de vocablos & 26,03 \\
\hline Promedio de palabras valencianas & 1.92 \\
\hline Promedio de vocablos valencianos & 0.40 \\
\hline Promedio de transferencias por CI & 8.47 \\
\hline
\end{tabular}

Tabla 5.4.1. Cifras globales de los valencianismos y su porcentaje

De los 354 estudiantes que conforman la muestra de la provincia de Castellón, 262 presentan valencianismos, lo que indica que un $74 \%$ de los estudiantes ha contestado en alguna ocasión con una palabra de origen catalán-valenciano. El número total de apariciones de estos términos se eleva a 682 (0,55\% del total de palabras); y en cuanto a vocablos se refiere, los 144 valencianismos hallados representan un $1.56 \%$ de la totalidad. Se trata de cifras bajas, que revelan una escasa incidencia de los valencianismos en el léxico disponible de los castellonenses.

Por otro lado, si atendemos a los promedios, cada individuo presenta una media de 1,92 de palabras valencianas y un 0,40 de vocablos. Por su parte, el promedio de transferencias en cada centro de interés se sitúa en 8,47 valencianismos. En la tabla 5.4.2 recogemos a continuación todos estos datos generales. En ella ofrecemos los resultados relativos al número de: palabras, vocablos, valencianismos y porcentajes que representan, tanto por centros de interés como en términos globales. Asimismo, la figura 
5.4.1 nos permite ver de manera más gráfica la diferente incidencia de los valencianismos entre las distintas esferas semánticas.

\begin{tabular}{|l|c|c|c|c|c|}
\hline $\begin{array}{c}\text { Centro de } \\
\text { interés }\end{array}$ & Palabras & Vocablos & $\begin{array}{c}\text { Palabras } \\
\text { valencianas }\end{array}$ & $\begin{array}{c}\text { Vocablos } \\
\text { valencianos }\end{array}$ & $\begin{array}{c}\text { \% Vocablos } \\
\text { valenc. }\end{array}$ \\
\hline 01. Cuerpo & 9.148 & 271 & 1 & 1 & $0,36 \%$ \\
\hline 02. Ropa & 8.095 & 312 & 4 & 3 & $0,96 \%$ \\
\hline 03. Casa & 5.904 & 307 & 7 & 5 & $1,62 \%$ \\
\hline 04. Muebles & 5.142 & 303 & 4 & 1 & $0,33 \%$ \\
\hline 05. Alimentos & 9.411 & 607 & 165 & 20 & $3,29 \%$ \\
\hline 06. Mesa & 5.277 & 317 & 52 & 8 & $2,52 \%$ \\
\hline 07. Cocina & 6.615 & 502 & 118 & 13 & $2,58 \%$ \\
\hline 08. Escuela & 8.393 & 623 & 4 & 4 & $0,64 \%$ \\
\hline 09. Iluminación & 4.677 & 479 & 25 & 5 & $1,04 \%$ \\
\hline 10. Ciudad & 8.749 & 949 & 8 & 7 & $0,73 \%$ \\
\hline 11. Campo & 7.472 & 1060 & 83 & 19 & $1,79 \%$ \\
\hline 12. Transporte & 6.826 & 344 & 0 & 0 & 0 \\
\hline 13. Jardín & 4.003 & 704 & 87 & 22 & $3,12 \%$ \\
\hline 14. Animales & 10.051 & 447 & 25 & 15 & $3.35 \%$ \\
\hline 15. Juegos & 6.890 & 908 & 85 & 15 & $1,65 \%$ \\
\hline 16. Profesiones & 8.107 & 732 & 12 & 4 & $0,54 \%$ \\
\hline 17. Colores & 7.032 & 350 & 2 & 2 & $0,57 \%$ \\
\hline Totales & 121.792 & 9.215 & 682 & 144 & $1,56 \%$ \\
\hline
\end{tabular}

Tabla 5.4.2. Valencianismos por centros de interés

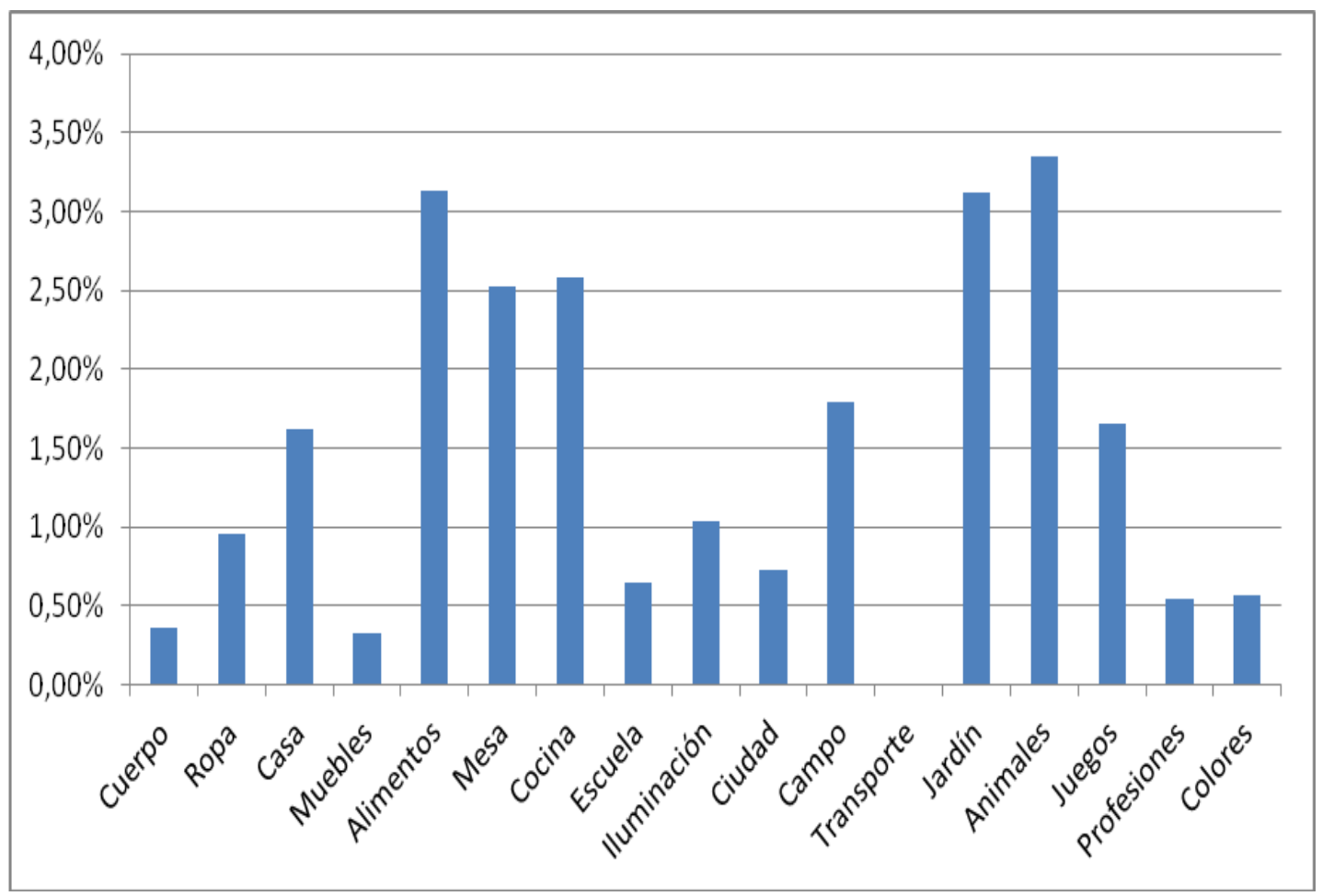

Gráfico 5.4.1. Porcentaje de valencianismos en los diecisiete centros de interés. 
Como podemos apreciar, los campos semánticos que más vocablos valencianos presentan, por orden descendente, son los siguientes centros de interés: Jardín (22), Alimentos (20), Campo (19), Juegos (15), Animales (15) y La cocina (13 vocablos). Un segundo grupo, con una incidencia menor, corresponde a los centros: Mesa (8), La ciudad (7), Iluminación (5), Casa (5), Profesión (4) y Ropa (4). Un tercer conjunto de áreas temáticas, con un número muy reducido de unidades léxicas, es el que recoge los centros relativos a Colores (2), Muebles (1) y Cuerpo (1). Por último, el centro de los Transportes, no presenta ningún valencianismo.

Destaca, pues, al área léxica de Jardín en la cantidad de fenómenos de contacto de lenguas que presenta. Lo mismo han constado Serrano en su investigación sobre Lérida (2014), o Bartol (2011), en su análisis comparativo entre diferentes zonas bilingües de España (Navarra, Álava, Vizcaya, Galicia, Valencia, Alicante y Lérida). Es revelador que sean los campos semánticos más relacionados con el ámbito rural los que reúnen un mayor número de palabras valencianas, un hecho que se justifica porque el valenciano es la lengua vernácula asociada con la agricultura en la mayoría de los municipios encuestados. También sería la razón de que el segundo centro de interés con más valencianismos sea, precisamente, el relativo al Campo, seguido por Alimentos, Juegos o Animales, todas ellas áreas semánticas que están relacionadas con la experiencia familiar de los alumnos o por ser el vocabulario que primero se aprende. Por otro lado, algunos campos léxicos muestran fenómenos de contacto que obedecen a respuestas meramente idiolectales, o lo que es lo mismo, algunos vocablos tan solo han sido apuntados por un único informante, como sucede en los centros de Ropa o Ciudad. Ahora bien, si nos fijamos en la densidad de los vocablos valencianos, constatamos que es ahora el centro de interés Animales el que supera a los demás, seguido por los de Alimentos y Jardín, respectivamente. Más correspondencia existe en la parta baja de la clasificación, donde las densidades y número de valencianismo van más a la par en centros como Muebles, Cuerpo, Colores o Profesiones (enumerados de forma ascendente).

Una vez mostrados los datos generales de los valencianismos en los párrafos anteriores, en el presente apartado realizamos un análisis más detallado de cada uno de ellos, clasificados por centros de interés. En las tablas siguientes presentamos estos valencianismos, así como diversos datos cuantitativos (rango e índice de disponibilidad 
tanto del valencianismo como del equivalente en castellano) y cualitativos (lema del vocablo en valenciano y del correspondiente castellano). ${ }^{197}$

01. El cuerpo humano

\begin{tabular}{|l|c|c|l|c|c|}
\hline $\begin{array}{l}\text { Vocablo } \\
\text { valenciano }\end{array}$ & Rango & $\begin{array}{c}\text { Índice de } \\
\text { disponibilidad }\end{array}$ & $\begin{array}{l}\text { Vocablo } \\
\text { castellano }\end{array}$ & Rango & $\begin{array}{c}\text { Índice de } \\
\text { disponibilidad }\end{array}$ \\
\hline Figa & 266 & 0.00053 & Vulva & 194 & 0.00197 \\
& & & chocho & 235 & 0.00095 \\
& & vagina & 41 & 0.06776 \\
\hline
\end{tabular}

El vocablo figa es un vulgarismo relativamente frecuente en la comunidad de habla castellonense. ${ }^{198}$ Blas Arroyo et al. (1992: 82) subrayan que en él tiene lugar un cambio semántico por "la existencia de un fundamento objetivo: similitud de aspectos y de formas. Figa es, como en el caso de chufa [término que no aparece en nuestro diccionario para referirse a pene], una designación corporal mediante el nombre de un objeto inanimado". Con todo, en los listados aparece solo en las respuestas de un único hablante masculino, de ahí su bajo rango e índice de disponibilidad. Algo mayores, pero no mucho más, son las cifras obtenidas por los correspondientes términos castellanos, vulva y chocho, especialmente en el caso de este último disfemismo. No ocurre así, por el contrario, con el mucho más neutro vagina (rango 41, ID: 0.06776), cuyo empleo se detecta en sesenta y tres informantes, lo que explica su elevado rango e índice de disponibilidad.

\footnotetext{
${ }^{197}$ En el apartado 8.3 aparecen las tablas de los valencianismos registrados en los listados castellonenses por centros de interés y con los datos relativos al índice de disponibilidad, la frecuencia relativa, el porcentaje de aparición y la frecuencia acumulada.

${ }^{198}$ Este vocablo también se registra en el Léxico disponible de Alicante (Martínez Olmos, 2008).
} 


\begin{tabular}{|l|c|c|l|c|c|}
\hline $\begin{array}{l}\text { Vocablo } \\
\text { valenciano }\end{array}$ & Rango & $\begin{array}{c}\text { Índice de } \\
\text { disponibilidad }\end{array}$ & $\begin{array}{l}\text { Vocablo } \\
\text { castellano }\end{array}$ & Rango & $\begin{array}{c}\text { Índice de } \\
\text { disponibilidad }\end{array}$ \\
\hline Samarreta & 161 & 0.00312 & Camiseta & 499 & 0.51007 \\
\hline Espardenya & 234 & 0.00123 & Alpargata & 134 & 0.00540 \\
\hline Brusa & 247 & 0.00115 & Blusa & 16 & 0.20288 \\
\hline
\end{tabular}

Como era de esperar, las palabras camiseta y blusa son vocablos mucho más disponibles para todos los estudiantes, frente a los correspondientes valencianismos. Y lo mismo ocurre, aunque con diferencias menores en los correspondientes rangos e índices de disponibilidad, con el par espardenya ${ }^{200}$ - alpargata.

03. Partes de la casa ( $\sin$ muebles)

\begin{tabular}{|c|c|c|c|c|c|}
\hline $\begin{array}{l}\text { Vocablo } \\
\text { valenciano }\end{array}$ & Rango & $\begin{array}{c}\text { Índice de } \\
\text { disponibilidad }\end{array}$ & $\begin{array}{l}\text { Vocablo } \\
\text { castellano }\end{array}$ & Rango & $\begin{array}{c}\text { Índice de } \\
\text { disponibilidad }\end{array}$ \\
\hline Saleta & 167 & 0.00244 & Salita & 8 & 0.37006 \\
\hline Paellero & 185 & 0.00211 & - & - & - \\
\hline Pica $^{201}$ & 189 & 0.00210 & Fregadero & 102 & 0.00739 \\
\hline Rebost & 246 & 0.00108 & Despensa & 18 & 0.16655 \\
\hline Desllunat & 277 & 0.00086 & Deslunado & 156 & 0.00279 \\
\hline
\end{tabular}

En esta área léxica, se muestra de nuevo cómo los vocablos castellanos superan en todos los índices a los correspondientes valencianismos, con la excepción de paellero, que no tiene equivalente en español. Asimismo, la palabra correspondiente a pica sería pila, que no aparece en los listados de este centro de interés, aunque sí lo hace fregadero, con un rango e índice mayores que los del valencianismo. Otro término equivalente a rebost, aparte del indicado en la tabla, es alacena, aunque esta vez con un rango (142) y un índice de disponibilidad (0.00349) más reducidos.

La traducción literal de desllunat, ${ }^{202}$ deslunado, que se registra en nuestros listados, no está recogida en el DRAE, aunque la traducción aproximada, patio de luces,

\footnotetext{
199 Camiseta se encuentra en muchas otras apariciones: camiseta de manga corta, camiseta vaquera, camiseta de tirantes, camiseta interior... lo que indica que su disponibilidad aun es mayor.

${ }^{200}$ Con todo, el termino espardenya podría eventualmente traducirse también como zapatilla, término castellano con un índice de disponibilidad mucho más elevado (0.23579).

${ }^{201}$ Encontramos pica de la cocina con un índice de disponibilidad de 0.00244 y una posición anterior (166).

${ }^{202}$ Celobert en catalán.
} 
se presenta con un índice de disponibilidad mucho mayor (0.08311). El término paellero, entendido como una especie de barbacoa donde se cocina la paella, y que se construye en un lugar independiente de la casa, podríamos considerarlo como un préstamo consolidado en esta comunidad de habla (sobre otras acepciones de este mismo término, véase más adelante el apartado dedicado al centro de interés Cocina).

04. Los muebles de la casa

\begin{tabular}{|l|l|l|l|l|l|}
\hline $\begin{array}{l}\text { Vocablo } \\
\text { valenciano }\end{array}$ & Rango & $\begin{array}{l}\text { Índice de } \\
\text { disponibilidad }\end{array}$ & $\begin{array}{l}\text { Vocablo } \\
\text { castellano }\end{array}$ & Rango & $\begin{array}{l}\text { Índice de } \\
\text { disponibilidad }\end{array}$ \\
\hline Pica & 153 & 0.00310 & Pila & 285 & 0.00086 \\
\hline
\end{tabular}

En este centro de interés, el valencianismo pica posee un rango y un índice de disponibilidad considerablemente mayores que el castellano pila, que es nombrado por un único informante. Por este motivo, podríamos hablar de un caso de sustitución léxica. En efecto, pica es una palabra que utilizan muchos valencianohablantes cuando se expresan en castellano, e incluso también muchos castellanohablantes exclusivos que viven en esta comunidad.

05. Alimentos y bebidas

\begin{tabular}{|l|c|c|l|c|c|}
\hline $\begin{array}{l}\text { Vocablo } \\
\text { valenciano }\end{array}$ & Rango & $\begin{array}{c}\text { Índice de } \\
\text { disponibilidad }\end{array}$ & $\begin{array}{l}\text { Vocablo } \\
\text { castellano }\end{array}$ & Rango & $\begin{array}{c}\text { Índice de } \\
\text { disponibilidad }\end{array}$ \\
\hline Botifarra & 396 & 0.00206 & Butifarra & 344 & 0.00281 \\
\hline Bajoca & 422 & 0.00179 & Judía & 46 & 0.08061 \\
\hline Fogassa & 447 & 0.00157 & - & - & - \\
\hline Mabra & 482 & 0.00126 & - & - & - \\
\hline Empedrat & 496 & 0.00119 & - & - & - \\
\hline Bajocó & 505 & 0.00113 & - & - & - \\
\hline Abadejo & 550 & 0.00084 & Bacalao & 213 & 0.00839 \\
\hline Lluç & 553 & 0.00084 & $\begin{array}{l}\text { Pescadilla/ } \\
\text { Merluza }\end{array}$ & 247 & 0.00668 \\
\hline Arròs caldós & 575 & 0.00075 & $\begin{array}{l}\text { Arroz } \\
\text { caldoso }\end{array}$ & 290 & 0.02684 \\
\hline Clòtxina & 577 & 0.00071 & Mejillón & 120 & 0.02375 \\
\hline $\begin{array}{l}\text { Coca de } \\
\text { tomate }\end{array}$ & 598 & 0.00056 & \multicolumn{1}{|l|}{-} & - & - \\
\hline Carlota & 198 & 0.00929 & Zanahoria & 33 & 0.10802 \\
\hline Rosquilleta & 117 & 0.02436 & \multicolumn{1}{|c}{} & - & - \\
\hline
\end{tabular}




\begin{tabular}{|l|c|c|c|c|c|}
\hline Fideuà & 162 & 0.01559 & - & - & - \\
\hline Fuet & 227 & 0.00774 & - & - & - \\
\hline Coca & 235 & 0.00733 & Torta & 169 & 0.00425 \\
\hline Pollo a l'ast & 545 & 0.00089 & - & - & - \\
\hline Paella & 41 & 0.08630 & - & - & - \\
\hline Mallorquina & 219 & 0.00814 & Sobrasada & 179 & 0.01278 \\
\hline Jamón dulce & 190 & 0.01061 & $\begin{array}{l}\text { Jamón de } \\
\text { York }\end{array}$ & 77 & 0.04751 \\
\hline chuleta & 68 & 0.05604 & - & - & - \\
\hline
\end{tabular}

En este centro de interés, comenzamos por los préstamos totalmente asimilados en español, como es el caso de paella, chuleta, fideuá o fuet ${ }^{203}$, como así lo reconoce el DRAE. Igualmente, la expresión Pollo a l'ast es un préstamo del catalán, bien asimilado en el castellano desde hace décadas, hasta tal punto que no aparece ningún otro término para referirse a este alimento. Lo mismo podríamos decir en la comunidad analizada del vocablo rosquilleta, ${ }^{204}$ y ello pese a que se trata de un término que no aparece ni en el diccionario académico ni en el diccionario catalán de Pompeu Fabra. Tampoco se registra en los estudios de Soria, Cuenca, Asturias, Zamora, Ávila, Salamanca, Cádiz. En cambio, sí lo hace en los listados de Valencia, aunque con un índice de disponibilidad menor que en Castellón (0,01004).

Junto a estos préstamos, encontramos valencianismos crudos, como empedrat, fogassa, bajocó o coca. Del primero (empredat) hay que decir que se trata de un plato típico de esta zona, muy famoso en poblaciones como La Vall d’Uixó. De hecho, ha sido un alumno del instituto Honori Garcia de este municipio del sur de Castellón quien ha hecho un uso del término. El término coca tendría su equivalente en torta, pero no encontramos torta de tomate, que sería el equivalente en castellano. La coca (de tomate) es, sin embargo, una comida salada muy popular por estas tierras. Junto a la forma compuesta, encontramos también la palabra coca de forma aislada, y con un rango más elevado que torta, que sería su traducción, tal como indica el DRAE en la $5^{\text {a }}$ entrada de este vocablo ('del catalán coca' y este del germánico koka 'torta').

En otros casos observamos la alternancia entre los términos patrimoniales del castellano y los del valenciano, aunque siempre con un índice de disponibilidad

\footnotetext{
${ }^{203}$ Fuet es un salchichón típico de Cataluña. El término general, salchichón, alcanza el rango 85 y un ID 0.04013 .

${ }^{204}$ Sí se registra en el DCVB, donde está marcado además como característico de Valencia. Se llama rosquilleta a una barrita de masa de pan elaborada con aceite y a la que, en ocasiones, se añade anís, pipas, cacahuetes, etc.
} 
considerablemente más alto para los primeros (judía, bacalao, merluza o pescadilla, mejillón, zanahoria, sobrasada) que para los segundos (bajoca, abadejo, lluç, clòtxina, carlota, mallorquina). Por último, hay que destacar un calco semántico en jamón dulce, traducción del valenciano pernil dolç.

06. Objetos colocados en la mesa para la comida

\begin{tabular}{|l|c|c|l|c|c|}
\hline $\begin{array}{l}\text { Vocablo } \\
\text { valenciano }\end{array}$ & Rango & $\begin{array}{c}\text { Índice de } \\
\text { disponibilidad }\end{array}$ & $\begin{array}{l}\text { Vocablo } \\
\text { castellano }\end{array}$ & Rango & $\begin{array}{c}\text { Índice de } \\
\text { disponibilidad }\end{array}$ \\
\hline Plato plano & 59 & 0.02113 & Plato llano & 143 & 0.00809 \\
\hline Paellera & 90 & 0.01188 & Sartén & 48 & 0.02724 \\
\hline Pitxer & 112 & 0.00701 & $\begin{array}{l}\text { Jarra / } \\
\text { jarro }\end{array}$ & $\begin{array}{c}9 / \\
184\end{array}$ & $\begin{array}{c}0.27356 / \\
0.00209\end{array}$ \\
\hline Setrill d'oli & 206 & 0.00171 & Aceitera & 21 & 0.07234 \\
\hline Cassoleta & 215 & 0.00159 & Cazuela & 28 & 0.04727 \\
\hline $\begin{array}{l}\text { Mortero } \\
\text { con allioli }\end{array}$ & 268 & 0.00111 & - & - & - \\
\hline Paella & 98 & 0.00875 & Sartén & 48 & 0.02724 \\
\hline Got & 183 & 0.00212 & Vaso & 5 & 0.63458 \\
\hline
\end{tabular}

El predominio de los vocablos castellanos nos permite determinar que, en esta ocasión, estamos ante dobletes (acerca de esta cuestión tipológica, véase más adelante el apartado 5.4.4). Sin embargo, el calco plato plano obtiene un índice de disponibilidad superior a la versión castellana (plato llano), por lo que estaríamos ante una transferencia plenamente asentada. Las palabras paellera y paella se utilizan con el significado de sartén. En el caso de paella, el término se utiliza con dos significados: 1. Comida típica valenciana; y 2. Sartén especial para cocinar el arroz de paella. Pitxer puede entenderse como jarra o como jarro. Cassoleta, un diminutivo de cassola, tiene su correspondiente vocablo castellano en cazuelita, si bien este no es utilizado por ninguno de los encuestados, por lo que estamos ante un nuevo préstamo consolidado en esta región. Lo mismo sucede con el catalán allioli, que no compite en los listados castellonenses con el patrimonial castellano ajoaceite. ${ }^{205}$

\footnotetext{
${ }^{205}$ El vocablo ajoaceite aparece en el centro de interés Alimentos en el rango 374 y con un índice de disponibilidad $0.00236 \mathrm{y}$ es empleado solo por tres informantes.
} 


\begin{tabular}{|c|c|c|c|c|c|}
\hline $\begin{array}{l}\text { Vocablo } \\
\text { valenciano }\end{array}$ & Rango & $\begin{array}{c}\text { Índice de } \\
\text { disponibilidad }\end{array}$ & $\begin{array}{l}\text { Vocablo } \\
\text { castellano }\end{array}$ & Rango & $\begin{array}{c}\text { Índice de } \\
\text { disponibilidad }\end{array}$ \\
\hline Paellero & 42 & 0.05868 & - & - & - \\
\hline Pica & 43 & 0.05740 & $\begin{array}{l}\text { Pila / } \\
\text { Fregadero }\end{array}$ & $78 / 19$ & $\begin{array}{c}0.02380 / \\
0.14462\end{array}$ \\
\hline Torradora & 105 & 0.01670 & Asadora & 163 & 0.00632 \\
\hline Perol & 155 & 0.00718 & $\begin{array}{l}\text { Caldera / } \\
\text { olla }\end{array}$ & $180 / 8$ & $\begin{array}{c}0.00543 / \\
0.28634\end{array}$ \\
\hline Fumeral & 260 & 0.00263 & Chimenea & 166 & 0.00617 \\
\hline Banquet $^{206}$ & 302 & 0.00193 & Banco & 87 & 0.02107 \\
\hline Escorredor & 305 & 0.00186 & Escurridor & 54 & 0.03886 \\
\hline Graella & 307 & 0.00186 & Parrilla & 60 & 0.03616 \\
\hline $\begin{array}{l}\text { Pica de } \\
\text { fregar }\end{array}$ & 330 & 0.00162 & $\begin{array}{l}\text { Pila de } \\
\text { fregar }\end{array}$ & 200 & 0.00421 \\
\hline Drap & 359 & 0.00141 & Trapo & 40 & 0.06600 \\
\hline $\begin{array}{l}\text { Mazo de } \\
\text { allioli }\end{array}$ & 402 & 0.00114 & - & - & - \\
\hline Foguer & 405 & 0.00113 & $\begin{array}{l}\text { Fuego / } \\
\text { Fogón }\end{array}$ & $73 / 22$ & $\begin{array}{c}0.02621 / \\
0.12662\end{array}$ \\
\hline Perola & 443 & 0.00086 & Caldera & 180 & 0.00543 \\
\hline $\begin{array}{l}\text { Recipiente } \\
\text { de allioli }\end{array}$ & 453 & 0.00081 & - & - & - \\
\hline Paellera & 488 & 0.00053 & Sartén & 3 & 0.45867 \\
\hline Misto & 325 & 0.00171 & Cerilla & 90 & 0.02034 \\
\hline Paella & 15 & 0.16447 & Sartén & 3 & 0.45867 \\
\hline
\end{tabular}

Volvemos a encontrar en esta área semántica un alto índice de disponibilidad en las palabras castellanas y rangos muy retrasados para los valencianismos, a excepción de paellero $^{207}$ (que, como vimos en el CI 3, no tiene traducción en español) y pica.

Sin embargo, no aparecen en castellano el diminutivo banquet y banquet de mármol que hacen referencia al banco de la cocina, sintagma que sí se registra (rango 76 e índice de disponibilidad de 0.00265) y banco (rango 87 e índice de disponibilidad de 0.02107), que en muchas ocasiones es de mármol.

En varios de los valencianismos hallamos correspondencia con más de una palabra del castellano. Por ejemplo, para torradora tenemos asadora, pero también asador,

\footnotetext{
${ }^{206}$ Hallamos este vocablo en banquet de mármol en la posición 446 y un índice de disponibilidad muy bajo (0.00086).

${ }^{207}$ El vocablo paellero en este centro de interés se refiere a "hornillo especial o parrilla preparada para hacer paellas" o también a un "recipiente metálico a modo de sartén, de poco fondo y con asas, que sirve para hacer paellas" (DRAE, 23 $3^{\mathrm{a}}$ ed.).
} 
aunque este con un menor índice de disponibilidad $(0.00570$ y una posición más retrasada, 173); para escorredor aparece escurridor, y también las variantes escurridera (0.00981) y escurridero (0.00175). Otro ejemplo es la palabra trapo, el equivalente a drap, que se halla especificado como trapo de cocina (rango 161, ID 0.00645), pero otras traducciones para drap en el campo de la cocina serían también paño (rango 79, ID. 0.02312) o bayeta (rango 80, ID 0.02300). Todos ellos, junto con misto 'cerilla' serían, pues dobletes léxicos, puesto que los estudiantes parecen conocer todos los términos. Los vocablos perol / perola, que pueden entenderse bien como olla (rango 8, ID. 0.28634), bien como cacerola (rango 30, ID. 0.10139), se registran en el diccionario académico y pueden entenderse, pues, como claros préstamos. Por último, la palabra paella, con un sentido idéntico al de sartén, ya ha sido comentada en el centro de interés anterior.

0.8. La escuela (muebles y materiales)

\begin{tabular}{|l|c|c|l|c|c|}
\hline $\begin{array}{l}\text { Vocablo } \\
\text { valenciano }\end{array}$ & Rango & $\begin{array}{c}\text { Índice de } \\
\text { disponibilidad }\end{array}$ & $\begin{array}{l}\text { Vocablo } \\
\text { castellano }\end{array}$ & Rango & $\begin{array}{c}\text { Índice de } \\
\text { disponibilidad }\end{array}$ \\
\hline Taula & 250 & 0.00282 & Mesa & 2 & 0.76540 \\
\hline Cadira & 262 & 0.00265 & Silla & 1 & 0.78325 \\
\hline Punxó & 499 & 0.00092 & Punzón & 196 & 0.00459 \\
\hline Salfumant & 580 & 0.00068 & - & - & - \\
\hline
\end{tabular}

Los términos españoles mesa y silla aparecen con una serie de especificaciones (mesa de profesor, mesa de alumno, de bar...; silla de alumno, de bar...), lo cual es un reflejo de un uso extraordinariamente elevado, que se refleja tanto en el rango alcanzado como en el índice de disponibilidad correspondiente. De esta forma, los sustantivos taula, cadira y punxó, actualizados por un solo informante, representan dobletes. En cambio, el vocablo salfumant (el DRAE en su 23ª edición lo registra como salfumán), enunciado por un único estudiante, es un claro préstamo del catalán. 
09. Iluminación, calefacción y medios de airear un recinto

\begin{tabular}{|l|c|c|l|c|c|}
\hline $\begin{array}{l}\text { Vocablo } \\
\text { valenciano }\end{array}$ & Rango & $\begin{array}{c}\text { Índice de } \\
\text { disponibilidad }\end{array}$ & $\begin{array}{l}\text { Vocablo } \\
\text { castellano }\end{array}$ & Rango & $\begin{array}{c}\text { Índice de } \\
\text { disponibilidad }\end{array}$ \\
\hline Palmito & 43 & 0.03335 & Abanico & 12 & 0.18190 \\
\hline Llar & 291 & 0.00185 & $\begin{array}{l}\text { Hogar / } \\
\text { chimenea }\end{array}$ & $\begin{array}{c}271 / \\
10\end{array}$ & $\begin{array}{c}0.00198 / \\
0.20479\end{array}$ \\
\hline Foguera & 383 & 0.00111 & Hoguera & 27 & 0.05650 \\
\hline Plafó & 405 & 0.00102 & Plafón & 52 & 0.02062 \\
\hline Misto & 422 & 0.00093 & $\begin{array}{l}\text { Fósforo / } \\
\text { Cerilla }\end{array}$ & $\begin{array}{c}284 / \\
39\end{array}$ & $\begin{array}{c}0.00185 / \\
0.00131\end{array}$ \\
\hline
\end{tabular}

Llar puede ser entendido como hogar (continente de fuego) y, en determinadas ocasiones, también como chimenea. Por su parte, palmito, representa una clara trasferencia del valenciano en el español de Castellón. Junto a la equivalencia primera de abanico (no otra cosa es el mencionado palmito), encontramos también paipái, entendido como una especie de abanico que desde Filipinas se ha exportado a todo el mundo, si bien este término aparece con rango (81) e índice de disponibilidad (0.01035) considerablemente menores. Todas las palabras son claros dobletes, con predominio de la palabra castellana. Misto puede traducirse bien por cerilla, bien por fósforo, términos en ambos casos con un índice de disponibilidad considerablemente mayor (en especial cerilla, enunciado por 30 estudiantes, frente a un solo informante en las demás palabras).

10. La ciudad

\begin{tabular}{|l|c|c|l|c|c|}
\hline $\begin{array}{l}\text { Vocablo } \\
\text { valenciano }\end{array}$ & Rango & $\begin{array}{c}\text { Índice de } \\
\text { disponibilidad }\end{array}$ & $\begin{array}{l}\text { Vocablo } \\
\text { castellano }\end{array}$ & Rango & $\begin{array}{c}\text { Índice de } \\
\text { disponibilidad }\end{array}$ \\
\hline Carrer & 406 & 0.00282 & Calle & 2 & 0.49998 \\
\hline Claveguera & 492 & 0.00232 & Alcantarilla & 113 & 0.02103 \\
\hline Fadrí & 500 & 0.00222 & - & - & - \\
\hline Placeta & 551 & 0.00193 & Plazoleta & 281 & 0.00489 \\
\hline Tauleta & 660 & 0.00152 & Kiosko & 61 & 0.05136 \\
\hline Conselleria & 341 & 0.00376 & Consejería & 794 & 0.00114 \\
\hline Casal & 900 & 0.00085 & - & - & - \\
\hline
\end{tabular}


Volvemos a comprobar que las palabras en español obtienen un índice de disponibilidad mayor que las correspondientes en valenciano. Solo dos no tienen traducción en castellano. Es el caso de Fadrí, nombre propio que se le da a la torre campanario de la ciudad de Castellón; ${ }^{208}$ y casal, que inicialmente hemos de entender como 'entidad popular con finalidades sociales' (ejemplo: casal faller 'casal fallero'). Sin embargo, algunos jóvenes castellonenses entienden casal como un local, sea del tipo que sea, donde se reúnen para oír música, jugar a las cartas, bailar, etc. en cualquier momento del año, aunque de manera particular durante las fiestas patronales. ${ }^{209}$ En suma, tanto fadrí como casal se podrían entender como préstamos culturales, puesto que señalan realidades específicas de la ciudad de Castellón, en el primer caso, y de la mayoría de las poblaciones de la provincia, en el segundo. Por ello, no hallamos un equivalente en español para estas palabras.

Otros términos para referirse a claveguera, que aparece como valencianismo en nuestros listados, son los vocablos del castellano alcantarillado (rango 186, ID. 0.00974) o cloaca (rango 196, ID. 0.00895), ambas en posiciones claramente anteriores a las de la palabra valenciana.

El vocablo carrer únicamente es utilizado por un informante, lo que hace que ocupe un lugar muy retrasado en los listados. Sin embargo, el equivalente castellano, calle, figura en la posición número dos, por no hablar de otras ocurrencias en las que va modificado por adjetivos como ancha, estrecha, peatonal, etc., haciendo su disponibilidad aun mayor; plazoleta no es el término exacto equivalente del valencianismo placeta, que sería placita, pero este último término no aparece en los listados. Por último, tauleta es un vocablo muy utilizado y popular entre los más jóvenes, puesto que designa al 'lugar donde se vende todo clase de chucherías y golosinas'. Hoy en día estos locales se han ampliado con la venta de prensa de todo tipo, así como juguetes, etc. De ahí que podamos traducirlo por el más habitual en castellano Kiosco (a su vez, procedente del francés).

\footnotetext{
${ }^{208}$ Se trata de una edificación que está construida de forma independiente y separada de la catedral, a diferencia de otros campanarios que se encuentran integrados en el mismo edificio eclesiástico, de ahí el nombre, puesto que fadrí significa 'soltero' en valenciano.

209 Usualmente, los jóvenes son socios de estas entidades lúdicas, a las que bautizan con nombres metafórico-festivos, como A tu qué te importe, Koki Meloki, PK2, etc.).
} 


\begin{tabular}{|c|c|c|c|c|c|}
\hline $\begin{array}{l}\text { Vocablo } \\
\text { valenciano }\end{array}$ & Rango & $\begin{array}{c}\text { Índice de } \\
\text { disponibilidad }\end{array}$ & $\begin{array}{l}\text { Vocablo } \\
\text { castellano }\end{array}$ & Rango & $\begin{array}{c}\text { Índice de } \\
\text { disponibilidad }\end{array}$ \\
\hline Caseta & 48 & 0.05392 & - & - & - \\
\hline Barraca & 222 & 0.00952 & - & - & - \\
\hline Paellero & 246 & 0.00853 & - & - & - \\
\hline Maset $^{210}$ & 250 & 0.00831 & Masía & 50 & 0.05074 \\
\hline Matxina & 434 & 0.00351 & Máquina & 571 & 0.00222 \\
\hline Marialluïsa & 467 & 0.00306 & - & - & - \\
\hline Perera & 475 & 0.00295 & Peral & 96 & 0.02476 \\
\hline Lligona & 503 & 0.00266 & - & - & - \\
\hline Argelaga $^{211}$ & 577 & 0.00222 & Aliaga & 640 & 0.00196 \\
\hline Cadernera & 661 & 0.00185 & Jilguero & 284 & 0.00718 \\
\hline Carxofa & 700 & 0.00174 & Alcachofa & 196 & 0.01091 \\
\hline Fava & 727 & 0.00164 & Haba & 438 & 0.00349 \\
\hline Corbella & 771 & 0.00145 & Hoz & 145 & 0.01631 \\
\hline Espardenya & 791 & 0.00137 & - & - & - \\
\hline Garrofera & 832 & 0.00128 & Algarrobo & 110 & 0.02201 \\
\hline $\begin{array}{l}\text { Caseta de } \\
\text { campo }\end{array}$ & 858 & 0.00121 & $\begin{array}{l}\text { Casa de } \\
\text { campo }\end{array}$ & 117 & 0.02077 \\
\hline Collidor & 930 & 0.00095 & Recogedor & 939 & 0.00089 \\
\hline Albercoquer & 944 & 0.00089 & - & - & - \\
\hline Teuladí & 1051 & 0.00052 & Gorrión & 175 & 0.01242 \\
\hline Guineu & 1028 & 0.00062 & Zorro & 104 & 0.02304 \\
\hline
\end{tabular}

Como vemos en la tabla anterior, la mayoría de las palabras son dobletes y los términos castellanos presentan en casi todos los casos un mayor índice de disponibilidad (para algunas excepciones, veáse más abajo en este mismo apartado). Así ocurre con los pares perera / peral, cadernera / jilguero, carxofa / alcachofa, fava / haba, corbella / hoz, garrofera / algarrobo, teuladí / gorrión, guineu / zorro. Por otro lado, cabe destacar el caso específico de los dos primeros vocablos, caseta y paellero, que no tienen correlato en español. Obviamente, caseta no se refiere a una casa pequeña o casa/casita para los perros, sino que, en estas comarcas, sirve para aludir a una especie de chalet, situado en el campo o montaña, con independencia de su tamaño. En sus orígenes, hacía referencia a un edificio pequeño, utilizado para guardar los aperos de labranza y que, además, se utilizaba para pasar un día en el campo. Sin embargo, hoy

210 En el DCVB se destaca que en Castellón maset equivale a lo que en Valencia se denomina habitualmente mas o masía, cuando la casa de labranza se encuentra en secano; si, por el contrario, esta se encuentra en regadío, el término más común es barraca.

${ }^{211}$ Colón (2015) apunta que es más corriente en Castellón la forma argilaga. 
estas edificaciones han pasado a ser, en muchos casos, auténticas residencias de verano. Y por lo que se refiere a paellero, recordemos que equivale a una especie de barbacoa en la que se hacen las paellas. En ocasiones se trata de un espacio abierto y, en otras, cerrado, como si fuera un cuarto, pero siempre independiente de la casa, como ya hemos apuntado anteriormente.

Cabe mencionar el caso de dos términos, matxina $^{212}$ y argelaga, que presentan mejores posiciones que sus correspondientes vocablos castellanos (máquina, aliaga). Por último, otros cuatro vocablos (maraillü̈sa, lligona, espardenya y albercoquer) no presentan equivalencias castellanas en este centro de interés.

12. Medios de transporte

Este es el único centro de interés en el que no recogemos ningún valencianismo. Aunque no sabemos si realmente es así, porque hay muchos vocablos que se escriben igual en las dos lenguas y, por tanto, no podemos saber a cuál de las dos se adscriben. Puesto que la encuesta se debe contestar en castellano, así hemos considerado esas palabras, tal como hace también Serrano (2003). Ejemplo de lo expuesto serían: carro, carreta, moto, motocicleta, dirigible, taxi, vagoneta, tren, entre otros

Otro problema añadido son las faltas de ortografía, que se comenten tanto en español como en catalán. De manera que, ante la duda, todas las palabras, se han registrado en castellano. Por ejemplo, hay dos lexías que se diferencian por la tilde: grúa y diligencia son castellanas, pero grua, diligència son valencianas.

\footnotetext{
${ }^{212}$ Matxina en Castellón se refiere a una máquina utilizada como pulverizador para sulfatar las plantas o árboles.
} 


\begin{tabular}{|c|c|c|c|c|c|}
\hline $\begin{array}{l}\text { Vocablo } \\
\text { valenciano }\end{array}$ & Rango & $\begin{array}{c}\text { Índice de } \\
\text { disponibilidad }\end{array}$ & $\begin{array}{l}\text { Vocablo } \\
\text { castellano }\end{array}$ & Rango & $\begin{array}{c}\text { Índice de } \\
\text { disponibilidad }\end{array}$ \\
\hline Empeltar & 28 & 0.04931 & Injertar & 21 & 0.08721 \\
\hline Collidor & 75 & 0.01313 & Recogedor & 65 & 0.01509 \\
\hline Hacer soquetes & 83 & 0.01037 & - & - & - \\
\hline Empeltador & 89 & 0.00922 & - & - & - \\
\hline Espigolar & 94 & 0.00872 & - & - & - \\
\hline Collir & 129 & 0.00646 & Coger & 57 & 0.01889 \\
\hline Saó & 142 & 0.00565 & Sazón & 125 & 0.00678 \\
\hline Hacer soques & 160 & 0.00479 & - & - & - \\
\hline Ramader & 169 & 0.00458 & Ganadero & 19 & 0.09189 \\
\hline Tallar & 196 & 0.00393 & Cortar & 12 & 0.16481 \\
\hline Arruixar & 244 & 0.00293 & Regar & 1 & 0.50496 \\
\hline Llaurador & 254 & 0.00282 & Labrador & 34 & 0.04385 \\
\hline Cremar leña & 296 & 0.00256 & Quemar leña & 39 & 0.03210 \\
\hline $\begin{array}{l}\text { Hacer els } \\
\text { cavallons }\end{array}$ & 329 & 0.00221 & $\begin{array}{l}\text { Hacer } \\
\text { caballones }\end{array}$ & 31 & 0.04418 \\
\hline Recoger collites & 360 & 0.00203 & $\begin{array}{l}\text { Recoger la } \\
\text { cosecha }\end{array}$ & 107 & 0.00788 \\
\hline Masover & 363 & 0.00203 & - & - & - \\
\hline Ensulfatador & 435 & 0.00173 & Sulfatador & 336 & 0.00221 \\
\hline Tirar fem & 562 & 0.00135 & Tirar estiércol & 301 & 0.00242 \\
\hline Fer paret & 577 & 0.00124 & - & - & - \\
\hline Ficar rectes & 607 & 0.00114 & - & - & - \\
\hline Escampar fem & 620 & 0.00105 & $\begin{array}{l}\text { Esparcir } \\
\text { estiércol }\end{array}$ & 389 & 0.00187 \\
\hline Fer cremador & 649 & 0.00089 & - & - & - \\
\hline Cavar soques & 167 & 0.00460 & Cavar troncos & 307 & 0.00240 \\
\hline Soquetes & & 0.00271 & - & - & - \\
\hline Fer saó & 309 & 0.00240 & Hacer sazón & 119 & 0.00699 \\
\hline Fer soquetes & & 0.00187 & - & - & - \\
\hline Cortar soques & 533 & 0.00146 & - & - & - \\
\hline Banyar soques & 625 & 0.00105 & Pintar troncos & 234 & 0.00322 \\
\hline
\end{tabular}

Es este el centro de interés con mayor número de valencianismos en nuestras listas, aunque vuelven a presentar mayor índice de disponibilidad los correspondientes castellanos, como ocurre con coger (vs collir), sazón (vs saó), ganadero (vs ramader), cortar (vs tallar), labrador (vs llaurador), quemar leña (vs cremar leña) o regar (vs arruixar), que alcanza el rango número uno. La mayoría de ellos se muestran como dobletes (junto a los nombrados anteriormente, tenemos empeltar / injertar, collidor / recogedor, ensulfatar / sulfatar, fer saó / hacer sazón, cremar leña / quemar leña, escampar fem / esparcir estiércol, tirar fem / tirar estiércol) puesto que aparecen los 
términos en valenciano y en castellano. Sin embargo, la palabra collidor no tiene una única correspondencia en castellano. Vemos recogedor, pero también aparecen cogedor (especificado con de naranjas (0.00805)) o, simplemente, recolector (0.06315).

Asimismo, hay vocablos valencianos que no tienen un correlato en castellano: hacer soquetes, empeltador, espigolar, hacer soques, banyar soques, masover, fer soquetes, fer paret, ficar rectes, fer cremador. ${ }^{213}$ Son conceptos corrientes dentro del entorno rural castellonense, que se refieren a labores concretas del campo. Cabe pensar que los padres de estos informantes sean agricultores o tengan alguna relación con las labores de cultivo (son propietarios de pequeños huertos, etc.), por lo que sus hijos están muy acostumbrados a escuchar estos vocablos. Y, con toda probabilidad, son términos cuya equivalencia en español es desconocida por los alumnos.

Al mismo tiempo, nos encontramos con sintagma híbridos, en los que se mezclan castellano y valenciano. Así, encontramos cortar soques, hacer els cavallons, hacer soques, cavar soques, ${ }^{214}$ donde aparece el verbo en la primera lengua y el complemento en la segunda. Como apuntábamos en un apartado anterior (ver capítulo 4.3), en estos casos hemos optado por mantenerlos como una sola unidad léxica (señalando en negrita la parte valenciana) con la finalidad de no perder información, y siguiendo así un criterio metodológico general.

\footnotetext{
${ }^{213}$ Empeltador 'injertador', espigolar 'espigar o, más comúnmente rebuscar', soquetes, 'diminutivo de tronco', masover 'persona que vive en un mas, una casa de campo (de secano habitualmente)', fer soquetes 'cavar la tierra alrededor de los troncos', fer paret 'hacer pared, habitualmente de piedras para preparar los bancales', fer cremador 'hacer quemador, lugar específico para quemar la leña'.

${ }_{214}$ Cortar soques 'cortar los troncos', hacer els cavallons 'preparar la tierrar para formar caballones', hacer soques y cavar soques 'cavar alrededor de los troncos con la finalidad de airear la tierra y eliminar las malas hierbas'.
} 


\begin{tabular}{|l|c|c|l|c|c|}
\hline $\begin{array}{l}\text { Vocablo } \\
\text { valenciano }\end{array}$ & Rango & $\begin{array}{c}\text { Índice de } \\
\text { disponibilidad }\end{array}$ & $\begin{array}{l}\text { Vocablo } \\
\text { castellano }\end{array}$ & Rango & $\begin{array}{c}\text { Índice de } \\
\text { disponibilidad }\end{array}$ \\
\hline Cadernera & 186 & 0.00750 & Gorrión & 75 & 0.04996 \\
\hline Titot & 226 & 0.00486 & Pavo & 122 & 0.02305 \\
\hline Mabre & 239 & 0.00395 & - & - & - \\
\hline Colom & 261 & 0.00307 & Paloma & 61 & 0.06609 \\
\hline Egua & 269 & 0.00283 & Yegua & & 0.08793 \\
\hline Cullerot & 300 & 0.00216 & Renacuajo & 249 & 0.00362 \\
\hline Vilero & 311 & 0.00194 & - & - & - \\
\hline Estornell & 334 & 0.00165 & Estornino & 196 & 0.00659 \\
\hline Griva & 339 & 0.00157 & zorzal & 402 & 0.00092 \\
\hline Rabosa & 350 & 0.00149 & Zorro & 41 & 0.10395 \\
\hline Escorpa & 354 & 0.00141 & - & - & - \\
\hline Llissa & 382 & 0.00114 & Lisa & 282 & 0.00254 \\
\hline Oroneta & 407 & 0.00087 & Golondrina & 106 & 0.02995 \\
\hline Granota & 416 & 0.00078 & Rana & 56 & 0.07414 \\
\hline Llobarro & 436 & 0.00060 & Lubina & 213 & 0.00576 \\
\hline
\end{tabular}

También en esta área temática los vocablos castellanos presentan mayor índice de disponibilidad que los correspondientes valencianismos, y además lo hacen en todos los casos. La griva es parecido al tordo, pero más grueso, y equivalente a zorzal; de él encontramos también las variantes zorzal alirrojo (355, ID. 0.00141), zorzal real (365, ID. 0.00127), zorzal charlo (373, ID. 0.00120 y zorzal común (379, ID. 0.00114), especificaciones todas ellas que aparecen en posicione anteriores a las del vocablo aislado (zorzal). Tan solo en tres ocasiones no hallamos el doblete en castellano, como es el caso de mabre/mabra, cuyo término español (herrera) ${ }^{215}$ no encontramos en los listados, escorpa (en castellano escorpina, escorpena, peje diablo o rescaza) y vilero. ${ }^{216}$ Tampoco hallamos mújol, aunque su correspondiente valenciano llisa si aparece en su versión castellanizada, lisa.

\footnotetext{
${ }^{215}$ El término herrera no se encuentra en el DRAE ni el DCVB. En cambio sí aparece en el diccionario Tabarca, de Vicent Pascual (1996), y es recogido por Gómez Molina y Gómez Devís en su investigación sobre Valencia (2004).

${ }^{216}$ Vilero es el nombre del gorrión en las comarcas de Castellón, Colón (2015) señala su uso en las poblaciones de Castellón, Borriol, Artana, Betxí y Vilafamés, aunque también se da en otros pueblos, como Alcora u Onda. En ciertas variedades del valenciano meridional recibe el nombre de teuladí, que también aparece en nuestros listados, si bien esta vez en el centro del Campo. En Cataluña este pájaro se conoce como pardal.
} 


\begin{tabular}{|l|c|c|c|c|c|}
\hline $\begin{array}{l}\text { Vocablo } \\
\text { valenciano }\end{array}$ & Rango & $\begin{array}{c}\text { Índice de } \\
\text { disponibilidad }\end{array}$ & $\begin{array}{l}\text { Vocablo } \\
\text { castellano }\end{array}$ & Rango & $\begin{array}{c}\text { Índice de } \\
\text { disponibilidad }\end{array}$ \\
\hline Sambori & 30 & 0.07546 & - & - & - \\
\hline Botifarra & 132 & 0.01490 & - & - & - \\
\hline Cinquet & 159 & 0.01128 & Cinquillo & 65 & 0.03488 \\
\hline Tres pamets & 172 & 0.01006 & - & - & - \\
\hline Truc & 174 & 0.00996 & Truque & 361 & 0.00302 \\
\hline Potet & 299 & 0.00407 & - & - & - \\
\hline Despullat & 393 & 0.00263 & Desnudado & 575 & 0.00162 \\
\hline Maquinetas & 469 & 0.00213 & Maquinitas & 342 & 0.00326 \\
\hline Ditet & 631 & 0.00141 & - & - & - \\
\hline Tres en ratlla & 684 & 0.00114 & Tres en raya & 21 & 0.10616 \\
\hline $\begin{array}{l}\text { Pedra paper } \\
\text { tisora }\end{array}$ & 720 & 0.00106 & $\begin{array}{l}\text { Piedra, papel, } \\
\text { tijeras }\end{array}$ & 283 & - \\
\hline $\begin{array}{l}\text { Platerets tets } \\
\text { tets }\end{array}$ & 759 & 0.00093 & - & - & - \\
\hline Voltar pins & 762 & 0.00093 & - & - & - \\
\hline Baldufa & 897 & 0.00049 & $\begin{array}{l}\text { Peonza / } \\
\text { Trompa }\end{array}$ & $184 /$ & $0.00947 /$ \\
& & & - & - & 0.00086 \\
\hline Casal & 437 & 0.00229 & - & - \\
\hline
\end{tabular}

A diferencia de otros centros de interés, y tal como se observa en la tabla anterior, en los listados castellonenses aparecen esta vez muchos vocablos relativos a juegos autóctonos, tradicionalmente designados en valenciano y que, o bien no tienen una traducción castellana, o bien esta no aparece en los listados de los estudiantes. Por ejemplo, Sambori, ${ }^{217}$ juego infantil muy conocido en toda la comunidad, no presenta su versión en castellano, infernáculo, que no ha sido mencionado por ningún estudiante. Igualmente no recogemos el término castellano correspondiente a tres pamets, ditet, plateret tets tets, potet y voltar pins. ${ }^{218}$ Tampoco aparece la traducción de botifarra, juego de cartas muy extendido en la zona, donde son frecuentes los campeonatos

\footnotetext{
${ }^{217}$ Sambori es un juego para el que se trazan en el suelo una serie de casillas y que consiste en desplazar un tejo, a puntapiés y a la pata coja, de una casilla a la otra, siguiendo para ello determinadas reglas.

${ }^{218}$ Tres pamets: juego de persecución donde el que paga tiene que tocar al resto de jugadores antes de que suban a un lugar elevado y que sea superior a tres palmos de altura, ya que solo pueden salvarse de esta forma si son tocados. Platerets tets tets es un juego similar a "Un dos tres pollito inglés", en él, quien paga dice "un, dos tres platerets tets test", y se gira para ver si alguien está moviéndose, si es así, este último pasa a ser quien paga. Potet es un juego semejante al escondite, uno paga y tiene un bote (relleno de piedras para hacer ruido), en su desarrollo, uno de los que se tiene que esconder pega una patada al bote, y mientras el que paga va en su busca, los demás se esconden; el que paga regresa al sitio y comienza a buscar a los otros jugadores y cuando ve a alguien tiene que ir a por el bote y decir (por ejemplo) "Potet, potet por María que está detrás de la puerta".
} 
populares. Con todo, sí aparecen algunos dobletes relacionados con otros juegos de cartas, como truc / truque, y despullat/ desnudado, ${ }^{219}$ pares donde el vocablo valenciano presenta esta vez, y a diferencia de los demás centros de interés, un mayor índice de disponibilidad. En cambio, en cinquet / cinquillo es el término castellano el que presenta un índice más elevado.

Lo mismo sucede con maquinitas, equivalente del valencianismo maquinetas, ambos relativos a juegos electrónicos manuales. No obstante, en castellano también se registran máquinas (rango 194, ID.0.00885), máquinas de juego (rango 385, ID. 0.00272) y máquinas recreativas (rango 697, ID. 0.00114).

En cuanto al término casal, remitimos a lo ya expuesto anteriormente en relación con otro centro de interés (La ciudad).

16. Profesiones y oficios

\begin{tabular}{|l|c|c|l|c|c|}
\hline $\begin{array}{l}\text { Vocablo } \\
\text { valenciano }\end{array}$ & Rango & $\begin{array}{c}\text { Índice de } \\
\text { disponibilidad }\end{array}$ & $\begin{array}{l}\text { Vocablo } \\
\text { castellano }\end{array}$ & Rango & $\begin{array}{c}\text { Índice de } \\
\text { disponibilidad }\end{array}$ \\
\hline Pescater & 215 & 0.00731 & Pescadero & 70 & 0.04058 \\
\hline Llaurador & 282 & 0.00491 & Labrador & 59 & 0.05208 \\
\hline Ramader & 493 & 0.00171 & Ganadero & 63 & 0.04624 \\
\hline Yesaire & 322 & 0.00377 & - & - & - \\
\hline
\end{tabular}

También en este centro temático encontramos ejemplos de dobletes léxicos, con términos valencianos y castellanos equivalentes recogidos en los listados. En algunas ocasiones, las palabras castellanas son en la práctica adaptaciones de valencianismos, como es el caso de pescatero y ramadero.

El vocablo yesaire, empleado por cuatro informantes, es una formación híbrida, que no aparece en la mayoría de los diccionarios de castellano ni de valenciano. ${ }^{220} \mathrm{Se}$ crea a partir de la raíz castellana yeso y la adición del sufijo derivativo valenciano -aire

\footnotetext{
${ }^{219}$ En el juego del Truc se utiliza la baraja española y se juega por parejas en el que las señas son imprescindibles. El nombre de las jugadas se mantienen en valenciano, y hay diversas variantes, dependiendo del lugar dónde se juegue. Lo fundamental es que el oponente no vea las señas para que no se pueda formar una idea de las cartas que se tienen, aunque, a veces, las señas también son falsas. Es un juego de envite, en el que se reparten tres cartas para jugarlas una a una y hacer las bazas. Despullat es otro juego de cartas en el que se distribuyen todas a los jugadores y pierde el que se queda primero sin cartas. Otras opiniones hacen equivalente este juego al strip poker.

${ }^{220}$ Tampoco la hemos hallado en los diccionarios de aragonés. Con todo, yesaire sí aparee en el Diccionario LID, de Construcción e Inmobiliario, con el significado de "oficial y peón caracterizado por hacer revestimiento continuo con pastas de yeso, como especialista de la albañilería. También se denomina yesero".
} 
(colombaire, drapaire, xarraire...). Su traducción sería yesero -palabra que sí aparece en el DRAE- , entendiendo como tal la persona que se dedica en las obras de albañilería a colocar yeso en paredes y techo, pero no se registra en el léxico disponible de Castellón. Un posible equivalente, que sí aparece en nuestros listados, es escayolista (rango 221, ID 0.00717). Josep Martines (1997: 243) apunta algunas variaciones de la palabra yesaire que han podido facilitar su aparición como *llesaire, iesssaire, *llixaire, *lleixaire.

17. Los colores

\begin{tabular}{|l|c|c|l|c|c|}
\hline $\begin{array}{l}\text { Vocablo } \\
\text { valenciano }\end{array}$ & Rango & $\begin{array}{c}\text { Índice de } \\
\text { disponibilidad }\end{array}$ & $\begin{array}{l}\text { Vocablo } \\
\text { castellano }\end{array}$ & Rango & $\begin{array}{c}\text { Índice de } \\
\text { disponibilidad }\end{array}$ \\
\hline Enrogit & 239 & 0.00194 & - & - & - \\
\hline Carabassa & 280 & 0.00194 & Calabaza & 50 & 0.02840 \\
\hline
\end{tabular}

Solo en dos ocasiones se muestran valencianismos cromáticos, enrogit y carabassa, aunque en ambos casos con índices de disponibilidad muy bajos. El primero se podría traducir por enrojecido, término que, sin embargo, no aparece en los listados, El otro término, por el contrario, sí tiene un doblete castellano en esta serie (color) calabaza, y además con un rango y un índice de disponibilidad considerablemente mayores.

Una vez comentadas todas las palabras valencianas que advertimos en los listados de los estudiantes castellonenses, constatamos que, globalmente, los valencianismos se registran en posiciones muy retrasadas del léxico disponible, con índices y rangos bajos o muy bajos, y en muchas ocasiones enunciados por tan solo uno o dos informantes. En la mayoría de los casos se trata de dobletes léxicos, con los términos equivalentes valenciano y castellano (en ocasiones, más de uno) presentes en los listados, si bien los castellanos aparecen casi siempre con un rango y un índice de disponibilidad más elevados, y, además, mencionados por un número significativamente mayor de informantes. Tan solo en algunas ocasiones no aparecen los correspondientes vocablos castellanos, como ocurre con paellero o casal, palabras muy utilizadas por los hablantes de Castellón, con independencia de su adscripción lingüística, o con préstamos culturales como Fadrí. En la tabla siguiente, observamos los valencianismos 
que se registran entre las primeras cien palabras emitidas por los estudiantes, y que se revelan como las verdaderamente disponibles. Como se verá, responden a un número poco significativo en relación con el léxico disponible total de la muestra de Castellón. De hecho, en la mayoría de los centros de interés no hay ninguna.

\begin{tabular}{|l|l|}
\hline Centro de interés & Vocablos \\
\hline 01.Cuerpo & \\
\hline 02. Ropa & \\
\hline 03. Casa & \\
\hline 04. Muebles & Paella (41) \\
\hline 05. Alimentos & Plato plano (59), paellera (90), paella (98) \\
\hline 06. Mesa & Paellero (42), pica (43) \\
\hline 07. Cocina & \\
\hline 08. Escuela & Palmito (43) \\
\hline O9. Iluminación & \\
\hline 10. Ciudad & Caseta (48) \\
\hline 11. Campo & \\
\hline 12. transportes & Empeltar (28), collidor (75), empeltador (89), espigolar (94) \\
\hline 13. Jardín & \\
\hline 14. Animales & Sambori (30) \\
\hline 15. Juegos & \\
\hline 16. Profesiones & \\
\hline 17. Colores & \\
\hline
\end{tabular}

Tabla 5.4.3. Vocablos entre las primeras cien palabras enunciadas. (El número que aparece al lado de cada palabra corresponde al rango de esta).

Más aún, si reducimos el espectro a las primeras cincuenta primeras palabras únicamente destacaríamos los casos de paella (Alimentos), paellero, pica (Cocina), palmito (Iluminación), caseta (Campo), empeltar (Jardín) y sambori (Juegos), estos sí vocablos ciertamente difundidos e integrados socialmente en la comunidad castellonense. Como destaca Serrano (2014: 492) "el hecho de que algunas de estas unidades tengan un porcentaje de aparición superior a la forma adecuada en la lengua de la encuesta nos indica la extensión social que pueden llegar a tener". 


\subsubsection{Tipología de los valencianismos}

A continuación nos ocuparemos de las diferencias taxonómicas que cabe advertir entre los valencianismos que hemos encontrado en los listados de disponibilidad léxica.

Weinreich (1953) ya apuntó que la proximidad estructural de dos sistemas lingüísticos es un agente primordial en la influencia mutua entre las lenguas, como ocurre en nuestro caso con dos lenguas tan emparentadas genéticamente como el español y el catalán. Y, en este contexto, es, sin duda, el material léxico el que más fácilmente muestra intercambios entre unas lenguas y otras.

La convivencia de lenguas provoca, a la larga, fenómenos diversos como interferencias en los niveles más profundos del análisis, préstamos léxicos, cambios de código, calcos semánticos y/o sintácticos, fenómenos de convergencia, por no hablar de otros desenlaces más radicales, como las lenguas pidgins y criollas. Sin embargo, los investigadores no se ponen de acuerdo en la terminología que se debe emplear en cada caso, y a veces ni siquiera en la propia identificación de los fenómenos analizados. A este respecto, Blas Arroyo (2000:15, nota 2) ha destacado que: "En el ámbito de los estudios sobre el contacto de lenguas, el problema de límites teoréticos entre unos fenómenos y otros representa uno de los escollos más relevantes con que se ha enfrentado la bibliografía especializada". ${ }^{221}$

Con todo, y limitando el espectro de estudios al par español-catalán, podemos ver que esta relativa anarquía terminológica y conceptual ha intentado corregirse en los trabajos de disponibilidad léxica. Así, Serrano (2014) divide los catalanismos hallados en los listados del castellano en su investigación del léxico disponible de Lérida en: interferencias, cambios de código, préstamos en vías de integración, préstamos integrados, combinaciones híbridas (divididos a su vez en sintagmas cuyo núcleo se encuentra en catalán o en castellano y aquellos que cuentan con algún elemento híbrido), calcos semánticos y calcos sintácticos. Para ello, basa su división en la suma de dos criterios, uno formal y otro de integración social del término, apoyado este en la frecuencia de mención y el porcentaje de aparición de los términos. Por su parte, Gómez Molina y Gómez Devís (2004), en su estudio sobre el léxico disponible de Valencia, reducen los fenómenos de contacto lingüístico a: transferencias, dobletes, préstamos y

${ }^{221}$ Véase Blas Arroyo $(1993,2000)$ para un estudio pormenorizado del tema. 
sustitución de código. Y en un sentido similar, esta vez en relación con el léxico disponible catalán de Valencia, Llopis $(2008$, 2009) diferencia igualmente entre dobletes, interferencias, préstamos en vías de integración, préstamos consolidados, compuestos híbridos, sustitución de código y cambio de código, guiándose para ello en el parámetro de la frecuencia de aparición de los vocablos. Por último, Martínez Olmos (2008: 380) sigue a los investigadores alicantinos F. Gimeno y M.V. Gimeno (2003), quienes "proponen una tipología de la transferencia léxica basada en la mayor o menor integración lingüística y social del préstamo"222 . A partir de ahí, clasifica los fenómenos de contacto de lenguas en interferencias, préstamos, cambio de código y calcos (calcos semánticos y calcos léxicos).

De acuerdo con estos criterios, en la siguiente tabla realizamos una clasificación de los valencianismos de acuerdo con el fenómeno de contacto lingüístico que mejor representan. Siguiendo específicamente la investigación de Gómez Molina y Gómez Devis, distinguiremos entre los siguientes fenómenos:

a) dobletes, cuando el índice de disponibilidad es mayor en la lengua española,

b) préstamos consolidados, es decir, aquellos que están lingüística y socialmente integrados,

c) préstamos no integrados, aquellos vocablos con una clara forma valenciana, y que, por lo general, no están adaptados lingüísticamente al español, al tiempo que su frecuencia de uso es significativamente menor que la de los préstamos consolidados; y

d) compuestos híbridos. ${ }^{223}$

\begin{tabular}{|l|l|l|l|l|}
\hline C. I. & Dobletes & $\begin{array}{l}\text { Préstamos } \\
\text { consolidados }\end{array}$ & $\begin{array}{l}\text { Préstamos no } \\
\text { integrados }\end{array}$ & $\begin{array}{l}\text { Compuestos } \\
\text { híbridos }\end{array}$ \\
\hline 01 & figa & & & \\
\hline 02 & $\begin{array}{l}\text { Samarreta } \\
\text { Espardenya } \\
\text { Brusa }\end{array}$ & & & \\
\hline 03 & $\begin{array}{l}\text { Saleta } \\
\text { Pica } \\
\text { Rebost } \\
\text { Desllunat }\end{array}$ & Paellero & & \\
\hline
\end{tabular}

${ }^{222}$ F. Gimeno y M.V. Gimeno (2003: 110) apuntan cuatro rasgos para que se produzca la integración lingüística y social: frecuencia de uso, desplazamiento de sinónimos de la lengua prestataria, integración morfofonológica y sintáctica y aceptabilidad.

${ }^{223}$ A estos habría que añadir los dos casos de calco semántico hallados en los listados: plato plano y jamón dulce. 


\begin{tabular}{|c|c|c|c|c|}
\hline 04 & Pica & & & \\
\hline 05 & $\begin{array}{l}\text { Botifarra } \\
\text { Bajoca } \\
\text { Abadejo } \\
\text { Lluç } \\
\text { Arròs caldós } \\
\text { Clòtxina } \\
\text { Carlota } \\
\text { Coca } \\
\text { Mallorquina }\end{array}$ & $\begin{array}{l}\text { Fideuà } \\
\text { Fuet } \\
\text { Paella } \\
\text { Rosquilleta } \\
\text { Chuleta }\end{array}$ & $\begin{array}{l}\text { Fogassa } \\
\text { Mabra } \\
\text { Empedrat } \\
\text { Bajocó }\end{array}$ & $\begin{array}{l}\text { Pollo a l'ast } \\
\text { Coca de tomate }\end{array}$ \\
\hline 06 & $\begin{array}{l}\text { Paellera } \\
\text { Pitxer } \\
\text { Setril d'oli } \\
\text { Cassoleta } \\
\text { Paella } \\
\text { Got }\end{array}$ & & & $\begin{array}{l}\text { Mortero con } \\
\text { allioli }\end{array}$ \\
\hline 07 & $\begin{array}{l}\text { Pica } \\
\text { Torradora } \\
\text { Perol } \\
\text { Funeral } \\
\text { Banquet } \\
\text { Escorredor } \\
\text { Graella } \\
\text { Drap } \\
\text { Foguer } \\
\text { Perola } \\
\text { Paellera } \\
\text { Misto } \\
\text { Paella }\end{array}$ & Paellero & & $\begin{array}{l}\text { Pica de fregar } \\
\text { Mazo de allioli } \\
\text { Recipiente de } \\
\text { allioli }\end{array}$ \\
\hline 08 & $\begin{array}{l}\text { Taula } \\
\text { Cadira } \\
\text { Punxó }\end{array}$ & Salfumant & & \\
\hline 09 & $\begin{array}{l}\text { Palmito } \\
\text { Llar } \\
\text { Foguera } \\
\text { Plafó } \\
\text { Misto }\end{array}$ & & & \\
\hline 10 & $\begin{array}{l}\text { Carrer } \\
\text { Claveguera } \\
\text { Placeta } \\
\text { Tauleta } \\
\text { Conselleria }\end{array}$ & Casal & & \\
\hline 11 & $\begin{array}{l}\text { Maset } \\
\text { Matxina } \\
\text { Perera } \\
\text { Argelaga } \\
\text { Cadernera } \\
\text { Carxofa }\end{array}$ & $\begin{array}{l}\text { Caseta } \\
\text { Paellero } \\
\text { Barraca }\end{array}$ & $\begin{array}{l}\text { Marialluïsa, } \\
\text { Lligona, } \\
\text { Espardenya, } \\
\text { Albercoquer }\end{array}$ & $\begin{array}{l}\text { Caseta de } \\
\text { campo }\end{array}$ \\
\hline
\end{tabular}




\begin{tabular}{|c|c|c|c|c|}
\hline & $\begin{array}{l}\text { Fava } \\
\text { Corbella } \\
\text { Garrofera } \\
\text { Collidor } \\
\text { Teuladí } \\
\text { Guineu }\end{array}$ & & & \\
\hline \multicolumn{5}{|c|}{12} \\
\hline 13 & $\begin{array}{l}\text { Empeltar } \\
\text { Collidor } \\
\text { Collir } \\
\text { Saó } \\
\text { Ramader } \\
\text { Tallar } \\
\text { Arruixar } \\
\text { Llaurador } \\
\text { Ensulfatador } \\
\text { Escampar fem } \\
\text { Banyar soques }\end{array}$ & & $\begin{array}{l}\text { Empeltador } \\
\text { Espigolar } \\
\text { Masover } \\
\text { Fer paret } \\
\text { Ficar rectes } \\
\text { Fer cremador } \\
\text { Fer soquetes }\end{array}$ & $\begin{array}{l}\text { Hacer soquetes } \\
\text { Hacer soques } \\
\text { Cremar leña } \\
\text { Hacer els } \\
\text { cavallons } \\
\text { Recoger } \\
\text { collites } \\
\text { Cavar soques } \\
\text { Cortar soques } \\
\text { Tirar fem }\end{array}$ \\
\hline 14 & $\begin{array}{l}\text { Cadernera } \\
\text { Titot } \\
\text { Colom } \\
\text { Egua } \\
\text { Cullerot } \\
\text { Estornell } \\
\text { Rabossa } \\
\text { Llisa } \\
\text { Oroneta } \\
\text { Granota } \\
\text { Llobarro } \\
\end{array}$ & & $\begin{array}{l}\text { Mabra } \\
\text { Vilero } \\
\text { Griva } \\
\text { Escorpa }\end{array}$ & \\
\hline 15 & $\begin{array}{l}\text { Cinquet } \\
\text { Truc } \\
\text { Despullat } \\
\text { Maquinetas } \\
\text { Tres en ratlla } \\
\text { Pedra paper tisora } \\
\text { Badulfa }\end{array}$ & Casal & $\begin{array}{l}\text { Sambori } \\
\text { Botifarra } \\
\text { Tres pamets, } \\
\text { Ditet } \\
\text { Platerets tets } \\
\text { tets } \\
\text { Voltar pins }\end{array}$ & \\
\hline 16 & $\begin{array}{l}\text { Pescater } \\
\text { Llaurador } \\
\text { Ramader }\end{array}$ & & Yesaire & \\
\hline 17 & Carabassa & & Enrogit & \\
\hline
\end{tabular}

Tabla 5.4.4. Clasificación de los valencianismos según los fenómenos de contacto lingüístico

Como se puede apreciar, los fenómenos de contacto lingüístico afectan, mayoritariamente, a la categoría de los sustantivos, así como a algunos verbos, especialmente en compuestos híbridos (hacer soquetes, recoger collites, cortar / cavar soques, etc.). Por otro lado, un análisis cuantitativo de los valencianismos muestra que 
una gran mayoría se integran dentro de la categoría de los dobletes $(66,9 \%)$, seguidos a distancia por los préstamos no integrados (19\%) y los compuestos híbridos (10,5\%). Tan solo un 9,2\% de las transferencias corresponde a préstamos consolidados.

\subsubsection{Comparación con otras sintopías}

Pasamos ahora a comparar los datos anteriores con los de otras sintopías que han analizado también el contacto entre castellano y catalán /valenciano. En la tabla 5.4.5 anotamos el número total de vocablos y el de valencianismos que aparecen en cada área temática por provincia. ${ }^{224}$

\begin{tabular}{|l|c|c|c|c|c|c|c|c|}
\hline CI & \multicolumn{2}{|c|}{ Castellón } & \multicolumn{2}{c|}{ Valencia } & \multicolumn{2}{c|}{ Alicante } & \multicolumn{2}{c|}{ Lérida } \\
\hline & 1 & 2 & 1 & 2 & 1 & 2 & 1 & 2 \\
\hline 01 & 271 & 1 & 339 & 18 & 328 & 1 & 386 & 20 \\
\hline 02 & 312 & 3 & 330 & 3 & 323 & 0 & 291 & 25 \\
\hline 03 & 307 & 5 & 263 & 11 & 350 & 2 & 238 & 29 \\
\hline 04 & 303 & 1 & 308 & 5 & 442 & 1 & 263 & 27 \\
\hline 05 & 607 & 20 & 561 & 15 & 627 & 7 & 476 & 30 \\
\hline 06 & 317 & 8 & 256 & 1 & 397 & 3 & 238 & 25 \\
\hline 07 & 502 & 13 & 372 & 6 & 519 & 5 & 347 & 31 \\
\hline 08 & 623 & 4 & 473 & 1 & 552 & 0 & 420 & 25 \\
\hline 09 & 479 & 5 & 256 & 6 & 541 & 4 & 297 & 16 \\
\hline 10 & 949 & 7 & 755 & 1 & 1011 & 3 & 678 & 28 \\
\hline 11 & 1060 & 19 & 967 & 31 & 1196 & 11 & 727 & 48 \\
\hline 12 & 344 & 0 & 280 & 1 & 317 & 2 & 276 & 5 \\
\hline 13 & 704 & 22 & 491 & 22 & 755 & 9 & 434 & 49 \\
\hline 14 & 447 & 15 & 467 & 31 & 425 & 6 & 347 & 35 \\
\hline 15 & 908 & 15 & 546 & 9 & 893 & 5 & 576 & 24 \\
\hline 16 & 732 & 4 & 715 & 7 & 831 & 2 & 591 & 41 \\
\hline 17 & 350 & 2 & 264 & 2 & 0 & 0 & 239 & 25 \\
\hline Total & 9215 & 144 & 7643 & 170 & 9507 & 61 & 6824 & 483 \\
\hline
\end{tabular}

Tabla 5.4.5. Número de vocablos y valencianismos/catalanismos en las diferentes sintopías

Leyenda:

1. Número de vocablos / 2. Número de valencianismos/catalanismos

\footnotetext{
${ }^{224}$ Bartol (2011:73) compara asimismo la densidad de los fenómenos de contacto de lenguas sobre el total de vocablos en distintas zonas geográficas: Galicia $(2,88 \%)$, Álava $(0,83)$, Vizcaya $(2,35 \%)$, Navarra $(0,55 \%)$.
} 
Como se puede comprobar, en la tabla se advierten algunas diferencias destacadas entre unos territorios y otros. De estos, la provincia de Lérida se muestra como la comunidad de habla con mayor número de ellos (483 vocablos), seguida a distancia por Valencia (170), Castellón (144) y, a mucha más todavía, por Alicante, que con apenas 61 valencianismos cierra la lista, y se perfila como la comunidad de habla menos valencianizada lingüísticamente. ${ }^{225}$ Estas desigualdades podrían achacarse, al menos parcialmente, a las distintas pautas generales seguidas en los criterios de edición de los materiales, aunque este riesgo es menor en los trabajos inmersos en el proyecto panhispánico del léxico disponible, en el que siempre se ha procurado seguir los mismos en todos los estudios. Por otro lado, hay que tener en cuenta que el número de estudiantes encuestados varía de un territorio a otro (Castellón, 354; Valencia, 465; Alicante, 460 y Lérida, 240). Sin embargo, el volumen de catalanismos hallados en Lérida frente a las provincias de la Comunidad Valenciana, parece indicar una situación sociolingüística distinta y un mayor porcentaje de hablantes nativos en catalán con mayores interferencias desde esta lengua hacia el castellano. Además, como apunta Serrano (2014:561), en Lérida todos los informantes están escolarizados en catalán, independientemente de cuál sea su lengua materna. Esta circunstancia, junto con un elevado prestigio de la lengua vernácula, podría explicar el mayor número de interferencias en el castellano de Lérida, como la propia autora de la investigación se encarga de señalar.

A pesar de esas notables diferencias cuantitativas, las cuatro áreas geográficas coinciden en los centros de interés donde se concentra la mayor densidad de fenómenos de contacto lingüístico: Jardín, Campo, Animales y Alimentos, aunque en rangos distintos en cada zona. De esta manera, si para Castellón y Alicante el estímulo verbal Juegos está entre las primeras cinco áreas nocionales más proclives a la entrada de palabras procedentes de la lengua autóctona, en Valencia este centro de interés desciende hasta el puesto noveno, y al décimo cuarto en el caso de Lérida.

En el extremo opuesto, los estudiantes de Alicante no aportan ningún vocablo en Ropa y Escuela, al igual que Castellón en el campo léxico del Transporte. Por otro lado, en todos los territorios, este centro de interés ocupa el último lugar en la escala de catalanismos. Valencia anota un solo término, mientras que Alicante registra dos y

\footnotetext{
${ }^{225}$ Hay que tener presente que Martínez Olmos (2008) no analiza el centro de interés Colores en su investigación sobre Alicante.
} 
Lérida cinco. En las demás áreas asociativas, coindicen en Cuerpo Castellón, Alicante y Lérida, mientras que en Valencia ocupa un cuarto lugar. Llama también la atención el campo semántico Ciudad, que aparece en penúltimo lugar en Valencia, con una sola mención, mientras que ocupa el octavo lugar en Lérida y Castellón y el noveno en Alicante.

En la tabla 5.4.6 ofrecemos ahora la densidad de los catalanismos en las cuatro provincias comparadas.

\begin{tabular}{|c|c|c|c|c|c|c|c|c|}
\hline $\begin{array}{c}\text { Centros } \\
\text { de interés }\end{array}$ & \multicolumn{2}{|c|}{ Castellón } & \multicolumn{2}{c|}{ Valencia } & \multicolumn{2}{c|}{ Alicante } & \multicolumn{2}{c|}{ Lérida } \\
\hline & Valen. & $\%$ & Valen. & $\%$ & Valen. & $\%$ & Catal. & $\%$ \\
\hline 01 & 1 & $0,36 \%$ & 18 & 5,03 & 1 & 0,30 & 20 & 5,18 \\
\hline 02 & 3 & $0,96 \%$ & 3 & 0,90 & 0 & 0 & 25 & 8,59 \\
\hline 03 & 5 & $1,62 \%$ & 11 & 4,18 & 2 & 0,57 & 29 & 12,18 \\
\hline 04 & 1 & $0,33 \%$ & 5 & 1,62 & 1 & 0,22 & 27 & 10,27 \\
\hline 05 & 20 & $3.29 \%$ & 15 & 2,67 & 7 & 1,11 & 30 & 6,30 \\
\hline 06 & 8 & $2,52 \%$ & 1 & 0,39 & 3 & 0,75 & 25 & 10,50 \\
\hline 07 & 13 & $2,58 \%$ & 6 & 1,61 & 5 & 0,96 & 31 & 8,93 \\
\hline 08 & 4 & $0,64 \%$ & 1 & 0,21 & 0 & 0 & 25 & 5,95 \\
\hline 09 & 5 & $1,04 \%$ & 6 & 2,34 & 4 & 0,73 & 16 & 5,39 \\
\hline 10 & 7 & $0,73 \%$ & 1 & 0,13 & 3 & 0,29 & 28 & 4,13 \\
\hline 11 & 19 & $1,79 \%$ & 31 & 3,20 & 11 & 0,91 & 48 & 6,60 \\
\hline 12 & 0 & 0 & 1 & 0,35 & 2 & 0,63 & 5 & 1,81 \\
\hline 13 & 22 & $3,12 \%$ & 22 & 4,48 & 9 & 1,19 & 49 & 11,29 \\
\hline 14 & 15 & $3.35 \%$ & 31 & 6,63 & 6 & 1,45 & 35 & 10,09 \\
\hline 15 & 15 & $1,65 \%$ & 9 & 1,64 & 5 & 0,55 & 24 & 4,17 \\
\hline 16 & 4 & $0,54 \%$ & 7 & 0,97 & 2 & 0,24 & 41 & 6,94 \\
\hline 17 & 2 & $0,57 \%$ & 2 & 0,75 & 0 & 0 & 25 & 10,46 \\
\hline Total & 142 & $1,56 \%$ & 170 & 2,22 & 61 & 0,64 & 483 & 7,07 \\
\hline
\end{tabular}

Tabla 5.4.6. Densidad de los valencianismos/catalanismos por centros de interés en las sintopías comparadas

Encontramos nuevamente el mismo orden en el porcentaje de aparición de catalanismos, esto es, en primer lugar Lérida (7.07\%), seguido de Valencia (2.22\%) y Castellón (1.56\%) y, en último lugar, Alicante, con tan solo un 0.64\%. El único centro de interés que se mantiene entre las cinco primeras posiciones y que comparten las cuatro provincias es el de Jardín. No sucede lo mismo con los demás campos léxicos. Así Castellón, Valencia y Alicante mantienen en la primera posición Animales y Lérida lo baja a la sexta; Cocina se encuentra en el cuarto rango en Castellón y Alicante, pero en Lérida baja hasta el séptimo y en Valencia al décimo lugar. Y entre las últimas 
posiciones, tampoco observamos coincidencias entre las cuatro zonas comparadas. De este modo, para Castellón y Lérida el campo semántico Transportes aparece en el último rango, posición ocupada por Ciudad en Valencia, así como en Alicante. Finalmente, recordemos que en esta última provincia no se han registrado valencianismo en los centros de interés Ropa y Escuela.

\subsubsection{Variables sociales}

Al igual que hiciéramos con los resultados generales y los anglicismos, en el estudio de los valencianismos analizamos también la potencial incidencia de diversas variables sociales, como el sexo, la titularidad pública o privada del centro educativo, la ubicación de este, la lengua materna de los estudiantes y el nivel educativo familiar. En la siguiente tabla mostramos para cada factor las cifras del número de alumnos que se ven afectados por los fenómenos de contacto de lenguas y su relación con el número total de alumnos en cada grupo.

\begin{tabular}{|c|c|c|c|}
\hline Variables & $\mathrm{N}^{\mathrm{o}}$ alumnos totales & $\begin{array}{l}\mathbf{N}^{0} \text { alumnos con } \\
\text { valencianismos }\end{array}$ & $\%$ \\
\hline \multicolumn{4}{|l|}{ Sexo } \\
\hline Hombre & 155 & 115 & 72 \\
\hline Mujer & 199 & 147 & 73.8 \\
\hline \multicolumn{4}{|c|}{ Ubicación centro } \\
\hline Urbano & 165 & 82 & 49.7 \\
\hline Rural & 189 & 180 & 95 \\
\hline \multicolumn{4}{|l|}{ Tipo centro } \\
\hline Público & 229 & 175 & 76.4 \\
\hline Privado & 125 & 87 & 70 \\
\hline \multicolumn{4}{|c|}{ Nivel educativo } \\
\hline Bajo & 144 & 109 & 75.6 \\
\hline Medio Bajo & 98 & 72 & 73.4 \\
\hline Medio Alto & 83 & 59 & 72 \\
\hline Alto & 29 & 22 & 75.8 \\
\hline \multicolumn{4}{|c|}{ Lengua materna } \\
\hline Valenciano & 158 & 130 & 83 \\
\hline Castellano & 139 & 86 & 62 \\
\hline Ambas & 57 & 46 & 81 \\
\hline
\end{tabular}

Tabla 5.4.7. Número de alumnos afectados por los valencianismos según las variables analizadas.

Apreciamos cómo las chicas ofrecen una mayor cantidad de valencianismos, pero esto obedece exclusivamente a que el número de mujeres es mayor. De hecho, 
cuando comparamos los porcentajes de cada grupo, las cifras son prácticamente idénticas. No ocurre así, por el contrario, cuando tomamos en consideración el entorno familiar de los alumnos. Como era previsible, el número de alumnos con empleo de valencianismos es claramente superior en el ámbito rural (95\%) que en el urbano, con cifras que se reducen a prácticamente a la mitad (49,7\%). Asimismo, la proporción de alumnos con interferencias es algo mayor en los centros públicos $(76,4 \%)$ que en los privados (70\%), aunque las distancias porcentuales son en este caso reducidas. También lo son, contrariamente a nuestras hipótesis iniciales, en relación con el nivel sociocultural de la esfera familiar, pues la distancia entre los diferentes grupos apenas rebasa el $3 \%$.

Una atención particular merece la adscripción lingüística de los alumnos, que estudiamos a partir de su lengua materna. En esta ocasión, y como era previsible, presentan mayor número de valencianismos los hablantes cuya lengua materna es el valenciano (83\%), seguidos muy de cerca por los bilingües equilibrados (81\%), y a considerable distancia ambos de los castellanohablantes exclusivos, cuyos informantes presentan una densidad de valencianismos significativamente menor (62\%). M. Casanovas (1996) nos explica con estas palabras la mayor incidencia de estos préstamos entre los hablantes cuya lengua materna es el catalán: "el déficit de recursos coloquiales del alumno catalonohablante cuando se comunica en español es el causante de que recurra a la posibilidad que le ofrece la lengua materna, que es su vehículo de comunicación oral habitual".

A continuación, observamos cada una de las variables con mayor detalle al precisar los valencianismos recogidos dentro cada uno de los centros de interés. Para ello comparamos las diferentes submuestras y comprobamos si las diferencias obtenidas entre ellas son significativas al aplicar diversas pruebas estadísticas.

\subsubsection{Sexo}

La tabla siguiente nos ofrece los datos referentes al sexo de los alumnos encuestados, el número de valencianismos empleados en cada centro de interés y el porcentaje que representan. Observamos una pequeña superioridad de los hombres sobre las mujeres (1.66 frente a un 1.23), que son avaladas por el estadístico t para la comparación de muestras emparejadas (t. 2,31; p. 0,03) 


\begin{tabular}{|l|c|c|c|c|c|c|}
\hline & \multicolumn{3}{|l|}{ HOMBRE } & \multicolumn{3}{l|}{ MUJER } \\
\hline Centro de interés & Voc. & Val. & $\%$ & Voc & Val. & $\%$ \\
\hline 1. Partes del cuerpo & 230 & 1 & 0.43 & 211 & 0 & 0 \\
\hline 2. Ropa & 221 & 1 & 0.45 & 252 & 2 & 0.79 \\
\hline 3. Partes casa & 228 & 3 & 1.31 & 228 & 3 & 1.31 \\
\hline 4. Muebles & 198 & 1 & 0.50 & 254 & 0 & 0 \\
\hline 5. Alimentos & 483 & 13 & 2.69 & 463 & 15 & 3.23 \\
\hline 6. Mesa & 225 & 7 & 3.11 & 245 & 3 & 1.22 \\
\hline 7. Cocina & 346 & 9 & 2.60 & 387 & 11 & 2.84 \\
\hline 8. Escuela & 424 & 3 & 0.70 & 456 & 1 & 0.21 \\
\hline 9. Iluminación & 326 & 3 & 0.92 & 328 & 3 & 0.91 \\
\hline 10. Ciudad & 646 & 6 & 0.92 & 655 & 2 & 0.30 \\
\hline 11. Campo & 771 & 16 & 2.07 & 741 & 9 & 1.21 \\
\hline 12. Transporte & 276 & 0 & 0 & 248 & 0 & 0 \\
\hline 13. Jardín & 476 & 22 & 4.62 & 423 & 15 & 3.54 \\
\hline 14. Animales & 387 & 12 & 3.10 & 319 & 6 & 1.88 \\
\hline 15. Juegos & 621 & 9 & 1.44 & 627 & 9 & 1.43 \\
\hline 16. Profesiones & 541 & 2 & 0.36 & 539 & 2 & 0.37 \\
\hline 17. Colores & 249 & 1 & 0.40 & 266 & 1 & 0.37 \\
\hline TOTAL & 6548 & 109 & 1.66 & 6642 & 82 & 1.23 \\
\hline
\end{tabular}

Tabla 5.4.8. Valencianismos según la variable sexo

Si nos fijamos con más detalle, los chicos destacan en tres campos semánticos (Mesa, Jardín y Animales) con más de un punto de distancia sobre las chicas. Aventajan asimismo a las mujeres en Cатрo, aunque esta vez las diferencias sean algo menores (0.86). Por el contrario, las estudiantes superan a sus compañeros en los centros de interés de Ropa, Alimentos y Cocina, aunque esta vez con una distancia porcentual considerablemente menor $(0.34,0,54$ y 0,24 respectivamente). En el resto de centros de interés, las diferencias entre unos y otras se neutralizan prácticamente.

Como se puede apreciar, las mujeres superan a los hombres en campos relacionados con el rol que la sociedad les asigna tradicionalmente (Ropa y Cocina), mientras que los hombres superan a las féminas en aquellas áreas léxicas que la sociedad determina también como especialmente vinculadas al género masculino (Trabajos del campo y del jardín y Animales).

El resumen de las diferencias entre los hombres y las mujeres queda reflejado en el gráfico siguiente. 


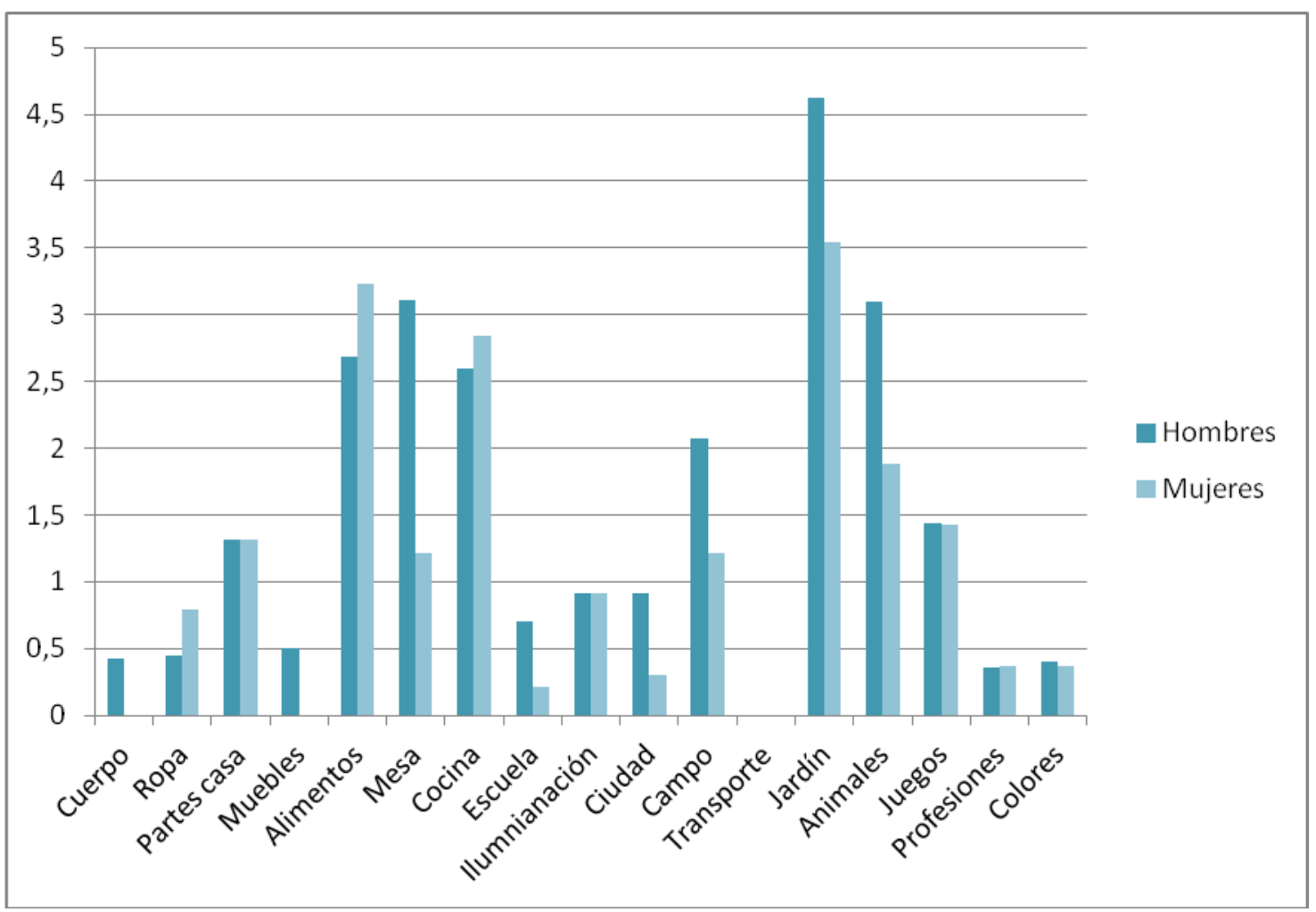

Gráfico 5.4.2. Valencianismos según la variable sexo.

\subsubsection{Tipo de centro}

Las cifras generales y las densidades de valencianismos según la variable titularidad de centro (privada o pública) aparecen en la tabla 5.4.9 y el gráfico 5.4.3.

En esta variable social no apreciamos diferencias significativas entre los alumnos que asisten a entidades públicas y privadas, como se desprende de unos porcentajes globales prácticamente idénticos (1.42 y 1,41 respectivamente) (t. 0,$21 ; \mathrm{p}$. 0,83). Por centros de interés, las primeras posiciones las encontramos en ambos grupos en Alimentos, Cocina, Jardín, Animales y Mesa, aunque con un orden distinto. Por ejemplo, el campo Alimentos se encuentra en primer lugar entre los alumnos de centros públicos, y, sin embargo, ocupa la quinta posición en los alumnos que acuden a los colegios privados. Como contrapartida, el área léxica Jardín se sitúa en la primera posición en estos últimos, mientras que entre los estudiantes de institutos públicos pasa al tercer lugar.

Por último, y aunque con diferencias poco apreciables, los informantes de institutos públicos aventajan a sus compañeros en Ropa, Muebles, Iluminación, Campo, 
Juegos y Color, mientras que los alumnos de centros privados lo hacen en los campos semánticos Cuerpo, Casa, Escuela, Ciudad y Profesiones.

\begin{tabular}{|l|c|c|c|c|c|c|}
\hline & \multicolumn{3}{|c|}{ PÚBLICO } & \multicolumn{3}{c|}{ PRIVADO } \\
\hline Centro de interés & Voc. & Valen. & $\%$ & Voc & Valen. & $\%$ \\
\hline 1. Partes del cuerpo & 252 & 0 & 0 & 190 & 1 & 0.52 \\
\hline 2. Rropa & 271 & 2 & 0.73 & 196 & 1 & 0.51 \\
\hline 3. Casa & 249 & 3 & 1.20 & 195 & 3 & 1.53 \\
\hline 4. Muebles & 255 & 1 & 0.39 & 189 & 0 & 0 \\
\hline 5. Alimentos & 521 & 18 & 3.45 & 407 & 8 & 1.96 \\
\hline 6. Mesa & 254 & 6 & 2.36 & 201 & 4 & 1.99 \\
\hline 7. Cocina & 417 & 11 & 2.63 & 318 & 8 & 2.51 \\
\hline 8. Escuela & 493 & 1 & 0.20 & 366 & 3 & 0.81 \\
\hline 9. Iluminación & 371 & 5 & 1.34 & 267 & 1 & 0.37 \\
\hline 10. Ciudad & 752 & 3 & 0.39 & 536 & 4 & 0.74 \\
\hline 11. Campo & 857 & 17 & 1.98 & 642 & 10 & 1.55 \\
\hline 12. Transporte & 315 & 0 & 0 & 170 & 0 & 0 \\
\hline 13. Jardín & 536 & 14 & 2.61 & 338 & 18 & 5.32 \\
\hline 14. Animales & 396 & 10 & 2.52 & 298 & 6 & 2.01 \\
\hline 15. Juegos & 722 & 14 & 1.93 & 522 & 7 & 1.34 \\
\hline 16. Profesiones & 642 & 2 & 0.31 & 426 & 3 & 0.70 \\
\hline 17. Colores & 326 & 2 & 0.61 & 166 & 0 & 0 \\
\hline TOTAL & 7629 & 109 & 1.42 & 5430 & 77 & 1.41 \\
\hline
\end{tabular}

Tabla 5.4.9. Valencianismos según la variable titularidad de centro. 


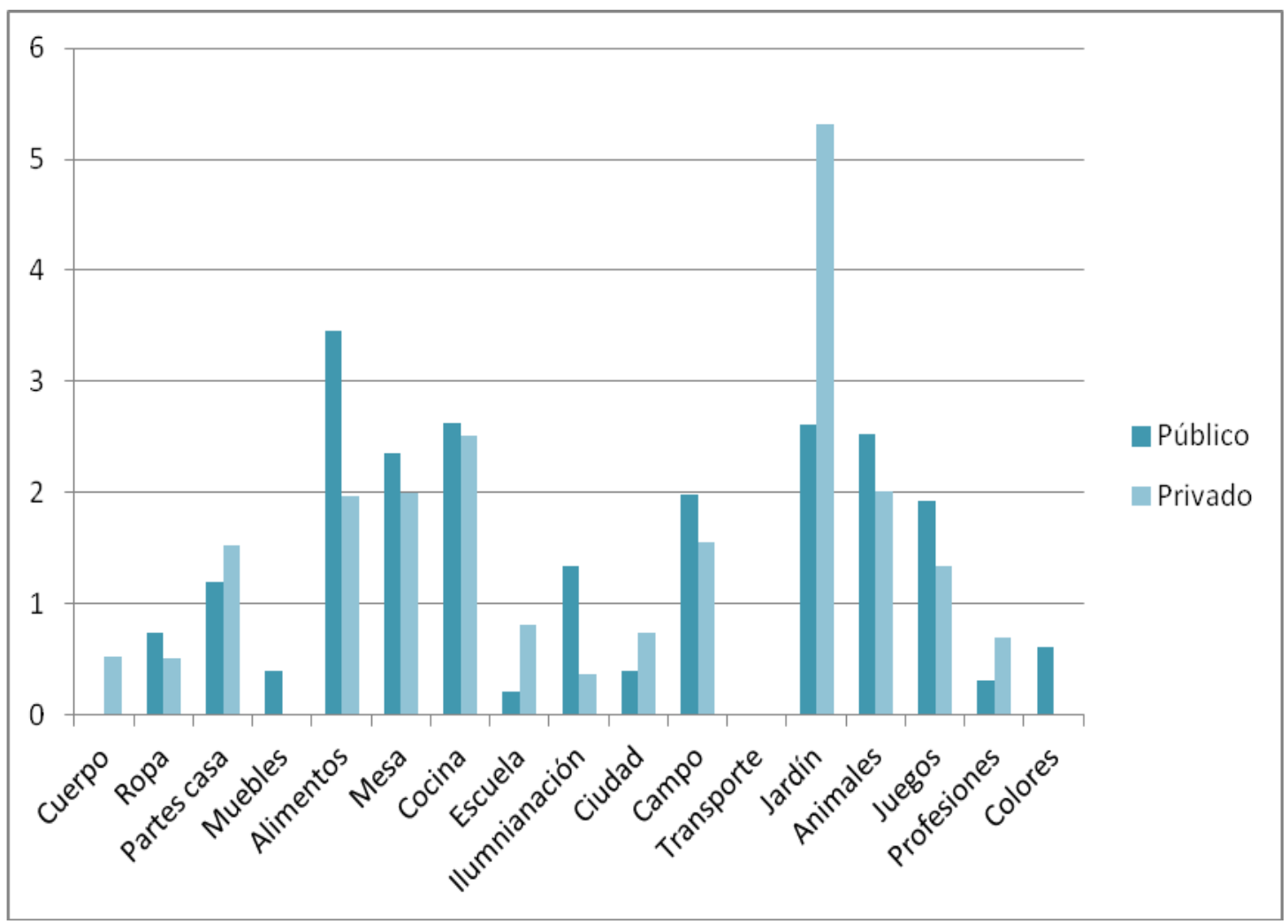

Gráfico 5.4.3. Valencianismos según el tipo de centro.

\subsubsection{Ubicación de centro}

Las diferencias favorables a los alumnos de centros situados en enclaves rurales que advertíamos más arriba en términos generales, se confirman también ahora cuando se consideran los diferentes centros de interés (t. -1,81; p. 0,07).

El contraste entre algunos de ellos (Cuerpo, Ropa, Casa, Muebles, Escuela y Ciudad) revela una mínima ventaja de los alumnos de centros urbanos, pero esta es mucho más clara en la mayoría de las áreas léxica en el sentido contrario, esto es, a favor de quienes estudian en centros de la provincia. Así sucede en Alimentos, Mesa, Cocina, Iluminación, Campo, Jardín, Animales, Juegos, Profesiones y Colores. Por mencionar algunos casos concretos, en el campo Alimentos, estos alumnos cosechan 18 valencianismos, y lo mismo sucede en Jardín con 17. Por el contrario, las cifras de sus compañeros de Castellón de la Plana no pasan de los 8 y 6 términos respectivamente.

En lo que sí coinciden los dos grupos es en el orden de preferencia para la selección de valencianismos, al menos en las primeras posiciones, aunque con algunas diferencias en la posición ocupada por cada centro de interés en ese continuum. Así, mientras que la prelación en los centros urbanos es como sigue: Mesa, Animales, 
Alimentos, Juegos, Campo, Jardín, Casa y Cocina, en los centros educativos rurales el orden pasa a ser este otro: Cocina, Jardín, Alimentos, Animales, Mesa, Campo, Juegos y Casa. De esta manera, si seguimos fijándonos en las densidades, vemos, por ejemplo, cómo Mesa ocupa el primer lugar entre los estudiantes urbanos, al tiempo que pasa a la quinta posición entre sus compañeros del resto de la provincia. Como contrapartida, el centro Cocina es un área semántica con una importante densidad de valencianismos entre estos últimos, mientras que ocupa una posición bastante más retrasada entre los alumnos que estudian en Castellón capital ( $8^{\circ}$ rango).

\begin{tabular}{|l|c|c|c|c|c|c|}
\hline Centro de interés & \multicolumn{3}{|c|}{ URBANO } & \multicolumn{3}{c|}{ RURAL } \\
\hline Centros de interés & Voc. & Val. & $\%$ & Voc. & Val. & $\%$ \\
\hline 1. Partes del cuerpo & 212 & 1 & 0.47 & 235 & 0 & 0 \\
\hline 2. Ropa & 212 & 2 & 0.94 & 256 & 1 & 0.39 \\
\hline 3. Partes casa & 208 & 3 & 1.44 & 243 & 3 & 1.23 \\
\hline 4. Muebles & 213 & 1 & 0.46 & 241 & 0 & 0 \\
\hline 5. Alimentos & 428 & 8 & 1.86 & 507 & 18 & 3.55 \\
\hline 6. Mesa & 204 & 4 & 1.96 & 262 & 7 & 2.67 \\
\hline 7. Cocina & 347 & 5 & 1.44 & 391 & 15 & 3.83 \\
\hline 8. Escuela & 400 & 3 & 0.75 & 472 & 1 & 0.21 \\
\hline 9. Iluminación & 279 & 2 & 0.69 & 360 & 4 & 1.11 \\
\hline 10. Ciudad & 610 & 4 & 0.65 & 694 & 3 & 0.43 \\
\hline 11. Campo & 731 & 11 & 1.50 & 786 & 14 & 1.78 \\
\hline 12. Transporte & 227 & 0 & 0 & 292 & 0 & 0 \\
\hline 13. Jardín & 412 & 6 & 1.45 & 476 & 17 & 3.57 \\
\hline 14. Animales & 315 & 6 & 1.90 & 385 & 11 & 2.85 \\
\hline 15. Juegos & 595 & 9 & 1.51 & 655 & 11 & 1.67 \\
\hline 16. Profesiones & 523 & 2 & 0.38 & 574 & 3 & 0.52 \\
\hline 17. Colores & 243 & 0 & 0 & 270 & 2 & 0.74 \\
\hline TOTAL & 6159 & 67 & 1.08 & 7099 & 120 & 1.69 \\
\hline
\end{tabular}

Tabla 5.4.10. Valencianismos según la variable ubicación del centro educativo. 


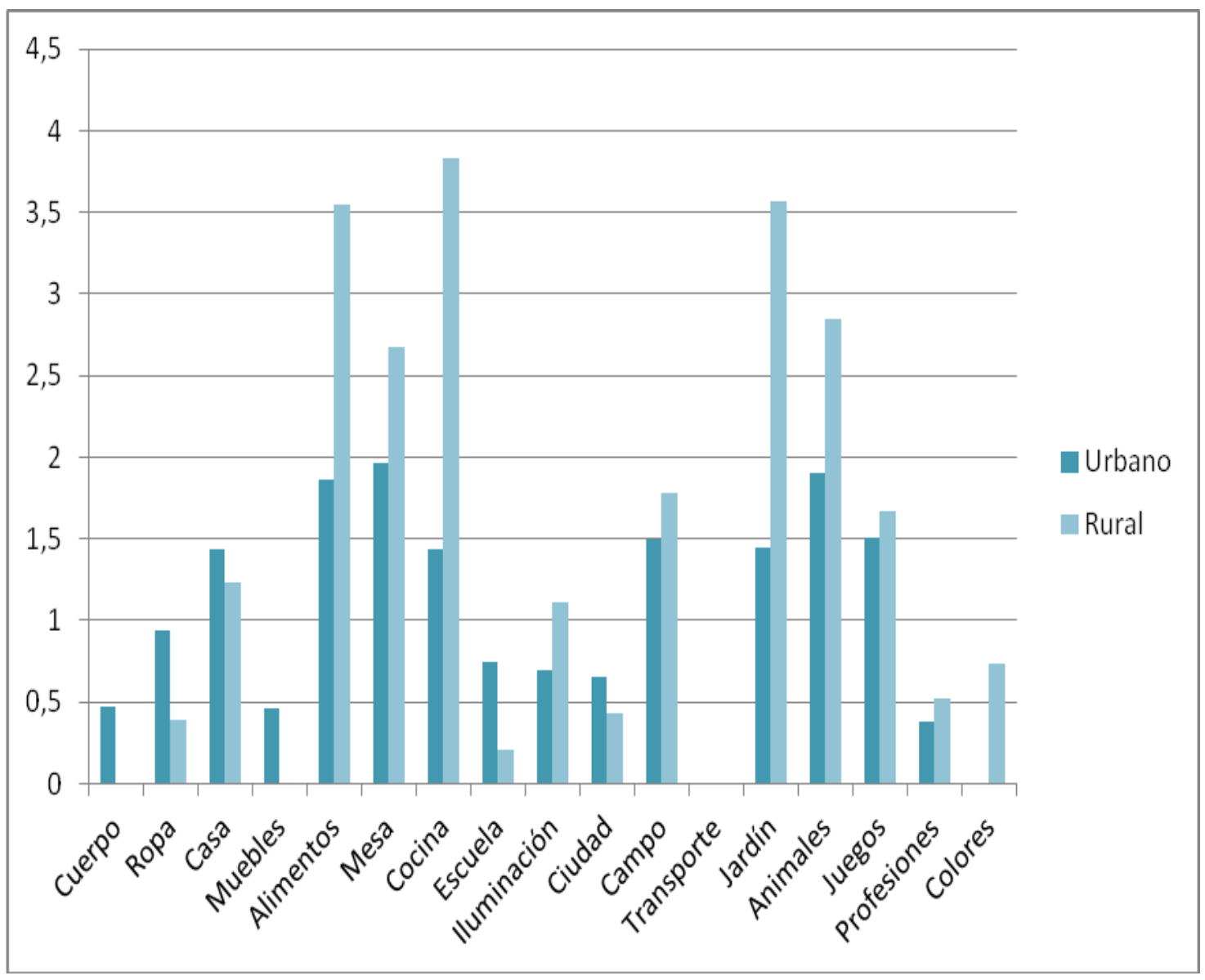

Gráfico 5.4.4. Valencianismos según la variable Ubicación de centro. 


\subsubsection{Lengua materna}

Los valencianismos empleados por los informantes castellonenses según la variable lengua materna quedan reflejados en la tabla y gráficos siguientes.

\begin{tabular}{|l|c|c|c|c|c|c|c|c|c|}
\hline & \multicolumn{3}{|c|}{ VALENCIANO } & \multicolumn{3}{c|}{ CASTELLANO } & \multicolumn{3}{c|}{ AMBAS } \\
\hline Centros de interés & Voc. & Val. & $\%$ & Voc. & Val. & $\%$ & Voc. & Val. & $\%$ \\
\hline 1. Cuerpo & 218 & 0 & 0 & 206 & 0 & 0 & 169 & 1 & 0.59 \\
\hline 2. Ropa & 228 & 1 & 0.43 & 226 & 1 & 0.44 & 168 & 1 & 0.59 \\
\hline 3. Partes casa & 219 & 2 & 0.91 & 200 & 3 & 1.5 & 153 & 3 & 1.96 \\
\hline 4. Muebles & 222 & 1 & 0.45 & 198 & 0 & 0 & 149 & 1 & 0.67 \\
\hline 5. Alimentos & 442 & 13 & 2.94 & 429 & 9 & 2.09 & 328 & 9 & 2.74 \\
\hline 6. Mesa & 226 & 6 & 2.65 & 210 & 4 & 1.90 & 148 & 2 & 1.35 \\
\hline 7. Cocina & 328 & 11 & 3.35 & 335 & 6 & 1.79 & 244 & 6 & 2.45 \\
\hline 8. Escuela & 419 & 4 & 0.95 & 391 & 0 & 0 & 264 & 0 & 0 \\
\hline 9. Iluminación & 312 & 3 & 0.96 & 273 & 2 & 0.73 & 201 & 2 & 0.99 \\
\hline 10. Ciudad & 608 & 2 & 0.32 & 581 & 5 & 0.86 & 370 & 1 & 0.27 \\
\hline 11. Campo & 721 & 14 & 1.94 & 666 & 7 & 1.05 & 459 & 4 & 0.87 \\
\hline 12. Transporte & 272 & 0 & 0 & 221 & 0 & 0 & 152 & 0 & 0 \\
\hline 13. Jardín & 429 & 19 & 4.42 & 360 & 9 & 2.5 & 239 & 17 & 7.11 \\
\hline 14. Animales & 362 & 12 & 3.31 & 298 & 4 & 1.34 & 256 & 3 & 1.17 \\
\hline 15. Juegos & 606 & 11 & 1.81 & 565 & 7 & 1.23 & 358 & 7 & 1.95 \\
\hline 16. Profesiones & 521 & 3 & 0.57 & 502 & 2 & 0.39 & 345 & 2 & 0.57 \\
\hline 17. Colores & 272 & 2 & 0.73 & 202 & 0 & 0 & 170 & 0 & 0 \\
\hline TOTAL & 6405 & 104 & 1.62 & 5863 & 59 & 1 & 4173 & 59 & 1.41 \\
\hline
\end{tabular}

Tabla 5.4.11. Valencianismos según la variable lengua materna

Como era de esperar, el mayor alcance de los fenómenos de contacto lingüístico recae en el grupo de los valencianohablantes, seguidos de cerca por los bilingües equilibrados, aquellos que tienen como lengua materna tanto el valenciano como el español. De hecho, las diferencias entre estos grupos no son significativas estadísticamente (t.: 0,56; p. 0,58). Por último, los monolingües castellanohablantes aparecen como los menos proclives al empleo de valencianismos, siendo esta vez las diferencias con los valencianohablantes claramente significativas (t.: -3,20; p. 0.05). Tan solo en el campo Ciudad, los alumnos castellanohablantes dan cuenta de un mayor número de valencianismos que sus compañeros. Por el contrario, los valencianohablantes dominantes aventajan a sus compañeros en siete estímulos verbales Alimentos, Mesa, Cocina, Escuela, Campo, Animales y Colores. Y los bilingües 
equilibrados en otros seis: Ropa, Casa, Muebles, Iluminación, Jardín y Juegos. Por otro lado, los representantes de estos dos últimos colectivos comparten la misma densidad en el campo semántico Profesiones.

Ahora bien, tal como ocurría con otros factores analizados más arriba, también aquí los diferentes grupos coinciden en los centros de interés con mayor número de valencianismos, si bien con densidades y rangos de aparición diferentes en cada caso. Este es el caso de los campos más asociados a la vida cotidiana en estas tierras, como Jardín, Cocina, Animales, Alimentos, Mesa, Campo y Juegos.

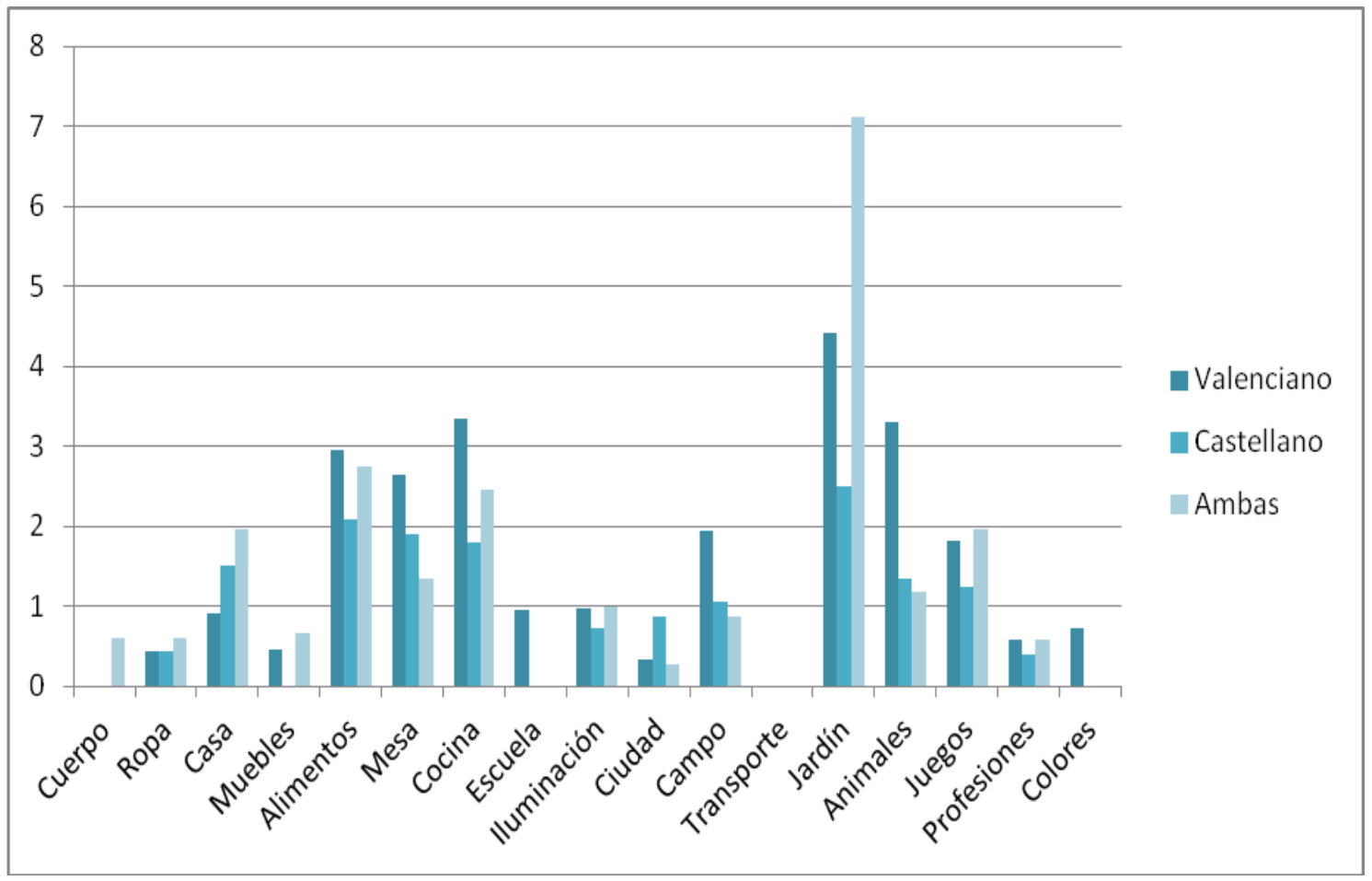

Gráfico 5.4.5. Valencianismos según la variable Lengua materna.

\subsubsection{Nivel educativo}

La tabla 5.4.12 y el gráfico 5.4.6 muestran a continuación los datos relativos a la aparición de valencianismos una vez considerado el nivel educativo de los padres de los alumnos encuestados. Aunque las diferencias globales no son significativas de acuerdo con el análisis de ANOVA de un factor (F.: 0,97; p. 0,41), una comparación de los índices porcentuales globales nos muestra una cierta jerarquización de los resultados en función de ese nivel sociocultural. El grupo social con mayor porcentaje de valencianismos corresponde al grupo de alumnos de Nivel Bajo (1.65\%) seguidos, por 
este orden, por los grupos Medio-bajo (1.24\%), Medio-alto (1.01\%), situándose los estudiantes del nivel Alto $(0.88 \%)$ en la última posición. ${ }^{226}$ Con todo, a la luz de la muestra disponible, las únicas diferencias estadísticamente significativas en virtud del estadístico $t$ de Student para la comparación de muestras emparejadas son las que aparecen entre los grupos extremos, bajos y alto respectivamente (t.: -2,44; p. 0,02).

Por áreas semánticas, el único centro de interés en el que destacan los alumnos del nivel Alto por encima de los demás es el de la Ropa. Por su parte, los alumnos del nivel Medio-bajo sobresalen en los centros de interés Cuerpo y Casa, cifra que todavía es mayor entre sus compañeros del nivel Medio-alto, quienes lo hacen en Muebles, Escuela, Iluminación, Ciudad, Animales y Profesiones. En último lugar, los informantes del nivel Bajo superan al resto en el mayor número de áreas nocionales: Alimentos, Mesa, Cocina, Campo, Jardín, Juegos y Colores.

Cabe señalar, por último, que los grupos que presentan mayor afinidad entre los centros de interés con más valencianismos y que aparecen entre los primeros rangos de los listados son el nivel Medio-bajo y el nivel Bajo, los cuales coinciden en la primera posición del centro Jardín, seguido de Animales, Alimentos, Cocina, Mesa, y Juegos. Este último, por cierto, es el único campo semántico que se sitúa entre los primeros rangos en los cuatro grupos sociales.

\footnotetext{
${ }^{226}$ La misma gradación observa Blas Arroyo (1993) cuando analiza las interferencias de valenciano sobre el castellano al estudiar varios fenómenos gramaticales en el distrito de Campanar de la ciudad de Valencia.
} 


\begin{tabular}{|l|c|c|c|c|c|c|c|c|c|c|c|c|}
\hline & \multicolumn{1}{|c|}{ NIVEL ALTO } & \multicolumn{3}{c|}{$\begin{array}{c}\text { N. MEDIO } \\
\text { ALTO }\end{array}$} & \multicolumn{3}{c|}{ N. MEDIO } & \multicolumn{2}{c|}{ NIVEL BAJO } \\
\hline CI & Voc. & Val. & $\%$ & Voc. & Val. & $\%$ & Voc. & Val. & $\%$ & Voc. & Val. & $\%$ \\
\hline Cuerpo & 138 & 0 & 0 & 174 & 0 & 0 & 188 & 1 & 0.53 & 213 & 0 & 0 \\
\hline Ropa & 139 & 3 & 2.15 & 184 & 0 & 0 & 200 & 0 & 0 & 216 & 1 & 0.46 \\
\hline Casa & 122 & 1 & 0.81 & 142 & 1 & 0.70 & 189 & 4 & 2.11 & 206 & 3 & 1.45 \\
\hline Muebles & 111 & 0 & 0 & 178 & 11 & 6.17 & 176 & 1 & 0.56 & 219 & 1 & 0.45 \\
\hline Alimentos & 239 & 3 & 1.25 & 354 & 3 & 0.84 & 391 & 10 & 2.55 & 439 & 13 & 2.96 \\
\hline Mesa & 105 & 1 & 0.95 & 177 & 3 & 1.69 & 188 & 3 & 1.59 & 216 & 5 & 2.31 \\
\hline Cocina & 176 & 3 & 1.70 & 268 & 2 & 0.74 & 286 & 7 & 2.44 & 340 & 12 & 3.52 \\
\hline Escuela & 196 & 0 & 0 & 301 & 3 & 0.99 & 339 & 0 & 0 & 398 & 2 & 0.50 \\
\hline Iluminación & 119 & 1 & 0.84 & 201 & 4 & 1.99 & 249 & 2 & 0.80 & 283 & 3 & 1.06 \\
\hline Ciudad & 247 & 1 & 0.40 & 442 & 5 & 1.13 & 482 & 0 & 0 & 576 & 3 & 0.52 \\
\hline Campo & 295 & 4 & 2.05 & 513 & 3 & 0.58 & 592 & 5 & 0.84 & 651 & 16 & 2.45 \\
\hline Transporte & 133 & 0 & 0 & 180 & 0 & 0 & 202 & 0 & 0 & 251 & 0 & 0 \\
\hline Jardín & 121 & 1 & 0.82 & 275 & 3 & 1.09 & 359 & 15 & 4.17 & 384 & 20 & 5.20 \\
\hline Animales & 207 & 1 & 0.48 & 257 & 2 & 0.77 & 293 & 10 & 3.41 & 331 & 6 & 1.81 \\
\hline Juegos & 261 & 5 & 1.91 & 461 & 6 & 1.30 & 447 & 5 & 1.11 & 548 & 12 & 2.18 \\
\hline Profesiones & 265 & 0 & 0 & 380 & 3 & 0.78 & 429 & 2 & 0.46 & 497 & 1 & 0.20 \\
\hline Colores & 124 & 0 & 0 & 155 & 0 & 0 & 215 & 0 & 0 & 262 & 2 & 0.76 \\
\hline Total & 2720 & 24 & 0.88 & 4542 & 46 & 1.01 & 5222 & 65 & 1.24 & 6030 & 100 & 1.65 \\
\hline
\end{tabular}

Tabla 5.4.12. Valencianismos según la variable Nivel educativo.

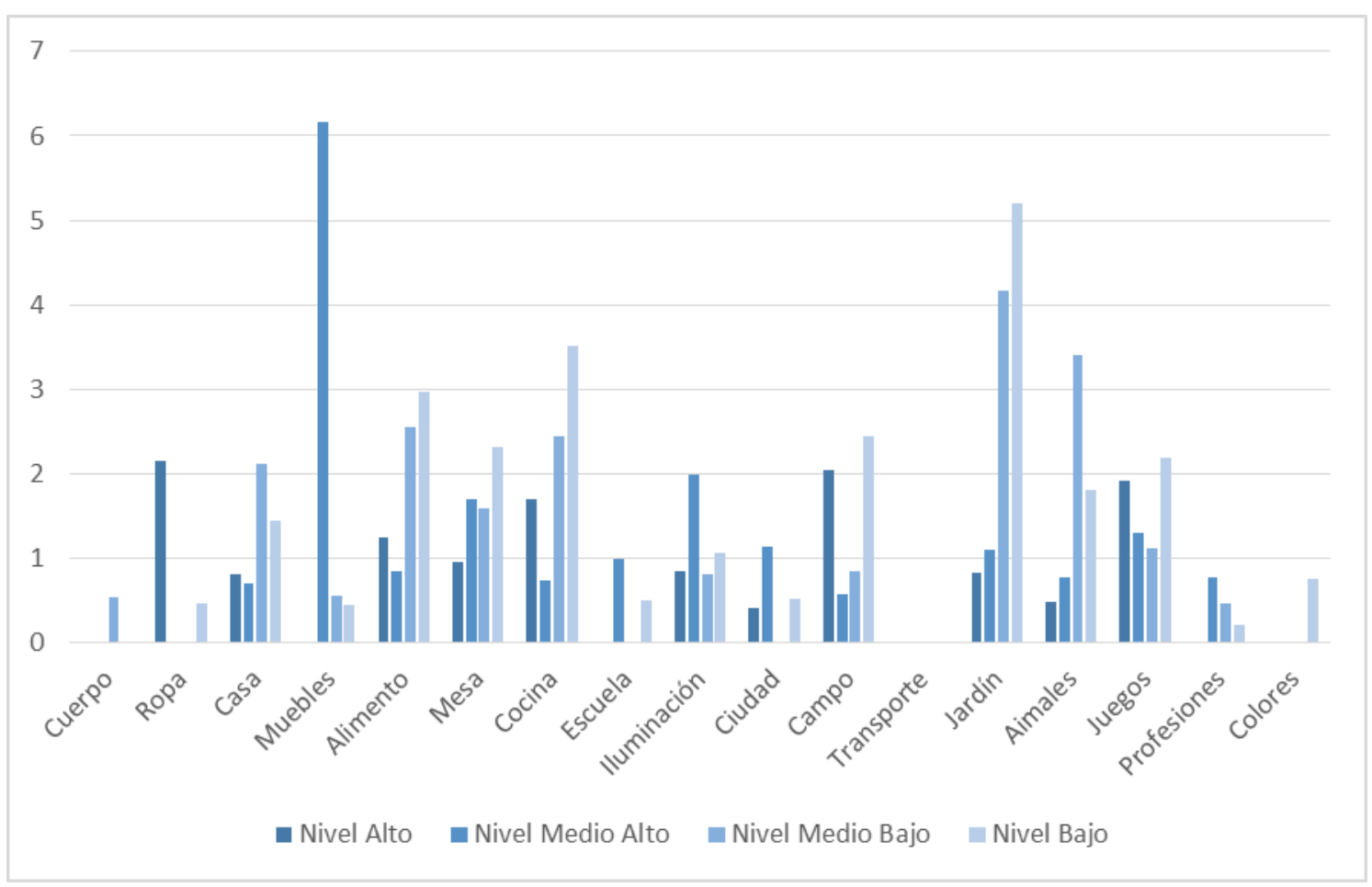

Gráfico 5.4.6. Número de valencianismos según la variable Nivel educativo 
5.4.7. Comparación entre valencianismos y anglicismos en el léxico disponible de Castellón

Hasta ahora hemos estudiado los valencianismos y los anglicismos del léxico disponible de la provincia de Castellón por separado. En el presente apartado compararemos la presencia de unos y otros en la muestra estudiantil castellonense.

En términos generales se observan algunas diferencias cuantitativas reseñables. Como hemos visto, de los 9215 vocablos recogidos en las encuestas, 380 son anglicismos y 142 son valencianismos, lo que representa un porcentaje de $4.12 \%$ y $1.54 \%$ respectivamente. Esto indica una clara mayor incursión de la lengua inglesa en el léxico español de los jóvenes que de la lengua propia de la comunidad.

Si nos fijamos ahora en las cifras por centros de interés, podremos concluir también que las dos lenguas siguen patrones diferentes en cuanto a la proporción de trasferencias. La tabla 5.4.13 nos ofrece los datos del empleo de palabras anglicadas y de procedencia valenciana. De entrada, encontramos una evidente oposición: los centros que mayor número de valencianismos presentan muestran los porcentajes más bajos de anglicismos y a la inversa, aquellas áreas temáticas con mayor incursión de anglicismos, son las que menos transferencias suscitan del valenciano.

Los campos léxicos con mayor número de anglicismos son por orden descendente: Transportes (13.66\%), Juegos (9.69\%) y Ropa (8.65\%), mientras que los que registran mayor número de valencianismos son los de Animales (3.35\%), Alimentos (3.13\%) y Jardín (3.12\%). Si nos ocupamos del primero, Transportes, con 47 anglicismos diferentes, comprobamos el empleo de muchas novedades científicas y tecnológicas que han llegado al español -y a otras muchas lenguas- procedentes del inglés (Boeing, jeep, cross, scooter...), mientras que no localizamos ningún valencianismo en este centro de interés. Lo mismo sucede con la esfera de los Juegos, donde numerosas formas y actividades de ocio en forma de deportes, música o nuevas tecnologías, nos han llegado también en las últimas décadas desde la cultura de habla inglesa (hockey, squash, rafting, windsurf...). Y lo mismo cabe añadir de la esfera de la Ropa (top, panty, body, slip...), cuyas modas siguen en muchos casos el patrón anglosajón. Todo ello alentado por los medios de comunicación (la televisión e Internet, fundamentalmente) y el mercado de consumo. 
Por otro lado, las áreas léxicas cuyo porcentaje es mayor en el empleo de valencianismos, esto es, Animales, Alimentos y Jardín son áreas relacionadas con ámbitos mucho más domésticos, como la esfera familiar o las tareas tradicionalmente vinculadas con el mundo agrícola y rural. En cuanto al primer centro, los lexemas recogidos se refieren sobre todo a los animales autóctonos o más conocidos (mabre, vilero, escorpa). Por lo que se refiere al segundo, Jardín, vinculado a las labores de la tierra, observamos que su posición privilegiada en el terreno de los valencianismos no se corresponde con la de los anglicismos, donde baja hasta la décima posición. Y lo mismo sucede con los Alimentos, especialmente los de raigambre más autóctona, (empedrat, rosquilleta, coca, fuet...), que desde la segunda posición en el ranking de valencianismos desciende al noveno lugar en las series de anglicismos. $\mathrm{O}$ el centro de interés Campo, marcado igualmente por experiencias de la vida campesina y la naturaleza cercanas al informante, cuya posición relativa en valencianismos y anglicismos es bien diferente.

Una de las pocas coincidencias se da en el centro de interés Colores, cuyo rango coincide en ambos listados (en la decimotercera posición). En el resto, no hay coincidencia alguna.

\begin{tabular}{|l|c|c|c|c|c|}
\hline & & \multicolumn{2}{|c|}{ ANGLICISMOS } & \multicolumn{2}{c|}{ VALENCIANISMOS } \\
\hline Centros de interés & $\mathrm{N}^{\text {o }}$ voc. & Voc. & $\%$ & Voc. & $\%$ \\
\hline 1. Partes del cuerpo & 271 & 0 & $0 \%$ & 1 & $0,36 \%$ \\
\hline 2. La ropa & 312 & 27 & $8.65 \%$ & 3 & $0,96 \%$ \\
\hline 3. Partes casa & 307 & 15 & $4.88 \%$ & 5 & $1,62 \%$ \\
\hline 4. Muebles & 303 & 13 & $4.29 \%$ & 1 & $0,33 \%$ \\
\hline 5. Alimentos & 607 & 21 & $3.45 \%$ & 19 & $3.13 \%$ \\
\hline 6. Mesa & 317 & 4 & $1.26 \%$ & 8 & $2,52 \%$ \\
\hline 7. La cocina & 502 & 12 & $2.39 \%$ & 13 & $2,58 \%$ \\
\hline 8. La escuela & 623 & 29 & $4.65 \%$ & 4 & $0,64 \%$ \\
\hline 9. Iluminación & 479 & 16 & $3.34 \%$ & 5 & $1,04 \%$ \\
\hline 10. La ciudad & 949 & 44 & $4.63 \%$ & 7 & $0,73 \%$ \\
\hline 11. El campo & 1060 & 15 & $1.41 \%$ & 19 & $1,79 \%$ \\
\hline 12. Transporte & 344 & 47 & $13.66 \%$ & 0 & 0 \\
\hline 13. Jardín & 704 & 2 & $0.28 \%$ & 22 & $3,12 \%$ \\
\hline 14. Los animales & 447 & 10 & $2.23 \%$ & 15 & $3.35 \%$ \\
\hline 15. Juegos & 908 & 88 & $9.69 \%$ & 15 & $1,65 \%$ \\
\hline 16. Profesiones & 732 & 31 & $4.23 \%$ & 4 & $0,54 \%$ \\
\hline 17. Los colores & 350 & 6 & $1.71 \%$ & 2 & $0,57 \%$ \\
\hline TOTALES & 9.215 & 380 & 4.12 & 142 & $1,54 \%$ \\
\hline
\end{tabular}

Tabla 5.4.13. Comparación en el porcentaje de anglicismos y valencianismos. 
Toda esta información se plasma con claridad en el gráfico siguiente

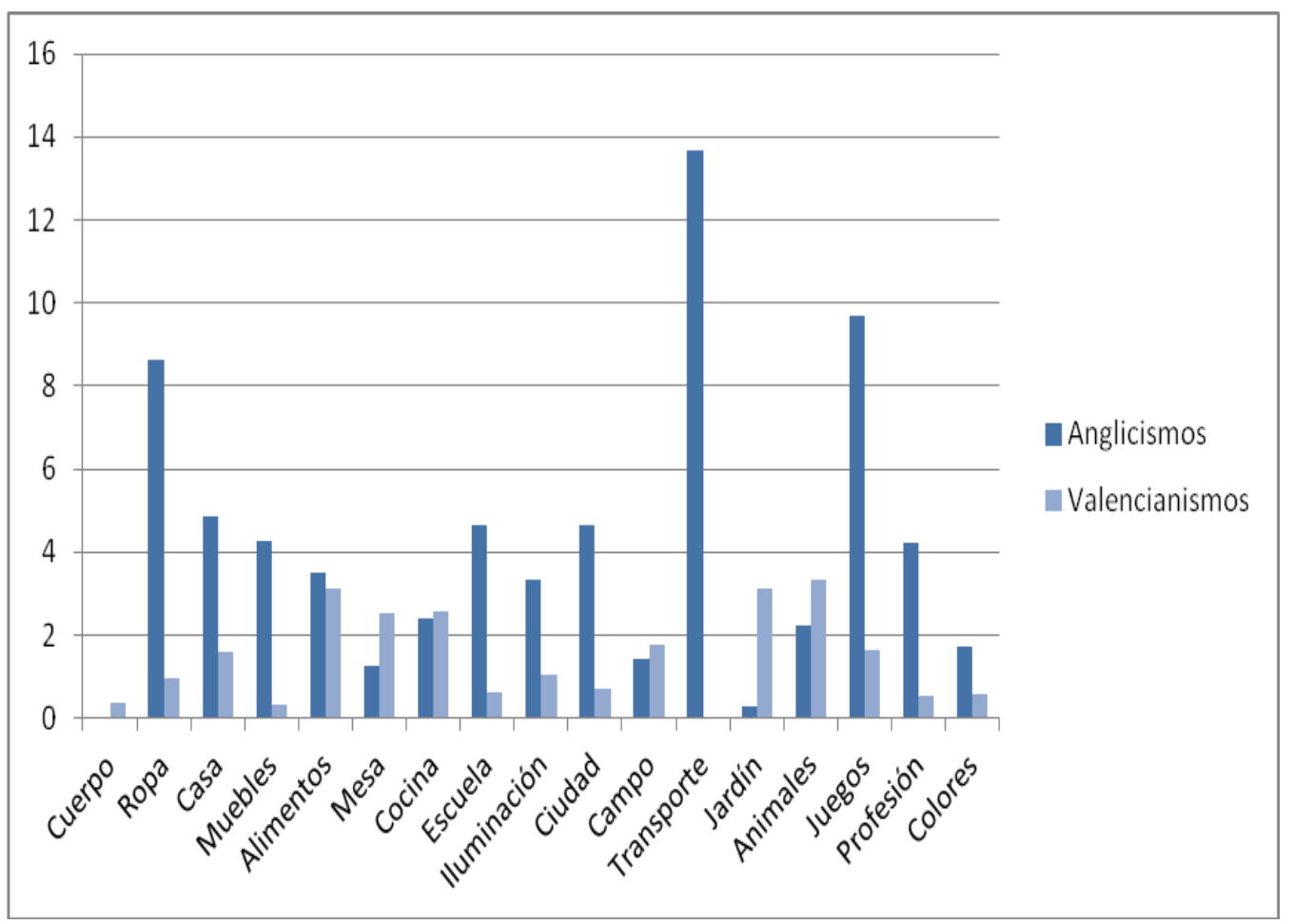

Gráfico 6.4.7. Porcentaje de los anglicismos y los valencianismos

\subsubsection{Conclusiones}

Nuestros resultados coinciden en buena parte con los registrados por W. Mackey (1971) en sus estudios sobre disponibilidad léxica en la región canadiense de la Acadia cuando se interesó por las palabras inglesas utilizadas en las encuestas escritas en francés: el porcentaje de las sustituciones variaba según los centros de interés, y en ninguno de ellos el vocabulario básico francés era sustituido mayoritariamente por el inglés.

Lo mismo podemos afirmar en relación con nuestro estudio: los valencianismos dependen de las áreas léxicas presentadas (predominan en el campo semántico 13. Trabajos del campo y del jardín, 11. El campo, 14. Los animales y 15. Juegos y distracciones), y en pocos casos sustituyen o desplazan a la palabra castellana. La 
mayoría de los vocablos presentan dobletes y la palabra castellana siempre aparece con un índice de disponibilidad mayor.

Cuando el valencianismo supera en disponibilidad a la palabra del castellano o ésta no aparece, podemos considerar este fenómeno como una transferencia léxica o como una sustitución de código, tal como apuntan Gómez Molina y Gómez Devís en su estudio sobre Valencia (2004: 259-269). En algunos casos rastreamos voces autóctonas debidas al entorno cultural de la zona (Fadrí, o Conselleria, que podríamos considerar cómo préstamos culturales), mientras que otras, incluso ya recogidas por el DRAE, como paella, fideuà y fuet, son préstamos totalmente incorporados y asimilados por el castellano. Con todo, a estas cabría añadir otras que, aun no apareciendo a día de hoy en el diccionario académico, se hallan plenamente difundidas en la sociedad castellonense, como pica, mallorquina, rosquilleta, paellero, garrofera o tauleta.

El número de valencianismos no adquiere gran importancia comparado con el número de vocablos y palabras totales. Y menos aún si lo comparamos con el que presentan otros estudios, como el realizado por M. Serrano (2014) en Lérida. Salvo excepciones, el porcentaje de los que encontramos no es alto, como tampoco lo es su índice de disponibilidad, casi siempre menor que el de los correspondiente vocablos castellanos. Asimismo, la mayoría de los valencianismos aparece en posiciones bajas de los listados. De hecho, muchos valencianismos solo son consignados por un informante, como es el caso de brusa 'blusa', mabre 'herrera', empedrat 'guiso con arroz y alubias', got 'vaso'... Otros, en cambio, muestran una recurrencia bastante mayor: (rosquilleta, 21; pica, 21; palmito, 21; caseta, 31; empeltar, 48...).

Pocas palabras han llegado a sustituir a la lexía castellana equivalente; un ejemplo sería el vocablo pica, que tiene un índice de disponibilidad mayor que fregadero y que pila, un resultado también hallado en el léxico disponible de Lérida.

Los centros que presentan mayor número de valencianismos, como ya hemos señalado, son, de mayor a menor: 13. Trabajos del campo y del jardín, (22) seguido de 11. El campo (19), 5. Alimentos y bebidas (20), 14. Los animales (15), 15. Juegos y distracciones (15), 6. Objetos colocados en la mesa para comer (8), 10. La ciudad (7). ${ }^{227}$

En otro orden de cosas, los alumnos cometen faltas de ortografía en valenciano (lo mismo que en castellano), lo que dificulta el reconocimiento de los valencianismos.

${ }^{227}$ Este mismo orden se da también en el estudio sobre Valencia. 
Otro problema añadido es que hay palabras que son exactamente iguales en ambas lenguas. En estos casos, todas las palabras se han marcado como vocablos castellanos, lo que ha podido influir, al menos parcialmente, en el bajo número de valencianismos que encontramos en los listados.

En estos, algunos vocablos adquieren significados específicos, como ocurre con maquinetas, que los alumnos identifican con las máquinas manuales electrónicas (tipo Game boy, Nintendo DS, etc.). Lo mismo sucede con caseta, entendida no como casa pequeña, sino como una especie de chalet en el campo, independientemente de su tamaño; o mallorquina, que designa (además del gentilicio femenino de Mallorca), un embutido originario de esa isla; o escampar fem, para indicar esparcir o diseminar estiércol; etc.

En cuanto a la incidencia de algunas variables sociales, hemos comprobado que, aun por poco, el número de valencianismos es mayor entre los hombres, los estudiantes matriculados en entornos rurales y centros públicos, los alumnos pertenecientes a un nivel sociocultural familiar bajo, y, como cabía esperar, los hablantes que tienen el valenciano como lengua materna y dominante.

Por último, en la comparación con los anglicismos, hemos visto cómo los centros de interés con mayor presencia de unos y otros muestran una especie de distribución complementaria. Así, mientras que el hablante tipo que presenta más interferencias procedentes del valenciano es el procedente de un estrato social bajo, estudiante de un centro público ubicado en una zona rural y cuya lengua materna es el valenciano, el estudiante que registra un mayor uso de anglicismos es el bilingüe equilibrado, matriculado en un centro privado y urbano, y perteneciente a un entorno familiar de nivel alto. 
6

\section{CONCLUSIONES}





\section{CONCLUSIONES}

Con este capítulo llegamos a las reflexiones finales, el momento de sintetizar e integrar los principales resultados obtenidos a lo largo del trabajo.

Iniciamos este apartado recordando que la metodología seguida ha sido la común a la mayoría de investigaciones que se inscriben en el Proyecto Panhispánico para el estudio de la disponibilidad léxica del español. Con esta se ha pretendido describir la variedad estándar del castellano de la provincia de Castellón, establecer la covariación entre ciertas variables lingüísticas (los centros de interés) y algunos factores sociales relevantes (sexo, ubicación y tipo de centro, lengua materna y nivel educativo familiar de los alumnos) y contrastar nuestros resultados con los de otros estudios similares.

El principal objetivo propuesto al iniciar este trabajo, que, recordemos, consistía en delimitar el léxico disponible del castellano de los estudiantes preuniversitarios castellonenses, se ha cumplido satisfactoriamente, con la obtención de un diccionario en el que aparece el repertorio de palabras actualizadas por los informantes a través de las pruebas asociativas empleadas en los diecisiete centros de interés previstos. Otros objetivos, más específicos, se resumen a continuación.

\subsection{Resultados cuantitativos}

En total, se han recogido 121.792 palabras, de las cuales 9.215 son vocablos o palabras diferentes, lo que supone un promedio de palabras por estudiante de $26.03 \%$. El orden de los centros de interés, según el rango de los índices estadísticos mencionados, queda de la siguiente manera:

a) Número total de palabras, relacionados por orden descendente: Animal, Alimentos, Cuerpo, Ciudad, Escuela, Profesión, Ropa, Campo, Color, Juegos, Transporte, Cocina, Partes de la casa, Mesa, Muebles, Iluminación y, por último, Jardin.

b) Número de vocablos (de mayor a menor número de palabras diferentes): Campo, ciudad, Juegos, Profesión, Jardín, Escuela, Alimentos, Cocina, Iluminación, Animales, Colores, Transportes, mesa, Ropa, Partes de la casa, Muebles y Cuerpo.

c) Promedios de respuestas por informante (ordenados también de forma decreciente): Animal, Alimentos, Cuerpo, Ciudad, Escuela, Profesión, Ropa, Campo, 
Color, Juegos, Transporte, Cocina, Partes de la casa, Mesa, Muebles, Iluminación y, por último, Jardín.

Advertimos que el orden de los centros de interés coincide cuando contrastamos el número total de palabras y el porcentaje de estas por informante. Sin embargo, esto no ocurre cuando los comparamos con el número de vocablos diferentes, cuya disposición es notablemente distinta.

Asimismo, se constata una considerable dispersión en la productividad léxica de los informantes castellonenses, ya que encontramos centros de interés con muchas respuestas (Animal, Alimentos, Cuerpo) y, en cambio, otras áreas semánticas con una riqueza significativamente menor (Jardín, Iluminación, Muebles). Por otro lado, se observa que la producción de unidades léxicas depende más de la composición interna de cada área nocional que de otros factores, es decir, la mayor o menor productividad léxica obedece fundamentalmente al ámbito de la realidad por la que se pregunta.

En algunos casos, las cifras bajas en determinados campos semánticos se hallan en relación con el hecho de tratarse de realidades un tanto alejadas de los intereses de los alumnos, como sucede con las Tareas del campo y del jardín, al tiempo que en otros (como sucede, por ejemplo, con los Muebles), una vez que los estudiantes han enunciado el mobiliario más común en sus casas, parecen desentenderse de otras posibilidades adicionales. Tampoco podemos desdeñar la influencia del sistema educativo en la adquisición y, por tanto, extensión, de vocablos en ciertas áreas semánticas estrechamente vinculadas con el currículo escolar, como ocurre con las Partes del cuerpo o los Animales, que aparecen en los primeros puestos de los listados. Así pues, las hipótesis iniciales, aquellas que apuntaban a que el mayor o menor número de unidades léxicas dependerá de la singularidad de los campos semánticos propuestos y del conocimiento (tanto académico como basado en la experiencia individual) de los alumnos, quedan confirmadas.

Por otro lado, estas hipótesis se ven corroboradas estadísticamente a través del promedio de respuestas de los estudiantes castellonenses, cuyo término medio se sitúa en 20 palabras por informante aproximadamente, aunque la dispersión entre los primeros centros de interés (Animales, 28.39; Alimentos, 26.58; Cuerpo, 25.84) y los últimos (Muebles, 14.53; Iluminación, 13.21; Jardín, 11) es, como se puede apreciar, muy grande.

Otro dato relevante para evaluar el léxico disponible de una comunidad es el que nos proporciona el índice de cohesión. Este nos indica el carácter de los centros, es 
decir, qué áreas léxicas son más bien cerradas o compactas -cuando todos los informantes han ofrecido similares respuestas- o, por el contrario, qué centros son prototípicamente abiertos o dispersos -cuando las respuestas son mucho más variadas y presentan un mayor número de asociaciones secundarias. En consecuencia, el índice de cohesión permite establecer las tendencias del léxico de una comunidad de habla al permitirnos ver en qué medida convergen o no las contestaciones de los alumnos según los estímulos verbales.

Según este parámetro, los centros de interés pueden agruparse en Castellón en tres grandes grupos:

a) Las áreas semánticas que ofrecen un nivel de cohesión más elevado, es decir, aquellas que presentan un mayor número de respuestas coincidentes, son, por este orden: Partes del cuerpo (0.0953), Ropa (0.0733), Animales (0.0635).

b) En una zona intermedia, cuyo índice oscila entre el 0.04 y 0.05 , se hallan los campos léxicos Colores (0.0567), Transporte (0.0560), Partes de la casa (0.0543), Muebles (0.0479), Mesa (0.0470) y Alimentos (0.0437).

c) Finalmente, en los últimos lugares aparecen algunas áreas semánticas que presentan un carácter más abierto y difuso, pues muestran un alto grado de diversificación en las respuestas de los informantes. Es el caso de Jardín (0.0160), Campo (0.0199), Juegos (0.0214), Ciudad (0.0260), Iluminación (0.0275), Profesión (0.0312), Cocina (0.0372) y Escuela (0.0380).

Como cabía esperar, existe una relación proporcionalmente inversa entre el número de vocablos y el índice de cohesión: cuánto más alto es el número de aquellos, menor es el índice de cohesión (y viceversa). Por ejemplo, el centro El campo, con 1060 palabras diferentes, obtiene un índice de cohesión de apenas 0.0199. Por el contrario, aquellas áreas temáticas con menor número de palabras diferentes alcanzan un índice de cohesión mayor, como ocurre con Cuerpo, que dispone de tan solo 271 vocablos, pero cosecha el índice de cohesión más alto (0.0953) entre los estudiantes castellonenses.

En el apartado contrastivo de la investigación, hemos cotejado los datos de Castellón con los recogidos en otras zonas bilingües (Valencia, Alicante, Lérida, Galicia y Bilbao), por medio del número de palabras por sujeto, el índice más apropiado para el cotejo interdialectal, puesto que no se ve afectado por variaciones debidas al número de individuos en cada muestra o la presencia de respuestas atípicas. Nuestra pretensión ha sido comprobar cómo se comportan los estudiantes de estas regiones en cuanto a la disponibilidad léxica se refiere, y si alguna de estas comunidades destaca sobre las 
demás en algunos índices particulares. Los datos de los promedios de respuestas en las distintas zonas geográficas nos permiten establecer diversos conjuntos entre los diferentes estímulos verbales:

a) Centros de interés con promedios que oscilan entre 24 y 29 palabras: Cuerpo, Alimento y Animales,

b) Centros de interés que superan la media de 20 respuestas: Escuela, Profesiones, Ropa, Campo, Colores.

c) Campos semánticos que no suelen alcanzar esa media de respuestas por informante: Muebles, Mesa, Partes de la casa, Cocina, Transporte.

d) Áreas semánticas que nunca sobrepasan esa media: Iluminación o Jardín.

La principal conclusión que se deriva de este cotejo es que las áreas semánticas más productivas en los estudios analizados son siempre las mismas: Animales, Alimentos y Partes del Cuerpo. Y lo mismo sucede con aquellas que presentan los índices más bajos de producción: Iluminación y Jardín. Entre ambas hay una zona intermedia, en la que se distribuyen los demás campos léxicos, con ligeras variaciones en las cifras de palabras por informante $y$, por tanto, con pequeñas oscilaciones en el rango de las áreas nocionales.

En definitiva, se manifiesta una tendencia de agrupación de los centros de interés en las distintas investigaciones, lo que indica ciertos patrones comunes de comportamiento léxico en las comunidades bilingües comparadas.

Respecto a los índices cuantitativos que arroja el promedio de respuestas por informantes, la provincia de Castellón (20.23) se sitúa ligeramente por encima del promedio global de las regiones bilingües analizadas en el presente estudio (19.85), entre Galicia (21.26) con el mayor porcentaje y Lérida (17.90), que puntúa más nítidamente por debajo de la media.

Por lo demás, estos resultados no difieren tampoco de los ofrecidos en áreas monolingües. Castellón se sitúa también aquí en una posición intermedia, entre los extremos representados por Soria (21.31), provincia con mayor disponibilidad léxica global, y Cantabria, que con un índice de 18.50, es la que obtiene un valor general más bajo entre las catorce zonas geográficas cotejadas en el estudio.

En suma, el carácter bilingüe o monolingüe de una comunidad no parece determinante en los resultados obtenidos por la productividad léxica de sus estudiantes. Por encima de este se sitúan otros factores sociales. 
Por lo que se refiere al índice de cohesión, advertimos también coincidencias entre los diferentes léxicos disponibles cotejados, con escasas variaciones en el rango de este valor en los respectivos estímulos verbales. Al igual que en otras comunidades, hallamos en los últimos lugares de los listados los centros más difusos o abiertos: Jardín, Juegos, Campo y Ciudad. E, igualmente, en los primeros puestos encontramos las áreas léxicas más compactas: Cuerpo, Ropa, Animales y Colores, centros de interés que presentan una mayor delimitación cognitiva y cultural desde un punto de vista semántico. Esto muestra que, si bien hay diferencias cuantitativas en la producción léxica de los estudiantes, existe una importante afinidad en la cohesión interna de los centros de interés.

En definitiva, estos datos contrastivos revelan "una distribución semejante de la cuantía léxica actualizada en los diferentes centros de interés" (Hernández Muñoz, 2006: 318), y una estructura del léxico relativamente común, que subyace a las eventuales diferencias dialectales.

\subsection{Variables sociales}

Como se recordará, otro de los objetivos planteados en esta investigación era descubrir la eventual repercusión de diversos factores sociales en el inventario léxico castellonense. Este propósito se ha alcanzado mediante el análisis de la covariación entre las variables lingüísticas (centros de interés) y cinco factores extralingüísticos (sexo, ubicación del centro, titularidad del centro, lengua materna y nivel educativo de las familias), cuyos principales resultados resumimos a continuación.

\subsubsection{Sexo}

La diferencia global entre los representantes de ambos sexos es de casi un punto a favor de las mujeres. Se trata de diferencias globalmente significativas de acuerdo con la prueba t para la comparación entre muestras independientes, que hemos utilizado, junto con la ANOVA de un factor, como principal prueba estadística inferencial en este trabajo. Por otro lado, las féminas aventajan a los hombres en once estímulos verbales y lo hacen, además, con índices mayores que en el sentido contrario. Así ocurre, por ejemplo, en la Ropa, Alimentos, Cocina, Escuela, Colores, Muebles o Profesiones. Por su parte, los chicos superan a las chicas por diferencias significativamente menores en Cuerpo, Casa, Iluminación, Ciudad, Transporte y Jardín. Así pues, la hipótesis 
referente al sexo, esto es, que las estudiantes obtendrán promedios de respuestas superiores a los de sus compañeros masculinos, queda corroborada tras el análisis.

Por otro lado, desde un punto de vista cualitativo, llaman también la atención las conexiones que parecen establecerse aún en la sociedad castellonense entre el sexo y ciertas temáticas, mediatizadas probablemente por los roles que la sociedad confiere todavía a las mujeres (y los hombres) en la actualidad. Así, observamos los estereotipos sociales de la mujer asociados con esferas como la moda y la cocina, así como, en el caso masculino, con la mayor disponibilidad de términos vinculados a automóviles y otros vehículos de locomoción -y diversión-, así como a los trabajos del campo.

En relación con el grado de homogeneidad en las respuestas, las chicas presentan mayor afinidad en seis categorías semánticas (Cuerpo, Alimentos, Transporte, Jardín, Animales y Colores), mientras que los jóvenes de sexo masculino solo lo hacen en dos centros (Ropa y Muebles). Con todo, estas diferencias no se han revelado esta vez significativas.

En suma, las estudiantes castellonenses exhiben un léxico disponible significativamente mayor, pero no necesariamente más cohesionado que sus compañeros del sexo contrario.

\subsubsection{Ubicación del centro}

En nuestra investigación hemos considerado como urbanos únicamente los centros educativos ubicados en la capital de la provincia (Castellón de la Plana), y como rurales los emplazados en el resto de poblaciones. En los promedios de respuestas por informantes, son los estudiantes de los centros urbanos los que, globalmente, aventajan a sus compañeros de los colegios rurales, con diferencias que son estadísticamente significativas. Esta ventaja se aprecia, además, en 14 de los 17 campos asociativos de que consta el estudio. Tan solo en tres áreas léxicas: Campo, Animales (áreas temáticas ligadas al ámbito rural) y Colores, los alumnos de institutos y colegios rurales superan a los alumnos urbanos. Con todo, ninguna de estas diferencias es significativa a la luz de la muestra disponible, a diferencia de lo que ocurre con los centros de interés donde los alumnos de centros urbanos puntúan por encima. De esta manera, la hipótesis 5, referente a la ubicación del centro educativo, también queda confirmada con los datos expuestos.

Al analizar el índice de cohesión, observamos cómo los alumnos de centros urbanos van siempre por encima respecto a los estudiantes rurales en cuanto al grado de 
congruencia de los respectivos léxicos disponibles. Estas diferencias son significativas, tanto globalmente como en el contraste entre los diferentes centros de interés. En efecto, los estudiantes de Castellón de la Plana superan en 15 de las 17 áreas temáticas a sus compañeros de centros rurales, mientras que se produce un empate en La cocina y El campo. Así pues, se constata una mayor convergencia asociativa en los alumnos que estudian en centros urbanos, cuyo vocabulario disponible aparece más cohesionado que en el rural.

\subsubsection{Tipo de centro}

De forma contraria a la mayoría de los estudios de la disponibilidad léxica, en Castellón los alumnos de centros públicos obtienen un promedio de respuestas (20.80) mayor que los estudiantes de centros privados (19.62), diferencias avaladas también estadísticamente. Además, los alumnos de los institutos públicos aventajan a sus compañeros de centros privados en 15 campos semánticos. Solo en dos estímulos verbales superan los estudiantes de colegios privados a los correspondientes de centros públicos en el número de unidades léxicas: Partes del cuerpo y Partes de la casa, pero con distancias mínimas y no significativas estadísticamente. Estos resultados, divergentes con lo encontrado en otras comunidades de habla, podrían explicarse quizá por algunas peculiaridades de la provincia de Castellón en el plano sociocultural, especialmente en lo que concierne a la elección de centro escolar por parte de las familias. Castellón es una provincia pequeña en la que, tradicionalmente, la distribución del alumnado entre colegios públicos y privados -muchos de ellos concertados- está bastante menos ligada al poder adquisitivo de las familias, y sí a otras consideraciones religiosas, sociales, culturales, etc. De ahí que, en los dos tipos de centros encontramos alumnado de distinta procedencia social: desde los hijos de las clases acomodadas a aquellos que proceden de clases medias-bajas.

Sin embargo, en lo referente al grado de cohesión de las respuestas, son esta vez los alumnos de centros privados quienes muestran un lexicón más congruente $(0,07)$ que los de colegios públicos $(0,05)$, con diferencias igualmente significativas. Con todo, estas son particularmente destacadas en algunos centros de interés, como Partes del cuerpo, La ropa y Medios de transporte. En los demás campos léxicos las diferencias son menores.

No obstante, ambos grupos coinciden en las áreas nocionales más compactas o cerradas (El cuerpo, La ropa, La casa, Animales y Los colores) y en las más abiertas a 
asociaciones secundarias o difusas (El campo, La ciudad, El jardín o Los juegos). Por lo tanto, a pesar de las divergencias, ambos grupos sociales actúan de la misma forma y tienen el mismo carácter (abierto o cerrado) en las diecisiete áreas léxicas.

Todo lo argumentado nos permite comprobar, por tanto, que la hipótesis 4 referida a la ubicación del centro escolar no se ha visto confirmada en la provincia de Castellón.

\subsubsection{Lengua materna.}

La influencia de la lengua materna de los estudiantes está íntimamente ligada al bilingüismo social e individual que encontramos en la provincia de Castellón, lo que nos ha permitido dividir la muestra en tres grupos con desigual distribución en el número de representantes: a) castellanohablantes, aquellos que tienen como lengua materna y dominante el castellano (39\%); b) valencianohablantes, con el valenciano como lengua principal desde la infancia (45\%); y c) bilingües equilibrados, aquellos en los que, por razones diversas (hijos de matrimonios mixtos, etc.) el dominio y uso de una y otra lengua se da al mismo nivel desde los primeros años de vida (16\%).

Los bilingües equilibrados aparecen en esta investigación como los informantes con una mayor disponibilidad léxica, seguidos por los castellanohablantes. Cierran la relación los valencianohablantes, quienes, como cabía esperar, ocupan la última posición. Sin embargo, hay que destacar que la competencia léxica no se ve disminuida necesariamente en las situaciones de bilingüismo individual, siempre que este se halle suficientemente equilibrado. De ahí que, al menos en el presente estudio, los representantes de este último grupo (bilingües equilibrados) hayan adelantado incluso a los castellanohablantes exclusivos. De hecho, los bilingües equilibrados superan a sus compañeros en todos los centros de interés, excepto en el primero, Partes del cuerpo, donde aparecen en primer lugar quienes tienen el castellano como lengua materna y dominante. Complementariamente, los castellanohablantes obtienen mejores resultados que los valencianohablantes en todas las áreas nocionales, a excepción de Trabajos del campo y del Jardín. Todas estas diferencias globales entre los grupos son significativas de nuevo de acuerdo con las pruebas de asociación estadística.

Al mismo tiempo, los bilingües equilibrados presentan mayores índices de cohesión, esto es, un vocabulario más congruente. A estos les siguen los estudiantes de lengua materna castellana y cierran de nuevo la lista los alumnos valencianohablantes. 
También en esta ocasión, las diferencias son significativas en todas las comparaciones posibles.

En el estudio de los preuniversitarios castellonenses la variable lengua materna se manifiesta como una de las más significativas de todo el estudio. Aunque las diferencias entre los grupos no sean grandes, hemos comprobado que existe una gradación idéntica tanto en los índices de disponibilidad como en los de cohesión léxica. Y la primera posición no es la ocupada, como podría esperarse en un principio, por los castellanohablantes, sino por aquellos que desde su infancia han utilizado indistintamente esta lengua y el catalán; por lo tanto, la hipótesis 6 queda parcialmente descartada.

\subsubsection{Nivel educativo.}

El nivel sociocultural se ha mostrado habitualmente como unos de los más significativos en los estudios de sociolingüística en general, y en los de disponibilidad léxica en particular. También en esta investigación se ha analizado este factor, que únicamente ha tenido en cuenta el nivel académico de los padres de los alumnos, a partir del cual hemos dividido la muestra en cuatro grupos, con diferente nivel de representación: a) nivel alto $(8 \%)$, b) nivel medio-alto $(23 \%)$; c) nivel medio-bajo (28\%); y d) nivel bajo (41\%).

Los índices totales indican que los alumnos que mayor disponibilidad obtienen son los que se engloban en el nivel medio-alto (20.55 palabras por informante), seguidos de cerca por el nivel alto (20.39), el nivel medio-bajo (20.38) y, en último lugar, los estudiantes del nivel bajo (19.86). Las diferencias que mantienen los tres primeros grupos entre sí no resultan estadísticamente significativas, ni en términos globales ni por centros de interés; sin embargo, sí lo son las que se establecen entre esos tres grupos y el nivel bajo, lo que confirma que se trata de los alumnos con un léxico disponible levemente más limitado que el resto de la pirámide social.

Si nos fijamos en los centros de interés, el nivel alto destaca en: Partes de la casa, La cocina, Campo, Jardín, Juegos y Colores; el nivel medio-alto en: Partes del cuerpo, Ropa, Alimentos, Escuela, Ciudad y Profesiones; el nivel medio-bajo en: Muebles, Mesa, Iluminación y Animales y, por último, el estrato bajo solo sobresale en Transportes. Sin embargo, las diferencias entre unos grupos y otros son también aquí limitadas. 
Finalmente, el índice de cohesión muestra una gradación perfecta en consonancia con la asociada a la pirámide social: el nivel alto presenta la mayor convergencia asociativa (0.12), seguido por el nivel medio-alto (0.08), el medio-bajo (0.7) y, en último lugar, el estrato bajo (0.06). Además, esta vez las comparaciones entre los grupos son todas estadísticamente significativas, lo que demuestra que conforme descendemos en el nivel sociocultural familiar de los estudiantes castellonenses, la cohesión del léxico disponible se debilita; y al revés, conforme mayor es ese nivel, mayores son también la congruencia y homogeneidad del vocabulario compartido.

En definitiva, entre los preuniversitarios de Castellón, la variable social correspondiente al nivel educativo familiar se mantiene como un factor que condiciona la distribución sociolingüística del léxico disponible. Existe una evidente relación entre la productividad y cohesión de este vocabulario, por un lado, y el nivel educativo de las familias, por otro. Los mayores contrastes se manifiestan entre el nivel bajo y el resto en la riqueza léxica, pero existe una asociación directa entre la estratificación social y la cohesión de ese léxico disponible, que aumenta conforme ascendemos de estrato social.

En consecuencia, la hipótesis 7 se ve verificada parcialmente, puesto que no han sido los alumnos del nivel alto quienes más palabras han aportado, sino los del nivel medio-alto, aunque las diferencias sean mínimas y no estadísticamente significativas. Con todo, la que se sí se ha visto confirmada es la posición más baja de los representantes del nivel bajo, tal como cabía esperar. Por otro lado, se cumple también la cadena establecida de antemano por lo que a la congruencia léxica se refiere: nivel alto $\rightarrow$ nivel medio alto $\rightarrow$ nivel medio bajo $\rightarrow$ nivel bajo.

\subsection{Anglicismos}

El número de anglicismos registrado en el Léxico disponible de Castellón es bajo en términos relativos, esto es, en relación con el conjunto del lexicón, al haber alcanzado la cifra de 380 vocablos, lo que representa apenas un $4.12 \%$ del total. La presencia de las palabras de procedencia inglesa viene motivada principalmente por el carácter temático de los centros de interés, lo que genera notables diferencias entre unos y otros. Así, aquellos campos semánticos abiertos a asociaciones significativas secundarias favorecen la entrada de anglicismos, frente a otros que por su carácter cerrado dificultan esa entrada. Según el porcentaje de anglicismos, los hemos dividido en cinco grupos:

a) Centros con alta incorporación de anglicismos: Juegos, Transportes y Ropa. 
b) Centros con un porcentaje medio de anglicismos: Ciudad, Escuela: muebles y materiales, Alimentos y bebidas, Profesiones, Muebles de la casa y Partes de la casa.

c) Centros con baja penetración de anglicismos: La cocina y sus utensilios, Iluminación, calefacción y medios para airear un recinto y Animales.

d) Centros con muy poca presencia de anglicismos: Objetos colocados en la mesa para la comida, Trabajos del campo y del jardín, El campo y Colores.

e) Finalmente, contamos con un centro de interés, el de las Partes de cuerpo, donde no hemos registrado ningún anglicismo.

Desde el punto de vista lingüístico, algunos anglicismos se encuentran completamente adaptados al español (fútbol, pijama, club, bote...) mientras que otros no lo están, a pesar de su empleo mayoritario (hall, short, camping...).

En lo referente a la incidencia de las variables sociales, no se aprecian diferencias significativas en la covariación entre el léxico disponible y el sexo, así como con la ubicación y la titularidad del centro educativo. Sin embargo, en la interacción entre estas variables, hemos podido comprobar que puntúan por encima los alumnos masculinos de centros urbanos y privados. Asimismo, hay una presencia algo mayor de anglicismos en los estudiantes bilingües equilibrados, quienes también aquí se sitúan por encima de castellanohablantes y valencianohablantes; por el contrario, las diferencias entre estos dos grupos no son significativas. Por último, el factor nivel educativo familiar arroja diferencias que superan el umbral de significación estadística entre los grupos extremos, esto es, entre los alumnos que pertenecen a un nivel alto y los que se adscriben al nivel más bajo.

En consecuencia, podemos decir que los alumnos que presentan un mayor empleo de palabras de procedencia inglesa se definen como: estudiantes masculinos, bilingües equilibrados, que estudian en centros urbanos y privados, y que pertenecen a un nivel educativo familiar alto. Por ello concluimos que la hipótesis 8 relacionada con la presencia y repercusión de los anglicismos en el léxico disponible de los preuniversitarios castellonenses queda confirmada en relación al tipo de centro, la zona de ubicación del centro y el nivel sociocultural. De igual modo, se verifica que la mayor o menor presencia de anglicismos viene determinada por el contenido referencial de las diversas áreas temáticas. 


\subsection{Valencianismos}

Un $74 \%$ del total del alumnado castellonense ha usado en alguna respuesta el valenciano. El número de términos de esta procedencia se eleva a 144 (un $1.56 \%$ del total). Asimismo, el promedio de transferencias en cada centro de interés se sitúa en 8,47 valencianismos. Cifras todas ellas muy bajas (menores que las de los anglicismos), y que revelan una escasa incidencia de estos términos en el léxico disponible de Castellón.

Al igual que las palabras de procedencia inglesa, la presencia de valencianismos depende también de los centros de interés implicados. Así, predominan en los campos semánticos más relacionados con la vida cotidiana, como Jardín, El Campo, Animales y Juegos y distracciones. No obstante, en pocos casos estos valencianismos llegan a sustituir a la correspondiente palabra en castellano, que presentan casi siempre un mayor índice de disponibilidad. Igualmente, los valencianismos aparecen en posiciones bajas de los listados. A veces son términos que aparecen una sola vez, como es el caso de brusa 'blusa', mabre 'herrera', empedrat 'guiso con arroz y alubias', got 'vaso', etc. En cambio, otros muestran una recurrencia significativamente mayor, lo que revela un mayor uso social, como rosquilleta o empeltar, entre otros. Finalmente, cabe resaltar que los vocablos valencianos adquieren en ocasiones un significado diferente al de sus equivalentes castellanos, como ocurre con la palabra mallorquina, que (además de otros sentidos) sirve para designar en esta comunidad un embutido originario de la isla de Mallorca.

Teniendo en cuenta la presencia de valencianismos en los centros de interés, podemos establecer cuatro grupos:

a) centros con mayor incidencia de términos valencianos: Jardín (22), Alimentos (20), Campo (19), Juegos (15), Animales (15) y La cocina (13 vocablos);

b) centros con una incidencia escasa: Mesa (8), La ciudad (7), Iluminación (5), Casa (5), Profesión (4) y Ropa (4);

c) centros con un número muy reducido de valencianismos: Colores (2), Muebles (1) y Cuerpo (1).

d) al igual que veíamos a propósito de los anglicismos, en esta ocasión encontramos también un centro de interés, el de Transportes, donde no hallamos ningún valencianismo.

En cuanto a la clasificación de los fenómenos de contacto lingüístico que se derivan del léxico disponible, los datos de Castellón pueden ser clasificados en los 
siguientes tipos: a) dobletes, cuando el índice de disponibilidad del término español es mayor que el correspondiente valenciano, lo que sucede en la mayoría de los casos (camiseta-samarreta, alpargata-espardenya, aceitera-setril d'oli...); b) préstamos consolidados, es decir, aquellos que están lingüística y socialmente integrados (paellero, rosquilleta, casal...); c) préstamos no integrados, aquellos vocablos con una clara forma valenciana, y que, por lo general, no están adaptados lingüísticamente al español, al tiempo que su frecuencia de uso es significativamente menor que la de los préstamos consolidados (fogassa, empedrat, mabra...); y d) compuestos híbridos (mazo de allioli, pollo a l'ast, hacer soquetes...).

En referencia a las variables sociales, hemos comprobado que, aunque por poco, el número de valencianismos es mayor entre los hombres, los estudiantes matriculados en entornos rurales, centros públicos y pertenecientes a un nivel sociocultural familiar bajo. Por otro lado, y, como cabía esperar, esa frecuencia se incrementa entre los hablantes que tienen el valenciano como lengua materna y dominante. Observamos que a mayor competencia bilingüe del informante, el número de transferencias del valenciano sobre el castellano es mayor, sobre todo en aquellas áreas temáticas cercanas a los entornos domésticos y familiares. Todo ello corrobora la hipótesis 9, que hacía referencia a que los valencianismos serían mayoritarios entre los valencianohablantes. Asimismo, la hipótesis 10, relativa a que la presencia de fenómenos de contacto lingüístico variaría en función de los centros de interés, se ha visto también confirmada.

Por último, cuando comparamos la presencia de valencianismos y anglicismos se observa que tanto los centros de interés como el tipo de informante muestran una distribución complementaria. De esta manera, mientras que el hablante tipo que presenta más interferencias procedentes del valenciano es el proveniente de un estrato social bajo, estudiante de un centro público ubicado en una zona rural y cuya lengua materna es el valenciano, el estudiante que registra un mayor uso de anglicismos es el bilingüe equilibrado, matriculado en un centro privado y urbano, y perteneciente a un entorno familiar de nivel alto.

Sin duda, los datos expuestos muestran solo una parte de las diversas posibilidades de análisis que se pueden obtener tras la vasta información que aporta el léxico disponible de los castellonenses. Aunque sin descuidar el estudio cualitativo, en estas páginas hemos privilegiado un análisis de índole cuantitativa, por lo que otros 
aspectos quedan aparcados para futuros trabajos. Así ocurre, por ejemplo, con el estudio sobre la convergencia léxica entre las veinte, cincuenta o cien palabras y su relación con los factores sociales, la ampliación a otros extranjerismos al margen de anglicismos, la descripción y análisis del lexicón mental, las asociaciones y redes semánticas, el léxico prototípico, los aspectos psicolingüísticos y etnolingüísticos más relevantes.... Quedan, pues, muchos datos que aprovechar y muchos campos y vías por explorar. Pero esto lo dejaremos para una ocasión futura. 


\section{REFERENCIAS BIBLIOGRÁFICAS}





\section{REFERENCIAS BIBLIOGRÁFICAS}

Alba, Orlando (1995a): Léxico disponible de la República Dominicana, Santiago de los Caballeros, Pontificia Universidad Católica "Madre y Maestra".

_ (1995b): "Disponibilidad léxica en el español dominicano: análisis cuantitativo" en RodríGuez-FonseCA, L. E I. VÁZQuez (eds.): Actas del III Seminario Internacional sobre Aportes de la lingüística a la enseñanza de la lengua materna, Revista de Adquisición de la Lengua Española, 353-365.

_ (1995c): “Anglicismos léxicos en el español dominicano: análisis cuantitativo" en AlbA, O.: El español dominicano dentro del contexto americano, Santo Domingo, Librería La Trinitaria, 11-38.

_ (1996): "Disponibilidad léxica en el español dominicano. Aspectos sociolingüísticos" en ARJONA IGLESIAS, MARINA et al. (eds.): Actas del X Congreso Internacional de ALFAL, México, UNAM, 742-749.

- (1998): "Variable léxica y dialectología hispánica", La torre, Revista de la Universidad de Puerto Rico, 7-8, 299-316.

- (1999): "Densidad de anglicismos en el léxico disponible de la República Dominicana”, en J.A. SAMPER y M. TroYA (eds.): Actas del XI Congreso Internacional de la ALFAL, Universidad de Las Palmas de Gran Canaria, vol II, 853-865.

— (2000): "Variable léxica y comparación dialectal", en ALBA, O.: Nuevos aspectos del español en Santo Domingo, Santo Domingo, Librería La Trinitaria y Brigham Young University, 99-132.

AHUmada LARA, IGNACIO (2006): El léxico disponible de los estudiantes preuniversitarios de la provincia de Jaén, Servicio de Publicaciones de la Universidad de Jaén.

Alfaro, RicArdo J. (1970): Diccionario de anglicismos, Madrid, Gredos. $2^{\mathrm{a}}$ ed. aumentada. (ed. or. 1950).

Almerich, J.M. Y HeRnÁNDEZ A. (2006): Pobles abandonats, Els paisatges de l'oblit, Valencia, Consell Valencià de Cultura, col. Maior.

Álvarez De la Granja, María (2011): "La presencia del gallego en el léxico disponible del español de Galicia. Análisis formal y funcional”, en LÓPEZ 
MeIRAMA, BelÉN: Estudios sobre disponibilidad léxica en el español de Galicia, Universidad de Santiago de Compostela, 17-102.

ANDOLZ, RAFAEL (1984): Diccionario aragonés, Zaragoza, Librería General.

APPEL, RENÉ Y PIETER MUYKens (1996): Bilingüismo y lenguas en contacto, Barcelona, Ariel.

ARETA LARA, MARÍA (2009): El léxico disponible de los estudiantes preuniversitarios navarros. Estudios sociolingüístico, Pamplona, Universidad de Navarra, tesis doctoral.

ARnAL, Ma. LuISA (coord.) et al. (2004): Léxico disponible de Aragón, Zaragoza, Libros Pórtico.

_ (2008a): "Los dialectalismos en el léxico disponible de los jóvenes aragoneses", en ARnAL, $\mathrm{M}^{\mathrm{a}}$ L. (ed.): Estudios sobre disponibilidad en los jóvenes aragoneses, Zaragoza, Institución Fernando el Católico, 17-49.

- (2008b): "Niveles socioculturales y léxico dialectal en el vocabulario disponible de Aragón”, en Blas, J.L., M. CASAnOVA, M. Velando y J. Vellón (2008): Discurso y sociedad II. Nuevas contribuciones al estudio de la lengua en un contexto social, Castellón, Universitat Jaume I, 457-469.

_ (2009): “Áreas lingüísticas y dialectalismos en los jóvenes aragoneses (materiales de disponibilidad léxica de Aragón)" en LAGÜENS, VICENTE (ed.): Baxar para subir. Colectánea de estudios en memoria de Tomás Buesa Oliver, Zaragoza, Institución "Fernando el Católico", 265-294.

ATIENZA, ENCARNA et al. (1996): “Una tipología de interferencias catalán-castellano a partir de las producciones escritas de los estudiantes universitarios" en CANTERO, Francisco José et al. (eds.): Didáctica de la lengua y la literatura para una sociedad plurilingüe del siglo XXI. Actas del IV Congreso Internacional de la Sociedad Española de Didáctica de la Lengua y la Literatura, Barcelona, Universitat de Barcelona, 577-582.

ÁvilA, RAÚl (1991): "Densidad léxica y adquisición del vocabulario: niños y adultos” en C. Hernández, G.P. Granda, C. Hoyos, V. Fernández, D. DieTrick Y Y. CARBALlera: El español de América, Actas del III Congreso Internacional de 'El español de América', Junta de Castilla-León, Consejería de Cultura y Turismo, 621-630.

Ávila Muñoz, Antonio Manuel (2006): Léxico disponible de los estudiantes preuniversitarios de Málaga, Málaga, Universidad de Málaga. 
Ávila Muñoz, A.M. Y J.A. ViLlenA PONSODA (eds.) (2010): Variación social del léxico disponible en la ciudad de Málaga. Diccionario y análisis, Málaga, Editorial Sarriá.

AyorA, Ma DEL CARMEN (2000): "La disponibilidad léxica en una situación de contacto de lenguas", en MuÑOZ, Ma D., A. I. RodríGueZ-PiÑERO, G. FERNÁNDEZ Y V. BENÍTEZ (eds.): Actas IV Congreso de Lingüística General. Cádiz. Servicio de Publicaciones de la Universidad de Cádiz, 159-170.

_ (2002): "Deficiencias en la adquisición del léxico como problema específico de las lenguas en contacto", Actas del V Congreso de Lingüística General (León, 5-8 de marzo), 281-293.

_ (2006): Disponibilidad léxica en Ceuta: aspectos sociolingüísticos, Cádiz, Servicio de Publicaciones de la Universidad de Cádiz.

_ (2007): "Los estudios de disponibilidad léxica: ámbitos de aplicación” en CANO LÓPEZ, PABLO (coord.) Actas del VI Congreso de Lingüística General, Madrid, Arco /Libros, vol. II, 2367-2378.

AZURMENDI, MARÍA JOSÉ (1983): Elaboración de un modelo para la descripción sociolingüística del bilingüismo y su aplicación parcial a la comarca de San Sebastián, Guipúzcoa, San Sebastián, Caja de Ahorros Provincial de Guipúzcoa.

BAILEY VICTERY, J. (1971): A study of lexical availability among monolingualbilingual speakers of spanish and english, Houston, Rice University, tesis doctoral.

BALBÁs, J.A. (1892) El libro de la provincia de Castellón, Castellón, Imprenta de J. Armengot. Edición facsímil Confederación Española de Cajas de Ahorro, 1987.

BARALO, MARTA (1977): "La organización del lexicón en la lengua extranjera", Revista de Filología Románica, 14, 1, 59-71.

BARTOL, José Antonio (1998): “Anglicismos en el español de finales de siglo. Anglicismos en el léxico disponible de dos regiones hispanas", en CONRAD, KENT Y Ma DOLORES DE LA CALLE (eds.): Visiones salmantinas, 1898-1998, Universidad de Salamanca y Ohio Wesleyan University, 97-124.

- (2001): "Reflexiones sobre la disponibilidad léxica", en BARTOL HÉRNÁNDEZ, J.A. et al. (eds.): Nuevas aportaciones al estudio de la lengua española, Salamanca, Luso-Española de Ediciones, 221-235. 
_ (2003): "Léxico disponible y norma lingüística", en MORENO FERNÁNDEZ, F. et al. (eds.): Lengua, variación y contexto. Estudios dedicados a Humberto López Morales, Madrid, Arco/ Libros, vol. I, 127-144.

_ (2004): Léxico disponible de Soria. Estudio y diccionarios, Burgos, Instituto Castellano Leonés de la Lengua.

- (2005): "Extranjerismos disponibles. Su integración y vitalidad en una comunidad de habla (Provincia de Soria, España)", Spanish in Context, 2, 203-229.

- (2006): "La disponibilidad léxica" Revista Española de Lingüística, RSEL, 36, 379-391.

- (2007): "El proyecto panhispánico de léxico disponible" en C. HERNÁNDEZ Alonso y L. Castañeda SAn Cirilo (coord.): Actas del VI Congreso Internacional de "El español de América" (Tordesillas, Valladolid, 25-29 octubre 2005), 305-318.

- (2008): "Variación léxica del español: los léxicos disponibles de Aragón y Soria”, en ARNAL, Ma LUISA (ed.): Estudios sobre la disponibilidad léxica en los jóvenes aragoneses, Zaragoza, Institución Fernando el Católico, 207-226.

- (2010): "Disponibilidad léxica y selección del vocabulario", en CASTAÑER, R. Y V. LAGÜENS (eds.): De moneda nunca usada. Estudios filológicos dedicados a José $M^{a}$ Enguita Utrilla, Zaragoza, Institución Fernando el Católico, 85107.

- (2011): "Léxicos disponibles de zonas bilingües: interferencias sobre el español" en LóPez MeIrama, B. (ed.): Estudios sobre la disponibilidad léxica en el español de Galicia, Santiago de Compostela, Universidad de Santiago de Compostela, 157-188.

— y N. HERnÁNDEZ MuÑoz (2006): "Proyecto del léxico disponible de España", en Blas Arroyo, J.L. y M. Casanova, M. Velando (eds.) Discurso y sociedad: contribuciones al estudio de la lengua en contexto social, Castellón, Universitat Jaume I, 731-742.

- (2007): "Dispolex: base de datos de la disponibilidad léxica", Actas del VI Congreso de Lingüística General, Santiago de Compostela.

BAthiA, TEJ K. Y William C. RitchiE (eds.) (2008): The Handbook of Bilingualism, Hoboke: Wiley-Blackwel. 
BAtTANer, M. PAZ (1994) “La investigación en enseñanza del español/lengua materna: vocabulario y léxico", en Actas del Congreso de Lengua Española, Alcalá, Publicaciones del Instituto Cervantes, 417-429.

Bellón Fernández, J. J. (2003): Léxico disponible de la provincia de Córdoba, Las Palmas de Gran Canaria, tesis doctoral.

_ (2004) "Anglicismos en el léxico disponible de la provincia de Córdoba”, VI Congreso Internacional de Lingüística General, Santiago de Compostela, Vol 2, 2391-2407.

— (2005): “Anglicismos en el centro de interés LA ROPA en el léxico disponible de la provincia de Córdoba", Philologica canariensia, 10-11, Universidad de las Palmas de Gran Canaria, 15-38.

_ (2011): Léxico disponible de la provincia de Córdoba, Servicio de Publicaciones de la Universidad de Las Palmas de Gran Canaria y Servicio de Publicaciones de la Universidad de Córdoba.

Benítez, Pedro (1992a) "Disponibilidad léxica de la zona metropolitana de Madrid”, Boletín de la Academia Puertorriqueña de la Lengua Española, $1,1,71-102$.

_ (1992b): "Listas abiertas y listas cerradas de palabras en disponibilidad léxica", en Actas del VIII Congreso Nacional de la Asociación Española de Lingüística Aplicada, Vigo, AESLA, 117-127.

- (1993): “Anglicismos en la disponibilidad léxica de Madrid", X Congreso Internacional de ALFAL. Ms.

_ (1994a): Léxico real/léxico irreal en los manuales de español para extranjeros", en Montesa Peydró, S. y A. Garrrido Moraga (eds.): Español para extranjeros: didáctica e investigación, Málaga, ASELE, 325-333.

_ (1994b): "Convergencias y divergencias en el léxico del alumnado de COU”, REALE, 2, 39-45.

- (1995): "Qué vocabulario hay que enseñar en las clases de español como lengua extranjera", Didáctica del español como lengua extranjera, Madrid, Fundación Actilibre, 9-12.

_, Ma A. ANDión HerRero y M a DEL C. FERnÁNDEZ LóPEZ (1996): "El aprendizaje del vocabulario en español como lengua extranjera. Proyecto de investigación”, en Segoviano, C. (ed.): La enseñanza del léxico español como lengua extranjera, Madrid, Vervuert Ibaroamerica, 140-149. 
_, Clara Eugenia Hernández y José Antonio SAmper (1995): "Léxicos Básicos de España (LEBAES) y de Canarias (LEBAICan). Proyectos de investigación”, Revista de Estudios de Adquisición de la lengua española, REALE, 3, 9-17.

BERnAL, JAANA (2004-2005): “Aspectos cuantitativos del léxico disponible de bilingües finés-español”, Documentos de Español Actual, 6-7, 7-34

Bernat Martí, J.S. (dir.) et alii (2015): La inmigración en Castellón de la Plana. Capital social, redes sociales y estrategias de adaptación a la crisis económica. Castellón, Fundación Davalos-Fletcher.

BERnSTEIN, BASIL B. (1989): Clases, códigos y control, Madrid, Akal.

Blas Arroyo, J.L. (1992a): Rasgos interferenciales en el español de una comunidad bilingüe. Aproximación sociolingüística, Liria, Ayuntamiento de Liria-I.B. Lliria.

_ (1992b): "Consecuencias del contacto de lenguas en el español de Valencia", Español Actual, 59.

_ (1993): La interferencia lingüística en Valencia. (Dirección catalán $\rightarrow$ español). Estudio sociolingüístico, Castellón, Servicio de Publicaciones de la Universitat Jaume I.

_ (1994a): "Valenciano y castellano. Actitudes lingüísticas en la sociedad valenciana", Hispania, 77,1, 143-156.

_ (1994b): "La comunidad de habla. Caracterización sociolingüística del concepto y aplicaciones posibles para la descripción del bilingüismo peninsular", The Bilingual Review, 19,1, 9-24.

_ (1996): "De nuevo el español y el catalán, juntos y en contraste. Estudio de actitudes lingüísticas”, RLA, Revista de Lingüística Teórica y Aplicada, 34, 49-62.

_ (1998): Las comunidades de habla bilingües. Temas de sociolingüística española, Zaragoza, Libros Pórtico.

_ (1999a): Lenguas en contacto. Consecuencias lingüísticas del bilingüismo social en las comunidades del este peninsular. Madrid/Frankfurt. Iberoamericana/Vervuert.

_ (1999b): "Están ahí bajo: un caso de variación gramatical en una situación de contacto de lenguas”, en SERRANO, M.J.: Estudios sobre variación sintáctica, Frankfurt am Main (Alemania). Ed. Iberoamericana/Vervuert, 173-196. 
_ (2000): Gramáticas en contacto: Un modelo de análisis variacionista para la desambiguación de los fenómenos de contacto en el discurso bilingüe catalán-español, Múnich, LIMCOM Europa.

_ (2002): "The Languages of the Valencian Educational System: The results of Two Decades of Decades of Language Policy", Internacional Journal of Bilingual Education and Bilingualism, Vol 5, 6, 318-338.

_ (2002): "Introducción a los fenómenos del contacto de lenguas en las comunidades de habla castellonenses", en Blas ARroyo, J.L., M. CASAnova, S. Fortuño Y M. PorCar (eds.): Estudios sobre lengua y sociedad, Castellón, Servicio de Publicaciones de la Universitat Jaume I, 155-168.

_ (2004): “El español actual en las comunidades del ámbito lingüístico catalán”, en CANO, R. (coord.): Historia de la lengua española, Barcelona, Ariel, 10651086.

_ (2005): Sociolingüística del español. Desarrollos y perspectivas en el estudio de la lengua española en contexto social, Madrid, Cátedra.

_ (2006a): «"Hasta aquí hemos llega(d)o”: ¿un caso de variación morfológica? Factores estructurales y estilísticos en el español de una comunidad bilingüe», Southwest Journal of Linguistics, 25, 2, 39-74.

_ (2006b): "Las lenguas de España en contacto", en DE Miguel, E. (ed.) Y M.C. BUITRAGO (coord.): Las lenguas de España: un enfoque filológico, Aulas de Verano, serie humanidades, Ed. del Instituto de Formación del Profesorado, 209-242.

_ (2007): "El contacto de lenguas como factor de retención en procesos de variación y cambio lingüístico. Datos sobre el español en una comunidad bilingüe peninsular", Spanish in context, 4, 2, 263-29.

_ (2008a): “Aspectos estructurales y sociolingüísticos de una variedad de contacto: el español de la comunidad Valenciana”, en BLAS ARroyo, J.L. Y M. Casanova, M. Velando y J. Vellón (eds.): Discurso y sociedad II. Nuevas contribuciones al estudio de la lengua en un contexto social, Castellón, Universitat Jaume I, 19- 41.

_ (2008b): "The variable expression of future tense in Peninsular Spanish: The present (and Future) of inflectional forms in the Spanish spoken in a bilingual región", Language Variation and Change, 20, 1, 85-126. 
_ (2011a): "From politeness to discourse marking: the process of pragmaticalization of muybien in vernacular Spanish" Journal of Pragmatics 43, 3, 855-874.

_ (2011b): "Spanish in Contact with Catalan", en DíAz CAMPOS, M. (ed.): Handbook of Hispanic Sociolinguistics, Oxford, Blackwell, 374-394.

_ (2016): "Entre la estabilidad y la hipercorrección en un antiguo 'cambio desde abajo': Haber existencial en las comunidades de habla castellonenses", Lingüística Española Actual, 38.1, 69-108.

_ " At the boundaries of linguistic convergence: variation in presentational haber / haver-hi. A sociolinguistic comparative analysis of Spanish and Catalan grammars", Languages in Contrast 18, 2 (en prensa).

_ (coord.), B. NAVARRo y J.C. CASAÑ (cols.) (2009): Corpus sociolingüístico de Castellón de la Plana y su área metropolitana; Publicaciones de la Universitat Jaume I.

Blas ARroyo et alii (1992): Variedades del castellano en Castellón, Diputación de Castellón.

Blas Arroyo, J.L y M. Casanova Ávalos (2001) "Interacción de factores sociales y de adscripción lingüística en el léxico disponible de una comunidad escolar española”, Lenguas Modernas, n 28-29, Universidad de Chile, 165-189.

_ (2003a): "La influencia de la red educativa y del entorno sociocultural en la disponibilidad léxica. Estudio de las comunidades de habla castellonenses", Actas del XIII Congreso Internacional de Lingüística y Filología Románica, Salamanca, Vol V, 17-33.

_ (2003b): "La influencia de la lengua materna en algunos valores de la disponibilidad léxica en el español de una comunidad bilingüe”, en DovAL ReIXA, Irene y Ma Rosa PÉREZ RodríGuez (eds.): Adquisición, enseñanza y contraste de lenguas, bilingüismo y traducción, Universidad de Vigo.

_ Y M. PORCAR (1994): "El empleo de las formas -ra y -se en las comunidades de habla castellonenses. Aproximación sociolingüística”, Español Actual, 62, 73-98.

_ (1997): “Aproximación sociolingüística al fenómeno de neutralización modal en las comunidades de habla castellonenses. Análisis de algunos contornos sintácticos", Sintagma, 9, 27-45. 
_ (1998): "Cuando vendrás... fase inicial de un cambio por interferencia", en $V$ Congreso de Filología e Historia de la Plana, Nules, Excmo. Ayuntamiento de Nules, 413-229.

Blasco Mateo, E. Y A. Torres Torres, Ma Á. Pérez Edo, M. Forment HERNÁNDEZ (2003): "La disponibilidad léxica en la provincia de Barcelona: aspectos metodológicos", XXXIII Simposio de la Sociedad Española de Lingüística, Gerona.

BorRego NieTO, JULIO (2002): "Estudiantes universitarios y jubilados, ¿dos culturas léxicas diferentes?" en Terceras Jornadas de Reflexión Filológica, Salamanca, Universidad de Salamanca.

_ (2004): "Algunas preguntas en relación con el concepto de "léxico disponible", en Prado Aragonés, Josefina y M ${ }^{a}$ Victoria Galloso CAMacho (eds.): Diccionario, léxico y cultura, Universidad de Huelva, 59-69.

_ (2008): "Edad y culturas léxicas" en ARnAl Purroy, Ma L. (ed.): Estudios sobre disponibilidad léxica en los jóvenes aragoneses, Zaragoza, Institución Fernando el Católico, 227-244.

— Y C. FERNÁNDEZ JunCAL (2002): "Léxico disponible: aplicaciones a los estudios dialectales", en Muñoz, M. D. et al. (eds.): Actas del IV Congreso de Lingüística General, Cádiz, Universidad de Cádiz, II, 297-306.

- (2003): “¿En qué cambia la universidad la disponibilidad léxica de los preuniversitarios?", en MORENO FERNÁNDEZ, FRANCISCO et al. (eds.): Lengua, variación y contexto. Estudios dedicados a Humberto López Morales, vol. I, Madrid, Arco/Libros, 167-178.

BUENO (1995): Bilingüisme i educació a la Comunitat Valenciana, Valencia, Universidad de Valencia, tesis doctoral.

Butrón, GloRIA (1987): El léxico disponible: índices de disponibilidad. Tesis doctoral.

_ (1989): “Aspectos sociolingüísticos de la disponibilidad léxica”, Asomante 1-2, 29-37.

_ (1991): "Nuevos índices de disponibilidad léxica" en LÓPEZ MoRALES, H. (ed.): La enseñanza del español como lengua materna, Río Piedras, Universidad de Puerto Rico, 79-89. 
CAÑIzal Arévalo, V. (1987): Disponibilidad léxica en escolares de primaria terminada. Análisis de seis centros de interés, México, Universidad Nacional Autónoma de México. Memoria de licenciatura inédita.

_ (1991): "Redes semánticas y disponibilidad léxica en el español de escolares mexicanos" en HeRnÁNDeZ Alonso, CesAr et al. (eds.): El español de América. Actas del III Congreso Internacional de "El español de América", Valladolid, Junta de Castilla y León, vol. II, 631-641.

CARCedo González, A. (1997-1998): "Desarrollo de la competencia léxica en español LE: análisis de cuatro fases de disponibilidad", Pragmalingüística, vols. 5-6, 75-94

_ (1998a): "Tradición y novedad en las aportaciones hispánicas a los estudios de disponibilidad léxica”, Lingüística, 10, 5-68.

_ (1998b): "Sobre las pruebas de disponibilidad léxica para estudiantes de español/LE” RILCE, 14,2, 205-224.

_ (1999a): "Índices léxico-estadísticos y graduación del vocabulario en la enseñanza de ELE (aspectos culturales)", en Franco FigueroA, M, C. SOler SANTOS, J. DE los RUIZ, M. RIVAS Y F. RUIZ (eds.): Nuevas perspectivas en la enseñanza del español como lengua extranjera, Actas del X Congreso Internacional de ASELE, Cádiz, Servicio de Publicaciones de la Universidad de Cádiz, tomo I, 175-183. También en línea http://cvc.cervantes.es/ensenanza/biblioteca_ele/asele/pdf/10/10_0173.pdf

_ (1999b): "Estudio comparativo del vocabulario español (LE) disponible de estudiantes finlandeses y el de la sintopía madrileña: propuestas didácticas", Documentos de español actual, 1, 73-87.

- (2000): Disponibilidad léxica en español como lengua extranjera: el caso del findanlés (estudio del nivel preuniversitario y cotejo con tres fases de adquisición), Annales Universitatis Turkuensis, Humaniora, Ser. B, Tom. 238, Turku, Universidad de Turku.

_ (2001): Léxico disponible de Asturias, Turku: Publicaciones del Departamento de Lengua Española de la Universidad de Turku.

- (2003): "Unidad y variedad diatópica de la disponibilidad léxica del español: comparación de los inventarios de Puerto Rico, Cádiz y Asturias", en MoReno, F. et al. (eds.): Lengua, variación y contexto. Estudios dedicados a Humberto López Morales, I, Madrid, Arco/Libros, 199-225. 
_ (2004): "La variable léxica disponible en la comparación interdialectal: compatibilidad de la norma asturiana con otras sintopías hispanohablantes", en SAncheZ Corrales, V.M. (ed.): Actas del XIII Congreso Internacional de la Asociación de Lingüística y Filología de la América Latina, San José de Costa Rica, Universidad de Costa Rica, 661-679.

CARRERA DE LA RED, FÁtimA Y WiniFred E. BRADLEy (2004):"Extranjerismos en el léxico disponible de Cantabria”, en MilKa Villayandre Llamazares (ed.): Actas del V Congreso de Lingüística General, Madrid, Arco/Libros, Tomo I, 535-545.

CASAlmiglia, H. Y E. TUSÓN (1980): “Ús i alternança de llengües en grups de joves d'un barri de Barcelona", Treballs de sociolingüística catalana, $\mathrm{n}^{\circ} 3,11-82$.

Casanova Ávalos, M. (2003): Diccionario del léxico disponible de Castellón. Trabajo inédito.

- (2006): "La disponibilidad léxica en la Comunidad Valenciana", en BLAS Arroyo, J.L. y M. Casanova, M. Velando (eds.): Discurso y sociedad: contribuciones al estudio de la lengua en contexto social, Castellón, Universitat de Jaume, 737-751.

- (2008) “Anglicismos en el léxico disponible de Castellón”, en Blas Arroyo, J.L. M. Casanova, M. Velando y J. Vellón (eds.): Discurso y sociedad II: contribuciones al estudio de la lengua en contexto social, Castellón, Universitat de Jaume I,. 471-499.

- (2012): "Valencianismos en el léxico disponible de Castellón", en CASANOVA Herrero, E, y C. Calvo Rigual (eds.): Actes del 26é Congrés de Lingüística i Filologia Romàniques (València, 6-11 de setembre de 2010), Berlín: W. de Gruyter, 531-543.

Y S. FORTUÑO (2014): "El paisaje literario castellonense y su evocación histórica”, en ChUMILlas, JORDI y RICARD GIRAMÉ (eds.): Geografies Literaries: Per vells carrers de poble. Territori, marca, educació $i$ patrimoni, Actas del II Congreso Internacional de Geografías literarias, Universitat de Vic, 201-211.

CAsanovas Catalá, Montse (1996): "Consecuencias de la interferencia lingüística en el léxico de una comunidad bilingüe catalán-español" en Actas del XI Congreso Internacional de la ALFAL, tomo II, Universidad de Las Palmas de Gran Canaria, 945-948. 
Castañer Martín, R. Ma. (2008): “Los extranjerismos en el léxico disponible de los estudios aragoneses", en ARnal PURroy, Mª. L. (ed.): Estudios sobre disponibilidad léxica en los jóvenes aragoneses, Zaragoza, Institución Fernando el Católico, Excma. Diputación de Zaragoza, 51-73.

Cavanilles, A.J. (1795) Observaciones sobre la Historia Natural, Geografía, Agricultura, Población y Frutos del Reyno de Valencia, Imprenta Real, Publicacions del Seminari d'Estudis Econòmics i Socials de la Caja de Ahorros y Monte de Piedad de Castelló, Madrid, 1991 y Bancaja. Obra Social, 1995.

CLAVE (2006) Diccionario de uso del español actual, Ediciones SM. www.smdiccionarios.com

Colón, G. (1976): El léxico catalán en la Romania, Madrid, Gredos.

_ (1989): El español y el catalán, junto y en contraste, Barcelona, Ariel.

_ (2015): Vocabulari castellonenc, Castellón de la Plana, Ajuntament de Castelló.

COROMINAS, JOAN Y J. ANTONIO PASCUAL (2000): Diccionario crítico etimológico castellano e hispánico, Madrid, Gredos. ( $3^{\mathrm{a}}$ reimpr.).

CRuz Alonso, R. (2016) El léxico disponible de Castilla y León, Salamanca, Vítor, Ediciones de la Universidad de Salamanca.

De Santiago Guervós, Javier (2008): Léxico disponible de Segovia. Estudio y diccionarios, Fundación Instituto Castellano y leonés de la Lengua.

DIEZ, I. (1995): Avaluació de l'experiencia de l'ús del valencià com llengua d'ensenyament a l'Educació General Bàsica, Valencia, Universidad de Valencia, tesis doctoral.

DCVB, Alcover, Antoni Ma y Francesc De BorJa Moll (2002): Diccionari català-valencià-balear, Barcelona. htpp://dcvb.iecat.net

DEA, Seco, Manuel, O. AndréS y G. RAmos (1999): Diccionario del español actual, Madrid, Aguilar.

DIEC, Institut D'Estudis CATAlans (2007): Diccionari de la llengua catalana, Barcelona, Edicions 62.

DimitriJEVIC, N.R. (1969). Lexical availability: A new aspect of the Lexical Availability of Secundary School Children, Heidelberg, Julius Gross Verlag. _ (1981): "A comparative study of the lexical availability of monolingual and bilingual schoolchildren”, en Studia Anglicata Posnaniensia, 13, 109-130 
Domínguez MejíAs, Elena (2002): "Los anglicismos en el Diccionario de la RAE 2001”,Panace@Vol. 3, nº 8 Junio, 28-33.

Domingo PÉREZ, C. (1985): La Plana de Castellón. Formación de un paisaje agrario mediterráneo, Caja de Ahorros y Monte de Piedad de Castellón. Edición facsímil, Castellón, Confederación Española de Cajas de Ahorro.

DUE. Moliner, MARÍA (1991): Diccionario del uso del español, Madrid, Gredos.

ECHEVERRÍA, MAX S. (1991): "Crecimiento de la disponibilidad léxica en estudiantes chilenos de nivel básico y medio”, en LóPEZ MORALES, H. (ed.): La enseñanza del español como lengua materna. Actas del II Seminario Internacional sobre Aportes de la lingüística a la enseñanza del español como Lengua materna. Río Piedras: Universidad de Puerto Rico, 61-78.

_ (1993): "Estructura de un perfil de competencia léxica", Revista de Lingüística Teórica y Aplicada, 31, 55-66.

_ (2001): "Estructura y funciones de un software de vocabulario disponible", $R L A$, $39,87-100$.

ECHEVERRÍA, M.S et alii (1987): “Disponibilidad léxica en la Educación Media. Resultados cuantitativos", en VII Seminario de Investigación y Enseñanza de la Lingüística, Valparaíso, Ediciones Universitarias de Valparaíso, 102-116.

_, R. Vargas, P. Urzúa y R. Ferreiar (2008): "DispoGrafo: una nueva herramienta computacional para el análisis de relaciones semánticas en el léxico disponible”, Revista de Lingüística Teórica y Aplicada, 46 (1), 81-91. http://www.scielo.cl/scielo.php?script=sci_arttext\&pid=S071848832008000100005

ENGUita UtRiLla, J. M. (2008): “Norma culta y norma rural en el léxico disponible de los jóvenes aragoneses", en ARNAL, Ma LUISA (ed.): Estudios sobre disponibilidad léxica en los jóvenes aragoneses, Zaragoza, Institución Fernando el Católico, 75-101.

EsCORIZA MORERA, L. (2003): "Lenguas en contacto y disponibilidad léxica: la situación lingüística e intercultural de Ceuta y Gibraltar", Linred, 1.

(2007): "Disponibilidad léxica y multilingüismo: el contacto entre inglés y español en Gibraltar” en CANO LóPEZ, P. (coord.): Actas del VI Congreso de Lingüística General, Madrid, Arco/Libros, vol. II, 2477-2484.

EtXebarria, Maitena (1995): El bilingüismo en el estado español. Bilbao, Ed. FBV, S.L. 
_ (1996): "Disponibilidad léxica en escolares del País Vasco: variación sociolingüística y modelos de enseñanza bilingüe”, Revista Española de Lingüística, 26, 2, 301-325.

_ (1997): "Disponibilidad léxica y caracterización sociolingüística: variación y diversidad” en Molina Redondo, J.A. y J. DE Dios LuQue DuRÁn (eds.): Estudios de lingüística general (II), Granada, Método Ediciones, 65-83.

_ (1999): "Disponibilidad léxica y enseñanza de la lengua materna en el área metropolitana del gran Bilbao", en SAMPER PADILlA, J.A, et al. (eds.): Actas del XI Congreso Internacional de la ALFAL, tomo II, Universidad de Las Palmas de Gran Canaria, 1479-1494.

FABRA, Pompeu (1983): DGLLC. Diccionari general de la Llengua catalana, Barcelona, Edhasa, $18^{\mathrm{a}} \mathrm{ed}$.

Fernández Juncal, CARMen (2008): El léxico disponible de Burgos. Burgos, Fundación Instituto Castellano y leonés de la Lengua.

_ (2013): Léxico disponible de Cantabria. Estudio sociolingüístico. Salamanca. Ediciones de la Universidad de Salamanca y Editorial de la Universidad de Cantabria.

FERnÁNDEZ-MERINO GuTIÉRREZ, P. (2011): “Disponibilidad léxica de inmigrantes: propuesta para una necesidad", Lengua y emigración, 3, vol. 2, 83-105.

_ (2013): Disponibilidad léxica de inmigrantes en Castilla y León, Universidad de Valladolid, Tesis doctoral.

FERnÁndeZ SMITH, G., A. RicO, Mª J. MolinA y Ma A. JimÉneZ (2006): "Proyecto sobre la disponibilidad léxica en alumnos preuniversitarios de Melilla”, en Blas, J.L., M. Casanova Y M. Velando (eds.): Discurso y sociedad: contribuciones al estudio de la lengua en contexto social, Castellón, Universitat Jaume I, 767-777.

Fernández Smith, GÉrard, A. M. Rico Martín, M. J. Molina García y M. A. JIMÉNEZ JIMÉNEZ (2008): Léxico disponible de Melilla: estudio sociolingüístico y repertorios léxicos, Madrid, Arco/ Libros.

FERnández SMith, Gerard, Marta SÁnchez-Saus y Luis Escoriza Morera (2012): "Studies on Lexical Availability: The Current Situation and Some Future Prospects", en Eizaga Rebollar, BÁrbara (ed.): Studies in Linguistics and Cognition, Bern, Peter Lang, 35-56. 
FERrANDO, A. (1988): "Vint-i-cinc anys de conflicte lingüístic al País Valencià (1962-1987)", en AlEMANY FERRER, R. (ed.): Els procesos de normalització lingüística a l'Estat español actual, Ayuntamiento de Benidorm y Universidad de Alicante, 179-203.

FERREIRA, R Y M. ECHEVERRÍA (2014) "Lexical availability of basic and advanced semantic categories in English L1and English L2" en JiMENEZ CATALÁN, R.M. (ed.): Lexical availability in English and Spanish as a second language, Springer: Dordrecht Heidelberg, 15-35.

Fortuño, Santiago, Manuela Casanova, Vicente J. Nebot y Ma Pareja (2010): Castellón en la literatura, Castellón, Fundación Davalos-Fletcher.

FRANCO, J. (1998): Las ciudades valencianas. Guía visual de nuestras tierras, Valencia, Bancaja, Obra Social.

Gallego Gallego, D. (2014): "Léxico disponible de 82 inmigrantes estudiantes de español en la ciudad de Alcalá de Henares", Lengua y Migración/Language and Migration, 6, 2.

Galloso CAmacho, Ma V. (1997): “Tratamiento y perspectivas del léxico disponible. El caso de la provincia de Zamora", Revista de estudios de adquisición de lengua española (REALE), 8, 23-33.

_ (1998a): "El léxico disponible en el nivel preuniversitario (provincia de Zamora), Interlingüística, 7, 75-80.

_ (1998b): El léxico disponible en el nivel preuniversitario (provincia de Zamora), Salamanca, Universidad de Salamanca, Memoria de Licenciatura.

_ (1999): "Hacia una definición de léxico disponible: posibles aplicaciones" en FERNÁNDEZ, J. et al. (eds.): Actas del III Congreso de Lingüística General. Lingüística para el siglo XXI, Salamanca Ediciones de la Universidad de Salamanca, 711-717.

_ (1999): "La heterogeneidad en los trabajos de Sociolingüística: el caso de la disponibilidad léxica", Interlingüística, 10, 139-143.

_ (2001): El léxico de los estudiantes preuniversitarios en el distrito universitario de Salamanca, Salamanca. Tesis doctoral.

_ (2002): “¿Para qué sirven los estudios de léxico disponible?” en DoloRES MuÑOZ, Ma T. et al. (eds.): Actas IV Congreso de Lingüística General, Cádiz, Universidad de Cádiz y Universidad de Alcalá, vol. III, 1143-1151. 
_ (2003a): Léxico disponible de Salamanca, Ávila y Zamora, Burgos, Instituto Castellano-Leonés de la Lengua.

_ (2003b): "Lematización en masculino y femenino de los nombres de profesiones y oficios", Documentos de Español Actual, 5, 33-46.

- (2012) (ed.): La investigación de la lengua y la literatura en la onubense, Universidad de Huelva.

— Y J. PRADO ARAgONÉS (2005): “Análisis cuantitativo del léxico disponible de los preuniversitarios de Huelva y contraste con el de los preuniversitarios de Salamanca”, en SANTOS Río, L., J. Borrego, J. F. GARcía, J.J. Gómez ASENSIO Y E. PRIETO (eds.): Palabras, norma, discurso. En memoria de Fernando Lázaro Carreter, Salamanca, Ediciones Universidad de Salamanca, 491-502.

García CASERo, Ma José (2013) El léxico disponible en estudiantes de $4^{o}$ de Educación Secundaria Obligatoria en Santander, Universidad de Santander. Tesis doctoral.

García Domínguez, M.J., V. Marrero Pulido, J.A. Pérez Martín y G. Piñero PIÑERO (1994): "Estudio de disponibilidad léxica en Gran Canaria. La variante geográfica y el tipo de educación", Revista de estudios de adquisición de lengua española (REALE), 2, 65-72.

GARCíA Hoz, Víctor (1953): Vocabulario usual, común y fundamental, Madrid, Instituto Pedagógico ‘San José de Calasanz’ del CSIC.

GARCía mARCOS, FRANCISCO J. (1999): Fundamentos críticos de Sociolingüística, Almería, Universidad de Almería.

García Marcos, Francisco Y Ma Victoria MAteo García (1995): "Disponibilidad léxica en Almería: primeros resultados", en RODRÍGUEZ FonseCA y VÁzQUEZ (eds.) Actas del III Seminario Internacional sobre “Aportes de la lingüística a la enseñanza de la lengua materna”, Carolina, Universidad de Puerto Rico.

_ (1996): "Disponibilidad léxica y enseñanza de lenguas extranjeras", Docencia e investigación, Universidad de Castilla-La Mancha.

(1997): "Resultados de las encuestas sobre la disponibilidad léxica realizadas en Almería" en Revista de Estudios de Adquisición de la Lengua Española (REALE), 7, 57-68. 
_ (2000): La selección de materiales léxicos en la enseñanza de lenguas extranjeras. Evaluación y propuestas desde la disponibilidad léxica. Ms.

García Megía, A. (2003): La disponibilidad léxica en la ciudad de Almería entre los nueve y los doce años, Almería, Universidad de Almería.

Gascó, A. (2014) Crónica de Castellón, Castellón, Ajuntament de Castelló.

Gimeno BeTí, LL. (1999): “Lèxic ramader en documents valencians del segle XIV”, Boletín de la Sociedad Castellonense de Cultura, Castellón, 461-498.

_ (2002): "Espanyol i català: dues llengues en contacte", en Blas ARroYO, J.L. M. CAsanova, S. Fortuño Y M. PORCAR (eds.): Estudios sobre Lengua y Sociedad, Publicaciones de la Universitat Jaume I, 169-187.

Gimeno MenÉndeZ, Francisco (2002): "Disponibilidad léxica en español como lengua extranjera: el caso finlandés”, Revista de Filología de la Universidad de La Laguna, 20, 354-358.

_ Y E. MARTínEZ OLMOS (2009): "Estándar y comunidad de habla en los estudios de disponibilidad léxica”, en Álvarez Tejedor, A., A. Bueno García, S. Hurtado GonzÁlez y N. MendizÁbal DE la CruZ (eds.): Lengua viva. Estudios ofrecidos a César Hernández Alonso, Valladolid, Universidad de Valladolid, Diputación de Valladolid, 373-387.

GIMENO, F. Y M.V. GIMENO (2003): El desplazamiento lingüístico del español por el inglés, Madrid, Cátedra.

Gómez Capuz, JuAn (2000): Anglicismos léxicos en el español coloquial, Cádiz, Universidad de Cádiz.

— (2004): Préstamos del español: lengua y sociedad, Madrid, Arco/Libros.

- (2005): La inmigración léxica, Madrid, Arco/Libros.

GÓMEZ DEvís, BEGOÑA (2003): La disponibilidad léxica de los estudiantes preuniversitarios valencianos: reflexión metodológica, análisis sociolingüístico y aplicaciones. Universidad de Valencia. Tesis doctoral _ (2005): “Aprovechamiento del léxico disponible”, Lenguaje y Textos, 23, 69-74.

_ (2010): “Aportes de la disponibilidad léxica a la investigación sobre los fenómenos de contacto lingüístico" en GARCÍA, MANUEL et al. (ed.): Interacció Comunicativa $i$ Ensenyament de Llengües, Universitat de Valencia, 233-240. 
_ (2013): "Fenómenos frecuentes del contacto lingüístico en el castellano-catalán (variedad valenciano)" en Gómez MolinA, J.R. (coord.): El español de Valencia. Estudio sociolingüístico, Peter Lang, 347-370.

Gómez Devís, B y F. Llopis Rodrigo (2010): "El léxico disponible de Valencia: convergencia conceptual”, Revista de Lingüística y Lengua Aplicadas, 5,5376.

_ (2010): El léxico disponible del catalán de Valencia. Hacia la necesaria planificación lingüística de una lengua minoritaria", Romanitas, lenguas y literaturas romances, 4, 2, 1-28.

_ (2016): "Xarxes semàntiques en el lèxic disponible de València. Una aproximació al lexicó bilingüe”, Studia Romanica Posnaniensia, 43,2, 65-83.

Gómez Molina, J.R. (1986): Estudio sociolingüístico de la comunidad de habla de Sagunto (Valencia), Valencia, Institució Alfons el Magnànim.

_ (1998): Actitudes lingüísticas en una comunidad bilingüe y multilectal. Área metropolitana de Valencia, Valencia, Universitat de València. Anejo XXVIII de Cuadernos de filología.

_ (2002): "Lenguas en contacto y actitudes lingüísticas en la comunidad valenciana”, en Blas J.L., M. CASAnOVA, S. FortuÑo Y M. PorCAR (eds.): Estudios sobre lengua y sociedad, Castellón, Publicaciones de la Universitat Jaume I, 53-86.

_ (2009): "Una aplicación psicolingüística de la disponibilidad léxica: la categoría nocional Animales", en Veyrat Rigat, Monserrat y ENRIQUE SERRA ALEGRE (eds.): La lingüística como reto epistemológico y como acción social. Estudios dedicados al profesor Ángel López García con ocasión de su sexagésimo aniversario, Madrid, Arco/ Libros, Vol. II. 1045-1060.

Gómez MolinA, J.R. y B. Gómez Devís (2004): La disponibilidad léxica de los estudiantes preuniversitarios valencianos. Estudio de estratificación sociolingüística, Valencia, Universitat de València.

Gómez TORREGO, L. (1995): El léxico en el español actual: uso y norma, Madrid, Arco/Libros.

González Becker, Mariana y PATricia VARgas SANdoval (1992): "La disponibilidad léxica como instrumento de planificación curricular: un diagnóstico al hablante medio en lengua materna en seis centros de interés (arte, derecho, economía, política, sentimientos y teología)", I Congreso 
internacional sobre la Enseñanza del español (27-31 Enero, Madrid), Universidad Católica de Valparaíso, Fundación Isabel Caces de Brown, 1-8. GonZÁLEZ, JosuÉ (ed.) (2008): Encyclopedia of Bilingual Education. Cambridge M.A.: Springer.

GONZÁlEZ FERNÁNDEZ, J. (2014): “Idoneidad de los centros de interés clásicos en los estudios de disponibilidad léxica aplicados al español como lengua extranjera", Revista Nebrija de Lingüística Aplicada, 8, 3,

GonzÁlez Martínez, AdOlfo (1999): “Andalucismos en el léxico disponible de Cádiz", TAVIRA 17, Cádiz, Facultad de CC de la Educación de la Universidad de Cádiz. 181-193

_ (2002): La disponibilidad léxica de los alumnos preuniversitarios de la provincia de Cádiz, Cádiz, Servicio de publicaciones de la Universidad de Cádiz.

_ Y PePa Orellana (1999): “Análisis del comportamiento de la variable sexo en el léxico disponible de Cádiz", Revista de Estudios de Adquisición de la Lengua Española, (REALE), 11, 65-73.

_ Y PePa ORellana (2000): "Cotejo de los léxicos de Cádiz y Zamora", Documentos del Español Actual (DEA), Turku (Finlandia), Departamento de Lengua Española de la Universidad de Turku, 139-160

_ (2001): “Compatibilidad y discrepancias entre los léxicos disponibles de Puerto Rico y Cádiz", Pragmalingüística, 8-9, Servicio de Publicaciones de la Universidad de Cádiz, 179-196.

_ (2006): “Anglicismos en el léxico disponible de la provincia de Cádiz", Boletín de Lingüística del Instituto de Filología Andrés Bello, XVIII/25, 3-21, Venezuela, Universidad Central de Venezuela.

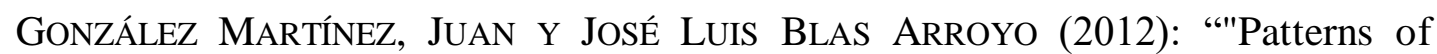
change and continuity in the language attitudes of several generations in two bilingual Spanish communities: the rural regions of Els Ports and Matarranya", International Journal of Bilingual Education and Bilingualism, $15,2,199-216$.

Gougenheim, G., R. MichÉA, P. Rivenc Y A. SAuvageot (1956): L'elaboration du français élémentaire (I Degré). Étude sur l'établissement d'un vocabulaire et d'une grammaire de base, Paris, Didier.

_ (1964): L'élaboration du français fondamental (I Degrée). Étude sur l'établissement d'un vocabulaire et d'une grammaire de base, Paris, Didier. 
GOUGENHEIM, GEORGES (1967): "La statistique de vocabulaire et son application dans l'enseignement des langues", Les langues modernes, 61, 137-144.

Grosjean, FrançoIs (2008): Studying Bilinguals, Oxford, Oxford University Press.

GUERRA SAlAS, LUIS Y Ma ElENA GóMEZ SÁNCHEZ (2004): “Español de los medios de comunicación: aspectos de disponibilidad lexica”, en PERDiguero, H. Y A. Álvarez (eds.): Medios de comunicación y enseñanza del español como lengua extranjera. Actas del XIV Congreso Internacional de ASELE (Burgos, 2003), Burgos, Universidad de Burgos, 336-371.

Guerrero RAmos, Gloria (1995) Neologismos en el español actual, Madrid, Arco/Libros.

Haugen, EINAR (1954): "Problems of bilingual descriptions", Monograph Series on Languages and Linguistics, 7, 9-19.

_ (1969): The Norwegian Language in America: A study in bilingual bahaviour, Bloomington-London, Indiana University Press ( $1^{\text {a }}$ ed, 1953).

_ (1970): "Linguistics and Dialinguistics" en AlatiS, J. (ed.): Monograph Series on Languages and Linguistics, 23, Washington, Georgetown University Press, 1-12.

Henríquez Guarín, Ma . Clara, Viviana Mahecha y Geral Eduardo Mateus (2016): “Análisis de los mecanismos cognitivos del léxico disponible de Cuerpo humano a través de grafos”, Lingüística y literatura, 69, 229-251.

HERnÁndez CABRERA, C.E. Y J.A. SAMPER PADILLA (2003): “Los dialectalismos en el léxico disponible de Gran Canaria. Análisis de un centro de interés” en F. Moreno, J.A. SAMPer, M. VAQUero, Ma L. GutiérReZ, C. HernándeZ y F. GIMENO, I, (coord.): Lengua, variación y contexto. Estudios dedicados a Humberto López Morales. Madrid: Arco/Libros, I, 339-353.

HERnÁNDEZ CABRERA, C.E. y J.A. SAMPER PADILla (2007): "Léxico regional en los materiales de disponibilidad léxica", Revista de Filología de la Universidad de la Laguna (Homenaje a Antonio Lorenzo Ramos), 25, 287-290.

_ Y M. SAMPER HERNÁNDEZ (2006): "Nivel educativo e índices de disponibilidad" en Blas Arroyo, J.L., M. Casanova y M. Velando Discurso y sociedad: contribuciones al estudio de la lengua en contexto social, Servicio de Publicaciones de la Universidad Jaume I de Castellón, 791-809. 
HERNÁNDEZ GARCÍA, C. (1998): “Una propuesta de clasificación de la interferencia lingüística a partir de dos lenguas en contacto: el catalán y el español”, Hesperia, 1- pp. 60-77.

File:///C:Users/seven/Downloads!dialnet/UnaPrpuestaDEClasificacionDeLaInterferenciaLin gui-198196.pdf

Hernández Muñoz, NATIVIDAd (2002): “Ciencias o letras? Apuntes sobre la especificación léxica de los estudiantes preuniversitarios", Terceras jornadas de Reflexión Lingüística, Salamanca.

_ (2004): El léxico disponible de los estudiantes conquenses, Salamanca, Ediciones Universidad de Salamanca.

_ (2006): Hacia una teoría cognitiva integrada de la disponibilidad léxica: el léxico disponible de los estudiantes castellano-manchegos, Colección Vítor, Ediciones Universidad de Salamanca.

_ (2006): "Disponibilidad léxica y palabras tempranas: un estudio preliminar", Actas del VI Congreso de Lingüística General, Madrid, Arco/ Libros, 217228.

_ (2009a): "Aspectos sociolectales del léxico dialectal", Spanish in Context, 6, 224-248.

_ (2009b): "Variación léxica y zonas dialectales de Castilla-La Mancha”, Revista de Filología Española, LXXXIX, 2, 279-300.

_ (2014): “Categorías en el léxico bilingüe: perspectivas desde el priming semántico interlenguas y la disponibilidad léxica", Revista Electrónica de Lingüística Aplicada, 1, 19-38.

_ (2015) "La evaluación de la competencia léxica adulta: una aproximación a través de la disponibilidad léxica y la especialización académica en preuniversitarios", Revista de Filología, 33, 79-99.

_, C. IZURA Y A. Ellis (2006): "Congitive aspects of lexical availability." The European Journal of Cognitive Psycology, 18 (5), 730-755.

_, C. IZURA Y C. TOMÉ (2014): "Cognitive factors of lexical availability in a second language”, en R.M. JIMÉNEZ CATALÁN (ed.): Lexical availability in English and Spanish as a second language, Springer: Dordrecht Heidelberg, 169186. 
HERnÁNDEZ MuÑOZ, N. Y J. BorREGO NIETO (2002): “Cuestiones metodológicas sobre los estudios de disponibilidad”, en Actas V Congreso de Lingüística General, León, 5-8 de marzo de 2002, Arco/Libros, 1519-1527.

HuyKe, IsABel (1978): “Índices de densidad léxica: anglicismos en la zona metropolitana de San Juan”, en H. LóPEZ MORALES (ed.): Corrientes actuales de la Dialectología del Caribe hispánico, San Juan, Editorial Universitaria, 144-163.

JiMÉNEZ BERRIO, F. (2012): “Aprendizaje integrado de contenidos y español para inmigrantes desde la perspectiva de la disponibilidad léxica: enseñanza del vocabulario”, en BREEZE, R., F. JimÉnEZ, C. Llamas, C. MARTíneZ y C. TABERnERO (eds.): Teaching Approaches to CLIL/Propuestas docentes en AICLE, Pamplona, Servicio de Publicaciones de la Universidad de Navarra, 149-163.

_ (2013): Léxico disponible de inmigrantes escolares no hispanohablantes, Pamplona, Servicio de Publicaciones de la Universidad de Navarra.

_ (2015): El léxico disponible de escolares navarros de primaria y secundaria obligatoria. Universidad de Navarra.

JimÉnez CATALÁN, Rosa Ma (2017): "Estudios de disponibilidad léxica en español y en inglés: revisión de sus fundamentos empíricos y metodológicos" Revista Nebrija de Lingüística Aplicada a la Enseñanza de las Lenguas, 22.

JuILlAND, AlPhONSE Y EUGENIO ChANG-RodRÍGUEZ (1964): Frequency Dictionary of Spanish Words, The Hague, Mouton.

Justo Hernández, Hortensia (1986): Disponibilidad léxica en colores, México, Universidad Nacional Autónoma de México. Memoria de licenciatura.

LABOV, WiLliam (1983): Modelos sociolingüísticos, Madrid, Cátedra.

_ (1996): Principios del cambio lingüístico, Madrid, Gredos.

LAPESA, RAFAel (1981): Historia de la lengua española, Madrid, Gredos, 9a edición.

LAGÜENS GRACIA, ViCENTE (2008): "La variable sexo en el léxico disponible de los jóvenes aragonenes" en ARNAL, ${ }^{a}$ LUISA (ed.): Estudios sobre la disponibilidad léxica en los jóvenes aragoneses, Zaragoza, Institución Fernando el Católico, 103-162.

LÁzARo CARRETER, FERnANDO (1968): Diccionario de términos lingüísticos, Madrid, Gredos, $3^{\text {a }}$ edición. 
Llistar, A. (1887) Historia de la provincia de Castellón, Valencia, Francisco Vives

y Compañía. Edición facsímil por la Editorial Confederación Española de Cajas de Ahorro.

Llopis RodRIGO, F. (2008): "Disponibilitat lèxica del valencià: classificació dels fenòmens de contacte lingüístic" en Blas Arroyo, JL., M. Casanova, M. VELANDO Y J. Vellón (eds.): Discurso y sociedad II. Nuevas contribuciones al estudio de la lengua en un contexto social, Castellón, Universitat Jaume I, 571-582.

_ (2009). El lèxic del valencià central: un estudi de disponibilitat lèxica, València, Servei de Publicacions de la Universitat de Valéncia.

_ (2010): "Convergència semàntica en comunitats de parla bilingües", en GARCÍA, MANUEL et al. (eds.): Interacció comunicativa $i$ ensenyamet de llengües, Valencia, Universitat de València, 257-264.

_ Y Begoña Gómez Devís (2010): El lèxic disponible de València, Valencia, Denes.

_ Y J. LÓPEZ Río (2013): “Transfèrencies lèxiques en els estudiants valencians” en Casanova, E. Y C. CALVo (eds.): Actas del XXVI Congreso Internacional de Lingüística y Filología Románicas, (Valencia 6-11septiembre de 2013), De Gruyter, vol. 8, 4493-5004.

Llorente, Ma DEL ROSARIO (2005): "Léxico disponible y léxico dialectal en la provincia de Ávila”, en L. SANTOS, J. BORREGO, J.F.GraCíA, J.J. GÓMEZ y E. PRIETO (eds.): Palabras, normas, discurso, en memoria de Fernando Lázaro Carreter, Salamanca, Ediciones Universidad de Salamanca, 681-694.

LÓPEZ CHÁVEZ, J. (1991): "Préstamos, extranjerismos y anglicismos en el español de México. Valores lexicométricos (planteamientos previos)" en HERnÁNDEZ Alonso, C. et al. (eds.): El español de América. Actas del III Congreso Internacional de "El español de América", Valladolid, Junta de Castilla y León, vol. II, 775-784.

_ (1992): “Alcances panhispánicos del léxico disponible”, Lingüística, 4, 26-124.

_ (1993): El léxico disponible de escolares mexicanos, México, D. F., Alhambra Mexicana.

_ (1993): "Léxico fundamental panhispánico: realidad o utopía", en Actas del IV Congreso Internacional de 'El Español de América', Santiago de Chile, Universidad Católica de Chile, vol. II, 1006-1014. 
_ (1995): "El léxico en estudiantes mexicanos de primaria", en RODRÍGUEZ FonseCA y VÁzQUeZ (eds.): Actas del III Seminario Internacional sobre “Aportes de la lingüística a la enseñanza de la lengua materna”, Carolina, Universidad de Puerto Rico.

_ et alii (1993): Colección de cuadernos de El léxico disponible de escolares mexicanos: 1. Léxico disponible de preescolares mexicanos (con Rosa $\mathrm{M}^{\mathrm{a}}$ Mesa Canales), 2. Léxico disponible de primer grado de primaria (con $\mathrm{M}^{\mathrm{a}}$ Trinidad Madrid), 3. Léxico disponible de segundo grado de primaria (con Martha Julián Peña), 4. Léxico disponible de tercer grado de primaria (con Rosalí Bolfeta Montes de Oca), 5. Léxico disponible de cuarto grado de primaria (con Marcela Flores Cervantes), 6. Léxico disponible de quinto grado de primaria (con Lilia Castellano Median), 7. Léxico disponible de sexto grado de primaria (con Eva Núñez Alonso), México, Alhambra Mexicana.

— y C. Strassburger FríAs (1987): “Otro cálculo del índice de disponibilidad léxica", en Presente y perspectiva de la investigación computacional en México. Actas del IV Simposio de la Asociación Mexicana de Lingüística Aplicada, México, UNAM.

— Y C. STRASSBURGER FRÍAS (1991): "Un modelo más para el cálculo del índice de disponibilidad léxica individual", en LÓPEZ MORALES, H.: La enseñanza del español como lengua materna, Río Piedras, Universidad de Puerto Rico, 91143.

_ (2000): El diseño de una fórmula matemática para obtener un índice de disponibilidad léxica confiable", Anuario de Letras, 38, 227-251.

LÓPEZ GonZÁlez, ANTONIO Ma . (2010): “Análisis de la compatibilidad de los léxicos disponibles de polacos e hispanohablantes", Kwartalnik Neofilologiczny, LVII, 2, 171-179.

_ (2014): "Desarrollo de los estudios de disponibilidad léxica en español lengua extranjera (ELE)", en CONTRERAS IZQUIERDO, N.M. (ed.): La enseñanza del español como E/LE 2 en el siglo XXI, 397-408.

_ (2016): "Las asociaciones léxicas en el léxico disponible en lengua materna y en lengua extranjera”, Tono digital: Revista electrónica de estudios filológicos, 31, 1-26. 
LÓPez Meirama, BelÉN (2008): Léxico disponible en el español de Galicia, Santiago de Compostela, Universidad de Santiago de Compostela.

_ (2011) (ed.): Estudios sobre disponibilidad léxica en el español de Galicia, Universidad de Santiago de Compostela.

LÓPEZ MoRALES, H. (1973): Disponibilidad léxica en escolares de San Juan, MS.

_ (1978): "Frecuencia léxica, disponibilidad y programación curricular”, Boletín de la Academia Puertorriqueña de la Lengua Española, 6/1, 73-86.

_ (1979): "Disponibilidad léxica y estratificación socioeconómica", en LÓPEZ MORALES, H.: Dialectología y sociolingüística. Temas puertorriqueños, Madrid, Hispanova Ediciones, 173-181.

_ (1983): "Lingüística estadística", en LÓPEZ MORALES, H. (coord): Introducción a la lingüística actual. Madrid. Playor, 209-225.

_ (1986): Enseñanza de la lengua materna. Lingüística para maestros de español, Madrid. Playor.

_ (1989): Sociolingüística, Madrid, Gredos.

_ (ed.) (1991): La enseñanza del español como lengua materna. Actas del II Seminario Internacional sobre 'Aportes de la lingüistica a la enseñanza del español como lengua materna', Río Piedras, Universidad de Puerto Rico.

_ (1992) "Muestra de léxico panantillano: el cuerpo humano", en LuNA TRAIL, EliZABETH (coord.): Scripta Philologica. In honorem Juan M. Lope Blanch, México, UNAM, Tomo II, 593-625.

_ (1995-1996): "Los estudios de disponibilidad léxica: pasado y presente", Boletín de Filología de la Universidad de Chile, 35: 245-259.

— (1999a): «Anglicismos en el léxico disponible de Puerto Rico», en LUIS A. ORTIZ LÓPEZ (ed.): El Caribe hispánico: perspectivas lingüísticas actuales. Homenaje a Manuel Alvar Nazario, Madrid, Vervuert Iberoamericana, 147170.

- (1999b): Léxico disponible de Puerto Rico, Madrid, Arco/Libros

- (2001): "Tendencias del léxico disponible en Hispanoamérica", Revista de Occidente, $\mathrm{n}^{\circ}$ 240, Abril, 5-24.

- (2005): "Un nuevo corpus para el estudio del español: la disponibilidad léxica", Oralia, 8, 141-160. 
_ (2008): "Un alto en el camino: el léxico disponible de Aragón” en ARNAL PURroY, Ma LuISA (ed.): Estudios sobre disponibilidad léxica en los jóvenes aragoneses, Zaragoza, Institución Fernando el Católico, 7-15

_ y F. GARCíA MARCos (1995): "Disponibilidad léxica en Andalucía. Proyecto de investigación", Revista de Estudios de Adquisición de la Lengua Española, 3, 67-76.

LoRÁn SANTOS, R. y H. LóPEZ Morales (1983): Nouveau calcul de l'indice de disponibilité, MS.

LoREnZO, Emilio (1995): “Anglicismos”, en SeCO, M. Y G. SAlVAdOR (coord.): La lengua española, hoy, Madrid, Fundación Juan March.

— (1996): Anglicismos hispánicos, Madrid, Gredos.

MAChuCA Ayuso, M.J. (2016): "Estructura silábica y bilingüismo", en POCH Olivé, D. (ed.) El español en contacto con las otras lenguas peninsulares, Madrid, Iberoamericana/Vervuert, 299-313.

MACKEY, WiLliam C. (1971): Le vocabulaire disponible du Français. ParisBruxelles-Montréal, Didier.

_ (1976): Bilingualisme et contact des Langues, Paris, Editions klincksieck.

MARTines, Josep (1997): “El sufix -aire al País Valencià" en JOSEP MASSOT I MUNTANER (coord.) Estudis de Llengua i Literatura catalanes/ XXXIV, Miscel-lània Germà Colón/ 7, Barcelona, Publicacions de l'Abadia de Montserrat, 229-262.

MARTinez Olmos, Esther (2008): Disponibilidad léxica en las comunidades de habla alicantinas, Universidad de Alicante. Tesis doctoral.

_ (2015): El léxico de las comunidades de habla alicantinas. Estudio sociolingüístico y diccionarios, Alicante, Publicaciones de la Universida de Alicante.

Mateo GarcíA, Ma. V. (1998): Disponibilidad léxica en el COU almeriense. Estudio de estratificación social, Almería, Universidad de Almería.

MATRAS, YARON (2009): Language contact, Cambridge, Cambridge University Press.

Medina LóPeZ, J. (1997): Lenguas en contacto, Madrid, Arco/Libros.

- (2004): El anglicismo en el español actual, Madrid, Arco/Libros. 
Mena Osorio, Mónica (1986): Disponibilidad léxica infantil en tres niveles de enseñanza básica, Concepción, Universidad de Concepción, Tesis de maestría.

Mesa Canales, Rosa M. (1989) Disponibilidad léxica en preescolares, México, Universidad Nacional Autónoma de México. Memoria de licenciatura inédita.

Meteus Ferro G.E. y A. William Santiago (2006): "Disponibilidad léxica en estudiantes bogotanos", Folios, Bogotá, Universidad Pedagógica Nacional, $3-26$.

MiCHÉA, RENÉ (1953): "Mots fréquents et mots disponibles. Un aspect nouveau de la statistique du langage", Les langues modernes, 47, 338-344.

Moliner, Ma (1991): Diccionario de uso del español. Madrid, Gredos, 2 vols.

Morales, Amparo (1986): Léxico básico del español de Puerto Rico. San Juan de Puerto Rico. Academia Puertorriqueña de la Lengua Española.

MORENO FERnÁNDEZ, F (2007) “Anglicismos en el léxico disponible de los adolescentes hispanos de Chicago" en Potowsky, K. Y R. CAMERON (eds.): Spanish in contac: Policy, Social and Linguistic Inquiries, Amsterdam, John Benjamins, 41-58.

_ (2012): "Disponibilidad léxica: cuestiones metodológicas. A propósito de la disponibilidad léxica de los estudiantes hispanos de Redwood City", Revista Nebrija de Lingüística Aplicada, 11, 51-59.

Moreno FernándeZ, F. et al. (1995): “Cálculo de disponibilidad léxica. E1 programa Lexidisp", Lingüística, ALFAL, 7, 243-249.

Muller, CHARLes (1973): Estadística lingüística, Madrid, Gredos.

MundinA, B. (1873) Historia, geografía y estadística de la provincia de Castellón, Castellón, Caja de Ahorros y Monte de Piedad de Castellón, 1988.

Murillo RoJAS, M (1993): "Disponibilidad léxica en los preescolares: estudio de cinco campos semánticos”, Káñina, revista de artes y letras, XVII, 2, 117127, Universidad de Costa Rica.

_ (1994): “Comidas y bebidas: un estudio de disponibilidad léxica en preescolares", Káñina, 18/2, 117-133.

(1998): “Crecimiento de la disponibilidad léxica: niños de preescolar y primer ciclo de la educación básica costarricense", Revista de Filología y Lingüística de la Universidad de Costa Rica, XXV, 2, 187-203. 
_ Y V. SÁNCHEZ CORRALES (2004): "Disponibilidad léxica y educación lingüística en niños preescolares costarricenses", en PRADO ARAGONÉS, J. Y M M $^{a}$ V. Galloso Camacho (eds.) Diccionario, léxico y cultura, Huelva, Universidad de Huelva, 215-232.

NinYOLES, R.L. (1988): Conflicte lingüístic valencià. Substitució lingüística $i$ ideologies diglòssiques, Valencia, L’ham (1ª ed. 1969).

_ (1992): El País Valencià a l'eix mediterrani, Valencia, L'Eixam D.L.

_ (2000): La societat valenciana: estructura social i institucional, Alzira, Bromera.

NJOCK, P.E. (1979): L'univers familier de l'enfant africain, Québec, CIRB. Université Laval.

ORTEGA OJEDA, GONZALO (1996): "Implicaciones dialectológicas y didácticas del léxico disponible", Segoviano, Carlos (ed.): La enseñanza del léxico español como lengua extranjera, Madrid, Vervuert Iberoamericana, 22-34.

ORTEll ChABRERA, ViCENT M. (1994): Geografía urbana y del poblamiento en la Plana de Castelló, Excmo. Ayuntamiento de Castellón.

PAREDES GARCíA, F. (2001a): "Disponibilidad léxica de alumnos de enseñanza secundaria de Alcalá y su comarca: resultados generales", en DE LA CRUZ CABANILla, I. et al. (eds.): La lingüística aplicada a finales de siglo XX. Ensayos y propuestas, Alcalá de Henares, Servicio de Publicaciones de la Universidad de Alcalá, tomo 2, 721-728.

_ (2001b): "Disponibilidad de los extranjerismos en estudiantes de Educación Secundaria” en Zorraquino, Ma. A. y Diez PELEgRín, CRISTINA (eds.) ¿Qué español enseñar? Norma y variación lingüísticas en la enseñanza del español a extranjeros. Actas del XI Congreso Internacional de ASELE, Universidad de Zaragoza, 567-576.

_ (2005): "El léxico de los colores: convergencias y divergencias en grupos sociales de Madrid", en XIV Congreso Internacional de la Asociación de Lingüística y Filología de la América Latina (ALFAL). Memorias, vol I, sección Dialectología y sociolingüística, Monterrey, Universidad Autónoma de Nuevo León, 131-140.

_ (2006): “Aportes de la disponibilidad léxica a la psicolingüística: una aproximación desde el léxico de los colores”, Lingüística, 18, 19-55. 
_ (1012): "Desarrollos teóricos y metodológicos recientes de los estudios de disponibilidad léxica", Revista Nebrija de Lingüística aplicada, 11 (6), 78100.

_ (2014): “A vueltas con la selección de 'centros de interés' en los estudios de disponibilidad léxica: para una propuesta renovadora a propósito de la disponibilidad léxica en ELE”, Revista Nebrija de Lingüística Aplicada, 8, 4.

_ (2015): "Disponibilidad Léxica y enseñanza de ELE: el léxico disponible como fuente curricular y como recurso en el aula", Linred, Lingüística en la red. V Jornadas de Lengua y Comunicación "Léxico, enseñanza e investigación".

_, L. Guerra y E. Gómez (en prensa): Léxico disponible de los estudiantes preuniversitarios madrileños, Madrid, Universidad de Alcalá y Universidad Europea de Madrid.

Pascual, Vicent (1996): Diccionari Tabarca Valencià-Castellà /CastellàValencià, Valencia, Tabarca.

_ (1997): "La educación en dos lenguas en el País Valenciano", en CALVo, J. Y J. GODENZZI (eds.): Multilingüismo y educación bilingüe en América y España, Valencia, Centro de Estudios Regionales Andinos Bartolomé de las Casas.

PASCUAL, V. Y V. SALA (1991): Un model educatiu per a un sistema escolar amb tres llengües, Valencia, Generalitat Valenciana (Conselleria de Cultura i Educació).

Pastor Millán, Ma A. y F.J. SÁnchez García (2008): El léxico disponible de Granada y su provincia, Granada, Universidad de Granada.

PAYRATÓ, LLUís (1985): La interferencia lingüística. Comentaris i exemples catalàcastellà, Barcelona, Publicacións de l'Abadia de Monserrat.

PEREZ JiMÉNEZ, ENMA (2016): El léxico disponible de los estudiantes preuniversitarios en La Rioja, La Rioja, Universidad de La Rioja. Tesis doctoral.

PITARCH, V. (1988): "Normalització lingüística: la vía cívica", en ALEMANY FERRER, R. (ed.): Els procesos de normalització lingüística a l'Estat español actual, Ayuntamiento de Benidorm y Universidad de Alicante, 205-223.

Poch Olivé, D. (2016): “El acento catalán: particularidades fonéticas del español de Cataluña", en POCH, D.: El español en contacto con las otras lenguas peninsulares, Madrid, Iberoamericana/Vervuert, 315-339. 
POPLACK, S. Y D. SANKOFF (1984): "Borrowing. The synchrony of integration", Linguistics, 22, 99-135.

PradiLla, M.A. (1999): "El secessionisme lingüístic valencià" en PradiLla, M.A. (ed.): La llengua catalana al tombant del mil.leni. Aproximació sociolingüística, Barcelona, Empúries.

Prado Aragonés, J. (2005): "La disponibilidad léxica de Huelva y sus posibilidades para la enseñanza", en PRADO J Y J. HERAS: Aspectos de Lengua y literatura y su enseñanza en Andalucía, Granada, Grupo Editorial Universitario, 151-164.

_ (2005): “Orientaciones didácticas para la planificación de la enseñanza del léxico a partir de los repertorios de disponibilidad léxica", en en PRADO J Y J. HERAS: Aspectos de Lengua y literatura y su enseñanza en Andalucía, Granada, Grupo Editorial Universitario,167-178.

_ (2008): “Anglicismos en el centro de interés Juegos y diversiones en el Léxico Disponible de los preuniversitarios de Huelva", en Actas del XI Simposio General de la Asociación de Profesores de Español, Toledo, Consejería de Educación y Ciencia, Junta de las Comunidades de Castilla -la Mancha, 123136.

(2009): "Dialectalismos en el Léxico Disponible de Huelva, en relación con el centro de interés Alimentos y bebidas", en CAMACHO TAOBADA, M V., J.J. RodríGUEZ Y J. SANTANA (eds.): Estudios de Lengua Española: Descripción, variación y uso. Homenaje a Humberto López Morales, Madrid-Frankfurt: Iberoamericana-Vervuert, 567-594.

Prado Aragonés, J. Y Ma V. GALloso (2005): Léxico disponible de la provincia de Huelva: Nivel Preuniversitario, Huelva, Servicio de Publicaciones de la Universidad de Huelva.

_ (2008a): Léxico disponible de Huelva. Nivel $6^{o}$ de Educación Primaria, Huelva, Servicio de Publicaciones de la Universidad de Huelva.

_ (2008b): "La variable sexo en el léxico disponible de alumnos de primaria y bachillerato de Huelva: resultados cuantitativos" en BLAS ARROYO, J.L. Y M. Casanova, M. Velando, J. Vellón (eds.): Discurso y sociedad. Nuevas contribuciones al estudio de la lengua en un contexto social, II. Castellón, Publicaciones de la Universitat de Castelló, 583-595. 
- (2012): "Disponibilidad léxica de Extremadura: aspectos metodológicos", en Ma. V. Galloso (ed.): La investigación de la lengua y la literatura en la onubense, Huelva, Universidad de Huelva.

_ (2015): El léxico disponible de Extremadura y comparación con el de Andalucía, Universidad de Huelva.

Prado Aragonés, J., Ma V. Galloso y Manuel Célio Conceição (2009): La disponibilidad léxica en situación de contacto de lenguas en las zonas limítrofes de Andalucía y Extremadura (España) y Algarve y Alentejo (Portugal), Huelva, Universidad de Huelva.

Prado Aragonés, J., Mª V. Galloso y M. VÁzQuez (2006): Diccionario del léxico disponible de alumnos de $4^{\circ}$ curso de Educación Secundaria Obligatoria de Huelva, Huelva, Universidad de Huelva.

PRATT, Chris (1980): El anglicismo en el español peninsular contemporáneo, Madrid, Gredos.

QUEROL, E. (2004) “Les normes sociolingüístiques de Castelló", en La Llengua i la Literatura: Història i actualitat, Institut d'Estudis Catalans i Universitat Jaume I, 21-43.

RAE (2001): Diccionario de la lengua española, Madrid, Espasa Calpe, $22^{\mathrm{a}} \mathrm{ed}$.

_ (2014): Diccionario de la lengua española, Madrid, Espasa Calpe, $23^{\mathrm{a}} \mathrm{ed}$.

- y Asociación de ACAdemias de la lengua española (2005): Diccionario panhispánico de dudas, Madrid, Santillana Ediciones Generales.

RAMíReZ, M.J. (2000): "La expresión variable del futuro verbal en el español castellonense", en $V$ Jornadas de Fomento a la Investigación, Servicio de Publicaciones de la Universitat Jaume I, (ed. en CD-ROM).

Rodríguez Bou, ISMAel (1952): Recuento de vocabulario español, Río Piedras, Consejo Superior de Enseñanza.

RodríGuez, F y A. LILLO (1997): Nuevo diccionario de anglicismos, Madrid, Gredos.

Román, Belén (1985): Disponibilidad léxica en escolares de Dorado, Río Piedras, Universidd de Puerto Rico. Memoria de licenciatura inédita.

SAMPER HERnÁNDEZ, MARTA (2001): "Dificultades de los estudios de disponibilidad léxica en ELE: los criterios de edición de los materiales" en BARTOL HERNÁNDEZ, J.A. et al. (eds.): Nuevas aportaciones al estudio de la 
lengua española. Investigaciones filológicas, Salamanca, Luso-Española Ediciones, 277-285.

_ (2002): Disponibilidad léxica en alumnos de español como lengua extranjera,

Colección Monografías, 4, Málaga, ASELE.

_ (2003): “Léxico disponible y 'nivel educativo' en escolares de Gran Canaria: datos cuantitativos", DEA, 5, 105-125.

_ (2005): "Dialectalismos en el léxico disponible de escolares grancanarios" en L.

Santos, J. Borrego, J.F. García, J.J. Gómez y E. Prieto (eds.) Palabras, normas, discurso, en memoria de Fernando Lázaro Carreter, Salamanca: Ediciones Universidad de Salamanca, 1065-1078.

_ (2008): "Datos comparativos entre dos léxicos disponibles: Aragón y Gran Canaria”, en ARNAL, $\mathrm{M}^{\mathrm{a}}$ L. (ed.): Estudios sobre disponibilidad léxica en los jóvenes aragoneses, Zaragoza, Institución Fernando el Católico, 245-282.

_ (2009): Evolución de la disponibilidad léxica en estudiantes grancanarios de enseñanza primaria y secundaria, Las Palmas de Gran Canaria, Cabildo de Gran Canaria.

__ Y R. Ma JiMÉNEZ CATALÁN (2014): "Researching Lexical Availability in L: Some Methodogical Issues” en JimÉNEZ CATALÁN, R.Mª (ed.): Lexical Availability in English and Spanish as a Second Language, Educational Linguistics, 17, Springer Sciencie+Business Media Dordrecht.

SAMPER PAdilla, José ANTONio (1998): "Criterios de edición del léxico disponible", Lingüística, 10, 311-333.

_ (1999): "Léxico disponible y variación dialectal: datos de Puerto Rico y Gran Canaria" en Forastieri, E., J. CARdonA, H. LóPez Morales, Y A. Morales de Walters (eds.): Estudios de lingüística hispánica. Homenaje a María Vaquero. San Juan de Puerto Rico, Universidad de Puerto Rico, 550573.

- (2006): "Disponibilidad léxica y sociolingüística", en BLAS, J.L., M. CASANOVA Y M. VELANDO (eds.): Discurso y sociedad: contribuciones al estudio de la lengua en contexto social, Castellón, Universitat Jaume I, 99-120.

SAMPer Padilla, J.A. Y C.E. Hernández CABrera (1997): "El estudio de la disponibilidad léxica en Gran Canaria: datos iniciales y variación sociolingüística", en AlmEDiA, M. Y J. DORTA (eds.): Contribuciones al 
estudio de la lingüística hispánica. Homenaje a Ramón Trujillo Carreño, Universidad de La Laguna, tomo II, 229-239.

(2006): "Densidad de dialectalismos y condicionantes sociales en el léxico disponible de Gran Canaria” en Sedano, M., A. BolíVAR Y M. ShIRo (eds.): Haciendo Lingüística. Homenaje a Paola Bentivoglio, Caracas, Universidad Central de Venezuela, 537-553.

—, JuAn José Bellón y MARTA SAMPer (2003a): "El proyecto de estudio de la disponibilidad léxica en español”, en Avila, RAúl, José A. SAMPER Y Hiroto Ubeda (eds.): Pautas y pistas en el análisis del léxico hispano (americano), Frankfurt-Madrid, Vevuert Iberoamaricana, 27-140.

_, C.E. HERnÁNDEZ Y J.J. BELlóN (2003b): "Léxico disponible y variación dialectal: datos de Gran Canaria y Córdoba” en DíAZ Alayón, C. (ed.): Estudios sobre el español de Canarias: I Congreso Internacional sobre el Español de Canarias, Islas Canarias, Academia Canaria de la Lengua, II, 1077-1099.

SAMPeR PADIlla, J.A. Y MARTA SAMPER HeRnÁNDEZ (2006): “Aportaciones recientes de los estudios de disponibilidad léxica", Lynx. Panorama de Estudios Lingüísticos, 5, 5-95.

- (2007): "El proyecto panhispánico de disponibilidad léxica y los cotejos dialectales", Lingüística, 19, 88-116.

- (2009): "Estudios sobre anglicismos en el proyecto panhispánico de léxico disponible", en Veyrat Rigat, M. y E. SERRA Alegre La lingüística como reto epistemológico y como acción social. Estudios dedicados al profesor Ángel López García con ocasión de su sexagésimo aniversario, Madrid, Arco/Libros, 869-880.

SÁNCHEZ AdELl, J. et al. (1990): Castellón de la Plana y su provincia, Castellón, Inculca.

SÁnchez Corrales, V.M. y M. Murillo Rojas (1993): “Campos semánticos y disponibilidad léxica en preescolares", Revista de Educación, 17/2, 15-25.

_ (2006): Disponibilidad léxica de los niños preescolares costarricenses, San José de Costa Rica, Universidad de Costa Rica.

SÁNCHEZ MACARro, ANTONia (1993): "La invasión del anglicismo en el español contemporáneo", en JiMÉNEZ MARTíneZ, J. y R. MORANT MARCO (eds.): 
Actas del Simposio sobre el español de España y el español de América, Universitat de València- University of Virginia, 19-34.

SÁNCHEZ-SAUS LASERNA, M. (2010): "La variación en el léxico disponible de los estudiantes de español como lengua extranjera. Resultados cuantitativos" en Bueno Alonso, J.L. et al.: Analizar datos: Describir variación /Analysing data: Describing variation, Universidad de Vigo, 265-273.

_ (2011): Bases semánticas para el estudio de los centros de interés del léxico disponible. Disponibilidad léxica de informantes extranjeros en las universidades andaluzas, Cádiz, Universidad de Cádiz. Tesis doctoral inédita.

_ (2016): Léxico disponible de los estudiantes de español como lengua extranjera en las universidades andaluzas, Sevilla, Editorial Universidad de Sevilla.

SANCHO SÁNCHEZ, MiRIAM (2006): "Disponibilidad léxica de los hispanos en EE.UU.”, Cuadernos Cervantes de la Lengua Española, 63, 22-31.

SANTIAgo Guervós, JAVIER DE (2008): El léxico disponible de Segovia, Burgos, Fundación Instituto Castellano y Leonés de la Lengua.

SARAlegui, CARMEn y CRistina TABernero (2008): “Aportación al proyecto panhispánico de léxico disponible: Navarra” en Olza Moreno, Ines, M. Casado Velarde y Ramón González (eds.): Actas del XXXVII Simposio Internacional de la Sociedad Española de Lingüística (SEL), Servicio de publicaciones de la universidad de Navarra, 745-761.

SARTHOU CARRERES, C. (1913) Geografia General del Reino de Valencia. Provincia de Castellón, Barcelona, Alberto Martín. Edición facsímil, Publicaciones del Seminario de estudios económicos y sociales de la Caja de Ahorros y Monte de Piedad de Castellón, 1989.

SeCo, Manuel (1977): "El léxico de hoy”, en Comunicación y lenguaje, Madrid, Karpos, 183-201.

_ (1986): Diccionario de dudas y dificultades de la lengua española, Madrid, Espasa Calpe. (2004, 10 a ed.).

Serrano Zapata, MARIBel (2002) Análisis sociolingüístico del léxico castellano disponible en la ciudad de Lleida, Lleida, Universitat de Lleida. Trabajo de investigación inédito.

- (2003): "Disponibilidad léxica en la provincia de Lleida: aspectos metodológicos", Interlingüística, 14, 929-937. 
- (2004): “Aspectos sociolingüísticos del léxico disponible castellano de los preuniversitarios leridanos", Pragmalingüística, 12,147-165.

- (2006): "Consecuencias del contacto de lenguas en Lérida: interferencias detectadas en las encuestas de disponibilidad léxica", en BLAS, J.L., M. CASAnOVA Y M. Velando (EDS.): Discurso y sociedad: contribuciones al estudio de la lengua en contexto social, Castellón, Universitat Jaume I, 811829.

(2014): Disponibilidad léxica en la provincia de Lleida: estudio comparado de dos lenguas en contacto, Lleida, Universitat de Lleida. Tesis doctoral. Hhtp://hdl.handle.net/10803/285008.

_ (2016): "Fenòmens de contacte lingüístic en el lèxic disponible català de Lleida", Studia Romanica Posnaniensia 43/2, 51-64.

SiguÁn, M (1994): Conocimiento y uso de las lenguas de España. (Investigación sobre el conocimiento y uso de las lenguas cooficiales en las Comunidades Autónomas bilingües), Madrid, Centro de Investigaciones sociológicas.

_ (1999): Conocimiento y uso de las lenguas, Madrid, CIS.

Silva-Corvalán, C. (1989): Sociolingüística. Teoría y análisis, Madrid, Alhambra.

TABernero Sala, Cristina (2008a): "Disponibilidad léxica y contacto de lenguas", Universidad de Navarra, Oihenart, 23, 545-565. www.euskomedia.org/PDFAnlt/literatura/23/23545565.pdf

_ (2008b): "El léxico disponible como fuente de aproximación al estudio de los regionalismos", en OlZA, I. et al. (ed.): Actas del XXXVII Simposio Internacional de la Sociedad Española de Lingüística. Pamplona, Servicio de Publicaciones de la Universidad de Navarra, 811-824.

Tej K. Bhatia y William C. Ritchie (eds.) (2008): The Handbook of Bilingualism, Hoboke: Wiley-Blackwel.

Tello, JAime (1995): “Anglicismos en el habla española”, Thesaurus, Tomo L. Núms. 1, 2 y 3. Centro Virtual Cervantes, 204-238.

Terrádez Gurrea, M (1997): "Estudio de la disponibilidad de los inmigrantes residentes en Valencia”, en HERnÁndeZ SACRISTÁN, CARLOS Y R. MORANT (eds.): Lenguaje y Emigración, 189-203.

Tomé CoRnejo, C. (2011): "Reflexiones en torno a los centros de interés", en Galloso CAmAChO, $\mathrm{M}^{\mathrm{a}} \mathrm{V}$. (ed.): La investigación de la lengua y la 
literatura en la onubense, Servicio de Publicaciones de la Universidad de Huelva, 119-159

TORRES GONZÁlEZ, A. N. Y A. B. GARCÍA FALERO (2009): "Planificación y primeros resultados de la disponibilidad léxica en Tenerife", en CoRbELla, D. Y J. DORTA (eds.): La investigación dialectológica en la actualidad, Santa Cruz de Tenerife, Agencia Canaria de Investigación, Innovación y Sociedad de la Información, 75-101.

TRIGo IbÁÑEZ, Ester (2007): El léxico disponible de la provincia de Sevilla: variación versus déficit. Universidad de Cádiz. Tesis doctoral.

_ (2011): Dialectología y cultura: El léxico disponible de los preuniversitarios sevillanos, Valencia, Aduana Vieja.

UnAmuno, Miguel de (1945): “Sobre la lengua española”, Ensayos, I, Madrid, Aguilar, 322.

VAlencia, Alba (1997): "Disponibilidad léxica. Muestreos y estadísticos", Onomazein 2, 197-226, Universidad de Chile.

_ (2005): "Dialectalismos en el léxico disponible chileno", en Actas del XIV Congreso Internacional de ALFAL I, Monterrey: Universidad Autónoma de Nuevo León, 230-239.

_ Y M. ECHEVERRÍA (1998): Disponibilidad léxica de cuarto año de Educación Media, Santiago de Chile, Universidad de Chile y Universidad de Concepción.

- (1999a): Disponibilidad léxica en estudiantes chilenos, Santiago de Chile, Ediciones Universidad de Chile.

_ (1999b): "El factor geográfico en la disponibilidad léxica chilena" en SAMPER PADILlA, J.A. et al. (eds.): Actas del XI Congreso Internacional de la $A L F A L$, Las Palmas de Gran Canaria, Universidad de Las Palmas de Gran Canaria, tomo II, 1705-1711.

VARGas SANDOVAL, PATRICIA (1991). "La disponibilidad léxica: un diagnóstico al hablante medio de la V Región en seis centros de interés", Nueva Revista del Pacífico, 33/36, Universidad de Playa Ancha, Valparaíso, 115-123.

VENY, J. (1982): Els parlars catalans, Palma de Mallorca, Ed. Moll.

Verdeses- Mirabal, Roberto (2012): “Disponibilidad léxica de los estudiantes hispanos de Redwood City, CA”, Revista Nebrija de Lingüística Aplicada, $11,6,72-74$. 
VV.AA. (1985) La provincia de Castellón de la Plana. Tierras y gentes, Seminario de Estudios Económicos y Sociales de la Caja de Ahorros y Monte de Piedad de Castellón.

WeInReICH, U. (1953): Languages in contact: Findings and Problems, La Haya, Mouton. Traducción al español, 1974.

WiCHEREK, MARTA (2008): “Los anglicismos en las lenguas española y polaca: un análisis contrastivo”, en Blas ARroyo, José LuIS y MANuEla CASANOVA, Mónica Velando, JaVier Vellón (eds.): Discurso y sociedad II. Nuevas contribuciones al estudio de la lengua en un contexto social, Publicaciones de la Universidad de Castellón, 773-780. 

8

\section{DICCIONARIOS DEL LÉXICO DISPONIBLE DE CASTELLÓN}





\section{DICCIONARIOS DISPONIBLES DE CASTELLÓN}

\subsection{Diccionario por orden de disponibilidad}

Los listados de palabras que presentamos a continuación constituyen el diccionario del Léxico Disponible de Castellón y aparecen ordenados según el índice de disponibilidad, de mayor a menor, y por centros de interés. Asimismo, los extranjerismos se lematizan en cursiva, los valencianismos en negrita y las marcas comerciales aparecerán en mayúscula y con asterisco.

\section{PARTES DEL CUERPO}

\begin{tabular}{|c|l|c|c|c|c|}
\hline $\mathrm{N}^{\mathbf{0}}$ & Palabra & Disponibilidad & $\begin{array}{c}\text { Frecuencia } \\
\text { relativa }\end{array}$ & Aparición & $\begin{array}{c}\text { Frecuencia } \\
\text { acumulada }\end{array}$ \\
\hline 1 & ojo & 0.64867 & $3.476 \%$ & $89.831 \%$ & $3.476 \%$ \\
\hline 2 & brazo & 0.63469 & $3.105 \%$ & $80.226 \%$ & $6.581 \%$ \\
\hline 3 & cabeza & 0.61583 & $2.842 \%$ & $73.446 \%$ & $9.423 \%$ \\
\hline 4 & pierna & 0.61548 & $3.192 \%$ & $82.486 \%$ & $12.615 \%$ \\
\hline 5 & mano & 0.59788 & $3.083 \%$ & $79.661 \%$ & $15.698 \%$ \\
\hline 6 & dedo & 0.57446 & $3.378 \%$ & $87.288 \%$ & $19.076 \%$ \\
\hline 7 & nariz & 0.57368 & $3.290 \%$ & $85.028 \%$ & $22.366 \%$ \\
\hline 8 & pie & 0.54637 & $3.214 \%$ & $83.051 \%$ & $25.580 \%$ \\
\hline 9 & oreja & 0.54542 & $3.301 \%$ & $85.311 \%$ & $28.881 \%$ \\
\hline 10 & boca & 0.44555 & $2.645 \%$ & $68.362 \%$ & $31.526 \%$ \\
\hline 11 & rodilla & 0.37113 & $2.766 \%$ & $71.469 \%$ & $34.292 \%$ \\
\hline 12 & codo & 0.32046 & $2.449 \%$ & $63.277 \%$ & $36.741 \%$ \\
\hline 13 & uña & 0.31063 & $2.449 \%$ & $63.277 \%$ & $39.190 \%$ \\
\hline 14 & cuello & 0.30377 & $2.099 \%$ & $54.237 \%$ & $41.289 \%$ \\
\hline 15 & hombro & 0.25667 & $2.022 \%$ & $52.260 \%$ & $43.311 \%$ \\
\hline 16 & diente & 0.25040 & $1.913 \%$ & $49.435 \%$ & $45.224 \%$ \\
\hline 17 & pecho & 0.24266 & $1.957 \%$ & $50.565 \%$ & $47.181 \%$ \\
\hline 18 & tobillo & 0.23970 & $2.022 \%$ & $52.260 \%$ & $49.203 \%$ \\
\hline 19 & pelo & 0.22604 & $1.607 \%$ & $41.525 \%$ & $50.810 \%$ \\
\hline 20 & muñeca & 0.21141 & $1.826 \%$ & $47.175 \%$ & $52.636 \%$ \\
\hline 21 & espalda & 0.19331 & $1.683 \%$ & $43.503 \%$ & $54.319 \%$ \\
\hline 22 & corazón & 0.19001 & $1.651 \%$ & $42.655 \%$ & $55.970 \%$ \\
\hline 23 & ceja & 0.18952 & $1.465 \%$ & $37.853 \%$ & $57.435 \%$ \\
\hline 24 & lengua & 0.17313 & $1.476 \%$ & $38.136 \%$ & $58.911 \%$ \\
\hline 25 & estómago & 0.16043 & $1.443 \%$ & $37.288 \%$ & $60.354 \%$ \\
\hline 26 & pulmón & 0.14802 & $1.410 \%$ & $36.441 \%$ & $61.764 \%$ \\
\hline 27 & pene & 0.14324 & $1.279 \%$ & $33.051 \%$ & $63.043 \%$ \\
\hline
\end{tabular}




\begin{tabular}{|c|c|c|c|c|c|}
\hline 28 & tronco & 0.13964 & $0.798 \%$ & $20.621 \%$ & $63.841 \%$ \\
\hline 29 & cadera & 0.13711 & $1.192 \%$ & $30.791 \%$ & $65.033 \%$ \\
\hline 30 & labio & 0.12346 & $0.940 \%$ & $24.294 \%$ & $65.973 \%$ \\
\hline 31 & pestaña & 0.12116 & $1.049 \%$ & $27.119 \%$ & $67.022 \%$ \\
\hline 32 & culo & 0.11874 & $1.071 \%$ & $27.684 \%$ & $68.093 \%$ \\
\hline 33 & hígado & 0.11516 & $1.115 \%$ & $28.814 \%$ & $69.208 \%$ \\
\hline 34 & antebrazo & 0.09827 & $0.754 \%$ & $19.492 \%$ & $69.962 \%$ \\
\hline 35 & riñón & 0.09778 & $0.962 \%$ & $24.859 \%$ & $70.924 \%$ \\
\hline 36 & muslo & 0.08656 & $0.787 \%$ & $20.339 \%$ & $71.711 \%$ \\
\hline 37 & ombligo & 0.08363 & $0.754 \%$ & $19.492 \%$ & $72.465 \%$ \\
\hline 38 & cara & 0.08173 & $0.448 \%$ & $11.582 \%$ & $72.913 \%$ \\
\hline 39 & cintura & 0.07168 & $0.634 \%$ & $16.384 \%$ & $73.547 \%$ \\
\hline 40 & cerebro & 0.06866 & $0.634 \%$ & $16.384 \%$ & $74.181 \%$ \\
\hline 41 & vagina & 0.06776 & $0.689 \%$ & $17.797 \%$ & $74.870 \%$ \\
\hline 42 & intestino & 0.06632 & $0.732 \%$ & $18.927 \%$ & $75.602 \%$ \\
\hline 43 & frente & 0.06357 & $0.557 \%$ & $14.407 \%$ & $76.159 \%$ \\
\hline 44 & barriga & 0.06242 & $0.579 \%$ & $14.972 \%$ & $76.738 \%$ \\
\hline 45 & tórax & 0.05885 & $0.448 \%$ & $11.582 \%$ & $77.186 \%$ \\
\hline 46 & páncreas & 0.05682 & $0.547 \%$ & $14.124 \%$ & $77.733 \%$ \\
\hline 47 & testículo & 0.05488 & $0.557 \%$ & $14.407 \%$ & $78.290 \%$ \\
\hline 48 & extremidad & 0.05015 & $0.262 \%$ & $6.780 \%$ & $78.552 \%$ \\
\hline 49 & tibia & 0.04866 & $0.459 \%$ & $11.864 \%$ & $79.011 \%$ \\
\hline 50 & gemelo & 0.04611 & $0.492 \%$ & $12.712 \%$ & $79.503 \%$ \\
\hline 51 & mejilla & 0.04532 & $0.481 \%$ & $12.429 \%$ & $79.984 \%$ \\
\hline 52 & abdomen & 0.04511 & $0.372 \%$ & $9.605 \%$ & $80.356 \%$ \\
\hline 53 & peroné & 0.04508 & $0.448 \%$ & $11.582 \%$ & $80.804 \%$ \\
\hline 54 & fémur & 0.04386 & $0.394 \%$ & $10.169 \%$ & $81.198 \%$ \\
\hline 55 & cabello & 0.04201 & $0.317 \%$ & $8.192 \%$ & $81.515 \%$ \\
\hline 56 & barbilla & 0.04144 & $0.426 \%$ & $11.017 \%$ & $81.941 \%$ \\
\hline 57 & tráquea & 0.04084 & $0.415 \%$ & $10.734 \%$ & $82.356 \%$ \\
\hline 58 & costilla & 0.04046 & $0.437 \%$ & $11.299 \%$ & $82.793 \%$ \\
\hline 59 & vena & 0.04011 & $0.470 \%$ & $12.147 \%$ & $83.263 \%$ \\
\hline 60 & esófago & 0.03915 & $0.437 \%$ & $11.299 \%$ & $83.700 \%$ \\
\hline 61 & talón & 0.03804 & $0.394 \%$ & $10.169 \%$ & $84.094 \%$ \\
\hline 62 & faringe & 0.03742 & $0.361 \%$ & $9.322 \%$ & $84.455 \%$ \\
\hline 63 & laringe & 0.03724 & $0.339 \%$ & $8.757 \%$ & $84.794 \%$ \\
\hline 64 & músculo & 0.03702 & $0.394 \%$ & $10.169 \%$ & $85.188 \%$ \\
\hline 65 & columna (vertebral) & 0.03546 & $0.372 \%$ & $9.605 \%$ & $85.560 \%$ \\
\hline 66 & pantorrilla & 0.03369 & $0.328 \%$ & $8.475 \%$ & $85.888 \%$ \\
\hline 67 & hueso & 0.03322 & $0.361 \%$ & $9.322 \%$ & $86.249 \%$ \\
\hline 68 & nudillo & 0.03210 & $0.361 \%$ & $9.322 \%$ & $86.610 \%$ \\
\hline 69 & axila & 0.03122 & $0.361 \%$ & $9.322 \%$ & $86.971 \%$ \\
\hline 70 & nuca & 0.03094 & $0.339 \%$ & $8.757 \%$ & $87.310 \%$ \\
\hline 71 & omóplato & 0.03005 & $0.284 \%$ & $7.345 \%$ & $87.594 \%$ \\
\hline 72 & nalga & 0.02815 & $0.273 \%$ & $7.062 \%$ & $87.867 \%$ \\
\hline 73 & párpado & 0.02810 & $0.240 \%$ & $6.215 \%$ & $88.107 \%$ \\
\hline 74 & esternón & 0.02801 & $0.284 \%$ & $7.345 \%$ & $88.391 \%$ \\
\hline 75 & bíceps & 0.02688 & $0.295 \%$ & $7.627 \%$ & $88.686 \%$ \\
\hline
\end{tabular}




\begin{tabular}{|c|c|c|c|c|c|}
\hline 76 & radio & 0.02599 & $0.273 \%$ & $7.062 \%$ & $88.959 \%$ \\
\hline 77 & pómulo & 0.02594 & $0.284 \%$ & $7.345 \%$ & $89.243 \%$ \\
\hline 78 & garganta & 0.02593 & $0.295 \%$ & $7.627 \%$ & $89.538 \%$ \\
\hline 79 & glúteo & 0.02572 & $0.284 \%$ & $7.345 \%$ & $89.822 \%$ \\
\hline 80 & arteria & 0.02212 & $0.251 \%$ & $6.497 \%$ & $90.073 \%$ \\
\hline 81 & ingle & 0.02211 & $0.240 \%$ & $6.215 \%$ & $90.313 \%$ \\
\hline 82 & ovario & 0.02175 & $0.240 \%$ & $6.215 \%$ & $90.553 \%$ \\
\hline 83 & tendón & 0.02114 & $0.219 \%$ & $5.650 \%$ & $90.772 \%$ \\
\hline 84 & cúbito & 0.02021 & $0.219 \%$ & $5.650 \%$ & $90.991 \%$ \\
\hline 85 & clavícula & 0.02018 & $0.186 \%$ & $4.802 \%$ & $91.177 \%$ \\
\hline 86 & espinilla & 0.01953 & $0.197 \%$ & $5.085 \%$ & $91.374 \%$ \\
\hline 87 & tríceps & 0.01913 & $0.219 \%$ & $5.650 \%$ & $91.593 \%$ \\
\hline 88 & teta & 0.01883 & $0.164 \%$ & $4.237 \%$ & $91.757 \%$ \\
\hline 89 & ano & 0.01866 & $0.197 \%$ & $5.085 \%$ & $91.954 \%$ \\
\hline 90 & genital & 0.01847 & $0.186 \%$ & $4.802 \%$ & $92.140 \%$ \\
\hline 91 & pubis & 0.01786 & $0.197 \%$ & $5.085 \%$ & $92.337 \%$ \\
\hline 92 & trasero & 0.01666 & $0.164 \%$ & $4.237 \%$ & $92.501 \%$ \\
\hline 93 & vientre & 0.01618 & $0.142 \%$ & $3.672 \%$ & $92.643 \%$ \\
\hline 94 & piel & 0.01515 & $0.186 \%$ & $4.802 \%$ & $92.829 \%$ \\
\hline 95 & rótula & 0.01490 & $0.164 \%$ & $4.237 \%$ & $92.993 \%$ \\
\hline 96 & pezón & 0.01482 & $0.142 \%$ & $3.672 \%$ & $93.135 \%$ \\
\hline 97 & seno & 0.01476 & $0.109 \%$ & $2.825 \%$ & $93.244 \%$ \\
\hline 98 & pectoral & 0.01457 & $0.131 \%$ & $3.390 \%$ & $93.375 \%$ \\
\hline 99 & cráneo & 0.01419 & $0.164 \%$ & $4.237 \%$ & $93.539 \%$ \\
\hline 100 & intestino grueso & 0.01409 & $0.131 \%$ & $3.390 \%$ & $93.670 \%$ \\
\hline 101 & dedo del pie & 0.01404 & $0.109 \%$ & $2.825 \%$ & $93.779 \%$ \\
\hline 102 & dedo de la mano & 0.01390 & $0.098 \%$ & $2.542 \%$ & $93.877 \%$ \\
\hline 103 & mandíbula & 0.01387 & $0.109 \%$ & $2.825 \%$ & $93.986 \%$ \\
\hline 104 & vejiga & 0.01334 & $0.164 \%$ & $4.237 \%$ & $94.150 \%$ \\
\hline 105 & tímpano & 0.01291 & $0.131 \%$ & $3.390 \%$ & $94.281 \%$ \\
\hline 106 & oído & 0.01247 & $0.109 \%$ & $2.825 \%$ & $94.390 \%$ \\
\hline 107 & escroto & 0.01238 & $0.120 \%$ & $3.107 \%$ & $94.510 \%$ \\
\hline 108 & abdominal & 0.01218 & $0.109 \%$ & $2.825 \%$ & $94.619 \%$ \\
\hline 109 & clítoris & 0.01216 & $0.109 \%$ & $2.825 \%$ & $94.728 \%$ \\
\hline 110 & húmero & 0.01152 & $0.087 \%$ & $2.260 \%$ & $94.815 \%$ \\
\hline 111 & intestino delgado & 0.01088 & $0.120 \%$ & $3.107 \%$ & $94.935 \%$ \\
\hline 112 & bazo & 0.01044 & $0.098 \%$ & $2.542 \%$ & $95.033 \%$ \\
\hline 113 & esternocleidomastoideo & 0.01033 & $0.066 \%$ & $1.695 \%$ & $95.099 \%$ \\
\hline 114 & menisco & 0.01010 & $0.087 \%$ & $2.260 \%$ & $95.186 \%$ \\
\hline 115 & tripa & 0.00966 & $0.109 \%$ & $2.825 \%$ & $95.295 \%$ \\
\hline 116 & pelvis & 0.00958 & $0.120 \%$ & $3.107 \%$ & $95.415 \%$ \\
\hline 117 & bronquio & 0.00955 & $0.120 \%$ & $3.107 \%$ & $95.535 \%$ \\
\hline 118 & útero & 0.00929 & $0.098 \%$ & $2.542 \%$ & $95.633 \%$ \\
\hline 119 & paladar & 0.00927 & $0.109 \%$ & $2.825 \%$ & $95.742 \%$ \\
\hline 120 & vértebra & 0.00901 & $0.098 \%$ & $2.542 \%$ & $95.840 \%$ \\
\hline 121 & médula & 0.00884 & $0.087 \%$ & $2.260 \%$ & $95.927 \%$ \\
\hline 122 & vello & 0.00862 & $0.066 \%$ & $1.695 \%$ & $95.993 \%$ \\
\hline 123 & prepucio & 0.00837 & $0.077 \%$ & $1.977 \%$ & $96.070 \%$ \\
\hline
\end{tabular}




\begin{tabular}{|c|c|c|c|c|c|}
\hline 124 & muela & 0.00828 & $0.077 \%$ & $1.977 \%$ & $96.147 \%$ \\
\hline 125 & cuádriceps & 0.00827 & $0.098 \%$ & $2.542 \%$ & $96.245 \%$ \\
\hline 126 & nuez & 0.00749 & $0.087 \%$ & $2.260 \%$ & $96.332 \%$ \\
\hline 127 & apéndice & 0.00739 & $0.109 \%$ & $2.825 \%$ & $96.441 \%$ \\
\hline 128 & torso & 0.00713 & $0.044 \%$ & $1.130 \%$ & $96.485 \%$ \\
\hline 129 & pupila & 0.00698 & $0.077 \%$ & $1.977 \%$ & $96.562 \%$ \\
\hline 130 & lumbar & 0.00686 & $0.066 \%$ & $1.695 \%$ & $96.628 \%$ \\
\hline 131 & cerebelo & 0.00666 & $0.055 \%$ & $1.412 \%$ & $96.683 \%$ \\
\hline 132 & falange & 0.00640 & $0.087 \%$ & $2.260 \%$ & $96.770 \%$ \\
\hline 133 & planta del pie & 0.00607 & $0.077 \%$ & $1.977 \%$ & $96.847 \%$ \\
\hline 134 & meñique & 0.00594 & $0.077 \%$ & $1.977 \%$ & $96.924 \%$ \\
\hline 135 & índice & 0.00555 & $0.066 \%$ & $1.695 \%$ & $96.990 \%$ \\
\hline 136 & sangre & 0.00554 & $0.066 \%$ & $1.695 \%$ & $97.056 \%$ \\
\hline 137 & moflete & 0.00551 & $0.066 \%$ & $1.695 \%$ & $97.122 \%$ \\
\hline 138 & empeine & 0.00545 & $0.077 \%$ & $1.977 \%$ & $97.199 \%$ \\
\hline 139 & extremidad superior & 0.00533 & $0.022 \%$ & $0.565 \%$ & $97.221 \%$ \\
\hline 140 & cervical & 0.00522 & $0.044 \%$ & $1.130 \%$ & $97.265 \%$ \\
\hline 141 & recto & 0.00518 & $0.033 \%$ & $0.847 \%$ & $97.298 \%$ \\
\hline 142 & uretra & 0.00508 & $0.055 \%$ & $1.412 \%$ & $97.353 \%$ \\
\hline 143 & ligamento & 0.00504 & $0.055 \%$ & $1.412 \%$ & $97.408 \%$ \\
\hline 144 & extremidad inferior & 0.00504 & $0.022 \%$ & $0.565 \%$ & $97.430 \%$ \\
\hline 145 & cartílago & 0.00495 & $0.055 \%$ & $1.412 \%$ & $97.485 \%$ \\
\hline 146 & iris & 0.00483 & $0.066 \%$ & $1.695 \%$ & $97.551 \%$ \\
\hline 147 & vesícula & 0.00465 & $0.055 \%$ & $1.412 \%$ & $97.606 \%$ \\
\hline 148 & bilis & 0.00459 & $0.055 \%$ & $1.412 \%$ & $97.661 \%$ \\
\hline 149 & articulación & 0.00458 & $0.055 \%$ & $1.412 \%$ & $97.716 \%$ \\
\hline 150 & trompa de Falopio & 0.00449 & $0.066 \%$ & $1.695 \%$ & $97.782 \%$ \\
\hline 151 & palma & 0.00439 & $0.055 \%$ & $1.412 \%$ & $97.837 \%$ \\
\hline 152 & colon & 0.00428 & $0.033 \%$ & $0.847 \%$ & $97.870 \%$ \\
\hline 153 & mama & 0.00423 & $0.033 \%$ & $0.847 \%$ & $97.903 \%$ \\
\hline 154 & espina dorsal & 0.00403 & $0.033 \%$ & $0.847 \%$ & $97.936 \%$ \\
\hline 155 & córnea & 0.00400 & $0.033 \%$ & $0.847 \%$ & $97.969 \%$ \\
\hline 156 & entrepierna & 0.00398 & $0.033 \%$ & $0.847 \%$ & $98.002 \%$ \\
\hline 157 & cóccix & 0.00397 & $0.044 \%$ & $1.130 \%$ & $98.046 \%$ \\
\hline 158 & abductor & 0.00382 & $0.044 \%$ & $1.130 \%$ & $98.090 \%$ \\
\hline 159 & alvéolo & 0.00382 & $0.044 \%$ & $1.130 \%$ & $98.134 \%$ \\
\hline 160 & lóbulo & 0.00381 & $0.044 \%$ & $1.130 \%$ & $98.178 \%$ \\
\hline 161 & nervio & 0.00367 & $0.044 \%$ & $1.130 \%$ & $98.222 \%$ \\
\hline 162 & fosa nasal & 0.00363 & $0.033 \%$ & $0.847 \%$ & $98.255 \%$ \\
\hline 163 & diafragma & 0.00356 & $0.044 \%$ & $1.130 \%$ & $98.299 \%$ \\
\hline 164 & metacarpo & 0.00351 & $0.033 \%$ & $0.847 \%$ & $98.332 \%$ \\
\hline 165 & anular & 0.00350 & $0.044 \%$ & $1.130 \%$ & $98.376 \%$ \\
\hline 166 & labio mayor & 0.00347 & $0.022 \%$ & $0.565 \%$ & $98.398 \%$ \\
\hline 167 & duodeno & 0.00345 & $0.033 \%$ & $0.847 \%$ & $98.431 \%$ \\
\hline 168 & amígdala & 0.00335 & $0.033 \%$ & $0.847 \%$ & $98.464 \%$ \\
\hline 169 & glande & 0.00335 & $0.044 \%$ & $1.130 \%$ & $98.508 \%$ \\
\hline 170 & glándula salival & 0.00331 & $0.022 \%$ & $0.565 \%$ & $98.530 \%$ \\
\hline 171 & mentón & 0.00329 & $0.044 \%$ & $1.130 \%$ & $98.574 \%$ \\
\hline
\end{tabular}




\begin{tabular}{|c|c|c|c|c|c|}
\hline 172 & talón de Aquiles & 0.00298 & $0.033 \%$ & $0.847 \%$ & $98.607 \%$ \\
\hline 173 & epiglotis & 0.00288 & $0.022 \%$ & $0.565 \%$ & $98.629 \%$ \\
\hline 174 & embarazo & 0.00282 & $0.011 \%$ & $0.282 \%$ & $98.640 \%$ \\
\hline 175 & pulgar & 0.00276 & $0.044 \%$ & $1.130 \%$ & $98.684 \%$ \\
\hline 176 & hipotálamo & 0.00267 & $0.011 \%$ & $0.282 \%$ & $98.695 \%$ \\
\hline 177 & próstata & 0.00252 & $0.011 \%$ & $0.282 \%$ & $98.706 \%$ \\
\hline 178 & bulbo raquídeo & 0.00252 & $0.011 \%$ & $0.282 \%$ & $98.717 \%$ \\
\hline 179 & hipófisis & 0.00252 & $0.011 \%$ & $0.282 \%$ & $98.728 \%$ \\
\hline 180 & peca & 0.00252 & $0.011 \%$ & $0.282 \%$ & $98.739 \%$ \\
\hline 181 & carpo & 0.00245 & $0.022 \%$ & $0.565 \%$ & $98.761 \%$ \\
\hline 182 & labio menor & 0.00238 & $0.011 \%$ & $0.282 \%$ & $98.772 \%$ \\
\hline 183 & cuerpo & 0.00238 & $0.011 \%$ & $0.282 \%$ & $98.783 \%$ \\
\hline 184 & mucosa & 0.00238 & $0.011 \%$ & $0.282 \%$ & $98.794 \%$ \\
\hline 185 & tendón de Aquiles & 0.00236 & $0.033 \%$ & $0.847 \%$ & $98.827 \%$ \\
\hline 186 & martillo & 0.00229 & $0.033 \%$ & $0.847 \%$ & $98.860 \%$ \\
\hline 187 & cuerda vocal & 0.00229 & $0.033 \%$ & $0.847 \%$ & $98.893 \%$ \\
\hline 188 & metatarso & 0.00220 & $0.033 \%$ & $0.847 \%$ & $98.926 \%$ \\
\hline 189 & busto & 0.00212 & $0.011 \%$ & $0.282 \%$ & $98.937 \%$ \\
\hline 190 & caracol & 0.00212 & $0.011 \%$ & $0.282 \%$ & $98.948 \%$ \\
\hline 191 & aparato reproductor & 0.00205 & $0.022 \%$ & $0.565 \%$ & $98.970 \%$ \\
\hline 192 & ciego & 0.00200 & $0.011 \%$ & $0.282 \%$ & $98.981 \%$ \\
\hline 193 & sóleo & 0.00200 & $0.011 \%$ & $0.282 \%$ & $98.992 \%$ \\
\hline 194 & vulva & 0.00197 & $0.022 \%$ & $0.565 \%$ & $99.014 \%$ \\
\hline 195 & bronquiolo & 0.00185 & $0.022 \%$ & $0.565 \%$ & $99.036 \%$ \\
\hline 196 & pituitaria & 0.00185 & $0.022 \%$ & $0.565 \%$ & $99.058 \%$ \\
\hline 197 & esfínter & 0.00178 & $0.011 \%$ & $0.282 \%$ & $99.069 \%$ \\
\hline 198 & tiroides & 0.00176 & $0.022 \%$ & $0.565 \%$ & $99.091 \%$ \\
\hline 199 & sobaco & 0.00173 & $0.033 \%$ & $0.847 \%$ & $99.124 \%$ \\
\hline 200 & nervio óptico & 0.00168 & $0.011 \%$ & $0.282 \%$ & $99.135 \%$ \\
\hline 201 & faz & 0.00168 & $0.011 \%$ & $0.282 \%$ & $99.146 \%$ \\
\hline 202 & esqueleto & 0.00168 & $0.011 \%$ & $0.282 \%$ & $99.157 \%$ \\
\hline 203 & órgano genital & 0.00166 & $0.022 \%$ & $0.565 \%$ & $99.179 \%$ \\
\hline 204 & puño & 0.00165 & $0.022 \%$ & $0.565 \%$ & $99.201 \%$ \\
\hline 205 & papada & 0.00162 & $0.022 \%$ & $0.565 \%$ & $99.223 \%$ \\
\hline 206 & pompis & 0.00161 & $0.022 \%$ & $0.565 \%$ & $99.245 \%$ \\
\hline 207 & cutícula & 0.00159 & $0.011 \%$ & $0.282 \%$ & $99.256 \%$ \\
\hline 208 & escafoides & 0.00159 & $0.011 \%$ & $0.282 \%$ & $99.267 \%$ \\
\hline 209 & musculatura & 0.00159 & $0.011 \%$ & $0.282 \%$ & $99.278 \%$ \\
\hline 210 & cogote & 0.00155 & $0.022 \%$ & $0.565 \%$ & $99.300 \%$ \\
\hline 211 & órgano sexual & 0.00150 & $0.011 \%$ & $0.282 \%$ & $99.311 \%$ \\
\hline 212 & cuero cabelludo & 0.00150 & $0.011 \%$ & $0.282 \%$ & $99.322 \%$ \\
\hline 213 & tabique nasal & 0.00142 & $0.011 \%$ & $0.282 \%$ & $99.333 \%$ \\
\hline 214 & falangeta & 0.00134 & $0.022 \%$ & $0.565 \%$ & $99.355 \%$ \\
\hline 215 & víscera & 0.00134 & $0.011 \%$ & $0.282 \%$ & $99.366 \%$ \\
\hline 216 & aorta & 0.00134 & $0.011 \%$ & $0.282 \%$ & $99.377 \%$ \\
\hline 217 & glándula sudorípara & 0.00134 & $0.011 \%$ & $0.282 \%$ & $99.388 \%$ \\
\hline 218 & glotis & 0.00126 & $0.011 \%$ & $0.282 \%$ & $99.399 \%$ \\
\hline 219 & huevo & 0.00126 & $0.011 \%$ & $0.282 \%$ & $99.410 \%$ \\
\hline
\end{tabular}




\begin{tabular}{|c|c|c|c|c|c|}
\hline 220 & colmillo & 0.00126 & $0.011 \%$ & $0.282 \%$ & $99.421 \%$ \\
\hline 221 & papila gustativa & 0.00126 & $0.011 \%$ & $0.282 \%$ & $99.432 \%$ \\
\hline 222 & palma de la mano & 0.00120 & $0.022 \%$ & $0.565 \%$ & $99.454 \%$ \\
\hline 223 & mitocondria & 0.00119 & $0.011 \%$ & $0.282 \%$ & $99.465 \%$ \\
\hline 224 & encía & 0.00117 & $0.022 \%$ & $0.565 \%$ & $99.487 \%$ \\
\hline 225 & dedo corazón & 0.00116 & $0.022 \%$ & $0.565 \%$ & $99.509 \%$ \\
\hline 226 & apéndice xifoides & 0.00113 & $0.011 \%$ & $0.282 \%$ & $99.520 \%$ \\
\hline 227 & bigote & 0.00106 & $0.011 \%$ & $0.282 \%$ & $99.531 \%$ \\
\hline 228 & michelín & 0.00106 & $0.011 \%$ & $0.282 \%$ & $99.542 \%$ \\
\hline 229 & tarso & 0.00100 & $0.011 \%$ & $0.282 \%$ & $99.553 \%$ \\
\hline 230 & trapecio & 0.00100 & $0.011 \%$ & $0.282 \%$ & $99.564 \%$ \\
\hline 231 & bulbo & 0.00100 & $0.011 \%$ & $0.282 \%$ & $99.575 \%$ \\
\hline 232 & incisivo & 0.00095 & $0.011 \%$ & $0.282 \%$ & $99.586 \%$ \\
\hline 233 & encéfalo & 0.00095 & $0.011 \%$ & $0.282 \%$ & $99.597 \%$ \\
\hline 234 & dorsal & 0.00095 & $0.011 \%$ & $0.282 \%$ & $99.608 \%$ \\
\hline 235 & chocho & 0.00095 & $0.011 \%$ & $0.282 \%$ & $99.619 \%$ \\
\hline 236 & monte de Venus & 0.00089 & $0.011 \%$ & $0.282 \%$ & $99.630 \%$ \\
\hline 237 & molar & 0.00089 & $0.011 \%$ & $0.282 \%$ & $99.641 \%$ \\
\hline 238 & coco & 0.00089 & $0.011 \%$ & $0.282 \%$ & $99.652 \%$ \\
\hline 239 & yema & 0.00084 & $0.011 \%$ & $0.282 \%$ & $99.663 \%$ \\
\hline 240 & órgano reproductor & 0.00084 & $0.011 \%$ & $0.282 \%$ & $99.674 \%$ \\
\hline 241 & moco & 0.00084 & $0.011 \%$ & $0.282 \%$ & $99.685 \%$ \\
\hline 242 & vena cava & 0.00084 & $0.011 \%$ & $0.282 \%$ & $99.696 \%$ \\
\hline 243 & vejiga urinaria & 0.00084 & $0.011 \%$ & $0.282 \%$ & $99.707 \%$ \\
\hline 244 & grasa & 0.00084 & $0.011 \%$ & $0.282 \%$ & $99.718 \%$ \\
\hline 245 & vesícula seminal & 0.00080 & $0.011 \%$ & $0.282 \%$ & $99.729 \%$ \\
\hline 246 & regazo & 0.00080 & $0.011 \%$ & $0.282 \%$ & $99.740 \%$ \\
\hline 247 & paletilla & 0.00080 & $0.011 \%$ & $0.282 \%$ & $99.751 \%$ \\
\hline 248 & hormona & 0.00080 & $0.011 \%$ & $0.282 \%$ & $99.762 \%$ \\
\hline 249 & uréter & 0.00075 & $0.011 \%$ & $0.282 \%$ & $99.773 \%$ \\
\hline 250 & ventrículo & 0.00075 & $0.011 \%$ & $0.282 \%$ & $99.784 \%$ \\
\hline 251 & dedo índice & 0.00075 & $0.011 \%$ & $0.282 \%$ & $99.795 \%$ \\
\hline 252 & rabadilla & 0.00071 & $0.011 \%$ & $0.282 \%$ & $99.806 \%$ \\
\hline 253 & capilar & 0.00071 & $0.011 \%$ & $0.282 \%$ & $99.817 \%$ \\
\hline 254 & planta & 0.00067 & $0.011 \%$ & $0.282 \%$ & $99.828 \%$ \\
\hline 255 & retina & 0.00067 & $0.011 \%$ & $0.282 \%$ & $99.839 \%$ \\
\hline 256 & tejido & 0.00067 & $0.011 \%$ & $0.282 \%$ & $99.850 \%$ \\
\hline 257 & matriz & 0.00067 & $0.011 \%$ & $0.282 \%$ & $99.861 \%$ \\
\hline 258 & seso & 0.00063 & $0.011 \%$ & $0.282 \%$ & $99.872 \%$ \\
\hline 259 & úvula & 0.00063 & $0.011 \%$ & $0.282 \%$ & $99.883 \%$ \\
\hline 260 & sien & 0.00063 & $0.011 \%$ & $0.282 \%$ & $99.894 \%$ \\
\hline 261 & falangina & 0.00060 & $0.011 \%$ & $0.282 \%$ & $99.905 \%$ \\
\hline 262 & orificio nasal & 0.00060 & $0.011 \%$ & $0.282 \%$ & $99.916 \%$ \\
\hline 263 & alvéolo dental & 0.00060 & $0.011 \%$ & $0.282 \%$ & $99.927 \%$ \\
\hline 264 & neurona & 0.00056 & $0.011 \%$ & $0.282 \%$ & $99.938 \%$ \\
\hline 265 & angina & 0.00056 & $0.011 \%$ & $0.282 \%$ & $99.949 \%$ \\
\hline 266 & figa & 0.00053 & $0.011 \%$ & $0.282 \%$ & $99.960 \%$ \\
\hline 267 & costado & 0.00053 & $0.011 \%$ & $0.282 \%$ & $99.971 \%$ \\
\hline
\end{tabular}




\begin{tabular}{|l|l|l|l|l|l|}
\hline 268 & lóbulo de la oreja & 0.00053 & $0.011 \%$ & $0.282 \%$ & $99.982 \%$ \\
\hline 269 & glándula & 0.00050 & $0.011 \%$ & $0.282 \%$ & $99.993 \%$ \\
\hline 270 & yunque & 0.00050 & $0.011 \%$ & $0.282 \%$ & $100.004 \%$ \\
\hline 271 & pleura & 0.00040 & $0.011 \%$ & $0.282 \%$ & $100.015 \%$ \\
\hline
\end{tabular}

\section{LA ROPA}

\begin{tabular}{|c|c|c|c|c|c|}
\hline $\mathrm{N}^{\mathrm{o}}$ & Palabra & Disponibilidad & $\begin{array}{c}\text { Frecuencia } \\
\text { relativa }\end{array}$ & \% Aparición & $\begin{array}{l}\text { Frecuencia } \\
\text { acumulada }\end{array}$ \\
\hline 1 & pantalón & 0.69828 & $3.743 \%$ & $85.593 \%$ & $3.743 \%$ \\
\hline 2 & camisa & 0.67710 & $3.780 \%$ & $86.441 \%$ & $7.523 \%$ \\
\hline 3 & calcetín & 0.56222 & $3.941 \%$ & $90.113 \%$ & $11.464 \%$ \\
\hline 4 & camiseta & 0.51007 & $3.162 \%$ & $72.316 \%$ & $14.626 \%$ \\
\hline 5 & braga & 0.48887 & $3.657 \%$ & $83.616 \%$ & $18.283 \%$ \\
\hline 6 & calzoncillo & 0.46769 & $3.434 \%$ & $78.531 \%$ & $21.717 \%$ \\
\hline 7 & jersey & 0.45409 & $2.817 \%$ & $64.407 \%$ & $24.534 \%$ \\
\hline 8 & chaqueta & 0.45189 & $3.286 \%$ & $75.141 \%$ & $27.820 \%$ \\
\hline 9 & falda & 0.44973 & $3.014 \%$ & $68.927 \%$ & $30.834 \%$ \\
\hline 10 & sujetador & 0.36533 & $2.977 \%$ & $68.079 \%$ & $33.811 \%$ \\
\hline 11 & zapato & 0.34572 & $2.693 \%$ & $61.582 \%$ & $36.504 \%$ \\
\hline 12 & media & 0.28741 & $2.458 \%$ & $56.215 \%$ & $38.962 \%$ \\
\hline 13 & zapatilla & 0.23579 & $2.014 \%$ & $46.045 \%$ & $40.976 \%$ \\
\hline 14 & abrigo & 0.23016 & $2.051 \%$ & $46.893 \%$ & $43.027 \%$ \\
\hline 15 & bufanda & 0.21657 & $1.964 \%$ & $44.915 \%$ & $44.991 \%$ \\
\hline 16 & blusa & 0.20288 & $1.470 \%$ & $33.616 \%$ & $46.461 \%$ \\
\hline 17 & guante & 0.20229 & $1.890 \%$ & $43.220 \%$ & $48.351 \%$ \\
\hline 18 & chándal & 0.18996 & $1.816 \%$ & $41.525 \%$ & $50.167 \%$ \\
\hline 19 & suéter & 0.18791 & $1.235 \%$ & $28.249 \%$ & $51.402 \%$ \\
\hline 20 & sudadera & 0.17789 & $1.470 \%$ & $33.616 \%$ & $52.872 \%$ \\
\hline 21 & bañador & 0.17112 & $1.841 \%$ & $42.090 \%$ & $54.713 \%$ \\
\hline 22 & corbata & 0.14844 & $1.347 \%$ & $30.791 \%$ & $56.060 \%$ \\
\hline 23 & vestido & 0.14606 & $1.272 \%$ & $29.096 \%$ & $57.332 \%$ \\
\hline 24 & (pantalón) vaquero & 0.14193 & $1.001 \%$ & $22.881 \%$ & $58.333 \%$ \\
\hline 25 & chaleco & 0.13819 & $1.272 \%$ & $29.096 \%$ & $59.605 \%$ \\
\hline 26 & bermudas & 0.13066 & $1.149 \%$ & $26.271 \%$ & $60.754 \%$ \\
\hline 27 & sombrero & 0.12827 & $1.272 \%$ & $29.096 \%$ & $62.026 \%$ \\
\hline 28 & gorro & 0.12230 & $1.260 \%$ & $28.814 \%$ & $63.286 \%$ \\
\hline 29 & cazadora & 0.11908 & $1.099 \%$ & $25.141 \%$ & $64.385 \%$ \\
\hline 30 & pijama & 0.11674 & $1.371 \%$ & $31.356 \%$ & $65.756 \%$ \\
\hline 31 & camiseta interior & 0.11011 & $0.926 \%$ & $21.186 \%$ & $66.682 \%$ \\
\hline 32 & biquini & 0.10512 & $1.186 \%$ & $27.119 \%$ & $67.868 \%$ \\
\hline 33 & cinturón & 0.10266 & $1.050 \%$ & $24.011 \%$ & $68.918 \%$ \\
\hline 34 & gorra & 0.09731 & $0.902 \%$ & $20.621 \%$ & $69.820 \%$ \\
\hline
\end{tabular}




\begin{tabular}{|c|c|c|c|c|c|}
\hline 35 & bota & 0.09526 & $0.976 \%$ & $22.316 \%$ & $70.796 \%$ \\
\hline 36 & polo & 0.09280 & $0.741 \%$ & $16.949 \%$ & $71.537 \%$ \\
\hline 37 & top & 0.08766 & $0.828 \%$ & $18.927 \%$ & $72.365 \%$ \\
\hline 38 & pantalón corto & 0.08654 & $0.704 \%$ & $16.102 \%$ & $73.069 \%$ \\
\hline 39 & anorak & 0.08406 & $0.815 \%$ & $18.644 \%$ & $73.884 \%$ \\
\hline 40 & minifalda & 0.08235 & $0.729 \%$ & $16.667 \%$ & $74.613 \%$ \\
\hline 41 & short & 0.08232 & $0.754 \%$ & $17.232 \%$ & $75.367 \%$ \\
\hline 42 & traje & 0.07965 & $0.778 \%$ & $17.797 \%$ & $76.145 \%$ \\
\hline 43 & camisón & 0.07840 & $0.889 \%$ & $20.339 \%$ & $77.034 \%$ \\
\hline 44 & americana & 0.07539 & $0.754 \%$ & $17.232 \%$ & $77.788 \%$ \\
\hline 45 & pañuelo & 0.07151 & $0.803 \%$ & $18.362 \%$ & $78.591 \%$ \\
\hline 46 & gabardina & 0.07114 & $0.692 \%$ & $15.819 \%$ & $79.283 \%$ \\
\hline 47 & faja & 0.06779 & $0.704 \%$ & $16.102 \%$ & $79.987 \%$ \\
\hline 48 & body & 0.06509 & $0.704 \%$ & $16.102 \%$ & $80.691 \%$ \\
\hline 49 & chubasquero & 0.05773 & $0.581 \%$ & $13.277 \%$ & $81.272 \%$ \\
\hline 50 & chaquetón & 0.05446 & $0.556 \%$ & $12.712 \%$ & $81.828 \%$ \\
\hline 51 & panty & 0.05273 & $0.506 \%$ & $11.582 \%$ & $82.334 \%$ \\
\hline 52 & pajarita & 0.05083 & $0.581 \%$ & $13.277 \%$ & $82.915 \%$ \\
\hline 53 & (zapatilla) deportiva & 0.04891 & $0.457 \%$ & $10.452 \%$ & $83.372 \%$ \\
\hline 54 & malla & 0.04700 & $0.506 \%$ & $11.582 \%$ & $83.878 \%$ \\
\hline 55 & tanga & 0.04137 & $0.432 \%$ & $9.887 \%$ & $84.310 \%$ \\
\hline 56 & (pantalón) tejano & 0.04100 & $0.284 \%$ & $6.497 \%$ & $84.594 \%$ \\
\hline 57 & orejera & 0.03873 & $0.383 \%$ & $8.757 \%$ & $84.977 \%$ \\
\hline 58 & mono & 0.03842 & $0.408 \%$ & $9.322 \%$ & $85.385 \%$ \\
\hline 59 & leotardo & 0.03748 & $0.445 \%$ & $10.169 \%$ & $85.830 \%$ \\
\hline 60 & chancla & 0.03643 & $0.420 \%$ & $9.605 \%$ & $86.250 \%$ \\
\hline 61 & falda pantalón & 0.03367 & $0.284 \%$ & $6.497 \%$ & $86.534 \%$ \\
\hline 62 & calzón & 0.03351 & $0.259 \%$ & $5.932 \%$ & $86.793 \%$ \\
\hline 63 & liguero & 0.03285 & $0.346 \%$ & $7.910 \%$ & $87.139 \%$ \\
\hline 64 & albornoz & 0.03148 & $0.346 \%$ & $7.910 \%$ & $87.485 \%$ \\
\hline 65 & slip & 0.03115 & $0.247 \%$ & $5.650 \%$ & $87.732 \%$ \\
\hline 66 & plumífero & 0.02932 & $0.296 \%$ & $6.780 \%$ & $88.028 \%$ \\
\hline 67 & sandalia & 0.02902 & $0.334 \%$ & $7.627 \%$ & $88.362 \%$ \\
\hline 68 & chal & 0.02483 & $0.284 \%$ & $6.497 \%$ & $88.646 \%$ \\
\hline 69 & calza & 0.02415 & $0.185 \%$ & $4.237 \%$ & $88.831 \%$ \\
\hline 70 & batín & 0.02220 & $0.296 \%$ & $6.780 \%$ & $89.127 \%$ \\
\hline 71 & sostén & 0.02179 & $0.161 \%$ & $3.672 \%$ & $89.288 \%$ \\
\hline 72 & camisa interior & 0.02164 & $0.173 \%$ & $3.955 \%$ & $89.461 \%$ \\
\hline 73 & esmoquin & 0.02146 & $0.247 \%$ & $5.650 \%$ & $89.708 \%$ \\
\hline 74 & impermeable & 0.02136 & $0.272 \%$ & $6.215 \%$ & $89.980 \%$ \\
\hline 75 & liga & 0.02132 & $0.235 \%$ & $5.367 \%$ & $90.215 \%$ \\
\hline 76 & pantalón largo & 0.02020 & $0.124 \%$ & $2.825 \%$ & $90.339 \%$ \\
\hline 77 & botín & 0.01939 & $0.222 \%$ & $5.085 \%$ & $90.561 \%$ \\
\hline 78 & bata & 0.01909 & $0.198 \%$ & $4.520 \%$ & $90.759 \%$ \\
\hline 79 & falda corta & 0.01651 & $0.099 \%$ & $2.260 \%$ & $90.858 \%$ \\
\hline 80 & tirante & 0.01636 & $0.198 \%$ & $4.520 \%$ & $91.056 \%$ \\
\hline 81 & pantalón de tela & 0.01619 & $0.111 \%$ & $2.542 \%$ & $91.167 \%$ \\
\hline
\end{tabular}




\begin{tabular}{|c|c|c|c|c|c|}
\hline 82 & capa & 0.01582 & $0.173 \%$ & $3.955 \%$ & $91.340 \%$ \\
\hline 83 & enagua & 0.01554 & $0.161 \%$ & $3.672 \%$ & $91.501 \%$ \\
\hline 84 & fular & 0.01508 & $0.148 \%$ & $3.390 \%$ & $91.649 \%$ \\
\hline 85 & blusón & 0.01494 & $0.148 \%$ & $3.390 \%$ & $91.797 \%$ \\
\hline 86 & falda larga & 0.01493 & $0.136 \%$ & $3.107 \%$ & $91.933 \%$ \\
\hline 87 & corsé & 0.01465 & $0.161 \%$ & $3.672 \%$ & $92.094 \%$ \\
\hline 88 & pantalón de pana & 0.01445 & $0.086 \%$ & $1.977 \%$ & $92.180 \%$ \\
\hline 89 & rebeca & 0.01432 & $0.173 \%$ & $3.955 \%$ & $92.353 \%$ \\
\hline 90 & boina & 0.01411 & $0.161 \%$ & $3.672 \%$ & $92.514 \%$ \\
\hline 91 & parka & 0.01390 & $0.148 \%$ & $3.390 \%$ & $92.662 \%$ \\
\hline 92 & pasamontañas & 0.01384 & $0.173 \%$ & $3.955 \%$ & $92.835 \%$ \\
\hline 93 & ropa interior & 0.01358 & $0.111 \%$ & $2.542 \%$ & $92.946 \%$ \\
\hline 94 & pareo & 0.01351 & $0.161 \%$ & $3.672 \%$ & $93.107 \%$ \\
\hline 95 & pichi & 0.01332 & $0.124 \%$ & $2.825 \%$ & $93.231 \%$ \\
\hline 96 & traje de chaqueta & 0.01289 & $0.173 \%$ & $3.955 \%$ & $93.404 \%$ \\
\hline 97 & mantón & 0.01271 & $0.161 \%$ & $3.672 \%$ & $93.565 \%$ \\
\hline 98 & camiseta de tirantes & 0.01149 & $0.124 \%$ & $2.825 \%$ & $93.689 \%$ \\
\hline 99 & frac & 0.01139 & $0.124 \%$ & $2.825 \%$ & $93.813 \%$ \\
\hline 100 & gemelo & 0.01122 & $0.099 \%$ & $2.260 \%$ & $93.912 \%$ \\
\hline 101 & manopla & 0.01070 & $0.136 \%$ & $3.107 \%$ & $94.048 \%$ \\
\hline 102 & peto & 0.01055 & $0.136 \%$ & $3.107 \%$ & $94.184 \%$ \\
\hline 103 & zapatilla de deporte & 0.01052 & $0.099 \%$ & $2.260 \%$ & $94.283 \%$ \\
\hline 104 & chupa & 0.01046 & $0.086 \%$ & $1.977 \%$ & $94.369 \%$ \\
\hline 105 & pamela & 0.00955 & $0.111 \%$ & $2.542 \%$ & $94.480 \%$ \\
\hline 106 & botón & 0.00919 & $0.074 \%$ & $1.695 \%$ & $94.554 \%$ \\
\hline 107 & mocasín & 0.00884 & $0.099 \%$ & $2.260 \%$ & $94.653 \%$ \\
\hline 108 & peúco & 0.00882 & $0.124 \%$ & $2.825 \%$ & $94.777 \%$ \\
\hline 109 & algodón & 0.00868 & $0.049 \%$ & $1.130 \%$ & $94.826 \%$ \\
\hline 110 & forro polar & 0.00862 & $0.074 \%$ & $1.695 \%$ & $94.900 \%$ \\
\hline 111 & correa & 0.00827 & $0.086 \%$ & $1.977 \%$ & $94.986 \%$ \\
\hline 112 & boxer & 0.00807 & $0.074 \%$ & $1.695 \%$ & $95.060 \%$ \\
\hline 113 & jeans & 0.00734 & $0.037 \%$ & $0.847 \%$ & $95.097 \%$ \\
\hline 114 & zapato de tacón & 0.00727 & $0.062 \%$ & $1.412 \%$ & $95.159 \%$ \\
\hline 115 & pantalón de pinzas & 0.00723 & $0.049 \%$ & $1.130 \%$ & $95.208 \%$ \\
\hline 116 & gafas & 0.00699 & $0.062 \%$ & $1.412 \%$ & $95.270 \%$ \\
\hline 117 & vestido largo & 0.00695 & $0.062 \%$ & $1.412 \%$ & $95.332 \%$ \\
\hline 118 & túnica & 0.00686 & $0.086 \%$ & $1.977 \%$ & $95.418 \%$ \\
\hline 119 & vestido corto & 0.00680 & $0.062 \%$ & $1.412 \%$ & $95.480 \%$ \\
\hline 120 & trenca & 0.00669 & $0.074 \%$ & $1.695 \%$ & $95.554 \%$ \\
\hline 121 & chaqué & 0.00645 & $0.049 \%$ & $1.130 \%$ & $95.603 \%$ \\
\hline 122 & pantalón de chándal & 0.00643 & $0.037 \%$ & $0.847 \%$ & $95.640 \%$ \\
\hline 123 & camisa de manga corta & 0.00639 & $0.049 \%$ & $1.130 \%$ & $95.689 \%$ \\
\hline 124 & zueco & 0.00638 & $0.086 \%$ & $1.977 \%$ & $95.775 \%$ \\
\hline 125 & corpiño & 0.00637 & $0.074 \%$ & $1.695 \%$ & $95.849 \%$ \\
\hline 126 & combinación & 0.00621 & $0.062 \%$ & $1.412 \%$ & $95.911 \%$ \\
\hline 127 & viso & 0.00593 & $0.062 \%$ & $1.412 \%$ & $95.973 \%$ \\
\hline 128 & poncho & 0.00591 & $0.049 \%$ & $1.130 \%$ & $96.022 \%$ \\
\hline
\end{tabular}




\begin{tabular}{|c|c|c|c|c|c|}
\hline 129 & muñequera & 0.00585 & $0.049 \%$ & $1.130 \%$ & $96.071 \%$ \\
\hline 130 & camisola & 0.00581 & $0.086 \%$ & $1.977 \%$ & $96.157 \%$ \\
\hline 131 & hilo & 0.00575 & $0.037 \%$ & $0.847 \%$ & $96.194 \%$ \\
\hline 132 & fajín & 0.00562 & $0.074 \%$ & $1.695 \%$ & $96.268 \%$ \\
\hline 133 & delantal & 0.00561 & $0.086 \%$ & $1.977 \%$ & $96.354 \%$ \\
\hline 134 & alpargata & 0.00540 & $0.074 \%$ & $1.695 \%$ & $96.428 \%$ \\
\hline 135 & zapatilla de casa & 0.00538 & $0.049 \%$ & $1.130 \%$ & $96.477 \%$ \\
\hline 136 & vestido de noche & 0.00536 & $0.049 \%$ & $1.130 \%$ & $96.526 \%$ \\
\hline 137 & pantufla & 0.00524 & $0.037 \%$ & $0.847 \%$ & $96.563 \%$ \\
\hline 138 & polar & 0.00492 & $0.074 \%$ & $1.695 \%$ & $96.637 \%$ \\
\hline 139 & bolso & 0.00486 & $0.062 \%$ & $1.412 \%$ & $96.699 \%$ \\
\hline 140 & levita & 0.00466 & $0.037 \%$ & $0.847 \%$ & $96.736 \%$ \\
\hline 141 & manga & 0.00460 & $0.037 \%$ & $0.847 \%$ & $96.773 \%$ \\
\hline 142 & visera & 0.00453 & $0.049 \%$ & $1.130 \%$ & $96.822 \%$ \\
\hline 143 & mantilla & 0.00451 & $0.037 \%$ & $0.847 \%$ & $96.859 \%$ \\
\hline 144 & bamba & 0.00442 & $0.037 \%$ & $0.847 \%$ & $96.896 \%$ \\
\hline 145 & capucha & 0.00430 & $0.049 \%$ & $1.130 \%$ & $96.945 \%$ \\
\hline 146 & camiseta de manga corta & 0.00413 & $0.037 \%$ & $0.847 \%$ & $96.982 \%$ \\
\hline 147 & pantalón elástico & 0.00408 & $0.037 \%$ & $0.847 \%$ & $97.019 \%$ \\
\hline 148 & chancleta & 0.00382 & $0.037 \%$ & $0.847 \%$ & $97.056 \%$ \\
\hline 149 & bombín & 0.00372 & $0.025 \%$ & $0.565 \%$ & $97.081 \%$ \\
\hline 150 & torera & 0.00367 & $0.074 \%$ & $1.695 \%$ & $97.155 \%$ \\
\hline 151 & bolsillo & 0.00364 & $0.025 \%$ & $0.565 \%$ & $97.180 \%$ \\
\hline 152 & calentador & 0.00362 & $0.037 \%$ & $0.847 \%$ & $97.217 \%$ \\
\hline 153 & turbante & 0.00361 & $0.049 \%$ & $1.130 \%$ & $97.266 \%$ \\
\hline 154 & traje largo & 0.00351 & $0.049 \%$ & $1.130 \%$ & $97.315 \%$ \\
\hline 155 & rodillera & 0.00347 & $0.037 \%$ & $0.847 \%$ & $97.352 \%$ \\
\hline 156 & camisa de tirantes & 0.00340 & $0.049 \%$ & $1.130 \%$ & $97.401 \%$ \\
\hline 157 & diadema & 0.00336 & $0.037 \%$ & $0.847 \%$ & $97.438 \%$ \\
\hline 158 & camisa vaquera & 0.00334 & $0.025 \%$ & $0.565 \%$ & $97.463 \%$ \\
\hline 159 & maillot & 0.00326 & $0.049 \%$ & $1.130 \%$ & $97.512 \%$ \\
\hline 160 & jubón & 0.00321 & $0.049 \%$ & $1.130 \%$ & $97.561 \%$ \\
\hline 161 & samarreta & 0.00312 & $0.025 \%$ & $0.565 \%$ & $97.586 \%$ \\
\hline 162 & mono vaquero & 0.00312 & $0.037 \%$ & $0.847 \%$ & $97.623 \%$ \\
\hline 163 & hombrera & 0.00293 & $0.025 \%$ & $0.565 \%$ & $97.648 \%$ \\
\hline 164 & pantalón de deporte & 0.00290 & $0.037 \%$ & $0.847 \%$ & $97.685 \%$ \\
\hline 165 & goma de pelo & 0.00282 & $0.012 \%$ & $0.282 \%$ & $97.697 \%$ \\
\hline 166 & bota deportiva & 0.00282 & $0.012 \%$ & $0.282 \%$ & $97.709 \%$ \\
\hline 167 & cordón & 0.00280 & $0.025 \%$ & $0.565 \%$ & $97.734 \%$ \\
\hline 168 & tres cuartos & 0.00277 & $0.037 \%$ & $0.847 \%$ & $97.771 \%$ \\
\hline 169 & manta & 0.00273 & $0.037 \%$ & $0.847 \%$ & $97.808 \%$ \\
\hline 170 & (vestido) playero & 0.00270 & $0.037 \%$ & $0.847 \%$ & $97.845 \%$ \\
\hline 171 & muda & 0.00265 & $0.012 \%$ & $0.282 \%$ & $97.857 \%$ \\
\hline 172 & jersey de lana & 0.00265 & $0.012 \%$ & $0.282 \%$ & $97.869 \%$ \\
\hline 173 & toca & 0.00263 & $0.037 \%$ & $0.847 \%$ & $97.906 \%$ \\
\hline 174 & bota campera & 0.00262 & $0.025 \%$ & $0.565 \%$ & $97.931 \%$ \\
\hline 175 & tobillera & 0.00253 & $0.025 \%$ & $0.565 \%$ & $97.956 \%$ \\
\hline
\end{tabular}




\begin{tabular}{|c|c|c|c|c|c|}
\hline 176 & babero & 0.00253 & $0.037 \%$ & $0.847 \%$ & $97.993 \%$ \\
\hline 177 & calzado & 0.00249 & $0.012 \%$ & $0.282 \%$ & $98.005 \%$ \\
\hline 178 & patrón & 0.00249 & $0.012 \%$ & $0.282 \%$ & $98.017 \%$ \\
\hline 179 & aguja & 0.00249 & $0.012 \%$ & $0.282 \%$ & $98.029 \%$ \\
\hline 180 & pantalón ancho & 0.00249 & $0.012 \%$ & $0.282 \%$ & $98.041 \%$ \\
\hline 181 & camisa de seda & 0.00249 & $0.012 \%$ & $0.282 \%$ & $98.053 \%$ \\
\hline 182 & jersey grueso & 0.00249 & $0.012 \%$ & $0.282 \%$ & $98.065 \%$ \\
\hline 183 & zapato plano & 0.00249 & $0.012 \%$ & $0.282 \%$ & $98.077 \%$ \\
\hline 184 & cremallera & 0.00243 & $0.025 \%$ & $0.565 \%$ & $98.102 \%$ \\
\hline 185 & visón & 0.00242 & $0.037 \%$ & $0.847 \%$ & $98.139 \%$ \\
\hline 186 & cuello & 0.00240 & $0.025 \%$ & $0.565 \%$ & $98.164 \%$ \\
\hline 187 & traje de noche & 0.00235 & $0.025 \%$ & $0.565 \%$ & $98.189 \%$ \\
\hline 188 & confección & 0.00233 & $0.012 \%$ & $0.282 \%$ & $98.201 \%$ \\
\hline 189 & máquina de coser & 0.00233 & $0.012 \%$ & $0.282 \%$ & $98.213 \%$ \\
\hline 190 & pantalón estrecho & 0.00233 & $0.012 \%$ & $0.282 \%$ & $98.225 \%$ \\
\hline 191 & mono de trabajo & 0.00233 & $0.012 \%$ & $0.282 \%$ & $98.237 \%$ \\
\hline 192 & camiseta corta & 0.00233 & $0.012 \%$ & $0.282 \%$ & $98.249 \%$ \\
\hline 193 & sombrero de copa & 0.00219 & $0.012 \%$ & $0.282 \%$ & $98.261 \%$ \\
\hline 194 & pantalón de tergal & 0.00219 & $0.012 \%$ & $0.282 \%$ & $98.273 \%$ \\
\hline 195 & piel & 0.00219 & $0.012 \%$ & $0.282 \%$ & $98.285 \%$ \\
\hline 196 & jersey de manga corta & 0.00219 & $0.012 \%$ & $0.282 \%$ & $98.297 \%$ \\
\hline 197 & cisne & 0.00219 & $0.012 \%$ & $0.282 \%$ & $98.309 \%$ \\
\hline 198 & Pikys* & 0.00218 & $0.037 \%$ & $0.847 \%$ & $98.346 \%$ \\
\hline 199 & toalla & 0.00217 & $0.025 \%$ & $0.565 \%$ & $98.371 \%$ \\
\hline 200 & picardías & 0.00214 & $0.025 \%$ & $0.565 \%$ & $98.396 \%$ \\
\hline 201 & ojal & 0.00211 & $0.025 \%$ & $0.565 \%$ & $98.421 \%$ \\
\hline 202 & playera & 0.00207 & $0.025 \%$ & $0.565 \%$ & $98.446 \%$ \\
\hline 203 & abrigo de piel & 0.00206 & $0.025 \%$ & $0.565 \%$ & $98.471 \%$ \\
\hline 204 & toga & 0.00205 & $0.012 \%$ & $0.282 \%$ & $98.483 \%$ \\
\hline 205 & camisa plisada & 0.00205 & $0.012 \%$ & $0.282 \%$ & $98.495 \%$ \\
\hline 206 & mantón de Manila & 0.00204 & $0.025 \%$ & $0.565 \%$ & $98.520 \%$ \\
\hline 207 & traje pantalón & 0.00197 & $0.025 \%$ & $0.565 \%$ & $98.545 \%$ \\
\hline 208 & Wonderbra* & 0.00196 & $0.025 \%$ & $0.565 \%$ & $98.570 \%$ \\
\hline 209 & leggings & 0.00193 & $0.012 \%$ & $0.282 \%$ & $98.582 \%$ \\
\hline 210 & Lycra* & 0.00193 & $0.012 \%$ & $0.282 \%$ & $98.594 \%$ \\
\hline 211 & paraguas & 0.00193 & $0.012 \%$ & $0.282 \%$ & $98.606 \%$ \\
\hline 212 & taparrabo & 0.00189 & $0.025 \%$ & $0.565 \%$ & $98.631 \%$ \\
\hline 213 & nailon & 0.00181 & $0.012 \%$ & $0.282 \%$ & $98.643 \%$ \\
\hline 214 & mono de vestir & 0.00181 & $0.012 \%$ & $0.282 \%$ & $98.655 \%$ \\
\hline 215 & uniforme & 0.00180 & $0.025 \%$ & $0.565 \%$ & $98.680 \%$ \\
\hline 216 & chaquetilla & 0.00180 & $0.025 \%$ & $0.565 \%$ & $98.705 \%$ \\
\hline 217 & braga de cuello & 0.00179 & $0.025 \%$ & $0.565 \%$ & $98.730 \%$ \\
\hline 218 & vestido palabra de honor & 0.00173 & $0.025 \%$ & $0.565 \%$ & $98.755 \%$ \\
\hline 219 & camiseta vaquera & 0.00169 & $0.012 \%$ & $0.282 \%$ & $98.767 \%$ \\
\hline 220 & camiseta de deporte & 0.00169 & $0.012 \%$ & $0.282 \%$ & $98.779 \%$ \\
\hline 221 & braga militar & 0.00159 & $0.012 \%$ & $0.282 \%$ & $98.791 \%$ \\
\hline 222 & collar & 0.00159 & $0.012 \%$ & $0.282 \%$ & $98.803 \%$ \\
\hline
\end{tabular}




\begin{tabular}{|c|c|c|c|c|c|}
\hline 223 & pantalón de pitillo & 0.00159 & $0.012 \%$ & $0.282 \%$ & $98.815 \%$ \\
\hline 224 & chaqueta de cuero & 0.00159 & $0.012 \%$ & $0.282 \%$ & $98.827 \%$ \\
\hline 225 & pañoleta & 0.00159 & $0.012 \%$ & $0.282 \%$ & $98.839 \%$ \\
\hline 226 & velo & 0.00155 & $0.025 \%$ & $0.565 \%$ & $98.864 \%$ \\
\hline 227 & bota de montaña & 0.00153 & $0.025 \%$ & $0.565 \%$ & $98.889 \%$ \\
\hline 228 & traje de baño & 0.00149 & $0.012 \%$ & $0.282 \%$ & $98.901 \%$ \\
\hline 229 & blazer & 0.00149 & $0.012 \%$ & $0.282 \%$ & $98.913 \%$ \\
\hline 230 & faldón & 0.00140 & $0.012 \%$ & $0.282 \%$ & $98.925 \%$ \\
\hline 231 & gabán & 0.00140 & $0.012 \%$ & $0.282 \%$ & $98.937 \%$ \\
\hline 232 & chistera & 0.00140 & $0.012 \%$ & $0.282 \%$ & $98.949 \%$ \\
\hline 233 & peluca & 0.00135 & $0.025 \%$ & $0.565 \%$ & $98.974 \%$ \\
\hline 234 & espardenya & 0.00123 & $0.012 \%$ & $0.282 \%$ & $98.986 \%$ \\
\hline 235 & pulóver & 0.00123 & $0.012 \%$ & $0.282 \%$ & $98.998 \%$ \\
\hline 236 & solapa & 0.00123 & $0.012 \%$ & $0.282 \%$ & $99.010 \%$ \\
\hline 237 & pantalón chino & 0.00123 & $0.012 \%$ & $0.282 \%$ & $99.022 \%$ \\
\hline 238 & niqui & 0.00123 & $0.012 \%$ & $0.282 \%$ & $99.034 \%$ \\
\hline 239 & ropa de deporte & 0.00123 & $0.012 \%$ & $0.282 \%$ & $99.046 \%$ \\
\hline 240 & gorro de lana & 0.00115 & $0.012 \%$ & $0.282 \%$ & $99.058 \%$ \\
\hline 241 & culote & 0.00115 & $0.012 \%$ & $0.282 \%$ & $99.070 \%$ \\
\hline 242 & falda escocesa & 0.00115 & $0.012 \%$ & $0.282 \%$ & $99.082 \%$ \\
\hline 243 & puño & 0.00115 & $0.012 \%$ & $0.282 \%$ & $99.094 \%$ \\
\hline 244 & gafas de sol & 0.00115 & $0.012 \%$ & $0.282 \%$ & $99.106 \%$ \\
\hline 245 & sobrecamisa & 0.00115 & $0.012 \%$ & $0.282 \%$ & $99.118 \%$ \\
\hline 246 & chaqueta vaquera & 0.00115 & $0.012 \%$ & $0.282 \%$ & $99.130 \%$ \\
\hline 247 & brusa & 0.00115 & $0.012 \%$ & $0.282 \%$ & $99.142 \%$ \\
\hline 248 & faldilla & 0.00115 & $0.012 \%$ & $0.282 \%$ & $99.154 \%$ \\
\hline 249 & corbatín & 0.00115 & $0.012 \%$ & $0.282 \%$ & $99.166 \%$ \\
\hline 250 & cinta de pelo & 0.00111 & $0.025 \%$ & $0.565 \%$ & $99.191 \%$ \\
\hline 251 & pantalón de tirantes & 0.00108 & $0.012 \%$ & $0.282 \%$ & $99.203 \%$ \\
\hline 252 & gayumbos & 0.00108 & $0.012 \%$ & $0.282 \%$ & $99.215 \%$ \\
\hline 253 & traje corto & 0.00108 & $0.012 \%$ & $0.282 \%$ & $99.227 \%$ \\
\hline 254 & pañuelo de cabeza & 0.00108 & $0.012 \%$ & $0.282 \%$ & $99.239 \%$ \\
\hline 255 & dobladillo & 0.00108 & $0.012 \%$ & $0.282 \%$ & $99.251 \%$ \\
\hline 256 & antifaz & 0.00108 & $0.012 \%$ & $0.282 \%$ & $99.263 \%$ \\
\hline 257 & chaqueta americana & 0.00108 & $0.012 \%$ & $0.282 \%$ & $99.275 \%$ \\
\hline 258 & lencería & 0.00108 & $0.012 \%$ & $0.282 \%$ & $99.287 \%$ \\
\hline 259 & pololo & 0.00104 & $0.025 \%$ & $0.565 \%$ & $99.312 \%$ \\
\hline 260 & saya & 0.00102 & $0.012 \%$ & $0.282 \%$ & $99.324 \%$ \\
\hline 261 & zamarra & 0.00102 & $0.012 \%$ & $0.282 \%$ & $99.336 \%$ \\
\hline 262 & traje de buzo & 0.00102 & $0.012 \%$ & $0.282 \%$ & $99.348 \%$ \\
\hline 263 & cancán & 0.00102 & $0.012 \%$ & $0.282 \%$ & $99.360 \%$ \\
\hline 264 & casaca & 0.00102 & $0.012 \%$ & $0.282 \%$ & $99.372 \%$ \\
\hline 265 & zapato de aguja & 0.00102 & $0.012 \%$ & $0.282 \%$ & $99.384 \%$ \\
\hline 266 & guante de lana & 0.00102 & $0.012 \%$ & $0.282 \%$ & $99.396 \%$ \\
\hline 267 & prenda & 0.00102 & $0.012 \%$ & $0.282 \%$ & $99.408 \%$ \\
\hline 268 & canguro & 0.00102 & $0.012 \%$ & $0.282 \%$ & $99.420 \%$ \\
\hline 269 & dalmática & 0.00095 & $0.012 \%$ & $0.282 \%$ & $99.432 \%$ \\
\hline
\end{tabular}




\begin{tabular}{|c|c|c|c|c|c|}
\hline 270 & cubrecama & 0.00095 & $0.012 \%$ & $0.282 \%$ & $99.444 \%$ \\
\hline 271 & calzoncillo largo & 0.00095 & $0.012 \%$ & $0.282 \%$ & $99.456 \%$ \\
\hline 272 & pantalón de traje & 0.00095 & $0.012 \%$ & $0.282 \%$ & $99.468 \%$ \\
\hline 273 & body interior & 0.00095 & $0.012 \%$ & $0.282 \%$ & $99.480 \%$ \\
\hline 274 & lencería femenina & 0.00095 & $0.012 \%$ & $0.282 \%$ & $99.492 \%$ \\
\hline 275 & cárdigan & 0.00095 & $0.012 \%$ & $0.282 \%$ & $99.504 \%$ \\
\hline 276 & cazadora vaquera & 0.00092 & $0.025 \%$ & $0.565 \%$ & $99.529 \%$ \\
\hline 277 & toquilla & 0.00089 & $0.012 \%$ & $0.282 \%$ & $99.541 \%$ \\
\hline 278 & cíngulo & 0.00089 & $0.012 \%$ & $0.282 \%$ & $99.553 \%$ \\
\hline 279 & bota de plataforma & 0.00089 & $0.012 \%$ & $0.282 \%$ & $99.565 \%$ \\
\hline 280 & zapato de charol & 0.00089 & $0.012 \%$ & $0.282 \%$ & $99.577 \%$ \\
\hline 281 & guardapolvo & 0.00089 & $0.012 \%$ & $0.282 \%$ & $99.589 \%$ \\
\hline 282 & pantalón ciclista & 0.00084 & $0.012 \%$ & $0.282 \%$ & $99.601 \%$ \\
\hline 283 & salto de cama & 0.00084 & $0.012 \%$ & $0.282 \%$ & $99.613 \%$ \\
\hline 284 & guardarropa & 0.00084 & $0.012 \%$ & $0.282 \%$ & $99.625 \%$ \\
\hline 285 & bastón & 0.00084 & $0.012 \%$ & $0.282 \%$ & $99.637 \%$ \\
\hline 286 & bota alta & 0.00084 & $0.012 \%$ & $0.282 \%$ & $99.649 \%$ \\
\hline 287 & bota de agua & 0.00084 & $0.012 \%$ & $0.282 \%$ & $99.661 \%$ \\
\hline 288 & poliéster & 0.00079 & $0.012 \%$ & $0.282 \%$ & $99.673 \%$ \\
\hline 289 & echarpe & 0.00079 & $0.012 \%$ & $0.282 \%$ & $99.685 \%$ \\
\hline 290 & pañuelo de cuello & 0.00079 & $0.012 \%$ & $0.282 \%$ & $99.697 \%$ \\
\hline 291 & capote & 0.00074 & $0.012 \%$ & $0.282 \%$ & $99.709 \%$ \\
\hline 292 & disfraz & 0.00074 & $0.012 \%$ & $0.282 \%$ & $99.721 \%$ \\
\hline 293 & capelina & 0.00074 & $0.012 \%$ & $0.282 \%$ & $99.733 \%$ \\
\hline 294 & kimono & 0.00074 & $0.012 \%$ & $0.282 \%$ & $99.745 \%$ \\
\hline 295 & body deportivo & 0.00074 & $0.012 \%$ & $0.282 \%$ & $99.757 \%$ \\
\hline 296 & seda & 0.00069 & $0.012 \%$ & $0.282 \%$ & $99.769 \%$ \\
\hline 297 & jersey de cuello alto & 0.00069 & $0.012 \%$ & $0.282 \%$ & $99.781 \%$ \\
\hline 298 & pantalón de campana & 0.00065 & $0.012 \%$ & $0.282 \%$ & $99.793 \%$ \\
\hline 299 & minimedia & 0.00065 & $0.012 \%$ & $0.282 \%$ & $99.805 \%$ \\
\hline 300 & mono de esquiar & 0.00065 & $0.012 \%$ & $0.282 \%$ & $99.817 \%$ \\
\hline 301 & camiseta de manga larga & 0.00057 & $0.012 \%$ & $0.282 \%$ & $99.829 \%$ \\
\hline 302 & plantilla & 0.00057 & $0.012 \%$ & $0.282 \%$ & $99.841 \%$ \\
\hline 303 & reloj & 0.00057 & $0.012 \%$ & $0.282 \%$ & $99.853 \%$ \\
\hline 304 & encaje & 0.00057 & $0.012 \%$ & $0.282 \%$ & $99.865 \%$ \\
\hline 305 & mono corto & 0.00054 & $0.012 \%$ & $0.282 \%$ & $99.877 \%$ \\
\hline 306 & mono largo & 0.00050 & $0.012 \%$ & $0.282 \%$ & $99.889 \%$ \\
\hline 307 & coletero & 0.00050 & $0.012 \%$ & $0.282 \%$ & $99.901 \%$ \\
\hline 308 & mochila & 0.00047 & $0.012 \%$ & $0.282 \%$ & $99.913 \%$ \\
\hline 309 & chinela & 0.00047 & $0.012 \%$ & $0.282 \%$ & $99.925 \%$ \\
\hline 310 & sotana & 0.00042 & $0.012 \%$ & $0.282 \%$ & $99.937 \%$ \\
\hline 311 & chupa de cuero & 0.00037 & $0.012 \%$ & $0.282 \%$ & $99.949 \%$ \\
\hline 312 & lazo & 0.00032 & $0.012 \%$ & $0.282 \%$ & $99.961 \%$ \\
\hline
\end{tabular}




\begin{tabular}{|c|c|c|c|c|c|}
\hline $\mathrm{N}^{\mathrm{o}}$ & Palabra & Disponibilidad & $\begin{array}{c}\text { Frecuencia } \\
\text { relativa }\end{array}$ & \% Aparición & $\begin{array}{l}\text { Frecuencia } \\
\text { acumulada }\end{array}$ \\
\hline 1 & cocina & 0.80613 & $5.911 \%$ & $98.588 \%$ & $5.911 \%$ \\
\hline 2 & comedor & 0.69735 & $5.318 \%$ & $88.701 \%$ & $11.229 \%$ \\
\hline 3 & (cuarto de) baño & 0.56879 & $4.810 \%$ & $80.226 \%$ & $16.039 \%$ \\
\hline 4 & recibidor & 0.43311 & $3.811 \%$ & $63.559 \%$ & $19.850 \%$ \\
\hline 5 & terraza & 0.37937 & $4.150 \%$ & $69.209 \%$ & $24.000 \%$ \\
\hline 6 & habitación & 0.37036 & $3.032 \%$ & $50.565 \%$ & $27.032 \%$ \\
\hline 7 & dormitorio & 0.37006 & $3.167 \%$ & $52.825 \%$ & $30.199 \%$ \\
\hline 8 & salita & 0.35862 & $3.100 \%$ & $51.695 \%$ & $33.299 \%$ \\
\hline 9 & salón & 0.34890 & $2.947 \%$ & $49.153 \%$ & $36.246 \%$ \\
\hline 10 & garaje & 0.24603 & $2.846 \%$ & $47.458 \%$ & $39.092 \%$ \\
\hline 11 & (cuarto) trastero & 0.24157 & $2.761 \%$ & $46.045 \%$ & $41.853 \%$ \\
\hline 12 & pasillo & 0.23418 & $2.625 \%$ & $43.785 \%$ & $44.478 \%$ \\
\hline 13 & balcón & 0.21205 & $2.710 \%$ & $45.198 \%$ & $47.188 \%$ \\
\hline 14 & sala de estar & 0.20329 & $1.897 \%$ & $31.638 \%$ & $49.085 \%$ \\
\hline 15 & galería & 0.20250 & $2.202 \%$ & $36.723 \%$ & $51.287 \%$ \\
\hline 16 & escalera & 0.19745 & $2.507 \%$ & $41.808 \%$ & $53.794 \%$ \\
\hline 17 & buhardilla & 0.16927 & $2.016 \%$ & $33.616 \%$ & $55.810 \%$ \\
\hline 18 & despensa & 0.16655 & $2.016 \%$ & $33.616 \%$ & $57.826 \%$ \\
\hline 19 & (cuarto de) aseo & 0.16262 & $1.507 \%$ & $25.141 \%$ & $59.333 \%$ \\
\hline 20 & jardín & 0.15858 & $1.948 \%$ & $32.486 \%$ & $61.281 \%$ \\
\hline 21 & sótano & 0.13990 & $1.711 \%$ & $28.531 \%$ & $62.992 \%$ \\
\hline 22 & despacho & 0.13392 & $1.660 \%$ & $27.684 \%$ & $64.652 \%$ \\
\hline 23 & entrada & 0.12285 & $1.186 \%$ & $19.774 \%$ & $65.838 \%$ \\
\hline 24 & tejado & 0.12285 & $1.541 \%$ & $25.706 \%$ & $67.379 \%$ \\
\hline 25 & puerta & 0.11207 & $1.118 \%$ & $18.644 \%$ & $68.497 \%$ \\
\hline 26 & pared & 0.10426 & $1.135 \%$ & $18.927 \%$ & $69.632 \%$ \\
\hline 27 & ventana & 0.09678 & $1.152 \%$ & $19.209 \%$ & $70.784 \%$ \\
\hline 28 & hall & 0.09356 & $0.881 \%$ & $14.689 \%$ & $71.665 \%$ \\
\hline 29 & patio de luces & 0.08311 & $1.118 \%$ & $18.644 \%$ & $72.783 \%$ \\
\hline 30 & estudio & 0.08063 & $1.033 \%$ & $17.232 \%$ & $73.816 \%$ \\
\hline 31 & desván & 0.06722 & $0.796 \%$ & $13.277 \%$ & $74.612 \%$ \\
\hline 32 & techo & 0.06663 & $0.745 \%$ & $12.429 \%$ & $75.357 \%$ \\
\hline 33 & patio & 0.06303 & $0.779 \%$ & $12.994 \%$ & $76.136 \%$ \\
\hline 34 & ático & 0.06068 & $0.728 \%$ & $12.147 \%$ & $76.864 \%$ \\
\hline 35 & bodega & 0.06015 & $0.864 \%$ & $14.407 \%$ & $77.728 \%$ \\
\hline 36 & biblioteca & 0.05778 & $0.779 \%$ & $12.994 \%$ & $78.507 \%$ \\
\hline 37 & servicio & 0.05553 & $0.491 \%$ & $8.192 \%$ & $78.998 \%$ \\
\hline 38 & váter & 0.05345 & $0.508 \%$ & $8.475 \%$ & $79.506 \%$ \\
\hline 39 & lavadero & 0.04889 & $0.678 \%$ & $11.299 \%$ & $80.184 \%$ \\
\hline 40 & chimenea & 0.04595 & $0.491 \%$ & $8.192 \%$ & $80.675 \%$ \\
\hline 41 & lavabo & 0.04589 & $0.457 \%$ & $7.627 \%$ & $81.132 \%$ \\
\hline 42 & piscina & 0.04194 & $0.644 \%$ & $10.734 \%$ & $81.776 \%$ \\
\hline 43 & suelo & 0.03805 & $0.508 \%$ & $8.475 \%$ & $82.284 \%$ \\
\hline
\end{tabular}




\begin{tabular}{|c|c|c|c|c|c|}
\hline 44 & cochera & 0.03659 & $0.491 \%$ & $8.192 \%$ & $82.775 \%$ \\
\hline 45 & vestíbulo & 0.03576 & $0.356 \%$ & $5.932 \%$ & $83.131 \%$ \\
\hline 46 & terrado & 0.03175 & $0.440 \%$ & $7.345 \%$ & $83.571 \%$ \\
\hline 47 & almacén & 0.03136 & $0.390 \%$ & $6.497 \%$ & $83.961 \%$ \\
\hline 48 & sala de juegos & 0.02922 & $0.457 \%$ & $7.627 \%$ & $84.418 \%$ \\
\hline 49 & viga & 0.02724 & $0.220 \%$ & $3.672 \%$ & $84.638 \%$ \\
\hline 50 & habitación de matrimonio & 0.02621 & $0.237 \%$ & $3.955 \%$ & $84.875 \%$ \\
\hline 51 & barbacoa & 0.02446 & $0.322 \%$ & $5.367 \%$ & $85.197 \%$ \\
\hline 52 & altillo & 0.02296 & $0.339 \%$ & $5.650 \%$ & $85.536 \%$ \\
\hline 53 & ascensor & 0.02222 & $0.390 \%$ & $6.497 \%$ & $85.926 \%$ \\
\hline 54 & cuarto de estar & 0.02217 & $0.203 \%$ & $3.390 \%$ & $86.129 \%$ \\
\hline 55 & cuarto de planchar & 0.02193 & $0.339 \%$ & $5.650 \%$ & $86.468 \%$ \\
\hline 56 & bañera & 0.02186 & $0.220 \%$ & $3.672 \%$ & $86.688 \%$ \\
\hline 57 & cuarto & 0.02148 & $0.203 \%$ & $3.390 \%$ & $86.891 \%$ \\
\hline 58 & corral & 0.02087 & $0.271 \%$ & $4.520 \%$ & $87.162 \%$ \\
\hline 59 & sala de estudio & 0.02085 & $0.288 \%$ & $4.802 \%$ & $87.450 \%$ \\
\hline 60 & fachada & 0.02036 & $0.237 \%$ & $3.955 \%$ & $87.687 \%$ \\
\hline 61 & gimnasio & 0.01964 & $0.322 \%$ & $5.367 \%$ & $88.009 \%$ \\
\hline 62 & salón comedor & 0.01937 & $0.203 \%$ & $3.390 \%$ & $88.212 \%$ \\
\hline 63 & WC & 0.01826 & $0.152 \%$ & $2.542 \%$ & $88.364 \%$ \\
\hline 64 & cuarto de estudio & 0.01809 & $0.254 \%$ & $4.237 \%$ & $88.618 \%$ \\
\hline 65 & sauna & 0.01804 & $0.254 \%$ & $4.237 \%$ & $88.872 \%$ \\
\hline 66 & tendedero & 0.01709 & $0.288 \%$ & $4.802 \%$ & $89.160 \%$ \\
\hline 67 & piso & 0.01705 & $0.220 \%$ & $3.672 \%$ & $89.380 \%$ \\
\hline 68 & portal & 0.01634 & $0.237 \%$ & $3.955 \%$ & $89.617 \%$ \\
\hline 69 & armario & 0.01588 & $0.152 \%$ & $2.542 \%$ & $89.769 \%$ \\
\hline 70 & ladrillo & 0.01584 & $0.203 \%$ & $3.390 \%$ & $89.972 \%$ \\
\hline 71 & pilar & 0.01555 & $0.186 \%$ & $3.107 \%$ & $90.158 \%$ \\
\hline 72 & rellano & 0.01508 & $0.220 \%$ & $3.672 \%$ & $90.378 \%$ \\
\hline 73 & ducha & 0.01450 & $0.186 \%$ & $3.107 \%$ & $90.564 \%$ \\
\hline 74 & habitación de invitados & 0.01426 & $0.186 \%$ & $3.107 \%$ & $90.750 \%$ \\
\hline 75 & cuarto de invitados & 0.01344 & $0.169 \%$ & $2.825 \%$ & $90.919 \%$ \\
\hline 76 & grifo & 0.01336 & $0.152 \%$ & $2.542 \%$ & $91.071 \%$ \\
\hline 77 & habitación de dormir & 0.01312 & $0.102 \%$ & $1.695 \%$ & $91.173 \%$ \\
\hline 78 & oficina & 0.01264 & $0.152 \%$ & $2.542 \%$ & $91.325 \%$ \\
\hline 79 & columna & 0.01199 & $0.152 \%$ & $2.542 \%$ & $91.477 \%$ \\
\hline 80 & vestidor & 0.01168 & $0.169 \%$ & $2.825 \%$ & $91.646 \%$ \\
\hline 81 & porche & 0.01144 & $0.169 \%$ & $2.825 \%$ & $91.815 \%$ \\
\hline 82 & azotea & 0.01099 & $0.136 \%$ & $2.260 \%$ & $91.951 \%$ \\
\hline 83 & salón de estar & 0.01098 & $0.085 \%$ & $1.412 \%$ & $92.036 \%$ \\
\hline 84 & office & 0.01049 & $0.102 \%$ & $1.695 \%$ & $92.138 \%$ \\
\hline 85 & entrador & 0.01017 & $0.085 \%$ & $1.412 \%$ & $92.223 \%$ \\
\hline 86 & baldosa & 0.01006 & $0.119 \%$ & $1.977 \%$ & $92.342 \%$ \\
\hline 87 & bidé & 0.01000 & $0.102 \%$ & $1.695 \%$ & $92.444 \%$ \\
\hline 88 & habitación individual & 0.00990 & $0.085 \%$ & $1.412 \%$ & $92.529 \%$ \\
\hline 89 & cuarto de los trastos & 0.00990 & $0.119 \%$ & $1.977 \%$ & $92.648 \%$ \\
\hline 90 & planta baja & 0.00961 & $0.136 \%$ & $2.260 \%$ & $92.784 \%$ \\
\hline
\end{tabular}




\begin{tabular}{|c|c|c|c|c|c|}
\hline 91 & sala & 0.00948 & $0.085 \%$ & $1.412 \%$ & $92.869 \%$ \\
\hline 92 & azulejo & 0.00921 & $0.119 \%$ & $1.977 \%$ & $92.988 \%$ \\
\hline 93 & pista de tenis & 0.00886 & $0.136 \%$ & $2.260 \%$ & $93.124 \%$ \\
\hline 94 & alcoba & 0.00870 & $0.085 \%$ & $1.412 \%$ & $93.209 \%$ \\
\hline 95 & habitación de estudio & 0.00852 & $0.085 \%$ & $1.412 \%$ & $93.294 \%$ \\
\hline 96 & ropero & 0.00849 & $0.102 \%$ & $1.695 \%$ & $93.396 \%$ \\
\hline 97 & solárium & 0.00812 & $0.119 \%$ & $1.977 \%$ & $93.515 \%$ \\
\hline 98 & tabique & 0.00769 & $0.085 \%$ & $1.412 \%$ & $93.600 \%$ \\
\hline 99 & cuarto de juegos & 0.00757 & $0.085 \%$ & $1.412 \%$ & $93.685 \%$ \\
\hline 100 & persiana & 0.00753 & $0.119 \%$ & $1.977 \%$ & $93.804 \%$ \\
\hline 101 & barandilla & 0.00746 & $0.136 \%$ & $2.260 \%$ & $93.940 \%$ \\
\hline 102 & fregadero & 0.00739 & $0.085 \%$ & $1.412 \%$ & $94.025 \%$ \\
\hline 103 & cimiento & 0.00704 & $0.102 \%$ & $1.695 \%$ & $94.127 \%$ \\
\hline 104 & armario empotrado & 0.00695 & $0.102 \%$ & $1.695 \%$ & $94.229 \%$ \\
\hline 105 & corredor & 0.00683 & $0.068 \%$ & $1.130 \%$ & $94.297 \%$ \\
\hline 106 & cemento & 0.00665 & $0.085 \%$ & $1.412 \%$ & $94.382 \%$ \\
\hline 107 & tubería & 0.00619 & $0.068 \%$ & $1.130 \%$ & $94.450 \%$ \\
\hline 108 & pintura & 0.00610 & $0.068 \%$ & $1.130 \%$ & $94.518 \%$ \\
\hline 109 & entresuelo & 0.00586 & $0.119 \%$ & $1.977 \%$ & $94.637 \%$ \\
\hline 110 & habitación grande & 0.00557 & $0.051 \%$ & $0.847 \%$ & $94.688 \%$ \\
\hline 111 & esquina & 0.00552 & $0.051 \%$ & $0.847 \%$ & $94.739 \%$ \\
\hline 112 & sala de espera & 0.00525 & $0.034 \%$ & $0.565 \%$ & $94.773 \%$ \\
\hline 113 & cuarto de juguetes & 0.00523 & $0.068 \%$ & $1.130 \%$ & $94.841 \%$ \\
\hline 114 & muro & 0.00512 & $0.068 \%$ & $1.130 \%$ & $94.909 \%$ \\
\hline 115 & escritorio & 0.00506 & $0.068 \%$ & $1.130 \%$ & $94.977 \%$ \\
\hline 116 & mirador & 0.00486 & $0.085 \%$ & $1.412 \%$ & $95.062 \%$ \\
\hline 117 & patio interior & 0.00466 & $0.068 \%$ & $1.130 \%$ & $95.130 \%$ \\
\hline 118 & puerta de entrada & 0.00463 & $0.034 \%$ & $0.565 \%$ & $95.164 \%$ \\
\hline 119 & primer piso & 0.00456 & $0.068 \%$ & $1.130 \%$ & $95.232 \%$ \\
\hline 120 & cuarto de lavar & 0.00452 & $0.085 \%$ & $1.412 \%$ & $95.317 \%$ \\
\hline 121 & rincón & 0.00448 & $0.051 \%$ & $0.847 \%$ & $95.368 \%$ \\
\hline 122 & segundo piso & 0.00428 & $0.051 \%$ & $0.847 \%$ & $95.419 \%$ \\
\hline 123 & caseta del perro & 0.00427 & $0.051 \%$ & $0.847 \%$ & $95.470 \%$ \\
\hline 124 & dormitorio de matrimonio & 0.00425 & $0.034 \%$ & $0.565 \%$ & $95.504 \%$ \\
\hline 125 & descansillo & 0.00422 & $0.068 \%$ & $1.130 \%$ & $95.572 \%$ \\
\hline 126 & casa del perro & 0.00404 & $0.068 \%$ & $1.130 \%$ & $95.640 \%$ \\
\hline 127 & habitación de hijos & 0.00394 & $0.034 \%$ & $0.565 \%$ & $95.674 \%$ \\
\hline 128 & habitación pequeña & 0.00390 & $0.034 \%$ & $0.565 \%$ & $95.708 \%$ \\
\hline 129 & pavimento & 0.00378 & $0.068 \%$ & $1.130 \%$ & $95.776 \%$ \\
\hline 130 & guardarropa & 0.00377 & $0.051 \%$ & $0.847 \%$ & $95.827 \%$ \\
\hline 131 & yeso & 0.00376 & $0.034 \%$ & $0.565 \%$ & $95.861 \%$ \\
\hline 132 & invernadero & 0.00366 & $0.051 \%$ & $0.847 \%$ & $95.912 \%$ \\
\hline 133 & cuarto de matrimonio & 0.00366 & $0.034 \%$ & $0.565 \%$ & $95.946 \%$ \\
\hline 134 & ventanal & 0.00364 & $0.051 \%$ & $0.847 \%$ & $95.997 \%$ \\
\hline 135 & sala de billar & 0.00363 & $0.034 \%$ & $0.565 \%$ & $96.031 \%$ \\
\hline 136 & primera planta & 0.00362 & $0.034 \%$ & $0.565 \%$ & $96.065 \%$ \\
\hline 137 & pajar & 0.00362 & $0.051 \%$ & $0.847 \%$ & $96.116 \%$ \\
\hline
\end{tabular}




\begin{tabular}{|c|c|c|c|c|c|}
\hline 138 & retrete & 0.00361 & $0.051 \%$ & $0.847 \%$ & $96.167 \%$ \\
\hline 139 & cuarto de estudiar & 0.00351 & $0.034 \%$ & $0.565 \%$ & $96.201 \%$ \\
\hline 140 & cuarto de dormir & 0.00349 & $0.034 \%$ & $0.565 \%$ & $96.235 \%$ \\
\hline 141 & terraza interior & 0.00349 & $0.034 \%$ & $0.565 \%$ & $96.269 \%$ \\
\hline 142 & alacena & 0.00349 & $0.034 \%$ & $0.565 \%$ & $96.303 \%$ \\
\hline 143 & escayola & 0.00349 & $0.034 \%$ & $0.565 \%$ & $96.337 \%$ \\
\hline 144 & leonera & 0.00344 & $0.034 \%$ & $0.565 \%$ & $96.371 \%$ \\
\hline 145 & segunda planta & 0.00336 & $0.034 \%$ & $0.565 \%$ & $96.405 \%$ \\
\hline 146 & falsa & 0.00326 & $0.034 \%$ & $0.565 \%$ & $96.439 \%$ \\
\hline 147 & habitación de juegos & 0.00320 & $0.051 \%$ & $0.847 \%$ & $96.490 \%$ \\
\hline 148 & terraza exterior & 0.00316 & $0.034 \%$ & $0.565 \%$ & $96.524 \%$ \\
\hline 149 & buzón & 0.00312 & $0.085 \%$ & $1.412 \%$ & $96.609 \%$ \\
\hline 150 & repisa & 0.00311 & $0.051 \%$ & $0.847 \%$ & $96.660 \%$ \\
\hline 151 & espejo & 0.00306 & $0.034 \%$ & $0.565 \%$ & $96.694 \%$ \\
\hline 152 & teja & 0.00300 & $0.034 \%$ & $0.565 \%$ & $96.728 \%$ \\
\hline 153 & habitación de juguetes & 0.00297 & $0.034 \%$ & $0.565 \%$ & $96.762 \%$ \\
\hline 154 & recepción & 0.00282 & $0.017 \%$ & $0.282 \%$ & $96.779 \%$ \\
\hline 155 & chaflán & 0.00282 & $0.017 \%$ & $0.282 \%$ & $96.796 \%$ \\
\hline 156 & deslunado & 0.00279 & $0.034 \%$ & $0.565 \%$ & $96.830 \%$ \\
\hline 157 & cuadra & 0.00275 & $0.051 \%$ & $0.847 \%$ & $96.881 \%$ \\
\hline 158 & salida & 0.00270 & $0.034 \%$ & $0.565 \%$ & $96.915 \%$ \\
\hline 159 & dúplex & 0.00264 & $0.034 \%$ & $0.565 \%$ & $96.949 \%$ \\
\hline 160 & rebotica & 0.00262 & $0.017 \%$ & $0.282 \%$ & $96.966 \%$ \\
\hline 161 & dormitorio doble & 0.00262 & $0.017 \%$ & $0.282 \%$ & $96.983 \%$ \\
\hline 162 & Jacuzzi* & 0.00261 & $0.034 \%$ & $0.565 \%$ & $97.017 \%$ \\
\hline 163 & habitación de padres & 0.00255 & $0.034 \%$ & $0.565 \%$ & $97.051 \%$ \\
\hline 164 & marco & 0.00251 & $0.051 \%$ & $0.847 \%$ & $97.102 \%$ \\
\hline 165 & habitación de niños & 0.00248 & $0.034 \%$ & $0.565 \%$ & $97.136 \%$ \\
\hline 166 & pica de la cocina & 0.00244 & $0.017 \%$ & $0.282 \%$ & $97.153 \%$ \\
\hline 167 & saleta & 0.00244 & $0.017 \%$ & $0.282 \%$ & $97.170 \%$ \\
\hline 168 & sala de lectura & 0.00244 & $0.017 \%$ & $0.282 \%$ & $97.187 \%$ \\
\hline 169 & lavador & 0.00244 & $0.017 \%$ & $0.282 \%$ & $97.204 \%$ \\
\hline 170 & dormitorio simple & 0.00244 & $0.017 \%$ & $0.282 \%$ & $97.221 \%$ \\
\hline 171 & Pórtland* & 0.00242 & $0.034 \%$ & $0.565 \%$ & $97.255 \%$ \\
\hline 172 & cuarto de niños & 0.00233 & $0.034 \%$ & $0.565 \%$ & $97.289 \%$ \\
\hline 173 & enchufe & 0.00233 & $0.034 \%$ & $0.565 \%$ & $97.323 \%$ \\
\hline 174 & verja & 0.00231 & $0.034 \%$ & $0.565 \%$ & $97.357 \%$ \\
\hline 175 & tragaluz & 0.00230 & $0.034 \%$ & $0.565 \%$ & $97.391 \%$ \\
\hline 176 & zona de juegos & 0.00226 & $0.017 \%$ & $0.282 \%$ & $97.408 \%$ \\
\hline 177 & baño principal & 0.00226 & $0.017 \%$ & $0.282 \%$ & $97.425 \%$ \\
\hline 178 & aljibe & 0.00226 & $0.017 \%$ & $0.282 \%$ & $97.442 \%$ \\
\hline 179 & bovedilla & 0.00226 & $0.017 \%$ & $0.282 \%$ & $97.459 \%$ \\
\hline 180 & agua & 0.00225 & $0.034 \%$ & $0.565 \%$ & $97.493 \%$ \\
\hline 181 & sala de máquinas & 0.00224 & $0.051 \%$ & $0.847 \%$ & $97.544 \%$ \\
\hline 182 & cuarto de jugar & 0.00215 & $0.034 \%$ & $0.565 \%$ & $97.578 \%$ \\
\hline 183 & rodapié & 0.00215 & $0.034 \%$ & $0.565 \%$ & $97.612 \%$ \\
\hline 184 & interruptor & 0.00214 & $0.034 \%$ & $0.565 \%$ & $97.646 \%$ \\
\hline
\end{tabular}




\begin{tabular}{|c|c|c|c|c|c|}
\hline 185 & paellero & 0.00211 & $0.051 \%$ & $0.847 \%$ & $97.697 \%$ \\
\hline 186 & habitación de recreo & 0.00210 & $0.017 \%$ & $0.282 \%$ & $97.714 \%$ \\
\hline 187 & baño de servicio & 0.00210 & $0.017 \%$ & $0.282 \%$ & $97.731 \%$ \\
\hline 188 & habitación con camas & 0.00210 & $0.017 \%$ & $0.282 \%$ & $97.748 \%$ \\
\hline 189 & pica & 0.00210 & $0.017 \%$ & $0.282 \%$ & $97.765 \%$ \\
\hline 190 & cañería & 0.00209 & $0.034 \%$ & $0.565 \%$ & $97.799 \%$ \\
\hline 191 & descansillo de la escalera & 0.00201 & $0.034 \%$ & $0.565 \%$ & $97.833 \%$ \\
\hline 192 & cristal & 0.00198 & $0.051 \%$ & $0.847 \%$ & $97.884 \%$ \\
\hline 193 & arquitrabe & 0.00195 & $0.017 \%$ & $0.282 \%$ & $97.901 \%$ \\
\hline 194 & sala de tortura & 0.00195 & $0.017 \%$ & $0.282 \%$ & $97.918 \%$ \\
\hline 195 & nevera & 0.00195 & $0.017 \%$ & $0.282 \%$ & $97.935 \%$ \\
\hline 196 & habitación de trabajo & 0.00195 & $0.017 \%$ & $0.282 \%$ & $97.952 \%$ \\
\hline 197 & nido & 0.00195 & $0.017 \%$ & $0.282 \%$ & $97.969 \%$ \\
\hline 198 & desagüe & 0.00194 & $0.034 \%$ & $0.565 \%$ & $98.003 \%$ \\
\hline 199 & habitación del gato & 0.00181 & $0.017 \%$ & $0.282 \%$ & $98.020 \%$ \\
\hline 200 & sala del café & 0.00181 & $0.017 \%$ & $0.282 \%$ & $98.037 \%$ \\
\hline 201 & habitación principal & 0.00181 & $0.017 \%$ & $0.282 \%$ & $98.054 \%$ \\
\hline 202 & cuarto oscuro & 0.00180 & $0.034 \%$ & $0.565 \%$ & $98.088 \%$ \\
\hline 203 & sala de ordenador & 0.00173 & $0.034 \%$ & $0.565 \%$ & $98.122 \%$ \\
\hline 204 & huerto & 0.00173 & $0.034 \%$ & $0.565 \%$ & $98.156 \%$ \\
\hline 205 & cuarto del termo & 0.00168 & $0.017 \%$ & $0.282 \%$ & $98.173 \%$ \\
\hline 206 & cuarto de la ropa & 0.00168 & $0.017 \%$ & $0.282 \%$ & $98.190 \%$ \\
\hline 207 & distribuidor & 0.00168 & $0.017 \%$ & $0.282 \%$ & $98.207 \%$ \\
\hline 208 & dormitorio de hijos & 0.00168 & $0.017 \%$ & $0.282 \%$ & $98.224 \%$ \\
\hline 209 & guardapolvo & 0.00168 & $0.017 \%$ & $0.282 \%$ & $98.241 \%$ \\
\hline 210 & encimera & 0.00168 & $0.017 \%$ & $0.282 \%$ & $98.258 \%$ \\
\hline 211 & sala de coser & 0.00168 & $0.017 \%$ & $0.282 \%$ & $98.275 \%$ \\
\hline 212 & librería & 0.00167 & $0.034 \%$ & $0.565 \%$ & $98.309 \%$ \\
\hline 213 & dormitorio individual & 0.00156 & $0.017 \%$ & $0.282 \%$ & $98.326 \%$ \\
\hline 214 & cuarto de trabajo & 0.00156 & $0.017 \%$ & $0.282 \%$ & $98.343 \%$ \\
\hline 215 & dintel & 0.00156 & $0.017 \%$ & $0.282 \%$ & $98.360 \%$ \\
\hline 216 & parqué & 0.00156 & $0.017 \%$ & $0.282 \%$ & $98.377 \%$ \\
\hline 217 & sala de ping-pong & 0.00156 & $0.017 \%$ & $0.282 \%$ & $98.394 \%$ \\
\hline 218 & dormitorio conyugal & 0.00156 & $0.017 \%$ & $0.282 \%$ & $98.411 \%$ \\
\hline 219 & bar & 0.00156 & $0.017 \%$ & $0.282 \%$ & $98.428 \%$ \\
\hline 220 & salón de juegos & 0.00156 & $0.017 \%$ & $0.282 \%$ & $98.445 \%$ \\
\hline 221 & respiradero & 0.00155 & $0.034 \%$ & $0.565 \%$ & $98.479 \%$ \\
\hline 222 & caldera & 0.00145 & $0.017 \%$ & $0.282 \%$ & $98.496 \%$ \\
\hline 223 & tapajuntas & 0.00145 & $0.017 \%$ & $0.282 \%$ & $98.513 \%$ \\
\hline 224 & estancia & 0.00145 & $0.017 \%$ & $0.282 \%$ & $98.530 \%$ \\
\hline 225 & armario interior & 0.00135 & $0.017 \%$ & $0.282 \%$ & $98.547 \%$ \\
\hline 226 & salón del piano & 0.00135 & $0.017 \%$ & $0.282 \%$ & $98.564 \%$ \\
\hline 227 & cable & 0.00135 & $0.017 \%$ & $0.282 \%$ & $98.581 \%$ \\
\hline 228 & valla & 0.00135 & $0.017 \%$ & $0.282 \%$ & $98.598 \%$ \\
\hline 229 & salón de estudio & 0.00135 & $0.017 \%$ & $0.282 \%$ & $98.615 \%$ \\
\hline 230 & arco & 0.00131 & $0.034 \%$ & $0.565 \%$ & $98.649 \%$ \\
\hline 231 & pista de básquet & 0.00127 & $0.051 \%$ & $0.847 \%$ & $98.700 \%$ \\
\hline
\end{tabular}




\begin{tabular}{|c|c|c|c|c|c|}
\hline 232 & parking & 0.00125 & $0.017 \%$ & $0.282 \%$ & $98.717 \%$ \\
\hline 233 & cuarto secundario & 0.00125 & $0.017 \%$ & $0.282 \%$ & $98.734 \%$ \\
\hline 234 & cisterna & 0.00125 & $0.017 \%$ & $0.282 \%$ & $98.751 \%$ \\
\hline 235 & cuarto ropero & 0.00125 & $0.017 \%$ & $0.282 \%$ & $98.768 \%$ \\
\hline 236 & salón de invitados & 0.00125 & $0.017 \%$ & $0.282 \%$ & $98.785 \%$ \\
\hline 237 & minigolf & 0.00117 & $0.051 \%$ & $0.847 \%$ & $98.836 \%$ \\
\hline 238 & placa solar & 0.00116 & $0.017 \%$ & $0.282 \%$ & $98.853 \%$ \\
\hline 239 & váter pequeño & 0.00116 & $0.017 \%$ & $0.282 \%$ & $98.870 \%$ \\
\hline 240 & solar & 0.00116 & $0.017 \%$ & $0.282 \%$ & $98.887 \%$ \\
\hline 241 & depósito & 0.00116 & $0.017 \%$ & $0.282 \%$ & $98.904 \%$ \\
\hline 242 & cornisa & 0.00116 & $0.017 \%$ & $0.282 \%$ & $98.921 \%$ \\
\hline 243 & foso & 0.00116 & $0.017 \%$ & $0.282 \%$ & $98.938 \%$ \\
\hline 244 & cuarto trasero & 0.00116 & $0.017 \%$ & $0.282 \%$ & $98.955 \%$ \\
\hline 245 & probador & 0.00108 & $0.017 \%$ & $0.282 \%$ & $98.972 \%$ \\
\hline 246 & rebost & 0.00108 & $0.017 \%$ & $0.282 \%$ & $98.989 \%$ \\
\hline 247 & salón de juguetes & 0.00108 & $0.017 \%$ & $0.282 \%$ & $99.006 \%$ \\
\hline 248 & cuarto de la lavadora & 0.00108 & $0.017 \%$ & $0.282 \%$ & $99.023 \%$ \\
\hline 249 & banco & 0.00108 & $0.017 \%$ & $0.282 \%$ & $99.040 \%$ \\
\hline 250 & sala de TV & 0.00108 & $0.017 \%$ & $0.282 \%$ & $99.057 \%$ \\
\hline 251 & radiador & 0.00108 & $0.017 \%$ & $0.282 \%$ & $99.074 \%$ \\
\hline 252 & termo & 0.00108 & $0.017 \%$ & $0.282 \%$ & $99.091 \%$ \\
\hline 253 & habitación del bebé & 0.00100 & $0.017 \%$ & $0.282 \%$ & $99.108 \%$ \\
\hline 254 & forjado & 0.00100 & $0.017 \%$ & $0.282 \%$ & $99.125 \%$ \\
\hline 255 & subterráneo & 0.00100 & $0.017 \%$ & $0.282 \%$ & $99.142 \%$ \\
\hline 256 & subsuelo & 0.00100 & $0.017 \%$ & $0.282 \%$ & $99.159 \%$ \\
\hline 257 & habitáculo & 0.00100 & $0.017 \%$ & $0.282 \%$ & $99.176 \%$ \\
\hline 258 & cuarto de la plancha & 0.00100 & $0.017 \%$ & $0.282 \%$ & $99.193 \%$ \\
\hline 259 & cancha de tenis & 0.00100 & $0.017 \%$ & $0.282 \%$ & $99.210 \%$ \\
\hline 260 & sala de música & 0.00100 & $0.017 \%$ & $0.282 \%$ & $99.227 \%$ \\
\hline 261 & gimnasio particular & 0.00100 & $0.017 \%$ & $0.282 \%$ & $99.244 \%$ \\
\hline 262 & cuarto de las ratas & 0.00093 & $0.017 \%$ & $0.282 \%$ & $99.261 \%$ \\
\hline 263 & aire climatizado & 0.00093 & $0.017 \%$ & $0.282 \%$ & $99.278 \%$ \\
\hline 264 & sala recreativa & 0.00093 & $0.017 \%$ & $0.282 \%$ & $99.295 \%$ \\
\hline 265 & zaguán & 0.00093 & $0.017 \%$ & $0.282 \%$ & $99.312 \%$ \\
\hline 266 & vestuario & 0.00093 & $0.017 \%$ & $0.282 \%$ & $99.329 \%$ \\
\hline 267 & granero & 0.00093 & $0.017 \%$ & $0.282 \%$ & $99.346 \%$ \\
\hline 268 & claraboya & 0.00093 & $0.017 \%$ & $0.282 \%$ & $99.363 \%$ \\
\hline 269 & escalón & 0.00093 & $0.017 \%$ & $0.282 \%$ & $99.380 \%$ \\
\hline 270 & aseo grande & 0.00093 & $0.017 \%$ & $0.282 \%$ & $99.397 \%$ \\
\hline 271 & salón de trofeos & 0.00093 & $0.017 \%$ & $0.282 \%$ & $99.414 \%$ \\
\hline 272 & cuarto de caldera & 0.00086 & $0.017 \%$ & $0.282 \%$ & $99.431 \%$ \\
\hline 273 & sala de baile & 0.00086 & $0.017 \%$ & $0.282 \%$ & $99.448 \%$ \\
\hline 274 & tapia & 0.00086 & $0.017 \%$ & $0.282 \%$ & $99.465 \%$ \\
\hline 275 & pasadizo & 0.00086 & $0.017 \%$ & $0.282 \%$ & $99.482 \%$ \\
\hline 276 & sala de televisión & 0.00086 & $0.017 \%$ & $0.282 \%$ & $99.499 \%$ \\
\hline 277 & desllunat & 0.00086 & $0.017 \%$ & $0.282 \%$ & $99.516 \%$ \\
\hline 278 & sala de costura & 0.00086 & $0.017 \%$ & $0.282 \%$ & $99.533 \%$ \\
\hline
\end{tabular}




\begin{tabular}{|l|l||l|l|l|l|}
\hline 279 & frontera & 0.00086 & $0.017 \%$ & $0.282 \%$ & $99.550 \%$ \\
\hline 280 & salón recreativo & 0.00074 & $0.017 \%$ & $0.282 \%$ & $99.567 \%$ \\
\hline 281 & baldosín & 0.00074 & $0.017 \%$ & $0.282 \%$ & $99.584 \%$ \\
\hline 282 & cuarto de castigo & 0.00074 & $0.017 \%$ & $0.282 \%$ & $99.601 \%$ \\
\hline 283 & ala este & 0.00074 & $0.017 \%$ & $0.282 \%$ & $99.618 \%$ \\
\hline 284 & hormigón & 0.00069 & $0.017 \%$ & $0.282 \%$ & $99.635 \%$ \\
\hline 285 & puerta de la tapia & 0.00069 & $0.017 \%$ & $0.282 \%$ & $99.652 \%$ \\
\hline 286 & sala de audiovisuales & 0.00069 & $0.017 \%$ & $0.282 \%$ & $99.669 \%$ \\
\hline 287 & habitación de la plancha & 0.00069 & $0.017 \%$ & $0.282 \%$ & $99.686 \%$ \\
\hline 288 & planta alta & 0.00069 & $0.017 \%$ & $0.282 \%$ & $99.703 \%$ \\
\hline 289 & puerta de garaje & 0.00069 & $0.017 \%$ & $0.282 \%$ & $99.720 \%$ \\
\hline 290 & arena & 0.00064 & $0.017 \%$ & $0.282 \%$ & $99.737 \%$ \\
\hline 291 & sala de calderas & 0.00064 & $0.017 \%$ & $0.282 \%$ & $99.754 \%$ \\
\hline 292 & salón de té & 0.00064 & $0.017 \%$ & $0.282 \%$ & $99.771 \%$ \\
\hline 293 & establo & 0.00064 & $0.017 \%$ & $0.282 \%$ & $99.788 \%$ \\
\hline 294 & mosquitera & 0.00064 & $0.017 \%$ & $0.282 \%$ & $99.805 \%$ \\
\hline 295 & tierra & 0.00059 & $0.017 \%$ & $0.282 \%$ & $99.822 \%$ \\
\hline 296 & luz & 0.00059 & $0.017 \%$ & $0.282 \%$ & $99.839 \%$ \\
\hline 297 & sala de descanso & 0.00059 & $0.017 \%$ & $0.282 \%$ & $99.856 \%$ \\
\hline 298 & sala de reunión & 0.00055 & $0.017 \%$ & $0.282 \%$ & $99.873 \%$ \\
\hline 299 & cerradura & 0.00051 & $0.017 \%$ & $0.282 \%$ & $99.890 \%$ \\
\hline 300 & llave & 0.00048 & $0.017 \%$ & $0.282 \%$ & $99.907 \%$ \\
\hline 301 & pasamano & 0.00048 & $0.017 \%$ & $0.282 \%$ & $99.924 \%$ \\
\hline 302 & jardinera & 0.00048 & $0.017 \%$ & $0.282 \%$ & $99.941 \%$ \\
\hline 303 & antesala & 0.00044 & $0.017 \%$ & $0.282 \%$ & $99.958 \%$ \\
\hline 304 & clavo & 0.00044 & $0.017 \%$ & $0.282 \%$ & $99.975 \%$ \\
\hline 305 & habitación de música & 0.00044 & $0.017 \%$ & $0.282 \%$ & $99.992 \%$ \\
\hline 306 & barra & 0.00044 & $0.017 \%$ & $0.282 \%$ & $100.009 \%$ \\
\hline 307 & torre & 0.00035 & $0.017 \%$ & $0.282 \%$ & $100.026 \%$ \\
\hline & & & & & \\
\hline
\end{tabular}

04. LOS MUEBLES DE LA CASA

\begin{tabular}{|c|l|c|c|c|c|}
\hline $\mathrm{N}^{\circ}$ & Palabra & Disponibilidad & $\begin{array}{c}\text { Frecuencia } \\
\text { relativa }\end{array}$ & $\%$ Aparición & $\begin{array}{c}\text { Frecuencia } \\
\text { acumulada }\end{array}$ \\
\hline 1 & silla & 0.78148 & $6.554 \%$ & $95.198 \%$ & $6.554 \%$ \\
\hline 2 & mesa & 0.73952 & $6.184 \%$ & $89.831 \%$ & $12.738 \%$ \\
\hline 3 & cama & 0.61464 & $6.068 \%$ & $88.136 \%$ & $18.806 \%$ \\
\hline 4 & armario & 0.61408 & $6.009 \%$ & $87.288 \%$ & $24.815 \%$ \\
\hline 5 & sillón & 0.57127 & $5.581 \%$ & $81.073 \%$ & $30.396 \%$ \\
\hline 6 & sofá & 0.57109 & $5.484 \%$ & $79.661 \%$ & $35.880 \%$ \\
\hline 7 & estantería & 0.38107 & $4.356 \%$ & $63.277 \%$ & $40.236 \%$ \\
\hline 8 & mesita & 0.33663 & $3.442 \%$ & $50.000 \%$ & $43.678 \%$ \\
\hline 9 & escritorio & 0.24283 & $2.975 \%$ & $43.220 \%$ & $46.653 \%$ \\
\hline
\end{tabular}




\begin{tabular}{|c|c|c|c|c|c|}
\hline 10 & cómoda & 0.18452 & $2.023 \%$ & $29.379 \%$ & $48.676 \%$ \\
\hline 11 & taburete & 0.17561 & $2.217 \%$ & $32.203 \%$ & $50.893 \%$ \\
\hline 12 & aparador & 0.17527 & $1.867 \%$ & $27.119 \%$ & $52.760 \%$ \\
\hline 13 & lámpara & 0.12840 & $1.614 \%$ & $23.446 \%$ & $54.374 \%$ \\
\hline 14 & mesita de noche & 0.12523 & $1.342 \%$ & $19.492 \%$ & $55.716 \%$ \\
\hline 15 & espejo & 0.11793 & $1.731 \%$ & $25.141 \%$ & $57.447 \%$ \\
\hline 16 & mecedora & 0.11166 & $1.439 \%$ & $20.904 \%$ & $58.886 \%$ \\
\hline 17 & cuadro & 0.08877 & $1.245 \%$ & $18.079 \%$ & $60.131 \%$ \\
\hline 18 & litera & 0.08474 & $1.167 \%$ & $16.949 \%$ & $61.298 \%$ \\
\hline 19 & tocador & 0.08022 & $1.128 \%$ & $16.384 \%$ & $62.426 \%$ \\
\hline 20 & mesa camilla & 0.07971 & $0.933 \%$ & $13.559 \%$ & $63.359 \%$ \\
\hline 21 & puerta & 0.06980 & $0.875 \%$ & $12.712 \%$ & $64.234 \%$ \\
\hline 22 & mueble bar & 0.06909 & $0.895 \%$ & $12.994 \%$ & $65.129 \%$ \\
\hline 23 & butaca & 0.06871 & $0.875 \%$ & $12.712 \%$ & $66.004 \%$ \\
\hline 24 & cajón & 0.06862 & $0.875 \%$ & $12.712 \%$ & $66.879 \%$ \\
\hline 25 & tele(visión) & 0.06564 & $0.681 \%$ & $9.887 \%$ & $67.560 \%$ \\
\hline 26 & nevera & 0.06195 & $0.739 \%$ & $10.734 \%$ & $68.299 \%$ \\
\hline 27 & armario empotrado & 0.06170 & $0.797 \%$ & $11.582 \%$ & $69.096 \%$ \\
\hline 28 & recibidor & 0.06135 & $0.661 \%$ & $9.605 \%$ & $69.757 \%$ \\
\hline 29 & (armario) ropero & 0.05858 & $0.700 \%$ & $10.169 \%$ & $70.457 \%$ \\
\hline 30 & librería & 0.05524 & $0.642 \%$ & $9.322 \%$ & $71.099 \%$ \\
\hline 31 & baúl & 0.05328 & $0.778 \%$ & $11.299 \%$ & $71.877 \%$ \\
\hline 32 & vitrina & 0.05245 & $0.642 \%$ & $9.322 \%$ & $72.519 \%$ \\
\hline 33 & percha & 0.04996 & $0.681 \%$ & $9.887 \%$ & $73.200 \%$ \\
\hline 34 & tresillo & 0.04793 & $0.525 \%$ & $7.627 \%$ & $73.725 \%$ \\
\hline 35 & lavadora & 0.04775 & $0.622 \%$ & $9.040 \%$ & $74.347 \%$ \\
\hline 36 & zapatero & 0.04399 & $0.622 \%$ & $9.040 \%$ & $74.969 \%$ \\
\hline 37 & perchero & 0.04350 & $0.758 \%$ & $11.017 \%$ & $75.727 \%$ \\
\hline 38 & microondas & 0.04059 & $0.525 \%$ & $7.627 \%$ & $76.252 \%$ \\
\hline 39 & encimera & 0.04031 & $0.447 \%$ & $6.497 \%$ & $76.699 \%$ \\
\hline 40 & pupitre & 0.04006 & $0.525 \%$ & $7.627 \%$ & $77.224 \%$ \\
\hline 41 & horno & 0.03887 & $0.467 \%$ & $6.780 \%$ & $77.691 \%$ \\
\hline 42 & mesilla & 0.03409 & $0.350 \%$ & $5.085 \%$ & $78.041 \%$ \\
\hline 43 & comodín & 0.03357 & $0.428 \%$ & $6.215 \%$ & $78.469 \%$ \\
\hline 44 & banqueta & 0.03344 & $0.447 \%$ & $6.497 \%$ & $78.916 \%$ \\
\hline 45 & mesa de estudio & 0.03303 & $0.370 \%$ & $5.367 \%$ & $79.286 \%$ \\
\hline 46 & mesa de comedor & 0.03182 & $0.272 \%$ & $3.955 \%$ & $79.558 \%$ \\
\hline 47 & alfombra & 0.03177 & $0.486 \%$ & $7.062 \%$ & $80.044 \%$ \\
\hline 48 & cocina & 0.03075 & $0.350 \%$ & $5.085 \%$ & $80.394 \%$ \\
\hline 49 & chifonier & 0.02897 & $0.389 \%$ & $5.650 \%$ & $80.783 \%$ \\
\hline 50 & sofá cama & 0.02850 & $0.408 \%$ & $5.932 \%$ & $81.191 \%$ \\
\hline 51 & lavabo & 0.02821 & $0.389 \%$ & $5.650 \%$ & $81.580 \%$ \\
\hline 52 & lavavajillas & 0.02814 & $0.389 \%$ & $5.650 \%$ & $81.969 \%$ \\
\hline 53 & hamaca & 0.02716 & $0.370 \%$ & $5.367 \%$ & $82.339 \%$ \\
\hline 54 & bañera & 0.02686 & $0.389 \%$ & $5.650 \%$ & $82.728 \%$ \\
\hline 55 & banco & 0.02564 & $0.350 \%$ & $5.085 \%$ & $83.078 \%$ \\
\hline 56 & diván & 0.02512 & $0.370 \%$ & $5.367 \%$ & $83.448 \%$ \\
\hline
\end{tabular}




\begin{tabular}{|c|c|c|c|c|c|}
\hline 57 & bidé & 0.02361 & $0.331 \%$ & $4.802 \%$ & $83.779 \%$ \\
\hline 58 & estante & 0.02349 & $0.311 \%$ & $4.520 \%$ & $84.090 \%$ \\
\hline 59 & mueble de tele(visión) & 0.02310 & $0.253 \%$ & $3.672 \%$ & $84.343 \%$ \\
\hline 60 & frigorífico & 0.02143 & $0.253 \%$ & $3.672 \%$ & $84.596 \%$ \\
\hline 61 & váter & 0.02113 & $0.311 \%$ & $4.520 \%$ & $84.907 \%$ \\
\hline 62 & despensa & 0.02071 & $0.253 \%$ & $3.672 \%$ & $85.160 \%$ \\
\hline 63 & mesa de cocina & 0.02040 & $0.194 \%$ & $2.825 \%$ & $85.354 \%$ \\
\hline 64 & mueble & 0.02021 & $0.233 \%$ & $3.390 \%$ & $85.587 \%$ \\
\hline 65 & mueble de cocina & 0.02012 & $0.253 \%$ & $3.672 \%$ & $85.840 \%$ \\
\hline 66 & balancín & 0.01973 & $0.233 \%$ & $3.390 \%$ & $86.073 \%$ \\
\hline 67 & mesa de noche & 0.01860 & $0.214 \%$ & $3.107 \%$ & $86.287 \%$ \\
\hline 68 & vídeo & 0.01793 & $0.214 \%$ & $3.107 \%$ & $86.501 \%$ \\
\hline 69 & televisor & 0.01789 & $0.253 \%$ & $3.672 \%$ & $86.754 \%$ \\
\hline 70 & rinconera & 0.01699 & $0.253 \%$ & $3.672 \%$ & $87.007 \%$ \\
\hline 71 & mueble de comedor & 0.01682 & $0.194 \%$ & $2.825 \%$ & $87.201 \%$ \\
\hline 72 & puf & 0.01679 & $0.253 \%$ & $3.672 \%$ & $87.454 \%$ \\
\hline 73 & consola & 0.01666 & $0.194 \%$ & $2.825 \%$ & $87.648 \%$ \\
\hline 74 & armario de cocina & 0.01619 & $0.233 \%$ & $3.390 \%$ & $87.881 \%$ \\
\hline 75 & reposapiés & 0.01585 & $0.233 \%$ & $3.390 \%$ & $88.114 \%$ \\
\hline 76 & banco de cocina & 0.01539 & $0.156 \%$ & $2.260 \%$ & $88.270 \%$ \\
\hline 77 & flexo & 0.01504 & $0.253 \%$ & $3.672 \%$ & $88.523 \%$ \\
\hline 78 & barra & 0.01487 & $0.194 \%$ & $2.825 \%$ & $88.717 \%$ \\
\hline 79 & mesilla de noche & 0.01462 & $0.194 \%$ & $2.825 \%$ & $88.911 \%$ \\
\hline 80 & ordenador & 0.01453 & $0.194 \%$ & $2.825 \%$ & $89.105 \%$ \\
\hline 81 & camilla & 0.01432 & $0.156 \%$ & $2.260 \%$ & $89.261 \%$ \\
\hline 82 & cama de matrimonio & 0.01425 & $0.175 \%$ & $2.542 \%$ & $89.436 \%$ \\
\hline 83 & taquillón & 0.01391 & $0.175 \%$ & $2.542 \%$ & $89.611 \%$ \\
\hline 84 & somier & 0.01348 & $0.214 \%$ & $3.107 \%$ & $89.825 \%$ \\
\hline 85 & biblioteca & 0.01326 & $0.175 \%$ & $2.542 \%$ & $90.000 \%$ \\
\hline 86 & mueble de baño & 0.01281 & $0.175 \%$ & $2.542 \%$ & $90.175 \%$ \\
\hline 87 & arcón & 0.01240 & $0.156 \%$ & $2.260 \%$ & $90.331 \%$ \\
\hline 88 & armario de ropa & 0.01203 & $0.097 \%$ & $1.412 \%$ & $90.428 \%$ \\
\hline 89 & cuna & 0.01158 & $0.194 \%$ & $2.825 \%$ & $90.622 \%$ \\
\hline 90 & mueble de recibidor & 0.01142 & $0.156 \%$ & $2.260 \%$ & $90.778 \%$ \\
\hline 91 & mesa de tele(visión) & 0.01125 & $0.156 \%$ & $2.260 \%$ & $90.934 \%$ \\
\hline 92 & cortina & 0.01115 & $0.194 \%$ & $2.825 \%$ & $91.128 \%$ \\
\hline 93 & cristalera & 0.01113 & $0.136 \%$ & $1.977 \%$ & $91.264 \%$ \\
\hline 94 & butacón & 0.01090 & $0.136 \%$ & $1.977 \%$ & $91.400 \%$ \\
\hline 95 & cabezal & 0.01086 & $0.175 \%$ & $2.542 \%$ & $91.575 \%$ \\
\hline 96 & minicadena & 0.01077 & $0.156 \%$ & $2.260 \%$ & $91.731 \%$ \\
\hline 97 & vidriera & 0.01055 & $0.136 \%$ & $1.977 \%$ & $91.867 \%$ \\
\hline 98 & camarera & 0.01054 & $0.175 \%$ & $2.542 \%$ & $92.042 \%$ \\
\hline 99 & paragüero & 0.00973 & $0.214 \%$ & $3.107 \%$ & $92.256 \%$ \\
\hline 100 & guardarropa & 0.00963 & $0.117 \%$ & $1.695 \%$ & $92.373 \%$ \\
\hline 101 & ventana & 0.00960 & $0.136 \%$ & $1.977 \%$ & $92.509 \%$ \\
\hline 102 & tumbona & 0.00948 & $0.136 \%$ & $1.977 \%$ & $92.645 \%$ \\
\hline 103 & secadora & 0.00942 & $0.136 \%$ & $1.977 \%$ & $92.781 \%$ \\
\hline
\end{tabular}




\begin{tabular}{|c|c|c|c|c|c|}
\hline 104 & cajonera & 0.00897 & $0.136 \%$ & $1.977 \%$ & $92.917 \%$ \\
\hline 105 & fogón & 0.00883 & $0.097 \%$ & $1.412 \%$ & $93.014 \%$ \\
\hline 106 & congelador & 0.00877 & $0.117 \%$ & $1.695 \%$ & $93.131 \%$ \\
\hline 107 & nido & 0.00866 & $0.136 \%$ & $1.977 \%$ & $93.267 \%$ \\
\hline 108 & chimenea & 0.00863 & $0.117 \%$ & $1.695 \%$ & $93.384 \%$ \\
\hline 109 & mesa de comer & 0.00849 & $0.097 \%$ & $1.412 \%$ & $93.481 \%$ \\
\hline 110 & silla de cocina & 0.00768 & $0.058 \%$ & $0.847 \%$ & $93.539 \%$ \\
\hline 111 & cama individual & 0.00733 & $0.078 \%$ & $1.130 \%$ & $93.617 \%$ \\
\hline 112 & teléfono & 0.00726 & $0.097 \%$ & $1.412 \%$ & $93.714 \%$ \\
\hline 113 & ducha & 0.00705 & $0.117 \%$ & $1.695 \%$ & $93.831 \%$ \\
\hline 114 & piano & 0.00704 & $0.097 \%$ & $1.412 \%$ & $93.928 \%$ \\
\hline 115 & altillo & 0.00678 & $0.097 \%$ & $1.412 \%$ & $94.025 \%$ \\
\hline 116 & armario de baño & 0.00674 & $0.117 \%$ & $1.695 \%$ & $94.142 \%$ \\
\hline 117 & cama nido & 0.00634 & $0.097 \%$ & $1.412 \%$ & $94.239 \%$ \\
\hline 118 & radio & 0.00624 & $0.097 \%$ & $1.412 \%$ & $94.336 \%$ \\
\hline 119 & estufa & 0.00607 & $0.097 \%$ & $1.412 \%$ & $94.433 \%$ \\
\hline 120 & caja fuerte & 0.00604 & $0.078 \%$ & $1.130 \%$ & $94.511 \%$ \\
\hline 121 & cojín & 0.00595 & $0.058 \%$ & $0.847 \%$ & $94.569 \%$ \\
\hline 122 & repisa & 0.00570 & $0.097 \%$ & $1.412 \%$ & $94.666 \%$ \\
\hline 123 & armario de luna & 0.00542 & $0.058 \%$ & $0.847 \%$ & $94.724 \%$ \\
\hline 124 & mesa de ordenador & 0.00538 & $0.097 \%$ & $1.412 \%$ & $94.821 \%$ \\
\hline 125 & trastero & 0.00528 & $0.058 \%$ & $0.847 \%$ & $94.879 \%$ \\
\hline 126 & mueble de televisor & 0.00511 & $0.078 \%$ & $1.130 \%$ & $94.957 \%$ \\
\hline 127 & revistero & 0.00483 & $0.078 \%$ & $1.130 \%$ & $95.035 \%$ \\
\hline 128 & silla de comedor & 0.00452 & $0.039 \%$ & $0.565 \%$ & $95.074 \%$ \\
\hline 129 & vestidor & 0.00451 & $0.058 \%$ & $0.847 \%$ & $95.132 \%$ \\
\hline 130 & lavaplatos & 0.00438 & $0.078 \%$ & $1.130 \%$ & $95.210 \%$ \\
\hline 131 & cadena & 0.00426 & $0.058 \%$ & $0.847 \%$ & $95.268 \%$ \\
\hline 132 & orejero & 0.00414 & $0.058 \%$ & $0.847 \%$ & $95.326 \%$ \\
\hline 133 & macetero & 0.00403 & $0.097 \%$ & $1.412 \%$ & $95.423 \%$ \\
\hline 134 & mesa de salón & 0.00399 & $0.058 \%$ & $0.847 \%$ & $95.481 \%$ \\
\hline 135 & jarrón & 0.00395 & $0.078 \%$ & $1.130 \%$ & $95.559 \%$ \\
\hline 136 & mesa de café & 0.00387 & $0.058 \%$ & $0.847 \%$ & $95.617 \%$ \\
\hline 137 & mueble cama & 0.00386 & $0.058 \%$ & $0.847 \%$ & $95.675 \%$ \\
\hline 138 & plancha & 0.00375 & $0.058 \%$ & $0.847 \%$ & $95.733 \%$ \\
\hline 139 & sombrilla & 0.00368 & $0.039 \%$ & $0.565 \%$ & $95.772 \%$ \\
\hline 140 & cama de agua & 0.00363 & $0.039 \%$ & $0.565 \%$ & $95.811 \%$ \\
\hline 141 & barandilla & 0.00362 & $0.039 \%$ & $0.565 \%$ & $95.850 \%$ \\
\hline 142 & inodoro & 0.00349 & $0.039 \%$ & $0.565 \%$ & $95.889 \%$ \\
\hline 143 & cofre & 0.00347 & $0.058 \%$ & $0.847 \%$ & $95.947 \%$ \\
\hline 144 & tostadora & 0.00344 & $0.039 \%$ & $0.565 \%$ & $95.986 \%$ \\
\hline 145 & mueble HI-FI & 0.00338 & $0.058 \%$ & $0.847 \%$ & $96.044 \%$ \\
\hline 146 & estudio & 0.00337 & $0.039 \%$ & $0.565 \%$ & $96.083 \%$ \\
\hline 147 & esquinera & 0.00324 & $0.039 \%$ & $0.565 \%$ & $96.122 \%$ \\
\hline 148 & lámpara de pie & 0.00324 & $0.039 \%$ & $0.565 \%$ & $96.161 \%$ \\
\hline 149 & mampara & 0.00320 & $0.039 \%$ & $0.565 \%$ & $96.200 \%$ \\
\hline 150 & mesa de TV & 0.00320 & $0.039 \%$ & $0.565 \%$ & $96.239 \%$ \\
\hline
\end{tabular}




\begin{tabular}{|c|c|c|c|c|c|}
\hline 151 & papelera & 0.00316 & $0.039 \%$ & $0.565 \%$ & $96.278 \%$ \\
\hline 152 & buró & 0.00311 & $0.039 \%$ & $0.565 \%$ & $96.317 \%$ \\
\hline 153 & pica & 0.00310 & $0.058 \%$ & $0.847 \%$ & $96.375 \%$ \\
\hline 154 & baño & 0.00309 & $0.058 \%$ & $0.847 \%$ & $96.433 \%$ \\
\hline 155 & cama plegable & 0.00307 & $0.058 \%$ & $0.847 \%$ & $96.491 \%$ \\
\hline 156 & mostrador & 0.00306 & $0.058 \%$ & $0.847 \%$ & $96.549 \%$ \\
\hline 157 & cadena de música & 0.00303 & $0.039 \%$ & $0.565 \%$ & $96.588 \%$ \\
\hline 158 & lamparilla & 0.00289 & $0.039 \%$ & $0.565 \%$ & $96.627 \%$ \\
\hline 159 & chaise longue & 0.00284 & $0.039 \%$ & $0.565 \%$ & $96.666 \%$ \\
\hline 160 & mueble de jardín & 0.00282 & $0.019 \%$ & $0.282 \%$ & $96.685 \%$ \\
\hline 161 & mesa de despacho & 0.00279 & $0.039 \%$ & $0.565 \%$ & $96.724 \%$ \\
\hline 162 & alacena & 0.00279 & $0.039 \%$ & $0.565 \%$ & $96.763 \%$ \\
\hline 163 & radiador & 0.00274 & $0.058 \%$ & $0.847 \%$ & $96.821 \%$ \\
\hline 164 & bar & 0.00267 & $0.039 \%$ & $0.565 \%$ & $96.860 \%$ \\
\hline 165 & florero & 0.00266 & $0.058 \%$ & $0.847 \%$ & $96.918 \%$ \\
\hline 166 & casilla & 0.00262 & $0.019 \%$ & $0.282 \%$ & $96.937 \%$ \\
\hline 167 & taza del váter & 0.00262 & $0.019 \%$ & $0.282 \%$ & $96.956 \%$ \\
\hline 168 & lámpara de mesa & 0.00262 & $0.019 \%$ & $0.282 \%$ & $96.975 \%$ \\
\hline 169 & cabecera & 0.00261 & $0.039 \%$ & $0.565 \%$ & $97.014 \%$ \\
\hline 170 & vitrocerámica & 0.00250 & $0.039 \%$ & $0.565 \%$ & $97.053 \%$ \\
\hline 171 & electrodoméstico & 0.00249 & $0.039 \%$ & $0.565 \%$ & $97.092 \%$ \\
\hline 172 & casete & 0.00244 & $0.019 \%$ & $0.282 \%$ & $97.111 \%$ \\
\hline 173 & comedor & 0.00244 & $0.019 \%$ & $0.282 \%$ & $97.130 \%$ \\
\hline 174 & canapé & 0.00244 & $0.019 \%$ & $0.282 \%$ & $97.149 \%$ \\
\hline 175 & camastro & 0.00244 & $0.019 \%$ & $0.282 \%$ & $97.168 \%$ \\
\hline 176 & mesita de recibidor & 0.00244 & $0.019 \%$ & $0.282 \%$ & $97.187 \%$ \\
\hline 177 & recibidor mueble & 0.00244 & $0.019 \%$ & $0.282 \%$ & $97.206 \%$ \\
\hline 178 & mesa de billar & 0.00241 & $0.039 \%$ & $0.565 \%$ & $97.245 \%$ \\
\hline 179 & máquina de coser & 0.00240 & $0.039 \%$ & $0.565 \%$ & $97.284 \%$ \\
\hline 180 & armario zapatero & 0.00234 & $0.039 \%$ & $0.565 \%$ & $97.323 \%$ \\
\hline 181 & mesita de tele(visión) & 0.00233 & $0.039 \%$ & $0.565 \%$ & $97.362 \%$ \\
\hline 182 & banco pequeño & 0.00226 & $0.019 \%$ & $0.282 \%$ & $97.381 \%$ \\
\hline 183 & luna & 0.00226 & $0.019 \%$ & $0.282 \%$ & $97.400 \%$ \\
\hline 184 & mobiliario de cocina & 0.00226 & $0.019 \%$ & $0.282 \%$ & $97.419 \%$ \\
\hline 185 & lámpara de techo & 0.00226 & $0.019 \%$ & $0.282 \%$ & $97.438 \%$ \\
\hline 186 & fregadero & 0.00214 & $0.039 \%$ & $0.565 \%$ & $97.477 \%$ \\
\hline 187 & archivador & 0.00214 & $0.039 \%$ & $0.565 \%$ & $97.516 \%$ \\
\hline 188 & foco & 0.00211 & $0.039 \%$ & $0.565 \%$ & $97.555 \%$ \\
\hline 189 & escurreplatos & 0.00211 & $0.039 \%$ & $0.565 \%$ & $97.594 \%$ \\
\hline 190 & escalera & 0.00210 & $0.019 \%$ & $0.282 \%$ & $97.613 \%$ \\
\hline 191 & mueble de estéreo & 0.00210 & $0.019 \%$ & $0.282 \%$ & $97.632 \%$ \\
\hline 192 & orinal & 0.00210 & $0.019 \%$ & $0.282 \%$ & $97.651 \%$ \\
\hline 193 & barra de cocina & 0.00210 & $0.019 \%$ & $0.282 \%$ & $97.670 \%$ \\
\hline 194 & láser disk & 0.00210 & $0.019 \%$ & $0.282 \%$ & $97.689 \%$ \\
\hline 195 & picadora & 0.00210 & $0.019 \%$ & $0.282 \%$ & $97.708 \%$ \\
\hline 196 & mueble de salita & 0.00210 & $0.019 \%$ & $0.282 \%$ & $97.727 \%$ \\
\hline 197 & mesa de mármol & 0.00210 & $0.019 \%$ & $0.282 \%$ & $97.746 \%$ \\
\hline
\end{tabular}




\begin{tabular}{|c|c|c|c|c|c|}
\hline 198 & mesita de comedor & 0.00210 & $0.019 \%$ & $0.282 \%$ & $97.765 \%$ \\
\hline 199 & aplique & 0.00210 & $0.019 \%$ & $0.282 \%$ & $97.784 \%$ \\
\hline 200 & figura & 0.00202 & $0.039 \%$ & $0.565 \%$ & $97.823 \%$ \\
\hline 201 & secreter & 0.00200 & $0.039 \%$ & $0.565 \%$ & $97.862 \%$ \\
\hline 202 & armario de recibidor & 0.00195 & $0.019 \%$ & $0.282 \%$ & $97.881 \%$ \\
\hline 203 & batería & 0.00195 & $0.019 \%$ & $0.282 \%$ & $97.900 \%$ \\
\hline 204 & María Antonieta & 0.00195 & $0.019 \%$ & $0.282 \%$ & $97.919 \%$ \\
\hline 205 & mueble de teléfono & 0.00195 & $0.019 \%$ & $0.282 \%$ & $97.938 \%$ \\
\hline 206 & mueble de lavadora & 0.00181 & $0.019 \%$ & $0.282 \%$ & $97.957 \%$ \\
\hline 207 & tocadiscos & 0.00181 & $0.019 \%$ & $0.282 \%$ & $97.976 \%$ \\
\hline 208 & mesa de cristal & 0.00181 & $0.019 \%$ & $0.282 \%$ & $97.995 \%$ \\
\hline 209 & galán de noche & 0.00181 & $0.019 \%$ & $0.282 \%$ & $98.014 \%$ \\
\hline 210 & mesa de televisor & 0.00181 & $0.019 \%$ & $0.282 \%$ & $98.033 \%$ \\
\hline 211 & cristalería & 0.00180 & $0.039 \%$ & $0.565 \%$ & $98.072 \%$ \\
\hline 212 & botellero & 0.00175 & $0.039 \%$ & $0.565 \%$ & $98.111 \%$ \\
\hline 213 & mueble de ordenador & 0.00168 & $0.019 \%$ & $0.282 \%$ & $98.130 \%$ \\
\hline 214 & mueble de aseo & 0.00168 & $0.019 \%$ & $0.282 \%$ & $98.149 \%$ \\
\hline 215 & armario de comedor & 0.00168 & $0.019 \%$ & $0.282 \%$ & $98.168 \%$ \\
\hline 216 & mueble para cubertería & 0.00168 & $0.019 \%$ & $0.282 \%$ & $98.187 \%$ \\
\hline 217 & estantería de cama & 0.00168 & $0.019 \%$ & $0.282 \%$ & $98.206 \%$ \\
\hline 218 & mesita de teléfono & 0.00168 & $0.019 \%$ & $0.282 \%$ & $98.225 \%$ \\
\hline 219 & mueble de salón & 0.00167 & $0.039 \%$ & $0.565 \%$ & $98.264 \%$ \\
\hline 220 & adorno & 0.00160 & $0.039 \%$ & $0.565 \%$ & $98.303 \%$ \\
\hline 221 & molinillo & 0.00156 & $0.019 \%$ & $0.282 \%$ & $98.322 \%$ \\
\hline 222 & billar & 0.00156 & $0.019 \%$ & $0.282 \%$ & $98.341 \%$ \\
\hline 223 & lavamanos & 0.00156 & $0.019 \%$ & $0.282 \%$ & $98.360 \%$ \\
\hline 224 & termo & 0.00156 & $0.019 \%$ & $0.282 \%$ & $98.379 \%$ \\
\hline 225 & mesa de dibujo & 0.00156 & $0.019 \%$ & $0.282 \%$ & $98.398 \%$ \\
\hline 226 & armero & 0.00156 & $0.019 \%$ & $0.282 \%$ & $98.417 \%$ \\
\hline 227 & mesita de cristal & 0.00156 & $0.019 \%$ & $0.282 \%$ & $98.436 \%$ \\
\hline 228 & cristal & 0.00156 & $0.019 \%$ & $0.282 \%$ & $98.455 \%$ \\
\hline 229 & mesa de centro & 0.00156 & $0.019 \%$ & $0.282 \%$ & $98.474 \%$ \\
\hline 230 & silla de bebé & 0.00145 & $0.019 \%$ & $0.282 \%$ & $98.493 \%$ \\
\hline 231 & mueble de cadena & 0.00145 & $0.019 \%$ & $0.282 \%$ & $98.512 \%$ \\
\hline 232 & parrilla & 0.00145 & $0.019 \%$ & $0.282 \%$ & $98.531 \%$ \\
\hline 233 & posavasos & 0.00145 & $0.019 \%$ & $0.282 \%$ & $98.550 \%$ \\
\hline 234 & cocina de gas & 0.00145 & $0.019 \%$ & $0.282 \%$ & $98.569 \%$ \\
\hline 235 & mesa de coser & 0.00145 & $0.019 \%$ & $0.282 \%$ & $98.588 \%$ \\
\hline 236 & ventana interior & 0.00145 & $0.019 \%$ & $0.282 \%$ & $98.607 \%$ \\
\hline 237 & freidora & 0.00141 & $0.039 \%$ & $0.565 \%$ & $98.646 \%$ \\
\hline 238 & báscula & 0.00135 & $0.019 \%$ & $0.282 \%$ & $98.665 \%$ \\
\hline 239 & lavapiés & 0.00135 & $0.019 \%$ & $0.282 \%$ & $98.684 \%$ \\
\hline 240 & equipo de música & 0.00135 & $0.019 \%$ & $0.282 \%$ & $98.703 \%$ \\
\hline 241 & mesa de teléfono & 0.00135 & $0.019 \%$ & $0.282 \%$ & $98.722 \%$ \\
\hline 242 & radiocasete & 0.00135 & $0.019 \%$ & $0.282 \%$ & $98.741 \%$ \\
\hline 243 & bandeja de ruedas & 0.00135 & $0.019 \%$ & $0.282 \%$ & $98.760 \%$ \\
\hline 244 & mesita central de comedor & 0.00135 & $0.019 \%$ & $0.282 \%$ & $98.779 \%$ \\
\hline
\end{tabular}




\begin{tabular}{|c|c|c|c|c|c|}
\hline 245 & mesa de cadena & 0.00135 & $0.019 \%$ & $0.282 \%$ & $98.798 \%$ \\
\hline 246 & cenicero & 0.00126 & $0.039 \%$ & $0.565 \%$ & $98.837 \%$ \\
\hline 247 & carretilla & 0.00125 & $0.019 \%$ & $0.282 \%$ & $98.856 \%$ \\
\hline 248 & expositor & 0.00125 & $0.019 \%$ & $0.282 \%$ & $98.875 \%$ \\
\hline 249 & sillón cama & 0.00125 & $0.019 \%$ & $0.282 \%$ & $98.894 \%$ \\
\hline 250 & mueble de váter & 0.00125 & $0.019 \%$ & $0.282 \%$ & $98.913 \%$ \\
\hline 251 & taquilla & 0.00125 & $0.019 \%$ & $0.282 \%$ & $98.932 \%$ \\
\hline 252 & armario de cuarto de baño & 0.00125 & $0.019 \%$ & $0.282 \%$ & $98.951 \%$ \\
\hline 253 & WC & 0.00125 & $0.019 \%$ & $0.282 \%$ & $98.970 \%$ \\
\hline 254 & caja & 0.00125 & $0.019 \%$ & $0.282 \%$ & $98.989 \%$ \\
\hline 255 & joyero & 0.00125 & $0.019 \%$ & $0.282 \%$ & $99.008 \%$ \\
\hline 256 & estante de platos & 0.00125 & $0.019 \%$ & $0.282 \%$ & $99.027 \%$ \\
\hline 257 & tendedero & 0.00122 & $0.039 \%$ & $0.565 \%$ & $99.066 \%$ \\
\hline 258 & mesa pequeña de comedor & 0.00116 & $0.019 \%$ & $0.282 \%$ & $99.085 \%$ \\
\hline 259 & videoteca & 0.00116 & $0.019 \%$ & $0.282 \%$ & $99.104 \%$ \\
\hline 260 & estatua & 0.00116 & $0.019 \%$ & $0.282 \%$ & $99.123 \%$ \\
\hline 261 & armario de la limpieza & 0.00116 & $0.019 \%$ & $0.282 \%$ & $99.142 \%$ \\
\hline 262 & mueble de cuarto de baño & 0.00116 & $0.019 \%$ & $0.282 \%$ & $99.161 \%$ \\
\hline 263 & grifo & 0.00116 & $0.019 \%$ & $0.282 \%$ & $99.180 \%$ \\
\hline 264 & planta de plástico & 0.00116 & $0.019 \%$ & $0.282 \%$ & $99.199 \%$ \\
\hline 265 & exprimidor & 0.00108 & $0.019 \%$ & $0.282 \%$ & $99.218 \%$ \\
\hline 266 & armario trastero & 0.00100 & $0.019 \%$ & $0.282 \%$ & $99.237 \%$ \\
\hline 267 & cesto & 0.00100 & $0.019 \%$ & $0.282 \%$ & $99.256 \%$ \\
\hline 268 & sofá nido & 0.00100 & $0.019 \%$ & $0.282 \%$ & $99.275 \%$ \\
\hline 269 & mueble de TV & 0.00100 & $0.019 \%$ & $0.282 \%$ & $99.294 \%$ \\
\hline 270 & mesa de planchar & 0.00100 & $0.019 \%$ & $0.282 \%$ & $99.313 \%$ \\
\hline 271 & mueble de entrada & 0.00100 & $0.019 \%$ & $0.282 \%$ & $99.332 \%$ \\
\hline 272 & aspiradora & 0.00093 & $0.019 \%$ & $0.282 \%$ & $99.351 \%$ \\
\hline 273 & atril & 0.00093 & $0.019 \%$ & $0.282 \%$ & $99.370 \%$ \\
\hline 274 & platero & 0.00093 & $0.019 \%$ & $0.282 \%$ & $99.389 \%$ \\
\hline 275 & mesa de trabajo & 0.00093 & $0.019 \%$ & $0.282 \%$ & $99.408 \%$ \\
\hline 276 & sandwichera & 0.00086 & $0.019 \%$ & $0.282 \%$ & $99.427 \%$ \\
\hline 277 & bombilla & 0.00086 & $0.019 \%$ & $0.282 \%$ & $99.446 \%$ \\
\hline 278 & mueble de música & 0.00086 & $0.019 \%$ & $0.282 \%$ & $99.465 \%$ \\
\hline 279 & tabla de planchar & 0.00086 & $0.019 \%$ & $0.282 \%$ & $99.484 \%$ \\
\hline 280 & columna & 0.00086 & $0.019 \%$ & $0.282 \%$ & $99.503 \%$ \\
\hline 281 & lavadero & 0.00086 & $0.019 \%$ & $0.282 \%$ & $99.522 \%$ \\
\hline 282 & mesa de escritorio & 0.00086 & $0.019 \%$ & $0.282 \%$ & $99.541 \%$ \\
\hline 283 & sombrerero & 0.00086 & $0.019 \%$ & $0.282 \%$ & $99.560 \%$ \\
\hline 284 & espejo de pie & 0.00086 & $0.019 \%$ & $0.282 \%$ & $99.579 \%$ \\
\hline 285 & pila & 0.00086 & $0.019 \%$ & $0.282 \%$ & $99.598 \%$ \\
\hline 286 & candelabro & 0.00080 & $0.019 \%$ & $0.282 \%$ & $99.617 \%$ \\
\hline 287 & marco de fotos & 0.00080 & $0.019 \%$ & $0.282 \%$ & $99.636 \%$ \\
\hline 288 & videoconsola & 0.00080 & $0.019 \%$ & $0.282 \%$ & $99.655 \%$ \\
\hline 289 & planta & 0.00080 & $0.019 \%$ & $0.282 \%$ & $99.674 \%$ \\
\hline 290 & consola de recibidor & 0.00074 & $0.019 \%$ & $0.282 \%$ & $99.693 \%$ \\
\hline 291 & maceta & 0.00069 & $0.019 \%$ & $0.282 \%$ & $99.712 \%$ \\
\hline
\end{tabular}




\begin{tabular}{|l|l|l|l|l|l|}
\hline 292 & reclinatorio & 0.00069 & $0.019 \%$ & $0.282 \%$ & $99.731 \%$ \\
\hline 293 & tacataca & 0.00069 & $0.019 \%$ & $0.282 \%$ & $99.750 \%$ \\
\hline 294 & marco & 0.00069 & $0.019 \%$ & $0.282 \%$ & $99.769 \%$ \\
\hline 295 & ventilador & 0.00064 & $0.019 \%$ & $0.282 \%$ & $99.788 \%$ \\
\hline 296 & tabla de la plancha & 0.00064 & $0.019 \%$ & $0.282 \%$ & $99.807 \%$ \\
\hline 297 & mesa archivador & 0.00064 & $0.019 \%$ & $0.282 \%$ & $99.826 \%$ \\
\hline 298 & mueble de radio & 0.00064 & $0.019 \%$ & $0.282 \%$ & $99.845 \%$ \\
\hline 299 & brasero & 0.00059 & $0.019 \%$ & $0.282 \%$ & $99.864 \%$ \\
\hline 300 & mueble zapatero & 0.00051 & $0.019 \%$ & $0.282 \%$ & $99.883 \%$ \\
\hline 301 & biombo & 0.00041 & $0.019 \%$ & $0.282 \%$ & $99.902 \%$ \\
\hline 302 & basurero & 0.00038 & $0.019 \%$ & $0.282 \%$ & $99.921 \%$ \\
\hline 303 & pecera & 0.00035 & $0.019 \%$ & $0.282 \%$ & $99.940 \%$ \\
\hline
\end{tabular}

05. ALIMENTOS Y BEBIDAS

\begin{tabular}{|c|l|c|c|c|c|}
\hline $\mathrm{N}^{\mathbf{}}$ & Palabra & Disponibilidad & $\begin{array}{c}\text { Frecuencia } \\
\text { relativa }\end{array}$ & \% Aparición & $\begin{array}{c}\text { Frecuencia } \\
\text { acumulada }\end{array}$ \\
\hline 1 & agua & 0.59770 & $3.220 \%$ & $85.593 \%$ & $3.220 \%$ \\
\hline 2 & vino & 0.37222 & $2.274 \%$ & $60.452 \%$ & $5.494 \%$ \\
\hline 3 & whisky & 0.36806 & $2.093 \%$ & $55.650 \%$ & $7.587 \%$ \\
\hline 4 & Coca cola* & 0.34356 & $1.732 \%$ & $46.045 \%$ & $9.319 \%$ \\
\hline 5 & zumo & 0.25759 & $1.605 \%$ & $42.655 \%$ & $10.924 \%$ \\
\hline 6 & cerveza & 0.25311 & $1.562 \%$ & $41.525 \%$ & $12.486 \%$ \\
\hline 7 & arroz & 0.25082 & $1.541 \%$ & $40.960 \%$ & $14.027 \%$ \\
\hline 8 & tomate & 0.24901 & $1.785 \%$ & $47.458 \%$ & $15.812 \%$ \\
\hline 9 & leche & 0.23035 & $1.583 \%$ & $42.090 \%$ & $17.395 \%$ \\
\hline 10 & patata & 0.22605 & $1.668 \%$ & $44.350 \%$ & $19.063 \%$ \\
\hline 11 & lechuga & 0.22509 & $1.573 \%$ & $41.808 \%$ & $20.636 \%$ \\
\hline 12 & carne & 0.21917 & $1.381 \%$ & $36.723 \%$ & $22.017 \%$ \\
\hline 13 & vodka & 0.21718 & $1.307 \%$ & $34.746 \%$ & $23.324 \%$ \\
\hline 14 & pan & 0.21643 & $1.700 \%$ & $45.198 \%$ & $25.024 \%$ \\
\hline 15 & macarrón & 0.21007 & $1.381 \%$ & $36.723 \%$ & $26.405 \%$ \\
\hline 16 & pescado & 0.20311 & $1.286 \%$ & $34.181 \%$ & $27.691 \%$ \\
\hline 17 & Fanta* & 0.18278 & $0.988 \%$ & $26.271 \%$ & $28.679 \%$ \\
\hline 18 & queso & 0.16994 & $1.445 \%$ & $38.418 \%$ & $30.124 \%$ \\
\hline 19 & espagueti & 0.16937 & $1.116 \%$ & $29.661 \%$ & $31.240 \%$ \\
\hline 20 & naranja & 0.16628 & $1.254 \%$ & $33.333 \%$ & $32.494 \%$ \\
\hline 21 & manzana & 0.15866 & $1.201 \%$ & $31.921 \%$ & $33.695 \%$ \\
\hline 22 & lenteja & 0.15277 & $1.137 \%$ & $30.226 \%$ & $34.832 \%$ \\
\hline 23 & gaseosa & 0.15275 & $0.956 \%$ & $25.424 \%$ & $35.788 \%$ \\
\hline 24 & carne de) pollo & 0.15274 & $1.063 \%$ & $28.249 \%$ & $36.851 \%$ \\
\hline 25 & refresco & 0.14167 & $0.776 \%$ & $20.621 \%$ & $37.627 \%$ \\
\hline 26 & huevo & 0.14137 & $1.063 \%$ & $28.249 \%$ & $38.690 \%$ \\
\hline & & & & & \\
\hline
\end{tabular}




\begin{tabular}{|c|c|c|c|c|c|}
\hline 27 & jamón & 0.14105 & $1.158 \%$ & $30.791 \%$ & $39.848 \%$ \\
\hline 28 & ginebra & 0.13678 & $0.829 \%$ & $22.034 \%$ & $40.677 \%$ \\
\hline 29 & plátano & 0.13261 & $1.052 \%$ & $27.966 \%$ & $41.729 \%$ \\
\hline 30 & pera & 0.12824 & $0.988 \%$ & $26.271 \%$ & $42.717 \%$ \\
\hline 31 & (carne de) ternera & 0.11702 & $0.850 \%$ & $22.599 \%$ & $43.567 \%$ \\
\hline 32 & limonada & 0.11623 & $0.701 \%$ & $18.644 \%$ & $44.268 \%$ \\
\hline 33 & zanahoria & 0.10802 & $0.829 \%$ & $22.034 \%$ & $45.097 \%$ \\
\hline 34 & garbanzo & 0.10670 & $0.765 \%$ & $20.339 \%$ & $45.862 \%$ \\
\hline 35 & yogur & 0.10388 & $0.797 \%$ & $21.186 \%$ & $46.659 \%$ \\
\hline 36 & cebolla & 0.09688 & $0.797 \%$ & $21.186 \%$ & $47.456 \%$ \\
\hline 37 & cola & 0.09630 & $0.499 \%$ & $13.277 \%$ & $47.955 \%$ \\
\hline 38 & Martini* & 0.09514 & $0.616 \%$ & $16.384 \%$ & $48.571 \%$ \\
\hline 39 & hamburguesa & 0.09205 & $0.744 \%$ & $19.774 \%$ & $49.315 \%$ \\
\hline 40 & verdura & 0.09074 & $0.606 \%$ & $16.102 \%$ & $49.921 \%$ \\
\hline 41 & paella & 0.08630 & $0.563 \%$ & $14.972 \%$ & $50.484 \%$ \\
\hline 42 & chorizo & 0.08442 & $0.786 \%$ & $20.904 \%$ & $51.270 \%$ \\
\hline 43 & pizza & 0.08403 & $0.701 \%$ & $18.644 \%$ & $51.971 \%$ \\
\hline 44 & chocolate & 0.08367 & $0.723 \%$ & $19.209 \%$ & $52.694 \%$ \\
\hline 45 & fresa & 0.08196 & $0.669 \%$ & $17.797 \%$ & $53.363 \%$ \\
\hline 46 & judía & 0.08061 & $0.648 \%$ & $17.232 \%$ & $54.011 \%$ \\
\hline 47 & café & 0.08023 & $0.627 \%$ & $16.667 \%$ & $54.638 \%$ \\
\hline 48 & licor & 0.07723 & $0.563 \%$ & $14.972 \%$ & $55.201 \%$ \\
\hline 49 & ron & 0.07609 & $0.478 \%$ & $12.712 \%$ & $55.679 \%$ \\
\hline 50 & fideo & 0.07392 & $0.542 \%$ & $14.407 \%$ & $56.221 \%$ \\
\hline 51 & sopa & 0.07094 & $0.553 \%$ & $14.689 \%$ & $56.774 \%$ \\
\hline 52 & canelón & 0.07050 & $0.478 \%$ & $12.712 \%$ & $57.252 \%$ \\
\hline 53 & (carne de) cordero & 0.06867 & $0.478 \%$ & $12.712 \%$ & $57.730 \%$ \\
\hline 54 & fruta & 0.06738 & $0.489 \%$ & $12.994 \%$ & $58.219 \%$ \\
\hline 55 & champán & 0.06576 & $0.468 \%$ & $12.429 \%$ & $58.687 \%$ \\
\hline 56 & limón & 0.06392 & $0.510 \%$ & $13.559 \%$ & $59.197 \%$ \\
\hline 57 & longaniza & 0.06359 & $0.542 \%$ & $14.407 \%$ & $59.739 \%$ \\
\hline 58 & naranjada & 0.06306 & $0.329 \%$ & $8.757 \%$ & $60.068 \%$ \\
\hline 59 & atún & 0.06303 & $0.574 \%$ & $15.254 \%$ & $60.642 \%$ \\
\hline 60 & azúcar & 0.06167 & $0.446 \%$ & $11.864 \%$ & $61.088 \%$ \\
\hline 61 & galleta & 0.06034 & $0.531 \%$ & $14.124 \%$ & $61.619 \%$ \\
\hline 62 & coñac & 0.05929 & $0.414 \%$ & $11.017 \%$ & $62.033 \%$ \\
\hline 63 & lomo & 0.05908 & $0.436 \%$ & $11.582 \%$ & $62.469 \%$ \\
\hline 64 & cereza & 0.05715 & $0.499 \%$ & $13.277 \%$ & $62.968 \%$ \\
\hline 65 & melocotón & 0.05695 & $0.489 \%$ & $12.994 \%$ & $63.457 \%$ \\
\hline 66 & (carne de) conejo & 0.05689 & $0.414 \%$ & $11.017 \%$ & $63.871 \%$ \\
\hline 67 & melón & 0.05664 & $0.499 \%$ & $13.277 \%$ & $64.370 \%$ \\
\hline 68 & chuleta & 0.05604 & $0.393 \%$ & $10.452 \%$ & $64.763 \%$ \\
\hline 69 & ensalada & 0.05459 & $0.425 \%$ & $11.299 \%$ & $65.188 \%$ \\
\hline 70 & pasta & 0.05182 & $0.404 \%$ & $10.734 \%$ & $65.592 \%$ \\
\hline 71 & (carne de) cerdo & 0.05157 & $0.361 \%$ & $9.605 \%$ & $65.953 \%$ \\
\hline 72 & legumbre & 0.05119 & $0.361 \%$ & $9.605 \%$ & $66.314 \%$ \\
\hline 73 & pimiento & 0.04950 & $0.457 \%$ & $12.147 \%$ & $66.771 \%$ \\
\hline
\end{tabular}




\begin{tabular}{|c|c|c|c|c|c|}
\hline 74 & kiwi & 0.04914 & $0.425 \%$ & $11.299 \%$ & $67.196 \%$ \\
\hline 75 & alcachofa & 0.04807 & $0.383 \%$ & $10.169 \%$ & $67.579 \%$ \\
\hline 76 & pepino & 0.04755 & $0.393 \%$ & $10.452 \%$ & $67.972 \%$ \\
\hline 77 & jamón de York & 0.04751 & $0.404 \%$ & $10.734 \%$ & $68.376 \%$ \\
\hline 78 & batido & 0.04632 & $0.340 \%$ & $9.040 \%$ & $68.716 \%$ \\
\hline 79 & sal & 0.04575 & $0.372 \%$ & $9.887 \%$ & $69.088 \%$ \\
\hline 80 & guisante & 0.04499 & $0.340 \%$ & $9.040 \%$ & $69.428 \%$ \\
\hline 81 & pacharán & 0.04397 & $0.298 \%$ & $7.910 \%$ & $69.726 \%$ \\
\hline 82 & Fanta* limón & 0.04352 & $0.244 \%$ & $6.497 \%$ & $69.970 \%$ \\
\hline 83 & tortilla & 0.04169 & $0.340 \%$ & $9.040 \%$ & $70.310 \%$ \\
\hline 84 & gamba & 0.04122 & $0.308 \%$ & $8.192 \%$ & $70.618 \%$ \\
\hline 85 & salchichón & 0.04013 & $0.383 \%$ & $10.169 \%$ & $71.001 \%$ \\
\hline 86 & Fanta* naranja & 0.03960 & $0.223 \%$ & $5.932 \%$ & $71.224 \%$ \\
\hline 87 & mantequilla & 0.03954 & $0.393 \%$ & $10.452 \%$ & $71.617 \%$ \\
\hline 88 & solomillo & 0.03887 & $0.319 \%$ & $8.475 \%$ & $71.936 \%$ \\
\hline 89 & jamón serrano & 0.03879 & $0.298 \%$ & $7.910 \%$ & $72.234 \%$ \\
\hline 90 & sandía & 0.03863 & $0.383 \%$ & $10.169 \%$ & $72.617 \%$ \\
\hline 91 & salchicha & 0.03700 & $0.255 \%$ & $6.780 \%$ & $72.872 \%$ \\
\hline 92 & aceituna & 0.03665 & $0.340 \%$ & $9.040 \%$ & $73.212 \%$ \\
\hline 93 & tequila & 0.03633 & $0.244 \%$ & $6.497 \%$ & $73.456 \%$ \\
\hline 94 & helado & 0.03514 & $0.351 \%$ & $9.322 \%$ & $73.807 \%$ \\
\hline 95 & cava & 0.03507 & $0.266 \%$ & $7.062 \%$ & $74.073 \%$ \\
\hline 96 & morcilla & 0.03478 & $0.298 \%$ & $7.910 \%$ & $74.371 \%$ \\
\hline 97 & chupito & 0.03471 & $0.244 \%$ & $6.497 \%$ & $74.615 \%$ \\
\hline 98 & magdalena & 0.03359 & $0.298 \%$ & $7.910 \%$ & $74.913 \%$ \\
\hline 99 & horchata & 0.03350 & $0.202 \%$ & $5.367 \%$ & $75.115 \%$ \\
\hline 100 & ajo & 0.03330 & $0.266 \%$ & $7.062 \%$ & $75.381 \%$ \\
\hline 101 & té & 0.03292 & $0.266 \%$ & $7.062 \%$ & $75.647 \%$ \\
\hline 102 & lenguado & 0.03286 & $0.244 \%$ & $6.497 \%$ & $75.891 \%$ \\
\hline 103 & mortadela & 0.03213 & $0.361 \%$ & $9.605 \%$ & $76.252 \%$ \\
\hline 104 & cacahuete & 0.03179 & $0.319 \%$ & $8.475 \%$ & $76.571 \%$ \\
\hline 105 & col & 0.02995 & $0.213 \%$ & $5.650 \%$ & $76.784 \%$ \\
\hline 106 & cereal & 0.02868 & $0.234 \%$ & $6.215 \%$ & $77.018 \%$ \\
\hline 107 & lasaña & 0.02866 & $0.191 \%$ & $5.085 \%$ & $77.209 \%$ \\
\hline 108 & aceite & 0.02828 & $0.255 \%$ & $6.780 \%$ & $77.464 \%$ \\
\hline 109 & merluza & 0.02684 & $0.255 \%$ & $6.780 \%$ & $77.719 \%$ \\
\hline 110 & piña & 0.02679 & $0.244 \%$ & $6.497 \%$ & $77.963 \%$ \\
\hline 111 & acelga & 0.02656 & $0.202 \%$ & $5.367 \%$ & $78.165 \%$ \\
\hline 112 & sardina & 0.02609 & $0.244 \%$ & $6.497 \%$ & $78.409 \%$ \\
\hline 113 & sangría & 0.02571 & $0.181 \%$ & $4.802 \%$ & $78.590 \%$ \\
\hline 114 & tónica & 0.02561 & $0.159 \%$ & $4.237 \%$ & $78.749 \%$ \\
\hline 115 & berenjena & 0.02471 & $0.202 \%$ & $5.367 \%$ & $78.951 \%$ \\
\hline 116 & sidra & 0.02453 & $0.191 \%$ & $5.085 \%$ & $79.142 \%$ \\
\hline 117 & rosquilleta & 0.02436 & $0.223 \%$ & $5.932 \%$ & $79.365 \%$ \\
\hline 118 & vermú & 0.02420 & $0.149 \%$ & $3.955 \%$ & $79.514 \%$ \\
\hline 119 & (vino) tinto & 0.02389 & $0.128 \%$ & $3.390 \%$ & $79.642 \%$ \\
\hline 120 & mejillón & 0.02375 & $0.223 \%$ & $5.932 \%$ & $79.865 \%$ \\
\hline
\end{tabular}




\begin{tabular}{|c|c|c|c|c|c|}
\hline 121 & marisco & 0.02355 & $0.181 \%$ & $4.802 \%$ & $80.046 \%$ \\
\hline 122 & calimocho & 0.02345 & $0.159 \%$ & $4.237 \%$ & $80.205 \%$ \\
\hline 123 & alubia & 0.02323 & $0.223 \%$ & $5.932 \%$ & $80.428 \%$ \\
\hline 124 & almendra & 0.02284 & $0.202 \%$ & $5.367 \%$ & $80.630 \%$ \\
\hline 125 & alcohol & 0.02282 & $0.117 \%$ & $3.107 \%$ & $80.747 \%$ \\
\hline 126 & anís & 0.02271 & $0.191 \%$ & $5.085 \%$ & $80.938 \%$ \\
\hline 127 & entrecot & 0.02230 & $0.159 \%$ & $4.237 \%$ & $81.097 \%$ \\
\hline 128 & Danone* & 0.02199 & $0.170 \%$ & $4.520 \%$ & $81.267 \%$ \\
\hline 129 & oliva & 0.02175 & $0.170 \%$ & $4.520 \%$ & $81.437 \%$ \\
\hline 130 & espinaca & 0.02163 & $0.202 \%$ & $5.367 \%$ & $81.639 \%$ \\
\hline 131 & calamares & 0.02158 & $0.202 \%$ & $5.367 \%$ & $81.841 \%$ \\
\hline 132 & Malibú* & 0.02101 & $0.149 \%$ & $3.955 \%$ & $81.990 \%$ \\
\hline 133 & papas & 0.02063 & $0.138 \%$ & $3.672 \%$ & $82.128 \%$ \\
\hline 134 & uva & 0.02040 & $0.191 \%$ & $5.085 \%$ & $82.319 \%$ \\
\hline 135 & puré & 0.02028 & $0.181 \%$ & $4.802 \%$ & $82.500 \%$ \\
\hline 136 & embutido & 0.02016 & $0.170 \%$ & $4.520 \%$ & $82.670 \%$ \\
\hline 137 & salmón & 0.01978 & $0.170 \%$ & $4.520 \%$ & $82.840 \%$ \\
\hline 138 & vino blanco & 0.01937 & $0.106 \%$ & $2.825 \%$ & $82.946 \%$ \\
\hline 139 & bocadillo & 0.01882 & $0.159 \%$ & $4.237 \%$ & $83.105 \%$ \\
\hline 140 & calabaza & 0.01867 & $0.149 \%$ & $3.955 \%$ & $83.254 \%$ \\
\hline 141 & pastel & 0.01866 & $0.170 \%$ & $4.520 \%$ & $83.424 \%$ \\
\hline 142 & emperador & 0.01843 & $0.159 \%$ & $4.237 \%$ & $83.583 \%$ \\
\hline 143 & albaricoque & 0.01797 & $0.159 \%$ & $4.237 \%$ & $83.742 \%$ \\
\hline 144 & granizado & 0.01779 & $0.096 \%$ & $2.542 \%$ & $83.838 \%$ \\
\hline 145 & mermelada & 0.01773 & $0.181 \%$ & $4.802 \%$ & $84.019 \%$ \\
\hline 146 & pavo & 0.01752 & $0.149 \%$ & $3.955 \%$ & $84.168 \%$ \\
\hline 147 & natillas & 0.01750 & $0.159 \%$ & $4.237 \%$ & $84.327 \%$ \\
\hline 148 & agua con gas & 0.01749 & $0.128 \%$ & $3.390 \%$ & $84.455 \%$ \\
\hline 149 & habichuela & 0.01737 & $0.138 \%$ & $3.672 \%$ & $84.593 \%$ \\
\hline 150 & pechuga & 0.01726 & $0.106 \%$ & $2.825 \%$ & $84.699 \%$ \\
\hline 151 & cocido & 0.01711 & $0.128 \%$ & $3.390 \%$ & $84.827 \%$ \\
\hline 152 & manzanilla & 0.01710 & $0.138 \%$ & $3.672 \%$ & $84.965 \%$ \\
\hline 153 & flan & 0.01702 & $0.138 \%$ & $3.672 \%$ & $85.103 \%$ \\
\hline 154 & sepia & 0.01693 & $0.149 \%$ & $3.955 \%$ & $85.252 \%$ \\
\hline 155 & tallarín & 0.01688 & $0.117 \%$ & $3.107 \%$ & $85.369 \%$ \\
\hline 156 & sándwich & 0.01680 & $0.128 \%$ & $3.390 \%$ & $85.497 \%$ \\
\hline 157 & brandy & 0.01659 & $0.138 \%$ & $3.672 \%$ & $85.635 \%$ \\
\hline 158 & fruto seco & 0.01656 & $0.159 \%$ & $4.237 \%$ & $85.794 \%$ \\
\hline 159 & paté & 0.01628 & $0.181 \%$ & $4.802 \%$ & $85.975 \%$ \\
\hline 160 & langostino & 0.01576 & $0.117 \%$ & $3.107 \%$ & $86.092 \%$ \\
\hline 161 & poleo & 0.01561 & $0.106 \%$ & $2.825 \%$ & $86.198 \%$ \\
\hline 162 & fideuà & 0.01559 & $0.117 \%$ & $3.107 \%$ & $86.315 \%$ \\
\hline 163 & maíz & 0.01510 & $0.138 \%$ & $3.672 \%$ & $86.453 \%$ \\
\hline 164 & Licor $43^{*}$ & 0.01503 & $0.085 \%$ & $2.260 \%$ & $86.538 \%$ \\
\hline 165 & perejil & 0.01501 & $0.128 \%$ & $3.390 \%$ & $86.666 \%$ \\
\hline 166 & vino rosado & 0.01496 & $0.074 \%$ & $1.977 \%$ & $86.740 \%$ \\
\hline 167 & rape & 0.01487 & $0.128 \%$ & $3.390 \%$ & $86.868 \%$ \\
\hline
\end{tabular}




\begin{tabular}{|c|c|c|c|c|c|}
\hline 168 & zumo de naranja & 0.01465 & $0.074 \%$ & $1.977 \%$ & $86.942 \%$ \\
\hline 169 & tarta & 0.01429 & $0.138 \%$ & $3.672 \%$ & $87.080 \%$ \\
\hline 170 & tortellini & 0.01419 & $0.117 \%$ & $3.107 \%$ & $87.197 \%$ \\
\hline 171 & albóndiga & 0.01419 & $0.128 \%$ & $3.390 \%$ & $87.325 \%$ \\
\hline 172 & beicon & 0.01412 & $0.106 \%$ & $2.825 \%$ & $87.431 \%$ \\
\hline 173 & ensaimada & 0.01402 & $0.159 \%$ & $4.237 \%$ & $87.590 \%$ \\
\hline 174 & Donut* & 0.01344 & $0.106 \%$ & $2.825 \%$ & $87.696 \%$ \\
\hline 175 & rábano & 0.01342 & $0.117 \%$ & $3.107 \%$ & $87.813 \%$ \\
\hline 176 & hervido & 0.01338 & $0.117 \%$ & $3.107 \%$ & $87.930 \%$ \\
\hline 177 & moscatel & 0.01307 & $0.096 \%$ & $2.542 \%$ & $88.026 \%$ \\
\hline 178 & ponche & 0.01296 & $0.096 \%$ & $2.542 \%$ & $88.122 \%$ \\
\hline 179 & sobrasada & 0.01278 & $0.138 \%$ & $3.672 \%$ & $88.260 \%$ \\
\hline 180 & espárrago & 0.01269 & $0.117 \%$ & $3.107 \%$ & $88.377 \%$ \\
\hline 181 & Choleck* $^{*}$ & 0.01253 & $0.096 \%$ & $2.542 \%$ & $88.473 \%$ \\
\hline 182 & tostada & 0.01235 & $0.138 \%$ & $3.672 \%$ & $88.611 \%$ \\
\hline 183 & Pepsi* & 0.01198 & $0.064 \%$ & $1.695 \%$ & $88.675 \%$ \\
\hline 184 & refresco de limón & 0.01161 & $0.064 \%$ & $1.695 \%$ & $88.739 \%$ \\
\hline 185 & cruasán & 0.01143 & $0.106 \%$ & $2.825 \%$ & $88.845 \%$ \\
\hline 186 & mosto & 0.01140 & $0.085 \%$ & $2.260 \%$ & $88.930 \%$ \\
\hline 187 & $\mathrm{JB} *$ & 0.01101 & $0.064 \%$ & $1.695 \%$ & $88.994 \%$ \\
\hline 188 & bizcocho & 0.01066 & $0.096 \%$ & $2.542 \%$ & $89.090 \%$ \\
\hline 189 & tila & 0.01066 & $0.074 \%$ & $1.977 \%$ & $89.164 \%$ \\
\hline 190 & jamón dulce & 0.01061 & $0.074 \%$ & $1.977 \%$ & $89.238 \%$ \\
\hline 191 & mayonesa & 0.01046 & $0.117 \%$ & $3.107 \%$ & $89.355 \%$ \\
\hline 192 & pamplonés & 0.01038 & $0.117 \%$ & $3.107 \%$ & $89.472 \%$ \\
\hline 193 & mero & 0.01032 & $0.106 \%$ & $2.825 \%$ & $89.578 \%$ \\
\hline 194 & salami & 0.01019 & $0.096 \%$ & $2.542 \%$ & $89.674 \%$ \\
\hline 195 & ciruela & 0.01018 & $0.096 \%$ & $2.542 \%$ & $89.770 \%$ \\
\hline 196 & hortaliza & 0.01003 & $0.096 \%$ & $2.542 \%$ & $89.866 \%$ \\
\hline 197 & caracoles & 0.00991 & $0.106 \%$ & $2.825 \%$ & $89.972 \%$ \\
\hline 198 & carlota & 0.00929 & $0.064 \%$ & $1.695 \%$ & $90.036 \%$ \\
\hline 199 & vinagre & 0.00925 & $0.074 \%$ & $1.977 \%$ & $90.110 \%$ \\
\hline 200 & pistacho & 0.00925 & $0.096 \%$ & $2.542 \%$ & $90.206 \%$ \\
\hline 201 & potaje & 0.00924 & $0.085 \%$ & $2.260 \%$ & $90.291 \%$ \\
\hline 202 & fiambre & 0.00917 & $0.096 \%$ & $2.542 \%$ & $90.387 \%$ \\
\hline 203 & harina & 0.00914 & $0.074 \%$ & $1.977 \%$ & $90.461 \%$ \\
\hline 204 & pomelo & 0.00906 & $0.085 \%$ & $2.260 \%$ & $90.546 \%$ \\
\hline 205 & apio & 0.00893 & $0.074 \%$ & $1.977 \%$ & $90.620 \%$ \\
\hline 206 & croqueta & 0.00883 & $0.074 \%$ & $1.977 \%$ & $90.694 \%$ \\
\hline 207 & níspero & 0.00881 & $0.085 \%$ & $2.260 \%$ & $90.779 \%$ \\
\hline 208 & postre & 0.00879 & $0.064 \%$ & $1.695 \%$ & $90.843 \%$ \\
\hline 209 & pepinillo & 0.00876 & $0.064 \%$ & $1.695 \%$ & $90.907 \%$ \\
\hline 210 & foie gras & 0.00850 & $0.096 \%$ & $2.542 \%$ & $91.003 \%$ \\
\hline 211 & puerro & 0.00848 & $0.074 \%$ & $1.977 \%$ & $91.077 \%$ \\
\hline 212 & aguacate & 0.00841 & $0.085 \%$ & $2.260 \%$ & $91.162 \%$ \\
\hline 213 & bacalao & 0.00839 & $0.074 \%$ & $1.977 \%$ & $91.236 \%$ \\
\hline 214 & magro & 0.00837 & $0.064 \%$ & $1.695 \%$ & $91.300 \%$ \\
\hline
\end{tabular}




\begin{tabular}{|c|c|c|c|c|c|}
\hline 215 & caldo & 0.00835 & $0.085 \%$ & $2.260 \%$ & $91.385 \%$ \\
\hline 216 & salsa & 0.00832 & $0.085 \%$ & $2.260 \%$ & $91.470 \%$ \\
\hline 217 & almeja & 0.00828 & $0.085 \%$ & $2.260 \%$ & $91.555 \%$ \\
\hline 218 & refresco de cola & 0.00826 & $0.053 \%$ & $1.412 \%$ & $91.608 \%$ \\
\hline 219 & mallorquina & 0.00814 & $0.074 \%$ & $1.977 \%$ & $91.682 \%$ \\
\hline 220 & licor de manzana & 0.00810 & $0.043 \%$ & $1.130 \%$ & $91.725 \%$ \\
\hline 221 & Nocilla* & 0.00804 & $0.074 \%$ & $1.977 \%$ & $91.799 \%$ \\
\hline 222 & nata & 0.00791 & $0.074 \%$ & $1.977 \%$ & $91.873 \%$ \\
\hline 223 & zumo de limón & 0.00790 & $0.043 \%$ & $1.130 \%$ & $91.916 \%$ \\
\hline 224 & coliflor & 0.00786 & $0.074 \%$ & $1.977 \%$ & $91.990 \%$ \\
\hline 225 & gazpacho & 0.00781 & $0.053 \%$ & $1.412 \%$ & $92.043 \%$ \\
\hline 226 & anchoa & 0.00779 & $0.085 \%$ & $2.260 \%$ & $92.128 \%$ \\
\hline 227 & fuet & 0.00774 & $0.074 \%$ & $1.977 \%$ & $92.202 \%$ \\
\hline 228 & refresco de naranja & 0.00764 & $0.043 \%$ & $1.130 \%$ & $92.245 \%$ \\
\hline 229 & Cola Cao* & 0.00762 & $0.074 \%$ & $1.977 \%$ & $92.319 \%$ \\
\hline 230 & ensaladilla & 0.00760 & $0.074 \%$ & $1.977 \%$ & $92.393 \%$ \\
\hline 231 & bíter & 0.00749 & $0.043 \%$ & $1.130 \%$ & $92.436 \%$ \\
\hline 232 & haba & 0.00746 & $0.064 \%$ & $1.695 \%$ & $92.500 \%$ \\
\hline 233 & cacao & 0.00741 & $0.064 \%$ & $1.695 \%$ & $92.564 \%$ \\
\hline 234 & bollo & 0.00738 & $0.053 \%$ & $1.412 \%$ & $92.617 \%$ \\
\hline 235 & coca & 0.00733 & $0.032 \%$ & $0.847 \%$ & $92.649 \%$ \\
\hline 236 & arroz al horno & 0.00726 & $0.053 \%$ & $1.412 \%$ & $92.702 \%$ \\
\hline 237 & costilla & 0.00710 & $0.053 \%$ & $1.412 \%$ & $92.755 \%$ \\
\hline 238 & Red Bull* & 0.00708 & $0.043 \%$ & $1.130 \%$ & $92.798 \%$ \\
\hline 239 & berberecho & 0.00703 & $0.064 \%$ & $1.695 \%$ & $92.862 \%$ \\
\hline 240 & calabacín & 0.00700 & $0.074 \%$ & $1.977 \%$ & $92.936 \%$ \\
\hline 241 & soda & 0.00700 & $0.043 \%$ & $1.130 \%$ & $92.979 \%$ \\
\hline 242 & arroz a la cubana & 0.00695 & $0.043 \%$ & $1.130 \%$ & $93.022 \%$ \\
\hline 243 & jerez & 0.00689 & $0.064 \%$ & $1.695 \%$ & $93.086 \%$ \\
\hline 244 & ketchup & 0.00679 & $0.053 \%$ & $1.412 \%$ & $93.139 \%$ \\
\hline 245 & pato & 0.00670 & $0.043 \%$ & $1.130 \%$ & $93.182 \%$ \\
\hline 246 & fabada & 0.00669 & $0.032 \%$ & $0.847 \%$ & $93.214 \%$ \\
\hline 247 & pescadilla & 0.00668 & $0.064 \%$ & $1.695 \%$ & $93.278 \%$ \\
\hline 248 & Sprite* & 0.00665 & $0.032 \%$ & $0.847 \%$ & $93.310 \%$ \\
\hline 249 & aguardiente & 0.00641 & $0.053 \%$ & $1.412 \%$ & $93.363 \%$ \\
\hline 250 & vegetal & 0.00606 & $0.032 \%$ & $0.847 \%$ & $93.395 \%$ \\
\hline 251 & boquerón & 0.00603 & $0.074 \%$ & $1.977 \%$ & $93.469 \%$ \\
\hline 252 & pipas & 0.00597 & $0.074 \%$ & $1.977 \%$ & $93.543 \%$ \\
\hline 253 & licor de melocotón & 0.00592 & $0.032 \%$ & $0.847 \%$ & $93.575 \%$ \\
\hline 254 & chóped & 0.00588 & $0.064 \%$ & $1.695 \%$ & $93.639 \%$ \\
\hline 255 & coco & 0.00581 & $0.043 \%$ & $1.130 \%$ & $93.682 \%$ \\
\hline 256 & menestra & 0.00576 & $0.043 \%$ & $1.130 \%$ & $93.725 \%$ \\
\hline 257 & crema catalana & 0.00574 & $0.043 \%$ & $1.130 \%$ & $93.768 \%$ \\
\hline 258 & (carne de) caballo & 0.00559 & $0.043 \%$ & $1.130 \%$ & $93.811 \%$ \\
\hline 259 & dulces & 0.00550 & $0.064 \%$ & $1.695 \%$ & $93.875 \%$ \\
\hline 260 & pimienta & 0.00547 & $0.064 \%$ & $1.695 \%$ & $93.939 \%$ \\
\hline 261 & ternasco & 0.00541 & $0.043 \%$ & $1.130 \%$ & $93.982 \%$ \\
\hline
\end{tabular}




\begin{tabular}{|c|c|c|c|c|c|}
\hline 262 & lubina & 0.00535 & $0.043 \%$ & $1.130 \%$ & $94.025 \%$ \\
\hline 263 & bebida & 0.00534 & $0.021 \%$ & $0.565 \%$ & $94.046 \%$ \\
\hline 264 & avellana & 0.00533 & $0.043 \%$ & $1.130 \%$ & $94.089 \%$ \\
\hline 265 & patata frita & 0.00526 & $0.064 \%$ & $1.695 \%$ & $94.153 \%$ \\
\hline 266 & mistela & 0.00523 & $0.053 \%$ & $1.412 \%$ & $94.206 \%$ \\
\hline 267 & turrón & 0.00520 & $0.064 \%$ & $1.695 \%$ & $94.270 \%$ \\
\hline 268 & hígado & 0.00515 & $0.053 \%$ & $1.412 \%$ & $94.323 \%$ \\
\hline 269 & estofado & 0.00512 & $0.043 \%$ & $1.130 \%$ & $94.366 \%$ \\
\hline 270 & filete & 0.00511 & $0.032 \%$ & $0.847 \%$ & $94.398 \%$ \\
\hline 271 & san Francisco & 0.00507 & $0.021 \%$ & $0.565 \%$ & $94.419 \%$ \\
\hline 272 & Larios* & 0.00501 & $0.032 \%$ & $0.847 \%$ & $94.451 \%$ \\
\hline 273 & pulpo & 0.00501 & $0.032 \%$ & $0.847 \%$ & $94.483 \%$ \\
\hline 274 & rollito de primavera & 0.00500 & $0.032 \%$ & $0.847 \%$ & $94.515 \%$ \\
\hline 275 & cubata & 0.00499 & $0.032 \%$ & $0.847 \%$ & $94.547 \%$ \\
\hline 276 & ravioli & 0.00495 & $0.053 \%$ & $1.412 \%$ & $94.600 \%$ \\
\hline 277 & zumo de piña & 0.00495 & $0.032 \%$ & $0.847 \%$ & $94.632 \%$ \\
\hline 278 & mandarina & 0.00483 & $0.053 \%$ & $1.412 \%$ & $94.685 \%$ \\
\hline 279 & agua sin gas & 0.00479 & $0.021 \%$ & $0.565 \%$ & $94.706 \%$ \\
\hline 280 & langosta & 0.00476 & $0.043 \%$ & $1.130 \%$ & $94.749 \%$ \\
\hline 281 & lombarda & 0.00473 & $0.043 \%$ & $1.130 \%$ & $94.792 \%$ \\
\hline 282 & caviar & 0.00470 & $0.032 \%$ & $0.847 \%$ & $94.824 \%$ \\
\hline 283 & empanadilla & 0.00465 & $0.043 \%$ & $1.130 \%$ & $94.867 \%$ \\
\hline 284 & chipirón & 0.00460 & $0.043 \%$ & $1.130 \%$ & $94.910 \%$ \\
\hline 285 & Kas* & 0.00457 & $0.032 \%$ & $0.847 \%$ & $94.942 \%$ \\
\hline 286 & ensaladilla rusa & 0.00446 & $0.043 \%$ & $1.130 \%$ & $94.985 \%$ \\
\hline 287 & paletilla & 0.00443 & $0.032 \%$ & $0.847 \%$ & $95.017 \%$ \\
\hline 288 & bombón & 0.00443 & $0.053 \%$ & $1.412 \%$ & $95.070 \%$ \\
\hline 289 & remolacha & 0.00436 & $0.032 \%$ & $0.847 \%$ & $95.102 \%$ \\
\hline 290 & arroz caldoso & 0.00435 & $0.021 \%$ & $0.565 \%$ & $95.123 \%$ \\
\hline 291 & puchero & 0.00431 & $0.043 \%$ & $1.130 \%$ & $95.166 \%$ \\
\hline 292 & conserva & 0.00430 & $0.032 \%$ & $0.847 \%$ & $95.198 \%$ \\
\hline 293 & cangrejo & 0.00428 & $0.043 \%$ & $1.130 \%$ & $95.241 \%$ \\
\hline 294 & cigala & 0.00428 & $0.032 \%$ & $0.847 \%$ & $95.273 \%$ \\
\hline 295 & torta & 0.00425 & $0.021 \%$ & $0.565 \%$ & $95.294 \%$ \\
\hline 296 & sifón & 0.00425 & $0.032 \%$ & $0.847 \%$ & $95.326 \%$ \\
\hline 297 & membrillo & 0.00412 & $0.021 \%$ & $0.565 \%$ & $95.347 \%$ \\
\hline 298 & zumo de tomate & 0.00397 & $0.021 \%$ & $0.565 \%$ & $95.368 \%$ \\
\hline 299 & bourbon & 0.00395 & $0.021 \%$ & $0.565 \%$ & $95.389 \%$ \\
\hline 300 & judía verde & 0.00395 & $0.043 \%$ & $1.130 \%$ & $95.432 \%$ \\
\hline 301 & golosina & 0.00387 & $0.032 \%$ & $0.847 \%$ & $95.464 \%$ \\
\hline 302 & palomitas & 0.00382 & $0.053 \%$ & $1.412 \%$ & $95.517 \%$ \\
\hline 303 & lima & 0.00378 & $0.021 \%$ & $0.565 \%$ & $95.538 \%$ \\
\hline 304 & perdiz & 0.00377 & $0.053 \%$ & $1.412 \%$ & $95.591 \%$ \\
\hline 305 & miel & 0.00375 & $0.032 \%$ & $0.847 \%$ & $95.623 \%$ \\
\hline 306 & dorada & 0.00372 & $0.032 \%$ & $0.847 \%$ & $95.655 \%$ \\
\hline 307 & sake & 0.00371 & $0.021 \%$ & $0.565 \%$ & $95.676 \%$ \\
\hline 308 & queso roquefort & 0.00371 & $0.021 \%$ & $0.565 \%$ & $95.697 \%$ \\
\hline
\end{tabular}




\begin{tabular}{|c|c|c|c|c|c|}
\hline 309 & maracuyá & 0.00368 & $0.043 \%$ & $1.130 \%$ & $95.740 \%$ \\
\hline 310 & Casera* & 0.00367 & $0.021 \%$ & $0.565 \%$ & $95.761 \%$ \\
\hline 311 & bocata & 0.00367 & $0.021 \%$ & $0.565 \%$ & $95.782 \%$ \\
\hline 312 & zumo de melocotón & 0.00366 & $0.021 \%$ & $0.565 \%$ & $95.803 \%$ \\
\hline 313 & tortilla de patatas & 0.00364 & $0.021 \%$ & $0.565 \%$ & $95.824 \%$ \\
\hline 314 & orégano & 0.00362 & $0.021 \%$ & $0.565 \%$ & $95.845 \%$ \\
\hline 315 & Aquarius* & 0.00357 & $0.021 \%$ & $0.565 \%$ & $95.866 \%$ \\
\hline 316 & bollería & 0.00353 & $0.032 \%$ & $0.847 \%$ & $95.898 \%$ \\
\hline 317 & levadura & 0.00351 & $0.021 \%$ & $0.565 \%$ & $95.919 \%$ \\
\hline 318 & chuletón & 0.00348 & $0.021 \%$ & $0.565 \%$ & $95.940 \%$ \\
\hline 319 & macedonia & 0.00344 & $0.021 \%$ & $0.565 \%$ & $95.961 \%$ \\
\hline 320 & arroz tres delicias & 0.00342 & $0.021 \%$ & $0.565 \%$ & $95.982 \%$ \\
\hline 321 & Nestea* & 0.00334 & $0.021 \%$ & $0.565 \%$ & $96.003 \%$ \\
\hline 322 & frambuesa & 0.00328 & $0.032 \%$ & $0.847 \%$ & $96.035 \%$ \\
\hline 323 & licor de frutas & 0.00328 & $0.021 \%$ & $0.565 \%$ & $96.056 \%$ \\
\hline 324 & lácteos & 0.00326 & $0.021 \%$ & $0.565 \%$ & $96.077 \%$ \\
\hline 325 & granada & 0.00326 & $0.032 \%$ & $0.847 \%$ & $96.109 \%$ \\
\hline 326 & rodaballo & 0.00323 & $0.032 \%$ & $0.847 \%$ & $96.141 \%$ \\
\hline 327 & leche condensada & 0.00320 & $0.032 \%$ & $0.847 \%$ & $96.173 \%$ \\
\hline 328 & salmonete & 0.00319 & $0.032 \%$ & $0.847 \%$ & $96.205 \%$ \\
\hline 329 & bebida alcohólica & 0.00319 & $0.021 \%$ & $0.565 \%$ & $96.226 \%$ \\
\hline 330 & licor de café & 0.00318 & $0.021 \%$ & $0.565 \%$ & $96.247 \%$ \\
\hline 331 & frankfurt & 0.00317 & $0.032 \%$ & $0.847 \%$ & $96.279 \%$ \\
\hline 332 & mozzarella & 0.00313 & $0.021 \%$ & $0.565 \%$ & $96.300 \%$ \\
\hline 333 & embuchado & 0.00312 & $0.021 \%$ & $0.565 \%$ & $96.321 \%$ \\
\hline 334 & tocino & 0.00305 & $0.032 \%$ & $0.847 \%$ & $96.353 \%$ \\
\hline 335 & Beefeater* & 0.00305 & $0.032 \%$ & $0.847 \%$ & $96.385 \%$ \\
\hline 336 & chuleta de cordero & 0.00305 & $0.021 \%$ & $0.565 \%$ & $96.406 \%$ \\
\hline 337 & fresa con nata & 0.00302 & $0.021 \%$ & $0.565 \%$ & $96.427 \%$ \\
\hline 338 & carne de buey & 0.00295 & $0.021 \%$ & $0.565 \%$ & $96.448 \%$ \\
\hline 339 & cebada & 0.00292 & $0.021 \%$ & $0.565 \%$ & $96.469 \%$ \\
\hline 340 & crema de whisky & 0.00290 & $0.021 \%$ & $0.565 \%$ & $96.490 \%$ \\
\hline 341 & chuleta de cerdo & 0.00284 & $0.021 \%$ & $0.565 \%$ & $96.511 \%$ \\
\hline 342 & agua mineral & 0.00282 & $0.011 \%$ & $0.282 \%$ & $96.522 \%$ \\
\hline 343 & chocolate blanco & 0.00282 & $0.011 \%$ & $0.282 \%$ & $96.533 \%$ \\
\hline 344 & butifarra & 0.00281 & $0.021 \%$ & $0.565 \%$ & $96.554 \%$ \\
\hline 345 & margarina & 0.00276 & $0.032 \%$ & $0.847 \%$ & $96.586 \%$ \\
\hline 346 & crema & 0.00275 & $0.021 \%$ & $0.565 \%$ & $96.607 \%$ \\
\hline 347 & pan de molde & 0.00272 & $0.021 \%$ & $0.565 \%$ & $96.628 \%$ \\
\hline 348 & trigo & 0.00272 & $0.032 \%$ & $0.847 \%$ & $96.660 \%$ \\
\hline 349 & licor de avellana & 0.00269 & $0.021 \%$ & $0.565 \%$ & $96.681 \%$ \\
\hline 350 & chocolate negro & 0.00267 & $0.011 \%$ & $0.282 \%$ & $96.692 \%$ \\
\hline 351 & tortilla francesa & 0.00267 & $0.011 \%$ & $0.282 \%$ & $96.703 \%$ \\
\hline 352 & queso parmesano & 0.00267 & $0.011 \%$ & $0.282 \%$ & $96.714 \%$ \\
\hline 353 & besugo & 0.00260 & $0.021 \%$ & $0.565 \%$ & $96.735 \%$ \\
\hline 354 & pan integral & 0.00259 & $0.021 \%$ & $0.565 \%$ & $96.756 \%$ \\
\hline 355 & mostaza & 0.00256 & $0.021 \%$ & $0.565 \%$ & $96.777 \%$ \\
\hline
\end{tabular}




\begin{tabular}{|c|c|c|c|c|c|}
\hline 356 & licor de fresa & 0.00256 & $0.021 \%$ & $0.565 \%$ & $96.798 \%$ \\
\hline 357 & olla & 0.00253 & $0.021 \%$ & $0.565 \%$ & $96.819 \%$ \\
\hline 358 & pimiento rojo & 0.00252 & $0.011 \%$ & $0.282 \%$ & $96.830 \%$ \\
\hline 359 & redondo & 0.00252 & $0.011 \%$ & $0.282 \%$ & $96.841 \%$ \\
\hline 360 & bebida de cola & 0.00252 & $0.011 \%$ & $0.282 \%$ & $96.852 \%$ \\
\hline 361 & tonificante & 0.00252 & $0.011 \%$ & $0.282 \%$ & $96.863 \%$ \\
\hline 362 & ternera frita & 0.00252 & $0.011 \%$ & $0.282 \%$ & $96.874 \%$ \\
\hline 363 & ron blanco & 0.00252 & $0.011 \%$ & $0.282 \%$ & $96.885 \%$ \\
\hline 364 & rosada & 0.00252 & $0.011 \%$ & $0.282 \%$ & $96.896 \%$ \\
\hline 365 & crep & 0.00244 & $0.032 \%$ & $0.847 \%$ & $96.928 \%$ \\
\hline 366 & frijol & 0.00240 & $0.021 \%$ & $0.565 \%$ & $96.949 \%$ \\
\hline 367 & pimiento verde & 0.00238 & $0.011 \%$ & $0.282 \%$ & $96.960 \%$ \\
\hline 368 & Gran Napoleón* & 0.00238 & $0.011 \%$ & $0.282 \%$ & $96.971 \%$ \\
\hline 369 & bambú & 0.00238 & $0.011 \%$ & $0.282 \%$ & $96.982 \%$ \\
\hline 370 & ron negro & 0.00238 & $0.011 \%$ & $0.282 \%$ & $96.993 \%$ \\
\hline 371 & pincho & 0.00238 & $0.011 \%$ & $0.282 \%$ & $97.004 \%$ \\
\hline 372 & refresco de piña & 0.00238 & $0.011 \%$ & $0.282 \%$ & $97.015 \%$ \\
\hline 373 & sopa de ajo & 0.00238 & $0.011 \%$ & $0.282 \%$ & $97.026 \%$ \\
\hline 374 & ajoaceite & 0.00236 & $0.032 \%$ & $0.847 \%$ & $97.058 \%$ \\
\hline 375 & piñón & 0.00235 & $0.032 \%$ & $0.847 \%$ & $97.090 \%$ \\
\hline 376 & Cacaolat* & 0.00231 & $0.021 \%$ & $0.565 \%$ & $97.111 \%$ \\
\hline 377 & dátil & 0.00227 & $0.032 \%$ & $0.847 \%$ & $97.143 \%$ \\
\hline 378 & kaki & 0.00225 & $0.021 \%$ & $0.565 \%$ & $97.164 \%$ \\
\hline 379 & nécora & 0.00224 & $0.011 \%$ & $0.282 \%$ & $97.175 \%$ \\
\hline 380 & muesli & 0.00224 & $0.011 \%$ & $0.282 \%$ & $97.186 \%$ \\
\hline 381 & $\operatorname{gin}$ & 0.00224 & $0.011 \%$ & $0.282 \%$ & $97.197 \%$ \\
\hline 382 & manteca & 0.00224 & $0.011 \%$ & $0.282 \%$ & $97.208 \%$ \\
\hline 383 & arroz chino & 0.00224 & $0.011 \%$ & $0.282 \%$ & $97.219 \%$ \\
\hline 384 & pimentón & 0.00218 & $0.021 \%$ & $0.565 \%$ & $97.240 \%$ \\
\hline 385 & napolitana & 0.00217 & $0.032 \%$ & $0.847 \%$ & $97.272 \%$ \\
\hline 386 & lengua de toro & 0.00214 & $0.021 \%$ & $0.565 \%$ & $97.293 \%$ \\
\hline 387 & arroz con leche & 0.00214 & $0.021 \%$ & $0.565 \%$ & $97.314 \%$ \\
\hline 388 & nuez & 0.00213 & $0.021 \%$ & $0.565 \%$ & $97.335 \%$ \\
\hline 389 & absenta & 0.00212 & $0.011 \%$ & $0.282 \%$ & $97.346 \%$ \\
\hline 390 & granizado de limón & 0.00212 & $0.011 \%$ & $0.282 \%$ & $97.357 \%$ \\
\hline 391 & pierna & 0.00212 & $0.011 \%$ & $0.282 \%$ & $97.368 \%$ \\
\hline 392 & vermú blanco & 0.00212 & $0.011 \%$ & $0.282 \%$ & $97.379 \%$ \\
\hline 393 & bollo de chocolate & 0.00212 & $0.011 \%$ & $0.282 \%$ & $97.390 \%$ \\
\hline 394 & arroz de paella & 0.00212 & $0.011 \%$ & $0.282 \%$ & $97.401 \%$ \\
\hline 395 & chirimoya & 0.00210 & $0.032 \%$ & $0.847 \%$ & $97.433 \%$ \\
\hline 396 & botifarra & 0.00206 & $0.021 \%$ & $0.565 \%$ & $97.454 \%$ \\
\hline 397 & endivia & 0.00206 & $0.021 \%$ & $0.565 \%$ & $97.475 \%$ \\
\hline 398 & jarabe & 0.00200 & $0.011 \%$ & $0.282 \%$ & $97.486 \%$ \\
\hline 399 & poleo tocado & 0.00200 & $0.011 \%$ & $0.282 \%$ & $97.497 \%$ \\
\hline 400 & zumo de frutas & 0.00200 & $0.011 \%$ & $0.282 \%$ & $97.508 \%$ \\
\hline 401 & bebida gaseosa & 0.00200 & $0.011 \%$ & $0.282 \%$ & $97.519 \%$ \\
\hline 402 & agua de valencia & 0.00200 & $0.011 \%$ & $0.282 \%$ & $97.530 \%$ \\
\hline
\end{tabular}




\begin{tabular}{|c|c|c|c|c|c|}
\hline 403 & vermú negro & 0.00200 & $0.011 \%$ & $0.282 \%$ & $97.541 \%$ \\
\hline 404 & bíter sin alcohol & 0.00200 & $0.011 \%$ & $0.282 \%$ & $97.552 \%$ \\
\hline 405 & entrantes & 0.00200 & $0.011 \%$ & $0.282 \%$ & $97.563 \%$ \\
\hline 406 & arroz blanco & 0.00200 & $0.011 \%$ & $0.282 \%$ & $97.574 \%$ \\
\hline 407 & bicarbonato & 0.00197 & $0.021 \%$ & $0.565 \%$ & $97.595 \%$ \\
\hline 408 & avena & 0.00197 & $0.021 \%$ & $0.565 \%$ & $97.616 \%$ \\
\hline 409 & jamón cocido & 0.00190 & $0.021 \%$ & $0.565 \%$ & $97.637 \%$ \\
\hline 410 & conejo al ajillo & 0.00190 & $0.021 \%$ & $0.565 \%$ & $97.658 \%$ \\
\hline 411 & ossobuco & 0.00189 & $0.011 \%$ & $0.282 \%$ & $97.669 \%$ \\
\hline 412 & Espetec* & 0.00189 & $0.011 \%$ & $0.282 \%$ & $97.680 \%$ \\
\hline 413 & Pepsi-cola* & 0.00189 & $0.011 \%$ & $0.282 \%$ & $97.691 \%$ \\
\hline 414 & bistec & 0.00189 & $0.011 \%$ & $0.282 \%$ & $97.702 \%$ \\
\hline 415 & líquida & 0.00189 & $0.011 \%$ & $0.282 \%$ & $97.713 \%$ \\
\hline 416 & fritos & 0.00189 & $0.011 \%$ & $0.282 \%$ & $97.724 \%$ \\
\hline 417 & cerveza negra & 0.00186 & $0.021 \%$ & $0.565 \%$ & $97.745 \%$ \\
\hline 418 & mango & 0.00184 & $0.021 \%$ & $0.565 \%$ & $97.766 \%$ \\
\hline 419 & galera & 0.00184 & $0.021 \%$ & $0.565 \%$ & $97.787 \%$ \\
\hline 420 & infusión & 0.00183 & $0.021 \%$ & $0.565 \%$ & $97.808 \%$ \\
\hline 421 & sémola & 0.00183 & $0.032 \%$ & $0.847 \%$ & $97.840 \%$ \\
\hline 422 & bajoca & 0.00179 & $0.021 \%$ & $0.565 \%$ & $97.861 \%$ \\
\hline 423 & carne roja & 0.00178 & $0.011 \%$ & $0.282 \%$ & $97.872 \%$ \\
\hline 424 & cazalla & 0.00178 & $0.011 \%$ & $0.282 \%$ & $97.883 \%$ \\
\hline 425 & capuchino & 0.00178 & $0.011 \%$ & $0.282 \%$ & $97.894 \%$ \\
\hline 426 & Anís del mono* & 0.00178 & $0.011 \%$ & $0.282 \%$ & $97.905 \%$ \\
\hline 427 & Rive* $^{*}$ sin alcohol & 0.00178 & $0.011 \%$ & $0.282 \%$ & $97.916 \%$ \\
\hline 428 & Nescafé* & 0.00178 & $0.011 \%$ & $0.282 \%$ & $97.927 \%$ \\
\hline 429 & Bacardí* & 0.00178 & $0.011 \%$ & $0.282 \%$ & $97.938 \%$ \\
\hline 430 & pollo frito & 0.00178 & $0.011 \%$ & $0.282 \%$ & $97.949 \%$ \\
\hline 431 & huevo frito & 0.00176 & $0.021 \%$ & $0.565 \%$ & $97.970 \%$ \\
\hline 432 & lomo de cerdo & 0.00172 & $0.021 \%$ & $0.565 \%$ & $97.991 \%$ \\
\hline 433 & pato a la naranja & 0.00169 & $0.021 \%$ & $0.565 \%$ & $98.012 \%$ \\
\hline 434 & cardo & 0.00168 & $0.011 \%$ & $0.282 \%$ & $98.023 \%$ \\
\hline 435 & $\mathrm{DYC}^{*}$ & 0.00168 & $0.011 \%$ & $0.282 \%$ & $98.034 \%$ \\
\hline 436 & vaca & 0.00168 & $0.011 \%$ & $0.282 \%$ & $98.045 \%$ \\
\hline 437 & pan Bimbo* & 0.00166 & $0.021 \%$ & $0.565 \%$ & $98.066 \%$ \\
\hline 438 & bogavante & 0.00161 & $0.021 \%$ & $0.565 \%$ & $98.087 \%$ \\
\hline 439 & Isostar* & 0.00159 & $0.011 \%$ & $0.282 \%$ & $98.098 \%$ \\
\hline 440 & filete de pechuga & 0.00159 & $0.011 \%$ & $0.282 \%$ & $98.109 \%$ \\
\hline 441 & tónica Schweppes* & 0.00159 & $0.011 \%$ & $0.282 \%$ & $98.120 \%$ \\
\hline 442 & agua bicarbonatada & 0.00159 & $0.011 \%$ & $0.282 \%$ & $98.131 \%$ \\
\hline 443 & orujo & 0.00159 & $0.011 \%$ & $0.282 \%$ & $98.142 \%$ \\
\hline 444 & bebida de alcohol & 0.00159 & $0.011 \%$ & $0.282 \%$ & $98.153 \%$ \\
\hline 445 & licor de mora & 0.00159 & $0.011 \%$ & $0.282 \%$ & $98.164 \%$ \\
\hline 446 & sopa de fideos & 0.00159 & $0.011 \%$ & $0.282 \%$ & $98.175 \%$ \\
\hline 447 & fogassa & 0.00157 & $0.021 \%$ & $0.565 \%$ & $98.196 \%$ \\
\hline 448 & alcaparra & 0.00152 & $0.021 \%$ & $0.565 \%$ & $98.217 \%$ \\
\hline 449 & empanada & 0.00151 & $0.021 \%$ & $0.565 \%$ & $98.238 \%$ \\
\hline
\end{tabular}




\begin{tabular}{|c|c|c|c|c|c|}
\hline 450 & cubito & 0.00150 & $0.011 \%$ & $0.282 \%$ & $98.249 \%$ \\
\hline 451 & filete de ternera & 0.00150 & $0.011 \%$ & $0.282 \%$ & $98.260 \%$ \\
\hline 452 & tónica Finley* & 0.00150 & $0.011 \%$ & $0.282 \%$ & $98.271 \%$ \\
\hline 453 & pan de fibra & 0.00150 & $0.011 \%$ & $0.282 \%$ & $98.282 \%$ \\
\hline 454 & zumo de uva & 0.00150 & $0.011 \%$ & $0.282 \%$ & $98.293 \%$ \\
\hline 455 & sopa de letras & 0.00150 & $0.011 \%$ & $0.282 \%$ & $98.304 \%$ \\
\hline 456 & rosbif & 0.00142 & $0.011 \%$ & $0.282 \%$ & $98.315 \%$ \\
\hline 457 & patata hervida & 0.00142 & $0.011 \%$ & $0.282 \%$ & $98.326 \%$ \\
\hline 458 & carajillo & 0.00142 & $0.011 \%$ & $0.282 \%$ & $98.337 \%$ \\
\hline 459 & ginseng & 0.00142 & $0.011 \%$ & $0.282 \%$ & $98.348 \%$ \\
\hline 460 & nabo & 0.00142 & $0.011 \%$ & $0.282 \%$ & $98.359 \%$ \\
\hline 461 & fibra & 0.00142 & $0.011 \%$ & $0.282 \%$ & $98.370 \%$ \\
\hline 462 & especias & 0.00142 & $0.021 \%$ & $0.565 \%$ & $98.391 \%$ \\
\hline 463 & licor de limón & 0.00142 & $0.011 \%$ & $0.282 \%$ & $98.402 \%$ \\
\hline 464 & sopa de huevo & 0.00142 & $0.011 \%$ & $0.282 \%$ & $98.413 \%$ \\
\hline 465 & aceite de oliva & 0.00142 & $0.011 \%$ & $0.282 \%$ & $98.424 \%$ \\
\hline 466 & brécol & 0.00140 & $0.021 \%$ & $0.565 \%$ & $98.445 \%$ \\
\hline 467 & granadina & 0.00138 & $0.021 \%$ & $0.565 \%$ & $98.466 \%$ \\
\hline 468 & higo & 0.00138 & $0.021 \%$ & $0.565 \%$ & $98.487 \%$ \\
\hline 469 & seso & 0.00134 & $0.011 \%$ & $0.282 \%$ & $98.498 \%$ \\
\hline 470 & palito de cangrejo & 0.00134 & $0.021 \%$ & $0.565 \%$ & $98.519 \%$ \\
\hline 471 & crema de chocolate & 0.00134 & $0.021 \%$ & $0.565 \%$ & $98.540 \%$ \\
\hline 472 & aperitivo & 0.00134 & $0.011 \%$ & $0.282 \%$ & $98.551 \%$ \\
\hline 473 & carabinero & 0.00134 & $0.011 \%$ & $0.282 \%$ & $98.562 \%$ \\
\hline 474 & puré de verduras & 0.00134 & $0.011 \%$ & $0.282 \%$ & $98.573 \%$ \\
\hline 475 & perrito & 0.00134 & $0.011 \%$ & $0.282 \%$ & $98.584 \%$ \\
\hline 476 & licor de plátano & 0.00134 & $0.011 \%$ & $0.282 \%$ & $98.595 \%$ \\
\hline 477 & copa de helado & 0.00134 & $0.011 \%$ & $0.282 \%$ & $98.606 \%$ \\
\hline 478 & aceite de girasol & 0.00134 & $0.011 \%$ & $0.282 \%$ & $98.617 \%$ \\
\hline 479 & centeno & 0.00127 & $0.021 \%$ & $0.565 \%$ & $98.638 \%$ \\
\hline 480 & riñón & 0.00126 & $0.011 \%$ & $0.282 \%$ & $98.649 \%$ \\
\hline 481 & kiko & 0.00126 & $0.011 \%$ & $0.282 \%$ & $98.660 \%$ \\
\hline 482 & mabra & 0.00126 & $0.011 \%$ & $0.282 \%$ & $98.671 \%$ \\
\hline 483 & vino de mesa & 0.00126 & $0.011 \%$ & $0.282 \%$ & $98.682 \%$ \\
\hline 484 & mousse & 0.00126 & $0.011 \%$ & $0.282 \%$ & $98.693 \%$ \\
\hline 485 & pasa & 0.00126 & $0.011 \%$ & $0.282 \%$ & $98.704 \%$ \\
\hline 486 & licor de kiwi & 0.00126 & $0.011 \%$ & $0.282 \%$ & $98.715 \%$ \\
\hline 487 & cerveza rubia & 0.00126 & $0.011 \%$ & $0.282 \%$ & $98.726 \%$ \\
\hline 488 & raya & 0.00120 & $0.021 \%$ & $0.565 \%$ & $98.747 \%$ \\
\hline 489 & ventresca & 0.00119 & $0.011 \%$ & $0.282 \%$ & $98.758 \%$ \\
\hline 490 & entremés & 0.00119 & $0.011 \%$ & $0.282 \%$ & $98.769 \%$ \\
\hline 491 & pan rallado & 0.00119 & $0.011 \%$ & $0.282 \%$ & $98.780 \%$ \\
\hline 492 & vino fino & 0.00119 & $0.011 \%$ & $0.282 \%$ & $98.791 \%$ \\
\hline 493 & refresco con gas & 0.00119 & $0.011 \%$ & $0.282 \%$ & $98.802 \%$ \\
\hline 494 & yogur líquido & 0.00119 & $0.011 \%$ & $0.282 \%$ & $98.813 \%$ \\
\hline 495 & mariscada & 0.00119 & $0.011 \%$ & $0.282 \%$ & $98.824 \%$ \\
\hline 496 & empedrat & 0.00119 & $0.011 \%$ & $0.282 \%$ & $98.835 \%$ \\
\hline
\end{tabular}




\begin{tabular}{|c|c|c|c|c|c|}
\hline 497 & pierna de cordero & 0.00119 & $0.011 \%$ & $0.282 \%$ & $98.846 \%$ \\
\hline 498 & licor de frambuesa & 0.00119 & $0.011 \%$ & $0.282 \%$ & $98.857 \%$ \\
\hline 499 & ostra & 0.00116 & $0.021 \%$ & $0.565 \%$ & $98.878 \%$ \\
\hline 500 & anca de rana & 0.00113 & $0.011 \%$ & $0.282 \%$ & $98.889 \%$ \\
\hline 501 & Jake Daniels* & 0.00113 & $0.011 \%$ & $0.282 \%$ & $98.900 \%$ \\
\hline 502 & cinta & 0.00113 & $0.011 \%$ & $0.282 \%$ & $98.911 \%$ \\
\hline 503 & pasta de cacao & 0.00113 & $0.011 \%$ & $0.282 \%$ & $98.922 \%$ \\
\hline 504 & cacao en polvo & 0.00113 & $0.011 \%$ & $0.282 \%$ & $98.933 \%$ \\
\hline 505 & bajocó & 0.00113 & $0.011 \%$ & $0.282 \%$ & $98.944 \%$ \\
\hline 506 & morro de cerdo & 0.00113 & $0.011 \%$ & $0.282 \%$ & $98.955 \%$ \\
\hline 507 & bebida con gas & 0.00113 & $0.011 \%$ & $0.282 \%$ & $98.966 \%$ \\
\hline 508 & pudin & 0.00113 & $0.011 \%$ & $0.282 \%$ & $98.977 \%$ \\
\hline 509 & papaya & 0.00113 & $0.011 \%$ & $0.282 \%$ & $98.988 \%$ \\
\hline 510 & carne de oveja & 0.00113 & $0.011 \%$ & $0.282 \%$ & $98.999 \%$ \\
\hline 511 & rebanada de pan & 0.00113 & $0.011 \%$ & $0.282 \%$ & $99.010 \%$ \\
\hline 512 & Fanta* piña & 0.00106 & $0.011 \%$ & $0.282 \%$ & $99.021 \%$ \\
\hline 513 & repostería & 0.00106 & $0.011 \%$ & $0.282 \%$ & $99.032 \%$ \\
\hline 514 & chucherías & 0.00106 & $0.011 \%$ & $0.282 \%$ & $99.043 \%$ \\
\hline 515 & jugo & 0.00106 & $0.011 \%$ & $0.282 \%$ & $99.054 \%$ \\
\hline 516 & café con leche & 0.00106 & $0.011 \%$ & $0.282 \%$ & $99.065 \%$ \\
\hline 517 & crema de cacao & 0.00106 & $0.011 \%$ & $0.282 \%$ & $99.076 \%$ \\
\hline 518 & soufflé & 0.00106 & $0.011 \%$ & $0.282 \%$ & $99.087 \%$ \\
\hline 519 & trucha & 0.00106 & $0.011 \%$ & $0.282 \%$ & $99.098 \%$ \\
\hline 520 & merienda & 0.00106 & $0.011 \%$ & $0.282 \%$ & $99.109 \%$ \\
\hline 521 & chile & 0.00106 & $0.011 \%$ & $0.282 \%$ & $99.120 \%$ \\
\hline 522 & pepperoni & 0.00104 & $0.021 \%$ & $0.565 \%$ & $99.141 \%$ \\
\hline 523 & congelado & 0.00100 & $0.011 \%$ & $0.282 \%$ & $99.152 \%$ \\
\hline 524 & catalana & 0.00100 & $0.011 \%$ & $0.282 \%$ & $99.163 \%$ \\
\hline 525 & requesón & 0.00100 & $0.011 \%$ & $0.282 \%$ & $99.174 \%$ \\
\hline 526 & leche entera & 0.00100 & $0.011 \%$ & $0.282 \%$ & $99.185 \%$ \\
\hline 527 & leche con Cola Cao* & 0.00100 & $0.011 \%$ & $0.282 \%$ & $99.196 \%$ \\
\hline 528 & navaja & 0.00100 & $0.011 \%$ & $0.282 \%$ & $99.207 \%$ \\
\hline 529 & toro & 0.00100 & $0.011 \%$ & $0.282 \%$ & $99.218 \%$ \\
\hline 530 & filete de carne & 0.00100 & $0.011 \%$ & $0.282 \%$ & $99.229 \%$ \\
\hline 531 & mate & 0.00100 & $0.011 \%$ & $0.282 \%$ & $99.240 \%$ \\
\hline 532 & limón granizado & 0.00100 & $0.011 \%$ & $0.282 \%$ & $99.251 \%$ \\
\hline 533 & digestivo & 0.00095 & $0.011 \%$ & $0.282 \%$ & $99.262 \%$ \\
\hline 534 & leche merengada & 0.00095 & $0.011 \%$ & $0.282 \%$ & $99.273 \%$ \\
\hline 535 & gusanitos & 0.00095 & $0.011 \%$ & $0.282 \%$ & $99.284 \%$ \\
\hline 536 & licor de flores & 0.00095 & $0.011 \%$ & $0.282 \%$ & $99.295 \%$ \\
\hline 537 & conejo al chilindrón & 0.00095 & $0.011 \%$ & $0.282 \%$ & $99.306 \%$ \\
\hline 538 & leche semi & 0.00095 & $0.011 \%$ & $0.282 \%$ & $99.317 \%$ \\
\hline 539 & cochinillo & 0.00095 & $0.011 \%$ & $0.282 \%$ & $99.328 \%$ \\
\hline 540 & carne picada & 0.00095 & $0.011 \%$ & $0.282 \%$ & $99.339 \%$ \\
\hline 541 & filete de pescado & 0.00095 & $0.011 \%$ & $0.282 \%$ & $99.350 \%$ \\
\hline 542 & fresón & 0.00089 & $0.011 \%$ & $0.282 \%$ & $99.361 \%$ \\
\hline 543 & soja & 0.00089 & $0.011 \%$ & $0.282 \%$ & $99.372 \%$ \\
\hline
\end{tabular}




\begin{tabular}{|c|c|c|c|c|c|}
\hline 544 & codorniz & 0.00089 & $0.011 \%$ & $0.282 \%$ & $99.383 \%$ \\
\hline 545 & pollo a l'ast & 0.00089 & $0.011 \%$ & $0.282 \%$ & $99.394 \%$ \\
\hline 546 & tía María* & 0.00089 & $0.011 \%$ & $0.282 \%$ & $99.405 \%$ \\
\hline 547 & leche desnatada & 0.00089 & $0.011 \%$ & $0.282 \%$ & $99.416 \%$ \\
\hline 548 & parrillada & 0.00089 & $0.011 \%$ & $0.282 \%$ & $99.427 \%$ \\
\hline 549 & muslito de mar & 0.00089 & $0.011 \%$ & $0.282 \%$ & $99.438 \%$ \\
\hline 550 & abadejo & 0.00084 & $0.011 \%$ & $0.282 \%$ & $99.449 \%$ \\
\hline 551 & picante & 0.00084 & $0.011 \%$ & $0.282 \%$ & $99.460 \%$ \\
\hline 552 & pimentón verde & 0.00084 & $0.011 \%$ & $0.282 \%$ & $99.471 \%$ \\
\hline 553 & lluç & 0.00084 & $0.011 \%$ & $0.282 \%$ & $99.482 \%$ \\
\hline 554 & callos & 0.00084 & $0.011 \%$ & $0.282 \%$ & $99.493 \%$ \\
\hline 555 & revuelto & 0.00084 & $0.011 \%$ & $0.282 \%$ & $99.504 \%$ \\
\hline 556 & Bollycao* & 0.00084 & $0.011 \%$ & $0.282 \%$ & $99.515 \%$ \\
\hline 557 & batido de chocolate & 0.00080 & $0.011 \%$ & $0.282 \%$ & $99.526 \%$ \\
\hline 558 & sopa de cardos & 0.00080 & $0.011 \%$ & $0.282 \%$ & $99.537 \%$ \\
\hline 559 & queso de tetilla & 0.00080 & $0.011 \%$ & $0.282 \%$ & $99.548 \%$ \\
\hline 560 & pimentón rojo & 0.00080 & $0.011 \%$ & $0.282 \%$ & $99.559 \%$ \\
\hline 561 & consomé & 0.00080 & $0.011 \%$ & $0.282 \%$ & $99.570 \%$ \\
\hline 562 & nuez moscada & 0.00080 & $0.011 \%$ & $0.282 \%$ & $99.581 \%$ \\
\hline 563 & bíter Kas* & 0.00080 & $0.011 \%$ & $0.282 \%$ & $99.592 \%$ \\
\hline 564 & lomo embuchado & 0.00080 & $0.011 \%$ & $0.282 \%$ & $99.603 \%$ \\
\hline 565 & pincho moruno & 0.00080 & $0.011 \%$ & $0.282 \%$ & $99.614 \%$ \\
\hline 566 & bebida energética & 0.00080 & $0.011 \%$ & $0.282 \%$ & $99.625 \%$ \\
\hline 567 & polvorón & 0.00080 & $0.011 \%$ & $0.282 \%$ & $99.636 \%$ \\
\hline 568 & bebida reconstituyente & 0.00080 & $0.011 \%$ & $0.282 \%$ & $99.647 \%$ \\
\hline 569 & Coca cola* light & 0.00080 & $0.011 \%$ & $0.282 \%$ & $99.658 \%$ \\
\hline 570 & chirla & 0.00075 & $0.011 \%$ & $0.282 \%$ & $99.669 \%$ \\
\hline 571 & batido de vainilla & 0.00075 & $0.011 \%$ & $0.282 \%$ & $99.680 \%$ \\
\hline 572 & agua carbonatada & 0.00075 & $0.011 \%$ & $0.282 \%$ & $99.691 \%$ \\
\hline 573 & chocolatina & 0.00075 & $0.011 \%$ & $0.282 \%$ & $99.702 \%$ \\
\hline 574 & queso francés & 0.00075 & $0.011 \%$ & $0.282 \%$ & $99.713 \%$ \\
\hline 575 & arròs caldós & 0.00075 & $0.011 \%$ & $0.282 \%$ & $99.724 \%$ \\
\hline 576 & Coca cola* sin cafeína & 0.00075 & $0.011 \%$ & $0.282 \%$ & $99.735 \%$ \\
\hline 577 & clòtxina & 0.00071 & $0.011 \%$ & $0.282 \%$ & $99.746 \%$ \\
\hline 578 & Enmental* & 0.00071 & $0.011 \%$ & $0.282 \%$ & $99.757 \%$ \\
\hline 579 & fritura & 0.00071 & $0.011 \%$ & $0.282 \%$ & $99.768 \%$ \\
\hline 580 & albahaca & 0.00071 & $0.011 \%$ & $0.282 \%$ & $99.779 \%$ \\
\hline 581 & charcutería & 0.00067 & $0.011 \%$ & $0.282 \%$ & $99.790 \%$ \\
\hline 582 & vainilla & 0.00067 & $0.011 \%$ & $0.282 \%$ & $99.801 \%$ \\
\hline 583 & conejo a la brasa & 0.00067 & $0.011 \%$ & $0.282 \%$ & $99.812 \%$ \\
\hline 584 & Baileys* & 0.00067 & $0.011 \%$ & $0.282 \%$ & $99.823 \%$ \\
\hline 585 & queso suizo & 0.00067 & $0.011 \%$ & $0.282 \%$ & $99.834 \%$ \\
\hline 586 & azafrán & 0.00067 & $0.011 \%$ & $0.282 \%$ & $99.845 \%$ \\
\hline 587 & valenciana & 0.00067 & $0.011 \%$ & $0.282 \%$ & $99.856 \%$ \\
\hline 588 & guisado & 0.00067 & $0.011 \%$ & $0.282 \%$ & $99.867 \%$ \\
\hline 589 & champiñón & 0.00063 & $0.011 \%$ & $0.282 \%$ & $99.878 \%$ \\
\hline 590 & pan tostado & 0.00063 & $0.011 \%$ & $0.282 \%$ & $99.889 \%$ \\
\hline
\end{tabular}




\begin{tabular}{|l|l|l|l|l|l|}
\hline 591 & banderilla & 0.00063 & $0.011 \%$ & $0.282 \%$ & $99.900 \%$ \\
\hline 592 & judía con tomate & 0.00063 & $0.011 \%$ & $0.282 \%$ & $99.911 \%$ \\
\hline 593 & barbacoa & 0.00063 & $0.011 \%$ & $0.282 \%$ & $99.922 \%$ \\
\hline 594 & mazapán & 0.00063 & $0.011 \%$ & $0.282 \%$ & $99.933 \%$ \\
\hline 595 & muslito & 0.00060 & $0.011 \%$ & $0.282 \%$ & $99.944 \%$ \\
\hline 596 & Dan up* & 0.00060 & $0.011 \%$ & $0.282 \%$ & $99.955 \%$ \\
\hline 597 & mora & 0.00056 & $0.011 \%$ & $0.282 \%$ & $99.966 \%$ \\
\hline 598 & coca de tomate & 0.00056 & $0.011 \%$ & $0.282 \%$ & $99.977 \%$ \\
\hline 599 & Revilla* & 0.00056 & $0.011 \%$ & $0.282 \%$ & $99.988 \%$ \\
\hline 600 & percebe & 0.00056 & $0.011 \%$ & $0.282 \%$ & $99.999 \%$ \\
\hline 601 & bebida refrescante & 0.00053 & $0.011 \%$ & $0.282 \%$ & $100.010 \%$ \\
\hline 602 & rosquilla & 0.00053 & $0.011 \%$ & $0.282 \%$ & $100.021 \%$ \\
\hline 603 & castaña & 0.00053 & $0.011 \%$ & $0.282 \%$ & $100.032 \%$ \\
\hline 604 & mojo picón & 0.00053 & $0.011 \%$ & $0.282 \%$ & $100.043 \%$ \\
\hline 605 & caramelo & 0.00050 & $0.011 \%$ & $0.282 \%$ & $100.054 \%$ \\
\hline 606 & espárrago triguero & 0.00050 & $0.011 \%$ & $0.282 \%$ & $100.065 \%$ \\
\hline 607 & paleta de cerdo & 0.00042 & $0.011 \%$ & $0.282 \%$ & $100.076 \%$ \\
\hline
\end{tabular}

\section{OBJETOS COLOCADOS EN LA MESA PARA LA COMIDA}

\begin{tabular}{|c|l|c|c|c|c|}
\hline $\mathrm{N}^{\mathrm{o}}$ & Palabra & Disponibilidad & $\begin{array}{c}\text { Frecuencia } \\
\text { relativa }\end{array}$ & $\%$ Aparición & $\begin{array}{c}\text { Frecuencia } \\
\text { acumulada }\end{array}$ \\
\hline 1 & tenedor & 0.79617 & $6.102 \%$ & $90.960 \%$ & $6.102 \%$ \\
\hline 2 & cuchillo & 0.75264 & $6.197 \%$ & $92.373 \%$ & $12.299 \%$ \\
\hline 3 & cuchara & 0.73130 & $6.102 \%$ & $90.960 \%$ & $18.401 \%$ \\
\hline 4 & servilleta & 0.65301 & $6.121 \%$ & $91.243 \%$ & $24.522 \%$ \\
\hline 5 & vaso & 0.63458 & $5.685 \%$ & $84.746 \%$ & $30.207 \%$ \\
\hline 6 & plato & 0.60742 & $5.628 \%$ & $83.898 \%$ & $35.835 \%$ \\
\hline 7 & mantel & 0.45928 & $4.984 \%$ & $74.294 \%$ & $40.819 \%$ \\
\hline 8 & botella & 0.28680 & $3.259 \%$ & $48.588 \%$ & $44.078 \%$ \\
\hline 9 & jarra & 0.27356 & $3.070 \%$ & $45.763 \%$ & $47.148 \%$ \\
\hline 10 & copa & 0.23276 & $2.786 \%$ & $41.525 \%$ & $49.934 \%$ \\
\hline 11 & salero & 0.18266 & $2.141 \%$ & $31.921 \%$ & $52.075 \%$ \\
\hline 12 & servilletero & 0.17709 & $2.141 \%$ & $31.921 \%$ & $54.216 \%$ \\
\hline 13 & cucharilla & 0.16290 & $1.800 \%$ & $26.836 \%$ & $56.016 \%$ \\
\hline 14 & ensaladera & 0.11846 & $1.535 \%$ & $22.881 \%$ & $57.551 \%$ \\
\hline 15 & fuente & 0.10690 & $1.535 \%$ & $22.881 \%$ & $59.086 \%$ \\
\hline 16 & bandeja & 0.10084 & $1.497 \%$ & $22.316 \%$ & $60.583 \%$ \\
\hline 17 & frutero & 0.09598 & $1.383 \%$ & $20.621 \%$ & $61.966 \%$ \\
\hline 18 & taza & 0.09260 & $1.327 \%$ & $19.774 \%$ & $63.293 \%$ \\
\hline 19 & panera & 0.08838 & $1.194 \%$ & $17.797 \%$ & $64.487 \%$ \\
\hline 20 & sopera & 0.08679 & $1.137 \%$ & $16.949 \%$ & $65.624 \%$ \\
\hline 21 & aceitera & 0.07234 & $0.985 \%$ & $14.689 \%$ & $66.609 \%$ \\
\hline
\end{tabular}




\begin{tabular}{|c|c|c|c|c|c|}
\hline 22 & palillo & 0.06644 & $0.948 \%$ & $14.124 \%$ & $67.557 \%$ \\
\hline 23 & posavasos & 0.06518 & $0.948 \%$ & $14.124 \%$ & $68.505 \%$ \\
\hline 24 & vinajera & 0.06375 & $0.758 \%$ & $11.299 \%$ & $69.263 \%$ \\
\hline 25 & plato hondo & 0.05924 & $0.663 \%$ & $9.887 \%$ & $69.926 \%$ \\
\hline 26 & vinagrera & 0.05913 & $0.739 \%$ & $11.017 \%$ & $70.665 \%$ \\
\hline 27 & azucarero & 0.04782 & $0.720 \%$ & $10.734 \%$ & $71.385 \%$ \\
\hline 28 & cazuela & 0.04727 & $0.739 \%$ & $11.017 \%$ & $72.124 \%$ \\
\hline 29 & salsera & 0.04614 & $0.587 \%$ & $8.757 \%$ & $72.711 \%$ \\
\hline 30 & tenedor de pescado & 0.04584 & $0.493 \%$ & $7.345 \%$ & $73.204 \%$ \\
\hline 31 & tenedor de carne & 0.04505 & $0.379 \%$ & $5.650 \%$ & $73.583 \%$ \\
\hline 32 & cucharón & 0.04313 & $0.663 \%$ & $9.887 \%$ & $74.246 \%$ \\
\hline 33 & botella de agua & 0.04300 & $0.493 \%$ & $7.345 \%$ & $74.739 \%$ \\
\hline 34 & pan & 0.04173 & $0.455 \%$ & $6.780 \%$ & $75.194 \%$ \\
\hline 35 & vela & 0.03836 & $0.606 \%$ & $9.040 \%$ & $75.800 \%$ \\
\hline 36 & cubierto & 0.03771 & $0.360 \%$ & $5.367 \%$ & $76.160 \%$ \\
\hline 37 & salvamanteles & 0.03587 & $0.512 \%$ & $7.627 \%$ & $76.672 \%$ \\
\hline 38 & cuchillo de carne & 0.03577 & $0.341 \%$ & $5.085 \%$ & $77.013 \%$ \\
\hline 39 & plato llano & 0.03561 & $0.398 \%$ & $5.932 \%$ & $77.411 \%$ \\
\hline 40 & cuchillo de pescado & 0.03554 & $0.455 \%$ & $6.780 \%$ & $77.866 \%$ \\
\hline 41 & tazón & 0.03372 & $0.455 \%$ & $6.780 \%$ & $78.321 \%$ \\
\hline 42 & plato de postre & 0.03256 & $0.417 \%$ & $6.215 \%$ & $78.738 \%$ \\
\hline 43 & botella de vino & 0.03172 & $0.417 \%$ & $6.215 \%$ & $79.155 \%$ \\
\hline 44 & vaso de agua & 0.02913 & $0.284 \%$ & $4.237 \%$ & $79.439 \%$ \\
\hline 45 & cafetera & 0.02890 & $0.512 \%$ & $7.627 \%$ & $79.951 \%$ \\
\hline 46 & cucharita & 0.02797 & $0.284 \%$ & $4.237 \%$ & $80.235 \%$ \\
\hline 47 & vaso de vino & 0.02756 & $0.284 \%$ & $4.237 \%$ & $80.519 \%$ \\
\hline 48 & sartén & 0.02724 & $0.436 \%$ & $6.497 \%$ & $80.955 \%$ \\
\hline 49 & aceite & 0.02468 & $0.265 \%$ & $3.955 \%$ & $81.220 \%$ \\
\hline 50 & olla & 0.02414 & $0.360 \%$ & $5.367 \%$ & $81.580 \%$ \\
\hline 51 & cuenco & 0.02374 & $0.417 \%$ & $6.215 \%$ & $81.997 \%$ \\
\hline 52 & copa de vino & 0.02352 & $0.303 \%$ & $4.520 \%$ & $82.300 \%$ \\
\hline 53 & sal & 0.02334 & $0.246 \%$ & $3.672 \%$ & $82.546 \%$ \\
\hline 54 & jarra de agua & 0.02333 & $0.284 \%$ & $4.237 \%$ & $82.830 \%$ \\
\hline 55 & cuchara de postre & 0.02316 & $0.265 \%$ & $3.955 \%$ & $83.095 \%$ \\
\hline 56 & sacacorchos & 0.02210 & $0.398 \%$ & $5.932 \%$ & $83.493 \%$ \\
\hline 57 & cesta del pan & 0.02209 & $0.265 \%$ & $3.955 \%$ & $83.758 \%$ \\
\hline 58 & cenicero & 0.02180 & $0.341 \%$ & $5.085 \%$ & $84.099 \%$ \\
\hline 59 & plato plano & 0.02113 & $0.227 \%$ & $3.390 \%$ & $84.326 \%$ \\
\hline 60 & cazo & 0.02043 & $0.265 \%$ & $3.955 \%$ & $84.591 \%$ \\
\hline 61 & abrelatas & 0.01998 & $0.341 \%$ & $5.085 \%$ & $84.932 \%$ \\
\hline 62 & agua & 0.01976 & $0.208 \%$ & $3.107 \%$ & $85.140 \%$ \\
\hline 63 & florero & 0.01973 & $0.322 \%$ & $4.802 \%$ & $85.462 \%$ \\
\hline 64 & palillero & 0.01893 & $0.303 \%$ & $4.520 \%$ & $85.765 \%$ \\
\hline 65 & bol & 0.01794 & $0.303 \%$ & $4.520 \%$ & $86.068 \%$ \\
\hline 66 & pinza & 0.01782 & $0.246 \%$ & $3.672 \%$ & $86.314 \%$ \\
\hline 67 & plato de ensalada & 0.01709 & $0.208 \%$ & $3.107 \%$ & $86.522 \%$ \\
\hline 68 & candelabro & 0.01704 & $0.265 \%$ & $3.955 \%$ & $86.787 \%$ \\
\hline
\end{tabular}




\begin{tabular}{|c|c|c|c|c|c|}
\hline 69 & tenedor de postre & 0.01679 & $0.208 \%$ & $3.107 \%$ & $86.995 \%$ \\
\hline 70 & cuchara sopera & 0.01665 & $0.152 \%$ & $2.260 \%$ & $87.147 \%$ \\
\hline 71 & porrón & 0.01663 & $0.227 \%$ & $3.390 \%$ & $87.374 \%$ \\
\hline 72 & flor & 0.01618 & $0.227 \%$ & $3.390 \%$ & $87.601 \%$ \\
\hline 73 & jarrón & 0.01611 & $0.246 \%$ & $3.672 \%$ & $87.847 \%$ \\
\hline 74 & copa de champán & 0.01577 & $0.190 \%$ & $2.825 \%$ & $88.037 \%$ \\
\hline 75 & trapo & 0.01574 & $0.208 \%$ & $3.107 \%$ & $88.245 \%$ \\
\hline 76 & vinagre & 0.01549 & $0.152 \%$ & $2.260 \%$ & $88.397 \%$ \\
\hline 77 & puchero & 0.01543 & $0.208 \%$ & $3.107 \%$ & $88.605 \%$ \\
\hline 78 & tetera & 0.01542 & $0.265 \%$ & $3.955 \%$ & $88.870 \%$ \\
\hline 79 & cubitera & 0.01483 & $0.284 \%$ & $4.237 \%$ & $89.154 \%$ \\
\hline 80 & abridor & 0.01446 & $0.171 \%$ & $2.542 \%$ & $89.325 \%$ \\
\hline 81 & tapete & 0.01374 & $0.171 \%$ & $2.542 \%$ & $89.496 \%$ \\
\hline 82 & servilleta de papel & 0.01355 & $0.171 \%$ & $2.542 \%$ & $89.667 \%$ \\
\hline 83 & plato de sopa & 0.01345 & $0.152 \%$ & $2.260 \%$ & $89.819 \%$ \\
\hline 84 & vino & 0.01299 & $0.133 \%$ & $1.977 \%$ & $89.952 \%$ \\
\hline 85 & plato pequeño & 0.01286 & $0.152 \%$ & $2.260 \%$ & $90.104 \%$ \\
\hline 86 & bote & 0.01263 & $0.208 \%$ & $3.107 \%$ & $90.312 \%$ \\
\hline 87 & cubremantel & 0.01221 & $0.152 \%$ & $2.260 \%$ & $90.464 \%$ \\
\hline 88 & fiambrera & 0.01215 & $0.171 \%$ & $2.542 \%$ & $90.635 \%$ \\
\hline 89 & copa de agua & 0.01205 & $0.152 \%$ & $2.260 \%$ & $90.787 \%$ \\
\hline 90 & paellera & 0.01188 & $0.208 \%$ & $3.107 \%$ & $90.995 \%$ \\
\hline 91 & plato sopero & 0.01181 & $0.114 \%$ & $1.695 \%$ & $91.109 \%$ \\
\hline 92 & cacerola & 0.01059 & $0.171 \%$ & $2.542 \%$ & $91.280 \%$ \\
\hline 93 & cuchara de sopa & 0.01028 & $0.114 \%$ & $1.695 \%$ & $91.394 \%$ \\
\hline 94 & paleta & 0.01010 & $0.133 \%$ & $1.977 \%$ & $91.527 \%$ \\
\hline 95 & ensalada & 0.00971 & $0.114 \%$ & $1.695 \%$ & $91.641 \%$ \\
\hline 96 & botijo & 0.00932 & $0.133 \%$ & $1.977 \%$ & $91.774 \%$ \\
\hline 97 & cuchara pequeña & 0.00930 & $0.095 \%$ & $1.412 \%$ & $91.869 \%$ \\
\hline 98 & paella & 0.00875 & $0.171 \%$ & $2.542 \%$ & $92.040 \%$ \\
\hline 99 & pimentero & 0.00860 & $0.190 \%$ & $2.825 \%$ & $92.230 \%$ \\
\hline 100 & copa de licor & 0.00858 & $0.095 \%$ & $1.412 \%$ & $92.325 \%$ \\
\hline 101 & bandeja de pan & 0.00851 & $0.133 \%$ & $1.977 \%$ & $92.458 \%$ \\
\hline 102 & cuchillo de pan & 0.00844 & $0.095 \%$ & $1.412 \%$ & $92.553 \%$ \\
\hline 103 & tenedor pequeño & 0.00842 & $0.114 \%$ & $1.695 \%$ & $92.667 \%$ \\
\hline 104 & comida & 0.00793 & $0.095 \%$ & $1.412 \%$ & $92.762 \%$ \\
\hline 105 & Coca cola* & 0.00785 & $0.076 \%$ & $1.130 \%$ & $92.838 \%$ \\
\hline 106 & mayonesa & 0.00784 & $0.114 \%$ & $1.695 \%$ & $92.952 \%$ \\
\hline 107 & cesta & 0.00771 & $0.114 \%$ & $1.695 \%$ & $93.066 \%$ \\
\hline 108 & pajita & 0.00761 & $0.095 \%$ & $1.412 \%$ & $93.161 \%$ \\
\hline 109 & cucharilla de postre & 0.00724 & $0.095 \%$ & $1.412 \%$ & $93.256 \%$ \\
\hline 110 & servilleta de tela & 0.00722 & $0.076 \%$ & $1.130 \%$ & $93.332 \%$ \\
\hline 111 & taza de café & 0.00706 & $0.133 \%$ & $1.977 \%$ & $93.465 \%$ \\
\hline 112 & pitxer & 0.00701 & $0.076 \%$ & $1.130 \%$ & $93.541 \%$ \\
\hline 113 & plástico & 0.00689 & $0.076 \%$ & $1.130 \%$ & $93.617 \%$ \\
\hline 114 & mando de tele(visión) & 0.00686 & $0.095 \%$ & $1.412 \%$ & $93.712 \%$ \\
\hline 115 & destapador & 0.00684 & $0.095 \%$ & $1.412 \%$ & $93.807 \%$ \\
\hline
\end{tabular}




\begin{tabular}{|c|c|c|c|c|c|}
\hline 116 & vaso de cava & 0.00678 & $0.076 \%$ & $1.130 \%$ & $93.883 \%$ \\
\hline 117 & cuchara de café & 0.00644 & $0.095 \%$ & $1.412 \%$ & $93.978 \%$ \\
\hline 118 & cirio & 0.00630 & $0.076 \%$ & $1.130 \%$ & $94.054 \%$ \\
\hline 119 & cucharita de postre & 0.00630 & $0.076 \%$ & $1.130 \%$ & $94.130 \%$ \\
\hline 120 & salsa & 0.00627 & $0.057 \%$ & $0.847 \%$ & $94.187 \%$ \\
\hline 121 & hule & 0.00614 & $0.114 \%$ & $1.695 \%$ & $94.301 \%$ \\
\hline 122 & azúcar & 0.00609 & $0.076 \%$ & $1.130 \%$ & $94.377 \%$ \\
\hline 123 & botella de Coca cola* & 0.00593 & $0.095 \%$ & $1.412 \%$ & $94.472 \%$ \\
\hline 124 & cesto de pan & 0.00593 & $0.076 \%$ & $1.130 \%$ & $94.548 \%$ \\
\hline 125 & copa de cava & 0.00589 & $0.076 \%$ & $1.130 \%$ & $94.624 \%$ \\
\hline 126 & vaso de champán & 0.00562 & $0.076 \%$ & $1.130 \%$ & $94.700 \%$ \\
\hline 127 & aliñador & 0.00540 & $0.076 \%$ & $1.130 \%$ & $94.776 \%$ \\
\hline 128 & jarrón de agua & 0.00526 & $0.057 \%$ & $0.847 \%$ & $94.833 \%$ \\
\hline 129 & cucharilla de café & 0.00524 & $0.057 \%$ & $0.847 \%$ & $94.890 \%$ \\
\hline 130 & recipiente del agua & 0.00515 & $0.057 \%$ & $0.847 \%$ & $94.947 \%$ \\
\hline 131 & recipiente & 0.00497 & $0.076 \%$ & $1.130 \%$ & $95.023 \%$ \\
\hline 132 & centro de mesa & 0.00492 & $0.095 \%$ & $1.412 \%$ & $95.118 \%$ \\
\hline 133 & cuchara de servir & 0.00486 & $0.076 \%$ & $1.130 \%$ & $95.194 \%$ \\
\hline 134 & botella de gaseosa & 0.00483 & $0.076 \%$ & $1.130 \%$ & $95.270 \%$ \\
\hline 135 & lata & 0.00483 & $0.057 \%$ & $0.847 \%$ & $95.327 \%$ \\
\hline 136 & cubierto de postre & 0.00457 & $0.057 \%$ & $0.847 \%$ & $95.384 \%$ \\
\hline 137 & mesa & 0.00434 & $0.038 \%$ & $0.565 \%$ & $95.422 \%$ \\
\hline 138 & cubertería & 0.00433 & $0.057 \%$ & $0.847 \%$ & $95.479 \%$ \\
\hline 139 & botella de cola & 0.00424 & $0.038 \%$ & $0.565 \%$ & $95.517 \%$ \\
\hline 140 & platillo & 0.00417 & $0.057 \%$ & $0.847 \%$ & $95.574 \%$ \\
\hline 141 & tenazas & 0.00402 & $0.057 \%$ & $0.847 \%$ & $95.631 \%$ \\
\hline 142 & pimienta & 0.00397 & $0.057 \%$ & $0.847 \%$ & $95.688 \%$ \\
\hline 143 & ketchup & 0.00395 & $0.038 \%$ & $0.565 \%$ & $95.726 \%$ \\
\hline 144 & cuchara grande & 0.00395 & $0.038 \%$ & $0.565 \%$ & $95.764 \%$ \\
\hline 145 & gaseosa & 0.00383 & $0.057 \%$ & $0.847 \%$ & $95.821 \%$ \\
\hline 146 & cerveza & 0.00363 & $0.057 \%$ & $0.847 \%$ & $95.878 \%$ \\
\hline 147 & huevera & 0.00356 & $0.057 \%$ & $0.847 \%$ & $95.935 \%$ \\
\hline 148 & primer plato & 0.00356 & $0.038 \%$ & $0.565 \%$ & $95.973 \%$ \\
\hline 149 & abrebotellas & 0.00343 & $0.057 \%$ & $0.847 \%$ & $96.030 \%$ \\
\hline 150 & cuchillo pequeño & 0.00340 & $0.038 \%$ & $0.565 \%$ & $96.068 \%$ \\
\hline 151 & bebida & 0.00331 & $0.038 \%$ & $0.565 \%$ & $96.106 \%$ \\
\hline 152 & segundo plato & 0.00331 & $0.038 \%$ & $0.565 \%$ & $96.144 \%$ \\
\hline 153 & especias & 0.00321 & $0.038 \%$ & $0.565 \%$ & $96.182 \%$ \\
\hline 154 & cuchillo de postre & 0.00318 & $0.038 \%$ & $0.565 \%$ & $96.220 \%$ \\
\hline 155 & tarrina & 0.00307 & $0.038 \%$ & $0.565 \%$ & $96.258 \%$ \\
\hline 156 & papel & 0.00300 & $0.038 \%$ & $0.565 \%$ & $96.296 \%$ \\
\hline 157 & tenedor de ensalada & 0.00298 & $0.057 \%$ & $0.847 \%$ & $96.353 \%$ \\
\hline 158 & quesera & 0.00297 & $0.038 \%$ & $0.565 \%$ & $96.391 \%$ \\
\hline 159 & taza de té & 0.00290 & $0.038 \%$ & $0.565 \%$ & $96.429 \%$ \\
\hline 160 & plato normal & 0.00287 & $0.038 \%$ & $0.565 \%$ & $96.467 \%$ \\
\hline 161 & canastilla de pan & 0.00282 & $0.057 \%$ & $0.847 \%$ & $96.524 \%$ \\
\hline 162 & plato de pan & 0.00282 & $0.019 \%$ & $0.282 \%$ & $96.543 \%$ \\
\hline
\end{tabular}




\begin{tabular}{|c|c|c|c|c|c|}
\hline 163 & rallador & 0.00281 & $0.057 \%$ & $0.847 \%$ & $96.600 \%$ \\
\hline 164 & cubierto de servir & 0.00278 & $0.038 \%$ & $0.565 \%$ & $96.638 \%$ \\
\hline 165 & jamonero & 0.00271 & $0.057 \%$ & $0.847 \%$ & $96.695 \%$ \\
\hline 166 & paño & 0.00270 & $0.038 \%$ & $0.565 \%$ & $96.733 \%$ \\
\hline 167 & cuchillo de cortar pan & 0.00267 & $0.038 \%$ & $0.565 \%$ & $96.771 \%$ \\
\hline 168 & canastillo de pan & 0.00267 & $0.038 \%$ & $0.565 \%$ & $96.809 \%$ \\
\hline 169 & tapadera & 0.00265 & $0.057 \%$ & $0.847 \%$ & $96.866 \%$ \\
\hline 170 & bota & 0.00264 & $0.057 \%$ & $0.847 \%$ & $96.923 \%$ \\
\hline 171 & tubo & 0.00263 & $0.019 \%$ & $0.282 \%$ & $96.942 \%$ \\
\hline 172 & maceta & 0.00263 & $0.019 \%$ & $0.282 \%$ & $96.961 \%$ \\
\hline 173 & entremés & 0.00263 & $0.019 \%$ & $0.282 \%$ & $96.980 \%$ \\
\hline 174 & copa de vino blanco & 0.00263 & $0.019 \%$ & $0.282 \%$ & $96.999 \%$ \\
\hline 175 & abridor de latas & 0.00256 & $0.038 \%$ & $0.565 \%$ & $97.037 \%$ \\
\hline 176 & copa de vino tinto & 0.00245 & $0.019 \%$ & $0.282 \%$ & $97.056 \%$ \\
\hline 177 & plato de café & 0.00240 & $0.057 \%$ & $0.847 \%$ & $97.113 \%$ \\
\hline 178 & tabla & 0.00231 & $0.038 \%$ & $0.565 \%$ & $97.151 \%$ \\
\hline 179 & cuchara de madera & 0.00228 & $0.019 \%$ & $0.282 \%$ & $97.170 \%$ \\
\hline 180 & recipiente de ensalada & 0.00222 & $0.038 \%$ & $0.565 \%$ & $97.208 \%$ \\
\hline 181 & cuchillo jamonero & 0.00215 & $0.038 \%$ & $0.565 \%$ & $97.246 \%$ \\
\hline 182 & cazuela de comida & 0.00212 & $0.019 \%$ & $0.282 \%$ & $97.265 \%$ \\
\hline 183 & got & 0.00212 & $0.019 \%$ & $0.282 \%$ & $97.284 \%$ \\
\hline 184 & jarro & 0.00209 & $0.038 \%$ & $0.565 \%$ & $97.322 \%$ \\
\hline 185 & fruta & 0.00207 & $0.038 \%$ & $0.565 \%$ & $97.360 \%$ \\
\hline 186 & pinza de hielo & 0.00198 & $0.038 \%$ & $0.565 \%$ & $97.398 \%$ \\
\hline 187 & salsa rosa & 0.00197 & $0.019 \%$ & $0.282 \%$ & $97.417 \%$ \\
\hline 188 & mostaza & 0.00197 & $0.019 \%$ & $0.282 \%$ & $97.436 \%$ \\
\hline 189 & botella de limón & 0.00197 & $0.019 \%$ & $0.282 \%$ & $97.455 \%$ \\
\hline 190 & cuchara de palo & 0.00197 & $0.019 \%$ & $0.282 \%$ & $97.474 \%$ \\
\hline 191 & plato grande & 0.00197 & $0.019 \%$ & $0.282 \%$ & $97.493 \%$ \\
\hline 192 & recipiente del pan & 0.00197 & $0.019 \%$ & $0.282 \%$ & $97.512 \%$ \\
\hline 193 & cuchillo de fruta & 0.00184 & $0.019 \%$ & $0.282 \%$ & $97.531 \%$ \\
\hline 194 & plato primero & 0.00184 & $0.019 \%$ & $0.282 \%$ & $97.550 \%$ \\
\hline 195 & botella de naranja & 0.00184 & $0.019 \%$ & $0.282 \%$ & $97.569 \%$ \\
\hline 196 & botella de vidrio & 0.00184 & $0.019 \%$ & $0.282 \%$ & $97.588 \%$ \\
\hline 197 & cuchara normal & 0.00184 & $0.019 \%$ & $0.282 \%$ & $97.607 \%$ \\
\hline 198 & bandeja de embutidos & 0.00184 & $0.019 \%$ & $0.282 \%$ & $97.626 \%$ \\
\hline 199 & recipiente de comida & 0.00184 & $0.019 \%$ & $0.282 \%$ & $97.645 \%$ \\
\hline 200 & vaso de flan & 0.00179 & $0.038 \%$ & $0.565 \%$ & $97.683 \%$ \\
\hline 201 & cascanueces & 0.00175 & $0.038 \%$ & $0.565 \%$ & $97.721 \%$ \\
\hline 202 & cuchillo grande & 0.00171 & $0.019 \%$ & $0.282 \%$ & $97.740 \%$ \\
\hline 203 & plato segundo & 0.00171 & $0.019 \%$ & $0.282 \%$ & $97.759 \%$ \\
\hline 204 & madera para cortar el pan & 0.00171 & $0.019 \%$ & $0.282 \%$ & $97.778 \%$ \\
\hline 205 & palillo chino & 0.00171 & $0.019 \%$ & $0.282 \%$ & $97.797 \%$ \\
\hline 206 & setrill d'oli & 0.00171 & $0.019 \%$ & $0.282 \%$ & $97.816 \%$ \\
\hline 207 & pala & 0.00171 & $0.019 \%$ & $0.282 \%$ & $97.835 \%$ \\
\hline 208 & lechera & 0.00167 & $0.038 \%$ & $0.565 \%$ & $97.873 \%$ \\
\hline 209 & tostada & 0.00159 & $0.019 \%$ & $0.282 \%$ & $97.892 \%$ \\
\hline
\end{tabular}




\begin{tabular}{|c|c|c|c|c|c|}
\hline 210 & tenedor grande & 0.00159 & $0.019 \%$ & $0.282 \%$ & $97.911 \%$ \\
\hline 211 & jarra de bebida & 0.00159 & $0.019 \%$ & $0.282 \%$ & $97.930 \%$ \\
\hline 212 & cucharilla de helado & 0.00159 & $0.019 \%$ & $0.282 \%$ & $97.949 \%$ \\
\hline 213 & tazón de leche & 0.00159 & $0.019 \%$ & $0.282 \%$ & $97.968 \%$ \\
\hline 214 & servilleta de ropa & 0.00159 & $0.019 \%$ & $0.282 \%$ & $97.987 \%$ \\
\hline 215 & cassoleta & 0.00159 & $0.019 \%$ & $0.282 \%$ & $98.006 \%$ \\
\hline 216 & plato de entrantes & 0.00159 & $0.019 \%$ & $0.282 \%$ & $98.025 \%$ \\
\hline 217 & fuente de ensalada & 0.00159 & $0.019 \%$ & $0.282 \%$ & $98.044 \%$ \\
\hline 218 & cucharita de café & 0.00159 & $0.019 \%$ & $0.282 \%$ & $98.063 \%$ \\
\hline 219 & plato de entremés & 0.00155 & $0.038 \%$ & $0.565 \%$ & $98.101 \%$ \\
\hline 220 & mantel individual & 0.00155 & $0.038 \%$ & $0.565 \%$ & $98.139 \%$ \\
\hline 221 & hacha & 0.00148 & $0.019 \%$ & $0.282 \%$ & $98.158 \%$ \\
\hline 222 & sifón & 0.00148 & $0.019 \%$ & $0.282 \%$ & $98.177 \%$ \\
\hline 223 & lata de Coca cola* & 0.00148 & $0.019 \%$ & $0.282 \%$ & $98.196 \%$ \\
\hline 224 & bayeta & 0.00148 & $0.019 \%$ & $0.282 \%$ & $98.215 \%$ \\
\hline 225 & plato liso & 0.00148 & $0.019 \%$ & $0.282 \%$ & $98.234 \%$ \\
\hline 226 & tapa & 0.00148 & $0.019 \%$ & $0.282 \%$ & $98.253 \%$ \\
\hline 227 & yogurtera & 0.00148 & $0.019 \%$ & $0.282 \%$ & $98.272 \%$ \\
\hline 228 & portarrollos & 0.00148 & $0.019 \%$ & $0.282 \%$ & $98.291 \%$ \\
\hline 229 & parrilla & 0.00139 & $0.038 \%$ & $0.565 \%$ & $98.329 \%$ \\
\hline 230 & botella de vino & 0.00138 & $0.019 \%$ & $0.282 \%$ & $98.348 \%$ \\
\hline 231 & adorno & 0.00138 & $0.019 \%$ & $0.282 \%$ & $98.367 \%$ \\
\hline 232 & cuchillo del jamón & 0.00138 & $0.019 \%$ & $0.282 \%$ & $98.386 \%$ \\
\hline 233 & sierra & 0.00138 & $0.019 \%$ & $0.282 \%$ & $98.405 \%$ \\
\hline 234 & descorchador & 0.00138 & $0.019 \%$ & $0.282 \%$ & $98.424 \%$ \\
\hline 235 & carta del menú & 0.00138 & $0.019 \%$ & $0.282 \%$ & $98.443 \%$ \\
\hline 236 & plato de desayuno & 0.00138 & $0.019 \%$ & $0.282 \%$ & $98.462 \%$ \\
\hline 237 & vela con fuego & 0.00138 & $0.019 \%$ & $0.282 \%$ & $98.481 \%$ \\
\hline 238 & botella de cerveza & 0.00138 & $0.019 \%$ & $0.282 \%$ & $98.500 \%$ \\
\hline 239 & centro & 0.00132 & $0.038 \%$ & $0.565 \%$ & $98.538 \%$ \\
\hline 240 & centro de flores & 0.00128 & $0.019 \%$ & $0.282 \%$ & $98.557 \%$ \\
\hline 241 & garrafa de agua & 0.00128 & $0.019 \%$ & $0.282 \%$ & $98.576 \%$ \\
\hline 242 & carne & 0.00128 & $0.019 \%$ & $0.282 \%$ & $98.595 \%$ \\
\hline 243 & pimiento & 0.00128 & $0.019 \%$ & $0.282 \%$ & $98.614 \%$ \\
\hline 244 & vaso de alcohol & 0.00128 & $0.019 \%$ & $0.282 \%$ & $98.633 \%$ \\
\hline 245 & plato de carne & 0.00128 & $0.019 \%$ & $0.282 \%$ & $98.652 \%$ \\
\hline 246 & plato de comida & 0.00128 & $0.019 \%$ & $0.282 \%$ & $98.671 \%$ \\
\hline 247 & Tetra brik* de vino & 0.00128 & $0.019 \%$ & $0.282 \%$ & $98.690 \%$ \\
\hline 248 & barril & 0.00128 & $0.019 \%$ & $0.282 \%$ & $98.709 \%$ \\
\hline 249 & copa de coñac & 0.00128 & $0.019 \%$ & $0.282 \%$ & $98.728 \%$ \\
\hline 250 & sopa & 0.00128 & $0.019 \%$ & $0.282 \%$ & $98.747 \%$ \\
\hline 251 & fuente de comida & 0.00128 & $0.019 \%$ & $0.282 \%$ & $98.766 \%$ \\
\hline 252 & hielo & 0.00119 & $0.019 \%$ & $0.282 \%$ & $98.785 \%$ \\
\hline 253 & vajilla & 0.00119 & $0.019 \%$ & $0.282 \%$ & $98.804 \%$ \\
\hline 254 & tabla de embutido & 0.00119 & $0.019 \%$ & $0.282 \%$ & $98.823 \%$ \\
\hline 255 & candil & 0.00119 & $0.019 \%$ & $0.282 \%$ & $98.842 \%$ \\
\hline 256 & toalla & 0.00119 & $0.019 \%$ & $0.282 \%$ & $98.861 \%$ \\
\hline
\end{tabular}




\begin{tabular}{|c|c|c|c|c|c|}
\hline 257 & plato de pescado & 0.00119 & $0.019 \%$ & $0.282 \%$ & $98.880 \%$ \\
\hline 258 & bote de pimienta & 0.00119 & $0.019 \%$ & $0.282 \%$ & $98.899 \%$ \\
\hline 259 & cesto de fruta & 0.00119 & $0.019 \%$ & $0.282 \%$ & $98.918 \%$ \\
\hline 260 & lata de refrescos & 0.00119 & $0.019 \%$ & $0.282 \%$ & $98.937 \%$ \\
\hline 261 & fiambre & 0.00111 & $0.019 \%$ & $0.282 \%$ & $98.956 \%$ \\
\hline 262 & cristalería & 0.00111 & $0.019 \%$ & $0.282 \%$ & $98.975 \%$ \\
\hline 263 & sujetamanteles & 0.00111 & $0.019 \%$ & $0.282 \%$ & $98.994 \%$ \\
\hline 264 & cuchillo de embutido & 0.00111 & $0.019 \%$ & $0.282 \%$ & $99.013 \%$ \\
\hline 265 & verdulero & 0.00111 & $0.019 \%$ & $0.282 \%$ & $99.032 \%$ \\
\hline 266 & trinchador & 0.00111 & $0.019 \%$ & $0.282 \%$ & $99.051 \%$ \\
\hline 267 & barral & 0.00111 & $0.019 \%$ & $0.282 \%$ & $99.070 \%$ \\
\hline 268 & mortero con allioli & 0.00111 & $0.019 \%$ & $0.282 \%$ & $99.089 \%$ \\
\hline 269 & espátula & 0.00111 & $0.019 \%$ & $0.282 \%$ & $99.108 \%$ \\
\hline 270 & búcaro con flores & 0.00111 & $0.019 \%$ & $0.282 \%$ & $99.127 \%$ \\
\hline 271 & bote de aceite & 0.00111 & $0.019 \%$ & $0.282 \%$ & $99.146 \%$ \\
\hline 272 & madera para cortar carne & 0.00111 & $0.019 \%$ & $0.282 \%$ & $99.165 \%$ \\
\hline 273 & trinchador de carne & 0.00111 & $0.019 \%$ & $0.282 \%$ & $99.184 \%$ \\
\hline 274 & madera & 0.00103 & $0.019 \%$ & $0.282 \%$ & $99.203 \%$ \\
\hline 275 & tazón de caldo & 0.00103 & $0.019 \%$ & $0.282 \%$ & $99.222 \%$ \\
\hline 276 & tenedor de servir & 0.00103 & $0.019 \%$ & $0.282 \%$ & $99.241 \%$ \\
\hline 277 & bandeja de comida & 0.00103 & $0.019 \%$ & $0.282 \%$ & $99.260 \%$ \\
\hline 278 & tapón & 0.00103 & $0.019 \%$ & $0.282 \%$ & $99.279 \%$ \\
\hline 279 & tinaja & 0.00103 & $0.019 \%$ & $0.282 \%$ & $99.298 \%$ \\
\hline 280 & papel de cocina & 0.00103 & $0.019 \%$ & $0.282 \%$ & $99.317 \%$ \\
\hline 281 & botellero & 0.00103 & $0.019 \%$ & $0.282 \%$ & $99.336 \%$ \\
\hline 282 & encendedor & 0.00103 & $0.019 \%$ & $0.282 \%$ & $99.355 \%$ \\
\hline 283 & tostadora & 0.00103 & $0.019 \%$ & $0.282 \%$ & $99.374 \%$ \\
\hline 284 & fuente de carne & 0.00103 & $0.019 \%$ & $0.282 \%$ & $99.393 \%$ \\
\hline 285 & mando del vídeo & 0.00096 & $0.019 \%$ & $0.282 \%$ & $99.412 \%$ \\
\hline 286 & planto hondo & 0.00096 & $0.019 \%$ & $0.282 \%$ & $99.431 \%$ \\
\hline 287 & plato de picoteo & 0.00096 & $0.019 \%$ & $0.282 \%$ & $99.450 \%$ \\
\hline 288 & madera para cortar & 0.00096 & $0.019 \%$ & $0.282 \%$ & $99.469 \%$ \\
\hline 289 & jarra de vino & 0.00096 & $0.019 \%$ & $0.282 \%$ & $99.488 \%$ \\
\hline 290 & vaso de café & 0.00096 & $0.019 \%$ & $0.282 \%$ & $99.507 \%$ \\
\hline 291 & botella de refresco & 0.00096 & $0.019 \%$ & $0.282 \%$ & $99.526 \%$ \\
\hline 292 & sazonador & 0.00089 & $0.019 \%$ & $0.282 \%$ & $99.545 \%$ \\
\hline 293 & zarzuela & 0.00089 & $0.019 \%$ & $0.282 \%$ & $99.564 \%$ \\
\hline 294 & mando a distancia & 0.00089 & $0.019 \%$ & $0.282 \%$ & $99.583 \%$ \\
\hline 295 & mantequilla & 0.00089 & $0.019 \%$ & $0.282 \%$ & $99.602 \%$ \\
\hline 296 & canasta del pan & 0.00083 & $0.019 \%$ & $0.282 \%$ & $99.621 \%$ \\
\hline 297 & Tetra brik* & 0.00083 & $0.019 \%$ & $0.282 \%$ & $99.640 \%$ \\
\hline 298 & menú & 0.00083 & $0.019 \%$ & $0.282 \%$ & $99.659 \%$ \\
\hline 299 & periódico & 0.00083 & $0.019 \%$ & $0.282 \%$ & $99.678 \%$ \\
\hline 300 & galleta & 0.00083 & $0.019 \%$ & $0.282 \%$ & $99.697 \%$ \\
\hline 301 & tijeras & 0.00083 & $0.019 \%$ & $0.282 \%$ & $99.716 \%$ \\
\hline 302 & cuchillo eléctrico & 0.00077 & $0.019 \%$ & $0.282 \%$ & $99.735 \%$ \\
\hline 303 & cuchara de helado & 0.00077 & $0.019 \%$ & $0.282 \%$ & $99.754 \%$ \\
\hline
\end{tabular}




\begin{tabular}{|l|l|l|l|l|l|}
\hline 304 & especiera & 0.00077 & $0.019 \%$ & $0.282 \%$ & $99.773 \%$ \\
\hline 305 & plato de plástico & 0.00077 & $0.019 \%$ & $0.282 \%$ & $99.792 \%$ \\
\hline 306 & cortador de tartas & 0.00077 & $0.019 \%$ & $0.282 \%$ & $99.811 \%$ \\
\hline 307 & esterilla & 0.00072 & $0.019 \%$ & $0.282 \%$ & $99.830 \%$ \\
\hline 308 & molde de flan & 0.00072 & $0.019 \%$ & $0.282 \%$ & $99.849 \%$ \\
\hline 309 & pinchito & 0.00067 & $0.019 \%$ & $0.282 \%$ & $99.868 \%$ \\
\hline 310 & tartera & 0.00062 & $0.019 \%$ & $0.282 \%$ & $99.887 \%$ \\
\hline 311 & recogemigas & 0.00062 & $0.019 \%$ & $0.282 \%$ & $99.906 \%$ \\
\hline 312 & flanera & 0.00054 & $0.019 \%$ & $0.282 \%$ & $99.925 \%$ \\
\hline 313 & radio & 0.00054 & $0.019 \%$ & $0.282 \%$ & $99.944 \%$ \\
\hline 314 & posacubiertos & 0.00047 & $0.019 \%$ & $0.282 \%$ & $99.963 \%$ \\
\hline 315 & mantelería & 0.00044 & $0.019 \%$ & $0.282 \%$ & $99.982 \%$ \\
\hline 316 & petaca & 0.00035 & $0.019 \%$ & $0.282 \%$ & $100.001 \%$ \\
\hline 317 & cortador de pan & 0.00035 & $0.019 \%$ & $0.282 \%$ & $100.020 \%$ \\
\hline
\end{tabular}

07. LA COCINA Y SUS UTENSILIOS

\begin{tabular}{|c|l|c||c|c|c|}
\hline $\mathrm{N}^{\mathbf{0}}$ & Palabra & Disponibilidad & $\begin{array}{c}\text { Frecuencia } \\
\text { relativa }\end{array}$ & $\%$ Aparición & $\begin{array}{c}\text { Frecuencia } \\
\text { acumulada }\end{array}$ \\
\hline 1 & (horno) microondas & 0.49741 & $3.961 \%$ & $74.011 \%$ & $3.961 \%$ \\
\hline 2 & horno & 0.49177 & $4.051 \%$ & $75.706 \%$ & $8.012 \%$ \\
\hline 3 & sartén & 0.45867 & $3.537 \%$ & $66.102 \%$ & $11.549 \%$ \\
\hline 4 & nevera & 0.41939 & $3.235 \%$ & $60.452 \%$ & $14.784 \%$ \\
\hline 5 & cuchillo & 0.41407 & $3.235 \%$ & $60.452 \%$ & $18.019 \%$ \\
\hline 6 & tenedor & 0.34193 & $2.706 \%$ & $50.565 \%$ & $20.725 \%$ \\
\hline 7 & cuchara & 0.31826 & $2.464 \%$ & $46.045 \%$ & $23.189 \%$ \\
\hline 8 & olla & 0.28634 & $2.419 \%$ & $45.198 \%$ & $25.608 \%$ \\
\hline 9 & lavavajillas & 0.24641 & $2.041 \%$ & $38.136 \%$ & $27.649 \%$ \\
\hline 10 & cazuela & 0.21500 & $1.784 \%$ & $33.333 \%$ & $29.433 \%$ \\
\hline 11 & plato & 0.19411 & $1.875 \%$ & $35.028 \%$ & $31.308 \%$ \\
\hline 12 & batidora & 0.17437 & $1.602 \%$ & $29.944 \%$ & $32.910 \%$ \\
\hline 13 & vaso & 0.16905 & $1.663 \%$ & $31.073 \%$ & $34.573 \%$ \\
\hline 14 & armario & 0.16836 & $1.557 \%$ & $29.096 \%$ & $36.130 \%$ \\
\hline 15 & paella & 0.16117 & $1.376 \%$ & $25.706 \%$ & $37.506 \%$ \\
\hline 16 & mesa & 0.15958 & $1.481 \%$ & $27.684 \%$ & $38.987 \%$ \\
\hline 17 & cazo & 0.15320 & $1.255 \%$ & $23.446 \%$ & $40.242 \%$ \\
\hline 18 & cucharón & 0.14813 & $1.361 \%$ & $25.424 \%$ & $41.603 \%$ \\
\hline 19 & fregadero & 0.14462 & $1.224 \%$ & $22.881 \%$ & $42.827 \%$ \\
\hline 20 & freidora & 0.13160 & $1.345 \%$ & $25.141 \%$ & $44.172 \%$ \\
\hline 21 & cocina & 0.12833 & $1.043 \%$ & $19.492 \%$ & $45.215 \%$ \\
\hline 22 & fogón & 0.12662 & $1.028 \%$ & $19.209 \%$ & $46.243 \%$ \\
\hline 23 & congelador & 0.12439 & $1.255 \%$ & $23.446 \%$ & $47.498 \%$ \\
\hline 24 & encimera & 0.12329 & $1.058 \%$ & $19.774 \%$ & $48.556 \%$ \\
\hline
\end{tabular}




\begin{tabular}{|c|c|c|c|c|c|}
\hline 25 & lavadora & 0.12176 & $1.058 \%$ & $19.774 \%$ & $49.614 \%$ \\
\hline 26 & lavaplatos & 0.10957 & $0.862 \%$ & $16.102 \%$ & $50.476 \%$ \\
\hline 27 & grifo & 0.10677 & $1.104 \%$ & $20.621 \%$ & $51.580 \%$ \\
\hline 28 & cafetera & 0.10518 & $1.088 \%$ & $20.339 \%$ & $52.668 \%$ \\
\hline 29 & exprimidor & 0.10184 & $1.028 \%$ & $19.209 \%$ & $53.696 \%$ \\
\hline 30 & cacerola & 0.10139 & $0.862 \%$ & $16.102 \%$ & $54.558 \%$ \\
\hline 31 & silla & 0.09273 & $0.907 \%$ & $16.949 \%$ & $55.465 \%$ \\
\hline 32 & frigorífico & 0.09195 & $0.771 \%$ & $14.407 \%$ & $56.236 \%$ \\
\hline 33 & sandwichera & 0.09151 & $1.013 \%$ & $18.927 \%$ & $57.249 \%$ \\
\hline 34 & paleta & 0.09084 & $0.831 \%$ & $15.537 \%$ & $58.080 \%$ \\
\hline 35 & despensa & 0.08009 & $0.816 \%$ & $15.254 \%$ & $58.896 \%$ \\
\hline 36 & extractor (de humo) & 0.07764 & $0.877 \%$ & $16.384 \%$ & $59.773 \%$ \\
\hline 37 & bandeja & 0.07482 & $0.831 \%$ & $15.537 \%$ & $60.604 \%$ \\
\hline 38 & salero & 0.06799 & $0.771 \%$ & $14.407 \%$ & $61.375 \%$ \\
\hline 39 & colador & 0.06696 & $0.786 \%$ & $14.689 \%$ & $62.161 \%$ \\
\hline 40 & trapo & 0.06600 & $0.892 \%$ & $16.667 \%$ & $63.053 \%$ \\
\hline 41 & vitrocerámica & 0.06097 & $0.529 \%$ & $9.887 \%$ & $63.582 \%$ \\
\hline 42 & paellero & 0.05868 & $0.590 \%$ & $11.017 \%$ & $64.172 \%$ \\
\hline 43 & pica & 0.05740 & $0.605 \%$ & $11.299 \%$ & $64.777 \%$ \\
\hline 44 & puchero & 0.05603 & $0.423 \%$ & $7.910 \%$ & $65.200 \%$ \\
\hline 45 & tostadora & 0.05437 & $0.605 \%$ & $11.299 \%$ & $65.805 \%$ \\
\hline 46 & licuadora & 0.05436 & $0.574 \%$ & $10.734 \%$ & $66.379 \%$ \\
\hline 47 & tijeras & 0.05288 & $0.559 \%$ & $10.452 \%$ & $66.938 \%$ \\
\hline 48 & mortero & 0.04639 & $0.559 \%$ & $10.452 \%$ & $67.497 \%$ \\
\hline 49 & servilleta & 0.04537 & $0.499 \%$ & $9.322 \%$ & $67.996 \%$ \\
\hline 50 & cubierto & 0.04469 & $0.423 \%$ & $7.910 \%$ & $68.419 \%$ \\
\hline 51 & olla exprés & 0.04454 & $0.378 \%$ & $7.062 \%$ & $68.797 \%$ \\
\hline 52 & pinza & 0.04378 & $0.544 \%$ & $10.169 \%$ & $69.341 \%$ \\
\hline 53 & cajón & 0.04191 & $0.469 \%$ & $8.757 \%$ & $69.810 \%$ \\
\hline 54 & escurridor & 0.03886 & $0.408 \%$ & $7.627 \%$ & $70.218 \%$ \\
\hline 55 & fuente & 0.03848 & $0.454 \%$ & $8.475 \%$ & $70.672 \%$ \\
\hline 56 & secadora & 0.03826 & $0.408 \%$ & $7.627 \%$ & $71.080 \%$ \\
\hline 57 & rallador & 0.03798 & $0.484 \%$ & $9.040 \%$ & $71.564 \%$ \\
\hline 58 & taza & 0.03737 & $0.469 \%$ & $8.757 \%$ & $72.033 \%$ \\
\hline 59 & estropajo & 0.03640 & $0.514 \%$ & $9.605 \%$ & $72.547 \%$ \\
\hline 60 & parrilla & 0.03616 & $0.333 \%$ & $6.215 \%$ & $72.880 \%$ \\
\hline 61 & abrelatas & 0.03534 & $0.408 \%$ & $7.627 \%$ & $73.288 \%$ \\
\hline 62 & picadora & 0.03478 & $0.363 \%$ & $6.780 \%$ & $73.651 \%$ \\
\hline 63 & trituradora & 0.03349 & $0.378 \%$ & $7.062 \%$ & $74.029 \%$ \\
\hline 64 & encendedor & 0.03287 & $0.378 \%$ & $7.062 \%$ & $74.407 \%$ \\
\hline 65 & delantal & 0.03163 & $0.363 \%$ & $6.780 \%$ & $74.770 \%$ \\
\hline 66 & azucarero & 0.03093 & $0.348 \%$ & $6.497 \%$ & $75.118 \%$ \\
\hline 67 & Minipimer* & 0.02950 & $0.287 \%$ & $5.367 \%$ & $75.405 \%$ \\
\hline 68 & mantel & 0.02947 & $0.302 \%$ & $5.650 \%$ & $75.707 \%$ \\
\hline 69 & copa & 0.02814 & $0.348 \%$ & $6.497 \%$ & $76.055 \%$ \\
\hline 70 & cuchara de madera & 0.02762 & $0.242 \%$ & $4.520 \%$ & $76.297 \%$ \\
\hline 71 & jarra & 0.02730 & $0.272 \%$ & $5.085 \%$ & $76.569 \%$ \\
\hline
\end{tabular}




\begin{tabular}{|c|c|c|c|c|c|}
\hline 72 & espumadera & 0.02675 & $0.227 \%$ & $4.237 \%$ & $76.796 \%$ \\
\hline 73 & fuego & 0.02621 & $0.227 \%$ & $4.237 \%$ & $77.023 \%$ \\
\hline 74 & jamonero & 0.02601 & $0.287 \%$ & $5.367 \%$ & $77.310 \%$ \\
\hline 75 & Turmix* & 0.02567 & $0.242 \%$ & $4.520 \%$ & $77.552 \%$ \\
\hline 76 & plancha & 0.02432 & $0.242 \%$ & $4.520 \%$ & $77.794 \%$ \\
\hline 77 & vajilla & 0.02389 & $0.197 \%$ & $3.672 \%$ & $77.991 \%$ \\
\hline 78 & pila & 0.02380 & $0.212 \%$ & $3.955 \%$ & $78.203 \%$ \\
\hline 79 & paño & 0.02312 & $0.302 \%$ & $5.650 \%$ & $78.505 \%$ \\
\hline 80 & bayeta & 0.02300 & $0.333 \%$ & $6.215 \%$ & $78.838 \%$ \\
\hline 81 & espátula & 0.02292 & $0.197 \%$ & $3.672 \%$ & $79.035 \%$ \\
\hline 82 & estantería & 0.02266 & $0.242 \%$ & $4.520 \%$ & $79.277 \%$ \\
\hline 83 & bol & 0.02256 & $0.242 \%$ & $4.520 \%$ & $79.519 \%$ \\
\hline 84 & mechero & 0.02241 & $0.333 \%$ & $6.215 \%$ & $79.852 \%$ \\
\hline 85 & frutero & 0.02135 & $0.302 \%$ & $5.650 \%$ & $80.154 \%$ \\
\hline 86 & reloj & 0.02115 & $0.272 \%$ & $5.085 \%$ & $80.426 \%$ \\
\hline 87 & banco & 0.02107 & $0.242 \%$ & $4.520 \%$ & $80.668 \%$ \\
\hline 88 & ensaladera & 0.02092 & $0.227 \%$ & $4.237 \%$ & $80.895 \%$ \\
\hline 89 & tazón & 0.02087 & $0.257 \%$ & $4.802 \%$ & $81.152 \%$ \\
\hline 90 & cerilla & 0.02034 & $0.272 \%$ & $5.085 \%$ & $81.424 \%$ \\
\hline 91 & hornillo & 0.02020 & $0.181 \%$ & $3.390 \%$ & $81.605 \%$ \\
\hline 92 & panera & 0.02004 & $0.272 \%$ & $5.085 \%$ & $81.877 \%$ \\
\hline 93 & tele(visión) & 0.01997 & $0.227 \%$ & $4.237 \%$ & $82.104 \%$ \\
\hline 94 & friegaplatos & 0.01979 & $0.197 \%$ & $3.672 \%$ & $82.301 \%$ \\
\hline 95 & cucharilla & 0.01882 & $0.181 \%$ & $3.390 \%$ & $82.482 \%$ \\
\hline 96 & robot (de cocina) & 0.01852 & $0.181 \%$ & $3.390 \%$ & $82.663 \%$ \\
\hline 97 & sopera & 0.01837 & $0.197 \%$ & $3.672 \%$ & $82.860 \%$ \\
\hline 98 & jabón & 0.01755 & $0.257 \%$ & $4.802 \%$ & $83.117 \%$ \\
\hline 99 & cuenco & 0.01752 & $0.212 \%$ & $3.955 \%$ & $83.329 \%$ \\
\hline 100 & esparto & 0.01732 & $0.212 \%$ & $3.955 \%$ & $83.541 \%$ \\
\hline 101 & manopla & 0.01711 & $0.227 \%$ & $4.237 \%$ & $83.768 \%$ \\
\hline 102 & gas & 0.01693 & $0.166 \%$ & $3.107 \%$ & $83.934 \%$ \\
\hline 103 & aceitera & 0.01688 & $0.227 \%$ & $4.237 \%$ & $84.161 \%$ \\
\hline 104 & cuchillo de carne & 0.01670 & $0.121 \%$ & $2.260 \%$ & $84.282 \%$ \\
\hline 105 & torradora & 0.01670 & $0.151 \%$ & $2.825 \%$ & $84.433 \%$ \\
\hline 106 & tetera & 0.01667 & $0.166 \%$ & $3.107 \%$ & $84.599 \%$ \\
\hline 107 & basura & 0.01563 & $0.181 \%$ & $3.390 \%$ & $84.780 \%$ \\
\hline 108 & cubo de basura & 0.01531 & $0.181 \%$ & $3.390 \%$ & $84.961 \%$ \\
\hline 109 & sacacorchos & 0.01496 & $0.197 \%$ & $3.672 \%$ & $85.158 \%$ \\
\hline 110 & puerta & 0.01479 & $0.136 \%$ & $2.542 \%$ & $85.294 \%$ \\
\hline 111 & botella de Butano* & 0.01430 & $0.151 \%$ & $2.825 \%$ & $85.445 \%$ \\
\hline 112 & botella & 0.01422 & $0.212 \%$ & $3.955 \%$ & $85.657 \%$ \\
\hline 113 & taburete & 0.01396 & $0.136 \%$ & $2.542 \%$ & $85.793 \%$ \\
\hline 114 & Butano* & 0.01383 & $0.106 \%$ & $1.977 \%$ & $85.899 \%$ \\
\hline 115 & escurreplatos & 0.01358 & $0.197 \%$ & $3.672 \%$ & $86.096 \%$ \\
\hline 116 & comida & 0.01346 & $0.181 \%$ & $3.390 \%$ & $86.277 \%$ \\
\hline 117 & campana (extractora) & 0.01328 & $0.166 \%$ & $3.107 \%$ & $86.443 \%$ \\
\hline 118 & grill & 0.01310 & $0.166 \%$ & $3.107 \%$ & $86.609 \%$ \\
\hline
\end{tabular}




\begin{tabular}{|c|c|c|c|c|c|}
\hline 119 & fiambrera & 0.01295 & $0.197 \%$ & $3.672 \%$ & $86.806 \%$ \\
\hline 120 & botella de gas & 0.01287 & $0.121 \%$ & $2.260 \%$ & $86.927 \%$ \\
\hline 121 & vinagrera & 0.01275 & $0.166 \%$ & $3.107 \%$ & $87.093 \%$ \\
\hline 122 & cuchillo jamonero & 0.01248 & $0.076 \%$ & $1.412 \%$ & $87.169 \%$ \\
\hline 123 & cubertería & 0.01156 & $0.106 \%$ & $1.977 \%$ & $87.275 \%$ \\
\hline 124 & servilletero & 0.01111 & $0.136 \%$ & $2.542 \%$ & $87.411 \%$ \\
\hline 125 & recipiente & 0.01070 & $0.151 \%$ & $2.825 \%$ & $87.562 \%$ \\
\hline 126 & ventana & 0.01066 & $0.121 \%$ & $2.260 \%$ & $87.683 \%$ \\
\hline 127 & basurero & 0.01005 & $0.166 \%$ & $3.107 \%$ & $87.849 \%$ \\
\hline 128 & escurridera & 0.00981 & $0.106 \%$ & $1.977 \%$ & $87.955 \%$ \\
\hline 129 & peso & 0.00965 & $0.121 \%$ & $2.260 \%$ & $88.076 \%$ \\
\hline 130 & guante & 0.00951 & $0.121 \%$ & $2.260 \%$ & $88.197 \%$ \\
\hline 131 & batería (de cocina) & 0.00950 & $0.076 \%$ & $1.412 \%$ & $88.273 \%$ \\
\hline 132 & abridor & 0.00949 & $0.121 \%$ & $2.260 \%$ & $88.394 \%$ \\
\hline 133 & detergente & 0.00907 & $0.151 \%$ & $2.825 \%$ & $88.545 \%$ \\
\hline 134 & cuchillo de pescado & 0.00898 & $0.076 \%$ & $1.412 \%$ & $88.621 \%$ \\
\hline 135 & fregona & 0.00896 & $0.121 \%$ & $2.260 \%$ & $88.742 \%$ \\
\hline 136 & plato hondo & 0.00893 & $0.091 \%$ & $1.695 \%$ & $88.833 \%$ \\
\hline 137 & pala & 0.00887 & $0.106 \%$ & $1.977 \%$ & $88.939 \%$ \\
\hline 138 & bombona de gas & 0.00870 & $0.121 \%$ & $2.260 \%$ & $89.060 \%$ \\
\hline 139 & televisor & 0.00848 & $0.076 \%$ & $1.412 \%$ & $89.136 \%$ \\
\hline 140 & especias & 0.00814 & $0.106 \%$ & $1.977 \%$ & $89.242 \%$ \\
\hline 141 & lámpara & 0.00813 & $0.106 \%$ & $1.977 \%$ & $89.348 \%$ \\
\hline 142 & hacha & 0.00811 & $0.076 \%$ & $1.412 \%$ & $89.424 \%$ \\
\hline 143 & plato llano & 0.00809 & $0.076 \%$ & $1.412 \%$ & $89.500 \%$ \\
\hline 144 & escoba & 0.00808 & $0.136 \%$ & $2.542 \%$ & $89.636 \%$ \\
\hline 145 & lavadero & 0.00779 & $0.076 \%$ & $1.412 \%$ & $89.712 \%$ \\
\hline 146 & tabla de madera & 0.00775 & $0.091 \%$ & $1.695 \%$ & $89.803 \%$ \\
\hline 147 & tragahumos & 0.00767 & $0.091 \%$ & $1.695 \%$ & $89.894 \%$ \\
\hline 148 & rodillo & 0.00766 & $0.091 \%$ & $1.695 \%$ & $89.985 \%$ \\
\hline 149 & cortina & 0.00765 & $0.106 \%$ & $1.977 \%$ & $90.091 \%$ \\
\hline 150 & embudo & 0.00764 & $0.106 \%$ & $1.977 \%$ & $90.197 \%$ \\
\hline 151 & mazo & 0.00760 & $0.091 \%$ & $1.695 \%$ & $90.288 \%$ \\
\hline 152 & madera & 0.00746 & $0.091 \%$ & $1.695 \%$ & $90.379 \%$ \\
\hline 153 & verdulero & 0.00741 & $0.091 \%$ & $1.695 \%$ & $90.470 \%$ \\
\hline 154 & bombona de Butano* & 0.00726 & $0.076 \%$ & $1.412 \%$ & $90.546 \%$ \\
\hline 155 & perol & 0.00718 & $0.060 \%$ & $1.130 \%$ & $90.606 \%$ \\
\hline 156 & calentador & 0.00697 & $0.091 \%$ & $1.695 \%$ & $90.697 \%$ \\
\hline 157 & rasera & 0.00691 & $0.121 \%$ & $2.260 \%$ & $90.818 \%$ \\
\hline 158 & tenedor de madera & 0.00673 & $0.076 \%$ & $1.412 \%$ & $90.894 \%$ \\
\hline 159 & salsera & 0.00663 & $0.091 \%$ & $1.695 \%$ & $90.985 \%$ \\
\hline 160 & cuchara sopera & 0.00648 & $0.060 \%$ & $1.130 \%$ & $91.045 \%$ \\
\hline 161 & trapo de cocina & 0.00645 & $0.076 \%$ & $1.412 \%$ & $91.121 \%$ \\
\hline 162 & cubo & 0.00642 & $0.106 \%$ & $1.977 \%$ & $91.227 \%$ \\
\hline 163 & asadora & 0.00632 & $0.060 \%$ & $1.130 \%$ & $91.287 \%$ \\
\hline 164 & cajón de cubiertos & 0.00629 & $0.045 \%$ & $0.847 \%$ & $91.332 \%$ \\
\hline 165 & tenazas & 0.00619 & $0.060 \%$ & $1.130 \%$ & $91.392 \%$ \\
\hline
\end{tabular}




\begin{tabular}{|c|c|c|c|c|c|}
\hline 166 & chimenea & 0.00617 & $0.060 \%$ & $1.130 \%$ & $91.452 \%$ \\
\hline 167 & cristalería & 0.00608 & $0.060 \%$ & $1.130 \%$ & $91.512 \%$ \\
\hline 168 & reloj de cocina & 0.00594 & $0.076 \%$ & $1.412 \%$ & $91.588 \%$ \\
\hline 169 & cazuela de barro & 0.00583 & $0.060 \%$ & $1.130 \%$ & $91.648 \%$ \\
\hline 170 & refrigerador & 0.00582 & $0.045 \%$ & $0.847 \%$ & $91.693 \%$ \\
\hline 171 & radio & 0.00581 & $0.045 \%$ & $0.847 \%$ & $91.738 \%$ \\
\hline 172 & yogurtera & 0.00580 & $0.060 \%$ & $1.130 \%$ & $91.798 \%$ \\
\hline 173 & asador & 0.00570 & $0.076 \%$ & $1.412 \%$ & $91.874 \%$ \\
\hline 174 & cuchara de palo & 0.00569 & $0.045 \%$ & $0.847 \%$ & $91.919 \%$ \\
\hline 175 & mesa de cocina & 0.00564 & $0.045 \%$ & $0.847 \%$ & $91.964 \%$ \\
\hline 176 & agua & 0.00562 & $0.076 \%$ & $1.412 \%$ & $92.040 \%$ \\
\hline 177 & lejía & 0.00551 & $0.106 \%$ & $1.977 \%$ & $92.146 \%$ \\
\hline 178 & bote & 0.00548 & $0.091 \%$ & $1.695 \%$ & $92.237 \%$ \\
\hline 179 & zumera & 0.00546 & $0.045 \%$ & $0.847 \%$ & $92.282 \%$ \\
\hline 180 & caldera & 0.00543 & $0.045 \%$ & $0.847 \%$ & $92.327 \%$ \\
\hline 181 & paño de cocina & 0.00538 & $0.076 \%$ & $1.412 \%$ & $92.403 \%$ \\
\hline 182 & salpicadero & 0.00536 & $0.045 \%$ & $0.847 \%$ & $92.448 \%$ \\
\hline 183 & tapadera & 0.00530 & $0.076 \%$ & $1.412 \%$ & $92.524 \%$ \\
\hline 184 & mármol & 0.00524 & $0.060 \%$ & $1.130 \%$ & $92.584 \%$ \\
\hline 185 & Mistol* & 0.00517 & $0.076 \%$ & $1.412 \%$ & $92.660 \%$ \\
\hline 186 & producto de limpieza & 0.00511 & $0.091 \%$ & $1.695 \%$ & $92.751 \%$ \\
\hline 187 & aspirador & 0.00508 & $0.045 \%$ & $0.847 \%$ & $92.796 \%$ \\
\hline 188 & pelapatatas & 0.00489 & $0.060 \%$ & $1.130 \%$ & $92.856 \%$ \\
\hline 189 & manga pastelera & 0.00488 & $0.076 \%$ & $1.412 \%$ & $92.932 \%$ \\
\hline 190 & pasapurés & 0.00486 & $0.045 \%$ & $0.847 \%$ & $92.977 \%$ \\
\hline 191 & estante & 0.00485 & $0.076 \%$ & $1.412 \%$ & $93.053 \%$ \\
\hline 192 & luz & 0.00481 & $0.060 \%$ & $1.130 \%$ & $93.113 \%$ \\
\hline 193 & cucharita & 0.00459 & $0.045 \%$ & $0.847 \%$ & $93.158 \%$ \\
\hline 194 & mueble & 0.00454 & $0.045 \%$ & $0.847 \%$ & $93.203 \%$ \\
\hline 195 & ventilador & 0.00449 & $0.030 \%$ & $0.565 \%$ & $93.233 \%$ \\
\hline 196 & mocho & 0.00448 & $0.076 \%$ & $1.412 \%$ & $93.309 \%$ \\
\hline 197 & amasador & 0.00437 & $0.045 \%$ & $0.847 \%$ & $93.354 \%$ \\
\hline 198 & barra & 0.00431 & $0.045 \%$ & $0.847 \%$ & $93.399 \%$ \\
\hline 199 & tostador & 0.00421 & $0.060 \%$ & $1.130 \%$ & $93.459 \%$ \\
\hline 200 & pila de fregar & 0.00421 & $0.045 \%$ & $0.847 \%$ & $93.504 \%$ \\
\hline 201 & pinza de carne & 0.00416 & $0.045 \%$ & $0.847 \%$ & $93.549 \%$ \\
\hline 202 & huevera & 0.00416 & $0.076 \%$ & $1.412 \%$ & $93.625 \%$ \\
\hline 203 & teléfono & 0.00413 & $0.045 \%$ & $0.847 \%$ & $93.670 \%$ \\
\hline 204 & bolsa del pan & 0.00408 & $0.060 \%$ & $1.130 \%$ & $93.730 \%$ \\
\hline 205 & cocina de gas & 0.00400 & $0.030 \%$ & $0.565 \%$ & $93.760 \%$ \\
\hline 206 & plato de postre & 0.00390 & $0.045 \%$ & $0.847 \%$ & $93.805 \%$ \\
\hline 207 & tabla & 0.00388 & $0.045 \%$ & $0.847 \%$ & $93.850 \%$ \\
\hline 208 & extintor & 0.00387 & $0.045 \%$ & $0.847 \%$ & $93.895 \%$ \\
\hline 209 & maza & 0.00386 & $0.045 \%$ & $0.847 \%$ & $93.940 \%$ \\
\hline 210 & aceite & 0.00374 & $0.045 \%$ & $0.847 \%$ & $93.985 \%$ \\
\hline 211 & escalera & 0.00370 & $0.045 \%$ & $0.847 \%$ & $94.030 \%$ \\
\hline 212 & palillo & 0.00369 & $0.045 \%$ & $0.847 \%$ & $94.075 \%$ \\
\hline
\end{tabular}




\begin{tabular}{|c|c|c|c|c|c|}
\hline 213 & jarrón & 0.00363 & $0.045 \%$ & $0.847 \%$ & $94.120 \%$ \\
\hline 214 & cajón de servilletas & 0.00359 & $0.030 \%$ & $0.565 \%$ & $94.150 \%$ \\
\hline 215 & posavasos & 0.00355 & $0.045 \%$ & $0.847 \%$ & $94.195 \%$ \\
\hline 216 & vinajera & 0.00354 & $0.030 \%$ & $0.565 \%$ & $94.225 \%$ \\
\hline 217 & recogedor & 0.00352 & $0.076 \%$ & $1.412 \%$ & $94.301 \%$ \\
\hline 218 & bombilla & 0.00352 & $0.076 \%$ & $1.412 \%$ & $94.377 \%$ \\
\hline 219 & tapadora & 0.00348 & $0.060 \%$ & $1.130 \%$ & $94.437 \%$ \\
\hline 220 & tapa & 0.00343 & $0.045 \%$ & $0.847 \%$ & $94.482 \%$ \\
\hline 221 & fregador & 0.00338 & $0.030 \%$ & $0.565 \%$ & $94.512 \%$ \\
\hline 222 & percha & 0.00338 & $0.030 \%$ & $0.565 \%$ & $94.542 \%$ \\
\hline 223 & alimento & 0.00336 & $0.030 \%$ & $0.565 \%$ & $94.572 \%$ \\
\hline 224 & tijeras de carne & 0.00331 & $0.030 \%$ & $0.565 \%$ & $94.602 \%$ \\
\hline 225 & cortadora & 0.00331 & $0.030 \%$ & $0.565 \%$ & $94.632 \%$ \\
\hline 226 & campana de humo & 0.00330 & $0.045 \%$ & $0.847 \%$ & $94.677 \%$ \\
\hline 227 & cuchillo de pan & 0.00327 & $0.030 \%$ & $0.565 \%$ & $94.707 \%$ \\
\hline 228 & molde & 0.00322 & $0.030 \%$ & $0.565 \%$ & $94.737 \%$ \\
\hline 229 & cuadro & 0.00322 & $0.030 \%$ & $0.565 \%$ & $94.767 \%$ \\
\hline 230 & trinchador & 0.00317 & $0.030 \%$ & $0.565 \%$ & $94.797 \%$ \\
\hline 231 & papel Albal* & 0.00313 & $0.060 \%$ & $1.130 \%$ & $94.857 \%$ \\
\hline 232 & cuchillo de jamón & 0.00313 & $0.030 \%$ & $0.565 \%$ & $94.887 \%$ \\
\hline 233 & utensilio de limpieza & 0.00307 & $0.045 \%$ & $0.847 \%$ & $94.932 \%$ \\
\hline 234 & cuchillero & 0.00304 & $0.030 \%$ & $0.565 \%$ & $94.962 \%$ \\
\hline 235 & olla a presión & 0.00302 & $0.030 \%$ & $0.565 \%$ & $94.992 \%$ \\
\hline 236 & barbacoa & 0.00302 & $0.030 \%$ & $0.565 \%$ & $95.022 \%$ \\
\hline 237 & balanza & 0.00298 & $0.045 \%$ & $0.847 \%$ & $95.067 \%$ \\
\hline 238 & palangana & 0.00298 & $0.045 \%$ & $0.847 \%$ & $95.112 \%$ \\
\hline 239 & bolsa & 0.00296 & $0.076 \%$ & $1.412 \%$ & $95.188 \%$ \\
\hline 240 & cubitera & 0.00294 & $0.060 \%$ & $1.130 \%$ & $95.248 \%$ \\
\hline 241 & tenedor de postre & 0.00294 & $0.030 \%$ & $0.565 \%$ & $95.278 \%$ \\
\hline 242 & Fairy* & 0.00292 & $0.045 \%$ & $0.847 \%$ & $95.323 \%$ \\
\hline 243 & tabla de cortar & 0.00292 & $0.030 \%$ & $0.565 \%$ & $95.353 \%$ \\
\hline 244 & perchero & 0.00286 & $0.030 \%$ & $0.565 \%$ & $95.383 \%$ \\
\hline 245 & plancha de cocina & 0.00282 & $0.015 \%$ & $0.282 \%$ & $95.398 \%$ \\
\hline 246 & cuchillo de sierra & 0.00282 & $0.015 \%$ & $0.282 \%$ & $95.413 \%$ \\
\hline 247 & planta & 0.00282 & $0.015 \%$ & $0.282 \%$ & $95.428 \%$ \\
\hline 248 & tapa de sartén & 0.00281 & $0.030 \%$ & $0.565 \%$ & $95.458 \%$ \\
\hline 249 & pimentero & 0.00279 & $0.045 \%$ & $0.847 \%$ & $95.503 \%$ \\
\hline 250 & botijo & 0.00275 & $0.030 \%$ & $0.565 \%$ & $95.533 \%$ \\
\hline 251 & armario de vasos & 0.00273 & $0.030 \%$ & $0.565 \%$ & $95.563 \%$ \\
\hline 252 & levantaclaras & 0.00272 & $0.030 \%$ & $0.565 \%$ & $95.593 \%$ \\
\hline 253 & cuchara de remover & 0.00266 & $0.030 \%$ & $0.565 \%$ & $95.623 \%$ \\
\hline 254 & banco de cocina & 0.00265 & $0.030 \%$ & $0.565 \%$ & $95.653 \%$ \\
\hline 255 & mostrador & 0.00263 & $0.015 \%$ & $0.282 \%$ & $95.668 \%$ \\
\hline 256 & cacharro & 0.00263 & $0.015 \%$ & $0.282 \%$ & $95.683 \%$ \\
\hline 257 & electrodoméstico & 0.00263 & $0.015 \%$ & $0.282 \%$ & $95.698 \%$ \\
\hline 258 & cuchara grande & 0.00263 & $0.015 \%$ & $0.282 \%$ & $95.713 \%$ \\
\hline 259 & centrifugadora & 0.00263 & $0.015 \%$ & $0.282 \%$ & $95.728 \%$ \\
\hline
\end{tabular}




\begin{tabular}{|c|c|c|c|c|c|}
\hline 260 & fumeral & 0.00263 & $0.015 \%$ & $0.282 \%$ & $95.743 \%$ \\
\hline 261 & placa del horno & 0.00263 & $0.015 \%$ & $0.282 \%$ & $95.758 \%$ \\
\hline 262 & cocinilla & 0.00261 & $0.030 \%$ & $0.565 \%$ & $95.788 \%$ \\
\hline 263 & barra americana & 0.00261 & $0.030 \%$ & $0.565 \%$ & $95.818 \%$ \\
\hline 264 & garrafa de agua & 0.00254 & $0.030 \%$ & $0.565 \%$ & $95.848 \%$ \\
\hline 265 & camarera & 0.00254 & $0.030 \%$ & $0.565 \%$ & $95.878 \%$ \\
\hline 266 & rollo de cocina & 0.00254 & $0.030 \%$ & $0.565 \%$ & $95.908 \%$ \\
\hline 267 & Tupper(ware)* & 0.00250 & $0.030 \%$ & $0.565 \%$ & $95.938 \%$ \\
\hline 268 & descorchador & 0.00247 & $0.030 \%$ & $0.565 \%$ & $95.968 \%$ \\
\hline 269 & salvamanteles & 0.00247 & $0.045 \%$ & $0.847 \%$ & $96.013 \%$ \\
\hline 270 & planchadora & 0.00246 & $0.015 \%$ & $0.282 \%$ & $96.028 \%$ \\
\hline 271 & heladera & 0.00246 & $0.015 \%$ & $0.282 \%$ & $96.043 \%$ \\
\hline 272 & cuchara de postre & 0.00246 & $0.015 \%$ & $0.282 \%$ & $96.058 \%$ \\
\hline 273 & azulejo & 0.00238 & $0.030 \%$ & $0.565 \%$ & $96.088 \%$ \\
\hline 274 & báscula & 0.00233 & $0.030 \%$ & $0.565 \%$ & $96.118 \%$ \\
\hline 275 & destapador & 0.00232 & $0.030 \%$ & $0.565 \%$ & $96.148 \%$ \\
\hline 276 & cocina de guisar & 0.00229 & $0.015 \%$ & $0.282 \%$ & $96.163 \%$ \\
\hline 277 & porrón & 0.00229 & $0.015 \%$ & $0.282 \%$ & $96.178 \%$ \\
\hline 278 & castañero & 0.00229 & $0.015 \%$ & $0.282 \%$ & $96.193 \%$ \\
\hline 279 & lima & 0.00229 & $0.015 \%$ & $0.282 \%$ & $96.208 \%$ \\
\hline 280 & pelador & 0.00221 & $0.030 \%$ & $0.565 \%$ & $96.238 \%$ \\
\hline 281 & termo & 0.00221 & $0.030 \%$ & $0.565 \%$ & $96.268 \%$ \\
\hline 282 & cucharilla de café & 0.00218 & $0.030 \%$ & $0.565 \%$ & $96.298 \%$ \\
\hline 283 & cucharilla de postre & 0.00215 & $0.030 \%$ & $0.565 \%$ & $96.328 \%$ \\
\hline 284 & cocina de fuegos & 0.00214 & $0.015 \%$ & $0.282 \%$ & $96.343 \%$ \\
\hline 285 & mesita & 0.00214 & $0.015 \%$ & $0.282 \%$ & $96.358 \%$ \\
\hline 286 & cortafiambres & 0.00214 & $0.030 \%$ & $0.565 \%$ & $96.388 \%$ \\
\hline 287 & armarios superiores & 0.00214 & $0.015 \%$ & $0.282 \%$ & $96.403 \%$ \\
\hline 288 & plato de pared & 0.00214 & $0.015 \%$ & $0.282 \%$ & $96.418 \%$ \\
\hline 289 & papel de plata & 0.00212 & $0.030 \%$ & $0.565 \%$ & $96.448 \%$ \\
\hline 290 & navaja & 0.00209 & $0.030 \%$ & $0.565 \%$ & $96.478 \%$ \\
\hline 291 & papel & 0.00207 & $0.030 \%$ & $0.565 \%$ & $96.508 \%$ \\
\hline 292 & quemador & 0.00202 & $0.030 \%$ & $0.565 \%$ & $96.538 \%$ \\
\hline 293 & papel de cocina & 0.00202 & $0.045 \%$ & $0.847 \%$ & $96.583 \%$ \\
\hline 294 & pelador de patatas & 0.00201 & $0.030 \%$ & $0.565 \%$ & $96.613 \%$ \\
\hline 295 & cuchillo de postre & 0.00199 & $0.015 \%$ & $0.282 \%$ & $96.628 \%$ \\
\hline 296 & bota & 0.00199 & $0.015 \%$ & $0.282 \%$ & $96.643 \%$ \\
\hline 297 & plato pequeño & 0.00199 & $0.015 \%$ & $0.282 \%$ & $96.658 \%$ \\
\hline 298 & pelazanahorias & 0.00199 & $0.015 \%$ & $0.282 \%$ & $96.673 \%$ \\
\hline 299 & conjunto de cuchillos & 0.00199 & $0.015 \%$ & $0.282 \%$ & $96.688 \%$ \\
\hline 300 & cortapasteles & 0.00199 & $0.015 \%$ & $0.282 \%$ & $96.703 \%$ \\
\hline 301 & armarios inferiores & 0.00199 & $0.015 \%$ & $0.282 \%$ & $96.718 \%$ \\
\hline 302 & banquet & 0.00193 & $0.030 \%$ & $0.565 \%$ & $96.748 \%$ \\
\hline 303 & peladora & 0.00189 & $0.030 \%$ & $0.565 \%$ & $96.778 \%$ \\
\hline 304 & máquina de pelar patatas & 0.00186 & $0.015 \%$ & $0.282 \%$ & $96.793 \%$ \\
\hline 305 & escorredor & 0.00186 & $0.015 \%$ & $0.282 \%$ & $96.808 \%$ \\
\hline 306 & soporte de jamón & 0.00186 & $0.015 \%$ & $0.282 \%$ & $96.823 \%$ \\
\hline
\end{tabular}




\begin{tabular}{|c|c|c|c|c|c|}
\hline 307 & graella & 0.00186 & $0.015 \%$ & $0.282 \%$ & $96.838 \%$ \\
\hline 308 & tabla para picar & 0.00186 & $0.015 \%$ & $0.282 \%$ & $96.853 \%$ \\
\hline 309 & alacena & 0.00186 & $0.015 \%$ & $0.282 \%$ & $96.868 \%$ \\
\hline 310 & vitrina & 0.00186 & $0.015 \%$ & $0.282 \%$ & $96.883 \%$ \\
\hline 311 & cazuela de horno & 0.00186 & $0.015 \%$ & $0.282 \%$ & $96.898 \%$ \\
\hline 312 & aspersor & 0.00186 & $0.015 \%$ & $0.282 \%$ & $96.913 \%$ \\
\hline 313 & horno de luz & 0.00186 & $0.015 \%$ & $0.282 \%$ & $96.928 \%$ \\
\hline 314 & afilador & 0.00184 & $0.030 \%$ & $0.565 \%$ & $96.958 \%$ \\
\hline 315 & molinillo & 0.00183 & $0.030 \%$ & $0.565 \%$ & $96.988 \%$ \\
\hline 316 & escurridero & 0.00175 & $0.030 \%$ & $0.565 \%$ & $97.018 \%$ \\
\hline 317 & plato hondo & 0.00173 & $0.015 \%$ & $0.282 \%$ & $97.033 \%$ \\
\hline 318 & cuchillo grande & 0.00173 & $0.015 \%$ & $0.282 \%$ & $97.048 \%$ \\
\hline 319 & cuchillo trinchador & 0.00173 & $0.015 \%$ & $0.282 \%$ & $97.063 \%$ \\
\hline 320 & tendedero & 0.00173 & $0.015 \%$ & $0.282 \%$ & $97.078 \%$ \\
\hline 321 & cocina de luz & 0.00173 & $0.015 \%$ & $0.282 \%$ & $97.093 \%$ \\
\hline 322 & pajita & 0.00173 & $0.015 \%$ & $0.282 \%$ & $97.108 \%$ \\
\hline 323 & armario platero & 0.00173 & $0.015 \%$ & $0.282 \%$ & $97.123 \%$ \\
\hline 324 & picadora de carne & 0.00173 & $0.015 \%$ & $0.282 \%$ & $97.138 \%$ \\
\hline 325 & misto & 0.00171 & $0.030 \%$ & $0.565 \%$ & $97.168 \%$ \\
\hline 326 & secadero & 0.00162 & $0.015 \%$ & $0.282 \%$ & $97.183 \%$ \\
\hline 327 & horno de gas & 0.00162 & $0.015 \%$ & $0.282 \%$ & $97.198 \%$ \\
\hline 328 & botella de refrescos & 0.00162 & $0.015 \%$ & $0.282 \%$ & $97.213 \%$ \\
\hline 329 & cuchara de servir & 0.00162 & $0.015 \%$ & $0.282 \%$ & $97.228 \%$ \\
\hline 330 & pica de fregar & 0.00162 & $0.015 \%$ & $0.282 \%$ & $97.243 \%$ \\
\hline 331 & cascanueces & 0.00162 & $0.030 \%$ & $0.565 \%$ & $97.273 \%$ \\
\hline 332 & hervidor de agua & 0.00162 & $0.015 \%$ & $0.282 \%$ & $97.288 \%$ \\
\hline 333 & sierra & 0.00162 & $0.015 \%$ & $0.282 \%$ & $97.303 \%$ \\
\hline 334 & hacha de carne & 0.00162 & $0.015 \%$ & $0.282 \%$ & $97.318 \%$ \\
\hline 335 & tostadora de pan & 0.00162 & $0.015 \%$ & $0.282 \%$ & $97.333 \%$ \\
\hline 336 & cuchillo pelapatatas & 0.00162 & $0.015 \%$ & $0.282 \%$ & $97.348 \%$ \\
\hline 337 & desagüe & 0.00162 & $0.015 \%$ & $0.282 \%$ & $97.363 \%$ \\
\hline 338 & secador & 0.00162 & $0.015 \%$ & $0.282 \%$ & $97.378 \%$ \\
\hline 339 & pinza grande & 0.00162 & $0.015 \%$ & $0.282 \%$ & $97.393 \%$ \\
\hline 340 & tortera & 0.00162 & $0.015 \%$ & $0.282 \%$ & $97.408 \%$ \\
\hline 341 & mandil & 0.00162 & $0.015 \%$ & $0.282 \%$ & $97.423 \%$ \\
\hline 342 & plato sopero & 0.00162 & $0.015 \%$ & $0.282 \%$ & $97.438 \%$ \\
\hline 343 & secamanos & 0.00156 & $0.030 \%$ & $0.565 \%$ & $97.468 \%$ \\
\hline 344 & paleta de pescado & 0.00151 & $0.015 \%$ & $0.282 \%$ & $97.483 \%$ \\
\hline 345 & cajonera & 0.00151 & $0.015 \%$ & $0.282 \%$ & $97.498 \%$ \\
\hline 346 & abridor de botellas & 0.00151 & $0.015 \%$ & $0.282 \%$ & $97.513 \%$ \\
\hline 347 & matarratas & 0.00151 & $0.015 \%$ & $0.282 \%$ & $97.528 \%$ \\
\hline 348 & machete & 0.00151 & $0.015 \%$ & $0.282 \%$ & $97.543 \%$ \\
\hline 349 & deshuesador & 0.00151 & $0.015 \%$ & $0.282 \%$ & $97.558 \%$ \\
\hline 350 & cuchillo eléctrico & 0.00151 & $0.015 \%$ & $0.282 \%$ & $97.573 \%$ \\
\hline 351 & rodilla & 0.00151 & $0.015 \%$ & $0.282 \%$ & $97.588 \%$ \\
\hline 352 & gas Butano* & 0.00143 & $0.030 \%$ & $0.565 \%$ & $97.618 \%$ \\
\hline 353 & sazonador & 0.00141 & $0.015 \%$ & $0.282 \%$ & $97.633 \%$ \\
\hline
\end{tabular}




\begin{tabular}{|c|c|c|c|c|c|}
\hline 354 & cenicero & 0.00141 & $0.015 \%$ & $0.282 \%$ & $97.648 \%$ \\
\hline 355 & taza de café & 0.00141 & $0.015 \%$ & $0.282 \%$ & $97.663 \%$ \\
\hline 356 & papel de plástico & 0.00141 & $0.015 \%$ & $0.282 \%$ & $97.678 \%$ \\
\hline 357 & bandeja del horno & 0.00141 & $0.015 \%$ & $0.282 \%$ & $97.693 \%$ \\
\hline 358 & trapo de secar & 0.00141 & $0.015 \%$ & $0.282 \%$ & $97.708 \%$ \\
\hline 359 & drap & 0.00141 & $0.015 \%$ & $0.282 \%$ & $97.723 \%$ \\
\hline 360 & vaso de plástico & 0.00141 & $0.015 \%$ & $0.282 \%$ & $97.738 \%$ \\
\hline 361 & friegasuelos & 0.00139 & $0.030 \%$ & $0.565 \%$ & $97.768 \%$ \\
\hline 362 & esponja & 0.00136 & $0.030 \%$ & $0.565 \%$ & $97.798 \%$ \\
\hline 363 & desinfectante & 0.00135 & $0.030 \%$ & $0.565 \%$ & $97.828 \%$ \\
\hline 364 & polvos de lavar & 0.00135 & $0.030 \%$ & $0.565 \%$ & $97.858 \%$ \\
\hline 365 & horno eléctrico & 0.00131 & $0.015 \%$ & $0.282 \%$ & $97.873 \%$ \\
\hline 366 & carnera & 0.00131 & $0.015 \%$ & $0.282 \%$ & $97.888 \%$ \\
\hline 367 & tijeras de pescado & 0.00131 & $0.015 \%$ & $0.282 \%$ & $97.903 \%$ \\
\hline 368 & calendario & 0.00131 & $0.015 \%$ & $0.282 \%$ & $97.918 \%$ \\
\hline 369 & mueble para el Butano* & 0.00131 & $0.015 \%$ & $0.282 \%$ & $97.933 \%$ \\
\hline 370 & máquina del café & 0.00131 & $0.015 \%$ & $0.282 \%$ & $97.948 \%$ \\
\hline 371 & plástico & 0.00131 & $0.015 \%$ & $0.282 \%$ & $97.963 \%$ \\
\hline 372 & guante de cocina & 0.00131 & $0.015 \%$ & $0.282 \%$ & $97.978 \%$ \\
\hline 373 & escurretallarines & 0.00131 & $0.015 \%$ & $0.282 \%$ & $97.993 \%$ \\
\hline 374 & batidora manual & 0.00131 & $0.015 \%$ & $0.282 \%$ & $98.008 \%$ \\
\hline 375 & medidor de harina & 0.00131 & $0.015 \%$ & $0.282 \%$ & $98.023 \%$ \\
\hline 376 & guante de fregar & 0.00131 & $0.015 \%$ & $0.282 \%$ & $98.038 \%$ \\
\hline 377 & sartén de huevos fritos & 0.00131 & $0.015 \%$ & $0.282 \%$ & $98.053 \%$ \\
\hline 378 & cuchillo de trinchar & 0.00131 & $0.015 \%$ & $0.282 \%$ & $98.068 \%$ \\
\hline 379 & tarrina & 0.00126 & $0.030 \%$ & $0.565 \%$ & $98.098 \%$ \\
\hline 380 & interruptor & 0.00122 & $0.015 \%$ & $0.282 \%$ & $98.113 \%$ \\
\hline 381 & cuchillo amplio & 0.00122 & $0.015 \%$ & $0.282 \%$ & $98.128 \%$ \\
\hline 382 & servilleta de tela & 0.00122 & $0.015 \%$ & $0.282 \%$ & $98.143 \%$ \\
\hline 383 & lata & 0.00122 & $0.015 \%$ & $0.282 \%$ & $98.158 \%$ \\
\hline 384 & bote de legumbres & 0.00122 & $0.015 \%$ & $0.282 \%$ & $98.173 \%$ \\
\hline 385 & tubería & 0.00122 & $0.015 \%$ & $0.282 \%$ & $98.188 \%$ \\
\hline 386 & plato plano & 0.00122 & $0.015 \%$ & $0.282 \%$ & $98.203 \%$ \\
\hline 387 & mesa camilla & 0.00122 & $0.015 \%$ & $0.282 \%$ & $98.218 \%$ \\
\hline 388 & escurrelechugas & 0.00122 & $0.015 \%$ & $0.282 \%$ & $98.233 \%$ \\
\hline 389 & Mepansa* & 0.00122 & $0.015 \%$ & $0.282 \%$ & $98.248 \%$ \\
\hline 390 & repisa & 0.00122 & $0.015 \%$ & $0.282 \%$ & $98.263 \%$ \\
\hline 391 & sartén de tortillas & 0.00122 & $0.015 \%$ & $0.282 \%$ & $98.278 \%$ \\
\hline 392 & foco & 0.00114 & $0.015 \%$ & $0.282 \%$ & $98.293 \%$ \\
\hline 393 & caja & 0.00114 & $0.015 \%$ & $0.282 \%$ & $98.308 \%$ \\
\hline 394 & medidor de arroz & 0.00114 & $0.015 \%$ & $0.282 \%$ & $98.323 \%$ \\
\hline 395 & sal del lavaplatos & 0.00114 & $0.015 \%$ & $0.282 \%$ & $98.338 \%$ \\
\hline 396 & bote de lentejas & 0.00114 & $0.015 \%$ & $0.282 \%$ & $98.353 \%$ \\
\hline 397 & servilleta de papel & 0.00114 & $0.015 \%$ & $0.282 \%$ & $98.368 \%$ \\
\hline 398 & lengüeta & 0.00114 & $0.015 \%$ & $0.282 \%$ & $98.383 \%$ \\
\hline 399 & medidor & 0.00114 & $0.015 \%$ & $0.282 \%$ & $98.398 \%$ \\
\hline 400 & piedra & 0.00114 & $0.015 \%$ & $0.282 \%$ & $98.413 \%$ \\
\hline
\end{tabular}




\begin{tabular}{|c|c|c|c|c|c|}
\hline 401 & sartén antiadherente & 0.00114 & $0.015 \%$ & $0.282 \%$ & $98.428 \%$ \\
\hline 402 & mazo de allioli & 0.00114 & $0.015 \%$ & $0.282 \%$ & $98.443 \%$ \\
\hline 403 & ladrillo & 0.00114 & $0.015 \%$ & $0.282 \%$ & $98.458 \%$ \\
\hline 404 & vaso de agua & 0.00114 & $0.015 \%$ & $0.282 \%$ & $98.473 \%$ \\
\hline 405 & foguer & 0.00113 & $0.030 \%$ & $0.565 \%$ & $98.503 \%$ \\
\hline 406 & cebollero & 0.00106 & $0.015 \%$ & $0.282 \%$ & $98.518 \%$ \\
\hline 407 & lugar del pan & 0.00106 & $0.015 \%$ & $0.282 \%$ & $98.533 \%$ \\
\hline 408 & sal & 0.00106 & $0.015 \%$ & $0.282 \%$ & $98.548 \%$ \\
\hline 409 & bote de garbanzos & 0.00106 & $0.015 \%$ & $0.282 \%$ & $98.563 \%$ \\
\hline 410 & tabla de cortar carne & 0.00106 & $0.015 \%$ & $0.282 \%$ & $98.578 \%$ \\
\hline 411 & jarro & 0.00106 & $0.015 \%$ & $0.282 \%$ & $98.593 \%$ \\
\hline 412 & reloj de horno & 0.00106 & $0.015 \%$ & $0.282 \%$ & $98.608 \%$ \\
\hline 413 & cajón de ropa sucia & 0.00106 & $0.015 \%$ & $0.282 \%$ & $98.623 \%$ \\
\hline 414 & cuenco de plástico & 0.00106 & $0.015 \%$ & $0.282 \%$ & $98.638 \%$ \\
\hline 415 & cocinera & 0.00106 & $0.015 \%$ & $0.282 \%$ & $98.653 \%$ \\
\hline 416 & depuradora & 0.00106 & $0.015 \%$ & $0.282 \%$ & $98.668 \%$ \\
\hline 417 & armario de platos & 0.00106 & $0.015 \%$ & $0.282 \%$ & $98.683 \%$ \\
\hline 418 & posaplatos & 0.00106 & $0.015 \%$ & $0.282 \%$ & $98.698 \%$ \\
\hline 419 & tartera & 0.00106 & $0.015 \%$ & $0.282 \%$ & $98.713 \%$ \\
\hline 420 & vaso de vino & 0.00106 & $0.015 \%$ & $0.282 \%$ & $98.728 \%$ \\
\hline 421 & bote de habichuelas & 0.00099 & $0.015 \%$ & $0.282 \%$ & $98.743 \%$ \\
\hline 422 & montaclaras & 0.00099 & $0.015 \%$ & $0.282 \%$ & $98.758 \%$ \\
\hline 423 & colador chino & 0.00099 & $0.015 \%$ & $0.282 \%$ & $98.773 \%$ \\
\hline 424 & pelador de fruta & 0.00099 & $0.015 \%$ & $0.282 \%$ & $98.788 \%$ \\
\hline 425 & estantería de especias & 0.00099 & $0.015 \%$ & $0.282 \%$ & $98.803 \%$ \\
\hline 426 & mopa & 0.00093 & $0.015 \%$ & $0.282 \%$ & $98.818 \%$ \\
\hline 427 & Ariel* $^{*}$ & 0.00093 & $0.015 \%$ & $0.282 \%$ & $98.833 \%$ \\
\hline 428 & bote de judías & 0.00093 & $0.015 \%$ & $0.282 \%$ & $98.848 \%$ \\
\hline 429 & enchufe & 0.00093 & $0.015 \%$ & $0.282 \%$ & $98.863 \%$ \\
\hline 430 & manguito & 0.00093 & $0.015 \%$ & $0.282 \%$ & $98.878 \%$ \\
\hline 431 & brasero & 0.00093 & $0.015 \%$ & $0.282 \%$ & $98.893 \%$ \\
\hline 432 & armario de cacerolas & 0.00093 & $0.015 \%$ & $0.282 \%$ & $98.908 \%$ \\
\hline 433 & cucharón de sopa & 0.00093 & $0.015 \%$ & $0.282 \%$ & $98.923 \%$ \\
\hline 434 & calefacción central & 0.00093 & $0.015 \%$ & $0.282 \%$ & $98.938 \%$ \\
\hline 435 & gancho & 0.00093 & $0.015 \%$ & $0.282 \%$ & $98.953 \%$ \\
\hline 436 & cuchara de helado & 0.00086 & $0.015 \%$ & $0.282 \%$ & $98.968 \%$ \\
\hline 437 & rollo de papel & 0.00086 & $0.015 \%$ & $0.282 \%$ & $98.983 \%$ \\
\hline 438 & bote de arroz & 0.00086 & $0.015 \%$ & $0.282 \%$ & $98.998 \%$ \\
\hline 439 & rascador & 0.00086 & $0.015 \%$ & $0.282 \%$ & $99.013 \%$ \\
\hline 440 & mesa de comer & 0.00086 & $0.015 \%$ & $0.282 \%$ & $99.028 \%$ \\
\hline 441 & pincho & 0.00086 & $0.015 \%$ & $0.282 \%$ & $99.043 \%$ \\
\hline 442 & limpiahornos & 0.00086 & $0.015 \%$ & $0.282 \%$ & $99.058 \%$ \\
\hline 443 & perola & 0.00086 & $0.015 \%$ & $0.282 \%$ & $99.073 \%$ \\
\hline 444 & Scotch Brite* & 0.00086 & $0.015 \%$ & $0.282 \%$ & $99.088 \%$ \\
\hline 445 & aire acondicionado & 0.00086 & $0.015 \%$ & $0.282 \%$ & $99.103 \%$ \\
\hline 446 & banquet de mármol & 0.00086 & $0.015 \%$ & $0.282 \%$ & $99.118 \%$ \\
\hline 447 & limpiacristales & 0.00081 & $0.015 \%$ & $0.282 \%$ & $99.133 \%$ \\
\hline
\end{tabular}




\begin{tabular}{|c|c|c|c|c|c|}
\hline 448 & objeto de limpieza & 0.00081 & $0.015 \%$ & $0.282 \%$ & $99.148 \%$ \\
\hline 449 & bote de pasta & 0.00081 & $0.015 \%$ & $0.282 \%$ & $99.163 \%$ \\
\hline 450 & cogedor & 0.00081 & $0.015 \%$ & $0.282 \%$ & $99.178 \%$ \\
\hline 451 & tamiz & 0.00081 & $0.015 \%$ & $0.282 \%$ & $99.193 \%$ \\
\hline 452 & manga de nata & 0.00081 & $0.015 \%$ & $0.282 \%$ & $99.208 \%$ \\
\hline 453 & recipiente de allioli & 0.00081 & $0.015 \%$ & $0.282 \%$ & $99.223 \%$ \\
\hline 454 & subeclaras & 0.00081 & $0.015 \%$ & $0.282 \%$ & $99.238 \%$ \\
\hline 455 & sostenedor de paletas & 0.00081 & $0.015 \%$ & $0.282 \%$ & $99.253 \%$ \\
\hline 456 & botellero & 0.00075 & $0.015 \%$ & $0.282 \%$ & $99.268 \%$ \\
\hline 457 & florero & 0.00075 & $0.015 \%$ & $0.282 \%$ & $99.283 \%$ \\
\hline 458 & amoniaco & 0.00075 & $0.015 \%$ & $0.282 \%$ & $99.298 \%$ \\
\hline 459 & tubo halógeno & 0.00075 & $0.015 \%$ & $0.282 \%$ & $99.313 \%$ \\
\hline 460 & prensador & 0.00075 & $0.015 \%$ & $0.282 \%$ & $99.328 \%$ \\
\hline 461 & repartidor & 0.00075 & $0.015 \%$ & $0.282 \%$ & $99.343 \%$ \\
\hline 462 & radiocasete & 0.00075 & $0.015 \%$ & $0.282 \%$ & $99.358 \%$ \\
\hline 463 & trapo de limpieza & 0.00075 & $0.015 \%$ & $0.282 \%$ & $99.373 \%$ \\
\hline 464 & aparador & 0.00070 & $0.015 \%$ & $0.282 \%$ & $99.388 \%$ \\
\hline 465 & tarro & 0.00070 & $0.015 \%$ & $0.282 \%$ & $99.403 \%$ \\
\hline 466 & guardaespecias & 0.00070 & $0.015 \%$ & $0.282 \%$ & $99.418 \%$ \\
\hline 467 & frasco & 0.00070 & $0.015 \%$ & $0.282 \%$ & $99.433 \%$ \\
\hline 468 & jamón & 0.00070 & $0.015 \%$ & $0.282 \%$ & $99.448 \%$ \\
\hline 469 & imán de nevera & 0.00070 & $0.015 \%$ & $0.282 \%$ & $99.463 \%$ \\
\hline 470 & recipiente metálico & 0.00070 & $0.015 \%$ & $0.282 \%$ & $99.478 \%$ \\
\hline 471 & cajón del pan & 0.00070 & $0.015 \%$ & $0.282 \%$ & $99.493 \%$ \\
\hline 472 & máquina de hielo & 0.00065 & $0.015 \%$ & $0.282 \%$ & $99.508 \%$ \\
\hline 473 & vídeo & 0.00065 & $0.015 \%$ & $0.282 \%$ & $99.523 \%$ \\
\hline 474 & Carmela* & 0.00065 & $0.015 \%$ & $0.282 \%$ & $99.538 \%$ \\
\hline 475 & mondadientes & 0.00065 & $0.015 \%$ & $0.282 \%$ & $99.553 \%$ \\
\hline 476 & rejilla & 0.00065 & $0.015 \%$ & $0.282 \%$ & $99.568 \%$ \\
\hline 477 & maza del mortero & 0.00065 & $0.015 \%$ & $0.282 \%$ & $99.583 \%$ \\
\hline 478 & vinagre & 0.00065 & $0.015 \%$ & $0.282 \%$ & $99.598 \%$ \\
\hline 479 & calefacción & 0.00061 & $0.015 \%$ & $0.282 \%$ & $99.613 \%$ \\
\hline 480 & banqueta & 0.00061 & $0.015 \%$ & $0.282 \%$ & $99.628 \%$ \\
\hline 481 & cortador de tortillas & 0.00061 & $0.015 \%$ & $0.282 \%$ & $99.643 \%$ \\
\hline 482 & refractor & 0.00061 & $0.015 \%$ & $0.282 \%$ & $99.658 \%$ \\
\hline 483 & multipicadora & 0.00057 & $0.015 \%$ & $0.282 \%$ & $99.673 \%$ \\
\hline 484 & afilacuchillos & 0.00057 & $0.015 \%$ & $0.282 \%$ & $99.688 \%$ \\
\hline 485 & garrafa & 0.00057 & $0.015 \%$ & $0.282 \%$ & $99.703 \%$ \\
\hline 486 & esterilla & 0.00057 & $0.015 \%$ & $0.282 \%$ & $99.718 \%$ \\
\hline 487 & gas central & 0.00053 & $0.015 \%$ & $0.282 \%$ & $99.733 \%$ \\
\hline 488 & paellera & 0.00053 & $0.015 \%$ & $0.282 \%$ & $99.748 \%$ \\
\hline 489 & gas natural & 0.00049 & $0.015 \%$ & $0.282 \%$ & $99.763 \%$ \\
\hline 490 & cubo de fregar & 0.00049 & $0.015 \%$ & $0.282 \%$ & $99.778 \%$ \\
\hline 491 & tablilla & 0.00049 & $0.015 \%$ & $0.282 \%$ & $99.793 \%$ \\
\hline 492 & escurrecubiertos & 0.00049 & $0.015 \%$ & $0.282 \%$ & $99.808 \%$ \\
\hline 493 & cuchara de metal & 0.00049 & $0.015 \%$ & $0.282 \%$ & $99.823 \%$ \\
\hline 494 & Spontex* & 0.00046 & $0.015 \%$ & $0.282 \%$ & $99.838 \%$ \\
\hline
\end{tabular}




\begin{tabular}{|l|l|l||c|c|c|}
\hline 495 & papel de aluminio & 0.00046 & $0.015 \%$ & $0.282 \%$ & $99.853 \%$ \\
\hline 496 & percha para paños & 0.00046 & $0.015 \%$ & $0.282 \%$ & $99.868 \%$ \\
\hline 497 & plato de café & 0.00043 & $0.015 \%$ & $0.282 \%$ & $99.883 \%$ \\
\hline 498 & cable & 0.00043 & $0.015 \%$ & $0.282 \%$ & $99.898 \%$ \\
\hline 499 & abrebotellas & 0.00043 & $0.015 \%$ & $0.282 \%$ & $99.913 \%$ \\
\hline 500 & mezclador & 0.00043 & $0.015 \%$ & $0.282 \%$ & $99.928 \%$ \\
\hline 501 & tapón de botella & 0.00037 & $0.015 \%$ & $0.282 \%$ & $99.943 \%$ \\
\hline 502 & bolsa de basura & 0.00035 & $0.015 \%$ & $0.282 \%$ & $99.958 \%$ \\
\hline
\end{tabular}

08. LA ESCUELA (MUEBLES Y MATERIALES)

\begin{tabular}{|c|l|c|c|c|c|}
\hline $\mathrm{N}^{\mathrm{o}}$ & Palabra & Disponibilidad & $\begin{array}{c}\text { Frecuencia } \\
\text { relativa }\end{array}$ & \% Aparición & $\begin{array}{c}\text { Frecuencia } \\
\text { acumulada }\end{array}$ \\
\hline 1 & silla & 0.78325 & $3.968 \%$ & $94.068 \%$ & $3.968 \%$ \\
\hline 2 & mesa & 0.76540 & $3.658 \%$ & $86.723 \%$ & $7.626 \%$ \\
\hline 3 & pizarra & 0.71538 & $4.039 \%$ & $95.763 \%$ & $11.665 \%$ \\
\hline 4 & lápiz & 0.59128 & $3.539 \%$ & $83.898 \%$ & $15.204 \%$ \\
\hline 5 & bolí(grafo) & 0.57191 & $3.574 \%$ & $84.746 \%$ & $18.778 \%$ \\
\hline 6 & goma & 0.41056 & $2.955 \%$ & $70.056 \%$ & $21.733 \%$ \\
\hline 7 & tiza & 0.39414 & $2.812 \%$ & $66.667 \%$ & $24.545 \%$ \\
\hline 8 & libro & 0.39021 & $3.026 \%$ & $71.751 \%$ & $27.571 \%$ \\
\hline 9 & estuche & 0.32512 & $2.585 \%$ & $61.299 \%$ & $30.156 \%$ \\
\hline 10 & libreta & 0.32133 & $2.574 \%$ & $61.017 \%$ & $32.730 \%$ \\
\hline 11 & folio & 0.25229 & $2.061 \%$ & $48.870 \%$ & $34.791 \%$ \\
\hline 12 & carpeta & 0.24304 & $2.300 \%$ & $54.520 \%$ & $37.091 \%$ \\
\hline 13 & rotulador & 0.24292 & $2.109 \%$ & $50.000 \%$ & $39.200 \%$ \\
\hline 14 & borrador & 0.23098 & $1.954 \%$ & $46.328 \%$ & $41.154 \%$ \\
\hline 15 & pupitre & 0.23095 & $1.168 \%$ & $27.684 \%$ & $42.322 \%$ \\
\hline 16 & armario & 0.21143 & $1.608 \%$ & $38.136 \%$ & $43.930 \%$ \\
\hline 17 & regla & 0.16897 & $1.477 \%$ & $35.028 \%$ & $45.407 \%$ \\
\hline 18 & sacapuntas & 0.16362 & $1.418 \%$ & $33.616 \%$ & $46.825 \%$ \\
\hline 19 & ventana & 0.14908 & $1.275 \%$ & $30.226 \%$ & $48.100 \%$ \\
\hline 20 & tablón (de anuncios) & 0.13753 & $1.239 \%$ & $29.379 \%$ & $49.339 \%$ \\
\hline 21 & cartera & 0.12659 & $1.215 \%$ & $28.814 \%$ & $50.554 \%$ \\
\hline 22 & puerta & 0.12085 & $0.941 \%$ & $22.316 \%$ & $51.495 \%$ \\
\hline 23 & percha & 0.10452 & $0.989 \%$ & $23.446 \%$ & $52.484 \%$ \\
\hline 24 & Tipp-ex* & 0.10264 & $1.013 \%$ & $24.011 \%$ & $53.497 \%$ \\
\hline 25 & compás & 0.10232 & $1.060 \%$ & $25.141 \%$ & $54.557 \%$ \\
\hline 26 & papel & 0.10187 & $0.727 \%$ & $17.232 \%$ & $55.284 \%$ \\
\hline 27 & papelera & 0.10172 & $0.965 \%$ & $22.881 \%$ & $56.249 \%$ \\
\hline 28 & ordenador & 0.10142 & $0.941 \%$ & $22.316 \%$ & $57.190 \%$ \\
\hline 29 & pluma & 0.09981 & $0.798 \%$ & $18.927 \%$ & $57.988 \%$ \\
\hline 30 & mesa de profesor & 0.09465 & $0.560 \%$ & $13.277 \%$ & $58.548 \%$ \\
\hline
\end{tabular}




\begin{tabular}{|c|c|c|c|c|c|}
\hline 31 & perchero & 0.09445 & $0.763 \%$ & $18.079 \%$ & $59.311 \%$ \\
\hline 32 & colores & 0.09333 & $0.763 \%$ & $18.079 \%$ & $60.074 \%$ \\
\hline 33 & escuadra & 0.09320 & $0.894 \%$ & $21.186 \%$ & $60.968 \%$ \\
\hline 34 & estantería & 0.09223 & $0.798 \%$ & $18.927 \%$ & $61.766 \%$ \\
\hline 35 & fotocopiadora & 0.08205 & $0.858 \%$ & $20.339 \%$ & $62.624 \%$ \\
\hline 36 & mochila & 0.08169 & $0.870 \%$ & $20.621 \%$ & $63.494 \%$ \\
\hline 37 & sillón & 0.08072 & $0.584 \%$ & $13.842 \%$ & $64.078 \%$ \\
\hline 38 & cartabón & 0.08036 & $0.810 \%$ & $19.209 \%$ & $64.888 \%$ \\
\hline 39 & hoja & 0.08031 & $0.667 \%$ & $15.819 \%$ & $65.555 \%$ \\
\hline 40 & vídeo & 0.06826 & $0.560 \%$ & $13.277 \%$ & $66.115 \%$ \\
\hline 41 & diccionario & 0.06716 & $0.643 \%$ & $15.254 \%$ & $66.758 \%$ \\
\hline 42 & calculadora & 0.06598 & $0.763 \%$ & $18.079 \%$ & $67.521 \%$ \\
\hline 43 & cajón & 0.06099 & $0.548 \%$ & $12.994 \%$ & $68.069 \%$ \\
\hline 44 & colorín & 0.05708 & $0.536 \%$ & $12.712 \%$ & $68.605 \%$ \\
\hline 45 & bolsa & 0.04992 & $0.465 \%$ & $11.017 \%$ & $69.070 \%$ \\
\hline 46 & tele(visión) & 0.04727 & $0.405 \%$ & $9.605 \%$ & $69.475 \%$ \\
\hline 47 & cuaderno & 0.04681 & $0.405 \%$ & $9.605 \%$ & $69.880 \%$ \\
\hline 48 & estufa & 0.04557 & $0.465 \%$ & $11.017 \%$ & $70.345 \%$ \\
\hline 49 & persiana & 0.04554 & $0.381 \%$ & $9.040 \%$ & $70.726 \%$ \\
\hline 50 & tarima & 0.04481 & $0.357 \%$ & $8.475 \%$ & $71.083 \%$ \\
\hline 51 & calendario & 0.04446 & $0.489 \%$ & $11.582 \%$ & $71.572 \%$ \\
\hline 52 & subrayador & 0.04281 & $0.381 \%$ & $9.040 \%$ & $71.953 \%$ \\
\hline 53 & tijeras & 0.04234 & $0.429 \%$ & $10.169 \%$ & $72.382 \%$ \\
\hline 54 & mapa & 0.04223 & $0.357 \%$ & $8.475 \%$ & $72.739 \%$ \\
\hline 55 & portaminas & 0.04188 & $0.369 \%$ & $8.757 \%$ & $73.108 \%$ \\
\hline 56 & grapadora & 0.04076 & $0.548 \%$ & $12.994 \%$ & $73.656 \%$ \\
\hline 57 & agenda & 0.03955 & $0.489 \%$ & $11.582 \%$ & $74.145 \%$ \\
\hline 58 & luz & 0.03940 & $0.381 \%$ & $9.040 \%$ & $74.526 \%$ \\
\hline 59 & profesor & 0.03937 & $0.298 \%$ & $7.062 \%$ & $74.824 \%$ \\
\hline 60 & cartulina & 0.03920 & $0.393 \%$ & $9.322 \%$ & $75.217 \%$ \\
\hline 61 & bloc & 0.03499 & $0.298 \%$ & $7.062 \%$ & $75.515 \%$ \\
\hline 62 & aula & 0.03454 & $0.262 \%$ & $6.215 \%$ & $75.777 \%$ \\
\hline 63 & pegamento & 0.03361 & $0.381 \%$ & $9.040 \%$ & $76.158 \%$ \\
\hline 64 & clip & 0.03193 & $0.381 \%$ & $9.040 \%$ & $76.539 \%$ \\
\hline 65 & $\operatorname{mina}$ & 0.03174 & $0.346 \%$ & $8.192 \%$ & $76.885 \%$ \\
\hline 66 & cuadro & 0.03140 & $0.310 \%$ & $7.345 \%$ & $77.195 \%$ \\
\hline 67 & corrector & 0.03106 & $0.298 \%$ & $7.062 \%$ & $77.493 \%$ \\
\hline 68 & banco & 0.03007 & $0.262 \%$ & $6.215 \%$ & $77.755 \%$ \\
\hline 69 & clase & 0.02937 & $0.203 \%$ & $4.802 \%$ & $77.958 \%$ \\
\hline 70 & apuntes & 0.02925 & $0.298 \%$ & $7.062 \%$ & $78.256 \%$ \\
\hline 71 & radiador & 0.02902 & $0.250 \%$ & $5.932 \%$ & $78.506 \%$ \\
\hline 72 & pantalla & 0.02824 & $0.250 \%$ & $5.932 \%$ & $78.756 \%$ \\
\hline 73 & silla de profesor & 0.02822 & $0.167 \%$ & $3.955 \%$ & $78.923 \%$ \\
\hline 74 & proyector & 0.02730 & $0.250 \%$ & $5.932 \%$ & $79.173 \%$ \\
\hline 75 & archivador & 0.02699 & $0.286 \%$ & $6.780 \%$ & $79.459 \%$ \\
\hline 76 & mesa de alumno & 0.02686 & $0.131 \%$ & $3.107 \%$ & $79.590 \%$ \\
\hline 77 & fotocopia & 0.02519 & $0.226 \%$ & $5.367 \%$ & $79.816 \%$ \\
\hline
\end{tabular}




\begin{tabular}{|c|c|c|c|c|c|}
\hline 78 & calefacción & 0.02491 & $0.262 \%$ & $6.215 \%$ & $80.078 \%$ \\
\hline 79 & corcho & 0.02466 & $0.203 \%$ & $4.802 \%$ & $80.281 \%$ \\
\hline 80 & gimnasio & 0.02232 & $0.226 \%$ & $5.367 \%$ & $80.507 \%$ \\
\hline 81 & cera & 0.02221 & $0.191 \%$ & $4.520 \%$ & $80.698 \%$ \\
\hline 82 & biblioteca & 0.02211 & $0.203 \%$ & $4.802 \%$ & $80.901 \%$ \\
\hline 83 & patio & 0.02167 & $0.238 \%$ & $5.650 \%$ & $81.139 \%$ \\
\hline 84 & examen & 0.02152 & $0.214 \%$ & $5.085 \%$ & $81.353 \%$ \\
\hline 85 & cortina & 0.02132 & $0.203 \%$ & $4.802 \%$ & $81.556 \%$ \\
\hline 86 & lápiz de colores & 0.02074 & $0.179 \%$ & $4.237 \%$ & $81.735 \%$ \\
\hline 87 & lámpara & 0.02071 & $0.214 \%$ & $5.085 \%$ & $81.949 \%$ \\
\hline 88 & diapositiva & 0.02063 & $0.226 \%$ & $5.367 \%$ & $82.175 \%$ \\
\hline 89 & despacho & 0.01977 & $0.179 \%$ & $4.237 \%$ & $82.354 \%$ \\
\hline 90 & silla de alumno & 0.01885 & $0.095 \%$ & $2.260 \%$ & $82.449 \%$ \\
\hline 91 & timbre & 0.01859 & $0.203 \%$ & $4.802 \%$ & $82.652 \%$ \\
\hline 92 & televisor & 0.01813 & $0.143 \%$ & $3.390 \%$ & $82.795 \%$ \\
\hline 93 & baño & 0.01721 & $0.179 \%$ & $4.237 \%$ & $82.974 \%$ \\
\hline 94 & sillón de profesor & 0.01701 & $0.095 \%$ & $2.260 \%$ & $83.069 \%$ \\
\hline 95 & portería & 0.01677 & $0.214 \%$ & $5.085 \%$ & $83.283 \%$ \\
\hline 96 & Rotring* & 0.01659 & $0.167 \%$ & $3.955 \%$ & $83.450 \%$ \\
\hline 97 & cartelera & 0.01646 & $0.155 \%$ & $3.672 \%$ & $83.605 \%$ \\
\hline 98 & alumno & 0.01625 & $0.131 \%$ & $3.107 \%$ & $83.736 \%$ \\
\hline 99 & tinta & 0.01572 & $0.179 \%$ & $4.237 \%$ & $83.915 \%$ \\
\hline 100 & plastilina & 0.01560 & $0.143 \%$ & $3.390 \%$ & $84.058 \%$ \\
\hline 101 & panel & 0.01513 & $0.131 \%$ & $3.107 \%$ & $84.189 \%$ \\
\hline 102 & Pilot* & 0.01506 & $0.119 \%$ & $2.825 \%$ & $84.308 \%$ \\
\hline 103 & hoja cuadriculada & 0.01485 & $0.131 \%$ & $3.107 \%$ & $84.439 \%$ \\
\hline 104 & escalera & 0.01476 & $0.179 \%$ & $4.237 \%$ & $84.618 \%$ \\
\hline 105 & pasillo & 0.01460 & $0.143 \%$ & $3.390 \%$ & $84.761 \%$ \\
\hline 106 & impresora & 0.01448 & $0.131 \%$ & $3.107 \%$ & $84.892 \%$ \\
\hline 107 & extintor & 0.01414 & $0.155 \%$ & $3.672 \%$ & $85.047 \%$ \\
\hline 108 & balón & 0.01367 & $0.167 \%$ & $3.955 \%$ & $85.214 \%$ \\
\hline 109 & servicio & 0.01333 & $0.131 \%$ & $3.107 \%$ & $85.345 \%$ \\
\hline 110 & póster & 0.01323 & $0.131 \%$ & $3.107 \%$ & $85.476 \%$ \\
\hline 111 & pintura & 0.01279 & $0.167 \%$ & $3.955 \%$ & $85.643 \%$ \\
\hline 112 & enciclopedia & 0.01276 & $0.155 \%$ & $3.672 \%$ & $85.798 \%$ \\
\hline 113 & (pluma) estilográfica & 0.01246 & $0.095 \%$ & $2.260 \%$ & $85.893 \%$ \\
\hline 114 & chincheta & 0.01241 & $0.203 \%$ & $4.802 \%$ & $86.096 \%$ \\
\hline 115 & teléfono & 0.01212 & $0.155 \%$ & $3.672 \%$ & $86.251 \%$ \\
\hline 116 & celo & 0.01207 & $0.167 \%$ & $3.955 \%$ & $86.418 \%$ \\
\hline 117 & lápiz de minas & 0.01188 & $0.095 \%$ & $2.260 \%$ & $86.513 \%$ \\
\hline 118 & canasta & 0.01180 & $0.143 \%$ & $3.390 \%$ & $86.656 \%$ \\
\hline 119 & portafolios & 0.01168 & $0.143 \%$ & $3.390 \%$ & $86.799 \%$ \\
\hline 120 & máquina de escribir & 0.01154 & $0.143 \%$ & $3.390 \%$ & $86.942 \%$ \\
\hline 121 & crucifijo & 0.01127 & $0.107 \%$ & $2.542 \%$ & $87.049 \%$ \\
\hline 122 & tablero & 0.01092 & $0.119 \%$ & $2.825 \%$ & $87.168 \%$ \\
\hline 123 & boli(grafo) azul & 0.01092 & $0.060 \%$ & $1.412 \%$ & $87.228 \%$ \\
\hline 124 & laboratorio & 0.01083 & $0.095 \%$ & $2.260 \%$ & $87.323 \%$ \\
\hline
\end{tabular}




\begin{tabular}{|c|c|c|c|c|c|}
\hline 125 & horario & 0.01071 & $0.143 \%$ & $3.390 \%$ & $87.466 \%$ \\
\hline 126 & fluorescente & 0.01070 & $0.107 \%$ & $2.542 \%$ & $87.573 \%$ \\
\hline 127 & escritorio & 0.01052 & $0.071 \%$ & $1.695 \%$ & $87.644 \%$ \\
\hline 128 & boli(grafo) negro & 0.01033 & $0.060 \%$ & $1.412 \%$ & $87.704 \%$ \\
\hline 129 & cartel & 0.01003 & $0.095 \%$ & $2.260 \%$ & $87.799 \%$ \\
\hline 130 & altavoz & 0.00989 & $0.131 \%$ & $3.107 \%$ & $87.930 \%$ \\
\hline 131 & librería & 0.00980 & $0.107 \%$ & $2.542 \%$ & $88.037 \%$ \\
\hline 132 & Plastidecor* & 0.00962 & $0.083 \%$ & $1.977 \%$ & $88.120 \%$ \\
\hline 133 & goma de borrar & 0.00947 & $0.083 \%$ & $1.977 \%$ & $88.203 \%$ \\
\hline 134 & basurero & 0.00939 & $0.071 \%$ & $1.695 \%$ & $88.274 \%$ \\
\hline 135 & colchoneta & 0.00913 & $0.095 \%$ & $2.260 \%$ & $88.369 \%$ \\
\hline 136 & taburete & 0.00898 & $0.048 \%$ & $1.130 \%$ & $88.417 \%$ \\
\hline 137 & grapa & 0.00888 & $0.131 \%$ & $3.107 \%$ & $88.548 \%$ \\
\hline 138 & parte & 0.00856 & $0.083 \%$ & $1.977 \%$ & $88.631 \%$ \\
\hline 139 & secretaría & 0.00843 & $0.071 \%$ & $1.695 \%$ & $88.702 \%$ \\
\hline 140 & boli(grafo) rojo & 0.00843 & $0.048 \%$ & $1.130 \%$ & $88.750 \%$ \\
\hline 141 & radiocasete & 0.00836 & $0.095 \%$ & $2.260 \%$ & $88.845 \%$ \\
\hline 142 & separador & 0.00830 & $0.107 \%$ & $2.542 \%$ & $88.952 \%$ \\
\hline 143 & escáner & 0.00818 & $0.071 \%$ & $1.695 \%$ & $89.023 \%$ \\
\hline 144 & libro de texto & 0.00809 & $0.095 \%$ & $2.260 \%$ & $89.118 \%$ \\
\hline 145 & cantina & 0.00809 & $0.095 \%$ & $2.260 \%$ & $89.213 \%$ \\
\hline 146 & clasificador & 0.00805 & $0.119 \%$ & $2.825 \%$ & $89.332 \%$ \\
\hline 147 & lavabo & 0.00803 & $0.107 \%$ & $2.542 \%$ & $89.439 \%$ \\
\hline 148 & semicírculo & 0.00802 & $0.095 \%$ & $2.260 \%$ & $89.534 \%$ \\
\hline 149 & microscopio & 0.00770 & $0.071 \%$ & $1.695 \%$ & $89.605 \%$ \\
\hline 150 & pincel & 0.00746 & $0.095 \%$ & $2.260 \%$ & $89.700 \%$ \\
\hline 151 & taquilla & 0.00742 & $0.095 \%$ & $2.260 \%$ & $89.795 \%$ \\
\hline 152 & chuleta & 0.00740 & $0.071 \%$ & $1.695 \%$ & $89.866 \%$ \\
\hline 153 & reloj & 0.00738 & $0.083 \%$ & $1.977 \%$ & $89.949 \%$ \\
\hline 154 & acuarela & 0.00731 & $0.095 \%$ & $2.260 \%$ & $90.044 \%$ \\
\hline 155 & sirena & 0.00730 & $0.071 \%$ & $1.695 \%$ & $90.115 \%$ \\
\hline 156 & sofá & 0.00729 & $0.060 \%$ & $1.412 \%$ & $90.175 \%$ \\
\hline 157 & cristal & 0.00724 & $0.048 \%$ & $1.130 \%$ & $90.223 \%$ \\
\hline 158 & bolso & 0.00707 & $0.095 \%$ & $2.260 \%$ & $90.318 \%$ \\
\hline 159 & interruptor & 0.00695 & $0.071 \%$ & $1.695 \%$ & $90.389 \%$ \\
\hline 160 & pelota & 0.00695 & $0.095 \%$ & $2.260 \%$ & $90.484 \%$ \\
\hline 161 & comedor & 0.00694 & $0.083 \%$ & $1.977 \%$ & $90.567 \%$ \\
\hline 162 & proyector de diapositivas & 0.00680 & $0.071 \%$ & $1.695 \%$ & $90.638 \%$ \\
\hline 163 & máquina de diapositivas & 0.00680 & $0.060 \%$ & $1.412 \%$ & $90.698 \%$ \\
\hline 164 & gafas & 0.00680 & $0.071 \%$ & $1.695 \%$ & $90.769 \%$ \\
\hline 165 & bureta & 0.00676 & $0.083 \%$ & $1.977 \%$ & $90.852 \%$ \\
\hline 166 & enchufe & 0.00673 & $0.095 \%$ & $2.260 \%$ & $90.947 \%$ \\
\hline 167 & maquina de café & 0.00669 & $0.071 \%$ & $1.695 \%$ & $91.018 \%$ \\
\hline 168 & estante & 0.00668 & $0.060 \%$ & $1.412 \%$ & $91.078 \%$ \\
\hline 169 & tubo de luz & 0.00666 & $0.060 \%$ & $1.412 \%$ & $91.138 \%$ \\
\hline 170 & mesa de dibujo & 0.00662 & $0.048 \%$ & $1.130 \%$ & $91.186 \%$ \\
\hline 171 & foto del rey & 0.00662 & $0.060 \%$ & $1.412 \%$ & $91.246 \%$ \\
\hline
\end{tabular}




\begin{tabular}{|c|c|c|c|c|c|}
\hline 172 & lapicero & 0.00657 & $0.060 \%$ & $1.412 \%$ & $91.306 \%$ \\
\hline 173 & pipeta & 0.00654 & $0.095 \%$ & $2.260 \%$ & $91.401 \%$ \\
\hline 174 & plumier & 0.00632 & $0.071 \%$ & $1.695 \%$ & $91.472 \%$ \\
\hline 175 & libro de mate(máticas) & 0.00626 & $0.036 \%$ & $0.847 \%$ & $91.508 \%$ \\
\hline 176 & cartel de anuncios & 0.00597 & $0.048 \%$ & $1.130 \%$ & $91.556 \%$ \\
\hline 177 & anilla & 0.00591 & $0.071 \%$ & $1.695 \%$ & $91.627 \%$ \\
\hline 178 & bombilla & 0.00587 & $0.060 \%$ & $1.412 \%$ & $91.687 \%$ \\
\hline 179 & pantalla de diapositivas & 0.00578 & $0.048 \%$ & $1.130 \%$ & $91.735 \%$ \\
\hline 180 & tubo de ensayo & 0.00563 & $0.071 \%$ & $1.695 \%$ & $91.806 \%$ \\
\hline 181 & vocabulario & 0.00557 & $0.071 \%$ & $1.695 \%$ & $91.877 \%$ \\
\hline 182 & bar & 0.00555 & $0.060 \%$ & $1.412 \%$ & $91.937 \%$ \\
\hline 183 & tiza de colores & 0.00553 & $0.036 \%$ & $0.847 \%$ & $91.973 \%$ \\
\hline 184 & cuadro del rey & 0.00543 & $0.048 \%$ & $1.130 \%$ & $92.021 \%$ \\
\hline 185 & pared & 0.00540 & $0.048 \%$ & $1.130 \%$ & $92.069 \%$ \\
\hline 186 & fuente & 0.00539 & $0.060 \%$ & $1.412 \%$ & $92.129 \%$ \\
\hline 187 & espaldera & 0.00539 & $0.060 \%$ & $1.412 \%$ & $92.189 \%$ \\
\hline 188 & polideportivo & 0.00531 & $0.060 \%$ & $1.412 \%$ & $92.249 \%$ \\
\hline 189 & azulejo & 0.00531 & $0.048 \%$ & $1.130 \%$ & $92.297 \%$ \\
\hline 190 & aire acondicionado & 0.00516 & $0.071 \%$ & $1.695 \%$ & $92.368 \%$ \\
\hline 191 & probeta & 0.00510 & $0.060 \%$ & $1.412 \%$ & $92.428 \%$ \\
\hline 192 & Cristo & 0.00485 & $0.060 \%$ & $1.412 \%$ & $92.488 \%$ \\
\hline 193 & recambio & 0.00474 & $0.071 \%$ & $1.695 \%$ & $92.559 \%$ \\
\hline 194 & pala & 0.00469 & $0.024 \%$ & $0.565 \%$ & $92.583 \%$ \\
\hline 195 & fichero & 0.00463 & $0.060 \%$ & $1.412 \%$ & $92.643 \%$ \\
\hline 196 & punzón & 0.00459 & $0.048 \%$ & $1.130 \%$ & $92.691 \%$ \\
\hline 197 & carpeta de anillas & 0.00457 & $0.048 \%$ & $1.130 \%$ & $92.739 \%$ \\
\hline 198 & cuerda & 0.00456 & $0.060 \%$ & $1.412 \%$ & $92.799 \%$ \\
\hline 199 & cafetería & 0.00450 & $0.036 \%$ & $0.847 \%$ & $92.835 \%$ \\
\hline 200 & suelo & 0.00445 & $0.036 \%$ & $0.847 \%$ & $92.871 \%$ \\
\hline 201 & reja & 0.00444 & $0.036 \%$ & $0.847 \%$ & $92.907 \%$ \\
\hline 202 & salón de actos & 0.00439 & $0.060 \%$ & $1.412 \%$ & $92.967 \%$ \\
\hline 203 & papel milimetrado & 0.00428 & $0.048 \%$ & $1.130 \%$ & $93.015 \%$ \\
\hline 204 & madera & 0.00415 & $0.024 \%$ & $0.565 \%$ & $93.039 \%$ \\
\hline 205 & archivo & 0.00405 & $0.036 \%$ & $0.847 \%$ & $93.075 \%$ \\
\hline 206 & cuarto de baño & 0.00401 & $0.048 \%$ & $1.130 \%$ & $93.123 \%$ \\
\hline 207 & paragüero & 0.00399 & $0.060 \%$ & $1.412 \%$ & $93.183 \%$ \\
\hline 208 & chaqueta & 0.00397 & $0.048 \%$ & $1.130 \%$ & $93.231 \%$ \\
\hline 209 & libro de historia & 0.00396 & $0.036 \%$ & $0.847 \%$ & $93.267 \%$ \\
\hline 210 & papel de charol & 0.00395 & $0.048 \%$ & $1.130 \%$ & $93.315 \%$ \\
\hline 211 & Dibujo & 0.00390 & $0.036 \%$ & $0.847 \%$ & $93.351 \%$ \\
\hline 212 & bocadillo & 0.00387 & $0.048 \%$ & $1.130 \%$ & $93.399 \%$ \\
\hline 213 & clasificadora & 0.00383 & $0.048 \%$ & $1.130 \%$ & $93.447 \%$ \\
\hline 214 & fosforito & 0.00383 & $0.060 \%$ & $1.412 \%$ & $93.507 \%$ \\
\hline 215 & mesa de laboratorio & 0.00379 & $0.024 \%$ & $0.565 \%$ & $93.531 \%$ \\
\hline 216 & goma de bolí(grafo) & 0.00376 & $0.036 \%$ & $0.847 \%$ & $93.567 \%$ \\
\hline 217 & vestuario & 0.00368 & $0.048 \%$ & $1.130 \%$ & $93.615 \%$ \\
\hline 218 & pinza & 0.00366 & $0.024 \%$ & $0.565 \%$ & $93.639 \%$ \\
\hline
\end{tabular}




\begin{tabular}{|c|c|c|c|c|c|}
\hline 219 & tubo fluorescente & 0.00357 & $0.036 \%$ & $0.847 \%$ & $93.675 \%$ \\
\hline 220 & váter & 0.00356 & $0.048 \%$ & $1.130 \%$ & $93.723 \%$ \\
\hline 221 & boli(grafo) verde & 0.00355 & $0.024 \%$ & $0.565 \%$ & $93.747 \%$ \\
\hline 222 & ladrillo & 0.00348 & $0.024 \%$ & $0.565 \%$ & $93.771 \%$ \\
\hline 223 & atril & 0.00346 & $0.024 \%$ & $0.565 \%$ & $93.795 \%$ \\
\hline 224 & equipo de música & 0.00346 & $0.024 \%$ & $0.565 \%$ & $93.819 \%$ \\
\hline 225 & maestro & 0.00346 & $0.024 \%$ & $0.565 \%$ & $93.843 \%$ \\
\hline 226 & bola del mundo & 0.00339 & $0.048 \%$ & $1.130 \%$ & $93.891 \%$ \\
\hline 227 & conserjería & 0.00336 & $0.036 \%$ & $0.847 \%$ & $93.927 \%$ \\
\hline 228 & sala de audiovisuales & 0.00331 & $0.024 \%$ & $0.565 \%$ & $93.951 \%$ \\
\hline 229 & ratón & 0.00329 & $0.024 \%$ & $0.565 \%$ & $93.975 \%$ \\
\hline 230 & parte de faltas & 0.00327 & $0.036 \%$ & $0.847 \%$ & $94.011 \%$ \\
\hline 231 & columna & 0.00324 & $0.024 \%$ & $0.565 \%$ & $94.035 \%$ \\
\hline 232 & folio cuadriculado & 0.00324 & $0.036 \%$ & $0.847 \%$ & $94.071 \%$ \\
\hline 233 & casete & 0.00324 & $0.036 \%$ & $0.847 \%$ & $94.107 \%$ \\
\hline 234 & cuartilla & 0.00315 & $0.036 \%$ & $0.847 \%$ & $94.143 \%$ \\
\hline 235 & bolsa de deporte & 0.00312 & $0.048 \%$ & $1.130 \%$ & $94.191 \%$ \\
\hline 236 & techo & 0.00309 & $0.036 \%$ & $0.847 \%$ & $94.227 \%$ \\
\hline 237 & expositor & 0.00306 & $0.024 \%$ & $0.565 \%$ & $94.251 \%$ \\
\hline 238 & teatro & 0.00306 & $0.024 \%$ & $0.565 \%$ & $94.275 \%$ \\
\hline 239 & bloc de anillas & 0.00305 & $0.036 \%$ & $0.847 \%$ & $94.311 \%$ \\
\hline 240 & carpesano & 0.00304 & $0.024 \%$ & $0.565 \%$ & $94.335 \%$ \\
\hline 241 & mural & 0.00294 & $0.024 \%$ & $0.565 \%$ & $94.359 \%$ \\
\hline 242 & planta & 0.00293 & $0.036 \%$ & $0.847 \%$ & $94.395 \%$ \\
\hline 243 & sala de profesores & 0.00289 & $0.036 \%$ & $0.847 \%$ & $94.431 \%$ \\
\hline 244 & novela & 0.00287 & $0.024 \%$ & $0.565 \%$ & $94.455 \%$ \\
\hline 245 & celofán & 0.00284 & $0.036 \%$ & $0.847 \%$ & $94.491 \%$ \\
\hline 246 & tintero & 0.00283 & $0.036 \%$ & $0.847 \%$ & $94.527 \%$ \\
\hline 247 & entrada & 0.00282 & $0.012 \%$ & $0.282 \%$ & $94.539 \%$ \\
\hline 248 & edificio & 0.00282 & $0.012 \%$ & $0.282 \%$ & $94.551 \%$ \\
\hline 249 & niño & 0.00282 & $0.012 \%$ & $0.282 \%$ & $94.563 \%$ \\
\hline 250 & taula & 0.00282 & $0.012 \%$ & $0.282 \%$ & $94.575 \%$ \\
\hline 251 & Pórtland* & 0.00282 & $0.012 \%$ & $0.282 \%$ & $94.587 \%$ \\
\hline 252 & líquido corrector & 0.00278 & $0.024 \%$ & $0.565 \%$ & $94.611 \%$ \\
\hline 253 & permanente & 0.00277 & $0.024 \%$ & $0.565 \%$ & $94.635 \%$ \\
\hline 254 & espejo & 0.00276 & $0.024 \%$ & $0.565 \%$ & $94.659 \%$ \\
\hline 255 & esqueleto & 0.00275 & $0.036 \%$ & $0.847 \%$ & $94.695 \%$ \\
\hline 256 & tiralíneas & 0.00270 & $0.024 \%$ & $0.565 \%$ & $94.719 \%$ \\
\hline 257 & cuño & 0.00267 & $0.024 \%$ & $0.565 \%$ & $94.743 \%$ \\
\hline 258 & vaso & 0.00267 & $0.036 \%$ & $0.847 \%$ & $94.779 \%$ \\
\hline 259 & micrófono & 0.00266 & $0.024 \%$ & $0.565 \%$ & $94.803 \%$ \\
\hline 260 & paquete de folios & 0.00265 & $0.012 \%$ & $0.282 \%$ & $94.815 \%$ \\
\hline 261 & ludoteca & 0.00265 & $0.012 \%$ & $0.282 \%$ & $94.827 \%$ \\
\hline 262 & cadira & 0.00265 & $0.012 \%$ & $0.282 \%$ & $94.839 \%$ \\
\hline 263 & yeso & 0.00265 & $0.012 \%$ & $0.282 \%$ & $94.851 \%$ \\
\hline 264 & conserje & 0.00263 & $0.036 \%$ & $0.847 \%$ & $94.887 \%$ \\
\hline 265 & lupa & 0.00260 & $0.024 \%$ & $0.565 \%$ & $94.911 \%$ \\
\hline
\end{tabular}




\begin{tabular}{|c|c|c|c|c|c|}
\hline 266 & salón & 0.00259 & $0.024 \%$ & $0.565 \%$ & $94.935 \%$ \\
\hline 267 & atlas & 0.00252 & $0.024 \%$ & $0.565 \%$ & $94.959 \%$ \\
\hline 268 & aro & 0.00251 & $0.036 \%$ & $0.847 \%$ & $94.995 \%$ \\
\hline 269 & entarimado & 0.00249 & $0.012 \%$ & $0.282 \%$ & $95.007 \%$ \\
\hline 270 & pila & 0.00249 & $0.012 \%$ & $0.282 \%$ & $95.019 \%$ \\
\hline 271 & rejilla & 0.00249 & $0.012 \%$ & $0.282 \%$ & $95.031 \%$ \\
\hline 272 & blanqueador & 0.00249 & $0.012 \%$ & $0.282 \%$ & $95.043 \%$ \\
\hline 273 & mina de lápices & 0.00246 & $0.024 \%$ & $0.565 \%$ & $95.067 \%$ \\
\hline 274 & lámina & 0.00245 & $0.036 \%$ & $0.847 \%$ & $95.103 \%$ \\
\hline 275 & horno & 0.00245 & $0.024 \%$ & $0.565 \%$ & $95.127 \%$ \\
\hline 276 & puntafina & 0.00244 & $0.024 \%$ & $0.565 \%$ & $95.151 \%$ \\
\hline 277 & cuadro de la Virgen & 0.00244 & $0.024 \%$ & $0.565 \%$ & $95.175 \%$ \\
\hline 278 & papel de váter & 0.00244 & $0.024 \%$ & $0.565 \%$ & $95.199 \%$ \\
\hline 279 & babero & 0.00239 & $0.036 \%$ & $0.847 \%$ & $95.235 \%$ \\
\hline 280 & corrector de tinta & 0.00237 & $0.024 \%$ & $0.565 \%$ & $95.259 \%$ \\
\hline 281 & falsilla & 0.00235 & $0.024 \%$ & $0.565 \%$ & $95.283 \%$ \\
\hline 282 & trípode & 0.00234 & $0.012 \%$ & $0.282 \%$ & $95.295 \%$ \\
\hline 283 & alarma & 0.00234 & $0.012 \%$ & $0.282 \%$ & $95.307 \%$ \\
\hline 284 & tablón de corcho & 0.00234 & $0.012 \%$ & $0.282 \%$ & $95.319 \%$ \\
\hline 285 & mueble de televisor & 0.00234 & $0.012 \%$ & $0.282 \%$ & $95.331 \%$ \\
\hline 286 & cuadernillo & 0.00233 & $0.024 \%$ & $0.565 \%$ & $95.355 \%$ \\
\hline 287 & dirección & 0.00228 & $0.024 \%$ & $0.565 \%$ & $95.379 \%$ \\
\hline 288 & revista & 0.00228 & $0.024 \%$ & $0.565 \%$ & $95.403 \%$ \\
\hline 289 & Paralex* & 0.00222 & $0.024 \%$ & $0.565 \%$ & $95.427 \%$ \\
\hline 290 & calefactor & 0.00221 & $0.024 \%$ & $0.565 \%$ & $95.451 \%$ \\
\hline 291 & capitel & 0.00220 & $0.012 \%$ & $0.282 \%$ & $95.463 \%$ \\
\hline 292 & sala de estudios & 0.00220 & $0.012 \%$ & $0.282 \%$ & $95.475 \%$ \\
\hline 293 & máquina fotocopiadora & 0.00220 & $0.012 \%$ & $0.282 \%$ & $95.487 \%$ \\
\hline 294 & sello & 0.00220 & $0.012 \%$ & $0.282 \%$ & $95.499 \%$ \\
\hline 295 & cuaderno de anillas & 0.00220 & $0.012 \%$ & $0.282 \%$ & $95.511 \%$ \\
\hline 296 & plato & 0.00217 & $0.024 \%$ & $0.565 \%$ & $95.535 \%$ \\
\hline 297 & cafetera & 0.00215 & $0.024 \%$ & $0.565 \%$ & $95.559 \%$ \\
\hline 298 & libro de lectura & 0.00215 & $0.036 \%$ & $0.847 \%$ & $95.595 \%$ \\
\hline 299 & fax & 0.00210 & $0.024 \%$ & $0.565 \%$ & $95.619 \%$ \\
\hline 300 & panel de anuncios & 0.00208 & $0.024 \%$ & $0.565 \%$ & $95.643 \%$ \\
\hline 301 & hierro & 0.00207 & $0.012 \%$ & $0.282 \%$ & $95.655 \%$ \\
\hline 302 & tubería & 0.00207 & $0.024 \%$ & $0.565 \%$ & $95.679 \%$ \\
\hline 303 & interruptor de luz & 0.00207 & $0.012 \%$ & $0.282 \%$ & $95.691 \%$ \\
\hline 304 & panel informativo & 0.00207 & $0.012 \%$ & $0.282 \%$ & $95.703 \%$ \\
\hline 305 & tapa de bolígrafo & 0.00207 & $0.012 \%$ & $0.282 \%$ & $95.715 \%$ \\
\hline 306 & impreso & 0.00207 & $0.012 \%$ & $0.282 \%$ & $95.727 \%$ \\
\hline 307 & parasol & 0.00207 & $0.012 \%$ & $0.282 \%$ & $95.739 \%$ \\
\hline 308 & mesa de tecnología & 0.00207 & $0.012 \%$ & $0.282 \%$ & $95.751 \%$ \\
\hline 309 & programa & 0.00207 & $0.012 \%$ & $0.282 \%$ & $95.763 \%$ \\
\hline 310 & director & 0.00206 & $0.036 \%$ & $0.847 \%$ & $95.799 \%$ \\
\hline 311 & aseo & 0.00202 & $0.024 \%$ & $0.565 \%$ & $95.823 \%$ \\
\hline 312 & diario & 0.00200 & $0.024 \%$ & $0.565 \%$ & $95.847 \%$ \\
\hline
\end{tabular}




\begin{tabular}{|c|c|c|c|c|c|}
\hline 313 & vaso de precipitados & 0.00200 & $0.024 \%$ & $0.565 \%$ & $95.871 \%$ \\
\hline 314 & papel de seda & 0.00198 & $0.024 \%$ & $0.565 \%$ & $95.895 \%$ \\
\hline 315 & cliché & 0.00197 & $0.024 \%$ & $0.565 \%$ & $95.919 \%$ \\
\hline 316 & película & 0.00195 & $0.012 \%$ & $0.282 \%$ & $95.931 \%$ \\
\hline 317 & tubo & 0.00195 & $0.012 \%$ & $0.282 \%$ & $95.943 \%$ \\
\hline 318 & patio de deportes & 0.00195 & $0.012 \%$ & $0.282 \%$ & $95.955 \%$ \\
\hline 319 & patio de juegos & 0.00195 & $0.012 \%$ & $0.282 \%$ & $95.967 \%$ \\
\hline 320 & clarión & 0.00195 & $0.012 \%$ & $0.282 \%$ & $95.979 \%$ \\
\hline 321 & mueble de televisión & 0.00195 & $0.012 \%$ & $0.282 \%$ & $95.991 \%$ \\
\hline 322 & colgador & 0.00194 & $0.024 \%$ & $0.565 \%$ & $96.015 \%$ \\
\hline 323 & árbol & 0.00192 & $0.036 \%$ & $0.847 \%$ & $96.051 \%$ \\
\hline 324 & maletín & 0.00191 & $0.024 \%$ & $0.565 \%$ & $96.075 \%$ \\
\hline 325 & sala de juegos & 0.00189 & $0.024 \%$ & $0.565 \%$ & $96.099 \%$ \\
\hline 326 & $\mathrm{WC}$ & 0.00183 & $0.012 \%$ & $0.282 \%$ & $96.111 \%$ \\
\hline 327 & auricular & 0.00183 & $0.012 \%$ & $0.282 \%$ & $96.123 \%$ \\
\hline 328 & sala de director & 0.00183 & $0.012 \%$ & $0.282 \%$ & $96.135 \%$ \\
\hline 329 & grifo & 0.00183 & $0.012 \%$ & $0.282 \%$ & $96.147 \%$ \\
\hline 330 & grabadora & 0.00183 & $0.012 \%$ & $0.282 \%$ & $96.159 \%$ \\
\hline 331 & cocina & 0.00179 & $0.024 \%$ & $0.565 \%$ & $96.183 \%$ \\
\hline 332 & habitación & 0.00176 & $0.024 \%$ & $0.565 \%$ & $96.207 \%$ \\
\hline 333 & red de voleibol & 0.00174 & $0.024 \%$ & $0.565 \%$ & $96.231 \%$ \\
\hline 334 & bloc de notas & 0.00173 & $0.036 \%$ & $0.847 \%$ & $96.267 \%$ \\
\hline 335 & cajonera & 0.00172 & $0.012 \%$ & $0.282 \%$ & $96.279 \%$ \\
\hline 336 & cinta & 0.00172 & $0.012 \%$ & $0.282 \%$ & $96.291 \%$ \\
\hline 337 & bolígrafo rosa & 0.00172 & $0.012 \%$ & $0.282 \%$ & $96.303 \%$ \\
\hline 338 & sala de jefe de estudios & 0.00172 & $0.012 \%$ & $0.282 \%$ & $96.315 \%$ \\
\hline 339 & cuarto de aseo & 0.00172 & $0.012 \%$ & $0.282 \%$ & $96.327 \%$ \\
\hline 340 & color pastel & 0.00172 & $0.012 \%$ & $0.282 \%$ & $96.339 \%$ \\
\hline 341 & cámara de fotos & 0.00172 & $0.012 \%$ & $0.282 \%$ & $96.351 \%$ \\
\hline 342 & aula desmontable & 0.00172 & $0.012 \%$ & $0.282 \%$ & $96.363 \%$ \\
\hline 343 & columpio & 0.00170 & $0.024 \%$ & $0.565 \%$ & $96.387 \%$ \\
\hline 344 & folleto & 0.00168 & $0.024 \%$ & $0.565 \%$ & $96.411 \%$ \\
\hline 345 & piano & 0.00166 & $0.024 \%$ & $0.565 \%$ & $96.435 \%$ \\
\hline 346 & hall & 0.00165 & $0.024 \%$ & $0.565 \%$ & $96.459 \%$ \\
\hline 347 & mechero Bunsen & 0.00162 & $0.024 \%$ & $0.565 \%$ & $96.483 \%$ \\
\hline 348 & aparato de diapositivas & 0.00161 & $0.012 \%$ & $0.282 \%$ & $96.495 \%$ \\
\hline 349 & videoteca & 0.00161 & $0.012 \%$ & $0.282 \%$ & $96.507 \%$ \\
\hline 350 & basura & 0.00161 & $0.012 \%$ & $0.282 \%$ & $96.519 \%$ \\
\hline 351 & pancarta & 0.00161 & $0.012 \%$ & $0.282 \%$ & $96.531 \%$ \\
\hline 352 & bolígrafo naranja & 0.00161 & $0.012 \%$ & $0.282 \%$ & $96.543 \%$ \\
\hline 353 & cámara de diapositivas & 0.00161 & $0.012 \%$ & $0.282 \%$ & $96.555 \%$ \\
\hline 354 & libro de lengua & 0.00161 & $0.012 \%$ & $0.282 \%$ & $96.567 \%$ \\
\hline 355 & información & 0.00161 & $0.012 \%$ & $0.282 \%$ & $96.579 \%$ \\
\hline 356 & vestíbulo & 0.00161 & $0.012 \%$ & $0.282 \%$ & $96.591 \%$ \\
\hline 357 & DIN A4* & 0.00161 & $0.012 \%$ & $0.282 \%$ & $96.603 \%$ \\
\hline 358 & cuaderno de ejercicios & 0.00161 & $0.012 \%$ & $0.282 \%$ & $96.615 \%$ \\
\hline 359 & subrayador amarillo & 0.00161 & $0.012 \%$ & $0.282 \%$ & $96.627 \%$ \\
\hline
\end{tabular}




\begin{tabular}{|c|c|c|c|c|c|}
\hline 360 & armario empotrado & 0.00161 & $0.012 \%$ & $0.282 \%$ & $96.639 \%$ \\
\hline 361 & cubo de reciclaje & 0.00161 & $0.012 \%$ & $0.282 \%$ & $96.651 \%$ \\
\hline 362 & ducha & 0.00160 & $0.024 \%$ & $0.565 \%$ & $96.675 \%$ \\
\hline 363 & perforadora & 0.00159 & $0.024 \%$ & $0.565 \%$ & $96.699 \%$ \\
\hline 364 & almuerzo & 0.00158 & $0.024 \%$ & $0.565 \%$ & $96.723 \%$ \\
\hline 365 & mesita & 0.00157 & $0.024 \%$ & $0.565 \%$ & $96.747 \%$ \\
\hline 366 & matraz aforado & 0.00154 & $0.024 \%$ & $0.565 \%$ & $96.771 \%$ \\
\hline 367 & plinto & 0.00154 & $0.024 \%$ & $0.565 \%$ & $96.795 \%$ \\
\hline 368 & megáfono & 0.00152 & $0.012 \%$ & $0.282 \%$ & $96.807 \%$ \\
\hline 369 & goma de precisión & 0.00152 & $0.012 \%$ & $0.282 \%$ & $96.819 \%$ \\
\hline 370 & libro de arte & 0.00152 & $0.012 \%$ & $0.282 \%$ & $96.831 \%$ \\
\hline 371 & fogón & 0.00152 & $0.012 \%$ & $0.282 \%$ & $96.843 \%$ \\
\hline 372 & cenicero & 0.00152 & $0.012 \%$ & $0.282 \%$ & $96.855 \%$ \\
\hline 373 & imagen de Jesús & 0.00152 & $0.012 \%$ & $0.282 \%$ & $96.867 \%$ \\
\hline 374 & subrayador verde & 0.00152 & $0.012 \%$ & $0.282 \%$ & $96.879 \%$ \\
\hline 375 & retrato & 0.00152 & $0.012 \%$ & $0.282 \%$ & $96.891 \%$ \\
\hline 376 & hoja de cuadros & 0.00149 & $0.024 \%$ & $0.565 \%$ & $96.915 \%$ \\
\hline 377 & documentación & 0.00143 & $0.012 \%$ & $0.282 \%$ & $96.927 \%$ \\
\hline 378 & pata & 0.00143 & $0.012 \%$ & $0.282 \%$ & $96.939 \%$ \\
\hline 379 & administración & 0.00143 & $0.012 \%$ & $0.282 \%$ & $96.951 \%$ \\
\hline 380 & anuncio & 0.00143 & $0.012 \%$ & $0.282 \%$ & $96.963 \%$ \\
\hline 381 & subrayador rojo & 0.00143 & $0.012 \%$ & $0.282 \%$ & $96.975 \%$ \\
\hline 382 & bloc de dibujo & 0.00141 & $0.024 \%$ & $0.565 \%$ & $96.999 \%$ \\
\hline 383 & ácido sulfúrico & 0.00141 & $0.024 \%$ & $0.565 \%$ & $97.023 \%$ \\
\hline 384 & matraz & 0.00136 & $0.024 \%$ & $0.565 \%$ & $97.047 \%$ \\
\hline 385 & pizarra de corcho & 0.00134 & $0.012 \%$ & $0.282 \%$ & $97.059 \%$ \\
\hline 386 & terraza & 0.00134 & $0.012 \%$ & $0.282 \%$ & $97.071 \%$ \\
\hline 387 & libro de filosofía & 0.00134 & $0.012 \%$ & $0.282 \%$ & $97.083 \%$ \\
\hline 388 & falta de asistencia & 0.00134 & $0.012 \%$ & $0.282 \%$ & $97.095 \%$ \\
\hline 389 & alarma antifuego & 0.00134 & $0.012 \%$ & $0.282 \%$ & $97.107 \%$ \\
\hline 390 & pañuelo & 0.00134 & $0.024 \%$ & $0.565 \%$ & $97.131 \%$ \\
\hline 391 & armario de pared & 0.00134 & $0.012 \%$ & $0.282 \%$ & $97.143 \%$ \\
\hline 392 & ácido cítrico & 0.00133 & $0.024 \%$ & $0.565 \%$ & $97.167 \%$ \\
\hline 393 & disquete & 0.00132 & $0.024 \%$ & $0.565 \%$ & $97.191 \%$ \\
\hline 394 & lista de exámenes & 0.00126 & $0.012 \%$ & $0.282 \%$ & $97.203 \%$ \\
\hline 395 & fosforito azul & 0.00126 & $0.012 \%$ & $0.282 \%$ & $97.215 \%$ \\
\hline 396 & maleta & 0.00126 & $0.012 \%$ & $0.282 \%$ & $97.227 \%$ \\
\hline 397 & libro de valenciano & 0.00126 & $0.012 \%$ & $0.282 \%$ & $97.239 \%$ \\
\hline 398 & tablón de notas & 0.00126 & $0.012 \%$ & $0.282 \%$ & $97.251 \%$ \\
\hline 399 & expediente & 0.00126 & $0.012 \%$ & $0.282 \%$ & $97.263 \%$ \\
\hline 400 & $\mathrm{CD}$ & 0.00126 & $0.012 \%$ & $0.282 \%$ & $97.275 \%$ \\
\hline 401 & palestra & 0.00126 & $0.012 \%$ & $0.282 \%$ & $97.287 \%$ \\
\hline 402 & megafonía & 0.00126 & $0.012 \%$ & $0.282 \%$ & $97.299 \%$ \\
\hline 403 & estuche de compás & 0.00126 & $0.012 \%$ & $0.282 \%$ & $97.311 \%$ \\
\hline 404 & disolvente & 0.00126 & $0.012 \%$ & $0.282 \%$ & $97.323 \%$ \\
\hline 405 & tubo de calefacción & 0.00126 & $0.012 \%$ & $0.282 \%$ & $97.335 \%$ \\
\hline 406 & tapadera de bolígrafo & 0.00126 & $0.012 \%$ & $0.282 \%$ & $97.347 \%$ \\
\hline
\end{tabular}




\begin{tabular}{|c|c|c|c|c|c|}
\hline 407 & potro & 0.00125 & $0.024 \%$ & $0.565 \%$ & $97.371 \%$ \\
\hline 408 & espátula & 0.00124 & $0.024 \%$ & $0.565 \%$ & $97.395 \%$ \\
\hline 409 & luz de emergencia & 0.00119 & $0.024 \%$ & $0.565 \%$ & $97.419 \%$ \\
\hline 410 & fosforito verde & 0.00118 & $0.012 \%$ & $0.282 \%$ & $97.431 \%$ \\
\hline 411 & libro de literatura valenciana & 0.00118 & $0.012 \%$ & $0.282 \%$ & $97.443 \%$ \\
\hline 412 & orla & 0.00118 & $0.012 \%$ & $0.282 \%$ & $97.455 \%$ \\
\hline 413 & mesilla & 0.00118 & $0.012 \%$ & $0.282 \%$ & $97.467 \%$ \\
\hline 414 & capilla & 0.00118 & $0.012 \%$ & $0.282 \%$ & $97.479 \%$ \\
\hline 415 & cúter & 0.00118 & $0.012 \%$ & $0.282 \%$ & $97.491 \%$ \\
\hline 416 & calco & 0.00118 & $0.012 \%$ & $0.282 \%$ & $97.503 \%$ \\
\hline 417 & detector de incendios & 0.00118 & $0.012 \%$ & $0.282 \%$ & $97.515 \%$ \\
\hline 418 & instrumento & 0.00118 & $0.012 \%$ & $0.282 \%$ & $97.527 \%$ \\
\hline 419 & sala & 0.00118 & $0.012 \%$ & $0.282 \%$ & $97.539 \%$ \\
\hline 420 & transparencia & 0.00118 & $0.012 \%$ & $0.282 \%$ & $97.551 \%$ \\
\hline 421 & foto de reyes & 0.00118 & $0.012 \%$ & $0.282 \%$ & $97.563 \%$ \\
\hline 422 & Kleenex* & 0.00118 & $0.012 \%$ & $0.282 \%$ & $97.575 \%$ \\
\hline 423 & cómic & 0.00118 & $0.012 \%$ & $0.282 \%$ & $97.587 \%$ \\
\hline 424 & palillo & 0.00118 & $0.012 \%$ & $0.282 \%$ & $97.599 \%$ \\
\hline 425 & calavera & 0.00118 & $0.012 \%$ & $0.282 \%$ & $97.611 \%$ \\
\hline 426 & máquina de Coca cola* & 0.00118 & $0.012 \%$ & $0.282 \%$ & $97.623 \%$ \\
\hline 427 & colores de Plastidecor* & 0.00118 & $0.012 \%$ & $0.282 \%$ & $97.635 \%$ \\
\hline 428 & lápiz de madera & 0.00116 & $0.024 \%$ & $0.565 \%$ & $97.659 \%$ \\
\hline 429 & cine & 0.00113 & $0.024 \%$ & $0.565 \%$ & $97.683 \%$ \\
\hline 430 & bedel & 0.00111 & $0.012 \%$ & $0.282 \%$ & $97.695 \%$ \\
\hline 431 & silla de pala & 0.00111 & $0.012 \%$ & $0.282 \%$ & $97.707 \%$ \\
\hline 432 & fosforito rosa & 0.00111 & $0.012 \%$ & $0.282 \%$ & $97.719 \%$ \\
\hline 433 & libro de inglés & 0.00111 & $0.012 \%$ & $0.282 \%$ & $97.731 \%$ \\
\hline 434 & premio deportivo & 0.00111 & $0.012 \%$ & $0.282 \%$ & $97.743 \%$ \\
\hline 435 & mueble de despacho & 0.00111 & $0.012 \%$ & $0.282 \%$ & $97.755 \%$ \\
\hline 436 & estuche de hierro & 0.00111 & $0.012 \%$ & $0.282 \%$ & $97.767 \%$ \\
\hline 437 & libreta de dibujo & 0.00111 & $0.012 \%$ & $0.282 \%$ & $97.779 \%$ \\
\hline 438 & estudiar & 0.00111 & $0.012 \%$ & $0.282 \%$ & $97.791 \%$ \\
\hline 439 & porche & 0.00111 & $0.012 \%$ & $0.282 \%$ & $97.803 \%$ \\
\hline 440 & encuadernador & 0.00111 & $0.012 \%$ & $0.282 \%$ & $97.815 \%$ \\
\hline 441 & escenario & 0.00111 & $0.012 \%$ & $0.282 \%$ & $97.827 \%$ \\
\hline 442 & Física & 0.00111 & $0.012 \%$ & $0.282 \%$ & $97.839 \%$ \\
\hline 443 & subcarpeta & 0.00111 & $0.012 \%$ & $0.282 \%$ & $97.851 \%$ \\
\hline 444 & recortable & 0.00111 & $0.012 \%$ & $0.282 \%$ & $97.863 \%$ \\
\hline 445 & colilla de tabaco & 0.00111 & $0.012 \%$ & $0.282 \%$ & $97.875 \%$ \\
\hline 446 & portaángulos & 0.00106 & $0.024 \%$ & $0.565 \%$ & $97.899 \%$ \\
\hline 447 & sala de administración & 0.00104 & $0.012 \%$ & $0.282 \%$ & $97.911 \%$ \\
\hline 448 & cruz de Cristo & 0.00104 & $0.012 \%$ & $0.282 \%$ & $97.923 \%$ \\
\hline 449 & frontón & 0.00104 & $0.012 \%$ & $0.282 \%$ & $97.935 \%$ \\
\hline 450 & bote & 0.00104 & $0.012 \%$ & $0.282 \%$ & $97.947 \%$ \\
\hline 451 & extractor & 0.00104 & $0.012 \%$ & $0.282 \%$ & $97.959 \%$ \\
\hline 452 & aula de diseño & 0.00104 & $0.012 \%$ & $0.282 \%$ & $97.971 \%$ \\
\hline 453 & aula de profesores & 0.00104 & $0.012 \%$ & $0.282 \%$ & $97.983 \%$ \\
\hline
\end{tabular}




\begin{tabular}{|c|c|c|c|c|c|}
\hline 454 & agobio & 0.00104 & $0.012 \%$ & $0.282 \%$ & $97.995 \%$ \\
\hline 455 & perforador & 0.00104 & $0.012 \%$ & $0.282 \%$ & $98.007 \%$ \\
\hline 456 & mando de puerta & 0.00104 & $0.012 \%$ & $0.282 \%$ & $98.019 \%$ \\
\hline 457 & Química & 0.00104 & $0.012 \%$ & $0.282 \%$ & $98.031 \%$ \\
\hline 458 & polvo & 0.00104 & $0.012 \%$ & $0.282 \%$ & $98.043 \%$ \\
\hline 459 & libro de pintar & 0.00104 & $0.012 \%$ & $0.282 \%$ & $98.055 \%$ \\
\hline 460 & color de cera & 0.00104 & $0.012 \%$ & $0.282 \%$ & $98.067 \%$ \\
\hline 461 & refrigerante & 0.00104 & $0.012 \%$ & $0.282 \%$ & $98.079 \%$ \\
\hline 462 & seminario & 0.00102 & $0.024 \%$ & $0.565 \%$ & $98.103 \%$ \\
\hline 463 & recargador & 0.00098 & $0.012 \%$ & $0.282 \%$ & $98.115 \%$ \\
\hline 464 & Virgen & 0.00098 & $0.012 \%$ & $0.282 \%$ & $98.127 \%$ \\
\hline 465 & cuadro de María & 0.00098 & $0.012 \%$ & $0.282 \%$ & $98.139 \%$ \\
\hline 466 & electricidad & 0.00098 & $0.012 \%$ & $0.282 \%$ & $98.151 \%$ \\
\hline 467 & laboratorio de idiomas & 0.00098 & $0.012 \%$ & $0.282 \%$ & $98.163 \%$ \\
\hline 468 & autobús & 0.00098 & $0.012 \%$ & $0.282 \%$ & $98.175 \%$ \\
\hline 469 & pesas & 0.00098 & $0.012 \%$ & $0.282 \%$ & $98.187 \%$ \\
\hline 470 & hoja milimetrada & 0.00098 & $0.012 \%$ & $0.282 \%$ & $98.199 \%$ \\
\hline 471 & foco & 0.00098 & $0.012 \%$ & $0.282 \%$ & $98.211 \%$ \\
\hline 472 & experimento & 0.00098 & $0.012 \%$ & $0.282 \%$ & $98.223 \%$ \\
\hline 473 & corrector de lápiz & 0.00098 & $0.012 \%$ & $0.282 \%$ & $98.235 \%$ \\
\hline 474 & cinta aislante & 0.00098 & $0.012 \%$ & $0.282 \%$ & $98.247 \%$ \\
\hline 475 & tabla de escribir & 0.00098 & $0.012 \%$ & $0.282 \%$ & $98.259 \%$ \\
\hline 476 & taladradora & 0.00098 & $0.012 \%$ & $0.282 \%$ & $98.271 \%$ \\
\hline 477 & folio blanco & 0.00098 & $0.012 \%$ & $0.282 \%$ & $98.283 \%$ \\
\hline 478 & café & 0.00098 & $0.012 \%$ & $0.282 \%$ & $98.295 \%$ \\
\hline 479 & Lengua & 0.00098 & $0.012 \%$ & $0.282 \%$ & $98.307 \%$ \\
\hline 480 & foto del rey y de la reina & 0.00098 & $0.012 \%$ & $0.282 \%$ & $98.319 \%$ \\
\hline 481 & caligrafía & 0.00098 & $0.012 \%$ & $0.282 \%$ & $98.331 \%$ \\
\hline 482 & precipitado & 0.00098 & $0.012 \%$ & $0.282 \%$ & $98.343 \%$ \\
\hline 483 & disco & 0.00098 & $0.012 \%$ & $0.282 \%$ & $98.355 \%$ \\
\hline 484 & hoja en blanco & 0.00092 & $0.012 \%$ & $0.282 \%$ & $98.367 \%$ \\
\hline 485 & rey & 0.00092 & $0.012 \%$ & $0.282 \%$ & $98.379 \%$ \\
\hline 486 & póster de David & 0.00092 & $0.012 \%$ & $0.282 \%$ & $98.391 \%$ \\
\hline 487 & aguja & 0.00092 & $0.012 \%$ & $0.282 \%$ & $98.403 \%$ \\
\hline 488 & fregadero & 0.00092 & $0.012 \%$ & $0.282 \%$ & $98.415 \%$ \\
\hline 489 & coche & 0.00092 & $0.012 \%$ & $0.282 \%$ & $98.427 \%$ \\
\hline 490 & pisapapeles & 0.00092 & $0.012 \%$ & $0.282 \%$ & $98.439 \%$ \\
\hline 491 & juguete & 0.00092 & $0.012 \%$ & $0.282 \%$ & $98.451 \%$ \\
\hline 492 & excursión & 0.00092 & $0.012 \%$ & $0.282 \%$ & $98.463 \%$ \\
\hline 493 & fosforescente & 0.00092 & $0.012 \%$ & $0.282 \%$ & $98.475 \%$ \\
\hline 494 & bote de lápices & 0.00092 & $0.012 \%$ & $0.282 \%$ & $98.487 \%$ \\
\hline 495 & agua & 0.00092 & $0.012 \%$ & $0.282 \%$ & $98.499 \%$ \\
\hline 496 & suciedad & 0.00092 & $0.012 \%$ & $0.282 \%$ & $98.511 \%$ \\
\hline 497 & Inglés & 0.00092 & $0.012 \%$ & $0.282 \%$ & $98.523 \%$ \\
\hline 498 & piscina & 0.00092 & $0.012 \%$ & $0.282 \%$ & $98.535 \%$ \\
\hline 499 & punxó & 0.00092 & $0.012 \%$ & $0.282 \%$ & $98.547 \%$ \\
\hline 500 & cruz & 0.00087 & $0.012 \%$ & $0.282 \%$ & $98.559 \%$ \\
\hline
\end{tabular}




\begin{tabular}{|c|c|c|c|c|c|}
\hline 501 & cuadro de $\mathrm{M}^{\mathrm{a}}$ Rosa & 0.00087 & $0.012 \%$ & $0.282 \%$ & $98.571 \%$ \\
\hline 502 & parte de asistencia & 0.00087 & $0.012 \%$ & $0.282 \%$ & $98.583 \%$ \\
\hline 503 & hilo & 0.00087 & $0.012 \%$ & $0.282 \%$ & $98.595 \%$ \\
\hline 504 & quitagrapas & 0.00087 & $0.012 \%$ & $0.282 \%$ & $98.607 \%$ \\
\hline 505 & moto & 0.00087 & $0.012 \%$ & $0.282 \%$ & $98.619 \%$ \\
\hline 506 & mesa de despacho & 0.00087 & $0.012 \%$ & $0.282 \%$ & $98.631 \%$ \\
\hline 507 & borrador de bolígrafo & 0.00087 & $0.012 \%$ & $0.282 \%$ & $98.643 \%$ \\
\hline 508 & revistero & 0.00087 & $0.012 \%$ & $0.282 \%$ & $98.655 \%$ \\
\hline 509 & hoja clasificadora & 0.00087 & $0.012 \%$ & $0.282 \%$ & $98.667 \%$ \\
\hline 510 & mueble & 0.00087 & $0.012 \%$ & $0.282 \%$ & $98.679 \%$ \\
\hline 511 & libreta de notas & 0.00087 & $0.012 \%$ & $0.282 \%$ & $98.691 \%$ \\
\hline 512 & pegatina & 0.00087 & $0.012 \%$ & $0.282 \%$ & $98.703 \%$ \\
\hline 513 & acido & 0.00087 & $0.012 \%$ & $0.282 \%$ & $98.715 \%$ \\
\hline 514 & mesa grande & 0.00087 & $0.012 \%$ & $0.282 \%$ & $98.727 \%$ \\
\hline 515 & Francés & 0.00087 & $0.012 \%$ & $0.282 \%$ & $98.739 \%$ \\
\hline 516 & cigarro & 0.00087 & $0.012 \%$ & $0.282 \%$ & $98.751 \%$ \\
\hline 517 & piso & 0.00087 & $0.012 \%$ & $0.282 \%$ & $98.763 \%$ \\
\hline 518 & libro de física & 0.00087 & $0.012 \%$ & $0.282 \%$ & $98.775 \%$ \\
\hline 519 & láser & 0.00087 & $0.012 \%$ & $0.282 \%$ & $98.787 \%$ \\
\hline 520 & ácido clorhídrico & 0.00087 & $0.012 \%$ & $0.282 \%$ & $98.799 \%$ \\
\hline 521 & centrifugador & 0.00087 & $0.012 \%$ & $0.282 \%$ & $98.811 \%$ \\
\hline 522 & lista de alumnos & 0.00081 & $0.012 \%$ & $0.282 \%$ & $98.823 \%$ \\
\hline 523 & aro de básquet & 0.00081 & $0.012 \%$ & $0.282 \%$ & $98.835 \%$ \\
\hline 524 & rollo de celo & 0.00081 & $0.012 \%$ & $0.282 \%$ & $98.847 \%$ \\
\hline 525 & folio reciclado & 0.00081 & $0.012 \%$ & $0.282 \%$ & $98.859 \%$ \\
\hline 526 & bicicleta & 0.00081 & $0.012 \%$ & $0.282 \%$ & $98.871 \%$ \\
\hline 527 & sujetapapeles & 0.00081 & $0.012 \%$ & $0.282 \%$ & $98.883 \%$ \\
\hline 528 & museo & 0.00081 & $0.012 \%$ & $0.282 \%$ & $98.895 \%$ \\
\hline 529 & uniforme & 0.00081 & $0.012 \%$ & $0.282 \%$ & $98.907 \%$ \\
\hline 530 & fotografía & 0.00081 & $0.012 \%$ & $0.282 \%$ & $98.919 \%$ \\
\hline 531 & red & 0.00081 & $0.012 \%$ & $0.282 \%$ & $98.931 \%$ \\
\hline 532 & bolsa de clase & 0.00081 & $0.012 \%$ & $0.282 \%$ & $98.943 \%$ \\
\hline 533 & mechero de laboratorio & 0.00081 & $0.012 \%$ & $0.282 \%$ & $98.955 \%$ \\
\hline 534 & emergencia & 0.00081 & $0.012 \%$ & $0.282 \%$ & $98.967 \%$ \\
\hline 535 & matemáticas & 0.00081 & $0.012 \%$ & $0.282 \%$ & $98.979 \%$ \\
\hline 536 & campo de fútbol & 0.00081 & $0.012 \%$ & $0.282 \%$ & $98.991 \%$ \\
\hline 537 & libro de geografía & 0.00081 & $0.012 \%$ & $0.282 \%$ & $99.003 \%$ \\
\hline 538 & máquina de vídeo & 0.00077 & $0.012 \%$ & $0.282 \%$ & $99.015 \%$ \\
\hline 539 & plástico & 0.00077 & $0.012 \%$ & $0.282 \%$ & $99.027 \%$ \\
\hline 540 & sala de actos & 0.00077 & $0.012 \%$ & $0.282 \%$ & $99.039 \%$ \\
\hline 541 & témpera & 0.00077 & $0.024 \%$ & $0.565 \%$ & $99.063 \%$ \\
\hline 542 & pista de tenis & 0.00077 & $0.012 \%$ & $0.282 \%$ & $99.075 \%$ \\
\hline 543 & observatorio & 0.00077 & $0.012 \%$ & $0.282 \%$ & $99.087 \%$ \\
\hline 544 & corchera & 0.00077 & $0.012 \%$ & $0.282 \%$ & $99.099 \%$ \\
\hline 545 & estatua & 0.00077 & $0.012 \%$ & $0.282 \%$ & $99.111 \%$ \\
\hline 546 & computadora & 0.00077 & $0.012 \%$ & $0.282 \%$ & $99.123 \%$ \\
\hline 547 & bola de papel & 0.00077 & $0.012 \%$ & $0.282 \%$ & $99.135 \%$ \\
\hline
\end{tabular}




\begin{tabular}{|c|c|c|c|c|c|}
\hline 548 & panel de corcho & 0.00077 & $0.012 \%$ & $0.282 \%$ & $99.147 \%$ \\
\hline 549 & mesa de bar & 0.00077 & $0.012 \%$ & $0.282 \%$ & $99.159 \%$ \\
\hline 550 & báscula & 0.00077 & $0.012 \%$ & $0.282 \%$ & $99.171 \%$ \\
\hline 551 & tachón & 0.00077 & $0.012 \%$ & $0.282 \%$ & $99.183 \%$ \\
\hline 552 & Biología & 0.00077 & $0.012 \%$ & $0.282 \%$ & $99.195 \%$ \\
\hline 553 & campo de baloncesto & 0.00077 & $0.012 \%$ & $0.282 \%$ & $99.207 \%$ \\
\hline 554 & móvil & 0.00077 & $0.012 \%$ & $0.282 \%$ & $99.219 \%$ \\
\hline 555 & cubeta de ondas & 0.00077 & $0.012 \%$ & $0.282 \%$ & $99.231 \%$ \\
\hline 556 & carta & 0.00072 & $0.012 \%$ & $0.282 \%$ & $99.243 \%$ \\
\hline 557 & ascensor & 0.00072 & $0.012 \%$ & $0.282 \%$ & $99.255 \%$ \\
\hline 558 & plástico transparente & 0.00072 & $0.012 \%$ & $0.282 \%$ & $99.267 \%$ \\
\hline 559 & traductor & 0.00072 & $0.012 \%$ & $0.282 \%$ & $99.279 \%$ \\
\hline 560 & pasamanos & 0.00072 & $0.012 \%$ & $0.282 \%$ & $99.291 \%$ \\
\hline 561 & carbón & 0.00072 & $0.012 \%$ & $0.282 \%$ & $99.303 \%$ \\
\hline 562 & libreta pequeña & 0.00072 & $0.012 \%$ & $0.282 \%$ & $99.315 \%$ \\
\hline 563 & silla de bar & 0.00072 & $0.012 \%$ & $0.282 \%$ & $99.327 \%$ \\
\hline 564 & araña & 0.00072 & $0.012 \%$ & $0.282 \%$ & $99.339 \%$ \\
\hline 565 & secretario & 0.00072 & $0.012 \%$ & $0.282 \%$ & $99.351 \%$ \\
\hline 566 & cartón & 0.00072 & $0.012 \%$ & $0.282 \%$ & $99.363 \%$ \\
\hline 567 & pirita & 0.00072 & $0.012 \%$ & $0.282 \%$ & $99.375 \%$ \\
\hline 568 & armario de televisión & 0.00072 & $0.012 \%$ & $0.282 \%$ & $99.387 \%$ \\
\hline 569 & pañuelo de papel & 0.00072 & $0.012 \%$ & $0.282 \%$ & $99.399 \%$ \\
\hline 570 & estuche de minas & 0.00068 & $0.012 \%$ & $0.282 \%$ & $99.411 \%$ \\
\hline 571 & botiquín & 0.00068 & $0.012 \%$ & $0.282 \%$ & $99.423 \%$ \\
\hline 572 & lámina ilustrativa & 0.00068 & $0.012 \%$ & $0.282 \%$ & $99.435 \%$ \\
\hline 573 & casilla & 0.00068 & $0.012 \%$ & $0.282 \%$ & $99.447 \%$ \\
\hline 574 & mostrador & 0.00068 & $0.012 \%$ & $0.282 \%$ & $99.459 \%$ \\
\hline 575 & teclado & 0.00068 & $0.012 \%$ & $0.282 \%$ & $99.471 \%$ \\
\hline 576 & colores de madera & 0.00068 & $0.012 \%$ & $0.282 \%$ & $99.483 \%$ \\
\hline 577 & barra de bar & 0.00068 & $0.012 \%$ & $0.282 \%$ & $99.495 \%$ \\
\hline 578 & bidé & 0.00068 & $0.012 \%$ & $0.282 \%$ & $99.507 \%$ \\
\hline 579 & bisturí & 0.00068 & $0.012 \%$ & $0.282 \%$ & $99.519 \%$ \\
\hline 580 & salfumant & 0.00068 & $0.012 \%$ & $0.282 \%$ & $99.531 \%$ \\
\hline 581 & caja & 0.00064 & $0.012 \%$ & $0.282 \%$ & $99.543 \%$ \\
\hline 582 & recreo & 0.00064 & $0.012 \%$ & $0.282 \%$ & $99.555 \%$ \\
\hline 583 & cartucho & 0.00064 & $0.012 \%$ & $0.282 \%$ & $99.567 \%$ \\
\hline 584 & iglesia & 0.00064 & $0.012 \%$ & $0.282 \%$ & $99.579 \%$ \\
\hline 585 & lápiz de cera & 0.00064 & $0.012 \%$ & $0.282 \%$ & $99.591 \%$ \\
\hline 586 & dossier & 0.00064 & $0.012 \%$ & $0.282 \%$ & $99.603 \%$ \\
\hline 587 & trabajo & 0.00064 & $0.012 \%$ & $0.282 \%$ & $99.615 \%$ \\
\hline 588 & ácido nítrico & 0.00064 & $0.012 \%$ & $0.282 \%$ & $99.627 \%$ \\
\hline 589 & limadura de hierro & 0.00064 & $0.012 \%$ & $0.282 \%$ & $99.639 \%$ \\
\hline 590 & cuadrícula & 0.00064 & $0.012 \%$ & $0.282 \%$ & $99.651 \%$ \\
\hline 591 & cinta de vídeo & 0.00064 & $0.012 \%$ & $0.282 \%$ & $99.663 \%$ \\
\hline 592 & patio de luces & 0.00060 & $0.012 \%$ & $0.282 \%$ & $99.675 \%$ \\
\hline 593 & pista de fútbol & 0.00060 & $0.012 \%$ & $0.282 \%$ & $99.687 \%$ \\
\hline 594 & Geología & 0.00060 & $0.012 \%$ & $0.282 \%$ & $99.699 \%$ \\
\hline
\end{tabular}




\begin{tabular}{|l|l|l|l|l|l|}
\hline 595 & máquina de bebidas & 0.00060 & $0.012 \%$ & $0.282 \%$ & $99.711 \%$ \\
\hline 596 & sal & 0.00060 & $0.012 \%$ & $0.282 \%$ & $99.723 \%$ \\
\hline 597 & gradilla & 0.00060 & $0.012 \%$ & $0.282 \%$ & $99.735 \%$ \\
\hline 598 & jefe de estudios & 0.00056 & $0.012 \%$ & $0.282 \%$ & $99.747 \%$ \\
\hline 599 & bote de colorines & 0.00056 & $0.012 \%$ & $0.282 \%$ & $99.759 \%$ \\
\hline 600 & cartapacio & 0.00056 & $0.012 \%$ & $0.282 \%$ & $99.771 \%$ \\
\hline 601 & papel de cebolla & 0.00056 & $0.012 \%$ & $0.282 \%$ & $99.783 \%$ \\
\hline 602 & portalápices & 0.00056 & $0.012 \%$ & $0.282 \%$ & $99.795 \%$ \\
\hline 603 & barandilla & 0.00056 & $0.012 \%$ & $0.282 \%$ & $99.807 \%$ \\
\hline 604 & subdirector & 0.00056 & $0.012 \%$ & $0.282 \%$ & $99.819 \%$ \\
\hline 605 & gravilla & 0.00056 & $0.012 \%$ & $0.282 \%$ & $99.831 \%$ \\
\hline 606 & paño & 0.00056 & $0.012 \%$ & $0.282 \%$ & $99.843 \%$ \\
\hline 607 & portero & 0.00053 & $0.012 \%$ & $0.282 \%$ & $99.855 \%$ \\
\hline 608 & papel cuadriculado & 0.00053 & $0.012 \%$ & $0.282 \%$ & $99.867 \%$ \\
\hline 609 & sala de vídeo & 0.00053 & $0.012 \%$ & $0.282 \%$ & $99.879 \%$ \\
\hline 610 & carbón activo & 0.00053 & $0.012 \%$ & $0.282 \%$ & $99.891 \%$ \\
\hline 611 & cepillo & 0.00053 & $0.012 \%$ & $0.282 \%$ & $99.903 \%$ \\
\hline 612 & tinta blanca & 0.00053 & $0.012 \%$ & $0.282 \%$ & $99.915 \%$ \\
\hline 613 & limpiadora & 0.00050 & $0.012 \%$ & $0.282 \%$ & $99.927 \%$ \\
\hline 614 & funda de folio & 0.00050 & $0.012 \%$ & $0.282 \%$ & $99.939 \%$ \\
\hline 615 & bebida & 0.00050 & $0.012 \%$ & $0.282 \%$ & $99.951 \%$ \\
\hline 616 & bafle & 0.00047 & $0.012 \%$ & $0.282 \%$ & $99.963 \%$ \\
\hline 617 & cartucho de pluma & 0.00047 & $0.012 \%$ & $0.282 \%$ & $99.975 \%$ \\
\hline 618 & raqueta & 0.00047 & $0.012 \%$ & $0.282 \%$ & $99.987 \%$ \\
\hline 619 & arena & 0.00047 & $0.012 \%$ & $0.282 \%$ & $99.999 \%$ \\
\hline 620 & boletín & 0.00044 & $0.012 \%$ & $0.282 \%$ & $100.011 \%$ \\
\hline 621 & agarratizas & 0.00044 & $0.012 \%$ & $0.282 \%$ & $100.023 \%$ \\
\hline 622 & temario & 0.00044 & $0.012 \%$ & $0.282 \%$ & $100.035 \%$ \\
\hline 623 & sala de teatro & 0.00041 & $0.012 \%$ & $0.282 \%$ & $100.047 \%$ \\
\hline
\end{tabular}

\section{ILUMINACIÓN, CALEFACCIÓN Y MEDIOS PARA AIREAR UN RECINTO}

\begin{tabular}{|c|l||c|c|c|c|}
\hline $\mathrm{N}^{\mathrm{o}}$ & Palabra & Disponibilidad & $\begin{array}{c}\text { Frecuencia } \\
\text { relativa }\end{array}$ & $\%$ Aparición & $\begin{array}{c}\text { Frecuencia } \\
\text { acumulada }\end{array}$ \\
\hline 1 & bombilla & 0.56904 & $5.602 \%$ & $74.011 \%$ & $5.602 \%$ \\
\hline 2 & aire acondicionado & 0.53261 & $5.837 \%$ & $77.119 \%$ & $11.439 \%$ \\
\hline 3 & lámpara & 0.49772 & $5.196 \%$ & $68.644 \%$ & $16.635 \%$ \\
\hline 4 & ventilador & 0.46083 & $5.281 \%$ & $69.774 \%$ & $21.916 \%$ \\
\hline 5 & estufa & 0.45066 & $5.003 \%$ & $66.102 \%$ & $26.919 \%$ \\
\hline 6 & ventana & 0.38967 & $4.105 \%$ & $54.237 \%$ & $31.024 \%$ \\
\hline 7 & foco & 0.28630 & $3.079 \%$ & $40.678 \%$ & $34.103 \%$ \\
\hline
\end{tabular}




\begin{tabular}{|c|c|c|c|c|c|}
\hline 8 & radiador & 0.26977 & $3.122 \%$ & $41.243 \%$ & $37.225 \%$ \\
\hline 9 & flexo & 0.23372 & $2.780 \%$ & $36.723 \%$ & $40.005 \%$ \\
\hline 10 & chimenea & 0.20479 & $2.822 \%$ & $37.288 \%$ & $42.827 \%$ \\
\hline 11 & linterna & 0.20028 & $2.886 \%$ & $38.136 \%$ & $45.713 \%$ \\
\hline 12 & abanico & 0.18190 & $2.352 \%$ & $31.073 \%$ & $48.065 \%$ \\
\hline 13 & calefactor & 0.15619 & $1.839 \%$ & $24.294 \%$ & $49.904 \%$ \\
\hline 14 & vela & 0.13991 & $2.074 \%$ & $27.401 \%$ & $51.978 \%$ \\
\hline 15 & calefacción & 0.13313 & $1.411 \%$ & $18.644 \%$ & $53.389 \%$ \\
\hline 16 & tubo fluorescente & 0.12439 & $1.390 \%$ & $18.362 \%$ & $54.779 \%$ \\
\hline 17 & puerta & 0.12246 & $1.497 \%$ & $19.774 \%$ & $56.276 \%$ \\
\hline 18 & halógeno & 0.08855 & $1.133 \%$ & $14.972 \%$ & $57.409 \%$ \\
\hline 19 & abrir ventana & 0.08553 & $1.176 \%$ & $15.537 \%$ & $58.585 \%$ \\
\hline 20 & mechero & 0.07797 & $1.326 \%$ & $17.514 \%$ & $59.911 \%$ \\
\hline 21 & calentador & 0.07367 & $0.898 \%$ & $11.864 \%$ & $60.809 \%$ \\
\hline 22 & tubo de neón & 0.07083 & $0.834 \%$ & $11.017 \%$ & $61.643 \%$ \\
\hline 23 & farola & 0.06827 & $0.898 \%$ & $11.864 \%$ & $62.541 \%$ \\
\hline 24 & brasero & 0.06790 & $0.984 \%$ & $12.994 \%$ & $63.525 \%$ \\
\hline 25 & tubo & 0.06344 & $0.706 \%$ & $9.322 \%$ & $64.231 \%$ \\
\hline 26 & caldera & 0.05957 & $0.727 \%$ & $9.605 \%$ & $64.958 \%$ \\
\hline 27 & hoguera & 0.05650 & $0.984 \%$ & $12.994 \%$ & $65.942 \%$ \\
\hline 28 & extractor & 0.05578 & $0.748 \%$ & $9.887 \%$ & $66.690 \%$ \\
\hline 29 & enchufe & 0.05504 & $0.748 \%$ & $9.887 \%$ & $67.438 \%$ \\
\hline 30 & luz & 0.05478 & $0.577 \%$ & $7.627 \%$ & $68.015 \%$ \\
\hline 31 & fuego & 0.05396 & $0.834 \%$ & $11.017 \%$ & $68.849 \%$ \\
\hline 32 & cable & 0.05321 & $0.706 \%$ & $9.322 \%$ & $69.555 \%$ \\
\hline 33 & tubo de luz & 0.04616 & $0.556 \%$ & $7.345 \%$ & $70.111 \%$ \\
\hline 34 & estufa de gas & 0.04527 & $0.577 \%$ & $7.627 \%$ & $70.688 \%$ \\
\hline 35 & sol & 0.04467 & $0.727 \%$ & $9.605 \%$ & $71.415 \%$ \\
\hline 36 & calefacción central & 0.04342 & $0.620 \%$ & $8.192 \%$ & $72.035 \%$ \\
\hline 37 & interruptor & 0.03926 & $0.535 \%$ & $7.062 \%$ & $72.570 \%$ \\
\hline 38 & manta & 0.03767 & $0.599 \%$ & $7.910 \%$ & $73.169 \%$ \\
\hline 39 & cerilla & 0.03568 & $0.641 \%$ & $8.475 \%$ & $73.810 \%$ \\
\hline 40 & fluorescente & 0.03519 & $0.385 \%$ & $5.085 \%$ & $74.195 \%$ \\
\hline 41 & luz solar & 0.03449 & $0.556 \%$ & $7.345 \%$ & $74.751 \%$ \\
\hline 42 & abrir puerta & 0.03342 & $0.492 \%$ & $6.497 \%$ & $75.243 \%$ \\
\hline 43 & palmito & 0.03335 & $0.449 \%$ & $5.932 \%$ & $75.692 \%$ \\
\hline 44 & gas & 0.02968 & $0.363 \%$ & $4.802 \%$ & $76.055 \%$ \\
\hline 45 & cirio & 0.02968 & $0.449 \%$ & $5.932 \%$ & $76.504 \%$ \\
\hline 46 & estufa eléctrica & 0.02896 & $0.406 \%$ & $5.367 \%$ & $76.910 \%$ \\
\hline 47 & respiradero & 0.02865 & $0.513 \%$ & $6.780 \%$ & $77.423 \%$ \\
\hline 48 & soplar & 0.02726 & $0.492 \%$ & $6.497 \%$ & $77.915 \%$ \\
\hline 49 & calefacción de gas & 0.02477 & $0.278 \%$ & $3.672 \%$ & $78.193 \%$ \\
\hline 50 & electricidad & 0.02432 & $0.342 \%$ & $4.520 \%$ & $78.535 \%$ \\
\hline 51 & farol & 0.02203 & $0.257 \%$ & $3.390 \%$ & $78.792 \%$ \\
\hline 52 & plafón & 0.02062 & $0.235 \%$ & $3.107 \%$ & $79.027 \%$ \\
\hline 53 & persiana & 0.02050 & $0.299 \%$ & $3.955 \%$ & $79.326 \%$ \\
\hline 54 & faro & 0.01897 & $0.257 \%$ & $3.390 \%$ & $79.583 \%$ \\
\hline
\end{tabular}




\begin{tabular}{|c|c|c|c|c|c|}
\hline 55 & antorcha & 0.01888 & $0.342 \%$ & $4.520 \%$ & $79.925 \%$ \\
\hline 56 & gas natural & 0.01735 & $0.192 \%$ & $2.542 \%$ & $80.117 \%$ \\
\hline 57 & estufa de leña & 0.01619 & $0.214 \%$ & $2.825 \%$ & $80.331 \%$ \\
\hline 58 & luz natural & 0.01600 & $0.235 \%$ & $3.107 \%$ & $80.566 \%$ \\
\hline 59 & ojo de buey & 0.01579 & $0.235 \%$ & $3.107 \%$ & $80.801 \%$ \\
\hline 60 & balcón & 0.01573 & $0.235 \%$ & $3.107 \%$ & $81.036 \%$ \\
\hline 61 & ventanal & 0.01567 & $0.214 \%$ & $2.825 \%$ & $81.250 \%$ \\
\hline 62 & tragaluz & 0.01518 & $0.214 \%$ & $2.825 \%$ & $81.464 \%$ \\
\hline 63 & lamparilla & 0.01492 & $0.192 \%$ & $2.542 \%$ & $81.656 \%$ \\
\hline 64 & placa solar & 0.01436 & $0.235 \%$ & $3.107 \%$ & $81.891 \%$ \\
\hline 65 & climatizador & 0.01349 & $0.171 \%$ & $2.260 \%$ & $82.062 \%$ \\
\hline 66 & ventana abierta & 0.01284 & $0.150 \%$ & $1.977 \%$ & $82.212 \%$ \\
\hline 67 & bombilla halógena & 0.01279 & $0.128 \%$ & $1.695 \%$ & $82.340 \%$ \\
\hline 68 & luz de emergencia & 0.01257 & $0.214 \%$ & $2.825 \%$ & $82.554 \%$ \\
\hline 69 & láser & 0.01230 & $0.150 \%$ & $1.977 \%$ & $82.704 \%$ \\
\hline 70 & termostato & 0.01215 & $0.171 \%$ & $2.260 \%$ & $82.875 \%$ \\
\hline 71 & refrigerador & 0.01211 & $0.150 \%$ & $1.977 \%$ & $83.025 \%$ \\
\hline 72 & calefacción eléctrica & 0.01141 & $0.128 \%$ & $1.695 \%$ & $83.153 \%$ \\
\hline 73 & secador & 0.01104 & $0.150 \%$ & $1.977 \%$ & $83.303 \%$ \\
\hline 74 & neón & 0.01086 & $0.107 \%$ & $1.412 \%$ & $83.410 \%$ \\
\hline 75 & foco halógeno & 0.01076 & $0.171 \%$ & $2.260 \%$ & $83.581 \%$ \\
\hline 76 & candil & 0.01074 & $0.171 \%$ & $2.260 \%$ & $83.752 \%$ \\
\hline 77 & ventilación & 0.01074 & $0.128 \%$ & $1.695 \%$ & $83.880 \%$ \\
\hline 78 & (lámpara de) araña & 0.01073 & $0.128 \%$ & $1.695 \%$ & $84.008 \%$ \\
\hline 79 & gasoil & 0.01046 & $0.128 \%$ & $1.695 \%$ & $84.136 \%$ \\
\hline 80 & gas Butano* & 0.01038 & $0.150 \%$ & $1.977 \%$ & $84.286 \%$ \\
\hline 81 & paipái & 0.01035 & $0.150 \%$ & $1.977 \%$ & $84.436 \%$ \\
\hline 82 & termo & 0.01007 & $0.150 \%$ & $1.977 \%$ & $84.586 \%$ \\
\hline 83 & horno & 0.00998 & $0.150 \%$ & $1.977 \%$ & $84.736 \%$ \\
\hline 84 & candelabro & 0.00972 & $0.150 \%$ & $1.977 \%$ & $84.886 \%$ \\
\hline 85 & corriente & 0.00964 & $0.150 \%$ & $1.977 \%$ & $85.036 \%$ \\
\hline 86 & cortina & 0.00921 & $0.150 \%$ & $1.977 \%$ & $85.186 \%$ \\
\hline 87 & flash & 0.00908 & $0.150 \%$ & $1.977 \%$ & $85.336 \%$ \\
\hline 88 & ambientador & 0.00906 & $0.128 \%$ & $1.695 \%$ & $85.464 \%$ \\
\hline 89 & agujero & 0.00904 & $0.107 \%$ & $1.412 \%$ & $85.571 \%$ \\
\hline 90 & aparato de aire acondicionado & 0.00891 & $0.086 \%$ & $1.130 \%$ & $85.657 \%$ \\
\hline 91 & pila & 0.00891 & $0.171 \%$ & $2.260 \%$ & $85.828 \%$ \\
\hline 92 & puerta abierta & 0.00886 & $0.128 \%$ & $1.695 \%$ & $85.956 \%$ \\
\hline 93 & tubo halógeno & 0.00886 & $0.107 \%$ & $1.412 \%$ & $86.063 \%$ \\
\hline 94 & hornillo & 0.00873 & $0.128 \%$ & $1.695 \%$ & $86.191 \%$ \\
\hline 95 & patio de luces & 0.00867 & $0.128 \%$ & $1.695 \%$ & $86.319 \%$ \\
\hline 96 & lámpara de pie & 0.00863 & $0.107 \%$ & $1.412 \%$ & $86.426 \%$ \\
\hline 97 & ventanilla & 0.00862 & $0.086 \%$ & $1.130 \%$ & $86.512 \%$ \\
\hline 98 & estufa de luz & 0.00852 & $0.107 \%$ & $1.412 \%$ & $86.619 \%$ \\
\hline 99 & soplando & 0.00843 & $0.086 \%$ & $1.130 \%$ & $86.705 \%$ \\
\hline 100 & luz artificial & 0.00810 & $0.086 \%$ & $1.130 \%$ & $86.791 \%$ \\
\hline 101 & agua & 0.00801 & $0.107 \%$ & $1.412 \%$ & $86.898 \%$ \\
\hline
\end{tabular}




\begin{tabular}{|c|c|c|c|c|c|}
\hline 102 & carbón & 0.00788 & $0.107 \%$ & $1.412 \%$ & $87.005 \%$ \\
\hline 103 & gas ciudad & 0.00786 & $0.107 \%$ & $1.412 \%$ & $87.112 \%$ \\
\hline 104 & manta eléctrica & 0.00779 & $0.128 \%$ & $1.695 \%$ & $87.240 \%$ \\
\hline 105 & calefacción de gasoil & 0.00777 & $0.086 \%$ & $1.130 \%$ & $87.326 \%$ \\
\hline 106 & patio & 0.00776 & $0.107 \%$ & $1.412 \%$ & $87.433 \%$ \\
\hline 107 & terraza & 0.00700 & $0.086 \%$ & $1.130 \%$ & $87.519 \%$ \\
\hline 108 & luna & 0.00692 & $0.107 \%$ & $1.412 \%$ & $87.626 \%$ \\
\hline 109 & papel & 0.00688 & $0.128 \%$ & $1.695 \%$ & $87.754 \%$ \\
\hline 110 & lámpara halógena & 0.00685 & $0.064 \%$ & $0.847 \%$ & $87.818 \%$ \\
\hline 111 & vidriera & 0.00685 & $0.086 \%$ & $1.130 \%$ & $87.904 \%$ \\
\hline 112 & tubería & 0.00670 & $0.086 \%$ & $1.130 \%$ & $87.990 \%$ \\
\hline 113 & lámpara fluorescente & 0.00662 & $0.064 \%$ & $0.847 \%$ & $88.054 \%$ \\
\hline 114 & Camping gas* & 0.00652 & $0.107 \%$ & $1.412 \%$ & $88.161 \%$ \\
\hline 115 & hoja & 0.00644 & $0.086 \%$ & $1.130 \%$ & $88.247 \%$ \\
\hline 116 & luz halógena & 0.00634 & $0.086 \%$ & $1.130 \%$ & $88.333 \%$ \\
\hline 117 & aparato de calefacción & 0.00622 & $0.064 \%$ & $0.847 \%$ & $88.397 \%$ \\
\hline 118 & abriendo ventana & 0.00620 & $0.107 \%$ & $1.412 \%$ & $88.504 \%$ \\
\hline 119 & solar & 0.00616 & $0.064 \%$ & $0.847 \%$ & $88.568 \%$ \\
\hline 120 & aire & 0.00604 & $0.128 \%$ & $1.695 \%$ & $88.696 \%$ \\
\hline 121 & máquina de humo & 0.00565 & $0.043 \%$ & $0.565 \%$ & $88.739 \%$ \\
\hline 122 & gases orgánicos & 0.00565 & $0.043 \%$ & $0.565 \%$ & $88.782 \%$ \\
\hline 123 & calor humano & 0.00562 & $0.086 \%$ & $1.130 \%$ & $88.868 \%$ \\
\hline 124 & luz eléctrica & 0.00548 & $0.086 \%$ & $1.130 \%$ & $88.954 \%$ \\
\hline 125 & viento & 0.00542 & $0.107 \%$ & $1.412 \%$ & $89.061 \%$ \\
\hline 126 & eléctrica & 0.00542 & $0.043 \%$ & $0.565 \%$ & $89.104 \%$ \\
\hline 127 & calefacción centralizada & 0.00540 & $0.064 \%$ & $0.847 \%$ & $89.168 \%$ \\
\hline 128 & Butano* & 0.00540 & $0.064 \%$ & $0.847 \%$ & $89.232 \%$ \\
\hline 129 & aplique & 0.00537 & $0.064 \%$ & $0.847 \%$ & $89.296 \%$ \\
\hline 130 & fusible & 0.00528 & $0.086 \%$ & $1.130 \%$ & $89.382 \%$ \\
\hline 131 & leña & 0.00525 & $0.107 \%$ & $1.412 \%$ & $89.489 \%$ \\
\hline 132 & calefacción individual & 0.00510 & $0.064 \%$ & $0.847 \%$ & $89.553 \%$ \\
\hline 133 & energía solar & 0.00505 & $0.064 \%$ & $0.847 \%$ & $89.617 \%$ \\
\hline 134 & rosetón & 0.00502 & $0.064 \%$ & $0.847 \%$ & $89.681 \%$ \\
\hline 135 & estufa de Butano* & 0.00499 & $0.064 \%$ & $0.847 \%$ & $89.745 \%$ \\
\hline 136 & hacer aire & 0.00498 & $0.043 \%$ & $0.565 \%$ & $89.788 \%$ \\
\hline 137 & cerrar ventana & 0.00490 & $0.086 \%$ & $1.130 \%$ & $89.874 \%$ \\
\hline 138 & levantar persiana & 0.00482 & $0.064 \%$ & $0.847 \%$ & $89.938 \%$ \\
\hline 139 & cristalera & 0.00479 & $0.086 \%$ & $1.130 \%$ & $90.024 \%$ \\
\hline 140 & rejilla & 0.00477 & $0.086 \%$ & $1.130 \%$ & $90.110 \%$ \\
\hline 141 & tragahumos & 0.00476 & $0.086 \%$ & $1.130 \%$ & $90.196 \%$ \\
\hline 142 & surtidor & 0.00476 & $0.043 \%$ & $0.565 \%$ & $90.239 \%$ \\
\hline 143 & sala de calderas & 0.00474 & $0.064 \%$ & $0.847 \%$ & $90.303 \%$ \\
\hline 144 & bombilla azul & 0.00473 & $0.064 \%$ & $0.847 \%$ & $90.367 \%$ \\
\hline 145 & portalámparas & 0.00455 & $0.086 \%$ & $1.130 \%$ & $90.453 \%$ \\
\hline 146 & aire climatizado & 0.00452 & $0.043 \%$ & $0.565 \%$ & $90.496 \%$ \\
\hline 147 & quinqué & 0.00451 & $0.064 \%$ & $0.847 \%$ & $90.560 \%$ \\
\hline 148 & abrigo & 0.00448 & $0.086 \%$ & $1.130 \%$ & $90.646 \%$ \\
\hline
\end{tabular}




\begin{tabular}{|c|c|c|c|c|c|}
\hline 149 & petromax & 0.00447 & $0.064 \%$ & $0.847 \%$ & $90.710 \%$ \\
\hline 150 & lamparita & 0.00438 & $0.064 \%$ & $0.847 \%$ & $90.774 \%$ \\
\hline 151 & gasolina & 0.00438 & $0.043 \%$ & $0.565 \%$ & $90.817 \%$ \\
\hline 152 & abriendo puerta & 0.00430 & $0.064 \%$ & $0.847 \%$ & $90.881 \%$ \\
\hline 153 & lámpara de gas & 0.00417 & $0.064 \%$ & $0.847 \%$ & $90.945 \%$ \\
\hline 154 & bolsa de agua caliente & 0.00414 & $0.086 \%$ & $1.130 \%$ & $91.031 \%$ \\
\hline 155 & ladrón & 0.00411 & $0.064 \%$ & $0.847 \%$ & $91.095 \%$ \\
\hline 156 & acondicionador de aire & 0.00409 & $0.064 \%$ & $0.847 \%$ & $91.159 \%$ \\
\hline 157 & calefacción de luz & 0.00403 & $0.043 \%$ & $0.565 \%$ & $91.202 \%$ \\
\hline 158 & refrigeración & 0.00403 & $0.043 \%$ & $0.565 \%$ & $91.245 \%$ \\
\hline 159 & gasóleo & 0.00402 & $0.043 \%$ & $0.565 \%$ & $91.288 \%$ \\
\hline 160 & aspersor & 0.00401 & $0.064 \%$ & $0.847 \%$ & $91.352 \%$ \\
\hline 161 & fogón & 0.00399 & $0.064 \%$ & $0.847 \%$ & $91.416 \%$ \\
\hline 162 & hilo & 0.00394 & $0.064 \%$ & $0.847 \%$ & $91.480 \%$ \\
\hline 163 & mano & 0.00388 & $0.043 \%$ & $0.565 \%$ & $91.523 \%$ \\
\hline 164 & bomba de calor & 0.00385 & $0.043 \%$ & $0.565 \%$ & $91.566 \%$ \\
\hline 165 & rayo & 0.00370 & $0.043 \%$ & $0.565 \%$ & $91.609 \%$ \\
\hline 166 & grifo & 0.00370 & $0.043 \%$ & $0.565 \%$ & $91.652 \%$ \\
\hline 167 & cuadro eléctrico & 0.00370 & $0.043 \%$ & $0.565 \%$ & $91.695 \%$ \\
\hline 168 & batería & 0.00366 & $0.064 \%$ & $0.847 \%$ & $91.759 \%$ \\
\hline 169 & subir persiana & 0.00365 & $0.064 \%$ & $0.847 \%$ & $91.823 \%$ \\
\hline 170 & agua caliente & 0.00364 & $0.064 \%$ & $0.847 \%$ & $91.887 \%$ \\
\hline 171 & luz de color & 0.00354 & $0.043 \%$ & $0.565 \%$ & $91.930 \%$ \\
\hline 172 & placa & 0.00350 & $0.043 \%$ & $0.565 \%$ & $91.973 \%$ \\
\hline 173 & aire caliente & 0.00345 & $0.043 \%$ & $0.565 \%$ & $92.016 \%$ \\
\hline 174 & mosquitera & 0.00341 & $0.064 \%$ & $0.847 \%$ & $92.080 \%$ \\
\hline 175 & farolillo & 0.00339 & $0.043 \%$ & $0.565 \%$ & $92.123 \%$ \\
\hline 176 & plomo & 0.00338 & $0.043 \%$ & $0.565 \%$ & $92.166 \%$ \\
\hline 177 & huracán & 0.00336 & $0.086 \%$ & $1.130 \%$ & $92.252 \%$ \\
\hline 178 & luz de tubo & 0.00332 & $0.043 \%$ & $0.565 \%$ & $92.295 \%$ \\
\hline 179 & claraboya & 0.00326 & $0.043 \%$ & $0.565 \%$ & $92.338 \%$ \\
\hline 180 & cerrar puerta & 0.00321 & $0.043 \%$ & $0.565 \%$ & $92.381 \%$ \\
\hline 181 & escotilla & 0.00320 & $0.043 \%$ & $0.565 \%$ & $92.424 \%$ \\
\hline 182 & humidificador de aire & 0.00312 & $0.043 \%$ & $0.565 \%$ & $92.467 \%$ \\
\hline 183 & poste de luz & 0.00310 & $0.064 \%$ & $0.847 \%$ & $92.531 \%$ \\
\hline 184 & empalme & 0.00304 & $0.043 \%$ & $0.565 \%$ & $92.574 \%$ \\
\hline 185 & tubo incandescente & 0.00303 & $0.043 \%$ & $0.565 \%$ & $92.617 \%$ \\
\hline 186 & hacer hoguera & 0.00299 & $0.043 \%$ & $0.565 \%$ & $92.660 \%$ \\
\hline 187 & trampilla & 0.00297 & $0.043 \%$ & $0.565 \%$ & $92.703 \%$ \\
\hline 188 & barra de luz & 0.00295 & $0.043 \%$ & $0.565 \%$ & $92.746 \%$ \\
\hline 189 & estufa catalítica & 0.00295 & $0.043 \%$ & $0.565 \%$ & $92.789 \%$ \\
\hline 190 & luz de seguridad & 0.00294 & $0.064 \%$ & $0.847 \%$ & $92.853 \%$ \\
\hline 191 & incendio & 0.00294 & $0.043 \%$ & $0.565 \%$ & $92.896 \%$ \\
\hline 192 & estufa de gasoil & 0.00290 & $0.043 \%$ & $0.565 \%$ & $92.939 \%$ \\
\hline 193 & lámpara normal & 0.00282 & $0.021 \%$ & $0.282 \%$ & $92.960 \%$ \\
\hline 194 & energía nuclear & 0.00282 & $0.064 \%$ & $0.847 \%$ & $93.024 \%$ \\
\hline 195 & calefactor de gas & 0.00282 & $0.021 \%$ & $0.282 \%$ & $93.045 \%$ \\
\hline
\end{tabular}




\begin{tabular}{|c|c|c|c|c|c|}
\hline 196 & semáforo & 0.00282 & $0.021 \%$ & $0.282 \%$ & $93.066 \%$ \\
\hline 197 & tubo luminiscente & 0.00282 & $0.021 \%$ & $0.282 \%$ & $93.087 \%$ \\
\hline 198 & a soplidos & 0.00282 & $0.021 \%$ & $0.282 \%$ & $93.108 \%$ \\
\hline 199 & tubo luminoso & 0.00280 & $0.043 \%$ & $0.565 \%$ & $93.151 \%$ \\
\hline 200 & infrarrojos & 0.00280 & $0.043 \%$ & $0.565 \%$ & $93.194 \%$ \\
\hline 201 & lumbre & 0.00280 & $0.043 \%$ & $0.565 \%$ & $93.237 \%$ \\
\hline 202 & reflector & 0.00278 & $0.043 \%$ & $0.565 \%$ & $93.280 \%$ \\
\hline 203 & energía eólica & 0.00272 & $0.064 \%$ & $0.847 \%$ & $93.344 \%$ \\
\hline 204 & foco fluorescente & 0.00267 & $0.043 \%$ & $0.565 \%$ & $93.387 \%$ \\
\hline 205 & desagüe & 0.00263 & $0.043 \%$ & $0.565 \%$ & $93.430 \%$ \\
\hline 206 & bombona de gas & 0.00263 & $0.043 \%$ & $0.565 \%$ & $93.473 \%$ \\
\hline 207 & mampara & 0.00262 & $0.043 \%$ & $0.565 \%$ & $93.516 \%$ \\
\hline 208 & petróleo & 0.00262 & $0.043 \%$ & $0.565 \%$ & $93.559 \%$ \\
\hline 209 & bombilla blanca & 0.00259 & $0.021 \%$ & $0.282 \%$ & $93.580 \%$ \\
\hline 210 & calefacción de gas natural & 0.00259 & $0.021 \%$ & $0.282 \%$ & $93.601 \%$ \\
\hline 211 & palmatoria & 0.00259 & $0.021 \%$ & $0.282 \%$ & $93.622 \%$ \\
\hline 212 & lámpara de alcohol & 0.00259 & $0.021 \%$ & $0.282 \%$ & $93.643 \%$ \\
\hline 213 & placa de calefacción & 0.00259 & $0.021 \%$ & $0.282 \%$ & $93.664 \%$ \\
\hline 214 & media luz & 0.00257 & $0.043 \%$ & $0.565 \%$ & $93.707 \%$ \\
\hline 215 & bombilla roja & 0.00255 & $0.043 \%$ & $0.565 \%$ & $93.750 \%$ \\
\hline 216 & espejo & 0.00249 & $0.043 \%$ & $0.565 \%$ & $93.793 \%$ \\
\hline 217 & calefacción de agua & 0.00242 & $0.043 \%$ & $0.565 \%$ & $93.836 \%$ \\
\hline 218 & tubo de cobre & 0.00242 & $0.043 \%$ & $0.565 \%$ & $93.879 \%$ \\
\hline 219 & cañón & 0.00241 & $0.043 \%$ & $0.565 \%$ & $93.922 \%$ \\
\hline 220 & serrucho & 0.00238 & $0.021 \%$ & $0.282 \%$ & $93.943 \%$ \\
\hline 221 & botella de Butano* & 0.00238 & $0.021 \%$ & $0.282 \%$ & $93.964 \%$ \\
\hline 222 & llave de luz & 0.00238 & $0.021 \%$ & $0.282 \%$ & $93.985 \%$ \\
\hline 223 & calefactor eléctrico & 0.00238 & $0.021 \%$ & $0.282 \%$ & $94.006 \%$ \\
\hline 224 & cenital & 0.00238 & $0.021 \%$ & $0.282 \%$ & $94.027 \%$ \\
\hline 225 & luz fluorescente & 0.00238 & $0.021 \%$ & $0.282 \%$ & $94.048 \%$ \\
\hline 226 & abanicando & 0.00238 & $0.021 \%$ & $0.282 \%$ & $94.069 \%$ \\
\hline 227 & cable eléctrico & 0.00238 & $0.021 \%$ & $0.282 \%$ & $94.090 \%$ \\
\hline 228 & calefactor de luz & 0.00238 & $0.021 \%$ & $0.282 \%$ & $94.111 \%$ \\
\hline 229 & limpiar & 0.00238 & $0.021 \%$ & $0.282 \%$ & $94.132 \%$ \\
\hline 230 & tubo de aire & 0.00238 & $0.021 \%$ & $0.282 \%$ & $94.153 \%$ \\
\hline 231 & cartón & 0.00233 & $0.043 \%$ & $0.565 \%$ & $94.196 \%$ \\
\hline 232 & tubo de calefacción & 0.00231 & $0.043 \%$ & $0.565 \%$ & $94.239 \%$ \\
\hline 233 & faro de coche & 0.00225 & $0.043 \%$ & $0.565 \%$ & $94.282 \%$ \\
\hline 234 & cúpula & 0.00219 & $0.021 \%$ & $0.282 \%$ & $94.303 \%$ \\
\hline 235 & circuito eléctrico & 0.00219 & $0.021 \%$ & $0.282 \%$ & $94.324 \%$ \\
\hline 236 & rendija & 0.00219 & $0.021 \%$ & $0.282 \%$ & $94.345 \%$ \\
\hline 237 & deshumidificador & 0.00219 & $0.021 \%$ & $0.282 \%$ & $94.366 \%$ \\
\hline 238 & aseo & 0.00219 & $0.021 \%$ & $0.282 \%$ & $94.387 \%$ \\
\hline 239 & calefacción de gasolina & 0.00219 & $0.021 \%$ & $0.282 \%$ & $94.408 \%$ \\
\hline 240 & proyector & 0.00219 & $0.021 \%$ & $0.282 \%$ & $94.429 \%$ \\
\hline 241 & buhardilla & 0.00219 & $0.021 \%$ & $0.282 \%$ & $94.450 \%$ \\
\hline 242 & foco rojo & 0.00219 & $0.021 \%$ & $0.282 \%$ & $94.471 \%$ \\
\hline
\end{tabular}




\begin{tabular}{|c|c|c|c|c|c|}
\hline 243 & hilo de luz & 0.00219 & $0.021 \%$ & $0.282 \%$ & $94.492 \%$ \\
\hline 244 & foco de luz & 0.00219 & $0.021 \%$ & $0.282 \%$ & $94.513 \%$ \\
\hline 245 & alumbrado & 0.00219 & $0.021 \%$ & $0.282 \%$ & $94.534 \%$ \\
\hline 246 & cristalería & 0.00219 & $0.021 \%$ & $0.282 \%$ & $94.555 \%$ \\
\hline 247 & torre & 0.00219 & $0.021 \%$ & $0.282 \%$ & $94.576 \%$ \\
\hline 248 & lámpara de techo & 0.00219 & $0.021 \%$ & $0.282 \%$ & $94.597 \%$ \\
\hline 249 & hélice & 0.00219 & $0.021 \%$ & $0.282 \%$ & $94.618 \%$ \\
\hline 250 & mirador & 0.00219 & $0.021 \%$ & $0.282 \%$ & $94.639 \%$ \\
\hline 251 & estufa de fuego & 0.00219 & $0.021 \%$ & $0.282 \%$ & $94.660 \%$ \\
\hline 252 & lámpara de mesita & 0.00219 & $0.021 \%$ & $0.282 \%$ & $94.681 \%$ \\
\hline 253 & bengala & 0.00217 & $0.043 \%$ & $0.565 \%$ & $94.724 \%$ \\
\hline 254 & bolsa de agua & 0.00217 & $0.043 \%$ & $0.565 \%$ & $94.767 \%$ \\
\hline 255 & bombilla amarilla & 0.00209 & $0.043 \%$ & $0.565 \%$ & $94.810 \%$ \\
\hline 256 & esfera climatizadora & 0.00206 & $0.043 \%$ & $0.565 \%$ & $94.853 \%$ \\
\hline 257 & lava & 0.00203 & $0.043 \%$ & $0.565 \%$ & $94.896 \%$ \\
\hline 258 & cristal & 0.00201 & $0.021 \%$ & $0.282 \%$ & $94.917 \%$ \\
\hline 259 & sauna & 0.00201 & $0.064 \%$ & $0.847 \%$ & $94.981 \%$ \\
\hline 260 & rayo violeta & 0.00201 & $0.021 \%$ & $0.282 \%$ & $95.002 \%$ \\
\hline 261 & aire de ventana & 0.00201 & $0.021 \%$ & $0.282 \%$ & $95.023 \%$ \\
\hline 262 & foco verde & 0.00201 & $0.021 \%$ & $0.282 \%$ & $95.044 \%$ \\
\hline 263 & calefacción de caldera & 0.00201 & $0.021 \%$ & $0.282 \%$ & $95.065 \%$ \\
\hline 264 & cable de luz & 0.00201 & $0.021 \%$ & $0.282 \%$ & $95.086 \%$ \\
\hline 265 & acumulador de energía & 0.00201 & $0.021 \%$ & $0.282 \%$ & $95.107 \%$ \\
\hline 266 & cinta aislante & 0.00201 & $0.021 \%$ & $0.282 \%$ & $95.128 \%$ \\
\hline 267 & lámpara de mesa & 0.00201 & $0.021 \%$ & $0.282 \%$ & $95.149 \%$ \\
\hline 268 & Ambipur* & 0.00201 & $0.021 \%$ & $0.282 \%$ & $95.170 \%$ \\
\hline 269 & calefacción de petróleo & 0.00201 & $0.021 \%$ & $0.282 \%$ & $95.191 \%$ \\
\hline 270 & techo corredizo & 0.00201 & $0.021 \%$ & $0.282 \%$ & $95.212 \%$ \\
\hline 271 & hogar & 0.00198 & $0.043 \%$ & $0.565 \%$ & $95.255 \%$ \\
\hline 272 & estufa de madera & 0.00195 & $0.043 \%$ & $0.565 \%$ & $95.298 \%$ \\
\hline 273 & diferencial & 0.00194 & $0.043 \%$ & $0.565 \%$ & $95.341 \%$ \\
\hline 274 & estrella & 0.00191 & $0.064 \%$ & $0.847 \%$ & $95.405 \%$ \\
\hline 275 & luz de coche & 0.00187 & $0.043 \%$ & $0.565 \%$ & $95.448 \%$ \\
\hline 276 & luz tenue & 0.00185 & $0.021 \%$ & $0.282 \%$ & $95.469 \%$ \\
\hline 277 & extintor & 0.00185 & $0.021 \%$ & $0.282 \%$ & $95.490 \%$ \\
\hline 278 & calefacción de propano & 0.00185 & $0.021 \%$ & $0.282 \%$ & $95.511 \%$ \\
\hline 279 & ventilación natural & 0.00185 & $0.021 \%$ & $0.282 \%$ & $95.532 \%$ \\
\hline 280 & polo positivo & 0.00185 & $0.021 \%$ & $0.282 \%$ & $95.553 \%$ \\
\hline 281 & frotamiento & 0.00185 & $0.021 \%$ & $0.282 \%$ & $95.574 \%$ \\
\hline 282 & foco azul & 0.00185 & $0.021 \%$ & $0.282 \%$ & $95.595 \%$ \\
\hline 283 & abanicar & 0.00185 & $0.021 \%$ & $0.282 \%$ & $95.616 \%$ \\
\hline 284 & fósforo & 0.00185 & $0.021 \%$ & $0.282 \%$ & $95.637 \%$ \\
\hline 285 & calor & 0.00185 & $0.021 \%$ & $0.282 \%$ & $95.658 \%$ \\
\hline 286 & brasero de gas & 0.00185 & $0.021 \%$ & $0.282 \%$ & $95.679 \%$ \\
\hline 287 & aireación & 0.00185 & $0.021 \%$ & $0.282 \%$ & $95.700 \%$ \\
\hline 288 & ventana levantada & 0.00185 & $0.021 \%$ & $0.282 \%$ & $95.721 \%$ \\
\hline 289 & tubo eléctrico & 0.00185 & $0.021 \%$ & $0.282 \%$ & $95.742 \%$ \\
\hline
\end{tabular}




\begin{tabular}{|c|c|c|c|c|c|}
\hline 290 & climatizador de aire & 0.00185 & $0.021 \%$ & $0.282 \%$ & $95.763 \%$ \\
\hline 291 & llar & 0.00185 & $0.021 \%$ & $0.282 \%$ & $95.784 \%$ \\
\hline 292 & cajón de chimenea & 0.00185 & $0.021 \%$ & $0.282 \%$ & $95.805 \%$ \\
\hline 293 & gas lacrimógeno & 0.00185 & $0.021 \%$ & $0.282 \%$ & $95.826 \%$ \\
\hline 294 & calentador de aire & 0.00185 & $0.021 \%$ & $0.282 \%$ & $95.847 \%$ \\
\hline 295 & pared respirable & 0.00185 & $0.021 \%$ & $0.282 \%$ & $95.868 \%$ \\
\hline 296 & calefacción por el suelo & 0.00183 & $0.043 \%$ & $0.565 \%$ & $95.911 \%$ \\
\hline 297 & brisa & 0.00180 & $0.043 \%$ & $0.565 \%$ & $95.954 \%$ \\
\hline 298 & aislante & 0.00177 & $0.043 \%$ & $0.565 \%$ & $95.997 \%$ \\
\hline 299 & hielo & 0.00172 & $0.043 \%$ & $0.565 \%$ & $96.040 \%$ \\
\hline 300 & aspiradora & 0.00169 & $0.021 \%$ & $0.282 \%$ & $96.061 \%$ \\
\hline 301 & polo negativo & 0.00169 & $0.021 \%$ & $0.282 \%$ & $96.082 \%$ \\
\hline 302 & folio & 0.00169 & $0.021 \%$ & $0.282 \%$ & $96.103 \%$ \\
\hline 303 & conductor de ventilación & 0.00169 & $0.021 \%$ & $0.282 \%$ & $96.124 \%$ \\
\hline 304 & foco amarillo & 0.00169 & $0.021 \%$ & $0.282 \%$ & $96.145 \%$ \\
\hline 305 & encender luz & 0.00169 & $0.021 \%$ & $0.282 \%$ & $96.166 \%$ \\
\hline 306 & encender mechero & 0.00169 & $0.021 \%$ & $0.282 \%$ & $96.187 \%$ \\
\hline 307 & verja & 0.00169 & $0.021 \%$ & $0.282 \%$ & $96.208 \%$ \\
\hline 308 & sin techo & 0.00169 & $0.021 \%$ & $0.282 \%$ & $96.229 \%$ \\
\hline 309 & iluminación artificial & 0.00169 & $0.021 \%$ & $0.282 \%$ & $96.250 \%$ \\
\hline 310 & salida de aire & 0.00169 & $0.021 \%$ & $0.282 \%$ & $96.271 \%$ \\
\hline 311 & rejilla para airear & 0.00169 & $0.021 \%$ & $0.282 \%$ & $96.292 \%$ \\
\hline 312 & soplete & 0.00169 & $0.021 \%$ & $0.282 \%$ & $96.313 \%$ \\
\hline 313 & farol de camping & 0.00169 & $0.021 \%$ & $0.282 \%$ & $96.334 \%$ \\
\hline 314 & vitrocerámica & 0.00169 & $0.021 \%$ & $0.282 \%$ & $96.355 \%$ \\
\hline 315 & luz de sol & 0.00167 & $0.043 \%$ & $0.565 \%$ & $96.398 \%$ \\
\hline 316 & altos hornos & 0.00164 & $0.043 \%$ & $0.565 \%$ & $96.441 \%$ \\
\hline 317 & panel solar & 0.00164 & $0.043 \%$ & $0.565 \%$ & $96.484 \%$ \\
\hline 318 & tensión & 0.00156 & $0.021 \%$ & $0.282 \%$ & $96.505 \%$ \\
\hline 319 & mucha ropa & 0.00156 & $0.021 \%$ & $0.282 \%$ & $96.526 \%$ \\
\hline 320 & tubería de aire & 0.00156 & $0.021 \%$ & $0.282 \%$ & $96.547 \%$ \\
\hline 321 & orientar al norte & 0.00156 & $0.021 \%$ & $0.282 \%$ & $96.568 \%$ \\
\hline 322 & cañería & 0.00156 & $0.021 \%$ & $0.282 \%$ & $96.589 \%$ \\
\hline 323 & foco violeta & 0.00156 & $0.021 \%$ & $0.282 \%$ & $96.610 \%$ \\
\hline 324 & luz de neón & 0.00156 & $0.021 \%$ & $0.282 \%$ & $96.631 \%$ \\
\hline 325 & iluminación solar & 0.00156 & $0.021 \%$ & $0.282 \%$ & $96.652 \%$ \\
\hline 326 & alabastro & 0.00156 & $0.021 \%$ & $0.282 \%$ & $96.673 \%$ \\
\hline 327 & extractor de humos & 0.00156 & $0.021 \%$ & $0.282 \%$ & $96.694 \%$ \\
\hline 328 & llave & 0.00156 & $0.021 \%$ & $0.282 \%$ & $96.715 \%$ \\
\hline 329 & tubo eléctrico de neón & 0.00156 & $0.021 \%$ & $0.282 \%$ & $96.736 \%$ \\
\hline 330 & conducto de aireación & 0.00156 & $0.021 \%$ & $0.282 \%$ & $96.757 \%$ \\
\hline 331 & nevera abierta & 0.00156 & $0.021 \%$ & $0.282 \%$ & $96.778 \%$ \\
\hline 332 & bufanda & 0.00156 & $0.021 \%$ & $0.282 \%$ & $96.799 \%$ \\
\hline 333 & lámpara de pared & 0.00156 & $0.021 \%$ & $0.282 \%$ & $96.820 \%$ \\
\hline 334 & patio interior & 0.00156 & $0.021 \%$ & $0.282 \%$ & $96.841 \%$ \\
\hline 335 & estufa de petróleo & 0.00156 & $0.021 \%$ & $0.282 \%$ & $96.862 \%$ \\
\hline 336 & estufa de queroseno & 0.00156 & $0.021 \%$ & $0.282 \%$ & $96.883 \%$ \\
\hline
\end{tabular}




\begin{tabular}{|c|c|c|c|c|c|}
\hline 337 & ventanuco & 0.00143 & $0.021 \%$ & $0.282 \%$ & $96.904 \%$ \\
\hline 338 & dispersor & 0.00143 & $0.021 \%$ & $0.282 \%$ & $96.925 \%$ \\
\hline 339 & poca ropa & 0.00143 & $0.021 \%$ & $0.282 \%$ & $96.946 \%$ \\
\hline 340 & tubería de agua & 0.00143 & $0.021 \%$ & $0.282 \%$ & $96.967 \%$ \\
\hline 341 & guante & 0.00143 & $0.021 \%$ & $0.282 \%$ & $96.988 \%$ \\
\hline 342 & celosía & 0.00143 & $0.021 \%$ & $0.282 \%$ & $97.009 \%$ \\
\hline 343 & caldera de gasóleo & 0.00143 & $0.021 \%$ & $0.282 \%$ & $97.030 \%$ \\
\hline 344 & estufa de aire & 0.00143 & $0.021 \%$ & $0.282 \%$ & $97.051 \%$ \\
\hline 345 & placa eléctrica & 0.00143 & $0.021 \%$ & $0.282 \%$ & $97.072 \%$ \\
\hline 346 & bombona de Butano* & 0.00143 & $0.021 \%$ & $0.282 \%$ & $97.093 \%$ \\
\hline 347 & puerta de cristal & 0.00143 & $0.021 \%$ & $0.282 \%$ & $97.114 \%$ \\
\hline 348 & reactancia & 0.00143 & $0.021 \%$ & $0.282 \%$ & $97.135 \%$ \\
\hline 349 & calentador de gas & 0.00143 & $0.021 \%$ & $0.282 \%$ & $97.156 \%$ \\
\hline 350 & explosión & 0.00139 & $0.043 \%$ & $0.565 \%$ & $97.199 \%$ \\
\hline 351 & lámpara solar & 0.00131 & $0.021 \%$ & $0.282 \%$ & $97.220 \%$ \\
\hline 352 & bombilla naranja & 0.00131 & $0.021 \%$ & $0.282 \%$ & $97.241 \%$ \\
\hline 353 & calefacción dispersa & 0.00131 & $0.021 \%$ & $0.282 \%$ & $97.262 \%$ \\
\hline 354 & bomba de aire & 0.00131 & $0.021 \%$ & $0.282 \%$ & $97.283 \%$ \\
\hline 355 & manta térmica & 0.00131 & $0.021 \%$ & $0.282 \%$ & $97.304 \%$ \\
\hline 356 & termo de agua & 0.00131 & $0.021 \%$ & $0.282 \%$ & $97.325 \%$ \\
\hline 357 & encender cerilla & 0.00131 & $0.021 \%$ & $0.282 \%$ & $97.346 \%$ \\
\hline 358 & electricidad eólica & 0.00131 & $0.021 \%$ & $0.282 \%$ & $97.367 \%$ \\
\hline 359 & enchufar ventilador & 0.00131 & $0.021 \%$ & $0.282 \%$ & $97.388 \%$ \\
\hline 360 & cañón de luz & 0.00131 & $0.021 \%$ & $0.282 \%$ & $97.409 \%$ \\
\hline 361 & instalación eléctrica & 0.00131 & $0.021 \%$ & $0.282 \%$ & $97.430 \%$ \\
\hline 362 & canal & 0.00131 & $0.021 \%$ & $0.282 \%$ & $97.451 \%$ \\
\hline 363 & propano & 0.00131 & $0.021 \%$ & $0.282 \%$ & $97.472 \%$ \\
\hline 364 & conductor de aire & 0.00131 & $0.021 \%$ & $0.282 \%$ & $97.493 \%$ \\
\hline 365 & calentador de electricidad & 0.00131 & $0.021 \%$ & $0.282 \%$ & $97.514 \%$ \\
\hline 366 & soporte & 0.00131 & $0.021 \%$ & $0.282 \%$ & $97.535 \%$ \\
\hline 367 & energía hidráulica & 0.00127 & $0.043 \%$ & $0.565 \%$ & $97.578 \%$ \\
\hline 368 & termo de comida & 0.00121 & $0.021 \%$ & $0.282 \%$ & $97.599 \%$ \\
\hline 369 & encender vela & 0.00121 & $0.021 \%$ & $0.282 \%$ & $97.620 \%$ \\
\hline 370 & solárium & 0.00121 & $0.021 \%$ & $0.282 \%$ & $97.641 \%$ \\
\hline 371 & piso radiante & 0.00121 & $0.021 \%$ & $0.282 \%$ & $97.662 \%$ \\
\hline 372 & electricidad nuclear & 0.00121 & $0.021 \%$ & $0.282 \%$ & $97.683 \%$ \\
\hline 373 & lámpara de gasolina & 0.00121 & $0.021 \%$ & $0.282 \%$ & $97.704 \%$ \\
\hline 374 & conector & 0.00121 & $0.021 \%$ & $0.282 \%$ & $97.725 \%$ \\
\hline 375 & ventilar & 0.00121 & $0.021 \%$ & $0.282 \%$ & $97.746 \%$ \\
\hline 376 & calefacción de agua caliente & 0.00121 & $0.021 \%$ & $0.282 \%$ & $97.767 \%$ \\
\hline 377 & spray & 0.00121 & $0.021 \%$ & $0.282 \%$ & $97.788 \%$ \\
\hline 378 & foco antiniebla & 0.00121 & $0.021 \%$ & $0.282 \%$ & $97.809 \%$ \\
\hline 379 & instalación de aire & 0.00121 & $0.021 \%$ & $0.282 \%$ & $97.830 \%$ \\
\hline 380 & zona de escape & 0.00111 & $0.021 \%$ & $0.282 \%$ & $97.851 \%$ \\
\hline 381 & luz normal & 0.00111 & $0.021 \%$ & $0.282 \%$ & $97.872 \%$ \\
\hline 382 & ventilador de techo & 0.00111 & $0.021 \%$ & $0.282 \%$ & $97.893 \%$ \\
\hline 383 & foguera & 0.00111 & $0.021 \%$ & $0.282 \%$ & $97.914 \%$ \\
\hline
\end{tabular}




\begin{tabular}{|c|c|c|c|c|c|}
\hline 384 & lámpara de aspas & 0.00111 & $0.021 \%$ & $0.282 \%$ & $97.935 \%$ \\
\hline 385 & encender linterna & 0.00111 & $0.021 \%$ & $0.282 \%$ & $97.956 \%$ \\
\hline 386 & anorak & 0.00111 & $0.021 \%$ & $0.282 \%$ & $97.977 \%$ \\
\hline 387 & electricidad hidráulica & 0.00111 & $0.021 \%$ & $0.282 \%$ & $97.998 \%$ \\
\hline 388 & caldera de agua & 0.00111 & $0.021 \%$ & $0.282 \%$ & $98.019 \%$ \\
\hline 389 & luz de moto & 0.00111 & $0.021 \%$ & $0.282 \%$ & $98.040 \%$ \\
\hline 390 & cámara de vídeo & 0.00111 & $0.021 \%$ & $0.282 \%$ & $98.061 \%$ \\
\hline 391 & descapotable & 0.00111 & $0.021 \%$ & $0.282 \%$ & $98.082 \%$ \\
\hline 392 & vatio & 0.00111 & $0.021 \%$ & $0.282 \%$ & $98.103 \%$ \\
\hline 393 & alternador & 0.00111 & $0.021 \%$ & $0.282 \%$ & $98.124 \%$ \\
\hline 394 & soplo & 0.00111 & $0.021 \%$ & $0.282 \%$ & $98.145 \%$ \\
\hline 395 & cuarto de luces & 0.00111 & $0.021 \%$ & $0.282 \%$ & $98.166 \%$ \\
\hline 396 & estrellita fluorescente & 0.00111 & $0.021 \%$ & $0.282 \%$ & $98.187 \%$ \\
\hline 397 & lupa & 0.00111 & $0.021 \%$ & $0.282 \%$ & $98.208 \%$ \\
\hline 398 & techo solar & 0.00111 & $0.021 \%$ & $0.282 \%$ & $98.229 \%$ \\
\hline 399 & manga arremangada & 0.00111 & $0.021 \%$ & $0.282 \%$ & $98.250 \%$ \\
\hline 400 & ventana acristalada & 0.00111 & $0.021 \%$ & $0.282 \%$ & $98.271 \%$ \\
\hline 401 & estufa de carbón & 0.00102 & $0.021 \%$ & $0.282 \%$ & $98.292 \%$ \\
\hline 402 & vapor de agua & 0.00102 & $0.021 \%$ & $0.282 \%$ & $98.313 \%$ \\
\hline 403 & apertura ventana & 0.00102 & $0.021 \%$ & $0.282 \%$ & $98.334 \%$ \\
\hline 404 & alarma & 0.00102 & $0.021 \%$ & $0.282 \%$ & $98.355 \%$ \\
\hline 405 & plafó & 0.00102 & $0.021 \%$ & $0.282 \%$ & $98.376 \%$ \\
\hline 406 & radiación & 0.00102 & $0.021 \%$ & $0.282 \%$ & $98.397 \%$ \\
\hline 407 & encender televisión & 0.00102 & $0.021 \%$ & $0.282 \%$ & $98.418 \%$ \\
\hline 408 & invernadero & 0.00102 & $0.021 \%$ & $0.282 \%$ & $98.439 \%$ \\
\hline 409 & calefacción solar & 0.00102 & $0.021 \%$ & $0.282 \%$ & $98.460 \%$ \\
\hline 410 & cubrecamas & 0.00102 & $0.021 \%$ & $0.282 \%$ & $98.481 \%$ \\
\hline 411 & voltio & 0.00102 & $0.021 \%$ & $0.282 \%$ & $98.502 \%$ \\
\hline 412 & rejilla en puerta & 0.00102 & $0.021 \%$ & $0.282 \%$ & $98.523 \%$ \\
\hline 413 & luz de cocina & 0.00102 & $0.021 \%$ & $0.282 \%$ & $98.544 \%$ \\
\hline 414 & cerrando ventana & 0.00102 & $0.021 \%$ & $0.282 \%$ & $98.565 \%$ \\
\hline 415 & mesa camilla & 0.00093 & $0.021 \%$ & $0.282 \%$ & $98.586 \%$ \\
\hline 416 & campana & 0.00093 & $0.021 \%$ & $0.282 \%$ & $98.607 \%$ \\
\hline 417 & mantón de Manila & 0.00093 & $0.021 \%$ & $0.282 \%$ & $98.628 \%$ \\
\hline 418 & bombilla normal & 0.00093 & $0.021 \%$ & $0.282 \%$ & $98.649 \%$ \\
\hline 419 & coche & 0.00093 & $0.021 \%$ & $0.282 \%$ & $98.670 \%$ \\
\hline 420 & frotarse las manos & 0.00093 & $0.021 \%$ & $0.282 \%$ & $98.691 \%$ \\
\hline 421 & resistencia & 0.00093 & $0.021 \%$ & $0.282 \%$ & $98.712 \%$ \\
\hline 422 & misto & 0.00093 & $0.021 \%$ & $0.282 \%$ & $98.733 \%$ \\
\hline 423 & abrir persiana & 0.00093 & $0.021 \%$ & $0.282 \%$ & $98.754 \%$ \\
\hline 424 & zócalo & 0.00093 & $0.021 \%$ & $0.282 \%$ & $98.775 \%$ \\
\hline 425 & foco de color & 0.00093 & $0.021 \%$ & $0.282 \%$ & $98.796 \%$ \\
\hline 426 & porche & 0.00093 & $0.021 \%$ & $0.282 \%$ & $98.817 \%$ \\
\hline 427 & encendedor & 0.00093 & $0.021 \%$ & $0.282 \%$ & $98.838 \%$ \\
\hline 428 & a soplos & 0.00093 & $0.021 \%$ & $0.282 \%$ & $98.859 \%$ \\
\hline 429 & calor corporal & 0.00093 & $0.021 \%$ & $0.282 \%$ & $98.880 \%$ \\
\hline 430 & contraventana & 0.00093 & $0.021 \%$ & $0.282 \%$ & $98.901 \%$ \\
\hline
\end{tabular}




\begin{tabular}{|c|c|c|c|c|c|}
\hline 431 & soplillo & 0.00093 & $0.021 \%$ & $0.282 \%$ & $98.922 \%$ \\
\hline 432 & conducto de ventilación & 0.00093 & $0.021 \%$ & $0.282 \%$ & $98.943 \%$ \\
\hline 433 & abrir trampilla & 0.00086 & $0.021 \%$ & $0.282 \%$ & $98.964 \%$ \\
\hline 434 & mosquitero & 0.00086 & $0.021 \%$ & $0.282 \%$ & $98.985 \%$ \\
\hline 435 & colcha & 0.00086 & $0.021 \%$ & $0.282 \%$ & $99.006 \%$ \\
\hline 436 & tener aires & 0.00086 & $0.021 \%$ & $0.282 \%$ & $99.027 \%$ \\
\hline 437 & parrilla & 0.00086 & $0.021 \%$ & $0.282 \%$ & $99.048 \%$ \\
\hline 438 & papel de plata & 0.00086 & $0.021 \%$ & $0.282 \%$ & $99.069 \%$ \\
\hline 439 & condensador & 0.00086 & $0.021 \%$ & $0.282 \%$ & $99.090 \%$ \\
\hline 440 & aire central & 0.00086 & $0.021 \%$ & $0.282 \%$ & $99.111 \%$ \\
\hline 441 & transformador & 0.00086 & $0.021 \%$ & $0.282 \%$ & $99.132 \%$ \\
\hline 442 & alfombra & 0.00086 & $0.021 \%$ & $0.282 \%$ & $99.153 \%$ \\
\hline 443 & aire exterior & 0.00086 & $0.021 \%$ & $0.282 \%$ & $99.174 \%$ \\
\hline 444 & esfera & 0.00086 & $0.021 \%$ & $0.282 \%$ & $99.195 \%$ \\
\hline 445 & pila de luz & 0.00086 & $0.021 \%$ & $0.282 \%$ & $99.216 \%$ \\
\hline 446 & lamparita de noche & 0.00086 & $0.021 \%$ & $0.282 \%$ & $99.237 \%$ \\
\hline 447 & plaqueta & 0.00086 & $0.021 \%$ & $0.282 \%$ & $99.258 \%$ \\
\hline 448 & red & 0.00079 & $0.021 \%$ & $0.282 \%$ & $99.279 \%$ \\
\hline 449 & fusión nuclear & 0.00079 & $0.021 \%$ & $0.282 \%$ & $99.300 \%$ \\
\hline 450 & luz de gas & 0.00079 & $0.021 \%$ & $0.282 \%$ & $99.321 \%$ \\
\hline 451 & corriente eléctrica & 0.00079 & $0.021 \%$ & $0.282 \%$ & $99.342 \%$ \\
\hline 452 & chimenea tradicional & 0.00079 & $0.021 \%$ & $0.282 \%$ & $99.363 \%$ \\
\hline 453 & fuelle & 0.00079 & $0.021 \%$ & $0.282 \%$ & $99.384 \%$ \\
\hline 454 & interruptor de luz & 0.00072 & $0.021 \%$ & $0.282 \%$ & $99.405 \%$ \\
\hline 455 & bombilla verde & 0.00072 & $0.021 \%$ & $0.282 \%$ & $99.426 \%$ \\
\hline 456 & luna llena & 0.00072 & $0.021 \%$ & $0.282 \%$ & $99.447 \%$ \\
\hline 457 & lamparilla de noche & 0.00072 & $0.021 \%$ & $0.282 \%$ & $99.468 \%$ \\
\hline 458 & brasa & 0.00072 & $0.021 \%$ & $0.282 \%$ & $99.489 \%$ \\
\hline 459 & bocanada de aire fresco & 0.00072 & $0.021 \%$ & $0.282 \%$ & $99.510 \%$ \\
\hline 460 & aire acondicionado centralizado & 0.00066 & $0.021 \%$ & $0.282 \%$ & $99.531 \%$ \\
\hline 461 & cielo despejado & 0.00066 & $0.021 \%$ & $0.282 \%$ & $99.552 \%$ \\
\hline 462 & madera & 0.00066 & $0.021 \%$ & $0.282 \%$ & $99.573 \%$ \\
\hline 463 & máquina de fotos & 0.00066 & $0.021 \%$ & $0.282 \%$ & $99.594 \%$ \\
\hline 464 & humidificador & 0.00066 & $0.021 \%$ & $0.282 \%$ & $99.615 \%$ \\
\hline 465 & bomba eléctrica & 0.00061 & $0.021 \%$ & $0.282 \%$ & $99.636 \%$ \\
\hline 466 & bombilla violeta & 0.00061 & $0.021 \%$ & $0.282 \%$ & $99.657 \%$ \\
\hline 467 & ventilador de bolsillo & 0.00061 & $0.021 \%$ & $0.282 \%$ & $99.678 \%$ \\
\hline 468 & explosión de aviones & 0.00061 & $0.021 \%$ & $0.282 \%$ & $99.699 \%$ \\
\hline 469 & a pleno día & 0.00061 & $0.021 \%$ & $0.282 \%$ & $99.720 \%$ \\
\hline 470 & bomba de gas & 0.00056 & $0.021 \%$ & $0.282 \%$ & $99.741 \%$ \\
\hline 471 & alargador & 0.00056 & $0.021 \%$ & $0.282 \%$ & $99.762 \%$ \\
\hline 472 & automático & 0.00056 & $0.021 \%$ & $0.282 \%$ & $99.783 \%$ \\
\hline 473 & meteorito & 0.00051 & $0.021 \%$ & $0.282 \%$ & $99.804 \%$ \\
\hline 474 & microondas & 0.00047 & $0.021 \%$ & $0.282 \%$ & $99.825 \%$ \\
\hline 475 & agua hirviendo & 0.00043 & $0.021 \%$ & $0.282 \%$ & $99.846 \%$ \\
\hline 476 & peúcos & 0.00040 & $0.021 \%$ & $0.282 \%$ & $99.867 \%$ \\
\hline 477 & soplido & 0.00040 & $0.021 \%$ & $0.282 \%$ & $99.888 \%$ \\
\hline
\end{tabular}




\begin{tabular}{|l|l||l|l|l|l|}
\hline 478 & rayos uva & 0.00034 & $0.021 \%$ & $0.282 \%$ & $99.909 \%$ \\
\hline 479 & cazadora & 0.00031 & $0.021 \%$ & $0.282 \%$ & $99.930 \%$ \\
\hline
\end{tabular}

\section{LA CIUDAD}

\begin{tabular}{|c|c|c|c|c|c|}
\hline $\mathrm{N}^{\mathrm{o}}$ & Palabra & Disponibilidad & $\begin{array}{c}\text { Frecuencia } \\
\text { relativa }\end{array}$ & \% Aparición & $\begin{array}{l}\text { Frecuencia } \\
\text { acumulada }\end{array}$ \\
\hline 1 & coche & 0.62481 & $3.120 \%$ & $77.119 \%$ & $3.120 \%$ \\
\hline 2 & calle & 0.49998 & $2.617 \%$ & $64.689 \%$ & $5.737 \%$ \\
\hline 3 & semáforo & 0.36658 & $2.149 \%$ & $53.107 \%$ & $7.886 \%$ \\
\hline 4 & casa & 0.35290 & $2.012 \%$ & $49.718 \%$ & $9.898 \%$ \\
\hline 5 & edificio & 0.34842 & $1.909 \%$ & $47.175 \%$ & $11.807 \%$ \\
\hline 6 & tienda & 0.34375 & $2.195 \%$ & $54.237 \%$ & $14.002 \%$ \\
\hline 7 & parque & 0.33562 & $2.035 \%$ & $50.282 \%$ & $16.037 \%$ \\
\hline 8 & plaza & 0.31392 & $2.012 \%$ & $49.718 \%$ & $18.049 \%$ \\
\hline 9 & moto & 0.27248 & $1.634 \%$ & $40.395 \%$ & $19.683 \%$ \\
\hline 10 & bar & 0.24033 & $1.714 \%$ & $42.373 \%$ & $21.397 \%$ \\
\hline 11 & (auto)bús & 0.23493 & $1.554 \%$ & $38.418 \%$ & $22.951 \%$ \\
\hline 12 & ayuntamiento & 0.23412 & $1.589 \%$ & $39.266 \%$ & $24.540 \%$ \\
\hline 13 & acera & 0.22614 & $1.394 \%$ & $34.463 \%$ & $25.934 \%$ \\
\hline 14 & avenida & 0.22360 & $1.337 \%$ & $33.051 \%$ & $27.271 \%$ \\
\hline 15 & farola & 0.21269 & $1.303 \%$ & $32.203 \%$ & $28.574 \%$ \\
\hline 16 & contaminación & 0.19231 & $1.166 \%$ & $28.814 \%$ & $29.740 \%$ \\
\hline 17 & instituto & 0.18828 & $1.486 \%$ & $36.723 \%$ & $31.226 \%$ \\
\hline 18 & piso & 0.17635 & $1.017 \%$ & $25.141 \%$ & $32.243 \%$ \\
\hline 19 & discoteca & 0.17056 & $1.303 \%$ & $32.203 \%$ & $33.546 \%$ \\
\hline 20 & supermercado & 0.16943 & $1.189 \%$ & $29.379 \%$ & $34.735 \%$ \\
\hline 21 & gente & 0.16737 & $1.097 \%$ & $27.119 \%$ & $35.832 \%$ \\
\hline 22 & bici(cleta) & 0.16407 & $1.132 \%$ & $27.966 \%$ & $36.964 \%$ \\
\hline 23 & carretera & 0.16369 & $0.960 \%$ & $23.729 \%$ & $37.924 \%$ \\
\hline 24 & árbol & 0.16185 & $1.143 \%$ & $28.249 \%$ & $39.067 \%$ \\
\hline 25 & colegio & 0.15633 & $1.200 \%$ & $29.661 \%$ & $40.267 \%$ \\
\hline 26 & jardín & 0.15339 & $0.994 \%$ & $24.576 \%$ & $41.261 \%$ \\
\hline 27 & banco & 0.14987 & $1.074 \%$ & $26.554 \%$ & $42.335 \%$ \\
\hline 28 & escuela & 0.14734 & $1.029 \%$ & $25.424 \%$ & $43.364 \%$ \\
\hline 29 & camión & 0.14730 & $0.960 \%$ & $23.729 \%$ & $44.324 \%$ \\
\hline 30 & policía & 0.14541 & $1.074 \%$ & $26.554 \%$ & $45.398 \%$ \\
\hline 31 & cine & 0.14288 & $0.972 \%$ & $24.011 \%$ & $46.370 \%$ \\
\hline 32 & biblioteca & 0.13665 & $0.994 \%$ & $24.576 \%$ & $47.364 \%$ \\
\hline 33 & iglesia & 0.13028 & $1.017 \%$ & $25.141 \%$ & $48.381 \%$ \\
\hline 34 & restaurante & 0.12536 & $0.994 \%$ & $24.576 \%$ & $49.375 \%$ \\
\hline 35 & pub & 0.11484 & $0.926 \%$ & $22.881 \%$ & $50.301 \%$ \\
\hline 36 & ruido & 0.11352 & $0.732 \%$ & $18.079 \%$ & $51.033 \%$ \\
\hline
\end{tabular}




\begin{tabular}{|c|c|c|c|c|c|}
\hline 37 & fuente & 0.10825 & $0.823 \%$ & $20.339 \%$ & $51.856 \%$ \\
\hline 38 & hospital & 0.10686 & $0.869 \%$ & $21.469 \%$ & $52.725 \%$ \\
\hline 39 & rascacielos & 0.10397 & $0.652 \%$ & $16.102 \%$ & $53.377 \%$ \\
\hline 40 & paso de cebra & 0.10289 & $0.697 \%$ & $17.232 \%$ & $54.074 \%$ \\
\hline 41 & museo & 0.10124 & $0.674 \%$ & $16.667 \%$ & $54.748 \%$ \\
\hline 42 & persona & 0.09496 & $0.594 \%$ & $14.689 \%$ & $55.342 \%$ \\
\hline 43 & metro & 0.08847 & $0.629 \%$ & $15.537 \%$ & $55.971 \%$ \\
\hline 44 & universidad & 0.08583 & $0.709 \%$ & $17.514 \%$ & $56.680 \%$ \\
\hline 45 & papelera & 0.08324 & $0.571 \%$ & $14.124 \%$ & $57.251 \%$ \\
\hline 46 & señal & 0.08237 & $0.526 \%$ & $12.994 \%$ & $57.777 \%$ \\
\hline 47 & $\operatorname{taxi}$ & 0.08065 & $0.606 \%$ & $14.972 \%$ & $58.383 \%$ \\
\hline 48 & humo & 0.08055 & $0.503 \%$ & $12.429 \%$ & $58.886 \%$ \\
\hline 49 & tráfico & 0.07094 & $0.446 \%$ & $11.017 \%$ & $59.332 \%$ \\
\hline 50 & tren & 0.06951 & $0.503 \%$ & $12.429 \%$ & $59.835 \%$ \\
\hline 51 & campo de fútbol & 0.06740 & $0.514 \%$ & $12.712 \%$ & $60.349 \%$ \\
\hline 52 & mercado & 0.06518 & $0.491 \%$ & $12.147 \%$ & $60.840 \%$ \\
\hline 53 & panadería & 0.06221 & $0.446 \%$ & $11.017 \%$ & $61.286 \%$ \\
\hline 54 & teatro & 0.06126 & $0.457 \%$ & $11.299 \%$ & $61.743 \%$ \\
\hline 55 & rotonda & 0.06104 & $0.423 \%$ & $10.452 \%$ & $62.166 \%$ \\
\hline 56 & parking & 0.06091 & $0.446 \%$ & $11.017 \%$ & $62.612 \%$ \\
\hline 57 & señal de tráfico & 0.05937 & $0.423 \%$ & $10.452 \%$ & $63.035 \%$ \\
\hline 58 & comercio & 0.05936 & $0.354 \%$ & $8.757 \%$ & $63.389 \%$ \\
\hline 59 & polideportivo & 0.05590 & $0.446 \%$ & $11.017 \%$ & $63.835 \%$ \\
\hline 60 & asfalto & 0.05293 & $0.354 \%$ & $8.757 \%$ & $64.189 \%$ \\
\hline 61 & kiosco & 0.05136 & $0.389 \%$ & $9.605 \%$ & $64.578 \%$ \\
\hline 62 & peatón & 0.05046 & $0.286 \%$ & $7.062 \%$ & $64.864 \%$ \\
\hline 63 & perro & 0.04939 & $0.411 \%$ & $10.169 \%$ & $65.275 \%$ \\
\hline 64 & cafetería & 0.04807 & $0.354 \%$ & $8.757 \%$ & $65.629 \%$ \\
\hline 65 & carnicería & 0.04709 & $0.309 \%$ & $7.627 \%$ & $65.938 \%$ \\
\hline 66 & callejón & 0.04695 & $0.343 \%$ & $8.475 \%$ & $66.281 \%$ \\
\hline 67 & monumento & 0.04585 & $0.343 \%$ & $8.475 \%$ & $66.624 \%$ \\
\hline 68 & tienda de ropa & 0.04561 & $0.286 \%$ & $7.062 \%$ & $66.910 \%$ \\
\hline 69 & paseo & 0.04507 & $0.331 \%$ & $8.192 \%$ & $67.241 \%$ \\
\hline 70 & aeropuerto & 0.04311 & $0.377 \%$ & $9.322 \%$ & $67.618 \%$ \\
\hline 71 & hotel & 0.04242 & $0.320 \%$ & $7.910 \%$ & $67.938 \%$ \\
\hline 72 & fábrica & 0.04227 & $0.331 \%$ & $8.192 \%$ & $68.269 \%$ \\
\hline 73 & piscina & 0.04062 & $0.331 \%$ & $8.192 \%$ & $68.600 \%$ \\
\hline 74 & estatua & 0.03996 & $0.297 \%$ & $7.345 \%$ & $68.897 \%$ \\
\hline 75 & calzada & 0.03888 & $0.240 \%$ & $5.932 \%$ & $69.137 \%$ \\
\hline 76 & grandes almacenes & 0.03844 & $0.309 \%$ & $7.627 \%$ & $69.446 \%$ \\
\hline 77 & centro comercial & 0.03670 & $0.263 \%$ & $6.497 \%$ & $69.709 \%$ \\
\hline 78 & oficina & 0.03612 & $0.286 \%$ & $7.062 \%$ & $69.995 \%$ \\
\hline 79 & estanco & 0.03565 & $0.263 \%$ & $6.497 \%$ & $70.258 \%$ \\
\hline 80 & basura & 0.03356 & $0.263 \%$ & $6.497 \%$ & $70.521 \%$ \\
\hline 81 & barrio & 0.03322 & $0.206 \%$ & $5.085 \%$ & $70.727 \%$ \\
\hline 82 & estación & 0.03306 & $0.297 \%$ & $7.345 \%$ & $71.024 \%$ \\
\hline 83 & motocicleta & 0.03302 & $0.229 \%$ & $5.650 \%$ & $71.253 \%$ \\
\hline
\end{tabular}




\begin{tabular}{|c|c|c|c|c|c|}
\hline 84 & puente & 0.03249 & $0.251 \%$ & $6.215 \%$ & $71.504 \%$ \\
\hline 85 & chalet & 0.03128 & $0.229 \%$ & $5.650 \%$ & $71.733 \%$ \\
\hline 86 & librería & 0.03111 & $0.240 \%$ & $5.932 \%$ & $71.973 \%$ \\
\hline 87 & niño & 0.03006 & $0.229 \%$ & $5.650 \%$ & $72.202 \%$ \\
\hline 88 & puerto & 0.02824 & $0.240 \%$ & $5.932 \%$ & $72.442 \%$ \\
\hline 89 & papelería & 0.02809 & $0.217 \%$ & $5.367 \%$ & $72.659 \%$ \\
\hline 90 & farmacia & 0.02802 & $0.229 \%$ & $5.650 \%$ & $72.888 \%$ \\
\hline 91 & almacén & 0.02753 & $0.206 \%$ & $5.085 \%$ & $73.094 \%$ \\
\hline 92 & furgoneta & 0.02622 & $0.160 \%$ & $3.955 \%$ & $73.254 \%$ \\
\hline 93 & garaje & 0.02606 & $0.217 \%$ & $5.367 \%$ & $73.471 \%$ \\
\hline 94 & bombero & 0.02595 & $0.206 \%$ & $5.085 \%$ & $73.677 \%$ \\
\hline 95 & gato & 0.02595 & $0.229 \%$ & $5.650 \%$ & $73.906 \%$ \\
\hline 96 & plaza de toros & 0.02537 & $0.240 \%$ & $5.932 \%$ & $74.146 \%$ \\
\hline 97 & columpio & 0.02490 & $0.194 \%$ & $4.802 \%$ & $74.340 \%$ \\
\hline 98 & ciclomotor & 0.02464 & $0.194 \%$ & $4.802 \%$ & $74.534 \%$ \\
\hline 99 & polución & 0.02464 & $0.160 \%$ & $3.955 \%$ & $74.694 \%$ \\
\hline 100 & catedral & 0.02445 & $0.206 \%$ & $5.085 \%$ & $74.900 \%$ \\
\hline 101 & juzgado & 0.02428 & $0.194 \%$ & $4.802 \%$ & $75.094 \%$ \\
\hline 102 & zapatería & 0.02394 & $0.171 \%$ & $4.237 \%$ & $75.265 \%$ \\
\hline 103 & peluquería & 0.02394 & $0.206 \%$ & $5.085 \%$ & $75.471 \%$ \\
\hline 104 & pescadería & 0.02342 & $0.183 \%$ & $4.520 \%$ & $75.654 \%$ \\
\hline 105 & paso de peatones & 0.02322 & $0.137 \%$ & $3.390 \%$ & $75.791 \%$ \\
\hline 106 & camino & 0.02312 & $0.149 \%$ & $3.672 \%$ & $75.940 \%$ \\
\hline 107 & apartamento & 0.02261 & $0.126 \%$ & $3.107 \%$ & $76.066 \%$ \\
\hline 108 & planta & 0.02233 & $0.149 \%$ & $3.672 \%$ & $76.215 \%$ \\
\hline 109 & atasco & 0.02225 & $0.126 \%$ & $3.107 \%$ & $76.341 \%$ \\
\hline 110 & playa & 0.02209 & $0.206 \%$ & $5.085 \%$ & $76.547 \%$ \\
\hline 111 & cabina (telefónica) & 0.02191 & $0.171 \%$ & $4.237 \%$ & $76.718 \%$ \\
\hline 112 & estación de tren & 0.02177 & $0.183 \%$ & $4.520 \%$ & $76.901 \%$ \\
\hline 113 & alcantarilla & 0.02103 & $0.183 \%$ & $4.520 \%$ & $77.084 \%$ \\
\hline 114 & parada de (auto)bús & 0.02101 & $0.194 \%$ & $4.802 \%$ & $77.278 \%$ \\
\hline 115 & heladería & 0.02071 & $0.171 \%$ & $4.237 \%$ & $77.449 \%$ \\
\hline 116 & gimnasio & 0.02068 & $0.183 \%$ & $4.520 \%$ & $77.632 \%$ \\
\hline 117 & ciudadano & 0.02049 & $0.126 \%$ & $3.107 \%$ & $77.758 \%$ \\
\hline 118 & buzón & 0.01995 & $0.137 \%$ & $3.390 \%$ & $77.895 \%$ \\
\hline 119 & flor & 0.01951 & $0.160 \%$ & $3.955 \%$ & $78.055 \%$ \\
\hline 120 & aparcamiento & 0.01946 & $0.137 \%$ & $3.390 \%$ & $78.192 \%$ \\
\hline 121 & estrés & 0.01921 & $0.137 \%$ & $3.390 \%$ & $78.329 \%$ \\
\hline 122 & guardia civil & 0.01902 & $0.160 \%$ & $3.955 \%$ & $78.489 \%$ \\
\hline 123 & ladrón & 0.01837 & $0.137 \%$ & $3.390 \%$ & $78.626 \%$ \\
\hline 124 & pájaro & 0.01799 & $0.137 \%$ & $3.390 \%$ & $78.763 \%$ \\
\hline 125 & villa & 0.01766 & $0.091 \%$ & $2.260 \%$ & $78.854 \%$ \\
\hline 126 & pastelería & 0.01748 & $0.126 \%$ & $3.107 \%$ & $78.980 \%$ \\
\hline 127 & residencia & 0.01744 & $0.160 \%$ & $3.955 \%$ & $79.140 \%$ \\
\hline 128 & correos & 0.01740 & $0.126 \%$ & $3.107 \%$ & $79.266 \%$ \\
\hline 129 & gasolinera & 0.01721 & $0.149 \%$ & $3.672 \%$ & $79.415 \%$ \\
\hline 130 & tranvía & 0.01717 & $0.137 \%$ & $3.390 \%$ & $79.552 \%$ \\
\hline
\end{tabular}




\begin{tabular}{|c|c|c|c|c|c|}
\hline 131 & agobio & 0.01686 & $0.103 \%$ & $2.542 \%$ & $79.655 \%$ \\
\hline 132 & río & 0.01680 & $0.137 \%$ & $3.390 \%$ & $79.792 \%$ \\
\hline 133 & estadio & 0.01680 & $0.137 \%$ & $3.390 \%$ & $79.929 \%$ \\
\hline 134 & automóvil & 0.01675 & $0.103 \%$ & $2.542 \%$ & $80.032 \%$ \\
\hline 135 & ventana & 0.01605 & $0.114 \%$ & $2.825 \%$ & $80.146 \%$ \\
\hline 136 & hipermercado & 0.01597 & $0.114 \%$ & $2.825 \%$ & $80.260 \%$ \\
\hline 137 & parvulario & 0.01585 & $0.149 \%$ & $3.672 \%$ & $80.409 \%$ \\
\hline 138 & auditorio & 0.01581 & $0.114 \%$ & $2.825 \%$ & $80.523 \%$ \\
\hline 139 & luz & 0.01580 & $0.114 \%$ & $2.825 \%$ & $80.637 \%$ \\
\hline 140 & taller & 0.01563 & $0.137 \%$ & $3.390 \%$ & $80.774 \%$ \\
\hline 141 & campanario & 0.01550 & $0.114 \%$ & $2.825 \%$ & $80.888 \%$ \\
\hline 142 & obras & 0.01441 & $0.137 \%$ & $3.390 \%$ & $81.025 \%$ \\
\hline 143 & arcén & 0.01410 & $0.091 \%$ & $2.260 \%$ & $81.116 \%$ \\
\hline 144 & guardería & 0.01409 & $0.137 \%$ & $3.390 \%$ & $81.253 \%$ \\
\hline 145 & manzana & 0.01379 & $0.091 \%$ & $2.260 \%$ & $81.344 \%$ \\
\hline 146 & finca & 0.01354 & $0.091 \%$ & $2.260 \%$ & $81.435 \%$ \\
\hline 147 & escaparate & 0.01337 & $0.091 \%$ & $2.260 \%$ & $81.526 \%$ \\
\hline 148 & guardia & 0.01328 & $0.091 \%$ & $2.260 \%$ & $81.617 \%$ \\
\hline 149 & ascensor & 0.01315 & $0.091 \%$ & $2.260 \%$ & $81.708 \%$ \\
\hline 150 & portal & 0.01309 & $0.103 \%$ & $2.542 \%$ & $81.811 \%$ \\
\hline 151 & suciedad & 0.01296 & $0.091 \%$ & $2.260 \%$ & $81.902 \%$ \\
\hline 152 & autopista & 0.01289 & $0.091 \%$ & $2.260 \%$ & $81.993 \%$ \\
\hline 153 & academia & 0.01288 & $0.114 \%$ & $2.825 \%$ & $82.107 \%$ \\
\hline 154 & banco de sentarse & 0.01266 & $0.091 \%$ & $2.260 \%$ & $82.198 \%$ \\
\hline 155 & urbanización & 0.01255 & $0.091 \%$ & $2.260 \%$ & $82.289 \%$ \\
\hline 156 & industria & 0.01208 & $0.080 \%$ & $1.977 \%$ & $82.369 \%$ \\
\hline 157 & vivienda & 0.01185 & $0.080 \%$ & $1.977 \%$ & $82.449 \%$ \\
\hline 158 & frutería & 0.01177 & $0.080 \%$ & $1.977 \%$ & $82.529 \%$ \\
\hline 159 & bordillo & 0.01171 & $0.091 \%$ & $2.260 \%$ & $82.620 \%$ \\
\hline 160 & tienda de deportes & 0.01163 & $0.080 \%$ & $1.977 \%$ & $82.700 \%$ \\
\hline 161 & ambulancia & 0.01161 & $0.114 \%$ & $2.825 \%$ & $82.814 \%$ \\
\hline 162 & callejuela & 0.01154 & $0.057 \%$ & $1.412 \%$ & $82.871 \%$ \\
\hline 163 & accidente & 0.01153 & $0.091 \%$ & $2.260 \%$ & $82.962 \%$ \\
\hline 164 & tránsito & 0.01135 & $0.057 \%$ & $1.412 \%$ & $83.019 \%$ \\
\hline 165 & contenedor & 0.01122 & $0.091 \%$ & $2.260 \%$ & $83.110 \%$ \\
\hline 166 & fiesta & 0.01105 & $0.114 \%$ & $2.825 \%$ & $83.224 \%$ \\
\hline 167 & conservatorio & 0.01093 & $0.091 \%$ & $2.260 \%$ & $83.315 \%$ \\
\hline 168 & establecimiento & 0.01091 & $0.080 \%$ & $1.977 \%$ & $83.395 \%$ \\
\hline 169 & clínica & 0.01077 & $0.103 \%$ & $2.542 \%$ & $83.498 \%$ \\
\hline 170 & balcón & 0.01077 & $0.080 \%$ & $1.977 \%$ & $83.578 \%$ \\
\hline 171 & médico & 0.01073 & $0.103 \%$ & $2.542 \%$ & $83.681 \%$ \\
\hline 172 & ambulatorio & 0.01058 & $0.091 \%$ & $2.260 \%$ & $83.772 \%$ \\
\hline 173 & paloma & 0.01045 & $0.069 \%$ & $1.695 \%$ & $83.841 \%$ \\
\hline 174 & edificio alto & 0.01045 & $0.057 \%$ & $1.412 \%$ & $83.898 \%$ \\
\hline 175 & avión & 0.01035 & $0.080 \%$ & $1.977 \%$ & $83.978 \%$ \\
\hline 176 & comisaría & 0.01026 & $0.080 \%$ & $1.977 \%$ & $84.058 \%$ \\
\hline 177 & descampado & 0.01025 & $0.091 \%$ & $2.260 \%$ & $84.149 \%$ \\
\hline
\end{tabular}




\begin{tabular}{|c|c|c|c|c|c|}
\hline 178 & basurero & 0.01023 & $0.080 \%$ & $1.977 \%$ & $84.229 \%$ \\
\hline 179 & club & 0.01014 & $0.057 \%$ & $1.412 \%$ & $84.286 \%$ \\
\hline 180 & robo & 0.01009 & $0.069 \%$ & $1.695 \%$ & $84.355 \%$ \\
\hline 181 & perfumería & 0.00998 & $0.069 \%$ & $1.695 \%$ & $84.424 \%$ \\
\hline 182 & pizzería & 0.00995 & $0.091 \%$ & $2.260 \%$ & $84.515 \%$ \\
\hline 183 & aglomeración & 0.00994 & $0.091 \%$ & $2.260 \%$ & $84.606 \%$ \\
\hline 184 & hombre & 0.00985 & $0.057 \%$ & $1.412 \%$ & $84.663 \%$ \\
\hline 185 & droguería & 0.00984 & $0.057 \%$ & $1.412 \%$ & $84.720 \%$ \\
\hline 186 & alcantarillado & 0.00974 & $0.057 \%$ & $1.412 \%$ & $84.777 \%$ \\
\hline 187 & sala de juegos & 0.00951 & $0.080 \%$ & $1.977 \%$ & $84.857 \%$ \\
\hline 188 & prostituta & 0.00947 & $0.046 \%$ & $1.130 \%$ & $84.903 \%$ \\
\hline 189 & zoo(lógico) & 0.00923 & $0.069 \%$ & $1.695 \%$ & $84.972 \%$ \\
\hline 190 & autoescuela & 0.00919 & $0.069 \%$ & $1.695 \%$ & $85.041 \%$ \\
\hline 191 & Diputación & 0.00912 & $0.080 \%$ & $1.977 \%$ & $85.121 \%$ \\
\hline 192 & zona verde & 0.00909 & $0.057 \%$ & $1.412 \%$ & $85.178 \%$ \\
\hline 193 & casa de cultura & 0.00907 & $0.057 \%$ & $1.412 \%$ & $85.235 \%$ \\
\hline 194 & diversión & 0.00902 & $0.057 \%$ & $1.412 \%$ & $85.292 \%$ \\
\hline 195 & asilo & 0.00901 & $0.091 \%$ & $2.260 \%$ & $85.383 \%$ \\
\hline 196 & cloaca & 0.00895 & $0.057 \%$ & $1.412 \%$ & $85.440 \%$ \\
\hline 197 & verdulería & 0.00887 & $0.069 \%$ & $1.695 \%$ & $85.509 \%$ \\
\hline 198 & pista de tenis & 0.00869 & $0.057 \%$ & $1.412 \%$ & $85.566 \%$ \\
\hline 199 & animal & 0.00865 & $0.069 \%$ & $1.695 \%$ & $85.635 \%$ \\
\hline 200 & escalera & 0.00859 & $0.069 \%$ & $1.695 \%$ & $85.704 \%$ \\
\hline 201 & esquina & 0.00852 & $0.057 \%$ & $1.412 \%$ & $85.761 \%$ \\
\hline 202 & cementerio & 0.00835 & $0.080 \%$ & $1.977 \%$ & $85.841 \%$ \\
\hline 203 & droga & 0.00815 & $0.069 \%$ & $1.695 \%$ & $85.910 \%$ \\
\hline 204 & césped & 0.00812 & $0.080 \%$ & $1.977 \%$ & $85.990 \%$ \\
\hline 205 & libertad & 0.00791 & $0.057 \%$ & $1.412 \%$ & $86.047 \%$ \\
\hline 206 & bulevar & 0.00779 & $0.046 \%$ & $1.130 \%$ & $86.093 \%$ \\
\hline 207 & vehículo & 0.00769 & $0.057 \%$ & $1.412 \%$ & $86.150 \%$ \\
\hline 208 & puerta & 0.00768 & $0.057 \%$ & $1.412 \%$ & $86.207 \%$ \\
\hline 209 & sex shop & 0.00755 & $0.046 \%$ & $1.130 \%$ & $86.253 \%$ \\
\hline 210 & centro de salud & 0.00753 & $0.069 \%$ & $1.695 \%$ & $86.322 \%$ \\
\hline 211 & prostíbulo & 0.00752 & $0.057 \%$ & $1.412 \%$ & $86.379 \%$ \\
\hline 212 & multitud & 0.00750 & $0.057 \%$ & $1.412 \%$ & $86.436 \%$ \\
\hline 213 & Barcelona & 0.00746 & $0.034 \%$ & $0.847 \%$ & $86.470 \%$ \\
\hline 214 & mar & 0.00742 & $0.057 \%$ & $1.412 \%$ & $86.527 \%$ \\
\hline 215 & gobierno civil & 0.00741 & $0.046 \%$ & $1.130 \%$ & $86.573 \%$ \\
\hline 216 & alcalde & 0.00741 & $0.069 \%$ & $1.695 \%$ & $86.642 \%$ \\
\hline 217 & estación de (auto)bús & 0.00736 & $0.057 \%$ & $1.412 \%$ & $86.699 \%$ \\
\hline 218 & óptica & 0.00731 & $0.069 \%$ & $1.695 \%$ & $86.768 \%$ \\
\hline 219 & limusina & 0.00730 & $0.046 \%$ & $1.130 \%$ & $86.814 \%$ \\
\hline 220 & delincuencia & 0.00727 & $0.057 \%$ & $1.412 \%$ & $86.871 \%$ \\
\hline 221 & floristería & 0.00720 & $0.057 \%$ & $1.412 \%$ & $86.928 \%$ \\
\hline 222 & empresa & 0.00718 & $0.057 \%$ & $1.412 \%$ & $86.985 \%$ \\
\hline 223 & dentista & 0.00718 & $0.057 \%$ & $1.412 \%$ & $87.042 \%$ \\
\hline 224 & Madrid & 0.00718 & $0.034 \%$ & $0.847 \%$ & $87.076 \%$ \\
\hline
\end{tabular}




\begin{tabular}{|c|c|c|c|c|c|}
\hline 225 & pabellón & 0.00710 & $0.057 \%$ & $1.412 \%$ & $87.133 \%$ \\
\hline 226 & ferretería & 0.00698 & $0.069 \%$ & $1.695 \%$ & $87.202 \%$ \\
\hline 227 & casino & 0.00694 & $0.046 \%$ & $1.130 \%$ & $87.248 \%$ \\
\hline 228 & calle peatonal & 0.00691 & $0.046 \%$ & $1.130 \%$ & $87.294 \%$ \\
\hline 229 & travesía & 0.00690 & $0.046 \%$ & $1.130 \%$ & $87.340 \%$ \\
\hline 230 & recreativos & 0.00687 & $0.057 \%$ & $1.412 \%$ & $87.397 \%$ \\
\hline 231 & cruce & 0.00682 & $0.057 \%$ & $1.412 \%$ & $87.454 \%$ \\
\hline 232 & bingo & 0.00668 & $0.069 \%$ & $1.695 \%$ & $87.523 \%$ \\
\hline 233 & acequia & 0.00661 & $0.057 \%$ & $1.412 \%$ & $87.580 \%$ \\
\hline 234 & recinto & 0.00658 & $0.046 \%$ & $1.130 \%$ & $87.626 \%$ \\
\hline 235 & anciano & 0.00650 & $0.046 \%$ & $1.130 \%$ & $87.672 \%$ \\
\hline 236 & embotellamiento & 0.00649 & $0.046 \%$ & $1.130 \%$ & $87.718 \%$ \\
\hline 237 & paleta & 0.00644 & $0.034 \%$ & $0.847 \%$ & $87.752 \%$ \\
\hline 238 & papel & 0.00641 & $0.069 \%$ & $1.695 \%$ & $87.821 \%$ \\
\hline 239 & trabajo & 0.00634 & $0.057 \%$ & $1.412 \%$ & $87.878 \%$ \\
\hline 240 & subterráneo & 0.00630 & $0.046 \%$ & $1.130 \%$ & $87.924 \%$ \\
\hline 241 & pabellón deportivo & 0.00630 & $0.046 \%$ & $1.130 \%$ & $87.970 \%$ \\
\hline 242 & marcha & 0.00625 & $0.046 \%$ & $1.130 \%$ & $88.016 \%$ \\
\hline 243 & caca de perro & 0.00624 & $0.034 \%$ & $0.847 \%$ & $88.050 \%$ \\
\hline 244 & tienda de zapatos & 0.00617 & $0.046 \%$ & $1.130 \%$ & $88.096 \%$ \\
\hline 245 & exposición & 0.00612 & $0.057 \%$ & $1.412 \%$ & $88.153 \%$ \\
\hline 246 & caja de ahorros & 0.00607 & $0.046 \%$ & $1.130 \%$ & $88.199 \%$ \\
\hline 247 & autocar & 0.00605 & $0.034 \%$ & $0.847 \%$ & $88.233 \%$ \\
\hline 248 & glorieta & 0.00595 & $0.046 \%$ & $1.130 \%$ & $88.279 \%$ \\
\hline 249 & pipican & 0.00594 & $0.046 \%$ & $1.130 \%$ & $88.325 \%$ \\
\hline 250 & pobre & 0.00593 & $0.034 \%$ & $0.847 \%$ & $88.359 \%$ \\
\hline 251 & dinero & 0.00589 & $0.057 \%$ & $1.412 \%$ & $88.416 \%$ \\
\hline 252 & huerto & 0.00583 & $0.046 \%$ & $1.130 \%$ & $88.462 \%$ \\
\hline 253 & campo & 0.00574 & $0.034 \%$ & $0.847 \%$ & $88.496 \%$ \\
\hline 254 & sidecar & 0.00572 & $0.046 \%$ & $1.130 \%$ & $88.542 \%$ \\
\hline 255 & alcohol & 0.00571 & $0.046 \%$ & $1.130 \%$ & $88.588 \%$ \\
\hline 256 & cárcel & 0.00570 & $0.057 \%$ & $1.412 \%$ & $88.645 \%$ \\
\hline 257 & prisa & 0.00563 & $0.046 \%$ & $1.130 \%$ & $88.691 \%$ \\
\hline 258 & piscina municipal & 0.00563 & $0.034 \%$ & $0.847 \%$ & $88.725 \%$ \\
\hline 259 & ambiente & 0.00556 & $0.046 \%$ & $1.130 \%$ & $88.771 \%$ \\
\hline 260 & cuartel de guardia civil & 0.00553 & $0.046 \%$ & $1.130 \%$ & $88.817 \%$ \\
\hline 261 & salón de juegos & 0.00544 & $0.034 \%$ & $0.847 \%$ & $88.851 \%$ \\
\hline 262 & putrefacción & 0.00539 & $0.023 \%$ & $0.565 \%$ & $88.874 \%$ \\
\hline 263 & estadio de fútbol & 0.00539 & $0.057 \%$ & $1.412 \%$ & $88.931 \%$ \\
\hline 264 & barco & 0.00534 & $0.034 \%$ & $0.847 \%$ & $88.965 \%$ \\
\hline 265 & mujer & 0.00531 & $0.034 \%$ & $0.847 \%$ & $88.999 \%$ \\
\hline 266 & vecino & 0.00527 & $0.034 \%$ & $0.847 \%$ & $89.033 \%$ \\
\hline 267 & turista & 0.00527 & $0.034 \%$ & $0.847 \%$ & $89.067 \%$ \\
\hline 268 & casco antiguo & 0.00526 & $0.023 \%$ & $0.565 \%$ & $89.090 \%$ \\
\hline 269 & café & 0.00523 & $0.057 \%$ & $1.412 \%$ & $89.147 \%$ \\
\hline 270 & publicidad & 0.00521 & $0.046 \%$ & $1.130 \%$ & $89.193 \%$ \\
\hline 271 & cartero & 0.00512 & $0.034 \%$ & $0.847 \%$ & $89.227 \%$ \\
\hline
\end{tabular}




\begin{tabular}{|c|c|c|c|c|c|}
\hline 272 & mercería & 0.00510 & $0.034 \%$ & $0.847 \%$ & $89.261 \%$ \\
\hline 273 & movimiento & 0.00506 & $0.034 \%$ & $0.847 \%$ & $89.295 \%$ \\
\hline 274 & abuelo & 0.00504 & $0.046 \%$ & $1.130 \%$ & $89.341 \%$ \\
\hline 275 & puticlub & 0.00499 & $0.046 \%$ & $1.130 \%$ & $89.387 \%$ \\
\hline 276 & terraza & 0.00499 & $0.046 \%$ & $1.130 \%$ & $89.433 \%$ \\
\hline 277 & pintada & 0.00494 & $0.034 \%$ & $0.847 \%$ & $89.467 \%$ \\
\hline 278 & videoclub & 0.00492 & $0.034 \%$ & $0.847 \%$ & $89.501 \%$ \\
\hline 279 & dúplex & 0.00490 & $0.034 \%$ & $0.847 \%$ & $89.535 \%$ \\
\hline 280 & polvo & 0.00490 & $0.023 \%$ & $0.565 \%$ & $89.558 \%$ \\
\hline 281 & plazoleta & 0.00489 & $0.023 \%$ & $0.565 \%$ & $89.581 \%$ \\
\hline 282 & ocupa & 0.00489 & $0.023 \%$ & $0.565 \%$ & $89.604 \%$ \\
\hline 283 & túnel & 0.00484 & $0.046 \%$ & $1.130 \%$ & $89.650 \%$ \\
\hline 284 & patio & 0.00467 & $0.023 \%$ & $0.565 \%$ & $89.673 \%$ \\
\hline 285 & bosque & 0.00466 & $0.023 \%$ & $0.565 \%$ & $89.696 \%$ \\
\hline 286 & cuartel de policía & 0.00466 & $0.034 \%$ & $0.847 \%$ & $89.730 \%$ \\
\hline 287 & charcutería & 0.00463 & $0.034 \%$ & $0.847 \%$ & $89.764 \%$ \\
\hline 288 & cervecería & 0.00462 & $0.034 \%$ & $0.847 \%$ & $89.798 \%$ \\
\hline 289 & isleta & 0.00459 & $0.023 \%$ & $0.565 \%$ & $89.821 \%$ \\
\hline 290 & atracador & 0.00456 & $0.034 \%$ & $0.847 \%$ & $89.855 \%$ \\
\hline 291 & stop & 0.00456 & $0.023 \%$ & $0.565 \%$ & $89.878 \%$ \\
\hline 292 & antena & 0.00453 & $0.034 \%$ & $0.847 \%$ & $89.912 \%$ \\
\hline 293 & circulación & 0.00453 & $0.034 \%$ & $0.847 \%$ & $89.946 \%$ \\
\hline 294 & bloque de pisos & 0.00453 & $0.034 \%$ & $0.847 \%$ & $89.980 \%$ \\
\hline 295 & atraco & 0.00449 & $0.034 \%$ & $0.847 \%$ & $90.014 \%$ \\
\hline 296 & casco urbano & 0.00449 & $0.023 \%$ & $0.565 \%$ & $90.037 \%$ \\
\hline 297 & bullicio & 0.00448 & $0.034 \%$ & $0.847 \%$ & $90.071 \%$ \\
\hline 298 & montaña & 0.00446 & $0.046 \%$ & $1.130 \%$ & $90.117 \%$ \\
\hline 299 & banco de dinero & 0.00444 & $0.034 \%$ & $0.847 \%$ & $90.151 \%$ \\
\hline 300 & trabajador & 0.00444 & $0.034 \%$ & $0.847 \%$ & $90.185 \%$ \\
\hline 301 & gris & 0.00440 & $0.023 \%$ & $0.565 \%$ & $90.208 \%$ \\
\hline 302 & alumbrado & 0.00436 & $0.034 \%$ & $0.847 \%$ & $90.242 \%$ \\
\hline 303 & ermita & 0.00436 & $0.034 \%$ & $0.847 \%$ & $90.276 \%$ \\
\hline 304 & pabellón de deportes & 0.00434 & $0.023 \%$ & $0.565 \%$ & $90.299 \%$ \\
\hline 305 & relojería & 0.00432 & $0.046 \%$ & $1.130 \%$ & $90.345 \%$ \\
\hline 306 & camello & 0.00432 & $0.023 \%$ & $0.565 \%$ & $90.368 \%$ \\
\hline 307 & navaja & 0.00424 & $0.023 \%$ & $0.565 \%$ & $90.391 \%$ \\
\hline 308 & yonqui & 0.00423 & $0.023 \%$ & $0.565 \%$ & $90.414 \%$ \\
\hline 309 & barrendero & 0.00421 & $0.034 \%$ & $0.847 \%$ & $90.448 \%$ \\
\hline 310 & aire & 0.00421 & $0.023 \%$ & $0.565 \%$ & $90.471 \%$ \\
\hline 311 & reloj & 0.00418 & $0.034 \%$ & $0.847 \%$ & $90.505 \%$ \\
\hline 312 & desagüe & 0.00415 & $0.034 \%$ & $0.847 \%$ & $90.539 \%$ \\
\hline 313 & centro & 0.00414 & $0.023 \%$ & $0.565 \%$ & $90.562 \%$ \\
\hline 314 & peligro & 0.00414 & $0.023 \%$ & $0.565 \%$ & $90.585 \%$ \\
\hline 315 & joyería & 0.00413 & $0.046 \%$ & $1.130 \%$ & $90.631 \%$ \\
\hline 316 & basílica & 0.00411 & $0.034 \%$ & $0.847 \%$ & $90.665 \%$ \\
\hline 317 & capilla & 0.00411 & $0.023 \%$ & $0.565 \%$ & $90.688 \%$ \\
\hline 318 & boutique & 0.00410 & $0.034 \%$ & $0.847 \%$ & $90.722 \%$ \\
\hline
\end{tabular}




\begin{tabular}{|c|c|c|c|c|c|}
\hline 319 & concejal & 0.00409 & $0.034 \%$ & $0.847 \%$ & $90.756 \%$ \\
\hline 320 & concesionario & 0.00408 & $0.034 \%$ & $0.847 \%$ & $90.790 \%$ \\
\hline 321 & chabola & 0.00404 & $0.023 \%$ & $0.565 \%$ & $90.813 \%$ \\
\hline 322 & construcción & 0.00404 & $0.057 \%$ & $1.412 \%$ & $90.870 \%$ \\
\hline 323 & vado & 0.00404 & $0.034 \%$ & $0.847 \%$ & $90.904 \%$ \\
\hline 324 & refugio & 0.00403 & $0.034 \%$ & $0.847 \%$ & $90.938 \%$ \\
\hline 325 & obrero & 0.00403 & $0.046 \%$ & $1.130 \%$ & $90.984 \%$ \\
\hline 326 & hostal & 0.00402 & $0.034 \%$ & $0.847 \%$ & $91.018 \%$ \\
\hline 327 & tienda de electrodomésticos & 0.00401 & $0.034 \%$ & $0.847 \%$ & $91.052 \%$ \\
\hline 328 & hamburguesería & 0.00400 & $0.034 \%$ & $0.847 \%$ & $91.086 \%$ \\
\hline 329 & palmera & 0.00395 & $0.023 \%$ & $0.565 \%$ & $91.109 \%$ \\
\hline 330 & zona residencial & 0.00391 & $0.023 \%$ & $0.565 \%$ & $91.132 \%$ \\
\hline 331 & pasaje & 0.00391 & $0.034 \%$ & $0.847 \%$ & $91.166 \%$ \\
\hline 332 & Seguridad Social & 0.00390 & $0.034 \%$ & $0.847 \%$ & $91.200 \%$ \\
\hline 333 & tienda de alimentos & 0.00389 & $0.023 \%$ & $0.565 \%$ & $91.223 \%$ \\
\hline 334 & Hacienda & 0.00388 & $0.034 \%$ & $0.847 \%$ & $91.257 \%$ \\
\hline 335 & Vespino* & 0.00385 & $0.023 \%$ & $0.565 \%$ & $91.280 \%$ \\
\hline 336 & solar & 0.00383 & $0.046 \%$ & $1.130 \%$ & $91.326 \%$ \\
\hline 337 & patín & 0.00383 & $0.034 \%$ & $0.847 \%$ & $91.360 \%$ \\
\hline 338 & mierda & 0.00381 & $0.023 \%$ & $0.565 \%$ & $91.383 \%$ \\
\hline 339 & senda & 0.00379 & $0.023 \%$ & $0.565 \%$ & $91.406 \%$ \\
\hline 340 & mercado central & 0.00378 & $0.034 \%$ & $0.847 \%$ & $91.440 \%$ \\
\hline 341 & Conselleria & 0.00376 & $0.023 \%$ & $0.565 \%$ & $91.463 \%$ \\
\hline 342 & barrio chino & 0.00376 & $0.023 \%$ & $0.565 \%$ & $91.486 \%$ \\
\hline 343 & ludoteca & 0.00375 & $0.034 \%$ & $0.847 \%$ & $91.520 \%$ \\
\hline 344 & circunvalación & 0.00372 & $0.034 \%$ & $0.847 \%$ & $91.554 \%$ \\
\hline 345 & bungalow & 0.00371 & $0.023 \%$ & $0.565 \%$ & $91.577 \%$ \\
\hline 346 & castillo & 0.00370 & $0.046 \%$ & $1.130 \%$ & $91.623 \%$ \\
\hline 347 & municipal & 0.00370 & $0.034 \%$ & $0.847 \%$ & $91.657 \%$ \\
\hline 348 & fútbol & 0.00370 & $0.034 \%$ & $0.847 \%$ & $91.691 \%$ \\
\hline 349 & tobogán & 0.00365 & $0.023 \%$ & $0.565 \%$ & $91.714 \%$ \\
\hline 350 & pista de atletismo & 0.00364 & $0.023 \%$ & $0.565 \%$ & $91.737 \%$ \\
\hline 351 & sala de exposiciones & 0.00364 & $0.034 \%$ & $0.847 \%$ & $91.771 \%$ \\
\hline 352 & vagabundo & 0.00361 & $0.034 \%$ & $0.847 \%$ & $91.805 \%$ \\
\hline 353 & grupo & 0.00360 & $0.023 \%$ & $0.565 \%$ & $91.828 \%$ \\
\hline 354 & traficante & 0.00355 & $0.023 \%$ & $0.565 \%$ & $91.851 \%$ \\
\hline 355 & zona de ocio & 0.00354 & $0.023 \%$ & $0.565 \%$ & $91.874 \%$ \\
\hline 356 & casa de coches & 0.00351 & $0.023 \%$ & $0.565 \%$ & $91.897 \%$ \\
\hline 357 & animal doméstico & 0.00350 & $0.023 \%$ & $0.565 \%$ & $91.920 \%$ \\
\hline 358 & asco & 0.00347 & $0.023 \%$ & $0.565 \%$ & $91.943 \%$ \\
\hline 359 & agencia de viajes & 0.00345 & $0.034 \%$ & $0.847 \%$ & $91.977 \%$ \\
\hline 360 & distrito & 0.00344 & $0.023 \%$ & $0.565 \%$ & $92.000 \%$ \\
\hline 361 & edificio público & 0.00344 & $0.023 \%$ & $0.565 \%$ & $92.023 \%$ \\
\hline 362 & asesinato & 0.00343 & $0.023 \%$ & $0.565 \%$ & $92.046 \%$ \\
\hline 363 & estanque & 0.00343 & $0.023 \%$ & $0.565 \%$ & $92.069 \%$ \\
\hline 364 & (auto)bús público & 0.00342 & $0.023 \%$ & $0.565 \%$ & $92.092 \%$ \\
\hline 365 & anuncio & 0.00342 & $0.023 \%$ & $0.565 \%$ & $92.115 \%$ \\
\hline
\end{tabular}




\begin{tabular}{|c|c|c|c|c|c|}
\hline 366 & indicador & 0.00340 & $0.023 \%$ & $0.565 \%$ & $92.138 \%$ \\
\hline 367 & gran edificio & 0.00337 & $0.023 \%$ & $0.565 \%$ & $92.161 \%$ \\
\hline 368 & ferrocarril & 0.00335 & $0.034 \%$ & $0.847 \%$ & $92.195 \%$ \\
\hline 369 & estudio & 0.00334 & $0.023 \%$ & $0.565 \%$ & $92.218 \%$ \\
\hline 370 & pitido & 0.00333 & $0.023 \%$ & $0.565 \%$ & $92.241 \%$ \\
\hline 371 & pabellón polideportivo & 0.00327 & $0.034 \%$ & $0.847 \%$ & $92.275 \%$ \\
\hline 372 & fascista & 0.00327 & $0.023 \%$ & $0.565 \%$ & $92.298 \%$ \\
\hline 373 & lago & 0.00326 & $0.023 \%$ & $0.565 \%$ & $92.321 \%$ \\
\hline 374 & agencia & 0.00326 & $0.023 \%$ & $0.565 \%$ & $92.344 \%$ \\
\hline 375 & chulo & 0.00322 & $0.023 \%$ & $0.565 \%$ & $92.367 \%$ \\
\hline 376 & feria & 0.00321 & $0.023 \%$ & $0.565 \%$ & $92.390 \%$ \\
\hline 377 & Mc Donalds* & 0.00321 & $0.023 \%$ & $0.565 \%$ & $92.413 \%$ \\
\hline 378 & todo a cien & 0.00321 & $0.023 \%$ & $0.565 \%$ & $92.436 \%$ \\
\hline 379 & pelota & 0.00320 & $0.034 \%$ & $0.847 \%$ & $92.470 \%$ \\
\hline 380 & graffiti & 0.00319 & $0.023 \%$ & $0.565 \%$ & $92.493 \%$ \\
\hline 381 & escultura & 0.00318 & $0.023 \%$ & $0.565 \%$ & $92.516 \%$ \\
\hline 382 & club nocturno & 0.00316 & $0.023 \%$ & $0.565 \%$ & $92.539 \%$ \\
\hline 383 & pared & 0.00315 & $0.034 \%$ & $0.847 \%$ & $92.573 \%$ \\
\hline 384 & excremento & 0.00315 & $0.034 \%$ & $0.847 \%$ & $92.607 \%$ \\
\hline 385 & poste de luz & 0.00313 & $0.034 \%$ & $0.847 \%$ & $92.641 \%$ \\
\hline 386 & comunista & 0.00312 & $0.023 \%$ & $0.565 \%$ & $92.664 \%$ \\
\hline 387 & mercadillo & 0.00310 & $0.023 \%$ & $0.565 \%$ & $92.687 \%$ \\
\hline 388 & velódromo & 0.00310 & $0.023 \%$ & $0.565 \%$ & $92.710 \%$ \\
\hline 389 & triciclo & 0.00307 & $0.023 \%$ & $0.565 \%$ & $92.733 \%$ \\
\hline 390 & muerte & 0.00307 & $0.034 \%$ & $0.847 \%$ & $92.767 \%$ \\
\hline 391 & lavandería & 0.00297 & $0.023 \%$ & $0.565 \%$ & $92.790 \%$ \\
\hline 392 & salón de belleza & 0.00291 & $0.023 \%$ & $0.565 \%$ & $92.813 \%$ \\
\hline 393 & cajero (automático) & 0.00290 & $0.023 \%$ & $0.565 \%$ & $92.836 \%$ \\
\hline 394 & barandilla & 0.00289 & $0.023 \%$ & $0.565 \%$ & $92.859 \%$ \\
\hline 395 & arbusto & 0.00286 & $0.023 \%$ & $0.565 \%$ & $92.882 \%$ \\
\hline 396 & centro médico & 0.00284 & $0.023 \%$ & $0.565 \%$ & $92.905 \%$ \\
\hline 397 & valla & 0.00284 & $0.023 \%$ & $0.565 \%$ & $92.928 \%$ \\
\hline 398 & salón & 0.00283 & $0.023 \%$ & $0.565 \%$ & $92.951 \%$ \\
\hline 399 & campana & 0.00282 & $0.011 \%$ & $0.282 \%$ & $92.962 \%$ \\
\hline 400 & centro urbano & 0.00282 & $0.011 \%$ & $0.282 \%$ & $92.973 \%$ \\
\hline 401 & estadio deportivo & 0.00282 & $0.023 \%$ & $0.565 \%$ & $92.996 \%$ \\
\hline 402 & chaflán & 0.00282 & $0.011 \%$ & $0.282 \%$ & $93.007 \%$ \\
\hline 403 & bombilla & 0.00282 & $0.011 \%$ & $0.282 \%$ & $93.018 \%$ \\
\hline 404 & chino & 0.00282 & $0.011 \%$ & $0.282 \%$ & $93.029 \%$ \\
\hline 405 & Peñíscola & 0.00282 & $0.011 \%$ & $0.282 \%$ & $93.040 \%$ \\
\hline 406 & carrer & 0.00282 & $0.011 \%$ & $0.282 \%$ & $93.051 \%$ \\
\hline 407 & centro de ciudad & 0.00282 & $0.011 \%$ & $0.282 \%$ & $93.062 \%$ \\
\hline 408 & monstruo de hierro & 0.00282 & $0.011 \%$ & $0.282 \%$ & $93.073 \%$ \\
\hline 409 & barbero & 0.00281 & $0.034 \%$ & $0.847 \%$ & $93.107 \%$ \\
\hline 410 & piscina cubierta & 0.00279 & $0.023 \%$ & $0.565 \%$ & $93.130 \%$ \\
\hline 411 & música & 0.00278 & $0.023 \%$ & $0.565 \%$ & $93.153 \%$ \\
\hline 412 & funcionario & 0.00278 & $0.023 \%$ & $0.565 \%$ & $93.176 \%$ \\
\hline
\end{tabular}




\begin{tabular}{|c|c|c|c|c|c|}
\hline 413 & cable de luz & 0.00278 & $0.023 \%$ & $0.565 \%$ & $93.199 \%$ \\
\hline 414 & prisión & 0.00277 & $0.023 \%$ & $0.565 \%$ & $93.222 \%$ \\
\hline 415 & vendedor & 0.00276 & $0.023 \%$ & $0.565 \%$ & $93.245 \%$ \\
\hline 416 & albergue & 0.00276 & $0.023 \%$ & $0.565 \%$ & $93.268 \%$ \\
\hline 417 & famosos & 0.00276 & $0.023 \%$ & $0.565 \%$ & $93.291 \%$ \\
\hline 418 & maestro & 0.00274 & $0.034 \%$ & $0.847 \%$ & $93.325 \%$ \\
\hline 419 & grito & 0.00270 & $0.023 \%$ & $0.565 \%$ & $93.348 \%$ \\
\hline 420 & árbol de Navidad & 0.00269 & $0.011 \%$ & $0.282 \%$ & $93.359 \%$ \\
\hline 421 & proxeneta & 0.00269 & $0.011 \%$ & $0.282 \%$ & $93.370 \%$ \\
\hline 422 & Benicarló & 0.00269 & $0.011 \%$ & $0.282 \%$ & $93.381 \%$ \\
\hline 423 & biblioteca municipal & 0.00269 & $0.011 \%$ & $0.282 \%$ & $93.392 \%$ \\
\hline 424 & miseria & 0.00269 & $0.011 \%$ & $0.282 \%$ & $93.403 \%$ \\
\hline 425 & alquitrán & 0.00269 & $0.011 \%$ & $0.282 \%$ & $93.414 \%$ \\
\hline 426 & caja & 0.00266 & $0.023 \%$ & $0.565 \%$ & $93.437 \%$ \\
\hline 427 & poste de teléfono & 0.00265 & $0.023 \%$ & $0.565 \%$ & $93.460 \%$ \\
\hline 428 & habitante & 0.00263 & $0.023 \%$ & $0.565 \%$ & $93.483 \%$ \\
\hline 429 & lencería & 0.00261 & $0.034 \%$ & $0.847 \%$ & $93.517 \%$ \\
\hline 430 & carro & 0.00257 & $0.034 \%$ & $0.847 \%$ & $93.551 \%$ \\
\hline 431 & borracho & 0.00257 & $0.034 \%$ & $0.847 \%$ & $93.585 \%$ \\
\hline 432 & drogadicto & 0.00257 & $0.023 \%$ & $0.565 \%$ & $93.608 \%$ \\
\hline 433 & desorden & 0.00257 & $0.011 \%$ & $0.282 \%$ & $93.619 \%$ \\
\hline 434 & mapa & 0.00257 & $0.011 \%$ & $0.282 \%$ & $93.630 \%$ \\
\hline 435 & banco de asiento & 0.00257 & $0.011 \%$ & $0.282 \%$ & $93.641 \%$ \\
\hline 436 & Vinaroz & 0.00257 & $0.011 \%$ & $0.282 \%$ & $93.652 \%$ \\
\hline 437 & aparcamiento de coches & 0.00257 & $0.011 \%$ & $0.282 \%$ & $93.663 \%$ \\
\hline 438 & local & 0.00257 & $0.011 \%$ & $0.282 \%$ & $93.674 \%$ \\
\hline 439 & aparcadero de coches & 0.00257 & $0.011 \%$ & $0.282 \%$ & $93.685 \%$ \\
\hline 440 & alegría & 0.00257 & $0.011 \%$ & $0.282 \%$ & $93.696 \%$ \\
\hline 441 & teléfono & 0.00256 & $0.023 \%$ & $0.565 \%$ & $93.719 \%$ \\
\hline 442 & bolsa & 0.00256 & $0.023 \%$ & $0.565 \%$ & $93.742 \%$ \\
\hline 443 & cooperativa & 0.00256 & $0.023 \%$ & $0.565 \%$ & $93.765 \%$ \\
\hline 444 & empresario & 0.00255 & $0.023 \%$ & $0.565 \%$ & $93.788 \%$ \\
\hline 445 & conservatorio de música & 0.00253 & $0.023 \%$ & $0.565 \%$ & $93.811 \%$ \\
\hline 446 & chimenea & 0.00253 & $0.023 \%$ & $0.565 \%$ & $93.834 \%$ \\
\hline 447 & galería de arte & 0.00253 & $0.023 \%$ & $0.565 \%$ & $93.857 \%$ \\
\hline 448 & viandante & 0.00252 & $0.023 \%$ & $0.565 \%$ & $93.880 \%$ \\
\hline 449 & mesa & 0.00252 & $0.034 \%$ & $0.847 \%$ & $93.914 \%$ \\
\hline 450 & tráiler & 0.00252 & $0.023 \%$ & $0.565 \%$ & $93.937 \%$ \\
\hline 451 & silla & 0.00247 & $0.034 \%$ & $0.847 \%$ & $93.971 \%$ \\
\hline 452 & pelea & 0.00246 & $0.023 \%$ & $0.565 \%$ & $93.994 \%$ \\
\hline 453 & zona industrial & 0.00245 & $0.023 \%$ & $0.565 \%$ & $94.017 \%$ \\
\hline 454 & centro deportivo & 0.00245 & $0.011 \%$ & $0.282 \%$ & $94.028 \%$ \\
\hline 455 & autovía & 0.00245 & $0.023 \%$ & $0.565 \%$ & $94.051 \%$ \\
\hline 456 & palacio & 0.00245 & $0.011 \%$ & $0.282 \%$ & $94.062 \%$ \\
\hline 457 & hacinamiento & 0.00245 & $0.011 \%$ & $0.282 \%$ & $94.073 \%$ \\
\hline 458 & señal de stop & 0.00245 & $0.011 \%$ & $0.282 \%$ & $94.084 \%$ \\
\hline 459 & carrito de niños & 0.00245 & $0.011 \%$ & $0.282 \%$ & $94.095 \%$ \\
\hline
\end{tabular}




\begin{tabular}{|c|c|c|c|c|c|}
\hline 460 & Ferrari* & 0.00245 & $0.011 \%$ & $0.282 \%$ & $94.106 \%$ \\
\hline 461 & zombi & 0.00245 & $0.011 \%$ & $0.282 \%$ & $94.117 \%$ \\
\hline 462 & joven & 0.00245 & $0.011 \%$ & $0.282 \%$ & $94.128 \%$ \\
\hline 463 & helado & 0.00245 & $0.011 \%$ & $0.282 \%$ & $94.139 \%$ \\
\hline 464 & centro de cultura & 0.00245 & $0.011 \%$ & $0.282 \%$ & $94.150 \%$ \\
\hline 465 & transeúnte & 0.00245 & $0.011 \%$ & $0.282 \%$ & $94.161 \%$ \\
\hline 466 & reja & 0.00245 & $0.011 \%$ & $0.282 \%$ & $94.172 \%$ \\
\hline 467 & compañía & 0.00245 & $0.011 \%$ & $0.282 \%$ & $94.183 \%$ \\
\hline 468 & barriada & 0.00245 & $0.011 \%$ & $0.282 \%$ & $94.194 \%$ \\
\hline 469 & desilusión & 0.00245 & $0.011 \%$ & $0.282 \%$ & $94.205 \%$ \\
\hline 470 & civismo & 0.00245 & $0.011 \%$ & $0.282 \%$ & $94.216 \%$ \\
\hline 471 & adoquín & 0.00245 & $0.011 \%$ & $0.282 \%$ & $94.227 \%$ \\
\hline 472 & paso peatonal & 0.00245 & $0.011 \%$ & $0.282 \%$ & $94.238 \%$ \\
\hline 473 & delegación de Hacienda & 0.00245 & $0.023 \%$ & $0.565 \%$ & $94.261 \%$ \\
\hline 474 & alumbrado eléctrico & 0.00245 & $0.011 \%$ & $0.282 \%$ & $94.272 \%$ \\
\hline 475 & consultorio médico & 0.00245 & $0.011 \%$ & $0.282 \%$ & $94.283 \%$ \\
\hline 476 & institución & 0.00245 & $0.011 \%$ & $0.282 \%$ & $94.294 \%$ \\
\hline 477 & toros & 0.00241 & $0.023 \%$ & $0.565 \%$ & $94.317 \%$ \\
\hline 478 & pobreza & 0.00236 & $0.023 \%$ & $0.565 \%$ & $94.340 \%$ \\
\hline 479 & sala de recreativos & 0.00236 & $0.023 \%$ & $0.565 \%$ & $94.363 \%$ \\
\hline 480 & ministerio & 0.00234 & $0.023 \%$ & $0.565 \%$ & $94.386 \%$ \\
\hline 481 & sendero & 0.00233 & $0.011 \%$ & $0.282 \%$ & $94.397 \%$ \\
\hline 482 & barrio marginal & 0.00233 & $0.011 \%$ & $0.282 \%$ & $94.408 \%$ \\
\hline 483 & revista & 0.00233 & $0.011 \%$ & $0.282 \%$ & $94.419 \%$ \\
\hline 484 & señal de ceda el paso & 0.00233 & $0.011 \%$ & $0.282 \%$ & $94.430 \%$ \\
\hline 485 & viga & 0.00233 & $0.011 \%$ & $0.282 \%$ & $94.441 \%$ \\
\hline 486 & pareja & 0.00233 & $0.011 \%$ & $0.282 \%$ & $94.452 \%$ \\
\hline 487 & Valencia & 0.00233 & $0.011 \%$ & $0.282 \%$ & $94.463 \%$ \\
\hline 488 & servicio público & 0.00233 & $0.011 \%$ & $0.282 \%$ & $94.474 \%$ \\
\hline 489 & señal vertical & 0.00233 & $0.011 \%$ & $0.282 \%$ & $94.485 \%$ \\
\hline 490 & frenazo & 0.00233 & $0.011 \%$ & $0.282 \%$ & $94.496 \%$ \\
\hline 491 & gentío & 0.00233 & $0.011 \%$ & $0.282 \%$ & $94.507 \%$ \\
\hline 492 & claveguera & 0.00233 & $0.011 \%$ & $0.282 \%$ & $94.518 \%$ \\
\hline 493 & edificio de correos & 0.00233 & $0.011 \%$ & $0.282 \%$ & $94.529 \%$ \\
\hline 494 & peña & 0.00233 & $0.011 \%$ & $0.282 \%$ & $94.540 \%$ \\
\hline 495 & calleja & 0.00233 & $0.011 \%$ & $0.282 \%$ & $94.551 \%$ \\
\hline 496 & manzana de casas & 0.00233 & $0.011 \%$ & $0.282 \%$ & $94.562 \%$ \\
\hline 497 & paso subterráneo & 0.00232 & $0.023 \%$ & $0.565 \%$ & $94.585 \%$ \\
\hline 498 & bodega & 0.00222 & $0.011 \%$ & $0.282 \%$ & $94.596 \%$ \\
\hline 499 & obelisco & 0.00222 & $0.011 \%$ & $0.282 \%$ & $94.607 \%$ \\
\hline 500 & Fadrí & 0.00222 & $0.011 \%$ & $0.282 \%$ & $94.618 \%$ \\
\hline 501 & señal de paso de peatones & 0.00222 & $0.011 \%$ & $0.282 \%$ & $94.629 \%$ \\
\hline 502 & tienda de comida & 0.00222 & $0.011 \%$ & $0.282 \%$ & $94.640 \%$ \\
\hline 503 & carricoche & 0.00222 & $0.011 \%$ & $0.282 \%$ & $94.651 \%$ \\
\hline 504 & tienda de comestibles & 0.00222 & $0.011 \%$ & $0.282 \%$ & $94.662 \%$ \\
\hline 505 & malestar & 0.00222 & $0.011 \%$ & $0.282 \%$ & $94.673 \%$ \\
\hline 506 & Castellón & 0.00222 & $0.011 \%$ & $0.282 \%$ & $94.684 \%$ \\
\hline
\end{tabular}




\begin{tabular}{|c|c|c|c|c|c|}
\hline 507 & choza & 0.00222 & $0.011 \%$ & $0.282 \%$ & $94.695 \%$ \\
\hline 508 & bloque & 0.00222 & $0.011 \%$ & $0.282 \%$ & $94.706 \%$ \\
\hline 509 & ceda el paso & 0.00222 & $0.011 \%$ & $0.282 \%$ & $94.717 \%$ \\
\hline 510 & señal horizontal & 0.00222 & $0.011 \%$ & $0.282 \%$ & $94.728 \%$ \\
\hline 511 & Amica* & 0.00222 & $0.011 \%$ & $0.282 \%$ & $94.739 \%$ \\
\hline 512 & concentración & 0.00222 & $0.011 \%$ & $0.282 \%$ & $94.750 \%$ \\
\hline 513 & paquetería & 0.00222 & $0.011 \%$ & $0.282 \%$ & $94.761 \%$ \\
\hline 514 & tienda de vestir & 0.00222 & $0.011 \%$ & $0.282 \%$ & $94.772 \%$ \\
\hline 515 & peatonal & 0.00222 & $0.011 \%$ & $0.282 \%$ & $94.783 \%$ \\
\hline 516 & funeraria & 0.00213 & $0.023 \%$ & $0.565 \%$ & $94.806 \%$ \\
\hline 517 & autoservicio & 0.00212 & $0.011 \%$ & $0.282 \%$ & $94.817 \%$ \\
\hline 518 & asesino & 0.00212 & $0.011 \%$ & $0.282 \%$ & $94.828 \%$ \\
\hline 519 & casa consistorial & 0.00212 & $0.011 \%$ & $0.282 \%$ & $94.839 \%$ \\
\hline 520 & señal de prohibido izquierda & 0.00212 & $0.011 \%$ & $0.282 \%$ & $94.850 \%$ \\
\hline 521 & acumulación & 0.00212 & $0.011 \%$ & $0.282 \%$ & $94.861 \%$ \\
\hline 522 & cabina de teléfono & 0.00212 & $0.011 \%$ & $0.282 \%$ & $94.872 \%$ \\
\hline 523 & barbería & 0.00212 & $0.011 \%$ & $0.282 \%$ & $94.883 \%$ \\
\hline 524 & centro recreativo & 0.00212 & $0.023 \%$ & $0.565 \%$ & $94.906 \%$ \\
\hline 525 & tienda de ropa usada & 0.00212 & $0.011 \%$ & $0.282 \%$ & $94.917 \%$ \\
\hline 526 & trolebús & 0.00212 & $0.011 \%$ & $0.282 \%$ & $94.928 \%$ \\
\hline 527 & tía & 0.00212 & $0.011 \%$ & $0.282 \%$ & $94.939 \%$ \\
\hline 528 & Alicante & 0.00212 & $0.011 \%$ & $0.282 \%$ & $94.950 \%$ \\
\hline 529 & campo de básquet & 0.00212 & $0.011 \%$ & $0.282 \%$ & $94.961 \%$ \\
\hline 530 & carromato & 0.00212 & $0.011 \%$ & $0.282 \%$ & $94.972 \%$ \\
\hline 531 & obra histórica & 0.00212 & $0.011 \%$ & $0.282 \%$ & $94.983 \%$ \\
\hline 532 & tranquilidad & 0.00212 & $0.011 \%$ & $0.282 \%$ & $94.994 \%$ \\
\hline 533 & orden público & 0.00212 & $0.011 \%$ & $0.282 \%$ & $95.005 \%$ \\
\hline 534 & finca de pisos & 0.00212 & $0.011 \%$ & $0.282 \%$ & $95.016 \%$ \\
\hline 535 & carpintería & 0.00210 & $0.023 \%$ & $0.565 \%$ & $95.039 \%$ \\
\hline 536 & restaurante chino & 0.00210 & $0.023 \%$ & $0.565 \%$ & $95.062 \%$ \\
\hline 537 & ultramarinos & 0.00203 & $0.023 \%$ & $0.565 \%$ & $95.085 \%$ \\
\hline 538 & sanidad & 0.00202 & $0.011 \%$ & $0.282 \%$ & $95.096 \%$ \\
\hline 539 & señal de prohibido derecha & 0.00202 & $0.011 \%$ & $0.282 \%$ & $95.107 \%$ \\
\hline 540 & oficina del paro & 0.00202 & $0.011 \%$ & $0.282 \%$ & $95.118 \%$ \\
\hline 541 & toldo & 0.00202 & $0.011 \%$ & $0.282 \%$ & $95.129 \%$ \\
\hline 542 & tienda de ropa nueva & 0.00202 & $0.011 \%$ & $0.282 \%$ & $95.140 \%$ \\
\hline 543 & váter & 0.00202 & $0.011 \%$ & $0.282 \%$ & $95.151 \%$ \\
\hline 544 & dolor de cabeza & 0.00202 & $0.011 \%$ & $0.282 \%$ & $95.162 \%$ \\
\hline 545 & Murcia & 0.00202 & $0.011 \%$ & $0.282 \%$ & $95.173 \%$ \\
\hline 546 & línea de carretera & 0.00202 & $0.011 \%$ & $0.282 \%$ & $95.184 \%$ \\
\hline 547 & calle mayor & 0.00202 & $0.023 \%$ & $0.565 \%$ & $95.207 \%$ \\
\hline 548 & campo de fútbol sala & 0.00202 & $0.011 \%$ & $0.282 \%$ & $95.218 \%$ \\
\hline 549 & casa de citas & 0.00202 & $0.011 \%$ & $0.282 \%$ & $95.229 \%$ \\
\hline 550 & jardinera & 0.00195 & $0.023 \%$ & $0.565 \%$ & $95.252 \%$ \\
\hline 551 & placeta & 0.00193 & $0.011 \%$ & $0.282 \%$ & $95.263 \%$ \\
\hline 552 & asesoría & 0.00193 & $0.011 \%$ & $0.282 \%$ & $95.274 \%$ \\
\hline 553 & tienda textil & 0.00193 & $0.011 \%$ & $0.282 \%$ & $95.285 \%$ \\
\hline
\end{tabular}




\begin{tabular}{|c|c|c|c|c|c|}
\hline 554 & rapto & 0.00193 & $0.011 \%$ & $0.282 \%$ & $95.296 \%$ \\
\hline 555 & establecimiento de comestibles & 0.00193 & $0.011 \%$ & $0.282 \%$ & $95.307 \%$ \\
\hline 556 & servicios & 0.00193 & $0.011 \%$ & $0.282 \%$ & $95.318 \%$ \\
\hline 557 & nido & 0.00193 & $0.011 \%$ & $0.282 \%$ & $95.329 \%$ \\
\hline 558 & golondrina & 0.00193 & $0.011 \%$ & $0.282 \%$ & $95.340 \%$ \\
\hline 559 & turismo & 0.00193 & $0.011 \%$ & $0.282 \%$ & $95.351 \%$ \\
\hline 560 & paro & 0.00193 & $0.011 \%$ & $0.282 \%$ & $95.362 \%$ \\
\hline 561 & marca vial & 0.00193 & $0.011 \%$ & $0.282 \%$ & $95.373 \%$ \\
\hline 562 & ronda & 0.00193 & $0.011 \%$ & $0.282 \%$ & $95.384 \%$ \\
\hline 563 & frontón & 0.00193 & $0.011 \%$ & $0.282 \%$ & $95.395 \%$ \\
\hline 564 & andén & 0.00193 & $0.011 \%$ & $0.282 \%$ & $95.406 \%$ \\
\hline 565 & Telepizza* & 0.00193 & $0.011 \%$ & $0.282 \%$ & $95.417 \%$ \\
\hline 566 & piscina climatizada & 0.00193 & $0.011 \%$ & $0.282 \%$ & $95.428 \%$ \\
\hline 567 & caos & 0.00193 & $0.011 \%$ & $0.282 \%$ & $95.439 \%$ \\
\hline 568 & nave industrial & 0.00193 & $0.011 \%$ & $0.282 \%$ & $95.450 \%$ \\
\hline 569 & Nueva York & 0.00193 & $0.011 \%$ & $0.282 \%$ & $95.461 \%$ \\
\hline 570 & plaza mayor & 0.00193 & $0.011 \%$ & $0.282 \%$ & $95.472 \%$ \\
\hline 571 & residencial & 0.00184 & $0.011 \%$ & $0.282 \%$ & $95.483 \%$ \\
\hline 572 & mutua & 0.00184 & $0.011 \%$ & $0.282 \%$ & $95.494 \%$ \\
\hline 573 & P.G.O.U. & 0.00184 & $0.011 \%$ & $0.282 \%$ & $95.505 \%$ \\
\hline 574 & ansiedad & 0.00184 & $0.011 \%$ & $0.282 \%$ & $95.516 \%$ \\
\hline 575 & acto cultural & 0.00184 & $0.011 \%$ & $0.282 \%$ & $95.527 \%$ \\
\hline 576 & Vespa* & 0.00184 & $0.011 \%$ & $0.282 \%$ & $95.538 \%$ \\
\hline 577 & estudiante & 0.00184 & $0.011 \%$ & $0.282 \%$ & $95.549 \%$ \\
\hline 578 & medicina & 0.00184 & $0.011 \%$ & $0.282 \%$ & $95.560 \%$ \\
\hline 579 & tienda de periódicos & 0.00184 & $0.011 \%$ & $0.282 \%$ & $95.571 \%$ \\
\hline 580 & codorniz & 0.00184 & $0.011 \%$ & $0.282 \%$ & $95.582 \%$ \\
\hline 581 & dibujo & 0.00184 & $0.011 \%$ & $0.282 \%$ & $95.593 \%$ \\
\hline 582 & soledad & 0.00184 & $0.011 \%$ & $0.282 \%$ & $95.604 \%$ \\
\hline 583 & Almería & 0.00184 & $0.011 \%$ & $0.282 \%$ & $95.615 \%$ \\
\hline 584 & coche bomba & 0.00184 & $0.011 \%$ & $0.282 \%$ & $95.626 \%$ \\
\hline 585 & municipio & 0.00184 & $0.011 \%$ & $0.282 \%$ & $95.637 \%$ \\
\hline 586 & desarrollo & 0.00184 & $0.011 \%$ & $0.282 \%$ & $95.648 \%$ \\
\hline 587 & camioneta & 0.00184 & $0.011 \%$ & $0.282 \%$ & $95.659 \%$ \\
\hline 588 & París & 0.00184 & $0.011 \%$ & $0.282 \%$ & $95.670 \%$ \\
\hline 589 & olor & 0.00180 & $0.023 \%$ & $0.565 \%$ & $95.693 \%$ \\
\hline 590 & vía & 0.00179 & $0.023 \%$ & $0.565 \%$ & $95.716 \%$ \\
\hline 591 & vía de tren & 0.00179 & $0.023 \%$ & $0.565 \%$ & $95.739 \%$ \\
\hline 592 & salón de fiestas & 0.00175 & $0.011 \%$ & $0.282 \%$ & $95.750 \%$ \\
\hline 593 & bocacalle & 0.00175 & $0.011 \%$ & $0.282 \%$ & $95.761 \%$ \\
\hline 594 & parcela & 0.00175 & $0.011 \%$ & $0.282 \%$ & $95.772 \%$ \\
\hline 595 & portería & 0.00175 & $0.011 \%$ & $0.282 \%$ & $95.783 \%$ \\
\hline 596 & comunicación & 0.00175 & $0.011 \%$ & $0.282 \%$ & $95.794 \%$ \\
\hline 597 & arena & 0.00175 & $0.011 \%$ & $0.282 \%$ & $95.805 \%$ \\
\hline 598 & pato & 0.00175 & $0.011 \%$ & $0.282 \%$ & $95.816 \%$ \\
\hline 599 & coche de policía & 0.00175 & $0.011 \%$ & $0.282 \%$ & $95.827 \%$ \\
\hline 600 & Sevilla & 0.00175 & $0.011 \%$ & $0.282 \%$ & $95.838 \%$ \\
\hline
\end{tabular}




\begin{tabular}{|c|c|c|c|c|c|}
\hline 601 & zona azul & 0.00175 & $0.011 \%$ & $0.282 \%$ & $95.849 \%$ \\
\hline 602 & barrio bajo & 0.00175 & $0.011 \%$ & $0.282 \%$ & $95.860 \%$ \\
\hline 603 & Corte Inglés* & 0.00175 & $0.011 \%$ & $0.282 \%$ & $95.871 \%$ \\
\hline 604 & terrorista & 0.00175 & $0.011 \%$ & $0.282 \%$ & $95.882 \%$ \\
\hline 605 & ateneo & 0.00175 & $0.011 \%$ & $0.282 \%$ & $95.893 \%$ \\
\hline 606 & lavabo & 0.00175 & $0.011 \%$ & $0.282 \%$ & $95.904 \%$ \\
\hline 607 & modernidad & 0.00175 & $0.011 \%$ & $0.282 \%$ & $95.915 \%$ \\
\hline 608 & Roma & 0.00175 & $0.011 \%$ & $0.282 \%$ & $95.926 \%$ \\
\hline 609 & baldosa & 0.00172 & $0.023 \%$ & $0.565 \%$ & $95.949 \%$ \\
\hline 610 & despacho & 0.00172 & $0.023 \%$ & $0.565 \%$ & $95.972 \%$ \\
\hline 611 & violencia & 0.00171 & $0.023 \%$ & $0.565 \%$ & $95.995 \%$ \\
\hline 612 & zona de peatones & 0.00167 & $0.011 \%$ & $0.282 \%$ & $96.006 \%$ \\
\hline 613 & campo de golf & 0.00167 & $0.011 \%$ & $0.282 \%$ & $96.017 \%$ \\
\hline 614 & piscina provincial & 0.00167 & $0.011 \%$ & $0.282 \%$ & $96.028 \%$ \\
\hline 615 & jardinería & 0.00167 & $0.011 \%$ & $0.282 \%$ & $96.039 \%$ \\
\hline 616 & entrada de garajes & 0.00167 & $0.011 \%$ & $0.282 \%$ & $96.050 \%$ \\
\hline 617 & pez & 0.00167 & $0.011 \%$ & $0.282 \%$ & $96.061 \%$ \\
\hline 618 & contaminación acústica & 0.00167 & $0.011 \%$ & $0.282 \%$ & $96.072 \%$ \\
\hline 619 & animal de compañía & 0.00167 & $0.011 \%$ & $0.282 \%$ & $96.083 \%$ \\
\hline 620 & ciclista & 0.00167 & $0.011 \%$ & $0.282 \%$ & $96.094 \%$ \\
\hline 621 & coche de guardia civil & 0.00167 & $0.011 \%$ & $0.282 \%$ & $96.105 \%$ \\
\hline 622 & Fallas & 0.00167 & $0.023 \%$ & $0.565 \%$ & $96.128 \%$ \\
\hline 623 & Ceuta & 0.00167 & $0.011 \%$ & $0.282 \%$ & $96.139 \%$ \\
\hline 624 & barrio de alta clase & 0.00167 & $0.011 \%$ & $0.282 \%$ & $96.150 \%$ \\
\hline 625 & conductor & 0.00167 & $0.011 \%$ & $0.282 \%$ & $96.161 \%$ \\
\hline 626 & tienda de muebles & 0.00167 & $0.011 \%$ & $0.282 \%$ & $96.172 \%$ \\
\hline 627 & frankfurt & 0.00167 & $0.011 \%$ & $0.282 \%$ & $96.183 \%$ \\
\hline 628 & número & 0.00167 & $0.011 \%$ & $0.282 \%$ & $96.194 \%$ \\
\hline 629 & concierto & 0.00167 & $0.011 \%$ & $0.282 \%$ & $96.205 \%$ \\
\hline 630 & ama de casa & 0.00167 & $0.011 \%$ & $0.282 \%$ & $96.216 \%$ \\
\hline 631 & monolito & 0.00167 & $0.011 \%$ & $0.282 \%$ & $96.227 \%$ \\
\hline 632 & cantina & 0.00159 & $0.011 \%$ & $0.282 \%$ & $96.238 \%$ \\
\hline 633 & calle estrecha & 0.00159 & $0.011 \%$ & $0.282 \%$ & $96.249 \%$ \\
\hline 634 & edificio cultural & 0.00159 & $0.011 \%$ & $0.282 \%$ & $96.260 \%$ \\
\hline 635 & casa antigua & 0.00159 & $0.011 \%$ & $0.282 \%$ & $96.271 \%$ \\
\hline 636 & PRYCA* & 0.00159 & $0.011 \%$ & $0.282 \%$ & $96.282 \%$ \\
\hline 637 & tasca & 0.00159 & $0.011 \%$ & $0.282 \%$ & $96.293 \%$ \\
\hline 638 & nerviosismo & 0.00159 & $0.011 \%$ & $0.282 \%$ & $96.304 \%$ \\
\hline 639 & ley & 0.00159 & $0.011 \%$ & $0.282 \%$ & $96.315 \%$ \\
\hline 640 & cultura & 0.00159 & $0.011 \%$ & $0.282 \%$ & $96.326 \%$ \\
\hline 641 & insecto & 0.00159 & $0.011 \%$ & $0.282 \%$ & $96.337 \%$ \\
\hline 642 & ejecutivo & 0.00159 & $0.011 \%$ & $0.282 \%$ & $96.348 \%$ \\
\hline 643 & indigente & 0.00159 & $0.011 \%$ & $0.282 \%$ & $96.359 \%$ \\
\hline 644 & Cádiz & 0.00159 & $0.011 \%$ & $0.282 \%$ & $96.370 \%$ \\
\hline 645 & periquito & 0.00159 & $0.011 \%$ & $0.282 \%$ & $96.381 \%$ \\
\hline 646 & tienda de pintura & 0.00159 & $0.011 \%$ & $0.282 \%$ & $96.392 \%$ \\
\hline 647 & frío & 0.00159 & $0.011 \%$ & $0.282 \%$ & $96.403 \%$ \\
\hline
\end{tabular}




\begin{tabular}{|c|c|c|c|c|c|}
\hline 648 & murmullo & 0.00159 & $0.011 \%$ & $0.282 \%$ & $96.414 \%$ \\
\hline 649 & gas & 0.00159 & $0.011 \%$ & $0.282 \%$ & $96.425 \%$ \\
\hline 650 & fotógrafo & 0.00159 & $0.011 \%$ & $0.282 \%$ & $96.436 \%$ \\
\hline 651 & ropa & 0.00157 & $0.023 \%$ & $0.565 \%$ & $96.459 \%$ \\
\hline 652 & taxista & 0.00152 & $0.011 \%$ & $0.282 \%$ & $96.470 \%$ \\
\hline 653 & edificio escolar & 0.00152 & $0.011 \%$ & $0.282 \%$ & $96.481 \%$ \\
\hline 654 & violador & 0.00152 & $0.011 \%$ & $0.282 \%$ & $96.492 \%$ \\
\hline 655 & propaganda & 0.00152 & $0.011 \%$ & $0.282 \%$ & $96.503 \%$ \\
\hline 656 & Alcampo* & 0.00152 & $0.011 \%$ & $0.282 \%$ & $96.514 \%$ \\
\hline 657 & pista de patinaje & 0.00152 & $0.011 \%$ & $0.282 \%$ & $96.525 \%$ \\
\hline 658 & paso a nivel & 0.00152 & $0.011 \%$ & $0.282 \%$ & $96.536 \%$ \\
\hline 659 & pintura & 0.00152 & $0.011 \%$ & $0.282 \%$ & $96.547 \%$ \\
\hline 660 & tauleta & 0.00152 & $0.011 \%$ & $0.282 \%$ & $96.558 \%$ \\
\hline 661 & agencia inmobiliaria & 0.00152 & $0.011 \%$ & $0.282 \%$ & $96.569 \%$ \\
\hline 662 & indisciplinado & 0.00152 & $0.011 \%$ & $0.282 \%$ & $96.580 \%$ \\
\hline 663 & Málaga & 0.00152 & $0.011 \%$ & $0.282 \%$ & $96.591 \%$ \\
\hline 664 & rambla & 0.00152 & $0.011 \%$ & $0.282 \%$ & $96.602 \%$ \\
\hline 665 & mansión & 0.00152 & $0.011 \%$ & $0.282 \%$ & $96.613 \%$ \\
\hline 666 & pabellón de la música & 0.00152 & $0.011 \%$ & $0.282 \%$ & $96.624 \%$ \\
\hline 667 & loro & 0.00152 & $0.011 \%$ & $0.282 \%$ & $96.635 \%$ \\
\hline 668 & zumería & 0.00152 & $0.011 \%$ & $0.282 \%$ & $96.646 \%$ \\
\hline 669 & sótano & 0.00152 & $0.011 \%$ & $0.282 \%$ & $96.657 \%$ \\
\hline 670 & libro & 0.00152 & $0.011 \%$ & $0.282 \%$ & $96.668 \%$ \\
\hline 671 & familia & 0.00152 & $0.011 \%$ & $0.282 \%$ & $96.679 \%$ \\
\hline 672 & jaleo & 0.00152 & $0.011 \%$ & $0.282 \%$ & $96.690 \%$ \\
\hline 673 & ortopedia & 0.00152 & $0.011 \%$ & $0.282 \%$ & $96.701 \%$ \\
\hline 674 & fotografía & 0.00144 & $0.011 \%$ & $0.282 \%$ & $96.712 \%$ \\
\hline 675 & instituto de bachillerato & 0.00144 & $0.011 \%$ & $0.282 \%$ & $96.723 \%$ \\
\hline 676 & confesionario & 0.00144 & $0.011 \%$ & $0.282 \%$ & $96.734 \%$ \\
\hline 677 & cancha & 0.00144 & $0.011 \%$ & $0.282 \%$ & $96.745 \%$ \\
\hline 678 & gran avenida & 0.00144 & $0.011 \%$ & $0.282 \%$ & $96.756 \%$ \\
\hline 679 & centro de distensión & 0.00144 & $0.011 \%$ & $0.282 \%$ & $96.767 \%$ \\
\hline 680 & N 340 & 0.00144 & $0.011 \%$ & $0.282 \%$ & $96.778 \%$ \\
\hline 681 & niñera & 0.00144 & $0.011 \%$ & $0.282 \%$ & $96.789 \%$ \\
\hline 682 & lámpara & 0.00144 & $0.011 \%$ & $0.282 \%$ & $96.800 \%$ \\
\hline 683 & carril & 0.00144 & $0.011 \%$ & $0.282 \%$ & $96.811 \%$ \\
\hline 684 & intranquilidad & 0.00144 & $0.011 \%$ & $0.282 \%$ & $96.822 \%$ \\
\hline 685 & Extremadura & 0.00144 & $0.011 \%$ & $0.282 \%$ & $96.833 \%$ \\
\hline 686 & escuela de música & 0.00144 & $0.011 \%$ & $0.282 \%$ & $96.844 \%$ \\
\hline 687 & vocal & 0.00144 & $0.011 \%$ & $0.282 \%$ & $96.855 \%$ \\
\hline 688 & horno & 0.00144 & $0.011 \%$ & $0.282 \%$ & $96.866 \%$ \\
\hline 689 & lugar de entretenimiento & 0.00144 & $0.011 \%$ & $0.282 \%$ & $96.877 \%$ \\
\hline 690 & comercial & 0.00144 & $0.011 \%$ & $0.282 \%$ & $96.888 \%$ \\
\hline 691 & diagonal & 0.00144 & $0.011 \%$ & $0.282 \%$ & $96.899 \%$ \\
\hline 692 & parque infantil & 0.00144 & $0.011 \%$ & $0.282 \%$ & $96.910 \%$ \\
\hline 693 & trinquete & 0.00144 & $0.011 \%$ & $0.282 \%$ & $96.921 \%$ \\
\hline 694 & parada & 0.00144 & $0.011 \%$ & $0.282 \%$ & $96.932 \%$ \\
\hline
\end{tabular}




\begin{tabular}{|c|c|c|c|c|c|}
\hline 695 & sociedad & 0.00144 & $0.011 \%$ & $0.282 \%$ & $96.943 \%$ \\
\hline 696 & negro & 0.00144 & $0.011 \%$ & $0.282 \%$ & $96.954 \%$ \\
\hline 697 & urbano & 0.00144 & $0.011 \%$ & $0.282 \%$ & $96.965 \%$ \\
\hline 698 & tejado & 0.00144 & $0.011 \%$ & $0.282 \%$ & $96.976 \%$ \\
\hline 699 & parada de taxi & 0.00144 & $0.011 \%$ & $0.282 \%$ & $96.987 \%$ \\
\hline 700 & lotería & 0.00138 & $0.011 \%$ & $0.282 \%$ & $96.998 \%$ \\
\hline 701 & chico & 0.00138 & $0.011 \%$ & $0.282 \%$ & $97.009 \%$ \\
\hline 702 & calle ancha & 0.00138 & $0.011 \%$ & $0.282 \%$ & $97.020 \%$ \\
\hline 703 & pavimento & 0.00138 & $0.011 \%$ & $0.282 \%$ & $97.031 \%$ \\
\hline 704 & prensa & 0.00138 & $0.011 \%$ & $0.282 \%$ & $97.042 \%$ \\
\hline 705 & universidad pública & 0.00138 & $0.011 \%$ & $0.282 \%$ & $97.053 \%$ \\
\hline 706 & videojuegos & 0.00138 & $0.011 \%$ & $0.282 \%$ & $97.064 \%$ \\
\hline 707 & mesón & 0.00138 & $0.011 \%$ & $0.282 \%$ & $97.075 \%$ \\
\hline 708 & termómetro & 0.00138 & $0.011 \%$ & $0.282 \%$ & $97.086 \%$ \\
\hline 709 & cancha de básquet & 0.00138 & $0.011 \%$ & $0.282 \%$ & $97.097 \%$ \\
\hline 710 & delincuente & 0.00138 & $0.023 \%$ & $0.565 \%$ & $97.120 \%$ \\
\hline 711 & escuela de idiomas & 0.00138 & $0.011 \%$ & $0.282 \%$ & $97.131 \%$ \\
\hline 712 & bota & 0.00138 & $0.011 \%$ & $0.282 \%$ & $97.142 \%$ \\
\hline 713 & petardo & 0.00138 & $0.011 \%$ & $0.282 \%$ & $97.153 \%$ \\
\hline 714 & puta & 0.00138 & $0.011 \%$ & $0.282 \%$ & $97.164 \%$ \\
\hline 715 & Galicia & 0.00138 & $0.011 \%$ & $0.282 \%$ & $97.175 \%$ \\
\hline 716 & asociación & 0.00138 & $0.011 \%$ & $0.282 \%$ & $97.186 \%$ \\
\hline 717 & suelo & 0.00138 & $0.011 \%$ & $0.282 \%$ & $97.197 \%$ \\
\hline 718 & centro de ancianos & 0.00138 & $0.011 \%$ & $0.282 \%$ & $97.208 \%$ \\
\hline 719 & carro de bebé & 0.00138 & $0.011 \%$ & $0.282 \%$ & $97.219 \%$ \\
\hline 720 & lugar de ocio & 0.00138 & $0.011 \%$ & $0.282 \%$ & $97.230 \%$ \\
\hline 721 & fachada & 0.00138 & $0.011 \%$ & $0.282 \%$ & $97.241 \%$ \\
\hline 722 & matrícula & 0.00138 & $0.011 \%$ & $0.282 \%$ & $97.252 \%$ \\
\hline 723 & cristal & 0.00138 & $0.011 \%$ & $0.282 \%$ & $97.263 \%$ \\
\hline 724 & facultad & 0.00138 & $0.011 \%$ & $0.282 \%$ & $97.274 \%$ \\
\hline 725 & estación de bomberos & 0.00138 & $0.011 \%$ & $0.282 \%$ & $97.285 \%$ \\
\hline 726 & medio de transporte & 0.00138 & $0.011 \%$ & $0.282 \%$ & $97.296 \%$ \\
\hline 727 & taberna & 0.00138 & $0.011 \%$ & $0.282 \%$ & $97.307 \%$ \\
\hline 728 & peluquero & 0.00136 & $0.023 \%$ & $0.565 \%$ & $97.330 \%$ \\
\hline 729 & transporte & 0.00131 & $0.011 \%$ & $0.282 \%$ & $97.341 \%$ \\
\hline 730 & televisión & 0.00131 & $0.011 \%$ & $0.282 \%$ & $97.352 \%$ \\
\hline 731 & parroquia & 0.00131 & $0.011 \%$ & $0.282 \%$ & $97.363 \%$ \\
\hline 732 & nave & 0.00131 & $0.011 \%$ & $0.282 \%$ & $97.374 \%$ \\
\hline 733 & hilo de tender & 0.00131 & $0.011 \%$ & $0.282 \%$ & $97.385 \%$ \\
\hline 734 & riqueza & 0.00131 & $0.011 \%$ & $0.282 \%$ & $97.396 \%$ \\
\hline 735 & independencia & 0.00131 & $0.011 \%$ & $0.282 \%$ & $97.407 \%$ \\
\hline 736 & tabaco & 0.00131 & $0.011 \%$ & $0.282 \%$ & $97.418 \%$ \\
\hline 737 & discusión & 0.00131 & $0.011 \%$ & $0.282 \%$ & $97.429 \%$ \\
\hline 738 & Asturias & 0.00131 & $0.011 \%$ & $0.282 \%$ & $97.440 \%$ \\
\hline 739 & fiesta patronal & 0.00131 & $0.011 \%$ & $0.282 \%$ & $97.451 \%$ \\
\hline 740 & poste eléctrico & 0.00131 & $0.011 \%$ & $0.282 \%$ & $97.462 \%$ \\
\hline 741 & parque de atracciones & 0.00131 & $0.011 \%$ & $0.282 \%$ & $97.473 \%$ \\
\hline
\end{tabular}




\begin{tabular}{|c|c|c|c|c|c|}
\hline 742 & jardín de infancia & 0.00131 & $0.011 \%$ & $0.282 \%$ & $97.484 \%$ \\
\hline 743 & masajista & 0.00131 & $0.011 \%$ & $0.282 \%$ & $97.495 \%$ \\
\hline 744 & vecindario & 0.00131 & $0.011 \%$ & $0.282 \%$ & $97.506 \%$ \\
\hline 745 & gobernante & 0.00131 & $0.011 \%$ & $0.282 \%$ & $97.517 \%$ \\
\hline 746 & cabina de ONCE & 0.00131 & $0.011 \%$ & $0.282 \%$ & $97.528 \%$ \\
\hline 747 & urbanismo & 0.00131 & $0.011 \%$ & $0.282 \%$ & $97.539 \%$ \\
\hline 748 & estación de ferrocarril & 0.00131 & $0.011 \%$ & $0.282 \%$ & $97.550 \%$ \\
\hline 749 & tienda de caramelos & 0.00125 & $0.011 \%$ & $0.282 \%$ & $97.561 \%$ \\
\hline 750 & anuncio publicitario & 0.00125 & $0.011 \%$ & $0.282 \%$ & $97.572 \%$ \\
\hline 751 & agente de bolsa & 0.00125 & $0.011 \%$ & $0.282 \%$ & $97.583 \%$ \\
\hline 752 & monopatín & 0.00125 & $0.011 \%$ & $0.282 \%$ & $97.594 \%$ \\
\hline 753 & casa adosada & 0.00125 & $0.011 \%$ & $0.282 \%$ & $97.605 \%$ \\
\hline 754 & lavadero & 0.00125 & $0.011 \%$ & $0.282 \%$ & $97.616 \%$ \\
\hline 755 & carné de conducir & 0.00125 & $0.011 \%$ & $0.282 \%$ & $97.627 \%$ \\
\hline 756 & sala recreativa & 0.00125 & $0.011 \%$ & $0.282 \%$ & $97.638 \%$ \\
\hline 757 & autocontrol & 0.00125 & $0.011 \%$ & $0.282 \%$ & $97.649 \%$ \\
\hline 758 & anillo & 0.00125 & $0.011 \%$ & $0.282 \%$ & $97.660 \%$ \\
\hline 759 & Andorra & 0.00125 & $0.011 \%$ & $0.282 \%$ & $97.671 \%$ \\
\hline 760 & instalación deportiva & 0.00125 & $0.011 \%$ & $0.282 \%$ & $97.682 \%$ \\
\hline 761 & político & 0.00125 & $0.011 \%$ & $0.282 \%$ & $97.693 \%$ \\
\hline 762 & aire contaminado & 0.00125 & $0.011 \%$ & $0.282 \%$ & $97.704 \%$ \\
\hline 763 & poste & 0.00125 & $0.011 \%$ & $0.282 \%$ & $97.715 \%$ \\
\hline 764 & acueducto & 0.00125 & $0.011 \%$ & $0.282 \%$ & $97.726 \%$ \\
\hline 765 & excavadora & 0.00125 & $0.011 \%$ & $0.282 \%$ & $97.737 \%$ \\
\hline 766 & disco & 0.00123 & $0.023 \%$ & $0.565 \%$ & $97.760 \%$ \\
\hline 767 & enfermería & 0.00123 & $0.023 \%$ & $0.565 \%$ & $97.783 \%$ \\
\hline 768 & hilo telefónico & 0.00119 & $0.011 \%$ & $0.282 \%$ & $97.794 \%$ \\
\hline 769 & colegio farmacéutico & 0.00119 & $0.011 \%$ & $0.282 \%$ & $97.805 \%$ \\
\hline 770 & lancha & 0.00119 & $0.011 \%$ & $0.282 \%$ & $97.816 \%$ \\
\hline 771 & cuartel & 0.00119 & $0.011 \%$ & $0.282 \%$ & $97.827 \%$ \\
\hline 772 & maleta & 0.00119 & $0.011 \%$ & $0.282 \%$ & $97.838 \%$ \\
\hline 773 & paraguas & 0.00119 & $0.011 \%$ & $0.282 \%$ & $97.849 \%$ \\
\hline 774 & conversación & 0.00119 & $0.011 \%$ & $0.282 \%$ & $97.860 \%$ \\
\hline 775 & prohibido el paso & 0.00119 & $0.011 \%$ & $0.282 \%$ & $97.871 \%$ \\
\hline 776 & bocatería & 0.00119 & $0.011 \%$ & $0.282 \%$ & $97.882 \%$ \\
\hline 777 & Berlín & 0.00119 & $0.011 \%$ & $0.282 \%$ & $97.893 \%$ \\
\hline 778 & rebeldía & 0.00119 & $0.011 \%$ & $0.282 \%$ & $97.904 \%$ \\
\hline 779 & boca de metro & 0.00119 & $0.011 \%$ & $0.282 \%$ & $97.915 \%$ \\
\hline 780 & equipo de fútbol & 0.00119 & $0.011 \%$ & $0.282 \%$ & $97.926 \%$ \\
\hline 781 & polígono & 0.00119 & $0.011 \%$ & $0.282 \%$ & $97.937 \%$ \\
\hline 782 & tienda de helados & 0.00119 & $0.011 \%$ & $0.282 \%$ & $97.948 \%$ \\
\hline 783 & sol & 0.00119 & $0.011 \%$ & $0.282 \%$ & $97.959 \%$ \\
\hline 784 & jubilado & 0.00119 & $0.011 \%$ & $0.282 \%$ & $97.970 \%$ \\
\hline 785 & cochera & 0.00119 & $0.011 \%$ & $0.282 \%$ & $97.981 \%$ \\
\hline 786 & gamberrismo & 0.00119 & $0.011 \%$ & $0.282 \%$ & $97.992 \%$ \\
\hline 787 & paleta de tráfico & 0.00119 & $0.011 \%$ & $0.282 \%$ & $98.003 \%$ \\
\hline 788 & banco de España & 0.00119 & $0.011 \%$ & $0.282 \%$ & $98.014 \%$ \\
\hline
\end{tabular}




\begin{tabular}{|c|c|c|c|c|c|}
\hline 789 & loco & 0.00114 & $0.011 \%$ & $0.282 \%$ & $98.025 \%$ \\
\hline 790 & lugar particular & 0.00114 & $0.011 \%$ & $0.282 \%$ & $98.036 \%$ \\
\hline 791 & colegio de médicos & 0.00114 & $0.011 \%$ & $0.282 \%$ & $98.047 \%$ \\
\hline 792 & carrito & 0.00114 & $0.011 \%$ & $0.282 \%$ & $98.058 \%$ \\
\hline 793 & canal & 0.00114 & $0.011 \%$ & $0.282 \%$ & $98.069 \%$ \\
\hline 794 & Consejería & 0.00114 & $0.011 \%$ & $0.282 \%$ & $98.080 \%$ \\
\hline 795 & jefatura & 0.00114 & $0.011 \%$ & $0.282 \%$ & $98.091 \%$ \\
\hline 796 & cable & 0.00114 & $0.011 \%$ & $0.282 \%$ & $98.102 \%$ \\
\hline 797 & chapado & 0.00114 & $0.011 \%$ & $0.282 \%$ & $98.113 \%$ \\
\hline 798 & bolso & 0.00114 & $0.011 \%$ & $0.282 \%$ & $98.124 \%$ \\
\hline 799 & salón de recreo & 0.00114 & $0.011 \%$ & $0.282 \%$ & $98.135 \%$ \\
\hline 800 & rosal & 0.00114 & $0.011 \%$ & $0.282 \%$ & $98.146 \%$ \\
\hline 801 & suburbio & 0.00114 & $0.011 \%$ & $0.282 \%$ & $98.157 \%$ \\
\hline 802 & nacimiento & 0.00114 & $0.011 \%$ & $0.282 \%$ & $98.168 \%$ \\
\hline 803 & sexo & 0.00114 & $0.011 \%$ & $0.282 \%$ & $98.179 \%$ \\
\hline 804 & cura & 0.00114 & $0.011 \%$ & $0.282 \%$ & $98.190 \%$ \\
\hline 805 & Amsterdam & 0.00114 & $0.011 \%$ & $0.282 \%$ & $98.201 \%$ \\
\hline 806 & gestoría & 0.00114 & $0.011 \%$ & $0.282 \%$ & $98.212 \%$ \\
\hline 807 & policía municipal & 0.00114 & $0.011 \%$ & $0.282 \%$ & $98.223 \%$ \\
\hline 808 & consulta de médico & 0.00114 & $0.011 \%$ & $0.282 \%$ & $98.234 \%$ \\
\hline 809 & bebé & 0.00114 & $0.011 \%$ & $0.282 \%$ & $98.245 \%$ \\
\hline 810 & estación de taxi & 0.00114 & $0.011 \%$ & $0.282 \%$ & $98.256 \%$ \\
\hline 811 & mafia & 0.00114 & $0.011 \%$ & $0.282 \%$ & $98.267 \%$ \\
\hline 812 & merendero & 0.00114 & $0.011 \%$ & $0.282 \%$ & $98.278 \%$ \\
\hline 813 & tanatorio & 0.00114 & $0.011 \%$ & $0.282 \%$ & $98.289 \%$ \\
\hline 814 & domicilio & 0.00108 & $0.011 \%$ & $0.282 \%$ & $98.300 \%$ \\
\hline 815 & centro clínico & 0.00108 & $0.011 \%$ & $0.282 \%$ & $98.311 \%$ \\
\hline 816 & ruina & 0.00108 & $0.011 \%$ & $0.282 \%$ & $98.322 \%$ \\
\hline 817 & ático & 0.00108 & $0.011 \%$ & $0.282 \%$ & $98.333 \%$ \\
\hline 818 & mendigo & 0.00108 & $0.011 \%$ & $0.282 \%$ & $98.344 \%$ \\
\hline 819 & barranco & 0.00108 & $0.011 \%$ & $0.282 \%$ & $98.355 \%$ \\
\hline 820 & centro de ocio & 0.00108 & $0.011 \%$ & $0.282 \%$ & $98.366 \%$ \\
\hline 821 & hormiga & 0.00108 & $0.011 \%$ & $0.282 \%$ & $98.377 \%$ \\
\hline 822 & incendio & 0.00108 & $0.011 \%$ & $0.282 \%$ & $98.388 \%$ \\
\hline 823 & rico & 0.00108 & $0.011 \%$ & $0.282 \%$ & $98.399 \%$ \\
\hline 824 & Zaragoza & 0.00108 & $0.011 \%$ & $0.282 \%$ & $98.410 \%$ \\
\hline 825 & piso adosado & 0.00108 & $0.011 \%$ & $0.282 \%$ & $98.421 \%$ \\
\hline 826 & centro cultural & 0.00108 & $0.011 \%$ & $0.282 \%$ & $98.432 \%$ \\
\hline 827 & policía nacional & 0.00108 & $0.011 \%$ & $0.282 \%$ & $98.443 \%$ \\
\hline 828 & veterinario & 0.00108 & $0.011 \%$ & $0.282 \%$ & $98.454 \%$ \\
\hline 829 & pasarela & 0.00108 & $0.011 \%$ & $0.282 \%$ & $98.465 \%$ \\
\hline 830 & urgencias & 0.00108 & $0.011 \%$ & $0.282 \%$ & $98.476 \%$ \\
\hline 831 & escándalo & 0.00108 & $0.011 \%$ & $0.282 \%$ & $98.487 \%$ \\
\hline 832 & monasterio & 0.00108 & $0.011 \%$ & $0.282 \%$ & $98.498 \%$ \\
\hline 833 & policía local & 0.00108 & $0.011 \%$ & $0.282 \%$ & $98.509 \%$ \\
\hline 834 & oculista & 0.00108 & $0.011 \%$ & $0.282 \%$ & $98.520 \%$ \\
\hline 835 & tintorería & 0.00103 & $0.011 \%$ & $0.282 \%$ & $98.531 \%$ \\
\hline
\end{tabular}




\begin{tabular}{|c|c|c|c|c|c|}
\hline 836 & recinto deportivo & 0.00103 & $0.011 \%$ & $0.282 \%$ & $98.542 \%$ \\
\hline 837 & monumento histórico & 0.00103 & $0.011 \%$ & $0.282 \%$ & $98.553 \%$ \\
\hline 838 & orquesta & 0.00103 & $0.011 \%$ & $0.282 \%$ & $98.564 \%$ \\
\hline 839 & boda & 0.00103 & $0.011 \%$ & $0.282 \%$ & $98.575 \%$ \\
\hline 840 & rata & 0.00103 & $0.011 \%$ & $0.282 \%$ & $98.586 \%$ \\
\hline 841 & Huesca & 0.00103 & $0.011 \%$ & $0.282 \%$ & $98.597 \%$ \\
\hline 842 & cruasantería & 0.00103 & $0.011 \%$ & $0.282 \%$ & $98.608 \%$ \\
\hline 843 & cuartelillo & 0.00103 & $0.011 \%$ & $0.282 \%$ & $98.619 \%$ \\
\hline 844 & perrera & 0.00103 & $0.011 \%$ & $0.282 \%$ & $98.630 \%$ \\
\hline 845 & sala de máquinas & 0.00103 & $0.011 \%$ & $0.282 \%$ & $98.641 \%$ \\
\hline 846 & emigrante & 0.00103 & $0.011 \%$ & $0.282 \%$ & $98.652 \%$ \\
\hline 847 & negocio & 0.00103 & $0.011 \%$ & $0.282 \%$ & $98.663 \%$ \\
\hline 848 & enfermero & 0.00103 & $0.011 \%$ & $0.282 \%$ & $98.674 \%$ \\
\hline 849 & maceta & 0.00103 & $0.011 \%$ & $0.282 \%$ & $98.685 \%$ \\
\hline 850 & balneario & 0.00098 & $0.011 \%$ & $0.282 \%$ & $98.696 \%$ \\
\hline 851 & alimentación & 0.00098 & $0.011 \%$ & $0.282 \%$ & $98.707 \%$ \\
\hline 852 & tienda musical & 0.00098 & $0.011 \%$ & $0.282 \%$ & $98.718 \%$ \\
\hline 853 & tienda de congelados & 0.00098 & $0.011 \%$ & $0.282 \%$ & $98.729 \%$ \\
\hline 854 & escenario & 0.00098 & $0.011 \%$ & $0.282 \%$ & $98.740 \%$ \\
\hline 855 & dirección de policía & 0.00098 & $0.011 \%$ & $0.282 \%$ & $98.751 \%$ \\
\hline 856 & banda & 0.00098 & $0.011 \%$ & $0.282 \%$ & $98.762 \%$ \\
\hline 857 & Cibeles & 0.00098 & $0.011 \%$ & $0.282 \%$ & $98.773 \%$ \\
\hline 858 & hoja & 0.00098 & $0.011 \%$ & $0.282 \%$ & $98.784 \%$ \\
\hline 859 & funeral & 0.00098 & $0.011 \%$ & $0.282 \%$ & $98.795 \%$ \\
\hline 860 & electricista & 0.00098 & $0.011 \%$ & $0.282 \%$ & $98.806 \%$ \\
\hline 861 & muro & 0.00098 & $0.011 \%$ & $0.282 \%$ & $98.817 \%$ \\
\hline 862 & amabilidad & 0.00098 & $0.011 \%$ & $0.282 \%$ & $98.828 \%$ \\
\hline 863 & cable de teléfono & 0.00098 & $0.011 \%$ & $0.282 \%$ & $98.839 \%$ \\
\hline 864 & celador & 0.00098 & $0.011 \%$ & $0.282 \%$ & $98.850 \%$ \\
\hline 865 & verja & 0.00098 & $0.011 \%$ & $0.282 \%$ & $98.861 \%$ \\
\hline 866 & gente pobre & 0.00098 & $0.011 \%$ & $0.282 \%$ & $98.872 \%$ \\
\hline 867 & casa cultural & 0.00098 & $0.011 \%$ & $0.282 \%$ & $98.883 \%$ \\
\hline 868 & mecánico & 0.00094 & $0.011 \%$ & $0.282 \%$ & $98.894 \%$ \\
\hline 869 & padre & 0.00094 & $0.011 \%$ & $0.282 \%$ & $98.905 \%$ \\
\hline 870 & lujo & 0.00094 & $0.011 \%$ & $0.282 \%$ & $98.916 \%$ \\
\hline 871 & cagada de perros & 0.00094 & $0.011 \%$ & $0.282 \%$ & $98.927 \%$ \\
\hline 872 & imprenta & 0.00094 & $0.011 \%$ & $0.282 \%$ & $98.938 \%$ \\
\hline 873 & comprar & 0.00094 & $0.011 \%$ & $0.282 \%$ & $98.949 \%$ \\
\hline 874 & galería & 0.00094 & $0.011 \%$ & $0.282 \%$ & $98.960 \%$ \\
\hline 875 & gafas & 0.00094 & $0.011 \%$ & $0.282 \%$ & $98.971 \%$ \\
\hline 876 & vendedor ambulante & 0.00094 & $0.011 \%$ & $0.282 \%$ & $98.982 \%$ \\
\hline 877 & barca & 0.00094 & $0.011 \%$ & $0.282 \%$ & $98.993 \%$ \\
\hline 878 & vía peatonal & 0.00094 & $0.011 \%$ & $0.282 \%$ & $99.004 \%$ \\
\hline 879 & taller de motos & 0.00094 & $0.011 \%$ & $0.282 \%$ & $99.015 \%$ \\
\hline 880 & cofradía & 0.00094 & $0.011 \%$ & $0.282 \%$ & $99.026 \%$ \\
\hline 881 & espectáculo & 0.00094 & $0.011 \%$ & $0.282 \%$ & $99.037 \%$ \\
\hline 882 & gente rica & 0.00094 & $0.011 \%$ & $0.282 \%$ & $99.048 \%$ \\
\hline
\end{tabular}




\begin{tabular}{|c|c|c|c|c|c|}
\hline 883 & hogar del jubilado & 0.00094 & $0.011 \%$ & $0.282 \%$ & $99.059 \%$ \\
\hline 884 & cantón & 0.00094 & $0.011 \%$ & $0.282 \%$ & $99.070 \%$ \\
\hline 885 & enfermedad & 0.00089 & $0.011 \%$ & $0.282 \%$ & $99.081 \%$ \\
\hline 886 & fontanería & 0.00089 & $0.011 \%$ & $0.282 \%$ & $99.092 \%$ \\
\hline 887 & madrileño & 0.00089 & $0.011 \%$ & $0.282 \%$ & $99.103 \%$ \\
\hline 888 & sede social & 0.00089 & $0.011 \%$ & $0.282 \%$ & $99.114 \%$ \\
\hline 889 & pista de básquet & 0.00089 & $0.011 \%$ & $0.282 \%$ & $99.125 \%$ \\
\hline 890 & instituto de FP & 0.00089 & $0.011 \%$ & $0.282 \%$ & $99.136 \%$ \\
\hline 891 & convento & 0.00089 & $0.011 \%$ & $0.282 \%$ & $99.147 \%$ \\
\hline 892 & humareda & 0.00089 & $0.011 \%$ & $0.282 \%$ & $99.158 \%$ \\
\hline 893 & línea amarilla & 0.00089 & $0.011 \%$ & $0.282 \%$ & $99.169 \%$ \\
\hline 894 & patinete & 0.00089 & $0.011 \%$ & $0.282 \%$ & $99.180 \%$ \\
\hline 895 & cansancio & 0.00089 & $0.011 \%$ & $0.282 \%$ & $99.191 \%$ \\
\hline 896 & centro de adopción & 0.00089 & $0.011 \%$ & $0.282 \%$ & $99.202 \%$ \\
\hline 897 & taller de coches & 0.00089 & $0.011 \%$ & $0.282 \%$ & $99.213 \%$ \\
\hline 898 & cubo & 0.00089 & $0.011 \%$ & $0.282 \%$ & $99.224 \%$ \\
\hline 899 & mercado de abastos & 0.00085 & $0.011 \%$ & $0.282 \%$ & $99.235 \%$ \\
\hline 900 & casal & 0.00085 & $0.011 \%$ & $0.282 \%$ & $99.246 \%$ \\
\hline 901 & neumático & 0.00085 & $0.011 \%$ & $0.282 \%$ & $99.257 \%$ \\
\hline 902 & parada de hippys & 0.00085 & $0.011 \%$ & $0.282 \%$ & $99.268 \%$ \\
\hline 903 & línea azul & 0.00085 & $0.011 \%$ & $0.282 \%$ & $99.279 \%$ \\
\hline 904 & tienda comercial & 0.00085 & $0.011 \%$ & $0.282 \%$ & $99.290 \%$ \\
\hline 905 & avioneta & 0.00085 & $0.011 \%$ & $0.282 \%$ & $99.301 \%$ \\
\hline 906 & campo deportivo & 0.00085 & $0.011 \%$ & $0.282 \%$ & $99.312 \%$ \\
\hline 907 & motorista & 0.00085 & $0.011 \%$ & $0.282 \%$ & $99.323 \%$ \\
\hline 908 & parlamento & 0.00085 & $0.011 \%$ & $0.282 \%$ & $99.334 \%$ \\
\hline 909 & caca & 0.00085 & $0.011 \%$ & $0.282 \%$ & $99.345 \%$ \\
\hline 910 & andamio & 0.00085 & $0.011 \%$ & $0.282 \%$ & $99.356 \%$ \\
\hline 911 & cartel & 0.00085 & $0.011 \%$ & $0.282 \%$ & $99.367 \%$ \\
\hline 912 & casa de animales & 0.00085 & $0.011 \%$ & $0.282 \%$ & $99.378 \%$ \\
\hline 913 & madero & 0.00081 & $0.011 \%$ & $0.282 \%$ & $99.389 \%$ \\
\hline 914 & estación ferroviaria & 0.00081 & $0.011 \%$ & $0.282 \%$ & $99.400 \%$ \\
\hline 915 & piscina pública & 0.00081 & $0.011 \%$ & $0.282 \%$ & $99.411 \%$ \\
\hline 916 & alquería & 0.00081 & $0.011 \%$ & $0.282 \%$ & $99.422 \%$ \\
\hline 917 & cuesta & 0.00081 & $0.011 \%$ & $0.282 \%$ & $99.433 \%$ \\
\hline 918 & consulta médica & 0.00081 & $0.011 \%$ & $0.282 \%$ & $99.444 \%$ \\
\hline 919 & línea discontinua & 0.00081 & $0.011 \%$ & $0.282 \%$ & $99.455 \%$ \\
\hline 920 & paseo marítimo & 0.00081 & $0.011 \%$ & $0.282 \%$ & $99.466 \%$ \\
\hline 921 & ventanal & 0.00081 & $0.011 \%$ & $0.282 \%$ & $99.477 \%$ \\
\hline 922 & centro de sanidad & 0.00081 & $0.011 \%$ & $0.282 \%$ & $99.488 \%$ \\
\hline 923 & campo de hockey & 0.00077 & $0.011 \%$ & $0.282 \%$ & $99.499 \%$ \\
\hline 924 & deporte & 0.00077 & $0.011 \%$ & $0.282 \%$ & $99.510 \%$ \\
\hline 925 & teléfono público & 0.00074 & $0.011 \%$ & $0.282 \%$ & $99.521 \%$ \\
\hline 926 & carril de bicicleta & 0.00074 & $0.011 \%$ & $0.282 \%$ & $99.532 \%$ \\
\hline 927 & cristalería & 0.00074 & $0.011 \%$ & $0.282 \%$ & $99.543 \%$ \\
\hline 928 & motel & 0.00070 & $0.011 \%$ & $0.282 \%$ & $99.554 \%$ \\
\hline 929 & cemento & 0.00070 & $0.011 \%$ & $0.282 \%$ & $99.565 \%$ \\
\hline
\end{tabular}




\begin{tabular}{|l|l|l|l|l|l|}
\hline 930 & motocultor & 0.00070 & $0.011 \%$ & $0.282 \%$ & $99.576 \%$ \\
\hline 931 & motor & 0.00070 & $0.011 \%$ & $0.282 \%$ & $99.587 \%$ \\
\hline 932 & dirección & 0.00070 & $0.011 \%$ & $0.282 \%$ & $99.598 \%$ \\
\hline 933 & futuro & 0.00070 & $0.011 \%$ & $0.282 \%$ & $99.609 \%$ \\
\hline 934 & carril de coche & 0.00070 & $0.011 \%$ & $0.282 \%$ & $99.620 \%$ \\
\hline 935 & copistería & 0.00067 & $0.011 \%$ & $0.282 \%$ & $99.631 \%$ \\
\hline 936 & porquería & 0.00067 & $0.011 \%$ & $0.282 \%$ & $99.642 \%$ \\
\hline 937 & pensión & 0.00067 & $0.011 \%$ & $0.282 \%$ & $99.653 \%$ \\
\hline 938 & homosexual & 0.00067 & $0.011 \%$ & $0.282 \%$ & $99.664 \%$ \\
\hline 939 & tribunal & 0.00067 & $0.011 \%$ & $0.282 \%$ & $99.675 \%$ \\
\hline 940 & porro & 0.00064 & $0.011 \%$ & $0.282 \%$ & $99.686 \%$ \\
\hline 941 & muelle & 0.00064 & $0.011 \%$ & $0.282 \%$ & $99.697 \%$ \\
\hline 942 & camping & 0.00061 & $0.011 \%$ & $0.282 \%$ & $99.708 \%$ \\
\hline 943 & luz de coches & 0.00061 & $0.011 \%$ & $0.282 \%$ & $99.719 \%$ \\
\hline 944 & antidisturbios & 0.00061 & $0.011 \%$ & $0.282 \%$ & $99.730 \%$ \\
\hline 945 & cobrador de impuestos & 0.00055 & $0.011 \%$ & $0.282 \%$ & $99.741 \%$ \\
\hline 946 & machista & 0.00050 & $0.011 \%$ & $0.282 \%$ & $99.752 \%$ \\
\hline 947 & videoteca & 0.00050 & $0.011 \%$ & $0.282 \%$ & $99.763 \%$ \\
\hline 948 & casa de Cruz Roja & 0.00050 & $0.011 \%$ & $0.282 \%$ & $99.774 \%$ \\
\hline 949 & nazi & 0.00048 & $0.011 \%$ & $0.282 \%$ & $99.785 \%$ \\
\hline
\end{tabular}

\section{EL CAMPO}

\begin{tabular}{|c|l|c|c|c|c|}
\hline $\mathrm{N}^{\mathbf{0}}$ & Palabra & Disponibilidad & $\begin{array}{c}\text { Frecuencia } \\
\text { relativa }\end{array}$ & $\%$ Aparición & $\begin{array}{c}\text { Frecuencia } \\
\text { acumulada }\end{array}$ \\
\hline 1 & árbol & 0.61782 & $3.533 \%$ & $74.576 \%$ & $3.533 \%$ \\
\hline 2 & hierba & 0.32520 & $2.155 \%$ & $45.480 \%$ & $5.688 \%$ \\
\hline 3 & flor & 0.30880 & $2.034 \%$ & $42.938 \%$ & $7.722 \%$ \\
\hline 4 & montaña & 0.24661 & $1.941 \%$ & $40.960 \%$ & $9.663 \%$ \\
\hline 5 & río & 0.24031 & $1.967 \%$ & $41.525 \%$ & $11.630 \%$ \\
\hline 6 & tierra & 0.21390 & $1.646 \%$ & $34.746 \%$ & $13.276 \%$ \\
\hline 7 & pájaro & 0.19918 & $1.566 \%$ & $33.051 \%$ & $14.842 \%$ \\
\hline 8 & piedra & 0.17762 & $1.499 \%$ & $31.638 \%$ & $16.341 \%$ \\
\hline 9 & animal & 0.16688 & $1.204 \%$ & $25.424 \%$ & $17.545 \%$ \\
\hline 10 & tractor & 0.16334 & $1.204 \%$ & $25.424 \%$ & $18.749 \%$ \\
\hline 11 & césped & 0.16158 & $1.057 \%$ & $22.316 \%$ & $19.806 \%$ \\
\hline 12 & naranjo & 0.16071 & $1.178 \%$ & $24.859 \%$ & $20.984 \%$ \\
\hline 13 & pino & 0.15355 & $1.258 \%$ & $26.554 \%$ & $22.242 \%$ \\
\hline 14 & vaca & 0.13421 & $1.044 \%$ & $22.034 \%$ & $23.286 \%$ \\
\hline 15 & insecto & 0.11990 & $0.964 \%$ & $20.339 \%$ & $24.250 \%$ \\
\hline 16 & planta & 0.11919 & $0.763 \%$ & $16.102 \%$ & $25.013 \%$ \\
\hline 17 & perro & 0.11325 & $0.977 \%$ & $20.621 \%$ & $25.990 \%$ \\
\hline 18 & conejo & 0.11196 & $0.897 \%$ & $18.927 \%$ & $26.887 \%$ \\
\hline
\end{tabular}




\begin{tabular}{|c|c|c|c|c|c|}
\hline 19 & agua & 0.10938 & $0.923 \%$ & $19.492 \%$ & $27.810 \%$ \\
\hline 20 & casa & 0.10919 & $0.736 \%$ & $15.537 \%$ & $28.546 \%$ \\
\hline 21 & arbusto & 0.10701 & $0.843 \%$ & $17.797 \%$ & $29.389 \%$ \\
\hline 22 & oveja & 0.10388 & $0.910 \%$ & $19.209 \%$ & $30.299 \%$ \\
\hline 23 & lago & 0.10322 & $0.923 \%$ & $19.492 \%$ & $31.222 \%$ \\
\hline 24 & tranquilidad & 0.10095 & $0.763 \%$ & $16.102 \%$ & $31.985 \%$ \\
\hline 25 & huerto & 0.09116 & $0.669 \%$ & $14.124 \%$ & $32.654 \%$ \\
\hline 26 & caballo & 0.08994 & $0.763 \%$ & $16.102 \%$ & $33.417 \%$ \\
\hline 27 & mosca & 0.07830 & $0.683 \%$ & $14.407 \%$ & $34.100 \%$ \\
\hline 28 & mosquito & 0.07713 & $0.696 \%$ & $14.689 \%$ & $34.796 \%$ \\
\hline 29 & hormiga & 0.07604 & $0.709 \%$ & $14.972 \%$ & $35.505 \%$ \\
\hline 30 & azada & 0.07488 & $0.482 \%$ & $10.169 \%$ & $35.987 \%$ \\
\hline 31 & camino & 0.07334 & $0.683 \%$ & $14.407 \%$ & $36.670 \%$ \\
\hline 32 & toro & 0.07106 & $0.616 \%$ & $12.994 \%$ & $37.286 \%$ \\
\hline 33 & abeja & 0.06928 & $0.642 \%$ & $13.559 \%$ & $37.928 \%$ \\
\hline 34 & margarita & 0.06427 & $0.468 \%$ & $9.887 \%$ & $38.396 \%$ \\
\hline 35 & granja & 0.06364 & $0.535 \%$ & $11.299 \%$ & $38.931 \%$ \\
\hline 36 & sol & 0.06273 & $0.549 \%$ & $11.582 \%$ & $39.480 \%$ \\
\hline 37 & cabra & 0.06247 & $0.549 \%$ & $11.582 \%$ & $40.029 \%$ \\
\hline 38 & serpiente & 0.06236 & $0.575 \%$ & $12.147 \%$ & $40.604 \%$ \\
\hline 39 & acequia & 0.06061 & $0.482 \%$ & $10.169 \%$ & $41.086 \%$ \\
\hline 40 & gato & 0.06004 & $0.535 \%$ & $11.299 \%$ & $41.621 \%$ \\
\hline 41 & mariposa & 0.05938 & $0.482 \%$ & $10.169 \%$ & $42.103 \%$ \\
\hline 42 & amapola & 0.05842 & $0.455 \%$ & $9.605 \%$ & $42.558 \%$ \\
\hline 43 & prado & 0.05724 & $0.401 \%$ & $8.475 \%$ & $42.959 \%$ \\
\hline 44 & aire puro & 0.05698 & $0.442 \%$ & $9.322 \%$ & $43.401 \%$ \\
\hline 45 & trigo & 0.05567 & $0.509 \%$ & $10.734 \%$ & $43.910 \%$ \\
\hline 46 & bosque & 0.05481 & $0.428 \%$ & $9.040 \%$ & $44.338 \%$ \\
\hline 47 & almendro & 0.05465 & $0.468 \%$ & $9.887 \%$ & $44.806 \%$ \\
\hline 48 & caseta & 0.05392 & $0.415 \%$ & $8.757 \%$ & $45.221 \%$ \\
\hline 49 & rosa & 0.05306 & $0.442 \%$ & $9.322 \%$ & $45.663 \%$ \\
\hline 50 & masía & 0.05074 & $0.388 \%$ & $8.192 \%$ & $46.051 \%$ \\
\hline 51 & agricultor & 0.05001 & $0.361 \%$ & $7.627 \%$ & $46.412 \%$ \\
\hline 52 & aire & 0.04985 & $0.415 \%$ & $8.757 \%$ & $46.827 \%$ \\
\hline 53 & limonero & 0.04835 & $0.428 \%$ & $9.040 \%$ & $47.255 \%$ \\
\hline 54 & manzano & 0.04823 & $0.375 \%$ & $7.910 \%$ & $47.630 \%$ \\
\hline 55 & tomate & 0.04624 & $0.401 \%$ & $8.475 \%$ & $48.031 \%$ \\
\hline 56 & abeto & 0.04622 & $0.375 \%$ & $7.910 \%$ & $48.406 \%$ \\
\hline 57 & matorral & 0.04573 & $0.335 \%$ & $7.062 \%$ & $48.741 \%$ \\
\hline 58 & naturaleza & 0.04564 & $0.348 \%$ & $7.345 \%$ & $49.089 \%$ \\
\hline 59 & verde & 0.04279 & $0.308 \%$ & $6.497 \%$ & $49.397 \%$ \\
\hline 60 & hortaliza & 0.04198 & $0.335 \%$ & $7.062 \%$ & $49.732 \%$ \\
\hline 61 & lechuga & 0.04188 & $0.294 \%$ & $6.215 \%$ & $50.026 \%$ \\
\hline 62 & fuente & 0.04176 & $0.415 \%$ & $8.757 \%$ & $50.441 \%$ \\
\hline 63 & olivo & 0.04123 & $0.388 \%$ & $8.192 \%$ & $50.829 \%$ \\
\hline 64 & cultivo & 0.04091 & $0.348 \%$ & $7.345 \%$ & $51.177 \%$ \\
\hline 65 & ardilla & 0.04026 & $0.375 \%$ & $7.910 \%$ & $51.552 \%$ \\
\hline
\end{tabular}




\begin{tabular}{|c|c|c|c|c|c|}
\hline 66 & roca & 0.03991 & $0.415 \%$ & $8.757 \%$ & $51.967 \%$ \\
\hline 67 & pala & 0.03916 & $0.348 \%$ & $7.345 \%$ & $52.315 \%$ \\
\hline 68 & avispa & 0.03867 & $0.361 \%$ & $7.627 \%$ & $52.676 \%$ \\
\hline 69 & libertad & 0.03762 & $0.308 \%$ & $6.497 \%$ & $52.984 \%$ \\
\hline 70 & valle & 0.03612 & $0.294 \%$ & $6.215 \%$ & $53.278 \%$ \\
\hline 71 & bicho & 0.03565 & $0.294 \%$ & $6.215 \%$ & $53.572 \%$ \\
\hline 72 & fruta & 0.03556 & $0.308 \%$ & $6.497 \%$ & $53.880 \%$ \\
\hline 73 & huerta & 0.03496 & $0.241 \%$ & $5.085 \%$ & $54.121 \%$ \\
\hline 74 & barranco & 0.03437 & $0.321 \%$ & $6.780 \%$ & $54.442 \%$ \\
\hline 75 & gallina & 0.03396 & $0.308 \%$ & $6.497 \%$ & $54.750 \%$ \\
\hline 76 & cerdo & 0.03361 & $0.321 \%$ & $6.780 \%$ & $55.071 \%$ \\
\hline 77 & hoja & 0.03262 & $0.268 \%$ & $5.650 \%$ & $55.339 \%$ \\
\hline 78 & pastor & 0.03234 & $0.335 \%$ & $7.062 \%$ & $55.674 \%$ \\
\hline 79 & silencio & 0.03179 & $0.254 \%$ & $5.367 \%$ & $55.928 \%$ \\
\hline 80 & patata & 0.03142 & $0.254 \%$ & $5.367 \%$ & $56.182 \%$ \\
\hline 81 & ciervo & 0.03086 & $0.268 \%$ & $5.650 \%$ & $56.450 \%$ \\
\hline 82 & mariquita & 0.03082 & $0.254 \%$ & $5.367 \%$ & $56.704 \%$ \\
\hline 83 & campesino & 0.03064 & $0.268 \%$ & $5.650 \%$ & $56.972 \%$ \\
\hline 84 & liebre & 0.02983 & $0.268 \%$ & $5.650 \%$ & $57.240 \%$ \\
\hline 85 & abono & 0.02936 & $0.268 \%$ & $5.650 \%$ & $57.508 \%$ \\
\hline 86 & naranja & 0.02929 & $0.241 \%$ & $5.085 \%$ & $57.749 \%$ \\
\hline 87 & nube & 0.02891 & $0.294 \%$ & $6.215 \%$ & $58.043 \%$ \\
\hline 88 & cielo & 0.02798 & $0.268 \%$ & $5.650 \%$ & $58.311 \%$ \\
\hline 89 & burro & 0.02778 & $0.228 \%$ & $4.802 \%$ & $58.539 \%$ \\
\hline 90 & sendero & 0.02735 & $0.268 \%$ & $5.650 \%$ & $58.807 \%$ \\
\hline 91 & roble & 0.02732 & $0.228 \%$ & $4.802 \%$ & $59.035 \%$ \\
\hline 92 & riachuelo & 0.02685 & $0.254 \%$ & $5.367 \%$ & $59.289 \%$ \\
\hline 93 & aire limpio & 0.02627 & $0.201 \%$ & $4.237 \%$ & $59.490 \%$ \\
\hline 94 & pico & 0.02583 & $0.254 \%$ & $5.367 \%$ & $59.744 \%$ \\
\hline 95 & águila & 0.02534 & $0.228 \%$ & $4.802 \%$ & $59.972 \%$ \\
\hline 96 & peral & 0.02476 & $0.228 \%$ & $4.802 \%$ & $60.200 \%$ \\
\hline 97 & saltamontes & 0.02456 & $0.214 \%$ & $4.520 \%$ & $60.414 \%$ \\
\hline 98 & chalet & 0.02392 & $0.187 \%$ & $3.955 \%$ & $60.601 \%$ \\
\hline 99 & cabaña & 0.02379 & $0.187 \%$ & $3.955 \%$ & $60.788 \%$ \\
\hline 100 & arado & 0.02362 & $0.174 \%$ & $3.672 \%$ & $60.962 \%$ \\
\hline 101 & colina & 0.02327 & $0.241 \%$ & $5.085 \%$ & $61.203 \%$ \\
\hline 102 & cerezo & 0.02320 & $0.187 \%$ & $3.955 \%$ & $61.390 \%$ \\
\hline 103 & lluvia & 0.02308 & $0.254 \%$ & $5.367 \%$ & $61.644 \%$ \\
\hline 104 & zorro & 0.02304 & $0.241 \%$ & $5.085 \%$ & $61.885 \%$ \\
\hline 105 & labrador & 0.02279 & $0.214 \%$ & $4.520 \%$ & $62.099 \%$ \\
\hline 106 & seta & 0.02267 & $0.214 \%$ & $4.520 \%$ & $62.313 \%$ \\
\hline 107 & araña & 0.02253 & $0.281 \%$ & $5.932 \%$ & $62.594 \%$ \\
\hline 108 & segadora & 0.02243 & $0.174 \%$ & $3.672 \%$ & $62.768 \%$ \\
\hline 109 & bici(cleta) & 0.02240 & $0.187 \%$ & $3.955 \%$ & $62.955 \%$ \\
\hline 110 & algarrobo & 0.02201 & $0.228 \%$ & $4.802 \%$ & $63.183 \%$ \\
\hline 111 & encina & 0.02166 & $0.187 \%$ & $3.955 \%$ & $63.370 \%$ \\
\hline 112 & jabalí & 0.02146 & $0.241 \%$ & $5.085 \%$ & $63.611 \%$ \\
\hline
\end{tabular}




\begin{tabular}{|c|c|c|c|c|c|}
\hline 113 & arena & 0.02093 & $0.201 \%$ & $4.237 \%$ & $63.812 \%$ \\
\hline 114 & cebolla & 0.02090 & $0.174 \%$ & $3.672 \%$ & $63.986 \%$ \\
\hline 115 & rama & 0.02088 & $0.187 \%$ & $3.955 \%$ & $64.173 \%$ \\
\hline 116 & palmera & 0.02083 & $0.161 \%$ & $3.390 \%$ & $64.334 \%$ \\
\hline 117 & casa de campo & 0.02077 & $0.147 \%$ & $3.107 \%$ & $64.481 \%$ \\
\hline 118 & fruto & 0.02072 & $0.187 \%$ & $3.955 \%$ & $64.668 \%$ \\
\hline 119 & tomillo & 0.02055 & $0.214 \%$ & $4.520 \%$ & $64.882 \%$ \\
\hline 120 & pato & 0.02051 & $0.174 \%$ & $3.672 \%$ & $65.056 \%$ \\
\hline 121 & lobo & 0.02043 & $0.214 \%$ & $4.520 \%$ & $65.270 \%$ \\
\hline 122 & aire fresco & 0.02042 & $0.134 \%$ & $2.825 \%$ & $65.404 \%$ \\
\hline 123 & vegetación & 0.02016 & $0.174 \%$ & $3.672 \%$ & $65.578 \%$ \\
\hline 124 & reguero & 0.02010 & $0.161 \%$ & $3.390 \%$ & $65.739 \%$ \\
\hline 125 & (árbol) frutal & 0.01982 & $0.147 \%$ & $3.107 \%$ & $65.886 \%$ \\
\hline 126 & caserío & 0.01961 & $0.120 \%$ & $2.542 \%$ & $66.006 \%$ \\
\hline 127 & gusano & 0.01913 & $0.201 \%$ & $4.237 \%$ & $66.207 \%$ \\
\hline 128 & pez & 0.01904 & $0.187 \%$ & $3.955 \%$ & $66.394 \%$ \\
\hline 129 & paz & 0.01903 & $0.174 \%$ & $3.672 \%$ & $66.568 \%$ \\
\hline 130 & monte & 0.01878 & $0.174 \%$ & $3.672 \%$ & $66.742 \%$ \\
\hline 131 & bancal & 0.01875 & $0.107 \%$ & $2.260 \%$ & $66.849 \%$ \\
\hline 132 & villa & 0.01832 & $0.147 \%$ & $3.107 \%$ & $66.996 \%$ \\
\hline 133 & nieve & 0.01797 & $0.214 \%$ & $4.520 \%$ & $67.210 \%$ \\
\hline 134 & chopo & 0.01795 & $0.134 \%$ & $2.825 \%$ & $67.344 \%$ \\
\hline 135 & cucaracha & 0.01727 & $0.161 \%$ & $3.390 \%$ & $67.505 \%$ \\
\hline 136 & balsa & 0.01709 & $0.161 \%$ & $3.390 \%$ & $67.666 \%$ \\
\hline 137 & jardín & 0.01684 & $0.107 \%$ & $2.260 \%$ & $67.773 \%$ \\
\hline 138 & establo & 0.01674 & $0.161 \%$ & $3.390 \%$ & $67.934 \%$ \\
\hline 139 & ciprés & 0.01663 & $0.161 \%$ & $3.390 \%$ & $68.095 \%$ \\
\hline 140 & pradera & 0.01657 & $0.147 \%$ & $3.107 \%$ & $68.242 \%$ \\
\hline 141 & tronco & 0.01646 & $0.147 \%$ & $3.107 \%$ & $68.389 \%$ \\
\hline 142 & romero & 0.01641 & $0.161 \%$ & $3.390 \%$ & $68.550 \%$ \\
\hline 143 & cosecha & 0.01633 & $0.147 \%$ & $3.107 \%$ & $68.697 \%$ \\
\hline 144 & pozo & 0.01631 & $0.161 \%$ & $3.390 \%$ & $68.858 \%$ \\
\hline 145 & hoz & 0.01631 & $0.120 \%$ & $2.542 \%$ & $68.978 \%$ \\
\hline 146 & caracol & 0.01628 & $0.161 \%$ & $3.390 \%$ & $69.139 \%$ \\
\hline 147 & pantano & 0.01620 & $0.174 \%$ & $3.672 \%$ & $69.313 \%$ \\
\hline 148 & cueva & 0.01610 & $0.187 \%$ & $3.955 \%$ & $69.500 \%$ \\
\hline 149 & soledad & 0.01594 & $0.147 \%$ & $3.107 \%$ & $69.647 \%$ \\
\hline 150 & cazador & 0.01575 & $0.187 \%$ & $3.955 \%$ & $69.834 \%$ \\
\hline 151 & pueblo & 0.01533 & $0.161 \%$ & $3.390 \%$ & $69.995 \%$ \\
\hline 152 & melón & 0.01518 & $0.134 \%$ & $2.825 \%$ & $70.129 \%$ \\
\hline 153 & valla & 0.01486 & $0.134 \%$ & $2.825 \%$ & $70.263 \%$ \\
\hline 154 & aire libre & 0.01467 & $0.120 \%$ & $2.542 \%$ & $70.383 \%$ \\
\hline 155 & perdiz & 0.01463 & $0.134 \%$ & $2.825 \%$ & $70.517 \%$ \\
\hline 156 & carro & 0.01460 & $0.134 \%$ & $2.825 \%$ & $70.651 \%$ \\
\hline 157 & violeta & 0.01457 & $0.134 \%$ & $2.825 \%$ & $70.785 \%$ \\
\hline 158 & barro & 0.01433 & $0.134 \%$ & $2.825 \%$ & $70.919 \%$ \\
\hline 159 & cascada & 0.01428 & $0.161 \%$ & $3.390 \%$ & $71.080 \%$ \\
\hline
\end{tabular}




\begin{tabular}{|c|c|c|c|c|c|}
\hline 160 & clavel & 0.01425 & $0.147 \%$ & $3.107 \%$ & $71.227 \%$ \\
\hline 161 & seto & 0.01417 & $0.134 \%$ & $2.825 \%$ & $71.361 \%$ \\
\hline 162 & ave & 0.01408 & $0.120 \%$ & $2.542 \%$ & $71.481 \%$ \\
\hline 163 & hacha & 0.01407 & $0.094 \%$ & $1.977 \%$ & $71.575 \%$ \\
\hline 164 & aldea & 0.01359 & $0.134 \%$ & $2.825 \%$ & $71.709 \%$ \\
\hline 165 & llanura & 0.01358 & $0.134 \%$ & $2.825 \%$ & $71.843 \%$ \\
\hline 166 & piscina & 0.01356 & $0.107 \%$ & $2.260 \%$ & $71.950 \%$ \\
\hline 167 & plantación & 0.01354 & $0.107 \%$ & $2.260 \%$ & $72.057 \%$ \\
\hline 168 & agricultura & 0.01335 & $0.120 \%$ & $2.542 \%$ & $72.177 \%$ \\
\hline 169 & trilladora & 0.01328 & $0.080 \%$ & $1.695 \%$ & $72.257 \%$ \\
\hline 170 & senda & 0.01326 & $0.134 \%$ & $2.825 \%$ & $72.391 \%$ \\
\hline 171 & hierbajo & 0.01313 & $0.120 \%$ & $2.542 \%$ & $72.511 \%$ \\
\hline 172 & charco & 0.01306 & $0.080 \%$ & $1.695 \%$ & $72.591 \%$ \\
\hline 173 & paja & 0.01274 & $0.134 \%$ & $2.825 \%$ & $72.725 \%$ \\
\hline 174 & pera & 0.01250 & $0.094 \%$ & $1.977 \%$ & $72.819 \%$ \\
\hline 175 & gorrión & 0.01242 & $0.094 \%$ & $1.977 \%$ & $72.913 \%$ \\
\hline 176 & espárrago & 0.01242 & $0.107 \%$ & $2.260 \%$ & $73.020 \%$ \\
\hline 177 & manzana & 0.01227 & $0.120 \%$ & $2.542 \%$ & $73.140 \%$ \\
\hline 178 & rata & 0.01215 & $0.120 \%$ & $2.542 \%$ & $73.260 \%$ \\
\hline 179 & azucena & 0.01213 & $0.094 \%$ & $1.977 \%$ & $73.354 \%$ \\
\hline 180 & escarabajo & 0.01212 & $0.161 \%$ & $3.390 \%$ & $73.515 \%$ \\
\hline 181 & fresa & 0.01200 & $0.107 \%$ & $2.260 \%$ & $73.622 \%$ \\
\hline 182 & persona & 0.01191 & $0.134 \%$ & $2.825 \%$ & $73.756 \%$ \\
\hline 183 & zanahoria & 0.01180 & $0.107 \%$ & $2.260 \%$ & $73.863 \%$ \\
\hline 184 & olivera & 0.01179 & $0.120 \%$ & $2.542 \%$ & $73.983 \%$ \\
\hline 185 & granjero & 0.01168 & $0.120 \%$ & $2.542 \%$ & $74.103 \%$ \\
\hline 186 & tomatera & 0.01160 & $0.094 \%$ & $1.977 \%$ & $74.197 \%$ \\
\hline 187 & sapo & 0.01160 & $0.134 \%$ & $2.825 \%$ & $74.331 \%$ \\
\hline 188 & meseta & 0.01151 & $0.094 \%$ & $1.977 \%$ & $74.425 \%$ \\
\hline 189 & pulverizar & 0.01150 & $0.107 \%$ & $2.260 \%$ & $74.532 \%$ \\
\hline 190 & manantial & 0.01149 & $0.134 \%$ & $2.825 \%$ & $74.666 \%$ \\
\hline 191 & pureza & 0.01149 & $0.080 \%$ & $1.695 \%$ & $74.746 \%$ \\
\hline 192 & león & 0.01108 & $0.094 \%$ & $1.977 \%$ & $74.840 \%$ \\
\hline 193 & pinar & 0.01100 & $0.094 \%$ & $1.977 \%$ & $74.934 \%$ \\
\hline 194 & afluente & 0.01097 & $0.120 \%$ & $2.542 \%$ & $75.054 \%$ \\
\hline 195 & sandía & 0.01091 & $0.107 \%$ & $2.260 \%$ & $75.161 \%$ \\
\hline 196 & alcachofa & 0.01091 & $0.094 \%$ & $1.977 \%$ & $75.255 \%$ \\
\hline 197 & lagartija & 0.01088 & $0.107 \%$ & $2.260 \%$ & $75.362 \%$ \\
\hline 198 & animal salvaje & 0.01078 & $0.080 \%$ & $1.695 \%$ & $75.442 \%$ \\
\hline 199 & arroz & 0.01075 & $0.107 \%$ & $2.260 \%$ & $75.549 \%$ \\
\hline 200 & carrasca & 0.01074 & $0.120 \%$ & $2.542 \%$ & $75.669 \%$ \\
\hline 201 & sauce & 0.01068 & $0.107 \%$ & $2.260 \%$ & $75.776 \%$ \\
\hline 202 & limpieza & 0.01068 & $0.080 \%$ & $1.695 \%$ & $75.856 \%$ \\
\hline 203 & verdura & 0.01056 & $0.107 \%$ & $2.260 \%$ & $75.963 \%$ \\
\hline 204 & no contaminación & 0.01055 & $0.080 \%$ & $1.695 \%$ & $76.043 \%$ \\
\hline 205 & latifundio & 0.01052 & $0.080 \%$ & $1.695 \%$ & $76.123 \%$ \\
\hline 206 & rana & 0.01051 & $0.134 \%$ & $2.825 \%$ & $76.257 \%$ \\
\hline
\end{tabular}




\begin{tabular}{|c|c|c|c|c|c|}
\hline 207 & higuera & 0.01039 & $0.094 \%$ & $1.977 \%$ & $76.351 \%$ \\
\hline 208 & culebra & 0.01029 & $0.094 \%$ & $1.977 \%$ & $76.445 \%$ \\
\hline 209 & puente & 0.01023 & $0.120 \%$ & $2.542 \%$ & $76.565 \%$ \\
\hline 210 & rosal & 0.01012 & $0.094 \%$ & $1.977 \%$ & $76.659 \%$ \\
\hline 211 & rastrillo & 0.01009 & $0.107 \%$ & $2.260 \%$ & $76.766 \%$ \\
\hline 212 & ortiga & 0.01009 & $0.080 \%$ & $1.695 \%$ & $76.846 \%$ \\
\hline 213 & estanque & 0.01006 & $0.080 \%$ & $1.695 \%$ & $76.926 \%$ \\
\hline 214 & lombriz & 0.01000 & $0.094 \%$ & $1.977 \%$ & $77.020 \%$ \\
\hline 215 & campo & 0.00996 & $0.080 \%$ & $1.695 \%$ & $77.100 \%$ \\
\hline 216 & luz & 0.00994 & $0.094 \%$ & $1.977 \%$ & $77.194 \%$ \\
\hline 217 & camión & 0.00987 & $0.094 \%$ & $1.977 \%$ & $77.288 \%$ \\
\hline 218 & laguna & 0.00983 & $0.080 \%$ & $1.695 \%$ & $77.368 \%$ \\
\hline 219 & coche & 0.00968 & $0.094 \%$ & $1.977 \%$ & $77.462 \%$ \\
\hline 220 & serenidad & 0.00966 & $0.094 \%$ & $1.977 \%$ & $77.556 \%$ \\
\hline 221 & carretera & 0.00954 & $0.067 \%$ & $1.412 \%$ & $77.623 \%$ \\
\hline 222 & barraca & 0.00952 & $0.094 \%$ & $1.977 \%$ & $77.717 \%$ \\
\hline 223 & halcón & 0.00950 & $0.094 \%$ & $1.977 \%$ & $77.811 \%$ \\
\hline 224 & descanso & 0.00940 & $0.107 \%$ & $2.260 \%$ & $77.918 \%$ \\
\hline 225 & arroyo & 0.00935 & $0.080 \%$ & $1.695 \%$ & $77.998 \%$ \\
\hline 226 & mineral & 0.00934 & $0.094 \%$ & $1.977 \%$ & $78.092 \%$ \\
\hline 227 & ganado & 0.00933 & $0.094 \%$ & $1.977 \%$ & $78.186 \%$ \\
\hline 228 & explanada & 0.00916 & $0.080 \%$ & $1.695 \%$ & $78.266 \%$ \\
\hline 229 & buey & 0.00914 & $0.080 \%$ & $1.695 \%$ & $78.346 \%$ \\
\hline 230 & cereza & 0.00911 & $0.080 \%$ & $1.695 \%$ & $78.426 \%$ \\
\hline 231 & granero & 0.00907 & $0.067 \%$ & $1.412 \%$ & $78.493 \%$ \\
\hline 232 & hanegada & 0.00905 & $0.067 \%$ & $1.412 \%$ & $78.560 \%$ \\
\hline 233 & nido & 0.00901 & $0.120 \%$ & $2.542 \%$ & $78.680 \%$ \\
\hline 234 & semilla & 0.00899 & $0.067 \%$ & $1.412 \%$ & $78.747 \%$ \\
\hline 235 & parcela & 0.00897 & $0.080 \%$ & $1.695 \%$ & $78.827 \%$ \\
\hline 236 & ratón & 0.00895 & $0.067 \%$ & $1.412 \%$ & $78.894 \%$ \\
\hline 237 & rebaño & 0.00889 & $0.080 \%$ & $1.695 \%$ & $78.974 \%$ \\
\hline 238 & matojo & 0.00884 & $0.067 \%$ & $1.412 \%$ & $79.041 \%$ \\
\hline 239 & gente & 0.00880 & $0.094 \%$ & $1.977 \%$ & $79.135 \%$ \\
\hline 240 & naranjero & 0.00875 & $0.067 \%$ & $1.412 \%$ & $79.202 \%$ \\
\hline 241 & maíz & 0.00867 & $0.067 \%$ & $1.412 \%$ & $79.269 \%$ \\
\hline 242 & manguera & 0.00865 & $0.094 \%$ & $1.977 \%$ & $79.363 \%$ \\
\hline 243 & molino & 0.00861 & $0.067 \%$ & $1.412 \%$ & $79.430 \%$ \\
\hline 244 & tienda de campaña & 0.00860 & $0.080 \%$ & $1.695 \%$ & $79.510 \%$ \\
\hline 245 & remolque & 0.00853 & $0.067 \%$ & $1.412 \%$ & $79.577 \%$ \\
\hline 246 & paellero & 0.00853 & $0.094 \%$ & $1.977 \%$ & $79.671 \%$ \\
\hline 247 & pollo & 0.00848 & $0.080 \%$ & $1.695 \%$ & $79.751 \%$ \\
\hline 248 & aceituna & 0.00835 & $0.080 \%$ & $1.695 \%$ & $79.831 \%$ \\
\hline 249 & cuadra & 0.00835 & $0.067 \%$ & $1.412 \%$ & $79.898 \%$ \\
\hline 250 & maset & 0.00831 & $0.067 \%$ & $1.412 \%$ & $79.965 \%$ \\
\hline 251 & buitre & 0.00830 & $0.067 \%$ & $1.412 \%$ & $80.032 \%$ \\
\hline 252 & regadío & 0.00825 & $0.094 \%$ & $1.977 \%$ & $80.126 \%$ \\
\hline 253 & alquería & 0.00823 & $0.067 \%$ & $1.412 \%$ & $80.193 \%$ \\
\hline
\end{tabular}




\begin{tabular}{|c|c|c|c|c|c|}
\hline 254 & finca & 0.00817 & $0.080 \%$ & $1.695 \%$ & $80.273 \%$ \\
\hline 255 & ladera & 0.00815 & $0.107 \%$ & $2.260 \%$ & $80.380 \%$ \\
\hline 256 & cebada & 0.00809 & $0.080 \%$ & $1.695 \%$ & $80.460 \%$ \\
\hline 257 & riego & 0.00805 & $0.067 \%$ & $1.412 \%$ & $80.527 \%$ \\
\hline 258 & vegetal & 0.00804 & $0.067 \%$ & $1.412 \%$ & $80.594 \%$ \\
\hline 259 & polvo & 0.00803 & $0.080 \%$ & $1.695 \%$ & $80.674 \%$ \\
\hline 260 & parque & 0.00791 & $0.067 \%$ & $1.412 \%$ & $80.741 \%$ \\
\hline 261 & alegría & 0.00791 & $0.080 \%$ & $1.695 \%$ & $80.821 \%$ \\
\hline 262 & estrella & 0.00790 & $0.067 \%$ & $1.412 \%$ & $80.888 \%$ \\
\hline 263 & gallo & 0.00789 & $0.094 \%$ & $1.977 \%$ & $80.982 \%$ \\
\hline 264 & girasol & 0.00788 & $0.067 \%$ & $1.412 \%$ & $81.049 \%$ \\
\hline 265 & belleza & 0.00787 & $0.054 \%$ & $1.130 \%$ & $81.103 \%$ \\
\hline 266 & papelera & 0.00785 & $0.067 \%$ & $1.412 \%$ & $81.170 \%$ \\
\hline 267 & flor silvestre & 0.00782 & $0.054 \%$ & $1.130 \%$ & $81.224 \%$ \\
\hline 268 & mora & 0.00782 & $0.080 \%$ & $1.695 \%$ & $81.304 \%$ \\
\hline 269 & cortijo & 0.00774 & $0.054 \%$ & $1.130 \%$ & $81.358 \%$ \\
\hline 270 & almendra & 0.00770 & $0.094 \%$ & $1.977 \%$ & $81.452 \%$ \\
\hline 271 & alcornoque & 0.00768 & $0.067 \%$ & $1.412 \%$ & $81.519 \%$ \\
\hline 272 & tulipán & 0.00757 & $0.080 \%$ & $1.695 \%$ & $81.599 \%$ \\
\hline 273 & níspero & 0.00751 & $0.067 \%$ & $1.412 \%$ & $81.666 \%$ \\
\hline 274 & oso & 0.00750 & $0.080 \%$ & $1.695 \%$ & $81.746 \%$ \\
\hline 275 & yegua & 0.00750 & $0.067 \%$ & $1.412 \%$ & $81.813 \%$ \\
\hline 276 & pasto & 0.00747 & $0.080 \%$ & $1.695 \%$ & $81.893 \%$ \\
\hline 277 & limón & 0.00743 & $0.080 \%$ & $1.695 \%$ & $81.973 \%$ \\
\hline 278 & mala hierba & 0.00734 & $0.067 \%$ & $1.412 \%$ & $82.040 \%$ \\
\hline 279 & topo & 0.00733 & $0.094 \%$ & $1.977 \%$ & $82.134 \%$ \\
\hline 280 & salud & 0.00732 & $0.067 \%$ & $1.412 \%$ & $82.201 \%$ \\
\hline 281 & muleta & 0.00727 & $0.054 \%$ & $1.130 \%$ & $82.255 \%$ \\
\hline 282 & poca gente & 0.00726 & $0.040 \%$ & $0.847 \%$ & $82.295 \%$ \\
\hline 283 & pliegue & 0.00722 & $0.040 \%$ & $0.847 \%$ & $82.335 \%$ \\
\hline 284 & jilguero & 0.00718 & $0.067 \%$ & $1.412 \%$ & $82.402 \%$ \\
\hline 285 & golondrina & 0.00712 & $0.054 \%$ & $1.130 \%$ & $82.456 \%$ \\
\hline 286 & tigre & 0.00703 & $0.067 \%$ & $1.412 \%$ & $82.523 \%$ \\
\hline 287 & diversión & 0.00694 & $0.067 \%$ & $1.412 \%$ & $82.590 \%$ \\
\hline 288 & madriguera & 0.00692 & $0.080 \%$ & $1.695 \%$ & $82.670 \%$ \\
\hline 289 & mirlo & 0.00692 & $0.054 \%$ & $1.130 \%$ & $82.724 \%$ \\
\hline 290 & sierra & 0.00687 & $0.067 \%$ & $1.412 \%$ & $82.791 \%$ \\
\hline 291 & bar & 0.00686 & $0.067 \%$ & $1.412 \%$ & $82.858 \%$ \\
\hline 292 & excursión & 0.00680 & $0.080 \%$ & $1.695 \%$ & $82.938 \%$ \\
\hline 293 & pulga & 0.00678 & $0.094 \%$ & $1.977 \%$ & $83.032 \%$ \\
\hline 294 & hectárea & 0.00678 & $0.054 \%$ & $1.130 \%$ & $83.086 \%$ \\
\hline 295 & castaño & 0.00675 & $0.054 \%$ & $1.130 \%$ & $83.140 \%$ \\
\hline 296 & garrofero & 0.00665 & $0.054 \%$ & $1.130 \%$ & $83.194 \%$ \\
\hline 297 & calma & 0.00664 & $0.054 \%$ & $1.130 \%$ & $83.248 \%$ \\
\hline 298 & iglesia & 0.00658 & $0.054 \%$ & $1.130 \%$ & $83.302 \%$ \\
\hline 299 & arboleda & 0.00654 & $0.067 \%$ & $1.412 \%$ & $83.369 \%$ \\
\hline 300 & verja & 0.00653 & $0.054 \%$ & $1.130 \%$ & $83.423 \%$ \\
\hline
\end{tabular}




\begin{tabular}{|c|c|c|c|c|c|}
\hline 301 & vida & 0.00645 & $0.067 \%$ & $1.412 \%$ & $83.490 \%$ \\
\hline 302 & camping & 0.00642 & $0.067 \%$ & $1.412 \%$ & $83.557 \%$ \\
\hline 303 & cosechadora & 0.00640 & $0.067 \%$ & $1.412 \%$ & $83.624 \%$ \\
\hline 304 & flora & 0.00636 & $0.054 \%$ & $1.130 \%$ & $83.678 \%$ \\
\hline 305 & fauna & 0.00635 & $0.054 \%$ & $1.130 \%$ & $83.732 \%$ \\
\hline 306 & pícnic & 0.00632 & $0.067 \%$ & $1.412 \%$ & $83.799 \%$ \\
\hline 307 & ermita & 0.00627 & $0.067 \%$ & $1.412 \%$ & $83.866 \%$ \\
\hline 308 & surco & 0.00623 & $0.054 \%$ & $1.130 \%$ & $83.920 \%$ \\
\hline 309 & paisaje & 0.00617 & $0.040 \%$ & $0.847 \%$ & $83.960 \%$ \\
\hline 310 & sequía & 0.00612 & $0.054 \%$ & $1.130 \%$ & $84.014 \%$ \\
\hline 311 & fuego & 0.00607 & $0.054 \%$ & $1.130 \%$ & $84.068 \%$ \\
\hline 312 & manzanilla & 0.00607 & $0.067 \%$ & $1.412 \%$ & $84.135 \%$ \\
\hline 313 & basura & 0.00604 & $0.080 \%$ & $1.695 \%$ & $84.215 \%$ \\
\hline 314 & pista & 0.00603 & $0.054 \%$ & $1.130 \%$ & $84.269 \%$ \\
\hline 315 & arrozal & 0.00600 & $0.054 \%$ & $1.130 \%$ & $84.323 \%$ \\
\hline 316 & suelo & 0.00599 & $0.040 \%$ & $0.847 \%$ & $84.363 \%$ \\
\hline 317 & merendero & 0.00598 & $0.054 \%$ & $1.130 \%$ & $84.417 \%$ \\
\hline 318 & mula & 0.00598 & $0.067 \%$ & $1.412 \%$ & $84.484 \%$ \\
\hline 319 & plaga & 0.00598 & $0.054 \%$ & $1.130 \%$ & $84.538 \%$ \\
\hline 320 & merienda & 0.00597 & $0.054 \%$ & $1.130 \%$ & $84.592 \%$ \\
\hline 321 & trébol & 0.00593 & $0.040 \%$ & $0.847 \%$ & $84.632 \%$ \\
\hline 322 & uva & 0.00580 & $0.067 \%$ & $1.412 \%$ & $84.699 \%$ \\
\hline 323 & mula mecánica & 0.00579 & $0.040 \%$ & $0.847 \%$ & $84.739 \%$ \\
\hline 324 & niño & 0.00576 & $0.054 \%$ & $1.130 \%$ & $84.793 \%$ \\
\hline 325 & terreno & 0.00575 & $0.040 \%$ & $0.847 \%$ & $84.833 \%$ \\
\hline 326 & codorniz & 0.00574 & $0.054 \%$ & $1.130 \%$ & $84.887 \%$ \\
\hline 327 & maleza & 0.00573 & $0.054 \%$ & $1.130 \%$ & $84.941 \%$ \\
\hline 328 & excremento & 0.00567 & $0.067 \%$ & $1.412 \%$ & $85.008 \%$ \\
\hline 329 & jazmín & 0.00563 & $0.054 \%$ & $1.130 \%$ & $85.062 \%$ \\
\hline 330 & ajo & 0.00560 & $0.054 \%$ & $1.130 \%$ & $85.116 \%$ \\
\hline 331 & papel & 0.00556 & $0.054 \%$ & $1.130 \%$ & $85.170 \%$ \\
\hline 332 & poleo & 0.00555 & $0.067 \%$ & $1.412 \%$ & $85.237 \%$ \\
\hline 333 & zarza & 0.00551 & $0.067 \%$ & $1.412 \%$ & $85.304 \%$ \\
\hline 334 & champiñón & 0.00550 & $0.040 \%$ & $0.847 \%$ & $85.344 \%$ \\
\hline 335 & regador & 0.00550 & $0.040 \%$ & $0.847 \%$ & $85.384 \%$ \\
\hline 336 & viñedo & 0.00546 & $0.054 \%$ & $1.130 \%$ & $85.438 \%$ \\
\hline 337 & viento & 0.00539 & $0.054 \%$ & $1.130 \%$ & $85.492 \%$ \\
\hline 338 & carretilla & 0.00538 & $0.040 \%$ & $0.847 \%$ & $85.532 \%$ \\
\hline 339 & motosierra & 0.00538 & $0.040 \%$ & $0.847 \%$ & $85.572 \%$ \\
\hline 340 & trabajo & 0.00535 & $0.067 \%$ & $1.412 \%$ & $85.639 \%$ \\
\hline 341 & cuervo & 0.00531 & $0.054 \%$ & $1.130 \%$ & $85.693 \%$ \\
\hline 342 & polen & 0.00531 & $0.040 \%$ & $0.847 \%$ & $85.733 \%$ \\
\hline 343 & charca & 0.00531 & $0.040 \%$ & $0.847 \%$ & $85.773 \%$ \\
\hline 344 & trabajador & 0.00522 & $0.054 \%$ & $1.130 \%$ & $85.827 \%$ \\
\hline 345 & legumbre & 0.00521 & $0.054 \%$ & $1.130 \%$ & $85.881 \%$ \\
\hline 346 & urbanización & 0.00518 & $0.027 \%$ & $0.565 \%$ & $85.908 \%$ \\
\hline 347 & parque natural & 0.00517 & $0.040 \%$ & $0.847 \%$ & $85.948 \%$ \\
\hline
\end{tabular}




\begin{tabular}{|c|c|c|c|c|c|}
\hline 348 & cereal & 0.00516 & $0.040 \%$ & $0.847 \%$ & $85.988 \%$ \\
\hline 349 & marmota & 0.00516 & $0.027 \%$ & $0.565 \%$ & $86.015 \%$ \\
\hline 350 & castor & 0.00512 & $0.040 \%$ & $0.847 \%$ & $86.055 \%$ \\
\hline 351 & calor & 0.00509 & $0.040 \%$ & $0.847 \%$ & $86.095 \%$ \\
\hline 352 & ciruelo & 0.00509 & $0.040 \%$ & $0.847 \%$ & $86.135 \%$ \\
\hline 353 & melocotón & 0.00507 & $0.040 \%$ & $0.847 \%$ & $86.175 \%$ \\
\hline 354 & claridad & 0.00505 & $0.040 \%$ & $0.847 \%$ & $86.215 \%$ \\
\hline 355 & paleto & 0.00504 & $0.027 \%$ & $0.565 \%$ & $86.242 \%$ \\
\hline 356 & pincho & 0.00503 & $0.067 \%$ & $1.412 \%$ & $86.309 \%$ \\
\hline 357 & ganadero & 0.00500 & $0.040 \%$ & $0.847 \%$ & $86.349 \%$ \\
\hline 358 & fertilizante & 0.00499 & $0.040 \%$ & $0.847 \%$ & $86.389 \%$ \\
\hline 359 & estiércol & 0.00496 & $0.054 \%$ & $1.130 \%$ & $86.443 \%$ \\
\hline 360 & llano & 0.00496 & $0.040 \%$ & $0.847 \%$ & $86.483 \%$ \\
\hline 361 & casa pequeña & 0.00495 & $0.054 \%$ & $1.130 \%$ & $86.537 \%$ \\
\hline 362 & columpio & 0.00492 & $0.040 \%$ & $0.847 \%$ & $86.577 \%$ \\
\hline 363 & geranio & 0.00492 & $0.054 \%$ & $1.130 \%$ & $86.631 \%$ \\
\hline 364 & tordo & 0.00490 & $0.067 \%$ & $1.412 \%$ & $86.698 \%$ \\
\hline 365 & apero & 0.00488 & $0.027 \%$ & $0.565 \%$ & $86.725 \%$ \\
\hline 366 & abejorro & 0.00486 & $0.054 \%$ & $1.130 \%$ & $86.779 \%$ \\
\hline 367 & caña & 0.00484 & $0.054 \%$ & $1.130 \%$ & $86.833 \%$ \\
\hline 368 & raíz & 0.00483 & $0.067 \%$ & $1.412 \%$ & $86.900 \%$ \\
\hline 369 & madera & 0.00480 & $0.054 \%$ & $1.130 \%$ & $86.954 \%$ \\
\hline 370 & capazo & 0.00479 & $0.040 \%$ & $0.847 \%$ & $86.994 \%$ \\
\hline 371 & insecticida & 0.00479 & $0.067 \%$ & $1.412 \%$ & $87.061 \%$ \\
\hline 372 & camino de tierra & 0.00476 & $0.040 \%$ & $0.847 \%$ & $87.101 \%$ \\
\hline 373 & libélula & 0.00473 & $0.040 \%$ & $0.847 \%$ & $87.141 \%$ \\
\hline 374 & acantilado & 0.00470 & $0.054 \%$ & $1.130 \%$ & $87.195 \%$ \\
\hline 375 & cuerda & 0.00470 & $0.040 \%$ & $0.847 \%$ & $87.235 \%$ \\
\hline 376 & recolección & 0.00462 & $0.040 \%$ & $0.847 \%$ & $87.275 \%$ \\
\hline 377 & calabaza & 0.00458 & $0.040 \%$ & $0.847 \%$ & $87.315 \%$ \\
\hline 378 & minifundio & 0.00458 & $0.040 \%$ & $0.847 \%$ & $87.355 \%$ \\
\hline 379 & ciruela & 0.00458 & $0.054 \%$ & $1.130 \%$ & $87.409 \%$ \\
\hline 380 & albufera & 0.00458 & $0.040 \%$ & $0.847 \%$ & $87.449 \%$ \\
\hline 381 & mata & 0.00456 & $0.040 \%$ & $0.847 \%$ & $87.489 \%$ \\
\hline 382 & quemador & 0.00455 & $0.040 \%$ & $0.847 \%$ & $87.529 \%$ \\
\hline 383 & oxígeno & 0.00448 & $0.054 \%$ & $1.130 \%$ & $87.583 \%$ \\
\hline 384 & barbecho & 0.00447 & $0.027 \%$ & $0.565 \%$ & $87.610 \%$ \\
\hline 385 & frescura & 0.00446 & $0.027 \%$ & $0.565 \%$ & $87.637 \%$ \\
\hline 386 & labrar & 0.00445 & $0.040 \%$ & $0.847 \%$ & $87.677 \%$ \\
\hline 387 & turista & 0.00443 & $0.040 \%$ & $0.847 \%$ & $87.717 \%$ \\
\hline 388 & leña & 0.00440 & $0.040 \%$ & $0.847 \%$ & $87.757 \%$ \\
\hline 389 & cordero & 0.00439 & $0.040 \%$ & $0.847 \%$ & $87.797 \%$ \\
\hline 390 & armonía & 0.00435 & $0.040 \%$ & $0.847 \%$ & $87.837 \%$ \\
\hline 391 & alergia & 0.00425 & $0.040 \%$ & $0.847 \%$ & $87.877 \%$ \\
\hline 392 & paseo & 0.00424 & $0.040 \%$ & $0.847 \%$ & $87.917 \%$ \\
\hline 393 & embalse & 0.00421 & $0.040 \%$ & $0.847 \%$ & $87.957 \%$ \\
\hline 394 & melocotonero & 0.00416 & $0.054 \%$ & $1.130 \%$ & $88.011 \%$ \\
\hline
\end{tabular}




\begin{tabular}{|c|c|c|c|c|c|}
\hline 395 & falla & 0.00414 & $0.027 \%$ & $0.565 \%$ & $88.038 \%$ \\
\hline 396 & goteo & 0.00414 & $0.040 \%$ & $0.847 \%$ & $88.078 \%$ \\
\hline 397 & regadera & 0.00413 & $0.040 \%$ & $0.847 \%$ & $88.118 \%$ \\
\hline 398 & boina & 0.00411 & $0.040 \%$ & $0.847 \%$ & $88.158 \%$ \\
\hline 399 & guadaña & 0.00410 & $0.040 \%$ & $0.847 \%$ & $88.198 \%$ \\
\hline 400 & grillo & 0.00407 & $0.040 \%$ & $0.847 \%$ & $88.238 \%$ \\
\hline 401 & paraje & 0.00404 & $0.027 \%$ & $0.565 \%$ & $88.265 \%$ \\
\hline 402 & abrevadero & 0.00402 & $0.040 \%$ & $0.847 \%$ & $88.305 \%$ \\
\hline 403 & madroño & 0.00399 & $0.054 \%$ & $1.130 \%$ & $88.359 \%$ \\
\hline 404 & casa rural & 0.00399 & $0.027 \%$ & $0.565 \%$ & $88.386 \%$ \\
\hline 405 & verderón & 0.00398 & $0.040 \%$ & $0.847 \%$ & $88.426 \%$ \\
\hline 406 & búho & 0.00397 & $0.054 \%$ & $1.130 \%$ & $88.480 \%$ \\
\hline 407 & saco & 0.00395 & $0.054 \%$ & $1.130 \%$ & $88.534 \%$ \\
\hline 408 & pueblerino & 0.00393 & $0.027 \%$ & $0.565 \%$ & $88.561 \%$ \\
\hline 409 & deporte & 0.00389 & $0.054 \%$ & $1.130 \%$ & $88.615 \%$ \\
\hline 410 & playa & 0.00387 & $0.027 \%$ & $0.565 \%$ & $88.642 \%$ \\
\hline 411 & relajación & 0.00386 & $0.027 \%$ & $0.565 \%$ & $88.669 \%$ \\
\hline 412 & rábano & 0.00380 & $0.027 \%$ & $0.565 \%$ & $88.696 \%$ \\
\hline 413 & viña & 0.00379 & $0.040 \%$ & $0.847 \%$ & $88.736 \%$ \\
\hline 414 & cielo azul & 0.00378 & $0.040 \%$ & $0.847 \%$ & $88.776 \%$ \\
\hline 415 & olmo & 0.00376 & $0.040 \%$ & $0.847 \%$ & $88.816 \%$ \\
\hline 416 & nogal & 0.00376 & $0.027 \%$ & $0.565 \%$ & $88.843 \%$ \\
\hline 417 & gravilla & 0.00372 & $0.027 \%$ & $0.565 \%$ & $88.870 \%$ \\
\hline 418 & centeno & 0.00369 & $0.040 \%$ & $0.847 \%$ & $88.910 \%$ \\
\hline 419 & glaciar & 0.00367 & $0.027 \%$ & $0.565 \%$ & $88.937 \%$ \\
\hline 420 & junco & 0.00367 & $0.027 \%$ & $0.565 \%$ & $88.964 \%$ \\
\hline 421 & hortelano & 0.00367 & $0.027 \%$ & $0.565 \%$ & $88.991 \%$ \\
\hline 422 & felicidad & 0.00367 & $0.054 \%$ & $1.130 \%$ & $89.045 \%$ \\
\hline 423 & ribazo & 0.00367 & $0.027 \%$ & $0.565 \%$ & $89.072 \%$ \\
\hline 424 & calle & 0.00364 & $0.027 \%$ & $0.565 \%$ & $89.099 \%$ \\
\hline 425 & musgo & 0.00362 & $0.054 \%$ & $1.130 \%$ & $89.153 \%$ \\
\hline 426 & viejo & 0.00360 & $0.027 \%$ & $0.565 \%$ & $89.180 \%$ \\
\hline 427 & sistema de riego & 0.00360 & $0.040 \%$ & $0.847 \%$ & $89.220 \%$ \\
\hline 428 & kiwi & 0.00359 & $0.027 \%$ & $0.565 \%$ & $89.247 \%$ \\
\hline 429 & caño & 0.00359 & $0.027 \%$ & $0.565 \%$ & $89.274 \%$ \\
\hline 430 & caza & 0.00357 & $0.027 \%$ & $0.565 \%$ & $89.301 \%$ \\
\hline 431 & vid & 0.00355 & $0.040 \%$ & $0.847 \%$ & $89.341 \%$ \\
\hline 432 & aburrimiento & 0.00355 & $0.027 \%$ & $0.565 \%$ & $89.368 \%$ \\
\hline 433 & injerto & 0.00354 & $0.027 \%$ & $0.565 \%$ & $89.395 \%$ \\
\hline 434 & matxina & 0.00351 & $0.027 \%$ & $0.565 \%$ & $89.422 \%$ \\
\hline 435 & col & 0.00350 & $0.027 \%$ & $0.565 \%$ & $89.449 \%$ \\
\hline 436 & collado & 0.00350 & $0.027 \%$ & $0.565 \%$ & $89.476 \%$ \\
\hline 437 & cuba & 0.00349 & $0.040 \%$ & $0.847 \%$ & $89.516 \%$ \\
\hline 438 & haba & 0.00349 & $0.027 \%$ & $0.565 \%$ & $89.543 \%$ \\
\hline 439 & hormiguero & 0.00349 & $0.027 \%$ & $0.565 \%$ & $89.570 \%$ \\
\hline 440 & guardabosques & 0.00349 & $0.027 \%$ & $0.565 \%$ & $89.597 \%$ \\
\hline 441 & invernadero & 0.00345 & $0.027 \%$ & $0.565 \%$ & $89.624 \%$ \\
\hline
\end{tabular}




\begin{tabular}{|c|c|c|c|c|c|}
\hline 442 & robellón & 0.00345 & $0.054 \%$ & $1.130 \%$ & $89.678 \%$ \\
\hline 443 & lechuza & 0.00345 & $0.027 \%$ & $0.565 \%$ & $89.705 \%$ \\
\hline 444 & zanja & 0.00344 & $0.040 \%$ & $0.847 \%$ & $89.745 \%$ \\
\hline 445 & albaricoque & 0.00343 & $0.027 \%$ & $0.565 \%$ & $89.772 \%$ \\
\hline 446 & luna & 0.00343 & $0.027 \%$ & $0.565 \%$ & $89.799 \%$ \\
\hline 447 & pimiento & 0.00341 & $0.040 \%$ & $0.847 \%$ & $89.839 \%$ \\
\hline 448 & lirio & 0.00337 & $0.027 \%$ & $0.565 \%$ & $89.866 \%$ \\
\hline 449 & avena & 0.00335 & $0.040 \%$ & $0.847 \%$ & $89.906 \%$ \\
\hline 450 & olivar & 0.00334 & $0.027 \%$ & $0.565 \%$ & $89.933 \%$ \\
\hline 451 & incendio & 0.00333 & $0.027 \%$ & $0.565 \%$ & $89.960 \%$ \\
\hline 452 & tijeras & 0.00331 & $0.027 \%$ & $0.565 \%$ & $89.987 \%$ \\
\hline 453 & fiesta & 0.00330 & $0.040 \%$ & $0.847 \%$ & $90.027 \%$ \\
\hline 454 & rural & 0.00330 & $0.027 \%$ & $0.565 \%$ & $90.054 \%$ \\
\hline 455 & sembrar & 0.00330 & $0.027 \%$ & $0.565 \%$ & $90.081 \%$ \\
\hline 456 & carnívoro & 0.00328 & $0.027 \%$ & $0.565 \%$ & $90.108 \%$ \\
\hline 457 & campo de trigo & 0.00328 & $0.027 \%$ & $0.565 \%$ & $90.135 \%$ \\
\hline 458 & abonar & 0.00328 & $0.027 \%$ & $0.565 \%$ & $90.162 \%$ \\
\hline 459 & enfermedad & 0.00328 & $0.027 \%$ & $0.565 \%$ & $90.189 \%$ \\
\hline 460 & color & 0.00324 & $0.040 \%$ & $0.847 \%$ & $90.229 \%$ \\
\hline 461 & espantapájaros & 0.00318 & $0.027 \%$ & $0.565 \%$ & $90.256 \%$ \\
\hline 462 & suciedad & 0.00317 & $0.040 \%$ & $0.847 \%$ & $90.296 \%$ \\
\hline 463 & mofeta & 0.00317 & $0.027 \%$ & $0.565 \%$ & $90.323 \%$ \\
\hline 464 & herbicida & 0.00316 & $0.027 \%$ & $0.565 \%$ & $90.350 \%$ \\
\hline 465 & sauce llorón & 0.00314 & $0.027 \%$ & $0.565 \%$ & $90.377 \%$ \\
\hline 466 & chabola & 0.00310 & $0.027 \%$ & $0.565 \%$ & $90.404 \%$ \\
\hline 467 & marialluïsa & 0.00306 & $0.027 \%$ & $0.565 \%$ & $90.431 \%$ \\
\hline 468 & cardo & 0.00306 & $0.027 \%$ & $0.565 \%$ & $90.458 \%$ \\
\hline 469 & espliego & 0.00304 & $0.027 \%$ & $0.565 \%$ & $90.485 \%$ \\
\hline 470 & helecho & 0.00301 & $0.040 \%$ & $0.847 \%$ & $90.525 \%$ \\
\hline 471 & torrente & 0.00300 & $0.027 \%$ & $0.565 \%$ & $90.552 \%$ \\
\hline 472 & ácaro & 0.00299 & $0.027 \%$ & $0.565 \%$ & $90.579 \%$ \\
\hline 473 & hinojo & 0.00298 & $0.027 \%$ & $0.565 \%$ & $90.606 \%$ \\
\hline 474 & sombra & 0.00298 & $0.040 \%$ & $0.847 \%$ & $90.646 \%$ \\
\hline 475 & perera & 0.00295 & $0.027 \%$ & $0.565 \%$ & $90.673 \%$ \\
\hline 476 & relax & 0.00292 & $0.027 \%$ & $0.565 \%$ & $90.700 \%$ \\
\hline 477 & mansión & 0.00292 & $0.027 \%$ & $0.565 \%$ & $90.727 \%$ \\
\hline 478 & ruina & 0.00292 & $0.027 \%$ & $0.565 \%$ & $90.754 \%$ \\
\hline 479 & campanilla & 0.00291 & $0.027 \%$ & $0.565 \%$ & $90.781 \%$ \\
\hline 480 & sembrado & 0.00291 & $0.027 \%$ & $0.565 \%$ & $90.808 \%$ \\
\hline 481 & fuente natural & 0.00288 & $0.027 \%$ & $0.565 \%$ & $90.835 \%$ \\
\hline 482 & buen olor & 0.00288 & $0.027 \%$ & $0.565 \%$ & $90.862 \%$ \\
\hline 483 & remolacha & 0.00288 & $0.027 \%$ & $0.565 \%$ & $90.889 \%$ \\
\hline 484 & arar & 0.00286 & $0.027 \%$ & $0.565 \%$ & $90.916 \%$ \\
\hline 485 & plaza & 0.00285 & $0.027 \%$ & $0.565 \%$ & $90.943 \%$ \\
\hline 486 & urraca & 0.00283 & $0.040 \%$ & $0.847 \%$ & $90.983 \%$ \\
\hline 487 & vejez & 0.00283 & $0.027 \%$ & $0.565 \%$ & $91.010 \%$ \\
\hline 488 & campo de fútbol & 0.00282 & $0.013 \%$ & $0.282 \%$ & $91.023 \%$ \\
\hline
\end{tabular}




\begin{tabular}{|c|c|c|c|c|c|}
\hline 489 & alacrán & 0.00282 & $0.013 \%$ & $0.282 \%$ & $91.036 \%$ \\
\hline 490 & mandarina & 0.00282 & $0.013 \%$ & $0.282 \%$ & $91.049 \%$ \\
\hline 491 & hanegada de tierra & 0.00282 & $0.013 \%$ & $0.282 \%$ & $91.062 \%$ \\
\hline 492 & cajón & 0.00281 & $0.040 \%$ & $0.847 \%$ & $91.102 \%$ \\
\hline 493 & fumigador & 0.00281 & $0.027 \%$ & $0.565 \%$ & $91.129 \%$ \\
\hline 494 & lagarto & 0.00276 & $0.040 \%$ & $0.847 \%$ & $91.169 \%$ \\
\hline 495 & algarroba & 0.00274 & $0.027 \%$ & $0.565 \%$ & $91.196 \%$ \\
\hline 496 & refugio & 0.00271 & $0.027 \%$ & $0.565 \%$ & $91.223 \%$ \\
\hline 497 & casa vieja & 0.00271 & $0.027 \%$ & $0.565 \%$ & $91.250 \%$ \\
\hline 498 & canal & 0.00271 & $0.027 \%$ & $0.565 \%$ & $91.277 \%$ \\
\hline 499 & montículo & 0.00269 & $0.027 \%$ & $0.565 \%$ & $91.304 \%$ \\
\hline 500 & zarzal & 0.00269 & $0.027 \%$ & $0.565 \%$ & $91.331 \%$ \\
\hline 501 & renacuajo & 0.00269 & $0.040 \%$ & $0.847 \%$ & $91.371 \%$ \\
\hline 502 & cultivador & 0.00266 & $0.013 \%$ & $0.282 \%$ & $91.384 \%$ \\
\hline 503 & lligona & 0.00266 & $0.013 \%$ & $0.282 \%$ & $91.397 \%$ \\
\hline 504 & cisne & 0.00266 & $0.013 \%$ & $0.282 \%$ & $91.410 \%$ \\
\hline 505 & pescador & 0.00266 & $0.040 \%$ & $0.847 \%$ & $91.450 \%$ \\
\hline 506 & dormir & 0.00266 & $0.013 \%$ & $0.282 \%$ & $91.463 \%$ \\
\hline 507 & secano & 0.00266 & $0.027 \%$ & $0.565 \%$ & $91.490 \%$ \\
\hline 508 & grúa & 0.00266 & $0.013 \%$ & $0.282 \%$ & $91.503 \%$ \\
\hline 509 & amor & 0.00266 & $0.013 \%$ & $0.282 \%$ & $91.516 \%$ \\
\hline 510 & moto de montaña & 0.00266 & $0.013 \%$ & $0.282 \%$ & $91.529 \%$ \\
\hline 511 & Satsuma & 0.00266 & $0.013 \%$ & $0.282 \%$ & $91.542 \%$ \\
\hline 512 & petirrojo & 0.00266 & $0.013 \%$ & $0.282 \%$ & $91.555 \%$ \\
\hline 513 & monotonía & 0.00266 & $0.013 \%$ & $0.282 \%$ & $91.568 \%$ \\
\hline 514 & motor de agua & 0.00266 & $0.013 \%$ & $0.282 \%$ & $91.581 \%$ \\
\hline 515 & castaña & 0.00265 & $0.027 \%$ & $0.565 \%$ & $91.608 \%$ \\
\hline 516 & tanque & 0.00258 & $0.027 \%$ & $0.565 \%$ & $91.635 \%$ \\
\hline 517 & frío & 0.00258 & $0.027 \%$ & $0.565 \%$ & $91.662 \%$ \\
\hline 518 & gacela & 0.00257 & $0.027 \%$ & $0.565 \%$ & $91.689 \%$ \\
\hline 519 & limpio & 0.00255 & $0.027 \%$ & $0.565 \%$ & $91.716 \%$ \\
\hline 520 & noria & 0.00255 & $0.027 \%$ & $0.565 \%$ & $91.743 \%$ \\
\hline 521 & cactus & 0.00253 & $0.027 \%$ & $0.565 \%$ & $91.770 \%$ \\
\hline 522 & motocultor & 0.00250 & $0.013 \%$ & $0.282 \%$ & $91.783 \%$ \\
\hline 523 & cubo & 0.00250 & $0.013 \%$ & $0.282 \%$ & $91.796 \%$ \\
\hline 524 & turba & 0.00250 & $0.013 \%$ & $0.282 \%$ & $91.809 \%$ \\
\hline 525 & señal & 0.00250 & $0.013 \%$ & $0.282 \%$ & $91.822 \%$ \\
\hline 526 & árbol de naranjas & 0.00250 & $0.013 \%$ & $0.282 \%$ & $91.835 \%$ \\
\hline 527 & fútbol & 0.00250 & $0.013 \%$ & $0.282 \%$ & $91.848 \%$ \\
\hline 528 & motorista & 0.00250 & $0.013 \%$ & $0.282 \%$ & $91.861 \%$ \\
\hline 529 & Navelate & 0.00250 & $0.013 \%$ & $0.282 \%$ & $91.874 \%$ \\
\hline 530 & aroma & 0.00250 & $0.013 \%$ & $0.282 \%$ & $91.887 \%$ \\
\hline 531 & ave de rapiña & 0.00250 & $0.013 \%$ & $0.282 \%$ & $91.900 \%$ \\
\hline 532 & verdor & 0.00250 & $0.013 \%$ & $0.282 \%$ & $91.913 \%$ \\
\hline 533 & tradición & 0.00250 & $0.013 \%$ & $0.282 \%$ & $91.926 \%$ \\
\hline 534 & alimento & 0.00250 & $0.013 \%$ & $0.282 \%$ & $91.939 \%$ \\
\hline 535 & aceitunero & 0.00250 & $0.013 \%$ & $0.282 \%$ & $91.952 \%$ \\
\hline
\end{tabular}




\begin{tabular}{|c|c|c|c|c|c|}
\hline 536 & catarata & 0.00249 & $0.027 \%$ & $0.565 \%$ & $91.979 \%$ \\
\hline 537 & escorpión & 0.00248 & $0.040 \%$ & $0.847 \%$ & $92.019 \%$ \\
\hline 538 & corral & 0.00247 & $0.040 \%$ & $0.847 \%$ & $92.059 \%$ \\
\hline 539 & comadreja & 0.00246 & $0.027 \%$ & $0.565 \%$ & $92.086 \%$ \\
\hline 540 & hongo & 0.00244 & $0.040 \%$ & $0.847 \%$ & $92.126 \%$ \\
\hline 541 & lila & 0.00244 & $0.027 \%$ & $0.565 \%$ & $92.153 \%$ \\
\hline 542 & cumbre & 0.00244 & $0.027 \%$ & $0.565 \%$ & $92.180 \%$ \\
\hline 543 & dehesa & 0.00243 & $0.027 \%$ & $0.565 \%$ & $92.207 \%$ \\
\hline 544 & presa & 0.00242 & $0.027 \%$ & $0.565 \%$ & $92.234 \%$ \\
\hline 545 & pinzón & 0.00242 & $0.027 \%$ & $0.565 \%$ & $92.261 \%$ \\
\hline 546 & higo & 0.00240 & $0.027 \%$ & $0.565 \%$ & $92.288 \%$ \\
\hline 547 & café & 0.00238 & $0.040 \%$ & $0.847 \%$ & $92.328 \%$ \\
\hline 548 & verdecillo & 0.00238 & $0.027 \%$ & $0.565 \%$ & $92.355 \%$ \\
\hline 549 & cielo limpio & 0.00236 & $0.013 \%$ & $0.282 \%$ & $92.368 \%$ \\
\hline 550 & árbol de limones & 0.00236 & $0.013 \%$ & $0.282 \%$ & $92.381 \%$ \\
\hline 551 & dóberman & 0.00236 & $0.013 \%$ & $0.282 \%$ & $92.394 \%$ \\
\hline 552 & olivero & 0.00236 & $0.013 \%$ & $0.282 \%$ & $92.407 \%$ \\
\hline 553 & chimenea & 0.00236 & $0.013 \%$ & $0.282 \%$ & $92.420 \%$ \\
\hline 554 & murciélago & 0.00236 & $0.013 \%$ & $0.282 \%$ & $92.433 \%$ \\
\hline 555 & tenis & 0.00236 & $0.013 \%$ & $0.282 \%$ & $92.446 \%$ \\
\hline 556 & cuco & 0.00236 & $0.013 \%$ & $0.282 \%$ & $92.459 \%$ \\
\hline 557 & terraza & 0.00236 & $0.013 \%$ & $0.282 \%$ & $92.472 \%$ \\
\hline 558 & pulgón & 0.00236 & $0.013 \%$ & $0.282 \%$ & $92.485 \%$ \\
\hline 559 & acampar & 0.00236 & $0.013 \%$ & $0.282 \%$ & $92.498 \%$ \\
\hline 560 & granja de animales & 0.00236 & $0.013 \%$ & $0.282 \%$ & $92.511 \%$ \\
\hline 561 & cosas pequeñas & 0.00236 & $0.013 \%$ & $0.282 \%$ & $92.524 \%$ \\
\hline 562 & caballón & 0.00236 & $0.013 \%$ & $0.282 \%$ & $92.537 \%$ \\
\hline 563 & peñasco & 0.00235 & $0.027 \%$ & $0.565 \%$ & $92.564 \%$ \\
\hline 564 & macho & 0.00232 & $0.027 \%$ & $0.565 \%$ & $92.591 \%$ \\
\hline 565 & cebra & 0.00226 & $0.027 \%$ & $0.565 \%$ & $92.618 \%$ \\
\hline 566 & lavadero & 0.00226 & $0.027 \%$ & $0.565 \%$ & $92.645 \%$ \\
\hline 567 & trampa & 0.00224 & $0.027 \%$ & $0.565 \%$ & $92.672 \%$ \\
\hline 568 & verano & 0.00224 & $0.027 \%$ & $0.565 \%$ & $92.699 \%$ \\
\hline 569 & trucha & 0.00224 & $0.027 \%$ & $0.565 \%$ & $92.726 \%$ \\
\hline 570 & selva & 0.00222 & $0.013 \%$ & $0.282 \%$ & $92.739 \%$ \\
\hline 571 & máquina & 0.00222 & $0.013 \%$ & $0.282 \%$ & $92.752 \%$ \\
\hline 572 & zona agropecuaria & 0.00222 & $0.013 \%$ & $0.282 \%$ & $92.765 \%$ \\
\hline 573 & pala elevadora & 0.00222 & $0.013 \%$ & $0.282 \%$ & $92.778 \%$ \\
\hline 574 & esparraguera & 0.00222 & $0.013 \%$ & $0.282 \%$ & $92.791 \%$ \\
\hline 575 & luminosidad & 0.00222 & $0.013 \%$ & $0.282 \%$ & $92.804 \%$ \\
\hline 576 & pastor alemán & 0.00222 & $0.013 \%$ & $0.282 \%$ & $92.817 \%$ \\
\hline 577 & argelaga & 0.00222 & $0.013 \%$ & $0.282 \%$ & $92.830 \%$ \\
\hline 578 & lavanda & 0.00222 & $0.013 \%$ & $0.282 \%$ & $92.843 \%$ \\
\hline 579 & aspersión & 0.00222 & $0.013 \%$ & $0.282 \%$ & $92.856 \%$ \\
\hline 580 & búfalo & 0.00222 & $0.013 \%$ & $0.282 \%$ & $92.869 \%$ \\
\hline 581 & aljibe & 0.00222 & $0.013 \%$ & $0.282 \%$ & $92.882 \%$ \\
\hline 582 & almacén & 0.00222 & $0.013 \%$ & $0.282 \%$ & $92.895 \%$ \\
\hline
\end{tabular}




\begin{tabular}{|c|c|c|c|c|c|}
\hline 583 & reja & 0.00222 & $0.013 \%$ & $0.282 \%$ & $92.908 \%$ \\
\hline 584 & serrucho & 0.00222 & $0.013 \%$ & $0.282 \%$ & $92.921 \%$ \\
\hline 585 & insolación & 0.00222 & $0.013 \%$ & $0.282 \%$ & $92.934 \%$ \\
\hline 586 & hilera de árboles & 0.00222 & $0.013 \%$ & $0.282 \%$ & $92.947 \%$ \\
\hline 587 & pienso & 0.00221 & $0.027 \%$ & $0.565 \%$ & $92.974 \%$ \\
\hline 588 & acampada & 0.00221 & $0.027 \%$ & $0.565 \%$ & $93.001 \%$ \\
\hline 589 & cima & 0.00220 & $0.040 \%$ & $0.847 \%$ & $93.041 \%$ \\
\hline 590 & perro pastor & 0.00220 & $0.027 \%$ & $0.565 \%$ & $93.068 \%$ \\
\hline 591 & colmena & 0.00216 & $0.027 \%$ & $0.565 \%$ & $93.095 \%$ \\
\hline 592 & pepino & 0.00216 & $0.027 \%$ & $0.565 \%$ & $93.122 \%$ \\
\hline 593 & guarda forestal & 0.00215 & $0.027 \%$ & $0.565 \%$ & $93.149 \%$ \\
\hline 594 & sosiego & 0.00213 & $0.027 \%$ & $0.565 \%$ & $93.176 \%$ \\
\hline 595 & maquinaria & 0.00211 & $0.027 \%$ & $0.565 \%$ & $93.203 \%$ \\
\hline 596 & escuela & 0.00211 & $0.027 \%$ & $0.565 \%$ & $93.230 \%$ \\
\hline 597 & picadero & 0.00211 & $0.027 \%$ & $0.565 \%$ & $93.257 \%$ \\
\hline 598 & cordillera & 0.00209 & $0.027 \%$ & $0.565 \%$ & $93.284 \%$ \\
\hline 599 & motocarro & 0.00209 & $0.013 \%$ & $0.282 \%$ & $93.297 \%$ \\
\hline 600 & porquera & 0.00209 & $0.013 \%$ & $0.282 \%$ & $93.310 \%$ \\
\hline 601 & cedro & 0.00209 & $0.013 \%$ & $0.282 \%$ & $93.323 \%$ \\
\hline 602 & medicina & 0.00209 & $0.013 \%$ & $0.282 \%$ & $93.336 \%$ \\
\hline 603 & ovni & 0.00209 & $0.013 \%$ & $0.282 \%$ & $93.349 \%$ \\
\hline 604 & puerro & 0.00209 & $0.013 \%$ & $0.282 \%$ & $93.362 \%$ \\
\hline 605 & tejón & 0.00209 & $0.013 \%$ & $0.282 \%$ & $93.375 \%$ \\
\hline 606 & cocotero & 0.00209 & $0.013 \%$ & $0.282 \%$ & $93.388 \%$ \\
\hline 607 & ternero & 0.00209 & $0.013 \%$ & $0.282 \%$ & $93.401 \%$ \\
\hline 608 & cauce & 0.00209 & $0.013 \%$ & $0.282 \%$ & $93.414 \%$ \\
\hline 609 & tanque de pulverizar & 0.00209 & $0.013 \%$ & $0.282 \%$ & $93.427 \%$ \\
\hline 610 & hierba mala & 0.00209 & $0.013 \%$ & $0.282 \%$ & $93.440 \%$ \\
\hline 611 & oxígeno puro & 0.00209 & $0.013 \%$ & $0.282 \%$ & $93.453 \%$ \\
\hline 612 & alcor & 0.00209 & $0.013 \%$ & $0.282 \%$ & $93.466 \%$ \\
\hline 613 & almendral & 0.00209 & $0.013 \%$ & $0.282 \%$ & $93.479 \%$ \\
\hline 614 & desierto de Las Palmas & 0.00209 & $0.013 \%$ & $0.282 \%$ & $93.492 \%$ \\
\hline 615 & lejanía & 0.00209 & $0.013 \%$ & $0.282 \%$ & $93.505 \%$ \\
\hline 616 & pueblo pequeño & 0.00209 & $0.013 \%$ & $0.282 \%$ & $93.518 \%$ \\
\hline 617 & glorieta & 0.00209 & $0.013 \%$ & $0.282 \%$ & $93.531 \%$ \\
\hline 618 & peligro & 0.00209 & $0.013 \%$ & $0.282 \%$ & $93.544 \%$ \\
\hline 619 & cerca & 0.00208 & $0.027 \%$ & $0.565 \%$ & $93.571 \%$ \\
\hline 620 & caparra & 0.00205 & $0.027 \%$ & $0.565 \%$ & $93.598 \%$ \\
\hline 621 & cítrico & 0.00205 & $0.027 \%$ & $0.565 \%$ & $93.625 \%$ \\
\hline 622 & cervatillo & 0.00203 & $0.027 \%$ & $0.565 \%$ & $93.652 \%$ \\
\hline 623 & bebedero & 0.00202 & $0.027 \%$ & $0.565 \%$ & $93.679 \%$ \\
\hline 624 & bienestar & 0.00199 & $0.027 \%$ & $0.565 \%$ & $93.706 \%$ \\
\hline 625 & pajar & 0.00199 & $0.027 \%$ & $0.565 \%$ & $93.733 \%$ \\
\hline 626 & mimosa & 0.00197 & $0.027 \%$ & $0.565 \%$ & $93.760 \%$ \\
\hline 627 & cesto & 0.00197 & $0.027 \%$ & $0.565 \%$ & $93.787 \%$ \\
\hline 628 & castillo & 0.00196 & $0.013 \%$ & $0.282 \%$ & $93.800 \%$ \\
\hline 629 & piedra rocosa & 0.00196 & $0.013 \%$ & $0.282 \%$ & $93.813 \%$ \\
\hline
\end{tabular}




\begin{tabular}{|c|c|c|c|c|c|}
\hline 630 & mapa & 0.00196 & $0.013 \%$ & $0.282 \%$ & $93.826 \%$ \\
\hline 631 & desintoxicación & 0.00196 & $0.013 \%$ & $0.282 \%$ & $93.839 \%$ \\
\hline 632 & picadora de ramas & 0.00196 & $0.013 \%$ & $0.282 \%$ & $93.852 \%$ \\
\hline 633 & aguacate & 0.00196 & $0.013 \%$ & $0.282 \%$ & $93.865 \%$ \\
\hline 634 & aguilucho & 0.00196 & $0.013 \%$ & $0.282 \%$ & $93.878 \%$ \\
\hline 635 & productor & 0.00196 & $0.013 \%$ & $0.282 \%$ & $93.891 \%$ \\
\hline 636 & moscarda & 0.00196 & $0.013 \%$ & $0.282 \%$ & $93.904 \%$ \\
\hline 637 & sudor & 0.00196 & $0.027 \%$ & $0.565 \%$ & $93.931 \%$ \\
\hline 638 & oso hormiguero & 0.00196 & $0.013 \%$ & $0.282 \%$ & $93.944 \%$ \\
\hline 639 & acelga & 0.00196 & $0.013 \%$ & $0.282 \%$ & $93.957 \%$ \\
\hline 640 & aliaga & 0.00196 & $0.013 \%$ & $0.282 \%$ & $93.970 \%$ \\
\hline 641 & regado & 0.00196 & $0.013 \%$ & $0.282 \%$ & $93.983 \%$ \\
\hline 642 & azud & 0.00196 & $0.013 \%$ & $0.282 \%$ & $93.996 \%$ \\
\hline 643 & sifón & 0.00196 & $0.013 \%$ & $0.282 \%$ & $94.009 \%$ \\
\hline 644 & canario & 0.00196 & $0.013 \%$ & $0.282 \%$ & $94.022 \%$ \\
\hline 645 & senderismo & 0.00196 & $0.013 \%$ & $0.282 \%$ & $94.035 \%$ \\
\hline 646 & vivero & 0.00196 & $0.013 \%$ & $0.282 \%$ & $94.048 \%$ \\
\hline 647 & plantar & 0.00196 & $0.013 \%$ & $0.282 \%$ & $94.061 \%$ \\
\hline 648 & inseguridad & 0.00196 & $0.013 \%$ & $0.282 \%$ & $94.074 \%$ \\
\hline 649 & mina & 0.00193 & $0.027 \%$ & $0.565 \%$ & $94.101 \%$ \\
\hline 650 & ruido & 0.00191 & $0.027 \%$ & $0.565 \%$ & $94.128 \%$ \\
\hline 651 & mono & 0.00190 & $0.027 \%$ & $0.565 \%$ & $94.155 \%$ \\
\hline 652 & pedrusco & 0.00190 & $0.027 \%$ & $0.565 \%$ & $94.182 \%$ \\
\hline 653 & azadón & 0.00190 & $0.027 \%$ & $0.565 \%$ & $94.209 \%$ \\
\hline 654 & herramienta & 0.00189 & $0.027 \%$ & $0.565 \%$ & $94.236 \%$ \\
\hline 655 & abuelo & 0.00189 & $0.027 \%$ & $0.565 \%$ & $94.263 \%$ \\
\hline 656 & ciempiés & 0.00187 & $0.027 \%$ & $0.565 \%$ & $94.290 \%$ \\
\hline 657 & fortificación & 0.00185 & $0.013 \%$ & $0.282 \%$ & $94.303 \%$ \\
\hline 658 & pavo & 0.00185 & $0.013 \%$ & $0.282 \%$ & $94.316 \%$ \\
\hline 659 & cigüeña & 0.00185 & $0.013 \%$ & $0.282 \%$ & $94.329 \%$ \\
\hline 660 & vitalidad & 0.00185 & $0.013 \%$ & $0.282 \%$ & $94.342 \%$ \\
\hline 661 & cadernera & 0.00185 & $0.013 \%$ & $0.282 \%$ & $94.355 \%$ \\
\hline 662 & camisa de cuadros & 0.00185 & $0.013 \%$ & $0.282 \%$ & $94.368 \%$ \\
\hline 663 & armadillo & 0.00185 & $0.013 \%$ & $0.282 \%$ & $94.381 \%$ \\
\hline 664 & mierda & 0.00185 & $0.013 \%$ & $0.282 \%$ & $94.394 \%$ \\
\hline 665 & ruta & 0.00185 & $0.027 \%$ & $0.565 \%$ & $94.421 \%$ \\
\hline 666 & cabrero & 0.00185 & $0.013 \%$ & $0.282 \%$ & $94.434 \%$ \\
\hline 667 & tridente & 0.00185 & $0.013 \%$ & $0.282 \%$ & $94.447 \%$ \\
\hline 668 & riada & 0.00185 & $0.013 \%$ & $0.282 \%$ & $94.460 \%$ \\
\hline 669 & frescor & 0.00185 & $0.013 \%$ & $0.282 \%$ & $94.473 \%$ \\
\hline 670 & hombre & 0.00185 & $0.013 \%$ & $0.282 \%$ & $94.486 \%$ \\
\hline 671 & puente de piedra & 0.00185 & $0.013 \%$ & $0.282 \%$ & $94.499 \%$ \\
\hline 672 & frutero & 0.00185 & $0.013 \%$ & $0.282 \%$ & $94.512 \%$ \\
\hline 673 & flor cultivada & 0.00185 & $0.013 \%$ & $0.282 \%$ & $94.525 \%$ \\
\hline 674 & supervivencia & 0.00185 & $0.013 \%$ & $0.282 \%$ & $94.538 \%$ \\
\hline 675 & cielo claro & 0.00185 & $0.013 \%$ & $0.282 \%$ & $94.551 \%$ \\
\hline 676 & orquídea & 0.00185 & $0.013 \%$ & $0.282 \%$ & $94.564 \%$ \\
\hline
\end{tabular}




\begin{tabular}{|c|c|c|c|c|c|}
\hline 677 & naranjal & 0.00185 & $0.013 \%$ & $0.282 \%$ & $94.577 \%$ \\
\hline 678 & casa de herramientas & 0.00185 & $0.013 \%$ & $0.282 \%$ & $94.590 \%$ \\
\hline 679 & judía & 0.00180 & $0.027 \%$ & $0.565 \%$ & $94.617 \%$ \\
\hline 680 & crisantemo & 0.00179 & $0.027 \%$ & $0.565 \%$ & $94.644 \%$ \\
\hline 681 & cenia & 0.00179 & $0.027 \%$ & $0.565 \%$ & $94.671 \%$ \\
\hline 682 & hierbabuena & 0.00177 & $0.027 \%$ & $0.565 \%$ & $94.698 \%$ \\
\hline 683 & laurel & 0.00176 & $0.040 \%$ & $0.847 \%$ & $94.738 \%$ \\
\hline 684 & muralla & 0.00174 & $0.013 \%$ & $0.282 \%$ & $94.751 \%$ \\
\hline 685 & tranquilo & 0.00174 & $0.013 \%$ & $0.282 \%$ & $94.764 \%$ \\
\hline 686 & plátano & 0.00174 & $0.013 \%$ & $0.282 \%$ & $94.777 \%$ \\
\hline 687 & arrocero & 0.00174 & $0.013 \%$ & $0.282 \%$ & $94.790 \%$ \\
\hline 688 & loro & 0.00174 & $0.013 \%$ & $0.282 \%$ & $94.803 \%$ \\
\hline 689 & segador & 0.00174 & $0.013 \%$ & $0.282 \%$ & $94.816 \%$ \\
\hline 690 & segar & 0.00174 & $0.013 \%$ & $0.282 \%$ & $94.829 \%$ \\
\hline 691 & fumigar & 0.00174 & $0.013 \%$ & $0.282 \%$ & $94.842 \%$ \\
\hline 692 & rastrojo & 0.00174 & $0.013 \%$ & $0.282 \%$ & $94.855 \%$ \\
\hline 693 & carretón & 0.00174 & $0.013 \%$ & $0.282 \%$ & $94.868 \%$ \\
\hline 694 & banco & 0.00174 & $0.013 \%$ & $0.282 \%$ & $94.881 \%$ \\
\hline 695 & camomila & 0.00174 & $0.013 \%$ & $0.282 \%$ & $94.894 \%$ \\
\hline 696 & yermo & 0.00174 & $0.013 \%$ & $0.282 \%$ & $94.907 \%$ \\
\hline 697 & vaquero & 0.00174 & $0.013 \%$ & $0.282 \%$ & $94.920 \%$ \\
\hline 698 & pino blanco & 0.00174 & $0.013 \%$ & $0.282 \%$ & $94.933 \%$ \\
\hline 699 & agua limpia & 0.00174 & $0.013 \%$ & $0.282 \%$ & $94.946 \%$ \\
\hline 700 & carxofa & 0.00174 & $0.013 \%$ & $0.282 \%$ & $94.959 \%$ \\
\hline 701 & sin contaminación & 0.00174 & $0.013 \%$ & $0.282 \%$ & $94.972 \%$ \\
\hline 702 & casa de montaña & 0.00174 & $0.013 \%$ & $0.282 \%$ & $94.985 \%$ \\
\hline 703 & vidrio & 0.00174 & $0.013 \%$ & $0.282 \%$ & $94.998 \%$ \\
\hline 704 & extensión & 0.00174 & $0.013 \%$ & $0.282 \%$ & $95.011 \%$ \\
\hline 705 & tanque de agua & 0.00174 & $0.013 \%$ & $0.282 \%$ & $95.024 \%$ \\
\hline 706 & sencillez & 0.00174 & $0.013 \%$ & $0.282 \%$ & $95.037 \%$ \\
\hline 707 & restaurante & 0.00174 & $0.013 \%$ & $0.282 \%$ & $95.050 \%$ \\
\hline 708 & perejil & 0.00171 & $0.040 \%$ & $0.847 \%$ & $95.090 \%$ \\
\hline 709 & campo de cultivo & 0.00169 & $0.027 \%$ & $0.565 \%$ & $95.117 \%$ \\
\hline 710 & cuesta & 0.00168 & $0.027 \%$ & $0.565 \%$ & $95.144 \%$ \\
\hline 711 & avestruz & 0.00167 & $0.027 \%$ & $0.565 \%$ & $95.171 \%$ \\
\hline 712 & albergue & 0.00167 & $0.027 \%$ & $0.565 \%$ & $95.198 \%$ \\
\hline 713 & carnero & 0.00166 & $0.027 \%$ & $0.565 \%$ & $95.225 \%$ \\
\hline 714 & fruto silvestre & 0.00165 & $0.027 \%$ & $0.565 \%$ & $95.252 \%$ \\
\hline 715 & descampado & 0.00164 & $0.013 \%$ & $0.282 \%$ & $95.265 \%$ \\
\hline 716 & martillo & 0.00164 & $0.027 \%$ & $0.565 \%$ & $95.292 \%$ \\
\hline 717 & picapinos & 0.00164 & $0.013 \%$ & $0.282 \%$ & $95.305 \%$ \\
\hline 718 & herbívoro & 0.00164 & $0.013 \%$ & $0.282 \%$ & $95.318 \%$ \\
\hline 719 & atomizador & 0.00164 & $0.013 \%$ & $0.282 \%$ & $95.331 \%$ \\
\hline 720 & berenjenal & 0.00164 & $0.013 \%$ & $0.282 \%$ & $95.344 \%$ \\
\hline 721 & paloma & 0.00164 & $0.013 \%$ & $0.282 \%$ & $95.357 \%$ \\
\hline 722 & pino negro & 0.00164 & $0.013 \%$ & $0.282 \%$ & $95.370 \%$ \\
\hline 723 & alcatraz & 0.00164 & $0.013 \%$ & $0.282 \%$ & $95.383 \%$ \\
\hline
\end{tabular}




\begin{tabular}{|c|c|c|c|c|c|}
\hline 724 & terrateniente & 0.00164 & $0.013 \%$ & $0.282 \%$ & $95.396 \%$ \\
\hline 725 & diente de león & 0.00164 & $0.013 \%$ & $0.282 \%$ & $95.409 \%$ \\
\hline 726 & recolectar & 0.00164 & $0.027 \%$ & $0.565 \%$ & $95.436 \%$ \\
\hline 727 & fava & 0.00164 & $0.013 \%$ & $0.282 \%$ & $95.449 \%$ \\
\hline 728 & tenazas & 0.00164 & $0.013 \%$ & $0.282 \%$ & $95.462 \%$ \\
\hline 729 & broza & 0.00164 & $0.013 \%$ & $0.282 \%$ & $95.475 \%$ \\
\hline 730 & pastor de ovejas & 0.00164 & $0.013 \%$ & $0.282 \%$ & $95.488 \%$ \\
\hline 731 & microbio & 0.00164 & $0.013 \%$ & $0.282 \%$ & $95.501 \%$ \\
\hline 732 & pichón & 0.00164 & $0.013 \%$ & $0.282 \%$ & $95.514 \%$ \\
\hline 733 & quietud & 0.00164 & $0.013 \%$ & $0.282 \%$ & $95.527 \%$ \\
\hline 734 & no ruidos & 0.00164 & $0.013 \%$ & $0.282 \%$ & $95.540 \%$ \\
\hline 735 & fumigadora & 0.00164 & $0.013 \%$ & $0.282 \%$ & $95.553 \%$ \\
\hline 736 & caléndula & 0.00164 & $0.013 \%$ & $0.282 \%$ & $95.566 \%$ \\
\hline 737 & garrapata & 0.00162 & $0.027 \%$ & $0.565 \%$ & $95.593 \%$ \\
\hline 738 & contaminación & 0.00157 & $0.027 \%$ & $0.565 \%$ & $95.620 \%$ \\
\hline 739 & tractor agrícola & 0.00154 & $0.013 \%$ & $0.282 \%$ & $95.633 \%$ \\
\hline 740 & haya & 0.00154 & $0.013 \%$ & $0.282 \%$ & $95.646 \%$ \\
\hline 741 & mierda de animal & 0.00154 & $0.013 \%$ & $0.282 \%$ & $95.659 \%$ \\
\hline 742 & caja & 0.00154 & $0.013 \%$ & $0.282 \%$ & $95.672 \%$ \\
\hline 743 & tórtola & 0.00154 & $0.013 \%$ & $0.282 \%$ & $95.685 \%$ \\
\hline 744 & anciano & 0.00154 & $0.013 \%$ & $0.282 \%$ & $95.698 \%$ \\
\hline 745 & natural & 0.00154 & $0.027 \%$ & $0.565 \%$ & $95.725 \%$ \\
\hline 746 & propietario & 0.00154 & $0.013 \%$ & $0.282 \%$ & $95.738 \%$ \\
\hline 747 & colorín & 0.00154 & $0.013 \%$ & $0.282 \%$ & $95.751 \%$ \\
\hline 748 & comida natural & 0.00154 & $0.013 \%$ & $0.282 \%$ & $95.764 \%$ \\
\hline 749 & infección & 0.00154 & $0.013 \%$ & $0.282 \%$ & $95.777 \%$ \\
\hline 750 & reptil & 0.00154 & $0.013 \%$ & $0.282 \%$ & $95.790 \%$ \\
\hline 751 & corte & 0.00154 & $0.013 \%$ & $0.282 \%$ & $95.803 \%$ \\
\hline 752 & perro de caza & 0.00154 & $0.013 \%$ & $0.282 \%$ & $95.816 \%$ \\
\hline 753 & puerto de montaña & 0.00154 & $0.013 \%$ & $0.282 \%$ & $95.829 \%$ \\
\hline 754 & ropa de deporte & 0.00154 & $0.013 \%$ & $0.282 \%$ & $95.842 \%$ \\
\hline 755 & vacaciones & 0.00154 & $0.013 \%$ & $0.282 \%$ & $95.855 \%$ \\
\hline 756 & álamo & 0.00154 & $0.013 \%$ & $0.282 \%$ & $95.868 \%$ \\
\hline 757 & labor & 0.00154 & $0.013 \%$ & $0.282 \%$ & $95.881 \%$ \\
\hline 758 & cala & 0.00154 & $0.013 \%$ & $0.282 \%$ & $95.894 \%$ \\
\hline 759 & utensilio & 0.00145 & $0.013 \%$ & $0.282 \%$ & $95.907 \%$ \\
\hline 760 & conejera & 0.00145 & $0.013 \%$ & $0.282 \%$ & $95.920 \%$ \\
\hline 761 & aridez & 0.00145 & $0.013 \%$ & $0.282 \%$ & $95.933 \%$ \\
\hline 762 & furgón & 0.00145 & $0.013 \%$ & $0.282 \%$ & $95.946 \%$ \\
\hline 763 & cacahuete & 0.00145 & $0.013 \%$ & $0.282 \%$ & $95.959 \%$ \\
\hline 764 & vino & 0.00145 & $0.013 \%$ & $0.282 \%$ & $95.972 \%$ \\
\hline 765 & pascua & 0.00145 & $0.013 \%$ & $0.282 \%$ & $95.985 \%$ \\
\hline 766 & carromato & 0.00145 & $0.013 \%$ & $0.282 \%$ & $95.998 \%$ \\
\hline 767 & desierto & 0.00145 & $0.013 \%$ & $0.282 \%$ & $96.011 \%$ \\
\hline 768 & fumigación & 0.00145 & $0.013 \%$ & $0.282 \%$ & $96.024 \%$ \\
\hline 769 & pared & 0.00145 & $0.013 \%$ & $0.282 \%$ & $96.037 \%$ \\
\hline 770 & pista de esquí & 0.00145 & $0.013 \%$ & $0.282 \%$ & $96.050 \%$ \\
\hline
\end{tabular}




\begin{tabular}{|c|c|c|c|c|c|}
\hline 771 & corbella & 0.00145 & $0.013 \%$ & $0.282 \%$ & $96.063 \%$ \\
\hline 772 & mar & 0.00145 & $0.013 \%$ & $0.282 \%$ & $96.076 \%$ \\
\hline 773 & tierra fértil & 0.00145 & $0.013 \%$ & $0.282 \%$ & $96.089 \%$ \\
\hline 774 & silo & 0.00145 & $0.013 \%$ & $0.282 \%$ & $96.102 \%$ \\
\hline 775 & lugar de visita & 0.00145 & $0.013 \%$ & $0.282 \%$ & $96.115 \%$ \\
\hline 776 & gallinero & 0.00137 & $0.013 \%$ & $0.282 \%$ & $96.128 \%$ \\
\hline 777 & caserón & 0.00137 & $0.013 \%$ & $0.282 \%$ & $96.141 \%$ \\
\hline 778 & chirimoya & 0.00137 & $0.013 \%$ & $0.282 \%$ & $96.154 \%$ \\
\hline 779 & koala & 0.00137 & $0.013 \%$ & $0.282 \%$ & $96.167 \%$ \\
\hline 780 & campo de hípica & 0.00137 & $0.013 \%$ & $0.282 \%$ & $96.180 \%$ \\
\hline$\overline{781}$ & parador & 0.00137 & $0.013 \%$ & $0.282 \%$ & $96.193 \%$ \\
\hline 782 & solidaridad & 0.00137 & $0.013 \%$ & $0.282 \%$ & $96.206 \%$ \\
\hline 783 & alicates & 0.00137 & $0.013 \%$ & $0.282 \%$ & $96.219 \%$ \\
\hline 784 & esquiador & 0.00137 & $0.013 \%$ & $0.282 \%$ & $96.232 \%$ \\
\hline 785 & salamandra & 0.00137 & $0.013 \%$ & $0.282 \%$ & $96.245 \%$ \\
\hline 786 & palo de luz & 0.00137 & $0.013 \%$ & $0.282 \%$ & $96.258 \%$ \\
\hline 787 & pazo & 0.00137 & $0.013 \%$ & $0.282 \%$ & $96.271 \%$ \\
\hline 788 & salida de excursión & 0.00137 & $0.013 \%$ & $0.282 \%$ & $96.284 \%$ \\
\hline 789 & alimento silvestre & 0.00137 & $0.013 \%$ & $0.282 \%$ & $96.297 \%$ \\
\hline 790 & claro del bosque & 0.00137 & $0.013 \%$ & $0.282 \%$ & $96.310 \%$ \\
\hline 791 & espardenya & 0.00137 & $0.013 \%$ & $0.282 \%$ & $96.323 \%$ \\
\hline 792 & cultivar & 0.00137 & $0.013 \%$ & $0.282 \%$ & $96.336 \%$ \\
\hline 793 & banco de sentarse & 0.00137 & $0.013 \%$ & $0.282 \%$ & $96.349 \%$ \\
\hline 794 & central térmica & 0.00137 & $0.013 \%$ & $0.282 \%$ & $96.362 \%$ \\
\hline 795 & rocío & 0.00137 & $0.013 \%$ & $0.282 \%$ & $96.375 \%$ \\
\hline 796 & fruta silvestre & 0.00137 & $0.013 \%$ & $0.282 \%$ & $96.388 \%$ \\
\hline 797 & tierra árida & 0.00137 & $0.013 \%$ & $0.282 \%$ & $96.401 \%$ \\
\hline 798 & pétalo & 0.00137 & $0.013 \%$ & $0.282 \%$ & $96.414 \%$ \\
\hline 799 & gente mayor & 0.00137 & $0.013 \%$ & $0.282 \%$ & $96.427 \%$ \\
\hline 800 & destral & 0.00137 & $0.013 \%$ & $0.282 \%$ & $96.440 \%$ \\
\hline 801 & pendiente & 0.00137 & $0.013 \%$ & $0.282 \%$ & $96.453 \%$ \\
\hline 802 & calvario & 0.00137 & $0.013 \%$ & $0.282 \%$ & $96.466 \%$ \\
\hline 803 & sembrador & 0.00137 & $0.013 \%$ & $0.282 \%$ & $96.479 \%$ \\
\hline 804 & té & 0.00129 & $0.013 \%$ & $0.282 \%$ & $96.492 \%$ \\
\hline 805 & castillo antiguo & 0.00129 & $0.013 \%$ & $0.282 \%$ & $96.505 \%$ \\
\hline 806 & oruga & 0.00129 & $0.013 \%$ & $0.282 \%$ & $96.518 \%$ \\
\hline 807 & concordia & 0.00129 & $0.013 \%$ & $0.282 \%$ & $96.531 \%$ \\
\hline 808 & cajón de madera & 0.00129 & $0.013 \%$ & $0.282 \%$ & $96.544 \%$ \\
\hline 809 & amplitud & 0.00129 & $0.013 \%$ & $0.282 \%$ & $96.557 \%$ \\
\hline 810 & molino de viento & 0.00129 & $0.013 \%$ & $0.282 \%$ & $96.570 \%$ \\
\hline 811 & cable & 0.00129 & $0.013 \%$ & $0.282 \%$ & $96.583 \%$ \\
\hline 812 & utensilio de labrar & 0.00129 & $0.013 \%$ & $0.282 \%$ & $96.596 \%$ \\
\hline 813 & pinzón real & 0.00129 & $0.013 \%$ & $0.282 \%$ & $96.609 \%$ \\
\hline 814 & gaviota & 0.00129 & $0.013 \%$ & $0.282 \%$ & $96.622 \%$ \\
\hline 815 & lata & 0.00129 & $0.013 \%$ & $0.282 \%$ & $96.635 \%$ \\
\hline 816 & lagar & 0.00129 & $0.013 \%$ & $0.282 \%$ & $96.648 \%$ \\
\hline 817 & cima de montaña & 0.00129 & $0.013 \%$ & $0.282 \%$ & $96.661 \%$ \\
\hline
\end{tabular}




\begin{tabular}{|c|c|c|c|c|c|}
\hline 818 & carretera de tierra & 0.00129 & $0.013 \%$ & $0.282 \%$ & $96.674 \%$ \\
\hline 819 & bolsa de basura & 0.00129 & $0.013 \%$ & $0.282 \%$ & $96.687 \%$ \\
\hline 820 & banco de madera & 0.00129 & $0.013 \%$ & $0.282 \%$ & $96.700 \%$ \\
\hline 821 & mochila & 0.00129 & $0.013 \%$ & $0.282 \%$ & $96.713 \%$ \\
\hline 822 & gato salvaje & 0.00129 & $0.013 \%$ & $0.282 \%$ & $96.726 \%$ \\
\hline 823 & campo de cereales & 0.00129 & $0.013 \%$ & $0.282 \%$ & $96.739 \%$ \\
\hline 824 & azúcar de caña & 0.00129 & $0.013 \%$ & $0.282 \%$ & $96.752 \%$ \\
\hline 825 & guardia forestal & 0.00129 & $0.013 \%$ & $0.282 \%$ & $96.765 \%$ \\
\hline 826 & placer & 0.00129 & $0.013 \%$ & $0.282 \%$ & $96.778 \%$ \\
\hline 827 & enjambre & 0.00129 & $0.013 \%$ & $0.282 \%$ & $96.791 \%$ \\
\hline 828 & Biología & 0.00129 & $0.013 \%$ & $0.282 \%$ & $96.804 \%$ \\
\hline 829 & pardillo & 0.00129 & $0.013 \%$ & $0.282 \%$ & $96.817 \%$ \\
\hline 830 & guantes & 0.00129 & $0.013 \%$ & $0.282 \%$ & $96.830 \%$ \\
\hline 831 & máquina de arar & 0.00129 & $0.013 \%$ & $0.282 \%$ & $96.843 \%$ \\
\hline 832 & garrofera & 0.00128 & $0.027 \%$ & $0.565 \%$ & $96.870 \%$ \\
\hline 833 & fósil & 0.00121 & $0.027 \%$ & $0.565 \%$ & $96.897 \%$ \\
\hline 834 & parra & 0.00121 & $0.013 \%$ & $0.282 \%$ & $96.910 \%$ \\
\hline 835 & orilla & 0.00121 & $0.013 \%$ & $0.282 \%$ & $96.923 \%$ \\
\hline 836 & zarzamora & 0.00121 & $0.013 \%$ & $0.282 \%$ & $96.936 \%$ \\
\hline 837 & amabilidad & 0.00121 & $0.013 \%$ & $0.282 \%$ & $96.949 \%$ \\
\hline 838 & molino de agua & 0.00121 & $0.013 \%$ & $0.282 \%$ & $96.962 \%$ \\
\hline 839 & campamento & 0.00121 & $0.013 \%$ & $0.282 \%$ & $96.975 \%$ \\
\hline 840 & barbacoa & 0.00121 & $0.013 \%$ & $0.282 \%$ & $96.988 \%$ \\
\hline 841 & fecundidad & 0.00121 & $0.013 \%$ & $0.282 \%$ & $97.001 \%$ \\
\hline 842 & poco ruido & 0.00121 & $0.013 \%$ & $0.282 \%$ & $97.014 \%$ \\
\hline 843 & bienal & 0.00121 & $0.013 \%$ & $0.282 \%$ & $97.027 \%$ \\
\hline 844 & campo de verdura & 0.00121 & $0.013 \%$ & $0.282 \%$ & $97.040 \%$ \\
\hline 845 & deforestación & 0.00121 & $0.013 \%$ & $0.282 \%$ & $97.053 \%$ \\
\hline 846 & rico & 0.00121 & $0.013 \%$ & $0.282 \%$ & $97.066 \%$ \\
\hline 847 & agua de río contaminada & 0.00121 & $0.013 \%$ & $0.282 \%$ & $97.079 \%$ \\
\hline 848 & siega & 0.00121 & $0.013 \%$ & $0.282 \%$ & $97.092 \%$ \\
\hline 849 & vendimia & 0.00121 & $0.013 \%$ & $0.282 \%$ & $97.105 \%$ \\
\hline 850 & mesa de madera & 0.00121 & $0.013 \%$ & $0.282 \%$ & $97.118 \%$ \\
\hline 851 & mesa & 0.00121 & $0.013 \%$ & $0.282 \%$ & $97.131 \%$ \\
\hline 852 & ocio & 0.00121 & $0.013 \%$ & $0.282 \%$ & $97.144 \%$ \\
\hline 853 & regadero & 0.00121 & $0.013 \%$ & $0.282 \%$ & $97.157 \%$ \\
\hline 854 & ecosistema & 0.00121 & $0.013 \%$ & $0.282 \%$ & $97.170 \%$ \\
\hline 855 & melancolía & 0.00121 & $0.013 \%$ & $0.282 \%$ & $97.183 \%$ \\
\hline 856 & callejón & 0.00121 & $0.013 \%$ & $0.282 \%$ & $97.196 \%$ \\
\hline 857 & sueño & 0.00121 & $0.013 \%$ & $0.282 \%$ & $97.209 \%$ \\
\hline 858 & caseta de campo & 0.00121 & $0.013 \%$ & $0.282 \%$ & $97.222 \%$ \\
\hline 859 & roca metamórfica & 0.00121 & $0.013 \%$ & $0.282 \%$ & $97.235 \%$ \\
\hline 860 & caballo salvaje & 0.00121 & $0.013 \%$ & $0.282 \%$ & $97.248 \%$ \\
\hline 861 & endibia & 0.00114 & $0.013 \%$ & $0.282 \%$ & $97.261 \%$ \\
\hline 862 & basurero & 0.00114 & $0.013 \%$ & $0.282 \%$ & $97.274 \%$ \\
\hline 863 & comarca & 0.00114 & $0.013 \%$ & $0.282 \%$ & $97.287 \%$ \\
\hline 864 & no polución & 0.00114 & $0.013 \%$ & $0.282 \%$ & $97.300 \%$ \\
\hline
\end{tabular}




\begin{tabular}{|c|c|c|c|c|c|}
\hline 865 & dominguero & 0.00114 & $0.013 \%$ & $0.282 \%$ & $97.313 \%$ \\
\hline 866 & hiena & 0.00114 & $0.013 \%$ & $0.282 \%$ & $97.326 \%$ \\
\hline 867 & siesta & 0.00114 & $0.013 \%$ & $0.282 \%$ & $97.339 \%$ \\
\hline 868 & lugano & 0.00114 & $0.013 \%$ & $0.282 \%$ & $97.352 \%$ \\
\hline 869 & trienal & 0.00114 & $0.013 \%$ & $0.282 \%$ & $97.365 \%$ \\
\hline 870 & casa de piedra & 0.00114 & $0.013 \%$ & $0.282 \%$ & $97.378 \%$ \\
\hline 871 & tila & 0.00114 & $0.013 \%$ & $0.282 \%$ & $97.391 \%$ \\
\hline 872 & aventura & 0.00114 & $0.013 \%$ & $0.282 \%$ & $97.404 \%$ \\
\hline 873 & silla & 0.00114 & $0.013 \%$ & $0.282 \%$ & $97.417 \%$ \\
\hline 874 & palo & 0.00114 & $0.013 \%$ & $0.282 \%$ & $97.430 \%$ \\
\hline 875 & pesca & 0.00114 & $0.013 \%$ & $0.282 \%$ & $97.443 \%$ \\
\hline 876 & cinegético & 0.00114 & $0.013 \%$ & $0.282 \%$ & $97.456 \%$ \\
\hline 877 & roca sedimentaria & 0.00114 & $0.013 \%$ & $0.282 \%$ & $97.469 \%$ \\
\hline 878 & sistema de regadío & 0.00107 & $0.013 \%$ & $0.282 \%$ & $97.482 \%$ \\
\hline 879 & granito & 0.00107 & $0.013 \%$ & $0.282 \%$ & $97.495 \%$ \\
\hline 880 & ICONA & 0.00107 & $0.013 \%$ & $0.282 \%$ & $97.508 \%$ \\
\hline 881 & obra de arte & 0.00107 & $0.013 \%$ & $0.282 \%$ & $97.521 \%$ \\
\hline 882 & mandril & 0.00107 & $0.013 \%$ & $0.282 \%$ & $97.534 \%$ \\
\hline 883 & potro & 0.00107 & $0.013 \%$ & $0.282 \%$ & $97.547 \%$ \\
\hline 884 & repetidor de TV & 0.00107 & $0.013 \%$ & $0.282 \%$ & $97.560 \%$ \\
\hline 885 & cagarruta & 0.00107 & $0.013 \%$ & $0.282 \%$ & $97.573 \%$ \\
\hline 886 & medio fluvial & 0.00107 & $0.013 \%$ & $0.282 \%$ & $97.586 \%$ \\
\hline 887 & alimento natural & 0.00107 & $0.013 \%$ & $0.282 \%$ & $97.599 \%$ \\
\hline 888 & cabra montés & 0.00107 & $0.013 \%$ & $0.282 \%$ & $97.612 \%$ \\
\hline 889 & paleta & 0.00107 & $0.013 \%$ & $0.282 \%$ & $97.625 \%$ \\
\hline 890 & pequeño animal & 0.00107 & $0.013 \%$ & $0.282 \%$ & $97.638 \%$ \\
\hline 891 & nutria & 0.00107 & $0.013 \%$ & $0.282 \%$ & $97.651 \%$ \\
\hline 892 & empaquetadora & 0.00107 & $0.013 \%$ & $0.282 \%$ & $97.664 \%$ \\
\hline 893 & turón & 0.00107 & $0.013 \%$ & $0.282 \%$ & $97.677 \%$ \\
\hline 894 & taburete & 0.00107 & $0.013 \%$ & $0.282 \%$ & $97.690 \%$ \\
\hline 895 & roedor & 0.00107 & $0.013 \%$ & $0.282 \%$ & $97.703 \%$ \\
\hline 896 & espina & 0.00107 & $0.013 \%$ & $0.282 \%$ & $97.716 \%$ \\
\hline 897 & altramuz & 0.00101 & $0.013 \%$ & $0.282 \%$ & $97.729 \%$ \\
\hline 898 & nido de pájaros & 0.00101 & $0.013 \%$ & $0.282 \%$ & $97.742 \%$ \\
\hline 899 & garbanzo & 0.00101 & $0.013 \%$ & $0.282 \%$ & $97.755 \%$ \\
\hline 900 & monasterio & 0.00101 & $0.013 \%$ & $0.282 \%$ & $97.768 \%$ \\
\hline 901 & nave de pollos & 0.00101 & $0.013 \%$ & $0.282 \%$ & $97.781 \%$ \\
\hline 902 & agujero & 0.00101 & $0.013 \%$ & $0.282 \%$ & $97.794 \%$ \\
\hline 903 & concha & 0.00101 & $0.013 \%$ & $0.282 \%$ & $97.807 \%$ \\
\hline 904 & cernícalo & 0.00101 & $0.013 \%$ & $0.282 \%$ & $97.820 \%$ \\
\hline 905 & colorido & 0.00101 & $0.013 \%$ & $0.282 \%$ & $97.833 \%$ \\
\hline 906 & puerco espín & 0.00101 & $0.013 \%$ & $0.282 \%$ & $97.846 \%$ \\
\hline 907 & huevo & 0.00101 & $0.027 \%$ & $0.565 \%$ & $97.873 \%$ \\
\hline 908 & furtivo & 0.00101 & $0.013 \%$ & $0.282 \%$ & $97.886 \%$ \\
\hline 909 & águila real & 0.00101 & $0.013 \%$ & $0.282 \%$ & $97.899 \%$ \\
\hline 910 & becerro & 0.00101 & $0.013 \%$ & $0.282 \%$ & $97.912 \%$ \\
\hline 911 & macizo & 0.00101 & $0.013 \%$ & $0.282 \%$ & $97.925 \%$ \\
\hline
\end{tabular}




\begin{tabular}{|c|c|c|c|c|c|}
\hline 912 & manta & 0.00101 & $0.013 \%$ & $0.282 \%$ & $97.938 \%$ \\
\hline 913 & choza & 0.00101 & $0.013 \%$ & $0.282 \%$ & $97.951 \%$ \\
\hline 914 & vado & 0.00101 & $0.013 \%$ & $0.282 \%$ & $97.964 \%$ \\
\hline 915 & fotosíntesis & 0.00101 & $0.013 \%$ & $0.282 \%$ & $97.977 \%$ \\
\hline 916 & boniato & 0.00101 & $0.013 \%$ & $0.282 \%$ & $97.990 \%$ \\
\hline 917 & rudimentario & 0.00101 & $0.013 \%$ & $0.282 \%$ & $98.003 \%$ \\
\hline 918 & mapache & 0.00095 & $0.013 \%$ & $0.282 \%$ & $98.016 \%$ \\
\hline 919 & tirante & 0.00095 & $0.013 \%$ & $0.282 \%$ & $98.029 \%$ \\
\hline 920 & rebeco & 0.00095 & $0.013 \%$ & $0.282 \%$ & $98.042 \%$ \\
\hline 921 & cantar de pájaros & 0.00095 & $0.013 \%$ & $0.282 \%$ & $98.055 \%$ \\
\hline 922 & jada & 0.00095 & $0.013 \%$ & $0.282 \%$ & $98.068 \%$ \\
\hline 923 & tren & 0.00095 & $0.013 \%$ & $0.282 \%$ & $98.081 \%$ \\
\hline 924 & bicho de bola & 0.00095 & $0.013 \%$ & $0.282 \%$ & $98.094 \%$ \\
\hline 925 & privatización & 0.00095 & $0.013 \%$ & $0.282 \%$ & $98.107 \%$ \\
\hline 926 & furgoneta & 0.00095 & $0.013 \%$ & $0.282 \%$ & $98.120 \%$ \\
\hline 927 & mayoral & 0.00095 & $0.013 \%$ & $0.282 \%$ & $98.133 \%$ \\
\hline 928 & comida & 0.00095 & $0.013 \%$ & $0.282 \%$ & $98.146 \%$ \\
\hline 929 & ganado bovino & 0.00095 & $0.013 \%$ & $0.282 \%$ & $98.159 \%$ \\
\hline 930 & collidor & 0.00095 & $0.013 \%$ & $0.282 \%$ & $98.172 \%$ \\
\hline 931 & cuchillo & 0.00095 & $0.013 \%$ & $0.282 \%$ & $98.185 \%$ \\
\hline 932 & riego por aspersión & 0.00095 & $0.013 \%$ & $0.282 \%$ & $98.198 \%$ \\
\hline 933 & herramienta de cultivo & 0.00095 & $0.013 \%$ & $0.282 \%$ & $98.211 \%$ \\
\hline 934 & rambla & 0.00095 & $0.013 \%$ & $0.282 \%$ & $98.224 \%$ \\
\hline 935 & medio ambiente & 0.00095 & $0.013 \%$ & $0.282 \%$ & $98.237 \%$ \\
\hline 936 & brisa & 0.00089 & $0.013 \%$ & $0.282 \%$ & $98.250 \%$ \\
\hline 937 & gladiolo & 0.00089 & $0.013 \%$ & $0.282 \%$ & $98.263 \%$ \\
\hline 938 & canguro & 0.00089 & $0.013 \%$ & $0.282 \%$ & $98.276 \%$ \\
\hline 939 & recogedor & 0.00089 & $0.013 \%$ & $0.282 \%$ & $98.289 \%$ \\
\hline 940 & campiña & 0.00089 & $0.013 \%$ & $0.282 \%$ & $98.302 \%$ \\
\hline 941 & avispón & 0.00089 & $0.013 \%$ & $0.282 \%$ & $98.315 \%$ \\
\hline 942 & recolector de cítricos & 0.00089 & $0.013 \%$ & $0.282 \%$ & $98.328 \%$ \\
\hline 943 & lirón & 0.00089 & $0.013 \%$ & $0.282 \%$ & $98.341 \%$ \\
\hline 944 & albercoquer & 0.00089 & $0.013 \%$ & $0.282 \%$ & $98.354 \%$ \\
\hline 945 & timón & 0.00089 & $0.013 \%$ & $0.282 \%$ & $98.367 \%$ \\
\hline 946 & torre & 0.00089 & $0.013 \%$ & $0.282 \%$ & $98.380 \%$ \\
\hline 947 & ganado vacuno & 0.00089 & $0.013 \%$ & $0.282 \%$ & $98.393 \%$ \\
\hline 948 & pesticida & 0.00089 & $0.013 \%$ & $0.282 \%$ & $98.406 \%$ \\
\hline 949 & bota & 0.00089 & $0.013 \%$ & $0.282 \%$ & $98.419 \%$ \\
\hline 950 & tenedor & 0.00089 & $0.013 \%$ & $0.282 \%$ & $98.432 \%$ \\
\hline 951 & irrigación & 0.00089 & $0.013 \%$ & $0.282 \%$ & $98.445 \%$ \\
\hline 952 & cepo & 0.00089 & $0.013 \%$ & $0.282 \%$ & $98.458 \%$ \\
\hline 953 & veraneante & 0.00089 & $0.013 \%$ & $0.282 \%$ & $98.471 \%$ \\
\hline 954 & moniato & 0.00089 & $0.013 \%$ & $0.282 \%$ & $98.484 \%$ \\
\hline 955 & canal de agua & 0.00089 & $0.013 \%$ & $0.282 \%$ & $98.497 \%$ \\
\hline 956 & quemador de leña & 0.00089 & $0.013 \%$ & $0.282 \%$ & $98.510 \%$ \\
\hline 957 & morca & 0.00084 & $0.013 \%$ & $0.282 \%$ & $98.523 \%$ \\
\hline 958 & calabacín & 0.00084 & $0.013 \%$ & $0.282 \%$ & $98.536 \%$ \\
\hline
\end{tabular}




\begin{tabular}{|c|c|c|c|c|c|}
\hline 959 & sombrero & 0.00084 & $0.013 \%$ & $0.282 \%$ & $98.549 \%$ \\
\hline 960 & pirómano & 0.00084 & $0.013 \%$ & $0.282 \%$ & $98.562 \%$ \\
\hline 961 & primavera & 0.00084 & $0.013 \%$ & $0.282 \%$ & $98.575 \%$ \\
\hline 962 & moto & 0.00084 & $0.013 \%$ & $0.282 \%$ & $98.588 \%$ \\
\hline 963 & moscardón & 0.00084 & $0.013 \%$ & $0.282 \%$ & $98.601 \%$ \\
\hline 964 & nardo & 0.00084 & $0.013 \%$ & $0.282 \%$ & $98.614 \%$ \\
\hline 965 & membrillero & 0.00084 & $0.013 \%$ & $0.282 \%$ & $98.627 \%$ \\
\hline 966 & miel & 0.00084 & $0.013 \%$ & $0.282 \%$ & $98.640 \%$ \\
\hline 967 & ganado porcino & 0.00084 & $0.013 \%$ & $0.282 \%$ & $98.653 \%$ \\
\hline 968 & leche & 0.00084 & $0.013 \%$ & $0.282 \%$ & $98.666 \%$ \\
\hline 969 & piña & 0.00084 & $0.013 \%$ & $0.282 \%$ & $98.679 \%$ \\
\hline 970 & hielo & 0.00084 & $0.013 \%$ & $0.282 \%$ & $98.692 \%$ \\
\hline 971 & emigración & 0.00084 & $0.013 \%$ & $0.282 \%$ & $98.705 \%$ \\
\hline 972 & pocilga & 0.00079 & $0.013 \%$ & $0.282 \%$ & $98.718 \%$ \\
\hline 973 & galán de noche & 0.00079 & $0.013 \%$ & $0.282 \%$ & $98.731 \%$ \\
\hline 974 & colilla & 0.00079 & $0.013 \%$ & $0.282 \%$ & $98.744 \%$ \\
\hline 975 & pub & 0.00079 & $0.013 \%$ & $0.282 \%$ & $98.757 \%$ \\
\hline 976 & hoja seca & 0.00079 & $0.013 \%$ & $0.282 \%$ & $98.770 \%$ \\
\hline 977 & luciérnaga & 0.00079 & $0.013 \%$ & $0.282 \%$ & $98.783 \%$ \\
\hline 978 & paella & 0.00079 & $0.013 \%$ & $0.282 \%$ & $98.796 \%$ \\
\hline 979 & puerco & 0.00079 & $0.013 \%$ & $0.282 \%$ & $98.809 \%$ \\
\hline 980 & vertedero & 0.00079 & $0.013 \%$ & $0.282 \%$ & $98.822 \%$ \\
\hline 981 & podar & 0.00079 & $0.013 \%$ & $0.282 \%$ & $98.835 \%$ \\
\hline 982 & coliflor & 0.00079 & $0.013 \%$ & $0.282 \%$ & $98.848 \%$ \\
\hline 983 & yugo & 0.00079 & $0.013 \%$ & $0.282 \%$ & $98.861 \%$ \\
\hline 984 & ganado equino & 0.00079 & $0.013 \%$ & $0.282 \%$ & $98.874 \%$ \\
\hline 985 & color verde & 0.00079 & $0.013 \%$ & $0.282 \%$ & $98.887 \%$ \\
\hline 986 & ciclista & 0.00079 & $0.013 \%$ & $0.282 \%$ & $98.900 \%$ \\
\hline 987 & precipicio & 0.00079 & $0.013 \%$ & $0.282 \%$ & $98.913 \%$ \\
\hline 988 & tubérculo & 0.00079 & $0.013 \%$ & $0.282 \%$ & $98.926 \%$ \\
\hline 989 & escopeta & 0.00079 & $0.013 \%$ & $0.282 \%$ & $98.939 \%$ \\
\hline 990 & labriego & 0.00079 & $0.013 \%$ & $0.282 \%$ & $98.952 \%$ \\
\hline 991 & visita & 0.00079 & $0.013 \%$ & $0.282 \%$ & $98.965 \%$ \\
\hline 992 & guisante & 0.00075 & $0.013 \%$ & $0.282 \%$ & $98.978 \%$ \\
\hline 993 & otoño & 0.00075 & $0.013 \%$ & $0.282 \%$ & $98.991 \%$ \\
\hline 994 & espiga & 0.00075 & $0.013 \%$ & $0.282 \%$ & $99.004 \%$ \\
\hline 995 & carreta & 0.00075 & $0.013 \%$ & $0.282 \%$ & $99.017 \%$ \\
\hline 996 & albahaca & 0.00075 & $0.013 \%$ & $0.282 \%$ & $99.030 \%$ \\
\hline 997 & hoyo & 0.00075 & $0.013 \%$ & $0.282 \%$ & $99.043 \%$ \\
\hline 998 & cuadrilla & 0.00075 & $0.013 \%$ & $0.282 \%$ & $99.056 \%$ \\
\hline 999 & Oronul & 0.00075 & $0.013 \%$ & $0.282 \%$ & $99.069 \%$ \\
\hline 1000 & lago limpio & 0.00075 & $0.013 \%$ & $0.282 \%$ & $99.082 \%$ \\
\hline 1001 & cigarra & 0.00075 & $0.013 \%$ & $0.282 \%$ & $99.095 \%$ \\
\hline 1002 & humus & 0.00070 & $0.013 \%$ & $0.282 \%$ & $99.108 \%$ \\
\hline 1003 & oro & 0.00070 & $0.013 \%$ & $0.282 \%$ & $99.121 \%$ \\
\hline 1004 & meditación & 0.00070 & $0.013 \%$ & $0.282 \%$ & $99.134 \%$ \\
\hline 1005 & tabaco & 0.00070 & $0.013 \%$ & $0.282 \%$ & $99.147 \%$ \\
\hline
\end{tabular}




\begin{tabular}{|c|c|c|c|c|c|}
\hline 1006 & invierno & 0.00070 & $0.013 \%$ & $0.282 \%$ & $99.160 \%$ \\
\hline 1007 & milpiés & 0.00070 & $0.013 \%$ & $0.282 \%$ & $99.173 \%$ \\
\hline 1008 & fabada & 0.00070 & $0.013 \%$ & $0.282 \%$ & $99.186 \%$ \\
\hline 1009 & lecho & 0.00070 & $0.013 \%$ & $0.282 \%$ & $99.199 \%$ \\
\hline 1010 & regar & 0.00070 & $0.013 \%$ & $0.282 \%$ & $99.212 \%$ \\
\hline 1011 & borrego & 0.00070 & $0.013 \%$ & $0.282 \%$ & $99.225 \%$ \\
\hline 1012 & horticultura & 0.00070 & $0.013 \%$ & $0.282 \%$ & $99.238 \%$ \\
\hline 1013 & río limpio & 0.00070 & $0.013 \%$ & $0.282 \%$ & $99.251 \%$ \\
\hline 1014 & esquiar & 0.00070 & $0.013 \%$ & $0.282 \%$ & $99.264 \%$ \\
\hline 1015 & ignorancia & 0.00070 & $0.013 \%$ & $0.282 \%$ & $99.277 \%$ \\
\hline 1016 & granada & 0.00070 & $0.013 \%$ & $0.282 \%$ & $99.290 \%$ \\
\hline 1017 & plata & 0.00066 & $0.013 \%$ & $0.282 \%$ & $99.303 \%$ \\
\hline 1018 & cacao & 0.00066 & $0.013 \%$ & $0.282 \%$ & $99.316 \%$ \\
\hline 1019 & porche & 0.00066 & $0.013 \%$ & $0.282 \%$ & $99.329 \%$ \\
\hline 1020 & ayuntamiento & 0.00066 & $0.013 \%$ & $0.282 \%$ & $99.342 \%$ \\
\hline 1021 & alpinista & 0.00066 & $0.013 \%$ & $0.282 \%$ & $99.355 \%$ \\
\hline 1022 & árbol centenario & 0.00066 & $0.013 \%$ & $0.282 \%$ & $99.368 \%$ \\
\hline 1023 & cangrejo & 0.00066 & $0.013 \%$ & $0.282 \%$ & $99.381 \%$ \\
\hline 1024 & ingeniero agrónomo & 0.00066 & $0.013 \%$ & $0.282 \%$ & $99.394 \%$ \\
\hline 1025 & finca trabajada & 0.00066 & $0.013 \%$ & $0.282 \%$ & $99.407 \%$ \\
\hline 1026 & sindicato de riegos & 0.00066 & $0.013 \%$ & $0.282 \%$ & $99.420 \%$ \\
\hline 1027 & caucho & 0.00062 & $0.013 \%$ & $0.282 \%$ & $99.433 \%$ \\
\hline 1028 & guineu & 0.00062 & $0.013 \%$ & $0.282 \%$ & $99.446 \%$ \\
\hline 1029 & paracaidista & 0.00062 & $0.013 \%$ & $0.282 \%$ & $99.459 \%$ \\
\hline 1030 & grano & 0.00062 & $0.013 \%$ & $0.282 \%$ & $99.472 \%$ \\
\hline 1031 & caminar & 0.00062 & $0.013 \%$ & $0.282 \%$ & $99.485 \%$ \\
\hline 1032 & recolecta & 0.00062 & $0.013 \%$ & $0.282 \%$ & $99.498 \%$ \\
\hline 1033 & sembradora & 0.00062 & $0.013 \%$ & $0.282 \%$ & $99.511 \%$ \\
\hline 1034 & cartel & 0.00059 & $0.013 \%$ & $0.282 \%$ & $99.524 \%$ \\
\hline 1035 & colegio & 0.00059 & $0.013 \%$ & $0.282 \%$ & $99.537 \%$ \\
\hline 1036 & hueso & 0.00059 & $0.013 \%$ & $0.282 \%$ & $99.550 \%$ \\
\hline 1037 & oliva & 0.00059 & $0.013 \%$ & $0.282 \%$ & $99.563 \%$ \\
\hline 1038 & siembra & 0.00059 & $0.013 \%$ & $0.282 \%$ & $99.576 \%$ \\
\hline 1039 & arcilla & 0.00055 & $0.013 \%$ & $0.282 \%$ & $99.589 \%$ \\
\hline 1040 & instituto & 0.00055 & $0.013 \%$ & $0.282 \%$ & $99.602 \%$ \\
\hline 1041 & ternera & 0.00055 & $0.013 \%$ & $0.282 \%$ & $99.615 \%$ \\
\hline 1042 & espacio abierto & 0.00055 & $0.013 \%$ & $0.282 \%$ & $99.628 \%$ \\
\hline 1043 & elefante & 0.00055 & $0.013 \%$ & $0.282 \%$ & $99.641 \%$ \\
\hline 1044 & panal & 0.00055 & $0.013 \%$ & $0.282 \%$ & $99.654 \%$ \\
\hline 1045 & arenisca & 0.00055 & $0.013 \%$ & $0.282 \%$ & $99.667 \%$ \\
\hline 1046 & falda de montaña & 0.00055 & $0.013 \%$ & $0.282 \%$ & $99.680 \%$ \\
\hline 1047 & tallo & 0.00055 & $0.013 \%$ & $0.282 \%$ & $99.693 \%$ \\
\hline 1048 & cuidado & 0.00055 & $0.013 \%$ & $0.282 \%$ & $99.706 \%$ \\
\hline 1049 & pozal & 0.00055 & $0.013 \%$ & $0.282 \%$ & $99.719 \%$ \\
\hline 1050 & orégano & 0.00052 & $0.013 \%$ & $0.282 \%$ & $99.732 \%$ \\
\hline 1051 & teuladí & 0.00052 & $0.013 \%$ & $0.282 \%$ & $99.745 \%$ \\
\hline 1052 & escolopendra & 0.00052 & $0.013 \%$ & $0.282 \%$ & $99.758 \%$ \\
\hline
\end{tabular}




\begin{tabular}{|l|l|l|l|l|l|}
\hline 1053 & bellota & 0.00052 & $0.013 \%$ & $0.282 \%$ & $99.771 \%$ \\
\hline 1054 & caliza & 0.00052 & $0.013 \%$ & $0.282 \%$ & $99.784 \%$ \\
\hline 1055 & huella & 0.00049 & $0.013 \%$ & $0.282 \%$ & $99.797 \%$ \\
\hline 1056 & cantera & 0.00049 & $0.013 \%$ & $0.282 \%$ & $99.810 \%$ \\
\hline 1057 & jirafa & 0.00049 & $0.013 \%$ & $0.282 \%$ & $99.823 \%$ \\
\hline 1058 & rinoceronte & 0.00046 & $0.013 \%$ & $0.282 \%$ & $99.836 \%$ \\
\hline 1059 & faisán & 0.00043 & $0.013 \%$ & $0.282 \%$ & $99.849 \%$ \\
\hline 1060 & navaja & 0.00041 & $0.013 \%$ & $0.282 \%$ & $99.862 \%$ \\
\hline
\end{tabular}

\section{MEDIOS DE TRANSPORTE}

\begin{tabular}{|c|l|c|c|c|c|}
\hline $\mathrm{N}^{\mathrm{o}}$ & Palabra & Disponibilidad & $\begin{array}{c}\text { Frecuencia } \\
\text { relativa }\end{array}$ & \% Aparición & $\begin{array}{c}\text { Frecuencia } \\
\text { acumulada }\end{array}$ \\
\hline 1 & coche & 0.83577 & $4.849 \%$ & $93.503 \%$ & $4.849 \%$ \\
\hline 2 & bici(cleta) & 0.66029 & $4.820 \%$ & $92.938 \%$ & $9.669 \%$ \\
\hline 3 & avión & 0.65116 & $5.025 \%$ & $96.893 \%$ & $14.694 \%$ \\
\hline 4 & auto)bús & 0.64466 & $4.424 \%$ & $85.311 \%$ & $19.118 \%$ \\
\hline 5 & tren & 0.54292 & $4.146 \%$ & $79.944 \%$ & $23.264 \%$ \\
\hline 6 & moto & 0.53645 & $3.736 \%$ & $72.034 \%$ & $27.000 \%$ \\
\hline 7 & barco & 0.42735 & $4.131 \%$ & $79.661 \%$ & $31.131 \%$ \\
\hline 8 & camión & 0.37313 & $3.238 \%$ & $62.429 \%$ & $34.369 \%$ \\
\hline 9 & patín & 0.35651 & $3.457 \%$ & $66.667 \%$ & $37.826 \%$ \\
\hline 10 & monopatín & 0.31142 & $2.930 \%$ & $56.497 \%$ & $40.756 \%$ \\
\hline 11 & metro & 0.27935 & $2.432 \%$ & $46.893 \%$ & $43.188 \%$ \\
\hline 12 & motocicleta & 0.24794 & $1.919 \%$ & $37.006 \%$ & $45.107 \%$ \\
\hline 13 & taxi & 0.23227 & $2.007 \%$ & $38.701 \%$ & $47.114 \%$ \\
\hline 14 & tranvía & 0.21481 & $1.934 \%$ & $37.288 \%$ & $49.048 \%$ \\
\hline 15 & helicóptero & 0.21452 & $2.300 \%$ & $44.350 \%$ & $51.348 \%$ \\
\hline 16 & triciclo & 0.21303 & $2.168 \%$ & $41.808 \%$ & $53.516 \%$ \\
\hline 17 & ciclomotor & 0.20384 & $1.568 \%$ & $30.226 \%$ & $55.084 \%$ \\
\hline 18 & avioneta & 0.19630 & $2.066 \%$ & $39.831 \%$ & $57.150 \%$ \\
\hline 19 & furgoneta & 0.18176 & $1.831 \%$ & $35.311 \%$ & $58.981 \%$ \\
\hline 20 & caballo & 0.17609 & $2.095 \%$ & $40.395 \%$ & $61.076 \%$ \\
\hline 21 & patinete & 0.12873 & $1.362 \%$ & $26.271 \%$ & $62.438 \%$ \\
\hline 22 & carro & 0.12807 & $1.465 \%$ & $28.249 \%$ & $63.903 \%$ \\
\hline 23 & barca & 0.11514 & $1.377 \%$ & $26.554 \%$ & $65.280 \%$ \\
\hline 24 & tractor & 0.11461 & $1.216 \%$ & $23.446 \%$ & $66.496 \%$ \\
\hline 25 & lancha & 0.10733 & $1.450 \%$ & $27.966 \%$ & $67.946 \%$ \\
\hline 26 & a pie & 0.09615 & $0.850 \%$ & $16.384 \%$ & $68.796 \%$ \\
\hline 27 & transatlántico & 0.08545 & $1.040 \%$ & $20.056 \%$ & $69.836 \%$ \\
\hline 28 & globo & 0.08463 & $1.113 \%$ & $21.469 \%$ & $70.949 \%$ \\
\hline 29 & burro & 0.08267 & $1.069 \%$ & $20.621 \%$ & $72.018 \%$ \\
\hline 30 & submarino & 0.07578 & $1.025 \%$ & $19.774 \%$ & $73.043 \%$ \\
\hline
\end{tabular}




\begin{tabular}{|c|c|c|c|c|c|}
\hline 31 & yate & 0.07464 & $0.879 \%$ & $16.949 \%$ & $73.922 \%$ \\
\hline 32 & camioneta & 0.06185 & $0.645 \%$ & $12.429 \%$ & $74.567 \%$ \\
\hline 33 & minibús & 0.05769 & $0.571 \%$ & $11.017 \%$ & $75.138 \%$ \\
\hline 34 & sidecar & 0.05666 & $0.615 \%$ & $11.864 \%$ & $75.753 \%$ \\
\hline 35 & ala delta & 0.05354 & $0.747 \%$ & $14.407 \%$ & $76.500 \%$ \\
\hline 36 & aeroplano & 0.05341 & $0.571 \%$ & $11.017 \%$ & $77.071 \%$ \\
\hline 37 & automóvil & 0.04526 & $0.322 \%$ & $6.215 \%$ & $77.393 \%$ \\
\hline 38 & moto acuática & 0.04357 & $0.645 \%$ & $12.429 \%$ & $78.038 \%$ \\
\hline 39 & tráiler & 0.04038 & $0.410 \%$ & $7.910 \%$ & $78.448 \%$ \\
\hline 40 & (barco) velero & 0.04034 & $0.527 \%$ & $10.169 \%$ & $78.975 \%$ \\
\hline 41 & limusina & 0.03849 & $0.381 \%$ & $7.345 \%$ & $79.356 \%$ \\
\hline 42 & esquí & 0.03463 & $0.498 \%$ & $9.605 \%$ & $79.854 \%$ \\
\hline 43 & cohete & 0.03462 & $0.513 \%$ & $9.887 \%$ & $80.367 \%$ \\
\hline 44 & paracaídas & 0.03420 & $0.483 \%$ & $9.322 \%$ & $80.850 \%$ \\
\hline 45 & canoa & 0.03351 & $0.513 \%$ & $9.887 \%$ & $81.363 \%$ \\
\hline 46 & tándem & 0.03257 & $0.366 \%$ & $7.062 \%$ & $81.729 \%$ \\
\hline 47 & nave espacial & 0.02978 & $0.381 \%$ & $7.345 \%$ & $82.110 \%$ \\
\hline 48 & caravana & 0.02927 & $0.322 \%$ & $6.215 \%$ & $82.432 \%$ \\
\hline 49 & parapente & 0.02912 & $0.381 \%$ & $7.345 \%$ & $82.813 \%$ \\
\hline 50 & trineo & 0.02872 & $0.396 \%$ & $7.627 \%$ & $83.209 \%$ \\
\hline 51 & corriendo & 0.02850 & $0.322 \%$ & $6.215 \%$ & $83.531 \%$ \\
\hline 52 & zepelín & 0.02744 & $0.396 \%$ & $7.627 \%$ & $83.927 \%$ \\
\hline 53 & andando & 0.02690 & $0.278 \%$ & $5.367 \%$ & $84.205 \%$ \\
\hline 54 & carromato & 0.02656 & $0.293 \%$ & $5.650 \%$ & $84.498 \%$ \\
\hline 55 & piragua & 0.02537 & $0.337 \%$ & $6.497 \%$ & $84.835 \%$ \\
\hline 56 & AVE & 0.02255 & $0.220 \%$ & $4.237 \%$ & $85.055 \%$ \\
\hline 57 & turismo & 0.02208 & $0.161 \%$ & $3.107 \%$ & $85.216 \%$ \\
\hline 58 & furgón & 0.02180 & $0.264 \%$ & $5.085 \%$ & $85.480 \%$ \\
\hline 59 & tabla de surf & 0.02074 & $0.278 \%$ & $5.367 \%$ & $85.758 \%$ \\
\hline 60 & pierna & 0.01983 & $0.190 \%$ & $3.672 \%$ & $85.948 \%$ \\
\hline 61 & ferrocarril & 0.01978 & $0.176 \%$ & $3.390 \%$ & $86.124 \%$ \\
\hline 62 & autocar & 0.01883 & $0.161 \%$ & $3.107 \%$ & $86.285 \%$ \\
\hline 63 & trolebús & 0.01843 & $0.176 \%$ & $3.390 \%$ & $86.461 \%$ \\
\hline 64 & reactor & 0.01809 & $0.220 \%$ & $4.237 \%$ & $86.681 \%$ \\
\hline 65 & telesilla & 0.01779 & $0.205 \%$ & $3.955 \%$ & $86.886 \%$ \\
\hline 66 & carreta & 0.01771 & $0.220 \%$ & $4.237 \%$ & $87.106 \%$ \\
\hline 67 & carroza & 0.01758 & $0.220 \%$ & $4.237 \%$ & $87.326 \%$ \\
\hline 68 & silla de ruedas & 0.01627 & $0.205 \%$ & $3.955 \%$ & $87.531 \%$ \\
\hline 69 & ferry & 0.01626 & $0.190 \%$ & $3.672 \%$ & $87.721 \%$ \\
\hline 70 & ambulancia & 0.01607 & $0.205 \%$ & $3.955 \%$ & $87.926 \%$ \\
\hline 71 & microbús & 0.01594 & $0.146 \%$ & $2.825 \%$ & $88.072 \%$ \\
\hline 72 & teleférico & 0.01584 & $0.205 \%$ & $3.955 \%$ & $88.277 \%$ \\
\hline 73 & todoterreno & 0.01580 & $0.161 \%$ & $3.107 \%$ & $88.438 \%$ \\
\hline 74 & remolque & 0.01531 & $0.161 \%$ & $3.107 \%$ & $88.599 \%$ \\
\hline 75 & góndola & 0.01510 & $0.205 \%$ & $3.955 \%$ & $88.804 \%$ \\
\hline 76 & jet & 0.01386 & $0.146 \%$ & $2.825 \%$ & $88.950 \%$ \\
\hline 77 & hidroavión & 0.01356 & $0.146 \%$ & $2.825 \%$ & $89.096 \%$ \\
\hline
\end{tabular}




\begin{tabular}{|c|c|c|c|c|c|}
\hline 78 & zodiac & 0.01339 & $0.190 \%$ & $3.672 \%$ & $89.286 \%$ \\
\hline 79 & caminar & 0.01331 & $0.132 \%$ & $2.542 \%$ & $89.418 \%$ \\
\hline 80 & locomotora & 0.01317 & $0.117 \%$ & $2.260 \%$ & $89.535 \%$ \\
\hline 81 & motocarro & 0.01297 & $0.146 \%$ & $2.825 \%$ & $89.681 \%$ \\
\hline 82 & transbordador & 0.01296 & $0.205 \%$ & $3.955 \%$ & $89.886 \%$ \\
\hline 83 & mula & 0.01259 & $0.176 \%$ & $3.390 \%$ & $90.062 \%$ \\
\hline 84 & portaaviones & 0.01258 & $0.161 \%$ & $3.107 \%$ & $90.223 \%$ \\
\hline 85 & concorde & 0.01237 & $0.146 \%$ & $2.825 \%$ & $90.369 \%$ \\
\hline 86 & camello & 0.01235 & $0.205 \%$ & $3.955 \%$ & $90.574 \%$ \\
\hline 87 & Vespino* & 0.01228 & $0.117 \%$ & $2.260 \%$ & $90.691 \%$ \\
\hline 88 & patín de línea & 0.01190 & $0.117 \%$ & $2.260 \%$ & $90.808 \%$ \\
\hline 89 & buque & 0.01170 & $0.132 \%$ & $2.542 \%$ & $90.940 \%$ \\
\hline 90 & tanque & 0.01148 & $0.161 \%$ & $3.107 \%$ & $91.101 \%$ \\
\hline 91 & monociclo & 0.01082 & $0.088 \%$ & $1.695 \%$ & $91.189 \%$ \\
\hline 92 & bote & 0.01044 & $0.161 \%$ & $3.107 \%$ & $91.350 \%$ \\
\hline 93 & nadando & 0.01029 & $0.176 \%$ & $3.390 \%$ & $91.526 \%$ \\
\hline 94 & (coche) deportivo & 0.00985 & $0.088 \%$ & $1.695 \%$ & $91.614 \%$ \\
\hline 95 & ultraligero & 0.00966 & $0.117 \%$ & $2.260 \%$ & $91.731 \%$ \\
\hline 96 & patera & 0.00953 & $0.117 \%$ & $2.260 \%$ & $91.848 \%$ \\
\hline 97 & carretilla & 0.00927 & $0.117 \%$ & $2.260 \%$ & $91.965 \%$ \\
\hline 98 & monovolumen & 0.00925 & $0.088 \%$ & $1.695 \%$ & $92.053 \%$ \\
\hline 99 & mountain bike & 0.00923 & $0.073 \%$ & $1.412 \%$ & $92.126 \%$ \\
\hline 100 & moto de agua & 0.00886 & $0.117 \%$ & $2.260 \%$ & $92.243 \%$ \\
\hline 101 & autostop & 0.00869 & $0.103 \%$ & $1.977 \%$ & $92.346 \%$ \\
\hline 102 & colchoneta & 0.00861 & $0.161 \%$ & $3.107 \%$ & $92.507 \%$ \\
\hline 103 & carricoche & 0.00851 & $0.073 \%$ & $1.412 \%$ & $92.580 \%$ \\
\hline 104 & balsa & 0.00834 & $0.132 \%$ & $2.542 \%$ & $92.712 \%$ \\
\hline 105 & vela & 0.00793 & $0.132 \%$ & $2.542 \%$ & $92.844 \%$ \\
\hline 106 & kart & 0.00780 & $0.088 \%$ & $1.695 \%$ & $92.932 \%$ \\
\hline 107 & crucero & 0.00767 & $0.103 \%$ & $1.977 \%$ & $93.035 \%$ \\
\hline 108 & andar & 0.00758 & $0.073 \%$ & $1.412 \%$ & $93.108 \%$ \\
\hline 109 & barco de vela & 0.00753 & $0.088 \%$ & $1.695 \%$ & $93.196 \%$ \\
\hline 110 & (tren de) cercanías & 0.00738 & $0.088 \%$ & $1.695 \%$ & $93.284 \%$ \\
\hline 111 & funicular & 0.00711 & $0.117 \%$ & $2.260 \%$ & $93.401 \%$ \\
\hline 112 & ascensor & 0.00698 & $0.117 \%$ & $2.260 \%$ & $93.518 \%$ \\
\hline 113 & elefante & 0.00697 & $0.103 \%$ & $1.977 \%$ & $93.621 \%$ \\
\hline 114 & a dedo & 0.00664 & $0.088 \%$ & $1.695 \%$ & $93.709 \%$ \\
\hline 115 & monorraíl & 0.00659 & $0.073 \%$ & $1.412 \%$ & $93.782 \%$ \\
\hline 116 & tren de alta velocidad & 0.00654 & $0.073 \%$ & $1.412 \%$ & $93.855 \%$ \\
\hline 117 & grúa & 0.00651 & $0.073 \%$ & $1.412 \%$ & $93.928 \%$ \\
\hline 118 & carruaje & 0.00617 & $0.088 \%$ & $1.695 \%$ & $94.016 \%$ \\
\hline 119 & Audi* & 0.00599 & $0.044 \%$ & $0.847 \%$ & $94.060 \%$ \\
\hline 120 & lancha motora & 0.00596 & $0.073 \%$ & $1.412 \%$ & $94.133 \%$ \\
\hline 121 & tartana & 0.00584 & $0.059 \%$ & $1.130 \%$ & $94.192 \%$ \\
\hline 122 & globo aerostático & 0.00580 & $0.088 \%$ & $1.695 \%$ & $94.280 \%$ \\
\hline 123 & petrolero & 0.00577 & $0.059 \%$ & $1.130 \%$ & $94.339 \%$ \\
\hline 124 & monoplaza & 0.00572 & $0.073 \%$ & $1.412 \%$ & $94.412 \%$ \\
\hline
\end{tabular}




\begin{tabular}{|c|c|c|c|c|c|}
\hline 125 & Vespa* & 0.00554 & $0.073 \%$ & $1.412 \%$ & $94.485 \%$ \\
\hline 126 & vagón & 0.00550 & $0.044 \%$ & $0.847 \%$ & $94.529 \%$ \\
\hline 127 & golondrina & 0.00548 & $0.073 \%$ & $1.412 \%$ & $94.602 \%$ \\
\hline 128 & tabla de windsurf & 0.00545 & $0.073 \%$ & $1.412 \%$ & $94.675 \%$ \\
\hline 129 & snowboard & 0.00538 & $0.059 \%$ & $1.130 \%$ & $94.734 \%$ \\
\hline 130 & coche de caballos & 0.00514 & $0.044 \%$ & $0.847 \%$ & $94.778 \%$ \\
\hline 131 & galera & 0.00504 & $0.059 \%$ & $1.130 \%$ & $94.837 \%$ \\
\hline 132 & motocultor & 0.00491 & $0.044 \%$ & $0.847 \%$ & $94.881 \%$ \\
\hline 133 & coche de carreras & 0.00482 & $0.073 \%$ & $1.412 \%$ & $94.954 \%$ \\
\hline 134 & hovercraft & 0.00452 & $0.073 \%$ & $1.412 \%$ & $95.027 \%$ \\
\hline 135 & Renault* & 0.00443 & $0.029 \%$ & $0.565 \%$ & $95.056 \%$ \\
\hline 136 & (auto)bús articulado & 0.00439 & $0.044 \%$ & $0.847 \%$ & $95.100 \%$ \\
\hline 137 & fueraborda & 0.00438 & $0.044 \%$ & $0.847 \%$ & $95.144 \%$ \\
\hline 138 & boeing & 0.00437 & $0.044 \%$ & $0.847 \%$ & $95.188 \%$ \\
\hline 139 & ciclo & 0.00437 & $0.029 \%$ & $0.565 \%$ & $95.217 \%$ \\
\hline 140 & tacataca & 0.00434 & $0.059 \%$ & $1.130 \%$ & $95.276 \%$ \\
\hline 141 & jeep & 0.00425 & $0.044 \%$ & $0.847 \%$ & $95.320 \%$ \\
\hline 142 & calesa & 0.00417 & $0.073 \%$ & $1.412 \%$ & $95.393 \%$ \\
\hline 143 & windsurf & 0.00417 & $0.073 \%$ & $1.412 \%$ & $95.466 \%$ \\
\hline 144 & vía & 0.00414 & $0.029 \%$ & $0.565 \%$ & $95.495 \%$ \\
\hline 145 & yegua & 0.00413 & $0.073 \%$ & $1.412 \%$ & $95.568 \%$ \\
\hline 146 & nadar & 0.00410 & $0.059 \%$ & $1.130 \%$ & $95.627 \%$ \\
\hline 147 & motora & 0.00401 & $0.044 \%$ & $0.847 \%$ & $95.671 \%$ \\
\hline 148 & catamarán & 0.00400 & $0.059 \%$ & $1.130 \%$ & $95.730 \%$ \\
\hline 149 & asno & 0.00398 & $0.059 \%$ & $1.130 \%$ & $95.789 \%$ \\
\hline 150 & coche cama & 0.00395 & $0.029 \%$ & $0.565 \%$ & $95.818 \%$ \\
\hline 151 & Talgo & 0.00387 & $0.044 \%$ & $0.847 \%$ & $95.862 \%$ \\
\hline 152 & acorazado & 0.00381 & $0.044 \%$ & $0.847 \%$ & $95.906 \%$ \\
\hline 153 & caminando & 0.00379 & $0.044 \%$ & $0.847 \%$ & $95.950 \%$ \\
\hline 154 & montacargas & 0.00376 & $0.044 \%$ & $0.847 \%$ & $95.994 \%$ \\
\hline 155 & carabela & 0.00373 & $0.044 \%$ & $0.847 \%$ & $96.038 \%$ \\
\hline 156 & a saltos & 0.00365 & $0.059 \%$ & $1.130 \%$ & $96.097 \%$ \\
\hline 157 & cochecito de bebé & 0.00363 & $0.044 \%$ & $0.847 \%$ & $96.141 \%$ \\
\hline 158 & diligencia & 0.00356 & $0.044 \%$ & $0.847 \%$ & $96.185 \%$ \\
\hline 159 & moto de cross & 0.00345 & $0.029 \%$ & $0.565 \%$ & $96.214 \%$ \\
\hline 160 & planeador & 0.00341 & $0.044 \%$ & $0.847 \%$ & $96.258 \%$ \\
\hline 161 & vehículo & 0.00336 & $0.029 \%$ & $0.565 \%$ & $96.287 \%$ \\
\hline 162 & skate & 0.00333 & $0.059 \%$ & $1.130 \%$ & $96.346 \%$ \\
\hline 163 & utilitario & 0.00328 & $0.029 \%$ & $0.565 \%$ & $96.375 \%$ \\
\hline 164 & nave & 0.00327 & $0.044 \%$ & $0.847 \%$ & $96.419 \%$ \\
\hline 165 & roulotte & 0.00324 & $0.029 \%$ & $0.565 \%$ & $96.448 \%$ \\
\hline 166 & biplaza & 0.00324 & $0.029 \%$ & $0.565 \%$ & $96.477 \%$ \\
\hline 167 & Harley Davidson* & 0.00323 & $0.044 \%$ & $0.847 \%$ & $96.521 \%$ \\
\hline 168 & a pata & 0.00322 & $0.029 \%$ & $0.565 \%$ & $96.550 \%$ \\
\hline 169 & zancos & 0.00318 & $0.044 \%$ & $0.847 \%$ & $96.594 \%$ \\
\hline 170 & flotador & 0.00315 & $0.059 \%$ & $1.130 \%$ & $96.653 \%$ \\
\hline 171 & vehículo de tracción animal & 0.00314 & $0.029 \%$ & $0.565 \%$ & $96.682 \%$ \\
\hline
\end{tabular}




\begin{tabular}{|c|c|c|c|c|c|}
\hline 172 & galeón & 0.00314 & $0.029 \%$ & $0.565 \%$ & $96.711 \%$ \\
\hline 173 & ovni & 0.00309 & $0.044 \%$ & $0.847 \%$ & $96.755 \%$ \\
\hline 174 & vehículo mixto & 0.00308 & $0.029 \%$ & $0.565 \%$ & $96.784 \%$ \\
\hline 175 & coche de San Fernando & 0.00307 & $0.029 \%$ & $0.565 \%$ & $96.813 \%$ \\
\hline 176 & a gatas & 0.00303 & $0.059 \%$ & $1.130 \%$ & $96.872 \%$ \\
\hline 177 & bólido & 0.00303 & $0.029 \%$ & $0.565 \%$ & $96.901 \%$ \\
\hline 178 & rueda & 0.00299 & $0.029 \%$ & $0.565 \%$ & $96.930 \%$ \\
\hline 179 & moto de nieve & 0.00290 & $0.044 \%$ & $0.847 \%$ & $96.974 \%$ \\
\hline 180 & tren cremallera & 0.00282 & $0.029 \%$ & $0.565 \%$ & $97.003 \%$ \\
\hline 181 & aire & 0.00282 & $0.015 \%$ & $0.282 \%$ & $97.018 \%$ \\
\hline 182 & dirigible & 0.00268 & $0.044 \%$ & $0.847 \%$ & $97.062 \%$ \\
\hline 183 & monopatín de gasolina & 0.00263 & $0.015 \%$ & $0.282 \%$ & $97.077 \%$ \\
\hline 184 & bicicleta de carretera & 0.00263 & $0.015 \%$ & $0.282 \%$ & $97.092 \%$ \\
\hline 185 & Smart* & 0.00263 & $0.015 \%$ & $0.282 \%$ & $97.107 \%$ \\
\hline 186 & macho & 0.00263 & $0.015 \%$ & $0.282 \%$ & $97.122 \%$ \\
\hline 187 & autobús público & 0.00263 & $0.015 \%$ & $0.282 \%$ & $97.137 \%$ \\
\hline 188 & zapatilla & 0.00263 & $0.015 \%$ & $0.282 \%$ & $97.152 \%$ \\
\hline 189 & rulo & 0.00261 & $0.029 \%$ & $0.565 \%$ & $97.181 \%$ \\
\hline 190 & volar & 0.00254 & $0.029 \%$ & $0.565 \%$ & $97.210 \%$ \\
\hline 191 & carro de caballos & 0.00254 & $0.029 \%$ & $0.565 \%$ & $97.239 \%$ \\
\hline 192 & remonte & 0.00250 & $0.029 \%$ & $0.565 \%$ & $97.268 \%$ \\
\hline 193 & poni & 0.00249 & $0.044 \%$ & $0.847 \%$ & $97.312 \%$ \\
\hline 194 & jumbo & 0.00248 & $0.029 \%$ & $0.565 \%$ & $97.341 \%$ \\
\hline 195 & maquinista & 0.00246 & $0.015 \%$ & $0.282 \%$ & $97.356 \%$ \\
\hline 196 & Mitsubishi* & 0.00246 & $0.015 \%$ & $0.282 \%$ & $97.371 \%$ \\
\hline 197 & aerotaxi & 0.00246 & $0.015 \%$ & $0.282 \%$ & $97.386 \%$ \\
\hline 198 & aeronave & 0.00244 & $0.044 \%$ & $0.847 \%$ & $97.430 \%$ \\
\hline 199 & carro de niños & 0.00238 & $0.029 \%$ & $0.565 \%$ & $97.459 \%$ \\
\hline 200 & autocaravana & 0.00233 & $0.029 \%$ & $0.565 \%$ & $97.488 \%$ \\
\hline 201 & buceando & 0.00232 & $0.059 \%$ & $1.130 \%$ & $97.547 \%$ \\
\hline 202 & escalera mecánica & 0.00231 & $0.029 \%$ & $0.565 \%$ & $97.576 \%$ \\
\hline 203 & skateboard & 0.00231 & $0.029 \%$ & $0.565 \%$ & $97.605 \%$ \\
\hline 204 & vagoneta & 0.00229 & $0.015 \%$ & $0.282 \%$ & $97.620 \%$ \\
\hline 205 & saltando & 0.00229 & $0.015 \%$ & $0.282 \%$ & $97.635 \%$ \\
\hline 206 & coche privado & 0.00229 & $0.015 \%$ & $0.282 \%$ & $97.650 \%$ \\
\hline 207 & rodilla & 0.00229 & $0.015 \%$ & $0.282 \%$ & $97.665 \%$ \\
\hline 208 & descapotable & 0.00229 & $0.029 \%$ & $0.565 \%$ & $97.694 \%$ \\
\hline 209 & container & 0.00229 & $0.015 \%$ & $0.282 \%$ & $97.709 \%$ \\
\hline 210 & vehículo especial & 0.00229 & $0.015 \%$ & $0.282 \%$ & $97.724 \%$ \\
\hline 211 & (tren) regional & 0.00224 & $0.029 \%$ & $0.565 \%$ & $97.753 \%$ \\
\hline 212 & a pata coja & 0.00223 & $0.029 \%$ & $0.565 \%$ & $97.782 \%$ \\
\hline 213 & correr & 0.00221 & $0.029 \%$ & $0.565 \%$ & $97.811 \%$ \\
\hline 214 & motor & 0.00221 & $0.029 \%$ & $0.565 \%$ & $97.840 \%$ \\
\hline 215 & velomotor & 0.00214 & $0.015 \%$ & $0.282 \%$ & $97.855 \%$ \\
\hline 216 & barco de vapor & 0.00209 & $0.029 \%$ & $0.565 \%$ & $97.884 \%$ \\
\hline 217 & rompehielos & 0.00206 & $0.029 \%$ & $0.565 \%$ & $97.913 \%$ \\
\hline 218 & muleta & 0.00203 & $0.029 \%$ & $0.565 \%$ & $97.942 \%$ \\
\hline
\end{tabular}




\begin{tabular}{|c|c|c|c|c|c|}
\hline 219 & cuadriga & 0.00199 & $0.029 \%$ & $0.565 \%$ & $97.971 \%$ \\
\hline 220 & de tracción animal & 0.00199 & $0.015 \%$ & $0.282 \%$ & $97.986 \%$ \\
\hline 221 & tierra & 0.00199 & $0.015 \%$ & $0.282 \%$ & $98.001 \%$ \\
\hline 222 & moto de carretera & 0.00199 & $0.015 \%$ & $0.282 \%$ & $98.016 \%$ \\
\hline 223 & monocarril & 0.00186 & $0.015 \%$ & $0.282 \%$ & $98.031 \%$ \\
\hline 224 & coche familiar & 0.00186 & $0.015 \%$ & $0.282 \%$ & $98.046 \%$ \\
\hline 225 & lanzadera espacial & 0.00186 & $0.015 \%$ & $0.282 \%$ & $98.061 \%$ \\
\hline 226 & goleta & 0.00186 & $0.015 \%$ & $0.282 \%$ & $98.076 \%$ \\
\hline 227 & asiento & 0.00186 & $0.015 \%$ & $0.282 \%$ & $98.091 \%$ \\
\hline 228 & volando & 0.00186 & $0.015 \%$ & $0.282 \%$ & $98.106 \%$ \\
\hline 229 & Mercedes* & 0.00186 & $0.015 \%$ & $0.282 \%$ & $98.121 \%$ \\
\hline 230 & jet privado & 0.00186 & $0.015 \%$ & $0.282 \%$ & $98.136 \%$ \\
\hline 231 & barco de pesca & 0.00186 & $0.015 \%$ & $0.282 \%$ & $98.151 \%$ \\
\hline 232 & autogiro & 0.00186 & $0.029 \%$ & $0.565 \%$ & $98.180 \%$ \\
\hline 233 & (tren de) mercancías & 0.00183 & $0.029 \%$ & $0.565 \%$ & $98.209 \%$ \\
\hline 234 & volante & 0.00173 & $0.015 \%$ & $0.282 \%$ & $98.224 \%$ \\
\hline 235 & Iberia & 0.00173 & $0.015 \%$ & $0.282 \%$ & $98.239 \%$ \\
\hline 236 & transporte especial & 0.00173 & $0.015 \%$ & $0.282 \%$ & $98.254 \%$ \\
\hline 237 & moto de alta cilindrada & 0.00173 & $0.015 \%$ & $0.282 \%$ & $98.269 \%$ \\
\hline 238 & Intercity & 0.00173 & $0.015 \%$ & $0.282 \%$ & $98.284 \%$ \\
\hline 239 & quad & 0.00171 & $0.029 \%$ & $0.565 \%$ & $98.313 \%$ \\
\hline 240 & carro de compra & 0.00169 & $0.029 \%$ & $0.565 \%$ & $98.342 \%$ \\
\hline 241 & barcaza & 0.00165 & $0.029 \%$ & $0.565 \%$ & $98.371 \%$ \\
\hline 242 & vehículo articulado & 0.00162 & $0.015 \%$ & $0.282 \%$ & $98.386 \%$ \\
\hline 243 & destructor & 0.00162 & $0.015 \%$ & $0.282 \%$ & $98.401 \%$ \\
\hline 244 & freno & 0.00162 & $0.015 \%$ & $0.282 \%$ & $98.416 \%$ \\
\hline 245 & Renfe & 0.00162 & $0.015 \%$ & $0.282 \%$ & $98.431 \%$ \\
\hline 246 & patín de cuatro ruedas & 0.00162 & $0.015 \%$ & $0.282 \%$ & $98.446 \%$ \\
\hline 247 & bimotor & 0.00156 & $0.029 \%$ & $0.565 \%$ & $98.475 \%$ \\
\hline 248 & surfing & 0.00156 & $0.029 \%$ & $0.565 \%$ & $98.504 \%$ \\
\hline 249 & ranchera & 0.00152 & $0.029 \%$ & $0.565 \%$ & $98.533 \%$ \\
\hline 250 & monoplano & 0.00151 & $0.015 \%$ & $0.282 \%$ & $98.548 \%$ \\
\hline 251 & ómnibus & 0.00151 & $0.015 \%$ & $0.282 \%$ & $98.563 \%$ \\
\hline 252 & máquina del tiempo & 0.00151 & $0.015 \%$ & $0.282 \%$ & $98.578 \%$ \\
\hline 253 & cinturón de seguridad & 0.00151 & $0.015 \%$ & $0.282 \%$ & $98.593 \%$ \\
\hline 254 & rodando & 0.00151 & $0.015 \%$ & $0.282 \%$ & $98.608 \%$ \\
\hline 255 & guagua & 0.00151 & $0.015 \%$ & $0.282 \%$ & $98.623 \%$ \\
\hline 256 & vehículo de minusválido & 0.00151 & $0.015 \%$ & $0.282 \%$ & $98.638 \%$ \\
\hline 257 & barco de remos & 0.00151 & $0.015 \%$ & $0.282 \%$ & $98.653 \%$ \\
\hline 258 & minivolumen & 0.00151 & $0.015 \%$ & $0.282 \%$ & $98.668 \%$ \\
\hline 259 & a cuatro patas & 0.00146 & $0.029 \%$ & $0.565 \%$ & $98.697 \%$ \\
\hline 260 & mulo & 0.00146 & $0.029 \%$ & $0.565 \%$ & $98.726 \%$ \\
\hline 261 & avión de pasajeros & 0.00141 & $0.015 \%$ & $0.282 \%$ & $98.741 \%$ \\
\hline 262 & maletero & 0.00141 & $0.015 \%$ & $0.282 \%$ & $98.756 \%$ \\
\hline 263 & calle & 0.00141 & $0.015 \%$ & $0.282 \%$ & $98.771 \%$ \\
\hline 264 & avión especial & 0.00141 & $0.015 \%$ & $0.282 \%$ & $98.786 \%$ \\
\hline 265 & bicicleta de montaña & 0.00141 & $0.015 \%$ & $0.282 \%$ & $98.801 \%$ \\
\hline
\end{tabular}




\begin{tabular}{|c|c|c|c|c|c|}
\hline 266 & bombardero & 0.00141 & $0.015 \%$ & $0.282 \%$ & $98.816 \%$ \\
\hline 267 & kayak & 0.00131 & $0.015 \%$ & $0.282 \%$ & $98.831 \%$ \\
\hline 268 & autopista & 0.00131 & $0.015 \%$ & $0.282 \%$ & $98.846 \%$ \\
\hline 269 & animal de montura & 0.00131 & $0.015 \%$ & $0.282 \%$ & $98.861 \%$ \\
\hline 270 & autobús de dos pisos & 0.00131 & $0.015 \%$ & $0.282 \%$ & $98.876 \%$ \\
\hline 271 & liana & 0.00128 & $0.029 \%$ & $0.565 \%$ & $98.905 \%$ \\
\hline 272 & planeadora & 0.00122 & $0.015 \%$ & $0.282 \%$ & $98.920 \%$ \\
\hline 273 & patinete de agua & 0.00122 & $0.015 \%$ & $0.282 \%$ & $98.935 \%$ \\
\hline 274 & esquiando & 0.00122 & $0.015 \%$ & $0.282 \%$ & $98.950 \%$ \\
\hline 275 & pájaro & 0.00122 & $0.015 \%$ & $0.282 \%$ & $98.965 \%$ \\
\hline 276 & ala & 0.00122 & $0.015 \%$ & $0.282 \%$ & $98.980 \%$ \\
\hline 277 & moto de tres ruedas & 0.00122 & $0.015 \%$ & $0.282 \%$ & $98.995 \%$ \\
\hline 278 & vuelo chárter & 0.00122 & $0.015 \%$ & $0.282 \%$ & $99.010 \%$ \\
\hline 279 & vehículo con remolque & 0.00122 & $0.015 \%$ & $0.282 \%$ & $99.025 \%$ \\
\hline 280 & motocicleta con sidecar & 0.00122 & $0.015 \%$ & $0.282 \%$ & $99.040 \%$ \\
\hline 281 & bote salvavidas & 0.00122 & $0.015 \%$ & $0.282 \%$ & $99.055 \%$ \\
\hline 282 & moto de cuatro ruedas & 0.00122 & $0.015 \%$ & $0.282 \%$ & $99.070 \%$ \\
\hline 283 & llama & 0.00118 & $0.029 \%$ & $0.565 \%$ & $99.099 \%$ \\
\hline 284 & mar & 0.00114 & $0.015 \%$ & $0.282 \%$ & $99.114 \%$ \\
\hline 285 & barca hinchable & 0.00114 & $0.029 \%$ & $0.565 \%$ & $99.143 \%$ \\
\hline 286 & biplano & 0.00114 & $0.015 \%$ & $0.282 \%$ & $99.158 \%$ \\
\hline 287 & motor de agua & 0.00106 & $0.015 \%$ & $0.282 \%$ & $99.173 \%$ \\
\hline 288 & gasolina & 0.00106 & $0.015 \%$ & $0.282 \%$ & $99.188 \%$ \\
\hline 289 & vehículo agrónomo & 0.00106 & $0.015 \%$ & $0.282 \%$ & $99.203 \%$ \\
\hline 290 & Euromed & 0.00106 & $0.015 \%$ & $0.282 \%$ & $99.218 \%$ \\
\hline 291 & trineo de perros & 0.00106 & $0.015 \%$ & $0.282 \%$ & $99.233 \%$ \\
\hline 292 & bicicleta a motor & 0.00106 & $0.015 \%$ & $0.282 \%$ & $99.248 \%$ \\
\hline 293 & Arco & 0.00106 & $0.015 \%$ & $0.282 \%$ & $99.263 \%$ \\
\hline 294 & tabla & 0.00099 & $0.015 \%$ & $0.282 \%$ & $99.278 \%$ \\
\hline 295 & rolar & 0.00099 & $0.015 \%$ & $0.282 \%$ & $99.293 \%$ \\
\hline 296 & autovía & 0.00099 & $0.015 \%$ & $0.282 \%$ & $99.308 \%$ \\
\hline 297 & avión a reacción & 0.00099 & $0.015 \%$ & $0.282 \%$ & $99.323 \%$ \\
\hline 298 & cinta transportadora & 0.00099 & $0.015 \%$ & $0.282 \%$ & $99.338 \%$ \\
\hline 299 & coche cuatro por cuatro & 0.00099 & $0.015 \%$ & $0.282 \%$ & $99.353 \%$ \\
\hline 300 & aerostático & 0.00099 & $0.015 \%$ & $0.282 \%$ & $99.368 \%$ \\
\hline 301 & chalupa & 0.00093 & $0.015 \%$ & $0.282 \%$ & $99.383 \%$ \\
\hline 302 & cosechadora & 0.00093 & $0.015 \%$ & $0.282 \%$ & $99.398 \%$ \\
\hline 303 & scooter & 0.00086 & $0.015 \%$ & $0.282 \%$ & $99.413 \%$ \\
\hline 304 & puenting & 0.00086 & $0.015 \%$ & $0.282 \%$ & $99.428 \%$ \\
\hline 305 & motorista & 0.00086 & $0.015 \%$ & $0.282 \%$ & $99.443 \%$ \\
\hline 306 & moto con sidecar & 0.00086 & $0.015 \%$ & $0.282 \%$ & $99.458 \%$ \\
\hline 307 & batiscafo & 0.00086 & $0.015 \%$ & $0.282 \%$ & $99.473 \%$ \\
\hline 308 & patín de agua & 0.00081 & $0.015 \%$ & $0.282 \%$ & $99.488 \%$ \\
\hline 309 & remo & 0.00081 & $0.015 \%$ & $0.282 \%$ & $99.503 \%$ \\
\hline 310 & casco & 0.00081 & $0.015 \%$ & $0.282 \%$ & $99.518 \%$ \\
\hline 311 & escalera automática & 0.00081 & $0.015 \%$ & $0.282 \%$ & $99.533 \%$ \\
\hline 312 & teledirigido & 0.00081 & $0.015 \%$ & $0.282 \%$ & $99.548 \%$ \\
\hline
\end{tabular}




\begin{tabular}{|l|l|l|l|l|l|}
\hline 313 & cabina & 0.00081 & $0.015 \%$ & $0.282 \%$ & $99.563 \%$ \\
\hline 314 & embarcación & 0.00081 & $0.015 \%$ & $0.282 \%$ & $99.578 \%$ \\
\hline 315 & barca de pesca & 0.00081 & $0.015 \%$ & $0.282 \%$ & $99.593 \%$ \\
\hline 316 & máquina excavadora & 0.00081 & $0.015 \%$ & $0.282 \%$ & $99.608 \%$ \\
\hline 317 & moto de carreras & 0.00081 & $0.015 \%$ & $0.282 \%$ & $99.623 \%$ \\
\hline 318 & camilla & 0.00081 & $0.015 \%$ & $0.282 \%$ & $99.638 \%$ \\
\hline 319 & footing & 0.00075 & $0.015 \%$ & $0.282 \%$ & $99.653 \%$ \\
\hline 320 & fórmula uno & 0.00075 & $0.015 \%$ & $0.282 \%$ & $99.668 \%$ \\
\hline 321 & cochecito de niño & 0.00075 & $0.015 \%$ & $0.282 \%$ & $99.683 \%$ \\
\hline 322 & remar & 0.00075 & $0.015 \%$ & $0.282 \%$ & $99.698 \%$ \\
\hline 323 & tubo de escape & 0.00075 & $0.015 \%$ & $0.282 \%$ & $99.713 \%$ \\
\hline 324 & quitanieves & 0.00070 & $0.015 \%$ & $0.282 \%$ & $99.728 \%$ \\
\hline 325 & subterráneo & 0.00070 & $0.015 \%$ & $0.282 \%$ & $99.758 \%$ \\
\hline 326 & zapato & 0.00070 & $0.015 \%$ & $0.282 \%$ & $99.773 \%$ \\
\hline 327 & paracaidismo & 0.00065 & $0.015 \%$ & $0.282 \%$ & $99.788 \%$ \\
\hline 328 & cochecito & 0.00065 & $0.015 \%$ & $0.282 \%$ & $99.803 \%$ \\
\hline 329 & furgón blindado & 0.00065 & $0.015 \%$ & $0.282 \%$ & $99.818 \%$ \\
\hline 330 & en brazos & 0.00061 & $0.015 \%$ & $0.282 \%$ & $99.833 \%$ \\
\hline 331 & camión cisterna & 0.00061 & $0.015 \%$ & $0.282 \%$ & $99.848 \%$ \\
\hline 332 & remolcador & 0.00061 & $0.015 \%$ & $0.282 \%$ & $99.863 \%$ \\
\hline 333 & escoba & 0.00057 & $0.015 \%$ & $0.282 \%$ & $99.878 \%$ \\
\hline 334 & paloma mensajera & 0.00057 & $0.015 \%$ & $0.282 \%$ & $99.893 \%$ \\
\hline 335 & buey & 0.00053 & $0.015 \%$ & $0.282 \%$ & $99.908 \%$ \\
\hline 336 & yugo & 0.00053 & $0.015 \%$ & $0.282 \%$ & $99.923 \%$ \\
\hline 337 & barca de remos & 0.00053 & $0.015 \%$ & $0.282 \%$ & $99.938 \%$ \\
\hline 338 & cohete espacial & 0.00049 & $0.015 \%$ & $0.282 \%$ & $99.953 \%$ \\
\hline 339 & barca de motor & 0.00049 & $0.015 \%$ & $0.282 \%$ & $99.968 \%$ \\
\hline 340 & aerodeslizador & 0.00049 & $0.015 \%$ & $0.282 \%$ & $99.983 \%$ \\
\hline 341 & a cuestas de alguien & 0.00046 & $0.015 \%$ & $0.282 \%$ & $99.998 \%$ \\
\hline 342 & catapulta & 0.00043 & $0.015 \%$ & $0.282 \%$ & $100.013 \%$ \\
\hline 343 & caza & 0.00040 & $0.015 \%$ & $0.282 \%$ & $100.028 \%$ \\
\hline & & & & & \\
\hline
\end{tabular}

\section{TRABAJOS DEL CAMPO Y DEL JARDÍN}

\begin{tabular}{|c|l|c|c|c|c|}
\hline $\mathrm{N}^{\mathrm{o}}$ & Palabra & Disponibilidad & $\begin{array}{c}\text { Frecuencia } \\
\text { relativa }\end{array}$ & $\%$ Aparición & $\begin{array}{c}\text { Frecuencia } \\
\text { acumulada }\end{array}$ \\
\hline 1 & regar & 0.50496 & $5.946 \%$ & $67.232 \%$ & $5.946 \%$ \\
\hline 2 & podar & 0.41746 & $4.821 \%$ & $54.520 \%$ & $10.767 \%$ \\
\hline 3 & plantar & 0.37736 & $4.771 \%$ & $53.955 \%$ & $15.538 \%$ \\
\hline 4 & abonar & 0.29316 & $4.022 \%$ & $45.480 \%$ & $19.560 \%$ \\
\hline 5 & jardinero & 0.25400 & $2.573 \%$ & $29.096 \%$ & $22.133 \%$ \\
\hline 6 & arar & 0.21548 & $2.698 \%$ & $30.508 \%$ & $24.831 \%$ \\
\hline 7 & sembrar & 0.20202 & $2.623 \%$ & $29.661 \%$ & $27.454 \%$ \\
\hline
\end{tabular}




\begin{tabular}{|c|c|c|c|c|c|}
\hline 8 & agricultor & 0.18835 & $1.899 \%$ & $21.469 \%$ & $29.353 \%$ \\
\hline 9 & recolectar & 0.18190 & $2.373 \%$ & $26.836 \%$ & $31.726 \%$ \\
\hline 10 & segar & 0.17778 & $2.373 \%$ & $26.836 \%$ & $34.099 \%$ \\
\hline 11 & cultivar & 0.17317 & $2.198 \%$ & $24.859 \%$ & $36.297 \%$ \\
\hline 12 & cortar & 0.16481 & $2.223 \%$ & $25.141 \%$ & $38.520 \%$ \\
\hline 13 & labrar & 0.14285 & $1.674 \%$ & $18.927 \%$ & $40.194 \%$ \\
\hline 14 & pulverizar & 0.12819 & $1.774 \%$ & $20.056 \%$ & $41.968 \%$ \\
\hline 15 & cavar & 0.11632 & $1.499 \%$ & $16.949 \%$ & $43.467 \%$ \\
\hline 16 & cortar el césped & 0.11448 & $1.474 \%$ & $16.667 \%$ & $44.941 \%$ \\
\hline 17 & recoger & 0.10878 & $1.499 \%$ & $16.949 \%$ & $46.440 \%$ \\
\hline 18 & transplantar & 0.10685 & $1.524 \%$ & $17.232 \%$ & $47.964 \%$ \\
\hline 19 & ganadero & 0.09189 & $1.149 \%$ & $12.994 \%$ & $49.113 \%$ \\
\hline 20 & regador & 0.08864 & $1.074 \%$ & $12.147 \%$ & $50.187 \%$ \\
\hline 21 & injertar & 0.08721 & $1.424 \%$ & $16.102 \%$ & $51.611 \%$ \\
\hline 22 & fumigar & 0.07871 & $1.124 \%$ & $12.712 \%$ & $52.735 \%$ \\
\hline 23 & pastor & 0.06858 & $0.899 \%$ & $10.169 \%$ & $53.634 \%$ \\
\hline 24 & podador & 0.06450 & $0.749 \%$ & $8.475 \%$ & $54.383 \%$ \\
\hline 25 & granjero & 0.06331 & $0.799 \%$ & $9.040 \%$ & $55.182 \%$ \\
\hline 26 & recolector & 0.06315 & $0.799 \%$ & $9.040 \%$ & $55.981 \%$ \\
\hline 27 & talar & 0.05114 & $0.724 \%$ & $8.192 \%$ & $56.705 \%$ \\
\hline 28 & empeltar & 0.04931 & $0.724 \%$ & $8.192 \%$ & $57.429 \%$ \\
\hline 29 & sulfatar & 0.04600 & $0.749 \%$ & $8.475 \%$ & $58.178 \%$ \\
\hline 30 & cosechar & 0.04509 & $0.600 \%$ & $6.780 \%$ & $58.778 \%$ \\
\hline 31 & hacer caballones & 0.04418 & $0.625 \%$ & $7.062 \%$ & $59.403 \%$ \\
\hline 32 & arrancar & 0.04398 & $0.724 \%$ & $8.192 \%$ & $60.127 \%$ \\
\hline 33 & guardabosques & 0.04393 & $0.600 \%$ & $6.780 \%$ & $60.727 \%$ \\
\hline 34 & labrador & 0.04385 & $0.500 \%$ & $5.650 \%$ & $61.227 \%$ \\
\hline 35 & limpiar & 0.03676 & $0.575 \%$ & $6.497 \%$ & $61.802 \%$ \\
\hline 36 & quemar & 0.03451 & $0.500 \%$ & $5.650 \%$ & $62.302 \%$ \\
\hline 37 & florista & 0.03437 & $0.400 \%$ & $4.520 \%$ & $62.702 \%$ \\
\hline 38 & cuidar & 0.03421 & $0.525 \%$ & $5.932 \%$ & $63.227 \%$ \\
\hline 39 & quemar leña & 0.03210 & $0.500 \%$ & $5.650 \%$ & $63.727 \%$ \\
\hline 40 & apicultor & 0.03050 & $0.375 \%$ & $4.237 \%$ & $64.102 \%$ \\
\hline 41 & campesino & 0.03009 & $0.375 \%$ & $4.237 \%$ & $64.477 \%$ \\
\hline 42 & leñador & 0.02875 & $0.400 \%$ & $4.520 \%$ & $64.877 \%$ \\
\hline 43 & trillar & 0.02760 & $0.500 \%$ & $5.650 \%$ & $65.377 \%$ \\
\hline 44 & recolección & 0.02746 & $0.300 \%$ & $3.390 \%$ & $65.677 \%$ \\
\hline 45 & polvorizar & 0.02717 & $0.400 \%$ & $4.520 \%$ & $66.077 \%$ \\
\hline 46 & cortador de césped & 0.02674 & $0.325 \%$ & $3.672 \%$ & $66.402 \%$ \\
\hline 47 & coger naranjas & 0.02498 & $0.325 \%$ & $3.672 \%$ & $66.727 \%$ \\
\hline 48 & cazador & 0.02350 & $0.325 \%$ & $3.672 \%$ & $67.052 \%$ \\
\hline 49 & recoger frutos & 0.02318 & $0.375 \%$ & $4.237 \%$ & $67.427 \%$ \\
\hline 50 & sembrador & 0.02296 & $0.275 \%$ & $3.107 \%$ & $67.702 \%$ \\
\hline 51 & quitar malas hierbas & 0.02250 & $0.325 \%$ & $3.672 \%$ & $68.027 \%$ \\
\hline 52 & segador & 0.02229 & $0.275 \%$ & $3.107 \%$ & $68.302 \%$ \\
\hline 53 & plantador & 0.02155 & $0.325 \%$ & $3.672 \%$ & $68.627 \%$ \\
\hline 54 & ordeñar & 0.02127 & $0.400 \%$ & $4.520 \%$ & $69.027 \%$ \\
\hline
\end{tabular}




\begin{tabular}{|c|c|c|c|c|c|}
\hline 55 & cortar leña & 0.01927 & $0.350 \%$ & $3.955 \%$ & $69.377 \%$ \\
\hline 56 & replantar & 0.01904 & $0.300 \%$ & $3.390 \%$ & $69.677 \%$ \\
\hline 57 & coger & 0.01889 & $0.225 \%$ & $2.542 \%$ & $69.902 \%$ \\
\hline 58 & fumigador & 0.01849 & $0.250 \%$ & $2.825 \%$ & $70.152 \%$ \\
\hline 59 & cortacésped & 0.01848 & $0.200 \%$ & $2.260 \%$ & $70.352 \%$ \\
\hline 60 & fertilizar & 0.01808 & $0.275 \%$ & $3.107 \%$ & $70.627 \%$ \\
\hline 61 & abonador & 0.01787 & $0.275 \%$ & $3.107 \%$ & $70.902 \%$ \\
\hline 62 & arreglar & 0.01761 & $0.325 \%$ & $3.672 \%$ & $71.227 \%$ \\
\hline 63 & jardinería & 0.01728 & $0.175 \%$ & $1.977 \%$ & $71.402 \%$ \\
\hline 64 & cortar ramas & 0.01548 & $0.200 \%$ & $2.260 \%$ & $71.602 \%$ \\
\hline 65 & recogedor & 0.01509 & $0.200 \%$ & $2.260 \%$ & $71.802 \%$ \\
\hline 66 & cultivador & 0.01499 & $0.225 \%$ & $2.542 \%$ & $72.027 \%$ \\
\hline 67 & regar plantas & 0.01496 & $0.150 \%$ & $1.695 \%$ & $72.177 \%$ \\
\hline 68 & cortar flores & 0.01483 & $0.175 \%$ & $1.977 \%$ & $72.352 \%$ \\
\hline 69 & talar árboles & 0.01476 & $0.200 \%$ & $2.260 \%$ & $72.552 \%$ \\
\hline 70 & plantar árboles & 0.01457 & $0.225 \%$ & $2.542 \%$ & $72.777 \%$ \\
\hline 71 & remover la tierra & 0.01382 & $0.200 \%$ & $2.260 \%$ & $72.977 \%$ \\
\hline 72 & quitar hierbas & 0.01375 & $0.175 \%$ & $1.977 \%$ & $73.152 \%$ \\
\hline 73 & plantar flores & 0.01348 & $0.175 \%$ & $1.977 \%$ & $73.327 \%$ \\
\hline 74 & siembra & 0.01332 & $0.150 \%$ & $1.695 \%$ & $73.477 \%$ \\
\hline 75 & collidor & 0.01313 & $0.150 \%$ & $1.695 \%$ & $73.627 \%$ \\
\hline 76 & pastorear & 0.01309 & $0.250 \%$ & $2.825 \%$ & $73.877 \%$ \\
\hline 77 & cortador & 0.01275 & $0.150 \%$ & $1.695 \%$ & $74.027 \%$ \\
\hline 78 & talador & 0.01184 & $0.175 \%$ & $1.977 \%$ & $74.202 \%$ \\
\hline 79 & esquilar & 0.01152 & $0.175 \%$ & $1.977 \%$ & $74.377 \%$ \\
\hline 80 & arar la tierra & 0.01143 & $0.125 \%$ & $1.412 \%$ & $74.502 \%$ \\
\hline 81 & cortar árboles & 0.01130 & $0.175 \%$ & $1.977 \%$ & $74.677 \%$ \\
\hline 82 & floristería & 0.01125 & $0.125 \%$ & $1.412 \%$ & $74.802 \%$ \\
\hline 83 & hacer soquetes & 0.01037 & $0.175 \%$ & $1.977 \%$ & $74.977 \%$ \\
\hline 84 & recoger fruta & 0.01020 & $0.150 \%$ & $1.695 \%$ & $75.127 \%$ \\
\hline 85 & agrónomo & 0.00942 & $0.125 \%$ & $1.412 \%$ & $75.252 \%$ \\
\hline 86 & vendimiar & 0.00937 & $0.150 \%$ & $1.695 \%$ & $75.402 \%$ \\
\hline 87 & arado & 0.00929 & $0.100 \%$ & $1.130 \%$ & $75.502 \%$ \\
\hline 88 & cortar malas hierbas & 0.00925 & $0.150 \%$ & $1.695 \%$ & $75.652 \%$ \\
\hline 89 & empeltador & 0.00922 & $0.125 \%$ & $1.412 \%$ & $75.777 \%$ \\
\hline 90 & quemar ramas & 0.00918 & $0.175 \%$ & $1.977 \%$ & $75.952 \%$ \\
\hline 91 & pintar & 0.00907 & $0.175 \%$ & $1.977 \%$ & $76.127 \%$ \\
\hline 92 & pasturar & 0.00907 & $0.175 \%$ & $1.977 \%$ & $76.302 \%$ \\
\hline 93 & recoger flores & 0.00885 & $0.100 \%$ & $1.130 \%$ & $76.402 \%$ \\
\hline 94 & espigolar & 0.00872 & $0.100 \%$ & $1.130 \%$ & $76.502 \%$ \\
\hline 95 & ordeñar vacas & 0.00866 & $0.175 \%$ & $1.977 \%$ & $76.677 \%$ \\
\hline 96 & vaquero & 0.00839 & $0.100 \%$ & $1.130 \%$ & $76.777 \%$ \\
\hline 97 & forestal & 0.00839 & $0.125 \%$ & $1.412 \%$ & $76.902 \%$ \\
\hline 98 & excavar & 0.00836 & $0.150 \%$ & $1.695 \%$ & $77.052 \%$ \\
\hline 99 & alimentar animales & 0.00835 & $0.150 \%$ & $1.695 \%$ & $77.202 \%$ \\
\hline 100 & cosechador & 0.00828 & $0.100 \%$ & $1.130 \%$ & $77.302 \%$ \\
\hline 101 & riego & 0.00820 & $0.100 \%$ & $1.130 \%$ & $77.402 \%$ \\
\hline
\end{tabular}




\begin{tabular}{|c|c|c|c|c|c|}
\hline 102 & pala & 0.00819 & $0.100 \%$ & $1.130 \%$ & $77.502 \%$ \\
\hline 103 & agricultura & 0.00811 & $0.100 \%$ & $1.130 \%$ & $77.602 \%$ \\
\hline 104 & cogedor de naranjas & 0.00805 & $0.075 \%$ & $0.847 \%$ & $77.677 \%$ \\
\hline 105 & pico & 0.00791 & $0.100 \%$ & $1.130 \%$ & $77.777 \%$ \\
\hline 106 & biólogo & 0.00790 & $0.150 \%$ & $1.695 \%$ & $77.927 \%$ \\
\hline 107 & recoger la cosecha & 0.00788 & $0.100 \%$ & $1.130 \%$ & $78.027 \%$ \\
\hline 108 & pulverizador & 0.00785 & $0.100 \%$ & $1.130 \%$ & $78.127 \%$ \\
\hline 109 & roturar & 0.00785 & $0.100 \%$ & $1.130 \%$ & $78.227 \%$ \\
\hline 110 & ganadería & 0.00773 & $0.100 \%$ & $1.130 \%$ & $78.327 \%$ \\
\hline 111 & trabajar la tierra & 0.00752 & $0.150 \%$ & $1.695 \%$ & $78.477 \%$ \\
\hline 112 & guarda forestal & 0.00751 & $0.125 \%$ & $1.412 \%$ & $78.602 \%$ \\
\hline 113 & azada & 0.00743 & $0.075 \%$ & $0.847 \%$ & $78.677 \%$ \\
\hline 114 & cabrero & 0.00740 & $0.100 \%$ & $1.130 \%$ & $78.777 \%$ \\
\hline 115 & escarbar & 0.00721 & $0.075 \%$ & $0.847 \%$ & $78.852 \%$ \\
\hline 116 & recoger leña & 0.00720 & $0.150 \%$ & $1.695 \%$ & $79.002 \%$ \\
\hline 117 & trillador & 0.00714 & $0.100 \%$ & $1.130 \%$ & $79.102 \%$ \\
\hline 118 & ovejero & 0.00700 & $0.100 \%$ & $1.130 \%$ & $79.202 \%$ \\
\hline 119 & hacer sazón & 0.00699 & $0.100 \%$ & $1.130 \%$ & $79.302 \%$ \\
\hline 120 & porquero & 0.00697 & $0.100 \%$ & $1.130 \%$ & $79.402 \%$ \\
\hline 121 & Apicultura & 0.00691 & $0.075 \%$ & $0.847 \%$ & $79.477 \%$ \\
\hline 122 & conductor de tractor & 0.00690 & $0.100 \%$ & $1.130 \%$ & $79.577 \%$ \\
\hline 123 & siega & 0.00690 & $0.125 \%$ & $1.412 \%$ & $79.702 \%$ \\
\hline 124 & recoger naranjas & 0.00681 & $0.075 \%$ & $0.847 \%$ & $79.777 \%$ \\
\hline 125 & sazón & 0.00678 & $0.100 \%$ & $1.130 \%$ & $79.877 \%$ \\
\hline 126 & recoger almendras & 0.00661 & $0.100 \%$ & $1.130 \%$ & $79.977 \%$ \\
\hline 127 & recoger huevos & 0.00658 & $0.125 \%$ & $1.412 \%$ & $80.102 \%$ \\
\hline 128 & sembrado & 0.00646 & $0.075 \%$ & $0.847 \%$ & $80.177 \%$ \\
\hline 129 & collir & 0.00646 & $0.075 \%$ & $0.847 \%$ & $80.252 \%$ \\
\hline 130 & flor & 0.00645 & $0.075 \%$ & $0.847 \%$ & $80.327 \%$ \\
\hline 131 & arrancar malas hierbas & 0.00641 & $0.100 \%$ & $1.130 \%$ & $80.427 \%$ \\
\hline 132 & arrancar hierbas & 0.00641 & $0.100 \%$ & $1.130 \%$ & $80.527 \%$ \\
\hline 133 & cortar hierba & 0.00632 & $0.075 \%$ & $0.847 \%$ & $80.602 \%$ \\
\hline 134 & quemar rastrojos & 0.00626 & $0.100 \%$ & $1.130 \%$ & $80.702 \%$ \\
\hline 135 & ingeniero de caminos & 0.00626 & $0.075 \%$ & $0.847 \%$ & $80.777 \%$ \\
\hline 136 & cuidar flores & 0.00616 & $0.100 \%$ & $1.130 \%$ & $80.877 \%$ \\
\hline 137 & recogedor de naranjas & 0.00607 & $0.075 \%$ & $0.847 \%$ & $80.952 \%$ \\
\hline 138 & manguera & 0.00589 & $0.125 \%$ & $1.412 \%$ & $81.077 \%$ \\
\hline 139 & enterrar & 0.00580 & $0.100 \%$ & $1.130 \%$ & $81.177 \%$ \\
\hline 140 & coger frutos & 0.00567 & $0.075 \%$ & $0.847 \%$ & $81.252 \%$ \\
\hline 141 & arrancar árboles & 0.00566 & $0.075 \%$ & $0.847 \%$ & $81.327 \%$ \\
\hline 142 & saó & 0.00565 & $0.050 \%$ & $0.565 \%$ & $81.377 \%$ \\
\hline 143 & aceitunero & 0.00563 & $0.075 \%$ & $0.847 \%$ & $81.452 \%$ \\
\hline 144 & desinfectar & 0.00558 & $0.100 \%$ & $1.130 \%$ & $81.552 \%$ \\
\hline 145 & ingeniero agrónomo & 0.00558 & $0.075 \%$ & $0.847 \%$ & $81.627 \%$ \\
\hline 146 & podar setos & 0.00543 & $0.050 \%$ & $0.565 \%$ & $81.677 \%$ \\
\hline 147 & alicatar & 0.00543 & $0.050 \%$ & $0.565 \%$ & $81.727 \%$ \\
\hline 148 & cambiar la tierra & 0.00533 & $0.075 \%$ & $0.847 \%$ & $81.802 \%$ \\
\hline
\end{tabular}




\begin{tabular}{|c|c|c|c|c|c|}
\hline 149 & podadora & 0.00522 & $0.050 \%$ & $0.565 \%$ & $81.852 \%$ \\
\hline 150 & césped & 0.00522 & $0.050 \%$ & $0.565 \%$ & $81.902 \%$ \\
\hline 151 & podar árboles & 0.00522 & $0.050 \%$ & $0.565 \%$ & $81.952 \%$ \\
\hline 152 & serrar & 0.00511 & $0.075 \%$ & $0.847 \%$ & $82.027 \%$ \\
\hline 153 & árbol & 0.00509 & $0.075 \%$ & $0.847 \%$ & $82.102 \%$ \\
\hline 154 & limpiar acequias & 0.00507 & $0.150 \%$ & $1.695 \%$ & $82.252 \%$ \\
\hline 155 & hoz & 0.00503 & $0.050 \%$ & $0.565 \%$ & $82.302 \%$ \\
\hline 156 & almacenar & 0.00501 & $0.075 \%$ & $0.847 \%$ & $82.377 \%$ \\
\hline 157 & pescador & 0.00486 & $0.100 \%$ & $1.130 \%$ & $82.477 \%$ \\
\hline 158 & tijeras & 0.00481 & $0.050 \%$ & $0.565 \%$ & $82.527 \%$ \\
\hline 159 & matar hierbas & 0.00480 & $0.100 \%$ & $1.130 \%$ & $82.627 \%$ \\
\hline 160 & hacer soques & 0.00479 & $0.050 \%$ & $0.565 \%$ & $82.677 \%$ \\
\hline 161 & ranchero & 0.00478 & $0.075 \%$ & $0.847 \%$ & $82.752 \%$ \\
\hline 162 & recogida & 0.00470 & $0.050 \%$ & $0.565 \%$ & $82.802 \%$ \\
\hline 163 & horticultor & 0.00470 & $0.050 \%$ & $0.565 \%$ & $82.852 \%$ \\
\hline 164 & carpintero & 0.00464 & $0.050 \%$ & $0.565 \%$ & $82.902 \%$ \\
\hline 165 & trasplantar & 0.00463 & $0.075 \%$ & $0.847 \%$ & $82.977 \%$ \\
\hline 166 & vinicultor & 0.00460 & $0.050 \%$ & $0.565 \%$ & $83.027 \%$ \\
\hline 167 & cavar soques & 0.00460 & $0.050 \%$ & $0.565 \%$ & $83.077 \%$ \\
\hline 168 & cuidador de caballos & 0.00459 & $0.075 \%$ & $0.847 \%$ & $83.152 \%$ \\
\hline 169 & ramader & 0.00458 & $0.075 \%$ & $0.847 \%$ & $83.227 \%$ \\
\hline 170 & implantar & 0.00451 & $0.075 \%$ & $0.847 \%$ & $83.302 \%$ \\
\hline 171 & observar & 0.00449 & $0.100 \%$ & $1.130 \%$ & $83.402 \%$ \\
\hline 172 & florero & 0.00448 & $0.050 \%$ & $0.565 \%$ & $83.452 \%$ \\
\hline 173 & tractorista & 0.00446 & $0.075 \%$ & $0.847 \%$ & $83.527 \%$ \\
\hline 174 & alimentar & 0.00443 & $0.075 \%$ & $0.847 \%$ & $83.602 \%$ \\
\hline 175 & tractor & 0.00442 & $0.050 \%$ & $0.565 \%$ & $83.652 \%$ \\
\hline 176 & airear la tierra & 0.00437 & $0.075 \%$ & $0.847 \%$ & $83.727 \%$ \\
\hline 177 & cazar & 0.00436 & $0.075 \%$ & $0.847 \%$ & $83.802 \%$ \\
\hline 178 & guardia forestal & 0.00435 & $0.075 \%$ & $0.847 \%$ & $83.877 \%$ \\
\hline 179 & vigilante & 0.00433 & $0.050 \%$ & $0.565 \%$ & $83.927 \%$ \\
\hline 180 & recoger la siembra & 0.00429 & $0.075 \%$ & $0.847 \%$ & $84.002 \%$ \\
\hline 181 & tirar & 0.00424 & $0.050 \%$ & $0.565 \%$ & $84.052 \%$ \\
\hline 182 & cultivo & 0.00424 & $0.050 \%$ & $0.565 \%$ & $84.102 \%$ \\
\hline 183 & plantar semillas & 0.00424 & $0.050 \%$ & $0.565 \%$ & $84.152 \%$ \\
\hline 184 & horticultura & 0.00424 & $0.050 \%$ & $0.565 \%$ & $84.202 \%$ \\
\hline 185 & echar agua & 0.00419 & $0.050 \%$ & $0.565 \%$ & $84.252 \%$ \\
\hline 186 & regar árboles & 0.00419 & $0.050 \%$ & $0.565 \%$ & $84.302 \%$ \\
\hline 187 & acaballonar & 0.00419 & $0.050 \%$ & $0.565 \%$ & $84.352 \%$ \\
\hline 188 & cosecha & 0.00417 & $0.050 \%$ & $0.565 \%$ & $84.402 \%$ \\
\hline 189 & recogedor de frutos & 0.00408 & $0.050 \%$ & $0.565 \%$ & $84.452 \%$ \\
\hline 190 & cambiar de maceta & 0.00406 & $0.075 \%$ & $0.847 \%$ & $84.527 \%$ \\
\hline 191 & agujerear & 0.00402 & $0.075 \%$ & $0.847 \%$ & $84.602 \%$ \\
\hline 192 & maceta & 0.00402 & $0.075 \%$ & $0.847 \%$ & $84.677 \%$ \\
\hline 193 & lechero & 0.00399 & $0.050 \%$ & $0.565 \%$ & $84.727 \%$ \\
\hline 194 & jardinera & 0.00395 & $0.050 \%$ & $0.565 \%$ & $84.777 \%$ \\
\hline 195 & vigilar & 0.00394 & $0.075 \%$ & $0.847 \%$ & $84.852 \%$ \\
\hline
\end{tabular}




\begin{tabular}{|c|c|c|c|c|c|}
\hline 196 & tallar & 0.00393 & $0.050 \%$ & $0.565 \%$ & $84.902 \%$ \\
\hline 197 & cuidador & 0.00391 & $0.050 \%$ & $0.565 \%$ & $84.952 \%$ \\
\hline 198 & molinero & 0.00391 & $0.050 \%$ & $0.565 \%$ & $85.002 \%$ \\
\hline 199 & hortelano & 0.00391 & $0.050 \%$ & $0.565 \%$ & $85.052 \%$ \\
\hline 200 & poner semillas & 0.00386 & $0.050 \%$ & $0.565 \%$ & $85.102 \%$ \\
\hline 201 & barrer & 0.00385 & $0.075 \%$ & $0.847 \%$ & $85.177 \%$ \\
\hline 202 & dar de comer a cerdos & 0.00384 & $0.075 \%$ & $0.847 \%$ & $85.252 \%$ \\
\hline 203 & hacer surcos & 0.00384 & $0.050 \%$ & $0.565 \%$ & $85.302 \%$ \\
\hline 204 & recoger hojas & 0.00383 & $0.075 \%$ & $0.847 \%$ & $85.377 \%$ \\
\hline 205 & recoger hierbas & 0.00380 & $0.050 \%$ & $0.565 \%$ & $85.427 \%$ \\
\hline 206 & espulgar & 0.00380 & $0.075 \%$ & $0.847 \%$ & $85.502 \%$ \\
\hline 207 & limpiar malas hierbas & 0.00380 & $0.050 \%$ & $0.565 \%$ & $85.552 \%$ \\
\hline 208 & rastrillar & 0.00376 & $0.075 \%$ & $0.847 \%$ & $85.627 \%$ \\
\hline 209 & veterinario & 0.00376 & $0.050 \%$ & $0.565 \%$ & $85.677 \%$ \\
\hline 210 & capataz & 0.00376 & $0.050 \%$ & $0.565 \%$ & $85.727 \%$ \\
\hline 211 & echar abono & 0.00376 & $0.050 \%$ & $0.565 \%$ & $85.777 \%$ \\
\hline 212 & naranjero & 0.00367 & $0.050 \%$ & $0.565 \%$ & $85.827 \%$ \\
\hline 213 & cortar el seto & 0.00367 & $0.050 \%$ & $0.565 \%$ & $85.877 \%$ \\
\hline 214 & construir & 0.00366 & $0.075 \%$ & $0.847 \%$ & $85.952 \%$ \\
\hline 215 & recoger aceitunas & 0.00362 & $0.050 \%$ & $0.565 \%$ & $86.002 \%$ \\
\hline 216 & hacer hoyos & 0.00362 & $0.050 \%$ & $0.565 \%$ & $86.052 \%$ \\
\hline 217 & arrasar & 0.00360 & $0.050 \%$ & $0.565 \%$ & $86.102 \%$ \\
\hline 218 & secar & 0.00360 & $0.050 \%$ & $0.565 \%$ & $86.152 \%$ \\
\hline 219 & insecticida & 0.00360 & $0.050 \%$ & $0.565 \%$ & $86.202 \%$ \\
\hline 220 & pasear las cabras & 0.00356 & $0.075 \%$ & $0.847 \%$ & $86.277 \%$ \\
\hline 221 & recoger fresas & 0.00354 & $0.050 \%$ & $0.565 \%$ & $86.327 \%$ \\
\hline 222 & cuidar plantas & 0.00354 & $0.050 \%$ & $0.565 \%$ & $86.377 \%$ \\
\hline 223 & pelar & 0.00350 & $0.050 \%$ & $0.565 \%$ & $86.427 \%$ \\
\hline 224 & dar de comer a animales & 0.00349 & $0.075 \%$ & $0.847 \%$ & $86.502 \%$ \\
\hline 225 & envenenar & 0.00346 & $0.050 \%$ & $0.565 \%$ & $86.552 \%$ \\
\hline 226 & pintor & 0.00346 & $0.050 \%$ & $0.565 \%$ & $86.602 \%$ \\
\hline 227 & adobar & 0.00346 & $0.050 \%$ & $0.565 \%$ & $86.652 \%$ \\
\hline 228 & recoger piedras & 0.00345 & $0.050 \%$ & $0.565 \%$ & $86.702 \%$ \\
\hline 229 & obrero & 0.00345 & $0.050 \%$ & $0.565 \%$ & $86.752 \%$ \\
\hline 230 & esclarecer & 0.00344 & $0.100 \%$ & $1.130 \%$ & $86.852 \%$ \\
\hline 231 & quitar hojas secas & 0.00335 & $0.050 \%$ & $0.565 \%$ & $86.902 \%$ \\
\hline 232 & abono & 0.00334 & $0.050 \%$ & $0.565 \%$ & $86.952 \%$ \\
\hline 233 & cuidar gallinas & 0.00334 & $0.075 \%$ & $0.847 \%$ & $87.027 \%$ \\
\hline 234 & pintar troncos & 0.00322 & $0.050 \%$ & $0.565 \%$ & $87.077 \%$ \\
\hline 235 & barbecho & 0.00319 & $0.050 \%$ & $0.565 \%$ & $87.127 \%$ \\
\hline 236 & plantar patatas & 0.00319 & $0.050 \%$ & $0.565 \%$ & $87.177 \%$ \\
\hline 237 & aclarar & 0.00319 & $0.050 \%$ & $0.565 \%$ & $87.227 \%$ \\
\hline 238 & recolección de la aceituna & 0.00319 & $0.050 \%$ & $0.565 \%$ & $87.277 \%$ \\
\hline 239 & reforestar & 0.00305 & $0.050 \%$ & $0.565 \%$ & $87.327 \%$ \\
\hline 240 & minar & 0.00305 & $0.075 \%$ & $0.847 \%$ & $87.402 \%$ \\
\hline 241 & surcar & 0.00305 & $0.050 \%$ & $0.565 \%$ & $87.452 \%$ \\
\hline 242 & poner cañas & 0.00297 & $0.050 \%$ & $0.565 \%$ & $87.502 \%$ \\
\hline
\end{tabular}




\begin{tabular}{|c|c|c|c|c|c|}
\hline 243 & recortar & 0.00293 & $0.050 \%$ & $0.565 \%$ & $87.552 \%$ \\
\hline 244 & arruixar & 0.00293 & $0.050 \%$ & $0.565 \%$ & $87.602 \%$ \\
\hline 245 & echar tierra & 0.00283 & $0.050 \%$ & $0.565 \%$ & $87.652 \%$ \\
\hline 246 & sembrar flores & 0.00282 & $0.025 \%$ & $0.282 \%$ & $87.677 \%$ \\
\hline 247 & podar flores & 0.00282 & $0.025 \%$ & $0.282 \%$ & $87.702 \%$ \\
\hline 248 & recoger hierbajos & 0.00282 & $0.025 \%$ & $0.282 \%$ & $87.727 \%$ \\
\hline 249 & plantación & 0.00282 & $0.025 \%$ & $0.282 \%$ & $87.752 \%$ \\
\hline 250 & quitar matas & 0.00282 & $0.025 \%$ & $0.282 \%$ & $87.777 \%$ \\
\hline 251 & recolector de cítricos & 0.00282 & $0.025 \%$ & $0.282 \%$ & $87.802 \%$ \\
\hline 252 & serrar naranjos & 0.00282 & $0.025 \%$ & $0.282 \%$ & $87.827 \%$ \\
\hline 253 & dar de comer a gallinas & 0.00282 & $0.025 \%$ & $0.282 \%$ & $87.852 \%$ \\
\hline 254 & llaurador & 0.00282 & $0.025 \%$ & $0.282 \%$ & $87.877 \%$ \\
\hline 255 & recolección de frutos & 0.00282 & $0.025 \%$ & $0.282 \%$ & $87.902 \%$ \\
\hline 256 & recolectar aceitunas & 0.00282 & $0.025 \%$ & $0.282 \%$ & $87.927 \%$ \\
\hline 257 & roturar la tierra & 0.00282 & $0.025 \%$ & $0.282 \%$ & $87.952 \%$ \\
\hline 258 & arboricultor & 0.00282 & $0.025 \%$ & $0.282 \%$ & $87.977 \%$ \\
\hline 259 & quemar malas hierbas & 0.00282 & $0.025 \%$ & $0.282 \%$ & $88.002 \%$ \\
\hline 260 & tenazas & 0.00282 & $0.025 \%$ & $0.282 \%$ & $88.027 \%$ \\
\hline 261 & cortar rosas & 0.00282 & $0.025 \%$ & $0.282 \%$ & $88.052 \%$ \\
\hline 262 & quitar flores muertas & 0.00282 & $0.025 \%$ & $0.282 \%$ & $88.077 \%$ \\
\hline 263 & recoger olivas & 0.00281 & $0.050 \%$ & $0.565 \%$ & $88.127 \%$ \\
\hline 264 & coger almendras & 0.00278 & $0.050 \%$ & $0.565 \%$ & $88.177 \%$ \\
\hline 265 & deshojar & 0.00277 & $0.050 \%$ & $0.565 \%$ & $88.227 \%$ \\
\hline 266 & airear & 0.00273 & $0.050 \%$ & $0.565 \%$ & $88.277 \%$ \\
\hline 267 & naturalista & 0.00273 & $0.050 \%$ & $0.565 \%$ & $88.327 \%$ \\
\hline 268 & granar & 0.00271 & $0.050 \%$ & $0.565 \%$ & $88.377 \%$ \\
\hline 269 & perseguir topos & 0.00271 & $0.050 \%$ & $0.565 \%$ & $88.427 \%$ \\
\hline 270 & soquetes & 0.00271 & $0.050 \%$ & $0.565 \%$ & $88.477 \%$ \\
\hline 271 & mover la tierra & 0.00270 & $0.050 \%$ & $0.565 \%$ & $88.527 \%$ \\
\hline 272 & coger tomates & 0.00270 & $0.050 \%$ & $0.565 \%$ & $88.577 \%$ \\
\hline 273 & cortar plantas & 0.00270 & $0.050 \%$ & $0.565 \%$ & $88.627 \%$ \\
\hline 274 & trasladar & 0.00262 & $0.050 \%$ & $0.565 \%$ & $88.677 \%$ \\
\hline 275 & motosierra & 0.00260 & $0.025 \%$ & $0.282 \%$ & $88.702 \%$ \\
\hline 276 & barrer hojas & 0.00260 & $0.025 \%$ & $0.282 \%$ & $88.727 \%$ \\
\hline 277 & ingeniero de puentes & 0.00260 & $0.025 \%$ & $0.282 \%$ & $88.752 \%$ \\
\hline 278 & trabajar el campo & 0.00260 & $0.025 \%$ & $0.282 \%$ & $88.777 \%$ \\
\hline 279 & pasar el motocultor & 0.00260 & $0.025 \%$ & $0.282 \%$ & $88.802 \%$ \\
\hline 280 & trabajar & 0.00260 & $0.025 \%$ & $0.282 \%$ & $88.827 \%$ \\
\hline 281 & lechera & 0.00260 & $0.025 \%$ & $0.282 \%$ & $88.852 \%$ \\
\hline 282 & recolecta & 0.00260 & $0.025 \%$ & $0.282 \%$ & $88.877 \%$ \\
\hline 283 & enterrador & 0.00260 & $0.025 \%$ & $0.282 \%$ & $88.902 \%$ \\
\hline 284 & camionero & 0.00260 & $0.025 \%$ & $0.282 \%$ & $88.927 \%$ \\
\hline 285 & recolectar algarrobas & 0.00260 & $0.025 \%$ & $0.282 \%$ & $88.952 \%$ \\
\hline 286 & selector & 0.00260 & $0.025 \%$ & $0.282 \%$ & $88.977 \%$ \\
\hline 287 & azadón & 0.00260 & $0.025 \%$ & $0.282 \%$ & $89.002 \%$ \\
\hline 288 & manipulador de cítricos & 0.00260 & $0.025 \%$ & $0.282 \%$ & $89.027 \%$ \\
\hline 289 & hacer esquejes & 0.00260 & $0.025 \%$ & $0.282 \%$ & $89.052 \%$ \\
\hline
\end{tabular}




\begin{tabular}{|c|c|c|c|c|c|}
\hline 290 & recoger cultivos & 0.00260 & $0.025 \%$ & $0.282 \%$ & $89.077 \%$ \\
\hline 291 & cavar la tierra & 0.00260 & $0.025 \%$ & $0.282 \%$ & $89.102 \%$ \\
\hline 292 & productor de melones & 0.00260 & $0.025 \%$ & $0.282 \%$ & $89.127 \%$ \\
\hline 293 & semilla & 0.00259 & $0.050 \%$ & $0.565 \%$ & $89.177 \%$ \\
\hline 294 & tierra & 0.00259 & $0.050 \%$ & $0.565 \%$ & $89.227 \%$ \\
\hline 295 & geólogo & 0.00256 & $0.050 \%$ & $0.565 \%$ & $89.277 \%$ \\
\hline 296 & cremar leña & 0.00256 & $0.050 \%$ & $0.565 \%$ & $89.327 \%$ \\
\hline 297 & pirómano & 0.00252 & $0.050 \%$ & $0.565 \%$ & $89.377 \%$ \\
\hline 298 & remover & 0.00248 & $0.050 \%$ & $0.565 \%$ & $89.427 \%$ \\
\hline 299 & segar el césped & 0.00248 & $0.050 \%$ & $0.565 \%$ & $89.477 \%$ \\
\hline 300 & criador & 0.00244 & $0.050 \%$ & $0.565 \%$ & $89.527 \%$ \\
\hline 301 & tirar estiércol & 0.00242 & $0.050 \%$ & $0.565 \%$ & $89.577 \%$ \\
\hline 302 & drenar & 0.00240 & $0.025 \%$ & $0.282 \%$ & $89.602 \%$ \\
\hline 303 & sembrar coles & 0.00240 & $0.025 \%$ & $0.282 \%$ & $89.627 \%$ \\
\hline 304 & poblar & 0.00240 & $0.025 \%$ & $0.282 \%$ & $89.652 \%$ \\
\hline 305 & conductor & 0.00240 & $0.025 \%$ & $0.282 \%$ & $89.677 \%$ \\
\hline 306 & empalmar & 0.00240 & $0.025 \%$ & $0.282 \%$ & $89.702 \%$ \\
\hline 307 & cavar troncos & 0.00240 & $0.025 \%$ & $0.282 \%$ & $89.727 \%$ \\
\hline 308 & criador de caballos & 0.00240 & $0.025 \%$ & $0.282 \%$ & $89.752 \%$ \\
\hline 309 & fer saó & 0.00240 & $0.025 \%$ & $0.282 \%$ & $89.777 \%$ \\
\hline 310 & jardín & 0.00240 & $0.025 \%$ & $0.282 \%$ & $89.802 \%$ \\
\hline 311 & transportador & 0.00240 & $0.025 \%$ & $0.282 \%$ & $89.827 \%$ \\
\hline 312 & guardia & 0.00240 & $0.025 \%$ & $0.282 \%$ & $89.852 \%$ \\
\hline 313 & recolectar almendras & 0.00240 & $0.025 \%$ & $0.282 \%$ & $89.877 \%$ \\
\hline 314 & trabajar el cultivo & 0.00240 & $0.025 \%$ & $0.282 \%$ & $89.902 \%$ \\
\hline 315 & regar el césped & 0.00240 & $0.025 \%$ & $0.282 \%$ & $89.927 \%$ \\
\hline 316 & empaquetar & 0.00240 & $0.025 \%$ & $0.282 \%$ & $89.952 \%$ \\
\hline 317 & avicultor & 0.00240 & $0.025 \%$ & $0.282 \%$ & $89.977 \%$ \\
\hline 318 & productor de sandías & 0.00240 & $0.025 \%$ & $0.282 \%$ & $90.002 \%$ \\
\hline 319 & domador & 0.00240 & $0.025 \%$ & $0.282 \%$ & $90.027 \%$ \\
\hline 320 & cerámica & 0.00240 & $0.025 \%$ & $0.282 \%$ & $90.052 \%$ \\
\hline 321 & cortar esquejes & 0.00230 & $0.050 \%$ & $0.565 \%$ & $90.102 \%$ \\
\hline 322 & plantar frutos & 0.00229 & $0.050 \%$ & $0.565 \%$ & $90.152 \%$ \\
\hline 323 & recoger ramas & 0.00229 & $0.050 \%$ & $0.565 \%$ & $90.202 \%$ \\
\hline 324 & peinar & 0.00221 & $0.025 \%$ & $0.282 \%$ & $90.227 \%$ \\
\hline 325 & sembrar zanahorias & 0.00221 & $0.025 \%$ & $0.282 \%$ & $90.252 \%$ \\
\hline 326 & extraer & 0.00221 & $0.025 \%$ & $0.282 \%$ & $90.277 \%$ \\
\hline 327 & escardar & 0.00221 & $0.025 \%$ & $0.282 \%$ & $90.302 \%$ \\
\hline 328 & limpiar malezas & 0.00221 & $0.025 \%$ & $0.282 \%$ & $90.327 \%$ \\
\hline 329 & hacer els cavallons & 0.00221 & $0.025 \%$ & $0.282 \%$ & $90.352 \%$ \\
\hline 330 & hacer regueros & 0.00221 & $0.025 \%$ & $0.282 \%$ & $90.377 \%$ \\
\hline 331 & recoger manzanas & 0.00221 & $0.025 \%$ & $0.282 \%$ & $90.402 \%$ \\
\hline 332 & flora & 0.00221 & $0.025 \%$ & $0.282 \%$ & $90.427 \%$ \\
\hline 333 & ingeniero forestal & 0.00221 & $0.025 \%$ & $0.282 \%$ & $90.452 \%$ \\
\hline 334 & mantenedor & 0.00221 & $0.025 \%$ & $0.282 \%$ & $90.477 \%$ \\
\hline 335 & rotar & 0.00221 & $0.025 \%$ & $0.282 \%$ & $90.502 \%$ \\
\hline 336 & sulfatador & 0.00221 & $0.025 \%$ & $0.282 \%$ & $90.527 \%$ \\
\hline
\end{tabular}




\begin{tabular}{|c|c|c|c|c|c|}
\hline 337 & recoger frutos & 0.00221 & $0.025 \%$ & $0.282 \%$ & $90.552 \%$ \\
\hline 338 & segador de césped & 0.00221 & $0.025 \%$ & $0.282 \%$ & $90.577 \%$ \\
\hline 339 & poda & 0.00221 & $0.025 \%$ & $0.282 \%$ & $90.602 \%$ \\
\hline 340 & podar el jardín & 0.00221 & $0.025 \%$ & $0.282 \%$ & $90.627 \%$ \\
\hline 341 & productor de tomates & 0.00221 & $0.025 \%$ & $0.282 \%$ & $90.652 \%$ \\
\hline 342 & cesta & 0.00221 & $0.025 \%$ & $0.282 \%$ & $90.677 \%$ \\
\hline 343 & ecologista & 0.00220 & $0.050 \%$ & $0.565 \%$ & $90.727 \%$ \\
\hline 344 & varear & 0.00220 & $0.050 \%$ & $0.565 \%$ & $90.777 \%$ \\
\hline 345 & coger cerezas & 0.00206 & $0.050 \%$ & $0.565 \%$ & $90.827 \%$ \\
\hline 346 & pasear los chivos & 0.00204 & $0.050 \%$ & $0.565 \%$ & $90.877 \%$ \\
\hline 347 & sembrar tomates & 0.00203 & $0.025 \%$ & $0.282 \%$ & $90.902 \%$ \\
\hline 348 & cortador de arbustos & 0.00203 & $0.025 \%$ & $0.282 \%$ & $90.927 \%$ \\
\hline 349 & amasar & 0.00203 & $0.025 \%$ & $0.282 \%$ & $90.952 \%$ \\
\hline 350 & esquilador & 0.00203 & $0.025 \%$ & $0.282 \%$ & $90.977 \%$ \\
\hline 351 & plantador de semillas & 0.00203 & $0.025 \%$ & $0.282 \%$ & $91.002 \%$ \\
\hline 352 & fertilizar tierra & 0.00203 & $0.025 \%$ & $0.282 \%$ & $91.027 \%$ \\
\hline 353 & fertilización & 0.00203 & $0.025 \%$ & $0.282 \%$ & $91.052 \%$ \\
\hline 354 & caballón & 0.00203 & $0.025 \%$ & $0.282 \%$ & $91.077 \%$ \\
\hline 355 & tractorar & 0.00203 & $0.025 \%$ & $0.282 \%$ & $91.102 \%$ \\
\hline 356 & balar & 0.00203 & $0.025 \%$ & $0.282 \%$ & $91.127 \%$ \\
\hline 357 & matar hormigas & 0.00203 & $0.025 \%$ & $0.282 \%$ & $91.152 \%$ \\
\hline 358 & criador de toros & 0.00203 & $0.025 \%$ & $0.282 \%$ & $91.177 \%$ \\
\hline 359 & serrar árboles & 0.00203 & $0.025 \%$ & $0.282 \%$ & $91.202 \%$ \\
\hline 360 & recoger collites & 0.00203 & $0.025 \%$ & $0.282 \%$ & $91.227 \%$ \\
\hline 361 & recoger cerezas & 0.00203 & $0.025 \%$ & $0.282 \%$ & $91.252 \%$ \\
\hline 362 & descansar & 0.00203 & $0.025 \%$ & $0.282 \%$ & $91.277 \%$ \\
\hline 363 & masover & 0.00203 & $0.025 \%$ & $0.282 \%$ & $91.302 \%$ \\
\hline 364 & etnólogo & 0.00203 & $0.025 \%$ & $0.282 \%$ & $91.327 \%$ \\
\hline 365 & manipulación & 0.00203 & $0.025 \%$ & $0.282 \%$ & $91.352 \%$ \\
\hline 366 & fumigadora & 0.00203 & $0.025 \%$ & $0.282 \%$ & $91.377 \%$ \\
\hline 367 & cortar flores muertas & 0.00203 & $0.025 \%$ & $0.282 \%$ & $91.402 \%$ \\
\hline 368 & pastor de cabras & 0.00203 & $0.025 \%$ & $0.282 \%$ & $91.427 \%$ \\
\hline 369 & cavar surcos & 0.00203 & $0.025 \%$ & $0.282 \%$ & $91.452 \%$ \\
\hline 370 & sacar a pastar ovejas & 0.00203 & $0.025 \%$ & $0.282 \%$ & $91.477 \%$ \\
\hline 371 & sanear la tierra & 0.00203 & $0.025 \%$ & $0.282 \%$ & $91.502 \%$ \\
\hline 372 & cercar & 0.00203 & $0.025 \%$ & $0.282 \%$ & $91.527 \%$ \\
\hline 373 & desplantar & 0.00203 & $0.025 \%$ & $0.282 \%$ & $91.552 \%$ \\
\hline 374 & falcar & 0.00203 & $0.025 \%$ & $0.282 \%$ & $91.577 \%$ \\
\hline 375 & tirar naranjos & 0.00203 & $0.025 \%$ & $0.282 \%$ & $91.602 \%$ \\
\hline 376 & recortar ramas & 0.00203 & $0.025 \%$ & $0.282 \%$ & $91.627 \%$ \\
\hline 377 & productor de pepinos & 0.00203 & $0.025 \%$ & $0.282 \%$ & $91.652 \%$ \\
\hline 378 & plantar melones & 0.00203 & $0.025 \%$ & $0.282 \%$ & $91.677 \%$ \\
\hline 379 & rastrillo & 0.00197 & $0.050 \%$ & $0.565 \%$ & $91.727 \%$ \\
\hline 380 & sembrar lechugas & 0.00187 & $0.025 \%$ & $0.282 \%$ & $91.752 \%$ \\
\hline 381 & germinar & 0.00187 & $0.025 \%$ & $0.282 \%$ & $91.777 \%$ \\
\hline 382 & rociar & 0.00187 & $0.025 \%$ & $0.282 \%$ & $91.802 \%$ \\
\hline 383 & matar plagas & 0.00187 & $0.025 \%$ & $0.282 \%$ & $91.827 \%$ \\
\hline
\end{tabular}




\begin{tabular}{|c|c|c|c|c|c|}
\hline 384 & romper & 0.00187 & $0.025 \%$ & $0.282 \%$ & $91.852 \%$ \\
\hline 385 & sembrar semillas & 0.00187 & $0.025 \%$ & $0.282 \%$ & $91.877 \%$ \\
\hline 386 & matadero & 0.00187 & $0.025 \%$ & $0.282 \%$ & $91.902 \%$ \\
\hline 387 & tirar herbicida & 0.00187 & $0.025 \%$ & $0.282 \%$ & $91.927 \%$ \\
\hline 388 & recoger tierra & 0.00187 & $0.025 \%$ & $0.282 \%$ & $91.952 \%$ \\
\hline 389 & esparcir estiércol & 0.00187 & $0.025 \%$ & $0.282 \%$ & $91.977 \%$ \\
\hline 390 & motocultor & 0.00187 & $0.025 \%$ & $0.282 \%$ & $92.002 \%$ \\
\hline 391 & arreglar plantas & 0.00187 & $0.025 \%$ & $0.282 \%$ & $92.027 \%$ \\
\hline 392 & empacar & 0.00187 & $0.025 \%$ & $0.282 \%$ & $92.052 \%$ \\
\hline 393 & mimar & 0.00187 & $0.025 \%$ & $0.282 \%$ & $92.077 \%$ \\
\hline 394 & esterilizar & 0.00187 & $0.025 \%$ & $0.282 \%$ & $92.102 \%$ \\
\hline 395 & recoger nueces & 0.00187 & $0.025 \%$ & $0.282 \%$ & $92.127 \%$ \\
\hline 396 & cuidador de ganado & 0.00187 & $0.025 \%$ & $0.282 \%$ & $92.152 \%$ \\
\hline 397 & cuidador de gallinas & 0.00187 & $0.025 \%$ & $0.282 \%$ & $92.177 \%$ \\
\hline 398 & bombero & 0.00187 & $0.025 \%$ & $0.282 \%$ & $92.202 \%$ \\
\hline 399 & labrar la tierra & 0.00187 & $0.025 \%$ & $0.282 \%$ & $92.227 \%$ \\
\hline 400 & ama de casa & 0.00187 & $0.025 \%$ & $0.282 \%$ & $92.252 \%$ \\
\hline 401 & cuidador de granja & 0.00187 & $0.025 \%$ & $0.282 \%$ & $92.277 \%$ \\
\hline 402 & controlador de plagas & 0.00187 & $0.025 \%$ & $0.282 \%$ & $92.302 \%$ \\
\hline 403 & distribuidor & 0.00187 & $0.025 \%$ & $0.282 \%$ & $92.327 \%$ \\
\hline 404 & poner fertilizantes & 0.00187 & $0.025 \%$ & $0.282 \%$ & $92.352 \%$ \\
\hline 405 & dar abono & 0.00187 & $0.025 \%$ & $0.282 \%$ & $92.377 \%$ \\
\hline 406 & camión & 0.00187 & $0.025 \%$ & $0.282 \%$ & $92.402 \%$ \\
\hline 407 & pastor de ovejas & 0.00187 & $0.025 \%$ & $0.282 \%$ & $92.427 \%$ \\
\hline 408 & fer soquetes & 0.00187 & $0.025 \%$ & $0.282 \%$ & $92.452 \%$ \\
\hline 409 & alinear & 0.00187 & $0.025 \%$ & $0.282 \%$ & $92.477 \%$ \\
\hline 410 & trabajo con azada & 0.00187 & $0.025 \%$ & $0.282 \%$ & $92.502 \%$ \\
\hline 411 & desintoxicar & 0.00187 & $0.025 \%$ & $0.282 \%$ & $92.527 \%$ \\
\hline 412 & arder las ramas & 0.00187 & $0.025 \%$ & $0.282 \%$ & $92.552 \%$ \\
\hline 413 & recoger algarrobas & 0.00187 & $0.025 \%$ & $0.282 \%$ & $92.577 \%$ \\
\hline 414 & cuidar animales & 0.00187 & $0.025 \%$ & $0.282 \%$ & $92.602 \%$ \\
\hline 415 & tirar naranjas & 0.00187 & $0.025 \%$ & $0.282 \%$ & $92.627 \%$ \\
\hline 416 & productor de pimientos & 0.00187 & $0.025 \%$ & $0.282 \%$ & $92.652 \%$ \\
\hline 417 & poda artística & 0.00187 & $0.025 \%$ & $0.282 \%$ & $92.677 \%$ \\
\hline 418 & hortícola & 0.00187 & $0.025 \%$ & $0.282 \%$ & $92.702 \%$ \\
\hline 419 & plantar plantas & 0.00187 & $0.025 \%$ & $0.282 \%$ & $92.727 \%$ \\
\hline 420 & moler & 0.00179 & $0.050 \%$ & $0.565 \%$ & $92.777 \%$ \\
\hline 421 & tapar & 0.00179 & $0.050 \%$ & $0.565 \%$ & $92.827 \%$ \\
\hline 422 & regar a goteo & 0.00179 & $0.050 \%$ & $0.565 \%$ & $92.877 \%$ \\
\hline 423 & sembrar nabos & 0.00173 & $0.025 \%$ & $0.282 \%$ & $92.902 \%$ \\
\hline 424 & matar & 0.00173 & $0.025 \%$ & $0.282 \%$ & $92.927 \%$ \\
\hline 425 & partir & 0.00173 & $0.025 \%$ & $0.282 \%$ & $92.952 \%$ \\
\hline 426 & minero & 0.00173 & $0.025 \%$ & $0.282 \%$ & $92.977 \%$ \\
\hline 427 & herbicida & 0.00173 & $0.025 \%$ & $0.282 \%$ & $93.002 \%$ \\
\hline 428 & hacer almendras & 0.00173 & $0.025 \%$ & $0.282 \%$ & $93.027 \%$ \\
\hline 429 & esqueje & 0.00173 & $0.025 \%$ & $0.282 \%$ & $93.052 \%$ \\
\hline 430 & invernadero & 0.00173 & $0.025 \%$ & $0.282 \%$ & $93.077 \%$ \\
\hline
\end{tabular}




\begin{tabular}{|c|c|c|c|c|c|}
\hline 431 & policía forestal & 0.00173 & $0.025 \%$ & $0.282 \%$ & $93.102 \%$ \\
\hline 432 & quitar leña & 0.00173 & $0.025 \%$ & $0.282 \%$ & $93.127 \%$ \\
\hline 433 & recogedor de hojas & 0.00173 & $0.025 \%$ & $0.282 \%$ & $93.152 \%$ \\
\hline 434 & cuidador de cerdos & 0.00173 & $0.025 \%$ & $0.282 \%$ & $93.177 \%$ \\
\hline 435 & ensulfatador & 0.00173 & $0.025 \%$ & $0.282 \%$ & $93.202 \%$ \\
\hline 436 & arreglar el césped & 0.00173 & $0.025 \%$ & $0.282 \%$ & $93.227 \%$ \\
\hline 437 & limpieza & 0.00173 & $0.025 \%$ & $0.282 \%$ & $93.252 \%$ \\
\hline 438 & criador de peces & 0.00173 & $0.025 \%$ & $0.282 \%$ & $93.277 \%$ \\
\hline 439 & cajón & 0.00173 & $0.025 \%$ & $0.282 \%$ & $93.302 \%$ \\
\hline 440 & embalse de agua & 0.00173 & $0.025 \%$ & $0.282 \%$ & $93.327 \%$ \\
\hline 441 & poner plástico & 0.00173 & $0.025 \%$ & $0.282 \%$ & $93.352 \%$ \\
\hline 442 & pastor de vacas & 0.00173 & $0.025 \%$ & $0.282 \%$ & $93.377 \%$ \\
\hline 443 & coger alimentos & 0.00173 & $0.025 \%$ & $0.282 \%$ & $93.402 \%$ \\
\hline 444 & cortador de árboles & 0.00173 & $0.025 \%$ & $0.282 \%$ & $93.427 \%$ \\
\hline 445 & domador de caballos & 0.00173 & $0.025 \%$ & $0.282 \%$ & $93.452 \%$ \\
\hline 446 & pulimentar & 0.00173 & $0.025 \%$ & $0.282 \%$ & $93.477 \%$ \\
\hline 447 & plantar alimentos & 0.00173 & $0.025 \%$ & $0.282 \%$ & $93.502 \%$ \\
\hline 448 & productor de berenjenas & 0.00173 & $0.025 \%$ & $0.282 \%$ & $93.527 \%$ \\
\hline 449 & moldear & 0.00173 & $0.025 \%$ & $0.282 \%$ & $93.552 \%$ \\
\hline 450 & frutero & 0.00173 & $0.025 \%$ & $0.282 \%$ & $93.577 \%$ \\
\hline 451 & sacar leche a vacas & 0.00173 & $0.025 \%$ & $0.282 \%$ & $93.602 \%$ \\
\hline 452 & arrancador & 0.00173 & $0.025 \%$ & $0.282 \%$ & $93.627 \%$ \\
\hline 453 & rebaño & 0.00173 & $0.025 \%$ & $0.282 \%$ & $93.652 \%$ \\
\hline 454 & pasear el ganado & 0.00173 & $0.025 \%$ & $0.282 \%$ & $93.677 \%$ \\
\hline 455 & quitar insectos & 0.00173 & $0.025 \%$ & $0.282 \%$ & $93.702 \%$ \\
\hline 456 & coger nísperos & 0.00169 & $0.050 \%$ & $0.565 \%$ & $93.752 \%$ \\
\hline 457 & almorzar & 0.00165 & $0.050 \%$ & $0.565 \%$ & $93.802 \%$ \\
\hline 458 & sembrar rábanos & 0.00159 & $0.025 \%$ & $0.282 \%$ & $93.827 \%$ \\
\hline 459 & regadera & 0.00159 & $0.025 \%$ & $0.282 \%$ & $93.852 \%$ \\
\hline 460 & almacenar la cosecha & 0.00159 & $0.025 \%$ & $0.282 \%$ & $93.877 \%$ \\
\hline 461 & vendimia & 0.00159 & $0.025 \%$ & $0.282 \%$ & $93.902 \%$ \\
\hline 462 & juntar & 0.00159 & $0.025 \%$ & $0.282 \%$ & $93.927 \%$ \\
\hline 463 & uvero & 0.00159 & $0.025 \%$ & $0.282 \%$ & $93.952 \%$ \\
\hline 464 & cuidado & 0.00159 & $0.025 \%$ & $0.282 \%$ & $93.977 \%$ \\
\hline 465 & coger aceitunas & 0.00159 & $0.025 \%$ & $0.282 \%$ & $94.002 \%$ \\
\hline 466 & crianza & 0.00159 & $0.025 \%$ & $0.282 \%$ & $94.027 \%$ \\
\hline 467 & echar herbicida & 0.00159 & $0.025 \%$ & $0.282 \%$ & $94.052 \%$ \\
\hline 468 & arrancar ramas & 0.00159 & $0.025 \%$ & $0.282 \%$ & $94.077 \%$ \\
\hline 469 & coger limones & 0.00159 & $0.025 \%$ & $0.282 \%$ & $94.102 \%$ \\
\hline 470 & coger manzanas & 0.00159 & $0.025 \%$ & $0.282 \%$ & $94.127 \%$ \\
\hline 471 & talador de árboles & 0.00159 & $0.025 \%$ & $0.282 \%$ & $94.152 \%$ \\
\hline 472 & encargado del abono & 0.00159 & $0.025 \%$ & $0.282 \%$ & $94.177 \%$ \\
\hline 473 & echar insecticida & 0.00159 & $0.025 \%$ & $0.282 \%$ & $94.202 \%$ \\
\hline 474 & cuidar árboles & 0.00159 & $0.025 \%$ & $0.282 \%$ & $94.227 \%$ \\
\hline 475 & arreglar jardín & 0.00159 & $0.025 \%$ & $0.282 \%$ & $94.252 \%$ \\
\hline 476 & mariquita & 0.00159 & $0.025 \%$ & $0.282 \%$ & $94.277 \%$ \\
\hline 477 & desparasitar & 0.00159 & $0.025 \%$ & $0.282 \%$ & $94.302 \%$ \\
\hline
\end{tabular}




\begin{tabular}{|c|c|c|c|c|c|}
\hline 478 & pintar cortes & 0.00159 & $0.025 \%$ & $0.282 \%$ & $94.327 \%$ \\
\hline 479 & pozal & 0.00159 & $0.025 \%$ & $0.282 \%$ & $94.352 \%$ \\
\hline 480 & pastar & 0.00159 & $0.025 \%$ & $0.282 \%$ & $94.377 \%$ \\
\hline 481 & limpiar los caballos & 0.00159 & $0.025 \%$ & $0.282 \%$ & $94.402 \%$ \\
\hline 482 & limpiar ramas & 0.00159 & $0.025 \%$ & $0.282 \%$ & $94.427 \%$ \\
\hline 483 & plantar trigo & 0.00159 & $0.025 \%$ & $0.282 \%$ & $94.452 \%$ \\
\hline 484 & picar & 0.00159 & $0.025 \%$ & $0.282 \%$ & $94.477 \%$ \\
\hline 485 & productor de algodón & 0.00159 & $0.025 \%$ & $0.282 \%$ & $94.502 \%$ \\
\hline 486 & cortador de lana de ovejas & 0.00159 & $0.025 \%$ & $0.282 \%$ & $94.527 \%$ \\
\hline 487 & hierba & 0.00159 & $0.025 \%$ & $0.282 \%$ & $94.552 \%$ \\
\hline 488 & hacer macetas & 0.00159 & $0.025 \%$ & $0.282 \%$ & $94.577 \%$ \\
\hline 489 & eliminar plagas & 0.00159 & $0.025 \%$ & $0.282 \%$ & $94.602 \%$ \\
\hline 490 & policía rural & 0.00159 & $0.025 \%$ & $0.282 \%$ & $94.627 \%$ \\
\hline 491 & buscar robellones & 0.00156 & $0.050 \%$ & $0.565 \%$ & $94.677 \%$ \\
\hline 492 & tirar pesticidas & 0.00146 & $0.025 \%$ & $0.282 \%$ & $94.702 \%$ \\
\hline 493 & resembrar & 0.00146 & $0.025 \%$ & $0.282 \%$ & $94.727 \%$ \\
\hline 494 & sembrar berenjenas & 0.00146 & $0.025 \%$ & $0.282 \%$ & $94.752 \%$ \\
\hline 495 & dar de comer & 0.00146 & $0.025 \%$ & $0.282 \%$ & $94.777 \%$ \\
\hline 496 & despedregar & 0.00146 & $0.025 \%$ & $0.282 \%$ & $94.802 \%$ \\
\hline 497 & recortar árboles & 0.00146 & $0.025 \%$ & $0.282 \%$ & $94.827 \%$ \\
\hline 498 & limpiar el jardín & 0.00146 & $0.025 \%$ & $0.282 \%$ & $94.852 \%$ \\
\hline 499 & pegar & 0.00146 & $0.025 \%$ & $0.282 \%$ & $94.877 \%$ \\
\hline 500 & revisar & 0.00146 & $0.025 \%$ & $0.282 \%$ & $94.902 \%$ \\
\hline 501 & coger alcachofas & 0.00146 & $0.025 \%$ & $0.282 \%$ & $94.927 \%$ \\
\hline 502 & recoger peras & 0.00146 & $0.025 \%$ & $0.282 \%$ & $94.952 \%$ \\
\hline 503 & mimar las plantas & 0.00146 & $0.025 \%$ & $0.282 \%$ & $94.977 \%$ \\
\hline 504 & echar productos & 0.00146 & $0.025 \%$ & $0.282 \%$ & $95.002 \%$ \\
\hline 505 & apuntalar & 0.00146 & $0.025 \%$ & $0.282 \%$ & $95.027 \%$ \\
\hline 506 & recolectar cítricos & 0.00146 & $0.025 \%$ & $0.282 \%$ & $95.052 \%$ \\
\hline 507 & arrancar hojas & 0.00146 & $0.025 \%$ & $0.282 \%$ & $95.077 \%$ \\
\hline 508 & quemar madera & 0.00146 & $0.025 \%$ & $0.282 \%$ & $95.102 \%$ \\
\hline 509 & goteo & 0.00146 & $0.025 \%$ & $0.282 \%$ & $95.127 \%$ \\
\hline 510 & regadora & 0.00146 & $0.025 \%$ & $0.282 \%$ & $95.152 \%$ \\
\hline 511 & podar ramas & 0.00146 & $0.025 \%$ & $0.282 \%$ & $95.177 \%$ \\
\hline 512 & ayudante & 0.00146 & $0.025 \%$ & $0.282 \%$ & $95.202 \%$ \\
\hline 513 & pisar & 0.00146 & $0.025 \%$ & $0.282 \%$ & $95.227 \%$ \\
\hline 514 & planta & 0.00146 & $0.025 \%$ & $0.282 \%$ & $95.252 \%$ \\
\hline 515 & fertilizador & 0.00146 & $0.025 \%$ & $0.282 \%$ & $95.277 \%$ \\
\hline 516 & colmenero & 0.00146 & $0.025 \%$ & $0.282 \%$ & $95.302 \%$ \\
\hline 517 & confeccionar & 0.00146 & $0.025 \%$ & $0.282 \%$ & $95.327 \%$ \\
\hline 518 & hacer implantes & 0.00146 & $0.025 \%$ & $0.282 \%$ & $95.352 \%$ \\
\hline 519 & repoblar & 0.00146 & $0.025 \%$ & $0.282 \%$ & $95.377 \%$ \\
\hline 520 & cultivar la tierra & 0.00146 & $0.025 \%$ & $0.282 \%$ & $95.402 \%$ \\
\hline 521 & polinizar & 0.00146 & $0.025 \%$ & $0.282 \%$ & $95.427 \%$ \\
\hline 522 & hacer zanjas & 0.00146 & $0.025 \%$ & $0.282 \%$ & $95.452 \%$ \\
\hline 523 & cuidador de vacas & 0.00146 & $0.025 \%$ & $0.282 \%$ & $95.477 \%$ \\
\hline 524 & reforestar un bosque & 0.00146 & $0.025 \%$ & $0.282 \%$ & $95.502 \%$ \\
\hline
\end{tabular}




\begin{tabular}{|c|c|c|c|c|c|}
\hline 525 & recogedor de almendras & 0.00146 & $0.025 \%$ & $0.282 \%$ & $95.527 \%$ \\
\hline 526 & limpiar el terreno & 0.00146 & $0.025 \%$ & $0.282 \%$ & $95.552 \%$ \\
\hline 527 & retocar & 0.00146 & $0.025 \%$ & $0.282 \%$ & $95.577 \%$ \\
\hline 528 & coger arena & 0.00146 & $0.025 \%$ & $0.282 \%$ & $95.602 \%$ \\
\hline 529 & tiempo de recogida & 0.00146 & $0.025 \%$ & $0.282 \%$ & $95.627 \%$ \\
\hline 530 & productor de café & 0.00146 & $0.025 \%$ & $0.282 \%$ & $95.652 \%$ \\
\hline 531 & químico & 0.00146 & $0.025 \%$ & $0.282 \%$ & $95.677 \%$ \\
\hline 532 & hierbajo & 0.00146 & $0.025 \%$ & $0.282 \%$ & $95.702 \%$ \\
\hline 533 & cortar soques & 0.00146 & $0.025 \%$ & $0.282 \%$ & $95.727 \%$ \\
\hline 534 & sembrar matorrales & 0.00135 & $0.025 \%$ & $0.282 \%$ & $95.752 \%$ \\
\hline 535 & organizar & 0.00135 & $0.025 \%$ & $0.282 \%$ & $95.777 \%$ \\
\hline 536 & clavar & 0.00135 & $0.025 \%$ & $0.282 \%$ & $95.802 \%$ \\
\hline 537 & vaporizar & 0.00135 & $0.025 \%$ & $0.282 \%$ & $95.827 \%$ \\
\hline 538 & injerto & 0.00135 & $0.025 \%$ & $0.282 \%$ & $95.852 \%$ \\
\hline 539 & domar & 0.00135 & $0.025 \%$ & $0.282 \%$ & $95.877 \%$ \\
\hline 540 & botánico & 0.00135 & $0.025 \%$ & $0.282 \%$ & $95.902 \%$ \\
\hline 541 & científico de medio ambiente & 0.00135 & $0.025 \%$ & $0.282 \%$ & $95.927 \%$ \\
\hline 542 & buscar trufas & 0.00135 & $0.025 \%$ & $0.282 \%$ & $95.952 \%$ \\
\hline 543 & plantar hortalizas & 0.00135 & $0.025 \%$ & $0.282 \%$ & $95.977 \%$ \\
\hline 544 & echar fertilizantes & 0.00135 & $0.025 \%$ & $0.282 \%$ & $96.002 \%$ \\
\hline 545 & cowboy & 0.00135 & $0.025 \%$ & $0.282 \%$ & $96.027 \%$ \\
\hline 546 & guardar & 0.00135 & $0.025 \%$ & $0.282 \%$ & $96.052 \%$ \\
\hline 547 & regadío & 0.00135 & $0.025 \%$ & $0.282 \%$ & $96.077 \%$ \\
\hline 548 & sacar ramas & 0.00135 & $0.025 \%$ & $0.282 \%$ & $96.102 \%$ \\
\hline 549 & viticultor & 0.00135 & $0.025 \%$ & $0.282 \%$ & $96.127 \%$ \\
\hline 550 & montador de caballos & 0.00135 & $0.025 \%$ & $0.282 \%$ & $96.152 \%$ \\
\hline 551 & explotar & 0.00135 & $0.025 \%$ & $0.282 \%$ & $96.177 \%$ \\
\hline 552 & vendimiador & 0.00135 & $0.025 \%$ & $0.282 \%$ & $96.202 \%$ \\
\hline 553 & recoger suciedad & 0.00135 & $0.025 \%$ & $0.282 \%$ & $96.227 \%$ \\
\hline 554 & cuidador de ovejas & 0.00135 & $0.025 \%$ & $0.282 \%$ & $96.252 \%$ \\
\hline 555 & dar comida & 0.00135 & $0.025 \%$ & $0.282 \%$ & $96.277 \%$ \\
\hline 556 & recogedor de aceituna & 0.00135 & $0.025 \%$ & $0.282 \%$ & $96.302 \%$ \\
\hline 557 & transportar & 0.00135 & $0.025 \%$ & $0.282 \%$ & $96.327 \%$ \\
\hline 558 & quitar piedras & 0.00135 & $0.025 \%$ & $0.282 \%$ & $96.352 \%$ \\
\hline 559 & productor de patatas & 0.00135 & $0.025 \%$ & $0.282 \%$ & $96.377 \%$ \\
\hline 560 & cuidador de piscina & 0.00135 & $0.025 \%$ & $0.282 \%$ & $96.402 \%$ \\
\hline 561 & picador & 0.00135 & $0.025 \%$ & $0.282 \%$ & $96.427 \%$ \\
\hline 562 & tirar fem & 0.00135 & $0.025 \%$ & $0.282 \%$ & $96.452 \%$ \\
\hline 563 & maderero & 0.00129 & $0.050 \%$ & $0.565 \%$ & $96.502 \%$ \\
\hline 564 & cabalgar & 0.00124 & $0.025 \%$ & $0.282 \%$ & $96.527 \%$ \\
\hline 565 & sembrar kiwis & 0.00124 & $0.025 \%$ & $0.282 \%$ & $96.552 \%$ \\
\hline 566 & descontaminar & 0.00124 & $0.025 \%$ & $0.282 \%$ & $96.577 \%$ \\
\hline 567 & cortar arbustos & 0.00124 & $0.025 \%$ & $0.282 \%$ & $96.602 \%$ \\
\hline 568 & tirar azufre & 0.00124 & $0.025 \%$ & $0.282 \%$ & $96.627 \%$ \\
\hline 569 & sacar leña & 0.00124 & $0.025 \%$ & $0.282 \%$ & $96.652 \%$ \\
\hline 570 & recoger paja & 0.00124 & $0.025 \%$ & $0.282 \%$ & $96.677 \%$ \\
\hline 571 & buscar hongos & 0.00124 & $0.025 \%$ & $0.282 \%$ & $96.702 \%$ \\
\hline
\end{tabular}




\begin{tabular}{|c|c|c|c|c|c|}
\hline 572 & coger uvas & 0.00124 & $0.025 \%$ & $0.282 \%$ & $96.727 \%$ \\
\hline 573 & secano & 0.00124 & $0.025 \%$ & $0.282 \%$ & $96.752 \%$ \\
\hline 574 & verdulero & 0.00124 & $0.025 \%$ & $0.282 \%$ & $96.777 \%$ \\
\hline 575 & seto & 0.00124 & $0.025 \%$ & $0.282 \%$ & $96.802 \%$ \\
\hline 576 & agua & 0.00124 & $0.025 \%$ & $0.282 \%$ & $96.827 \%$ \\
\hline 577 & fer paret & 0.00124 & $0.025 \%$ & $0.282 \%$ & $96.852 \%$ \\
\hline 578 & aguadero & 0.00124 & $0.025 \%$ & $0.282 \%$ & $96.877 \%$ \\
\hline 579 & embellecer & 0.00124 & $0.025 \%$ & $0.282 \%$ & $96.902 \%$ \\
\hline 580 & cosechero & 0.00124 & $0.025 \%$ & $0.282 \%$ & $96.927 \%$ \\
\hline 581 & zanja & 0.00124 & $0.025 \%$ & $0.282 \%$ & $96.952 \%$ \\
\hline 582 & olivero & 0.00124 & $0.025 \%$ & $0.282 \%$ & $96.977 \%$ \\
\hline 583 & prensar & 0.00124 & $0.025 \%$ & $0.282 \%$ & $97.002 \%$ \\
\hline 584 & limpiar hojas & 0.00124 & $0.025 \%$ & $0.282 \%$ & $97.027 \%$ \\
\hline 585 & productor de miel & 0.00124 & $0.025 \%$ & $0.282 \%$ & $97.052 \%$ \\
\hline 586 & quitar maleza & 0.00124 & $0.025 \%$ & $0.282 \%$ & $97.077 \%$ \\
\hline 587 & iluminador & 0.00124 & $0.025 \%$ & $0.282 \%$ & $97.102 \%$ \\
\hline 588 & plantar platanero & 0.00114 & $0.025 \%$ & $0.282 \%$ & $97.127 \%$ \\
\hline 589 & apisonadora & 0.00114 & $0.025 \%$ & $0.282 \%$ & $97.152 \%$ \\
\hline 590 & alquería & 0.00114 & $0.025 \%$ & $0.282 \%$ & $97.177 \%$ \\
\hline 591 & horadar & 0.00114 & $0.025 \%$ & $0.282 \%$ & $97.202 \%$ \\
\hline 592 & zoólogo & 0.00114 & $0.025 \%$ & $0.282 \%$ & $97.227 \%$ \\
\hline 593 & cazar saltamontes & 0.00114 & $0.025 \%$ & $0.282 \%$ & $97.252 \%$ \\
\hline 594 & buscar setas & 0.00114 & $0.025 \%$ & $0.282 \%$ & $97.277 \%$ \\
\hline 595 & hacer rocas & 0.00114 & $0.025 \%$ & $0.282 \%$ & $97.302 \%$ \\
\hline 596 & cochero & 0.00114 & $0.025 \%$ & $0.282 \%$ & $97.327 \%$ \\
\hline 597 & poner goteo & 0.00114 & $0.025 \%$ & $0.282 \%$ & $97.352 \%$ \\
\hline 598 & panadero & 0.00114 & $0.025 \%$ & $0.282 \%$ & $97.377 \%$ \\
\hline 599 & hacer diques & 0.00114 & $0.025 \%$ & $0.282 \%$ & $97.402 \%$ \\
\hline 600 & coger flores & 0.00114 & $0.025 \%$ & $0.282 \%$ & $97.427 \%$ \\
\hline 601 & extirpar & 0.00114 & $0.025 \%$ & $0.282 \%$ & $97.452 \%$ \\
\hline 602 & nutrir & 0.00114 & $0.025 \%$ & $0.282 \%$ & $97.477 \%$ \\
\hline 603 & aceitero & 0.00114 & $0.025 \%$ & $0.282 \%$ & $97.502 \%$ \\
\hline 604 & vender & 0.00114 & $0.025 \%$ & $0.282 \%$ & $97.527 \%$ \\
\hline 605 & cercar árboles & 0.00114 & $0.025 \%$ & $0.282 \%$ & $97.552 \%$ \\
\hline 606 & quemar restos & 0.00114 & $0.025 \%$ & $0.282 \%$ & $97.577 \%$ \\
\hline 607 & ficar rectes & 0.00114 & $0.025 \%$ & $0.282 \%$ & $97.602 \%$ \\
\hline 608 & arrancar arbustos & 0.00114 & $0.025 \%$ & $0.282 \%$ & $97.627 \%$ \\
\hline 609 & rascar & 0.00114 & $0.025 \%$ & $0.282 \%$ & $97.652 \%$ \\
\hline 610 & sembrar fresas & 0.00105 & $0.025 \%$ & $0.282 \%$ & $97.677 \%$ \\
\hline 611 & repartidor & 0.00105 & $0.025 \%$ & $0.282 \%$ & $97.702 \%$ \\
\hline 612 & villa & 0.00105 & $0.025 \%$ & $0.282 \%$ & $97.727 \%$ \\
\hline 613 & recoger albaricoques & 0.00105 & $0.025 \%$ & $0.282 \%$ & $97.752 \%$ \\
\hline 614 & triar & 0.00105 & $0.025 \%$ & $0.282 \%$ & $97.777 \%$ \\
\hline 615 & matar pulgones & 0.00105 & $0.025 \%$ & $0.282 \%$ & $97.802 \%$ \\
\hline 616 & pino & 0.00105 & $0.025 \%$ & $0.282 \%$ & $97.827 \%$ \\
\hline 617 & cortar trigo & 0.00105 & $0.025 \%$ & $0.282 \%$ & $97.852 \%$ \\
\hline 618 & montar invernadero & 0.00105 & $0.025 \%$ & $0.282 \%$ & $97.877 \%$ \\
\hline
\end{tabular}




\begin{tabular}{|c|c|c|c|c|c|}
\hline 619 & paleta & 0.00105 & $0.025 \%$ & $0.282 \%$ & $97.902 \%$ \\
\hline 620 & escampar fem & 0.00105 & $0.025 \%$ & $0.282 \%$ & $97.927 \%$ \\
\hline 621 & eliminar malas hierbas & 0.00105 & $0.025 \%$ & $0.282 \%$ & $97.952 \%$ \\
\hline 622 & comprar & 0.00105 & $0.025 \%$ & $0.282 \%$ & $97.977 \%$ \\
\hline 623 & varear la almendra & 0.00105 & $0.025 \%$ & $0.282 \%$ & $98.002 \%$ \\
\hline 624 & esquilar ovejas & 0.00105 & $0.025 \%$ & $0.282 \%$ & $98.027 \%$ \\
\hline 625 & banyar soques & 0.00105 & $0.025 \%$ & $0.282 \%$ & $98.052 \%$ \\
\hline 626 & aventar & 0.00105 & $0.025 \%$ & $0.282 \%$ & $98.077 \%$ \\
\hline 627 & sembrar moras & 0.00097 & $0.025 \%$ & $0.282 \%$ & $98.102 \%$ \\
\hline 628 & buey & 0.00097 & $0.025 \%$ & $0.282 \%$ & $98.127 \%$ \\
\hline 629 & pulir & 0.00097 & $0.025 \%$ & $0.282 \%$ & $98.152 \%$ \\
\hline 630 & comer cítricos & 0.00097 & $0.025 \%$ & $0.282 \%$ & $98.177 \%$ \\
\hline 631 & coger Navel & 0.00097 & $0.025 \%$ & $0.282 \%$ & $98.202 \%$ \\
\hline 632 & coger olivas & 0.00097 & $0.025 \%$ & $0.282 \%$ & $98.227 \%$ \\
\hline 633 & caballo & 0.00097 & $0.025 \%$ & $0.282 \%$ & $98.252 \%$ \\
\hline 634 & purgar & 0.00097 & $0.025 \%$ & $0.282 \%$ & $98.277 \%$ \\
\hline 635 & hombre del tiempo & 0.00097 & $0.025 \%$ & $0.282 \%$ & $98.302 \%$ \\
\hline 636 & ventilar & 0.00097 & $0.025 \%$ & $0.282 \%$ & $98.327 \%$ \\
\hline 637 & cuerda & 0.00097 & $0.025 \%$ & $0.282 \%$ & $98.352 \%$ \\
\hline 638 & criar & 0.00097 & $0.025 \%$ & $0.282 \%$ & $98.377 \%$ \\
\hline 639 & vallar & 0.00097 & $0.025 \%$ & $0.282 \%$ & $98.402 \%$ \\
\hline 640 & matar insectos & 0.00097 & $0.025 \%$ & $0.282 \%$ & $98.427 \%$ \\
\hline 641 & cactus & 0.00097 & $0.025 \%$ & $0.282 \%$ & $98.452 \%$ \\
\hline 642 & sembrar frambuesas & 0.00089 & $0.025 \%$ & $0.282 \%$ & $98.477 \%$ \\
\hline 643 & cortar pinos & 0.00089 & $0.025 \%$ & $0.282 \%$ & $98.502 \%$ \\
\hline 644 & ermita & 0.00089 & $0.025 \%$ & $0.282 \%$ & $98.527 \%$ \\
\hline 645 & barnizar & 0.00089 & $0.025 \%$ & $0.282 \%$ & $98.552 \%$ \\
\hline 646 & coger Navelate & 0.00089 & $0.025 \%$ & $0.282 \%$ & $98.577 \%$ \\
\hline 647 & malas hierbas & 0.00089 & $0.025 \%$ & $0.282 \%$ & $98.602 \%$ \\
\hline 648 & caña & 0.00089 & $0.025 \%$ & $0.282 \%$ & $98.627 \%$ \\
\hline 649 & fer cremador & 0.00089 & $0.025 \%$ & $0.282 \%$ & $98.652 \%$ \\
\hline 650 & arrancar hierbajos & 0.00089 & $0.025 \%$ & $0.282 \%$ & $98.677 \%$ \\
\hline 651 & dar de comer a conejos & 0.00089 & $0.025 \%$ & $0.282 \%$ & $98.702 \%$ \\
\hline 652 & recoger setas & 0.00089 & $0.025 \%$ & $0.282 \%$ & $98.727 \%$ \\
\hline 653 & hacer injertos & 0.00089 & $0.025 \%$ & $0.282 \%$ & $98.752 \%$ \\
\hline 654 & cuidar el campo & 0.00082 & $0.025 \%$ & $0.282 \%$ & $98.777 \%$ \\
\hline 655 & abonar árboles & 0.00082 & $0.025 \%$ & $0.282 \%$ & $98.802 \%$ \\
\hline 656 & espeleólogo & 0.00082 & $0.025 \%$ & $0.282 \%$ & $98.827 \%$ \\
\hline 657 & rastrear & 0.00082 & $0.025 \%$ & $0.282 \%$ & $98.852 \%$ \\
\hline 658 & coger Clementina & 0.00082 & $0.025 \%$ & $0.282 \%$ & $98.877 \%$ \\
\hline 659 & alicates & 0.00082 & $0.025 \%$ & $0.282 \%$ & $98.902 \%$ \\
\hline 660 & seleccionar & 0.00082 & $0.025 \%$ & $0.282 \%$ & $98.927 \%$ \\
\hline 661 & adornar & 0.00082 & $0.025 \%$ & $0.282 \%$ & $98.952 \%$ \\
\hline 662 & remojar & 0.00082 & $0.025 \%$ & $0.282 \%$ & $98.977 \%$ \\
\hline 663 & recoger espárragos & 0.00082 & $0.025 \%$ & $0.282 \%$ & $99.002 \%$ \\
\hline 664 & pescar & 0.00082 & $0.025 \%$ & $0.282 \%$ & $99.027 \%$ \\
\hline 665 & matar malas hierbas & 0.00082 & $0.025 \%$ & $0.282 \%$ & $99.052 \%$ \\
\hline
\end{tabular}




\begin{tabular}{|c|c|c|c|c|c|}
\hline 666 & viñedo & 0.00082 & $0.025 \%$ & $0.282 \%$ & $99.077 \%$ \\
\hline 667 & abonar el huerto & 0.00076 & $0.025 \%$ & $0.282 \%$ & $99.102 \%$ \\
\hline 668 & triturar & 0.00076 & $0.025 \%$ & $0.282 \%$ & $99.127 \%$ \\
\hline 669 & medir & 0.00076 & $0.025 \%$ & $0.282 \%$ & $99.152 \%$ \\
\hline 670 & cuidar patos & 0.00076 & $0.025 \%$ & $0.282 \%$ & $99.177 \%$ \\
\hline 671 & comer fresas & 0.00076 & $0.025 \%$ & $0.282 \%$ & $99.202 \%$ \\
\hline 672 & coger China & 0.00076 & $0.025 \%$ & $0.282 \%$ & $99.227 \%$ \\
\hline 673 & salpicar & 0.00076 & $0.025 \%$ & $0.282 \%$ & $99.252 \%$ \\
\hline 674 & pinzas & 0.00076 & $0.025 \%$ & $0.282 \%$ & $99.277 \%$ \\
\hline 675 & estriar & 0.00076 & $0.025 \%$ & $0.282 \%$ & $99.302 \%$ \\
\hline 676 & abonar la huerta & 0.00070 & $0.025 \%$ & $0.282 \%$ & $99.327 \%$ \\
\hline 677 & cuidar conejos & 0.00070 & $0.025 \%$ & $0.282 \%$ & $99.352 \%$ \\
\hline 678 & comer naranjas & 0.00070 & $0.025 \%$ & $0.282 \%$ & $99.377 \%$ \\
\hline 679 & coger Marisol & 0.00070 & $0.025 \%$ & $0.282 \%$ & $99.402 \%$ \\
\hline 680 & saltar & 0.00070 & $0.025 \%$ & $0.282 \%$ & $99.427 \%$ \\
\hline 681 & sazonar & 0.00070 & $0.025 \%$ & $0.282 \%$ & $99.452 \%$ \\
\hline 682 & lavar & 0.00070 & $0.025 \%$ & $0.282 \%$ & $99.477 \%$ \\
\hline 683 & pastorear cabras & 0.00070 & $0.025 \%$ & $0.282 \%$ & $99.502 \%$ \\
\hline 684 & abonar plantas & 0.00064 & $0.025 \%$ & $0.282 \%$ & $99.527 \%$ \\
\hline 685 & recoger la semilla & 0.00064 & $0.025 \%$ & $0.282 \%$ & $99.552 \%$ \\
\hline 686 & cuidar cerdos & 0.00064 & $0.025 \%$ & $0.282 \%$ & $99.577 \%$ \\
\hline 687 & comer peras & 0.00064 & $0.025 \%$ & $0.282 \%$ & $99.602 \%$ \\
\hline 688 & coger Clementina del terreno & 0.00064 & $0.025 \%$ & $0.282 \%$ & $99.627 \%$ \\
\hline 689 & foco & 0.00064 & $0.025 \%$ & $0.282 \%$ & $99.652 \%$ \\
\hline 690 & pastorear ovejas & 0.00064 & $0.025 \%$ & $0.282 \%$ & $99.677 \%$ \\
\hline 691 & abonar flores & 0.00059 & $0.025 \%$ & $0.282 \%$ & $99.702 \%$ \\
\hline 692 & matar cerdos & 0.00059 & $0.025 \%$ & $0.282 \%$ & $99.727 \%$ \\
\hline 693 & cuidar caballos & 0.00059 & $0.025 \%$ & $0.282 \%$ & $99.752 \%$ \\
\hline 694 & comer limones & 0.00059 & $0.025 \%$ & $0.282 \%$ & $99.777 \%$ \\
\hline 695 & socavar & 0.00059 & $0.025 \%$ & $0.282 \%$ & $99.802 \%$ \\
\hline 696 & pastorear vacas & 0.00059 & $0.025 \%$ & $0.282 \%$ & $99.827 \%$ \\
\hline 697 & abonar frutas & 0.00055 & $0.025 \%$ & $0.282 \%$ & $99.852 \%$ \\
\hline 698 & cuidar pollos & 0.00055 & $0.025 \%$ & $0.282 \%$ & $99.877 \%$ \\
\hline 699 & comer cerezas & 0.00055 & $0.025 \%$ & $0.282 \%$ & $99.902 \%$ \\
\hline 700 & combatir plagas & 0.00055 & $0.025 \%$ & $0.282 \%$ & $99.927 \%$ \\
\hline 701 & llenar & 0.00055 & $0.025 \%$ & $0.282 \%$ & $99.952 \%$ \\
\hline 702 & buscar champiñones & 0.00046 & $0.025 \%$ & $0.282 \%$ & $99.977 \%$ \\
\hline 703 & entrar vacas & 0.00036 & $0.025 \%$ & $0.282 \%$ & $100.002 \%$ \\
\hline 704 & alimentar vacas & 0.00033 & $0.025 \%$ & $0.282 \%$ & $100.027 \%$ \\
\hline
\end{tabular}




\begin{tabular}{|c|c|c|c|c|c|}
\hline $\mathrm{N}^{\mathrm{o}}$ & Palabra & Disponibilidad & $\begin{array}{c}\text { Frecuencia } \\
\text { relativa }\end{array}$ & \% Aparición & $\begin{array}{l}\text { Frecuencia } \\
\text { acumulada }\end{array}$ \\
\hline 1 & perro & 0.82144 & $3.293 \%$ & $93.503 \%$ & $3.293 \%$ \\
\hline 2 & gato & 0.79932 & $3.323 \%$ & $94.350 \%$ & $6.616 \%$ \\
\hline 3 & león & 0.48481 & $2.726 \%$ & $77.401 \%$ & $9.342 \%$ \\
\hline 4 & caballo & 0.41554 & $2.209 \%$ & $62.712 \%$ & $11.551 \%$ \\
\hline 5 & tigre & 0.39051 & $2.358 \%$ & $66.949 \%$ & $13.909 \%$ \\
\hline 6 & elefante & 0.32571 & $1.960 \%$ & $55.650 \%$ & $15.869 \%$ \\
\hline 7 & vaca & 0.31631 & $1.900 \%$ & $53.955 \%$ & $17.769 \%$ \\
\hline 8 & toro & 0.28119 & $1.771 \%$ & $50.282 \%$ & $19.540 \%$ \\
\hline 9 & serpiente & 0.27352 & $1.940 \%$ & $55.085 \%$ & $21.480 \%$ \\
\hline 10 & jirafa & 0.24585 & $1.632 \%$ & $46.328 \%$ & $23.112 \%$ \\
\hline 11 & ballena & 0.23110 & $1.791 \%$ & $50.847 \%$ & $24.903 \%$ \\
\hline 12 & tiburón & 0.21646 & $1.662 \%$ & $47.175 \%$ & $26.565 \%$ \\
\hline 13 & canario & 0.21029 & $1.214 \%$ & $34.463 \%$ & $27.779 \%$ \\
\hline 14 & mono & 0.20591 & $1.572 \%$ & $44.633 \%$ & $29.351 \%$ \\
\hline 15 & cerdo & 0.20268 & $1.323 \%$ & $37.571 \%$ & $30.674 \%$ \\
\hline 16 & gallina & 0.20158 & $1.443 \%$ & $40.960 \%$ & $32.117 \%$ \\
\hline 17 & águila & 0.19554 & $1.492 \%$ & $42.373 \%$ & $33.609 \%$ \\
\hline 18 & conejo & 0.18316 & $1.224 \%$ & $34.746 \%$ & $34.833 \%$ \\
\hline 19 & ratón & 0.18205 & $1.154 \%$ & $32.768 \%$ & $35.987 \%$ \\
\hline 20 & loro & 0.17805 & $1.104 \%$ & $31.356 \%$ & $37.091 \%$ \\
\hline 21 & pez & 0.16446 & $1.015 \%$ & $28.814 \%$ & $38.106 \%$ \\
\hline 22 & mosca & 0.16312 & $1.144 \%$ & $32.486 \%$ & $39.250 \%$ \\
\hline 23 & pájaro & 0.16118 & $0.846 \%$ & $24.011 \%$ & $40.096 \%$ \\
\hline 24 & pantera & 0.15967 & $1.084 \%$ & $30.791 \%$ & $41.180 \%$ \\
\hline 25 & OsO & 0.15485 & $1.075 \%$ & $30.508 \%$ & $42.255 \%$ \\
\hline 26 & burro & 0.15438 & $0.945 \%$ & $26.836 \%$ & $43.200 \%$ \\
\hline 27 & delfín & 0.15336 & $1.234 \%$ & $35.028 \%$ & $44.434 \%$ \\
\hline 28 & cocodrilo & 0.15086 & $1.144 \%$ & $32.486 \%$ & $45.578 \%$ \\
\hline 29 & periquito & 0.14687 & $0.866 \%$ & $24.576 \%$ & $46.444 \%$ \\
\hline 30 & tortuga & 0.14675 & $1.055 \%$ & $29.944 \%$ & $47.499 \%$ \\
\hline 31 & oveja & 0.14523 & $1.005 \%$ & $28.531 \%$ & $48.504 \%$ \\
\hline 32 & rata & 0.14288 & $0.895 \%$ & $25.424 \%$ & $49.399 \%$ \\
\hline 33 & leopardo & 0.14271 & $0.985 \%$ & $27.966 \%$ & $50.384 \%$ \\
\hline 34 & rinoceronte & 0.14196 & $1.055 \%$ & $29.944 \%$ & $51.439 \%$ \\
\hline 35 & cabra & 0.14145 & $0.975 \%$ & $27.684 \%$ & $52.414 \%$ \\
\hline 36 & mosquito & 0.12777 & $0.915 \%$ & $25.989 \%$ & $53.329 \%$ \\
\hline 37 & pato & 0.11967 & $0.796 \%$ & $22.599 \%$ & $54.125 \%$ \\
\hline 38 & hormiga & 0.11965 & $0.806 \%$ & $22.881 \%$ & $54.931 \%$ \\
\hline 39 & hipopótamo & 0.11588 & $0.895 \%$ & $25.424 \%$ & $55.826 \%$ \\
\hline 40 & cebra & 0.11023 & $0.846 \%$ & $24.011 \%$ & $56.672 \%$ \\
\hline 41 & zorro & 0.10395 & $0.696 \%$ & $19.774 \%$ & $57.368 \%$ \\
\hline 42 & abeja & 0.10387 & $0.716 \%$ & $20.339 \%$ & $58.084 \%$ \\
\hline 43 & lobo & 0.10054 & $0.667 \%$ & $18.927 \%$ & $58.751 \%$ \\
\hline
\end{tabular}




\begin{tabular}{|c|c|c|c|c|c|}
\hline 44 & araña & 0.09375 & $0.677 \%$ & $19.209 \%$ & $59.428 \%$ \\
\hline 45 & avestruz & 0.09061 & $0.716 \%$ & $20.339 \%$ & $60.144 \%$ \\
\hline 46 & pollo & 0.08860 & $0.657 \%$ & $18.644 \%$ & $60.801 \%$ \\
\hline 47 & jabalí & 0.08851 & $0.657 \%$ & $18.644 \%$ & $61.458 \%$ \\
\hline 48 & yegua & 0.08793 & $0.577 \%$ & $16.384 \%$ & $62.035 \%$ \\
\hline 49 & gorila & 0.08443 & $0.716 \%$ & $20.339 \%$ & $62.751 \%$ \\
\hline 50 & hámster & 0.08423 & $0.557 \%$ & $15.819 \%$ & $63.308 \%$ \\
\hline 51 & gallo & 0.08403 & $0.607 \%$ & $17.232 \%$ & $63.915 \%$ \\
\hline 52 & ardilla & 0.08371 & $0.587 \%$ & $16.667 \%$ & $64.502 \%$ \\
\hline 53 & ciervo & 0.08318 & $0.617 \%$ & $17.514 \%$ & $65.119 \%$ \\
\hline 54 & hiena & 0.08304 & $0.587 \%$ & $16.667 \%$ & $65.706 \%$ \\
\hline 55 & cucaracha & 0.07642 & $0.587 \%$ & $16.667 \%$ & $66.293 \%$ \\
\hline 56 & rana & 0.07414 & $0.617 \%$ & $17.514 \%$ & $66.910 \%$ \\
\hline 57 & foca & 0.07020 & $0.597 \%$ & $16.949 \%$ & $67.507 \%$ \\
\hline 58 & lagartija & 0.06872 & $0.537 \%$ & $15.254 \%$ & $68.044 \%$ \\
\hline 59 & gusano & 0.06821 & $0.567 \%$ & $16.102 \%$ & $68.611 \%$ \\
\hline 60 & lagarto & 0.06764 & $0.557 \%$ & $15.819 \%$ & $69.168 \%$ \\
\hline 61 & paloma & 0.06609 & $0.497 \%$ & $14.124 \%$ & $69.665 \%$ \\
\hline 62 & perdiz & 0.06590 & $0.468 \%$ & $13.277 \%$ & $70.133 \%$ \\
\hline 63 & koala & 0.06158 & $0.468 \%$ & $13.277 \%$ & $70.601 \%$ \\
\hline 64 & halcón & 0.05873 & $0.488 \%$ & $13.842 \%$ & $71.089 \%$ \\
\hline 65 & saltamontes & 0.05848 & $0.388 \%$ & $11.017 \%$ & $71.477 \%$ \\
\hline 66 & sapo & 0.05781 & $0.517 \%$ & $14.689 \%$ & $71.994 \%$ \\
\hline 67 & camello & 0.05779 & $0.408 \%$ & $11.582 \%$ & $72.402 \%$ \\
\hline 68 & guepardo & 0.05765 & $0.418 \%$ & $11.864 \%$ & $72.820 \%$ \\
\hline 69 & lince & 0.05731 & $0.378 \%$ & $10.734 \%$ & $73.198 \%$ \\
\hline 70 & buitre & 0.05348 & $0.458 \%$ & $12.994 \%$ & $73.656 \%$ \\
\hline 71 & jilguero & 0.05331 & $0.318 \%$ & $9.040 \%$ & $73.974 \%$ \\
\hline 72 & avispa & 0.05239 & $0.438 \%$ & $12.429 \%$ & $74.412 \%$ \\
\hline 73 & búho & 0.05205 & $0.388 \%$ & $11.017 \%$ & $74.800 \%$ \\
\hline 74 & liebre & 0.05047 & $0.348 \%$ & $9.887 \%$ & $75.148 \%$ \\
\hline 75 & gorrión & 0.04996 & $0.368 \%$ & $10.452 \%$ & $75.516 \%$ \\
\hline 76 & mariposa & 0.04975 & $0.378 \%$ & $10.734 \%$ & $75.894 \%$ \\
\hline 77 & buey & 0.04705 & $0.338 \%$ & $9.605 \%$ & $76.232 \%$ \\
\hline 78 & pez espada & 0.04580 & $0.348 \%$ & $9.887 \%$ & $76.580 \%$ \\
\hline 79 & iguana & 0.04516 & $0.328 \%$ & $9.322 \%$ & $76.908 \%$ \\
\hline 80 & dinosaurio & 0.04420 & $0.318 \%$ & $9.040 \%$ & $77.226 \%$ \\
\hline 81 & ornitorrinco & 0.04388 & $0.269 \%$ & $7.627 \%$ & $77.495 \%$ \\
\hline 82 & codorniz & 0.04349 & $0.298 \%$ & $8.475 \%$ & $77.793 \%$ \\
\hline 83 & pulpo & 0.04319 & $0.358 \%$ & $10.169 \%$ & $78.151 \%$ \\
\hline 84 & orca & 0.04181 & $0.378 \%$ & $10.734 \%$ & $78.529 \%$ \\
\hline 85 & camaleón & 0.04172 & $0.338 \%$ & $9.605 \%$ & $78.867 \%$ \\
\hline 86 & sardina & 0.04171 & $0.348 \%$ & $9.887 \%$ & $79.215 \%$ \\
\hline 87 & pulga & 0.04110 & $0.308 \%$ & $8.757 \%$ & $79.523 \%$ \\
\hline 88 & calamar & 0.04071 & $0.338 \%$ & $9.605 \%$ & $79.861 \%$ \\
\hline 89 & puma & 0.04061 & $0.298 \%$ & $8.475 \%$ & $80.159 \%$ \\
\hline 90 & caimán & 0.03977 & $0.298 \%$ & $8.475 \%$ & $80.457 \%$ \\
\hline
\end{tabular}




\begin{tabular}{|c|c|c|c|c|c|}
\hline 91 & escorpión & 0.03957 & $0.348 \%$ & $9.887 \%$ & $80.805 \%$ \\
\hline 92 & canguro & 0.03829 & $0.348 \%$ & $9.887 \%$ & $81.153 \%$ \\
\hline 93 & chimpancé & 0.03814 & $0.358 \%$ & $10.169 \%$ & $81.511 \%$ \\
\hline 94 & asno & 0.03750 & $0.269 \%$ & $7.627 \%$ & $81.780 \%$ \\
\hline 95 & hombre & 0.03519 & $0.219 \%$ & $6.215 \%$ & $81.999 \%$ \\
\hline 96 & sepia & 0.03496 & $0.318 \%$ & $9.040 \%$ & $82.317 \%$ \\
\hline 97 & búfalo & 0.03412 & $0.338 \%$ & $9.605 \%$ & $82.655 \%$ \\
\hline 98 & cangrejo & 0.03338 & $0.318 \%$ & $9.040 \%$ & $82.973 \%$ \\
\hline 99 & salmón & 0.03303 & $0.298 \%$ & $8.475 \%$ & $83.271 \%$ \\
\hline 100 & orangután & 0.03301 & $0.328 \%$ & $9.322 \%$ & $83.599 \%$ \\
\hline 101 & gaviota & 0.03123 & $0.279 \%$ & $7.910 \%$ & $83.878 \%$ \\
\hline 102 & libélula & 0.03105 & $0.229 \%$ & $6.497 \%$ & $84.107 \%$ \\
\hline 103 & topo & 0.03102 & $0.229 \%$ & $6.497 \%$ & $84.336 \%$ \\
\hline 104 & cuervo & 0.03057 & $0.249 \%$ & $7.062 \%$ & $84.585 \%$ \\
\hline 105 & murciélago & 0.03036 & $0.229 \%$ & $6.497 \%$ & $84.814 \%$ \\
\hline 106 & golondrina & 0.02995 & $0.229 \%$ & $6.497 \%$ & $85.043 \%$ \\
\hline 107 & caracol & 0.02951 & $0.269 \%$ & $7.627 \%$ & $85.312 \%$ \\
\hline 108 & gacela & 0.02826 & $0.229 \%$ & $6.497 \%$ & $85.541 \%$ \\
\hline 109 & escarabajo & 0.02825 & $0.219 \%$ & $6.215 \%$ & $85.760 \%$ \\
\hline 110 & culebra & 0.02795 & $0.229 \%$ & $6.497 \%$ & $85.989 \%$ \\
\hline 111 & cacatúa & 0.02784 & $0.219 \%$ & $6.215 \%$ & $86.208 \%$ \\
\hline 112 & mariquita & 0.02743 & $0.239 \%$ & $6.780 \%$ & $86.447 \%$ \\
\hline 113 & $\tilde{n} u$ & 0.02708 & $0.219 \%$ & $6.215 \%$ & $86.666 \%$ \\
\hline 114 & cigüeña & 0.02687 & $0.209 \%$ & $5.932 \%$ & $86.875 \%$ \\
\hline 115 & tordo & 0.02627 & $0.189 \%$ & $5.367 \%$ & $87.064 \%$ \\
\hline 116 & atún & 0.02604 & $0.209 \%$ & $5.932 \%$ & $87.273 \%$ \\
\hline 117 & medusa & 0.02482 & $0.229 \%$ & $6.497 \%$ & $87.502 \%$ \\
\hline 118 & cordero & 0.02440 & $0.189 \%$ & $5.367 \%$ & $87.691 \%$ \\
\hline 119 & pingüino & 0.02394 & $0.219 \%$ & $6.215 \%$ & $87.910 \%$ \\
\hline 120 & potro & 0.02355 & $0.179 \%$ & $5.085 \%$ & $88.089 \%$ \\
\hline 121 & mula & 0.02322 & $0.159 \%$ & $4.520 \%$ & $88.248 \%$ \\
\hline 122 & pavo & 0.02305 & $0.169 \%$ & $4.802 \%$ & $88.417 \%$ \\
\hline 123 & gamba & 0.02252 & $0.229 \%$ & $6.497 \%$ & $88.646 \%$ \\
\hline 124 & cisne & 0.02184 & $0.169 \%$ & $4.802 \%$ & $88.815 \%$ \\
\hline 125 & piraña & 0.02133 & $0.179 \%$ & $5.085 \%$ & $88.994 \%$ \\
\hline 126 & lombriz & 0.02049 & $0.139 \%$ & $3.955 \%$ & $89.133 \%$ \\
\hline 127 & mofeta & 0.01886 & $0.179 \%$ & $5.085 \%$ & $89.312 \%$ \\
\hline 128 & jaguar & 0.01858 & $0.129 \%$ & $3.672 \%$ & $89.441 \%$ \\
\hline 129 & salamandra & 0.01847 & $0.189 \%$ & $5.367 \%$ & $89.630 \%$ \\
\hline 130 & dromedario & 0.01810 & $0.169 \%$ & $4.802 \%$ & $89.799 \%$ \\
\hline 131 & oca & 0.01799 & $0.139 \%$ & $3.955 \%$ & $89.938 \%$ \\
\hline 132 & tarántula & 0.01783 & $0.129 \%$ & $3.672 \%$ & $90.067 \%$ \\
\hline 133 & colibrí & 0.01754 & $0.129 \%$ & $3.672 \%$ & $90.196 \%$ \\
\hline 134 & poni & 0.01676 & $0.149 \%$ & $4.237 \%$ & $90.345 \%$ \\
\hline 135 & trucha & 0.01667 & $0.129 \%$ & $3.672 \%$ & $90.474 \%$ \\
\hline 136 & garrapata & 0.01580 & $0.090 \%$ & $2.542 \%$ & $90.564 \%$ \\
\hline 137 & grillo & 0.01554 & $0.109 \%$ & $3.107 \%$ & $90.673 \%$ \\
\hline
\end{tabular}




\begin{tabular}{|c|c|c|c|c|c|}
\hline 138 & oso hormiguero & 0.01520 & $0.139 \%$ & $3.955 \%$ & $90.812 \%$ \\
\hline 139 & lechuza & 0.01501 & $0.119 \%$ & $3.390 \%$ & $90.931 \%$ \\
\hline 140 & tórtola & 0.01482 & $0.090 \%$ & $2.542 \%$ & $91.021 \%$ \\
\hline 141 & kiwi & 0.01444 & $0.099 \%$ & $2.825 \%$ & $91.120 \%$ \\
\hline 142 & merluza & 0.01436 & $0.139 \%$ & $3.955 \%$ & $91.259 \%$ \\
\hline 143 & morsa & 0.01399 & $0.119 \%$ & $3.390 \%$ & $91.378 \%$ \\
\hline 144 & mulo & 0.01378 & $0.080 \%$ & $2.260 \%$ & $91.458 \%$ \\
\hline 145 & insecto & 0.01377 & $0.090 \%$ & $2.542 \%$ & $91.548 \%$ \\
\hline 146 & cóndor & 0.01373 & $0.109 \%$ & $3.107 \%$ & $91.657 \%$ \\
\hline 147 & papagayo & 0.01367 & $0.109 \%$ & $3.107 \%$ & $91.766 \%$ \\
\hline 148 & anguila & 0.01311 & $0.099 \%$ & $2.825 \%$ & $91.865 \%$ \\
\hline 149 & langosta & 0.01293 & $0.139 \%$ & $3.955 \%$ & $92.004 \%$ \\
\hline 150 & perezoso & 0.01264 & $0.090 \%$ & $2.542 \%$ & $92.094 \%$ \\
\hline 151 & gato montés & 0.01227 & $0.099 \%$ & $2.825 \%$ & $92.193 \%$ \\
\hline 152 & ternera & 0.01208 & $0.099 \%$ & $2.825 \%$ & $92.292 \%$ \\
\hline 153 & nutria & 0.01166 & $0.119 \%$ & $3.390 \%$ & $92.411 \%$ \\
\hline 154 & dorada & 0.01163 & $0.090 \%$ & $2.542 \%$ & $92.501 \%$ \\
\hline 155 & mejillón & 0.01130 & $0.129 \%$ & $3.672 \%$ & $92.630 \%$ \\
\hline 156 & cotorra & 0.01127 & $0.060 \%$ & $1.695 \%$ & $92.690 \%$ \\
\hline 157 & mandril & 0.01107 & $0.090 \%$ & $2.542 \%$ & $92.780 \%$ \\
\hline 158 & lenguado & 0.01092 & $0.099 \%$ & $2.825 \%$ & $92.879 \%$ \\
\hline 159 & ciempiés & 0.01052 & $0.099 \%$ & $2.825 \%$ & $92.978 \%$ \\
\hline 160 & antílope & 0.01048 & $0.099 \%$ & $2.825 \%$ & $93.077 \%$ \\
\hline 161 & pez martillo & 0.01030 & $0.099 \%$ & $2.825 \%$ & $93.176 \%$ \\
\hline 162 & flamenco & 0.01023 & $0.099 \%$ & $2.825 \%$ & $93.275 \%$ \\
\hline 163 & marmota & 0.01018 & $0.080 \%$ & $2.260 \%$ & $93.355 \%$ \\
\hline 164 & pelícano & 0.00990 & $0.080 \%$ & $2.260 \%$ & $93.435 \%$ \\
\hline 165 & reptil & 0.00976 & $0.080 \%$ & $2.260 \%$ & $93.515 \%$ \\
\hline 166 & oso polar & 0.00974 & $0.070 \%$ & $1.977 \%$ & $93.585 \%$ \\
\hline 167 & moscardón & 0.00970 & $0.060 \%$ & $1.695 \%$ & $93.645 \%$ \\
\hline 168 & carpa & 0.00960 & $0.080 \%$ & $2.260 \%$ & $93.725 \%$ \\
\hline 169 & dragón & 0.00960 & $0.080 \%$ & $2.260 \%$ & $93.805 \%$ \\
\hline 170 & cachalote & 0.00949 & $0.080 \%$ & $2.260 \%$ & $93.885 \%$ \\
\hline 171 & pavo real & 0.00948 & $0.090 \%$ & $2.542 \%$ & $93.975 \%$ \\
\hline 172 & erizo & 0.00938 & $0.090 \%$ & $2.542 \%$ & $94.065 \%$ \\
\hline 173 & abejorro & 0.00938 & $0.080 \%$ & $2.260 \%$ & $94.145 \%$ \\
\hline 174 & tucán & 0.00937 & $0.070 \%$ & $1.977 \%$ & $94.215 \%$ \\
\hline 175 & boa & 0.00909 & $0.070 \%$ & $1.977 \%$ & $94.285 \%$ \\
\hline 176 & choto & 0.00836 & $0.050 \%$ & $1.412 \%$ & $94.335 \%$ \\
\hline 177 & oruga & 0.00819 & $0.080 \%$ & $2.260 \%$ & $94.415 \%$ \\
\hline 178 & anaconda & 0.00816 & $0.060 \%$ & $1.695 \%$ & $94.475 \%$ \\
\hline 179 & mamut & 0.00811 & $0.070 \%$ & $1.977 \%$ & $94.545 \%$ \\
\hline 180 & piojo & 0.00780 & $0.070 \%$ & $1.977 \%$ & $94.615 \%$ \\
\hline 181 & faisán & 0.00773 & $0.070 \%$ & $1.977 \%$ & $94.685 \%$ \\
\hline 182 & simio & 0.00764 & $0.050 \%$ & $1.412 \%$ & $94.735 \%$ \\
\hline 183 & coyote & 0.00763 & $0.070 \%$ & $1.977 \%$ & $94.805 \%$ \\
\hline 184 & cobra & 0.00760 & $0.040 \%$ & $1.130 \%$ & $94.845 \%$ \\
\hline
\end{tabular}




\begin{tabular}{|c|c|c|c|c|c|}
\hline 185 & mamífero & 0.00759 & $0.040 \%$ & $1.130 \%$ & $94.885 \%$ \\
\hline 186 & cadernera & 0.00750 & $0.050 \%$ & $1.412 \%$ & $94.935 \%$ \\
\hline 187 & albatros & 0.00734 & $0.030 \%$ & $0.847 \%$ & $94.965 \%$ \\
\hline 188 & ser humano & 0.00730 & $0.050 \%$ & $1.412 \%$ & $95.015 \%$ \\
\hline 189 & castor & 0.00710 & $0.080 \%$ & $2.260 \%$ & $95.095 \%$ \\
\hline 190 & mero & 0.00706 & $0.060 \%$ & $1.695 \%$ & $95.155 \%$ \\
\hline 191 & pulgón & 0.00704 & $0.040 \%$ & $1.130 \%$ & $95.195 \%$ \\
\hline 192 & emperador & 0.00698 & $0.050 \%$ & $1.412 \%$ & $95.245 \%$ \\
\hline 193 & morena & 0.00690 & $0.080 \%$ & $2.260 \%$ & $95.325 \%$ \\
\hline 194 & caniche & 0.00690 & $0.030 \%$ & $0.847 \%$ & $95.355 \%$ \\
\hline 195 & tejón & 0.00686 & $0.050 \%$ & $1.412 \%$ & $95.405 \%$ \\
\hline 196 & estornino & 0.00659 & $0.060 \%$ & $1.695 \%$ & $95.465 \%$ \\
\hline 197 & cachorro & 0.00654 & $0.030 \%$ & $0.847 \%$ & $95.495 \%$ \\
\hline 198 & garza & 0.00654 & $0.040 \%$ & $1.130 \%$ & $95.535 \%$ \\
\hline 199 & almeja & 0.00649 & $0.080 \%$ & $2.260 \%$ & $95.615 \%$ \\
\hline 200 & ruiseñor & 0.00647 & $0.040 \%$ & $1.130 \%$ & $95.655 \%$ \\
\hline 201 & cuco & 0.00641 & $0.030 \%$ & $0.847 \%$ & $95.685 \%$ \\
\hline 202 & conejillo de indias & 0.00638 & $0.040 \%$ & $1.130 \%$ & $95.725 \%$ \\
\hline 203 & mapache & 0.00634 & $0.050 \%$ & $1.412 \%$ & $95.775 \%$ \\
\hline 204 & ave & 0.00629 & $0.030 \%$ & $0.847 \%$ & $95.805 \%$ \\
\hline 205 & llama & 0.00627 & $0.050 \%$ & $1.412 \%$ & $95.855 \%$ \\
\hline 206 & mirlo & 0.00617 & $0.050 \%$ & $1.412 \%$ & $95.905 \%$ \\
\hline 207 & hurón & 0.00614 & $0.060 \%$ & $1.695 \%$ & $95.965 \%$ \\
\hline 208 & borrego & 0.00608 & $0.040 \%$ & $1.130 \%$ & $96.005 \%$ \\
\hline 209 & estrella de mar & 0.00601 & $0.050 \%$ & $1.412 \%$ & $96.055 \%$ \\
\hline 210 & gusano de seda & 0.00599 & $0.040 \%$ & $1.130 \%$ & $96.095 \%$ \\
\hline 211 & quebrantahuesos & 0.00594 & $0.060 \%$ & $1.695 \%$ & $96.155 \%$ \\
\hline 212 & doméstico & 0.00591 & $0.030 \%$ & $0.847 \%$ & $96.185 \%$ \\
\hline 213 & lubina & 0.00576 & $0.050 \%$ & $1.412 \%$ & $96.235 \%$ \\
\hline 214 & oso panda & 0.00572 & $0.060 \%$ & $1.695 \%$ & $96.295 \%$ \\
\hline 215 & pez sierra & 0.00555 & $0.040 \%$ & $1.130 \%$ & $96.335 \%$ \\
\hline 216 & boquerón & 0.00550 & $0.050 \%$ & $1.412 \%$ & $96.385 \%$ \\
\hline 217 & caballa & 0.00540 & $0.030 \%$ & $0.847 \%$ & $96.415 \%$ \\
\hline 218 & pastor alemán & 0.00536 & $0.020 \%$ & $0.565 \%$ & $96.435 \%$ \\
\hline 219 & león marino & 0.00535 & $0.060 \%$ & $1.695 \%$ & $96.495 \%$ \\
\hline 220 & lirón & 0.00509 & $0.040 \%$ & $1.130 \%$ & $96.535 \%$ \\
\hline 221 & urraca & 0.00505 & $0.050 \%$ & $1.412 \%$ & $96.585 \%$ \\
\hline 222 & verderón & 0.00499 & $0.020 \%$ & $0.565 \%$ & $96.605 \%$ \\
\hline 223 & mujer & 0.00498 & $0.040 \%$ & $1.130 \%$ & $96.645 \%$ \\
\hline 224 & petirrojo & 0.00494 & $0.030 \%$ & $0.847 \%$ & $96.675 \%$ \\
\hline 225 & bacalao & 0.00489 & $0.050 \%$ & $1.412 \%$ & $96.725 \%$ \\
\hline 226 & titot & 0.00486 & $0.030 \%$ & $0.847 \%$ & $96.755 \%$ \\
\hline 227 & becerro & 0.00475 & $0.040 \%$ & $1.130 \%$ & $96.795 \%$ \\
\hline 228 & bonito & 0.00473 & $0.040 \%$ & $1.130 \%$ & $96.835 \%$ \\
\hline 229 & ternero & 0.00468 & $0.040 \%$ & $1.130 \%$ & $96.875 \%$ \\
\hline 230 & felino & 0.00467 & $0.020 \%$ & $0.565 \%$ & $96.895 \%$ \\
\hline 231 & comadreja & 0.00467 & $0.030 \%$ & $0.847 \%$ & $96.925 \%$ \\
\hline
\end{tabular}




\begin{tabular}{|c|c|c|c|c|c|}
\hline 232 & lechón & 0.00445 & $0.030 \%$ & $0.847 \%$ & $96.955 \%$ \\
\hline 233 & lugano & 0.00428 & $0.020 \%$ & $0.565 \%$ & $96.975 \%$ \\
\hline 234 & (gato) siamés & 0.00425 & $0.020 \%$ & $0.565 \%$ & $96.995 \%$ \\
\hline 235 & barbo & 0.00412 & $0.030 \%$ & $0.847 \%$ & $97.025 \%$ \\
\hline 236 & langostino & 0.00405 & $0.040 \%$ & $1.130 \%$ & $97.065 \%$ \\
\hline 237 & bisonte & 0.00404 & $0.040 \%$ & $1.130 \%$ & $97.105 \%$ \\
\hline 238 & armadillo & 0.00398 & $0.030 \%$ & $0.847 \%$ & $97.135 \%$ \\
\hline 239 & mabra & 0.00395 & $0.030 \%$ & $0.847 \%$ & $97.165 \%$ \\
\hline 240 & puerco espín & 0.00395 & $0.040 \%$ & $1.130 \%$ & $97.205 \%$ \\
\hline 241 & perico & 0.00394 & $0.020 \%$ & $0.565 \%$ & $97.225 \%$ \\
\hline 242 & musaraña & 0.00392 & $0.030 \%$ & $0.847 \%$ & $97.255 \%$ \\
\hline 243 & macaco & 0.00388 & $0.030 \%$ & $0.847 \%$ & $97.285 \%$ \\
\hline 244 & tritón & 0.00385 & $0.030 \%$ & $0.847 \%$ & $97.315 \%$ \\
\hline 245 & caballito de mar & 0.00385 & $0.030 \%$ & $0.847 \%$ & $97.345 \%$ \\
\hline 246 & salvaje & 0.00374 & $0.020 \%$ & $0.565 \%$ & $97.365 \%$ \\
\hline 247 & macho & 0.00367 & $0.020 \%$ & $0.565 \%$ & $97.385 \%$ \\
\hline 248 & aguilucho & 0.00365 & $0.030 \%$ & $0.847 \%$ & $97.415 \%$ \\
\hline 249 & renacuajo & 0.00362 & $0.020 \%$ & $0.565 \%$ & $97.435 \%$ \\
\hline 250 & alacrán & 0.00360 & $0.040 \%$ & $1.130 \%$ & $97.475 \%$ \\
\hline 251 & alce & 0.00348 & $0.020 \%$ & $0.565 \%$ & $97.495 \%$ \\
\hline 252 & cigala & 0.00341 & $0.030 \%$ & $0.847 \%$ & $97.525 \%$ \\
\hline 253 & carnero & 0.00340 & $0.020 \%$ & $0.565 \%$ & $97.545 \%$ \\
\hline 254 & tijereta & 0.00338 & $0.020 \%$ & $0.565 \%$ & $97.565 \%$ \\
\hline 255 & lapa & 0.00337 & $0.030 \%$ & $0.847 \%$ & $97.595 \%$ \\
\hline 256 & puerco & 0.00336 & $0.020 \%$ & $0.565 \%$ & $97.615 \%$ \\
\hline 257 & chinche & 0.00328 & $0.020 \%$ & $0.565 \%$ & $97.635 \%$ \\
\hline 258 & oso pardo & 0.00323 & $0.030 \%$ & $0.847 \%$ & $97.665 \%$ \\
\hline 259 & san Bernardo & 0.00315 & $0.020 \%$ & $0.565 \%$ & $97.685 \%$ \\
\hline 260 & rape & 0.00308 & $0.020 \%$ & $0.565 \%$ & $97.705 \%$ \\
\hline 261 & colom & 0.00307 & $0.020 \%$ & $0.565 \%$ & $97.725 \%$ \\
\hline 262 & pinzón & 0.00306 & $0.020 \%$ & $0.565 \%$ & $97.745 \%$ \\
\hline 263 & galápago & 0.00306 & $0.020 \%$ & $0.565 \%$ & $97.765 \%$ \\
\hline 264 & luciérnaga & 0.00304 & $0.030 \%$ & $0.847 \%$ & $97.795 \%$ \\
\hline 265 & cabra montés & 0.00299 & $0.020 \%$ & $0.565 \%$ & $97.815 \%$ \\
\hline 266 & pájaro carpintero & 0.00294 & $0.030 \%$ & $0.847 \%$ & $97.845 \%$ \\
\hline 267 & vampiro & 0.00293 & $0.030 \%$ & $0.847 \%$ & $97.875 \%$ \\
\hline 268 & marsupial & 0.00292 & $0.020 \%$ & $0.565 \%$ & $97.895 \%$ \\
\hline 269 & egua & 0.00283 & $0.020 \%$ & $0.565 \%$ & $97.915 \%$ \\
\hline 270 & tapir & 0.00282 & $0.010 \%$ & $0.282 \%$ & $97.925 \%$ \\
\hline 271 & ácaro & 0.00276 & $0.020 \%$ & $0.565 \%$ & $97.945 \%$ \\
\hline 272 & sargo & 0.00271 & $0.020 \%$ & $0.565 \%$ & $97.965 \%$ \\
\hline 273 & marta & 0.00271 & $0.020 \%$ & $0.565 \%$ & $97.985 \%$ \\
\hline 274 & chivo & 0.00268 & $0.010 \%$ & $0.282 \%$ & $97.995 \%$ \\
\hline 275 & pescadilla & 0.00262 & $0.020 \%$ & $0.565 \%$ & $98.015 \%$ \\
\hline 276 & besugo & 0.00262 & $0.030 \%$ & $0.847 \%$ & $98.045 \%$ \\
\hline 277 & raya & 0.00261 & $0.020 \%$ & $0.565 \%$ & $98.065 \%$ \\
\hline 278 & larva & 0.00257 & $0.030 \%$ & $0.847 \%$ & $98.095 \%$ \\
\hline
\end{tabular}




\begin{tabular}{|c|c|c|c|c|c|}
\hline 279 & husky siberiano & 0.00254 & $0.010 \%$ & $0.282 \%$ & $98.105 \%$ \\
\hline 280 & gato persa & 0.00254 & $0.010 \%$ & $0.282 \%$ & $98.115 \%$ \\
\hline 281 & dóberman & 0.00254 & $0.010 \%$ & $0.282 \%$ & $98.125 \%$ \\
\hline 282 & lisa & 0.00254 & $0.010 \%$ & $0.282 \%$ & $98.135 \%$ \\
\hline 283 & cobaya & 0.00248 & $0.030 \%$ & $0.847 \%$ & $98.165 \%$ \\
\hline 284 & merla & 0.00241 & $0.020 \%$ & $0.565 \%$ & $98.185 \%$ \\
\hline 285 & vacuna de la rabia & 0.00241 & $0.010 \%$ & $0.282 \%$ & $98.195 \%$ \\
\hline 286 & anfibio & 0.00241 & $0.010 \%$ & $0.282 \%$ & $98.205 \%$ \\
\hline 287 & pardillo & 0.00241 & $0.010 \%$ & $0.282 \%$ & $98.215 \%$ \\
\hline 288 & colorín & 0.00241 & $0.010 \%$ & $0.282 \%$ & $98.225 \%$ \\
\hline 289 & salmonete & 0.00231 & $0.030 \%$ & $0.847 \%$ & $98.255 \%$ \\
\hline 290 & animal de zoológico & 0.00228 & $0.010 \%$ & $0.282 \%$ & $98.265 \%$ \\
\hline 291 & collar & 0.00228 & $0.010 \%$ & $0.282 \%$ & $98.275 \%$ \\
\hline 292 & verdecillo & 0.00228 & $0.010 \%$ & $0.282 \%$ & $98.285 \%$ \\
\hline 293 & galgo & 0.00228 & $0.020 \%$ & $0.565 \%$ & $98.305 \%$ \\
\hline 294 & chacal & 0.00228 & $0.010 \%$ & $0.282 \%$ & $98.315 \%$ \\
\hline 295 & guacamayo & 0.00228 & $0.010 \%$ & $0.282 \%$ & $98.325 \%$ \\
\hline 296 & manta & 0.00223 & $0.020 \%$ & $0.565 \%$ & $98.345 \%$ \\
\hline 297 & ganso & 0.00217 & $0.020 \%$ & $0.565 \%$ & $98.365 \%$ \\
\hline 298 & correa & 0.00216 & $0.010 \%$ & $0.282 \%$ & $98.375 \%$ \\
\hline 299 & plancton & 0.00216 & $0.030 \%$ & $0.847 \%$ & $98.405 \%$ \\
\hline 300 & cullerot & 0.00216 & $0.010 \%$ & $0.282 \%$ & $98.415 \%$ \\
\hline 301 & mantis religiosa & 0.00216 & $0.010 \%$ & $0.282 \%$ & $98.425 \%$ \\
\hline 302 & ratón de campo & 0.00216 & $0.010 \%$ & $0.282 \%$ & $98.435 \%$ \\
\hline 303 & mochuelo & 0.00215 & $0.020 \%$ & $0.565 \%$ & $98.455 \%$ \\
\hline 304 & pienso & 0.00205 & $0.010 \%$ & $0.282 \%$ & $98.465 \%$ \\
\hline 305 & torcaz & 0.00205 & $0.010 \%$ & $0.282 \%$ & $98.475 \%$ \\
\hline 306 & osezno & 0.00205 & $0.010 \%$ & $0.282 \%$ & $98.485 \%$ \\
\hline 307 & mastodonte & 0.00205 & $0.010 \%$ & $0.282 \%$ & $98.495 \%$ \\
\hline 308 & tigre blanco & 0.00205 & $0.010 \%$ & $0.282 \%$ & $98.505 \%$ \\
\hline 309 & bebedor & 0.00194 & $0.010 \%$ & $0.282 \%$ & $98.515 \%$ \\
\hline 310 & gamo & 0.00194 & $0.010 \%$ & $0.282 \%$ & $98.525 \%$ \\
\hline 311 & vilero & 0.00194 & $0.010 \%$ & $0.282 \%$ & $98.535 \%$ \\
\hline 312 & reno & 0.00194 & $0.020 \%$ & $0.565 \%$ & $98.555 \%$ \\
\hline 313 & mastín & 0.00194 & $0.010 \%$ & $0.282 \%$ & $98.565 \%$ \\
\hline 314 & crustáceo & 0.00194 & $0.010 \%$ & $0.282 \%$ & $98.575 \%$ \\
\hline 315 & tigre de la sabana & 0.00194 & $0.010 \%$ & $0.282 \%$ & $98.585 \%$ \\
\hline 316 & ñandú & 0.00194 & $0.010 \%$ & $0.282 \%$ & $98.595 \%$ \\
\hline 317 & nécora & 0.00193 & $0.020 \%$ & $0.565 \%$ & $98.615 \%$ \\
\hline 318 & víbora & 0.00192 & $0.020 \%$ & $0.565 \%$ & $98.635 \%$ \\
\hline 319 & sargantana & 0.00190 & $0.020 \%$ & $0.565 \%$ & $98.655 \%$ \\
\hline 320 & torzal & 0.00184 & $0.010 \%$ & $0.282 \%$ & $98.665 \%$ \\
\hline 321 & limpiar & 0.00184 & $0.010 \%$ & $0.282 \%$ & $98.675 \%$ \\
\hline 322 & pequinés & 0.00184 & $0.010 \%$ & $0.282 \%$ & $98.685 \%$ \\
\hline 323 & corzo & 0.00180 & $0.020 \%$ & $0.565 \%$ & $98.705 \%$ \\
\hline 324 & esturión & 0.00177 & $0.020 \%$ & $0.565 \%$ & $98.725 \%$ \\
\hline 325 & llevar a pasear & 0.00175 & $0.010 \%$ & $0.282 \%$ & $98.735 \%$ \\
\hline
\end{tabular}




\begin{tabular}{|c|c|c|c|c|c|}
\hline 326 & ninfa & 0.00175 & $0.010 \%$ & $0.282 \%$ & $98.745 \%$ \\
\hline 327 & azor & 0.00175 & $0.020 \%$ & $0.565 \%$ & $98.765 \%$ \\
\hline 328 & milpiés & 0.00175 & $0.010 \%$ & $0.282 \%$ & $98.775 \%$ \\
\hline 329 & marsopa & 0.00175 & $0.010 \%$ & $0.282 \%$ & $98.785 \%$ \\
\hline 330 & coatí & 0.00175 & $0.010 \%$ & $0.282 \%$ & $98.795 \%$ \\
\hline 331 & lucio & 0.00165 & $0.010 \%$ & $0.282 \%$ & $98.805 \%$ \\
\hline 332 & cuidar & 0.00165 & $0.010 \%$ & $0.282 \%$ & $98.815 \%$ \\
\hline 333 & fletán & 0.00165 & $0.010 \%$ & $0.282 \%$ & $98.825 \%$ \\
\hline 334 & estornell & 0.00165 & $0.010 \%$ & $0.282 \%$ & $98.835 \%$ \\
\hline 335 & mosca tse-tsé & 0.00165 & $0.010 \%$ & $0.282 \%$ & $98.845 \%$ \\
\hline 336 & quetzal & 0.00165 & $0.010 \%$ & $0.282 \%$ & $98.855 \%$ \\
\hline 337 & tiburón blanco & 0.00165 & $0.010 \%$ & $0.282 \%$ & $98.865 \%$ \\
\hline 338 & lémur & 0.00162 & $0.020 \%$ & $0.565 \%$ & $98.885 \%$ \\
\hline 339 & griva & 0.00157 & $0.010 \%$ & $0.282 \%$ & $98.895 \%$ \\
\hline 340 & serrano & 0.00157 & $0.010 \%$ & $0.282 \%$ & $98.905 \%$ \\
\hline 341 & dar comida & 0.00157 & $0.010 \%$ & $0.282 \%$ & $98.915 \%$ \\
\hline 342 & pinzón real & 0.00157 & $0.010 \%$ & $0.282 \%$ & $98.925 \%$ \\
\hline 343 & angula & 0.00157 & $0.010 \%$ & $0.282 \%$ & $98.935 \%$ \\
\hline 344 & tiburón toro & 0.00157 & $0.010 \%$ & $0.282 \%$ & $98.945 \%$ \\
\hline 345 & jumento & 0.00156 & $0.020 \%$ & $0.565 \%$ & $98.965 \%$ \\
\hline 346 & turcazo & 0.00154 & $0.020 \%$ & $0.565 \%$ & $98.985 \%$ \\
\hline 347 & perdigacho & 0.00149 & $0.010 \%$ & $0.282 \%$ & $98.995 \%$ \\
\hline 348 & jineta & 0.00149 & $0.010 \%$ & $0.282 \%$ & $99.005 \%$ \\
\hline 349 & gamuza & 0.00149 & $0.010 \%$ & $0.282 \%$ & $99.015 \%$ \\
\hline 350 & rabosa & 0.00149 & $0.010 \%$ & $0.282 \%$ & $99.025 \%$ \\
\hline 351 & áspid & 0.00149 & $0.010 \%$ & $0.282 \%$ & $99.035 \%$ \\
\hline 352 & unicornio & 0.00141 & $0.010 \%$ & $0.282 \%$ & $99.045 \%$ \\
\hline 353 & pollino & 0.00141 & $0.010 \%$ & $0.282 \%$ & $99.055 \%$ \\
\hline 354 & escorpa & 0.00141 & $0.010 \%$ & $0.282 \%$ & $99.065 \%$ \\
\hline 355 & zorzal alirrojo & 0.00141 & $0.010 \%$ & $0.282 \%$ & $99.075 \%$ \\
\hline 356 & ballenato & 0.00141 & $0.010 \%$ & $0.282 \%$ & $99.085 \%$ \\
\hline 357 & marabunta & 0.00141 & $0.010 \%$ & $0.282 \%$ & $99.095 \%$ \\
\hline 358 & manso & 0.00137 & $0.020 \%$ & $0.565 \%$ & $99.115 \%$ \\
\hline 359 & termita & 0.00134 & $0.010 \%$ & $0.282 \%$ & $99.125 \%$ \\
\hline 360 & cebú & 0.00134 & $0.010 \%$ & $0.282 \%$ & $99.135 \%$ \\
\hline 361 & abejaruco & 0.00134 & $0.010 \%$ & $0.282 \%$ & $99.145 \%$ \\
\hline 362 & arácnido & 0.00134 & $0.010 \%$ & $0.282 \%$ & $99.155 \%$ \\
\hline 363 & marrano & 0.00134 & $0.010 \%$ & $0.282 \%$ & $99.165 \%$ \\
\hline 364 & ameba & 0.00133 & $0.020 \%$ & $0.565 \%$ & $99.185 \%$ \\
\hline 365 & zorzal real & 0.00127 & $0.010 \%$ & $0.282 \%$ & $99.195 \%$ \\
\hline 366 & tigre de Bengala & 0.00127 & $0.010 \%$ & $0.282 \%$ & $99.205 \%$ \\
\hline 367 & dálmata & 0.00127 & $0.010 \%$ & $0.282 \%$ & $99.215 \%$ \\
\hline 368 & alcotán & 0.00127 & $0.010 \%$ & $0.282 \%$ & $99.225 \%$ \\
\hline 369 & lobezno & 0.00127 & $0.010 \%$ & $0.282 \%$ & $99.235 \%$ \\
\hline 370 & cochino & 0.00127 & $0.010 \%$ & $0.282 \%$ & $99.245 \%$ \\
\hline 371 & bogavante & 0.00120 & $0.010 \%$ & $0.282 \%$ & $99.255 \%$ \\
\hline 372 & avutarda & 0.00120 & $0.010 \%$ & $0.282 \%$ & $99.265 \%$ \\
\hline
\end{tabular}




\begin{tabular}{|c|c|c|c|c|c|}
\hline 373 & zorzal charlo & 0.00120 & $0.010 \%$ & $0.282 \%$ & $99.275 \%$ \\
\hline 374 & molusco & 0.00120 & $0.010 \%$ & $0.282 \%$ & $99.285 \%$ \\
\hline 375 & herbívoro & 0.00120 & $0.010 \%$ & $0.282 \%$ & $99.295 \%$ \\
\hline 376 & centollo & 0.00120 & $0.010 \%$ & $0.282 \%$ & $99.305 \%$ \\
\hline 377 & caparra & 0.00117 & $0.020 \%$ & $0.565 \%$ & $99.325 \%$ \\
\hline 378 & serpiente cascabel & 0.00114 & $0.010 \%$ & $0.282 \%$ & $99.335 \%$ \\
\hline 379 & zorzal común & 0.00114 & $0.010 \%$ & $0.282 \%$ & $99.345 \%$ \\
\hline 380 & erizo de mar & 0.00114 & $0.010 \%$ & $0.282 \%$ & $99.355 \%$ \\
\hline 381 & pez de color & 0.00114 & $0.010 \%$ & $0.282 \%$ & $99.365 \%$ \\
\hline 382 & llissa & 0.00114 & $0.010 \%$ & $0.282 \%$ & $99.375 \%$ \\
\hline 383 & caracola & 0.00114 & $0.010 \%$ & $0.282 \%$ & $99.385 \%$ \\
\hline 384 & chihuahua & 0.00114 & $0.010 \%$ & $0.282 \%$ & $99.395 \%$ \\
\hline 385 & rodaballo & 0.00114 & $0.010 \%$ & $0.282 \%$ & $99.405 \%$ \\
\hline 386 & gavilán & 0.00108 & $0.010 \%$ & $0.282 \%$ & $99.415 \%$ \\
\hline 387 & ocelote & 0.00108 & $0.010 \%$ & $0.282 \%$ & $99.425 \%$ \\
\hline 388 & tiburón tigre & 0.00108 & $0.010 \%$ & $0.282 \%$ & $99.435 \%$ \\
\hline 389 & gato salvaje & 0.00108 & $0.010 \%$ & $0.282 \%$ & $99.445 \%$ \\
\hline 390 & visón & 0.00108 & $0.010 \%$ & $0.282 \%$ & $99.455 \%$ \\
\hline 391 & pajel & 0.00108 & $0.010 \%$ & $0.282 \%$ & $99.465 \%$ \\
\hline 392 & águila real & 0.00108 & $0.010 \%$ & $0.282 \%$ & $99.475 \%$ \\
\hline 393 & corneja & 0.00102 & $0.010 \%$ & $0.282 \%$ & $99.485 \%$ \\
\hline 394 & cabrito & 0.00102 & $0.010 \%$ & $0.282 \%$ & $99.495 \%$ \\
\hline 395 & tiburón martillo & 0.00102 & $0.010 \%$ & $0.282 \%$ & $99.505 \%$ \\
\hline 396 & pichón & 0.00097 & $0.010 \%$ & $0.282 \%$ & $99.515 \%$ \\
\hline 397 & cochinillo & 0.00097 & $0.010 \%$ & $0.282 \%$ & $99.525 \%$ \\
\hline 398 & selva & 0.00097 & $0.010 \%$ & $0.282 \%$ & $99.535 \%$ \\
\hline 399 & búho chico & 0.00097 & $0.010 \%$ & $0.282 \%$ & $99.545 \%$ \\
\hline 400 & tiburón común & 0.00097 & $0.010 \%$ & $0.282 \%$ & $99.555 \%$ \\
\hline 401 & frailecillo & 0.00097 & $0.010 \%$ & $0.282 \%$ & $99.565 \%$ \\
\hline 402 & zorzal & 0.00092 & $0.010 \%$ & $0.282 \%$ & $99.575 \%$ \\
\hline 403 & ovíparo & 0.00092 & $0.010 \%$ & $0.282 \%$ & $99.585 \%$ \\
\hline 404 & pez gato & 0.00092 & $0.010 \%$ & $0.282 \%$ & $99.595 \%$ \\
\hline 405 & abubilla & 0.00087 & $0.010 \%$ & $0.282 \%$ & $99.605 \%$ \\
\hline 406 & búho real & 0.00087 & $0.010 \%$ & $0.282 \%$ & $99.615 \%$ \\
\hline 407 & oroneta & 0.00087 & $0.010 \%$ & $0.282 \%$ & $99.625 \%$ \\
\hline 408 & vivíparo & 0.00087 & $0.010 \%$ & $0.282 \%$ & $99.635 \%$ \\
\hline 409 & águila culebrera & 0.00083 & $0.010 \%$ & $0.282 \%$ & $99.645 \%$ \\
\hline 410 & estornino negro & 0.00083 & $0.010 \%$ & $0.282 \%$ & $99.655 \%$ \\
\hline 411 & arce & 0.00083 & $0.010 \%$ & $0.282 \%$ & $99.665 \%$ \\
\hline 412 & fardacho & 0.00083 & $0.010 \%$ & $0.282 \%$ & $99.675 \%$ \\
\hline 413 & escualo & 0.00083 & $0.010 \%$ & $0.282 \%$ & $99.685 \%$ \\
\hline 414 & salmónido & 0.00083 & $0.010 \%$ & $0.282 \%$ & $99.695 \%$ \\
\hline 415 & pescado & 0.00078 & $0.010 \%$ & $0.282 \%$ & $99.705 \%$ \\
\hline 416 & granota & 0.00078 & $0.010 \%$ & $0.282 \%$ & $99.715 \%$ \\
\hline 417 & urraca cabecinegra & 0.00078 & $0.010 \%$ & $0.282 \%$ & $99.725 \%$ \\
\hline 418 & ardilla negra & 0.00074 & $0.010 \%$ & $0.282 \%$ & $99.735 \%$ \\
\hline 419 & chochín & 0.00074 & $0.010 \%$ & $0.282 \%$ & $99.745 \%$ \\
\hline
\end{tabular}




\begin{tabular}{|l|l|l|l|l|l|}
\hline 420 & enjambre & 0.00074 & $0.010 \%$ & $0.282 \%$ & $99.755 \%$ \\
\hline 421 & sanguijuela & 0.00074 & $0.010 \%$ & $0.282 \%$ & $99.765 \%$ \\
\hline 422 & galera & 0.00074 & $0.010 \%$ & $0.282 \%$ & $99.775 \%$ \\
\hline 423 & hipocampo & 0.00070 & $0.010 \%$ & $0.282 \%$ & $99.785 \%$ \\
\hline 424 & buitre negro & 0.00070 & $0.010 \%$ & $0.282 \%$ & $99.795 \%$ \\
\hline 425 & estornino pinto & 0.00070 & $0.010 \%$ & $0.282 \%$ & $99.805 \%$ \\
\hline 426 & carcoma & 0.00070 & $0.010 \%$ & $0.282 \%$ & $99.815 \%$ \\
\hline 427 & okapi & 0.00070 & $0.010 \%$ & $0.282 \%$ & $99.825 \%$ \\
\hline 428 & buitre grande & 0.00067 & $0.010 \%$ & $0.282 \%$ & $99.835 \%$ \\
\hline 429 & ostra & 0.00067 & $0.010 \%$ & $0.282 \%$ & $99.845 \%$ \\
\hline 430 & polilla & 0.00067 & $0.010 \%$ & $0.282 \%$ & $99.855 \%$ \\
\hline 431 & gazapo & 0.00067 & $0.010 \%$ & $0.282 \%$ & $99.865 \%$ \\
\hline 432 & persa & 0.00063 & $0.010 \%$ & $0.282 \%$ & $99.875 \%$ \\
\hline 433 & babosa & 0.00063 & $0.010 \%$ & $0.282 \%$ & $99.885 \%$ \\
\hline 434 & coral & 0.00060 & $0.010 \%$ & $0.282 \%$ & $99.895 \%$ \\
\hline 435 & tocino & 0.00060 & $0.010 \%$ & $0.282 \%$ & $99.905 \%$ \\
\hline 436 & llobarro & 0.00060 & $0.010 \%$ & $0.282 \%$ & $99.915 \%$ \\
\hline 437 & solitaria & 0.00057 & $0.010 \%$ & $0.282 \%$ & $99.925 \%$ \\
\hline 438 & tenia & 0.00057 & $0.010 \%$ & $0.282 \%$ & $99.935 \%$ \\
\hline 439 & gula & 0.00057 & $0.010 \%$ & $0.282 \%$ & $99.945 \%$ \\
\hline 440 & venado & 0.00057 & $0.010 \%$ & $0.282 \%$ & $99.955 \%$ \\
\hline 441 & cuco intestinal & 0.00054 & $0.010 \%$ & $0.282 \%$ & $99.965 \%$ \\
\hline 442 & acémila & 0.00051 & $0.010 \%$ & $0.282 \%$ & $99.975 \%$ \\
\hline 443 & grulla & 0.00051 & $0.010 \%$ & $0.282 \%$ & $99.985 \%$ \\
\hline 444 & pájaro bobo & 0.00051 & $0.010 \%$ & $0.282 \%$ & $99.995 \%$ \\
\hline 445 & berberecho & 0.00046 & $0.010 \%$ & $0.282 \%$ & $100.005 \%$ \\
\hline 446 & gasterópodo & 0.00046 & $0.010 \%$ & $0.282 \%$ & $100.015 \%$ \\
\hline 447 & escolopendra & 0.00033 & $0.010 \%$ & $0.282 \%$ & $100.025 \%$ \\
\hline & & & & & \\
\hline
\end{tabular}

\section{JUEGOS Y DISTRACCIONES}

\begin{tabular}{|c|l|c|c|c|c|}
\hline $\mathrm{N}^{\mathbf{0}}$ & Palabra & Disponibilidad & $\begin{array}{c}\text { Frecuencia } \\
\text { relativa }\end{array}$ & $\%$ Aparición & $\begin{array}{c}\text { Frecuencia } \\
\text { acumulada }\end{array}$ \\
\hline 1 & parchís & 0.53599 & $3.425 \%$ & $66.667 \%$ & $3.425 \%$ \\
\hline 2 & fútbol & 0.44770 & $3.527 \%$ & $68.644 \%$ & $6.952 \%$ \\
\hline 3 & cartas & 0.31235 & $2.250 \%$ & $43.785 \%$ & $9.202 \%$ \\
\hline 4 & (juego de la) oca & 0.28116 & $2.090 \%$ & $40.678 \%$ & $11.292 \%$ \\
\hline 5 & baloncesto & 0.26536 & $2.250 \%$ & $43.785 \%$ & $13.542 \%$ \\
\hline 6 & ajedrez & 0.23591 & $1.887 \%$ & $36.723 \%$ & $15.429 \%$ \\
\hline 7 & tenis & 0.20488 & $1.887 \%$ & $36.723 \%$ & $17.316 \%$ \\
\hline 8 & leer & 0.19877 & $1.698 \%$ & $33.051 \%$ & $19.014 \%$ \\
\hline 9 & escondite & 0.18504 & $1.611 \%$ & $31.356 \%$ & $20.625 \%$ \\
\hline 10 & Trivial* & 0.18431 & $1.466 \%$ & $28.531 \%$ & $22.091 \%$ \\
\hline
\end{tabular}




\begin{tabular}{|c|c|c|c|c|c|}
\hline 11 & guiñote & 0.18195 & $1.277 \%$ & $24.859 \%$ & $23.368 \%$ \\
\hline 12 & balonmano & 0.16787 & $1.640 \%$ & $31.921 \%$ & $25.008 \%$ \\
\hline 13 & damas & 0.16550 & $1.437 \%$ & $27.966 \%$ & $26.445 \%$ \\
\hline 14 & correr & 0.14141 & $1.393 \%$ & $27.119 \%$ & $27.838 \%$ \\
\hline 15 & ver tele(visión) & 0.13497 & $1.176 \%$ & $22.881 \%$ & $29.014 \%$ \\
\hline 16 & Monopoly* & 0.12574 & $1.001 \%$ & $19.492 \%$ & $30.015 \%$ \\
\hline 17 & tele(visión) & 0.12519 & $1.074 \%$ & $20.904 \%$ & $31.089 \%$ \\
\hline 18 & dominó & 0.12477 & $0.958 \%$ & $18.644 \%$ & $32.047 \%$ \\
\hline 19 & bailar & 0.12204 & $1.147 \%$ & $22.316 \%$ & $33.194 \%$ \\
\hline 20 & voleibol & 0.11177 & $1.103 \%$ & $21.469 \%$ & $34.297 \%$ \\
\hline 21 & tres en raya & 0.10616 & $0.987 \%$ & $19.209 \%$ & $35.284 \%$ \\
\hline 22 & comba & 0.10539 & $0.929 \%$ & $18.079 \%$ & $36.213 \%$ \\
\hline 23 & póquer & 0.10437 & $0.842 \%$ & $16.384 \%$ & $37.055 \%$ \\
\hline 24 & ordenador & 0.10239 & $0.943 \%$ & $18.362 \%$ & $37.998 \%$ \\
\hline 25 & mus & 0.09507 & $0.668 \%$ & $12.994 \%$ & $38.666 \%$ \\
\hline 26 & natación & 0.09225 & $0.885 \%$ & $17.232 \%$ & $39.551 \%$ \\
\hline 27 & bingo & 0.09194 & $0.740 \%$ & $14.407 \%$ & $40.291 \%$ \\
\hline 28 & pasear & 0.09148 & $0.972 \%$ & $18.927 \%$ & $41.263 \%$ \\
\hline 29 & cantar & 0.08770 & $0.929 \%$ & $18.079 \%$ & $42.192 \%$ \\
\hline 30 & sambori & 0.07546 & $0.682 \%$ & $13.277 \%$ & $42.874 \%$ \\
\hline 31 & videojuego & 0.07417 & $0.624 \%$ & $12.147 \%$ & $43.498 \%$ \\
\hline 32 & escuchar música & 0.07382 & $0.668 \%$ & $12.994 \%$ & $44.166 \%$ \\
\hline 33 & dados & 0.07167 & $0.624 \%$ & $12.147 \%$ & $44.790 \%$ \\
\hline 34 & nadar & 0.07050 & $0.813 \%$ & $15.819 \%$ & $45.603 \%$ \\
\hline 35 & tute & 0.06937 & $0.552 \%$ & $10.734 \%$ & $46.155 \%$ \\
\hline 36 & cine & 0.06754 & $0.595 \%$ & $11.582 \%$ & $46.750 \%$ \\
\hline 37 & pillar & 0.06725 & $0.682 \%$ & $13.277 \%$ & $47.432 \%$ \\
\hline 38 & Scattergories* & 0.06287 & $0.552 \%$ & $10.734 \%$ & $47.984 \%$ \\
\hline 39 & dormir & 0.06166 & $0.682 \%$ & $13.277 \%$ & $48.666 \%$ \\
\hline 40 & saltar & 0.05927 & $0.566 \%$ & $11.017 \%$ & $49.232 \%$ \\
\hline 41 & música & 0.05827 & $0.522 \%$ & $10.169 \%$ & $49.754 \%$ \\
\hline 42 & billar & 0.05536 & $0.566 \%$ & $11.017 \%$ & $50.320 \%$ \\
\hline 43 & ir al cine & 0.05435 & $0.537 \%$ & $10.452 \%$ & $50.857 \%$ \\
\hline 44 & básquet & 0.05260 & $0.493 \%$ & $9.605 \%$ & $51.350 \%$ \\
\hline 45 & pelota & 0.04936 & $0.406 \%$ & $7.910 \%$ & $51.756 \%$ \\
\hline 46 & consola & 0.04879 & $0.421 \%$ & $8.192 \%$ & $52.177 \%$ \\
\hline 47 & goma & 0.04752 & $0.450 \%$ & $8.757 \%$ & $52.627 \%$ \\
\hline 48 & juegos de mesa & 0.04710 & $0.406 \%$ & $7.910 \%$ & $53.033 \%$ \\
\hline 49 & Tabú* & 0.04510 & $0.348 \%$ & $6.780 \%$ & $53.381 \%$ \\
\hline 50 & discoteca & 0.04496 & $0.406 \%$ & $7.910 \%$ & $53.787 \%$ \\
\hline 51 & fumar & 0.04455 & $0.348 \%$ & $6.780 \%$ & $54.135 \%$ \\
\hline 52 & golf & 0.04388 & $0.450 \%$ & $8.757 \%$ & $54.585 \%$ \\
\hline 53 & escribir & 0.04368 & $0.406 \%$ & $7.910 \%$ & $54.991 \%$ \\
\hline 54 & beber & 0.04338 & $0.406 \%$ & $7.910 \%$ & $55.397 \%$ \\
\hline 55 & patinar & 0.04328 & $0.435 \%$ & $8.475 \%$ & $55.832 \%$ \\
\hline 56 & (juegos de) rol & 0.04305 & $0.319 \%$ & $6.215 \%$ & $56.151 \%$ \\
\hline 57 & hablar & 0.04285 & $0.479 \%$ & $9.322 \%$ & $56.630 \%$ \\
\hline
\end{tabular}




\begin{tabular}{|c|c|c|c|c|c|}
\hline 58 & gallinita ciega & 0.03988 & $0.377 \%$ & $7.345 \%$ & $57.007 \%$ \\
\hline 59 & béisbol & 0.03936 & $0.363 \%$ & $7.062 \%$ & $57.370 \%$ \\
\hline 60 & futbolín & 0.03802 & $0.377 \%$ & $7.345 \%$ & $57.747 \%$ \\
\hline 61 & pintar & 0.03799 & $0.377 \%$ & $7.345 \%$ & $58.124 \%$ \\
\hline 62 & pimpón & 0.03721 & $0.392 \%$ & $7.627 \%$ & $58.516 \%$ \\
\hline 63 & videoconsola & 0.03611 & $0.290 \%$ & $5.650 \%$ & $58.806 \%$ \\
\hline 64 & estudiar & 0.03531 & $0.392 \%$ & $7.627 \%$ & $59.198 \%$ \\
\hline 65 & cinquillo & 0.03488 & $0.305 \%$ & $5.932 \%$ & $59.503 \%$ \\
\hline 66 & brisca & 0.03474 & $0.305 \%$ & $5.932 \%$ & $59.808 \%$ \\
\hline 67 & hockey & 0.03410 & $0.406 \%$ & $7.910 \%$ & $60.214 \%$ \\
\hline 68 & atletismo & 0.03401 & $0.377 \%$ & $7.345 \%$ & $60.591 \%$ \\
\hline 69 & (máquina) tragaperras & 0.03262 & $0.276 \%$ & $5.367 \%$ & $60.867 \%$ \\
\hline 70 & dardos & 0.03153 & $0.348 \%$ & $6.780 \%$ & $61.215 \%$ \\
\hline 71 & dibujar & 0.03070 & $0.348 \%$ & $6.780 \%$ & $61.563 \%$ \\
\hline 72 & teatro & 0.02996 & $0.261 \%$ & $5.085 \%$ & $61.824 \%$ \\
\hline 73 & mirar la tele(visión) & 0.02878 & $0.247 \%$ & $4.802 \%$ & $62.071 \%$ \\
\hline 74 & ruleta & 0.02869 & $0.247 \%$ & $4.802 \%$ & $62.318 \%$ \\
\hline 75 & muñecas & 0.02860 & $0.334 \%$ & $6.497 \%$ & $62.652 \%$ \\
\hline 76 & saltar a la comba & 0.02841 & $0.218 \%$ & $4.237 \%$ & $62.870 \%$ \\
\hline 77 & radio & 0.02803 & $0.261 \%$ & $5.085 \%$ & $63.131 \%$ \\
\hline 78 & feria & 0.02714 & $0.232 \%$ & $4.520 \%$ & $63.363 \%$ \\
\hline 79 & oír música & 0.02677 & $0.276 \%$ & $5.367 \%$ & $63.639 \%$ \\
\hline 80 & películas & 0.02619 & $0.290 \%$ & $5.650 \%$ & $63.929 \%$ \\
\hline 81 & puzle & 0.02374 & $0.247 \%$ & $4.802 \%$ & $64.176 \%$ \\
\hline 82 & pasatiempo & 0.02360 & $0.218 \%$ & $4.237 \%$ & $64.394 \%$ \\
\hline 83 & cuerda & 0.02355 & $0.218 \%$ & $4.237 \%$ & $64.612 \%$ \\
\hline 84 & crucigramas & 0.02313 & $0.232 \%$ & $4.520 \%$ & $64.844 \%$ \\
\hline 85 & mentiroso & 0.02292 & $0.174 \%$ & $3.390 \%$ & $65.018 \%$ \\
\hline 86 & ciclismo & 0.02269 & $0.290 \%$ & $5.650 \%$ & $65.308 \%$ \\
\hline 87 & canicas & 0.02268 & $0.276 \%$ & $5.367 \%$ & $65.584 \%$ \\
\hline 88 & solitario & 0.02252 & $0.232 \%$ & $4.520 \%$ & $65.816 \%$ \\
\hline 89 & bici(cleta) & 0.02251 & $0.261 \%$ & $5.085 \%$ & $66.077 \%$ \\
\hline 90 & esquiar & 0.02240 & $0.305 \%$ & $5.932 \%$ & $66.382 \%$ \\
\hline 91 & lectura & 0.02240 & $0.218 \%$ & $4.237 \%$ & $66.600 \%$ \\
\hline 92 & Pictionary* & 0.02193 & $0.189 \%$ & $3.672 \%$ & $66.789 \%$ \\
\hline 93 & viajar & 0.02134 & $0.319 \%$ & $6.215 \%$ & $67.108 \%$ \\
\hline 94 & comer & 0.02110 & $0.305 \%$ & $5.932 \%$ & $67.413 \%$ \\
\hline 95 & Hotel* $^{*}$ & 0.02105 & $0.261 \%$ & $5.085 \%$ & $67.674 \%$ \\
\hline 96 & frontón & 0.02088 & $0.232 \%$ & $4.520 \%$ & $67.906 \%$ \\
\hline 97 & ir en bici(cleta) & 0.02066 & $0.247 \%$ & $4.802 \%$ & $68.153 \%$ \\
\hline 98 & aeróbic & 0.02060 & $0.232 \%$ & $4.520 \%$ & $68.385 \%$ \\
\hline 99 & squash & 0.02059 & $0.247 \%$ & $4.802 \%$ & $68.632 \%$ \\
\hline 100 & burro & 0.02057 & $0.189 \%$ & $3.672 \%$ & $68.821 \%$ \\
\hline 101 & baraja & 0.02054 & $0.145 \%$ & $2.825 \%$ & $68.966 \%$ \\
\hline 102 & waterpolo & 0.02027 & $0.203 \%$ & $3.955 \%$ & $69.169 \%$ \\
\hline 103 & rugby & 0.01985 & $0.218 \%$ & $4.237 \%$ & $69.387 \%$ \\
\hline 104 & deporte & 0.01982 & $0.174 \%$ & $3.390 \%$ & $69.561 \%$ \\
\hline
\end{tabular}




\begin{tabular}{|c|c|c|c|c|c|}
\hline 105 & conducir & 0.01979 & $0.218 \%$ & $4.237 \%$ & $69.779 \%$ \\
\hline 106 & corro de la patata & 0.01943 & $0.174 \%$ & $3.390 \%$ & $69.953 \%$ \\
\hline 107 & quiniela & 0.01936 & $0.160 \%$ & $3.107 \%$ & $70.113 \%$ \\
\hline 108 & fútbol sala & 0.01925 & $0.189 \%$ & $3.672 \%$ & $70.302 \%$ \\
\hline 109 & revista & 0.01879 & $0.174 \%$ & $3.390 \%$ & $70.476 \%$ \\
\hline 110 & veo veo & 0.01870 & $0.189 \%$ & $3.672 \%$ & $70.665 \%$ \\
\hline 111 & salir & 0.01864 & $0.131 \%$ & $2.542 \%$ & $70.796 \%$ \\
\hline 112 & gimnasia & 0.01862 & $0.232 \%$ & $4.520 \%$ & $71.028 \%$ \\
\hline 113 & pilla pilla & 0.01861 & $0.160 \%$ & $3.107 \%$ & $71.188 \%$ \\
\hline 114 & motociclismo & 0.01848 & $0.232 \%$ & $4.520 \%$ & $71.420 \%$ \\
\hline 115 & Tetris* & 0.01848 & $0.145 \%$ & $2.825 \%$ & $71.565 \%$ \\
\hline 116 & ahorcado & 0.01841 & $0.203 \%$ & $3.955 \%$ & $71.768 \%$ \\
\hline 117 & pescar & 0.01764 & $0.189 \%$ & $3.672 \%$ & $71.957 \%$ \\
\hline 118 & Hundir la flota* & 0.01754 & $0.189 \%$ & $3.672 \%$ & $72.146 \%$ \\
\hline 119 & montar a caballo & 0.01751 & $0.218 \%$ & $4.237 \%$ & $72.364 \%$ \\
\hline 120 & puenting & 0.01749 & $0.232 \%$ & $4.520 \%$ & $72.596 \%$ \\
\hline 121 & lotería & 0.01745 & $0.160 \%$ & $3.107 \%$ & $72.756 \%$ \\
\hline 122 & ramundino & 0.01694 & $0.131 \%$ & $2.542 \%$ & $72.887 \%$ \\
\hline 123 & futbito & 0.01692 & $0.203 \%$ & $3.955 \%$ & $73.090 \%$ \\
\hline 124 & sexo & 0.01649 & $0.116 \%$ & $2.260 \%$ & $73.206 \%$ \\
\hline 125 & contar chistes & 0.01595 & $0.174 \%$ & $3.390 \%$ & $73.380 \%$ \\
\hline 126 & salir con amigos & 0.01576 & $0.145 \%$ & $2.825 \%$ & $73.525 \%$ \\
\hline 127 & amigos & 0.01556 & $0.160 \%$ & $3.107 \%$ & $73.685 \%$ \\
\hline 128 & polis y cacos & 0.01530 & $0.174 \%$ & $3.390 \%$ & $73.859 \%$ \\
\hline 129 & recreativos & 0.01515 & $0.131 \%$ & $2.542 \%$ & $73.990 \%$ \\
\hline 130 & excursión & 0.01506 & $0.174 \%$ & $3.390 \%$ & $74.164 \%$ \\
\hline 131 & Primitiva & 0.01498 & $0.131 \%$ & $2.542 \%$ & $74.295 \%$ \\
\hline 132 & botifarra & 0.01490 & $0.116 \%$ & $2.260 \%$ & $74.411 \%$ \\
\hline 133 & footing & 0.01489 & $0.174 \%$ & $3.390 \%$ & $74.585 \%$ \\
\hline 134 & un dos tres pared & 0.01489 & $0.189 \%$ & $3.672 \%$ & $74.774 \%$ \\
\hline 135 & cazar & 0.01482 & $0.160 \%$ & $3.107 \%$ & $74.934 \%$ \\
\hline 136 & siete y medio & 0.01461 & $0.145 \%$ & $2.825 \%$ & $75.079 \%$ \\
\hline 137 & libro & 0.01411 & $0.116 \%$ & $2.260 \%$ & $75.195 \%$ \\
\hline 138 & senderismo & 0.01391 & $0.160 \%$ & $3.107 \%$ & $75.355 \%$ \\
\hline 139 & reír & 0.01364 & $0.160 \%$ & $3.107 \%$ & $75.515 \%$ \\
\hline 140 & ¿Quién es quién?* & 0.01330 & $0.131 \%$ & $2.542 \%$ & $75.646 \%$ \\
\hline 141 & jugar & 0.01305 & $0.102 \%$ & $1.977 \%$ & $75.748 \%$ \\
\hline 142 & cocinar & 0.01298 & $0.131 \%$ & $2.542 \%$ & $75.879 \%$ \\
\hline 143 & caza & 0.01290 & $0.160 \%$ & $3.107 \%$ & $76.039 \%$ \\
\hline 144 & chinos & 0.01280 & $0.145 \%$ & $2.825 \%$ & $76.184 \%$ \\
\hline 145 & tebeo & 0.01257 & $0.102 \%$ & $1.977 \%$ & $76.286 \%$ \\
\hline 146 & diana & 0.01252 & $0.102 \%$ & $1.977 \%$ & $76.388 \%$ \\
\hline 147 & petanca & 0.01222 & $0.145 \%$ & $2.825 \%$ & $76.533 \%$ \\
\hline 148 & adivinanzas & 0.01210 & $0.131 \%$ & $2.542 \%$ & $76.664 \%$ \\
\hline 149 & pub & 0.01203 & $0.116 \%$ & $2.260 \%$ & $76.780 \%$ \\
\hline 150 & vídeo & 0.01179 & $0.116 \%$ & $2.260 \%$ & $76.896 \%$ \\
\hline 151 & alto el fuego & 0.01170 & $0.160 \%$ & $3.107 \%$ & $77.056 \%$ \\
\hline
\end{tabular}




\begin{tabular}{|c|c|c|c|c|c|}
\hline 152 & carreras & 0.01166 & $0.116 \%$ & $2.260 \%$ & $77.172 \%$ \\
\hline 153 & ir al teatro & 0.01159 & $0.145 \%$ & $2.825 \%$ & $77.317 \%$ \\
\hline 154 & sopa de letras & 0.01140 & $0.116 \%$ & $2.260 \%$ & $77.433 \%$ \\
\hline 155 & motos & 0.01140 & $0.087 \%$ & $1.695 \%$ & $77.520 \%$ \\
\hline 156 & leer un libro & 0.01137 & $0.102 \%$ & $1.977 \%$ & $77.622 \%$ \\
\hline 157 & hacer deporte & 0.01130 & $0.102 \%$ & $1.977 \%$ & $77.724 \%$ \\
\hline 158 & bucear & 0.01130 & $0.102 \%$ & $1.977 \%$ & $77.826 \%$ \\
\hline 159 & cinquet & 0.01128 & $0.087 \%$ & $1.695 \%$ & $77.913 \%$ \\
\hline 160 & toros & 0.01116 & $0.102 \%$ & $1.977 \%$ & $78.015 \%$ \\
\hline 161 & Juegos reunidos* & 0.01103 & $0.116 \%$ & $2.260 \%$ & $78.131 \%$ \\
\hline 162 & Barbies* & 0.01095 & $0.116 \%$ & $2.260 \%$ & $78.247 \%$ \\
\hline 163 & casino & 0.01092 & $0.073 \%$ & $1.412 \%$ & $78.320 \%$ \\
\hline 164 & escoba & 0.01082 & $0.087 \%$ & $1.695 \%$ & $78.407 \%$ \\
\hline 165 & parque de atracciones & 0.01081 & $0.073 \%$ & $1.412 \%$ & $78.480 \%$ \\
\hline 166 & oír la radio & 0.01059 & $0.102 \%$ & $1.977 \%$ & $78.582 \%$ \\
\hline 167 & cuentos & 0.01039 & $0.087 \%$ & $1.695 \%$ & $78.669 \%$ \\
\hline 168 & montaña rusa & 0.01024 & $0.087 \%$ & $1.695 \%$ & $78.756 \%$ \\
\hline 169 & Conecta cuatro* & 0.01022 & $0.116 \%$ & $2.260 \%$ & $78.872 \%$ \\
\hline 170 & saltar a la cuerda & 0.01020 & $0.073 \%$ & $1.412 \%$ & $78.945 \%$ \\
\hline 171 & salir de marcha & 0.01015 & $0.102 \%$ & $1.977 \%$ & $79.047 \%$ \\
\hline 172 & tres pamets & 0.01006 & $0.102 \%$ & $1.977 \%$ & $79.149 \%$ \\
\hline 173 & judo & 0.01000 & $0.145 \%$ & $2.825 \%$ & $79.294 \%$ \\
\hline 174 & truc & 0.00996 & $0.073 \%$ & $1.412 \%$ & $79.367 \%$ \\
\hline 175 & Party* & 0.00982 & $0.073 \%$ & $1.412 \%$ & $79.440 \%$ \\
\hline 176 & Bonoloto & 0.00978 & $0.087 \%$ & $1.695 \%$ & $79.527 \%$ \\
\hline 177 & escalar & 0.00976 & $0.131 \%$ & $2.542 \%$ & $79.658 \%$ \\
\hline 178 & black jack & 0.00966 & $0.102 \%$ & $1.977 \%$ & $79.760 \%$ \\
\hline 179 & drogarse & 0.00961 & $0.073 \%$ & $1.412 \%$ & $79.833 \%$ \\
\hline 180 & balón & 0.00960 & $0.102 \%$ & $1.977 \%$ & $79.935 \%$ \\
\hline 181 & Scrabble* & 0.00959 & $0.087 \%$ & $1.695 \%$ & $80.022 \%$ \\
\hline 182 & naipes & 0.00950 & $0.073 \%$ & $1.412 \%$ & $80.095 \%$ \\
\hline 183 & Internet & 0.00949 & $0.087 \%$ & $1.695 \%$ & $80.182 \%$ \\
\hline 184 & peonza & 0.00947 & $0.102 \%$ & $1.977 \%$ & $80.284 \%$ \\
\hline 185 & balontiro & 0.00930 & $0.145 \%$ & $2.825 \%$ & $80.429 \%$ \\
\hline 186 & columpio & 0.00923 & $0.073 \%$ & $1.412 \%$ & $80.502 \%$ \\
\hline 187 & tocar un instrumento & 0.00922 & $0.102 \%$ & $1.977 \%$ & $80.604 \%$ \\
\hline 188 & ir a la playa & 0.00918 & $0.131 \%$ & $2.542 \%$ & $80.735 \%$ \\
\hline 189 & andar & 0.00913 & $0.116 \%$ & $2.260 \%$ & $80.851 \%$ \\
\hline 190 & bar & 0.00912 & $0.102 \%$ & $1.977 \%$ & $80.953 \%$ \\
\hline 191 & tocar la guitarra & 0.00911 & $0.087 \%$ & $1.695 \%$ & $81.040 \%$ \\
\hline 192 & baile & 0.00902 & $0.073 \%$ & $1.412 \%$ & $81.113 \%$ \\
\hline 193 & cómic & 0.00899 & $0.087 \%$ & $1.695 \%$ & $81.200 \%$ \\
\hline 194 & máquinas & 0.00885 & $0.087 \%$ & $1.695 \%$ & $81.287 \%$ \\
\hline 195 & concierto & 0.00884 & $0.102 \%$ & $1.977 \%$ & $81.389 \%$ \\
\hline 196 & churro & 0.00883 & $0.087 \%$ & $1.695 \%$ & $81.476 \%$ \\
\hline 197 & ruleta rusa & 0.00882 & $0.087 \%$ & $1.695 \%$ & $81.563 \%$ \\
\hline 198 & pesca & 0.00880 & $0.102 \%$ & $1.977 \%$ & $81.665 \%$ \\
\hline
\end{tabular}




\begin{tabular}{|c|c|c|c|c|c|}
\hline 199 & noria & 0.00870 & $0.073 \%$ & $1.412 \%$ & $81.738 \%$ \\
\hline 200 & coches & 0.00868 & $0.116 \%$ & $2.260 \%$ & $81.854 \%$ \\
\hline 201 & bádminton & 0.00867 & $0.102 \%$ & $1.977 \%$ & $81.956 \%$ \\
\hline 202 & volar & 0.00834 & $0.102 \%$ & $1.977 \%$ & $82.058 \%$ \\
\hline 203 & periódico & 0.00824 & $0.073 \%$ & $1.412 \%$ & $82.131 \%$ \\
\hline 204 & submarinismo & 0.00822 & $0.116 \%$ & $2.260 \%$ & $82.247 \%$ \\
\hline 205 & policías y ladrones & 0.00814 & $0.058 \%$ & $1.130 \%$ & $82.305 \%$ \\
\hline 206 & ir a un museo & 0.00804 & $0.102 \%$ & $1.977 \%$ & $82.407 \%$ \\
\hline 207 & Twister* & 0.00804 & $0.058 \%$ & $1.130 \%$ & $82.465 \%$ \\
\hline 208 & charlar & 0.00796 & $0.102 \%$ & $1.977 \%$ & $82.567 \%$ \\
\hline 209 & Dicciopinta* & 0.00788 & $0.073 \%$ & $1.412 \%$ & $82.640 \%$ \\
\hline 210 & gimnasio & 0.00769 & $0.058 \%$ & $1.130 \%$ & $82.698 \%$ \\
\hline 211 & pintura & 0.00762 & $0.073 \%$ & $1.412 \%$ & $82.771 \%$ \\
\hline 212 & piragüismo & 0.00758 & $0.087 \%$ & $1.695 \%$ & $82.858 \%$ \\
\hline 213 & fiesta & 0.00756 & $0.073 \%$ & $1.412 \%$ & $82.931 \%$ \\
\hline 214 & balonvolea & 0.00750 & $0.073 \%$ & $1.412 \%$ & $83.004 \%$ \\
\hline 215 & Risk* & 0.00748 & $0.087 \%$ & $1.695 \%$ & $83.091 \%$ \\
\hline 216 & mamás y papás & 0.00740 & $0.116 \%$ & $2.260 \%$ & $83.207 \%$ \\
\hline 217 & coser & 0.00735 & $0.116 \%$ & $2.260 \%$ & $83.323 \%$ \\
\hline 218 & patinaje & 0.00729 & $0.087 \%$ & $1.695 \%$ & $83.410 \%$ \\
\hline 219 & aeromodelismo & 0.00718 & $0.058 \%$ & $1.130 \%$ & $83.468 \%$ \\
\hline 220 & esquí & 0.00704 & $0.116 \%$ & $2.260 \%$ & $83.584 \%$ \\
\hline 221 & rafting & 0.00691 & $0.087 \%$ & $1.695 \%$ & $83.671 \%$ \\
\hline 222 & paracaidismo & 0.00684 & $0.087 \%$ & $1.695 \%$ & $83.758 \%$ \\
\hline 223 & fútbol americano & 0.00674 & $0.058 \%$ & $1.130 \%$ & $83.816 \%$ \\
\hline 224 & escuchar la radio & 0.00671 & $0.073 \%$ & $1.412 \%$ & $83.889 \%$ \\
\hline 225 & esgrima & 0.00669 & $0.087 \%$ & $1.695 \%$ & $83.976 \%$ \\
\hline 226 & masturbarse & 0.00659 & $0.044 \%$ & $0.847 \%$ & $84.020 \%$ \\
\hline 227 & hablar por teléfono & 0.00652 & $0.073 \%$ & $1.412 \%$ & $84.093 \%$ \\
\hline 228 & coleccionar sellos & 0.00633 & $0.058 \%$ & $1.130 \%$ & $84.151 \%$ \\
\hline 229 & strip póquer & 0.00630 & $0.044 \%$ & $0.847 \%$ & $84.195 \%$ \\
\hline 230 & chapas & 0.00624 & $0.087 \%$ & $1.695 \%$ & $84.282 \%$ \\
\hline 231 & juegos de azar & 0.00621 & $0.044 \%$ & $0.847 \%$ & $84.326 \%$ \\
\hline 232 & paddle & 0.00616 & $0.073 \%$ & $1.412 \%$ & $84.399 \%$ \\
\hline 233 & Scalextric* & 0.00616 & $0.044 \%$ & $0.847 \%$ & $84.443 \%$ \\
\hline 234 & gimnasia rítmica & 0.00609 & $0.073 \%$ & $1.412 \%$ & $84.516 \%$ \\
\hline 235 & escultura & 0.00599 & $0.044 \%$ & $0.847 \%$ & $84.560 \%$ \\
\hline 236 & ir de compras & 0.00596 & $0.058 \%$ & $1.130 \%$ & $84.618 \%$ \\
\hline 237 & caminar & 0.00595 & $0.073 \%$ & $1.412 \%$ & $84.691 \%$ \\
\hline 238 & ir al campo & 0.00586 & $0.058 \%$ & $1.130 \%$ & $84.749 \%$ \\
\hline 239 & películas de vídeo & 0.00571 & $0.058 \%$ & $1.130 \%$ & $84.807 \%$ \\
\hline 240 & soñar & 0.00570 & $0.087 \%$ & $1.695 \%$ & $84.894 \%$ \\
\hline 241 & patín & 0.00566 & $0.073 \%$ & $1.412 \%$ & $84.967 \%$ \\
\hline 242 & frontenis & 0.00563 & $0.073 \%$ & $1.412 \%$ & $85.040 \%$ \\
\hline 243 & viajes & 0.00562 & $0.073 \%$ & $1.412 \%$ & $85.113 \%$ \\
\hline 244 & damas chinas & 0.00562 & $0.073 \%$ & $1.412 \%$ & $85.186 \%$ \\
\hline 245 & montañismo & 0.00552 & $0.073 \%$ & $1.412 \%$ & $85.259 \%$ \\
\hline
\end{tabular}




\begin{tabular}{|c|c|c|c|c|c|}
\hline 246 & tomar el sol & 0.00551 & $0.102 \%$ & $1.977 \%$ & $85.361 \%$ \\
\hline 247 & polo & 0.00550 & $0.044 \%$ & $0.847 \%$ & $85.405 \%$ \\
\hline 248 & filatelia & 0.00547 & $0.058 \%$ & $1.130 \%$ & $85.463 \%$ \\
\hline 249 & esquí acuático & 0.00540 & $0.058 \%$ & $1.130 \%$ & $85.521 \%$ \\
\hline 250 & bolos & 0.00532 & $0.087 \%$ & $1.695 \%$ & $85.608 \%$ \\
\hline 251 & surf & 0.00528 & $0.073 \%$ & $1.412 \%$ & $85.681 \%$ \\
\hline 252 & montar en bici(cleta) & 0.00520 & $0.058 \%$ & $1.130 \%$ & $85.739 \%$ \\
\hline 253 & escalera & 0.00512 & $0.044 \%$ & $0.847 \%$ & $85.783 \%$ \\
\hline 254 & ir de paseo & 0.00512 & $0.044 \%$ & $0.847 \%$ & $85.827 \%$ \\
\hline 255 & pegar a los pollos & 0.00512 & $0.029 \%$ & $0.565 \%$ & $85.856 \%$ \\
\hline 256 & médicos & 0.00510 & $0.058 \%$ & $1.130 \%$ & $85.914 \%$ \\
\hline 257 & carrera de caballos & 0.00509 & $0.058 \%$ & $1.130 \%$ & $85.972 \%$ \\
\hline 258 & tiro con arco & 0.00508 & $0.073 \%$ & $1.412 \%$ & $86.045 \%$ \\
\hline 259 & navegar & 0.00504 & $0.073 \%$ & $1.412 \%$ & $86.118 \%$ \\
\hline 260 & burro va & 0.00503 & $0.058 \%$ & $1.130 \%$ & $86.176 \%$ \\
\hline 261 & boxeo & 0.00497 & $0.073 \%$ & $1.412 \%$ & $86.249 \%$ \\
\hline 262 & taba & 0.00496 & $0.029 \%$ & $0.565 \%$ & $86.278 \%$ \\
\hline 263 & kamasutra & 0.00493 & $0.029 \%$ & $0.565 \%$ & $86.307 \%$ \\
\hline 264 & automovilismo & 0.00491 & $0.087 \%$ & $1.695 \%$ & $86.394 \%$ \\
\hline 265 & cafetería & 0.00489 & $0.044 \%$ & $0.847 \%$ & $86.438 \%$ \\
\hline 266 & barcos & 0.00489 & $0.044 \%$ & $0.847 \%$ & $86.482 \%$ \\
\hline 267 & dialogar & 0.00488 & $0.044 \%$ & $0.847 \%$ & $86.526 \%$ \\
\hline 268 & Continental* & 0.00481 & $0.044 \%$ & $0.847 \%$ & $86.570 \%$ \\
\hline 269 & culturismo & 0.00480 & $0.073 \%$ & $1.412 \%$ & $86.643 \%$ \\
\hline 270 & danza & 0.00479 & $0.058 \%$ & $1.130 \%$ & $86.701 \%$ \\
\hline 271 & casitas & 0.00478 & $0.044 \%$ & $0.847 \%$ & $86.745 \%$ \\
\hline 272 & segundos fuera & 0.00477 & $0.029 \%$ & $0.565 \%$ & $86.774 \%$ \\
\hline 273 & vela & 0.00476 & $0.073 \%$ & $1.412 \%$ & $86.847 \%$ \\
\hline 274 & pegar & 0.00475 & $0.044 \%$ & $0.847 \%$ & $86.891 \%$ \\
\hline 275 & discutir & 0.00471 & $0.058 \%$ & $1.130 \%$ & $86.949 \%$ \\
\hline 276 & tinieblas & 0.00465 & $0.058 \%$ & $1.130 \%$ & $87.007 \%$ \\
\hline 277 & esconderse & 0.00459 & $0.029 \%$ & $0.565 \%$ & $87.036 \%$ \\
\hline 278 & leer el periódico & 0.00459 & $0.044 \%$ & $0.847 \%$ & $87.080 \%$ \\
\hline 279 & maratón & 0.00457 & $0.073 \%$ & $1.412 \%$ & $87.153 \%$ \\
\hline 280 & tenis de mesa & 0.00457 & $0.058 \%$ & $1.130 \%$ & $87.211 \%$ \\
\hline 281 & bote bote & 0.00455 & $0.058 \%$ & $1.130 \%$ & $87.269 \%$ \\
\hline 282 & estar con amigos & 0.00453 & $0.044 \%$ & $0.847 \%$ & $87.313 \%$ \\
\hline 283 & piedra papel tijeras & 0.00451 & $0.058 \%$ & $1.130 \%$ & $87.371 \%$ \\
\hline 284 & juego de las sillas & 0.00447 & $0.044 \%$ & $0.847 \%$ & $87.415 \%$ \\
\hline 285 & equitación & 0.00440 & $0.058 \%$ & $1.130 \%$ & $87.473 \%$ \\
\hline 286 & kárate & 0.00437 & $0.073 \%$ & $1.412 \%$ & $87.546 \%$ \\
\hline 287 & concursos & 0.00437 & $0.044 \%$ & $0.847 \%$ & $87.590 \%$ \\
\hline 288 & planchar & 0.00436 & $0.044 \%$ & $0.847 \%$ & $87.634 \%$ \\
\hline 289 & ir al fútbol & 0.00435 & $0.044 \%$ & $0.847 \%$ & $87.678 \%$ \\
\hline 290 & taekwondo & 0.00434 & $0.058 \%$ & $1.130 \%$ & $87.736 \%$ \\
\hline 291 & montaña & 0.00433 & $0.058 \%$ & $1.130 \%$ & $87.794 \%$ \\
\hline 292 & escalada & 0.00428 & $0.073 \%$ & $1.412 \%$ & $87.867 \%$ \\
\hline
\end{tabular}




\begin{tabular}{|c|c|c|c|c|c|}
\hline 293 & playa & 0.00428 & $0.044 \%$ & $0.847 \%$ & $87.911 \%$ \\
\hline 294 & alpinismo & 0.00423 & $0.044 \%$ & $0.847 \%$ & $87.955 \%$ \\
\hline 295 & halterofilia & 0.00420 & $0.044 \%$ & $0.847 \%$ & $87.999 \%$ \\
\hline 296 & hípica & 0.00415 & $0.029 \%$ & $0.565 \%$ & $88.028 \%$ \\
\hline 297 & ver fútbol & 0.00414 & $0.029 \%$ & $0.565 \%$ & $88.057 \%$ \\
\hline 298 & carrera de coches & 0.00411 & $0.044 \%$ & $0.847 \%$ & $88.101 \%$ \\
\hline 299 & potet & 0.00407 & $0.029 \%$ & $0.565 \%$ & $88.130 \%$ \\
\hline 300 & comprar & 0.00400 & $0.058 \%$ & $1.130 \%$ & $88.188 \%$ \\
\hline 301 & drogas & 0.00399 & $0.044 \%$ & $0.847 \%$ & $88.232 \%$ \\
\hline 302 & Cluedo* & 0.00392 & $0.044 \%$ & $0.847 \%$ & $88.276 \%$ \\
\hline 303 & cuadrado & 0.00387 & $0.029 \%$ & $0.565 \%$ & $88.305 \%$ \\
\hline 304 & goma de saltar & 0.00386 & $0.029 \%$ & $0.565 \%$ & $88.334 \%$ \\
\hline 305 & no hacer nada & 0.00383 & $0.058 \%$ & $1.130 \%$ & $88.392 \%$ \\
\hline 306 & Playstation* & 0.00382 & $0.029 \%$ & $0.565 \%$ & $88.421 \%$ \\
\hline 307 & ballet & 0.00378 & $0.044 \%$ & $0.847 \%$ & $88.465 \%$ \\
\hline 308 & ir de tiendas & 0.00374 & $0.044 \%$ & $0.847 \%$ & $88.509 \%$ \\
\hline 309 & guitarra & 0.00373 & $0.029 \%$ & $0.565 \%$ & $88.538 \%$ \\
\hline 310 & follar & 0.00373 & $0.029 \%$ & $0.565 \%$ & $88.567 \%$ \\
\hline 311 & $s k i$ & 0.00372 & $0.029 \%$ & $0.565 \%$ & $88.596 \%$ \\
\hline 312 & rappel & 0.00372 & $0.058 \%$ & $1.130 \%$ & $88.654 \%$ \\
\hline 313 & besar & 0.00372 & $0.029 \%$ & $0.565 \%$ & $88.683 \%$ \\
\hline 314 & Enredo* & 0.00370 & $0.029 \%$ & $0.565 \%$ & $88.712 \%$ \\
\hline 315 & canasta & 0.00369 & $0.044 \%$ & $0.847 \%$ & $88.756 \%$ \\
\hline 316 & cochecitos & 0.00369 & $0.044 \%$ & $0.847 \%$ & $88.800 \%$ \\
\hline 317 & escuchar & 0.00365 & $0.058 \%$ & $1.130 \%$ & $88.858 \%$ \\
\hline 318 & pelota valenciana & 0.00365 & $0.044 \%$ & $0.847 \%$ & $88.902 \%$ \\
\hline 319 & vacaciones & 0.00364 & $0.058 \%$ & $1.130 \%$ & $88.960 \%$ \\
\hline 320 & alcohol & 0.00363 & $0.029 \%$ & $0.565 \%$ & $88.989 \%$ \\
\hline 321 & Superpoli* & 0.00362 & $0.044 \%$ & $0.847 \%$ & $89.033 \%$ \\
\hline 322 & pasear al perro & 0.00361 & $0.044 \%$ & $0.847 \%$ & $89.077 \%$ \\
\hline 323 & motocross & 0.00360 & $0.044 \%$ & $0.847 \%$ & $89.121 \%$ \\
\hline 324 & imaginar & 0.00357 & $0.058 \%$ & $1.130 \%$ & $89.179 \%$ \\
\hline 325 & pi & 0.00354 & $0.044 \%$ & $0.847 \%$ & $89.223 \%$ \\
\hline 326 & palabras encadenadas & 0.00353 & $0.058 \%$ & $1.130 \%$ & $89.281 \%$ \\
\hline 327 & tobogán & 0.00352 & $0.029 \%$ & $0.565 \%$ & $89.310 \%$ \\
\hline 328 & voley playa & 0.00348 & $0.044 \%$ & $0.847 \%$ & $89.354 \%$ \\
\hline 329 & matar & 0.00347 & $0.029 \%$ & $0.565 \%$ & $89.383 \%$ \\
\hline 330 & rabino & 0.00345 & $0.044 \%$ & $0.847 \%$ & $89.427 \%$ \\
\hline 331 & tirar piedras & 0.00344 & $0.029 \%$ & $0.565 \%$ & $89.456 \%$ \\
\hline 332 & colores & 0.00343 & $0.044 \%$ & $0.847 \%$ & $89.500 \%$ \\
\hline 333 & caballitos & 0.00341 & $0.044 \%$ & $0.847 \%$ & $89.544 \%$ \\
\hline 334 & robar & 0.00341 & $0.044 \%$ & $0.847 \%$ & $89.588 \%$ \\
\hline 335 & chillar & 0.00340 & $0.029 \%$ & $0.565 \%$ & $89.617 \%$ \\
\hline 336 & corro chirimbolo & 0.00340 & $0.029 \%$ & $0.565 \%$ & $89.646 \%$ \\
\hline 337 & misa & 0.00340 & $0.029 \%$ & $0.565 \%$ & $89.675 \%$ \\
\hline 338 & balompié & 0.00337 & $0.044 \%$ & $0.847 \%$ & $89.719 \%$ \\
\hline 339 & magia & 0.00335 & $0.044 \%$ & $0.847 \%$ & $89.763 \%$ \\
\hline
\end{tabular}




\begin{tabular}{|c|c|c|c|c|c|}
\hline 340 & profesores & 0.00335 & $0.044 \%$ & $0.847 \%$ & $89.807 \%$ \\
\hline 341 & estar con la novia & 0.00326 & $0.044 \%$ & $0.847 \%$ & $89.851 \%$ \\
\hline 342 & maquinitas & 0.00326 & $0.044 \%$ & $0.847 \%$ & $89.895 \%$ \\
\hline 343 & cuatro en raya & 0.00326 & $0.029 \%$ & $0.565 \%$ & $89.924 \%$ \\
\hline 344 & ir de marcha & 0.00324 & $0.029 \%$ & $0.565 \%$ & $89.953 \%$ \\
\hline 345 & hockey sobre hielo & 0.00322 & $0.029 \%$ & $0.565 \%$ & $89.982 \%$ \\
\hline 346 & coleccionar & 0.00322 & $0.044 \%$ & $0.847 \%$ & $90.026 \%$ \\
\hline 347 & salto de altura & 0.00318 & $0.044 \%$ & $0.847 \%$ & $90.070 \%$ \\
\hline 348 & autodefinidos & 0.00317 & $0.029 \%$ & $0.565 \%$ & $90.099 \%$ \\
\hline 349 & mirar & 0.00313 & $0.044 \%$ & $0.847 \%$ & $90.143 \%$ \\
\hline 350 & hockey sobre patines & 0.00313 & $0.029 \%$ & $0.565 \%$ & $90.172 \%$ \\
\hline 351 & Pasapalabra* & 0.00313 & $0.029 \%$ & $0.565 \%$ & $90.201 \%$ \\
\hline 352 & Dibujo & 0.00311 & $0.029 \%$ & $0.565 \%$ & $90.230 \%$ \\
\hline 353 & saltar a la goma & 0.00309 & $0.044 \%$ & $0.847 \%$ & $90.274 \%$ \\
\hline 354 & la llevas & 0.00308 & $0.029 \%$ & $0.565 \%$ & $90.303 \%$ \\
\hline 355 & juego de la botella & 0.00308 & $0.029 \%$ & $0.565 \%$ & $90.332 \%$ \\
\hline 356 & monopatín & 0.00305 & $0.044 \%$ & $0.847 \%$ & $90.376 \%$ \\
\hline 357 & salidas & 0.00305 & $0.029 \%$ & $0.565 \%$ & $90.405 \%$ \\
\hline 358 & piscina & 0.00304 & $0.029 \%$ & $0.565 \%$ & $90.434 \%$ \\
\hline 359 & pañuelo & 0.00303 & $0.029 \%$ & $0.565 \%$ & $90.463 \%$ \\
\hline 360 & bañarse & 0.00302 & $0.044 \%$ & $0.847 \%$ & $90.507 \%$ \\
\hline 361 & truque & 0.00302 & $0.029 \%$ & $0.565 \%$ & $90.536 \%$ \\
\hline 362 & ópera & 0.00300 & $0.029 \%$ & $0.565 \%$ & $90.565 \%$ \\
\hline 363 & Cifras y letras* & 0.00300 & $0.029 \%$ & $0.565 \%$ & $90.594 \%$ \\
\hline 364 & carrera de motos & 0.00299 & $0.029 \%$ & $0.565 \%$ & $90.623 \%$ \\
\hline 365 & tomar café & 0.00299 & $0.029 \%$ & $0.565 \%$ & $90.652 \%$ \\
\hline 366 & comecocos & 0.00298 & $0.044 \%$ & $0.847 \%$ & $90.696 \%$ \\
\hline 367 & parque & 0.00289 & $0.044 \%$ & $0.847 \%$ & $90.740 \%$ \\
\hline 368 & ver TV & 0.00287 & $0.044 \%$ & $0.847 \%$ & $90.784 \%$ \\
\hline 369 & un dos tres pollito inglés & 0.00287 & $0.044 \%$ & $0.847 \%$ & $90.828 \%$ \\
\hline 370 & Tibidabo & 0.00282 & $0.015 \%$ & $0.282 \%$ & $90.843 \%$ \\
\hline 371 & ocio & 0.00282 & $0.015 \%$ & $0.282 \%$ & $90.858 \%$ \\
\hline 372 & jugar con un perro & 0.00282 & $0.029 \%$ & $0.565 \%$ & $90.887 \%$ \\
\hline 373 & masturbación & 0.00282 & $0.015 \%$ & $0.282 \%$ & $90.902 \%$ \\
\hline 374 & mirar a una mosca & 0.00282 & $0.015 \%$ & $0.282 \%$ & $90.917 \%$ \\
\hline 375 & cuatro sotas & 0.00282 & $0.015 \%$ & $0.282 \%$ & $90.932 \%$ \\
\hline 376 & patio & 0.00282 & $0.015 \%$ & $0.282 \%$ & $90.947 \%$ \\
\hline 377 & puticlub & 0.00282 & $0.015 \%$ & $0.282 \%$ & $90.962 \%$ \\
\hline 378 & tirarse naranjas & 0.00282 & $0.015 \%$ & $0.282 \%$ & $90.977 \%$ \\
\hline 379 & salir de noche & 0.00282 & $0.015 \%$ & $0.282 \%$ & $90.992 \%$ \\
\hline 380 & juego de la verdad & 0.00280 & $0.029 \%$ & $0.565 \%$ & $91.021 \%$ \\
\hline 381 & ir a clase & 0.00279 & $0.044 \%$ & $0.847 \%$ & $91.065 \%$ \\
\hline 382 & copas & 0.00276 & $0.044 \%$ & $0.847 \%$ & $91.109 \%$ \\
\hline 383 & decatlón & 0.00272 & $0.029 \%$ & $0.565 \%$ & $91.138 \%$ \\
\hline 384 & Intellect* & 0.00272 & $0.029 \%$ & $0.565 \%$ & $91.167 \%$ \\
\hline 385 & máquinas de juegos & 0.00272 & $0.029 \%$ & $0.565 \%$ & $91.196 \%$ \\
\hline 386 & escribir cartas & 0.00269 & $0.029 \%$ & $0.565 \%$ & $91.225 \%$ \\
\hline
\end{tabular}




\begin{tabular}{|c|c|c|c|c|c|}
\hline 387 & ir de camping & 0.00267 & $0.029 \%$ & $0.565 \%$ & $91.254 \%$ \\
\hline 388 & fregar & 0.00266 & $0.029 \%$ & $0.565 \%$ & $91.283 \%$ \\
\hline 389 & hombre rico hombre pobre & 0.00266 & $0.029 \%$ & $0.565 \%$ & $91.312 \%$ \\
\hline 390 & pares y nones & 0.00265 & $0.029 \%$ & $0.565 \%$ & $91.341 \%$ \\
\hline 391 & salir de casa & 0.00263 & $0.015 \%$ & $0.282 \%$ & $91.356 \%$ \\
\hline 392 & parque para niños & 0.00263 & $0.015 \%$ & $0.282 \%$ & $91.371 \%$ \\
\hline 393 & despullat & 0.00263 & $0.015 \%$ & $0.282 \%$ & $91.386 \%$ \\
\hline 394 & botar a la comba & 0.00263 & $0.015 \%$ & $0.282 \%$ & $91.401 \%$ \\
\hline 395 & escalar un pino & 0.00263 & $0.015 \%$ & $0.282 \%$ & $91.416 \%$ \\
\hline 396 & ir en tren & 0.00263 & $0.015 \%$ & $0.282 \%$ & $91.431 \%$ \\
\hline 397 & mountain bike & 0.00261 & $0.029 \%$ & $0.565 \%$ & $91.460 \%$ \\
\hline 398 & zapping & 0.00260 & $0.029 \%$ & $0.565 \%$ & $91.489 \%$ \\
\hline 399 & diábolo & 0.00260 & $0.029 \%$ & $0.565 \%$ & $91.518 \%$ \\
\hline 400 & culturizarse & 0.00257 & $0.029 \%$ & $0.565 \%$ & $91.547 \%$ \\
\hline 401 & indios y vaqueros & 0.00257 & $0.029 \%$ & $0.565 \%$ & $91.576 \%$ \\
\hline 402 & tiro al plato & 0.00255 & $0.044 \%$ & $0.847 \%$ & $91.620 \%$ \\
\hline 403 & pelear & 0.00254 & $0.029 \%$ & $0.565 \%$ & $91.649 \%$ \\
\hline 404 & teléfono estropeado & 0.00254 & $0.029 \%$ & $0.565 \%$ & $91.678 \%$ \\
\hline 405 & tómbola & 0.00249 & $0.029 \%$ & $0.565 \%$ & $91.707 \%$ \\
\hline 406 & diseñar & 0.00247 & $0.029 \%$ & $0.565 \%$ & $91.736 \%$ \\
\hline 407 & dar clase & 0.00246 & $0.015 \%$ & $0.282 \%$ & $91.751 \%$ \\
\hline 408 & perejila & 0.00246 & $0.015 \%$ & $0.282 \%$ & $91.766 \%$ \\
\hline 409 & empujar & 0.00246 & $0.015 \%$ & $0.282 \%$ & $91.781 \%$ \\
\hline 410 & Hero quest* & 0.00246 & $0.015 \%$ & $0.282 \%$ & $91.796 \%$ \\
\hline 411 & juegos de aventuras & 0.00246 & $0.015 \%$ & $0.282 \%$ & $91.811 \%$ \\
\hline 412 & drácula & 0.00246 & $0.015 \%$ & $0.282 \%$ & $91.826 \%$ \\
\hline 413 & papiroflexia & 0.00246 & $0.015 \%$ & $0.282 \%$ & $91.841 \%$ \\
\hline 414 & cromos & 0.00246 & $0.015 \%$ & $0.282 \%$ & $91.856 \%$ \\
\hline 415 & parque temático & 0.00246 & $0.015 \%$ & $0.282 \%$ & $91.871 \%$ \\
\hline 416 & beber vodka & 0.00246 & $0.015 \%$ & $0.282 \%$ & $91.886 \%$ \\
\hline 417 & romper morros & 0.00246 & $0.015 \%$ & $0.282 \%$ & $91.901 \%$ \\
\hline 418 & top model & 0.00246 & $0.015 \%$ & $0.282 \%$ & $91.916 \%$ \\
\hline 419 & fin de semana & 0.00246 & $0.015 \%$ & $0.282 \%$ & $91.931 \%$ \\
\hline 420 & karaoke & 0.00244 & $0.029 \%$ & $0.565 \%$ & $91.960 \%$ \\
\hline 421 & ONCE & 0.00238 & $0.029 \%$ & $0.565 \%$ & $91.989 \%$ \\
\hline 422 & salto de longitud & 0.00237 & $0.029 \%$ & $0.565 \%$ & $92.018 \%$ \\
\hline 423 & raqueta & 0.00237 & $0.029 \%$ & $0.565 \%$ & $92.047 \%$ \\
\hline 424 & volar la cometa & 0.00235 & $0.029 \%$ & $0.565 \%$ & $92.076 \%$ \\
\hline 425 & contar cuentos & 0.00233 & $0.044 \%$ & $0.847 \%$ & $92.120 \%$ \\
\hline 426 & jabalina & 0.00233 & $0.029 \%$ & $0.565 \%$ & $92.149 \%$ \\
\hline 427 & reloj & 0.00233 & $0.029 \%$ & $0.565 \%$ & $92.178 \%$ \\
\hline 428 & cubalibre & 0.00233 & $0.029 \%$ & $0.565 \%$ & $92.207 \%$ \\
\hline 429 & marcianos & 0.00233 & $0.029 \%$ & $0.565 \%$ & $92.236 \%$ \\
\hline 430 & colchoneta & 0.00232 & $0.029 \%$ & $0.565 \%$ & $92.265 \%$ \\
\hline 431 & pesas & 0.00232 & $0.029 \%$ & $0.565 \%$ & $92.294 \%$ \\
\hline 432 & windsurf & 0.00229 & $0.029 \%$ & $0.565 \%$ & $92.323 \%$ \\
\hline 433 & atracciones & 0.00229 & $0.015 \%$ & $0.282 \%$ & $92.338 \%$ \\
\hline
\end{tabular}




\begin{tabular}{|c|c|c|c|c|c|}
\hline 434 & juegos tradicionales & 0.00229 & $0.015 \%$ & $0.282 \%$ & $92.353 \%$ \\
\hline 435 & leer un cómic & 0.00229 & $0.015 \%$ & $0.282 \%$ & $92.368 \%$ \\
\hline 436 & trinquete & 0.00229 & $0.015 \%$ & $0.282 \%$ & $92.383 \%$ \\
\hline 437 & casal & 0.00229 & $0.015 \%$ & $0.282 \%$ & $92.398 \%$ \\
\hline 438 & Pokémon* & 0.00229 & $0.015 \%$ & $0.282 \%$ & $92.413 \%$ \\
\hline 439 & coral & 0.00229 & $0.015 \%$ & $0.282 \%$ & $92.428 \%$ \\
\hline 440 & beber Martini* & 0.00229 & $0.015 \%$ & $0.282 \%$ & $92.443 \%$ \\
\hline 441 & patear & 0.00229 & $0.015 \%$ & $0.282 \%$ & $92.458 \%$ \\
\hline 442 & Un dos tres* & 0.00229 & $0.015 \%$ & $0.282 \%$ & $92.473 \%$ \\
\hline 443 & gimnasia deportiva & 0.00229 & $0.015 \%$ & $0.282 \%$ & $92.488 \%$ \\
\hline 444 & Pinta y colorea* & 0.00229 & $0.015 \%$ & $0.282 \%$ & $92.503 \%$ \\
\hline 445 & bomba va & 0.00229 & $0.015 \%$ & $0.282 \%$ & $92.518 \%$ \\
\hline 446 & deportes de aventura & 0.00229 & $0.015 \%$ & $0.282 \%$ & $92.533 \%$ \\
\hline 447 & programa televisivo & 0.00229 & $0.015 \%$ & $0.282 \%$ & $92.548 \%$ \\
\hline 448 & exposiciones & 0.00224 & $0.029 \%$ & $0.565 \%$ & $92.577 \%$ \\
\hline 449 & rompecabezas & 0.00222 & $0.029 \%$ & $0.565 \%$ & $92.606 \%$ \\
\hline 450 & tren de la bruja & 0.00221 & $0.029 \%$ & $0.565 \%$ & $92.635 \%$ \\
\hline 451 & coleccionar monedas & 0.00221 & $0.029 \%$ & $0.565 \%$ & $92.664 \%$ \\
\hline 452 & lucha libre & 0.00217 & $0.044 \%$ & $0.847 \%$ & $92.708 \%$ \\
\hline 453 & siesta & 0.00215 & $0.029 \%$ & $0.565 \%$ & $92.737 \%$ \\
\hline 454 & horticultura & 0.00214 & $0.015 \%$ & $0.282 \%$ & $92.752 \%$ \\
\hline 455 & coches de choque & 0.00214 & $0.015 \%$ & $0.282 \%$ & $92.767 \%$ \\
\hline 456 & violín & 0.00214 & $0.015 \%$ & $0.282 \%$ & $92.782 \%$ \\
\hline 457 & juegos de estrategia & 0.00214 & $0.015 \%$ & $0.282 \%$ & $92.797 \%$ \\
\hline 458 & club & 0.00214 & $0.015 \%$ & $0.282 \%$ & $92.812 \%$ \\
\hline 459 & colgado & 0.00214 & $0.015 \%$ & $0.282 \%$ & $92.827 \%$ \\
\hline 460 & chicas & 0.00214 & $0.015 \%$ & $0.282 \%$ & $92.842 \%$ \\
\hline 461 & banda & 0.00214 & $0.015 \%$ & $0.282 \%$ & $92.857 \%$ \\
\hline 462 & beber cola & 0.00214 & $0.015 \%$ & $0.282 \%$ & $92.872 \%$ \\
\hline 463 & joder & 0.00214 & $0.015 \%$ & $0.282 \%$ & $92.887 \%$ \\
\hline 464 & El tiempo es oro* & 0.00214 & $0.015 \%$ & $0.282 \%$ & $92.902 \%$ \\
\hline 465 & Playmobil* & 0.00214 & $0.015 \%$ & $0.282 \%$ & $92.917 \%$ \\
\hline 466 & diseño & 0.00214 & $0.015 \%$ & $0.282 \%$ & $92.932 \%$ \\
\hline 467 & póquer-strip & 0.00214 & $0.015 \%$ & $0.282 \%$ & $92.947 \%$ \\
\hline 468 & TV & 0.00214 & $0.015 \%$ & $0.282 \%$ & $92.962 \%$ \\
\hline 469 & maquinetas & 0.00213 & $0.029 \%$ & $0.565 \%$ & $92.991 \%$ \\
\hline 470 & observar & 0.00212 & $0.044 \%$ & $0.847 \%$ & $93.035 \%$ \\
\hline 471 & palmitas & 0.00211 & $0.029 \%$ & $0.565 \%$ & $93.064 \%$ \\
\hline 472 & marcha & 0.00207 & $0.044 \%$ & $0.847 \%$ & $93.108 \%$ \\
\hline 473 & bricolaje & 0.00207 & $0.029 \%$ & $0.565 \%$ & $93.137 \%$ \\
\hline 474 & circo & 0.00206 & $0.029 \%$ & $0.565 \%$ & $93.166 \%$ \\
\hline 475 & perder el tiempo & 0.00206 & $0.029 \%$ & $0.565 \%$ & $93.195 \%$ \\
\hline 476 & trial & 0.00206 & $0.029 \%$ & $0.565 \%$ & $93.224 \%$ \\
\hline 477 & descansar & 0.00203 & $0.029 \%$ & $0.565 \%$ & $93.253 \%$ \\
\hline 478 & lavar & 0.00203 & $0.029 \%$ & $0.565 \%$ & $93.282 \%$ \\
\hline 479 & hacer parapente & 0.00201 & $0.029 \%$ & $0.565 \%$ & $93.311 \%$ \\
\hline 480 & churro va & 0.00199 & $0.015 \%$ & $0.282 \%$ & $93.326 \%$ \\
\hline
\end{tabular}




\begin{tabular}{|c|c|c|c|c|c|}
\hline 481 & castillo del terror & 0.00199 & $0.015 \%$ & $0.282 \%$ & $93.341 \%$ \\
\hline 482 & coche teledirigido & 0.00199 & $0.029 \%$ & $0.565 \%$ & $93.370 \%$ \\
\hline 483 & encuentro & 0.00199 & $0.015 \%$ & $0.282 \%$ & $93.385 \%$ \\
\hline 484 & Play* & 0.00199 & $0.015 \%$ & $0.282 \%$ & $93.400 \%$ \\
\hline 485 & apuestas & 0.00199 & $0.015 \%$ & $0.282 \%$ & $93.415 \%$ \\
\hline 486 & bate & 0.00199 & $0.015 \%$ & $0.282 \%$ & $93.430 \%$ \\
\hline 487 & ramiro & 0.00199 & $0.015 \%$ & $0.282 \%$ & $93.445 \%$ \\
\hline 488 & beber limón & 0.00199 & $0.015 \%$ & $0.282 \%$ & $93.460 \%$ \\
\hline 489 & amar & 0.00199 & $0.015 \%$ & $0.282 \%$ & $93.475 \%$ \\
\hline 490 & recreo & 0.00199 & $0.015 \%$ & $0.282 \%$ & $93.490 \%$ \\
\hline 491 & juego electrónico & 0.00199 & $0.015 \%$ & $0.282 \%$ & $93.505 \%$ \\
\hline 492 & torear & 0.00199 & $0.015 \%$ & $0.282 \%$ & $93.520 \%$ \\
\hline 493 & fumarse un "peta" & 0.00199 & $0.015 \%$ & $0.282 \%$ & $93.535 \%$ \\
\hline 494 & tocar la flauta & 0.00198 & $0.029 \%$ & $0.565 \%$ & $93.564 \%$ \\
\hline 495 & lanzamiento de disco & 0.00195 & $0.029 \%$ & $0.565 \%$ & $93.593 \%$ \\
\hline 496 & pensar & 0.00192 & $0.044 \%$ & $0.847 \%$ & $93.637 \%$ \\
\hline 497 & cocinitas & 0.00192 & $0.029 \%$ & $0.565 \%$ & $93.666 \%$ \\
\hline 498 & canguro & 0.00192 & $0.029 \%$ & $0.565 \%$ & $93.695 \%$ \\
\hline 499 & comer helados & 0.00189 & $0.029 \%$ & $0.565 \%$ & $93.724 \%$ \\
\hline 500 & sentarse & 0.00186 & $0.015 \%$ & $0.282 \%$ & $93.739 \%$ \\
\hline 501 & Disney* world & 0.00186 & $0.015 \%$ & $0.282 \%$ & $93.754 \%$ \\
\hline 502 & corro & 0.00186 & $0.015 \%$ & $0.282 \%$ & $93.769 \%$ \\
\hline 503 & jugar a toros & 0.00186 & $0.015 \%$ & $0.282 \%$ & $93.784 \%$ \\
\hline 504 & ayudar & 0.00186 & $0.015 \%$ & $0.282 \%$ & $93.799 \%$ \\
\hline 505 & imitaciones & 0.00186 & $0.015 \%$ & $0.282 \%$ & $93.814 \%$ \\
\hline 506 & juegos de palabras & 0.00186 & $0.015 \%$ & $0.282 \%$ & $93.829 \%$ \\
\hline 507 & danzar & 0.00186 & $0.015 \%$ & $0.282 \%$ & $93.844 \%$ \\
\hline 508 & juegos deportivos & 0.00186 & $0.015 \%$ & $0.282 \%$ & $93.859 \%$ \\
\hline 509 & subastado & 0.00186 & $0.015 \%$ & $0.282 \%$ & $93.874 \%$ \\
\hline 510 & juegos de computadora & 0.00186 & $0.015 \%$ & $0.282 \%$ & $93.889 \%$ \\
\hline 511 & juegos electrónicos & 0.00186 & $0.015 \%$ & $0.282 \%$ & $93.904 \%$ \\
\hline 512 & jogging & 0.00186 & $0.015 \%$ & $0.282 \%$ & $93.919 \%$ \\
\hline 513 & canciones & 0.00186 & $0.015 \%$ & $0.282 \%$ & $93.934 \%$ \\
\hline 514 & buscar setas & 0.00186 & $0.015 \%$ & $0.282 \%$ & $93.949 \%$ \\
\hline 515 & julepe & 0.00186 & $0.015 \%$ & $0.282 \%$ & $93.964 \%$ \\
\hline 516 & relevos & 0.00186 & $0.015 \%$ & $0.282 \%$ & $93.979 \%$ \\
\hline 517 & beber pacharán & 0.00186 & $0.015 \%$ & $0.282 \%$ & $93.994 \%$ \\
\hline 518 & lujuria & 0.00186 & $0.015 \%$ & $0.282 \%$ & $94.009 \%$ \\
\hline 519 & test & 0.00186 & $0.015 \%$ & $0.282 \%$ & $94.024 \%$ \\
\hline 520 & costura & 0.00186 & $0.015 \%$ & $0.282 \%$ & $94.039 \%$ \\
\hline 521 & Port-aventura* & 0.00186 & $0.015 \%$ & $0.282 \%$ & $94.054 \%$ \\
\hline 522 & salto de pértiga & 0.00185 & $0.029 \%$ & $0.565 \%$ & $94.083 \%$ \\
\hline 523 & zoo(lógico) & 0.00184 & $0.029 \%$ & $0.565 \%$ & $94.112 \%$ \\
\hline 524 & oír el CD & 0.00182 & $0.029 \%$ & $0.565 \%$ & $94.141 \%$ \\
\hline 525 & hijo puta & 0.00181 & $0.029 \%$ & $0.565 \%$ & $94.170 \%$ \\
\hline 526 & hacer el amor & 0.00180 & $0.029 \%$ & $0.565 \%$ & $94.199 \%$ \\
\hline 527 & sacar al perro & 0.00180 & $0.029 \%$ & $0.565 \%$ & $94.228 \%$ \\
\hline
\end{tabular}




\begin{tabular}{|c|c|c|c|c|c|}
\hline 528 & chistes & 0.00179 & $0.029 \%$ & $0.565 \%$ & $94.257 \%$ \\
\hline 529 & pelota vasca & 0.00179 & $0.029 \%$ & $0.565 \%$ & $94.286 \%$ \\
\hline 530 & boli-bola & 0.00179 & $0.029 \%$ & $0.565 \%$ & $94.315 \%$ \\
\hline 531 & cupón de la ONCE & 0.00179 & $0.029 \%$ & $0.565 \%$ & $94.344 \%$ \\
\hline 532 & manualidades & 0.00175 & $0.029 \%$ & $0.565 \%$ & $94.373 \%$ \\
\hline 533 & autos de choque & 0.00173 & $0.015 \%$ & $0.282 \%$ & $94.388 \%$ \\
\hline 534 & palillos chinos & 0.00173 & $0.015 \%$ & $0.282 \%$ & $94.403 \%$ \\
\hline 535 & guiñol & 0.00173 & $0.015 \%$ & $0.282 \%$ & $94.418 \%$ \\
\hline 536 & componer canciones & 0.00173 & $0.015 \%$ & $0.282 \%$ & $94.433 \%$ \\
\hline 537 & cetrería & 0.00173 & $0.015 \%$ & $0.282 \%$ & $94.448 \%$ \\
\hline 538 & palabra prohibida & 0.00173 & $0.015 \%$ & $0.282 \%$ & $94.463 \%$ \\
\hline 539 & cotillear & 0.00173 & $0.029 \%$ & $0.565 \%$ & $94.492 \%$ \\
\hline 540 & disfrazarse & 0.00173 & $0.015 \%$ & $0.282 \%$ & $94.507 \%$ \\
\hline 541 & comiditas & 0.00173 & $0.015 \%$ & $0.282 \%$ & $94.522 \%$ \\
\hline 542 & ludoteca & 0.00173 & $0.015 \%$ & $0.282 \%$ & $94.537 \%$ \\
\hline 543 & salir en bicicleta de carretera & 0.00173 & $0.015 \%$ & $0.282 \%$ & $94.552 \%$ \\
\hline 544 & pasear en moto & 0.00173 & $0.015 \%$ & $0.282 \%$ & $94.567 \%$ \\
\hline 545 & mirar por la ventana & 0.00173 & $0.015 \%$ & $0.282 \%$ & $94.582 \%$ \\
\hline 546 & galería & 0.00173 & $0.015 \%$ & $0.282 \%$ & $94.597 \%$ \\
\hline 547 & PC fútbol & 0.00173 & $0.015 \%$ & $0.282 \%$ & $94.612 \%$ \\
\hline 548 & Simón dice* & 0.00173 & $0.015 \%$ & $0.282 \%$ & $94.627 \%$ \\
\hline 549 & acariciarse & 0.00173 & $0.015 \%$ & $0.282 \%$ & $94.642 \%$ \\
\hline 550 & hacer muñecos de papel & 0.00173 & $0.015 \%$ & $0.282 \%$ & $94.657 \%$ \\
\hline 551 & ir de pícnic & 0.00173 & $0.015 \%$ & $0.282 \%$ & $94.672 \%$ \\
\hline 552 & leer cuentos & 0.00173 & $0.015 \%$ & $0.282 \%$ & $94.687 \%$ \\
\hline 553 & walkie talkie & 0.00173 & $0.015 \%$ & $0.282 \%$ & $94.702 \%$ \\
\hline 554 & jardinería & 0.00173 & $0.015 \%$ & $0.282 \%$ & $94.717 \%$ \\
\hline 555 & intercambiar cromos & 0.00173 & $0.015 \%$ & $0.282 \%$ & $94.732 \%$ \\
\hline 556 & componer & 0.00173 & $0.015 \%$ & $0.282 \%$ & $94.747 \%$ \\
\hline 557 & jugar con amigos & 0.00173 & $0.015 \%$ & $0.282 \%$ & $94.762 \%$ \\
\hline 558 & Geografía & 0.00173 & $0.015 \%$ & $0.282 \%$ & $94.777 \%$ \\
\hline 559 & patinaje sobre hielo & 0.00173 & $0.015 \%$ & $0.282 \%$ & $94.792 \%$ \\
\hline 560 & teto & 0.00173 & $0.015 \%$ & $0.282 \%$ & $94.807 \%$ \\
\hline 561 & yoga & 0.00171 & $0.029 \%$ & $0.565 \%$ & $94.836 \%$ \\
\hline 562 & documentales & 0.00168 & $0.029 \%$ & $0.565 \%$ & $94.865 \%$ \\
\hline 563 & túnel del terror & 0.00167 & $0.029 \%$ & $0.565 \%$ & $94.894 \%$ \\
\hline 564 & trekking & 0.00162 & $0.015 \%$ & $0.282 \%$ & $94.909 \%$ \\
\hline 565 & espeleología & 0.00162 & $0.015 \%$ & $0.282 \%$ & $94.924 \%$ \\
\hline 566 & fútbol playa & 0.00162 & $0.015 \%$ & $0.282 \%$ & $94.939 \%$ \\
\hline 567 & juegos de mente & 0.00162 & $0.015 \%$ & $0.282 \%$ & $94.954 \%$ \\
\hline 568 & salir por ahí & 0.00162 & $0.015 \%$ & $0.282 \%$ & $94.969 \%$ \\
\hline 569 & hacer castillos de arena & 0.00162 & $0.015 \%$ & $0.282 \%$ & $94.984 \%$ \\
\hline 570 & gimnasia artística & 0.00162 & $0.015 \%$ & $0.282 \%$ & $94.999 \%$ \\
\hline 571 & planear & 0.00162 & $0.015 \%$ & $0.282 \%$ & $95.014 \%$ \\
\hline 572 & tres esquinas & 0.00162 & $0.015 \%$ & $0.282 \%$ & $95.029 \%$ \\
\hline 573 & cabalgar & 0.00162 & $0.029 \%$ & $0.565 \%$ & $95.058 \%$ \\
\hline 574 & repasar & 0.00162 & $0.015 \%$ & $0.282 \%$ & $95.073 \%$ \\
\hline
\end{tabular}




\begin{tabular}{|c|c|c|c|c|c|}
\hline 575 & desnudado & 0.00162 & $0.015 \%$ & $0.282 \%$ & $95.088 \%$ \\
\hline 576 & ruido & 0.00162 & $0.015 \%$ & $0.282 \%$ & $95.103 \%$ \\
\hline 577 & matar pájaros & 0.00162 & $0.015 \%$ & $0.282 \%$ & $95.118 \%$ \\
\hline 578 & sufrir & 0.00162 & $0.015 \%$ & $0.282 \%$ & $95.133 \%$ \\
\hline 579 & ver tías & 0.00162 & $0.015 \%$ & $0.282 \%$ & $95.148 \%$ \\
\hline 580 & salto de la comba & 0.00162 & $0.015 \%$ & $0.282 \%$ & $95.163 \%$ \\
\hline 581 & adivina adivinanza & 0.00162 & $0.015 \%$ & $0.282 \%$ & $95.178 \%$ \\
\hline 582 & ir al circo & 0.00162 & $0.015 \%$ & $0.282 \%$ & $95.193 \%$ \\
\hline 583 & piano & 0.00162 & $0.015 \%$ & $0.282 \%$ & $95.208 \%$ \\
\hline 584 & cambiar cromos & 0.00162 & $0.015 \%$ & $0.282 \%$ & $95.223 \%$ \\
\hline 585 & Historia & 0.00162 & $0.015 \%$ & $0.282 \%$ & $95.238 \%$ \\
\hline 586 & lotería de quintos & 0.00161 & $0.029 \%$ & $0.565 \%$ & $95.267 \%$ \\
\hline 587 & remar & 0.00160 & $0.029 \%$ & $0.565 \%$ & $95.296 \%$ \\
\hline 588 & morderse las uñas & 0.00154 & $0.029 \%$ & $0.565 \%$ & $95.325 \%$ \\
\hline 589 & pistolas & 0.00154 & $0.029 \%$ & $0.565 \%$ & $95.354 \%$ \\
\hline 590 & aviones & 0.00154 & $0.029 \%$ & $0.565 \%$ & $95.383 \%$ \\
\hline 591 & tiro al blanco & 0.00151 & $0.015 \%$ & $0.282 \%$ & $95.398 \%$ \\
\hline 592 & trucos de mesa & 0.00151 & $0.015 \%$ & $0.282 \%$ & $95.413 \%$ \\
\hline 593 & kung-fu & 0.00151 & $0.015 \%$ & $0.282 \%$ & $95.428 \%$ \\
\hline 594 & cuerda de saltar & 0.00151 & $0.015 \%$ & $0.282 \%$ & $95.443 \%$ \\
\hline 595 & jeroglíficos & 0.00151 & $0.015 \%$ & $0.282 \%$ & $95.458 \%$ \\
\hline 596 & tarot & 0.00151 & $0.015 \%$ & $0.282 \%$ & $95.473 \%$ \\
\hline 597 & momia & 0.00151 & $0.015 \%$ & $0.282 \%$ & $95.488 \%$ \\
\hline 598 & buscar caracoles & 0.00151 & $0.015 \%$ & $0.282 \%$ & $95.503 \%$ \\
\hline 599 & surfear & 0.00151 & $0.015 \%$ & $0.282 \%$ & $95.518 \%$ \\
\hline 600 & El pale* & 0.00151 & $0.015 \%$ & $0.282 \%$ & $95.533 \%$ \\
\hline 601 & palillos & 0.00151 & $0.015 \%$ & $0.282 \%$ & $95.548 \%$ \\
\hline 602 & Saber y ganar* & 0.00151 & $0.015 \%$ & $0.282 \%$ & $95.563 \%$ \\
\hline 603 & ver payasos & 0.00151 & $0.015 \%$ & $0.282 \%$ & $95.578 \%$ \\
\hline 604 & cromos de petar & 0.00151 & $0.015 \%$ & $0.282 \%$ & $95.593 \%$ \\
\hline 605 & seguir cuento & 0.00151 & $0.015 \%$ & $0.282 \%$ & $95.608 \%$ \\
\hline 606 & hablar por la radio & 0.00151 & $0.015 \%$ & $0.282 \%$ & $95.623 \%$ \\
\hline 607 & demografía & 0.00151 & $0.015 \%$ & $0.282 \%$ & $95.638 \%$ \\
\hline 608 & trabajar & 0.00149 & $0.029 \%$ & $0.565 \%$ & $95.667 \%$ \\
\hline 609 & tocar instrumentos & 0.00147 & $0.029 \%$ & $0.565 \%$ & $95.696 \%$ \\
\hline 610 & ver museos & 0.00145 & $0.029 \%$ & $0.565 \%$ & $95.725 \%$ \\
\hline 611 & perseguir & 0.00141 & $0.015 \%$ & $0.282 \%$ & $95.740 \%$ \\
\hline 612 & arco & 0.00141 & $0.015 \%$ & $0.282 \%$ & $95.755 \%$ \\
\hline 613 & ver videoclips & 0.00141 & $0.015 \%$ & $0.282 \%$ & $95.770 \%$ \\
\hline 614 & carrera de galgos & 0.00141 & $0.015 \%$ & $0.282 \%$ & $95.785 \%$ \\
\hline 615 & tocar música & 0.00141 & $0.015 \%$ & $0.282 \%$ & $95.800 \%$ \\
\hline 616 & sellos & 0.00141 & $0.015 \%$ & $0.282 \%$ & $95.815 \%$ \\
\hline 617 & cuidar las plantas & 0.00141 & $0.015 \%$ & $0.282 \%$ & $95.830 \%$ \\
\hline 618 & rodar en bicicleta & 0.00141 & $0.015 \%$ & $0.282 \%$ & $95.845 \%$ \\
\hline 619 & portería & 0.00141 & $0.015 \%$ & $0.282 \%$ & $95.860 \%$ \\
\hline 620 & representar & 0.00141 & $0.015 \%$ & $0.282 \%$ & $95.875 \%$ \\
\hline 621 & cultivar gardenias & 0.00141 & $0.015 \%$ & $0.282 \%$ & $95.890 \%$ \\
\hline
\end{tabular}




\begin{tabular}{|c|c|c|c|c|c|}
\hline 622 & el del medio & 0.00141 & $0.015 \%$ & $0.282 \%$ & $95.905 \%$ \\
\hline 623 & fiestas patronales & 0.00141 & $0.015 \%$ & $0.282 \%$ & $95.920 \%$ \\
\hline 624 & ir a bañarte & 0.00141 & $0.015 \%$ & $0.282 \%$ & $95.935 \%$ \\
\hline 625 & macarrón chistero & 0.00141 & $0.015 \%$ & $0.282 \%$ & $95.950 \%$ \\
\hline 626 & copular & 0.00141 & $0.015 \%$ & $0.282 \%$ & $95.965 \%$ \\
\hline 627 & cartear & 0.00141 & $0.015 \%$ & $0.282 \%$ & $95.980 \%$ \\
\hline 628 & juegos de tablero & 0.00141 & $0.015 \%$ & $0.282 \%$ & $95.995 \%$ \\
\hline 629 & beso verdad atrevimiento & 0.00141 & $0.015 \%$ & $0.282 \%$ & $96.010 \%$ \\
\hline 630 & conejito de la suerte & 0.00141 & $0.015 \%$ & $0.282 \%$ & $96.025 \%$ \\
\hline 631 & ditet & 0.00141 & $0.015 \%$ & $0.282 \%$ & $96.040 \%$ \\
\hline 632 & tres piedras & 0.00141 & $0.015 \%$ & $0.282 \%$ & $96.055 \%$ \\
\hline 633 & correr con el coche & 0.00141 & $0.015 \%$ & $0.282 \%$ & $96.070 \%$ \\
\hline 634 & hablar por la emisora & 0.00141 & $0.015 \%$ & $0.282 \%$ & $96.085 \%$ \\
\hline 635 & Clics* & 0.00139 & $0.029 \%$ & $0.565 \%$ & $96.114 \%$ \\
\hline 636 & teléfono loco & 0.00134 & $0.029 \%$ & $0.565 \%$ & $96.143 \%$ \\
\hline 637 & gymkhana & 0.00133 & $0.029 \%$ & $0.565 \%$ & $96.172 \%$ \\
\hline 638 & paracaídas & 0.00131 & $0.015 \%$ & $0.282 \%$ & $96.187 \%$ \\
\hline 639 & Nenuco* & 0.00131 & $0.015 \%$ & $0.282 \%$ & $96.202 \%$ \\
\hline 640 & patinaje artístico & 0.00131 & $0.015 \%$ & $0.282 \%$ & $96.217 \%$ \\
\hline 641 & kit de montaje & 0.00131 & $0.015 \%$ & $0.282 \%$ & $96.232 \%$ \\
\hline 642 & Nintendo* & 0.00131 & $0.015 \%$ & $0.282 \%$ & $96.247 \%$ \\
\hline 643 & tocar el piano & 0.00131 & $0.015 \%$ & $0.282 \%$ & $96.262 \%$ \\
\hline 644 & molestar & 0.00131 & $0.015 \%$ & $0.282 \%$ & $96.277 \%$ \\
\hline 645 & contar hormigas & 0.00131 & $0.015 \%$ & $0.282 \%$ & $96.292 \%$ \\
\hline 646 & portero & 0.00131 & $0.015 \%$ & $0.282 \%$ & $96.307 \%$ \\
\hline 647 & hacer comedias & 0.00131 & $0.015 \%$ & $0.282 \%$ & $96.322 \%$ \\
\hline 648 & juegos de guerra & 0.00131 & $0.015 \%$ & $0.282 \%$ & $96.337 \%$ \\
\hline 649 & trabalenguas & 0.00131 & $0.015 \%$ & $0.282 \%$ & $96.352 \%$ \\
\hline 650 & buscaminas & 0.00131 & $0.015 \%$ & $0.282 \%$ & $96.367 \%$ \\
\hline 651 & Diseña la moda* & 0.00131 & $0.015 \%$ & $0.282 \%$ & $96.382 \%$ \\
\hline 652 & recoger setas & 0.00131 & $0.015 \%$ & $0.282 \%$ & $96.397 \%$ \\
\hline 653 & mirar cuadros & 0.00131 & $0.015 \%$ & $0.282 \%$ & $96.412 \%$ \\
\hline 654 & tiburón & 0.00131 & $0.015 \%$ & $0.282 \%$ & $96.427 \%$ \\
\hline 655 & mirar la calle & 0.00131 & $0.015 \%$ & $0.282 \%$ & $96.442 \%$ \\
\hline 656 & Barriguitas* & 0.00131 & $0.015 \%$ & $0.282 \%$ & $96.457 \%$ \\
\hline 657 & sex-shop & 0.00131 & $0.015 \%$ & $0.282 \%$ & $96.472 \%$ \\
\hline 658 & cuatro esquinas & 0.00131 & $0.015 \%$ & $0.282 \%$ & $96.487 \%$ \\
\hline 659 & trepar & 0.00123 & $0.029 \%$ & $0.565 \%$ & $96.516 \%$ \\
\hline 660 & lanzamiento de martillo & 0.00122 & $0.015 \%$ & $0.282 \%$ & $96.531 \%$ \\
\hline 661 & tertulias & 0.00122 & $0.015 \%$ & $0.282 \%$ & $96.546 \%$ \\
\hline 662 & feria de abril & 0.00122 & $0.015 \%$ & $0.282 \%$ & $96.561 \%$ \\
\hline 663 & arrancarse pelos & 0.00122 & $0.015 \%$ & $0.282 \%$ & $96.576 \%$ \\
\hline 664 & pasear por el campo & 0.00122 & $0.015 \%$ & $0.282 \%$ & $96.591 \%$ \\
\hline 665 & actuar & 0.00122 & $0.015 \%$ & $0.282 \%$ & $96.606 \%$ \\
\hline 666 & buceo & 0.00122 & $0.015 \%$ & $0.282 \%$ & $96.621 \%$ \\
\hline 667 & leer una revista & 0.00122 & $0.015 \%$ & $0.282 \%$ & $96.636 \%$ \\
\hline 668 & surfing & 0.00122 & $0.015 \%$ & $0.282 \%$ & $96.651 \%$ \\
\hline
\end{tabular}




\begin{tabular}{|c|c|c|c|c|c|}
\hline 669 & tute cabrón & 0.00122 & $0.015 \%$ & $0.282 \%$ & $96.666 \%$ \\
\hline 670 & Bancarrota* & 0.00122 & $0.015 \%$ & $0.282 \%$ & $96.681 \%$ \\
\hline 671 & contar & 0.00122 & $0.015 \%$ & $0.282 \%$ & $96.696 \%$ \\
\hline 672 & abdominales & 0.00122 & $0.015 \%$ & $0.282 \%$ & $96.711 \%$ \\
\hline 673 & construir palabras & 0.00122 & $0.015 \%$ & $0.282 \%$ & $96.726 \%$ \\
\hline 674 & camiones & 0.00122 & $0.015 \%$ & $0.282 \%$ & $96.741 \%$ \\
\hline 675 & tonto el que pierda & 0.00122 & $0.015 \%$ & $0.282 \%$ & $96.756 \%$ \\
\hline 676 & comer pan & 0.00122 & $0.015 \%$ & $0.282 \%$ & $96.771 \%$ \\
\hline 677 & baraja de cartas & 0.00122 & $0.015 \%$ & $0.282 \%$ & $96.786 \%$ \\
\hline 678 & yoyo & 0.00122 & $0.015 \%$ & $0.282 \%$ & $96.801 \%$ \\
\hline 679 & cocina & 0.00122 & $0.015 \%$ & $0.282 \%$ & $96.816 \%$ \\
\hline 680 & cazar gatos & 0.00122 & $0.015 \%$ & $0.282 \%$ & $96.831 \%$ \\
\hline 681 & minigolf & 0.00114 & $0.015 \%$ & $0.282 \%$ & $96.846 \%$ \\
\hline 682 & parque acuático & 0.00114 & $0.015 \%$ & $0.282 \%$ & $96.861 \%$ \\
\hline 683 & juegos de memoria & 0.00114 & $0.015 \%$ & $0.282 \%$ & $96.876 \%$ \\
\hline 684 & tres en ratlla & 0.00114 & $0.015 \%$ & $0.282 \%$ & $96.891 \%$ \\
\hline 685 & observar alguna cosa & 0.00114 & $0.015 \%$ & $0.282 \%$ & $96.906 \%$ \\
\hline 686 & ver pájaros & 0.00114 & $0.015 \%$ & $0.282 \%$ & $96.921 \%$ \\
\hline 687 & ver fotos & 0.00114 & $0.015 \%$ & $0.282 \%$ & $96.936 \%$ \\
\hline 688 & alturitas & 0.00114 & $0.015 \%$ & $0.282 \%$ & $96.951 \%$ \\
\hline 689 & birlas & 0.00114 & $0.015 \%$ & $0.282 \%$ & $96.966 \%$ \\
\hline 690 & numismática & 0.00114 & $0.015 \%$ & $0.282 \%$ & $96.981 \%$ \\
\hline 691 & caligrama & 0.00114 & $0.015 \%$ & $0.282 \%$ & $96.996 \%$ \\
\hline 692 & juegos de informática & 0.00114 & $0.015 \%$ & $0.282 \%$ & $97.011 \%$ \\
\hline 693 & la peste & 0.00114 & $0.015 \%$ & $0.282 \%$ & $97.026 \%$ \\
\hline 694 & escribir cuentos & 0.00114 & $0.015 \%$ & $0.282 \%$ & $97.041 \%$ \\
\hline 695 & descenso & 0.00114 & $0.015 \%$ & $0.282 \%$ & $97.056 \%$ \\
\hline 696 & flexiones & 0.00114 & $0.015 \%$ & $0.282 \%$ & $97.071 \%$ \\
\hline 697 & máquinas recreativas & 0.00114 & $0.015 \%$ & $0.282 \%$ & $97.086 \%$ \\
\hline 698 & comer manzanas & 0.00114 & $0.015 \%$ & $0.282 \%$ & $97.101 \%$ \\
\hline 699 & dinero & 0.00114 & $0.029 \%$ & $0.565 \%$ & $97.130 \%$ \\
\hline 700 & pies quietos & 0.00114 & $0.015 \%$ & $0.282 \%$ & $97.145 \%$ \\
\hline 701 & correr con la moto & 0.00114 & $0.015 \%$ & $0.282 \%$ & $97.160 \%$ \\
\hline 702 & cena & 0.00114 & $0.015 \%$ & $0.282 \%$ & $97.175 \%$ \\
\hline 703 & aguantar la respiración & 0.00106 & $0.015 \%$ & $0.282 \%$ & $97.190 \%$ \\
\hline 704 & juegos infantiles & 0.00106 & $0.015 \%$ & $0.282 \%$ & $97.205 \%$ \\
\hline 705 & karting & 0.00106 & $0.015 \%$ & $0.282 \%$ & $97.220 \%$ \\
\hline 706 & juego de construcción & 0.00106 & $0.015 \%$ & $0.282 \%$ & $97.235 \%$ \\
\hline 707 & espadas & 0.00106 & $0.015 \%$ & $0.282 \%$ & $97.250 \%$ \\
\hline 708 & trampolín & 0.00106 & $0.015 \%$ & $0.282 \%$ & $97.265 \%$ \\
\hline 709 & hacer ejercicio & 0.00106 & $0.015 \%$ & $0.282 \%$ & $97.280 \%$ \\
\hline 710 & correr en bicicleta & 0.00106 & $0.015 \%$ & $0.282 \%$ & $97.295 \%$ \\
\hline 711 & hacer el vándalo & 0.00106 & $0.015 \%$ & $0.282 \%$ & $97.310 \%$ \\
\hline 712 & libro de aventuras & 0.00106 & $0.015 \%$ & $0.282 \%$ & $97.325 \%$ \\
\hline 713 & recortar & 0.00106 & $0.015 \%$ & $0.282 \%$ & $97.340 \%$ \\
\hline 714 & ver el paisaje & 0.00106 & $0.015 \%$ & $0.282 \%$ & $97.355 \%$ \\
\hline 715 & escritura & 0.00106 & $0.015 \%$ & $0.282 \%$ & $97.370 \%$ \\
\hline
\end{tabular}




\begin{tabular}{|c|c|c|c|c|c|}
\hline 716 & pescar ranas & 0.00106 & $0.015 \%$ & $0.282 \%$ & $97.385 \%$ \\
\hline 717 & familia & 0.00106 & $0.015 \%$ & $0.282 \%$ & $97.400 \%$ \\
\hline 718 & corre corre & 0.00106 & $0.015 \%$ & $0.282 \%$ & $97.415 \%$ \\
\hline 719 & mímica & 0.00106 & $0.015 \%$ & $0.282 \%$ & $97.430 \%$ \\
\hline 720 & pedra paper tisora & 0.00106 & $0.015 \%$ & $0.282 \%$ & $97.445 \%$ \\
\hline 721 & comer peras & 0.00106 & $0.015 \%$ & $0.282 \%$ & $97.460 \%$ \\
\hline 722 & sonreír & 0.00106 & $0.015 \%$ & $0.282 \%$ & $97.475 \%$ \\
\hline 723 & estar con un chico & 0.00106 & $0.015 \%$ & $0.282 \%$ & $97.490 \%$ \\
\hline 724 & números & 0.00106 & $0.015 \%$ & $0.282 \%$ & $97.505 \%$ \\
\hline 725 & escapada & 0.00106 & $0.015 \%$ & $0.282 \%$ & $97.520 \%$ \\
\hline 726 & entrenar & 0.00106 & $0.015 \%$ & $0.282 \%$ & $97.535 \%$ \\
\hline 727 & baile regional & 0.00099 & $0.015 \%$ & $0.282 \%$ & $97.550 \%$ \\
\hline 728 & fitness & 0.00099 & $0.015 \%$ & $0.282 \%$ & $97.565 \%$ \\
\hline 729 & espiar & 0.00099 & $0.015 \%$ & $0.282 \%$ & $97.580 \%$ \\
\hline 730 & prensa & 0.00099 & $0.015 \%$ & $0.282 \%$ & $97.595 \%$ \\
\hline 731 & jugar con animales & 0.00099 & $0.015 \%$ & $0.282 \%$ & $97.610 \%$ \\
\hline 732 & lancha teledirigida & 0.00099 & $0.015 \%$ & $0.282 \%$ & $97.625 \%$ \\
\hline 733 & frontón a mano & 0.00099 & $0.015 \%$ & $0.282 \%$ & $97.640 \%$ \\
\hline 734 & Lingo* & 0.00099 & $0.015 \%$ & $0.282 \%$ & $97.655 \%$ \\
\hline 735 & conversar con un amigo & 0.00099 & $0.015 \%$ & $0.282 \%$ & $97.670 \%$ \\
\hline 736 & libro de ciencia ficción & 0.00099 & $0.015 \%$ & $0.282 \%$ & $97.685 \%$ \\
\hline 737 & zancadilla & 0.00099 & $0.015 \%$ & $0.282 \%$ & $97.700 \%$ \\
\hline 738 & corre corre que te pillo & 0.00099 & $0.015 \%$ & $0.282 \%$ & $97.715 \%$ \\
\hline 739 & hacer parejas & 0.00099 & $0.015 \%$ & $0.282 \%$ & $97.730 \%$ \\
\hline 740 & instituto & 0.00099 & $0.015 \%$ & $0.282 \%$ & $97.745 \%$ \\
\hline 741 & al del paracaídas & 0.00099 & $0.015 \%$ & $0.282 \%$ & $97.760 \%$ \\
\hline 742 & alucinar & 0.00099 & $0.015 \%$ & $0.282 \%$ & $97.775 \%$ \\
\hline 743 & OsO & 0.00099 & $0.015 \%$ & $0.282 \%$ & $97.790 \%$ \\
\hline 744 & churro media manga mangotero & 0.00099 & $0.015 \%$ & $0.282 \%$ & $97.805 \%$ \\
\hline 745 & comer naranjas & 0.00099 & $0.015 \%$ & $0.282 \%$ & $97.820 \%$ \\
\hline 746 & peste & 0.00099 & $0.015 \%$ & $0.282 \%$ & $97.835 \%$ \\
\hline 747 & tiempo libre & 0.00099 & $0.015 \%$ & $0.282 \%$ & $97.850 \%$ \\
\hline 748 & Literatura & 0.00099 & $0.015 \%$ & $0.282 \%$ & $97.865 \%$ \\
\hline 749 & hacer test & 0.00093 & $0.015 \%$ & $0.282 \%$ & $97.880 \%$ \\
\hline 750 & escribir un diario & 0.00093 & $0.015 \%$ & $0.282 \%$ & $97.895 \%$ \\
\hline 751 & fotografiar & 0.00093 & $0.015 \%$ & $0.282 \%$ & $97.910 \%$ \\
\hline 752 & divertirse & 0.00093 & $0.015 \%$ & $0.282 \%$ & $97.925 \%$ \\
\hline 753 & idiomas & 0.00093 & $0.015 \%$ & $0.282 \%$ & $97.940 \%$ \\
\hline 754 & gancho & 0.00093 & $0.015 \%$ & $0.282 \%$ & $97.955 \%$ \\
\hline 755 & vaca lechera & 0.00093 & $0.015 \%$ & $0.282 \%$ & $97.970 \%$ \\
\hline 756 & hockey sobre hierba & 0.00093 & $0.015 \%$ & $0.282 \%$ & $97.985 \%$ \\
\hline 757 & mirar fotos & 0.00093 & $0.015 \%$ & $0.282 \%$ & $98.000 \%$ \\
\hline 758 & emborracharse & 0.00093 & $0.015 \%$ & $0.282 \%$ & $98.015 \%$ \\
\hline 759 & platerets tets tets & 0.00093 & $0.015 \%$ & $0.282 \%$ & $98.030 \%$ \\
\hline 760 & pedalear & 0.00093 & $0.015 \%$ & $0.282 \%$ & $98.045 \%$ \\
\hline 761 & hacer cosas & 0.00093 & $0.015 \%$ & $0.282 \%$ & $98.060 \%$ \\
\hline 762 & voltar pins & 0.00093 & $0.015 \%$ & $0.282 \%$ & $98.075 \%$ \\
\hline
\end{tabular}




\begin{tabular}{|c|c|c|c|c|c|}
\hline 763 & tragabolas & 0.00093 & $0.015 \%$ & $0.282 \%$ & $98.090 \%$ \\
\hline 764 & juegos de niños & 0.00093 & $0.015 \%$ & $0.282 \%$ & $98.105 \%$ \\
\hline 765 & sacos & 0.00093 & $0.015 \%$ & $0.282 \%$ & $98.120 \%$ \\
\hline 766 & salto al vacío & 0.00093 & $0.015 \%$ & $0.282 \%$ & $98.135 \%$ \\
\hline 767 & Lengua & 0.00093 & $0.015 \%$ & $0.282 \%$ & $98.150 \%$ \\
\hline 768 & revista de ocio & 0.00093 & $0.015 \%$ & $0.282 \%$ & $98.165 \%$ \\
\hline 769 & teléfono roto & 0.00093 & $0.015 \%$ & $0.282 \%$ & $98.180 \%$ \\
\hline 770 & fotografía & 0.00086 & $0.015 \%$ & $0.282 \%$ & $98.195 \%$ \\
\hline 771 & carrera de 100 metros & 0.00086 & $0.015 \%$ & $0.282 \%$ & $98.210 \%$ \\
\hline 772 & sevillanas & 0.00086 & $0.015 \%$ & $0.282 \%$ & $98.225 \%$ \\
\hline 773 & mirar el cielo & 0.00086 & $0.015 \%$ & $0.282 \%$ & $98.240 \%$ \\
\hline 774 & teléfono & 0.00086 & $0.015 \%$ & $0.282 \%$ & $98.255 \%$ \\
\hline 775 & hacer la cama & 0.00086 & $0.015 \%$ & $0.282 \%$ & $98.270 \%$ \\
\hline 776 & hacer chapuzas & 0.00086 & $0.015 \%$ & $0.282 \%$ & $98.285 \%$ \\
\hline 777 & hacer la siesta & 0.00086 & $0.015 \%$ & $0.282 \%$ & $98.300 \%$ \\
\hline 778 & ver & 0.00086 & $0.015 \%$ & $0.282 \%$ & $98.315 \%$ \\
\hline 779 & tiro de pichón & 0.00086 & $0.015 \%$ & $0.282 \%$ & $98.330 \%$ \\
\hline 780 & hablar con gente & 0.00086 & $0.015 \%$ & $0.282 \%$ & $98.345 \%$ \\
\hline 781 & trompa & 0.00086 & $0.015 \%$ & $0.282 \%$ & $98.360 \%$ \\
\hline 782 & tiro & 0.00086 & $0.015 \%$ & $0.282 \%$ & $98.375 \%$ \\
\hline 783 & fisgonear & 0.00086 & $0.015 \%$ & $0.282 \%$ & $98.390 \%$ \\
\hline 784 & tren con batería & 0.00086 & $0.015 \%$ & $0.282 \%$ & $98.405 \%$ \\
\hline 785 & revolcarse & 0.00086 & $0.015 \%$ & $0.282 \%$ & $98.420 \%$ \\
\hline 786 & arreglar grifos & 0.00086 & $0.015 \%$ & $0.282 \%$ & $98.435 \%$ \\
\hline 787 & juego de las preguntas & 0.00086 & $0.015 \%$ & $0.282 \%$ & $98.450 \%$ \\
\hline 788 & un dos tres fuera & 0.00086 & $0.015 \%$ & $0.282 \%$ & $98.465 \%$ \\
\hline 789 & lotería de navidad & 0.00086 & $0.015 \%$ & $0.282 \%$ & $98.480 \%$ \\
\hline 790 & juegos populares & 0.00086 & $0.015 \%$ & $0.282 \%$ & $98.495 \%$ \\
\hline 791 & aquí te pillo aquí te mato & 0.00086 & $0.015 \%$ & $0.282 \%$ & $98.510 \%$ \\
\hline 792 & Valenciano & 0.00086 & $0.015 \%$ & $0.282 \%$ & $98.525 \%$ \\
\hline 793 & fornicar & 0.00081 & $0.015 \%$ & $0.282 \%$ & $98.540 \%$ \\
\hline 794 & carrera de 60 metros & 0.00081 & $0.015 \%$ & $0.282 \%$ & $98.555 \%$ \\
\hline 795 & colorear & 0.00081 & $0.015 \%$ & $0.282 \%$ & $98.570 \%$ \\
\hline 796 & soldaditos & 0.00081 & $0.015 \%$ & $0.282 \%$ & $98.585 \%$ \\
\hline 797 & tejer & 0.00081 & $0.015 \%$ & $0.282 \%$ & $98.600 \%$ \\
\hline 798 & campismo & 0.00081 & $0.015 \%$ & $0.282 \%$ & $98.615 \%$ \\
\hline 799 & maquetar & 0.00081 & $0.015 \%$ & $0.282 \%$ & $98.630 \%$ \\
\hline 800 & juguetes & 0.00081 & $0.015 \%$ & $0.282 \%$ & $98.645 \%$ \\
\hline 801 & programas de TV & 0.00081 & $0.015 \%$ & $0.282 \%$ & $98.660 \%$ \\
\hline 802 & patinar sobre hielo & 0.00081 & $0.015 \%$ & $0.282 \%$ & $98.675 \%$ \\
\hline 803 & La herencia de tía Ágata* & 0.00081 & $0.015 \%$ & $0.282 \%$ & $98.690 \%$ \\
\hline 804 & juegos de familia & 0.00081 & $0.015 \%$ & $0.282 \%$ & $98.705 \%$ \\
\hline 805 & gritar & 0.00081 & $0.015 \%$ & $0.282 \%$ & $98.720 \%$ \\
\hline 806 & sin palabras & 0.00081 & $0.015 \%$ & $0.282 \%$ & $98.735 \%$ \\
\hline 807 & lanzamiento de jabalina & 0.00075 & $0.015 \%$ & $0.282 \%$ & $98.750 \%$ \\
\hline 808 & carrera de 400 metros & 0.00075 & $0.015 \%$ & $0.282 \%$ & $98.765 \%$ \\
\hline 809 & indiaca & 0.00075 & $0.015 \%$ & $0.282 \%$ & $98.780 \%$ \\
\hline
\end{tabular}




\begin{tabular}{|c|c|c|c|c|c|}
\hline 810 & artes marciales & 0.00075 & $0.015 \%$ & $0.282 \%$ & $98.795 \%$ \\
\hline 811 & rally & 0.00075 & $0.015 \%$ & $0.282 \%$ & $98.810 \%$ \\
\hline 812 & bolera & 0.00075 & $0.015 \%$ & $0.282 \%$ & $98.825 \%$ \\
\hline 813 & línea directa & 0.00075 & $0.015 \%$ & $0.282 \%$ & $98.840 \%$ \\
\hline 814 & tres en línea & 0.00075 & $0.015 \%$ & $0.282 \%$ & $98.855 \%$ \\
\hline 815 & globos de agua & 0.00075 & $0.015 \%$ & $0.282 \%$ & $98.870 \%$ \\
\hline 816 & hacer encuestas & 0.00075 & $0.015 \%$ & $0.282 \%$ & $98.885 \%$ \\
\hline 817 & disfraz & 0.00075 & $0.015 \%$ & $0.282 \%$ & $98.900 \%$ \\
\hline 818 & arrancar árboles & 0.00075 & $0.015 \%$ & $0.282 \%$ & $98.915 \%$ \\
\hline 819 & trepar a los árboles & 0.00075 & $0.015 \%$ & $0.282 \%$ & $98.930 \%$ \\
\hline 820 & lotería de fin de curso & 0.00075 & $0.015 \%$ & $0.282 \%$ & $98.945 \%$ \\
\hline 821 & enseñar & 0.00075 & $0.015 \%$ & $0.282 \%$ & $98.960 \%$ \\
\hline 822 & ver un partido & 0.00075 & $0.015 \%$ & $0.282 \%$ & $98.975 \%$ \\
\hline 823 & carrera de 400 metros vallas & 0.00070 & $0.015 \%$ & $0.282 \%$ & $98.990 \%$ \\
\hline 824 & oír el casete & 0.00070 & $0.015 \%$ & $0.282 \%$ & $99.005 \%$ \\
\hline 825 & jugar con hermanos & 0.00070 & $0.015 \%$ & $0.282 \%$ & $99.020 \%$ \\
\hline 826 & gato & 0.00070 & $0.015 \%$ & $0.282 \%$ & $99.035 \%$ \\
\hline 827 & estar en la cama & 0.00070 & $0.015 \%$ & $0.282 \%$ & $99.050 \%$ \\
\hline 828 & limpiar & 0.00070 & $0.015 \%$ & $0.282 \%$ & $99.065 \%$ \\
\hline 829 & maderitas & 0.00070 & $0.015 \%$ & $0.282 \%$ & $99.080 \%$ \\
\hline 830 & el patio de mi casa & 0.00070 & $0.015 \%$ & $0.282 \%$ & $99.095 \%$ \\
\hline 831 & excursionismo & 0.00070 & $0.015 \%$ & $0.282 \%$ & $99.110 \%$ \\
\hline 832 & acuarela & 0.00070 & $0.015 \%$ & $0.282 \%$ & $99.125 \%$ \\
\hline 833 & carrera de caracoles & 0.00070 & $0.015 \%$ & $0.282 \%$ & $99.140 \%$ \\
\hline 834 & asistir a clase & 0.00070 & $0.015 \%$ & $0.282 \%$ & $99.155 \%$ \\
\hline 835 & componer música & 0.00070 & $0.015 \%$ & $0.282 \%$ & $99.170 \%$ \\
\hline 836 & liebre & 0.00070 & $0.015 \%$ & $0.282 \%$ & $99.185 \%$ \\
\hline 837 & cortarme el pelo & 0.00070 & $0.015 \%$ & $0.282 \%$ & $99.200 \%$ \\
\hline 838 & disparar & 0.00070 & $0.015 \%$ & $0.282 \%$ & $99.215 \%$ \\
\hline 839 & coger robellones & 0.00070 & $0.015 \%$ & $0.282 \%$ & $99.230 \%$ \\
\hline 840 & pegarse & 0.00070 & $0.015 \%$ & $0.282 \%$ & $99.245 \%$ \\
\hline 841 & Loto $6 / 49$ & 0.00070 & $0.015 \%$ & $0.282 \%$ & $99.260 \%$ \\
\hline 842 & ir al monte & 0.00070 & $0.015 \%$ & $0.282 \%$ & $99.275 \%$ \\
\hline 843 & levantamiento & 0.00065 & $0.015 \%$ & $0.282 \%$ & $99.290 \%$ \\
\hline 844 & apuestas de caballos & 0.00065 & $0.015 \%$ & $0.282 \%$ & $99.305 \%$ \\
\hline 845 & ganchillo & 0.00065 & $0.015 \%$ & $0.282 \%$ & $99.320 \%$ \\
\hline 846 & pasear en bicicleta & 0.00065 & $0.015 \%$ & $0.282 \%$ & $99.335 \%$ \\
\hline 847 & backgammon & 0.00065 & $0.015 \%$ & $0.282 \%$ & $99.350 \%$ \\
\hline 848 & jugar con el gato & 0.00065 & $0.015 \%$ & $0.282 \%$ & $99.365 \%$ \\
\hline 849 & coger flores & 0.00065 & $0.015 \%$ & $0.282 \%$ & $99.380 \%$ \\
\hline 850 & hacer punto & 0.00065 & $0.015 \%$ & $0.282 \%$ & $99.395 \%$ \\
\hline 851 & tirarse en paracaídas & 0.00065 & $0.015 \%$ & $0.282 \%$ & $99.410 \%$ \\
\hline 852 & coleccionar mecheros & 0.00065 & $0.015 \%$ & $0.282 \%$ & $99.425 \%$ \\
\hline 853 & restaurante & 0.00065 & $0.015 \%$ & $0.282 \%$ & $99.440 \%$ \\
\hline 854 & marionetas & 0.00065 & $0.015 \%$ & $0.282 \%$ & $99.455 \%$ \\
\hline 855 & ducharse & 0.00065 & $0.015 \%$ & $0.282 \%$ & $99.470 \%$ \\
\hline 856 & jugar a ladrones & 0.00065 & $0.015 \%$ & $0.282 \%$ & $99.485 \%$ \\
\hline
\end{tabular}




\begin{tabular}{|c|c|c|c|c|c|}
\hline 857 & chatear & 0.00065 & $0.015 \%$ & $0.282 \%$ & $99.500 \%$ \\
\hline 858 & mirar al infinito & 0.00065 & $0.015 \%$ & $0.282 \%$ & $99.515 \%$ \\
\hline 859 & cuerda de colores & 0.00065 & $0.015 \%$ & $0.282 \%$ & $99.530 \%$ \\
\hline 860 & Hula hop* & 0.00065 & $0.015 \%$ & $0.282 \%$ & $99.545 \%$ \\
\hline 861 & gordo de la Primitiva & 0.00065 & $0.015 \%$ & $0.282 \%$ & $99.560 \%$ \\
\hline 862 & trasnochar & 0.00065 & $0.015 \%$ & $0.282 \%$ & $99.575 \%$ \\
\hline 863 & dibujos animados & 0.00061 & $0.015 \%$ & $0.282 \%$ & $99.590 \%$ \\
\hline 864 & snow & 0.00061 & $0.015 \%$ & $0.282 \%$ & $99.605 \%$ \\
\hline 865 & montar en moto & 0.00061 & $0.015 \%$ & $0.282 \%$ & $99.620 \%$ \\
\hline 866 & palabras cruzadas & 0.00061 & $0.015 \%$ & $0.282 \%$ & $99.635 \%$ \\
\hline 867 & motocicletas & 0.00061 & $0.015 \%$ & $0.282 \%$ & $99.650 \%$ \\
\hline 868 & coleccionar discos & 0.00061 & $0.015 \%$ & $0.282 \%$ & $99.665 \%$ \\
\hline 869 & secarse el pelo & 0.00061 & $0.015 \%$ & $0.282 \%$ & $99.680 \%$ \\
\hline 870 & relajarse & 0.00061 & $0.015 \%$ & $0.282 \%$ & $99.695 \%$ \\
\hline 871 & estrellas chinas & 0.00061 & $0.015 \%$ & $0.282 \%$ & $99.710 \%$ \\
\hline 872 & handball & 0.00061 & $0.015 \%$ & $0.282 \%$ & $99.725 \%$ \\
\hline 873 & rock and roll & 0.00061 & $0.015 \%$ & $0.282 \%$ & $99.740 \%$ \\
\hline 874 & mentir & 0.00061 & $0.015 \%$ & $0.282 \%$ & $99.755 \%$ \\
\hline 875 & beber alcohol & 0.00061 & $0.015 \%$ & $0.282 \%$ & $99.770 \%$ \\
\hline 876 & fondo & 0.00057 & $0.015 \%$ & $0.282 \%$ & $99.785 \%$ \\
\hline 877 & skate & 0.00057 & $0.015 \%$ & $0.282 \%$ & $99.800 \%$ \\
\hline 878 & luchar & 0.00057 & $0.015 \%$ & $0.282 \%$ & $99.815 \%$ \\
\hline 879 & coleccionar llaveros & 0.00057 & $0.015 \%$ & $0.282 \%$ & $99.830 \%$ \\
\hline 880 & construir & 0.00057 & $0.015 \%$ & $0.282 \%$ & $99.845 \%$ \\
\hline 881 & témpera & 0.00057 & $0.015 \%$ & $0.282 \%$ & $99.860 \%$ \\
\hline 882 & ligar & 0.00057 & $0.015 \%$ & $0.282 \%$ & $99.875 \%$ \\
\hline 883 & equilibrio & 0.00053 & $0.015 \%$ & $0.282 \%$ & $99.890 \%$ \\
\hline 884 & arte acrobático & 0.00053 & $0.015 \%$ & $0.282 \%$ & $99.905 \%$ \\
\hline 885 & lucha & 0.00053 & $0.015 \%$ & $0.282 \%$ & $99.920 \%$ \\
\hline 886 & marquetería & 0.00053 & $0.015 \%$ & $0.282 \%$ & $99.935 \%$ \\
\hline 887 & parque infantil & 0.00053 & $0.015 \%$ & $0.282 \%$ & $99.950 \%$ \\
\hline 888 & escribir novela & 0.00053 & $0.015 \%$ & $0.282 \%$ & $99.965 \%$ \\
\hline 889 & tela & 0.00053 & $0.015 \%$ & $0.282 \%$ & $99.980 \%$ \\
\hline 890 & matar moscas & 0.00053 & $0.015 \%$ & $0.282 \%$ & $99.995 \%$ \\
\hline 891 & series & 0.00053 & $0.015 \%$ & $0.282 \%$ & $100.010 \%$ \\
\hline 892 & cross & 0.00049 & $0.015 \%$ & $0.282 \%$ & $100.025 \%$ \\
\hline 893 & salto de trampolín & 0.00049 & $0.015 \%$ & $0.282 \%$ & $100.040 \%$ \\
\hline 894 & escribir poesía & 0.00049 & $0.015 \%$ & $0.282 \%$ & $100.055 \%$ \\
\hline 895 & cartón & 0.00049 & $0.015 \%$ & $0.282 \%$ & $100.070 \%$ \\
\hline 896 & full contact & 0.00049 & $0.015 \%$ & $0.282 \%$ & $100.085 \%$ \\
\hline 897 & baldufa & 0.00049 & $0.015 \%$ & $0.282 \%$ & $100.100 \%$ \\
\hline 898 & programas & 0.00049 & $0.015 \%$ & $0.282 \%$ & $100.115 \%$ \\
\hline 899 & pesca submarina & 0.00046 & $0.015 \%$ & $0.282 \%$ & $100.130 \%$ \\
\hline 900 & cortar & 0.00046 & $0.015 \%$ & $0.282 \%$ & $100.145 \%$ \\
\hline 901 & araña & 0.00046 & $0.015 \%$ & $0.282 \%$ & $100.160 \%$ \\
\hline 902 & escalar una montaña & 0.00046 & $0.015 \%$ & $0.282 \%$ & $100.175 \%$ \\
\hline 903 & arreglar & 0.00043 & $0.015 \%$ & $0.282 \%$ & $100.190 \%$ \\
\hline
\end{tabular}




\begin{tabular}{|l|l|l|l|l|l|}
\hline 904 & utensilios de peluquería & 0.00043 & $0.015 \%$ & $0.282 \%$ & $100.205 \%$ \\
\hline 905 & Atmosfear* & 0.00040 & $0.015 \%$ & $0.282 \%$ & $100.220 \%$ \\
\hline 906 & roer regaliz & 0.00040 & $0.015 \%$ & $0.282 \%$ & $100.235 \%$ \\
\hline 907 & ver cuadros & 0.00037 & $0.015 \%$ & $0.282 \%$ & $100.250 \%$ \\
\hline 908 & peluche & 0.00037 & $0.015 \%$ & $0.282 \%$ & $100.265 \%$ \\
\hline
\end{tabular}

16. PROFESIONES Y OFICIOS

\begin{tabular}{|c|c|c|c|c|c|}
\hline $\mathrm{N}^{\mathrm{o}}$ & Palabra & Disponibilidad & $\begin{array}{c}\text { Frecuencia } \\
\text { relativa }\end{array}$ & $\%$ Aparición & $\begin{array}{l}\text { Frecuencia } \\
\text { acumulada }\end{array}$ \\
\hline 1 & profesor & 0.50630 & $3.133 \%$ & $71.751 \%$ & $3.133 \%$ \\
\hline 2 & médico & 0.33934 & $2.455 \%$ & $56.215 \%$ & $5.588 \%$ \\
\hline 3 & maestro & 0.28272 & $1.813 \%$ & $41.525 \%$ & $7.401 \%$ \\
\hline 4 & abogado & 0.28065 & $2.060 \%$ & $47.175 \%$ & $9.461 \%$ \\
\hline 5 & agricultor & 0.22343 & $1.604 \%$ & $36.723 \%$ & $11.065 \%$ \\
\hline 6 & carpintero & 0.20483 & $1.443 \%$ & $33.051 \%$ & $12.508 \%$ \\
\hline 7 & policía & 0.17133 & $1.369 \%$ & $31.356 \%$ & $13.877 \%$ \\
\hline 8 & camarero & 0.16667 & $1.394 \%$ & $31.921 \%$ & $15.271 \%$ \\
\hline 9 & fontanero & 0.16425 & $1.332 \%$ & $30.508 \%$ & $16.603 \%$ \\
\hline 10 & panadero & 0.16311 & $1.258 \%$ & $28.814 \%$ & $17.861 \%$ \\
\hline 11 & banquero & 0.16145 & $1.271 \%$ & $29.096 \%$ & $19.132 \%$ \\
\hline 12 & empresario & 0.15447 & $1.221 \%$ & $27.966 \%$ & $20.353 \%$ \\
\hline 13 & ingeniero & 0.15382 & $1.332 \%$ & $30.508 \%$ & $21.685 \%$ \\
\hline 14 & arquitecto & 0.14977 & $1.357 \%$ & $31.073 \%$ & $23.042 \%$ \\
\hline 15 & albañil & 0.14571 & $1.073 \%$ & $24.576 \%$ & $24.115 \%$ \\
\hline 16 & electricista & 0.13859 & $1.135 \%$ & $25.989 \%$ & $25.250 \%$ \\
\hline 17 & jardinero & 0.13786 & $1.085 \%$ & $24.859 \%$ & $26.335 \%$ \\
\hline 18 & enfermero & 0.13257 & $1.196 \%$ & $27.401 \%$ & $27.531 \%$ \\
\hline 19 & estudiante & 0.12916 & $0.913 \%$ & $20.904 \%$ & $28.444 \%$ \\
\hline 20 & periodista & 0.12717 & $1.122 \%$ & $25.706 \%$ & $29.566 \%$ \\
\hline 21 & pintor & 0.12475 & $1.172 \%$ & $26.836 \%$ & $30.738 \%$ \\
\hline 22 & cocinero & 0.12378 & $1.085 \%$ & $24.859 \%$ & $31.823 \%$ \\
\hline 23 & carnicero & 0.12331 & $0.888 \%$ & $20.339 \%$ & $32.711 \%$ \\
\hline 24 & psicólogo & 0.12215 & $1.122 \%$ & $25.706 \%$ & $33.833 \%$ \\
\hline 25 & secretario & 0.11923 & $1.011 \%$ & $23.164 \%$ & $34.844 \%$ \\
\hline 26 & basurero & 0.11879 & $0.999 \%$ & $22.881 \%$ & $35.843 \%$ \\
\hline 27 & bombero & 0.11433 & $0.925 \%$ & $21.186 \%$ & $36.768 \%$ \\
\hline 28 & camionero & 0.11323 & $0.987 \%$ & $22.599 \%$ & $37.755 \%$ \\
\hline 29 & futbolista & 0.10724 & $0.987 \%$ & $22.599 \%$ & $38.742 \%$ \\
\hline 30 & juez & 0.10512 & $0.913 \%$ & $20.904 \%$ & $39.655 \%$ \\
\hline 31 & director & 0.09708 & $0.913 \%$ & $20.904 \%$ & $40.568 \%$ \\
\hline 32 & mecánico & 0.09555 & $0.789 \%$ & $18.079 \%$ & $41.357 \%$ \\
\hline 33 & ama de casa & 0.09453 & $0.765 \%$ & $17.514 \%$ & $42.122 \%$ \\
\hline
\end{tabular}




\begin{tabular}{|c|c|c|c|c|c|}
\hline 34 & peluquero & 0.09426 & $0.851 \%$ & $19.492 \%$ & $42.973 \%$ \\
\hline 35 & taxista & 0.09384 & $0.802 \%$ & $18.362 \%$ & $43.775 \%$ \\
\hline 36 & dependiente & 0.09319 & $0.814 \%$ & $18.644 \%$ & $44.589 \%$ \\
\hline 37 & barrendero & 0.09220 & $0.765 \%$ & $17.514 \%$ & $45.354 \%$ \\
\hline 38 & obrero & 0.09056 & $0.802 \%$ & $18.362 \%$ & $46.156 \%$ \\
\hline 39 & oficinista & 0.08150 & $0.580 \%$ & $13.277 \%$ & $46.736 \%$ \\
\hline 40 & vendedor & 0.07984 & $0.802 \%$ & $18.362 \%$ & $47.538 \%$ \\
\hline 41 & químico & 0.07753 & $0.752 \%$ & $17.232 \%$ & $48.290 \%$ \\
\hline 42 & dentista & 0.06963 & $0.641 \%$ & $14.689 \%$ & $48.931 \%$ \\
\hline 43 & zapatero & 0.06894 & $0.592 \%$ & $13.559 \%$ & $49.523 \%$ \\
\hline 44 & actor & 0.06858 & $0.789 \%$ & $18.079 \%$ & $50.312 \%$ \\
\hline 45 & tendero & 0.06818 & $0.567 \%$ & $12.994 \%$ & $50.879 \%$ \\
\hline 46 & cantante & 0.06659 & $0.789 \%$ & $18.079 \%$ & $51.668 \%$ \\
\hline 47 & administrativo & 0.06468 & $0.469 \%$ & $10.734 \%$ & $52.137 \%$ \\
\hline 48 & farmacéutico & 0.06438 & $0.617 \%$ & $14.124 \%$ & $52.754 \%$ \\
\hline 49 & escritor & 0.06094 & $0.654 \%$ & $14.972 \%$ & $53.408 \%$ \\
\hline 50 & conductor & 0.05891 & $0.543 \%$ & $12.429 \%$ & $53.951 \%$ \\
\hline 51 & informático & 0.05837 & $0.481 \%$ & $11.017 \%$ & $54.432 \%$ \\
\hline 52 & torero & 0.05748 & $0.567 \%$ & $12.994 \%$ & $54.999 \%$ \\
\hline 53 & cartero & 0.05522 & $0.469 \%$ & $10.734 \%$ & $55.468 \%$ \\
\hline 54 & prostituta & 0.05416 & $0.382 \%$ & $8.757 \%$ & $55.850 \%$ \\
\hline 55 & pescador & 0.05300 & $0.506 \%$ & $11.582 \%$ & $56.356 \%$ \\
\hline 56 & político & 0.05276 & $0.518 \%$ & $11.864 \%$ & $56.874 \%$ \\
\hline 57 & biólogo & 0.05237 & $0.444 \%$ & $10.169 \%$ & $57.318 \%$ \\
\hline 58 & economista & 0.05221 & $0.419 \%$ & $9.605 \%$ & $57.737 \%$ \\
\hline 59 & labrador & 0.05208 & $0.345 \%$ & $7.910 \%$ & $58.082 \%$ \\
\hline 60 & comerciante & 0.04861 & $0.407 \%$ & $9.322 \%$ & $58.489 \%$ \\
\hline 61 & físico & 0.04679 & $0.456 \%$ & $10.452 \%$ & $58.945 \%$ \\
\hline 62 & guardia civil & 0.04647 & $0.395 \%$ & $9.040 \%$ & $59.340 \%$ \\
\hline 63 & ganadero & 0.04624 & $0.382 \%$ & $8.757 \%$ & $59.722 \%$ \\
\hline 64 & herrero & 0.04526 & $0.358 \%$ & $8.192 \%$ & $60.080 \%$ \\
\hline 65 & ATS & 0.04480 & $0.358 \%$ & $8.192 \%$ & $60.438 \%$ \\
\hline 66 & escultor & 0.04355 & $0.493 \%$ & $11.299 \%$ & $60.931 \%$ \\
\hline 67 & verdulero & 0.04291 & $0.395 \%$ & $9.040 \%$ & $61.326 \%$ \\
\hline 68 & psiquiatra & 0.04271 & $0.444 \%$ & $10.169 \%$ & $61.770 \%$ \\
\hline 69 & ladrón & 0.04183 & $0.296 \%$ & $6.780 \%$ & $62.066 \%$ \\
\hline 70 & pescadero & 0.04058 & $0.370 \%$ & $8.475 \%$ & $62.436 \%$ \\
\hline 71 & veterinario & 0.03983 & $0.382 \%$ & $8.757 \%$ & $62.818 \%$ \\
\hline 72 & funcionario & 0.03977 & $0.259 \%$ & $5.932 \%$ & $63.077 \%$ \\
\hline 73 & alcalde & 0.03839 & $0.370 \%$ & $8.475 \%$ & $63.447 \%$ \\
\hline 74 & traductor & 0.03736 & $0.382 \%$ & $8.757 \%$ & $63.829 \%$ \\
\hline 75 & músico & 0.03722 & $0.395 \%$ & $9.040 \%$ & $64.224 \%$ \\
\hline 76 & limpiador & 0.03711 & $0.370 \%$ & $8.475 \%$ & $64.594 \%$ \\
\hline 77 & piloto & 0.03622 & $0.382 \%$ & $8.757 \%$ & $64.976 \%$ \\
\hline 78 & presidente & 0.03548 & $0.296 \%$ & $6.780 \%$ & $65.272 \%$ \\
\hline 79 & fisioterapeuta & 0.03542 & $0.284 \%$ & $6.497 \%$ & $65.556 \%$ \\
\hline 80 & fotógrafo & 0.03459 & $0.407 \%$ & $9.322 \%$ & $65.963 \%$ \\
\hline
\end{tabular}




\begin{tabular}{|c|c|c|c|c|c|}
\hline 81 & deportista & 0.03422 & $0.345 \%$ & $7.910 \%$ & $66.308 \%$ \\
\hline 82 & doctor & 0.03351 & $0.296 \%$ & $6.780 \%$ & $66.604 \%$ \\
\hline 83 & fílólogo & 0.03347 & $0.358 \%$ & $8.192 \%$ & $66.962 \%$ \\
\hline 84 & constructor & 0.03333 & $0.308 \%$ & $7.062 \%$ & $67.270 \%$ \\
\hline 85 & matemático & 0.03265 & $0.333 \%$ & $7.627 \%$ & $67.603 \%$ \\
\hline 86 & presentador & 0.03239 & $0.407 \%$ & $9.322 \%$ & $68.010 \%$ \\
\hline 87 & cirujano & 0.03219 & $0.321 \%$ & $7.345 \%$ & $68.331 \%$ \\
\hline 88 & ginecólogo & 0.03091 & $0.284 \%$ & $6.497 \%$ & $68.615 \%$ \\
\hline 89 & bailarín & 0.03028 & $0.308 \%$ & $7.062 \%$ & $68.923 \%$ \\
\hline 90 & azulejero & 0.02980 & $0.271 \%$ & $6.215 \%$ & $69.194 \%$ \\
\hline 91 & cura & 0.02819 & $0.271 \%$ & $6.215 \%$ & $69.465 \%$ \\
\hline 92 & pastelero & 0.02785 & $0.259 \%$ & $5.932 \%$ & $69.724 \%$ \\
\hline 93 & cajero & 0.02775 & $0.296 \%$ & $6.780 \%$ & $70.020 \%$ \\
\hline 94 & pediatra & 0.02741 & $0.321 \%$ & $7.345 \%$ & $70.341 \%$ \\
\hline 95 & modista & 0.02704 & $0.284 \%$ & $6.497 \%$ & $70.625 \%$ \\
\hline 96 & fílósofo & 0.02691 & $0.271 \%$ & $6.215 \%$ & $70.896 \%$ \\
\hline 97 & diseñador & 0.02688 & $0.308 \%$ & $7.062 \%$ & $71.204 \%$ \\
\hline 98 & ministro & 0.02652 & $0.222 \%$ & $5.085 \%$ & $71.426 \%$ \\
\hline 99 & militar & 0.02602 & $0.210 \%$ & $4.802 \%$ & $71.636 \%$ \\
\hline 100 & representante & 0.02594 & $0.234 \%$ & $5.367 \%$ & $71.870 \%$ \\
\hline 101 & puta & 0.02562 & $0.173 \%$ & $3.955 \%$ & $72.043 \%$ \\
\hline 102 & astronauta & 0.02539 & $0.271 \%$ & $6.215 \%$ & $72.314 \%$ \\
\hline 103 & gerente & 0.02538 & $0.173 \%$ & $3.955 \%$ & $72.487 \%$ \\
\hline 104 & notario & 0.02440 & $0.210 \%$ & $4.802 \%$ & $72.697 \%$ \\
\hline 105 & actriz & 0.02396 & $0.259 \%$ & $5.932 \%$ & $72.956 \%$ \\
\hline 106 & peón & 0.02354 & $0.247 \%$ & $5.650 \%$ & $73.203 \%$ \\
\hline 107 & cerrajero & 0.02337 & $0.222 \%$ & $5.085 \%$ & $73.425 \%$ \\
\hline 108 & dibujante & 0.02302 & $0.222 \%$ & $5.085 \%$ & $73.647 \%$ \\
\hline 109 & repartidor & 0.02292 & $0.259 \%$ & $5.932 \%$ & $73.906 \%$ \\
\hline 110 & odontólogo & 0.02263 & $0.185 \%$ & $4.237 \%$ & $74.091 \%$ \\
\hline 111 & recepcionista & 0.02242 & $0.234 \%$ & $5.367 \%$ & $74.325 \%$ \\
\hline 112 & entrenador & 0.02214 & $0.222 \%$ & $5.085 \%$ & $74.547 \%$ \\
\hline 113 & modelo & 0.02206 & $0.271 \%$ & $6.215 \%$ & $74.818 \%$ \\
\hline 114 & pedagogo & 0.02171 & $0.185 \%$ & $4.237 \%$ & $75.003 \%$ \\
\hline 115 & oculista & 0.02157 & $0.222 \%$ & $5.085 \%$ & $75.225 \%$ \\
\hline 116 & leñador & 0.02129 & $0.136 \%$ & $3.107 \%$ & $75.361 \%$ \\
\hline 117 & aparejador & 0.02046 & $0.222 \%$ & $5.085 \%$ & $75.583 \%$ \\
\hline 118 & delineante & 0.02008 & $0.210 \%$ & $4.802 \%$ & $75.793 \%$ \\
\hline 119 & científico & 0.01980 & $0.197 \%$ & $4.520 \%$ & $75.990 \%$ \\
\hline 120 & frutero & 0.01967 & $0.185 \%$ & $4.237 \%$ & $76.175 \%$ \\
\hline 121 & esthéticien & 0.01922 & $0.185 \%$ & $4.237 \%$ & $76.360 \%$ \\
\hline 122 & bibliotecario & 0.01910 & $0.210 \%$ & $4.802 \%$ & $76.570 \%$ \\
\hline 123 & pastor & 0.01872 & $0.136 \%$ & $3.107 \%$ & $76.706 \%$ \\
\hline 124 & soldado & 0.01859 & $0.148 \%$ & $3.390 \%$ & $76.854 \%$ \\
\hline 125 & granjero & 0.01849 & $0.173 \%$ & $3.955 \%$ & $77.027 \%$ \\
\hline 126 & chófer & 0.01844 & $0.160 \%$ & $3.672 \%$ & $77.187 \%$ \\
\hline 127 & ebanista & 0.01825 & $0.197 \%$ & $4.520 \%$ & $77.384 \%$ \\
\hline
\end{tabular}




\begin{tabular}{|c|c|c|c|c|c|}
\hline 128 & podólogo & 0.01783 & $0.197 \%$ & $4.520 \%$ & $77.581 \%$ \\
\hline 129 & celador & 0.01753 & $0.148 \%$ & $3.390 \%$ & $77.729 \%$ \\
\hline 130 & gigoló & 0.01735 & $0.099 \%$ & $2.260 \%$ & $77.828 \%$ \\
\hline 131 & administrador & 0.01724 & $0.148 \%$ & $3.390 \%$ & $77.976 \%$ \\
\hline 132 & publicista & 0.01692 & $0.173 \%$ & $3.955 \%$ & $78.149 \%$ \\
\hline 133 & conserje & 0.01680 & $0.160 \%$ & $3.672 \%$ & $78.309 \%$ \\
\hline 134 & bedel & 0.01675 & $0.160 \%$ & $3.672 \%$ & $78.469 \%$ \\
\hline 135 & portero & 0.01672 & $0.185 \%$ & $4.237 \%$ & $78.654 \%$ \\
\hline 136 & minero & 0.01618 & $0.136 \%$ & $3.107 \%$ & $78.790 \%$ \\
\hline 137 & historiador & 0.01611 & $0.185 \%$ & $4.237 \%$ & $78.975 \%$ \\
\hline 138 & asistente social & 0.01577 & $0.173 \%$ & $3.955 \%$ & $79.148 \%$ \\
\hline 139 & joyero & 0.01574 & $0.185 \%$ & $4.237 \%$ & $79.333 \%$ \\
\hline 140 & butanero & 0.01560 & $0.173 \%$ & $3.955 \%$ & $79.506 \%$ \\
\hline 141 & poeta & 0.01554 & $0.136 \%$ & $3.107 \%$ & $79.642 \%$ \\
\hline 142 & ingeniero industrial & 0.01552 & $0.111 \%$ & $2.542 \%$ & $79.753 \%$ \\
\hline 143 & relaciones públicas & 0.01545 & $0.148 \%$ & $3.390 \%$ & $79.901 \%$ \\
\hline 144 & chulo & 0.01536 & $0.148 \%$ & $3.390 \%$ & $80.049 \%$ \\
\hline 145 & conductor de autobús & 0.01532 & $0.160 \%$ & $3.672 \%$ & $80.209 \%$ \\
\hline 146 & diputado & 0.01525 & $0.148 \%$ & $3.390 \%$ & $80.357 \%$ \\
\hline 147 & tenista & 0.01521 & $0.185 \%$ & $4.237 \%$ & $80.542 \%$ \\
\hline 148 & azafata & 0.01507 & $0.197 \%$ & $4.520 \%$ & $80.739 \%$ \\
\hline 149 & canguro & 0.01503 & $0.148 \%$ & $3.390 \%$ & $80.887 \%$ \\
\hline 150 & intérprete & 0.01474 & $0.136 \%$ & $3.107 \%$ & $81.023 \%$ \\
\hline 151 & geólogo & 0.01464 & $0.148 \%$ & $3.390 \%$ & $81.171 \%$ \\
\hline 152 & barbero & 0.01435 & $0.123 \%$ & $2.825 \%$ & $81.294 \%$ \\
\hline 153 & catedrático & 0.01414 & $0.136 \%$ & $3.107 \%$ & $81.430 \%$ \\
\hline 154 & telefonista & 0.01403 & $0.123 \%$ & $2.825 \%$ & $81.553 \%$ \\
\hline 155 & dermatólogo & 0.01400 & $0.136 \%$ & $3.107 \%$ & $81.689 \%$ \\
\hline 156 & sastre & 0.01349 & $0.148 \%$ & $3.390 \%$ & $81.837 \%$ \\
\hline 157 & aviador & 0.01334 & $0.148 \%$ & $3.390 \%$ & $81.985 \%$ \\
\hline 158 & gestor & 0.01287 & $0.111 \%$ & $2.542 \%$ & $82.096 \%$ \\
\hline 159 & artista & 0.01277 & $0.173 \%$ & $3.955 \%$ & $82.269 \%$ \\
\hline 160 & contable & 0.01272 & $0.123 \%$ & $2.825 \%$ & $82.392 \%$ \\
\hline 161 & niñera & 0.01245 & $0.123 \%$ & $2.825 \%$ & $82.515 \%$ \\
\hline 162 & ejecutivo & 0.01239 & $0.099 \%$ & $2.260 \%$ & $82.614 \%$ \\
\hline 163 & director de cine & 0.01218 & $0.148 \%$ & $3.390 \%$ & $82.762 \%$ \\
\hline 164 & otorrino(laringólogo) & 0.01206 & $0.123 \%$ & $2.825 \%$ & $82.885 \%$ \\
\hline 165 & transportista & 0.01191 & $0.123 \%$ & $2.825 \%$ & $83.008 \%$ \\
\hline 166 & traumatólogo & 0.01188 & $0.111 \%$ & $2.542 \%$ & $83.119 \%$ \\
\hline 167 & reportero & 0.01167 & $0.099 \%$ & $2.260 \%$ & $83.218 \%$ \\
\hline 168 & camello & 0.01156 & $0.099 \%$ & $2.260 \%$ & $83.317 \%$ \\
\hline 169 & corredor & 0.01129 & $0.123 \%$ & $2.825 \%$ & $83.440 \%$ \\
\hline 170 & socorrista & 0.01120 & $0.136 \%$ & $3.107 \%$ & $83.576 \%$ \\
\hline 171 & concejal & 0.01114 & $0.099 \%$ & $2.260 \%$ & $83.675 \%$ \\
\hline 172 & masajista & 0.01101 & $0.160 \%$ & $3.672 \%$ & $83.835 \%$ \\
\hline 173 & jugador de fútbol & 0.01101 & $0.111 \%$ & $2.542 \%$ & $83.946 \%$ \\
\hline 174 & atleta & 0.01100 & $0.111 \%$ & $2.542 \%$ & $84.057 \%$ \\
\hline
\end{tabular}




\begin{tabular}{|c|c|c|c|c|c|}
\hline 175 & estanquero & 0.01094 & $0.111 \%$ & $2.542 \%$ & $84.168 \%$ \\
\hline 176 & fiscal & 0.01084 & $0.111 \%$ & $2.542 \%$ & $84.279 \%$ \\
\hline 177 & sacerdote & 0.01079 & $0.099 \%$ & $2.260 \%$ & $84.378 \%$ \\
\hline 178 & ingeniero agrónomo & 0.01075 & $0.074 \%$ & $1.695 \%$ & $84.452 \%$ \\
\hline 179 & cristalero & 0.01061 & $0.111 \%$ & $2.542 \%$ & $84.563 \%$ \\
\hline 180 & puericultor & 0.01053 & $0.074 \%$ & $1.695 \%$ & $84.637 \%$ \\
\hline 181 & recolector & 0.01039 & $0.099 \%$ & $2.260 \%$ & $84.736 \%$ \\
\hline 182 & oftalmólogo & 0.00996 & $0.086 \%$ & $1.977 \%$ & $84.822 \%$ \\
\hline 183 & hostelero & 0.00982 & $0.074 \%$ & $1.695 \%$ & $84.896 \%$ \\
\hline 184 & guardabosques & 0.00971 & $0.099 \%$ & $2.260 \%$ & $84.995 \%$ \\
\hline 185 & lavandera & 0.00964 & $0.074 \%$ & $1.695 \%$ & $85.069 \%$ \\
\hline 186 & barman & 0.00959 & $0.136 \%$ & $3.107 \%$ & $85.205 \%$ \\
\hline 187 & campesino & 0.00958 & $0.086 \%$ & $1.977 \%$ & $85.291 \%$ \\
\hline 188 & vigilante & 0.00952 & $0.111 \%$ & $2.542 \%$ & $85.402 \%$ \\
\hline 189 & botones & 0.00946 & $0.099 \%$ & $2.260 \%$ & $85.501 \%$ \\
\hline 190 & maquillador & 0.00933 & $0.111 \%$ & $2.542 \%$ & $85.612 \%$ \\
\hline 191 & regador & 0.00928 & $0.074 \%$ & $1.695 \%$ & $85.686 \%$ \\
\hline 192 & jefe & 0.00918 & $0.074 \%$ & $1.695 \%$ & $85.760 \%$ \\
\hline 193 & relojero & 0.00917 & $0.099 \%$ & $2.260 \%$ & $85.859 \%$ \\
\hline 194 & quiosquero & 0.00899 & $0.111 \%$ & $2.542 \%$ & $85.970 \%$ \\
\hline 195 & maquinista & 0.00891 & $0.099 \%$ & $2.260 \%$ & $86.069 \%$ \\
\hline 196 & guardaespaldas & 0.00886 & $0.074 \%$ & $1.695 \%$ & $86.143 \%$ \\
\hline 197 & óptico & 0.00880 & $0.123 \%$ & $2.825 \%$ & $86.266 \%$ \\
\hline 198 & sociólogo & 0.00844 & $0.086 \%$ & $1.977 \%$ & $86.352 \%$ \\
\hline 199 & arqueólogo & 0.00842 & $0.099 \%$ & $2.260 \%$ & $86.451 \%$ \\
\hline 200 & marinero & 0.00838 & $0.099 \%$ & $2.260 \%$ & $86.550 \%$ \\
\hline 201 & corredor de bolsa & 0.00835 & $0.086 \%$ & $1.977 \%$ & $86.636 \%$ \\
\hline 202 & empleado de banca & 0.00834 & $0.049 \%$ & $1.130 \%$ & $86.685 \%$ \\
\hline 203 & payaso & 0.00819 & $0.086 \%$ & $1.977 \%$ & $86.771 \%$ \\
\hline 204 & cazador & 0.00812 & $0.074 \%$ & $1.695 \%$ & $86.845 \%$ \\
\hline 205 & agente de seguros & 0.00806 & $0.049 \%$ & $1.130 \%$ & $86.894 \%$ \\
\hline 206 & productor & 0.00801 & $0.086 \%$ & $1.977 \%$ & $86.980 \%$ \\
\hline 207 & educador & 0.00794 & $0.074 \%$ & $1.695 \%$ & $87.054 \%$ \\
\hline 208 & guardia jurado & 0.00785 & $0.099 \%$ & $2.260 \%$ & $87.153 \%$ \\
\hline 209 & esteticista & 0.00775 & $0.086 \%$ & $1.977 \%$ & $87.239 \%$ \\
\hline 210 & alguacil & 0.00773 & $0.062 \%$ & $1.412 \%$ & $87.301 \%$ \\
\hline 211 & empleado & 0.00768 & $0.074 \%$ & $1.695 \%$ & $87.375 \%$ \\
\hline 212 & decorador & 0.00763 & $0.086 \%$ & $1.977 \%$ & $87.461 \%$ \\
\hline 213 & encajador & 0.00763 & $0.049 \%$ & $1.130 \%$ & $87.510 \%$ \\
\hline 214 & cardiólogo & 0.00739 & $0.074 \%$ & $1.695 \%$ & $87.584 \%$ \\
\hline 215 & pescater & 0.00731 & $0.062 \%$ & $1.412 \%$ & $87.646 \%$ \\
\hline 216 & ceramista & 0.00726 & $0.049 \%$ & $1.130 \%$ & $87.695 \%$ \\
\hline 217 & ingeniero de caminos & 0.00726 & $0.049 \%$ & $1.130 \%$ & $87.744 \%$ \\
\hline 218 & monja & 0.00723 & $0.062 \%$ & $1.412 \%$ & $87.806 \%$ \\
\hline 219 & árbitro & 0.00721 & $0.086 \%$ & $1.977 \%$ & $87.892 \%$ \\
\hline 220 & jugador de baloncesto & 0.00719 & $0.062 \%$ & $1.412 \%$ & $87.954 \%$ \\
\hline 221 & escayolista & 0.00717 & $0.074 \%$ & $1.695 \%$ & $88.028 \%$ \\
\hline
\end{tabular}




\begin{tabular}{|c|c|c|c|c|c|}
\hline 222 & chapista & 0.00712 & $0.099 \%$ & $2.260 \%$ & $88.127 \%$ \\
\hline 223 & nadador & 0.00690 & $0.074 \%$ & $1.695 \%$ & $88.201 \%$ \\
\hline 224 & astrónomo & 0.00685 & $0.062 \%$ & $1.412 \%$ & $88.263 \%$ \\
\hline 225 & locutor & 0.00679 & $0.086 \%$ & $1.977 \%$ & $88.349 \%$ \\
\hline 226 & cogedor de naranjas & 0.00676 & $0.062 \%$ & $1.412 \%$ & $88.411 \%$ \\
\hline 227 & florista & 0.00666 & $0.049 \%$ & $1.130 \%$ & $88.460 \%$ \\
\hline 228 & conductor de tren & 0.00661 & $0.037 \%$ & $0.847 \%$ & $88.497 \%$ \\
\hline 229 & asesor & 0.00654 & $0.062 \%$ & $1.412 \%$ & $88.559 \%$ \\
\hline 230 & guardia & 0.00654 & $0.049 \%$ & $1.130 \%$ & $88.608 \%$ \\
\hline 231 & mecanógrafo & 0.00653 & $0.062 \%$ & $1.412 \%$ & $88.670 \%$ \\
\hline 232 & ingeniero de teleco(municaciones) & 0.00652 & $0.049 \%$ & $1.130 \%$ & $88.719 \%$ \\
\hline 233 & alfarero & 0.00645 & $0.049 \%$ & $1.130 \%$ & $88.768 \%$ \\
\hline 234 & asesino & 0.00642 & $0.037 \%$ & $0.847 \%$ & $88.805 \%$ \\
\hline 235 & tejedor & 0.00635 & $0.049 \%$ & $1.130 \%$ & $88.854 \%$ \\
\hline 236 & presidente de gobierno & 0.00618 & $0.062 \%$ & $1.412 \%$ & $88.916 \%$ \\
\hline 237 & lechero & 0.00611 & $0.099 \%$ & $2.260 \%$ & $89.015 \%$ \\
\hline 238 & compositor & 0.00605 & $0.086 \%$ & $1.977 \%$ & $89.101 \%$ \\
\hline 239 & distribuidor & 0.00604 & $0.049 \%$ & $1.130 \%$ & $89.150 \%$ \\
\hline 240 & prostitución & 0.00603 & $0.037 \%$ & $0.847 \%$ & $89.187 \%$ \\
\hline 241 & alumno & 0.00600 & $0.037 \%$ & $0.847 \%$ & $89.224 \%$ \\
\hline 242 & ingeniero químico & 0.00599 & $0.037 \%$ & $0.847 \%$ & $89.261 \%$ \\
\hline 243 & librero & 0.00599 & $0.074 \%$ & $1.695 \%$ & $89.335 \%$ \\
\hline 244 & urólogo & 0.00597 & $0.062 \%$ & $1.412 \%$ & $89.397 \%$ \\
\hline 245 & conductor de taxi & 0.00590 & $0.037 \%$ & $0.847 \%$ & $89.434 \%$ \\
\hline 246 & contratista & 0.00588 & $0.049 \%$ & $1.130 \%$ & $89.483 \%$ \\
\hline 247 & chapero & 0.00578 & $0.037 \%$ & $0.847 \%$ & $89.520 \%$ \\
\hline 248 & mercader & 0.00577 & $0.037 \%$ & $0.847 \%$ & $89.557 \%$ \\
\hline 249 & detective & 0.00566 & $0.074 \%$ & $1.695 \%$ & $89.631 \%$ \\
\hline 250 & armador & 0.00566 & $0.037 \%$ & $0.847 \%$ & $89.668 \%$ \\
\hline 251 & mercenario & 0.00566 & $0.037 \%$ & $0.847 \%$ & $89.705 \%$ \\
\hline 252 & cogedor & 0.00566 & $0.037 \%$ & $0.847 \%$ & $89.742 \%$ \\
\hline 253 & terrorista & 0.00564 & $0.062 \%$ & $1.412 \%$ & $89.804 \%$ \\
\hline 254 & inspector & 0.00560 & $0.049 \%$ & $1.130 \%$ & $89.853 \%$ \\
\hline 255 & mâ̂tre & 0.00559 & $0.049 \%$ & $1.130 \%$ & $89.902 \%$ \\
\hline 256 & jefe de estudios & 0.00555 & $0.062 \%$ & $1.412 \%$ & $89.964 \%$ \\
\hline 257 & encargado & 0.00555 & $0.049 \%$ & $1.130 \%$ & $90.013 \%$ \\
\hline 258 & gimnasta & 0.00552 & $0.049 \%$ & $1.130 \%$ & $90.062 \%$ \\
\hline 259 & cultivador & 0.00550 & $0.037 \%$ & $0.847 \%$ & $90.099 \%$ \\
\hline 260 & médico general & 0.00549 & $0.049 \%$ & $1.130 \%$ & $90.148 \%$ \\
\hline 261 & ciclista & 0.00548 & $0.062 \%$ & $1.412 \%$ & $90.210 \%$ \\
\hline 262 & profesor de Educación Física & 0.00547 & $0.037 \%$ & $0.847 \%$ & $90.247 \%$ \\
\hline 263 & topógrafo & 0.00540 & $0.074 \%$ & $1.695 \%$ & $90.321 \%$ \\
\hline 264 & novelista & 0.00539 & $0.062 \%$ & $1.412 \%$ & $90.383 \%$ \\
\hline 265 & industrial & 0.00534 & $0.062 \%$ & $1.412 \%$ & $90.445 \%$ \\
\hline 266 & piloto de avión & 0.00534 & $0.049 \%$ & $1.130 \%$ & $90.494 \%$ \\
\hline 267 & modisto & 0.00532 & $0.037 \%$ & $0.847 \%$ & $90.531 \%$ \\
\hline 268 & disc-jockey & 0.00528 & $0.062 \%$ & $1.412 \%$ & $90.593 \%$ \\
\hline
\end{tabular}




\begin{tabular}{|c|c|c|c|c|c|}
\hline 269 & guía & 0.00526 & $0.049 \%$ & $1.130 \%$ & $90.642 \%$ \\
\hline 270 & investigador & 0.00519 & $0.062 \%$ & $1.412 \%$ & $90.704 \%$ \\
\hline 271 & analista & 0.00514 & $0.062 \%$ & $1.412 \%$ & $90.766 \%$ \\
\hline 272 & costurera & 0.00513 & $0.062 \%$ & $1.412 \%$ & $90.828 \%$ \\
\hline 273 & almacenista & 0.00511 & $0.049 \%$ & $1.130 \%$ & $90.877 \%$ \\
\hline 274 & logopeda & 0.00511 & $0.049 \%$ & $1.130 \%$ & $90.926 \%$ \\
\hline 275 & redactor & 0.00509 & $0.049 \%$ & $1.130 \%$ & $90.975 \%$ \\
\hline 276 & practicante & 0.00508 & $0.062 \%$ & $1.412 \%$ & $91.037 \%$ \\
\hline 277 & gasolinero & 0.00498 & $0.062 \%$ & $1.412 \%$ & $91.099 \%$ \\
\hline 278 & limpieza & 0.00498 & $0.062 \%$ & $1.412 \%$ & $91.161 \%$ \\
\hline 279 & golfista & 0.00497 & $0.074 \%$ & $1.695 \%$ & $91.235 \%$ \\
\hline 280 & psicopedagogo & 0.00496 & $0.049 \%$ & $1.130 \%$ & $91.284 \%$ \\
\hline 281 & guionista & 0.00494 & $0.037 \%$ & $0.847 \%$ & $91.321 \%$ \\
\hline 282 & llaurador & 0.00491 & $0.025 \%$ & $0.565 \%$ & $91.346 \%$ \\
\hline 283 & sus labores & 0.00491 & $0.025 \%$ & $0.565 \%$ & $91.371 \%$ \\
\hline 284 & obispo & 0.00488 & $0.049 \%$ & $1.130 \%$ & $91.420 \%$ \\
\hline 285 & gogó & 0.00484 & $0.062 \%$ & $1.412 \%$ & $91.482 \%$ \\
\hline 286 & pianista & 0.00479 & $0.074 \%$ & $1.695 \%$ & $91.556 \%$ \\
\hline 287 & artesano & 0.00472 & $0.062 \%$ & $1.412 \%$ & $91.618 \%$ \\
\hline 288 & paleta & 0.00461 & $0.049 \%$ & $1.130 \%$ & $91.667 \%$ \\
\hline 289 & jugador de balonmano & 0.00461 & $0.037 \%$ & $0.847 \%$ & $91.704 \%$ \\
\hline 290 & anestesista & 0.00460 & $0.049 \%$ & $1.130 \%$ & $91.753 \%$ \\
\hline 291 & radiólogo & 0.00460 & $0.049 \%$ & $1.130 \%$ & $91.802 \%$ \\
\hline 292 & estilista & 0.00457 & $0.074 \%$ & $1.695 \%$ & $91.876 \%$ \\
\hline 293 & tutor & 0.00457 & $0.025 \%$ & $0.565 \%$ & $91.901 \%$ \\
\hline 294 & fotocopiador & 0.00457 & $0.025 \%$ & $0.565 \%$ & $91.926 \%$ \\
\hline 295 & geógrafo & 0.00455 & $0.037 \%$ & $0.847 \%$ & $91.963 \%$ \\
\hline 296 & mánager & 0.00454 & $0.062 \%$ & $1.412 \%$ & $92.025 \%$ \\
\hline 297 & técnico & 0.00452 & $0.049 \%$ & $1.130 \%$ & $92.074 \%$ \\
\hline 298 & capitán & 0.00450 & $0.037 \%$ & $0.847 \%$ & $92.111 \%$ \\
\hline 299 & jugador & 0.00450 & $0.062 \%$ & $1.412 \%$ & $92.173 \%$ \\
\hline 300 & capataz & 0.00450 & $0.037 \%$ & $0.847 \%$ & $92.210 \%$ \\
\hline 301 & consejero & 0.00449 & $0.037 \%$ & $0.847 \%$ & $92.247 \%$ \\
\hline 302 & mensajero & 0.00448 & $0.062 \%$ & $1.412 \%$ & $92.309 \%$ \\
\hline 303 & viajante & 0.00434 & $0.037 \%$ & $0.847 \%$ & $92.346 \%$ \\
\hline 304 & podador & 0.00431 & $0.037 \%$ & $0.847 \%$ & $92.383 \%$ \\
\hline 305 & catador & 0.00429 & $0.037 \%$ & $0.847 \%$ & $92.420 \%$ \\
\hline 306 & monitor & 0.00429 & $0.062 \%$ & $1.412 \%$ & $92.482 \%$ \\
\hline 307 & agente de bolsa & 0.00429 & $0.062 \%$ & $1.412 \%$ & $92.544 \%$ \\
\hline 308 & escalador & 0.00428 & $0.037 \%$ & $0.847 \%$ & $92.581 \%$ \\
\hline 309 & chef & 0.00425 & $0.062 \%$ & $1.412 \%$ & $92.643 \%$ \\
\hline 310 & subdirector & 0.00422 & $0.037 \%$ & $0.847 \%$ & $92.680 \%$ \\
\hline 311 & vendedor ambulante & 0.00417 & $0.049 \%$ & $1.130 \%$ & $92.729 \%$ \\
\hline 312 & taquillero & 0.00415 & $0.037 \%$ & $0.847 \%$ & $92.766 \%$ \\
\hline 313 & licenciado & 0.00414 & $0.049 \%$ & $1.130 \%$ & $92.815 \%$ \\
\hline 314 & agrónomo & 0.00412 & $0.037 \%$ & $0.847 \%$ & $92.852 \%$ \\
\hline 315 & neurólogo & 0.00411 & $0.049 \%$ & $1.130 \%$ & $92.901 \%$ \\
\hline
\end{tabular}




\begin{tabular}{|c|c|c|c|c|c|}
\hline 316 & editor & 0.00410 & $0.037 \%$ & $0.847 \%$ & $92.938 \%$ \\
\hline 317 & auxiliar & 0.00397 & $0.049 \%$ & $1.130 \%$ & $92.987 \%$ \\
\hline 318 & mayordomo & 0.00395 & $0.037 \%$ & $0.847 \%$ & $93.024 \%$ \\
\hline 319 & antropólogo & 0.00389 & $0.037 \%$ & $0.847 \%$ & $93.061 \%$ \\
\hline 320 & Papa & 0.00387 & $0.049 \%$ & $1.130 \%$ & $93.110 \%$ \\
\hline 321 & cámara & 0.00383 & $0.049 \%$ & $1.130 \%$ & $93.159 \%$ \\
\hline 322 & yesaire & 0.00377 & $0.049 \%$ & $1.130 \%$ & $93.208 \%$ \\
\hline 323 & hotelero & 0.00376 & $0.049 \%$ & $1.130 \%$ & $93.257 \%$ \\
\hline 324 & graduado social & 0.00373 & $0.025 \%$ & $0.565 \%$ & $93.282 \%$ \\
\hline 325 & misionero & 0.00373 & $0.025 \%$ & $0.565 \%$ & $93.307 \%$ \\
\hline 326 & pinche & 0.00369 & $0.037 \%$ & $0.847 \%$ & $93.344 \%$ \\
\hline 327 & perito & 0.00366 & $0.037 \%$ & $0.847 \%$ & $93.381 \%$ \\
\hline 328 & interlocutor & 0.00359 & $0.025 \%$ & $0.565 \%$ & $93.406 \%$ \\
\hline 329 & curandero & 0.00357 & $0.037 \%$ & $0.847 \%$ & $93.443 \%$ \\
\hline 330 & recolector de cítricos & 0.00346 & $0.025 \%$ & $0.565 \%$ & $93.468 \%$ \\
\hline 331 & jornalero & 0.00345 & $0.025 \%$ & $0.565 \%$ & $93.493 \%$ \\
\hline 332 & tallista & 0.00343 & $0.037 \%$ & $0.847 \%$ & $93.530 \%$ \\
\hline 333 & fabricante & 0.00335 & $0.037 \%$ & $0.847 \%$ & $93.567 \%$ \\
\hline 334 & usurero & 0.00330 & $0.025 \%$ & $0.565 \%$ & $93.592 \%$ \\
\hline 335 & recadero & 0.00325 & $0.049 \%$ & $1.130 \%$ & $93.641 \%$ \\
\hline 336 & financiero & 0.00324 & $0.037 \%$ & $0.847 \%$ & $93.678 \%$ \\
\hline 337 & forense & 0.00324 & $0.025 \%$ & $0.565 \%$ & $93.703 \%$ \\
\hline 338 & director de empresa & 0.00323 & $0.049 \%$ & $1.130 \%$ & $93.752 \%$ \\
\hline 339 & heladero & 0.00317 & $0.037 \%$ & $0.847 \%$ & $93.789 \%$ \\
\hline 340 & sindicalista & 0.00317 & $0.025 \%$ & $0.565 \%$ & $93.814 \%$ \\
\hline 341 & lingüista & 0.00317 & $0.037 \%$ & $0.847 \%$ & $93.851 \%$ \\
\hline 342 & camillero & 0.00311 & $0.037 \%$ & $0.847 \%$ & $93.888 \%$ \\
\hline 343 & senador & 0.00305 & $0.037 \%$ & $0.847 \%$ & $93.925 \%$ \\
\hline 344 & forestal & 0.00300 & $0.025 \%$ & $0.565 \%$ & $93.950 \%$ \\
\hline 345 & Teleco(municaciones) & 0.00300 & $0.025 \%$ & $0.565 \%$ & $93.975 \%$ \\
\hline 346 & guardacostas & 0.00296 & $0.049 \%$ & $1.130 \%$ & $94.024 \%$ \\
\hline 347 & médico de cabecera & 0.00295 & $0.037 \%$ & $0.847 \%$ & $94.061 \%$ \\
\hline 348 & director de banco & 0.00293 & $0.037 \%$ & $0.847 \%$ & $94.098 \%$ \\
\hline 349 & municipal & 0.00293 & $0.025 \%$ & $0.565 \%$ & $94.123 \%$ \\
\hline 350 & botánico & 0.00290 & $0.025 \%$ & $0.565 \%$ & $94.148 \%$ \\
\hline 351 & afilador & 0.00287 & $0.037 \%$ & $0.847 \%$ & $94.185 \%$ \\
\hline 352 & bailador & 0.00283 & $0.037 \%$ & $0.847 \%$ & $94.222 \%$ \\
\hline 353 & peajero & 0.00282 & $0.012 \%$ & $0.282 \%$ & $94.234 \%$ \\
\hline 354 & salvavidas & 0.00282 & $0.037 \%$ & $0.847 \%$ & $94.271 \%$ \\
\hline 355 & trabajador & 0.00282 & $0.012 \%$ & $0.282 \%$ & $94.283 \%$ \\
\hline 356 & barquero & 0.00282 & $0.012 \%$ & $0.282 \%$ & $94.295 \%$ \\
\hline 357 & asesor fiscal & 0.00282 & $0.025 \%$ & $0.565 \%$ & $94.320 \%$ \\
\hline 358 & obra & 0.00282 & $0.012 \%$ & $0.282 \%$ & $94.332 \%$ \\
\hline 359 & docencia & 0.00282 & $0.012 \%$ & $0.282 \%$ & $94.344 \%$ \\
\hline 360 & director de transportes & 0.00282 & $0.012 \%$ & $0.282 \%$ & $94.356 \%$ \\
\hline 361 & maestro de EGB & 0.00282 & $0.012 \%$ & $0.282 \%$ & $94.368 \%$ \\
\hline 362 & auxiliar administrativo & 0.00282 & $0.012 \%$ & $0.282 \%$ & $94.380 \%$ \\
\hline
\end{tabular}




\begin{tabular}{|c|c|c|c|c|c|}
\hline 363 & teatrero & 0.00282 & $0.012 \%$ & $0.282 \%$ & $94.392 \%$ \\
\hline 364 & hornero & 0.00282 & $0.012 \%$ & $0.282 \%$ & $94.404 \%$ \\
\hline 365 & metalúrgico & 0.00282 & $0.012 \%$ & $0.282 \%$ & $94.416 \%$ \\
\hline 366 & bioquímico & 0.00280 & $0.025 \%$ & $0.565 \%$ & $94.441 \%$ \\
\hline 367 & aeronáutico & 0.00280 & $0.025 \%$ & $0.565 \%$ & $94.466 \%$ \\
\hline 368 & vigilante de playa & 0.00273 & $0.037 \%$ & $0.847 \%$ & $94.503 \%$ \\
\hline 369 & estomatólogo & 0.00266 & $0.037 \%$ & $0.847 \%$ & $94.540 \%$ \\
\hline 370 & operador & 0.00266 & $0.025 \%$ & $0.565 \%$ & $94.565 \%$ \\
\hline 371 & publicitario & 0.00263 & $0.012 \%$ & $0.282 \%$ & $94.577 \%$ \\
\hline 372 & técnico industrial & 0.00263 & $0.012 \%$ & $0.282 \%$ & $94.589 \%$ \\
\hline 373 & policía municipal & 0.00263 & $0.012 \%$ & $0.282 \%$ & $94.601 \%$ \\
\hline 374 & recogepelotas & 0.00263 & $0.012 \%$ & $0.282 \%$ & $94.613 \%$ \\
\hline 375 & correos & 0.00263 & $0.012 \%$ & $0.282 \%$ & $94.625 \%$ \\
\hline 376 & director comercial & 0.00263 & $0.012 \%$ & $0.282 \%$ & $94.637 \%$ \\
\hline 377 & Turismo & 0.00263 & $0.012 \%$ & $0.282 \%$ & $94.649 \%$ \\
\hline 378 & famoso & 0.00263 & $0.012 \%$ & $0.282 \%$ & $94.661 \%$ \\
\hline 379 & lector & 0.00263 & $0.012 \%$ & $0.282 \%$ & $94.673 \%$ \\
\hline 380 & comercial & 0.00263 & $0.012 \%$ & $0.282 \%$ & $94.685 \%$ \\
\hline 381 & comandante & 0.00260 & $0.025 \%$ & $0.565 \%$ & $94.710 \%$ \\
\hline 382 & realizador & 0.00260 & $0.025 \%$ & $0.565 \%$ & $94.735 \%$ \\
\hline 383 & proxeneta & 0.00259 & $0.025 \%$ & $0.565 \%$ & $94.760 \%$ \\
\hline 384 & chacha & 0.00259 & $0.025 \%$ & $0.565 \%$ & $94.785 \%$ \\
\hline 385 & asegurador & 0.00259 & $0.037 \%$ & $0.847 \%$ & $94.822 \%$ \\
\hline 386 & carcelero & 0.00257 & $0.025 \%$ & $0.565 \%$ & $94.847 \%$ \\
\hline 387 & rey & 0.00256 & $0.037 \%$ & $0.847 \%$ & $94.884 \%$ \\
\hline 388 & guardia de seguridad & 0.00255 & $0.025 \%$ & $0.565 \%$ & $94.909 \%$ \\
\hline 389 & sirvienta & 0.00254 & $0.025 \%$ & $0.565 \%$ & $94.934 \%$ \\
\hline 390 & perito agrónomo & 0.00251 & $0.025 \%$ & $0.565 \%$ & $94.959 \%$ \\
\hline 391 & cobrador del frac & 0.00249 & $0.025 \%$ & $0.565 \%$ & $94.984 \%$ \\
\hline 392 & trapecista & 0.00249 & $0.025 \%$ & $0.565 \%$ & $95.009 \%$ \\
\hline 393 & churrero & 0.00248 & $0.025 \%$ & $0.565 \%$ & $95.034 \%$ \\
\hline 394 & terapeuta & 0.00247 & $0.025 \%$ & $0.565 \%$ & $95.059 \%$ \\
\hline 395 & cabrero & 0.00245 & $0.012 \%$ & $0.282 \%$ & $95.071 \%$ \\
\hline 396 & técnico operador & 0.00245 & $0.012 \%$ & $0.282 \%$ & $95.083 \%$ \\
\hline 397 & limpiabotas & 0.00245 & $0.012 \%$ & $0.282 \%$ & $95.095 \%$ \\
\hline 398 & inspector de Hacienda & 0.00245 & $0.012 \%$ & $0.282 \%$ & $95.107 \%$ \\
\hline 399 & ingeniero técnico & 0.00245 & $0.037 \%$ & $0.847 \%$ & $95.144 \%$ \\
\hline 400 & trabajador del campo & 0.00245 & $0.012 \%$ & $0.282 \%$ & $95.156 \%$ \\
\hline 401 & cosechador & 0.00245 & $0.012 \%$ & $0.282 \%$ & $95.168 \%$ \\
\hline 402 & fabricante de platos & 0.00245 & $0.012 \%$ & $0.282 \%$ & $95.180 \%$ \\
\hline 403 & opositor & 0.00245 & $0.012 \%$ & $0.282 \%$ & $95.192 \%$ \\
\hline 404 & ingeniero aeronáutico & 0.00244 & $0.025 \%$ & $0.565 \%$ & $95.217 \%$ \\
\hline 405 & restaurador & 0.00244 & $0.037 \%$ & $0.847 \%$ & $95.254 \%$ \\
\hline 406 & traficante & 0.00240 & $0.037 \%$ & $0.847 \%$ & $95.291 \%$ \\
\hline 407 & diplomático & 0.00239 & $0.025 \%$ & $0.565 \%$ & $95.316 \%$ \\
\hline 408 & timador & 0.00237 & $0.025 \%$ & $0.565 \%$ & $95.341 \%$ \\
\hline 409 & guía turístico & 0.00235 & $0.037 \%$ & $0.847 \%$ & $95.378 \%$ \\
\hline
\end{tabular}




\begin{tabular}{|c|c|c|c|c|c|}
\hline 410 & jefe de empresa & 0.00231 & $0.025 \%$ & $0.565 \%$ & $95.403 \%$ \\
\hline 411 & naturista & 0.00228 & $0.012 \%$ & $0.282 \%$ & $95.415 \%$ \\
\hline 412 & oncólogo & 0.00228 & $0.012 \%$ & $0.282 \%$ & $95.427 \%$ \\
\hline 413 & recogedor & 0.00228 & $0.012 \%$ & $0.282 \%$ & $95.439 \%$ \\
\hline 414 & pocero & 0.00228 & $0.012 \%$ & $0.282 \%$ & $95.451 \%$ \\
\hline 415 & escenógrafo & 0.00228 & $0.012 \%$ & $0.282 \%$ & $95.463 \%$ \\
\hline 416 & ingeniero de diseño industrial & 0.00228 & $0.012 \%$ & $0.282 \%$ & $95.475 \%$ \\
\hline 417 & Publicidad & 0.00228 & $0.012 \%$ & $0.282 \%$ & $95.487 \%$ \\
\hline 418 & conductor de automóvil & 0.00228 & $0.012 \%$ & $0.282 \%$ & $95.499 \%$ \\
\hline 419 & dirigente & 0.00228 & $0.012 \%$ & $0.282 \%$ & $95.511 \%$ \\
\hline 420 & fabricante de ladrillos & 0.00228 & $0.012 \%$ & $0.282 \%$ & $95.523 \%$ \\
\hline 421 & ingeniero del medio ambiente & 0.00228 & $0.012 \%$ & $0.282 \%$ & $95.535 \%$ \\
\hline 422 & accionista & 0.00225 & $0.025 \%$ & $0.565 \%$ & $95.560 \%$ \\
\hline 423 & sexólogo & 0.00222 & $0.037 \%$ & $0.847 \%$ & $95.597 \%$ \\
\hline 424 & casero & 0.00222 & $0.025 \%$ & $0.565 \%$ & $95.622 \%$ \\
\hline 425 & comadrona & 0.00221 & $0.025 \%$ & $0.565 \%$ & $95.647 \%$ \\
\hline 426 & motorista & 0.00219 & $0.037 \%$ & $0.847 \%$ & $95.684 \%$ \\
\hline 427 & ingeniero técnico en industria & 0.00212 & $0.012 \%$ & $0.282 \%$ & $95.696 \%$ \\
\hline 428 & endocrino & 0.00212 & $0.012 \%$ & $0.282 \%$ & $95.708 \%$ \\
\hline 429 & gerente comercial & 0.00212 & $0.012 \%$ & $0.282 \%$ & $95.720 \%$ \\
\hline 430 & conductor de metro & 0.00212 & $0.012 \%$ & $0.282 \%$ & $95.732 \%$ \\
\hline 431 & ayudante de ayuntamiento & 0.00212 & $0.012 \%$ & $0.282 \%$ & $95.744 \%$ \\
\hline 432 & Derecho & 0.00212 & $0.012 \%$ & $0.282 \%$ & $95.756 \%$ \\
\hline 433 & ballestero & 0.00212 & $0.012 \%$ & $0.282 \%$ & $95.768 \%$ \\
\hline 434 & gemólogo & 0.00212 & $0.012 \%$ & $0.282 \%$ & $95.780 \%$ \\
\hline 435 & ingeniero de minas & 0.00212 & $0.012 \%$ & $0.282 \%$ & $95.792 \%$ \\
\hline 436 & mujer de la limpieza & 0.00209 & $0.025 \%$ & $0.565 \%$ & $95.817 \%$ \\
\hline 437 & humorista & 0.00208 & $0.037 \%$ & $0.847 \%$ & $95.854 \%$ \\
\hline 438 & apicultor & 0.00206 & $0.025 \%$ & $0.565 \%$ & $95.879 \%$ \\
\hline 439 & sepulturero & 0.00206 & $0.025 \%$ & $0.565 \%$ & $95.904 \%$ \\
\hline 440 & vendedor de ropa & 0.00206 & $0.025 \%$ & $0.565 \%$ & $95.929 \%$ \\
\hline 441 & embajador & 0.00206 & $0.025 \%$ & $0.565 \%$ & $95.954 \%$ \\
\hline 442 & segurata & 0.00204 & $0.037 \%$ & $0.847 \%$ & $95.991 \%$ \\
\hline 443 & charcutero & 0.00199 & $0.037 \%$ & $0.847 \%$ & $96.028 \%$ \\
\hline 444 & soldador & 0.00197 & $0.012 \%$ & $0.282 \%$ & $96.040 \%$ \\
\hline 445 & negociante & 0.00197 & $0.012 \%$ & $0.282 \%$ & $96.052 \%$ \\
\hline 446 & pollero & 0.00197 & $0.012 \%$ & $0.282 \%$ & $96.064 \%$ \\
\hline 447 & jugador de voleibol & 0.00197 & $0.012 \%$ & $0.282 \%$ & $96.076 \%$ \\
\hline 448 & aeronauta & 0.00197 & $0.012 \%$ & $0.282 \%$ & $96.088 \%$ \\
\hline 449 & pajarero & 0.00197 & $0.012 \%$ & $0.282 \%$ & $96.100 \%$ \\
\hline 450 & conductor de autocar & 0.00197 & $0.012 \%$ & $0.282 \%$ & $96.112 \%$ \\
\hline 451 & currante & 0.00197 & $0.012 \%$ & $0.282 \%$ & $96.124 \%$ \\
\hline 452 & trillador & 0.00197 & $0.012 \%$ & $0.282 \%$ & $96.136 \%$ \\
\hline 453 & mecánico de coches & 0.00197 & $0.012 \%$ & $0.282 \%$ & $96.148 \%$ \\
\hline 454 & cochero & 0.00197 & $0.012 \%$ & $0.282 \%$ & $96.160 \%$ \\
\hline 455 & profesor de Magisterio Musical & 0.00197 & $0.012 \%$ & $0.282 \%$ & $96.172 \%$ \\
\hline 456 & electrónico & 0.00194 & $0.025 \%$ & $0.565 \%$ & $96.197 \%$ \\
\hline
\end{tabular}




\begin{tabular}{|c|c|c|c|c|c|}
\hline 457 & profesor de Matemáticas & 0.00192 & $0.025 \%$ & $0.565 \%$ & $96.222 \%$ \\
\hline 458 & parapsicólogo & 0.00192 & $0.025 \%$ & $0.565 \%$ & $96.247 \%$ \\
\hline 459 & criado & 0.00192 & $0.025 \%$ & $0.565 \%$ & $96.272 \%$ \\
\hline 460 & monje & 0.00188 & $0.025 \%$ & $0.565 \%$ & $96.297 \%$ \\
\hline 461 & director de orquesta & 0.00186 & $0.025 \%$ & $0.565 \%$ & $96.322 \%$ \\
\hline 462 & gobernante & 0.00186 & $0.025 \%$ & $0.565 \%$ & $96.347 \%$ \\
\hline 463 & magnate & 0.00184 & $0.012 \%$ & $0.282 \%$ & $96.359 \%$ \\
\hline 464 & astillero & 0.00184 & $0.012 \%$ & $0.282 \%$ & $96.371 \%$ \\
\hline 465 & loquero & 0.00184 & $0.012 \%$ & $0.282 \%$ & $96.383 \%$ \\
\hline 466 & cuentista & 0.00184 & $0.012 \%$ & $0.282 \%$ & $96.395 \%$ \\
\hline 467 & trabajo social & 0.00184 & $0.012 \%$ & $0.282 \%$ & $96.407 \%$ \\
\hline 468 & conductor de trolebús & 0.00184 & $0.012 \%$ & $0.282 \%$ & $96.419 \%$ \\
\hline 469 & esterilizador & 0.00184 & $0.012 \%$ & $0.282 \%$ & $96.431 \%$ \\
\hline 470 & mecánico de motores & 0.00184 & $0.012 \%$ & $0.282 \%$ & $96.443 \%$ \\
\hline 471 & chocolatero & 0.00184 & $0.012 \%$ & $0.282 \%$ & $96.455 \%$ \\
\hline 472 & agente de seguridad & 0.00184 & $0.012 \%$ & $0.282 \%$ & $96.467 \%$ \\
\hline 473 & conductor de camiones & 0.00184 & $0.012 \%$ & $0.282 \%$ & $96.479 \%$ \\
\hline 474 & mantenedor & 0.00182 & $0.025 \%$ & $0.565 \%$ & $96.504 \%$ \\
\hline 475 & guarda forestal & 0.00182 & $0.025 \%$ & $0.565 \%$ & $96.529 \%$ \\
\hline 476 & peón caminero & 0.00175 & $0.025 \%$ & $0.565 \%$ & $96.554 \%$ \\
\hline 477 & señora de la limpieza & 0.00174 & $0.025 \%$ & $0.565 \%$ & $96.579 \%$ \\
\hline 478 & domador & 0.00173 & $0.025 \%$ & $0.565 \%$ & $96.604 \%$ \\
\hline 479 & ortodoncista & 0.00173 & $0.025 \%$ & $0.565 \%$ & $96.629 \%$ \\
\hline 480 & boxeador & 0.00171 & $0.037 \%$ & $0.847 \%$ & $96.666 \%$ \\
\hline 481 & pulimentador & 0.00171 & $0.012 \%$ & $0.282 \%$ & $96.678 \%$ \\
\hline 482 & gánster & 0.00171 & $0.012 \%$ & $0.282 \%$ & $96.690 \%$ \\
\hline 483 & empleada de casa & 0.00171 & $0.012 \%$ & $0.282 \%$ & $96.702 \%$ \\
\hline 484 & triador & 0.00171 & $0.012 \%$ & $0.282 \%$ & $96.714 \%$ \\
\hline 485 & rehabilitador & 0.00171 & $0.012 \%$ & $0.282 \%$ & $96.726 \%$ \\
\hline 486 & ingeniero agrícola & 0.00171 & $0.012 \%$ & $0.282 \%$ & $96.738 \%$ \\
\hline 487 & oficial & 0.00171 & $0.012 \%$ & $0.282 \%$ & $96.750 \%$ \\
\hline 488 & profesor infantil & 0.00171 & $0.012 \%$ & $0.282 \%$ & $96.762 \%$ \\
\hline 489 & piloto de avioneta & 0.00171 & $0.012 \%$ & $0.282 \%$ & $96.774 \%$ \\
\hline 490 & ingeniero físico & 0.00171 & $0.012 \%$ & $0.282 \%$ & $96.786 \%$ \\
\hline 491 & motociclista & 0.00171 & $0.012 \%$ & $0.282 \%$ & $96.798 \%$ \\
\hline 492 & música & 0.00171 & $0.012 \%$ & $0.282 \%$ & $96.810 \%$ \\
\hline 493 & ramader & 0.00171 & $0.012 \%$ & $0.282 \%$ & $96.822 \%$ \\
\hline 494 & diseño técnico & 0.00171 & $0.012 \%$ & $0.282 \%$ & $96.834 \%$ \\
\hline 495 & profesor de Lengua & 0.00171 & $0.012 \%$ & $0.282 \%$ & $96.846 \%$ \\
\hline 496 & jubilado & 0.00171 & $0.012 \%$ & $0.282 \%$ & $96.858 \%$ \\
\hline 497 & humanista & 0.00163 & $0.025 \%$ & $0.565 \%$ & $96.883 \%$ \\
\hline 498 & jefe de ventas & 0.00161 & $0.025 \%$ & $0.565 \%$ & $96.908 \%$ \\
\hline 499 & agente del FBI & 0.00161 & $0.025 \%$ & $0.565 \%$ & $96.933 \%$ \\
\hline 500 & baloncestista & 0.00159 & $0.012 \%$ & $0.282 \%$ & $96.945 \%$ \\
\hline 501 & vaquero & 0.00159 & $0.012 \%$ & $0.282 \%$ & $96.957 \%$ \\
\hline 502 & sargento & 0.00159 & $0.012 \%$ & $0.282 \%$ & $96.969 \%$ \\
\hline 503 & ingeniero nuclear & 0.00159 & $0.012 \%$ & $0.282 \%$ & $96.981 \%$ \\
\hline
\end{tabular}




\begin{tabular}{|c|c|c|c|c|c|}
\hline 504 & vulcanólogo & 0.00159 & $0.012 \%$ & $0.282 \%$ & $96.993 \%$ \\
\hline 505 & tornero & 0.00159 & $0.025 \%$ & $0.565 \%$ & $97.018 \%$ \\
\hline 506 & receptor & 0.00159 & $0.012 \%$ & $0.282 \%$ & $97.030 \%$ \\
\hline 507 & horticultor & 0.00159 & $0.012 \%$ & $0.282 \%$ & $97.042 \%$ \\
\hline 508 & documentalista & 0.00159 & $0.012 \%$ & $0.282 \%$ & $97.054 \%$ \\
\hline 509 & repartidor de gas & 0.00159 & $0.012 \%$ & $0.282 \%$ & $97.066 \%$ \\
\hline 510 & conductor de avión & 0.00159 & $0.012 \%$ & $0.282 \%$ & $97.078 \%$ \\
\hline 511 & Cruz Roja & 0.00159 & $0.012 \%$ & $0.282 \%$ & $97.090 \%$ \\
\hline 512 & seguros & 0.00159 & $0.012 \%$ & $0.282 \%$ & $97.102 \%$ \\
\hline 513 & moda & 0.00159 & $0.012 \%$ & $0.282 \%$ & $97.114 \%$ \\
\hline 514 & coreógrafo & 0.00159 & $0.012 \%$ & $0.282 \%$ & $97.126 \%$ \\
\hline 515 & futurólogo & 0.00159 & $0.012 \%$ & $0.282 \%$ & $97.138 \%$ \\
\hline 516 & cerámico & 0.00159 & $0.012 \%$ & $0.282 \%$ & $97.150 \%$ \\
\hline 517 & físico nuclear & 0.00159 & $0.012 \%$ & $0.282 \%$ & $97.162 \%$ \\
\hline 518 & revisor & 0.00155 & $0.025 \%$ & $0.565 \%$ & $97.187 \%$ \\
\hline 519 & karateca & 0.00150 & $0.025 \%$ & $0.565 \%$ & $97.212 \%$ \\
\hline 520 & matador de cerdos & 0.00148 & $0.012 \%$ & $0.282 \%$ & $97.224 \%$ \\
\hline 521 & almirante & 0.00148 & $0.012 \%$ & $0.282 \%$ & $97.236 \%$ \\
\hline 522 & vividor & 0.00148 & $0.012 \%$ & $0.282 \%$ & $97.248 \%$ \\
\hline 523 & dictador & 0.00148 & $0.012 \%$ & $0.282 \%$ & $97.260 \%$ \\
\hline 524 & ama de llaves & 0.00148 & $0.012 \%$ & $0.282 \%$ & $97.272 \%$ \\
\hline 525 & archivador & 0.00148 & $0.012 \%$ & $0.282 \%$ & $97.284 \%$ \\
\hline 526 & piloto de helicóptero & 0.00148 & $0.012 \%$ & $0.282 \%$ & $97.296 \%$ \\
\hline 527 & ingeniero de puertos y caminos & 0.00148 & $0.012 \%$ & $0.282 \%$ & $97.308 \%$ \\
\hline 528 & Comunicación audiovisual & 0.00148 & $0.012 \%$ & $0.282 \%$ & $97.320 \%$ \\
\hline 529 & droguero & 0.00148 & $0.012 \%$ & $0.282 \%$ & $97.332 \%$ \\
\hline 530 & concertista & 0.00148 & $0.012 \%$ & $0.282 \%$ & $97.344 \%$ \\
\hline 531 & matador & 0.00148 & $0.012 \%$ & $0.282 \%$ & $97.356 \%$ \\
\hline 532 & talador & 0.00148 & $0.012 \%$ & $0.282 \%$ & $97.368 \%$ \\
\hline 533 & acomodador & 0.00146 & $0.025 \%$ & $0.565 \%$ & $97.393 \%$ \\
\hline 534 & general & 0.00144 & $0.025 \%$ & $0.565 \%$ & $97.418 \%$ \\
\hline 535 & Económicas & 0.00144 & $0.025 \%$ & $0.565 \%$ & $97.443 \%$ \\
\hline 536 & programador & 0.00139 & $0.025 \%$ & $0.565 \%$ & $97.468 \%$ \\
\hline 537 & pizzero & 0.00138 & $0.012 \%$ & $0.282 \%$ & $97.480 \%$ \\
\hline 538 & académico & 0.00138 & $0.012 \%$ & $0.282 \%$ & $97.492 \%$ \\
\hline 539 & manicura & 0.00138 & $0.012 \%$ & $0.282 \%$ & $97.504 \%$ \\
\hline 540 & agente & 0.00138 & $0.012 \%$ & $0.282 \%$ & $97.516 \%$ \\
\hline 541 & literato & 0.00138 & $0.012 \%$ & $0.282 \%$ & $97.528 \%$ \\
\hline 542 & repartidor de pizzas & 0.00138 & $0.012 \%$ & $0.282 \%$ & $97.540 \%$ \\
\hline 543 & funerario & 0.00138 & $0.012 \%$ & $0.282 \%$ & $97.552 \%$ \\
\hline 544 & director de escuela & 0.00138 & $0.012 \%$ & $0.282 \%$ & $97.564 \%$ \\
\hline 545 & jefe de personal & 0.00138 & $0.012 \%$ & $0.282 \%$ & $97.576 \%$ \\
\hline 546 & inversor & 0.00138 & $0.012 \%$ & $0.282 \%$ & $97.588 \%$ \\
\hline 547 & especulador & 0.00138 & $0.012 \%$ & $0.282 \%$ & $97.600 \%$ \\
\hline 548 & mafioso & 0.00138 & $0.012 \%$ & $0.282 \%$ & $97.612 \%$ \\
\hline 549 & artista circense & 0.00138 & $0.012 \%$ & $0.282 \%$ & $97.624 \%$ \\
\hline 550 & sereno & 0.00138 & $0.012 \%$ & $0.282 \%$ & $97.636 \%$ \\
\hline
\end{tabular}




\begin{tabular}{|c|c|c|c|c|c|}
\hline 551 & trabajador de empresa & 0.00138 & $0.012 \%$ & $0.282 \%$ & $97.648 \%$ \\
\hline 552 & propietario & 0.00138 & $0.012 \%$ & $0.282 \%$ & $97.660 \%$ \\
\hline 553 & delegado & 0.00130 & $0.025 \%$ & $0.565 \%$ & $97.685 \%$ \\
\hline 554 & estafador & 0.00130 & $0.025 \%$ & $0.565 \%$ & $97.710 \%$ \\
\hline 555 & espía & 0.00128 & $0.012 \%$ & $0.282 \%$ & $97.722 \%$ \\
\hline 556 & matrona & 0.00128 & $0.012 \%$ & $0.282 \%$ & $97.734 \%$ \\
\hline 557 & preparador físico & 0.00128 & $0.012 \%$ & $0.282 \%$ & $97.746 \%$ \\
\hline 558 & copista & 0.00128 & $0.012 \%$ & $0.282 \%$ & $97.758 \%$ \\
\hline 559 & bodeguero & 0.00128 & $0.012 \%$ & $0.282 \%$ & $97.770 \%$ \\
\hline 560 & zoólogo & 0.00128 & $0.012 \%$ & $0.282 \%$ & $97.782 \%$ \\
\hline 561 & fumigador & 0.00128 & $0.012 \%$ & $0.282 \%$ & $97.794 \%$ \\
\hline 562 & profesor de Gimnasia & 0.00128 & $0.012 \%$ & $0.282 \%$ & $97.806 \%$ \\
\hline 563 & agente comercial & 0.00128 & $0.012 \%$ & $0.282 \%$ & $97.818 \%$ \\
\hline 564 & cortador & 0.00128 & $0.012 \%$ & $0.282 \%$ & $97.830 \%$ \\
\hline 565 & titiritero & 0.00128 & $0.012 \%$ & $0.282 \%$ & $97.842 \%$ \\
\hline 566 & inventor & 0.00128 & $0.012 \%$ & $0.282 \%$ & $97.854 \%$ \\
\hline 567 & broker & 0.00128 & $0.012 \%$ & $0.282 \%$ & $97.866 \%$ \\
\hline 568 & emperador & 0.00128 & $0.012 \%$ & $0.282 \%$ & $97.878 \%$ \\
\hline 569 & carretero & 0.00128 & $0.012 \%$ & $0.282 \%$ & $97.890 \%$ \\
\hline 570 & recogedor de naranjas & 0.00128 & $0.012 \%$ & $0.282 \%$ & $97.902 \%$ \\
\hline 571 & directivo & 0.00128 & $0.012 \%$ & $0.282 \%$ & $97.914 \%$ \\
\hline 572 & corredor de seguros & 0.00126 & $0.025 \%$ & $0.565 \%$ & $97.939 \%$ \\
\hline 573 & showman & 0.00121 & $0.025 \%$ & $0.565 \%$ & $97.964 \%$ \\
\hline 574 & patrón & 0.00121 & $0.025 \%$ & $0.565 \%$ & $97.989 \%$ \\
\hline 575 & madero & 0.00119 & $0.012 \%$ & $0.282 \%$ & $98.001 \%$ \\
\hline 576 & jugador de béisbol & 0.00119 & $0.012 \%$ & $0.282 \%$ & $98.013 \%$ \\
\hline 577 & mandatario & 0.00119 & $0.012 \%$ & $0.282 \%$ & $98.025 \%$ \\
\hline 578 & cineasta & 0.00119 & $0.012 \%$ & $0.282 \%$ & $98.037 \%$ \\
\hline 579 & profesor de Física y Química & 0.00119 & $0.012 \%$ & $0.282 \%$ & $98.049 \%$ \\
\hline 580 & policía local & 0.00119 & $0.012 \%$ & $0.282 \%$ & $98.061 \%$ \\
\hline 581 & feriante & 0.00119 & $0.012 \%$ & $0.282 \%$ & $98.073 \%$ \\
\hline 582 & vendedor de comida & 0.00119 & $0.012 \%$ & $0.282 \%$ & $98.085 \%$ \\
\hline 583 & montador de coches & 0.00119 & $0.012 \%$ & $0.282 \%$ & $98.097 \%$ \\
\hline 584 & astrólogo & 0.00119 & $0.012 \%$ & $0.282 \%$ & $98.109 \%$ \\
\hline 585 & pintor de brocha gorda & 0.00119 & $0.012 \%$ & $0.282 \%$ & $98.121 \%$ \\
\hline 586 & viticultor & 0.00116 & $0.025 \%$ & $0.565 \%$ & $98.146 \%$ \\
\hline 587 & crítico literario & 0.00111 & $0.012 \%$ & $0.282 \%$ & $98.158 \%$ \\
\hline 588 & piloto de aviación & 0.00111 & $0.012 \%$ & $0.282 \%$ & $98.170 \%$ \\
\hline 589 & corredor de comercio & 0.00111 & $0.012 \%$ & $0.282 \%$ & $98.182 \%$ \\
\hline 590 & rector & 0.00111 & $0.012 \%$ & $0.282 \%$ & $98.194 \%$ \\
\hline 591 & técnico en electricidad & 0.00111 & $0.012 \%$ & $0.282 \%$ & $98.206 \%$ \\
\hline 592 & cazarrecompensas & 0.00111 & $0.012 \%$ & $0.282 \%$ & $98.218 \%$ \\
\hline 593 & profesor de Inglés & 0.00111 & $0.012 \%$ & $0.282 \%$ & $98.230 \%$ \\
\hline 594 & comprador & 0.00111 & $0.012 \%$ & $0.282 \%$ & $98.242 \%$ \\
\hline 595 & ajedrecista & 0.00111 & $0.012 \%$ & $0.282 \%$ & $98.254 \%$ \\
\hline 596 & asistente & 0.00111 & $0.012 \%$ & $0.282 \%$ & $98.266 \%$ \\
\hline 597 & cómico & 0.00111 & $0.012 \%$ & $0.282 \%$ & $98.278 \%$ \\
\hline
\end{tabular}




\begin{tabular}{|c|c|c|c|c|c|}
\hline 598 & ingeniero de puentes y caminos & 0.00111 & $0.012 \%$ & $0.282 \%$ & $98.290 \%$ \\
\hline 599 & funcionario de prisiones & 0.00111 & $0.012 \%$ & $0.282 \%$ & $98.302 \%$ \\
\hline 600 & estadístico & 0.00111 & $0.012 \%$ & $0.282 \%$ & $98.314 \%$ \\
\hline 601 & cantador & 0.00111 & $0.012 \%$ & $0.282 \%$ & $98.326 \%$ \\
\hline 602 & obrero fabril & 0.00111 & $0.012 \%$ & $0.282 \%$ & $98.338 \%$ \\
\hline 603 & director administrativo de empresas & 0.00111 & $0.012 \%$ & $0.282 \%$ & $98.350 \%$ \\
\hline 604 & presidente bancario & 0.00103 & $0.012 \%$ & $0.282 \%$ & $98.362 \%$ \\
\hline 605 & jugador de ajedrez & 0.00103 & $0.012 \%$ & $0.282 \%$ & $98.374 \%$ \\
\hline 606 & autónomo & 0.00103 & $0.012 \%$ & $0.282 \%$ & $98.386 \%$ \\
\hline 607 & ingeniero informático & 0.00103 & $0.012 \%$ & $0.282 \%$ & $98.398 \%$ \\
\hline 608 & corresponsal de guerra & 0.00103 & $0.012 \%$ & $0.282 \%$ & $98.410 \%$ \\
\hline 609 & profesor de Religión & 0.00103 & $0.012 \%$ & $0.282 \%$ & $98.422 \%$ \\
\hline 610 & profesor de autoescuela & 0.00103 & $0.012 \%$ & $0.282 \%$ & $98.434 \%$ \\
\hline 611 & limonero & 0.00103 & $0.012 \%$ & $0.282 \%$ & $98.446 \%$ \\
\hline 612 & endocrinólogo & 0.00103 & $0.012 \%$ & $0.282 \%$ & $98.458 \%$ \\
\hline 613 & diseñador de moda & 0.00103 & $0.012 \%$ & $0.282 \%$ & $98.470 \%$ \\
\hline 614 & cámara de televisión & 0.00103 & $0.012 \%$ & $0.282 \%$ & $98.482 \%$ \\
\hline 615 & ADEM & 0.00103 & $0.012 \%$ & $0.282 \%$ & $98.494 \%$ \\
\hline 616 & callista & 0.00096 & $0.012 \%$ & $0.282 \%$ & $98.506 \%$ \\
\hline 617 & serrador & 0.00096 & $0.012 \%$ & $0.282 \%$ & $98.518 \%$ \\
\hline 618 & buceador & 0.00096 & $0.012 \%$ & $0.282 \%$ & $98.530 \%$ \\
\hline 619 & trabajo doméstico & 0.00096 & $0.012 \%$ & $0.282 \%$ & $98.542 \%$ \\
\hline 620 & procurador & 0.00096 & $0.012 \%$ & $0.282 \%$ & $98.554 \%$ \\
\hline 621 & presentador de TV & 0.00096 & $0.012 \%$ & $0.282 \%$ & $98.566 \%$ \\
\hline 622 & empleada de hogar & 0.00096 & $0.012 \%$ & $0.282 \%$ & $98.578 \%$ \\
\hline 623 & Historia & 0.00096 & $0.012 \%$ & $0.282 \%$ & $98.590 \%$ \\
\hline 624 & venta ambulante & 0.00096 & $0.012 \%$ & $0.282 \%$ & $98.602 \%$ \\
\hline 625 & esquiador & 0.00096 & $0.012 \%$ & $0.282 \%$ & $98.614 \%$ \\
\hline 626 & técnico de sonido & 0.00096 & $0.012 \%$ & $0.282 \%$ & $98.626 \%$ \\
\hline 627 & importador & 0.00096 & $0.012 \%$ & $0.282 \%$ & $98.638 \%$ \\
\hline 628 & religioso & 0.00096 & $0.012 \%$ & $0.282 \%$ & $98.650 \%$ \\
\hline 629 & relaciones laborales & 0.00096 & $0.012 \%$ & $0.282 \%$ & $98.662 \%$ \\
\hline 630 & banderillero & 0.00091 & $0.025 \%$ & $0.565 \%$ & $98.687 \%$ \\
\hline 631 & encargado de sección & 0.00089 & $0.012 \%$ & $0.282 \%$ & $98.699 \%$ \\
\hline 632 & montador & 0.00089 & $0.012 \%$ & $0.282 \%$ & $98.711 \%$ \\
\hline 633 & comisario & 0.00089 & $0.012 \%$ & $0.282 \%$ & $98.723 \%$ \\
\hline 634 & auxiliar de cocina & 0.00089 & $0.012 \%$ & $0.282 \%$ & $98.735 \%$ \\
\hline 635 & culturista & 0.00089 & $0.012 \%$ & $0.282 \%$ & $98.747 \%$ \\
\hline 636 & profesor de ciencias & 0.00089 & $0.012 \%$ & $0.282 \%$ & $98.759 \%$ \\
\hline 637 & buscador de tesoros & 0.00089 & $0.012 \%$ & $0.282 \%$ & $98.771 \%$ \\
\hline 638 & profesor de colegio & 0.00089 & $0.012 \%$ & $0.282 \%$ & $98.783 \%$ \\
\hline 639 & paleontólogo & 0.00089 & $0.012 \%$ & $0.282 \%$ & $98.795 \%$ \\
\hline 640 & papelero & 0.00089 & $0.012 \%$ & $0.282 \%$ & $98.807 \%$ \\
\hline 641 & patinador & 0.00089 & $0.012 \%$ & $0.282 \%$ & $98.819 \%$ \\
\hline 642 & bordadora & 0.00089 & $0.012 \%$ & $0.282 \%$ & $98.831 \%$ \\
\hline 643 & exportador & 0.00089 & $0.012 \%$ & $0.282 \%$ & $98.843 \%$ \\
\hline 644 & vendedor de huevos & 0.00083 & $0.012 \%$ & $0.282 \%$ & $98.855 \%$ \\
\hline
\end{tabular}




\begin{tabular}{|c|c|c|c|c|c|}
\hline 645 & animador & 0.00083 & $0.012 \%$ & $0.282 \%$ & $98.867 \%$ \\
\hline 646 & troquelador & 0.00083 & $0.012 \%$ & $0.282 \%$ & $98.879 \%$ \\
\hline 647 & guerrillero & 0.00083 & $0.012 \%$ & $0.282 \%$ & $98.891 \%$ \\
\hline 648 & striptease & 0.00083 & $0.012 \%$ & $0.282 \%$ & $98.903 \%$ \\
\hline 649 & fraile & 0.00083 & $0.012 \%$ & $0.282 \%$ & $98.915 \%$ \\
\hline 650 & vendedor de frutas & 0.00083 & $0.012 \%$ & $0.282 \%$ & $98.927 \%$ \\
\hline 651 & profesor de universidad & 0.00083 & $0.012 \%$ & $0.282 \%$ & $98.939 \%$ \\
\hline 652 & jugador de golf & 0.00083 & $0.012 \%$ & $0.282 \%$ & $98.951 \%$ \\
\hline 653 & diplomado & 0.00083 & $0.012 \%$ & $0.282 \%$ & $98.963 \%$ \\
\hline 654 & meteorólogo & 0.00083 & $0.012 \%$ & $0.282 \%$ & $98.975 \%$ \\
\hline 655 & guitarrista & 0.00077 & $0.012 \%$ & $0.282 \%$ & $98.987 \%$ \\
\hline 656 & calefactor & 0.00077 & $0.012 \%$ & $0.282 \%$ & $98.999 \%$ \\
\hline 657 & lavaplatos & 0.00077 & $0.012 \%$ & $0.282 \%$ & $99.011 \%$ \\
\hline 658 & mago & 0.00077 & $0.012 \%$ & $0.282 \%$ & $99.023 \%$ \\
\hline 659 & detective privado & 0.00077 & $0.012 \%$ & $0.282 \%$ & $99.035 \%$ \\
\hline 660 & cuidador & 0.00077 & $0.012 \%$ & $0.282 \%$ & $99.047 \%$ \\
\hline 661 & reponedor & 0.00077 & $0.012 \%$ & $0.282 \%$ & $99.059 \%$ \\
\hline 662 & autor literario & 0.00072 & $0.012 \%$ & $0.282 \%$ & $99.071 \%$ \\
\hline 663 & aprendiz de zapatero & 0.00072 & $0.012 \%$ & $0.282 \%$ & $99.083 \%$ \\
\hline 664 & broker de bolsa & 0.00072 & $0.012 \%$ & $0.282 \%$ & $99.095 \%$ \\
\hline 665 & iluminación & 0.00072 & $0.012 \%$ & $0.282 \%$ & $99.107 \%$ \\
\hline 666 & bohemio & 0.00072 & $0.012 \%$ & $0.282 \%$ & $99.119 \%$ \\
\hline 667 & acróbata & 0.00072 & $0.012 \%$ & $0.282 \%$ & $99.131 \%$ \\
\hline 668 & aeromoza & 0.00072 & $0.012 \%$ & $0.282 \%$ & $99.143 \%$ \\
\hline 669 & utillero & 0.00072 & $0.012 \%$ & $0.282 \%$ & $99.155 \%$ \\
\hline 670 & diseñador gráfico & 0.00072 & $0.012 \%$ & $0.282 \%$ & $99.167 \%$ \\
\hline 671 & comunicador & 0.00067 & $0.012 \%$ & $0.282 \%$ & $99.179 \%$ \\
\hline 672 & baby-sitter & 0.00067 & $0.012 \%$ & $0.282 \%$ & $99.191 \%$ \\
\hline 673 & colchonero & 0.00067 & $0.012 \%$ & $0.282 \%$ & $99.203 \%$ \\
\hline 674 & escolta & 0.00067 & $0.012 \%$ & $0.282 \%$ & $99.215 \%$ \\
\hline 675 & asistenta & 0.00067 & $0.012 \%$ & $0.282 \%$ & $99.227 \%$ \\
\hline 676 & recogedor de cartón & 0.00067 & $0.012 \%$ & $0.282 \%$ & $99.239 \%$ \\
\hline 677 & ludópata & 0.00067 & $0.012 \%$ & $0.282 \%$ & $99.251 \%$ \\
\hline 678 & institutriz & 0.00067 & $0.012 \%$ & $0.282 \%$ & $99.263 \%$ \\
\hline 679 & alumbrador & 0.00067 & $0.012 \%$ & $0.282 \%$ & $99.275 \%$ \\
\hline 680 & dramaturgo & 0.00067 & $0.012 \%$ & $0.282 \%$ & $99.287 \%$ \\
\hline 681 & presentador de televisión & 0.00067 & $0.012 \%$ & $0.282 \%$ & $99.299 \%$ \\
\hline 682 & prestamista & 0.00062 & $0.012 \%$ & $0.282 \%$ & $99.311 \%$ \\
\hline 683 & planchador & 0.00062 & $0.012 \%$ & $0.282 \%$ & $99.323 \%$ \\
\hline 684 & psicoterapeuta & 0.00062 & $0.012 \%$ & $0.282 \%$ & $99.335 \%$ \\
\hline 685 & mesonero & 0.00062 & $0.012 \%$ & $0.282 \%$ & $99.347 \%$ \\
\hline 686 & mamporrero & 0.00062 & $0.012 \%$ & $0.282 \%$ & $99.359 \%$ \\
\hline 687 & crítico & 0.00062 & $0.012 \%$ & $0.282 \%$ & $99.371 \%$ \\
\hline 688 & luchador & 0.00058 & $0.012 \%$ & $0.282 \%$ & $99.383 \%$ \\
\hline 689 & guardia rural & 0.00058 & $0.012 \%$ & $0.282 \%$ & $99.395 \%$ \\
\hline 690 & pasante & 0.00058 & $0.012 \%$ & $0.282 \%$ & $99.407 \%$ \\
\hline 691 & yudoca & 0.00058 & $0.012 \%$ & $0.282 \%$ & $99.419 \%$ \\
\hline
\end{tabular}




\begin{tabular}{|c|c|c|c|c|c|}
\hline 692 & arquitecto técnico & 0.00058 & $0.012 \%$ & $0.282 \%$ & $99.431 \%$ \\
\hline 693 & orfebre & 0.00058 & $0.012 \%$ & $0.282 \%$ & $99.443 \%$ \\
\hline 694 & vicepresidente & 0.00058 & $0.012 \%$ & $0.282 \%$ & $99.455 \%$ \\
\hline 695 & obrero textil & 0.00058 & $0.012 \%$ & $0.282 \%$ & $99.467 \%$ \\
\hline 696 & violinista & 0.00058 & $0.012 \%$ & $0.282 \%$ & $99.479 \%$ \\
\hline 697 & marmolista & 0.00058 & $0.012 \%$ & $0.282 \%$ & $99.491 \%$ \\
\hline 698 & agente de la CIA & 0.00054 & $0.012 \%$ & $0.282 \%$ & $99.503 \%$ \\
\hline 699 & consejero matrimonial & 0.00054 & $0.012 \%$ & $0.282 \%$ & $99.515 \%$ \\
\hline 700 & cardenal & 0.00054 & $0.012 \%$ & $0.282 \%$ & $99.527 \%$ \\
\hline 701 & tesorero & 0.00054 & $0.012 \%$ & $0.282 \%$ & $99.539 \%$ \\
\hline 702 & doblador de voz & 0.00054 & $0.012 \%$ & $0.282 \%$ & $99.551 \%$ \\
\hline 703 & videocámara & 0.00050 & $0.012 \%$ & $0.282 \%$ & $99.563 \%$ \\
\hline 704 & director de colegio & 0.00050 & $0.012 \%$ & $0.282 \%$ & $99.575 \%$ \\
\hline 705 & Empresariales & 0.00050 & $0.012 \%$ & $0.282 \%$ & $99.587 \%$ \\
\hline 706 & empleado de fábrica & 0.00050 & $0.012 \%$ & $0.282 \%$ & $99.599 \%$ \\
\hline 707 & agente de la KGB & 0.00047 & $0.012 \%$ & $0.282 \%$ & $99.611 \%$ \\
\hline 708 & camorrista & 0.00047 & $0.012 \%$ & $0.282 \%$ & $99.623 \%$ \\
\hline 709 & jugador de básquet & 0.00047 & $0.012 \%$ & $0.282 \%$ & $99.635 \%$ \\
\hline 710 & mantenimiento & 0.00047 & $0.012 \%$ & $0.282 \%$ & $99.647 \%$ \\
\hline 711 & submarinista & 0.00047 & $0.012 \%$ & $0.282 \%$ & $99.659 \%$ \\
\hline 712 & avicultor & 0.00047 & $0.012 \%$ & $0.282 \%$ & $99.671 \%$ \\
\hline 713 & vendedor de cupones & 0.00044 & $0.012 \%$ & $0.282 \%$ & $99.683 \%$ \\
\hline 714 & agente publicitario & 0.00044 & $0.012 \%$ & $0.282 \%$ & $99.695 \%$ \\
\hline 715 & ensayista & 0.00044 & $0.012 \%$ & $0.282 \%$ & $99.707 \%$ \\
\hline 716 & acupuntor & 0.00044 & $0.012 \%$ & $0.282 \%$ & $99.719 \%$ \\
\hline 717 & piloto de guerra & 0.00044 & $0.012 \%$ & $0.282 \%$ & $99.731 \%$ \\
\hline 718 & linier & 0.00044 & $0.012 \%$ & $0.282 \%$ & $99.743 \%$ \\
\hline 719 & batería & 0.00041 & $0.012 \%$ & $0.282 \%$ & $99.755 \%$ \\
\hline 720 & monitor de gimnasio & 0.00041 & $0.012 \%$ & $0.282 \%$ & $99.767 \%$ \\
\hline 721 & malabarista & 0.00041 & $0.012 \%$ & $0.282 \%$ & $99.779 \%$ \\
\hline 722 & paparazzi & 0.00041 & $0.012 \%$ & $0.282 \%$ & $99.791 \%$ \\
\hline 723 & naturalista & 0.00041 & $0.012 \%$ & $0.282 \%$ & $99.803 \%$ \\
\hline 724 & artillero & 0.00041 & $0.012 \%$ & $0.282 \%$ & $99.815 \%$ \\
\hline 725 & piloto de moto & 0.00041 & $0.012 \%$ & $0.282 \%$ & $99.827 \%$ \\
\hline 726 & bajista & 0.00038 & $0.012 \%$ & $0.282 \%$ & $99.839 \%$ \\
\hline 727 & picador & 0.00038 & $0.012 \%$ & $0.282 \%$ & $99.851 \%$ \\
\hline 728 & balonmanista & 0.00038 & $0.012 \%$ & $0.282 \%$ & $99.863 \%$ \\
\hline 729 & sociolingüista & 0.00038 & $0.012 \%$ & $0.282 \%$ & $99.875 \%$ \\
\hline 730 & faquir & 0.00038 & $0.012 \%$ & $0.282 \%$ & $99.887 \%$ \\
\hline 731 & organista & 0.00035 & $0.012 \%$ & $0.282 \%$ & $99.899 \%$ \\
\hline 732 & abogado criminalista & 0.00035 & $0.012 \%$ & $0.282 \%$ & $99.911 \%$ \\
\hline
\end{tabular}

\section{LOS COLORES}




\begin{tabular}{|c|c|c|c|c|c|}
\hline $\mathrm{N}^{\mathrm{o}}$ & Palabra & Disponibilidad & $\begin{array}{c}\text { Frecuencia } \\
\text { relativa }\end{array}$ & \% Aparición & $\begin{array}{l}\text { Frecuencia } \\
\text { acumulada }\end{array}$ \\
\hline 1 & rojo & 0.90111 & $4.977 \%$ & $98.870 \%$ & $4.977 \%$ \\
\hline 2 & amarillo & 0.84346 & $5.020 \%$ & $99.718 \%$ & $9.997 \%$ \\
\hline 3 & azul & 0.81385 & $4.494 \%$ & $89.266 \%$ & $14.491 \%$ \\
\hline 4 & negro & 0.80400 & $5.006 \%$ & $99.435 \%$ & $19.497 \%$ \\
\hline 5 & blanco & 0.79160 & $4.949 \%$ & $98.305 \%$ & $24.446 \%$ \\
\hline 6 & verde & 0.78027 & $4.650 \%$ & $92.373 \%$ & $29.096 \%$ \\
\hline 7 & naranja & 0.66191 & $4.508 \%$ & $89.548 \%$ & $33.604 \%$ \\
\hline 8 & gris & 0.61716 & $4.465 \%$ & $88.701 \%$ & $38.069 \%$ \\
\hline 9 & marrón & 0.60691 & $4.423 \%$ & $87.853 \%$ & $42.492 \%$ \\
\hline 10 & rosa & 0.58367 & $4.110 \%$ & $81.638 \%$ & $46.602 \%$ \\
\hline 11 & violeta & 0.57762 & $3.882 \%$ & $77.119 \%$ & $50.484 \%$ \\
\hline 12 & morado & 0.39232 & $2.702 \%$ & $53.672 \%$ & $53.186 \%$ \\
\hline 13 & granate & 0.30934 & $2.446 \%$ & $48.588 \%$ & $55.632 \%$ \\
\hline 14 & fucsia & 0.27583 & $2.133 \%$ & $42.373 \%$ & $57.765 \%$ \\
\hline 15 & beige & 0.24737 & $2.090 \%$ & $41.525 \%$ & $59.855 \%$ \\
\hline 16 & (azul) marino & 0.22781 & $1.721 \%$ & $34.181 \%$ & $61.576 \%$ \\
\hline 17 & lila & 0.20740 & $1.522 \%$ & $30.226 \%$ & $63.098 \%$ \\
\hline 18 & turquesa & 0.20332 & $1.536 \%$ & $30.508 \%$ & $64.634 \%$ \\
\hline 19 & ocre & 0.19060 & $1.422 \%$ & $28.249 \%$ & $66.056 \%$ \\
\hline 20 & dorado & 0.18676 & $1.578 \%$ & $31.356 \%$ & $67.634 \%$ \\
\hline 21 & plateado & 0.17340 & $1.507 \%$ & $29.944 \%$ & $69.141 \%$ \\
\hline 22 & (azul) celeste & 0.16278 & $1.280 \%$ & $25.424 \%$ & $70.421 \%$ \\
\hline 23 & añil & 0.14235 & $0.953 \%$ & $18.927 \%$ & $71.374 \%$ \\
\hline 24 & pistacho & 0.13167 & $1.166 \%$ & $23.164 \%$ & $72.540 \%$ \\
\hline 25 & magenta & 0.10929 & $0.768 \%$ & $15.254 \%$ & $73.308 \%$ \\
\hline 26 & púrpura & 0.10868 & $0.839 \%$ & $16.667 \%$ & $74.147 \%$ \\
\hline 27 & caqui & 0.09552 & $0.839 \%$ & $16.667 \%$ & $74.986 \%$ \\
\hline 28 & (color) carne & 0.08836 & $0.782 \%$ & $15.537 \%$ & $75.768 \%$ \\
\hline 29 & azul claro & 0.08741 & $0.597 \%$ & $11.864 \%$ & $76.365 \%$ \\
\hline 30 & salmón & 0.08122 & $0.697 \%$ & $13.842 \%$ & $77.062 \%$ \\
\hline 31 & oro & 0.08079 & $0.725 \%$ & $14.407 \%$ & $77.787 \%$ \\
\hline 32 & (azul) cielo & 0.07973 & $0.654 \%$ & $12.994 \%$ & $78.441 \%$ \\
\hline 33 & bermellón & 0.07521 & $0.597 \%$ & $11.864 \%$ & $79.038 \%$ \\
\hline 34 & plata & 0.07187 & $0.683 \%$ & $13.559 \%$ & $79.721 \%$ \\
\hline 35 & verde botella & 0.06341 & $0.540 \%$ & $10.734 \%$ & $80.261 \%$ \\
\hline 36 & verde claro & 0.05200 & $0.427 \%$ & $8.475 \%$ & $80.688 \%$ \\
\hline 37 & tostado & 0.05025 & $0.455 \%$ & $9.040 \%$ & $81.143 \%$ \\
\hline 38 & (color) hueso & 0.04693 & $0.441 \%$ & $8.757 \%$ & $81.584 \%$ \\
\hline 39 & verde oscuro & 0.04650 & $0.384 \%$ & $7.627 \%$ & $81.968 \%$ \\
\hline 40 & transparente & 0.04489 & $0.441 \%$ & $8.757 \%$ & $82.409 \%$ \\
\hline 41 & azulón & 0.04425 & $0.341 \%$ & $6.780 \%$ & $82.750 \%$ \\
\hline 42 & carmín & 0.04394 & $0.327 \%$ & $6.497 \%$ & $83.077 \%$ \\
\hline 43 & caoba & 0.04232 & $0.384 \%$ & $7.627 \%$ & $83.461 \%$ \\
\hline 44 & ámbar & 0.03970 & $0.299 \%$ & $5.932 \%$ & $83.760 \%$ \\
\hline 45 & crema & 0.03876 & $0.356 \%$ & $7.062 \%$ & $84.116 \%$ \\
\hline
\end{tabular}




\begin{tabular}{|c|c|c|c|c|c|}
\hline 46 & azul oscuro & 0.03611 & $0.256 \%$ & $5.085 \%$ & $84.372 \%$ \\
\hline 47 & pastel & 0.03435 & $0.299 \%$ & $5.932 \%$ & $84.671 \%$ \\
\hline 48 & mostaza & 0.03137 & $0.313 \%$ & $6.215 \%$ & $84.984 \%$ \\
\hline 49 & burdeos & 0.02852 & $0.228 \%$ & $4.520 \%$ & $85.212 \%$ \\
\hline 50 & calabaza & 0.02840 & $0.199 \%$ & $3.955 \%$ & $85.411 \%$ \\
\hline 51 & crudo & 0.02801 & $0.270 \%$ & $5.367 \%$ & $85.681 \%$ \\
\hline 52 & castaño & 0.02498 & $0.242 \%$ & $4.802 \%$ & $85.923 \%$ \\
\hline 53 & malva & 0.02450 & $0.185 \%$ & $3.672 \%$ & $86.108 \%$ \\
\hline 54 & esmeralda & 0.02335 & $0.185 \%$ & $3.672 \%$ & $86.293 \%$ \\
\hline 55 & amarillo limón & 0.02321 & $0.199 \%$ & $3.955 \%$ & $86.492 \%$ \\
\hline 56 & verde azulado & 0.02311 & $0.185 \%$ & $3.672 \%$ & $86.677 \%$ \\
\hline 57 & marfil & 0.02305 & $0.242 \%$ & $4.802 \%$ & $86.919 \%$ \\
\hline 58 & rojizo & 0.02132 & $0.171 \%$ & $3.390 \%$ & $87.090 \%$ \\
\hline 59 & marrón claro & 0.02073 & $0.185 \%$ & $3.672 \%$ & $87.275 \%$ \\
\hline 60 & (gris) marengo & 0.02033 & $0.171 \%$ & $3.390 \%$ & $87.446 \%$ \\
\hline 61 & fosforito & 0.02028 & $0.185 \%$ & $3.672 \%$ & $87.631 \%$ \\
\hline 62 & fluorescente & 0.02027 & $0.185 \%$ & $3.672 \%$ & $87.816 \%$ \\
\hline 63 & marrón oscuro & 0.01988 & $0.185 \%$ & $3.672 \%$ & $88.001 \%$ \\
\hline 64 & oscuro & 0.01974 & $0.171 \%$ & $3.390 \%$ & $88.172 \%$ \\
\hline 65 & verde pistacho & 0.01934 & $0.156 \%$ & $3.107 \%$ & $88.328 \%$ \\
\hline 66 & azul turquesa & 0.01932 & $0.156 \%$ & $3.107 \%$ & $88.484 \%$ \\
\hline 67 & escarlata & 0.01809 & $0.156 \%$ & $3.107 \%$ & $88.640 \%$ \\
\hline 68 & amarillo fosforito & 0.01807 & $0.171 \%$ & $3.390 \%$ & $88.811 \%$ \\
\hline 69 & cobrizo & 0.01780 & $0.185 \%$ & $3.672 \%$ & $88.996 \%$ \\
\hline 70 & azulado & 0.01737 & $0.142 \%$ & $2.825 \%$ & $89.138 \%$ \\
\hline 71 & azul mar & 0.01704 & $0.142 \%$ & $2.825 \%$ & $89.280 \%$ \\
\hline 72 & carmesí & 0.01658 & $0.128 \%$ & $2.542 \%$ & $89.408 \%$ \\
\hline 73 & verde fosforito & 0.01632 & $0.156 \%$ & $3.107 \%$ & $89.564 \%$ \\
\hline 74 & grisáceo & 0.01616 & $0.128 \%$ & $2.542 \%$ & $89.692 \%$ \\
\hline 75 & rojo claro & 0.01567 & $0.128 \%$ & $2.542 \%$ & $89.820 \%$ \\
\hline 76 & cian & 0.01566 & $0.128 \%$ & $2.542 \%$ & $89.948 \%$ \\
\hline 77 & amarillo chillón & 0.01550 & $0.142 \%$ & $2.825 \%$ & $90.090 \%$ \\
\hline 78 & limón & 0.01510 & $0.142 \%$ & $2.825 \%$ & $90.232 \%$ \\
\hline 79 & cobre & 0.01439 & $0.156 \%$ & $3.107 \%$ & $90.388 \%$ \\
\hline 80 & berenjena & 0.01437 & $0.128 \%$ & $2.542 \%$ & $90.516 \%$ \\
\hline 81 & verde oliva & 0.01417 & $0.142 \%$ & $2.825 \%$ & $90.658 \%$ \\
\hline 82 & fresa & 0.01386 & $0.114 \%$ & $2.260 \%$ & $90.772 \%$ \\
\hline 83 & claro & 0.01385 & $0.128 \%$ & $2.542 \%$ & $90.900 \%$ \\
\hline 84 & bronce & 0.01367 & $0.156 \%$ & $3.107 \%$ & $91.056 \%$ \\
\hline 85 & anaranjado & 0.01351 & $0.100 \%$ & $1.977 \%$ & $91.156 \%$ \\
\hline 86 & tierra & 0.01312 & $0.128 \%$ & $2.542 \%$ & $91.284 \%$ \\
\hline 87 & caca & 0.01311 & $0.128 \%$ & $2.542 \%$ & $91.412 \%$ \\
\hline 88 & pardo & 0.01302 & $0.114 \%$ & $2.260 \%$ & $91.526 \%$ \\
\hline 89 & amarillento & 0.01293 & $0.114 \%$ & $2.260 \%$ & $91.640 \%$ \\
\hline 90 & rosado & 0.01280 & $0.128 \%$ & $2.542 \%$ & $91.768 \%$ \\
\hline 91 & grana & 0.01274 & $0.100 \%$ & $1.977 \%$ & $91.868 \%$ \\
\hline 92 & azabache & 0.01250 & $0.100 \%$ & $1.977 \%$ & $91.968 \%$ \\
\hline
\end{tabular}




\begin{tabular}{|c|c|c|c|c|c|}
\hline 93 & rojo pasión & 0.01184 & $0.114 \%$ & $2.260 \%$ & $92.082 \%$ \\
\hline 94 & brillante & 0.01103 & $0.114 \%$ & $2.260 \%$ & $92.196 \%$ \\
\hline 95 & azul verde & 0.01101 & $0.071 \%$ & $1.412 \%$ & $92.267 \%$ \\
\hline 96 & azul pastel & 0.01100 & $0.100 \%$ & $1.977 \%$ & $92.367 \%$ \\
\hline 97 & verde militar & 0.01088 & $0.100 \%$ & $1.977 \%$ & $92.467 \%$ \\
\hline 98 & metalizado & 0.01079 & $0.100 \%$ & $1.977 \%$ & $92.567 \%$ \\
\hline 99 & azul eléctrico & 0.01019 & $0.085 \%$ & $1.695 \%$ & $92.652 \%$ \\
\hline 100 & fosforescente & 0.01018 & $0.100 \%$ & $1.977 \%$ & $92.752 \%$ \\
\hline 101 & rosa pálido & 0.01005 & $0.085 \%$ & $1.695 \%$ & $92.837 \%$ \\
\hline 102 & chillón & 0.00959 & $0.085 \%$ & $1.695 \%$ & $92.922 \%$ \\
\hline 103 & platino & 0.00946 & $0.085 \%$ & $1.695 \%$ & $93.007 \%$ \\
\hline 104 & rubio & 0.00942 & $0.100 \%$ & $1.977 \%$ & $93.107 \%$ \\
\hline 105 & rojo fuerte & 0.00937 & $0.085 \%$ & $1.695 \%$ & $93.192 \%$ \\
\hline 106 & verde fuerte & 0.00930 & $0.085 \%$ & $1.695 \%$ & $93.277 \%$ \\
\hline 107 & madera & 0.00903 & $0.100 \%$ & $1.977 \%$ & $93.377 \%$ \\
\hline 108 & miel & 0.00902 & $0.100 \%$ & $1.977 \%$ & $93.477 \%$ \\
\hline 109 & colorado & 0.00900 & $0.071 \%$ & $1.412 \%$ & $93.548 \%$ \\
\hline 110 & azul verdoso & 0.00890 & $0.071 \%$ & $1.412 \%$ & $93.619 \%$ \\
\hline 111 & mate & 0.00881 & $0.085 \%$ & $1.695 \%$ & $93.704 \%$ \\
\hline 112 & vainilla & 0.00836 & $0.071 \%$ & $1.412 \%$ & $93.775 \%$ \\
\hline 113 & verde esmeralda & 0.00836 & $0.071 \%$ & $1.412 \%$ & $93.846 \%$ \\
\hline 114 & vaquero & 0.00821 & $0.085 \%$ & $1.695 \%$ & $93.931 \%$ \\
\hline 115 & gris oscuro & 0.00814 & $0.085 \%$ & $1.695 \%$ & $94.016 \%$ \\
\hline 116 & azul fuerte & 0.00791 & $0.057 \%$ & $1.130 \%$ & $94.073 \%$ \\
\hline 117 & canela & 0.00774 & $0.071 \%$ & $1.412 \%$ & $94.144 \%$ \\
\hline 118 & verde pastel & 0.00773 & $0.057 \%$ & $1.130 \%$ & $94.201 \%$ \\
\hline 119 & (azul) pitufo & 0.00770 & $0.085 \%$ & $1.695 \%$ & $94.286 \%$ \\
\hline 120 & rosa fosforito & 0.00767 & $0.071 \%$ & $1.412 \%$ & $94.357 \%$ \\
\hline 121 & azul fosforito & 0.00753 & $0.071 \%$ & $1.412 \%$ & $94.428 \%$ \\
\hline 122 & teja & 0.00748 & $0.071 \%$ & $1.412 \%$ & $94.499 \%$ \\
\hline 123 & carbón & 0.00726 & $0.071 \%$ & $1.412 \%$ & $94.570 \%$ \\
\hline 124 & amarillo fosforescente & 0.00708 & $0.057 \%$ & $1.130 \%$ & $94.627 \%$ \\
\hline 125 & rubí & 0.00691 & $0.057 \%$ & $1.130 \%$ & $94.684 \%$ \\
\hline 126 & melocotón & 0.00688 & $0.071 \%$ & $1.412 \%$ & $94.755 \%$ \\
\hline 127 & cereza & 0.00666 & $0.071 \%$ & $1.412 \%$ & $94.826 \%$ \\
\hline 128 & butano & 0.00660 & $0.057 \%$ & $1.130 \%$ & $94.883 \%$ \\
\hline 129 & ceniza & 0.00648 & $0.057 \%$ & $1.130 \%$ & $94.940 \%$ \\
\hline 130 & rojo oscuro & 0.00636 & $0.043 \%$ & $0.847 \%$ & $94.983 \%$ \\
\hline 131 & rosa pastel & 0.00633 & $0.057 \%$ & $1.130 \%$ & $95.040 \%$ \\
\hline 132 & rojo chillón & 0.00631 & $0.071 \%$ & $1.412 \%$ & $95.111 \%$ \\
\hline 133 & metálico & 0.00631 & $0.057 \%$ & $1.130 \%$ & $95.168 \%$ \\
\hline 134 & ultravioleta & 0.00615 & $0.043 \%$ & $0.847 \%$ & $95.211 \%$ \\
\hline 135 & violáceo & 0.00614 & $0.043 \%$ & $0.847 \%$ & $95.254 \%$ \\
\hline 136 & cálido & 0.00605 & $0.043 \%$ & $0.847 \%$ & $95.297 \%$ \\
\hline 137 & apagado & 0.00594 & $0.043 \%$ & $0.847 \%$ & $95.340 \%$ \\
\hline 138 & frío & 0.00593 & $0.043 \%$ & $0.847 \%$ & $95.383 \%$ \\
\hline 139 & verde limón & 0.00591 & $0.043 \%$ & $0.847 \%$ & $95.426 \%$ \\
\hline
\end{tabular}




\begin{tabular}{|c|c|c|c|c|c|}
\hline 140 & verde manzana & 0.00585 & $0.057 \%$ & $1.130 \%$ & $95.483 \%$ \\
\hline 141 & gris perla & 0.00585 & $0.057 \%$ & $1.130 \%$ & $95.540 \%$ \\
\hline 142 & kiwi & 0.00571 & $0.057 \%$ & $1.130 \%$ & $95.597 \%$ \\
\hline 143 & rosa fucsia & 0.00557 & $0.043 \%$ & $0.847 \%$ & $95.640 \%$ \\
\hline 144 & fosfi & 0.00554 & $0.043 \%$ & $0.847 \%$ & $95.683 \%$ \\
\hline 145 & verde hierba & 0.00538 & $0.043 \%$ & $0.847 \%$ & $95.726 \%$ \\
\hline 146 & aguamarina & 0.00534 & $0.043 \%$ & $0.847 \%$ & $95.769 \%$ \\
\hline 147 & verde pino & 0.00529 & $0.043 \%$ & $0.847 \%$ & $95.812 \%$ \\
\hline 148 & terracota & 0.00516 & $0.043 \%$ & $0.847 \%$ & $95.855 \%$ \\
\hline 149 & siena & 0.00513 & $0.043 \%$ & $0.847 \%$ & $95.898 \%$ \\
\hline 150 & mierda & 0.00504 & $0.043 \%$ & $0.847 \%$ & $95.941 \%$ \\
\hline 151 & verdoso & 0.00503 & $0.043 \%$ & $0.847 \%$ & $95.984 \%$ \\
\hline 152 & opaco & 0.00500 & $0.043 \%$ & $0.847 \%$ & $96.027 \%$ \\
\hline 153 & verde turquesa & 0.00496 & $0.043 \%$ & $0.847 \%$ & $96.070 \%$ \\
\hline 154 & azul de metilo & 0.00495 & $0.028 \%$ & $0.565 \%$ & $96.098 \%$ \\
\hline 155 & nácar & 0.00489 & $0.043 \%$ & $0.847 \%$ & $96.141 \%$ \\
\hline 156 & naranja fosforito & 0.00486 & $0.043 \%$ & $0.847 \%$ & $96.184 \%$ \\
\hline 157 & vivo & 0.00483 & $0.043 \%$ & $0.847 \%$ & $96.227 \%$ \\
\hline 158 & marrón fuerte & 0.00478 & $0.043 \%$ & $0.847 \%$ & $96.270 \%$ \\
\hline 159 & verde mar & 0.00478 & $0.043 \%$ & $0.847 \%$ & $96.313 \%$ \\
\hline 160 & vino & 0.00469 & $0.043 \%$ & $0.847 \%$ & $96.356 \%$ \\
\hline 161 & verde fosfi & 0.00463 & $0.043 \%$ & $0.847 \%$ & $96.399 \%$ \\
\hline 162 & tejano & 0.00461 & $0.043 \%$ & $0.847 \%$ & $96.442 \%$ \\
\hline 163 & sepia & 0.00456 & $0.043 \%$ & $0.847 \%$ & $96.485 \%$ \\
\hline 164 & violín & 0.00456 & $0.043 \%$ & $0.847 \%$ & $96.528 \%$ \\
\hline 165 & verde chillón & 0.00452 & $0.043 \%$ & $0.847 \%$ & $96.571 \%$ \\
\hline 166 & bermejo & 0.00437 & $0.028 \%$ & $0.565 \%$ & $96.599 \%$ \\
\hline 167 & aceituna & 0.00434 & $0.028 \%$ & $0.565 \%$ & $96.627 \%$ \\
\hline 168 & cetrino & 0.00412 & $0.028 \%$ & $0.565 \%$ & $96.655 \%$ \\
\hline 169 & gris claro & 0.00401 & $0.043 \%$ & $0.847 \%$ & $96.698 \%$ \\
\hline 170 & negro azulado & 0.00396 & $0.043 \%$ & $0.847 \%$ & $96.741 \%$ \\
\hline 171 & infrarrojo & 0.00395 & $0.028 \%$ & $0.565 \%$ & $96.769 \%$ \\
\hline 172 & marrón caca & 0.00390 & $0.028 \%$ & $0.565 \%$ & $96.797 \%$ \\
\hline 173 & verde fluorescente & 0.00379 & $0.043 \%$ & $0.847 \%$ & $96.840 \%$ \\
\hline 174 & piedra & 0.00378 & $0.043 \%$ & $0.847 \%$ & $96.883 \%$ \\
\hline 175 & amarillo oro & 0.00369 & $0.028 \%$ & $0.565 \%$ & $96.911 \%$ \\
\hline 176 & cobalto & 0.00366 & $0.028 \%$ & $0.565 \%$ & $96.939 \%$ \\
\hline 177 & natural & 0.00366 & $0.043 \%$ & $0.847 \%$ & $96.982 \%$ \\
\hline 178 & rojo Ferrari* & 0.00349 & $0.028 \%$ & $0.565 \%$ & $97.010 \%$ \\
\hline 179 & rosa chillón & 0.00347 & $0.028 \%$ & $0.565 \%$ & $97.038 \%$ \\
\hline 180 & manzana & 0.00344 & $0.043 \%$ & $0.847 \%$ & $97.081 \%$ \\
\hline 181 & amarillo canario & 0.00340 & $0.028 \%$ & $0.565 \%$ & $97.109 \%$ \\
\hline 182 & perla & 0.00333 & $0.028 \%$ & $0.565 \%$ & $97.137 \%$ \\
\hline 183 & camel & 0.00328 & $0.028 \%$ & $0.565 \%$ & $97.165 \%$ \\
\hline 184 & amarillo fluorescente & 0.00324 & $0.043 \%$ & $0.847 \%$ & $97.208 \%$ \\
\hline 185 & carnoso & 0.00316 & $0.028 \%$ & $0.565 \%$ & $97.236 \%$ \\
\hline 186 & eléctrico & 0.00315 & $0.028 \%$ & $0.565 \%$ & $97.264 \%$ \\
\hline
\end{tabular}




\begin{tabular}{|c|c|c|c|c|c|}
\hline 187 & rojo burdeos & 0.00315 & $0.028 \%$ & $0.565 \%$ & $97.292 \%$ \\
\hline 188 & verde fosforescente & 0.00310 & $0.028 \%$ & $0.565 \%$ & $97.320 \%$ \\
\hline 189 & primario & 0.00310 & $0.028 \%$ & $0.565 \%$ & $97.348 \%$ \\
\hline 190 & champán & 0.00301 & $0.028 \%$ & $0.565 \%$ & $97.376 \%$ \\
\hline 191 & ciruela & 0.00300 & $0.028 \%$ & $0.565 \%$ & $97.404 \%$ \\
\hline 192 & incoloro & 0.00300 & $0.028 \%$ & $0.565 \%$ & $97.432 \%$ \\
\hline 193 & coral & 0.00300 & $0.028 \%$ & $0.565 \%$ & $97.460 \%$ \\
\hline 194 & secundario & 0.00298 & $0.028 \%$ & $0.565 \%$ & $97.488 \%$ \\
\hline 195 & azul metálico & 0.00298 & $0.028 \%$ & $0.565 \%$ & $97.516 \%$ \\
\hline 196 & verde caqui & 0.00295 & $0.028 \%$ & $0.565 \%$ & $97.544 \%$ \\
\hline 197 & amarillo fosfi & 0.00285 & $0.028 \%$ & $0.565 \%$ & $97.572 \%$ \\
\hline 198 & pimienta & 0.00282 & $0.028 \%$ & $0.565 \%$ & $97.600 \%$ \\
\hline 199 & fuerte & 0.00282 & $0.014 \%$ & $0.282 \%$ & $97.614 \%$ \\
\hline 200 & rojo sangre & 0.00279 & $0.028 \%$ & $0.565 \%$ & $97.642 \%$ \\
\hline 201 & color militar & 0.00275 & $0.028 \%$ & $0.565 \%$ & $97.670 \%$ \\
\hline 202 & café & 0.00271 & $0.028 \%$ & $0.565 \%$ & $97.698 \%$ \\
\hline 203 & piel & 0.00271 & $0.028 \%$ & $0.565 \%$ & $97.726 \%$ \\
\hline 204 & gris azulado & 0.00271 & $0.028 \%$ & $0.565 \%$ & $97.754 \%$ \\
\hline 205 & negro brillante & 0.00271 & $0.028 \%$ & $0.565 \%$ & $97.782 \%$ \\
\hline 206 & huevo & 0.00266 & $0.028 \%$ & $0.565 \%$ & $97.810 \%$ \\
\hline 207 & plástico & 0.00259 & $0.028 \%$ & $0.565 \%$ & $97.838 \%$ \\
\hline 208 & verde marrón & 0.00252 & $0.014 \%$ & $0.282 \%$ & $97.852 \%$ \\
\hline 209 & muerto & 0.00252 & $0.014 \%$ & $0.282 \%$ & $97.866 \%$ \\
\hline 210 & chocolate & 0.00249 & $0.028 \%$ & $0.565 \%$ & $97.894 \%$ \\
\hline 211 & negro zaino & 0.00248 & $0.028 \%$ & $0.565 \%$ & $97.922 \%$ \\
\hline 212 & lapislázuli & 0.00243 & $0.014 \%$ & $0.282 \%$ & $97.936 \%$ \\
\hline 213 & merengue & 0.00243 & $0.014 \%$ & $0.282 \%$ & $97.950 \%$ \\
\hline 214 & albo & 0.00243 & $0.014 \%$ & $0.282 \%$ & $97.964 \%$ \\
\hline 215 & llamativo & 0.00243 & $0.014 \%$ & $0.282 \%$ & $97.978 \%$ \\
\hline 216 & verde monte & 0.00239 & $0.028 \%$ & $0.565 \%$ & $98.006 \%$ \\
\hline 217 & azul ultramar & 0.00230 & $0.028 \%$ & $0.565 \%$ & $98.034 \%$ \\
\hline 218 & verde esperanza & 0.00225 & $0.014 \%$ & $0.282 \%$ & $98.048 \%$ \\
\hline 219 & malta & 0.00225 & $0.014 \%$ & $0.282 \%$ & $98.062 \%$ \\
\hline 220 & verde lechuga & 0.00225 & $0.014 \%$ & $0.282 \%$ & $98.076 \%$ \\
\hline 221 & rojo carmín & 0.00221 & $0.028 \%$ & $0.565 \%$ & $98.104 \%$ \\
\hline 222 & pelirrojo & 0.00220 & $0.028 \%$ & $0.565 \%$ & $98.132 \%$ \\
\hline 223 & amatista & 0.00217 & $0.014 \%$ & $0.282 \%$ & $98.146 \%$ \\
\hline 224 & amarillo cadmio claro & 0.00217 & $0.014 \%$ & $0.282 \%$ & $98.160 \%$ \\
\hline 225 & ultramar & 0.00217 & $0.014 \%$ & $0.282 \%$ & $98.174 \%$ \\
\hline 226 & amarillo pálido & 0.00217 & $0.014 \%$ & $0.282 \%$ & $98.188 \%$ \\
\hline 227 & amarillo anaranjado & 0.00217 & $0.014 \%$ & $0.282 \%$ & $98.202 \%$ \\
\hline 228 & verde pálido & 0.00217 & $0.014 \%$ & $0.282 \%$ & $98.216 \%$ \\
\hline 229 & carmín claro & 0.00209 & $0.014 \%$ & $0.282 \%$ & $98.230 \%$ \\
\hline 230 & rojo azulado & 0.00209 & $0.014 \%$ & $0.282 \%$ & $98.244 \%$ \\
\hline 231 & lima & 0.00202 & $0.028 \%$ & $0.565 \%$ & $98.272 \%$ \\
\hline 232 & azul de bolígrafo & 0.00201 & $0.014 \%$ & $0.282 \%$ & $98.286 \%$ \\
\hline 233 & carmín oscuro & 0.00201 & $0.014 \%$ & $0.282 \%$ & $98.300 \%$ \\
\hline
\end{tabular}




\begin{tabular}{|c|c|c|c|c|c|}
\hline 234 & rojo amarillento & 0.00201 & $0.014 \%$ & $0.282 \%$ & $98.314 \%$ \\
\hline 235 & bronceado & 0.00200 & $0.028 \%$ & $0.565 \%$ & $98.342 \%$ \\
\hline 236 & rojo fucsia & 0.00194 & $0.014 \%$ & $0.282 \%$ & $98.356 \%$ \\
\hline 237 & rojo anaranjado & 0.00194 & $0.014 \%$ & $0.282 \%$ & $98.370 \%$ \\
\hline 238 & rojo magenta & 0.00194 & $0.014 \%$ & $0.282 \%$ & $98.384 \%$ \\
\hline 239 & enrogit & 0.00194 & $0.014 \%$ & $0.282 \%$ & $98.398 \%$ \\
\hline 240 & rojo tomate & 0.00187 & $0.014 \%$ & $0.282 \%$ & $98.412 \%$ \\
\hline 241 & rosa fosfi & 0.00187 & $0.014 \%$ & $0.282 \%$ & $98.426 \%$ \\
\hline 242 & violeta verdoso & 0.00187 & $0.014 \%$ & $0.282 \%$ & $98.440 \%$ \\
\hline 243 & alegre & 0.00187 & $0.014 \%$ & $0.282 \%$ & $98.454 \%$ \\
\hline 244 & gris metálico & 0.00180 & $0.014 \%$ & $0.282 \%$ & $98.468 \%$ \\
\hline 245 & metacrilato & 0.00180 & $0.014 \%$ & $0.282 \%$ & $98.482 \%$ \\
\hline 246 & rojo apagado & 0.00180 & $0.014 \%$ & $0.282 \%$ & $98.496 \%$ \\
\hline 247 & cristal & 0.00179 & $0.028 \%$ & $0.565 \%$ & $98.524 \%$ \\
\hline 248 & azul pálido & 0.00173 & $0.014 \%$ & $0.282 \%$ & $98.538 \%$ \\
\hline 249 & marrón salvaje & 0.00173 & $0.014 \%$ & $0.282 \%$ & $98.552 \%$ \\
\hline 250 & gris metalizado & 0.00173 & $0.014 \%$ & $0.282 \%$ & $98.566 \%$ \\
\hline 251 & naranja butano & 0.00173 & $0.014 \%$ & $0.282 \%$ & $98.580 \%$ \\
\hline 252 & rosa pasión & 0.00173 & $0.014 \%$ & $0.282 \%$ & $98.594 \%$ \\
\hline 253 & rojo violín & 0.00173 & $0.014 \%$ & $0.282 \%$ & $98.608 \%$ \\
\hline 254 & descolorido & 0.00173 & $0.014 \%$ & $0.282 \%$ & $98.622 \%$ \\
\hline 255 & diamante & 0.00173 & $0.014 \%$ & $0.282 \%$ & $98.636 \%$ \\
\hline 256 & cristalino & 0.00173 & $0.014 \%$ & $0.282 \%$ & $98.650 \%$ \\
\hline 257 & anaranjado de metilo & 0.00173 & $0.014 \%$ & $0.282 \%$ & $98.664 \%$ \\
\hline 258 & tabaco & 0.00173 & $0.014 \%$ & $0.282 \%$ & $98.678 \%$ \\
\hline 259 & azul cian & 0.00167 & $0.014 \%$ & $0.282 \%$ & $98.692 \%$ \\
\hline 260 & verde cobrizo & 0.00167 & $0.014 \%$ & $0.282 \%$ & $98.706 \%$ \\
\hline 261 & blanco perla & 0.00167 & $0.014 \%$ & $0.282 \%$ & $98.720 \%$ \\
\hline 262 & grosella & 0.00167 & $0.014 \%$ & $0.282 \%$ & $98.734 \%$ \\
\hline 263 & cristalizado & 0.00160 & $0.014 \%$ & $0.282 \%$ & $98.748 \%$ \\
\hline 264 & acido & 0.00160 & $0.014 \%$ & $0.282 \%$ & $98.762 \%$ \\
\hline 265 & amarillo verdoso & 0.00160 & $0.014 \%$ & $0.282 \%$ & $98.776 \%$ \\
\hline 266 & amarillo plátano & 0.00160 & $0.014 \%$ & $0.282 \%$ & $98.790 \%$ \\
\hline 267 & rosa claro & 0.00160 & $0.014 \%$ & $0.282 \%$ & $98.804 \%$ \\
\hline 268 & siena oscuro & 0.00160 & $0.014 \%$ & $0.282 \%$ & $98.818 \%$ \\
\hline 269 & azul noche & 0.00160 & $0.014 \%$ & $0.282 \%$ & $98.832 \%$ \\
\hline 270 & rojo caoba & 0.00160 & $0.014 \%$ & $0.282 \%$ & $98.846 \%$ \\
\hline 271 & ópalo & 0.00160 & $0.014 \%$ & $0.282 \%$ & $98.860 \%$ \\
\hline 272 & blanco azulado & 0.00155 & $0.014 \%$ & $0.282 \%$ & $98.874 \%$ \\
\hline 273 & niquelado & 0.00155 & $0.014 \%$ & $0.282 \%$ & $98.888 \%$ \\
\hline 274 & violeta oscuro & 0.00155 & $0.014 \%$ & $0.282 \%$ & $98.902 \%$ \\
\hline 275 & siena claro & 0.00155 & $0.014 \%$ & $0.282 \%$ & $98.916 \%$ \\
\hline 276 & verde alga & 0.00155 & $0.014 \%$ & $0.282 \%$ & $98.930 \%$ \\
\hline 277 & rojo de metilo & 0.00155 & $0.014 \%$ & $0.282 \%$ & $98.944 \%$ \\
\hline 278 & áureo & 0.00155 & $0.014 \%$ & $0.282 \%$ & $98.958 \%$ \\
\hline 279 & ennegrecido & 0.00155 & $0.014 \%$ & $0.282 \%$ & $98.972 \%$ \\
\hline 280 & carabassa & 0.00155 & $0.014 \%$ & $0.282 \%$ & $98.986 \%$ \\
\hline
\end{tabular}




\begin{tabular}{|c|c|c|c|c|c|}
\hline 281 & visón & 0.00149 & $0.014 \%$ & $0.282 \%$ & $99.000 \%$ \\
\hline 282 & violeta pastel & 0.00149 & $0.014 \%$ & $0.282 \%$ & $99.014 \%$ \\
\hline 283 & rojo láser & 0.00149 & $0.014 \%$ & $0.282 \%$ & $99.028 \%$ \\
\hline 284 & verde césped & 0.00149 & $0.014 \%$ & $0.282 \%$ & $99.042 \%$ \\
\hline 285 & caldera & 0.00149 & $0.014 \%$ & $0.282 \%$ & $99.056 \%$ \\
\hline 286 & verde rama & 0.00149 & $0.014 \%$ & $0.282 \%$ & $99.070 \%$ \\
\hline 287 & blanco roto & 0.00149 & $0.014 \%$ & $0.282 \%$ & $99.084 \%$ \\
\hline 288 & aluminio & 0.00149 & $0.014 \%$ & $0.282 \%$ & $99.098 \%$ \\
\hline 289 & pálido & 0.00143 & $0.014 \%$ & $0.282 \%$ & $99.112 \%$ \\
\hline 290 & coco & 0.00143 & $0.014 \%$ & $0.282 \%$ & $99.126 \%$ \\
\hline 291 & rubio oro & 0.00143 & $0.014 \%$ & $0.282 \%$ & $99.140 \%$ \\
\hline 292 & naranja cítrico & 0.00143 & $0.014 \%$ & $0.282 \%$ & $99.154 \%$ \\
\hline 293 & verde agua & 0.00143 & $0.014 \%$ & $0.282 \%$ & $99.168 \%$ \\
\hline 294 & nata & 0.00143 & $0.014 \%$ & $0.282 \%$ & $99.182 \%$ \\
\hline 295 & azulgrana & 0.00138 & $0.014 \%$ & $0.282 \%$ & $99.196 \%$ \\
\hline 296 & verde kiwi & 0.00138 & $0.014 \%$ & $0.282 \%$ & $99.210 \%$ \\
\hline 297 & verde vivo & 0.00138 & $0.014 \%$ & $0.282 \%$ & $99.224 \%$ \\
\hline 298 & gris fuerte & 0.00138 & $0.014 \%$ & $0.282 \%$ & $99.238 \%$ \\
\hline 299 & irisado & 0.00138 & $0.014 \%$ & $0.282 \%$ & $99.252 \%$ \\
\hline 300 & verde moco & 0.00138 & $0.014 \%$ & $0.282 \%$ & $99.266 \%$ \\
\hline 301 & verde metalizado & 0.00138 & $0.014 \%$ & $0.282 \%$ & $99.280 \%$ \\
\hline 302 & rosa blanquecino & 0.00138 & $0.014 \%$ & $0.282 \%$ & $99.294 \%$ \\
\hline 303 & naranja fosforescente & 0.00138 & $0.014 \%$ & $0.282 \%$ & $99.308 \%$ \\
\hline 304 & blanqueado & 0.00133 & $0.014 \%$ & $0.282 \%$ & $99.322 \%$ \\
\hline 305 & negro fosforito & 0.00133 & $0.014 \%$ & $0.282 \%$ & $99.336 \%$ \\
\hline 306 & azul metalizado & 0.00133 & $0.014 \%$ & $0.282 \%$ & $99.350 \%$ \\
\hline 307 & violeta anaranjado & 0.00133 & $0.014 \%$ & $0.282 \%$ & $99.364 \%$ \\
\hline 308 & azul laguna & 0.00133 & $0.014 \%$ & $0.282 \%$ & $99.378 \%$ \\
\hline 309 & azul vaquero & 0.00128 & $0.014 \%$ & $0.282 \%$ & $99.392 \%$ \\
\hline 310 & azul fosforescente & 0.00128 & $0.014 \%$ & $0.282 \%$ & $99.406 \%$ \\
\hline 311 & rojo verdeado & 0.00128 & $0.014 \%$ & $0.282 \%$ & $99.420 \%$ \\
\hline 312 & rosa intenso & 0.00128 & $0.014 \%$ & $0.282 \%$ & $99.434 \%$ \\
\hline 313 & sangre & 0.00123 & $0.014 \%$ & $0.282 \%$ & $99.448 \%$ \\
\hline 314 & color metal & 0.00123 & $0.014 \%$ & $0.282 \%$ & $99.462 \%$ \\
\hline 315 & fucsia fosforito & 0.00123 & $0.014 \%$ & $0.282 \%$ & $99.476 \%$ \\
\hline 316 & gris plata & 0.00123 & $0.014 \%$ & $0.282 \%$ & $99.490 \%$ \\
\hline 317 & marrón tierra & 0.00123 & $0.014 \%$ & $0.282 \%$ & $99.504 \%$ \\
\hline 318 & azul sombreado & 0.00123 & $0.014 \%$ & $0.282 \%$ & $99.518 \%$ \\
\hline 319 & verde amarillo & 0.00123 & $0.014 \%$ & $0.282 \%$ & $99.532 \%$ \\
\hline 320 & verde sapo & 0.00119 & $0.014 \%$ & $0.282 \%$ & $99.546 \%$ \\
\hline 321 & azul chillón & 0.00119 & $0.014 \%$ & $0.282 \%$ & $99.560 \%$ \\
\hline 322 & rojo fluorescente & 0.00119 & $0.014 \%$ & $0.282 \%$ & $99.574 \%$ \\
\hline 323 & rojo metalizado & 0.00119 & $0.014 \%$ & $0.282 \%$ & $99.588 \%$ \\
\hline 324 & color membrillo & 0.00114 & $0.014 \%$ & $0.282 \%$ & $99.602 \%$ \\
\hline 325 & violeta fluorescente & 0.00114 & $0.014 \%$ & $0.282 \%$ & $99.616 \%$ \\
\hline 326 & azul fosfi & 0.00114 & $0.014 \%$ & $0.282 \%$ & $99.630 \%$ \\
\hline 327 & verde amarillento & 0.00114 & $0.014 \%$ & $0.282 \%$ & $99.644 \%$ \\
\hline
\end{tabular}




\begin{tabular}{|l|l|l|l|l|l|}
\hline 328 & frambuesa & 0.00110 & $0.014 \%$ & $0.282 \%$ & $99.658 \%$ \\
\hline 329 & berenjena rojo & 0.00110 & $0.014 \%$ & $0.282 \%$ & $99.672 \%$ \\
\hline 330 & óxido & 0.00110 & $0.014 \%$ & $0.282 \%$ & $99.686 \%$ \\
\hline 331 & rojo intenso & 0.00110 & $0.014 \%$ & $0.282 \%$ & $99.700 \%$ \\
\hline 332 & rojo amoratado & 0.00110 & $0.014 \%$ & $0.282 \%$ & $99.714 \%$ \\
\hline 333 & morado pastel & 0.00110 & $0.014 \%$ & $0.282 \%$ & $99.728 \%$ \\
\hline 334 & rosa chicle & 0.00110 & $0.014 \%$ & $0.282 \%$ & $99.742 \%$ \\
\hline 335 & pizarra & 0.00106 & $0.014 \%$ & $0.282 \%$ & $99.756 \%$ \\
\hline 336 & artificial & 0.00106 & $0.014 \%$ & $0.282 \%$ & $99.770 \%$ \\
\hline 337 & azul intenso & 0.00106 & $0.014 \%$ & $0.282 \%$ & $99.784 \%$ \\
\hline 338 & ciruela rojo & 0.00106 & $0.014 \%$ & $0.282 \%$ & $99.798 \%$ \\
\hline 339 & rojo pálido & 0.00106 & $0.014 \%$ & $0.282 \%$ & $99.812 \%$ \\
\hline 340 & oliva & 0.00106 & $0.014 \%$ & $0.282 \%$ & $99.826 \%$ \\
\hline 341 & color paja & 0.00106 & $0.014 \%$ & $0.282 \%$ & $99.840 \%$ \\
\hline 342 & topacio & 0.00098 & $0.014 \%$ & $0.282 \%$ & $99.854 \%$ \\
\hline 343 & verde guerra & 0.00095 & $0.014 \%$ & $0.282 \%$ & $99.868 \%$ \\
\hline 344 & color petróleo & 0.00075 & $0.014 \%$ & $0.282 \%$ & $99.882 \%$ \\
\hline 345 & rosa fluorescente & 0.00070 & $0.014 \%$ & $0.282 \%$ & $99.896 \%$ \\
\hline 346 & azul fluorescente & 0.00063 & $0.014 \%$ & $0.282 \%$ & $99.910 \%$ \\
\hline 347 & moreno & 0.00038 & $0.014 \%$ & $0.282 \%$ & $99.924 \%$ \\
\hline 348 & color caña & 0.00034 & $0.014 \%$ & $0.282 \%$ & $99.938 \%$ \\
\hline 349 & café oscuro & 0.00033 & $0.014 \%$ & $0.282 \%$ & $99.952 \%$ \\
\hline 350 & color suave & 0.00029 & $0.014 \%$ & $0.282 \%$ & $99.966 \%$ \\
\hline
\end{tabular}




\subsection{Tablas de los anglicismos}

\section{Partes del cuerpo}

No se dan anglicismos

\section{La ropa}

\begin{tabular}{|c|l|c|c|c|c|}
\hline $\mathrm{N}^{\mathrm{o}}$ & Palabra & Disponibilidad & $\begin{array}{c}\text { Frecuencia } \\
\text { relativa }\end{array}$ & Aparición & $\begin{array}{c}\text { Frecuencia } \\
\text { acumulada }\end{array}$ \\
\hline 7 & jersey & & & & \\
\hline 19 & suéter & 0.45409 & $2.817 \%$ & $64.407 \%$ & $24.534 \%$ \\
\hline 20 & sudadera & 0.18791 & $1.235 \%$ & $28.249 \%$ & $51.402 \%$ \\
\hline 26 & bermudas & 0.17789 & $1.470 \%$ & $33.616 \%$ & $52.872 \%$ \\
\hline 30 & pijama & 0.13066 & $1.149 \%$ & $26.271 \%$ & $60.754 \%$ \\
\hline 32 & biquini & 0.11674 & $1.371 \%$ & $31.356 \%$ & $65.756 \%$ \\
\hline 36 & polo & 0.10512 & $1.186 \%$ & $27.119 \%$ & $67.868 \%$ \\
\hline 37 & top & 0.09280 & $0.741 \%$ & $16.949 \%$ & $71.537 \%$ \\
\hline 39 & anorak & 0.08766 & $0.828 \%$ & $18.927 \%$ & $72.365 \%$ \\
\hline 40 & minifalda & 0.08406 & $0.815 \%$ & $18.644 \%$ & $73.884 \%$ \\
\hline 41 & short & 0.08235 & $0.729 \%$ & $16.667 \%$ & $74.613 \%$ \\
\hline 48 & body ${ }^{230}$ & 0.08232 & $0.754 \%$ & $17.232 \%$ & $75.367 \%$ \\
\hline 51 & panty & 0.06509 & $0.704 \%$ & $16.102 \%$ & $80.691 \%$ \\
\hline 65 & slip & 0.05273 & $0.506 \%$ & $11.582 \%$ & $82.334 \%$ \\
\hline 73 & esmoquin & 0.03115 & $0.247 \%$ & $5.650 \%$ & $87.732 \%$ \\
\hline 91 & parka ${ }^{231}$ & 0.02146 & $0.247 \%$ & $5.650 \%$ & $89.708 \%$ \\
\hline 94 & pareo & 0.01390 & $0.148 \%$ & $3.390 \%$ & $92.662 \%$ \\
\hline 112 & bóxer & 0.01351 & $0.161 \%$ & $3.672 \%$ & $93.107 \%$ \\
\hline 113 & jeans & 0.00807 & $0.074 \%$ & $1.695 \%$ & $95.060 \%$ \\
\hline 107 & mocasín & 0.00734 & $0.037 \%$ & $0.847 \%$ & $95.097 \%$ \\
\hline 208 & Wonderbra*232 & 0.00884 & $0.099 \%$ & $2.260 \%$ & $94.653 \%$ \\
\hline 209 & leggings & 0.00196 & $0.025 \%$ & $0.565 \%$ & $98.570 \%$ \\
\hline 213 & nailon & 0.00193 & $0.012 \%$ & $0.282 \%$ & $98.582 \%$ \\
\hline 229 & blazer & 0.00181 & $0.012 \%$ & $0.282 \%$ & $98.643 \%$ \\
\hline 235 & pulóver & 0.00149 & $0.012 \%$ & $0.282 \%$ & $98.913 \%$ \\
\hline 268 & canguro & 0.00123 & $0.012 \%$ & $0.282 \%$ & $98.998 \%$ \\
\hline 275 & cárdigan & 0.00102 & $0.012 \%$ & $0.282 \%$ & $99.420 \%$ \\
\hline 288 & poliéster & 0.00095 & $0.012 \%$ & $0.282 \%$ & $99.504 \%$ \\
\hline & 0.00079 & $0.012 \%$ & $0.282 \%$ & $99.673 \%$ \\
\hline
\end{tabular}

\footnotetext{
${ }^{228}$ Jersey aparece modificado en otras entradas, cada una con un solo empleo, como: "jersey de cuello alto", jersey grueso", "jersey de manga corta" y "jersey de lana".

${ }^{229}$ Este vocablo está recogido como anglicismo por Pratt (1980) y Lorenzo (1996). Este último apunta que es un término de difícil vía de penetración. Procede de otras lenguas pero quien lo ha expandido es el inglés. El Diccionario académico en su vigésima tercera edición dice que es de origen francés y este de origen esquimal.

${ }^{230}$ La palabra body viene matizada por "body interior" y body deportivo", con un uso cada uno.

${ }^{231}$ Lexema de difícil situación por parte de los investigadores. Mientras Lorenzo y Bartol sí lo cuentan entre los anglicismos puesto que el uso proviene del inglés, Alfaro y Gómez Capuz no.. La Real Academia , por su parte, dice que procede del ruso y este del samoyedo.

${ }^{232}$ Marca registrada que se utiliza para todo tipo de sujetador que eleva el pecho.
} 
0.3. Partes de la casa (sin los muebles)

\begin{tabular}{|c|c|c|c|c|c|}
\hline $\mathrm{N}^{\mathrm{o}}$ & Palabra & Disponibilidad & $\begin{array}{c}\text { Frecuencia } \\
\text { relativa }\end{array}$ & \% Aparición & $\begin{array}{l}\text { Frecuencia } \\
\text { acumulada }\end{array}$ \\
\hline 28 & hall & 0.09356 & $0.881 \%$ & $14.689 \%$ & $71.665 \%$ \\
\hline 38 & váter $^{233}$ & 0.05345 & $0.508 \%$ & $8.475 \%$ & $79.506 \%$ \\
\hline 63 & WC & 0.01826 & $0.152 \%$ & $2.542 \%$ & $88.364 \%$ \\
\hline 84 & office & 0.01049 & $0.102 \%$ & $1.695 \%$ & $92.138 \%$ \\
\hline 93 & pista de tenis ${ }^{234}$ & 0.00886 & $0.136 \%$ & $2.260 \%$ & $93.124 \%$ \\
\hline 97 & solárium & 0.00812 & $0.119 \%$ & $1.977 \%$ & $93.515 \%$ \\
\hline 171 & Portland* ${ }^{235}$ & 0.00242 & $0.034 \%$ & $0.565 \%$ & $97.255 \%$ \\
\hline 162 & Jacuzzi $*^{236}$ & 0.00261 & $0.034 \%$ & $0.565 \%$ & $97.017 \%$ \\
\hline 217 & sala de ping-pong & 0.00156 & $0.017 \%$ & $0.282 \%$ & $98.394 \%$ \\
\hline 219 & bar & 0.00156 & $0.017 \%$ & $0.282 \%$ & $98.428 \%$ \\
\hline 231 & pista de básquet & 0.00127 & $0.051 \%$ & $0.847 \%$ & $98.700 \%$ \\
\hline 232 & parking & 0.00125 & $0.017 \%$ & $0.282 \%$ & $98.717 \%$ \\
\hline 237 & minigolf & 0.00117 & $0.051 \%$ & $0.847 \%$ & $98.836 \%$ \\
\hline 250 & sala de TV & 0.00108 & $0.017 \%$ & $0.282 \%$ & $99.057 \%$ \\
\hline 276 & sala de televisión & 0.00086 & $0.017 \%$ & $0.282 \%$ & $99.499 \%$ \\
\hline
\end{tabular}

\subsection{Los muebles de la casa}

\begin{tabular}{|c|c|c|c|c|c|}
\hline $\mathrm{N}^{\circ}$ & Palabra & Disponibilidad & $\begin{array}{l}\text { Frecuencia } \\
\text { relativa }\end{array}$ & \% Aparición & $\begin{array}{l}\text { Frecuencia } \\
\text { acumulada }\end{array}$ \\
\hline 22 & mueble bar & 0.06909 & $0.895 \%$ & $12.994 \%$ & $65.129 \%$ \\
\hline 25 & tele(visión) ${ }^{237}$ & 0.06564 & $0.681 \%$ & $9.887 \%$ & $67.560 \%$ \\
\hline 38 & microondas & 0.04059 & $0.525 \%$ & $7.627 \%$ & $76.252 \%$ \\
\hline 61 & váter $^{238}$ & 0.02113 & $0.311 \%$ & $4.520 \%$ & $84.907 \%$ \\
\hline 68 & vídeo & 0.01793 & $0.214 \%$ & $3.107 \%$ & $86.501 \%$ \\
\hline 145 & mueble HI-FI & 0.00338 & $0.058 \%$ & $0.847 \%$ & $96.044 \%$ \\
\hline 150 & mesa de TV ${ }^{239}$ & 0.00320 & $0.039 \%$ & $0.565 \%$ & $96.239 \%$ \\
\hline 164 & bar & 0.00267 & $0.039 \%$ & $0.565 \%$ & $96.860 \%$ \\
\hline 194 & láser disk & 0.00210 & $0.019 \%$ & $0.282 \%$ & $97.689 \%$ \\
\hline 253 & WC & 0.00125 & $0.019 \%$ & $0.282 \%$ & $98.970 \%$ \\
\hline 259 & videoteca & 0.00116 & $0.019 \%$ & $0.282 \%$ & $99.104 \%$ \\
\hline 276 & sandwichera & 0.00086 & $0.019 \%$ & $0.282 \%$ & $99.427 \%$ \\
\hline 288 & videoconsola & 0.00080 & $0.019 \%$ & $0.282 \%$ & $99.655 \%$ \\
\hline
\end{tabular}

\footnotetext{
${ }^{233}$ El vocablo váter tiene otro empleo en "váter pequeño".

${ }^{234}$ Asimismo la unidad léxica tenis aparece en la lexía compleja "cancha de tenis"

${ }^{235}$ El DRAE anota que es un cemento hidráulico llamado de esta manera por su color, semejante al de la piedra de las canteras inglesas de Pórtland.

${ }^{236}$ Este vocablo es una marca registrada, recogida en la última edición del diccionario de la Academia (vigésima tercera edición) y también por Lorenzo (1996).

237 Este lexema aparece en los sintagmas "mueble de televisión" con un alto índice disponibildad (0.02310), “mesa de televisión" y" mesita de televisión"

${ }^{238}$ Váter está contenido en otros dos sintagmas: "taza de váter" (un empleo) y "mueble de váter" (un uso).

${ }^{239}$ En los listados de este centro de interés se registra "mueble de TV".
} 


\subsection{Alimentos y bebidas ${ }^{240}$}

\begin{tabular}{|c|l|c|c|c|c|}
\hline $\mathrm{N}^{\mathrm{o}}$ & Palabra & Disponibilidad & $\begin{array}{c}\text { Frecuencia } \\
\text { relativa }\end{array}$ & Aparición & $\begin{array}{c}\text { Frecuencia } \\
\text { acumulada }\end{array}$ \\
\hline 3 & whisky & & & \\
\hline 39 & hamburguesa & 0.36806 & $2.093 \%$ & $55.650 \%$ & $7.587 \%$ \\
\hline 49 & ron $^{242}$ & 0.09205 & $0.744 \%$ & $19.774 \%$ & $49.315 \%$ \\
\hline 74 & kiwi $^{243}$ & 0.07609 & $0.478 \%$ & $12.712 \%$ & $55.679 \%$ \\
\hline 77 & jamón de York & 0.04914 & $0.425 \%$ & $11.299 \%$ & $67.196 \%$ \\
\hline 156 & sándwich & 0.04751 & $0.404 \%$ & $10.734 \%$ & $68.376 \%$ \\
\hline 157 & brandy & 0.01680 & $0.128 \%$ & $3.390 \%$ & $85.497 \%$ \\
\hline 172 & beicon & 0.01659 & $0.138 \%$ & $3.672 \%$ & $85.635 \%$ \\
\hline 178 & ponche & 0.01412 & $0.106 \%$ & $2.825 \%$ & $87.431 \%$ \\
\hline 204 & pomelo & 0.01296 & $0.096 \%$ & $2.542 \%$ & $88.122 \%$ \\
\hline 244 & kétchup & 0.00906 & $0.085 \%$ & $2.260 \%$ & $90.546 \%$ \\
\hline 254 & chóped & 0.00679 & $0.053 \%$ & $1.412 \%$ & $93.139 \%$ \\
\hline 299 & bourbon & 0.00588 & $0.064 \%$ & $1.695 \%$ & $93.639 \%$ \\
\hline 331 & frankfurt & 0.00395 & $0.021 \%$ & $0.565 \%$ & $95.389 \%$ \\
\hline 381 & gin & 0.00317 & $0.032 \%$ & $0.847 \%$ & $96.279 \%$ \\
\hline 414 & bistec & 0.00224 & $0.011 \%$ & $0.282 \%$ & $97.197 \%$ \\
\hline 418 & mango & 0.00189 & $0.011 \%$ & $0.282 \%$ & $97.702 \%$ \\
\hline 456 & rosbif & 0.00184 & $0.021 \%$ & $0.565 \%$ & $97.766 \%$ \\
\hline 459 & ginseng & 0.00142 & $0.011 \%$ & $0.282 \%$ & $98.315 \%$ \\
\hline 475 & perrito & 0.00142 & $0.011 \%$ & $0.282 \%$ & $98.348 \%$ \\
\hline 508 & pudin & 0.00134 & $0.011 \%$ & $0.282 \%$ & $98.584 \%$ \\
\hline & & 0.00113 & $0.011 \%$ & $0.282 \%$ & $98.977 \%$ \\
\hline
\end{tabular}

\subsection{Objetos colocados en la mesa para comer}

\begin{tabular}{|c|l|c|c|c|c|}
\hline $\mathrm{N}^{\mathrm{o}}$ & Palabra & Disponibilidad & $\begin{array}{c}\text { Frecuencia } \\
\text { relativa }\end{array}$ & Aparición & $\begin{array}{c}\text { Frecuencia } \\
\text { acumulada }\end{array}$ \\
\hline 65 & bol & 0.01794 & $0.303 \%$ & $4.520 \%$ & $86.068 \%$ \\
\hline 80 & mando de tele(visión) & 0.01252 & $0.177 \%$ & $2.581 \%$ & $90.359 \%$ \\
\hline 143 & kétchup & 0.00395 & $0.038 \%$ & $0.565 \%$ & $95.726 \%$ \\
\hline 285 & mando del vídeo & 0.00096 & $0.019 \%$ & $0.282 \%$ & $99.412 \%$ \\
\hline
\end{tabular}

\footnotetext{
${ }^{240}$ No hemos recogido Coca-cola* en el cómputo de anglicismo porque la mayoría de autores consultados no lo hacen. Sí lo incluye Gómez Capuz(2000: 90), reconociendo que es una marca registrada de procedencia norteamericana pero que revela una "perfecta aclimatación de este anglicismo a la vida española", nosotros diríamos que al resto del mundo. Hay que decir que en el Léxico disponible de Castellón ocupa el cuarto lugar con un índice de disponibilidad de 0.34356 y con un empleo de 163 informantes. Lorenzo (1996) lo admitiría pero no está recogido en Pratt (1980).

${ }^{241}$ En los listados castellonenses encontramos también la entrada "crema de whisky", con dos empleos.

${ }^{242}$ Hallamos la especificación "ron blanco" y "ron negro" con un uso cada uno.

${ }^{243}$ Kiwi aparece también en la lexía compleja "licor de kiwi" con un solo empleo.
} 
07. La cocina y sus utensilios

\begin{tabular}{|c|l|c|c|c|c|}
\hline $\mathrm{N}^{\mathbf{o}}$ & Palabra & Disponibilidad & $\begin{array}{c}\text { Frecuencia } \\
\text { relativa }\end{array}$ & Aparición & $\begin{array}{c}\text { Frecuencia } \\
\text { acumulada }\end{array}$ \\
\hline 1 & (horno) microondas & 0.49741 & $3.961 \%$ & $74.011 \%$ & $3.961 \%$ \\
\hline 33 & sandwichera & 0.09151 & $1.013 \%$ & $18.927 \%$ & $57.249 \%$ \\
\hline 51 & olla exprés ${ }^{244}$ & 0.04454 & $0.378 \%$ & $7.062 \%$ & $68.797 \%$ \\
\hline 83 & bol & 0.02256 & $0.242 \%$ & $4.520 \%$ & $79.519 \%$ \\
\hline 87 & tele(visión) & 0.02227 & $0.297 \%$ & $5.161 \%$ & $81.591 \%$ \\
\hline 96 & robot (de cocina) & 0.01852 & $0.181 \%$ & $3.390 \%$ & $82.663 \%$ \\
\hline 118 & grill & 0.01310 & $0.166 \%$ & $3.107 \%$ & $86.609 \%$ \\
\hline 267 & Tupper(ware) & 0.00250 & $0.030 \%$ & $0.565 \%$ & $95.938 \%$ \\
\hline 315 & aire acondicionado & 0.00185 & $0.032 \%$ & $0.606 \%$ & $99.002 \%$ \\
\hline 473 & vídeo & 0.00065 & $0.015 \%$ & $0.282 \%$ & $99.523 \%$ \\
\hline 494 & Spontex* & 0.00046 & $0.015 \%$ & $0.282 \%$ & $99.838 \%$ \\
\hline 495 & papel de aluminio & 0.00046 & $0.015 \%$ & $0.282 \%$ & $99.853 \%$ \\
\hline
\end{tabular}

08. La escuela (muebles y materiales)

\begin{tabular}{|c|c|c|c|c|c|}
\hline $\mathrm{N}^{\mathrm{o}}$ & Palabra & Disponibilidad & $\begin{array}{c}\text { Frecuencia } \\
\text { relativa }\end{array}$ & \%Aparición & $\begin{array}{l}\text { Frecuencia } \\
\text { acumulada }\end{array}$ \\
\hline 12 & carpeta $^{245}$ & 0.24304 & $2.300 \%$ & $54.520 \%$ & $37.091 \%$ \\
\hline 40 & $v^{\prime \prime}{ }^{2}{ }^{246}$ & 0.06826 & $0.560 \%$ & $13.277 \%$ & $66.115 \%$ \\
\hline 46 & tele(visión) ${ }^{247}$ & 0.04727 & $0.405 \%$ & $9.605 \%$ & $69.475 \%$ \\
\hline 61 & bloc $^{248}$ & 0.03499 & $0.298 \%$ & $7.062 \%$ & $75.515 \%$ \\
\hline 64 & clip & 0.03193 & $0.381 \%$ & $9.040 \%$ & $76.539 \%$ \\
\hline 101 & panel $^{249}$ & 0.01513 & $0.131 \%$ & $3.107 \%$ & $84.189 \%$ \\
\hline 110 & póster $^{250}$ & 0.01323 & $0.131 \%$ & $3.107 \%$ & $85.476 \%$ \\
\hline 116 & celo $^{251}$ & 0.01207 & $0.167 \%$ & $3.955 \%$ & $86.418 \%$ \\
\hline 143 & escáner & 0.00818 & $0.071 \%$ & $1.695 \%$ & $89.023 \%$ \\
\hline 182 & bar $^{252}$ & 0.00555 & $0.060 \%$ & $1.412 \%$ & $91.937 \%$ \\
\hline 220 & váter $^{253}$ & 0.00356 & $0.048 \%$ & $1.130 \%$ & $93.723 \%$ \\
\hline 251 & Portland* & 0.00282 & $0.012 \%$ & $0.282 \%$ & $94.587 \%$ \\
\hline 299 & fax & 0.00210 & $0.024 \%$ & $0.565 \%$ & $95.619 \%$ \\
\hline 326 & $\mathrm{WC}$ & 0.00183 & $0.012 \%$ & $0.282 \%$ & $96.111 \%$ \\
\hline 333 & red de voleibol & 0.00174 & $0.024 \%$ & $0.565 \%$ & $96.231 \%$ \\
\hline
\end{tabular}

\footnotetext{
${ }^{244}$ Exprés viene del francés y este del inglés express.

${ }^{245}$ Encontramos este vocablo modificado por "de anillas" con cuatro empleos.

${ }^{246}$ Esta unidad léxica la vemos utilizada una sola vez en los siguientes sintagmas: "máquina de vídeo", "cinta de vídeo" y "sala de vídeo"

${ }^{247}$ Hallamos también "mueble de televisión" y "armario de televisión"

${ }^{248}$ La palabra bloc la registramos igualmente en: "bloc de notas", "bloc de dibujo" y "bloc de anillas" con tres, dos y tres empleos respectivamente.

${ }^{249}$ Este lexema viene modificado por "de anuncios", "informativo" y "de corcho" (cuatro usos).

${ }^{250}$ Póster lo encontramos también en el sintagma "póster de David"

${ }^{251}$ En los listados de este centro de interés registramos dicha palabra en "rollo de celo" con un empleo.

${ }^{252}$ El vocablo bar aparece en tres sintagmas: "mesa de bar", "silla de bar" y "barra de bar" con un empleo cada una.

${ }^{253}$ Asimismo anotamos el sintagma "papel de váter" con dos empleos.
} 


\begin{tabular}{|l|l|c|c|c|c|}
\hline & & & & & \\
\hline 339 & $\begin{array}{l}\text { sala de } \\
\text { audiovisuales }\end{array}$ & 0.00172 & $0.018 \%$ & $0.437 \%$ & $97.118 \%$ \\
\hline 346 & hall & 0.00165 & $0.024 \%$ & $0.565 \%$ & $96.459 \%$ \\
\hline 349 & videoteca & 0.00161 & $0.012 \%$ & $0.282 \%$ & $96.507 \%$ \\
\hline 393 & disquete & 0.00132 & $0.024 \%$ & $0.565 \%$ & $97.191 \%$ \\
\hline 400 & CD & 0.00126 & $0.012 \%$ & $0.282 \%$ & $97.275 \%$ \\
\hline 415 & cúter & 0.00118 & $0.012 \%$ & $0.282 \%$ & $97.491 \%$ \\
\hline 422 & Kleenex & 0.00118 & $0.012 \%$ & $0.282 \%$ & $97.575 \%$ \\
\hline 423 & cómic & 0.00118 & $0.012 \%$ & $0.282 \%$ & $97.587 \%$ \\
\hline 443 & subcarpeta & 0.00111 & $0.012 \%$ & $0.282 \%$ & $97.851 \%$ \\
\hline 519 & láser & 0.00087 & $0.012 \%$ & $0.282 \%$ & $98.787 \%$ \\
\hline 523 & aro de básquet & 0.00081 & $0.012 \%$ & $0.282 \%$ & $98.835 \%$ \\
\hline 536 & campo de fútbol ${ }^{254}$ & 0.00081 & $0.012 \%$ & $0.282 \%$ & $98.991 \%$ \\
\hline 542 & pista de tenis & 0.00077 & $0.012 \%$ & $0.282 \%$ & $99.075 \%$ \\
\hline 616 & bafle & 0.00047 & $0.012 \%$ & $0.282 \%$ & $99.963 \%$ \\
\hline
\end{tabular}

09. Iluminación, calefacción y medios para airear un recinto

\begin{tabular}{|c|c|c|c|c|c|}
\hline $\mathrm{N}^{\circ}$ & Palabra & Disponibilidad & $\begin{array}{c}\text { Frecuencia } \\
\text { relativa }\end{array}$ & \% Aparición & $\begin{array}{l}\text { Frecuencia } \\
\text { acumulada }\end{array}$ \\
\hline 2 & aire acondicionado ${ }^{255}$ & 0.53261 & $5.837 \%$ & $77.119 \%$ & $11.439 \%$ \\
\hline 22 & tubo de neón ${ }^{256}$ & 0.07083 & $0.834 \%$ & $11.017 \%$ & $61.643 \%$ \\
\hline 69 & láser & 0.01230 & $0.150 \%$ & $1.977 \%$ & $82.704 \%$ \\
\hline 79 & gasoil $^{257}$ & 0.01046 & $0.128 \%$ & $1.695 \%$ & $84.136 \%$ \\
\hline 87 & flash & 0.00908 & $0.150 \%$ & $1.977 \%$ & $85.336 \%$ \\
\hline 114 & Camping gas*258 & 0.00652 & $0.107 \%$ & $1.412 \%$ & $88.161 \%$ \\
\hline 151 & gasolina $^{259}$ & 0.00438 & $0.043 \%$ & $0.565 \%$ & $90.817 \%$ \\
\hline 159 & gasóleo $^{260}$ & 0.00402 & $0.043 \%$ & $0.565 \%$ & $91.288 \%$ \\
\hline 317 & panel solar & 0.00164 & $0.043 \%$ & $0.565 \%$ & $96.484 \%$ \\
\hline 377 & spray & 0.00121 & $0.021 \%$ & $0.282 \%$ & $97.788 \%$ \\
\hline 386 & anorak & 0.00111 & $0.021 \%$ & $0.282 \%$ & $97.977 \%$ \\
\hline 390 & cámara de vídeo & 0.00111 & $0.021 \%$ & $0.282 \%$ & $98.061 \%$ \\
\hline 392 & vatio & 0.00111 & $0.021 \%$ & $0.282 \%$ & $98.103 \%$ \\
\hline 407 & encender televisión & 0.00102 & $0.021 \%$ & $0.282 \%$ & $98.418 \%$ \\
\hline 411 & voltio & 0.00102 & $0.021 \%$ & $0.282 \%$ & $98.502 \%$ \\
\hline
\end{tabular}

\footnotetext{
${ }^{254}$ Hallamos "pista de fútbol” (un empleo) que no es muy usual.

255 Esta unidad léxica se utiliza también en "aparato de aire acondicionado" (cuatro empleos) y "aire acondicionado centralizado"(un uso).

${ }^{256}$ El sintagma tubo de neón tiene un índice de disponibilidad más alto que la palabra neón sola con un índice de disponibilidad de 0.01086 y que luz de neón que solo aparece una vez, igual que tubo eléctrico de neón.

257 Asimismo gasoil, aparece en los sintagmas: "calefacción de gasoil” (cuatro empleos), "estufa de gasoil" (dos empleos).

${ }^{258}$ Hallamos en los listados castellonenses la palabra camping en "farol de camping" empleado por un solo informante.

${ }^{259}$ La palabra gasolina se halla también acompañando a "calefacción de gasolina" y "lámpara de gasolina" con un uso cada una.

${ }^{260}$ También en este caso encontramos una especificación: “caldera de gasóleo” (un empleo).
} 


\section{La ciudad $^{261}$}

\begin{tabular}{|c|l|c|c|c|c|}
\hline $\mathrm{N}^{\mathrm{o}}$ & Palabra & Disponibilidad & $\begin{array}{c}\text { Frecuencia } \\
\text { relativa }\end{array}$ & Aparición & $\begin{array}{c}\text { Frecuencia } \\
\text { acumulada }\end{array}$ \\
\hline 10 & bar & 0.24033 & $1.714 \%$ & $42.373 \%$ & $21.397 \%$ \\
\hline 20 & supermercado & 0.16943 & $1.189 \%$ & $29.379 \%$ & $34.735 \%$ \\
\hline 35 & pub & 0.11484 & $0.926 \%$ & $22.881 \%$ & $50.301 \%$ \\
\hline 39 & rascacielos & 0.10397 & $0.652 \%$ & $16.102 \%$ & $53.377 \%$ \\
\hline 40 & paso de cebra & 0.10289 & $0.697 \%$ & $17.232 \%$ & $54.074 \%$ \\
\hline 49 & tráfico ${ }^{262}$ & 0.07094 & $0.446 \%$ & $11.017 \%$ & $59.332 \%$ \\
\hline 56 & parking & 0.06091 & $0.446 \%$ & $11.017 \%$ & $62.612 \%$ \\
\hline 77 & centro comercial & 0.03670 & $0.263 \%$ & $6.497 \%$ & $69.709 \%$ \\
\hline 121 & estrés & 0.01921 & $0.137 \%$ & $3.390 \%$ & $78.329 \%$ \\
\hline 129 & gasolinera & 0.01721 & $0.149 \%$ & $3.672 \%$ & $79.415 \%$ \\
\hline 130 & tranvía & 0.01717 & $0.137 \%$ & $3.390 \%$ & $79.552 \%$ \\
\hline 165 & contenedor & 0.01122 & $0.091 \%$ & $2.260 \%$ & $83.110 \%$ \\
\hline 179 & club ${ }^{263}$ & 0.01014 & $0.057 \%$ & $1.412 \%$ & $84.286 \%$ \\
\hline 180 & sidecar & 0.01018 & $0.081 \%$ & $2.010 \%$ & $86.555 \%$ \\
\hline 198 & pista de tenis & 0.00869 & $0.057 \%$ & $1.412 \%$ & $85.566 \%$ \\
\hline 209 & sex shop & 0.00755 & $0.046 \%$ & $1.130 \%$ & $86.253 \%$ \\
\hline 232 & bingo & 0.00668 & $0.069 \%$ & $1.695 \%$ & $87.523 \%$ \\
\hline 247 & autocar & 0.00605 & $0.034 \%$ & $0.847 \%$ & $88.233 \%$ \\
\hline 263 & estadio de fútbol ${ }^{264}$ & 0.00539 & $0.057 \%$ & $1.412 \%$ & $88.931 \%$ \\
\hline 267 & turista & 0.00527 & $0.034 \%$ & $0.847 \%$ & $89.067 \%$ \\
\hline 275 & puticlub & 0.00499 & $0.046 \%$ & $1.130 \%$ & $89.387 \%$ \\
\hline 278 & videoclub & 0.00492 & $0.034 \%$ & $0.847 \%$ & $89.501 \%$ \\
\hline 283 & túnel & 0.00484 & $0.046 \%$ & $1.130 \%$ & $89.650 \%$ \\
\hline 291 & stop ${ }^{265}$ & 0.00456 & $0.023 \%$ & $0.565 \%$ & $89.878 \%$ \\
\hline 308 & yonqui & 0.00423 & $0.023 \%$ & $0.565 \%$ & $90.414 \%$ \\
\hline 328 & hamburguesería & 0.00400 & $0.034 \%$ & $0.847 \%$ & $91.086 \%$ \\
\hline 345 & bungalow $_{349}$ tobogán & 0.00371 & $0.023 \%$ & $0.565 \%$ & $91.577 \%$ \\
\hline 432 & drogadicto & 0.00365 & $0.023 \%$ & $0.565 \%$ & $91.714 \%$ \\
\hline 450 & tráiler & 0.00257 & $0.023 \%$ & $0.565 \%$ & $93.608 \%$ \\
\hline 461 & zombi & 0.00252 & $0.023 \%$ & $0.565 \%$ & $93.937 \%$ \\
\hline 526 & trolebús & 0.00245 & $0.011 \%$ & $0.282 \%$ & $94.117 \%$ \\
\hline 529 & campo de básquet 266 & 0.00212 & $0.011 \%$ & $0.282 \%$ & $94.928 \%$ \\
\hline & 0.00212 & $0.011 \%$ & $0.282 \%$ & $94.961 \%$ \\
\hline
\end{tabular}

\footnotetext{
${ }^{261}$ No contabilizamos nombres propios como Mc'Donalds.

262 Aunque el Diccionario Académico anota que procede del italiano traffico, lo consideran como anglicismo Pratt, Lorenzo y Alfaro y tiene una frecuencia de uso - 11.017 \%- mayor que su sinónimo transito $-1.412 \%$.

${ }^{263}$ En las listas de este centro léxico aparece esta palabra modificada por "nocturno".

${ }^{264}$ Vemos asimismo anotados los sintagmas "equipo de fútbol", "campo de fútbol sala"con un uso cada uno y el lexema "fútbol", enumerado por tres informantes en la posición 348.

${ }^{265}$ En el rango número 458 volvemos a encontrar stop en "señal de stop".
} 


\begin{tabular}{|l|l|l|l|l|l|}
\hline 543 & váter & 0.00202 & $0.011 \%$ & $0.282 \%$ & $95.151 \%$ \\
\hline 559 & turismo & 0.00193 & $0.011 \%$ & $0.282 \%$ & $95.351 \%$ \\
\hline 613 & campo de golf & 0.00167 & $0.011 \%$ & $0.282 \%$ & $96.017 \%$ \\
\hline 627 & frankfurt & 0.00167 & $0.011 \%$ & $0.282 \%$ & $96.183 \%$ \\
\hline 706 & videojuegos & 0.00138 & $0.011 \%$ & $0.282 \%$ & $97.064 \%$ \\
\hline 730 & televisión & 0.00131 & $0.011 \%$ & $0.282 \%$ & $97.352 \%$ \\
\hline 902 & parada de hippys & 0.00085 & $0.011 \%$ & $0.282 \%$ & $99.268 \%$ \\
\hline 923 & campo de hockey & 0.00077 & $0.011 \%$ & $0.282 \%$ & $99.499 \%$ \\
\hline 928 & motel & 0.00070 & $0.011 \%$ & $0.282 \%$ & $99.554 \%$ \\
\hline 942 & camping & 0.00061 & $0.011 \%$ & $0.282 \%$ & $99.708 \%$ \\
\hline 947 & videoteca & 0.00050 & $0.011 \%$ & $0.282 \%$ & $99.763 \%$ \\
\hline
\end{tabular}

\section{El campo}

\begin{tabular}{|c|l|c|c|c|c|}
\hline $\mathrm{N}^{\mathrm{o}}$ & Palabra & Disponibilidad & $\begin{array}{c}\text { Frecuencia } \\
\text { relativa }\end{array}$ & Aparición & $\begin{array}{c}\text { Frecuencia } \\
\text { acumulada }\end{array}$ \\
\hline 10 & tractor $^{267}$ & 0.16334 & $1.204 \%$ & $25.424 \%$ & $18.749 \%$ \\
\hline 291 & bar & 0.00686 & $0.067 \%$ & $1.412 \%$ & $82.858 \%$ \\
\hline 302 & camping & 0.00642 & $0.067 \%$ & $1.412 \%$ & $83.557 \%$ \\
\hline 306 & picnic & 0.00632 & $0.067 \%$ & $1.412 \%$ & $83.799 \%$ \\
\hline 387 & turista & 0.00443 & $0.040 \%$ & $0.847 \%$ & $87.717 \%$ \\
\hline 428 & kiwi & 0.00359 & $0.027 \%$ & $0.565 \%$ & $89.247 \%$ \\
\hline 476 & relax & 0.00292 & $0.027 \%$ & $0.565 \%$ & $90.700 \%$ \\
\hline 516 & tanque 268 & 0.00258 & $0.027 \%$ & $0.565 \%$ & $91.635 \%$ \\
\hline 527 & fútbol 269 & 0.00250 & $0.013 \%$ & $0.282 \%$ & $91.848 \%$ \\
\hline 555 & tenis & 0.00236 & $0.013 \%$ & $0.282 \%$ & $92.446 \%$ \\
\hline 779 & koala & 0.00137 & $0.013 \%$ & $0.282 \%$ & $96.167 \%$ \\
\hline 882 & mandril & 0.00107 & $0.013 \%$ & $0.282 \%$ & $97.534 \%$ \\
\hline 884 & repetidor de TV & 0.00107 & $0.013 \%$ & $0.282 \%$ & $97.560 \%$ \\
\hline 938 & canguro & 0.00089 & $0.013 \%$ & $0.282 \%$ & $98.276 \%$ \\
\hline 975 & pub & 0.00079 & $0.013 \%$ & $0.282 \%$ & $98.757 \%$ \\
\hline
\end{tabular}

12. Medios de transporte ${ }^{270}$

\begin{tabular}{|c|l|c|c|c|c|}
\hline $\mathrm{N}^{\mathbf{0}}$ & Palabra & Disponibilidad & $\begin{array}{c}\text { Frecuencia } \\
\text { relativa }\end{array}$ & Aparición & $\begin{array}{c}\text { Frecuencia } \\
\text { acumulada }\end{array}$ \\
\hline 14 & tranvía & 0.21481 & $1.934 \%$ & $37.288 \%$ & $49.048 \%$ \\
\hline 31 & yate & 0.07464 & $0.879 \%$ & $16.949 \%$ & $73.922 \%$ \\
\hline 24 & tractor & 0.11461 & $1.216 \%$ & $23.446 \%$ & $66.496 \%$ \\
\hline 34 & sidecar & & &
\end{tabular}

\footnotetext{
${ }^{266}$ Básquet aparece con tres sustantivos: "campo de básquet”, “cancha de básquet", "pista de básquet” con un empleo cada uno.

${ }^{267}$ Encontramos, asimismo, "tractor agrícola" con un empleo.

${ }^{268}$ La unidad tanque aparece matizada por "tanque de agua" y "tanque de pulverizar" con un uso cada uno.

${ }^{269}$ Hallamos también el sintagma "campo de fútbol" con un empleo.

${ }^{270}$ No contabilizamos Harley Davidson*, así como otras marcas de vehículos.
} 


\begin{tabular}{|c|c|c|c|c|c|}
\hline 39 & tráiler & 0.04038 & $0.410 \%$ & $7.910 \%$ & $78.448 \%$ \\
\hline 46 & tándem & 0.03257 & $0.366 \%$ & $7.062 \%$ & $81.729 \%$ \\
\hline 57 & turismo & 0.02208 & $0.161 \%$ & $3.107 \%$ & $85.216 \%$ \\
\hline 59 & tabla de surf & 0.02074 & $0.278 \%$ & $5.367 \%$ & $85.758 \%$ \\
\hline 62 & autocar & 0.01883 & $0.161 \%$ & $3.107 \%$ & $86.285 \%$ \\
\hline 63 & trolebús & 0.01843 & $0.176 \%$ & $3.390 \%$ & $86.461 \%$ \\
\hline 64 & reactor & 0.01809 & $0.220 \%$ & $4.237 \%$ & $86.681 \%$ \\
\hline 69 & ferry & 0.01626 & $0.190 \%$ & $3.672 \%$ & $87.721 \%$ \\
\hline 73 & todoterreno & 0.01580 & $0.161 \%$ & $3.107 \%$ & $88.438 \%$ \\
\hline 76 & jet $^{272}$ & 0.01386 & $0.146 \%$ & $2.825 \%$ & $88.950 \%$ \\
\hline 78 & zódiac & 0.01339 & $0.190 \%$ & $3.672 \%$ & $89.286 \%$ \\
\hline 85 & Concorde & 0.01237 & $0.146 \%$ & $2.825 \%$ & $90.369 \%$ \\
\hline 90 & tanque & 0.01148 & $0.161 \%$ & $3.107 \%$ & $91.101 \%$ \\
\hline 92 & bote $^{273}$ & 0.01044 & $0.161 \%$ & $3.107 \%$ & $91.350 \%$ \\
\hline 99 & mountain bike & 0.00923 & $0.073 \%$ & $1.412 \%$ & $92.126 \%$ \\
\hline 101 & autostop & 0.00869 & $0.103 \%$ & $1.977 \%$ & $92.346 \%$ \\
\hline 106 & kart & 0.00780 & $0.088 \%$ & $1.695 \%$ & $92.932 \%$ \\
\hline 107 & crucero & 0.00767 & $0.103 \%$ & $1.977 \%$ & $93.035 \%$ \\
\hline 115 & monorraíl & 0.00659 & $0.073 \%$ & $1.412 \%$ & $93.782 \%$ \\
\hline 126 & vagón & 0.00550 & $0.044 \%$ & $0.847 \%$ & $94.529 \%$ \\
\hline 128 & tabla de windsurf & 0.00545 & $0.073 \%$ & $1.412 \%$ & $94.675 \%$ \\
\hline 129 & snowboard & 0.00538 & $0.059 \%$ & $1.130 \%$ & $94.734 \%$ \\
\hline 134 & hovercraft & 0.00452 & $0.073 \%$ & $1.412 \%$ & $95.027 \%$ \\
\hline 138 & boeing & 0.00437 & $0.044 \%$ & $0.847 \%$ & $95.188 \%$ \\
\hline 141 & jeep & 0.00425 & $0.044 \%$ & $0.847 \%$ & $95.320 \%$ \\
\hline 143 & windsurf & 0.00417 & $0.073 \%$ & $1.412 \%$ & $95.466 \%$ \\
\hline 148 & catamarán & 0.00400 & $0.059 \%$ & $1.130 \%$ & $95.730 \%$ \\
\hline 159 & moto de cross & 0.00345 & $0.029 \%$ & $0.565 \%$ & $96.214 \%$ \\
\hline 162 & skate & 0.00333 & $0.059 \%$ & $1.130 \%$ & $96.346 \%$ \\
\hline 193 & poni & 0.00249 & $0.044 \%$ & $0.847 \%$ & $97.312 \%$ \\
\hline 194 & jumbo & 0.00248 & $0.029 \%$ & $0.565 \%$ & $97.341 \%$ \\
\hline 203 & skateboard & 0.00231 & $0.029 \%$ & $0.565 \%$ & $97.605 \%$ \\
\hline 204 & vagoneta & 0.00229 & $0.015 \%$ & $0.282 \%$ & $97.620 \%$ \\
\hline 209 & container & 0.00229 & $0.015 \%$ & $0.282 \%$ & $97.709 \%$ \\
\hline 238 & Intercity & 0.00173 & $0.015 \%$ & $0.282 \%$ & $98.284 \%$ \\
\hline 239 & quad & 0.00171 & $0.029 \%$ & $0.565 \%$ & $98.313 \%$ \\
\hline 248 & surfing & 0.00156 & $0.029 \%$ & $0.565 \%$ & $98.504 \%$ \\
\hline 267 & kayak & 0.00131 & $0.015 \%$ & $0.282 \%$ & $98.831 \%$ \\
\hline 278 & vuelo chárter & 0.00122 & $0.015 \%$ & $0.282 \%$ & $99.010 \%$ \\
\hline 288 & gasolina $^{274}$ & 0.00106 & $0.015 \%$ & $0.282 \%$ & $99.188 \%$ \\
\hline 303 & scooter & 0.00086 & $0.015 \%$ & $0.282 \%$ & $99.413 \%$ \\
\hline 304 & puenting $^{275}$ & 0.00086 & $0.015 \%$ & $0.282 \%$ & $99.428 \%$ \\
\hline 319 & footing & 0.00075 & $0.015 \%$ & $0.282 \%$ & $99.653 \%$ \\
\hline
\end{tabular}

271 Este vocablo se encuentra también en "moto con sidecar" y "motocicleta con sidecar" con un empleo cada una.

${ }^{272}$ Este lexema lo vemos modificado por "privado" en un solo informante.

273 Otro uso que aparece es "bote salvavidas".

274 Aparece también en el sintagma "monopatín de gasolina" con un solo empleo.

${ }^{275}$ Palabra inexistente en inglés formada con una raíz española (puente) y un morfema inglés (-ing). 


\section{Trabajos del campo y del jardín}

\begin{tabular}{|c|l|c|c|c|c|}
\hline $\mathrm{N}^{\mathrm{o}}$ & Palabra & Disponibilidad & $\begin{array}{c}\text { Frecuencia } \\
\text { relativa }\end{array}$ & \%Aparición & $\begin{array}{c}\text { Frecuencia } \\
\text { acumulada }\end{array}$ \\
\hline 545 & cowboy & 0.00135 & $0.025 \%$ & $0.282 \%$ & $96.027 \%$ \\
\hline 565 & sembrar kiwis & 0.00124 & $0.025 \%$ & $0.282 \%$ & $96.552 \%$ \\
\hline
\end{tabular}

\section{Los animales}

\begin{tabular}{|c|l|c|c|c|c|}
\hline $\mathrm{N}^{\mathbf{0}}$ & Palabra & Disponibilidad & $\begin{array}{c}\text { Frecuencia } \\
\text { relativa }\end{array}$ & $\%$ Aparición & $\begin{array}{c}\text { Frecuencia } \\
\text { acumulada }\end{array}$ \\
\hline 50 & hámster & 0.08423 & $0.557 \%$ & $15.819 \%$ & $63.308 \%$ \\
\hline 92 & canguro & 0.03829 & $0.348 \%$ & $9.887 \%$ & $81.153 \%$ \\
\hline 134 & poni (pony) & 0.01676 & $0.149 \%$ & $4.237 \%$ & $90.345 \%$ \\
\hline 141 & kiwi ${ }^{276}$ & 0.01444 & $0.099 \%$ & $2.825 \%$ & $91.120 \%$ \\
\hline 157 & mandril & 0.01107 & $0.090 \%$ & $2.542 \%$ & $92.780 \%$ \\
\hline 178 & anaconda & 0.00816 & $0.060 \%$ & $1.695 \%$ & $94.475 \%$ \\
\hline 187 & albatros & 0.00734 & $0.030 \%$ & $0.847 \%$ & $94.965 \%$ \\
\hline 279 & husky siberiano & 0.00254 & $0.010 \%$ & $0.282 \%$ & $98.105 \%$ \\
\hline 427 & okapi & 0.00070 & $0.010 \%$ & $0.282 \%$ & $99.825 \%$ \\
\hline 779 & koala & 0.00137 & $0.013 \%$ & $0.282 \%$ & $96.167 \%$ \\
\hline
\end{tabular}

15. Juegos y distracciones ${ }^{277}$

\begin{tabular}{|c|c|c|c|c|c|}
\hline $\mathrm{N}^{\circ}$ & Palabra & Disponibilidad & $\begin{array}{l}\text { Frecuencia } \\
\text { relativa }\end{array}$ & \% Aparición & $\begin{array}{l}\text { Frecuencia } \\
\text { acumulada }\end{array}$ \\
\hline 2 & fútbol $^{278}$ & 0.44770 & $3.527 \%$ & $68.644 \%$ & $6.952 \%$ \\
\hline 5 & baloncesto & 0.26536 & $2.250 \%$ & $43.785 \%$ & $13.542 \%$ \\
\hline 7 & tenis $^{279}$ & 0.20488 & $1.887 \%$ & $36.723 \%$ & $17.316 \%$ \\
\hline 10 & Trivial* $^{*}$ & 0.18431 & $1.466 \%$ & $28.531 \%$ & $22.091 \%$ \\
\hline 16 & Monopoly* & 0.12574 & $1.001 \%$ & $19.492 \%$ & $30.015 \%$ \\
\hline 17 & tele(visión) ${ }^{280}$ & 0.12519 & $1.074 \%$ & $20.904 \%$ & $31.089 \%$ \\
\hline 23 & póquer & 0.10437 & $0.842 \%$ & $16.384 \%$ & $37.055 \%$ \\
\hline 27 & bingo & 0.09194 & $0.740 \%$ & $14.407 \%$ & $40.291 \%$ \\
\hline
\end{tabular}

\footnotetext{
${ }^{276}$ Kiwi es una voz de origen maorí introducida al español a través del inglés.

277 Aparecen en los listados definitivos del diccionario del léxico disponible de Castellón (§ 8.1) algunos vocablos ingleses que se corresponden con los nombres de juegos patentados que no se han contabilizado en las tablas de este capítulo y que se muestran con mayúscula y asterisco al final, como, por ejemplo, Party*, Risk*, Playstation*, Continental*, Hero quest*, Twister* o Disney world*. Sí que incluimos, sin embargo, aquellos nombres de productos que se han lexicalizado.

${ }^{278}$ Encontramos esta palabra en "ir al fútbol", "ver fútbol”, "fútbol americano", y "fútbol playa" con tres, dos, cuatro y un empleos respectivamente. Así mismo, un deporte distinto pero que contiene el mismo anglicismo "fútbol sala" en el rango número 108.

${ }^{279}$ Hallamos también la lexía compleja "tenis de mesa" en la posición 280 de nuestros listados.

${ }^{280}$ También aparecen los sintagmas "ver la televisión” y “mirar la televisión”.
} 


\begin{tabular}{|c|c|c|c|c|c|}
\hline 31 & videojuego & 0.07417 & $0.624 \%$ & $12.147 \%$ & $43.498 \%$ \\
\hline 44 & básquet & 0.05260 & $0.493 \%$ & $9.605 \%$ & $51.350 \%$ \\
\hline 52 & golf & 0.04388 & $0.450 \%$ & $8.757 \%$ & $54.585 \%$ \\
\hline 56 & (juegos de) rol & 0.04305 & $0.319 \%$ & $6.215 \%$ & $56.151 \%$ \\
\hline 59 & béisbol & 0.03936 & $0.363 \%$ & $7.062 \%$ & $57.370 \%$ \\
\hline 60 & futbolín & 0.03802 & $0.377 \%$ & $7.345 \%$ & $57.747 \%$ \\
\hline 63 & videoconsola & 0.03611 & $0.290 \%$ & $5.650 \%$ & $58.806 \%$ \\
\hline 62 & pimpón & 0.03721 & $0.392 \%$ & $7.627 \%$ & $58.516 \%$ \\
\hline 67 & hockey ${ }^{281}$ & 0.03410 & $0.406 \%$ & $7.910 \%$ & $60.214 \%$ \\
\hline 81 & puzle & 0.02374 & $0.247 \%$ & $4.802 \%$ & $64.176 \%$ \\
\hline 98 & aeróbic & 0.02060 & $0.232 \%$ & $4.520 \%$ & $68.385 \%$ \\
\hline 99 & squash & 0.02059 & $0.247 \%$ & $4.802 \%$ & $68.632 \%$ \\
\hline 102 & waterpolo & 0.02027 & $0.203 \%$ & $3.955 \%$ & $69.169 \%$ \\
\hline 103 & rugby & 0.01985 & $0.218 \%$ & $4.237 \%$ & $69.387 \%$ \\
\hline 120 & puenting $^{282}$ & 0.01749 & $0.232 \%$ & $4.520 \%$ & $72.596 \%$ \\
\hline 123 & futbito & 0.01692 & $0.203 \%$ & $3.955 \%$ & $73.090 \%$ \\
\hline 133 & footing & 0.01489 & $0.174 \%$ & $3.390 \%$ & $74.585 \%$ \\
\hline 149 & $p u b$ & 0.01203 & $0.116 \%$ & $2.260 \%$ & $76.780 \%$ \\
\hline 150 & vídeo ${ }^{283}$ & 0.01179 & $0.116 \%$ & $2.260 \%$ & $76.896 \%$ \\
\hline 178 & black jack & 0.00966 & $0.102 \%$ & $1.977 \%$ & $79.760 \%$ \\
\hline 183 & Internet & 0.00949 & $0.087 \%$ & $1.695 \%$ & $80.182 \%$ \\
\hline 190 & bar & 0.00912 & $0.102 \%$ & $1.977 \%$ & $80.953 \%$ \\
\hline 193 & cómic $^{284}$ & 0.00899 & $0.087 \%$ & $1.695 \%$ & $81.200 \%$ \\
\hline 201 & bádminton & 0.00867 & $0.102 \%$ & $1.977 \%$ & $81.956 \%$ \\
\hline 214 & balonvolea & 0.00750 & $0.073 \%$ & $1.412 \%$ & $83.004 \%$ \\
\hline 221 & rafting & 0.00691 & $0.087 \%$ & $1.695 \%$ & $83.671 \%$ \\
\hline 229 & strip póquer ${ }^{285}$ & 0.00630 & $0.044 \%$ & $0.847 \%$ & $84.195 \%$ \\
\hline 232 & paddle & 0.00616 & $0.073 \%$ & $1.412 \%$ & $84.399 \%$ \\
\hline 242 & frontenis & 0.00563 & $0.073 \%$ & $1.412 \%$ & $85.040 \%$ \\
\hline 247 & polo & 0.00550 & $0.044 \%$ & $0.847 \%$ & $85.405 \%$ \\
\hline 251 & surf & 0.00528 & $0.073 \%$ & $1.412 \%$ & $85.681 \%$ \\
\hline 261 & boxeo & 0.00497 & $0.073 \%$ & $1.412 \%$ & $86.249 \%$ \\
\hline 281 & bote bote & 0.00455 & $0.058 \%$ & $1.130 \%$ & $87.269 \%$ \\
\hline 312 & rappel & 0.00372 & $0.058 \%$ & $1.130 \%$ & $88.654 \%$ \\
\hline 323 & motocross & 0.00360 & $0.044 \%$ & $0.847 \%$ & $89.121 \%$ \\
\hline 327 & tobogán & 0.00352 & $0.029 \%$ & $0.565 \%$ & $89.310 \%$ \\
\hline 328 & vóley playa & 0.00348 & $0.044 \%$ & $0.847 \%$ & $89.354 \%$ \\
\hline 338 & balompié & 0.00337 & $0.044 \%$ & $0.847 \%$ & $89.719 \%$ \\
\hline 377 & puticlub & 0.00282 & $0.015 \%$ & $0.282 \%$ & $90.962 \%$ \\
\hline 387 & ir de camping & 0.00267 & $0.029 \%$ & $0.565 \%$ & $91.254 \%$ \\
\hline 397 & mountain bike & 0.00261 & $0.029 \%$ & $0.565 \%$ & $91.460 \%$ \\
\hline 398 & zapping & 0.00260 & $0.029 \%$ & $0.565 \%$ & $91.489 \%$ \\
\hline
\end{tabular}

${ }^{281}$ Observamos el vocablo hockey en sus diferentes variantes de juego: "hockey sobre hielo" (dos usos), "hockey sobre patines" (dos empleos), y "hockey sobre hierba" (un empleo).

${ }^{282}$ Este vocablo, ciertamente, no existe en la lengua inglesa. Es una creación similar a footing, rafting...

Se trataría, pues, de lo que se ha llamado "pseudoanglicismo".

${ }^{283}$ Asimismo hallamos esta palabra en "películas de vídeo" con cuatro usos.

${ }^{284}$ El vocablo cómic aparece en el sintagma "leer un cómic" con solo un empleo.

${ }^{285}$ Anotamos, igualmente, el orden inverso de los lexemas en la posición 467 "póquer-strip". 


\begin{tabular}{|c|c|c|c|c|c|}
\hline 418 & top model & 0.00246 & $0.015 \%$ & $0.282 \%$ & $91.916 \%$ \\
\hline 432 & windsurf & 0.00229 & $0.029 \%$ & $0.565 \%$ & $92.323 \%$ \\
\hline 458 & club & 0.00214 & $0.015 \%$ & $0.282 \%$ & $92.812 \%$ \\
\hline 468 & $\mathrm{TV}^{286}$ & 0.00214 & $0.015 \%$ & $0.282 \%$ & $92.962 \%$ \\
\hline 476 & trial & 0.00206 & $0.029 \%$ & $0.565 \%$ & $93.224 \%$ \\
\hline 486 & bate & 0.00199 & $0.015 \%$ & $0.282 \%$ & $93.430 \%$ \\
\hline 498 & canguro & 0.00192 & $0.029 \%$ & $0.565 \%$ & $93.695 \%$ \\
\hline 512 & jogging & 0.00186 & $0.015 \%$ & $0.282 \%$ & $93.919 \%$ \\
\hline 519 & test & 0.00186 & $0.015 \%$ & $0.282 \%$ & $94.024 \%$ \\
\hline 524 & oír el CD & 0.00182 & $0.029 \%$ & $0.565 \%$ & $94.141 \%$ \\
\hline 547 & PC fútbol & 0.00173 & $0.015 \%$ & $0.282 \%$ & $94.612 \%$ \\
\hline 551 & ir de picnic & 0.00173 & $0.015 \%$ & $0.282 \%$ & $94.672 \%$ \\
\hline 553 & walkie talkie & 0.00173 & $0.015 \%$ & $0.282 \%$ & $94.702 \%$ \\
\hline 563 & túnel del terror & 0.00167 & $0.029 \%$ & $0.565 \%$ & $94.894 \%$ \\
\hline 564 & trekking & 0.00162 & $0.015 \%$ & $0.282 \%$ & $94.909 \%$ \\
\hline 593 & kung-fu & 0.00151 & $0.015 \%$ & $0.282 \%$ & $95.428 \%$ \\
\hline 599 & surfear & 0.00151 & $0.015 \%$ & $0.282 \%$ & $95.518 \%$ \\
\hline 613 & ver videoclips & 0.00141 & $0.015 \%$ & $0.282 \%$ & $95.770 \%$ \\
\hline 637 & gymkhana & 0.00133 & $0.029 \%$ & $0.565 \%$ & $96.172 \%$ \\
\hline 641 & kit de montaje & 0.00131 & $0.015 \%$ & $0.282 \%$ & $96.232 \%$ \\
\hline 657 & sex-shop & 0.00131 & $0.015 \%$ & $0.282 \%$ & $96.472 \%$ \\
\hline 668 & surfing & 0.00122 & $0.015 \%$ & $0.282 \%$ & $96.651 \%$ \\
\hline 681 & minigolf & 0.00114 & $0.015 \%$ & $0.282 \%$ & $96.846 \%$ \\
\hline 705 & karting & 0.00106 & $0.015 \%$ & $0.282 \%$ & $97.220 \%$ \\
\hline 728 & fitness & 0.00099 & $0.015 \%$ & $0.282 \%$ & $97.565 \%$ \\
\hline 749 & hacer test & 0.00093 & $0.015 \%$ & $0.282 \%$ & $97.880 \%$ \\
\hline 798 & campismo & 0.00081 & $0.015 \%$ & $0.282 \%$ & $98.615 \%$ \\
\hline 811 & rally & 0.00075 & $0.015 \%$ & $0.282 \%$ & $98.810 \%$ \\
\hline 847 & backgammon & 0.00065 & $0.015 \%$ & $0.282 \%$ & $99.350 \%$ \\
\hline 857 & chatear & 0.00065 & $0.015 \%$ & $0.282 \%$ & $99.500 \%$ \\
\hline 860 & Hula hop* & 0.00065 & $0.015 \%$ & $0.282 \%$ & $99.545 \%$ \\
\hline 864 & snow & 0.00061 & $0.015 \%$ & $0.282 \%$ & $99.605 \%$ \\
\hline 872 & handball & 0.00061 & $0.015 \%$ & $0.282 \%$ & $99.725 \%$ \\
\hline 873 & rock and roll & 0.00061 & $0.015 \%$ & $0.282 \%$ & $99.740 \%$ \\
\hline 877 & skate & 0.00057 & $0.015 \%$ & $0.282 \%$ & $99.800 \%$ \\
\hline 892 & cross & 0.00049 & $0.015 \%$ & $0.282 \%$ & $100.025 \%$ \\
\hline 896 & full contact & 0.00049 & $0.015 \%$ & $0.282 \%$ & $100.085 \%$ \\
\hline
\end{tabular}

16. Profesiones y oficios

\begin{tabular}{|l|l|c|c|c|c|}
\hline $\mathrm{N}^{\mathbf{0}}$ & Palabra & $\begin{array}{c}\text { Disponibilida } \\
\mathrm{d}\end{array}$ & $\begin{array}{c}\text { Frecuenci } \\
\mathrm{a} \\
\text { relativa }\end{array}$ & $\begin{array}{c}\% \\
\text { Aparición }\end{array}$ & $\begin{array}{c}\text { Frecuenci } \\
\text { a } \\
\text { acumulada }\end{array}$ \\
\hline 29 & futbolista & 0.10724 & $0.987 \%$ & $22.599 \%$ & $38.742 \%$ \\
\hline 102 & astronauta & 0.02539 & $0.271 \%$ & $6.215 \%$ & $72.314 \%$ \\
\hline
\end{tabular}

\footnotetext{
${ }^{286}$ Se encuentran también los sintagmas "programas de TV", "ver TV", "programa televisivo".
} 


\begin{tabular}{|l|l|l|l|l|l|}
\hline 143 & relaciones públicas & 0.01545 & $0.148 \%$ & $3.390 \%$ & $79.901 \%$ \\
\hline 147 & tenista & 0.01521 & $0.185 \%$ & $4.237 \%$ & $80.542 \%$ \\
\hline 173 & jugador de fútbol & 0.01101 & $0.111 \%$ & $2.542 \%$ & $83.946 \%$ \\
\hline 186 & barman & 0.00959 & $0.136 \%$ & $3.107 \%$ & $85.205 \%$ \\
\hline 209 & esteticista & 0.00775 & $0.086 \%$ & $1.977 \%$ & $87.239 \%$ \\
\hline 249 & detective ${ }^{287}$ & 0.00566 & $0.074 \%$ & $1.695 \%$ & $89.631 \%$ \\
\hline 268 & disc-jockey & 0.00528 & $0.062 \%$ & $1.412 \%$ & $90.593 \%$ \\
\hline 277 & gasolinero & 0.00498 & $0.062 \%$ & $1.412 \%$ & $91.099 \%$ \\
\hline 279 & golfista & 0.00497 & $0.074 \%$ & $1.695 \%$ & $91.235 \%$ \\
\hline 296 & mánager & 0.00454 & $0.062 \%$ & $1.412 \%$ & $92.025 \%$ \\
\hline 377 & Turismo & 0.00263 & $0.012 \%$ & $0.282 \%$ & $94.649 \%$ \\
\hline 447 & jugador de voleibol & 0.00197 & $0.012 \%$ & $0.282 \%$ & $96.076 \%$ \\
\hline 450 & conductor de autocar & 0.00197 & $0.012 \%$ & $0.282 \%$ & $96.112 \%$ \\
\hline 468 & conductor de trolebús & 0.00184 & $0.012 \%$ & $0.282 \%$ & $96.419 \%$ \\
\hline 480 & boxeador & 0.00171 & $0.037 \%$ & $0.847 \%$ & $96.666 \%$ \\
\hline 482 & gánster & 0.00171 & $0.012 \%$ & $0.282 \%$ & $96.690 \%$ \\
\hline 500 & baloncestista & 0.00159 & $0.012 \%$ & $0.282 \%$ & $96.945 \%$ \\
\hline 567 & bróker 288 & 0.00128 & $0.012 \%$ & $0.282 \%$ & $97.866 \%$ \\
\hline 573 & showman & 0.00121 & $0.025 \%$ & $0.565 \%$ & $97.964 \%$ \\
\hline 576 & jugador de béisbol & 0.00119 & $0.012 \%$ & $0.282 \%$ & $98.013 \%$ \\
\hline 648 & striptease & 0.00083 & $0.012 \%$ & $0.282 \%$ & $98.903 \%$ \\
\hline 652 & jugador de golf & 0.00083 & $0.012 \%$ & $0.282 \%$ & $98.951 \%$ \\
\hline 614 & cámara de & 0.00103 & $0.012 \%$ & $0.282 \%$ & $98.482 \%$ \\
& televisión 289 & & & & \\
\hline 621 & presentador de TV & 0.00096 & $0.012 \%$ & $0.282 \%$ & $98.566 \%$ \\
\hline 652 & jugador de golf & 0.00083 & $0.012 \%$ & $0.282 \%$ & $98.951 \%$ \\
\hline 672 & baby-sitter & 0.00067 & $0.012 \%$ & $0.282 \%$ & $99.191 \%$ \\
\hline 703 & videocámara & 0.00050 & $0.012 \%$ & $0.282 \%$ & $99.563 \%$ \\
\hline 709 & jugador de básquet & 0.00047 & $0.012 \%$ & $0.282 \%$ & $99.635 \%$ \\
\hline 718 & linier & 0.00044 & $0.012 \%$ & $0.282 \%$ & $99.743 \%$ \\
\hline
\end{tabular}

\section{Los colores}

\begin{tabular}{|c|l|c|c|c|c|}
\hline $\mathrm{N}^{\mathbf{0}}$ & Palabra & Disponibilidad & $\begin{array}{c}\text { Frecuencia } \\
\text { relativa }\end{array}$ & Aparición & $\begin{array}{c}\text { Frecuencia } \\
\text { acumulada }\end{array}$ \\
\hline 27 & caqui $^{290}$ & 0.09552 & $0.839 \%$ & $16.667 \%$ & $74.986 \%$ \\
\hline 76 & cian $^{291}$ & 0.01566 & $0.128 \%$ & $2.542 \%$ & $89.948 \%$ \\
\hline 142 & kiwi $^{292}$ & 0.00571 & $0.057 \%$ & $1.130 \%$ & $95.597 \%$ \\
\hline 183 & camel & 0.00328 & $0.028 \%$ & $0.565 \%$ & $97.165 \%$ \\
\hline 283 & rojo láser & 0.00149 & $0.014 \%$ & $0.282 \%$ & $99.028 \%$ \\
\hline 288 & aluminio & 0.00149 & $0.014 \%$ & $0.282 \%$ & $99.098 \%$ \\
\hline
\end{tabular}

\footnotetext{
${ }^{287}$ Observamos un solo empleo de "detective privado".

${ }^{288}$ También aparece en nuestro listados "broker de bolsa" con una sola aplicación.

${ }^{289}$ Encontramos la palabra televisión en "presentador de televisión" con un empleo.

${ }^{290}$ El color caqui sirve de complemento en el sintagma "verde caqui" con dos empleos

${ }^{291}$ Cian en este centro de interés aparece también en "azul cian" con un solo empleo.

${ }^{292}$ Registramos asimismo verde kiwi con un empleo.
} 


\subsection{Tablas de los valencianismos}

\section{El cuerpo humano.}

\begin{tabular}{|c|c|c|c|c|c|}
\hline $\mathrm{N}^{\mathbf{0}}$ & Palabra & Disponibilidad & $\begin{array}{c}\text { Frecuencia } \\
\text { relativa }\end{array}$ & $\%$ Aparición & $\begin{array}{c}\text { Frecuencia } \\
\text { acumulada }\end{array}$ \\
\hline 266 & figa $^{293}$ & 0.00053 & $0.011 \%$ & $0.282 \%$ & $99.960 \%$ \\
\hline
\end{tabular}

02. La ropa

\begin{tabular}{|c|l|c|c|c|c|}
\hline $\mathrm{N}^{\mathbf{0}}$ & Palabra & Disponibilidad & $\begin{array}{c}\text { Frecuencia } \\
\text { relativa }\end{array}$ & $\%$ Aparición & $\begin{array}{c}\text { Frecuencia } \\
\text { acumulada }\end{array}$ \\
\hline 161 & samarreta & 0.00312 & $0.025 \%$ & $0.565 \%$ & $97.586 \%$ \\
\hline 234 & espardenya & 0.00123 & $0.012 \%$ & $0.282 \%$ & $98.986 \%$ \\
\hline 247 & brusa & 0.00115 & $0.012 \%$ & $0.282 \%$ & $99.142 \%$ \\
\hline
\end{tabular}

\section{Partes de la casa}

\begin{tabular}{|c|c|c|c|c|c|}
\hline $\mathrm{N}^{\circ}$ & Palabra & Disponibilidad & $\begin{array}{l}\text { Frecuencia } \\
\text { relativa }\end{array}$ & \%Aparición & $\begin{array}{l}\text { Frecuencia } \\
\text { acumulada }\end{array}$ \\
\hline 167 & saleta & 0.00244 & $0.017 \%$ & $0.282 \%$ & $97.170 \%$ \\
\hline 185 & paellero & 0.00211 & $0.051 \%$ & $0.847 \%$ & $97.697 \%$ \\
\hline 189 & pica ${ }^{294}$ & 0.00210 & $0.017 \%$ & $0.282 \%$ & $97.765 \%$ \\
\hline 246 & rebost & 0.00108 & $0.017 \%$ & $0.282 \%$ & $98.989 \%$ \\
\hline 277 & desllunat & 0.00086 & $0.017 \%$ & $0.282 \%$ & $99.516 \%$ \\
\hline
\end{tabular}

\section{Los muebles de la casa}

\begin{tabular}{|c|c|c|c|c|c|}
\hline $\mathrm{N}^{\mathbf{0}}$ & Palabra & Disponibilidad & $\begin{array}{c}\text { Frecuencia } \\
\text { relativa }\end{array}$ & $\%$ Aparición & $\begin{array}{c}\text { Frecuencia } \\
\text { acumulada }\end{array}$ \\
\hline 153 & pica & 0.00310 & $0.058 \%$ & $0.847 \%$ & $96.375 \%$ \\
\hline
\end{tabular}

\section{Alimentos}

\begin{tabular}{|c|c|c|c|c|c|}
\hline $\mathrm{N}^{\mathbf{0}}$ & Palabra & Disponibilidad & $\begin{array}{c}\text { Frecuencia } \\
\text { relativa }\end{array}$ & \%Aparición & $\begin{array}{c}\text { Frecuencia } \\
\text { acumulada }\end{array}$ \\
\hline 41 & paella & 0.08630 & $0.563 \%$ & $14.972 \%$ & $50.484 \%$ \\
\hline 162 & fideuà & 0.01559 & $0.117 \%$ & $3.107 \%$ & $86.315 \%$ \\
\hline
\end{tabular}

\footnotetext{
${ }^{293}$ Ver el comentario de esta palabra en Blas et al., 1992: 82

${ }^{294}$ También encontramos este vocablos en el sintagma "pica de la cocina" con un solo uso y en el puesto 166.
} 


\begin{tabular}{|l|l|l|l|l|l|}
\hline 190 & jamón dulce & 0.01061 & $0.074 \%$ & $1.977 \%$ & $89.238 \%$ \\
\hline 227 & fuet & 0.00774 & $0.074 \%$ & $1.977 \%$ & $92.202 \%$ \\
\hline 396 & botifarra & 0.00206 & $0.021 \%$ & $0.565 \%$ & $97.454 \%$ \\
\hline 422 & bajoca & 0.00179 & $0.021 \%$ & $0.565 \%$ & $97.861 \%$ \\
\hline 447 & fogassa & 0.00157 & $0.021 \%$ & $0.565 \%$ & $98.196 \%$ \\
\hline 482 & mabra & 0.00126 & $0.011 \%$ & $0.282 \%$ & $98.671 \%$ \\
\hline 496 & empedrat & 0.00119 & $0.011 \%$ & $0.282 \%$ & $98.835 \%$ \\
\hline 505 & bajocó & 0.00113 & $0.011 \%$ & $0.282 \%$ & $98.944 \%$ \\
\hline 550 & abadejo & 0.00084 & $0.011 \%$ & $0.282 \%$ & $99.449 \%$ \\
\hline 553 & lluç & 0.00084 & $0.011 \%$ & $0.282 \%$ & $99.482 \%$ \\
\hline 575 & arròs caldós & 0.00075 & $0.011 \%$ & $0.282 \%$ & $99.724 \%$ \\
\hline 577 & clòtxina & 0.00071 & $0.011 \%$ & $0.282 \%$ & $99.746 \%$ \\
\hline 198 & carlota & 0.00929 & $0.064 \%$ & $1.695 \%$ & $90.036 \%$ \\
\hline 117 & rosquilleta & 0.02436 & $0.223 \%$ & $5.932 \%$ & $79.365 \%$ \\
\hline 235 & coca 295 & 0.00733 & $0.032 \%$ & $0.847 \%$ & $92.649 \%$ \\
\hline 545 & pollo a l'ast & 0.00089 & $0.011 \%$ & $0.282 \%$ & $99.394 \%$ \\
\hline 219 & mallorquina & 0.00814 & $0.074 \%$ & $1.977 \%$ & $91.682 \%$ \\
\hline 68 & chuleta & 0.05604 & $0.393 \%$ & $10.452 \%$ & $64.763 \%$ \\
\hline
\end{tabular}

06. Objetos colocados en la mesa para la comida

\begin{tabular}{|c|l|c|c|c|c|}
\hline $\mathrm{N}^{\mathrm{O}}$ & Palabra & Disponibilidad & $\begin{array}{c}\text { Frecuencia } \\
\text { relativa }\end{array}$ & \%Aparición & $\begin{array}{c}\text { Frecuencia } \\
\text { acumulada }\end{array}$ \\
\hline 59 & plato plano & 0.02113 & $0.227 \%$ & $3.390 \%$ & $84.326 \%$ \\
\hline 90 & paellera & 0.01188 & $0.208 \%$ & $3.107 \%$ & $90.995 \%$ \\
\hline 112 & pitxer & 0.00701 & $0.076 \%$ & $1.130 \%$ & $93.541 \%$ \\
\hline 183 & got & 0.00212 & $0.019 \%$ & $0.282 \%$ & $97.284 \%$ \\
\hline 206 & setrill d'oli & 0.00171 & $0.019 \%$ & $0.282 \%$ & $97.816 \%$ \\
\hline 215 & cassoleta & 0.00159 & $0.019 \%$ & $0.282 \%$ & $98.006 \%$ \\
\hline 268 & mortero con allioli & 0.00111 & $0.019 \%$ & $0.282 \%$ & $99.089 \%$ \\
\hline 98 & paella & 0.00875 & $0.171 \%$ & $2.542 \%$ & $92.040 \%$ \\
\hline
\end{tabular}

07. La cocina y sus utensilios

\begin{tabular}{|c|l|c|c|c|c|}
\hline $\mathbf{N}^{\mathbf{0}}$ & Palabra & Disponibilidad & $\begin{array}{c}\text { Frecuencia } \\
\text { relativa }\end{array}$ & \%Aparición & $\begin{array}{c}\text { Frecuencia } \\
\text { acumulada }\end{array}$ \\
\hline 42 & paellero & 0.05868 & $0.590 \%$ & $11.017 \%$ & $64.172 \%$ \\
\hline 43 & pica & 0.05740 & $0.605 \%$ & $11.299 \%$ & $64.777 \%$ \\
\hline 105 & torradora & 0.01670 & $0.151 \%$ & $2.825 \%$ & $84.433 \%$ \\
\hline 155 & perol & 0.00718 & $0.060 \%$ & $1.130 \%$ & $90.606 \%$ \\
\hline 260 & fumeral & 0.00263 & $0.015 \%$ & $0.282 \%$ & $95.743 \%$ \\
\hline 302 & banquet $^{297}$ & 0.00193 & $0.030 \%$ & $0.565 \%$ & $96.748 \%$ \\
\hline 305 & escorredor & 0.00186 & $0.015 \%$ & $0.282 \%$ & $96.808 \%$ \\
\hline
\end{tabular}

\footnotetext{
${ }^{295}$ Aparece el sintagma "coca de tomate" con un empleo solo y un índice de disponibilidad de 0.00056 y posición 598.

${ }^{296}$ Hallamos también “pica de fregar” con un solo empleo, ID 0.00162 u posición 330.

${ }^{297}$ Encontramos "banquet de mármol” en la posición 446, ID 0.00086 y un empleo.
} 


\begin{tabular}{|l|l|l|l|l|l|}
\hline 307 & graella & 0.00186 & $0.015 \%$ & $0.282 \%$ & $96.838 \%$ \\
\hline 325 & misto & 0.00171 & $0.030 \%$ & $0.565 \%$ & $97.168 \%$ \\
\hline 359 & drap & 0.00141 & $0.015 \%$ & $0.282 \%$ & $97.723 \%$ \\
\hline 402 & mazo de allioli ${ }^{298}$ & 0.00114 & $0.015 \%$ & $0.282 \%$ & $98.443 \%$ \\
\hline 405 & foguer & 0.00113 & $0.030 \%$ & $0.565 \%$ & $98.503 \%$ \\
\hline 443 & perola & 0.00086 & $0.015 \%$ & $0.282 \%$ & $99.073 \%$ \\
\hline
\end{tabular}

08. La escuela (muebles y materiales)

\begin{tabular}{|c|l|c|c|c|c|}
\hline $\mathrm{N}^{\mathbf{0}}$ & Palabra & Disponibilidad & $\begin{array}{c}\text { Frecuencia } \\
\text { relativa }\end{array}$ & $\%$ Aparición & $\begin{array}{c}\text { Frecuencia } \\
\text { acumulada }\end{array}$ \\
\hline 250 & taula & 0.00282 & $0.012 \%$ & $0.282 \%$ & $94.575 \%$ \\
\hline 262 & cadira & 0.00265 & $0.012 \%$ & $0.282 \%$ & $94.839 \%$ \\
\hline 499 & punxó & 0.00092 & $0.012 \%$ & $0.282 \%$ & $98.547 \%$ \\
\hline 580 & salfumant & 0.00068 & $0.012 \%$ & $0.282 \%$ & $99.531 \%$ \\
\hline
\end{tabular}

09. Iluminación, calefacción y medios de airear un recinto

\begin{tabular}{|c|l|c|c|c|c|}
\hline $\mathrm{N}^{\mathbf{0}}$ & Palabra & Disponibilidad & $\begin{array}{c}\text { Frecuencia } \\
\text { relativa }\end{array}$ & $\%$ Aparición & $\begin{array}{c}\text { Frecuencia } \\
\text { acumulada }\end{array}$ \\
\hline 43 & palmito & 0.03335 & $0.449 \%$ & $5.932 \%$ & $75.692 \%$ \\
\hline 291 & llar & 0.00185 & $0.021 \%$ & $0.282 \%$ & $95.784 \%$ \\
\hline 383 & foguera & 0.00111 & $0.021 \%$ & $0.282 \%$ & $97.914 \%$ \\
\hline 405 & plafó & 0.00102 & $0.021 \%$ & $0.282 \%$ & $98.376 \%$ \\
\hline 422 & misto & 0.00093 & $0.021 \%$ & $0.282 \%$ & $98.733 \%$ \\
\hline
\end{tabular}

\section{La ciudad}

\begin{tabular}{|c|l|c|c|c|c|}
\hline $\mathrm{N}^{\circ}$ & Palabra & Disponibilidad & $\begin{array}{c}\text { Frecuencia } \\
\text { relativa }\end{array}$ & Aparición & $\begin{array}{c}\text { Frecuencia } \\
\text { acumulada }\end{array}$ \\
\hline 406 & carrer & 0.00282 & $0.011 \%$ & $0.282 \%$ & $93.051 \%$ \\
\hline 492 & claveguera & 0.00233 & $0.011 \%$ & $0.282 \%$ & $94.518 \%$ \\
\hline 500 & Fadrí & 0.00222 & $0.011 \%$ & $0.282 \%$ & $94.618 \%$ \\
\hline 551 & placeta & 0.00193 & $0.011 \%$ & $0.282 \%$ & $95.263 \%$ \\
\hline 660 & tauleta & 0.00152 & $0.011 \%$ & $0.282 \%$ & $96.558 \%$ \\
\hline 341 & Conselleria & 0.00376 & $0.023 \%$ & $0.565 \%$ & $91.463 \%$ \\
\hline 900 & casal & 0.00085 & $0.011 \%$ & $0.282 \%$ & $99.246 \%$ \\
\hline
\end{tabular}

\section{El campo}

\begin{tabular}{|c|l|c|c|c|c|}
\hline $\mathrm{N}^{\mathbf{o}}$ & Palabra & Disponibilidad & $\begin{array}{c}\text { Frecuencia } \\
\text { relativa }\end{array}$ & \% Aparición & $\begin{array}{c}\text { Frecuencia } \\
\text { acumulada }\end{array}$ \\
\hline 48 & caseta $^{299}$ & 0.05392 & $0.415 \%$ & $8.757 \%$ & $45.221 \%$ \\
\hline 222 & barraca & 0.00952 & $0.094 \%$ & $1.977 \%$ & $77.717 \%$ \\
\hline
\end{tabular}

${ }^{298}$ Asimismo encontramos "recipiente de alioli" con un empleo, ID 0.00081, posición 453.
${ }^{299}$ Registramos "caseta de campo" con un solo empleo, posición 858, ID 0.00121. 


\begin{tabular}{|c|l|l|l|l|l|}
\hline 246 & paellero & 0.00853 & $0.094 \%$ & $1.977 \%$ & $79.671 \%$ \\
\hline 250 & maset / masset & 0.00831 & $0.067 \%$ & $1.412 \%$ & $79.965 \%$ \\
\hline 434 & matxina & 0.00351 & $0.027 \%$ & $0.565 \%$ & $89.422 \%$ \\
\hline 467 & marialluïsa & 0.00306 & $0.027 \%$ & $0.565 \%$ & $90.431 \%$ \\
\hline 475 & perera & 0.00295 & $0.027 \%$ & $0.565 \%$ & $90.673 \%$ \\
\hline 503 & lligona & 0.00266 & $0.013 \%$ & $0.282 \%$ & $91.397 \%$ \\
\hline 577 & argelaga & 0.00222 & $0.013 \%$ & $0.282 \%$ & $92.830 \%$ \\
\hline 661 & cadernera & 0.00185 & $0.013 \%$ & $0.282 \%$ & $94.355 \%$ \\
\hline 700 & carxofa & 0.00174 & $0.013 \%$ & $0.282 \%$ & $94.959 \%$ \\
\hline 727 & fava & 0.00164 & $0.013 \%$ & $0.282 \%$ & $95.449 \%$ \\
\hline 771 & corbella & 0.00145 & $0.013 \%$ & $0.282 \%$ & $96.063 \%$ \\
\hline 791 & espardenya & 0.00137 & $0.013 \%$ & $0.282 \%$ & $96.323 \%$ \\
\hline 832 & garrofera & 0.00128 & $0.027 \%$ & $0.565 \%$ & $96.870 \%$ \\
\hline 930 & collidor & 0.00095 & $0.013 \%$ & $0.282 \%$ & $98.172 \%$ \\
\hline 944 & albercoquer & 0.00089 & $0.013 \%$ & $0.282 \%$ & $98.354 \%$ \\
\hline 1051 & teuladí & 0.00052 & $0.013 \%$ & $0.282 \%$ & $99.745 \%$ \\
\hline 1028 & guineu & 0.00062 & $0.013 \%$ & $0.282 \%$ & $99.446 \%$ \\
\hline
\end{tabular}

\section{Trabajos del campo y del jardín}

\begin{tabular}{|c|l|c|c|c|c|}
\hline $\mathrm{N}^{\mathbf{0}}$ & Palabra & Disponibilidad & $\begin{array}{c}\text { Frecuencia } \\
\text { relativa }\end{array}$ & \%parición & $\begin{array}{c}\text { Frecuencia } \\
\text { acumulada }\end{array}$ \\
\hline 28 & empeltar & 0.04931 & $0.724 \%$ & $8.192 \%$ & $57.429 \%$ \\
\hline 75 & collidor & 0.01313 & $0.150 \%$ & $1.695 \%$ & $73.627 \%$ \\
\hline 83 & hacer soquetes ${ }^{300}$ & 0.01037 & $0.175 \%$ & $1.977 \%$ & $74.977 \%$ \\
\hline 89 & empeltador & 0.00922 & $0.125 \%$ & $1.412 \%$ & $75.777 \%$ \\
\hline 94 & espigolar & 0.00872 & $0.100 \%$ & $1.130 \%$ & $76.502 \%$ \\
\hline 129 & collir & 0.00646 & $0.075 \%$ & $0.847 \%$ & $80.252 \%$ \\
\hline 142 & saó $^{301}$ & 0.00565 & $0.050 \%$ & $0.565 \%$ & $81.377 \%$ \\
\hline 160 & hacer soques $^{302}$ & 0.00479 & $0.050 \%$ & $0.565 \%$ & $82.677 \%$ \\
\hline 169 & ramader & 0.00458 & $0.075 \%$ & $0.847 \%$ & $83.227 \%$ \\
\hline 196 & tallar & 0.00393 & $0.050 \%$ & $0.565 \%$ & $84.902 \%$ \\
\hline 244 & arruixar & 0.00293 & $0.050 \%$ & $0.565 \%$ & $87.602 \%$ \\
\hline 254 & llaurador & 0.00282 & $0.025 \%$ & $0.282 \%$ & $87.877 \%$ \\
\hline 296 & cremar leña & 0.00256 & $0.050 \%$ & $0.565 \%$ & $89.327 \%$ \\
\hline 329 & hacer els cavallons & 0.00221 & $0.025 \%$ & $0.282 \%$ & $90.352 \%$ \\
\hline 360 & recoger collites & 0.00203 & $0.025 \%$ & $0.282 \%$ & $91.227 \%$ \\
\hline 363 & masover & 0.00203 & $0.025 \%$ & $0.282 \%$ & $91.302 \%$ \\
\hline 435 & ensulfatador & 0.00173 & $0.025 \%$ & $0.282 \%$ & $93.202 \%$ \\
\hline 562 & tirar fem & 0.00135 & $0.025 \%$ & $0.282 \%$ & $96.452 \%$ \\
\hline 577 & fer paret & 0.00124 & $0.025 \%$ & $0.282 \%$ & $96.852 \%$ \\
\hline 607 & ficar rectes & 0.00114 & $0.025 \%$ & $0.282 \%$ & $97.602 \%$ \\
\hline 620 & escampar fem & 0.00105 & $0.025 \%$ & $0.282 \%$ & $97.927 \%$ \\
\hline
\end{tabular}

\footnotetext{
${ }^{300}$ Aparece el término "soquetes" de forma individual (posición270) y "fer soquetes" (408) con dos y un empleo respectivamente.

${ }^{301}$ Encontramos "fer saó" en la posición 309 y un solo empleo.

302 Hallamos "cavar soques" (167), "cortar soques" (533) y "banyar soques"(625) con dos empleos la primeras y las siguientes con un empleo cada una.
} 


\begin{tabular}{|l|l|l|l|l|l|}
\hline 649 & fer cremador & 0.00089 & $0.025 \%$ & $0.282 \%$ & $98.652 \%$ \\
\hline
\end{tabular}

\section{Los animales}

\begin{tabular}{|l|l|c|c|c|c|}
\hline $\mathrm{N}^{\mathbf{0}}$ & Palabra & Disponibilidad & $\begin{array}{c}\text { Frecuencia } \\
\text { relativa }\end{array}$ & $\%$ Aparición & $\begin{array}{c}\text { Frecuencia } \\
\text { acumulada }\end{array}$ \\
\hline 186 & cadernera & 0.00750 & $0.050 \%$ & $1.412 \%$ & $94.935 \%$ \\
\hline 226 & titot & 0.00486 & $0.030 \%$ & $0.847 \%$ & $96.755 \%$ \\
\hline 239 & mabre & 0.00395 & $0.030 \%$ & $0.847 \%$ & $97.165 \%$ \\
\hline 261 & colom & 0.00307 & $0.020 \%$ & $0.565 \%$ & $97.725 \%$ \\
\hline 269 & egua & 0.00283 & $0.020 \%$ & $0.565 \%$ & $97.915 \%$ \\
\hline 300 & cullerot & 0.00216 & $0.010 \%$ & $0.282 \%$ & $98.415 \%$ \\
\hline 311 & vilero & 0.00194 & $0.010 \%$ & $0.282 \%$ & $98.535 \%$ \\
\hline 334 & estornell & 0.00165 & $0.010 \%$ & $0.282 \%$ & $98.835 \%$ \\
\hline 339 & griva & 0.00157 & $0.010 \%$ & $0.282 \%$ & $98.895 \%$ \\
\hline 350 & rabosa & 0.00149 & $0.010 \%$ & $0.282 \%$ & $99.025 \%$ \\
\hline 354 & escorpa & 0.00141 & $0.010 \%$ & $0.282 \%$ & $99.065 \%$ \\
\hline 382 & llissa & 0.00114 & $0.010 \%$ & $0.282 \%$ & $99.375 \%$ \\
\hline 407 & oroneta & 0.00087 & $0.010 \%$ & $0.282 \%$ & $99.625 \%$ \\
\hline 416 & granota & 0.00078 & $0.010 \%$ & $0.282 \%$ & $99.715 \%$ \\
\hline 436 & llobarro & 0.00060 & $0.010 \%$ & $0.282 \%$ & $99.915 \%$ \\
\hline
\end{tabular}

\section{Juegos y distracciones}

\begin{tabular}{|c|l|c|c|c|c|}
\hline $\mathrm{N}^{\mathrm{o}}$ & Palabra & Disponibilidad & $\begin{array}{c}\text { Frecuencia } \\
\text { relativa }\end{array}$ & \% Aparición & $\begin{array}{c}\text { Frecuencia } \\
\text { acumulada }\end{array}$ \\
\hline 30 & sambori & 0.07546 & $0.682 \%$ & $13.277 \%$ & $42.874 \%$ \\
\hline 132 & botifarra & 0.01490 & $0.116 \%$ & $2.260 \%$ & $74.411 \%$ \\
\hline 159 & cinquet & 0.01128 & $0.087 \%$ & $1.695 \%$ & $77.913 \%$ \\
\hline 172 & tres pamets & 0.01006 & $0.102 \%$ & $1.977 \%$ & $79.149 \%$ \\
\hline 174 & truc & 0.00996 & $0.073 \%$ & $1.412 \%$ & $79.367 \%$ \\
\hline 299 & potet & 0.00407 & $0.029 \%$ & $0.565 \%$ & $88.130 \%$ \\
\hline 393 & despullat & 0.00263 & $0.015 \%$ & $0.282 \%$ & $91.386 \%$ \\
\hline 469 & maquinetas & 0.00213 & $0.029 \%$ & $0.565 \%$ & $92.991 \%$ \\
\hline 631 & ditet & 0.00141 & $0.015 \%$ & $0.282 \%$ & $96.040 \%$ \\
\hline 684 & tres en ratlla & 0.00114 & $0.015 \%$ & $0.282 \%$ & $96.891 \%$ \\
\hline 720 & pedra paper tisora & 0.00106 & $0.015 \%$ & $0.282 \%$ & $97.445 \%$ \\
\hline 759 & platerets tets tets & 0.00093 & $0.015 \%$ & $0.282 \%$ & $98.030 \%$ \\
\hline 762 & voltar pins & 0.00093 & $0.015 \%$ & $0.282 \%$ & $98.075 \%$ \\
\hline 897 & baldufa & 0.00049 & $0.015 \%$ & $0.282 \%$ & $100.100 \%$ \\
\hline 437 & casal & 0.00229 & $0.015 \%$ & $0.282 \%$ & $92.398 \%$ \\
\hline
\end{tabular}




\section{Profesiones y oficios}

\begin{tabular}{|c|l|c|c|c|c|}
\hline $\mathrm{N}^{\mathbf{0}}$ & Palabra & Disponibilidad & $\begin{array}{c}\text { Frecuencia } \\
\text { relativa }\end{array}$ & \% Aparición & $\begin{array}{c}\text { Frecuencia } \\
\text { acumulada }\end{array}$ \\
\hline 215 & pescater & 0.00731 & $0.062 \%$ & $1.412 \%$ & $87.646 \%$ \\
\hline 282 & llaurador & 0.00491 & $0.025 \%$ & $0.565 \%$ & $91.346 \%$ \\
\hline 493 & ramader & 0.00171 & $0.012 \%$ & $0.282 \%$ & $96.822 \%$ \\
\hline 322 & yesaire $^{303}$ & 0.00377 & $0.049 \%$ & $1.130 \%$ & $93.208 \%$ \\
\hline
\end{tabular}

\section{Los colores}

\begin{tabular}{|c|l|c|c|c|c|}
\hline $\mathrm{N}^{\mathbf{0}}$ & Palabra & Disponibilidad & $\begin{array}{c}\text { Frecuencia } \\
\text { relativa }\end{array}$ & \%parición & $\begin{array}{c}\text { Frecuencia } \\
\text { acumulada }\end{array}$ \\
\hline 239 & enrogit & 0.00194 & $0.014 \%$ & $0.282 \%$ & $98.398 \%$ \\
\hline 280 & carabassa & 0.00155 & $0.014 \%$ & $0.282 \%$ & $98.986 \%$ \\
\hline
\end{tabular}

\footnotetext{
${ }^{303}$ Ver Josep Martines, “El sufix - aire al País Valencià” (1997: 229-262).
} 
ANEXOS 



\begin{abstract}
ANEXOS
En el CD-ROM adjunto se recoge el diccionario del léxico disponible de los preuniversitarios castellonenses, ordenado alfabéticamente y en el que solo se muestran las palabras junto al índice de disponibilidad en los diferentes centros de interés. A continuación, aparecen los diccionarios según las variables consideradas en la presente investigación (sexo, titularidad y ubicación del centro educativo, la lengua materna y el nivel educativo familiar), también separados en los diecisiete campos semánticos estudiados. Por último, presentamos dos páginas del test de disponibilidad empleado en las encuestas; en la primera, se recogen los datos sociológicos de los informantes para su posterior estratificación y, en la segunda, se ve el modelo que los alumnos han utilizado en sus respuestas.
\end{abstract}

